\title{
Prediction of An(III)/Ln(III) Separation by 1,2,4-Triazinyl-Pyridine Derivatives
}

\author{
Marcos M. Mason, ${ }^{1}$ Caris Smith, ${ }^{1}$ Monica Vasiliu, ${ }^{1}$ Jesse D. Carrick, ${ }^{2}$ and David A. Dixon ${ }^{1, *}, 1$ \\ ${ }^{1}$ Department of Chemistry and Biochemistry, The University of Alabama, Shelby Hall,
}

Tuscaloosa, AL 35487-0336

${ }^{2}$ Department of Chemistry, Tennessee Technological University, 55 University Drive,

Cookeville, TN 38505-0001

\section{Complete references}

25. Jensen, M. P.; Chiarizia, R.; Shkrob, I. A.; Ulicki, J. S.; Spindler, B. D.; Murphy, D. J.; Hossain, M.; Roca-Sabio, A.; Platas-Iglesias, C.; de Blas, A.; Rodríguez-Blas, T. Aqueous Complexes for Efficient Size-Based Separation of Americium from Curium. Inorg. Chem. 2014, $53,6003-6012$

35. Lewis, F. W.; Harwood, L. M.; Hudson, M. J.; Drew, M. G. B.; Sypula, M.; Modolo, G.; Whittaker, D.; Sharrad, C. A.; Videva, V.; Hubscher-Bruder, V.; Arnaud-Neu, F. Complexation of Lanthanides, Actinides and Transition Metal Cations with a 6-(1,2,4-Triazin-3-Y1)-2,2':6',2'Terpyridine Ligand: Implications for Actinide(III)/Lanthanide(III) Partitioning. Dalton Trans. 2012, 41, 9209-9219

38. Bremer, A.; Ruff, C. M.; Girnt, D.; Müllich, U.; Rothe, J.; Roesky, P. W.; Panak, P. J.; Karpov, A.; Müller, T. J. J.; Denecke, M. A.; Geist, A. 2,6-Bis(5-(2,2-Dimethylpropyl)-1 $H$ Pyrazol-3-Y1)Pyridine as a Ligand for Efficient Actinide(III)/Lanthanide(III) Separation. Inorg. Chem. 2012, 51, 5199-5207

55. Frisch, M. J.; Trucks, G. W.; Schlegel, H. B.; Scuseria, G. E.; Robb, M. A.; Cheeseman, J. R.; Scalmani, G.; Barone, V.; Petersson, G. A.; Nakatsuji, H.; Li, X.; Caricato, M.; Marenich, A. V.; Bloino, J.; Janesko, B. G.; Gomperts, R.; Mennucci, B.; Hratchian, H. P.; Ortiz, J. V.; Izmaylov, A. F.; Sonnenberg, J. L.; Williams-Young, D.; Ding, F.; Lipparini, F.; Egidi, F.; Goings, J.; Peng, B.; Petrone, A.; Henderson, T.; Ranasinghe, D.; Zakrzewski, V. G.; Gao, J.; Rega, N.; Zheng, G.; Liang, W.; Hada, M.; Ehara, M.; Toyota, K.; Fukuda, R.; Hasegawa, J.; Ishida, M.; Nakajima, T.; Honda, Y.; Kitao, O.; Nakai, H.; Vreven, T.; Throssell, K.; Montgomery, J. A., Jr.; Peralta, J. E.; Ogliaro, F.; Bearpark, M. J.; Heyd, J. J.; Brothers, E. N.; Kudin, K. N.; Staroverov, V. N.; Keith, T. A.; Kobayashi, R.; Normand, J.; Raghavachari, K.; Rendell, A. P.; Burant, J. C.; Iyengar, S. S.; Tomasi, J.; Cossi, M.; Millam, J. M.; Klene, M.; Adamo, C.; Cammi, R.; Ochterski, J. W.; Martin, R. L.; Morokuma, K.; Farkas, O.; Foresman, J. B.; Fox, D. J. Gaussian 16, Revision A.03, Gaussian, Inc., Wallingford CT, 2016.

\footnotetext{
${ }^{1}$ Email: dadixon@ua.edu
} 
74. Servis, M. J.; Liu, Z.; Martinez-Baez, E.; Clark, A. E.; Su, J.; Batista, E. R.; Yang, P.; Wildman, A.; Stetina, T.; Li, X.; Newcomb, K.; Maginn, E. J.; Autschbach, J.; Dixon, D. A. Solvent Extraction through the Lens of Advanced Modeling and Simulation. in Ion Exchange and Solvent Extraction, Ed. Moyer, B. CRC Press, Boca Raton, FL. 2019, Ch. 5, pp. 147-218.

84. Lewis, F. W.; Harwood, L. M.; Hudson, M. J.; Drew, M. G. B.; Desreux, J. F.; Vidick, G.; Bouslimani, N.; Modolo, G.; Wilden, A.; Sypula, M.; Vu, T.-H.; Simonin, J.-P. Highly Efficient Separation of Actinides from Lanthanides by a Phenanthroline-Derived Bis-triazine Ligand. $J$. Am. Chem. Soc. 2011, 133, 13093-13102. 
Table S1. Ionization Potentials (IP, eV), Electron Affinities (EA, eV), Hardness ( $\eta$ ) and Electronegativities $(\chi)$ of ligands in the gas phase, water (aq) and butanol (but) in eV.

\begin{tabular}{|l|l|l|l|l|l|l|l|l|l|l|l|l|}
\hline & \multicolumn{3}{|c|}{ IP } & \multicolumn{3}{c|}{ EA } & \multicolumn{3}{|c|}{$\chi$} & \multicolumn{3}{c|}{$\eta$} \\
\hline & gas & aq & But & gas & aq & but & gas & aq & but & gas & aq & but \\
\hline $\mathbf{1}$ & 7.04 & 5.42 & 5.51 & 1.21 & 2.91 & 2.81 & 4.12 & 4.16 & 4.16 & 2.92 & 1.26 & 1.35 \\
\hline $\mathbf{1 a}$ & 6.95 & 5.41 & 5.54 & 1.07 & 2.71 & 2.59 & 4.01 & 4.06 & 4.06 & 2.94 & 1.35 & 1.48 \\
\hline $\mathbf{1 b}$ & 6.77 & 5.54 & 5.64 & 1.37 & 3.02 & 2.91 & 4.07 & 4.28 & 4.27 & 2.70 & 1.26 & 1.37 \\
\hline $\mathbf{2}$ & 7.97 & 6.38 & 6.45 & 1.18 & 2.88 & 2.78 & 4.57 & 4.63 & 4.62 & 3.39 & 1.75 & 1.83 \\
\hline $\mathbf{2 a e}$ & 7.62 & 5.96 & 6.07 & 1.20 & 2.67 & 2.59 & 4.41 & 4.32 & 4.33 & 3.21 & 1.64 & 1.74 \\
\hline $\mathbf{2 a m}$ & 7.44 & 6.11 & 6.18 & 1.04 & 2.69 & 2.60 & 4.24 & 4.40 & 4.39 & 3.20 & 1.71 & 1.79 \\
\hline 2ap & 7.18 & 6.08 & 6.13 & 1.14 & 2.70 & 2.60 & 4.16 & 4.39 & 4.36 & 3.02 & 1.69 & 1.77 \\
\hline 2be & 7.28 & 5.77 & 5.87 & 1.52 & 3.00 & 2.91 & 4.40 & 4.38 & 4.39 & 2.88 & 1.38 & 1.48 \\
\hline 2bm & 7.13 & 5.82 & 5.91 & 1.39 & 3.00 & 2.90 & 4.26 & 4.41 & 4.40 & 2.87 & 1.41 & 1.51 \\
\hline 2bp & 7.00 & 5.92 & 5.98 & 1.47 & 3.02 & 2.91 & 4.23 & 4.47 & 4.45 & 2.76 & 1.45 & 1.53 \\
\hline
\end{tabular}

Table S2. Mulliken spin for $M=$ Eu complexes in the gas phase at the B3LYP/Stuttgart'97ECP/ DZVP2 level from Gaussian16 and in water (aq) and butanol (but) at the BLYP/TZ2P/ZORA level from ADF.

\begin{tabular}{|c|c|c|c|c|c|c|c|c|c|c|c|c|}
\hline & \multicolumn{3}{|c|}{$\left[\mathrm{ML}\left(\mathrm{H}_{2} \mathrm{O}\right)_{6}\right]^{3+}$} & \multicolumn{3}{|c|}{$\left[\mathrm{ML}\left(\mathrm{H}_{2} \mathrm{O}\right)_{5}\right]^{3+}$} & \multicolumn{3}{|c|}{$\left[\mathrm{ML}_{2}\left(\mathrm{H}_{2} \mathrm{O}\right)_{2}\right]^{3+}$} & \multicolumn{3}{|c|}{$\left[\mathrm{ML}_{2}\right]^{3+}$} \\
\hline ligand & gas & $\mathrm{aq}$ & but & gas & $\mathrm{aq}$ & but & gas & $\mathrm{aq}$ & but & gas & $\mathrm{aq}$ & but \\
\hline 1 & 6.99 & 6.57 & 6.59 & 6.99 & 6.57 & 6.59 & 6.68 & 6.45 & 6.45 & 6.98 & 5.72 & 6.59 \\
\hline $1 \mathbf{a}$ & 6.99 & 6.58 & 6.59 & 7.00 & 6.60 & 6.62 & 6.63 & 6.46 & 6.24 & 6.77 & 6.51 & 6.53 \\
\hline $\mathbf{1 b}$ & 6.73 & 6.45 & 6.46 & 6.77 & 6.75 & 6.47 & 6.70 & 6.45 & 5.77 & 6.96 & 6.57 & 6.60 \\
\hline 2 & 6.33 & 6.26 & 6.26 & 6.35 & 6.26 & 6.27 & 6.07 & 6.17 & 6.17 & 6.25 & 6.28 & 6.28 \\
\hline $2 a e$ & 6.31 & 6.26 & 6.26 & 6.37 & 6.28 & 6.28 & 6.15 & 6.19 & 6.20 & 6.35 & 6.32 & 6.33 \\
\hline 2 am & 6.29 & 6.25 & 6.25 & 6.34 & 6.26 & 6.27 & 6.07 & 6.17 & 6.16 & 6.31 & 6.30 & 6.30 \\
\hline 2ap & 6.56 & 6.35 & 6.36 & 6.59 & 6.36 & 6.37 & 6.34 & 6.27 & 6.29 & 6.52 & 6.37 & 6.39 \\
\hline $2 \mathrm{be}$ & 6.78 & 6.45 & 6.46 & 6.80 & 6.45 & 6.47 & 6.59 & 6.39 & 6.41 & 6.89 & 6.52 & 6.56 \\
\hline $2 \mathrm{bm}$ & 6.76 & 6.44 & 6.45 & 6.79 & 6.44 & 6.45 & 6.55 & 6.35 & 6.37 & 6.85 & 6.50 & 6.52 \\
\hline 2bp & 6.75 & 6.43 & 6.45 & 6.78 & 6.44 & 6.46 & 6.53 & 6.36 & 6.38 & 6.81 & 6.49 & 6.52 \\
\hline
\end{tabular}


Table S3. Natural Bond Orbital (NBO) population on central metal in complex $\left[\mathrm{ML}\left(\mathrm{H}_{2} \mathrm{O}\right)_{5}\right]^{3+}$ at the B3LYP/Stuttgart'97ECP/DZVP2 level in units of e. ' $n$ ' refers to valence shell, 7 for actinides, 6 for lanthanides. For ns $<0.05$ e, the value is not shown.

\begin{tabular}{|c|c|c|c|c|}
\hline Complex & M & $(n-2) f$ & (n-1)d & ns \\
\hline \multicolumn{5}{|c|}{ Core 1} \\
\hline \multirow[t]{4}{*}[\mathrm{ML}(\mathrm{H}_{2}\mathrm{O})_{6}]{$^{3+}$} & $\mathrm{Am}$ & 6.10 & 0.74 & 0.18 \\
\hline & $\mathrm{Cm}$ & 7.05 & 0.66 & 0.18 \\
\hline & $\mathrm{Eu}$ & 6.98 & 0.08 & \\
\hline & $\mathrm{Gd}$ & 7.03 & 0.31 & \\
\hline \multirow[t]{4}{*}[\mathrm{ML}(\mathrm{H}_{2}\mathrm{O})_{5}]{$^{3+}$} & $\mathrm{Am}$ & 6.11 & 0.67 & 0.17 \\
\hline & $\mathrm{Cm}$ & 7.06 & 0.64 & 0.18 \\
\hline & $\mathrm{Eu}$ & 6.99 & 0.09 & \\
\hline & $\mathrm{Gd}$ & 7.03 & 0.33 & \\
\hline \multirow[t]{4}{*}[\mathrm{ML}_{2}(\mathrm{H}_{2}\mathrm{O})_{2}]{$^{3+}$} & $\mathrm{Am}$ & 6.10 & 0.64 & 0.18 \\
\hline & $\mathrm{Cm}$ & 6.95 & 0.56 & 0.18 \\
\hline & $\mathrm{Eu}$ & 6.68 & 0.19 & \\
\hline & $\mathrm{Gd}$ & 7.03 & 0.37 & \\
\hline \multirow[t]{4}{*}[\mathrm{ML}_{2}]{$^{3+}$} & $\mathrm{Am}$ & 6.08 & 0.48 & 0.15 \\
\hline & $\mathrm{Cm}$ & 7.04 & 0.44 & 0.16 \\
\hline & $\mathrm{Eu}$ & 6.96 & 0.14 & 0.09 \\
\hline & $\mathrm{Gd}$ & 7.04 & 0.44 & \\
\hline \multicolumn{5}{|c|}{$1 \mathrm{a}$} \\
\hline \multirow[t]{4}{*}[\mathrm{ML}(\mathrm{H}_{2}\mathrm{O})_{6}]{$^{3+}$} & $\mathrm{Am}$ & 6.11 & 0.75 & 0.18 \\
\hline & $\mathrm{Cm}$ & 7.05 & 0.67 & 0.19 \\
\hline & $\mathrm{Eu}$ & 6.98 & 0.09 & \\
\hline & $\mathrm{Gd}$ & 7.03 & 0.32 & \\
\hline \multirow[t]{4}{*}[\mathrm{ML}(\mathrm{H}_{2}\mathrm{O})_{5}]{$^{3+}$} & $\mathrm{Am}$ & 6.13 & 0.66 & 0.17 \\
\hline & $\mathrm{Cm}$ & 7.06 & 0.62 & 0.17 \\
\hline & $\mathrm{Eu}$ & 7.00 & 0.08 & \\
\hline & $\mathrm{Gd}$ & 7.03 & 0.33 & \\
\hline \multirow[t]{4}{*}[\mathrm{ML}_{2}(\mathrm{H}_{2}\mathrm{O})_{2}]{$^{3+}$} & $\mathrm{Am}$ & 6.09 & 0.66 & 0.18 \\
\hline & $\mathrm{Cm}$ & 6.93 & 0.58 & 0.18 \\
\hline & $\mathrm{Eu}$ & 6.62 & 0.22 & \\
\hline & $\mathrm{Gd}$ & 7.03 & 0.38 & \\
\hline \multirow[t]{4}{*}[\mathrm{ML}_{2}]{$^{3+}$} & $\mathrm{Am}$ & 6.07 & 0.48 & 0.15 \\
\hline & $\mathrm{Cm}$ & 7.03 & 0.44 & 0.16 \\
\hline & $\mathrm{Eu}$ & 6.75 & 0.21 & 0.1 \\
\hline & $\mathrm{Gd}$ & 7.04 & 0.45 & \\
\hline \multicolumn{5}{|c|}{$1 b$} \\
\hline$\left[\mathrm{ML}\left(\mathrm{H}_{2} \mathrm{O}\right)_{6}\right]^{3+}$ & $\mathrm{Am}$ & 6.25 & 0.69 & 0.17 \\
\hline
\end{tabular}




\begin{tabular}{|c|c|c|c|c|}
\hline & $\mathrm{Cm}$ & 7.05 & 0.67 & 0.18 \\
\hline & $\mathrm{Eu}$ & 6.73 & 0.14 & \\
\hline & $\mathrm{Gd}$ & 7.03 & 0.32 & \\
\hline \multirow{4}{*}[\mathrm{ML}(\mathrm{H}_{2}\mathrm{O})_{5}]{$^{3+}$} & $\mathrm{Am}$ & 6.28 & 0.61 & 0.16 \\
\hline & $\mathrm{Cm}$ & 7.06 & 0.65 & 0.18 \\
\hline & $\mathrm{Eu}$ & 6.77 & 0.14 & \\
\hline & $\mathrm{Gd}$ & 7.03 & 0.34 & \\
\hline \multirow{4}{*}[\mathrm{ML}_{2}(\mathrm{H}_{2}\mathrm{O})_{2}]{$^{3+}$} & $\mathrm{Am}$ & 6.09 & 0.67 & 0.18 \\
\hline & $\mathrm{Cm}$ & 6.94 & 0.59 & 0.18 \\
\hline & $\mathrm{Eu}$ & 6.69 & 0.2 & \\
\hline & Gd & 7.03 & 0.39 & \\
\hline \multirow{4}{*}[\mathrm{ML}_{2}]{$^{3+}$} & $\mathrm{Am}$ & 6.08 & 0.51 & 0.15 \\
\hline & $\mathrm{Cm}$ & 7.02 & 0.46 & 0.16 \\
\hline & $\mathrm{Eu}$ & 6.94 & 0.15 & 0.09 \\
\hline & Gd & 7.04 & 0.47 & \\
\hline \multicolumn{5}{|c|}{ Core 2} \\
\hline \multirow[t]{4}{*}[\mathrm{ML}(\mathrm{H}_{2}\mathrm{O})_{6}]{$^{3+}$} & $\mathrm{Am}$ & 6.10 & 0.77 & 0.19 \\
\hline & $\mathrm{Cm}$ & 7.05 & 0.70 & 0.19 \\
\hline & $\mathrm{Eu}$ & 6.33 & 0.25 & \\
\hline & $\mathrm{Gd}$ & 7.03 & 0.31 & \\
\hline \multirow{4}{*}[\mathrm{ML}(\mathrm{H}_{2}\mathrm{O})_{5}]{$^{3+}$} & $\mathrm{Am}$ & 6.11 & 0.69 & 0.18 \\
\hline & $\mathrm{Cm}$ & 7.06 & 0.66 & 0.18 \\
\hline & $\mathrm{Eu}$ & 6.40 & 0.25 & \\
\hline & Gd & 7.03 & 0.32 & \\
\hline \multirow[t]{4}{*}[\mathrm{ML}_{2}(\mathrm{H}_{2}\mathrm{O})_{2}]{$^{3+}$} & $\mathrm{Am}$ & 6.07 & 0.74 & 0.2 \\
\hline & $\mathrm{Cm}$ & 7.02 & 0.63 & 0.2 \\
\hline & $\mathrm{Eu}$ & 6.09 & 0.43 & \\
\hline & Gd & 7.03 & 0.37 & \\
\hline \multirow[t]{4}{*}[\mathrm{ML}_{2}]{$^{3+}$} & $\mathrm{Am}$ & 6.11 & 0.60 & 0.18 \\
\hline & $\mathrm{Cm}$ & 7.06 & 0.58 & 0.18 \\
\hline & $\mathrm{Eu}$ & 6.26 & 0.41 & \\
\hline & $\mathrm{Gd}$ & 7.04 & 0.43 & \\
\hline \multicolumn{5}{|c|}{$2 a e$} \\
\hline \multirow[t]{4}{*}[\mathrm{ML}(\mathrm{H}_{2}\mathrm{O})_{6}]{$^{3+}$} & $\mathrm{Am}$ & 6.10 & 0.77 & 0.19 \\
\hline & $\mathrm{Cm}$ & 7.05 & 0.70 & 0.19 \\
\hline & $\mathrm{Eu}$ & 6.31 & 0.27 & \\
\hline & $\mathrm{Gd}$ & 7.03 & 0.32 & \\
\hline \multirow[t]{2}{*}[\mathrm{ML}(\mathrm{H}_{2}\mathrm{O})_{5}]{$^{3+}$} & $\mathrm{Am}$ & 6.11 & 0.70 & 0.18 \\
\hline & $\mathrm{Cm}$ & 7.06 & 0.68 & 0.18 \\
\hline
\end{tabular}




\begin{tabular}{|c|c|c|c|c|}
\hline & $\mathrm{Eu}$ & 6.38 & 0.26 & \\
\hline & $\mathrm{Gd}$ & 7.03 & 0.33 & \\
\hline \multirow[t]{4}{*}[\mathrm{ML}_{2}(\mathrm{H}_{2}\mathrm{O})_{2}]{$^{3+}$} & $\mathrm{Am}$ & 6.06 & 0.75 & 0.20 \\
\hline & $\mathrm{Cm}$ & 7.02 & 0.69 & 0.20 \\
\hline & $\mathrm{Eu}$ & 6.17 & 0.40 & \\
\hline & $\mathrm{Gd}$ & 7.03 & 0.37 & \\
\hline \multirow[t]{4}{*}[\mathrm{ML}_{2}]{$^{3+}$} & $\mathrm{Am}$ & 6.09 & 0.60 & 0.17 \\
\hline & $\mathrm{Cm}$ & 7.06 & 0.58 & 0.18 \\
\hline & $\mathrm{Eu}$ & 6.35 & 0.36 & \\
\hline & $\mathrm{Gd}$ & 7.04 & 0.44 & \\
\hline \multicolumn{5}{|c|}{ 2am } \\
\hline \multirow[t]{4}{*}[\mathrm{ML}(\mathrm{H}_{2}\mathrm{O})_{6}]{$^{3+}$} & $\mathrm{Am}$ & 6.10 & 0.79 & 0.19 \\
\hline & $\mathrm{Cm}$ & 7.05 & 0.71 & 0.19 \\
\hline & $\mathrm{Eu}$ & 6.34 & 0.27 & \\
\hline & $\mathrm{Gd}$ & 7.03 & 0.32 & \\
\hline \multirow[t]{4}{*}[\mathrm{ML}(\mathrm{H}_{2}\mathrm{O})_{5}]{$^{3+}$} & Am & 6.11 & 0.70 & 0.18 \\
\hline & $\mathrm{Cm}$ & 7.06 & 0.68 & 0.18 \\
\hline & $\mathrm{Eu}$ & 6.35 & 0.27 & \\
\hline & $\mathrm{Gd}$ & 7.03 & 0.34 & \\
\hline \multirow[t]{4}{*}[\mathrm{ML}_{2}(\mathrm{H}_{2}\mathrm{O})_{2}]{$^{3+}$} & $\mathrm{Am}$ & 6.07 & 0.75 & 0.20 \\
\hline & $\mathrm{Cm}$ & 7.02 & 0.70 & 0.20 \\
\hline & $\mathrm{Eu}$ & 6.10 & 0.43 & \\
\hline & $\mathrm{Gd}$ & 7.03 & 0.37 & \\
\hline \multirow[t]{4}{*}[\mathrm{ML}_{2}]{$^{3+}$} & $\mathrm{Am}$ & 6.07 & 0.64 & 0.17 \\
\hline & $\mathrm{Cm}$ & 7.06 & 0.59 & 0.18 \\
\hline & $\mathrm{Eu}$ & 6.32 & 0.38 & \\
\hline & $\mathrm{Gd}$ & 7.04 & 0.45 & \\
\hline \multicolumn{5}{|c|}{ 2ap } \\
\hline \multirow[t]{4}{*}[\mathrm{ML}(\mathrm{H}_{2}\mathrm{O})_{6}]{$^{3+}$} & $\mathrm{Am}$ & 6.13 & 0.77 & 0.18 \\
\hline & $\mathrm{Cm}$ & 7.06 & 0.71 & 0.19 \\
\hline & $\mathrm{Eu}$ & 6.55 & 0.19 & \\
\hline & $\mathrm{Gd}$ & 7.03 & 0.32 & \\
\hline \multirow[t]{4}{*}[\mathrm{ML}(\mathrm{H}_{2}\mathrm{O})_{5}]{$^{3+}$} & $\mathrm{Am}$ & 6.14 & 0.70 & 0.18 \\
\hline & $\mathrm{Cm}$ & 7.06 & 0.68 & 0.18 \\
\hline & $\mathrm{Eu}$ & 6.58 & 0.19 & \\
\hline & $\mathrm{Gd}$ & 7.03 & 0.34 & \\
\hline \multirow[t]{3}{*}[\mathrm{ML}_{2}(\mathrm{H}_{2}\mathrm{O})_{2}]{$^{3+}$} & $\mathrm{Am}$ & 6.06 & 0.76 & 0.20 \\
\hline & $\mathrm{Cm}$ & 7.01 & 0.70 & 0.20 \\
\hline & $\mathrm{Eu}$ & 6.34 & 0.32 & \\
\hline
\end{tabular}




\begin{tabular}{|c|c|c|c|c|}
\hline & $\mathrm{Gd}$ & 7.03 & 0.37 & \\
\hline \multirow{4}{*}[\mathrm{ML}_{2}]{$^{3+}$} & $\mathrm{Am}$ & 6.08 & 0.62 & 0.18 \\
\hline & $\mathrm{Cm}$ & 7.06 & 0.60 & 0.18 \\
\hline & $\mathrm{Eu}$ & 6.51 & 0.29 & \\
\hline & $\mathrm{Gd}$ & 7.04 & 0.45 & \\
\hline \multicolumn{5}{|c|}{ 2be } \\
\hline \multirow[t]{4}{*}[\mathrm{ML}(\mathrm{H}_{2}\mathrm{O})_{6}]{$^{3+}$} & $\mathrm{Am}$ & 6.22 & 0.73 & 0.18 \\
\hline & $\mathrm{Cm}$ & 7.06 & 0.71 & 0.19 \\
\hline & $\mathrm{Eu}$ & 6.77 & 0.13 & \\
\hline & $\mathrm{Gd}$ & 7.03 & 0.32 & \\
\hline \multirow{4}{*}[\mathrm{ML}(\mathrm{H}_{2}\mathrm{O})_{5}]{$^{3+}$} & $\mathrm{Am}$ & 6.31 & 0.62 & 0.16 \\
\hline & $\mathrm{Cm}$ & 7.06 & 0.68 & 0.18 \\
\hline & $\mathrm{Eu}$ & 6.80 & 0.13 & \\
\hline & $\mathrm{Gd}$ & 7.03 & 0.34 & \\
\hline \multirow{4}{*}[\mathrm{ML}_{2}(\mathrm{H}_{2}\mathrm{O})_{2}]{$^{3+}$} & $\mathrm{Am}$ & 6.07 & 0.75 & 0.20 \\
\hline & $\mathrm{Cm}$ & 7.02 & 0.70 & 0.20 \\
\hline & $\mathrm{Eu}$ & 6.59 & 0.22 & \\
\hline & $\mathrm{Gd}$ & 7.03 & 0.37 & \\
\hline \multirow[t]{4}{*}[\mathrm{ML}_{2}]{$^{3+}$} & $\mathrm{Am}$ & 6.10 & 0.63 & 0.17 \\
\hline & $\mathrm{Cm}$ & 7.06 & 0.61 & 0.18 \\
\hline & $\mathrm{Eu}$ & 6.88 & 0.17 & \\
\hline & $\mathrm{Gd}$ & 7.04 & 0.45 & \\
\hline \multicolumn{5}{|c|}{$2 \mathrm{bm}$} \\
\hline \multirow[t]{4}{*}[\mathrm{ML}(\mathrm{H}_{2}\mathrm{O})_{6}]{$^{3+}$} & $\mathrm{Am}$ & 6.17 & 0.75 & 0.18 \\
\hline & $\mathrm{Cm}$ & 7.06 & 0.71 & 0.19 \\
\hline & $\mathrm{Eu}$ & 6.76 & 0.14 & \\
\hline & $\mathrm{Gd}$ & 7.03 & 0.33 & \\
\hline \multirow[t]{4}{*}[\mathrm{ML}(\mathrm{H}_{2}\mathrm{O})_{5}]{$^{3+}$} & $\mathrm{Am}$ & 6.29 & 0.64 & 0.17 \\
\hline & $\mathrm{Cm}$ & 7.06 & 0.69 & 0.18 \\
\hline & $\mathrm{Eu}$ & 6.78 & 0.14 & \\
\hline & $\mathrm{Gd}$ & 7.03 & 0.34 & \\
\hline \multirow[t]{4}{*}[\mathrm{ML}_{2}(\mathrm{H}_{2}\mathrm{O})_{2}]{$^{3+}$} & $\mathrm{Am}$ & 6.08 & 0.76 & 0.20 \\
\hline & $\mathrm{Cm}$ & 7.02 & 0.70 & 0.20 \\
\hline & $\mathrm{Eu}$ & 6.54 & 0.24 & \\
\hline & $\mathrm{Gd}$ & 7.03 & 0.37 & \\
\hline \multirow[t]{4}{*}[\mathrm{ML}_{2}]{$^{3+}$} & $\mathrm{Am}$ & 6.10 & 0.63 & 0.17 \\
\hline & $\mathrm{Cm}$ & 7.06 & 0.61 & 0.18 \\
\hline & $\mathrm{Eu}$ & 6.83 & 0.18 & \\
\hline & $\mathrm{Gd}$ & 7.04 & 0.45 & \\
\hline
\end{tabular}




\begin{tabular}{|c|c|c|c|c|}
\hline \multicolumn{5}{|c|}{$2 \mathrm{bp}$} \\
\hline \multirow[t]{4}{*}[\mathrm{ML}(\mathrm{H}_{2}\mathrm{O})_{6}]{$^{3+}$} & $\mathrm{Am}$ & 6.14 & 0.76 & 0.18 \\
\hline & $\mathrm{Cm}$ & 7.06 & 0.71 & 0.19 \\
\hline & $\mathrm{Eu}$ & 6.74 & 0.14 & \\
\hline & $\mathrm{Gd}$ & 7.03 & 0.33 & \\
\hline \multirow[t]{4}{*}[\mathrm{ML}(\mathrm{H}_{2}\mathrm{O})_{5}]{$^{3+}$} & $\mathrm{Am}$ & 6.23 & 0.66 & 0.17 \\
\hline & $\mathrm{Cm}$ & 7.06 & 0.69 & 0.18 \\
\hline & $\mathrm{Eu}$ & 6.78 & 0.14 & \\
\hline & $\mathrm{Gd}$ & 7.03 & 0.35 & \\
\hline \multirow[t]{4}{*}[\mathrm{ML}_{2}(\mathrm{H}_{2}\mathrm{O})_{2}]{$^{3+}$} & $\mathrm{Am}$ & 6.07 & 0.76 & 0.20 \\
\hline & $\mathrm{Cm}$ & 7.02 & 0.70 & 0.20 \\
\hline & $\mathrm{Eu}$ & 6.52 & 0.24 & \\
\hline & $\mathrm{Gd}$ & 7.03 & 0.37 & \\
\hline \multirow[t]{4}{*}[\mathrm{ML}_{2}]{$^{3+}$} & $\mathrm{Am}$ & 6.09 & 0.64 & 0.17 \\
\hline & $\mathrm{Cm}$ & 7.06 & 0.62 & 0.18 \\
\hline & $\mathrm{Eu}$ & 6.81 & 0.19 & 0.12 \\
\hline & $\mathrm{Gd}$ & 7.04 & 0.46 & \\
\hline \multicolumn{5}{|c|}{ 1i } \\
\hline \multirow[t]{4}{*}[\mathrm{ML}(\mathrm{H}_{2}\mathrm{O})_{6}]{$^{2+}$} & $\mathrm{Am}$ & 6.12 & 0.76 & 0.18 \\
\hline & $\mathrm{Cm}$ & 7.06 & 0.69 & 0.19 \\
\hline & $\mathrm{Eu}$ & 6.82 & 0.13 & \\
\hline & $\mathrm{Gd}$ & 7.04 & 0.35 & \\
\hline \multirow[t]{4}{*}[\mathrm{ML}(\mathrm{H}_{2}\mathrm{O})_{5}]{$^{2+}$} & $\mathrm{Am}$ & 6.19 & 0.68 & 0.17 \\
\hline & $\mathrm{Cm}$ & 7.07 & 0.67 & 0.18 \\
\hline & $\mathrm{Eu}$ & 6.83 & 0.14 & \\
\hline & $\mathrm{Gd}$ & 7.04 & 0.37 & \\
\hline \multirow[t]{4}{*}[\mathrm{ML}_{2}(\mathrm{H}_{2}\mathrm{O})_{2}]{$^{1+}$} & $\mathrm{Am}$ & 6.12 & 0.68 & 0.19 \\
\hline & $\mathrm{Cm}$ & 6.95 & 0.61 & 0.20 \\
\hline & $\mathrm{Eu}$ & 6.48 & 0.28 & \\
\hline & $\mathrm{Gd}$ & 7.04 & 0.40 & \\
\hline \multirow[t]{4}{*}[\mathrm{ML}_{2}]{$^{1+}$} & $\mathrm{Am}$ & 6.03 & 0.59 & 0.18 \\
\hline & $\mathrm{Cm}$ & 7.04 & 0.55 & 0.18 \\
\hline & $\mathrm{Eu}$ & 6.64 & 0.27 & 0.13 \\
\hline & $\mathrm{Gd}$ & 7.04 & 0.49 & \\
\hline \multicolumn{5}{|c|}{ 1ai } \\
\hline \multirow[t]{4}{*}[\mathrm{ML}(\mathrm{H}_{2}\mathrm{O})_{6}]{$^{2+}$} & $\mathrm{Am}$ & 6.14 & 0.75 & 0.18 \\
\hline & $\mathrm{Cm}$ & 7.06 & 0.69 & 0.19 \\
\hline & $\mathrm{Eu}$ & 6.84 & 0.13 & \\
\hline & $\mathrm{Gd}$ & 7.04 & 0.35 & \\
\hline
\end{tabular}




\begin{tabular}{|c|c|c|c|c|}
\hline \multirow[t]{4}{*}[\mathrm{ML}(\mathrm{H}_{2}\mathrm{O})_{5}]{$^{2+}$} & $\mathrm{Am}$ & 6.14 & 0.70 & 0.17 \\
\hline & $\mathrm{Cm}$ & 7.07 & 0.69 & 0.18 \\
\hline & $\mathrm{Eu}$ & 6.84 & 0.14 & \\
\hline & $\mathrm{Gd}$ & 7.04 & 0.38 & \\
\hline \multirow[t]{4}{*}[\mathrm{ML}_{2}(\mathrm{H}_{2}\mathrm{O})_{2}]{$^{1+}$} & $\mathrm{Am}$ & 6.11 & 0.61 & 0.19 \\
\hline & $\mathrm{Cm}$ & 6.94 & 0.60 & 0.20 \\
\hline & $\mathrm{Eu}$ & 6.26 & 0.33 & \\
\hline & $\mathrm{Gd}$ & 7.04 & 0.39 & \\
\hline \multirow[t]{4}{*}[\mathrm{ML}_{2}]{$^{1+}$} & $\mathrm{Am}$ & 6.02 & 0.58 & 0.18 \\
\hline & $\mathrm{Cm}$ & 7.03 & 0.55 & 0.18 \\
\hline & $\mathrm{Eu}$ & 6.59 & 0.29 & \\
\hline & $\mathrm{Gd}$ & 7.04 & 0.48 & \\
\hline \multicolumn{5}{|c|}{$1 \mathrm{bi}$} \\
\hline \multirow[t]{4}{*}[\mathrm{ML}(\mathrm{H}_{2}\mathrm{O})_{6}]{$^{2+}$} & $\mathrm{Am}$ & 6.15 & 0.76 & 0.18 \\
\hline & $\mathrm{Cm}$ & 7.06 & 0.70 & 0.19 \\
\hline & $\mathrm{Eu}$ & 6.82 & 0.13 & \\
\hline & $\mathrm{Gd}$ & 7.04 & 0.35 & \\
\hline \multirow[t]{4}{*}[\mathrm{ML}(\mathrm{H}_{2}\mathrm{O})_{5}]{$^{2+}$} & $\mathrm{Am}$ & 6.12 & 0.71 & 0.17 \\
\hline & $\mathrm{Cm}$ & 7.07 & 0.69 & 0.18 \\
\hline & $\mathrm{Eu}$ & 6.82 & 0.14 & \\
\hline & $\mathrm{Gd}$ & 7.04 & 0.38 & \\
\hline \multirow[t]{4}{*}[\mathrm{ML}_{2}(\mathrm{H}_{2}\mathrm{O})_{2}]{$^{1+}$} & $\mathrm{Am}$ & 6.08 & 0.69 & 0.20 \\
\hline & $\mathrm{Cm}$ & 6.95 & 0.61 & 0.20 \\
\hline & $\mathrm{Eu}$ & 6.47 & 0.28 & \\
\hline & $\mathrm{Gd}$ & 7.04 & 0.39 & \\
\hline \multirow[t]{4}{*}[\mathrm{ML}_{2}]{$^{1+}$} & $\mathrm{Am}$ & 6.01 & 0.59 & 0.18 \\
\hline & $\mathrm{Cm}$ & 7.03 & 0.55 & 0.18 \\
\hline & $\mathrm{Eu}$ & 6.59 & 0.29 & \\
\hline & $\mathrm{Gd}$ & 7.04 & 0.48 & \\
\hline \multicolumn{5}{|c|}{$2 \mathbf{i}$} \\
\hline \multirow[t]{4}{*}[\mathrm{ML}(\mathrm{H}_{2}\mathrm{O})_{6}]{$^{2+}$} & $\mathrm{Am}$ & 6.13 & 0.76 & 0.18 \\
\hline & $\mathrm{Cm}$ & 7.06 & 0.71 & 0.18 \\
\hline & $\mathrm{Eu}$ & 6.45 & 0.24 & \\
\hline & $\mathrm{Gd}$ & 7.03 & 0.35 & \\
\hline \multirow[t]{4}{*}[\mathrm{ML}(\mathrm{H}_{2}\mathrm{O})_{5}]{$^{2+}$} & $\mathrm{Am}$ & 6.13 & 0.70 & 0.17 \\
\hline & $\mathrm{Cm}$ & 7.07 & 0.69 & 0.18 \\
\hline & $\mathrm{Eu}$ & 6.49 & 0.24 & \\
\hline & $\mathrm{Gd}$ & 7.04 & 0.36 & \\
\hline$\left[\mathrm{ML}_{2}\left(\mathrm{H}_{2} \mathrm{O}\right)_{2}\right]^{1+}$ & $\mathrm{Am}$ & 6.10 & 0.74 & 0.19 \\
\hline
\end{tabular}




\begin{tabular}{|c|c|c|c|c|}
\hline & $\mathrm{Cm}$ & 7.03 & 0.68 & 0.19 \\
\hline & $\mathrm{Eu}$ & 6.19 & 0.42 & \\
\hline & $\mathrm{Gd}$ & 7.03 & 0.40 & \\
\hline \multirow{4}{*}[\mathrm{ML}_{2}]{$^{1+}$} & $\mathrm{Am}$ & 6.09 & 0.64 & 0.17 \\
\hline & $\mathrm{Cm}$ & 7.06 & 0.61 & 0.18 \\
\hline & $\mathrm{Eu}$ & 6.36 & 0.41 & \\
\hline & $\mathrm{Gd}$ & 7.04 & 0.50 & \\
\hline \multicolumn{5}{|c|}{ 2aei } \\
\hline \multirow[t]{4}{*}[\mathrm{ML}(\mathrm{H}_{2}\mathrm{O})_{6}]{$^{2+}$} & $\mathrm{Am}$ & 6.12 & 0.77 & 0.18 \\
\hline & $\mathrm{Cm}$ & 7.06 & 0.72 & 0.19 \\
\hline & $\mathrm{Eu}$ & 6.38 & 0.28 & \\
\hline & $\mathrm{Gd}$ & 7.03 & 0.35 & \\
\hline \multirow[t]{4}{*}[\mathrm{ML}(\mathrm{H}_{2}\mathrm{O})_{5}]{$^{2+}$} & $\mathrm{Am}$ & 6.13 & 0.70 & 0.17 \\
\hline & $\mathrm{Cm}$ & 7.07 & 0.69 & 0.18 \\
\hline & $\mathrm{Eu}$ & 6.44 & 0.25 & \\
\hline & $\mathrm{Gd}$ & 7.03 & 0.36 & \\
\hline \multirow[t]{4}{*}[\mathrm{ML}_{2}(\mathrm{H}_{2}\mathrm{O})_{2}]{$^{1+}$} & $\mathrm{Am}$ & 6.10 & 0.71 & 0.19 \\
\hline & $\mathrm{Cm}$ & 7.01 & 0.67 & 0.19 \\
\hline & $\mathrm{Eu}$ & 6.21 & 0.41 & \\
\hline & $\mathrm{Gd}$ & 7.03 & 0.40 & \\
\hline \multirow[t]{4}{*}[\mathrm{ML}_{2}]{$^{1+}$} & $\mathrm{Am}$ & 6.07 & 0.63 & 0.17 \\
\hline & $\mathrm{Cm}$ & 7.06 & 0.60 & 0.17 \\
\hline & $\mathrm{Eu}$ & 6.28 & 0.44 & \\
\hline & Gd & 7.04 & 0.49 & \\
\hline \multicolumn{5}{|c|}{ 2ami } \\
\hline \multirow[t]{4}{*}[\mathrm{ML}(\mathrm{H}_{2}\mathrm{O})_{6}]{$^{2+}$} & $\mathrm{Am}$ & 6.13 & 0.77 & 0.18 \\
\hline & $\mathrm{Cm}$ & 7.06 & 0.72 & 0.18 \\
\hline & $\mathrm{Eu}$ & 6.49 & 0.23 & \\
\hline & $\mathrm{Gd}$ & 7.03 & 0.35 & \\
\hline \multirow[t]{4}{*}[\mathrm{ML}(\mathrm{H}_{2}\mathrm{O})_{5}]{$^{2+}$} & $\mathrm{Am}$ & 6.14 & 0.71 & 0.17 \\
\hline & $\mathrm{Cm}$ & 7.07 & 0.70 & 0.18 \\
\hline & $\mathrm{Eu}$ & 6.51 & 0.23 & \\
\hline & $\mathrm{Gd}$ & 7.04 & 0.37 & \\
\hline \multirow[t]{4}{*}[\mathrm{ML}_{2}(\mathrm{H}_{2}\mathrm{O})_{2}]{$^{1+}$} & $\mathrm{Am}$ & 6.10 & 0.72 & 0.19 \\
\hline & $\mathrm{Cm}$ & 7.02 & 0.67 & 0.19 \\
\hline & $\mathrm{Eu}$ & 6.22 & 0.41 & \\
\hline & $\mathrm{Gd}$ & 7.04 & 0.41 & \\
\hline \multirow[t]{2}{*}[\mathrm{ML}_{2}]{$^{1+}$} & $\mathrm{Am}$ & 6.08 & 0.63 & 0.17 \\
\hline & $\mathrm{Cm}$ & 7.06 & 0.61 & 0.17 \\
\hline
\end{tabular}




\begin{tabular}{|c|c|c|c|c|}
\hline & $\mathrm{Eu}$ & 6.37 & 0.40 & \\
\hline & Gd & 7.04 & 0.49 & \\
\hline & & & & \\
\hline$\left[\mathrm{ML}\left(\mathrm{H}_{2} \mathrm{O}\right)_{6}\right]^{2+}$ & $\mathrm{Am}$ & 6.12 & 0.78 & 0.18 \\
\hline & $\mathrm{Cm}$ & 7.06 & 0.72 & 0.18 \\
\hline & $\mathrm{Eu}$ & 6.61 & 0.20 & \\
\hline & Gd & 7.03 & 0.36 & \\
\hline$\left[\mathrm{ML}\left(\mathrm{H}_{2} \mathrm{O}\right)_{5}\right]^{2+}$ & $\mathrm{Am}$ & 6.14 & 0.71 & 0.17 \\
\hline & $\mathrm{Cm}$ & 7.07 & 0.70 & 0.18 \\
\hline & $\mathrm{Eu}$ & 6.73 & 0.16 & \\
\hline & Gd & 7.04 & 0.37 & \\
\hline$\left[\mathrm{ML}_{2}\left(\mathrm{H}_{2} \mathrm{O}\right)_{2}\right]^{1+}$ & $\mathrm{Am}$ & 6.09 & 0.73 & 0.19 \\
\hline & $\mathrm{Cm}$ & 7.01 & 0.68 & 0.20 \\
\hline & $\mathrm{Eu}$ & 6.36 & 0.34 & \\
\hline & Gd & 7.04 & 0.41 & \\
\hline${ }\left[\mathrm{ML}_{2}\right]^{1+}$ & $\mathrm{Am}$ & 6.08 & 0.63 & 0.16 \\
\hline & $\mathrm{Cm}$ & 7.06 & 0.61 & 0.17 \\
\hline & $\mathrm{Eu}$ & 6.56 & 0.31 & \\
\hline & Gd & 7.04 & 0.49 & \\
\hline & & & & \\
\hline$\left[\mathrm{ML}\left(\mathrm{H}_{2} \mathrm{O}\right)_{6}\right]^{2+}$ & $\mathrm{Am}$ & 6.13 & 0.76 & 0.18 \\
\hline & $\mathrm{Cm}$ & 7.06 & 0.72 & 0.19 \\
\hline & $\mathrm{Eu}$ & 6.44 & 0.26 & \\
\hline & Gd & 7.03 & 0.36 & \\
\hline$\left[\mathrm{ML}\left(\mathrm{H}_{2} \mathrm{O}\right)_{5}\right]^{2+}$ & $\mathrm{Am}$ & 6.13 & 0.71 & 0.17 \\
\hline & $\mathrm{Cm}$ & 7.07 & 0.70 & 0.18 \\
\hline & Eu & 6.48 & 0.25 & \\
\hline & Gd & 7.04 & 0.36 & \\
\hline$\left[\mathrm{ML}_{2}\left(\mathrm{H}_{2} \mathrm{O}\right)_{2}\right]^{1+}$ & $\mathrm{Am}$ & 6.09 & 0.72 & 0.19 \\
\hline & $\mathrm{Cm}$ & 7.02 & 0.67 & 0.19 \\
\hline & $\mathrm{Eu}$ & 6.12 & 0.45 & \\
\hline & Gd & 7.03 & 0.39 & \\
\hline$\left[\mathrm{ML}_{2}\right]^{1+}$ & $\mathrm{Am}$ & 6.08 & 0.63 & 0.17 \\
\hline & $\mathrm{Cm}$ & 7.06 & 0.61 & 0.17 \\
\hline & $\mathrm{Eu}$ & 6.25 & 0.46 & 0.13 \\
\hline & $\mathrm{Gd}$ & 7.04 & 0.49 & \\
\hline & & & & \\
\hline$\left[\mathrm{ML}\left(\mathrm{H}_{2} \mathrm{O}\right)_{6}\right]^{2+}$ & $\mathrm{Am}$ & 6.13 & 0.76 & 0.18 \\
\hline & $\mathrm{Cm}$ & 7.06 & 0.72 & 0.19 \\
\hline
\end{tabular}




\begin{tabular}{|c|c|c|c|c|}
\hline & $\mathrm{Eu}$ & 6.45 & 0.26 & \\
\hline & $\mathrm{Gd}$ & 7.03 & 0.36 & \\
\hline \multirow[t]{4}{*}[\mathrm{ML}(\mathrm{H}_{2}\mathrm{O})_{5}]{$^{2+}$} & $\mathrm{Am}$ & 6.13 & 0.71 & 0.17 \\
\hline & $\mathrm{Cm}$ & 7.07 & 0.70 & 0.18 \\
\hline & $\mathrm{Eu}$ & 6.53 & 0.23 & \\
\hline & $\mathrm{Gd}$ & 7.04 & 0.37 & \\
\hline \multirow[t]{4}{*}[\mathrm{ML}_{2}(\mathrm{H}_{2}\mathrm{O})_{2}]{$^{1+}$} & $\mathrm{Am}$ & 6.09 & 0.73 & 0.19 \\
\hline & $\mathrm{Cm}$ & 7.02 & 0.67 & 0.19 \\
\hline & $\mathrm{Eu}$ & 6.15 & 0.44 & \\
\hline & $\mathrm{Gd}$ & 7.03 & 0.40 & \\
\hline \multirow[t]{4}{*}[\mathrm{ML}_{2}]{$^{1+}$} & $\mathrm{Am}$ & 6.08 & 0.64 & 0.17 \\
\hline & $\mathrm{Cm}$ & 7.06 & 0.62 & 0.17 \\
\hline & $\mathrm{Eu}$ & 6.38 & 0.39 & \\
\hline & $\mathrm{Gd}$ & 7.04 & 0.49 & \\
\hline \multicolumn{5}{|c|}{ 2bpi } \\
\hline \multirow[t]{4}{*}[\mathrm{ML}(\mathrm{H}_{2}\mathrm{O})_{6}]{$^{2+}$} & $\mathrm{Am}$ & 6.14 & 0.76 & 0.18 \\
\hline & $\mathrm{Cm}$ & 7.06 & 0.72 & 0.19 \\
\hline & $\mathrm{Eu}$ & 6.63 & 0.19 & \\
\hline & $\mathrm{Gd}$ & 7.03 & 0.36 & \\
\hline \multirow[t]{4}{*}[\mathrm{ML}(\mathrm{H}_{2}\mathrm{O})_{5}]{$^{2+}$} & $\mathrm{Am}$ & 6.14 & 0.71 & 0.17 \\
\hline & $\mathrm{Cm}$ & 7.07 & 0.70 & 0.18 \\
\hline & $\mathrm{Eu}$ & 6.69 & 0.18 & \\
\hline & $\mathrm{Gd}$ & 7.04 & 0.37 & \\
\hline \multirow[t]{4}{*}[\mathrm{ML}_{2}(\mathrm{H}_{2}\mathrm{O})_{2}]{$^{1+}$} & $\mathrm{Am}$ & 6.09 & 0.73 & 0.19 \\
\hline & $\mathrm{Cm}$ & 7.02 & 0.67 & 0.19 \\
\hline & $\mathrm{Eu}$ & 6.27 & 0.39 & \\
\hline & $\mathrm{Gd}$ & 7.03 & 0.39 & \\
\hline \multirow[t]{4}{*}[\mathrm{ML}_{2}]{$^{1+}$} & $\mathrm{Am}$ & 6.07 & 0.64 & 0.17 \\
\hline & $\mathrm{Cm}$ & 7.06 & 0.61 & 0.17 \\
\hline & $\mathrm{Eu}$ & 6.54 & 0.31 & 0.12 \\
\hline & $\mathrm{Gd}$ & 7.04 & 0.49 & \\
\hline
\end{tabular}


Table S4. $\Delta \mathrm{G}_{298 \mathrm{~K}}(\mathrm{kcal} / \mathrm{mol})$ of $2 \mathrm{~N}$ to $3 \mathrm{~N}$ proton transfer in pyrazole ring of Core 2 ligands in the gas phase, water, and butanol for each metal, calculated at the B3LYP/Stuttgart'97ECP/DZVP2 gas phase level with solvent corrections at the BLYP/TZ2P/ZORA level.

\begin{tabular}{|c|c|c|c|c|}
\hline Complex & M & $\Delta \mathbf{G}_{298 K, g a s}$ & $\Delta \mathbf{G}_{\text {sol,aq }}$ & $\Delta G_{\text {sol,but }}$ \\
\hline \multicolumn{5}{|c|}{ Core 2} \\
\hline \multirow[t]{4}{*}[\mathrm{ML}(\mathrm{H}_{2}\mathrm{O})_{6}]{$^{3+}$} & $\mathbf{E u}$ & -18.5 & -15.2 & -16.0 \\
\hline & Gd & -22.5 & -21.5 & -21.1 \\
\hline & Am & -22.7 & -20.6 & -21.4 \\
\hline & $\mathbf{C m}$ & -23.9 & -22.9 & -23.1 \\
\hline \multirow[t]{4}{*}[\mathrm{ML}(\mathrm{H}_{2}\mathrm{O})_{5}]{$^{3+}$} & $\mathbf{E u}$ & -24.3 & -20.7 & -21.7 \\
\hline & Gd & -25.3 & -22.6 & -23.6 \\
\hline & Am & -26.3 & -24.0 & -24.1 \\
\hline & $\mathbf{C m}$ & -25.5 & -22.5 & -23.1 \\
\hline \multirow[t]{4}{*}[\mathrm{ML}_{2}(\mathrm{H}_{2}\mathrm{O})_{2}]{$^{3+}$} & $\mathbf{E u}$ & -41.9 & -41.1 & -42.6 \\
\hline & Gd & -38.2 & -46.0 & -45.9 \\
\hline & Am & -48.0 & -47.0 & -47.6 \\
\hline & $\mathbf{C m}$ & -38.5 & -45.4 & -45.5 \\
\hline \multirow[t]{4}{*}[\mathrm{ML}_{2}]{$^{3+}$} & Eu & -54.3 & $-47.3^{\mathrm{a}}$ & $-47.8^{\mathrm{a}}$ \\
\hline & Gd & -61.4 & -59.4 & -58.4 \\
\hline & Am & -58.5 & -55.1 & -56.7 \\
\hline & $\mathbf{C m}$ & -60.0 & -58.4 & -57.2 \\
\hline \multicolumn{5}{|c|}{$2 a e$} \\
\hline \multirow[t]{4}{*}[\mathrm{ML}(\mathrm{H}_{2}\mathrm{O})6]{$^{3+}$} & $\mathbf{E u}$ & -19.6 & -17.2 & -16.2 \\
\hline & Gd & -22.8 & -21.6 & -20.3 \\
\hline & Am & -22.2 & -20.5 & -19.0 \\
\hline & $\mathbf{C m}$ & -22.6 & -21.0 & -19.7 \\
\hline \multirow[t]{4}{*}[\mathrm{ML}(\mathrm{H}_{2}\mathrm{O})5]{$^{3+}$} & Eu & -23.2 & -19.2 & -19.3 \\
\hline & Gd & -28.7 & -25.3 & -25.1 \\
\hline & Am & -27.1 & -24.1 & -24.3 \\
\hline & $\mathbf{C m}$ & -28.5 & -24.4 & -24.6 \\
\hline \multirow[t]{4}{*}[\mathrm{ML}_{2}(\mathrm{H}_{2}\mathrm{O})_{2}]{$^{3+}$} & $\mathbf{E u}$ & -46.5 & -36.9 & -37.4 \\
\hline & Gd & -54.2 & -43.5 & -44.8 \\
\hline & Am & -51.0 & -41.7 & -41.6 \\
\hline & $\mathbf{C m}$ & -52.8 & -43.3 & -43.3 \\
\hline \multirow[t]{4}{*}[\mathrm{ML}_{2}]{$^{3+}$} & $\mathbf{E u}$ & -55.3 & -55.7 & -58.1 \\
\hline & Gd & -60.3 & -63.9 & -58.1 \\
\hline & Am & -57.4 & -60.2 & -61.4 \\
\hline & $\mathbf{C m}$ & -59.1 & -59.6 & -56.5 \\
\hline \multicolumn{5}{|c|}{$2 \mathrm{am}$} \\
\hline$\left[\mathrm{ML}\left(\mathrm{H}_{2} \mathrm{O}\right)_{6}\right]^{3+}$ & $\mathbf{E u}$ & -19.7 & -18.4 & -18.3 \\
\hline
\end{tabular}




\begin{tabular}{|c|c|c|c|c|}
\hline & Gd & -21.7 & -20.3 & -20.0 \\
\hline & $\mathbf{A m}$ & -20.2 & -19.0 & -18.6 \\
\hline & $\mathbf{C m}$ & -21.7 & -20.9 & -20.7 \\
\hline$\left[\mathrm{ML}\left(\mathrm{H}_{2} \mathrm{O}\right)_{5}\right]^{3+}$ & $\mathbf{E u}$ & -22.6 & -22.0 & -23.7 \\
\hline & Gd & -25.3 & -24.5 & -25.3 \\
\hline & $\mathbf{A m}$ & -24.1 & -23.9 & -23.9 \\
\hline & $\mathbf{C m}$ & -24.8 & -23.1 & -24.4 \\
\hline$\left[\mathrm{ML}_{2}\left(\mathrm{H}_{2} \mathrm{O}\right)_{2}\right]^{3+}$ & Eu & -48.7 & -44.6 & -40.1 \\
\hline & Gd & -55.1 & -47.5 & -43.2 \\
\hline & $\mathbf{A m}$ & -52.7 & -48.7 & -44.5 \\
\hline & $\mathbf{C m}$ & -54.0 & -48.7 & -42.4 \\
\hline$\left[\mathrm{ML}_{2}\right]^{3+}$ & Eu & -51.3 & $-43.1^{\mathrm{a}}$ & $-43.5^{\mathrm{a}}$ \\
\hline & Gd & -57.6 & -61.9 & -62.7 \\
\hline & Am & -55.0 & -55.9 & -61.6 \\
\hline & $\mathbf{C m}$ & -57.5 & -53.8 & -61.7 \\
\hline & & & & \\
\hline$\left[\mathrm{ML}\left(\mathrm{H}_{2} \mathrm{O}\right)_{6}\right]^{3+}$ & Eu & -12.4 & -11.3 & -10.9 \\
\hline & Gd & -22.5 & -23.7 & -22.1 \\
\hline & $\mathbf{A m}$ & -21.6 & -21.8 & -22.0 \\
\hline & $\mathbf{C m}$ & -22.8 & -23.1 & -23.4 \\
\hline$\left[\mathrm{ML}\left(\mathrm{H}_{2} \mathrm{O}\right)_{5}\right]^{3+}$ & Eu & -16.3 & -12.0 & -12.9 \\
\hline & Gd & -23.7 & -22.6 & -21.9 \\
\hline & $\mathbf{A m}$ & -23.4 & -22.2 & -22.0 \\
\hline & $\mathbf{C m}$ & -23.6 & -21.8 & -21.8 \\
\hline$\left[\mathrm{ML}_{2}\left(\mathrm{H}_{2} \mathrm{O}\right)_{2}\right]^{3+}$ & Eu & -36.6 & $-40.5^{\mathrm{a}}$ & $-40.3^{\mathrm{a}}$ \\
\hline & Gd & -47.6 & -39.3 & -36.6 \\
\hline & Am & -46.8 & -40.5 & -36.4 \\
\hline & $\mathbf{C m}$ & -51.0 & -43.0 & -41.0 \\
\hline$\left[\mathrm{ML}_{2}\right]^{3+}$ & Eu & -42.3 & -48.4 & -48.3 \\
\hline & Gd & -55.8 & -60.7 & -56.7 \\
\hline & Am & -51.7 & -60.2 & -56.4 \\
\hline & $\mathbf{C m}$ & -54.5 & -59.0 & -56.2 \\
\hline & & & & \\
\hline$\left[\mathrm{ML}\left(\mathrm{H}_{2} \mathrm{O}\right)_{6}\right]^{3+}$ & Eu & -11.9 & -12.4 & -12.0 \\
\hline & Gd & -18.2 & -29.1 & -26.9 \\
\hline & $\mathbf{A m}$ & -19.5 & -22.6 & -21.6 \\
\hline & $\mathbf{C m}$ & -26.5 & -25.2 & -24.7 \\
\hline$\left[\mathrm{ML}\left(\mathrm{H}_{2} \mathrm{O}\right)_{5}\right]^{3+}$ & Eu & -18.0 & -17.3 & -16.3 \\
\hline & Gd & -26.0 & -25.3 & -25.0 \\
\hline
\end{tabular}




\begin{tabular}{|c|c|c|c|c|}
\hline & Am & -22.9 & -25.6 & -24.7 \\
\hline & $\mathrm{Cm}$ & -25.7 & -24.4 & -24.3 \\
\hline$\left[\mathrm{ML}_{2}\left(\mathrm{H}_{2} \mathrm{O}\right)_{2}\right]^{3+}$ & $\mathbf{E u}$ & -35.4 & -36.0 & -26.8 \\
\hline & Gd & -49.5 & -47.5 & -41.5 \\
\hline & Am & -47.0 & $-45.8^{a}$ & $-45.9^{a}$ \\
\hline & $\mathrm{Cm}$ & -47.8 & -47.4 & -39.9 \\
\hline$\left[\mathrm{ML}_{2}\right]^{3+}$ & $\mathbf{E u}$ & -44.0 & $-35.0^{\mathrm{a}}$ & $-35.3^{a}$ \\
\hline & Gd & -60.4 & -54.8 & -57.6 \\
\hline & Am & -54.6 & -44.4 & -61.1 \\
\hline & $\mathrm{Cm}$ & -58.3 & -47.2 & -57.3 \\
\hline & & & & \\
\hline$\left[\mathrm{ML}\left(\mathrm{H}_{2} \mathrm{O}\right)_{6}\right]^{3+}$ & $\mathbf{E u}$ & -10.4 & -17.8 & -11.8 \\
\hline & Gd & -21.0 & -19.9 & -19.5 \\
\hline & Am & -19.2 & -23.1 & -23.9 \\
\hline & $\mathrm{Cm}$ & -24.8 & -23.5 & -24.1 \\
\hline$\left[\mathrm{ML}\left(\mathrm{H}_{2} \mathrm{O}\right)_{5}\right]^{3+}$ & $\mathbf{E u}$ & -17.5 & -18.4 & -18.5 \\
\hline & Gd & -24.7 & -20.6 & -23.5 \\
\hline & Am & -22.1 & -25.4 & -24.4 \\
\hline & $\mathrm{Cm}$ & -24.6 & -22.9 & -24.1 \\
\hline$\left[\mathrm{ML}_{2}\left(\mathrm{H}_{2} \mathrm{O}\right)_{2}\right]^{3+}$ & $\mathbf{E u}$ & -35.8 & $-37.4^{\mathrm{a}}$ & $-39.1^{\mathrm{a}}$ \\
\hline & Gd & -47.8 & -48.9 & -40.6 \\
\hline & Am & -45.0 & -48.3 & -39.3 \\
\hline & $\mathrm{Cm}$ & -46.2 & -48.4 & -39.4 \\
\hline$\left[\mathrm{ML}_{2}\right]^{3+}$ & $\mathbf{E u}$ & -44.6 & -32.3 & -36.7 \\
\hline & Gd & -57.3 & -55.7 & -61.4 \\
\hline & Am & -53.8 & -49.8 & -63.8 \\
\hline & $\mathrm{Cm}$ & -55.8 & -50.1 & -60.3 \\
\hline & & & & \\
\hline$\left[\mathrm{ML}\left(\mathrm{H}_{2} \mathrm{O}\right)_{6}\right]^{3+}$ & $\mathbf{E u}$ & -10.4 & -11.8 & -10.9 \\
\hline & Gd & -19.8 & -20.3 & -19.6 \\
\hline & Am & -19.5 & -23.7 & -22.6 \\
\hline & $\mathrm{Cm}$ & -23.5 & -24.0 & -23.4 \\
\hline$\left[\mathrm{ML}\left(\mathrm{H}_{2} \mathrm{O}\right)_{5}\right]^{3+}$ & $\mathbf{E u}$ & -17.6 & -16.1 & -18.0 \\
\hline & Gd & -22.4 & -23.9 & -22.9 \\
\hline & Am & -20.4 & -23.4 & -23.3 \\
\hline & $\mathrm{Cm}$ & -22.2 & -21.6 & -22.4 \\
\hline$\left[\mathrm{ML}_{2}\left(\mathrm{H}_{2} \mathrm{O}\right)_{2}\right]^{3+}$ & $\mathbf{E u}$ & -33.5 & -16.0 & -23.1 \\
\hline & Gd & -44.7 & -43.0 & -36.3 \\
\hline & Am & -39.5 & -36.5 & -30.6 \\
\hline
\end{tabular}




\begin{tabular}{|l|l|r|r|r|}
\hline & $\mathbf{C m}$ & -43.7 & -43.1 & -35.3 \\
\hline$\left[\mathbf{M L}_{2}\right]^{3+}$ & $\mathbf{E u}$ & -41.5 & $-37.0^{\mathrm{a}}$ & $-36.9^{\mathrm{a}}$ \\
\cline { 2 - 5 } & $\mathbf{G d}$ & -56.3 & -56.7 & -56.3 \\
\cline { 2 - 5 } & $\mathbf{A m}$ & -52.5 & -60.1 & -59.2 \\
\cline { 2 - 5 } & $\mathbf{C m}$ & -54.8 & -51.0 & -56.0 \\
\hline
\end{tabular}

${ }^{a}$ Due to convergence issues, these solvation energy calculations were obtained at the B3LYP/Stuttgart'97/DZVP2/COSMO level with Gaussian16

Table S5. $\Delta \mathrm{G}_{298 \mathrm{~K}}$ energies $(\mathrm{kcal} / \mathrm{mol})$ in the gas phase, water, and butanol for complexation reactions where $\mathrm{L}=\mathbf{1}$

\begin{tabular}{|c|c|c|c|c|}
\hline $\mathbf{M}$ & Rxn & $\Delta \mathbf{G}_{298 K, g a s}$ & $\Delta \mathbf{G}_{298 K, \mathbf{a q}}$ & $\Delta \mathbf{G}_{298 K, b u t}$ \\
\hline \multirow[t]{4}{*}{$\mathbf{E u}$} & $(4 a)$ & -85.4 & -18.7 & -35.0 \\
\hline & $(5 a)$ & -83.2 & -19.0 & -34.6 \\
\hline & (6a) & -107.8 & 0.6 & -29.8 \\
\hline & (7a) & -90.2 & 11.2 & -31.1 \\
\hline \multirow[t]{4}{*}{ Gd } & $(4 a)$ & -54.9 & 2.6 & -9.5 \\
\hline & (5a) & -51.9 & 0.3 & -15.0 \\
\hline & (6a) & -89.9 & 11.3 & -18.5 \\
\hline & (7a) & -63.9 & 38.4 & 0.3 \\
\hline \multirow[t]{4}{*}{ Am } & $(4 a)$ & -58.9 & 2.1 & -11.0 \\
\hline & $(5 a)$ & -55.3 & 0.2 & -16.0 \\
\hline & (6a) & -95.4 & 8.5 & -21.6 \\
\hline & (7a) & -74.4 & 29.3 & -9.2 \\
\hline \multirow[t]{4}{*}{$\mathrm{Cm}$} & $(4 a)$ & -54.3 & 2.1 & -10.9 \\
\hline & $(5 a)$ & -50.6 & 0.7 & -15.8 \\
\hline & (6a) & -89.7 & 9.4 & -19.7 \\
\hline & (7a) & -65.2 & 34.5 & -3.8 \\
\hline
\end{tabular}


Table S6. $\Delta \mathrm{G}_{298 \mathrm{~K}}$ energies $(\mathrm{kcal} / \mathrm{mol})$ in the gas phase, water, and butanol for complexation reactions where $\mathrm{L}=\mathbf{1 a}$

\begin{tabular}{|c|c|c|c|c|}
\hline $\mathbf{M}$ & $\operatorname{Rxn}$ & $\Delta \mathbf{G}_{298 K, g a s}$ & $\Delta \mathbf{G}_{298 K, \mathbf{a q}}$ & $\Delta \mathbf{G}_{298 K, b u t}$ \\
\hline $\mathbf{E u}$ & $\begin{array}{l}(4 a) \\
(5 a) \\
(6 a) \\
(7 a)\end{array}$ & $\begin{array}{l}-100.4 \\
-105.3 \\
-136.2 \\
-107.5\end{array}$ & $\begin{array}{r}-15.9 \\
-28.4 \\
-25.3 \\
9.0\end{array}$ & $\begin{array}{l}-28.7 \\
-39.7 \\
-40.4 \\
-22.5\end{array}$ \\
\hline Gd & $\begin{array}{l}(4 a) \\
(5 a) \\
(6 a) \\
(7 a)\end{array}$ & $\begin{array}{r}-72.4 \\
-65.2 \\
-123.1 \\
-90.4\end{array}$ & $\begin{array}{r}-2.2 \\
0.2 \\
1.5 \\
26.5\end{array}$ & $\begin{array}{r}-12.9 \\
-13.9 \\
-29.3 \\
-5.9\end{array}$ \\
\hline Am & $\begin{array}{l}(4 a) \\
(5 a) \\
(6 a) \\
(7 a)\end{array}$ & $\begin{array}{r}-78.3 \\
-70.3 \\
-126.5 \\
-100.3\end{array}$ & $\begin{array}{r}-5.8 \\
-1.7 \\
1.4 \\
20.4\end{array}$ & $\begin{array}{l}-17.1 \\
-16.5 \\
-29.7 \\
-14.0\end{array}$ \\
\hline $\mathrm{Cm}$ & $\begin{array}{l}(4 a) \\
(5 a) \\
(6 a) \\
(7 a)\end{array}$ & $\begin{array}{r}-71.5 \\
-64.2 \\
-122.1 \\
-91.7\end{array}$ & $\begin{array}{r}-2.9 \\
-1.1 \\
0.1 \\
24.4\end{array}$ & $\begin{array}{l}-13.4 \\
-15.2 \\
-30.1 \\
-10.1\end{array}$ \\
\hline
\end{tabular}

Table S7. $\Delta \mathrm{G}_{298 \mathrm{~K}}$ energies $(\mathrm{kcal} / \mathrm{mol})$ in the gas phase, water, and butanol for complexation reactions where $\mathrm{L}=\mathbf{1 b}$

\begin{tabular}{|c|c|c|c|c|}
\hline $\mathbf{M}$ & Rxn & $\Delta \mathbf{G}_{298 K \text {,gas }}$ & $\Delta \mathbf{G}_{298 K, \mathbf{a q}}$ & $\Delta \mathbf{G}_{298 K, b u t}$ \\
\hline \multirow[t]{4}{*}{$\mathbf{E u}$} & (4a) & -118.5 & -12.4 & -24.9 \\
\hline & (5a) & -116.4 & 1.8 & -20.0 \\
\hline & (6a) & -164.0 & -6.7 & -41.1 \\
\hline & (7a) & -146.6 & 9.9 & -26.3 \\
\hline \multirow{4}{*}{ Gd } & $(4 a)$ & -90.3 & -4.5 & -15.4 \\
\hline & $(5 a)$ & -87.1 & -5.9 & -20.7 \\
\hline & (6a) & -145.4 & 2.0 & -26.2 \\
\hline & (7a) & -117.2 & 28.7 & -5.7 \\
\hline \multirow[t]{4}{*}{ Am } & (4a) & -96.3 & -3.8 & -14.3 \\
\hline & (5a) & -93.0 & -4.7 & -18.7 \\
\hline & (6a) & -148.9 & 3.3 & -26.4 \\
\hline & (7a) & -126.7 & 22.7 & -11.1 \\
\hline \multirow[t]{4}{*}{$\mathrm{Cm}$} & (4a) & -89.2 & -5.5 & -17.0 \\
\hline & (5a) & -85.6 & -6.3 & -21.0 \\
\hline & (6a) & -144.5 & 1.0 & -28.5 \\
\hline & (7a) & -116.4 & 30.1 & -3.3 \\
\hline
\end{tabular}


Table S8. $\Delta \mathrm{G}_{298 \mathrm{~K}}$ energies $(\mathrm{kcal} / \mathrm{mol})$ in the gas phase, water, and butanol for complexation reactions where $\mathrm{L}=\mathbf{2}$

\begin{tabular}{|c|c|c|c|c|}
\hline $\mathbf{M}$ & Rxn & $\Delta \mathbf{G}_{298 K \text {,gas }}$ & $\Delta \mathbf{G}_{298 K, \mathbf{a q}}$ & $\Delta \mathbf{G}_{298 K, b u t}$ \\
\hline Eu & $\begin{array}{l}(4 a) \\
(5 a) \\
(6 a) \\
(7 a)\end{array}$ & $\begin{array}{r}-77.2 \\
-73.2 \\
-127.5 \\
-102.4\end{array}$ & $\begin{array}{r}-13.2 \\
-15.4 \\
-22.1 \\
-6.3\end{array}$ & $\begin{array}{l}-27.6 \\
-33.4 \\
-54.0 \\
-43.7\end{array}$ \\
\hline Gd & $\begin{array}{l}(4 a) \\
(5 a) \\
(6 a) \\
(7 a)\end{array}$ & $\begin{array}{r}-71.3 \\
-65.2 \\
-118.5 \\
-97.6\end{array}$ & $\begin{array}{r}-14.9 \\
-14.2 \\
-24.1 \\
-4.4\end{array}$ & $\begin{array}{l}-28.3 \\
-31.6 \\
-54.5 \\
-40.7\end{array}$ \\
\hline Am & $\begin{array}{l}(4 a) \\
(5 a) \\
(6 a) \\
(7 a)\end{array}$ & $\begin{array}{r}-75.9 \\
-70.1 \\
-131.2 \\
-105.5\end{array}$ & $\begin{array}{l}-15.5 \\
-15.9 \\
-26.1 \\
-10.4\end{array}$ & $\begin{array}{l}-29.8 \\
-33.6 \\
-57.7 \\
-48.0\end{array}$ \\
\hline $\mathrm{Cm}$ & $\begin{array}{l}(4 a) \\
(5 a) \\
(6 a) \\
(7 a)\end{array}$ & $\begin{array}{r}-72.0 \\
-64.1 \\
-117.7 \\
-98.1\end{array}$ & $\begin{array}{r}-15.7 \\
-13.8 \\
-24.2 \\
-7.6\end{array}$ & $\begin{array}{l}-30.1 \\
-31.3 \\
-55.3 \\
-44.3\end{array}$ \\
\hline
\end{tabular}

Table S9. $\Delta \mathrm{G}_{298 \mathrm{~K}}$ energies $(\mathrm{kcal} / \mathrm{mol})$ in the gas phase, water, and butanol for complexation reactions where $\mathrm{L}=\mathbf{2 a e}$

\begin{tabular}{|l|l|r|r|r|}
\hline $\mathbf{M}$ & $\mathbf{R x n}$ & $\Delta \mathbf{G}$ 298K,gas & $\Delta \mathbf{G}$ 298K,aq & $\Delta \mathbf{G}$ 298K,but \\
\hline Eu & $(4 \mathrm{a})$ & -96.9 & -18.2 & -28.0 \\
& $(5 \mathrm{a})$ & -93.4 & -20.2 & -33.9 \\
& $(6 \mathrm{a})$ & -155.5 & -17.2 & -43.9 \\
& $(7 \mathrm{a})$ & -133.2 & -9.8 & -40.4 \\
\hline \multirow{2}{*}{ Gd } & $(4 \mathrm{a})$ & -89.8 & -18.6 & -27.5 \\
& $(5 \mathrm{a})$ & -85.8 & -19.0 & -31.9 \\
& $(6 \mathrm{a})$ & -156.9 & -20.4 & -47.3 \\
& $(7 \mathrm{a})$ & -126.4 & -5.5 & -29.2 \\
\hline \multirow{2}{*}{ Am } & $(4 \mathrm{a})$ & -93.1 & -18.0 & -27.9 \\
& $(5 \mathrm{a})$ & -88.8 & -19.4 & -33.3 \\
& $(6 a)$ & -158.8 & -21.5 & -48.0 \\
& $(7 \mathrm{a})$ & -133.8 & -11.9 & -42.6 \\
\hline \multirow{2}{*}{$\mathbf{C m}$} & $(4 \mathrm{a})$ & -88.7 & -18.2 & -28.5 \\
& $(5 \mathrm{a})$ & -83.9 & -18.4 & -32.2 \\
& $(6 a)$ & -154.4 & -21.1 & -47.5 \\
& $(7 a)$ & -126.4 & -7.9 & -33.1 \\
\hline
\end{tabular}


Table S10. $\Delta \mathrm{G}_{298 \mathrm{~K}}$ energies $(\mathrm{kcal} / \mathrm{mol})$ in the gas phase, water, and butanol for complexation reactions where $\mathrm{L}=\mathbf{2} \mathbf{a m}$

\begin{tabular}{|l|c|r|r|r|}
\hline $\mathbf{M}$ & $\mathbf{R x n}$ & $\Delta \mathbf{G}_{\mathbf{2 9 8 K}, \mathbf{g a s}}$ & $\Delta \mathbf{G}_{\mathbf{2 9 8 K} \text {,aq }}$ & $\Delta \mathbf{G}_{\mathbf{2 9 8 K}, \mathbf{b u t}}$ \\
\hline Eu & $(4 \mathrm{a})$ & -103.1 & -21.0 & -33.2 \\
& $(5 \mathrm{a})$ & -99.6 & -22.5 & -39.2 \\
& $(6 \mathrm{a})$ & -168.4 & -33.6 & -58.3 \\
& $(7 \mathrm{a})$ & -143.8 & -16.7 & -51.4 \\
\hline $\mathbf{G d}$ & $(4 \mathrm{a})$ & -96.2 & -21.2 & -33.2 \\
& $(5 \mathrm{a})$ & -92.4 & -22.3 & -37.6 \\
& $(6 \mathrm{a})$ & -168.7 & -36.0 & -58.3 \\
& $(7 \mathrm{a})$ & -139.5 & -16.7 & -51.4 \\
\hline \multirow{2}{*}{$\mathbf{A m}$} & $(4 \mathrm{a})$ & -98.7 & -20.3 & -33.1 \\
& $(5 \mathrm{a})$ & -95.4 & -22.4 & -38.6 \\
& $(6 \mathrm{a})$ & -171.1 & -37.5 & -61.8 \\
& $(7 \mathrm{a})$ & -146.5 & -22.0 & -58.6 \\
\hline $\mathbf{C m}$ & $(4 \mathrm{a})$ & -95.0 & -21.4 & -34.2 \\
& $(5 \mathrm{a})$ & -90.5 & -21.3 & -37.2 \\
& $(6 \mathrm{a})$ & -166.3 & -37.3 & -60.2 \\
& $(7 \mathrm{a})$ & -139.5 & -18.5 & -54.6 \\
\hline
\end{tabular}

Table S11. $\Delta \mathrm{G}_{298 \mathrm{~K}}$ energies $(\mathrm{kcal} / \mathrm{mol})$ in the gas phase, water, and butanol for complexation reactions where $\mathrm{L}=\mathbf{2 a p}$

\begin{tabular}{|l|l|r|r|r|}
\hline $\mathbf{M}$ & $\mathbf{R x n}$ & $\Delta \mathbf{G}_{\mathbf{2 9 8 K} \text {,gas }}$ & $\Delta \mathbf{G}_{\mathbf{2 9 8 K} \text {,aq }}$ & $\Delta \mathbf{G}_{\mathbf{2 9 8 K}, \mathbf{b u t}}$ \\
\hline Eu & $(4 \mathrm{a})$ & -116.5 & -25.7 & -36.0 \\
& $(5 \mathrm{a})$ & -114.5 & -27.2 & -41.9 \\
& $(6 \mathrm{a})$ & -175.9 & -27.5 & -53.5 \\
& $(7 \mathrm{a})$ & -153.8 & -19.5 & -50.4 \\
\hline Gd & $(4 \mathrm{a})$ & -99.4 & -21.7 & -31.2 \\
& $(5 \mathrm{a})$ & -96.1 & -22.7 & -36.7 \\
& $(6 \mathrm{a})$ & -170.8 & -26.7 & -53.5 \\
& $(7 \mathrm{a})$ & -144.5 & -14.0 & -43.3 \\
\hline \multirow{2}{*}{$\mathbf{A m}$} & $(4 \mathrm{a})$ & -102.3 & -20.3 & -31.0 \\
& $(5 \mathrm{a})$ & -99.5 & -22.7 & -37.2 \\
& $(6 \mathrm{a})$ & -173.0 & -28.6 & -55.1 \\
& $(7 \mathrm{a})$ & -150.1 & -21.0 & -50.6 \\
\hline \multirow{2}{*}{$\mathbf{C m}$} & $(4 \mathrm{a})$ & -98.5 & -22.0 & -32.7 \\
& $(5 \mathrm{a})$ & -94.2 & -21.9 & -36.5 \\
& $(6 \mathrm{a})$ & -168.3 & -27.3 & -54.3 \\
& $(7 \mathrm{a})$ & -143.7 & -15.6 & -46.1 \\
\hline
\end{tabular}


Table S12. $\Delta \mathrm{G}_{298 \mathrm{~K}}$ energies $(\mathrm{kcal} / \mathrm{mol})$ in the gas phase, water, and butanol for complexation reactions where $\mathrm{L}=\mathbf{2}$ be

\begin{tabular}{|c|c|c|c|c|}
\hline $\mathbf{M}$ & Rxn & $\Delta \mathbf{G}_{298 K \text {,gas }}$ & $\Delta \mathbf{G}_{298 K, \mathbf{a q}}$ & $\Delta \mathbf{G}_{298 K, b u t}$ \\
\hline Eu & $\begin{array}{l}(4 a) \\
(5 a) \\
(6 a) \\
(7 a)\end{array}$ & $\begin{array}{l}-126.6 \\
-128.3 \\
-183.9 \\
-167.0\end{array}$ & $\begin{array}{l}-24.8 \\
-29.6 \\
-30.6 \\
-23.3\end{array}$ & $\begin{array}{l}-37.1 \\
-45.2 \\
-52.2 \\
-48.2\end{array}$ \\
\hline Gd & $\begin{array}{l}(4 a) \\
(5 a) \\
(6 a) \\
(7 a)\end{array}$ & $\begin{array}{r}-100.4 \\
-96.9 \\
-170.8 \\
-140.2\end{array}$ & $\begin{array}{r}-21.9 \\
-22.4 \\
-27.0 \\
-7.8\end{array}$ & $\begin{array}{l}-30.8 \\
-34.7 \\
-47.4 \\
-31.2\end{array}$ \\
\hline Am & $\begin{array}{l}(4 a) \\
(5 a) \\
(6 a) \\
(7 a)\end{array}$ & $\begin{array}{l}-104.8 \\
-102.1 \\
-173.2 \\
-147.4\end{array}$ & $\begin{array}{r}-19.8 \\
-17.8 \\
-27.1 \\
-11.8\end{array}$ & $\begin{array}{l}-28.4 \\
-30.9 \\
-47.0 \\
-42.2\end{array}$ \\
\hline $\mathrm{Cm}$ & $\begin{array}{l}(4 a) \\
(5 a) \\
(6 a) \\
(7 a)\end{array}$ & $\begin{array}{r}-99.1 \\
-94.8 \\
-168.3 \\
-140.2\end{array}$ & $\begin{array}{l}-21.4 \\
-21.6 \\
-28.7 \\
-10.2\end{array}$ & $\begin{array}{l}-30.6 \\
-34.8 \\
-47.8 \\
-37.0\end{array}$ \\
\hline
\end{tabular}

Table S13. $\Delta \mathrm{G}_{298 \mathrm{~K}}$ energies $(\mathrm{kcal} / \mathrm{mol})$ in the gas phase, water, and butanol for complexation reactions where $\mathrm{L}=\mathbf{2} \mathbf{b m}$

\begin{tabular}{|c|c|c|c|c|}
\hline $\mathbf{M}$ & Rxn & $\Delta \mathbf{G} 298 K$,gas & $\Delta \mathbf{G} 298 \mathrm{~K}, \mathbf{a q}$ & $\Delta \mathbf{G}$ 298K,but \\
\hline $\mathbf{E u}$ & $\begin{array}{l}(4 a) \\
(5 a) \\
(6 a) \\
(7 a)\end{array}$ & $\begin{array}{l}-130.2 \\
-133.4 \\
-193.4 \\
-178.3\end{array}$ & $\begin{array}{l}-26.5 \\
-32.2 \\
-41.8 \\
-31.0\end{array}$ & $\begin{array}{l}-39.8 \\
-49.5 \\
-64.9 \\
-64.5\end{array}$ \\
\hline Gd & $\begin{array}{l}(4 a) \\
(5 a) \\
(6 a) \\
(7 a)\end{array}$ & $\begin{array}{l}-106.4 \\
-103.0 \\
-182.4 \\
-152.4\end{array}$ & $\begin{array}{l}-23.4 \\
-25.6 \\
-40.6 \\
-17.9\end{array}$ & $\begin{array}{l}-34.4 \\
-39.9 \\
-61.1 \\
-51.6\end{array}$ \\
\hline Am & $\begin{array}{l}(4 a) \\
(5 a) \\
(6 a) \\
(7 a)\end{array}$ & $\begin{array}{l}-110.7 \\
-108.0 \\
-184.5 \\
-159.8\end{array}$ & $\begin{array}{l}-23.8 \\
-21.9 \\
-41.1 \\
-23.6\end{array}$ & $\begin{array}{l}-36.6 \\
-36.7 \\
-61.7 \\
-58.9\end{array}$ \\
\hline $\mathrm{Cm}$ & $\begin{array}{l}(4 a) \\
(5 a) \\
(6 a) \\
(7 a)\end{array}$ & $\begin{array}{l}-105.1 \\
-100.9 \\
-179.6 \\
-152.3\end{array}$ & $\begin{array}{l}-23.6 \\
-24.6 \\
-41.2 \\
-20.7\end{array}$ & $\begin{array}{l}-35.5 \\
-40.1 \\
-61.6 \\
-55.8\end{array}$ \\
\hline
\end{tabular}


Table S14. $\Delta \mathrm{G}_{298 \mathrm{~K}}$ energies $(\mathrm{kcal} / \mathrm{mol})$ in the gas phase, water, and butanol for complexation reactions where $\mathrm{L}=\mathbf{2} \mathbf{b p}$

\begin{tabular}{|c|c|c|c|c|}
\hline $\mathbf{M}$ & Rxn & $\Delta \mathbf{G}_{298 K \text {,gas }}$ & $\Delta \mathbf{G}_{298 K, \mathbf{a q}}$ & $\Delta \mathbf{G}_{298 K, b u t}$ \\
\hline Eu & $\begin{array}{l}(4 a) \\
(5 a) \\
(6 a) \\
(7 a)\end{array}$ & $\begin{array}{l}-122.0 \\
-117.8 \\
-193.4 \\
-177.1\end{array}$ & $\begin{array}{l}-17.3 \\
-31.7 \\
-34.2 \\
-26.6\end{array}$ & $\begin{array}{l}-28.3 \\
-48.4 \\
-57.3 \\
-54.0\end{array}$ \\
\hline Gd & $\begin{array}{l}(4 a) \\
(5 a) \\
(6 a) \\
(7 a)\end{array}$ & $\begin{array}{l}-109.2 \\
-106.6 \\
-183.5 \\
-155.6\end{array}$ & $\begin{array}{l}-24.3 \\
-26.1 \\
-32.3 \\
-15.7\end{array}$ & $\begin{array}{l}-34.5 \\
-38.8 \\
-54.0 \\
-41.8\end{array}$ \\
\hline Am & $\begin{array}{l}(4 a) \\
(5 a) \\
(6 a) \\
(7 a)\end{array}$ & $\begin{array}{l}-112.7 \\
-110.0 \\
-182.8 \\
-159.8\end{array}$ & $\begin{array}{l}-23.5 \\
-22.4 \\
-27.1 \\
-23.6\end{array}$ & $\begin{array}{l}-33.2 \\
-36.4 \\
-50.9 \\
-58.9\end{array}$ \\
\hline $\mathrm{Cm}$ & $\begin{array}{l}(4 a) \\
(5 a) \\
(6 a) \\
(7 a)\end{array}$ & $\begin{array}{l}-107.8 \\
-104.1 \\
-181.0 \\
-152.3\end{array}$ & $\begin{array}{l}-24.3 \\
-24.6 \\
-33.1 \\
-20.7\end{array}$ & $\begin{array}{l}-34.4 \\
-38.8 \\
-54.7 \\
-55.8\end{array}$ \\
\hline
\end{tabular}

Table S15. $\Delta \mathrm{G}_{298 \mathrm{~K}}$ energies $(\mathrm{kcal} / \mathrm{mol})$ in the gas phase, water, and butanol for complexation reactions where $\mathrm{L}=\mathbf{1 i}$

\begin{tabular}{|c|c|c|c|c|}
\hline $\mathbf{M}$ & $\operatorname{Rxn}$ & $\Delta \mathbf{G}_{298 K, g a s}$ & $\Delta \mathbf{G}_{298 K, \mathbf{a q}}$ & $\Delta \mathbf{G}_{298 K, b u t}$ \\
\hline \multirow[t]{4}{*}{$\mathbf{E u}$} & $(4 a)$ & -329.4 & -42.7 & -70.6 \\
\hline & (5a) & -330.0 & -45.3 & -77.5 \\
\hline & (6a) & -501.0 & -49.6 & -105.5 \\
\hline & (7a) & -497.6 & -48.2 & -111.7 \\
\hline \multirow[t]{4}{*}{ Gd } & $(4 a)$ & -301.5 & -25.5 & -52.0 \\
\hline & $(5 a)$ & -302.2 & -25.3 & -56.2 \\
\hline & (6a) & -490.4 & -42.0 & -96.7 \\
\hline & (7a) & -484.3 & -39.0 & -101.8 \\
\hline \multirow[t]{4}{*}{ Am } & $(4 a)$ & -303.3 & -22.3 & -49.6 \\
\hline & $(5 a)$ & -306.1 & -25.0 & -56.9 \\
\hline & (6a) & -496.5 & -45.6 & -101.5 \\
\hline & (7a) & -491.1 & -43.0 & -107.0 \\
\hline \multirow[t]{4}{*}{$\mathrm{Cm}$} & $(4 a)$ & -300.4 & -26.3 & -53.2 \\
\hline & $(5 a)$ & -299.9 & -25.3 & -56.4 \\
\hline & (6a) & -489.4 & -43.5 & -98.5 \\
\hline & (7a) & -484.8 & -42.1 & -105.3 \\
\hline
\end{tabular}


Table S16. $\Delta \mathrm{G}_{298 \mathrm{~K}}$ energies $(\mathrm{kcal} / \mathrm{mol})$ in the gas phase, water, and butanol for complexation reactions where $\mathrm{L}=\mathbf{1} \mathbf{a i}$

\begin{tabular}{|c|c|c|c|c|}
\hline $\mathbf{M}$ & Rxn & $\Delta \mathbf{G}_{298 K \text {,gas }}$ & $\Delta \mathbf{G}_{298 K, \mathbf{a q}}$ & $\Delta \mathbf{G}_{298 K, b u t}$ \\
\hline Eu & $\begin{array}{l}(4 a) \\
(5 a) \\
(6 a) \\
(7 a)\end{array}$ & $\begin{array}{l}-334.2 \\
-334.8 \\
-503.0 \\
-498.4\end{array}$ & $\begin{array}{l}-51.0 \\
-52.7 \\
-66.7 \\
-61.8\end{array}$ & $\begin{array}{r}-77.3 \\
-83.4 \\
-121.1 \\
-125.2\end{array}$ \\
\hline Gd & $\begin{array}{l}(4 a) \\
(5 a) \\
(6 a) \\
(7 a)\end{array}$ & $\begin{array}{l}-308.7 \\
-309.5 \\
-493.3 \\
-486.8\end{array}$ & $\begin{array}{l}-33.9 \\
-36.7 \\
-60.0 \\
-53.2\end{array}$ & $\begin{array}{r}-58.9 \\
-65.7 \\
-114.0 \\
-116.2\end{array}$ \\
\hline Am & $\begin{array}{l}(4 a) \\
(5 a) \\
(6 a) \\
(7 a)\end{array}$ & $\begin{array}{l}-312.3 \\
-312.9 \\
-495.3 \\
-493.1\end{array}$ & $\begin{array}{l}-33.7 \\
-35.6 \\
-59.6 \\
-57.8\end{array}$ & $\begin{array}{r}-59.0 \\
-66.2 \\
-114.2 \\
-121.4\end{array}$ \\
\hline $\mathrm{Cm}$ & $\begin{array}{l}(4 a) \\
(5 a) \\
(6 a) \\
(7 a)\end{array}$ & $\begin{array}{l}-307.4 \\
-307.4 \\
-491.9 \\
-487.0\end{array}$ & $\begin{array}{l}-34.6 \\
-36.3 \\
-61.2 \\
-56.2\end{array}$ & $\begin{array}{r}-59.9 \\
-66.7 \\
-115.7 \\
-119.3\end{array}$ \\
\hline
\end{tabular}

Table S17. $\Delta \mathrm{G}_{298 \mathrm{~K}}$ energies $(\mathrm{kcal} / \mathrm{mol})$ in the gas phase, water, and butanol for complexation reactions where $\mathrm{L}=\mathbf{1 b i}$

\begin{tabular}{|c|c|c|c|c|}
\hline $\mathbf{M}$ & Rxn & $\Delta \mathbf{G}$ 298K,gas & $\Delta \mathbf{G}_{298 K, \mathbf{a q}}$ & $\Delta \mathbf{G}_{298 K, b u t}$ \\
\hline \multirow[t]{4}{*}{$\mathbf{E u}$} & $(4 a)$ & -342.0 & -45.5 & -72.3 \\
\hline & $(5 a)$ & -343.1 & -50.4 & -81.3 \\
\hline & (6a) & -509.6 & -59.9 & -112.9 \\
\hline & (7a) & -502.8 & -54.6 & -115.1 \\
\hline \multirow[t]{4}{*}{ Gd } & $(4 a)$ & -316.8 & -29.8 & -54.8 \\
\hline & $(5 a)$ & -318.5 & -33.2 & -62.8 \\
\hline & (6a) & -500.0 & -52.7 & -104.9 \\
\hline & (7a) & -491.5 & -45.6 & -105.7 \\
\hline \multirow[t]{4}{*}{ Am } & $(4 a)$ & -320.4 & -28.3 & -54.9 \\
\hline & $(5 a)$ & -321.8 & -32.2 & -63.3 \\
\hline & (6a) & -501.2 & -52.3 & -105.7 \\
\hline & (7a) & -498.1 & -51.5 & -112.1 \\
\hline \multirow[t]{4}{*}{$\mathrm{Cm}$} & $(4 a)$ & -315.4 & -29.9 & -56.3 \\
\hline & $(5 a)$ & -316.4 & -33.0 & -63.1 \\
\hline & (6a) & -499.2 & -54.4 & -107.4 \\
\hline & (7a) & -492.0 & -49.2 & -109.4 \\
\hline
\end{tabular}


Table S18. $\Delta \mathrm{G}_{298 \mathrm{~K}}$ energies $(\mathrm{kcal} / \mathrm{mol})$ in the gas phase, water, and butanol for complexation reactions where $\mathrm{L}=\mathbf{2} \mathbf{i}$

\begin{tabular}{|c|c|c|c|c|}
\hline $\mathbf{M}$ & Rxn & $\Delta \mathbf{G}_{298 K \text {,gas }}$ & $\Delta \mathbf{G}_{298 K, \mathbf{a q}}$ & $\Delta \mathbf{G}_{298 K, b u t}$ \\
\hline Eu & $\begin{array}{l}(4 a) \\
(5 a) \\
(6 a) \\
(7 a)\end{array}$ & $\begin{array}{l}-322.2 \\
-321.7 \\
-514.1 \\
-492.7\end{array}$ & $\begin{array}{l}-27.5 \\
-31.5 \\
-45.3 \\
-34.0\end{array}$ & $\begin{array}{r}-55.7 \\
-63.4 \\
-100.5 \\
-93.1\end{array}$ \\
\hline Gd & $\begin{array}{l}(4 a) \\
(5 a) \\
(6 a) \\
(7 a)\end{array}$ & $\begin{array}{l}-313.0 \\
-312.3 \\
-515.1 \\
-487.2\end{array}$ & $\begin{array}{l}-23.7 \\
-27.9 \\
-47.4 \\
-28.9\end{array}$ & $\begin{array}{r}-51.2 \\
-58.9 \\
-102.4 \\
-89.5\end{array}$ \\
\hline Am & $\begin{array}{l}(4 a) \\
(5 a) \\
(6 a) \\
(7 a)\end{array}$ & $\begin{array}{l}-316.6 \\
-315.8 \\
-518.2 \\
-494.2\end{array}$ & $\begin{array}{l}-24.4 \\
-28.8 \\
-49.1 \\
-35.8\end{array}$ & $\begin{array}{r}-52.8 \\
-61.0 \\
-104.8 \\
-98.3\end{array}$ \\
\hline $\mathrm{Cm}$ & $\begin{array}{l}(4 a) \\
(5 a) \\
(6 a) \\
(7 a)\end{array}$ & $\begin{array}{l}-311.3 \\
-309.9 \\
-512.5 \\
-488.0\end{array}$ & $\begin{array}{l}-23.7 \\
-27.3 \\
-47.8 \\
-33.3\end{array}$ & $\begin{array}{r}-51.6 \\
-59.1 \\
-103.2 \\
-93.5\end{array}$ \\
\hline
\end{tabular}

Table S19. $\Delta \mathrm{G}_{298 \mathrm{~K}}$ energies $(\mathrm{kcal} / \mathrm{mol})$ in the gas phase, water, and butanol for complexation reactions where $\mathrm{L}=\mathbf{2}$ aei

\begin{tabular}{|c|c|c|c|c|}
\hline $\mathbf{M}$ & Rxn & $\Delta \mathbf{G}_{298 K \text {,gas }}$ & $\Delta \mathbf{G}_{298 K, \mathbf{a q}}$ & $\Delta \mathbf{G}_{298 K, b u t}$ \\
\hline $\mathbf{E u}$ & $\begin{array}{l}(4 a) \\
(5 a) \\
(6 a) \\
(7 a)\end{array}$ & $\begin{array}{l}-320.1 \\
-320.8 \\
-494.5 \\
-481.5\end{array}$ & $\begin{array}{l}-24.6 \\
-30.3 \\
-35.3 \\
-23.0\end{array}$ & $\begin{array}{l}-53.8 \\
-60.3 \\
-87.6 \\
-83.6\end{array}$ \\
\hline Gd & $\begin{array}{l}(4 a) \\
(5 a) \\
(6 a) \\
(7 a)\end{array}$ & $\begin{array}{l}-313.0 \\
-312.2 \\
-495.8 \\
-478.0\end{array}$ & $\begin{array}{l}-22.8 \\
-26.9 \\
-37.6 \\
-20.7\end{array}$ & $\begin{array}{l}-47.0 \\
-55.4 \\
-90.3 \\
-81.1\end{array}$ \\
\hline Am & $\begin{array}{l}(4 a) \\
(5 a) \\
(6 a) \\
(7 a)\end{array}$ & $\begin{array}{l}-315.6 \\
-315.5 \\
-499.2 \\
-483.9\end{array}$ & $\begin{array}{l}-22.6 \\
-21.6 \\
-39.0 \\
-28.4\end{array}$ & $\begin{array}{l}-48.0 \\
-52.8 \\
-92.5 \\
-87.9\end{array}$ \\
\hline $\mathrm{Cm}$ & $\begin{array}{l}(4 a) \\
(5 a) \\
(6 a) \\
(7 a)\end{array}$ & $\begin{array}{l}-310.8 \\
-309.6 \\
-493.6 \\
-477.9\end{array}$ & $\begin{array}{l}-22.1 \\
-26.1 \\
-37.6 \\
-23.9\end{array}$ & $\begin{array}{l}-47.6 \\
-55.7 \\
-90.7 \\
-84.5\end{array}$ \\
\hline
\end{tabular}


Table S20. $\Delta \mathrm{G}_{298 \mathrm{~K}}$ energies $(\mathrm{kcal} / \mathrm{mol})$ in the gas phase, water, and butanol for complexation reactions where $\mathrm{L}=\mathbf{2} \mathbf{a m i}$

\begin{tabular}{|c|c|c|c|c|}
\hline $\mathbf{M}$ & Rxn & $\Delta \mathbf{G}_{298 K \text {,gas }}$ & $\Delta \mathbf{G}_{298 K, \mathbf{a q}}$ & $\Delta \mathbf{G}_{298 K, b u t}$ \\
\hline Eu & $\begin{array}{l}(4 a) \\
(5 a) \\
(6 a) \\
(7 a)\end{array}$ & $\begin{array}{l}-336.9 \\
-338.0 \\
-520.4 \\
-502.5\end{array}$ & $\begin{array}{l}-28.6 \\
-34.9 \\
-42.0 \\
-43.2\end{array}$ & $\begin{array}{r}-57.3 \\
-66.4 \\
-97.3 \\
-104.7\end{array}$ \\
\hline Gd & $\begin{array}{l}(4 a) \\
(5 a) \\
(6 a) \\
(7 a)\end{array}$ & $\begin{array}{l}-327.5 \\
-326.6 \\
-517.6 \\
-500.1\end{array}$ & $\begin{array}{l}-24.4 \\
-28.6 \\
-41.2 \\
-28.2\end{array}$ & $\begin{array}{l}-52.3 \\
-58.9 \\
-95.9 \\
-88.8\end{array}$ \\
\hline Am & $\begin{array}{l}(4 a) \\
(5 a) \\
(6 a) \\
(7 a)\end{array}$ & $\begin{array}{l}-330.2 \\
-329.9 \\
-520.8 \\
-505.4\end{array}$ & $\begin{array}{l}-24.7 \\
-29.1 \\
-42.4 \\
-33.0\end{array}$ & $\begin{array}{l}-53.6 \\
-61.1 \\
-98.0 \\
-94.7\end{array}$ \\
\hline $\mathrm{Cm}$ & $\begin{array}{l}(4 a) \\
(5 a) \\
(6 a) \\
(7 a)\end{array}$ & $\begin{array}{l}-325.5 \\
-324.0 \\
-515.2 \\
-500.5\end{array}$ & $\begin{array}{l}-24.8 \\
-28.0 \\
-41.2 \\
-34.7\end{array}$ & $\begin{array}{l}-52.9 \\
-59.3 \\
-96.3 \\
-92.2\end{array}$ \\
\hline
\end{tabular}

Table S21. $\Delta \mathrm{G}_{298 \mathrm{~K}}$ energies $(\mathrm{kcal} / \mathrm{mol})$ in the gas phase, water, and butanol for complexation reactions where $\mathrm{L}=\mathbf{2 a p i}$

\begin{tabular}{|c|c|c|c|c|}
\hline $\mathbf{M}$ & Rxn & $\Delta \mathbf{G}_{298 K, g a s}$ & $\Delta \mathbf{G}_{298 K, \mathbf{a q}}$ & $\Delta \mathbf{G}_{298 K, b u t}$ \\
\hline \multirow[t]{4}{*}{$\mathbf{E u}$} & $(4 a)$ & -337.6 & -31.2 & -76.0 \\
\hline & (5a) & -338.7 & -36.2 & -67.6 \\
\hline & (6a) & -508.2 & -40.8 & -95.8 \\
\hline & $(7 a)$ & -495.8 & -34.6 & -95.4 \\
\hline \multirow[t]{4}{*}{ Gd } & $(4 a)$ & -319.9 & -23.8 & -49.5 \\
\hline & $(5 a)$ & -319.4 & -28.1 & -57.9 \\
\hline & $(6 a)$ & -503.3 & -39.0 & -93.3 \\
\hline & $(7 a)$ & -486.5 & -24.0 & -85.9 \\
\hline \multirow[t]{4}{*}{ Am } & $(4 a)$ & -322.5 & -23.3 & -49.8 \\
\hline & $(5 a)$ & -321.9 & -27.0 & -57.6 \\
\hline & (6a) & -503.8 & -37.3 & -93.3 \\
\hline & $(7 a)$ & -492.3 & -28.2 & -91.1 \\
\hline \multirow[t]{4}{*}{$\mathrm{Cm}$} & $(4 a)$ & -317.7 & -23.2 & -49.8 \\
\hline & $(5 a)$ & -316.7 & -27.3 & -57.8 \\
\hline & (6a) & -500.8 & -38.6 & -93.6 \\
\hline & $(7 a)$ & -486.5 & -26.4 & -88.9 \\
\hline
\end{tabular}


Table S22. $\Delta \mathrm{G}_{298 \mathrm{~K}}$ energies $(\mathrm{kcal} / \mathrm{mol})$ in the gas phase, water, and butanol for complexation reactions where $\mathrm{L}=\mathbf{2}$ bei

\begin{tabular}{|c|c|c|c|c|}
\hline $\mathbf{M}$ & Rxn & $\Delta \mathbf{G}_{298 K \text {,gas }}$ & $\Delta \mathbf{G}_{298 K, \mathbf{a q}}$ & $\Delta \mathbf{G}_{298 K, b u t}$ \\
\hline Eu & $\begin{array}{l}(4 a) \\
(5 a) \\
(6 a) \\
(7 a)\end{array}$ & $\begin{array}{l}-324.5 \\
-324.0 \\
-501.0 \\
-475.6\end{array}$ & $\begin{array}{l}-26.1 \\
-29.0 \\
-44.9 \\
-33.6\end{array}$ & $\begin{array}{l}-53.1 \\
-59.5 \\
-99.3 \\
-89.7\end{array}$ \\
\hline Gd & $\begin{array}{l}(4 a) \\
(5 a) \\
(6 a) \\
(7 a)\end{array}$ & $\begin{array}{l}-314.9 \\
-314.1 \\
-499.9 \\
-472.9\end{array}$ & $\begin{array}{l}-27.3 \\
-30.0 \\
-45.1 \\
-30.0\end{array}$ & $\begin{array}{l}-52.2 \\
-59.4 \\
-99.2 \\
-86.2\end{array}$ \\
\hline Am & $\begin{array}{l}(4 a) \\
(5 a) \\
(6 a) \\
(7 a)\end{array}$ & $\begin{array}{l}-317.9 \\
-317.4 \\
-502.3 \\
-479.6\end{array}$ & $\begin{array}{l}-27.5 \\
-31.6 \\
-46.7 \\
-35.6\end{array}$ & $\begin{array}{r}-53.4 \\
-61.2 \\
-101.4 \\
-93.1\end{array}$ \\
\hline $\mathrm{Cm}$ & $\begin{array}{l}(4 a) \\
(5 a) \\
(6 a) \\
(7 a)\end{array}$ & $\begin{array}{l}-312.7 \\
-311.5 \\
-497.2 \\
-473.1\end{array}$ & $\begin{array}{l}-27.4 \\
-29.7 \\
-45.4 \\
-32.4\end{array}$ & $\begin{array}{l}-52.6 \\
-59.3 \\
-99.8 \\
-89.6\end{array}$ \\
\hline
\end{tabular}

Table S23. $\Delta \mathrm{G}_{298 \mathrm{~K}}$ energies $(\mathrm{kcal} / \mathrm{mol})$ in the gas phase, water, and butanol for complexation reactions where $\mathrm{L}=\mathbf{2} \mathbf{b m i}$

\begin{tabular}{|c|c|c|c|c|}
\hline $\mathbf{M}$ & Rxn & $\Delta \mathbf{G}_{298 K \text {,gas }}$ & $\Delta \mathbf{G}_{298 K, \mathbf{a q}}$ & $\Delta \mathbf{G}_{298 K, b u t}$ \\
\hline Eu & $\begin{array}{l}(4 a) \\
(5 a) \\
(6 a) \\
(7 a)\end{array}$ & $\begin{array}{l}-338.7 \\
-339.3 \\
-524.2 \\
-502.5\end{array}$ & $\begin{array}{l}-26.8 \\
-37.7 \\
-55.1 \\
-43.2\end{array}$ & $\begin{array}{r}-55.6 \\
-67.5 \\
-112.2 \\
-104.7\end{array}$ \\
\hline Gd & $\begin{array}{l}(4 a) \\
(5 a) \\
(6 a) \\
(7 a)\end{array}$ & $\begin{array}{l}-329.3 \\
-329.0 \\
-522.6 \\
-497.0\end{array}$ & $\begin{array}{l}-31.0 \\
-33.6 \\
-54.7 \\
-39.2\end{array}$ & $\begin{array}{r}-57.6 \\
-64.7 \\
-111.5 \\
-99.5\end{array}$ \\
\hline Am & $\begin{array}{l}(4 a) \\
(5 a) \\
(6 a) \\
(7 a)\end{array}$ & $\begin{array}{l}-332.4 \\
-332.3 \\
-525.4 \\
-503.6\end{array}$ & $\begin{array}{l}-31.0 \\
-35.1 \\
-56.5 \\
-44.8\end{array}$ & $\begin{array}{r}-59.1 \\
-67.0 \\
-114.1 \\
-105.6\end{array}$ \\
\hline $\mathrm{Cm}$ & $\begin{array}{l}(4 a) \\
(5 a) \\
(6 a) \\
(7 a)\end{array}$ & $\begin{array}{l}-327.1 \\
-326.4 \\
-520.2 \\
-497.5\end{array}$ & $\begin{array}{l}-30.6 \\
-33.3 \\
-55.2 \\
-42.5\end{array}$ & $\begin{array}{r}-57.8 \\
-64.8 \\
-112.3 \\
-102.5\end{array}$ \\
\hline
\end{tabular}


Table S24. $\Delta \mathrm{G}_{298 \mathrm{~K}}$ energies $(\mathrm{kcal} / \mathrm{mol})$ in the gas phase, water, and butanol for complexation reactions where $\mathrm{L}=\mathbf{2} \mathbf{b p i}$

\begin{tabular}{|c|c|c|c|c|}
\hline $\mathbf{M}$ & Rxn & $\Delta \mathbf{G}_{298 K \text {,gas }}$ & $\Delta \mathbf{G}_{298 K, \mathbf{a q}}$ & $\Delta \mathbf{G}_{298 K, b u t}$ \\
\hline $\mathbf{E u}$ & $\begin{array}{l}(4 a) \\
(5 a) \\
(6 a) \\
(7 a)\end{array}$ & $\begin{array}{l}-338.7 \\
-338.2 \\
-508.7 \\
-490.1\end{array}$ & $\begin{array}{l}-36.7 \\
-35.8 \\
-48.9 \\
-37.9\end{array}$ & $\begin{array}{r}-64.5 \\
-68.2 \\
-105.4 \\
-99.5\end{array}$ \\
\hline Gd & $\begin{array}{l}(4 a) \\
(5 a) \\
(6 a) \\
(7 a)\end{array}$ & $\begin{array}{l}-321.2 \\
-320.9 \\
-505.5 \\
-481.3\end{array}$ & $\begin{array}{l}-28.2 \\
-31.5 \\
-47.6 \\
-32.2\end{array}$ & $\begin{array}{r}-55.0 \\
-62.4 \\
-103.7 \\
-92.7\end{array}$ \\
\hline Am & $\begin{array}{l}(4 a) \\
(5 a) \\
(6 a) \\
(7 a)\end{array}$ & $\begin{array}{l}-324.7 \\
-324.0 \\
-508.1 \\
-487.6\end{array}$ & $\begin{array}{l}-28.3 \\
-32.4 \\
-49.1 \\
-37.7\end{array}$ & $\begin{array}{r}-55.5 \\
-63.7 \\
-106.3 \\
-99.0\end{array}$ \\
\hline $\mathrm{Cm}$ & $\begin{array}{l}(4 a) \\
(5 a) \\
(6 a) \\
(7 a)\end{array}$ & $\begin{array}{l}-319.0 \\
-318.2 \\
-502.6 \\
-481.3\end{array}$ & $\begin{array}{l}-28.2 \\
-31.1 \\
-47.6 \\
-34.5\end{array}$ & $\begin{array}{r}-55.1 \\
-62.2 \\
-104.2 \\
-95.9\end{array}$ \\
\hline
\end{tabular}

Table S25. $\Delta \Delta \mathrm{G}_{(\mathrm{aq})}$ and $\Delta \Delta \mathrm{G}_{(\mathrm{but})}$ in $\mathrm{kcal} / \mathrm{mol}$ used for Metal Selectivity Equilibria of Core 1 in Aqueous and Butanol Solutions for Complexes $\left[\mathrm{ML}\left(\mathrm{H}_{2} \mathrm{O}\right)_{5}\right]^{3+}$ and $\left[\mathrm{ML}_{2}\left(\mathrm{H}_{2} \mathrm{O}\right)_{2}\right]^{3+}$.

\begin{tabular}{|c|c|c|c|c|}
\hline \multirow{2}{*}{$\begin{array}{c}\mathrm{Rxn} . \\
\mathrm{M} 2 \rightarrow \mathrm{M} 1)\end{array}$} & \multicolumn{2}{|c|}{$\left[\mathrm{ML}\left(\mathrm{H}_{2} \mathrm{O}\right)_{5}\right]^{3+}$} & \multicolumn{2}{c|}{$\left[\mathrm{ML}_{2}\left(\mathrm{H}_{2} \mathrm{O}\right)_{2}\right]^{3+}$} \\
\cline { 2 - 5 } & $\Delta \Delta \mathrm{G}_{(\mathrm{aq})}$ & $\Delta \Delta \mathrm{G}_{(\text {but })}$ & $\Delta \Delta \mathrm{G}_{(\mathrm{aq})}$ & $\Delta \Delta \mathrm{G}_{(\text {but })}$ \\
\hline $\mathrm{Am} \rightarrow \mathrm{Eu}$ & -19.2 & -18.6 & -7.9 & -8.2 \\
\hline $\mathrm{Cm} \rightarrow \mathrm{Eu}$ & -19.7 & -18.8 & -8.7 & -10.0 \\
\hline $\mathrm{Gd} \rightarrow \mathrm{Eu}$ & -19.3 & -19.6 & -10.7 & -11.4 \\
\hline $\mathrm{Cm} \rightarrow \mathrm{Am}$ & -0.4 & -0.2 & -0.8 & -1.8 \\
\hline $\mathrm{Gd} \rightarrow \mathrm{Am}$ & -0.1 & -0.9 & -2.8 & -3.1 \\
\hline $\mathrm{Gd} \rightarrow \mathrm{Cm}$ & 0.3 & -0.7 & -2.0 & -1.3 \\
\hline
\end{tabular}

Table S26. $\Delta \Delta \mathrm{G}_{(\mathrm{aq})}$ and $\Delta \Delta \mathrm{G}_{(\text {but })}$ in $\mathrm{kcal} / \mathrm{mol}$ used for Metal Selectivity Equilibria of $\mathbf{1 a}$ in Aqueous and Butanol Solutions for Complexes $\left[\mathrm{ML}\left(\mathrm{H}_{2} \mathrm{O}\right)_{6}\right]^{3+},\left[\mathrm{ML}\left(\mathrm{H}_{2} \mathrm{O}\right)_{5}\right]^{3+}$, and $\left[\mathrm{ML}_{2}\left(\mathrm{H}_{2} \mathrm{O}\right)_{2}\right]^{3+}$.

\begin{tabular}{|c|c|c|c|c|c|c|}
\hline \multirow{2}{*}{$\begin{array}{c}\mathrm{Rxn} . \\
(\mathrm{M} 2 \rightarrow \mathrm{M} 1)\end{array}$} & \multicolumn{2}{|c|}{$\left[\mathrm{ML}\left(\mathrm{H}_{2} \mathrm{O}\right)_{6}\right]^{3+}$} & \multicolumn{2}{c|}{$\left[\mathrm{ML}\left(\mathrm{H}_{2} \mathrm{O}\right)_{5}\right]^{3+}$} & \multicolumn{2}{c|}{$\left[\mathrm{ML}_{2}\left(\mathrm{H}_{2} \mathrm{O}\right)_{2}\right]^{3+}$} \\
\cline { 2 - 7 } & $\Delta \Delta \mathrm{G}_{(\mathrm{aq})}$ & $\Delta \Delta \mathrm{G}_{(\text {but })}$ & $\Delta \Delta \mathrm{G}_{(\mathrm{aq})}$ & $\Delta \Delta \mathrm{G}_{(\text {but })}$ & $\Delta \Delta \mathrm{G}_{(\mathrm{aq})}$ & $\Delta \Delta \mathrm{G}_{(\text {but })}$ \\
\hline $\mathrm{Am} \rightarrow \mathrm{Eu}$ & -10.1 & -11.6 & -26.7 & -23.2 & -26.6 & -10.7 \\
\hline
\end{tabular}




\begin{tabular}{|c|c|c|c|c|c|c|}
\hline $\mathrm{Cm} \rightarrow \mathrm{Eu}$ & -13.0 & -15.3 & -27.3 & -24.4 & -25.4 & -10.3 \\
\hline $\mathrm{Gd} \rightarrow \mathrm{Eu}$ & -13.7 & -15.8 & -28.6 & -25.8 & -26.8 & -11.2 \\
\hline $\mathrm{Cm} \rightarrow \mathrm{Am}$ & -2.9 & -3.7 & -0.6 & -1.2 & 1.3 & 0.4 \\
\hline $\mathrm{Gd} \rightarrow \mathrm{Am}$ & -3.6 & -4.2 & -1.9 & -2.6 & -0.2 & -0.4 \\
\hline $\mathrm{Gd} \rightarrow \mathrm{Cm}$ & -0.7 & -0.5 & -1.3 & -1.4 & -1.4 & -0.8 \\
\hline
\end{tabular}

Table S27. $\Delta \Delta \mathrm{G}_{(\mathrm{aq})}$ and $\Delta \Delta \mathrm{G}_{(\mathrm{but})}$ in $\mathrm{kcal} / \mathrm{mol}$ used for Metal Selectivity Equilibria of $\mathbf{1 b}$ in Aqueous and Butanol Solutions for Complexes $\left[\mathrm{ML}\left(\mathrm{H}_{2} \mathrm{O}\right)_{6}\right]^{3+},\left[\mathrm{ML}\left(\mathrm{H}_{2} \mathrm{O}\right)_{5}\right]^{3+}$, and $\left[\mathrm{ML}_{2}\left(\mathrm{H}_{2} \mathrm{O}\right)_{2}\right]^{3+}$.

\begin{tabular}{|c|c|c|c|c|c|c|}
\hline \multirow{2}{*}{$\begin{array}{c}\mathrm{Rxn} . \\
\mathrm{M} 2 \rightarrow \mathrm{M} 1)\end{array}$} & \multicolumn{2}{|c|}{$\left[\mathrm{ML}\left(\mathrm{H}_{2} \mathrm{O}\right)_{6}\right]^{3+}$} & \multicolumn{2}{c|}{$\left[\mathrm{ML}\left(\mathrm{H}_{2} \mathrm{O}\right)_{5}\right]^{3+}$} & \multicolumn{2}{c|}{$\left[\mathrm{ML}_{2}\left(\mathrm{H}_{2} \mathrm{O}\right)_{2}\right]^{3+}$} \\
\cline { 2 - 7 } & $\Delta \Delta \mathrm{G}_{(\mathrm{aq})}$ & $\Delta \Delta \mathrm{G}_{(\text {but })}$ & $\Delta \Delta \mathrm{G}_{(\mathrm{aq})}$ & $\Delta \Delta \mathrm{G}_{(\text {but })}$ & $\Delta \Delta \mathrm{G}_{(\mathrm{aq})}$ & $\Delta \Delta \mathrm{G}_{(\text {but })}$ \\
\hline $\mathrm{Am} \rightarrow \mathrm{Eu}$ & -8.6 & -10.6 & 6.5 & -1.3 & -10.0 & -14.7 \\
\hline $\mathrm{Cm} \rightarrow \mathrm{Eu}$ & -6.9 & -7.9 & 8.1 & 1.0 & -7.7 & -12.6 \\
\hline $\mathrm{Gd} \rightarrow \mathrm{Eu}$ & -7.9 & -9.5 & 7.6 & 0.8 & -8.7 & -14.9 \\
\hline $\mathrm{Cm} \rightarrow \mathrm{Am}$ & 1.7 & 2.7 & 1.6 & 2.3 & 2.3 & 2.1 \\
\hline $\mathrm{Gd} \rightarrow \mathrm{Am}$ & 0.7 & 1.1 & 1.2 & 2.1 & 1.4 & -0.2 \\
\hline $\mathrm{Gd} \rightarrow \mathrm{Cm}$ & -1.0 & -1.6 & -0.5 & -0.3 & -1.0 & -2.3 \\
\hline
\end{tabular}

Table S28. $\Delta \Delta \mathrm{G}_{(\mathrm{aq})}$ and $\Delta \Delta \mathrm{G}_{(\mathrm{but})}$ in $\mathrm{kcal} / \mathrm{mol}$ used for Metal Selectivity Equilibria for Core 2 in Aqueous and Butanol Solutions for Complexes $\left[\mathrm{ML}\left(\mathrm{H}_{2} \mathrm{O}\right)_{5}\right]^{3+}$ and $\left[\mathrm{ML}_{2}\left(\mathrm{H}_{2} \mathrm{O}\right)_{2}\right]^{3+}$.

\begin{tabular}{|c|c|c|c|c|}
\hline \multirow{2}{*}{$\begin{array}{c}\mathrm{Rxn} . \\
\mathrm{M} 2 \rightarrow \mathrm{M} 1)\end{array}$} & \multicolumn{2}{|c|}{$\left[\mathrm{ML}\left(\mathrm{H}_{2} \mathrm{O}\right)_{5}\right]^{3+}$} & \multicolumn{2}{c|}{$\left[\mathrm{ML}_{2}\left(\mathrm{H}_{2} \mathrm{O}\right)_{2}\right]^{3+}$} \\
\cline { 2 - 5 } & $\Delta \Delta \mathrm{G}_{(\mathrm{aq})}$ & $\Delta \Delta \mathrm{G}_{(\mathrm{but})}$ & $\Delta \Delta \mathrm{G}_{(\mathrm{aq})}$ & $\Delta \Delta \mathrm{G}_{(\text {but })}$ \\
\hline $\mathrm{Am} \rightarrow \mathrm{Eu}$ & 0.5 & 0.2 & 4.0 & 3.7 \\
\hline $\mathrm{Cm} \rightarrow \mathrm{Eu}$ & -1.6 & -2.1 & 2.1 & 1.3 \\
\hline $\mathrm{Gd} \rightarrow \mathrm{Eu}$ & -1.2 & -1.7 & 2.0 & 0.5 \\
\hline $\mathrm{Cm} \rightarrow \mathrm{Am}$ & -2.1 & -2.3 & -1.8 & -2.4 \\
\hline $\mathrm{Gd} \rightarrow \mathrm{Am}$ & -1.7 & -1.9 & -2.0 & -3.2 \\
\hline $\mathrm{Gd} \rightarrow \mathrm{Cm}$ & 0.4 & 0.3 & -0.1 & -0.8 \\
\hline
\end{tabular}


Table S29. $\Delta \Delta \mathrm{G}_{(\mathrm{aq})}$ and $\Delta \Delta \mathrm{G}_{(\mathrm{but})}$ in $\mathrm{kcal} / \mathrm{mol}$ used for Metal Selectivity Equilibria for $\mathbf{2 a R}(\mathbf{R}=\mathbf{e}, \mathbf{m}, \mathbf{p})$ Ligands in Aqueous and Butanol Solutions for $\left[\mathrm{ML}\left(\mathrm{H}_{2} \mathrm{O}\right)_{5}\right]^{3+}$.

\begin{tabular}{|c|c|c|c|c|c|c|c|c|c|c|c|c|}
\hline \multirow{3}{*}{$\begin{array}{c}\text { Rxn. } \\
(\mathrm{M} 2 \rightarrow \mathrm{M} 1)\end{array}$} & \multicolumn{4}{|c|}{2 ae } & \multicolumn{4}{|c|}{$2 \mathrm{am}$} & \multicolumn{4}{|c|}{$2 a p$} \\
\hline & \multicolumn{2}{|c|}{$\left[\mathrm{ML}\left(\mathrm{H}_{2} \mathrm{O}\right)_{5}\right]^{3+}$} & \multicolumn{2}{|c|}{$\left[\mathrm{ML}_{2}\left(\mathrm{H}_{2} \mathrm{O}\right)_{2}\right]^{3+}$} & \multicolumn{2}{|c|}{$\left[\mathrm{ML}\left(\mathrm{H}_{2} \mathrm{O}\right)_{5}\right]^{3+}$} & \multicolumn{2}{|c|}{$\left[\mathrm{ML}_{2}\left(\mathrm{H}_{2} \mathrm{O}\right)_{2}\right]^{3+}$} & \multicolumn{2}{|c|}{$\left[\mathrm{ML}\left(\mathrm{H}_{2} \mathrm{O}\right)_{5}\right]^{3+}$} & \multicolumn{2}{|c|}{$\left[\mathrm{ML}_{2}\left(\mathrm{H}_{2} \mathrm{O}\right)_{2}\right]^{3+}$} \\
\hline & $\Delta \Delta \mathrm{G}_{(\mathrm{aq})}$ & $\Delta \Delta \mathrm{G}_{(\text {but })}$ & $\Delta \Delta \mathrm{G}_{(\mathrm{aq})}$ & $\Delta \Delta \mathrm{G}_{\text {(but) }}$ & $\Delta \Delta \mathrm{G}_{(\mathrm{aq})}$ & $\Delta \Delta \mathrm{G}_{(\text {but })}$ & $\Delta \Delta \mathrm{G}_{(\mathrm{aq})}$ & $\Delta \Delta \mathrm{G}_{\text {(but) }}$ & $\Delta \Delta \mathrm{G}_{(\mathrm{aq})}$ & $\Delta \Delta \mathrm{G}_{\text {(but) }}$ & $\Delta \Delta \mathrm{G}_{(\mathrm{aq})}$ & $\Delta \Delta \mathrm{G}_{\text {(but) }}$ \\
\hline $\mathrm{Am} \rightarrow \mathrm{Eu}$ & -0.8 & -0.6 & 4.3 & 4.1 & -0.1 & -0.6 & 3.9 & 3.6 & -4.5 & -4.7 & 1.2 & 1.6 \\
\hline $\mathrm{Cm} \rightarrow \mathrm{Eu}$ & -1.8 & -1.7 & 3.9 & 3.6 & -1.1 & -2.0 & 3.8 & 2.0 & -5.3 & -5.5 & -0.2 & 0.8 \\
\hline $\mathrm{Gd} \rightarrow \mathrm{Eu}$ & -1.2 & -2.0 & 3.2 & 3.5 & -0.2 & -1.7 & 2.4 & 1.6 & -4.6 & -5.3 & -0.8 & 0.0 \\
\hline $\mathrm{Cm} \rightarrow \mathrm{Am}$ & -1.0 & -1.1 & -0.4 & -0.5 & -1.0 & -1.4 & -0.2 & -1.6 & -0.8 & -0.8 & -2.0 & -1.6 \\
\hline $\mathrm{Gd} \rightarrow \mathrm{Am}$ & -0.4 & -1.4 & -1.1 & -0.7 & -0.1 & -1.1 & -1.5 & -1.9 & 0.0 & -0.6 & -2.0 & -1.6 \\
\hline $\mathrm{Gd} \rightarrow \mathrm{Cm}$ & 0.6 & -0.2 & -0.7 & -0.2 & 1.0 & 0.3 & -1.4 & -0.3 & 0.8 & 0.2 & -0.6 & -0.8 \\
\hline
\end{tabular}

Table S30. $\Delta \Delta \mathrm{G}_{(\mathrm{aq})}$ and $\Delta \Delta \mathrm{G}_{(\text {but })}$ in $\mathrm{kcal} / \mathrm{mol}$ used for Metal Selectivity Equilibria for $\mathbf{2 b R}(\mathbf{R}=\mathbf{e}, \mathbf{m}, \mathbf{p})$ Ligands in Aqueous and Butanol Solutions for $\left[\mathrm{ML}\left(\mathrm{H}_{2} \mathrm{O}\right)_{5}\right]^{3+}$ and $\left[\mathrm{ML}_{2}\left(\mathrm{H}_{2} \mathrm{O}\right)_{2}\right]^{3+}$.

\begin{tabular}{|c|c|c|c|c|c|c|c|c|c|c|c|c|}
\hline \multirow{3}{*}{$\begin{array}{c}\text { Rxn. } \\
(\mathrm{M} 2 \rightarrow \mathrm{M} 1)\end{array}$} & \multicolumn{4}{|c|}{$2 \mathrm{be}$} & \multicolumn{4}{|c|}{$2 \mathrm{bm}$} & \multicolumn{4}{|c|}{$2 \mathrm{bp}$} \\
\hline & \multicolumn{2}{|c|}{$\left[\mathrm{ML}\left(\mathrm{H}_{2} \mathrm{O}\right)_{5}\right]^{3+}$} & \multicolumn{2}{|c|}{$\left[\mathrm{ML}_{2}\left(\mathrm{H}_{2} \mathrm{O}\right)_{2}\right]^{3+}$} & \multicolumn{2}{|c|}{$\left[\mathrm{ML}\left(\mathrm{H}_{2} \mathrm{O}\right)_{5}\right]^{3+}$} & \multicolumn{2}{|c|}{$\left[\mathrm{ML}_{2}\left(\mathrm{H}_{2} \mathrm{O}\right)_{2}\right]^{3+}$} & \multicolumn{2}{|c|}{$\left[\mathrm{ML}\left(\mathrm{H}_{2} \mathrm{O}\right)_{5}\right]^{3+}$} & \multicolumn{2}{|c|}{$\left[\mathrm{ML}_{2}\left(\mathrm{H}_{2} \mathrm{O}\right)_{2}\right]^{3+}$} \\
\hline & $\Delta \Delta \mathrm{G}_{(\mathrm{aq})}$ & $\Delta \Delta \mathrm{G}_{(\text {but })}$ & $\Delta \Delta \mathrm{G}_{(\mathrm{aq})}$ & $\Delta \Delta \mathrm{G}_{\text {(but) }}$ & $\Delta \Delta \mathrm{G}_{(\mathrm{aq})}$ & $\Delta \Delta \mathrm{G}_{\text {(but) }}$ & $\Delta \Delta \mathrm{G}_{(\mathrm{aq})}$ & $\Delta \Delta \mathrm{G}_{\text {(but) }}$ & $\Delta \Delta \mathrm{G}_{(\mathrm{aq})}$ & $\Delta \Delta \mathrm{G}_{\text {(but) }}$ & $\Delta \Delta \mathrm{G}_{(\mathrm{aq})}$ & $\Delta \Delta \mathrm{G}_{\text {(but) }}$ \\
\hline $\mathrm{Am} \rightarrow \mathrm{Eu}$ & -11.8 & -14.3 & -3.5 & -5.2 & -7.6 & -9.5 & -0.7 & -3.2 & -9.4 & -12.0 & -7.1 & -6.4 \\
\hline $\mathrm{Cm} \rightarrow \mathrm{Eu}$ & -8.1 & -10.5 & -1.9 & -4.4 & -6.5 & -9.7 & -0.6 & -3.3 & -7.1 & -9.7 & -1.1 & -2.7 \\
\hline $\mathrm{Gd} \rightarrow \mathrm{Eu}$ & -7.3 & -10.6 & -3.6 & -4.8 & -10.3 & -12.9 & -1.2 & -3.8 & -5.6 & -9.7 & -2.0 & -3.3 \\
\hline
\end{tabular}




\begin{tabular}{|c|c|c|c|c|c|c|c|c|c|c|c|c|}
\hline $\mathrm{Cm} \rightarrow \mathrm{Am}$ & 3.7 & 3.9 & 1.6 & 0.8 & 1.1 & 0.2 & 0.1 & 0.0 & 2.3 & 2.3 & 6.0 & 3.7 \\
\hline $\mathrm{Gd} \rightarrow \mathrm{Am}$ & 4.6 & 3.7 & -0.1 & 0.4 & -2.7 & -3.4 & -0.4 & -0.5 & 3.8 & 2.4 & 5.1 & 3.1 \\
\hline $\mathrm{Gd} \rightarrow \mathrm{Cm}$ & 0.8 & -0.1 & -1.7 & -0.4 & -3.8 & -3.2 & -0.6 & -0.5 & 1.5 & 0.0 & -0.9 & -0.7 \\
\hline
\end{tabular}


Table S31. Total energies (Hartrees) at the B3LYP/Stuttgart'97ECP/DZVP2 level from Gaussian 16 and solvation energies $(\mathrm{kcal} / \mathrm{mol})$ at the BLYP/TZ2P/ZORA level in ADF for reactants and products in complexation reactions.

\begin{tabular}{|c|c|c|c|c|}
\hline Complex & Species & $\mathrm{E}$ & $\Delta \mathrm{G}_{\text {solv,water }}$ & $\Delta \mathrm{G}_{\text {solv,butanol }}$ \\
\hline - & $\mathrm{H}_{2} \mathrm{O}$ & -76.456993 & -7.3 & -6.8 \\
\hline - & 1 & -890.225612 & -14.6 & -13.0 \\
\hline - & $1 \mathrm{a}$ & -1203.621812 & -12.1 & -10.3 \\
\hline - & $1 \mathrm{~b}$ & -1581.530937 & -18.5 & -16.4 \\
\hline - & 2 & -752.587477 & -16.7 & -15.0 \\
\hline - & $2 \mathrm{ae}$ & -1293.920797 & -19.9 & -17.7 \\
\hline - & $2 \mathrm{am}$ & -1105.311765 & -15.9 & -14.0 \\
\hline - & 2ap & -1297.080630 & -17.1 & -14.9 \\
\hline - & 2be & -1671.831962 & -23.5 & -20.6 \\
\hline - & $2 \mathrm{bm}$ & -1483.223084 & -19.4 & -17.0 \\
\hline - & 2 bp & -1674.991888 & -20.7 & -17.8 \\
\hline \multirow[t]{4}{*}[\mathbf{M}(\mathbf{H}_{2}\mathbf{O})_{9}]{$^{3+}$} & Eu & -1397.828961 & -379.4 & -360.7 \\
\hline & Gd & -1453.022593 & -378.5 & -360.2 \\
\hline & Am & -1282.893847 & -379.2 & -360.1 \\
\hline & $\mathbf{C m}$ & -1326.537695 & -375.5 & -356.8 \\
\hline \multicolumn{5}{|c|}{ Core 1} \\
\hline \multirow[t]{4}{*}[\mathrm{ML}(\mathrm{H}_{2}\mathrm{O})_{6}]{$^{3+}$} & Eu & -2058.779251 & -318.4 & -302.7 \\
\hline & Gd & -2113.934967 & -326.6 & -307.2 \\
\hline & Am & -1943.812177 & -324.0 & -304.8 \\
\hline & $\mathbf{C m}$ & -1987.449841 & -324.9 & -305.9 \\
\hline \multirow[t]{4}{*}[\mathrm{ML}(\mathrm{H}_{2}\mathrm{O})_{5}]{$^{3+}$} & $\mathbf{E u}$ & -1982.298647 & -317.9 & -297.8 \\
\hline & Gd & -2037.454891 & -329.0 & -308.9 \\
\hline & $\mathbf{A m}$ & -1867.330879 & -326.5 & -306.4 \\
\hline & $\mathbf{C m}$ & -1910.968748 & -327.1 & -307.6 \\
\hline \multirow[t]{4}{*}[\mathrm{ML}_{2}(\mathrm{H}_{2}\mathrm{O})_{2}]{$^{3+}$} & Eu & -2643.169919 & -279.5 & -260.9 \\
\hline & Gd & -2698.343061 & -285.8 & -266.9 \\
\hline & Am & -2528.222965 & -283.8 & -264.5 \\
\hline & $\mathbf{C m}$ & -2571.859162 & -285.0 & -265.0 \\
\hline \multirow[t]{4}{*}[\mathrm{ML}_{2}]{$^{3+}$} & Eu & -2490.192176 & -280.5 & -266.2 \\
\hline & Gd & -2545.344616 & -278.8 & -260.5 \\
\hline & Am & -2375.234563 & -278.1 & -259.4 \\
\hline & $\mathbf{C m}$ & -2418.864224 & -278.5 & -259.9 \\
\hline \multicolumn{5}{|c|}{$1 \mathrm{a}$} \\
\hline \multirow[t]{2}{*}[\mathrm{ML}(\mathrm{H}_{2}\mathrm{O})_{6}]{$^{3+}$} & Eu & -2372.197884 & -298.1 & -278.9 \\
\hline & Gd & -2427.359027 & -311.5 & -290.4 \\
\hline
\end{tabular}




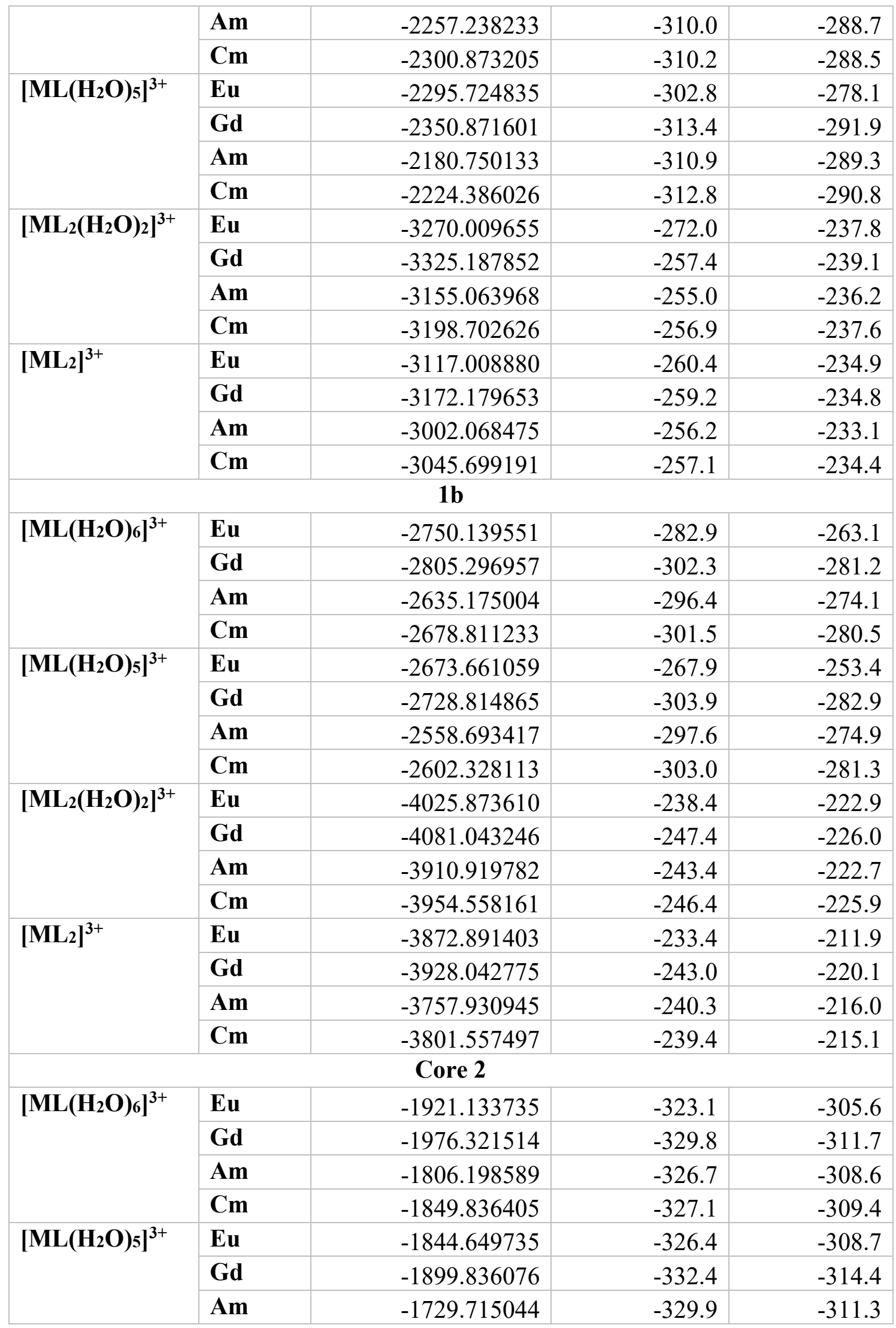




\begin{tabular}{|c|c|c|c|c|}
\hline & $\mathbf{C m}$ & -1773.350404 & -330.0 & -311.7 \\
\hline \multirow[t]{4}{*}[\mathrm{ML}_{2}(\mathrm{H}_{2}\mathrm{O})_{2}]{$^{3+}$} & Eu & -2367.929737 & -286.7 & -269.6 \\
\hline & Gd & -2423.107172 & -296.8 & -278.5 \\
\hline & Am & -2253.001614 & -286.7 & -268.9 \\
\hline & $\mathbf{C m}$ & -2296.622180 & -294.7 & -276.7 \\
\hline \multirow[t]{4}{*}[\mathrm{ML}_{2}]{$^{3+}$} & Eu & -2214.934619 & -290.1 & -270.7 \\
\hline & Gd & -2270.121929 & -292.0 & -271.9 \\
\hline & Am & -2100.007707 & -291.0 & -271.3 \\
\hline & $\mathbf{C m}$ & -2143.640194 & -291.8 & -271.7 \\
\hline \multicolumn{5}{|c|}{ 2ae } \\
\hline \multirow[t]{4}{*}[\mathrm{ML}(\mathrm{H}_{2}\mathrm{O})_{6}]{$^{3+}$} & Eu & -1921.133735 & -323.1 & -305.6 \\
\hline & Gd & -1976.321514 & -329.8 & -311.7 \\
\hline & Am & -1806.198589 & -326.7 & -308.6 \\
\hline & $\mathbf{C m}$ & -1849.836405 & -327.1 & -309.4 \\
\hline \multirow[t]{4}{*}[\mathrm{ML}(\mathrm{H}_{2}\mathrm{O})_{5}]{$^{3+}$} & Eu & -1844.649735 & -326.4 & -308.7 \\
\hline & Gd & -1899.836076 & -332.4 & -314.4 \\
\hline & Am & -1729.715044 & -329.9 & -311.3 \\
\hline & $\mathbf{C m}$ & -1773.350404 & -330.0 & -311.7 \\
\hline \multirow[t]{4}{*}[\mathrm{ML}_{2}(\mathrm{H}_{2}\mathrm{O})_{2}]{$^{3+}$} & $\mathbf{E u}$ & -2367.929737 & -286.7 & -269.6 \\
\hline & Gd & -2423.107172 & -296.8 & -278.5 \\
\hline & Am & -2253.001614 & -286.7 & -268.9 \\
\hline & $\mathbf{C m}$ & -2296.622180 & -294.7 & -276.7 \\
\hline \multirow[t]{4}{*}[\mathrm{ML}_{2}]{$^{3+}$} & Eu & -2214.934619 & -290.1 & -270.7 \\
\hline & Gd & -2270.121929 & -292.0 & -271.9 \\
\hline & Am & -2100.007707 & -291.0 & -271.3 \\
\hline & $\mathbf{C m}$ & -2143.640194 & -291.8 & -271.7 \\
\hline \multicolumn{5}{|c|}{$2 a m$} \\
\hline \multirow[t]{4}{*}[\mathrm{ML}(\mathrm{H}_{2}\mathrm{O})_{6}]{$^{3+}$} & Eu & -2273.898091 & -304.3 & -284.4 \\
\hline & Gd & -2329.085843 & -310.5 & -290.1 \\
\hline & Am & -2158.959748 & -307.9 & -288.1 \\
\hline & $\mathbf{C m}$ & -2202.599622 & -309.0 & -289.5 \\
\hline \multirow[t]{4}{*}[\mathrm{ML}(\mathrm{H}_{2}\mathrm{O})_{5}]{$^{3+}$} & Eu & -2197.416585 & -306.3 & -287.0 \\
\hline & Gd & -2252.603488 & -312.5 & -292.0 \\
\hline & Am & -2082.479436 & -310.4 & -290.1 \\
\hline & $\mathbf{C m}$ & -2126.116796 & -310.5 & -290.2 \\
\hline \multirow[t]{4}{*}[\mathrm{ML}_{2}(\mathrm{H}_{2}\mathrm{O})_{2}]{$^{3+}$} & Eu & -3073.442891 & -255.7 & -230.8 \\
\hline & Gd & -3128.638346 & -256.9 & -231.6 \\
\hline & Am & -2958.512603 & -256.8 & -231.0 \\
\hline & $\mathbf{C m}$ & -3002.150447 & -257.8 & -230.9 \\
\hline
\end{tabular}




\begin{tabular}{|c|c|c|c|c|}
\hline \multirow[t]{4}{*}[\mathrm{ML}_{2}]{$^{3+}$} & Eu & -2920.448884 & -257.5 & -234.9 \\
\hline & Gd & -2975.638482 & -260.9 & -237.9 \\
\hline & Am & -2805.522258 & -260.0 & -238.8 \\
\hline & $\mathbf{C m}$ & -2849.155544 & -259.8 & -238.4 \\
\hline \multicolumn{5}{|c|}{ 2ap } \\
\hline \multirow[t]{4}{*}[\mathrm{ML}(\mathrm{H}_{2}\mathrm{O})_{6}]{$^{3+}$} & Eu & -2465.688474 & -296.8 & -274.7 \\
\hline & Gd & -2520.860324 & -308.9 & -286.4 \\
\hline & $\mathbf{A m}$ & -2350.735209 & -305.5 & -283.3 \\
\hline & $\mathbf{C m}$ & -2394.374260 & -307.3 & -285.5 \\
\hline \multirow[t]{4}{*}[\mathrm{ML}(\mathrm{H}_{2}\mathrm{O})_{5}]{$^{3+}$} & Eu & -2389.209161 & -297.4 & -275.9 \\
\hline & Gd & -2444.378588 & -310.3 & -288.3 \\
\hline & Am & -2274.254683 & -307.7 & -285.5 \\
\hline & $\mathbf{C m}$ & -2317.891823 & -308.5 & -286.7 \\
\hline \multirow[t]{4}{*}[\mathrm{ML}_{2}(\mathrm{H}_{2}\mathrm{O})_{2}]{$^{3+}$} & Eu & -3456.993625 & -244.5 & -220.5 \\
\hline & Gd & -3512.181730 & -247.9 & -225.0 \\
\hline & Am & -3342.054944 & -248.4 & -224.4 \\
\hline & $\mathbf{C m}$ & -3385.693911 & -248.0 & -224.8 \\
\hline \multirow[t]{4}{*}[\mathrm{ML}_{2}]{$^{3+}$} & Eu & -3304.004367 & -252.7 & -225.8 \\
\hline & Gd & -3359.184604 & -255.5 & -227.4 \\
\hline & Am & -3189.068142 & -257.7 & -229.0 \\
\hline & $\mathbf{C m}$ & -3232.701761 & -255.1 & -227.7 \\
\hline \multicolumn{5}{|c|}{$2 \mathrm{be}$} \\
\hline \multirow[t]{4}{*}[\mathrm{ML}(\mathrm{H}_{2}\mathrm{O})_{6}]{$^{3+}$} & Eu & -2840.452161 & -292.2 & -271.4 \\
\hline & Gd & -2895.612206 & -314.5 & -290.7 \\
\hline & Am & -2725.488882 & -308.8 & -284.0 \\
\hline & $\mathbf{C m}$ & -2769.126010 & -312.5 & -288.5 \\
\hline \multirow[t]{4}{*}[\mathrm{ML}(\mathrm{H}_{2}\mathrm{O})_{5}]{$^{3+}$} & $\mathbf{E u}$ & -2763.979428 & -292.4 & -271.0 \\
\hline & Gd & -2819.129360 & -315.6 & -291.3 \\
\hline & Am & -2649.007474 & -306.6 & -282.2 \\
\hline & $\mathbf{C m}$ & -2692.642583 & -314.0 & -290.1 \\
\hline \multirow[t]{4}{*}[\mathrm{ML}_{2}(\mathrm{H}_{2}\mathrm{O})_{2}]{$^{3+}$} & $\mathbf{E u}$ & -4206.506369 & -252.3 & -222.5 \\
\hline & Gd & -4261.683515 & -260.9 & -230.3 \\
\hline & Am & -4091.558492 & -259.3 & -227.4 \\
\hline & $\mathbf{C m}$ & -4135.195792 & -262.2 & -229.8 \\
\hline \multirow[t]{4}{*}[\mathrm{ML}_{2}]{$^{3+}$} & $\mathbf{E u}$ & -4053.525470 & -256.0 & -221.7 \\
\hline & Gd & -4108.680377 & -266.4 & -231.0 \\
\hline & Am & -3938.564015 & -264.0 & -234.8 \\
\hline & $\mathbf{C m}$ & -3982.197461 & -265.9 & -233.3 \\
\hline
\end{tabular}




\begin{tabular}{|c|c|c|c|c|}
\hline \multirow[t]{4}{*}[\mathrm{ML}(\mathrm{H}_{2}\mathrm{O})_{6}]{$^{3+}$} & $\mathbf{E u}$ & -2651.850545 & -286.2 & -267.0 \\
\hline & Gd & -2707.012819 & -306.0 & -284.7 \\
\hline & Am & -2536.888709 & -302.9 & -282.5 \\
\hline & $\mathrm{Cm}$ & -2580.526523 & -304.6 & -283.8 \\
\hline \multirow[t]{4}{*}[\mathrm{ML}(\mathrm{H}_{2}\mathrm{O})_{5}]{$^{3+}$} & $\mathbf{E u}$ & -2575.378360 & -285.7 & -266.5 \\
\hline & Gd & -2630.530484 & -308.7 & -286.7 \\
\hline & Am & -2460.407937 & -300.7 & -278.5 \\
\hline & $\mathrm{Cm}$ & -2504.043610 & -306.8 & -285.7 \\
\hline \multirow[t]{4}{*}[\mathrm{ML}_{2}(\mathrm{H}_{2}\mathrm{O})_{2}]{$^{3+}$} & $\mathbf{E u}$ & -3829.302553 & -245.9 & -218.5 \\
\hline & Gd & -3884.482331 & -254.9 & -225.2 \\
\hline & Am & -3714.357108 & -254.0 & -223.6 \\
\hline & $\mathrm{Cm}$ & -3757.994388 & -255.3 & -225.2 \\
\hline \multirow[t]{4}{*}[\mathrm{ML}_{2}]{$^{3+}$} & $\mathbf{E u}$ & -3676.322176 & -244.3 & -219.6 \\
\hline & Gd & -3731.481462 & -256.2 & -232.0 \\
\hline & Am & -3561.364549 & -255.3 & -231.8 \\
\hline & $\mathrm{Cm}$ & -3604.998314 & -256.2 & -232.9 \\
\hline \multicolumn{5}{|c|}{$2 b p$} \\
\hline \multirow[t]{4}{*}[\mathrm{ML}(\mathrm{H}_{2}\mathrm{O})_{6}]{$^{3+}$} & $\mathbf{E u}$ & -2843.607752 & -286.4 & -264.8 \\
\hline & Gd & -2898.786493 & -305.4 & -282.8 \\
\hline & Am & -2728.662440 & -301.9 & -278.0 \\
\hline & $\mathrm{Cm}$ & -2772.300162 & -303.9 & -280.7 \\
\hline \multirow[t]{4}{*}[\mathrm{ML}(\mathrm{H}_{2}\mathrm{O})_{5}]{$^{3+}$} & $\mathbf{E u}$ & -2767.126165 & -284.5 & -264.3 \\
\hline & Gd & -2822.304796 & -306.9 & -282.9 \\
\hline & Am & -2652.180352 & -300.5 & -277.1 \\
\hline & $\mathrm{Cm}$ & -2695.817829 & -304.9 & -282.0 \\
\hline \multirow[t]{4}{*}[\mathrm{ML}_{2}(\mathrm{H}_{2}\mathrm{O})_{2}]{$^{3+}$} & $\mathbf{E u}$ & -4212.842250 & -240.9 & -212.5 \\
\hline & Gd & -4268.024474 & -247.9 & -218.6 \\
\hline & Am & -4097.893968 & -244.2 & -216.1 \\
\hline & $\mathrm{Cm}$ & -4141.536647 & -248.4 & -218.4 \\
\hline \multirow[t]{4}{*}[\mathrm{ML}_{2}]{$^{3+}$} & $\mathbf{E u}$ & -4059.862799 & -243.7 & -211.9 \\
\hline & Gd & -4115.025850 & -253.3 & -220.6 \\
\hline & Am & -3944.908906 & -253.3 & -221.1 \\
\hline & $\mathrm{Cm}$ & -3988.542839 & -253.3 & -221.2 \\
\hline \multicolumn{5}{|c|}{$\mathbf{1 i}$} \\
\hline \multirow[t]{4}{*}[\mathrm{ML}(\mathrm{H}_{2}\mathrm{O})_{6}]{$^{3+}$} & $\mathbf{E u}$ & -2058.592967 & -157.2 & -147.6 \\
\hline & Gd & -2113.752315 & -167.0 & -156.3 \\
\hline & Am & -1943.625783 & -162.9 & -152.1 \\
\hline & $\mathrm{Cm}$ & -1987.266430 & -166.0 & -155.2 \\
\hline$\left[\mathrm{ML}\left(\mathrm{H}_{2} \mathrm{O}\right)_{5}\right]^{3+}$ & $\mathbf{E u}$ & -1982.119516 & -156.3 & -147.1 \\
\hline
\end{tabular}




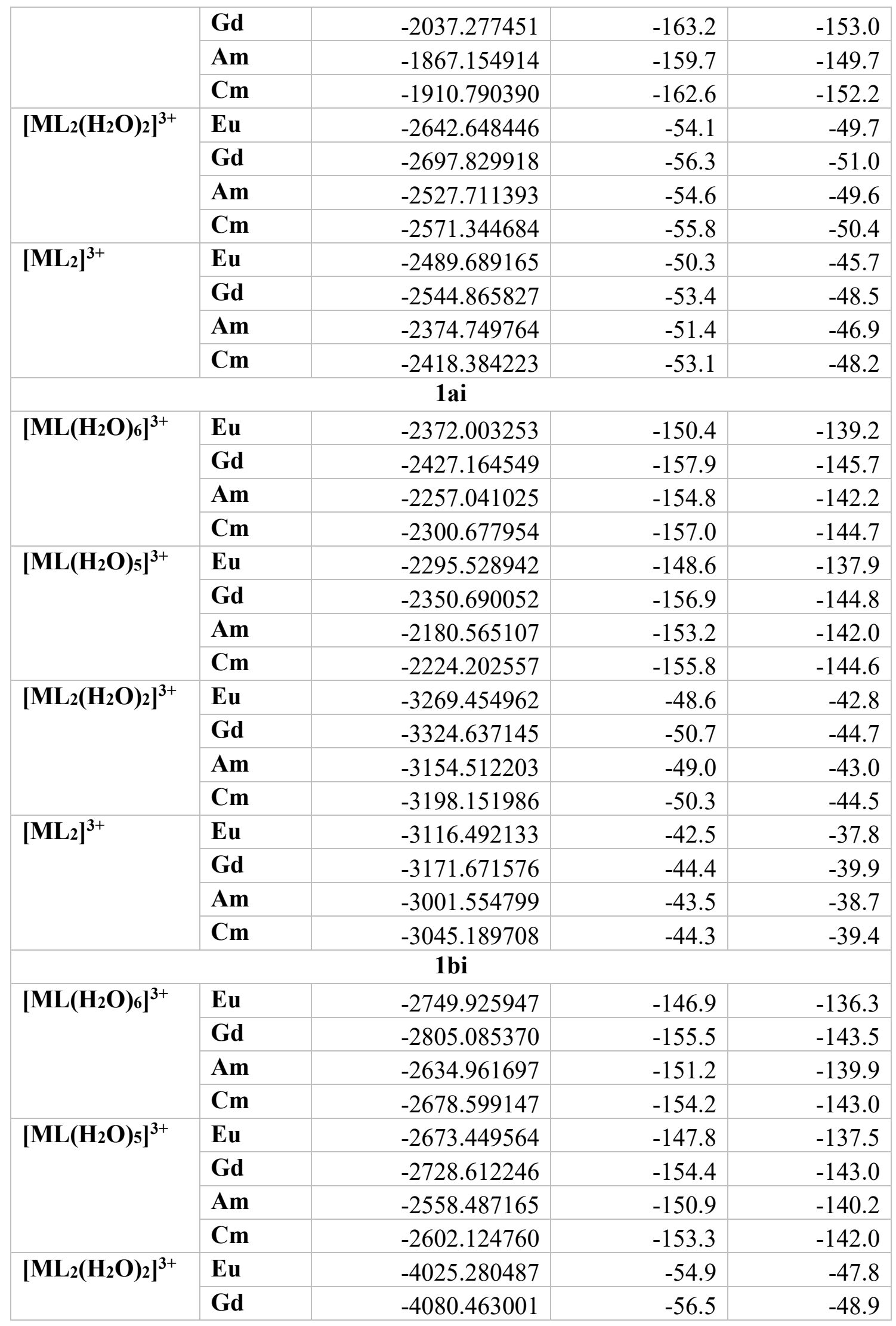




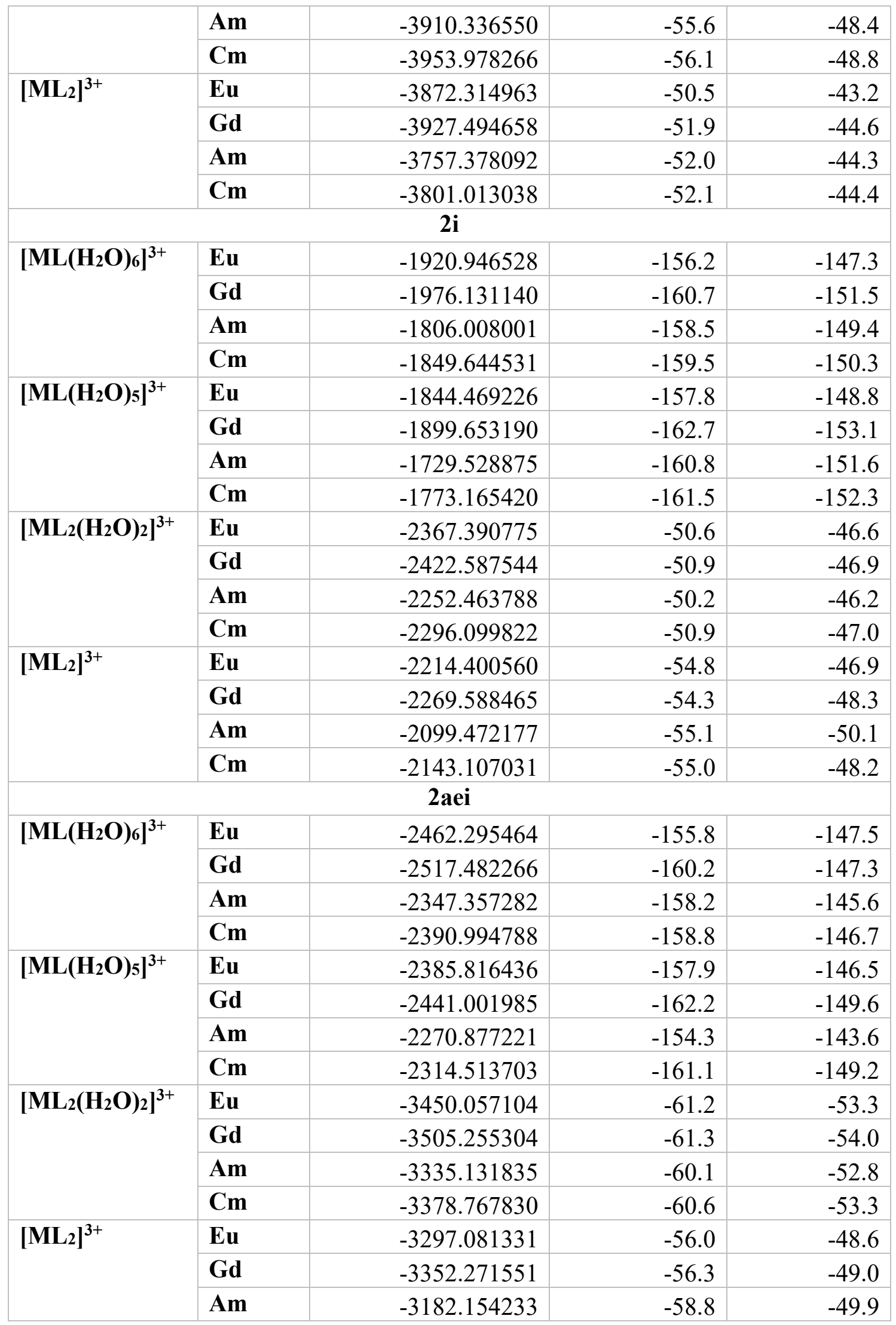




\begin{tabular}{|c|c|c|c|c|}
\hline & $\mathbf{C m}$ & -3225.789001 & -56.6 & -49.1 \\
\hline \multicolumn{5}{|c|}{$2 a m i$} \\
\hline \multirow[t]{4}{*}[\mathrm{ML}(\mathrm{H}_{2}\mathrm{O})_{6}]{$^{3+}$} & Eu & -2273.693105 & -145.0 & -135.8 \\
\hline & Gd & -2328.875665 & -149.3 & -139.7 \\
\hline & Am & -2158.751562 & -147.7 & -138.3 \\
\hline & $\mathbf{C m}$ & -2202.388456 & -148.8 & -138.9 \\
\hline \multirow[t]{4}{*}[\mathrm{ML}(\mathrm{H}_{2}\mathrm{O})_{5}]{$^{3+}$} & Eu & -2197.216961 & -147.2 & -137.0 \\
\hline & Gd & -2252.398860 & -151.5 & -140.4 \\
\hline & Am & -2082.274072 & -149.4 & -139.1 \\
\hline & $\mathbf{C m}$ & -2125.910465 & -150.6 & -140.0 \\
\hline \multirow[t]{4}{*}[\mathrm{ML}_{2}(\mathrm{H}_{2}\mathrm{O})_{2}]{$^{3+}$} & Eu & -3072.845620 & -45.9 & -40.2 \\
\hline & Gd & -3128.037304 & -47.0 & -41.0 \\
\hline & Am & -2957.914158 & -45.9 & -39.9 \\
\hline & $\mathbf{C m}$ & -3001.549967 & -46.6 & -40.5 \\
\hline \multirow[t]{4}{*}[\mathrm{ML}_{2}]{$^{3+}$} & Eu & -2919.868170 & -42.9 & -36.6 \\
\hline & Gd & -2975.055631 & -45.6 & -37.8 \\
\hline & $\mathbf{A m}$ & -2804.938086 & -45.9 & -38.4 \\
\hline & $\mathbf{C m}$ & -2848.573135 & -48.8 & -37.3 \\
\hline \multicolumn{5}{|c|}{ 2api } \\
\hline \multirow[t]{4}{*}[\mathrm{ML}(\mathrm{H}_{2}\mathrm{O})_{6}]{$^{3+}$} & Eu & -2465.476139 & -143.4 & -150.4 \\
\hline & Gd & -2520.647146 & -152.7 & -141.0 \\
\hline & Am & -2350.522224 & -150.4 & -138.8 \\
\hline & $\mathbf{C m}$ & -2394.159617 & -151.5 & -140.2 \\
\hline \multirow[t]{4}{*}[\mathrm{ML}(\mathrm{H}_{2}\mathrm{O})_{5}]{$^{3+}$} & Eu & -2389.000372 & -144.3 & -134.0 \\
\hline & Gd & -2444.167177 & -154.7 & -143.1 \\
\hline & Am & -2274.040879 & -151.9 & -140.3 \\
\hline & $\mathbf{C m}$ & -2317.678750 & -153.6 & -142.3 \\
\hline \multirow[t]{4}{*}[\mathrm{ML}_{2}(\mathrm{H}_{2}\mathrm{O})_{2}]{$^{3+}$} & Eu & -3456.386046 & -49.8 & -44.0 \\
\hline & Gd & -3511.574420 & -52.1 & -46.0 \\
\hline & Am & -3341.446629 & -50.5 & -45.3 \\
\hline & $\mathbf{C m}$ & -3385.084820 & -50.5 & -45.1 \\
\hline \multirow[t]{4}{*}[\mathrm{ML}_{2}]{$^{3+}$} & Eu & -3303.412172 & -50.1 & -42.4 \\
\hline & Gd & -3358.592966 & -47.9 & -41.6 \\
\hline & Am & -3188.475559 & -47.1 & -41.0 \\
\hline & $\mathbf{C m}$ & -3232.110281 & -47.5 & -41.3 \\
\hline \multicolumn{5}{|c|}{2 bei } \\
\hline \multirow[t]{3}{*}[\mathrm{ML}(\mathrm{H}_{2}\mathrm{O})_{6}]{$^{3+}$} & Eu & -2840.218009 & -151.2 & -139.9 \\
\hline & Gd & -2895.398338 & -161.1 & -148.1 \\
\hline & Am & -2725.274332 & -159.0 & -146.2 \\
\hline
\end{tabular}




\begin{tabular}{|c|c|c|c|c|}
\hline & $\mathrm{Cm}$ & -2768.911277 & -160.4 & -147.3 \\
\hline $\left.\multirow[t]{4}{*}{\mathrm{ML}\left(\mathrm{H}_{2} \mathrm{O}\right)}_{5}\right]^{3+}$ & $\mathbf{E u}$ & -2763.737774 & -151.6 & -140.0 \\
\hline & Gd & -2818.919463 & -161.7 & -149.3 \\
\hline & Am & -2648.794499 & -160.7 & -147.8 \\
\hline & $\mathbf{C m}$ & -2692.431129 & -161.0 & -148.4 \\
\hline \multirow[t]{4}{*}[\mathrm{ML}_{2}(\mathrm{H}_{2}\mathrm{O})_{2}]{$^{3+}$} & $\mathbf{E u}$ & -4205.900288 & -60.8 & -53.4 \\
\hline & Gd & -4261.093264 & -61.1 & -53.9 \\
\hline & Am & -4090.968846 & -61.1 & -53.7 \\
\hline & $\mathbf{C m}$ & -4134.605142 & -61.2 & -53.9 \\
\hline \multirow[t]{4}{*}[\mathrm{ML}_{2}]{$^{3+}$} & Eu & -4052.903468 & -69.0 & -55.7 \\
\hline & Gd & -4108.094270 & -67.2 & -54.3 \\
\hline & Am & -3937.977544 & -66.8 & -54.5 \\
\hline & $\mathbf{C m}$ & -3981.611975 & -66.4 & -54.1 \\
\hline \multicolumn{5}{|c|}{ 2bmi } \\
\hline \multirow[t]{4}{*}[\mathrm{ML}(\mathrm{H}_{2}\mathrm{O})_{6}]{$^{3+}$} & $\mathbf{E u}$ & -2651.612427 & -138.7 & -128.8 \\
\hline & Gd & -2706.794345 & -151.4 & -139.5 \\
\hline & Am & -2536.670635 & -149.1 & -137.9 \\
\hline & $\mathbf{C m}$ & -2580.307297 & -150.3 & -138.6 \\
\hline \multirow[t]{4}{*}[\mathrm{ML}(\mathrm{H}_{2}\mathrm{O})5]{$^{3+}$} & $\mathbf{E u}$ & -2575.134504 & -146.1 & -133.3 \\
\hline & Gd & -2630.315947 & -151.4 & -140.1 \\
\hline & Am & -2460.190967 & -150.4 & -139.2 \\
\hline & $\mathrm{Cm}$ & -2503.827510 & -150.8 & -139.5 \\
\hline \multirow[t]{4}{*}[\mathrm{ML}_{2}(\mathrm{H}_{2}\mathrm{O})_{2}]{$^{3+}$} & $\mathbf{E u}$ & -3828.680716 & -49.8 & -44.1 \\
\hline & Gd & -3883.873150 & -50.1 & -44.4 \\
\hline & Am & -3713.749178 & -50.0 & -44.3 \\
\hline & $\mathbf{C m}$ & -3757.385215 & -50.1 & -44.2 \\
\hline \multirow[t]{4}{*}[\mathrm{ML}_{2}]{$^{3+}$} & $\mathbf{E u}$ & -3675.689750 & -53.8 & -44.7 \\
\hline & Gd & -3730.878075 & -54.3 & -44.4 \\
\hline & Am & -3560.761042 & -54.0 & -43.8 \\
\hline & $\mathbf{C m}$ & -3604.395731 & -54.2 & -43.6 \\
\hline \multicolumn{5}{|c|}{ 2bpi } \\
\hline \multirow[t]{4}{*}[\mathrm{ML}(\mathrm{H}_{2}\mathrm{O})_{6}]{$^{3+}$} & Eu & -2843.391093 & -145.7 & -134.6 \\
\hline & Gd & -2898.562773 & -153.8 & -142.0 \\
\hline & Am & -2728.439077 & -151.3 & -139.1 \\
\hline & $\mathbf{C m}$ & -2772.075683 & -153.1 & -141.0 \\
\hline \multirow[t]{4}{*}[\mathrm{ML}(\mathrm{H}_{2}\mathrm{O})5]{$^{3+}$} & $\mathbf{E u}$ & -2766.915417 & -142.3 & -131.9 \\
\hline & Gd & -2822.084160 & -154.4 & -142.8 \\
\hline & Am & -2651.959193 & -153.0 & -141.0 \\
\hline & $\mathbf{C m}$ & -2695.595685 & -153.9 & -142.1 \\
\hline
\end{tabular}




\begin{tabular}{|l|l|r|r|r|}
\hline $\left.\mathbf{M L}_{2}\left(\mathbf{H}_{\mathbf{2}} \mathbf{O}\right)_{2}\right]^{3+}$ & $\mathbf{E u}$ & -4212.219368 & -53.2 & -46.6 \\
\cline { 2 - 5 } & $\mathbf{G d}$ & -4267.410556 & -54.2 & -47.6 \\
\cline { 2 - 5 } & $\mathbf{A m}$ & -4097.286214 & -54.1 & -47.6 \\
\hline & $\mathbf{C m}$ & -4140.922425 & -54.2 & -47.6 \\
\hline $\left.\mathbf{M L}_{2}\right]^{3+}$ & $\mathbf{E u}$ & -4059.233598 & -55.0 & -45.8 \\
\cline { 2 - 5 } & $\mathbf{G d}$ & -4114.415341 & -57.2 & -47.1 \\
\cline { 2 - 5 } & $\mathbf{A m}$ & -3944.298144 & -57.2 & -47.2 \\
\hline & $\mathbf{C m}$ & -3987.932811 & -56.7 & -47.1 \\
\hline
\end{tabular}

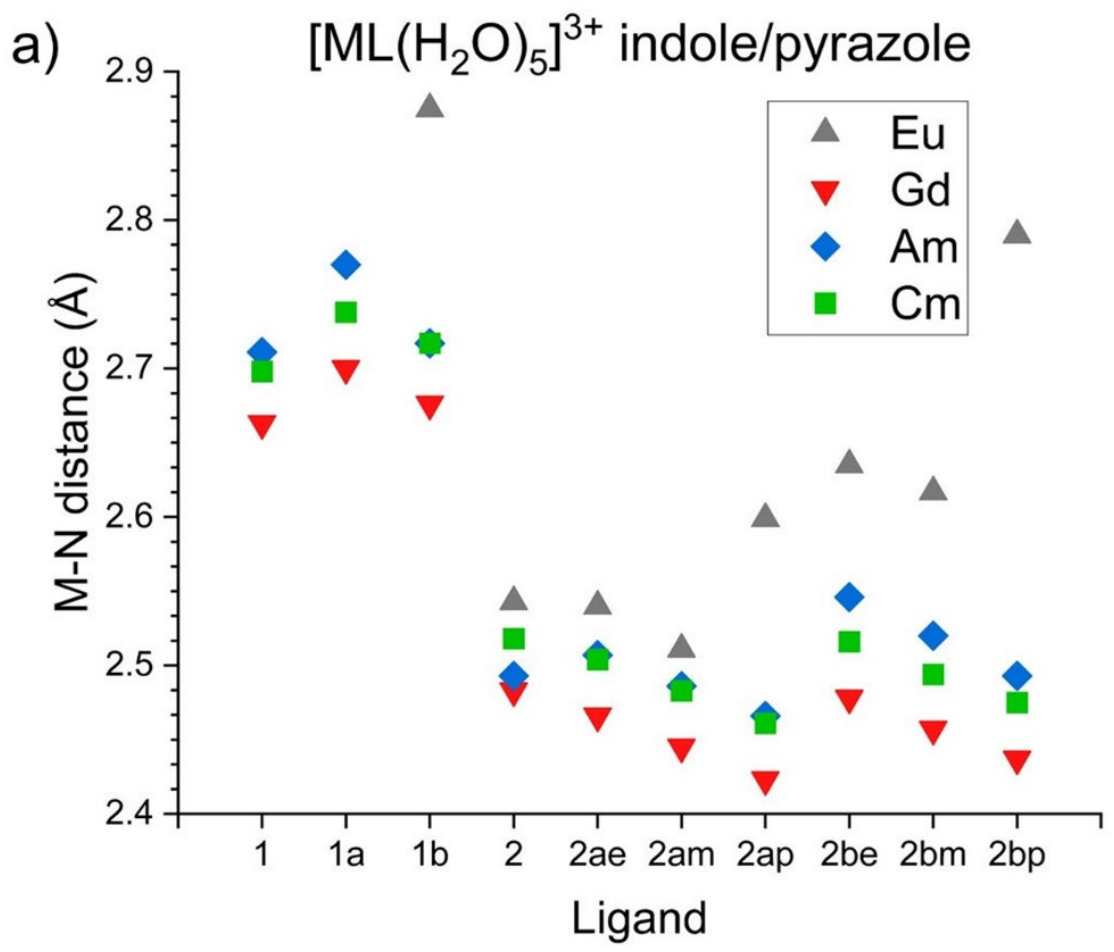



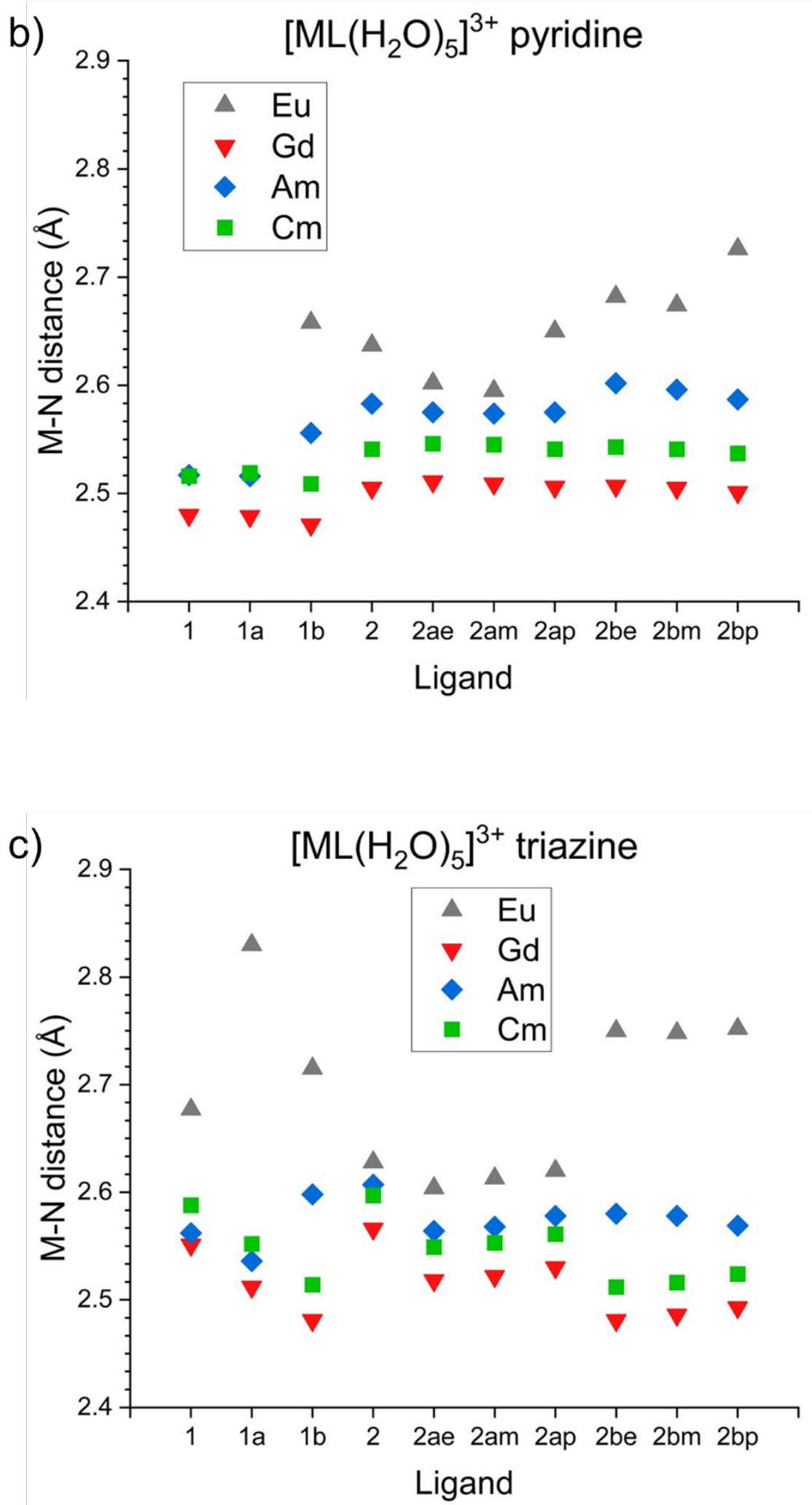

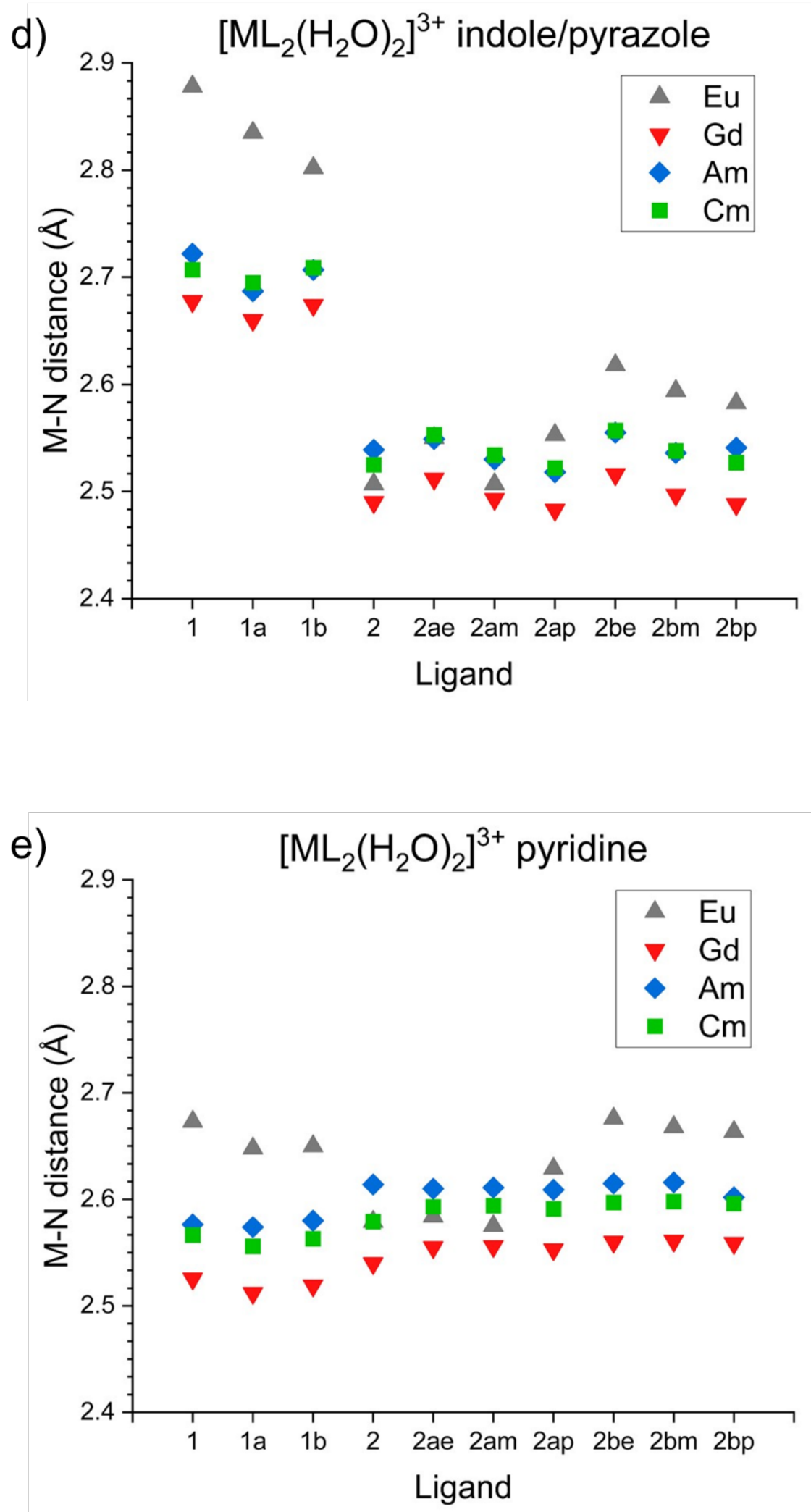


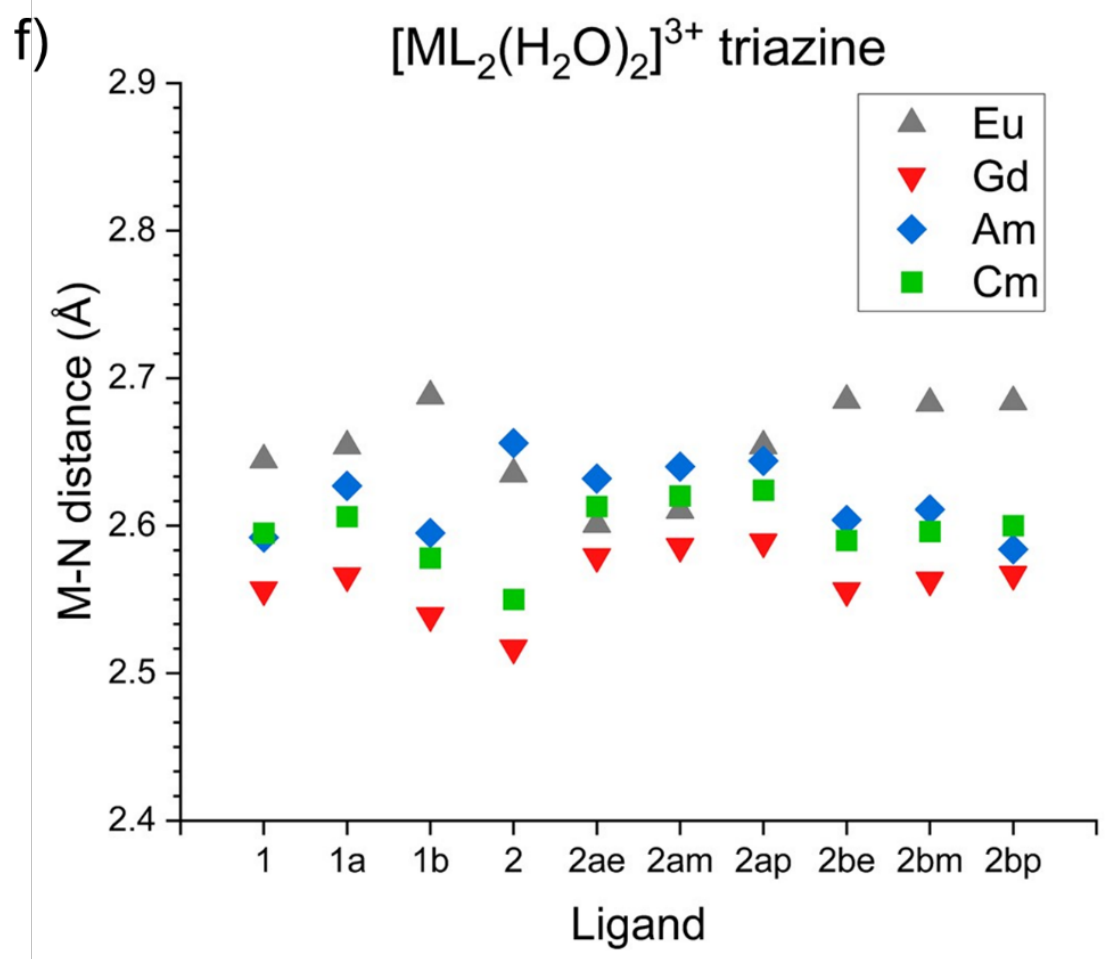

Figure S1.a. Distances between the donor nitrogen and the complexed metal. a) $\left[\mathrm{ML}\left(\mathrm{H}_{2} \mathrm{O}\right)_{5}\right]^{3+}$, $\mathrm{N}=1$-H indole(Core 1) or 1,2-pyrazole(Core 2). b) $\left[\mathrm{ML}\left(\mathrm{H}_{2} \mathrm{O}\right)_{5}\right]^{3+}, \mathrm{N}=$ pyridine. c) $\left[\mathrm{ML}\left(\mathrm{H}_{2} \mathrm{O}\right)_{5}\right]^{3+}$, $\mathrm{N}=$ 1,2,4-triazine; d) $\left[\mathrm{ML}_{2}\left(\mathrm{H}_{2} \mathrm{O}\right)_{2}\right]^{3+}, \mathrm{N}=1 \mathrm{H}$-indole(Core 1) or 1,2-pyrazole(Core 2); e) $\left[\mathrm{ML}_{2}\left(\mathrm{H}_{2} \mathrm{O}\right)_{2}\right]^{3+}, \mathrm{N}=$ pyridine; f) $\left[\mathrm{ML}_{2}\left(\mathrm{H}_{2} \mathrm{O}\right)_{2}\right]^{3+}, \mathrm{N}=1,2$,4-triazine. 1 and $\mathbf{1 a}$ Eu distances not shown $(\mathrm{R}>3 \AA$ ) for $\mathrm{a})$ and $\mathrm{b})$ 
a)

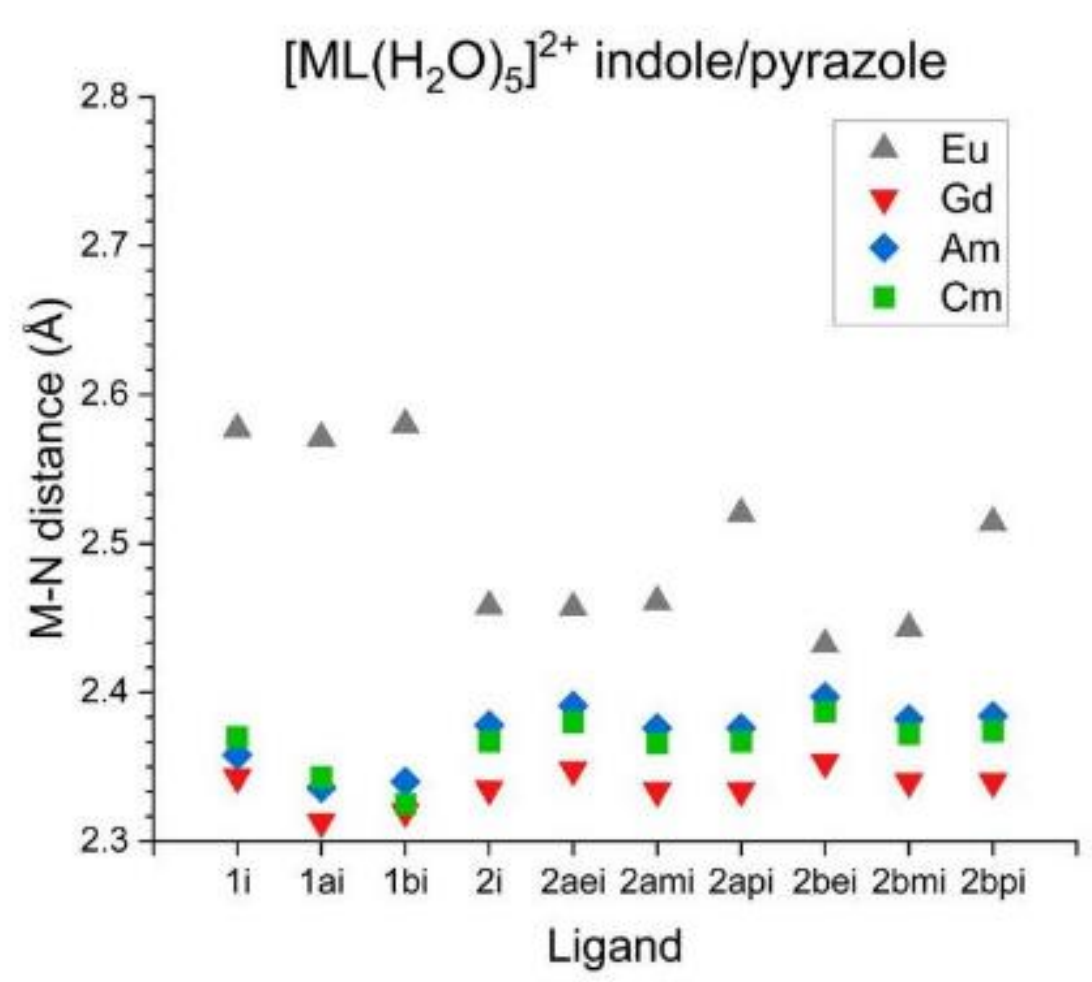

b)

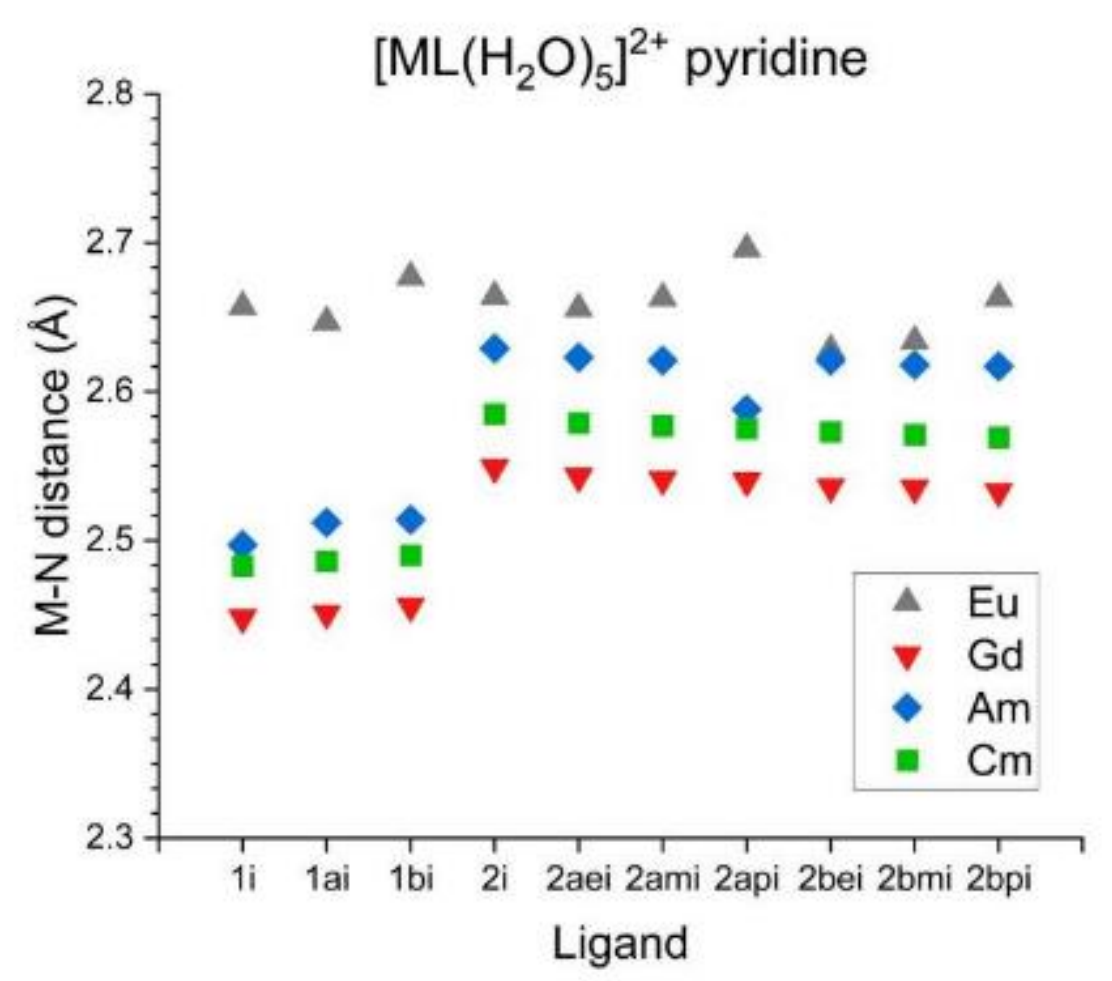


c)
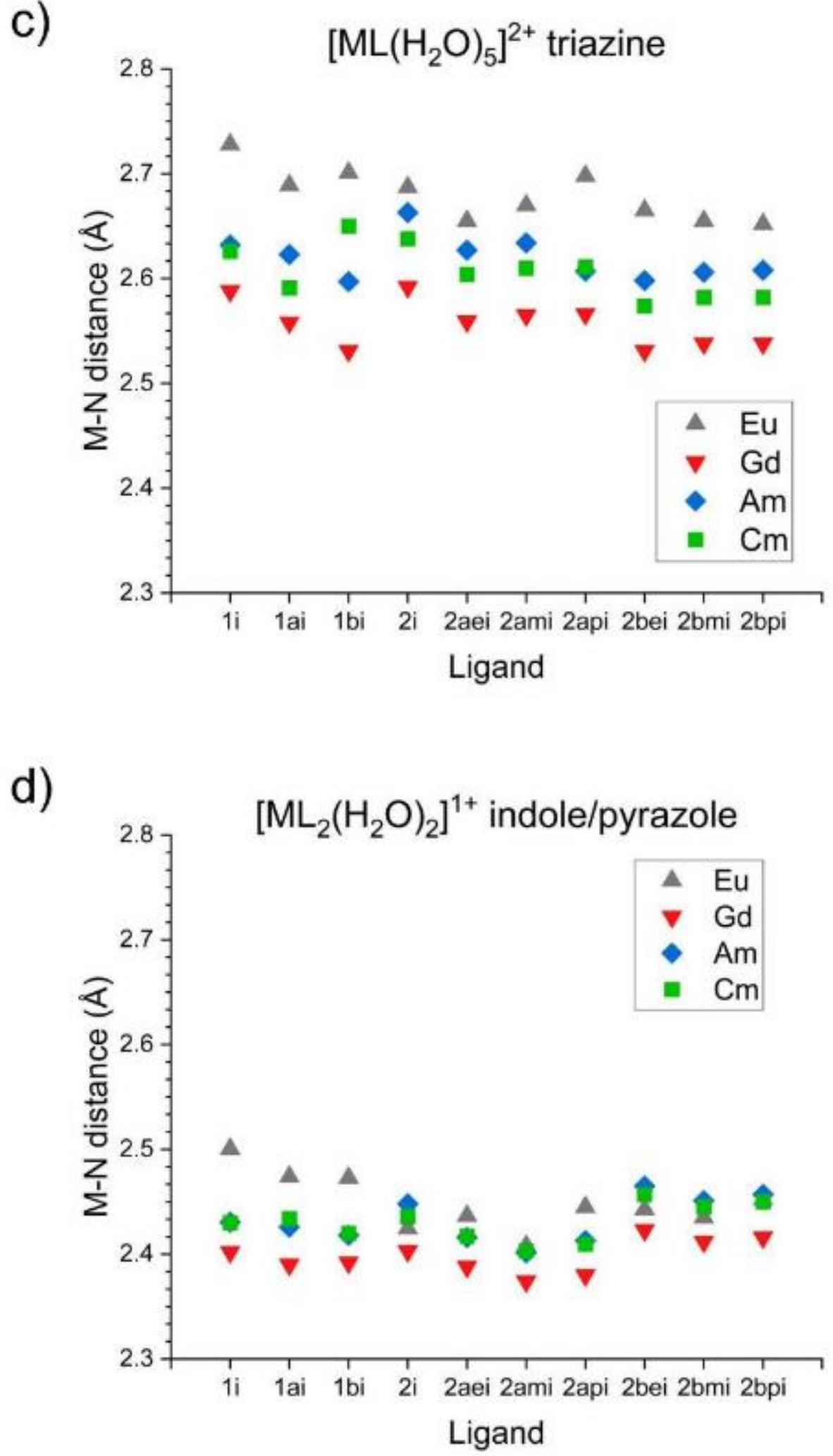

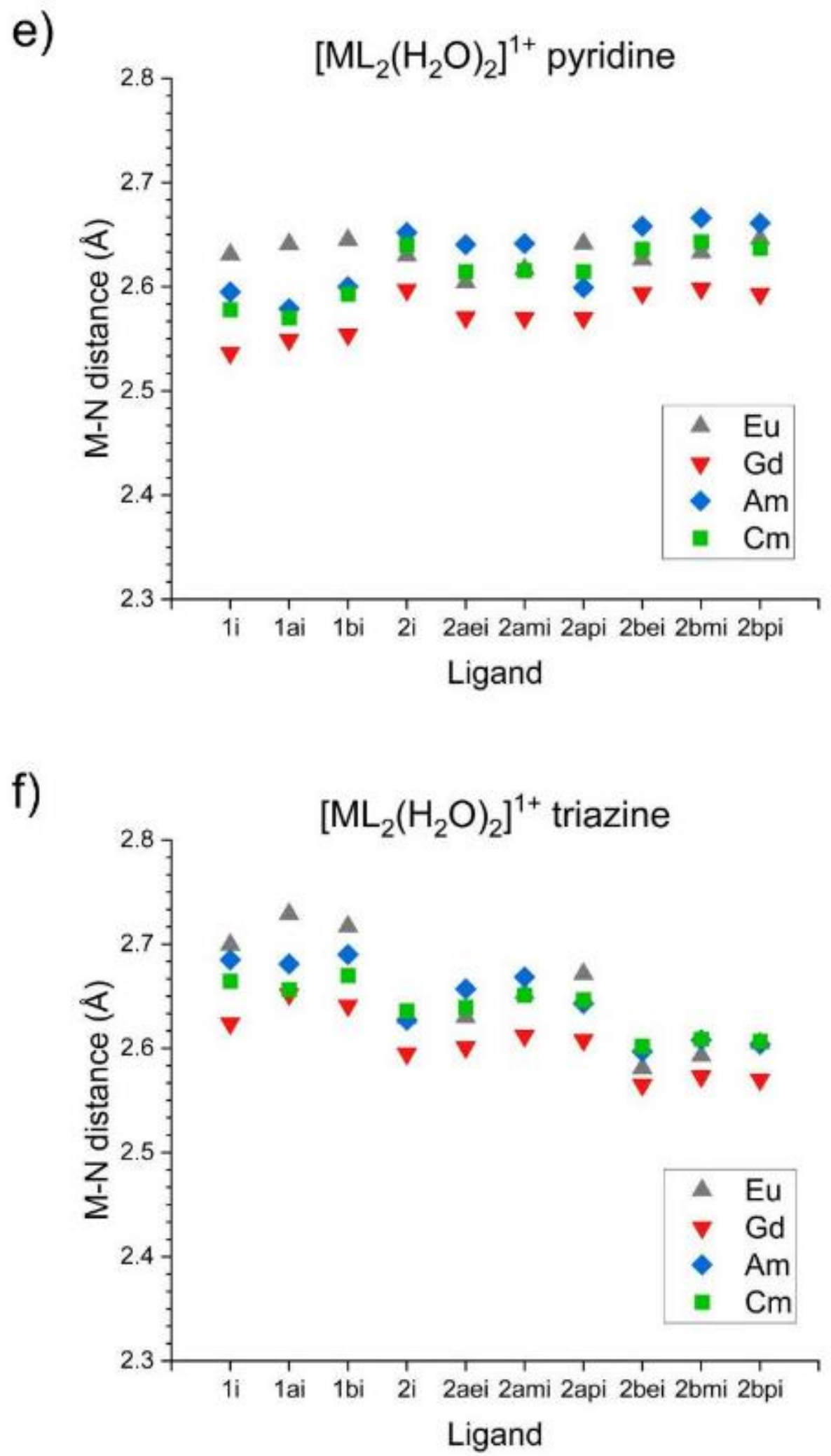
Figure S1.b. Plots of distances between $\mathrm{M}(\mathrm{III})$ and each $\mathrm{N}$ donor in complexes with anionic ligands for complexes $\left[\mathrm{ML}\left(\mathrm{H}_{2} \mathrm{O}\right)_{5}\right]^{2+}$ and $\left[\mathrm{ML}_{2}\left(\mathrm{H}_{2} \mathrm{O}\right)_{2}\right]^{+}$optimized by B3LYP/Stuttgart'97ECP/DZVP2. a) $\left[\mathrm{ML}\left(\mathrm{H}_{2} \mathrm{O}\right)_{5}\right]^{2+}, \mathrm{N}=$ indole(Core 1) or pyrazole(Core 2). b) $\left[\mathrm{ML}\left(\mathrm{H}_{2} \mathrm{O}\right)_{5}\right]^{2+}, \mathrm{N}=$ pyridine. c) $\left[\mathrm{ML}\left(\mathrm{H}_{2} \mathrm{O}\right)_{5}\right]^{2+}, \mathrm{N}=$ triazine; d) $\left[\mathrm{ML}_{2}\left(\mathrm{H}_{2} \mathrm{O}\right)_{2}\right]^{1+}, \mathrm{N}=$ indole $($ Core 1) or pyrazole(Core 2); e) $\left[\mathrm{ML}_{2}\left(\mathrm{H}_{2} \mathrm{O}\right)_{2}\right]^{1+}, \mathrm{N}=$ pyridine; f) $\left[\mathrm{ML}_{2}\left(\mathrm{H}_{2} \mathrm{O}\right)_{2}\right]^{1+}, \mathrm{N}=$ triazine. 1 and $\mathbf{1 a} \mathrm{Eu}$ distances not shown $(\mathrm{R}>3 \AA$ ) for $\mathrm{a})$ and $\mathrm{b})$. 


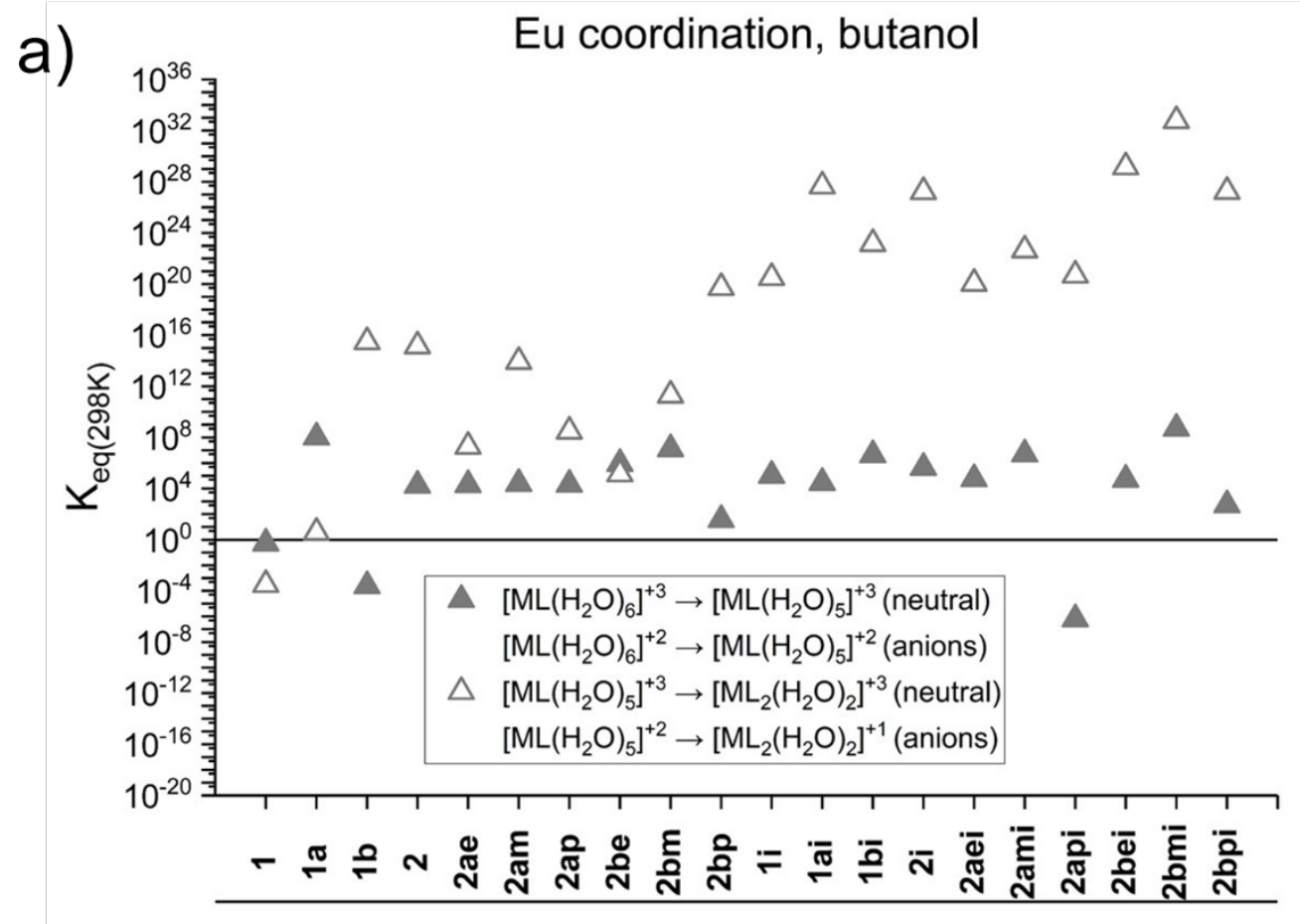

ligand

b)

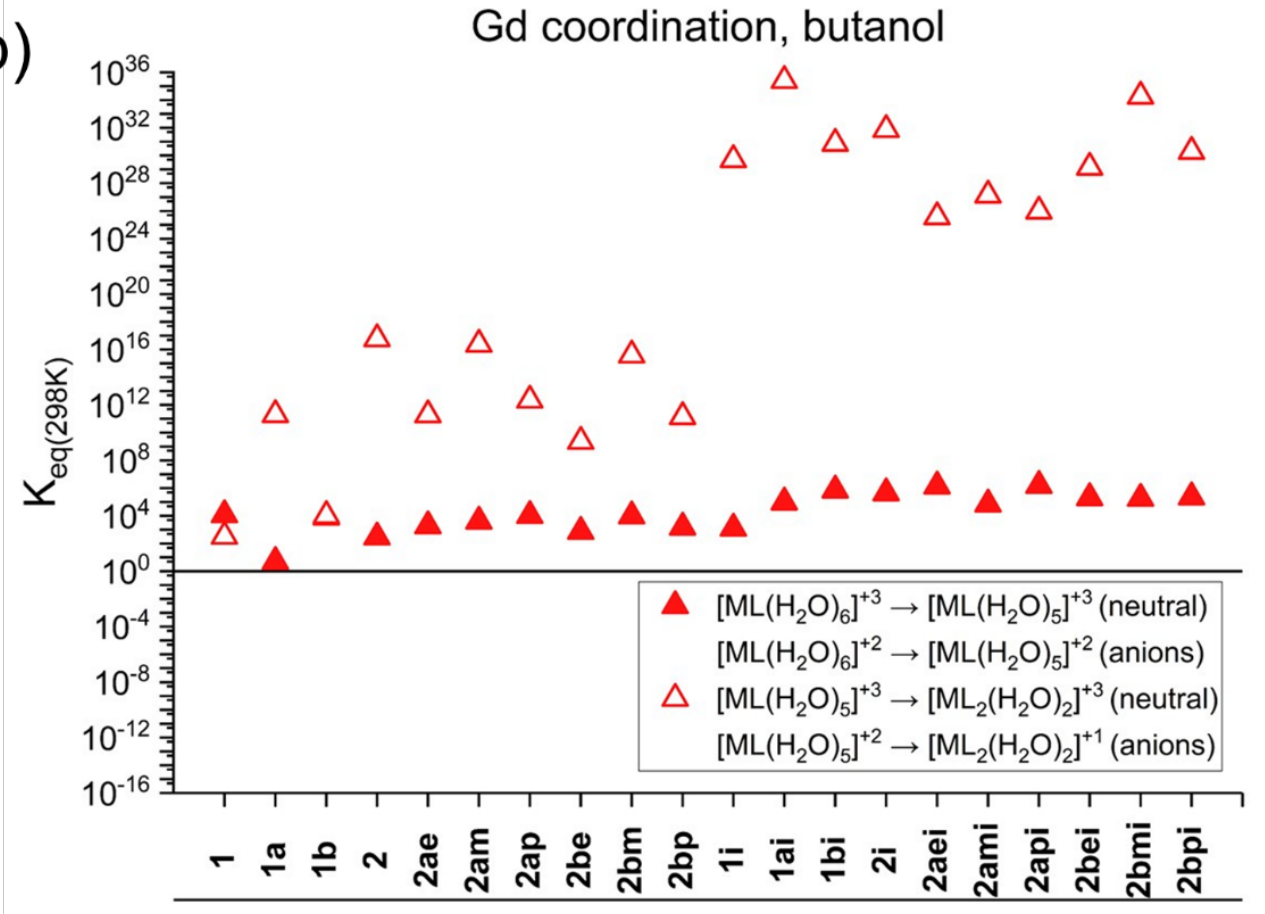

ligand 
c)

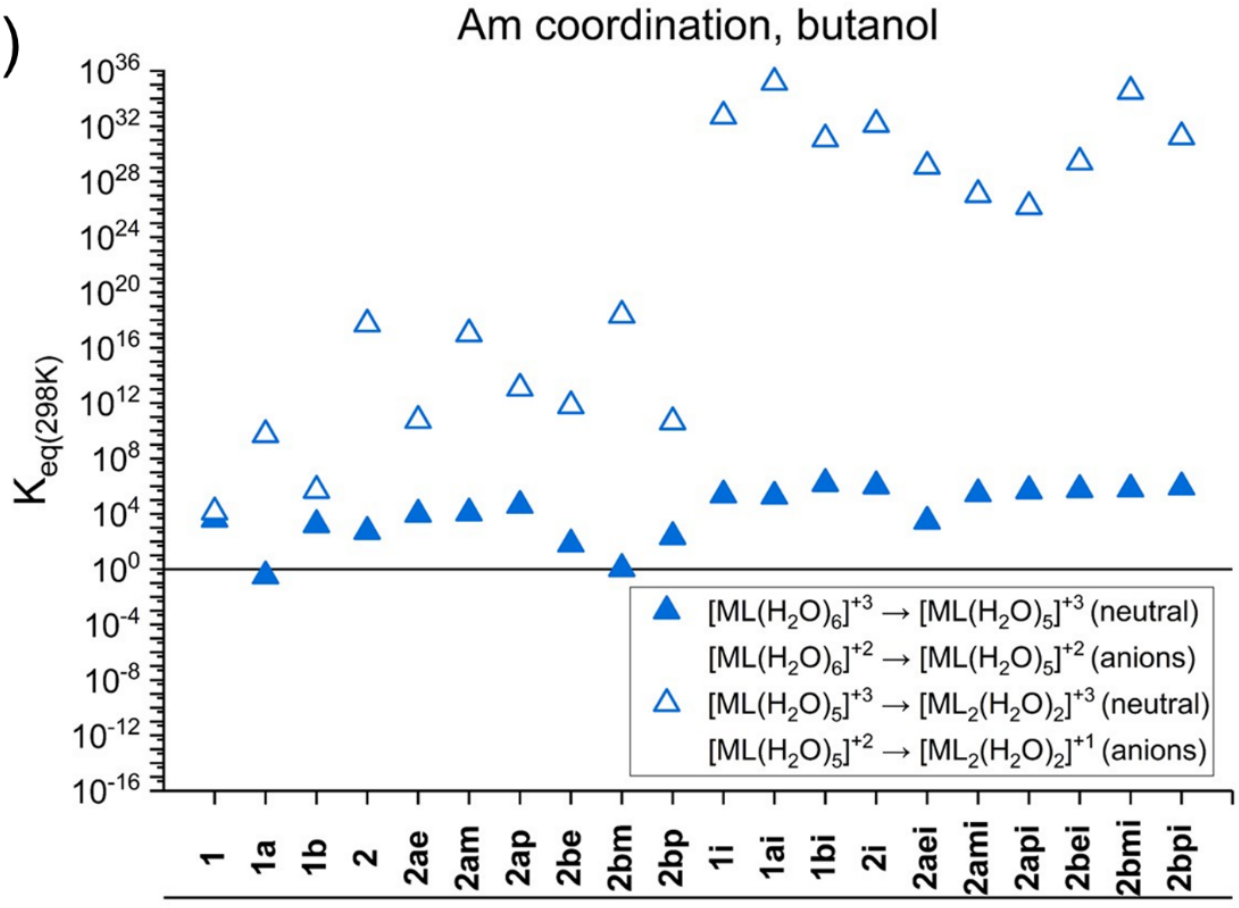

ligand

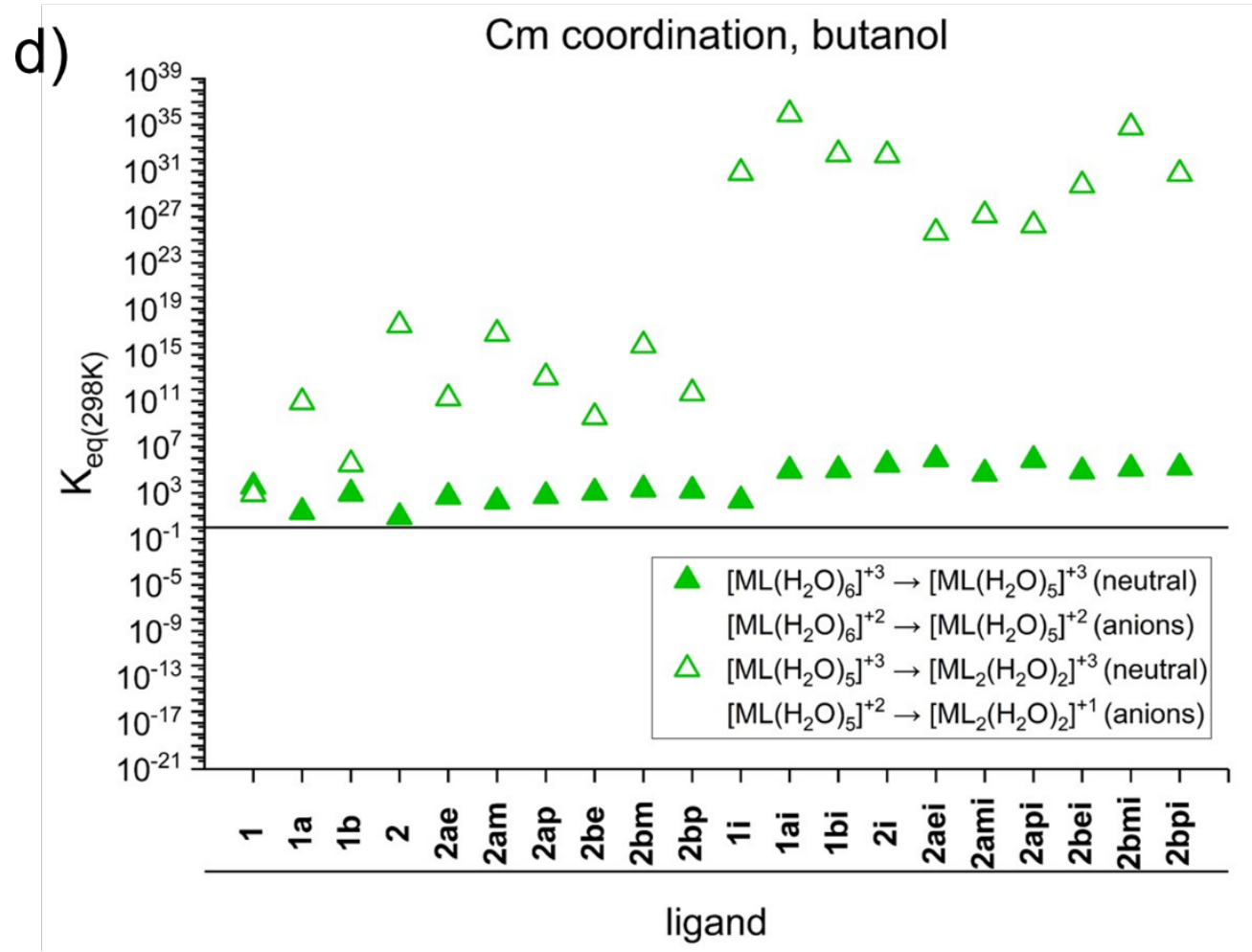

Figure S2. Equilibrium constants for reactions (12) and (13) in butanol graphed on a logarithmic scale. Calculated by B3LYP/Stuttgart'97ECP/DZVP2. a) $\mathrm{M}=\mathrm{Eu}$; b) $\mathrm{M}=\mathrm{Gd}$; c) $\mathrm{M}=\mathrm{Am}$; d) M=Cm. 


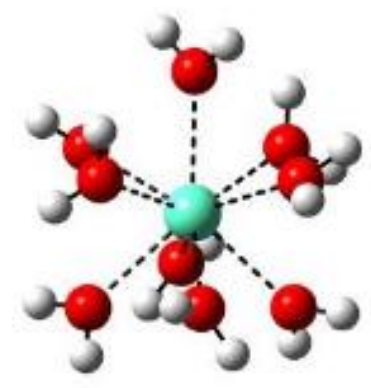

Eu

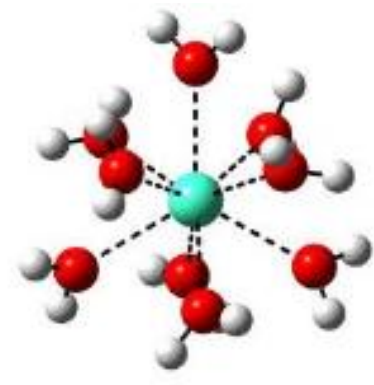

$\mathrm{Gd}$

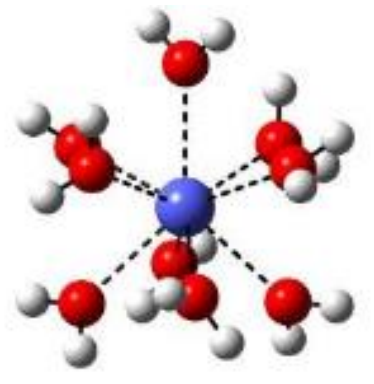

Am

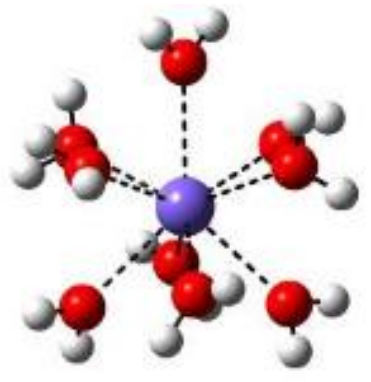

$\mathrm{Cm}$

Figure S3. Images of explicitly solvated M(III) clusters $\left(\left[\mathrm{M}\left(\mathrm{H}_{2} \mathrm{O}\right)_{9}\right]^{3+}\right)$ optimized at the B3LYP/Stuttgart'97ECP/DZVP2 level.
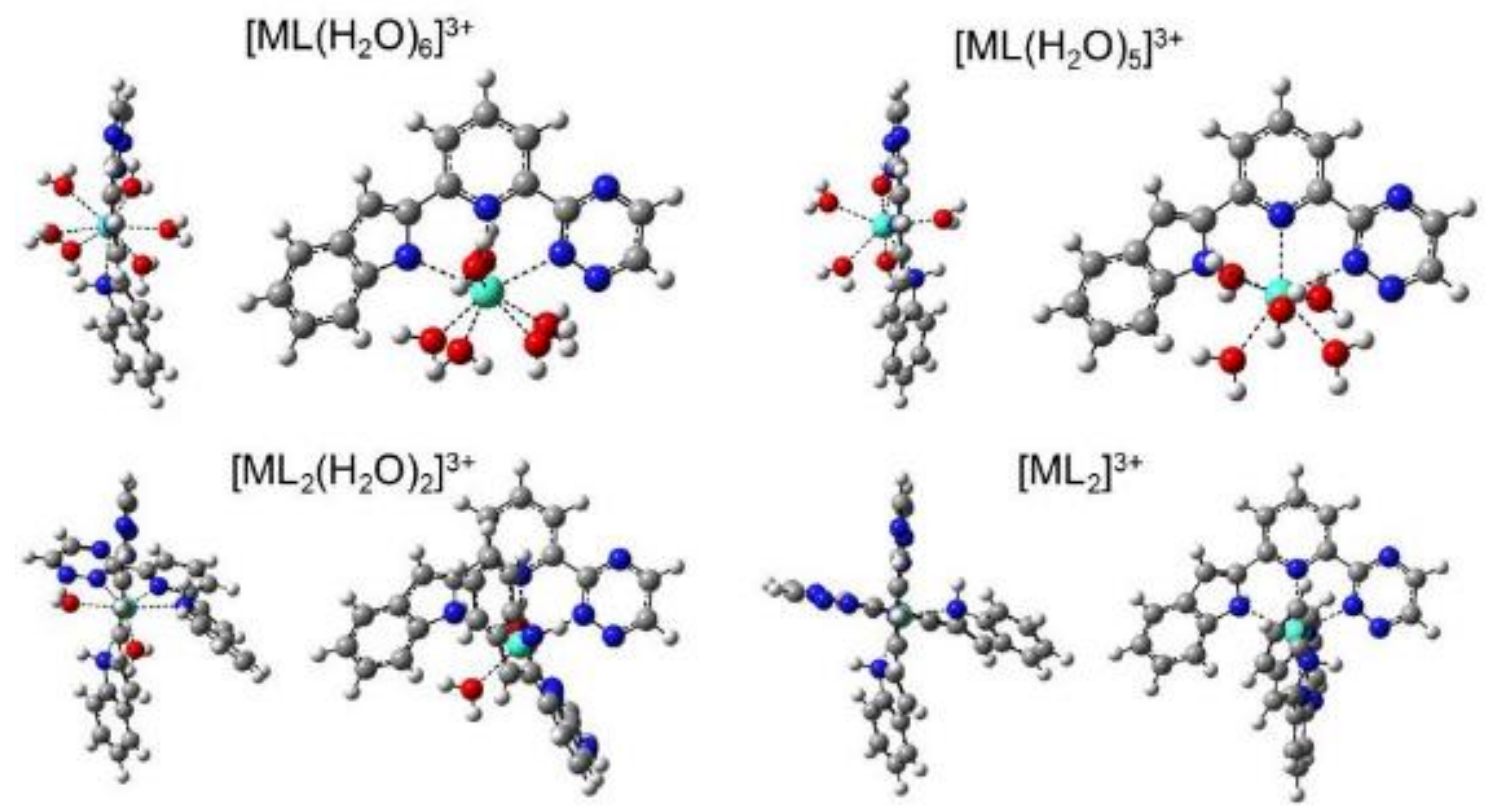

Figure S4. Images of Core 1(1) complexes optimized at the B3LYP/Stuttgart'97ECP/DZVP2 level for $\mathrm{M}=\mathrm{Gd}$ as an example. 

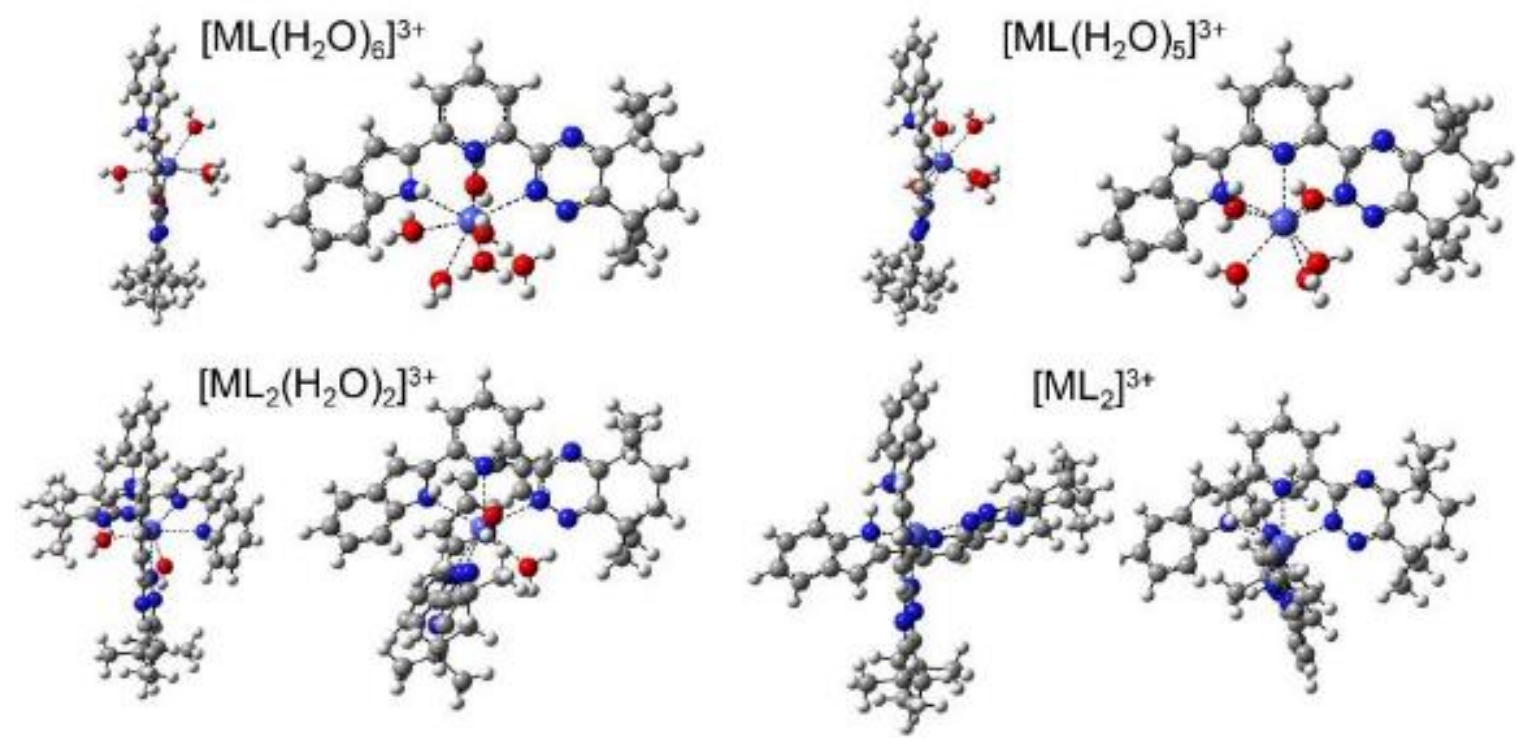

Figure S5. Images of 1a complexes optimized at the B3LYP/Stuttgart'97ECP/DZVP2 level for $\mathrm{M}=\mathrm{Am}$ as an example.
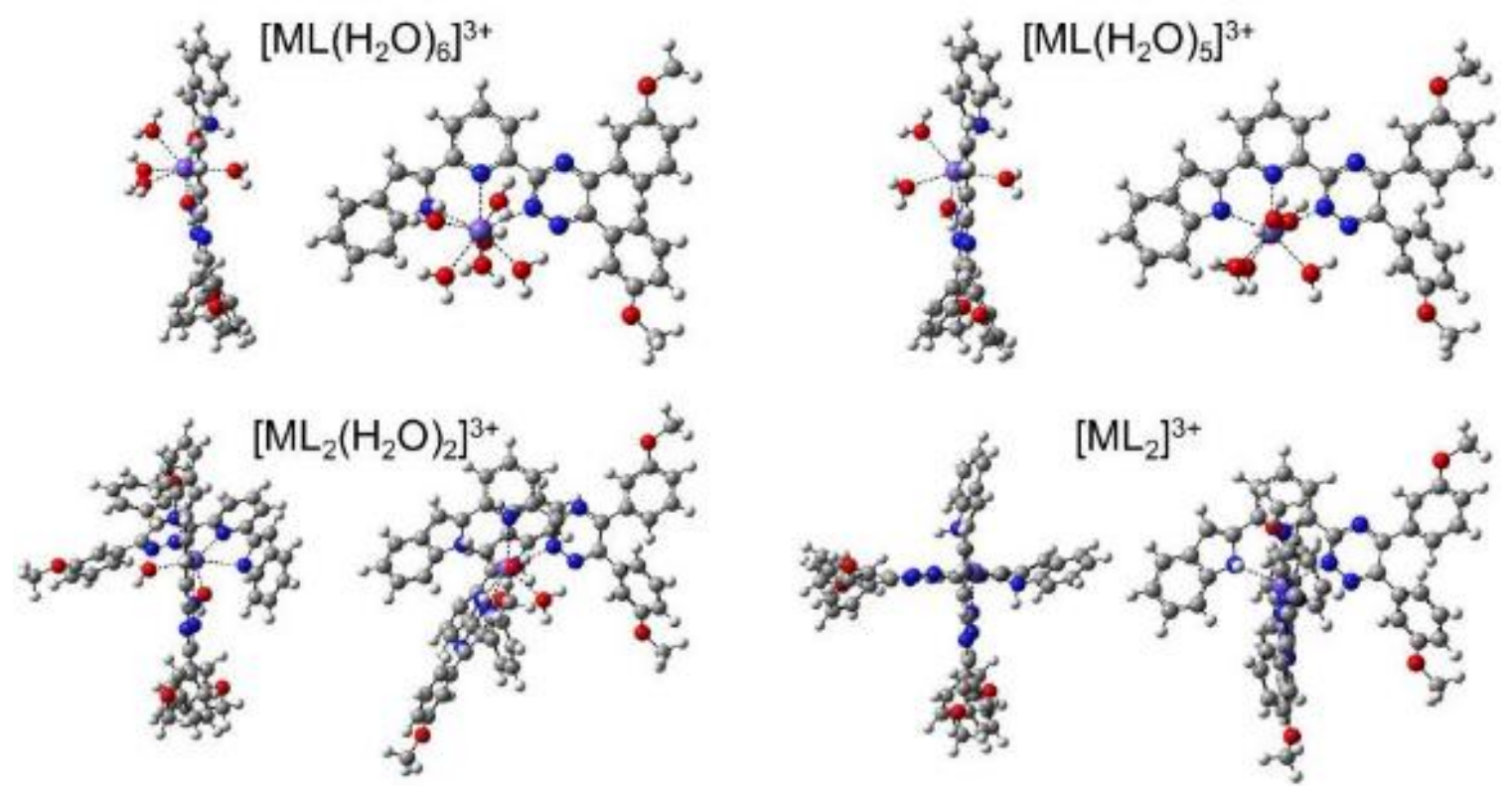

Figure S6. Images of $\mathbf{1 b}$ complexes optimized at the B3LYP/Stuttgart'97ECP/DZVP2 level for $\mathrm{M}=\mathrm{Cm}$ as an example. 

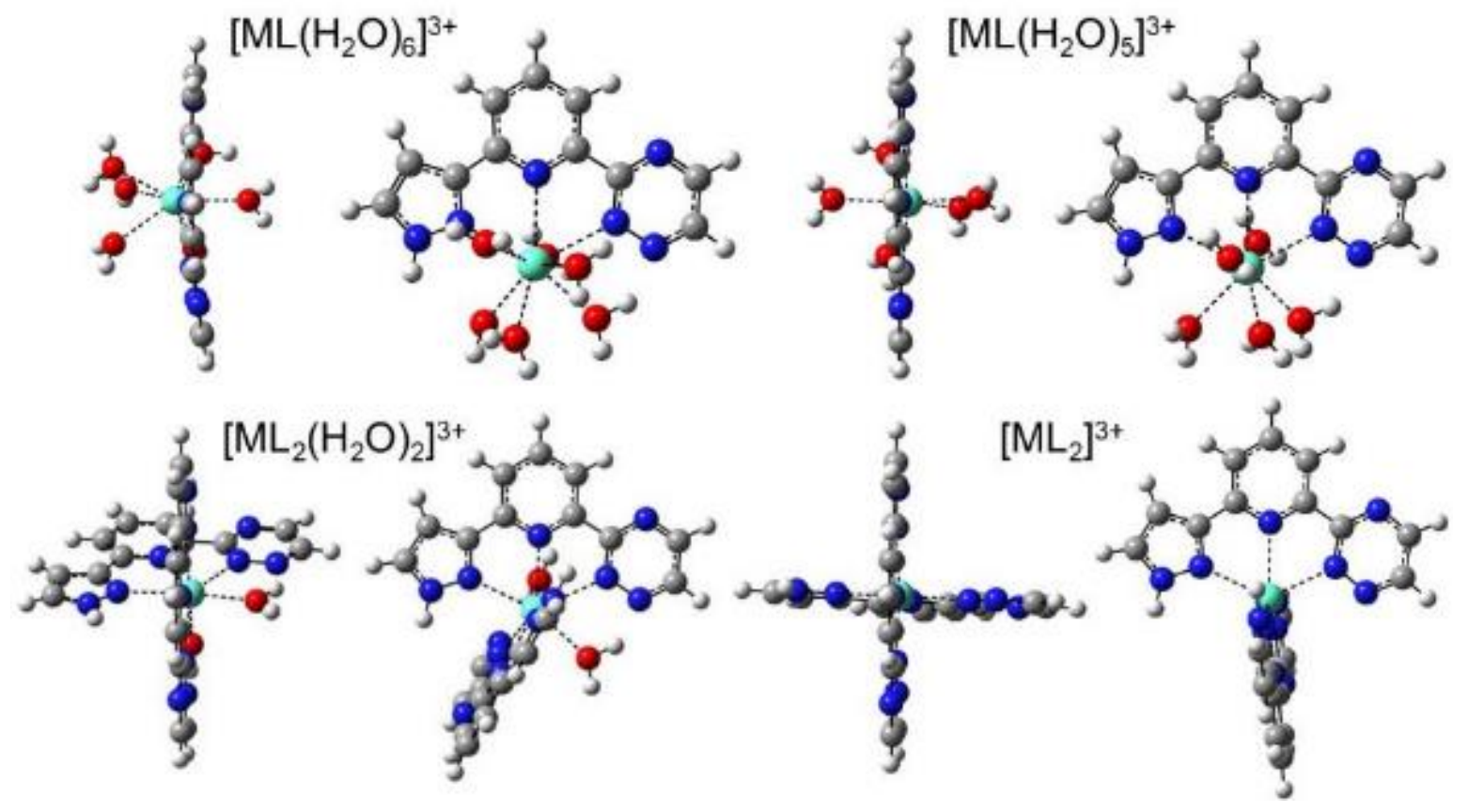

Figure S7. Images of Core 2 complexes optimized at the B3LYP/Stuttgart'97ECP/DZVP2 level for $\mathrm{M}=\mathrm{Eu}$ as an example.

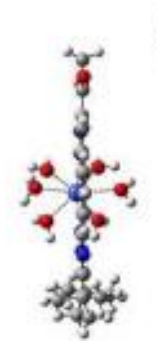

$\left[\mathrm{ML}\left(\mathrm{H}_{2} \mathrm{O}\right)_{6}\right]^{3+}$
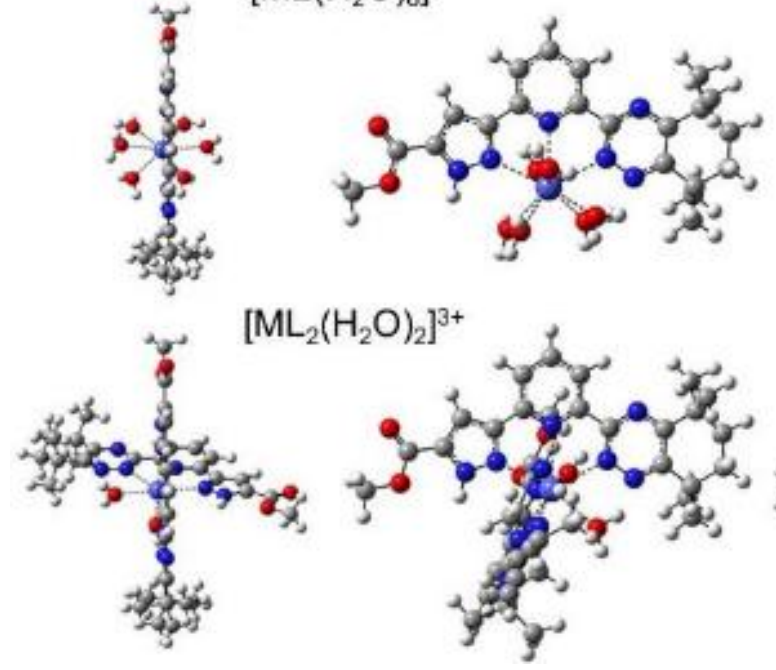

$\left[\mathrm{ML}\left(\mathrm{H}_{2} \mathrm{O}\right)_{5}\right]^{3+}$
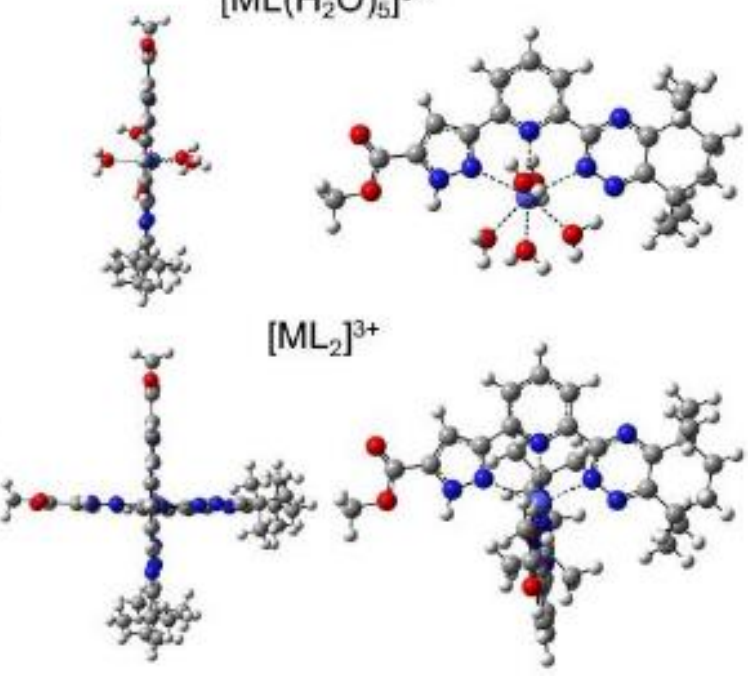

Figure S8. Images of 2ae complexes optimized at the B3LYP/Stuttgart'97ECP/DZVP2 level for $\mathrm{M}=\mathrm{Am}$ as an example. 


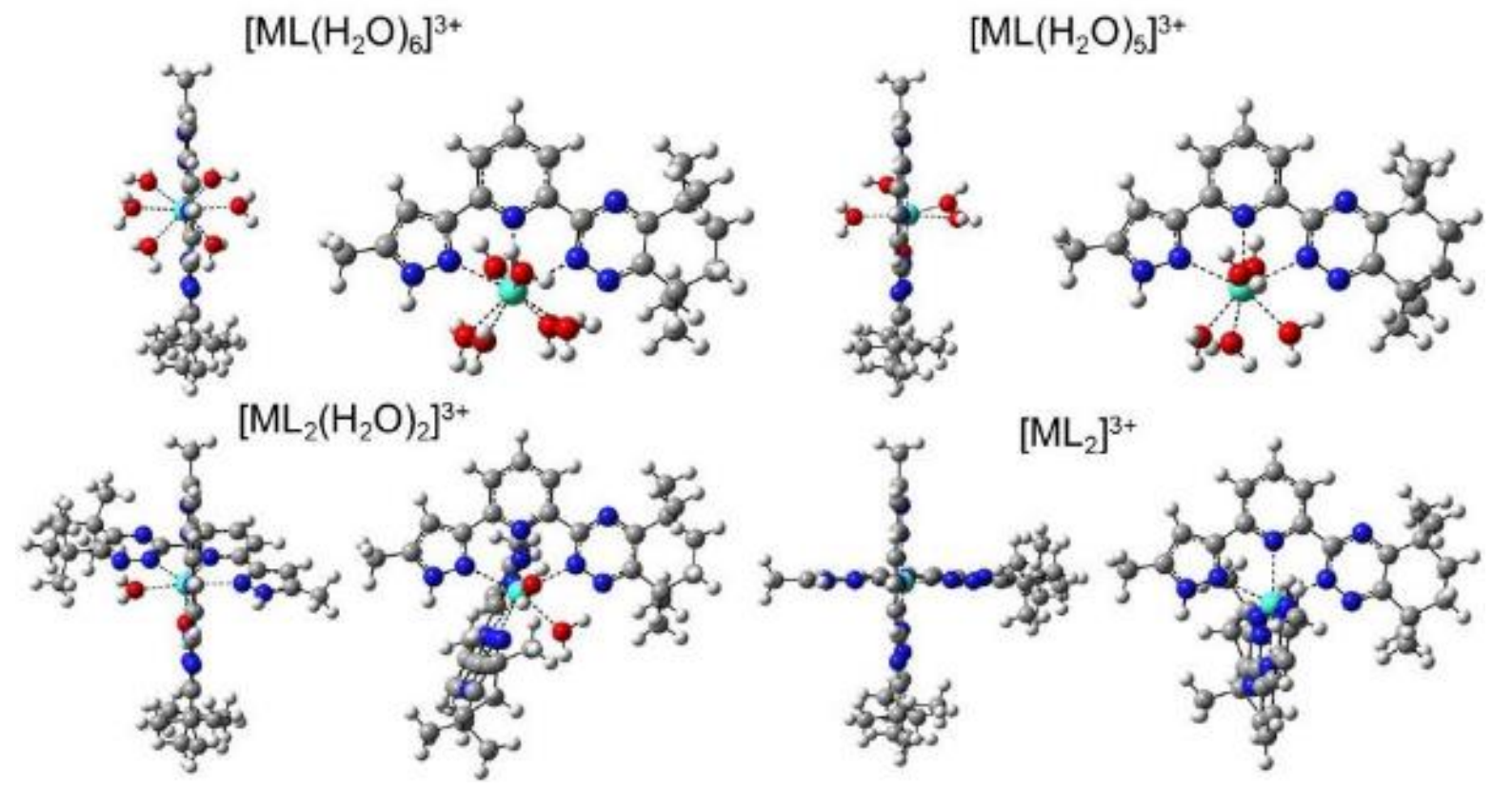

Figure S9. Images of 2am complexes optimized at the B3LYP/Stuttgart'97ECP/DZVP2 level for $\mathrm{M}=\mathrm{Gd}$ as an example.
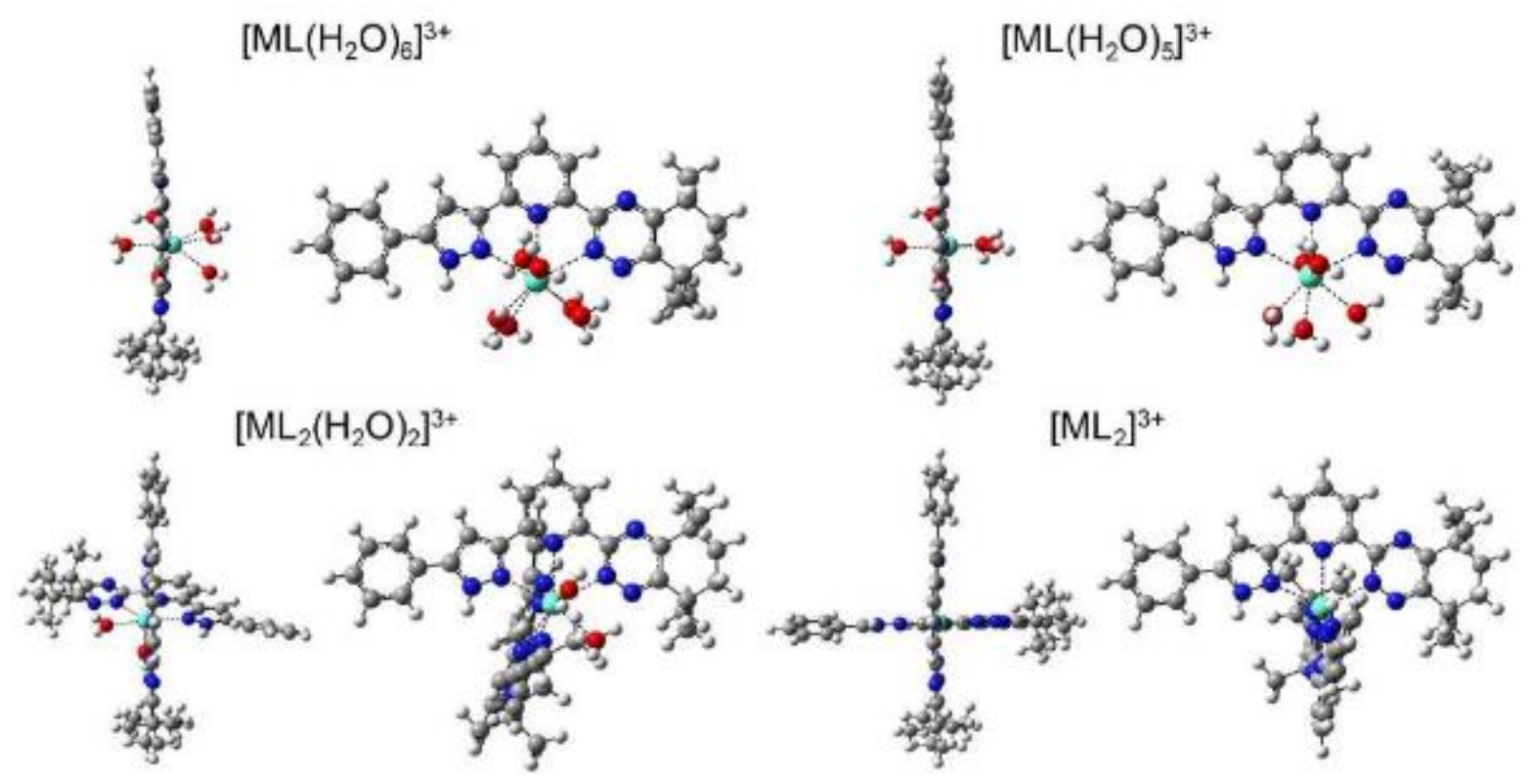

Figure S10. Images of 2ap complexes optimized at the B3LYP/Stuttgart'97ECP/DZVP2 level for $\mathrm{M}=\mathrm{Eu}$ as an example. 

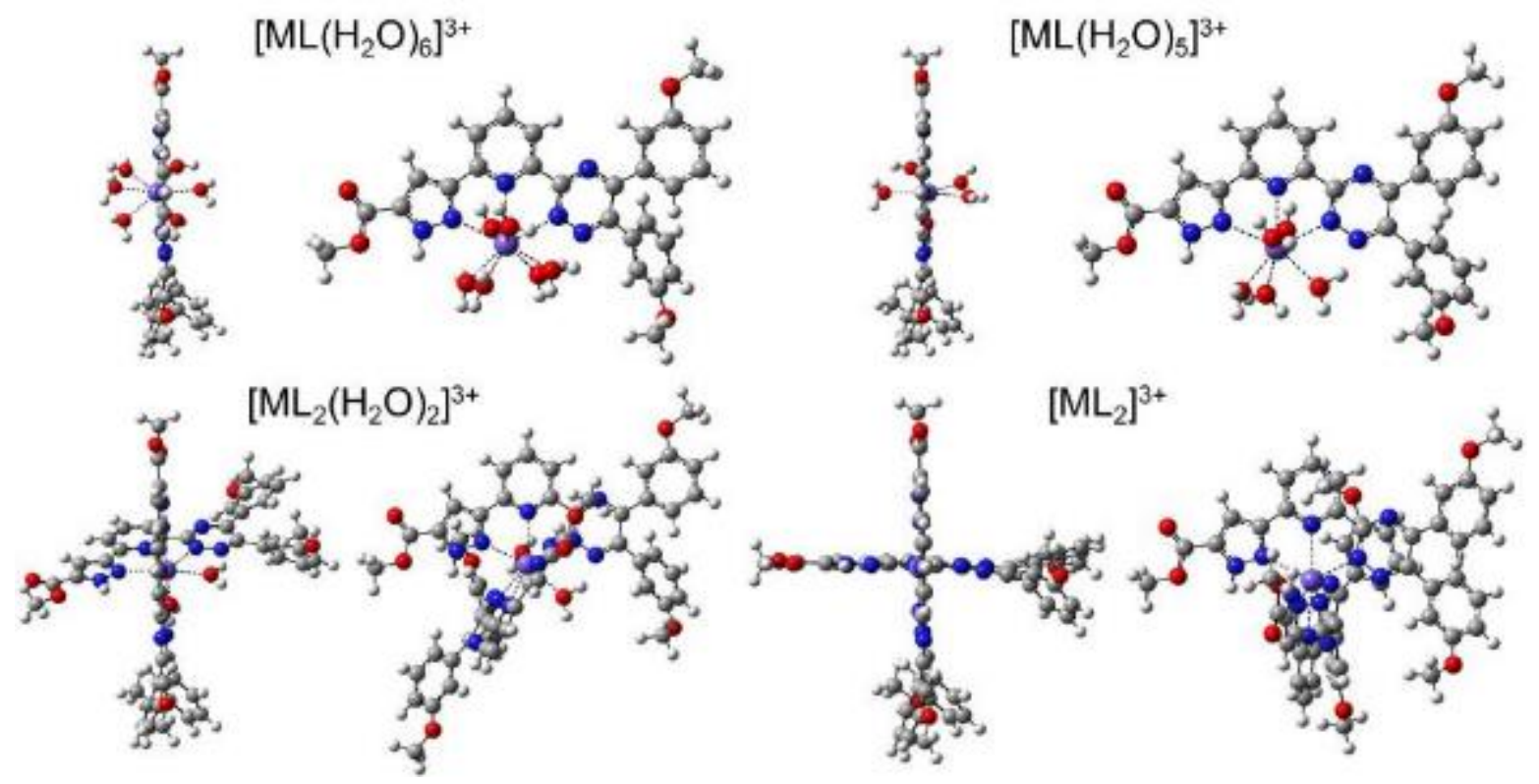

Figure S11. Images of 2be complexes optimized at the B3LYP/Stuttgart'97ECP/DZVP2 level for $\mathrm{M}=\mathrm{Cm}$ as an example.

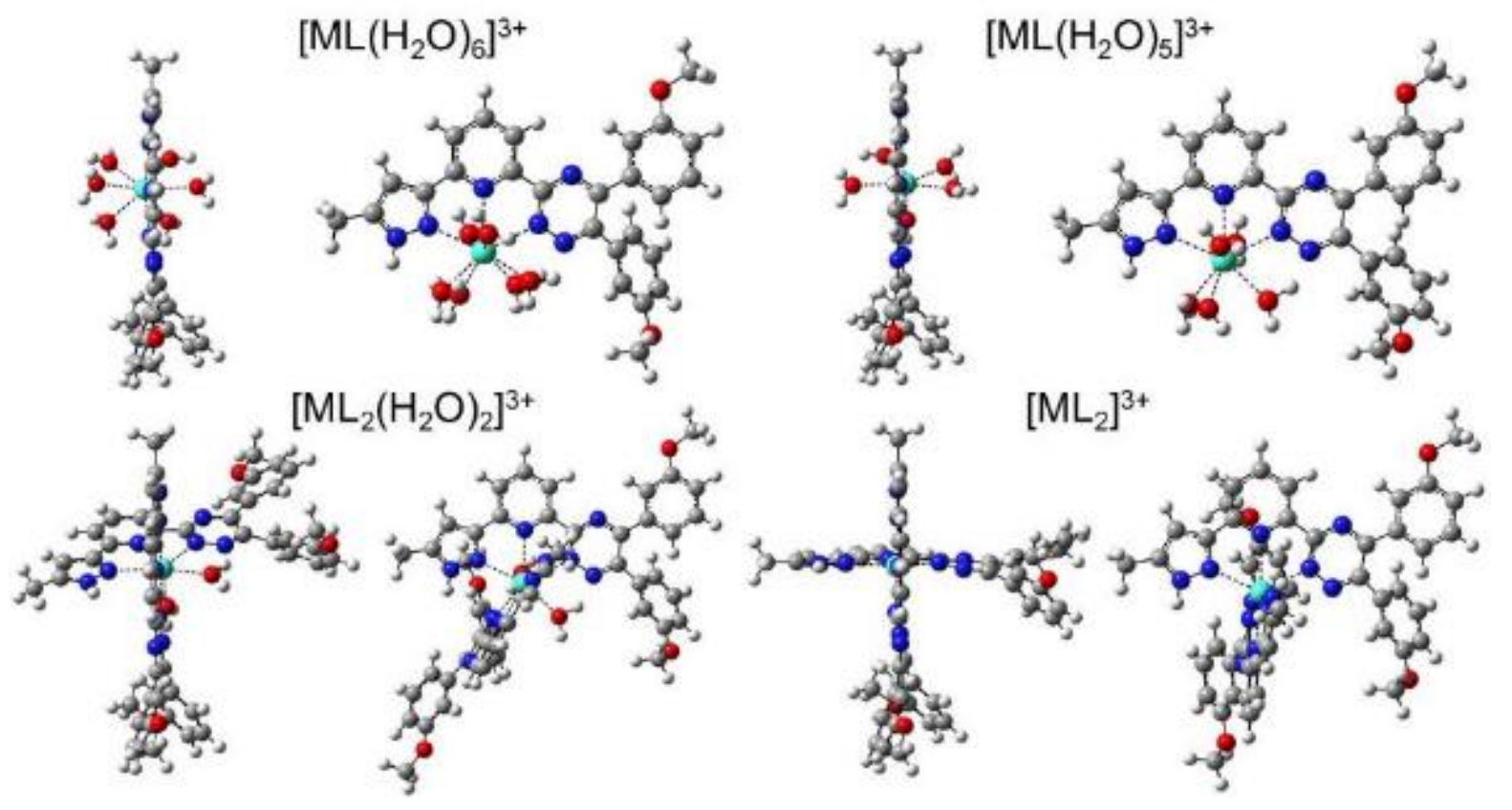

Figure S12. Images of $\mathbf{2 b m}$ complexes optimized at the B3LYP/Stuttgart'97ECP/DZVP2 level for $\mathrm{M}=\mathrm{Gd}$ as an example. 

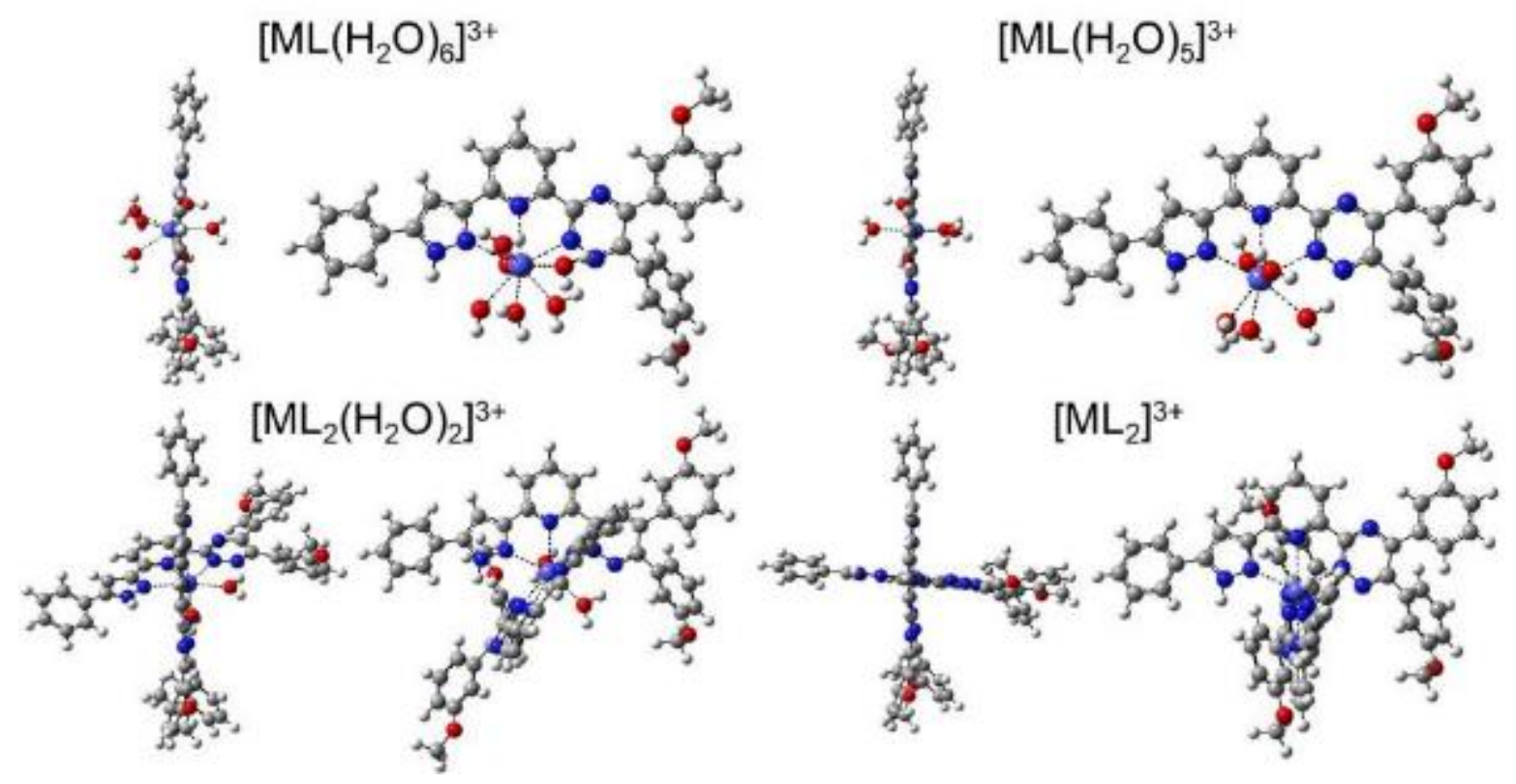

Figure S13. Images of $\mathbf{2 b p}$ complexes optimized at the B3LYP/Stuttgart'97ECP/DZVP2 level for $\mathrm{M}=\mathrm{Am}$ as an example.

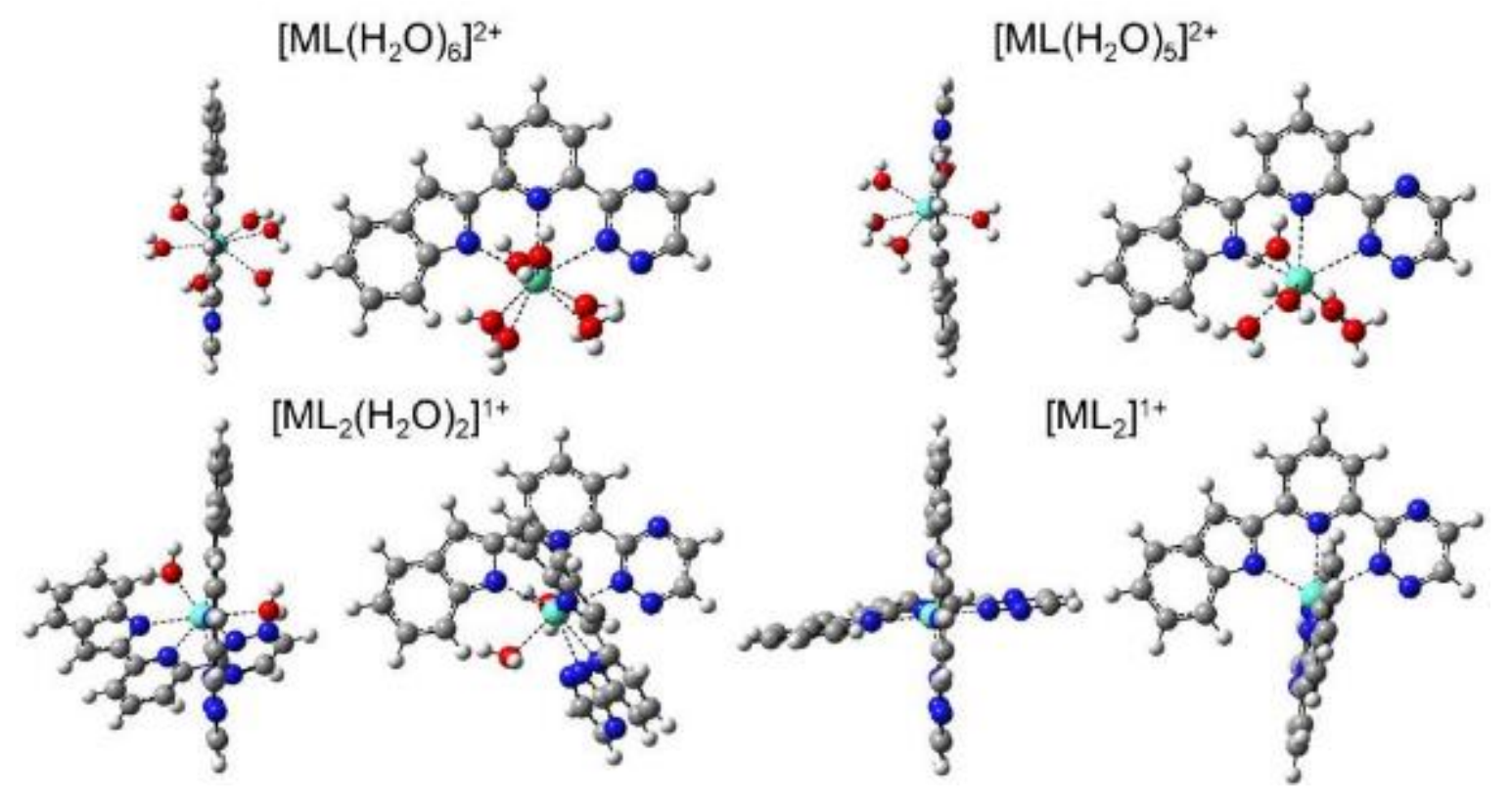

Figure S14. Images of 1i complexes optimized at the B3LYP/Stuttgart'97ECP/DZVP2 level for $\mathrm{M}=\mathrm{Eu}$ as an example. 

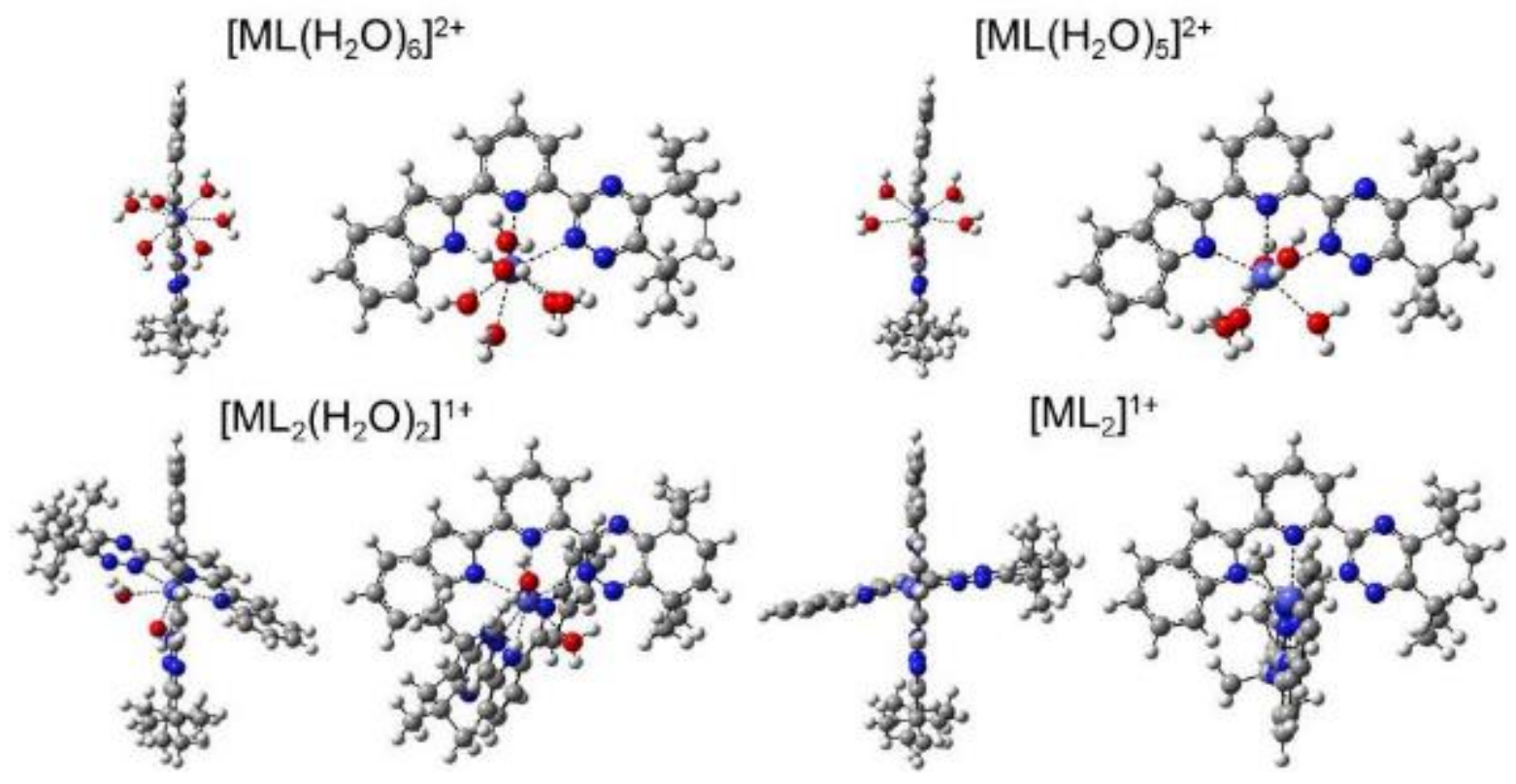

Figure S15. Images of 1ai complexes optimized at the B3LYP/Stuttgart'97ECP/DZVP2 level for $\mathrm{M}=\mathrm{Am}$ as an example.
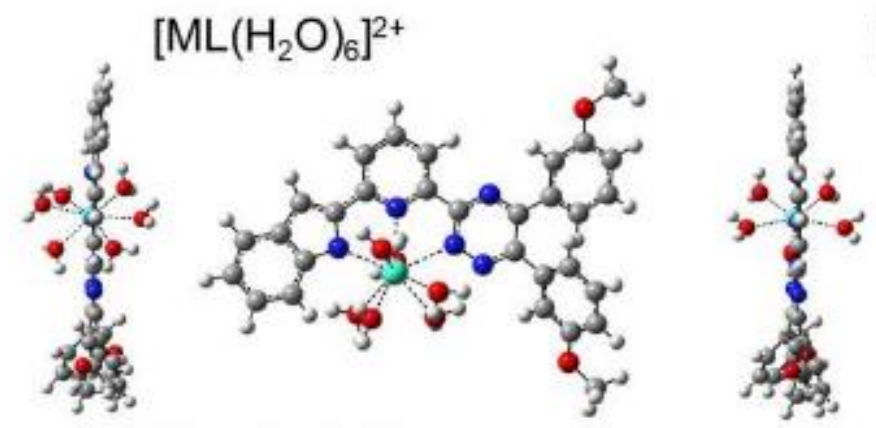

$\left[\mathrm{ML}\left(\mathrm{H}_{2} \mathrm{O}\right)_{5}\right]^{2+}$

$$
\left[\mathrm{ML}_{2}\left(\mathrm{H}_{2} \mathrm{O}\right)_{2}\right]^{1+}
$$
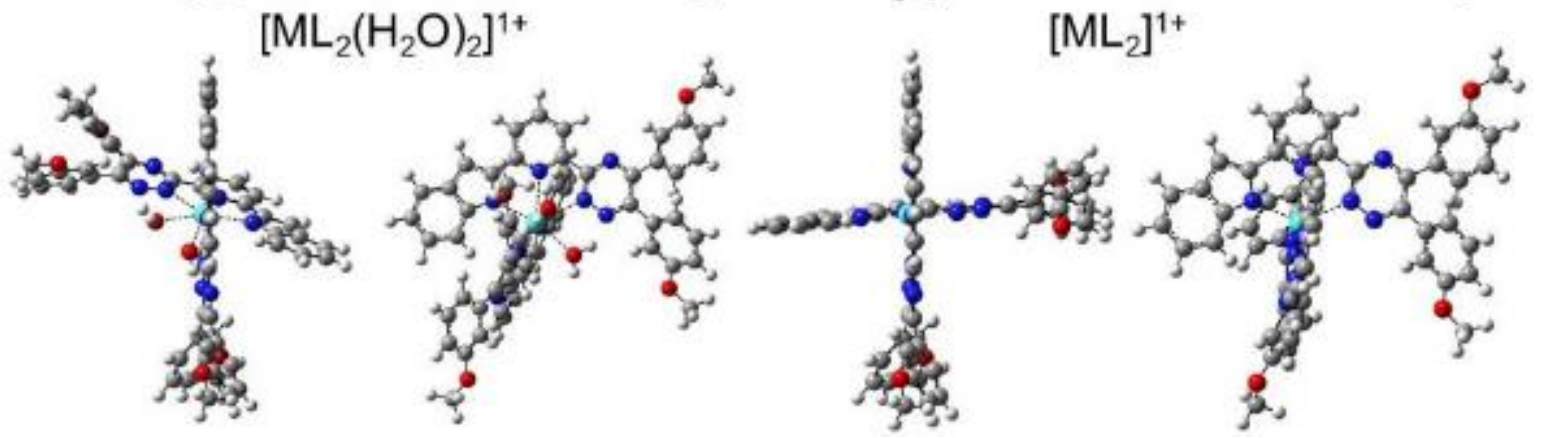

Figure S16. Images of 1bi complexes optimized at the B3LYP/Stuttgart'97ECP/DZVP2 level for $\mathrm{M}=\mathrm{Gd}$ as an example. 


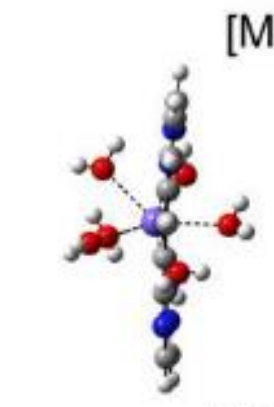

$\left.\mathrm{ML}\left(\mathrm{H}_{2} \mathrm{O}\right)_{6}\right]^{2+}$
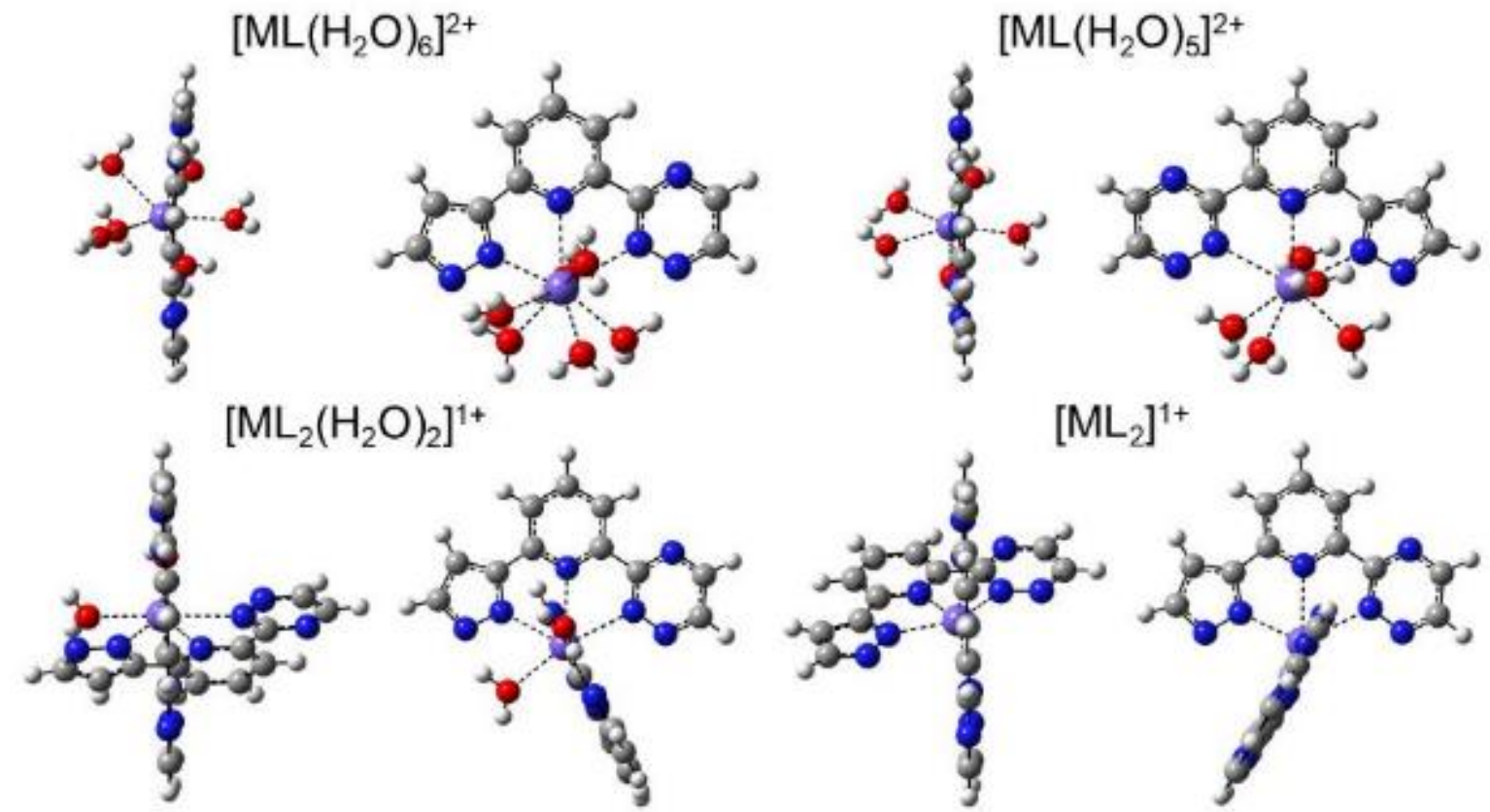

$\left[\mathrm{ML}_{2}\right]^{1+}$
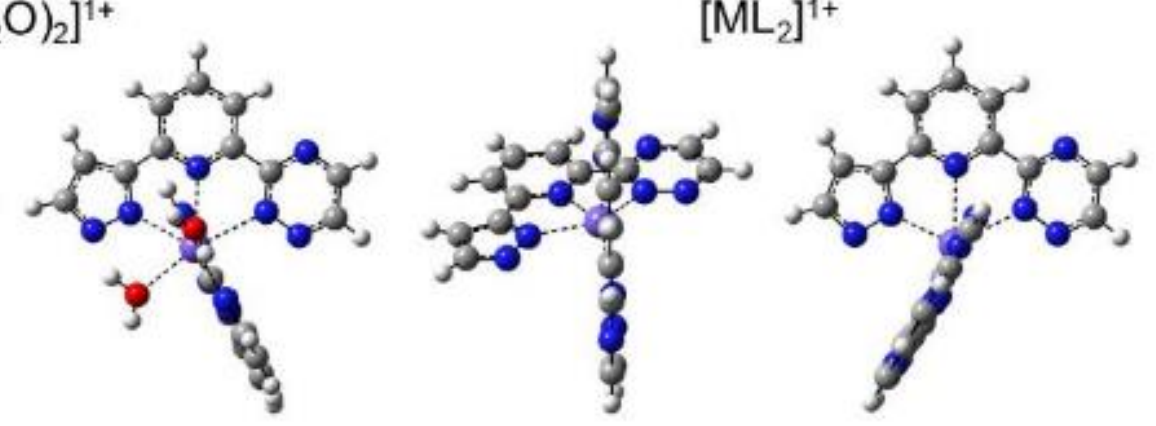

Figure S17. Images of $\mathbf{2} \mathbf{i}$ complexes optimized at the B3LYP/Stuttgart'97ECP/DZVP2 level for $\mathrm{M}=\mathrm{Cm}$ as an example.

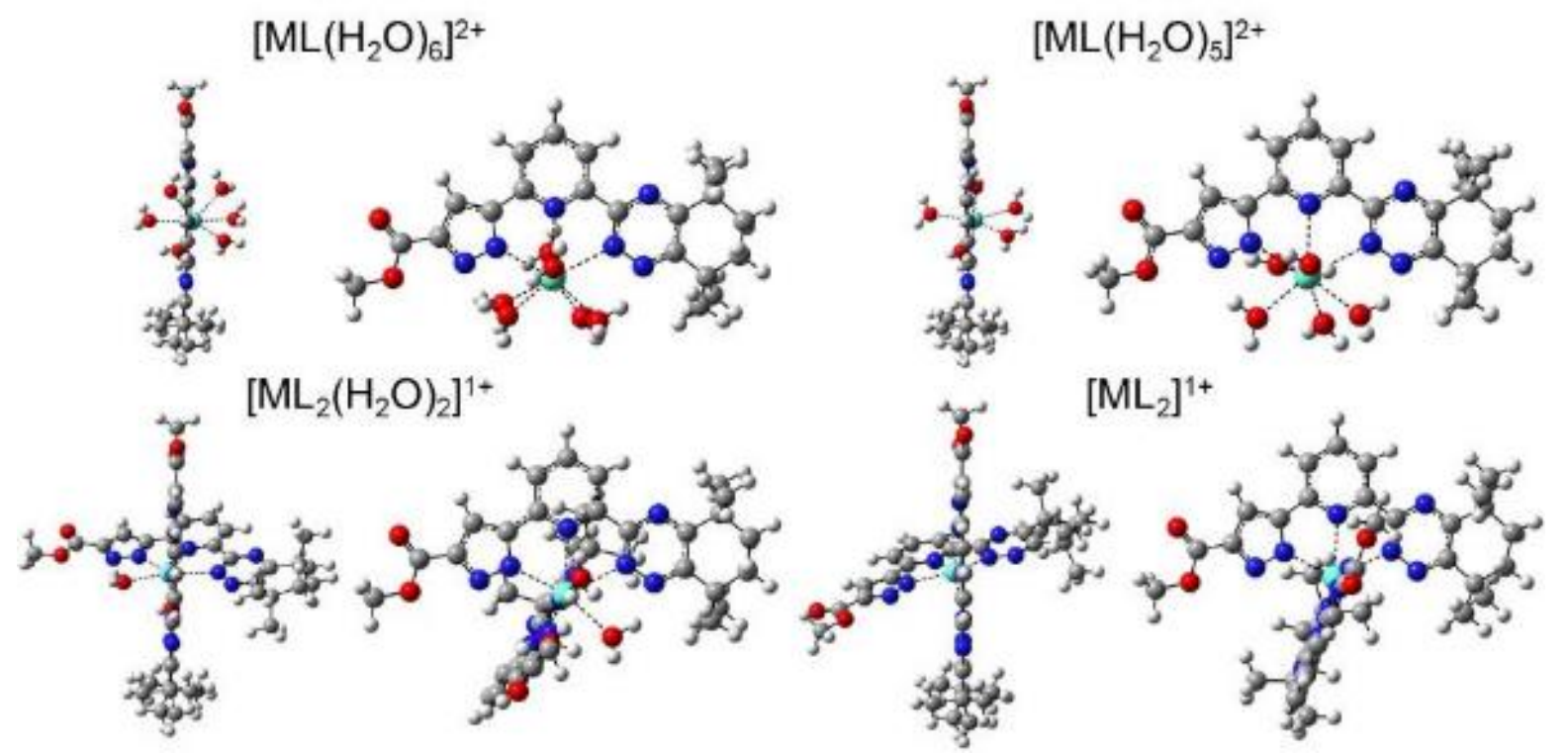

Figure S18. Images of 2aei complexes optimized at the B3LYP/Stuttgart'97ECP/DZVP2 level for $\mathrm{M}=\mathrm{Eu}$ as an example. 


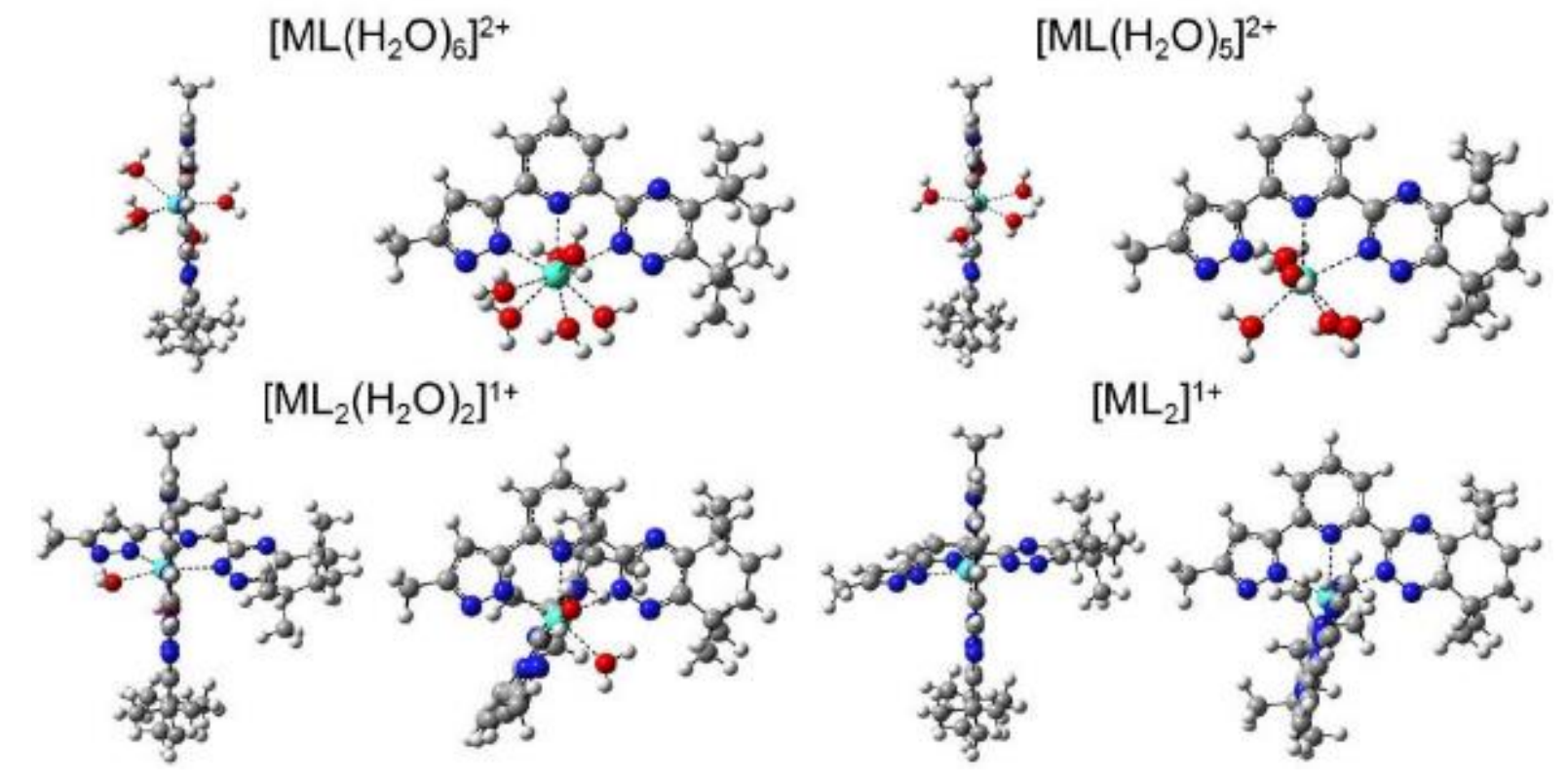

Figure S19. Images of 2ami complexes optimized at the B3LYP/Stuttgart'97ECP/DZVP2 level for $\mathrm{M}=\mathrm{Gd}$ as an example.

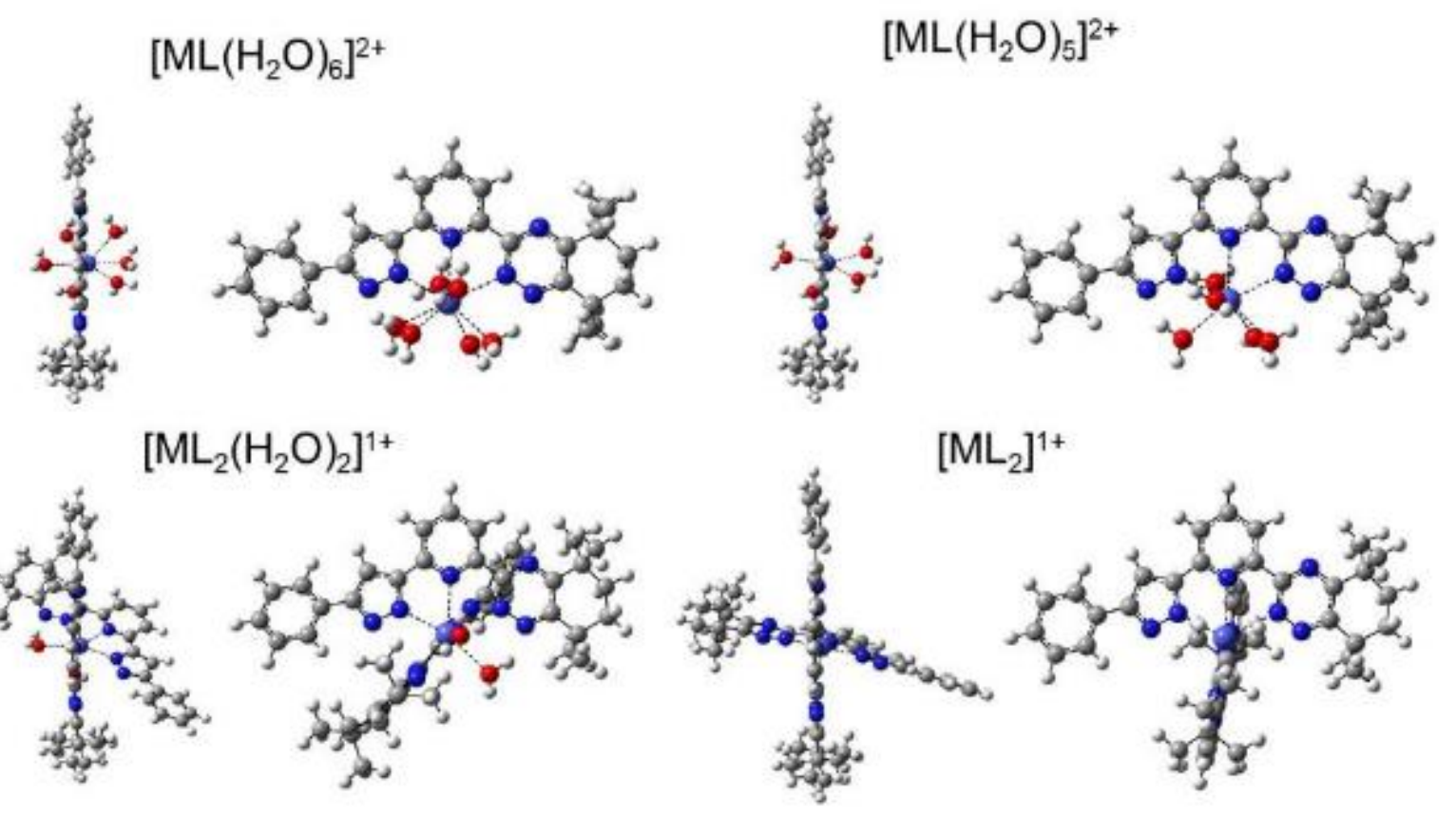

Figure S20. Images of 2api complexes optimized at the B3LYP/Stuttgart'97ECP/DZVP2 level for $\mathrm{M}=\mathrm{Am}$ as an example. 

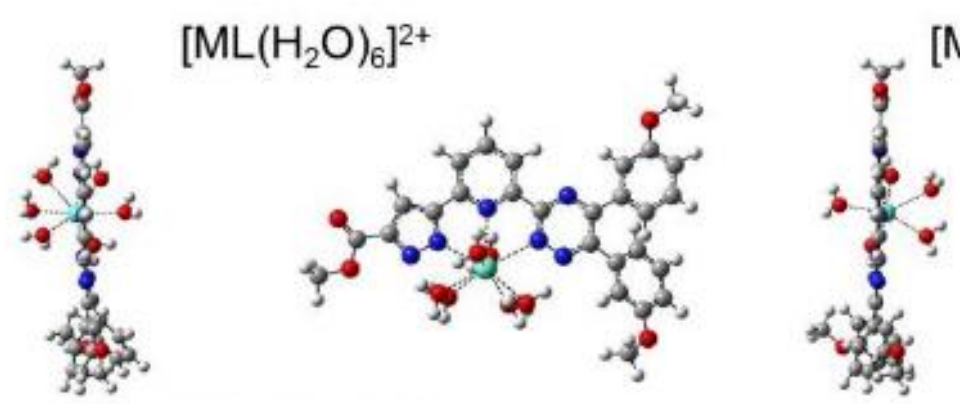

$\left[\mathrm{ML}\left(\mathrm{H}_{2} \mathrm{O}\right)_{5}\right]^{2+}$

$\left[\mathrm{ML}_{2}\left(\mathrm{H}_{2} \mathrm{O}\right)_{2}\right]^{1+}$

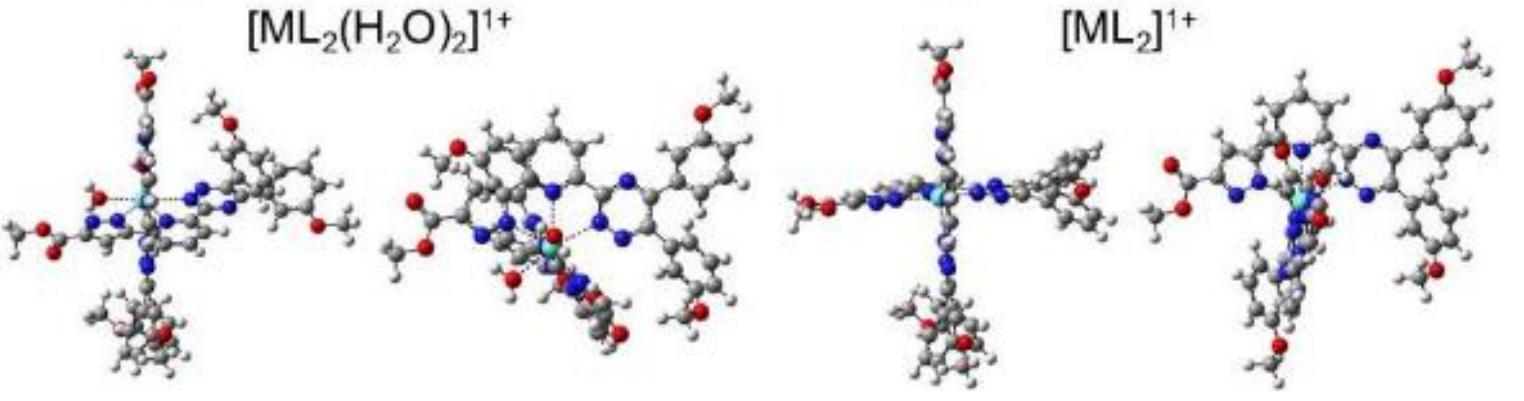

Figure S21. Images of 2 bei complexes optimized at the B3LYP/Stuttgart'97ECP/DZVP2 level for $\mathrm{M}=\mathrm{Eu}$ as an example.
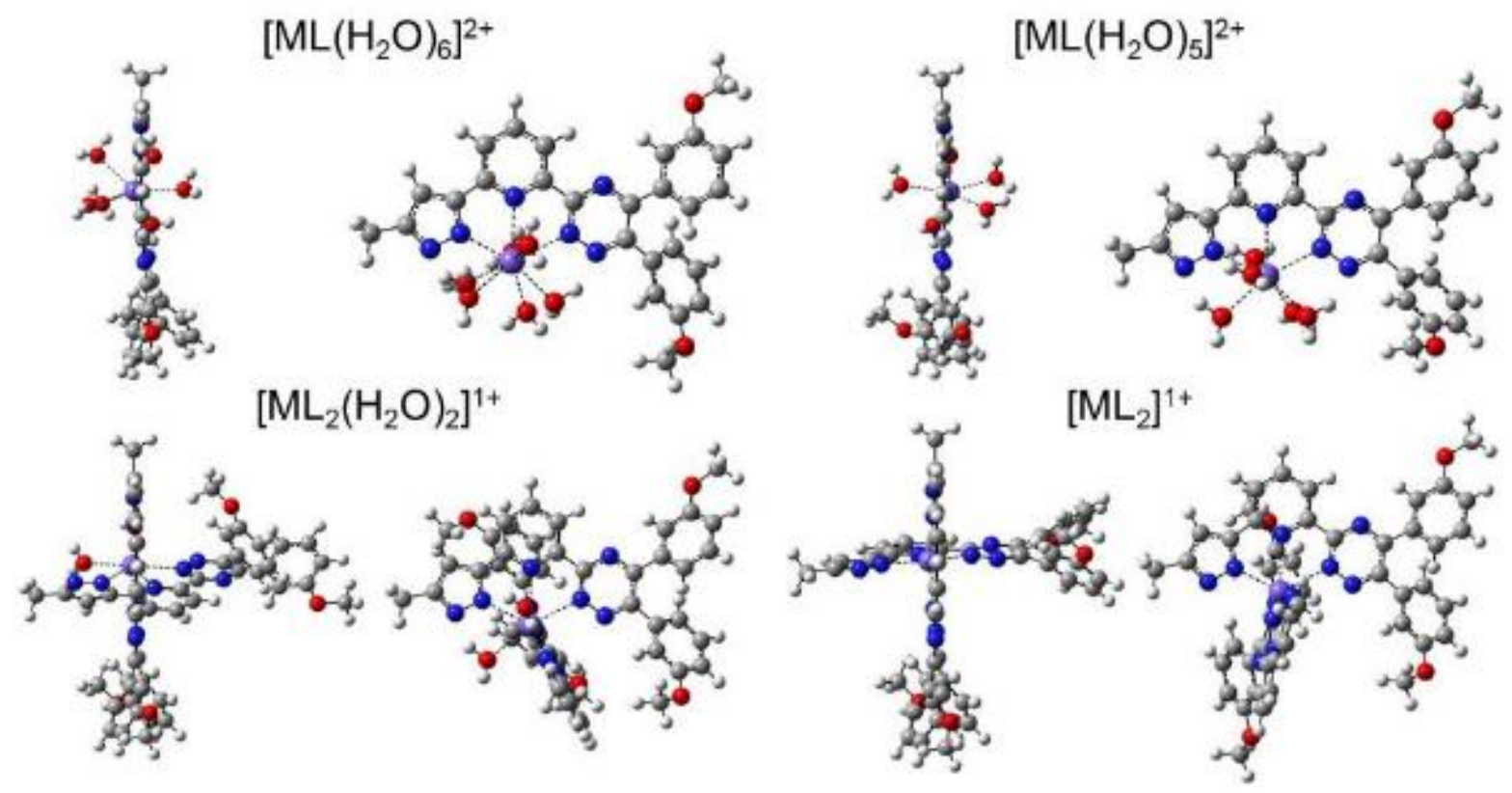

Figure S22. Images of 2bmi complexes optimized at the B3LYP/Stuttgart'97ECP/DZVP2 level for $\mathrm{M}=\mathrm{Cm}$ as an example. 

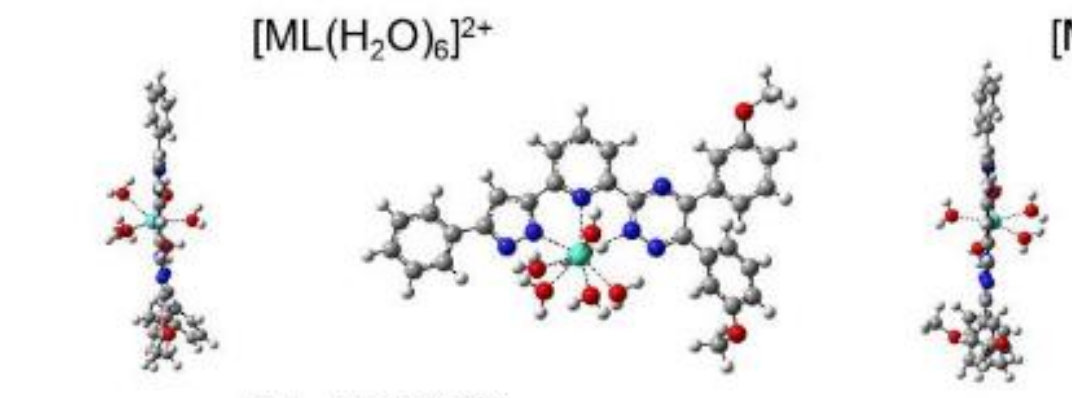

$\left[\mathrm{ML}\left(\mathrm{H}_{2} \mathrm{O}\right)_{5}\right]^{2+}$
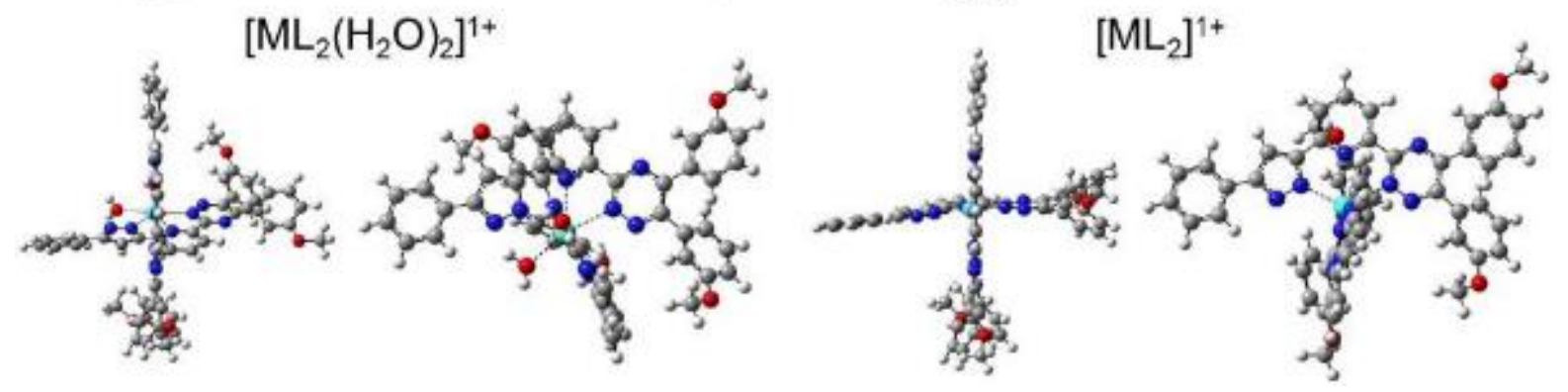

Figure S23. Images of 2bpi complexes optimized by B3LYP/Stuttgart'97ECP/DZVP2. Only $\mathrm{M}=\mathrm{Gd}$ shown as an example for space considerations. 

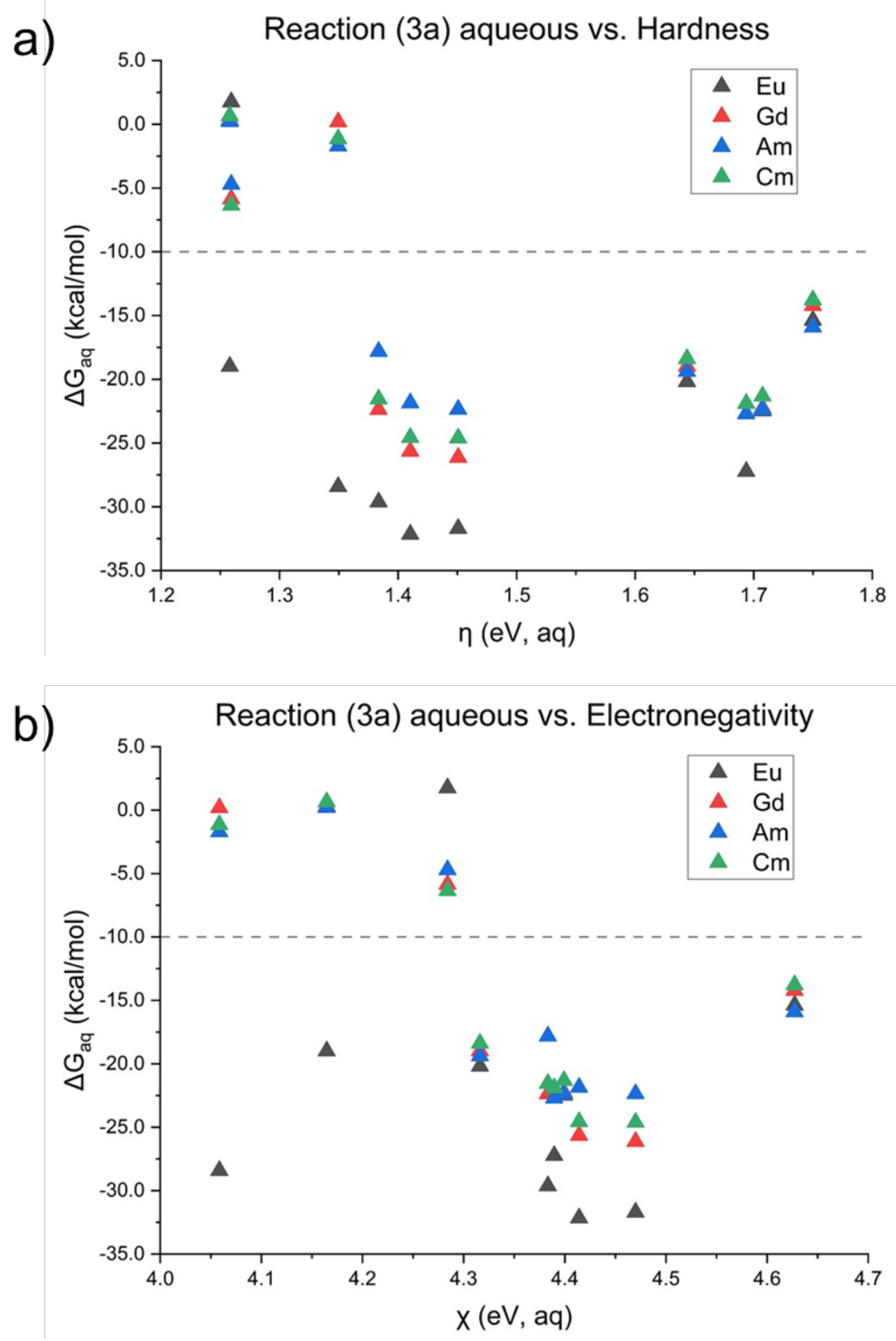
c)

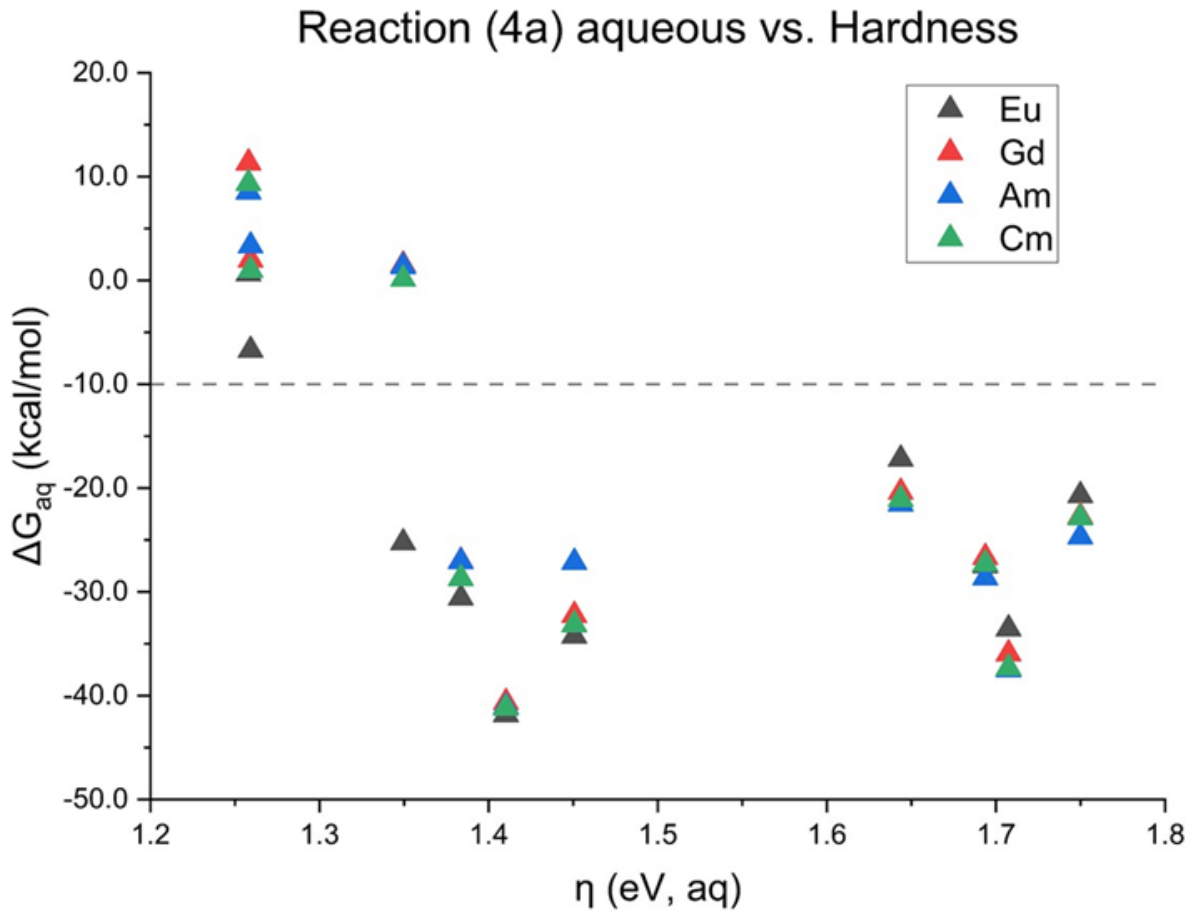

d)

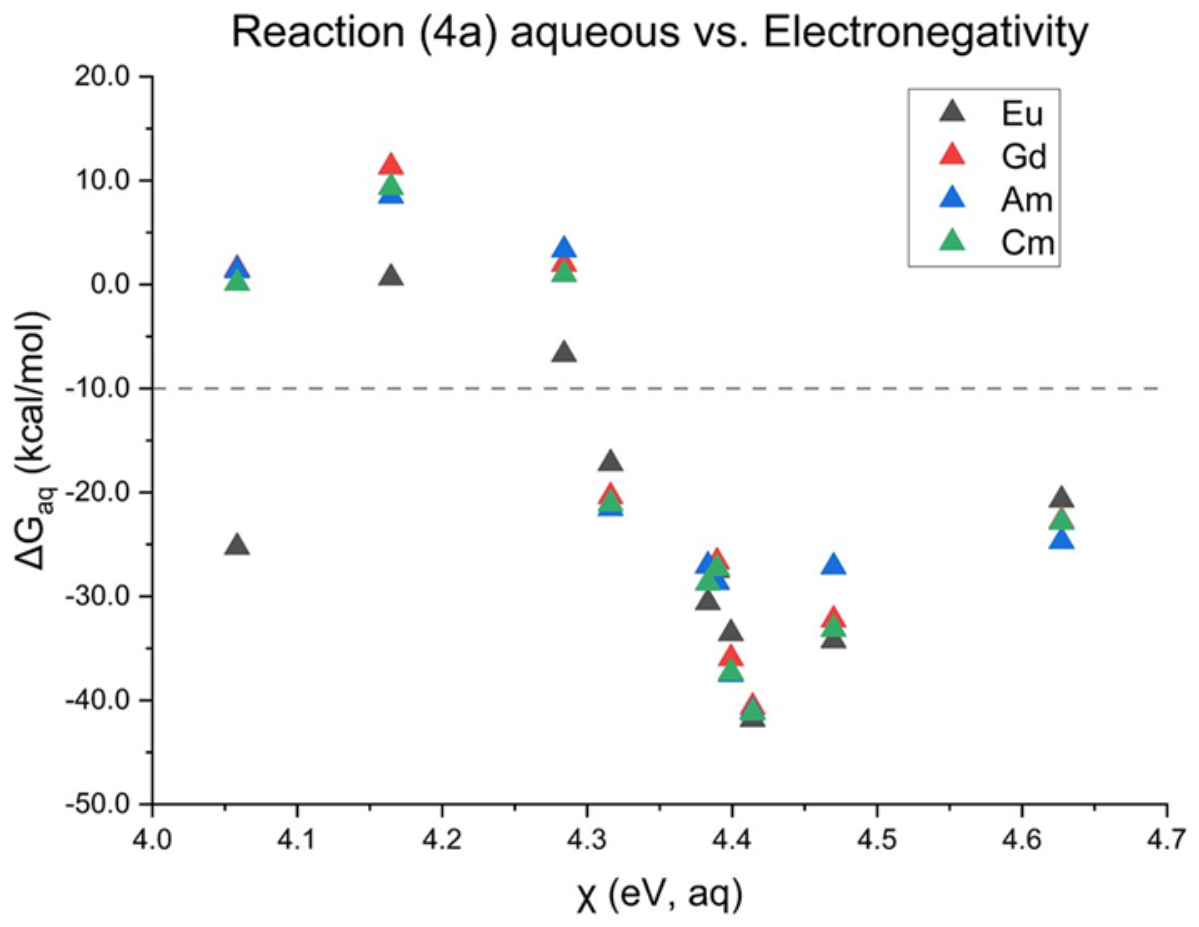

Figure S24. Plots of the aqueous binding energy against hardness $(\eta)$ or electronegativity $(\chi)$ in the formation of $\left[\mathrm{ML}\left(\mathrm{H}_{2} \mathrm{O}\right)_{5}\right]^{3+}$ (reaction 5a) and $\left[\mathrm{ML}_{2}\left(\mathrm{H}_{2} \mathrm{O}\right)_{2}\right]^{3+}$ (reaction 6a) optimized by B3LYP/Stuttgart'97ECP/DZVP2. 

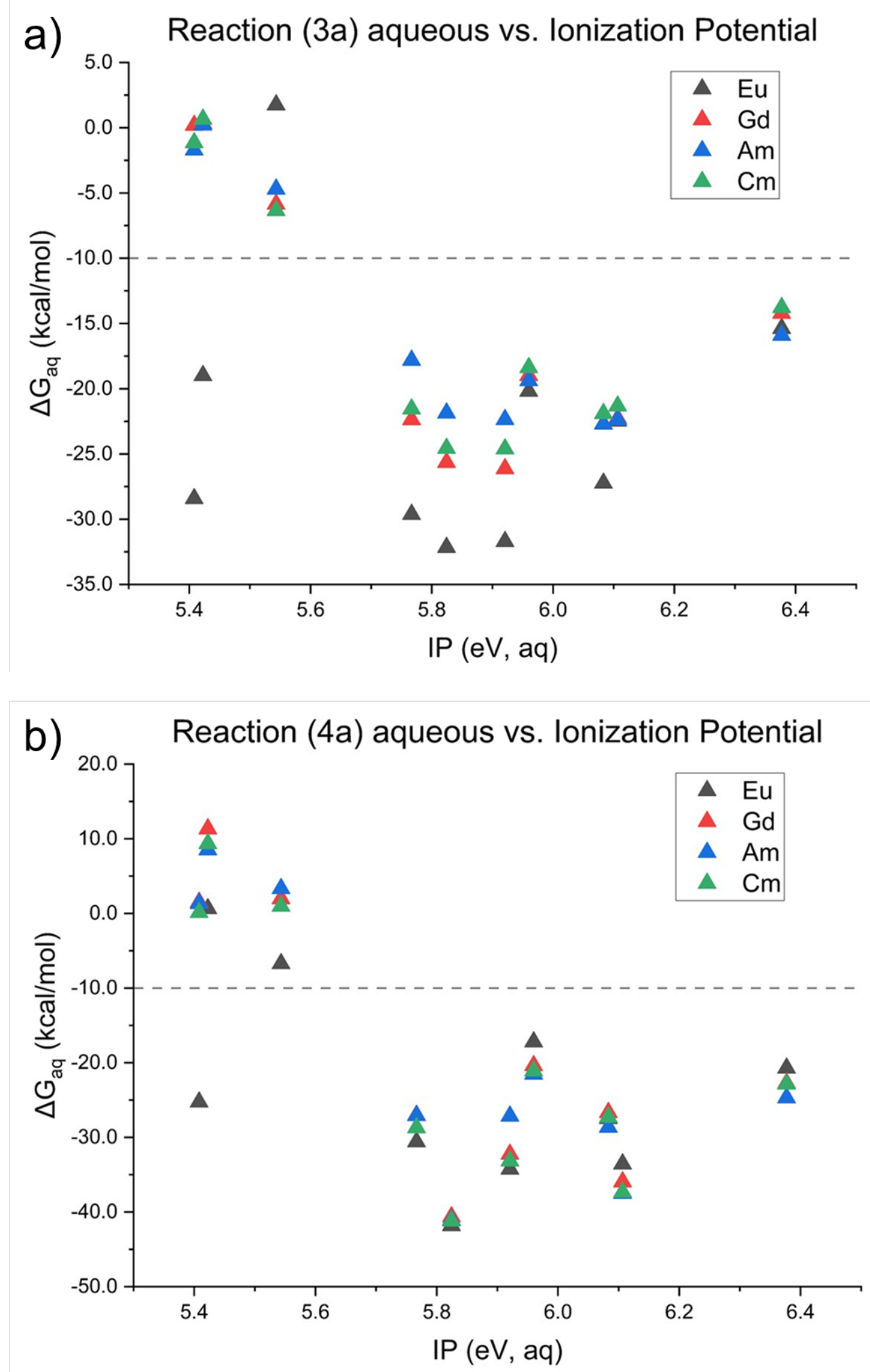

Figure S25. Plots of the aqueous binding energy against ionization potential (IP) in the formation of $\left[\mathrm{ML}\left(\mathrm{H}_{2} \mathrm{O}\right)_{5}\right]^{3+}$ (reaction 5a) and $\left[\mathrm{ML}_{2}\left(\mathrm{H}_{2} \mathrm{O}\right)_{2}\right]^{3+}$ (reaction 6a) optimized by B3LYP/Stuttgart'97ECP/DZVP2. 
Table S32. Cartesian Coordinates in Å for B3LYP/Stuttgart'97ECP/DZVP2 Gas Phase Geometries

\section{Unbound Core 1}

$\begin{array}{lrrr}\text { C } & 2.989563 & -0.819078 & 0.000116 \\ \mathrm{C} & 3.687135 & 0.429221 & -0.000244 \\ \mathrm{C} & 5.099348 & 0.427538 & -0.000283 \\ \mathrm{C} & 5.769608 & -0.792071 & 0.000009 \\ \mathrm{C} & 5.058309 & -2.018644 & 0.000358 \\ \mathrm{C} & 3.664854 & -2.049139 & 0.000421 \\ \mathrm{C} & 1.456371 & 0.835055 & -0.000077 \\ \mathrm{C} & 2.692000 & 1.461838 & -0.000488 \\ \mathrm{H} & 5.652945 & 1.362043 & -0.000547 \\ \mathrm{H} & 6.855407 & -0.811434 & -0.000035 \\ \mathrm{H} & 5.611695 & -2.952887 & 0.000571 \\ \mathrm{H} & 3.125508 & -2.991162 & 0.000678 \\ \mathrm{H} & 0.861168 & -1.178653 & 0.000095 \\ \mathrm{H} & 2.868824 & 2.527899 & -0.000778 \\ \mathrm{C} & 0.088851 & 1.353522 & -0.000023 \\ \mathrm{C} & -0.202175 & 2.732351 & 0.000242 \\ \mathrm{C} & -1.536371 & 3.129900 & 0.000313 \\ \mathrm{H} & 0.598810 & 3.463133 & 0.000455 \\ \mathrm{C} & -2.156815 & 0.808522 & -0.000142 \\ \mathrm{C} & -2.542682 & 2.155882 & 0.000125 \\ \mathrm{H} & -1.794919 & 4.184791 & 0.000531 \\ \mathrm{H} & -3.593075 & 2.416070 & 0.000197 \\ \mathrm{C} & -3.195312 & -0.268078 & -0.000174 \\ \mathrm{C} & -5.383083 & -0.854614 & 0.000208 \\ \mathrm{C} & -4.973879 & -2.195166 & -0.000004 \\ \mathrm{H} & -6.436448 & -0.580364 & 0.000515 \\ \mathrm{H} & -5.680326 & -3.020274 & 0.000038 \\ \mathrm{~N} & 1.643397 & -0.535969 & 0.000101 \\ \mathrm{~N} & -0.876076 & 0.418139 & -0.000159 \\ \mathrm{~N} & -4.487843 & 0.125011 & 0.000181 \\ \mathrm{~N} & -2.768971 & -1.547147 & -0.000334 \\ \mathrm{~N} & -3.676782 & -2.523091 & -0.000340 \\ & & & \end{array}$

\section{Unbound 1a}
C $\quad 4.366344-1.094306$
0.015422
C $\quad 5.422265-0.130228$
0.019585
C $\quad 6.761086-0.578259$
0.031189
C $\quad 7.012159-1.947469$
0.038111
C $\quad 5.950439 \quad-2.886458$
0.033646
$\begin{array}{llll}\text { C } & 4.618500 & -2.474380 & 0.022266\end{array}$ 


\begin{tabular}{|c|c|c|c|}
\hline $\mathrm{C}$ & 3.434278 & 0.961404 & 0.000989 \\
\hline $\mathrm{C}$ & 4.804305 & 1.164464 & 0.010210 \\
\hline $\mathrm{H}$ & 7.581595 & 0.133428 & 0.034629 \\
\hline $\mathrm{H}$ & 8.036344 & -2.308378 & 0.047025 \\
\hline$\pi$ & 6.180274 & -3.947659 & 0.039145 \\
\hline $\mathrm{H}$ & 3.809693 & -3.198537 & 0.018768 \\
\hline $\mathrm{H}$ & 2.232982 & -0.756868 & -0.001921 \\
\hline $\mathrm{H}$ & 5.309429 & 2.119686 & 0.010655 \\
\hline $\mathrm{C}$ & 2.299624 & 1.886366 & -0.010266 \\
\hline $\mathrm{C}$ & 2.466112 & 3.283866 & -0.016212 \\
\hline$C$ & 1.328289 & 4.087538 & -0.025325 \\
\hline $\mathrm{H}$ & 3.459010 & 3.719378 & -0.013471 \\
\hline$C$ & -0.003789 & 2.086344 & -0.023278 \\
\hline $\mathrm{C}$ & 0.064780 & 3.487008 & -0.028208 \\
\hline $\mathrm{H}$ & 1.419897 & 5.169853 & -0.029772 \\
\hline $\mathrm{H}$ & -0.848391 & 4.067555 & -0.033886 \\
\hline $\mathrm{C}$ & -1.331149 & 1.394612 & -0.026372 \\
\hline $\mathrm{C}$ & -2.564206 & -0.523892 & -0.036528 \\
\hline $\mathrm{C}$ & -3.728234 & 0.282812 & 0.023457 \\
\hline $\mathrm{N}$ & 3.179004 & -0.398667 & 0.004347 \\
\hline $\mathrm{N}$ & 1.085703 & 1.306446 & -0.014565 \\
\hline $\mathrm{N}$ & -1.363429 & 0.054183 & -0.044393 \\
\hline $\mathrm{N}$ & -2.416443 & 2.189453 & -0.019840 \\
\hline $\mathrm{N}$ & -3.615199 & 1.619816 & 0.011051 \\
\hline $\mathrm{C}$ & -2.601529 & -2.051204 & -0.067034 \\
\hline $\mathrm{C}$ & -4.033783 & -2.541405 & -0.374376 \\
\hline $\mathrm{H}$ & -4.222254 & -2.447464 & -1.450141 \\
\hline $\mathrm{H}$ & -4.095075 & -3.611603 & -0.147164 \\
\hline $\mathrm{C}$ & -5.110996 & -1.779341 & 0.404162 \\
\hline $\mathrm{C}$ & -5.151473 & -0.271933 & 0.067440 \\
\hline $\mathrm{H}$ & -4.943687 & -1.902394 & 1.480537 \\
\hline $\mathrm{H}$ & -6.096422 & -2.211773 & 0.197764 \\
\hline $\mathrm{C}$ & -1.634887 & -2.573271 & -1.149946 \\
\hline $\mathrm{H}$ & -0.610882 & -2.253163 & -0.948897 \\
\hline $\mathrm{H}$ & -1.664874 & -3.667757 & -1.174774 \\
\hline $\mathrm{H}$ & -1.915507 & -2.204296 & -2.141983 \\
\hline $\mathrm{C}$ & -2.125790 & -2.562137 & 1.315318 \\
\hline $\mathrm{H}$ & -2.083675 & -3.656283 & 1.312984 \\
\hline $\mathrm{H}$ & -1.127599 & -2.176285 & 1.538367 \\
\hline $\mathrm{H}$ & -2.795047 & -2.249673 & 2.122357 \\
\hline $\mathrm{C}$ & -5.807459 & -0.031900 & -1.314193 \\
\hline $\mathrm{H}$ & -6.846032 & -0.379062 & -1.301151 \\
\hline $\mathrm{H}$ & -5.801563 & 1.034692 & -1.553614 \\
\hline $\mathrm{H}$ & -5.282779 & -0.559325 & -2.116538 \\
\hline $\mathrm{C}$ & -5.973941 & 0.468893 & 1.142681 \\
\hline $\mathrm{H}$ & -6.043385 & 1.535097 & 0.919821 \\
\hline
\end{tabular}




$\begin{array}{llll}\mathrm{H} & -6.985674 & 0.051229 & 1.185812 \\ \mathrm{H} & -5.519500 & 0.358240 & 2.132834\end{array}$

\section{Unbound 1b}

$\begin{array}{lrrr}\mathrm{C} & -5.370355 & 0.549682 & 0.016546 \\ \mathrm{C} & -6.441669 & -0.394818 & 0.085725 \\ \mathrm{C} & -7.771440 & 0.077556 & 0.132519 \\ \mathrm{C} & -7.998460 & 1.450745 & 0.109142 \\ \mathrm{C} & -6.921456 & 2.369877 & 0.039945 \\ \mathrm{C} & -5.598047 & 1.933874 & -0.007016 \\ \mathrm{C} & -4.474011 & -1.521090 & 0.027061 \\ \mathrm{C} & -5.846175 & -1.699902 & 0.090793 \\ \mathrm{H} & -8.603419 & -0.618705 & 0.185660 \\ \mathrm{H} & -9.015356 & 1.830320 & 0.144264 \\ \mathrm{H} & -7.133077 & 3.434814 & 0.023407 \\ \mathrm{H} & -4.776328 & 2.641382 & -0.059168 \\ \mathrm{H} & -3.246034 & 0.177584 & -0.072394 \\ \mathrm{H} & -6.366490 & -2.645814 & 0.137429 \\ \mathrm{C} & -3.356234 & -2.465876 & 0.000656 \\ \mathrm{C} & -3.544005 & -3.861025 & 0.020609 \\ \mathrm{C} & -2.419605 & -4.682913 & -0.009918 \\ \mathrm{H} & -4.542949 & -4.280910 & 0.057913 \\ \mathrm{C} & -1.058204 & -2.703954 & -0.078310 \\ \mathrm{C} & -1.147034 & -4.103166 & -0.059209 \\ \mathrm{H} & -2.528349 & -5.763515 & 0.005082 \\ \mathrm{H} & -0.243482 & -4.698375 & -0.083094 \\ \mathrm{C} & 0.275083 & -2.031076 & -0.129760 \\ \mathrm{C} & 1.529617 & -0.119580 & -0.136815 \\ \mathrm{C} & 2.681566 & -0.944971 & 0.022814 \\ \mathrm{~N} & -4.196059 & -0.166290 & -0.016462 \\ \mathrm{~N} & -2.134360 & -1.906535 & -0.048056 \\ \mathrm{~N} & 0.324908 & -0.693064 & -0.141852 \\ \mathrm{~N} & 1.354236 & -2.833599 & -0.210749 \\ \mathrm{~N} & 2.551778 & -2.279708 & -0.089083 \\ \mathrm{C} & 1.555039 & 1.351971 & -0.354165 \\ \mathrm{C} & 2.558069 & 1.966444 & -1.131391 \\ \mathrm{C} & 0.510260 & 2.124413 & 0.165122 \\ \mathrm{C} & 2.496718 & 3.338301 & -1.364364 \\ \mathrm{H} & 3.363613 & 1.379167 & -1.555064 \\ \mathrm{C} & 0.467356 & 3.508924 & -0.058541 \\ \mathrm{H} & -0.277518 & 1.656878 & 0.743826 \\ & 1.464856 & 4.124468 & -0.829532 \\ \mathrm{H} & 1.4498454 & 5.190465 & -1.021942 \\ & & -0.466402 & 0.332616\end{array}$




$\begin{array}{lrrc}\mathrm{C} & 4.266365 & 0.568713 & 1.266542 \\ \mathrm{C} & 5.151384 & -1.102758 & -0.256588 \\ \mathrm{C} & 5.568361 & 0.949005 & 1.582491 \\ \mathrm{H} & 3.425979 & 1.058984 & 1.743897 \\ \mathrm{C} & 6.460048 & -0.701905 & 0.056643 \\ \mathrm{H} & 5.003338 & -1.917629 & -0.955355 \\ \mathrm{C} & 6.675375 & 0.329741 & 0.982573 \\ \mathrm{H} & 5.736024 & 1.739028 & 2.308927 \\ \mathrm{H} & 7.675972 & 0.652176 & 1.243915 \\ \mathrm{O} & -0.592446 & 4.166743 & 0.512729 \\ \mathrm{O} & 7.456652 & -1.383588 & -0.593974 \\ \mathrm{C} & 8.807113 & -1.035438 & -0.295873 \\ \mathrm{H} & 9.425889 & -1.694728 & -0.906378 \\ \mathrm{H} & 9.019918 & 0.008313 & -0.559467 \\ \mathrm{H} & 9.038308 & -1.199672 & 0.764012 \\ \mathrm{C} & -0.688532 & 5.576173 & 0.312749 \\ \mathrm{H} & -1.586069 & 5.891863 & 0.846537 \\ \mathrm{H} & 0.182270 & 6.099511 & 0.726967 \\ \mathrm{H} & -0.792871 & 5.823585 & -0.751037\end{array}$

Unbound Core 2

$\begin{array}{lrrr}\mathrm{C} & -0.861820 & 0.776526 & 0.000248 \\ \mathrm{C} & -0.900284 & 2.178902 & 0.000102 \\ \mathrm{C} & 0.314582 & 2.871537 & -0.000082 \\ \mathrm{C} & 1.509578 & 2.152998 & -0.000137 \\ \mathrm{C} & 1.446228 & 0.747970 & -0.000003 \\ \mathrm{H} & -1.854361 & 2.689686 & 0.000161 \\ \mathrm{H} & 0.326209 & 3.957497 & -0.000181 \\ \mathrm{H} & 2.468393 & 2.659595 & -0.000281 \\ \mathrm{C} & -2.129584 & -0.018011 & 0.000504 \\ \mathrm{C} & -3.205650 & -2.002642 & -0.000117 \\ \mathrm{C} & -4.417685 & -1.295902 & -0.000351 \\ \mathrm{H} & -3.185974 & -3.091302 & -0.000152 \\ \mathrm{H} & -5.382951 & -1.793983 & -0.000583 \\ \mathrm{C} & 2.648734 & -0.090649 & -0.000042 \\ \mathrm{C} & 4.017369 & 0.174672 & -0.000211 \\ \mathrm{C} & 4.630068 & -1.099620 & -0.000098 \\ \mathrm{H} & 4.501701 & 1.139342 & -0.000367 \\ \mathrm{H} & 5.684400 & -1.340479 & -0.000159 \\ \mathrm{~N} & -2.042040 & -1.364471 & 0.000271 \\ \mathrm{~N} & -3.275893 & 0.690146 & 0.000053 \\ \mathrm{~N} & -4.439264 & 0.041367 & -0.000280 \\ \mathrm{~N} & 0.281006 & 0.079185 & 0.000177 \\ \mathrm{~N} & 2.536445 & -1.449600 & 0.000121 \\ \mathrm{H} & 1.659891 & -1.956448 & 0.000280\end{array}$




\section{$\begin{array}{llll}\mathrm{N} & 3.721671 & -2.087857 & 0.000001\end{array}$}

\section{Unbound 2ae}

\begin{tabular}{|c|c|c|c|}
\hline $\mathrm{C}$ & 2.170349 & -1.408423 & 0.004918 \\
\hline $\mathrm{C}$ & 2.160246 & -2.813445 & 0.017312 \\
\hline $\mathrm{C}$ & 0.925483 & -3.461996 & 0.017337 \\
\hline $\mathrm{H}$ & 3.089205 & -3.372735 & 0.026393 \\
\hline $\mathrm{C}$ & -0.135332 & -1.302105 & -0.006297 \\
\hline $\mathrm{C}$ & -0.247133 & -2.700655 & 0.004882 \\
\hline $\mathrm{H}$ & 0.875759 & -4.546925 & 0.026369 \\
\hline $\mathrm{H}$ & -1.227179 & -3.159470 & 0.003067 \\
\hline $\mathrm{C}$ & -1.362944 & -0.445778 & -0.018675 \\
\hline $\mathrm{C}$ & -3.645140 & -0.307694 & -0.015869 \\
\hline $\mathrm{C}$ & -3.502879 & 1.101969 & 0.003663 \\
\hline $\mathrm{N}$ & 1.047031 & -0.674575 & -0.006169 \\
\hline $\mathrm{N}$ & -2.551622 & -1.069916 & -0.011923 \\
\hline $\mathrm{N}$ & -1.192173 & 0.887307 & -0.045764 \\
\hline $\mathrm{N}$ & -2.278949 & 1.651649 & -0.029614 \\
\hline $\mathrm{C}$ & -4.997856 & -1.017556 & -0.014084 \\
\hline $\mathrm{C}$ & -6.120193 & -0.012285 & -0.355533 \\
\hline $\mathrm{H}$ & -6.126952 & 0.163565 & -1.437489 \\
\hline $\mathrm{H}$ & -7.086165 & -0.470408 & -0.115412 \\
\hline $\mathrm{C}$ & -5.977133 & 1.323153 & 0.381405 \\
\hline $\mathrm{C}$ & -4.677741 & 2.078790 & 0.023401 \\
\hline $\mathrm{H}$ & -6.006487 & 1.151470 & 1.463660 \\
\hline $\mathrm{H}$ & -6.832648 & 1.968205 & 0.152420 \\
\hline $\mathrm{C}$ & -4.995168 & -2.156060 & -1.054912 \\
\hline $\mathrm{H}$ & -4.235335 & -2.904385 & -0.821253 \\
\hline $\mathrm{H}$ & -5.974716 & -2.645506 & -1.067097 \\
\hline $\mathrm{H}$ & -4.796014 & -1.772584 & -2.060975 \\
\hline $\mathrm{C}$ & -5.211469 & -1.627818 & 1.393205 \\
\hline $\mathrm{H}$ & -6.151488 & -2.188741 & 1.416099 \\
\hline $\mathrm{H}$ & -4.394741 & -2.311874 & 1.638980 \\
\hline $\mathrm{H}$ & -5.253918 & -0.861431 & 2.172529 \\
\hline $\mathrm{C}$ & -4.785806 & 2.731035 & -1.376599 \\
\hline $\mathrm{H}$ & -5.590905 & 3.473274 & -1.382199 \\
\hline $\mathrm{H}$ & -3.849120 & 3.233654 & -1.631091 \\
\hline $\mathrm{H}$ & -4.996121 & 1.995438 & -2.158947 \\
\hline $\mathrm{C}$ & -4.425976 & 3.185630 & 1.068797 \\
\hline $\mathrm{H}$ & -3.526372 & 3.755275 & 0.829426 \\
\hline $\mathrm{H}$ & -5.280760 & 3.870099 & 1.093676 \\
\hline $\mathrm{H}$ & -4.302396 & 2.761685 & 2.070875 \\
\hline $\mathrm{C}$ & 3.414076 & -0.630483 & 0.002671 \\
\hline $\mathrm{C}$ & 4.763788 & -0.955789 & 0.011736 \\
\hline $\mathrm{C}$ & 5.433305 & 0.292291 & 0.001308 \\
\hline
\end{tabular}




$\begin{array}{lrrr}\mathrm{H} & 5.224680 & -1.930824 & 0.023968 \\ \mathrm{~N} & 3.363633 & 0.737635 & -0.011945 \\ \mathrm{H} & 2.507392 & 1.281577 & -0.021746 \\ \mathrm{~N} & 4.565666 & 1.322422 & -0.013237 \\ \mathrm{C} & 6.904455 & 0.469633 & 0.005231 \\ \mathrm{O} & 7.688957 & -0.470367 & 0.018788 \\ \mathrm{O} & 7.280563 & 1.766146 & -0.007774 \\ \mathrm{C} & 8.704994 & 1.989449 & -0.004868 \\ \mathrm{H} & 9.165497 & 1.539503 & -0.888165 \\ \mathrm{H} & 8.827169 & 3.072762 & -0.016483 \\ \mathrm{H} & 9.158783 & 1.559322 & 0.891673\end{array}$

\section{Unbound 2am}

\begin{tabular}{lrrr}
$\mathrm{C}$ & 3.231527 & 0.940836 & 0.003431 \\
$\mathrm{C}$ & 3.358036 & 2.341489 & -0.000867 \\
$\mathrm{C}$ & 2.195361 & 3.110838 & 0.005469 \\
$\mathrm{H}$ & 4.338059 & 2.805530 & -0.008935 \\
$\mathrm{C}$ & 0.925338 & 1.068187 & 0.019760 \\
$\mathrm{C}$ & 0.951905 & 2.470979 & 0.015991 \\
$\mathrm{H}$ & 2.254661 & 4.195439 & 0.002782 \\
$\mathrm{H}$ & 0.022627 & 3.025329 & 0.021823 \\
$\mathrm{C}$ & -0.382368 & 0.339507 & 0.030556 \\
$\mathrm{C}$ & -2.667434 & 0.431518 & 0.011665 \\
$\mathrm{C}$ & -2.668311 & -0.984973 & 0.005417 \\
$\mathrm{~N}$ & 2.038395 & 0.324762 & 0.013694 \\
$\mathrm{~N}$ & -1.502747 & 1.079617 & 0.010298 \\
$\mathrm{~N}$ & -0.347944 & -1.004169 & 0.070031 \\
$\mathrm{~N}$ & -1.506240 & -1.654775 & 0.052844 \\
$\mathrm{C}$ & -3.941663 & 1.274290 & -0.007752 \\
$\mathrm{C}$ & -5.162364 & 0.391011 & 0.333321 \\
$\mathrm{H}$ & -5.194780 & 0.227369 & 1.416744 \\
$\mathrm{H}$ & -6.075426 & 0.941820 & 0.080982 \\
$\mathrm{C}$ & -5.149486 & -0.959553 & -0.390160 \\
$\mathrm{C}$ & -3.935627 & -1.838531 & -0.014462 \\
$\mathrm{H}$ & -5.153241 & -0.796397 & -1.474144 \\
$\mathrm{H}$ & -6.067516 & -1.512648 & -0.162489 \\
$\mathrm{C}$ & -3.831775 & 2.416703 & 1.022915 \\
$\mathrm{H}$ & -2.998338 & 3.081986 & 0.788992 \\
$\mathrm{H}$ & -4.756916 & 3.002774 & 1.022908 \\
$\mathrm{H}$ & -3.679549 & 2.024596 & 2.033853 \\
$\mathrm{C}$ & -4.082317 & 1.889426 & -1.422003 \\
$\mathrm{H}$ & -4.960072 & 2.543034 & -1.457591 \\
$\mathrm{H}$ & -3.198231 & 2.484041 & -1.667360 \\
$\mathrm{H}$ & -4.197181 & 1.123675 & -2.194653 \\
$\mathrm{C}$ & -4.119298 & -2.462484 & 1.390483 \\
& & & \\
\hline
\end{tabular}




$\begin{array}{lrrr}\mathrm{H} & -4.994769 & -3.120343 & 1.396353 \\ \mathrm{H} & -3.239528 & -3.053627 & 1.657600 \\ \mathrm{H} & -4.260653 & -1.701527 & 2.164062 \\ \mathrm{C} & -3.789435 & -2.975715 & -1.047360 \\ \mathrm{H} & -2.953392 & -3.630433 & -0.795414 \\ \mathrm{H} & -4.708601 & -3.571028 & -1.073092 \\ \mathrm{H} & -3.616293 & -2.576373 & -2.052217 \\ \mathrm{C} & 4.393659 & 0.047449 & -0.003050 \\ \mathrm{C} & 5.772168 & 0.249115 & -0.016792 \\ \mathrm{C} & 6.339812 & -1.051063 & -0.015935 \\ \mathrm{H} & 6.297520 & 1.192683 & -0.026381 \\ \mathrm{~N} & 4.218846 & -1.303267 & 0.004901 \\ \mathrm{H} & 3.321059 & -1.771683 & 0.016244 \\ \mathrm{~N} & 5.379166 & -1.991121 & -0.002467 \\ \mathrm{C} & 7.790825 & -1.439751 & -0.027759 \\ \mathrm{H} & 8.315195 & -1.045317 & 0.849310 \\ \mathrm{H} & 7.879218 & -2.528061 & -0.023352 \\ \mathrm{H} & 8.298500 & -1.053841 & -0.918343\end{array}$

\section{Unbound 2ap}

$\begin{array}{lrrr}\mathrm{C} & 1.697544 & -1.409213 & 0.002513 \\ \mathrm{C} & 1.682120 & -2.814912 & 0.014240 \\ \mathrm{C} & 0.446567 & -3.461443 & 0.014183 \\ \mathrm{H} & 2.609355 & -3.376961 & 0.022935 \\ \mathrm{C} & -0.609104 & -1.299921 & -0.008209 \\ \mathrm{C} & -0.724934 & -2.698206 & 0.002305 \\ \mathrm{H} & 0.394861 & -4.546350 & 0.022682 \\ \mathrm{H} & -1.705869 & -3.155011 & 0.000430 \\ \mathrm{C} & -1.835391 & -0.441437 & -0.019937 \\ \mathrm{C} & -4.117727 & -0.299673 & -0.015210 \\ \mathrm{C} & -3.973673 & 1.109542 & 0.003944 \\ \mathrm{~N} & 0.574014 & -0.674378 & -0.007990 \\ \mathrm{~N} & -3.025347 & -1.063452 & -0.012112 \\ \mathrm{~N} & -1.663191 & 0.891706 & -0.047501 \\ \mathrm{~N} & -2.748924 & 1.657378 & -0.030598 \\ \mathrm{C} & -5.471487 & -1.007864 & -0.012321 \\ \mathrm{C} & -6.592822 & -0.001082 & -0.352691 \\ \mathrm{H} & -6.600313 & 0.174785 & -1.434658 \\ \mathrm{H} & -7.559247 & -0.457849 & -0.111684 \\ \mathrm{C} & -6.447242 & 1.334257 & 0.383989 \\ \mathrm{C} & -5.147172 & 2.088088 & 0.024613 \\ \mathrm{H} & -6.475620 & 1.162624 & 1.466286 \\ \mathrm{H} & -7.302211 & 1.980402 & 0.155918 \\ \mathrm{C} & -5.471010 & -2.146141 & -1.053374 \\ \mathrm{H} & -4.711320 & -2.894922 & -0.820716\end{array}$




\begin{tabular}{lrrr}
$\mathrm{H}$ & -6.450929 & -2.634939 & -1.064722 \\
$\mathrm{H}$ & -5.272530 & -1.762527 & -2.059521 \\
$\mathrm{C}$ & -5.684700 & -1.618137 & 1.394980 \\
$\mathrm{H}$ & -6.625211 & -2.178263 & 1.418734 \\
$\mathrm{H}$ & -4.868263 & -2.302820 & 1.639977 \\
$\mathrm{H}$ & -5.725748 & -0.851768 & 2.174409 \\
$\mathrm{C}$ & -5.255777 & 2.740446 & -1.375259 \\
$\mathrm{H}$ & -6.059706 & 3.484002 & -1.380287 \\
$\mathrm{H}$ & -4.318480 & 3.241434 & -1.630726 \\
$\mathrm{H}$ & -5.467937 & 2.005043 & -2.157302 \\
$\mathrm{C}$ & -4.892831 & 3.194624 & 1.069685 \\
$\mathrm{H}$ & -3.992269 & 3.762449 & 0.829580 \\
$\mathrm{H}$ & -5.746311 & 3.880742 & 1.095208 \\
$\mathrm{H}$ & -4.769189 & 2.770487 & 2.071680 \\
$\mathrm{C}$ & 2.942689 & -0.635748 & 0.000409 \\
$\mathrm{C}$ & 4.292033 & -0.971412 & 0.008806 \\
$\mathrm{C}$ & 4.987135 & 0.267998 & -0.000989 \\
$\mathrm{H}$ & 4.710286 & -1.965980 & 0.019996 \\
$\mathrm{~N}$ & 2.900884 & 0.726922 & -0.013212 \\
$\mathrm{H}$ & 2.051713 & 1.279738 & -0.022469 \\
$\mathrm{~N}$ & 4.116248 & 1.297820 & -0.014472 \\
$\mathrm{C}$ & 6.442690 & 0.507979 & 0.001584 \\
$\mathrm{C}$ & 7.354367 & -0.563472 & 0.017438 \\
$\mathrm{C}$ & 6.949067 & 1.821940 & -0.012111 \\
$\mathrm{C}$ & 8.733522 & -0.330149 & 0.019523 \\
$\mathrm{H}$ & 6.990449 & -1.586042 & 0.028297 \\
$\mathrm{C}$ & 8.326534 & 2.054278 & -0.010031 \\
$\mathrm{H}$ & 6.250127 & 2.650753 & -0.024396 \\
$\mathrm{C}$ & 9.227579 & 0.980056 & 0.005776 \\
$\mathrm{H}$ & 9.422441 & -1.169976 & 0.031875 \\
$\mathrm{H}$ & 8.700088 & 3.074458 & -0.020815 \\
$\mathrm{H}$ & 10.298177 & 1.162112 & 0.007334 \\
& & & \\
\hline
\end{tabular}

\section{Unbound 2be}

$\begin{array}{lrrc}\mathrm{C} & 0.721481 & -2.571980 & -0.009996 \\ \mathrm{C} & 0.804561 & -3.972008 & 0.044521 \\ \mathrm{C} & 2.071696 & -4.559612 & 0.091686 \\ \mathrm{C} & 3.203199 & -3.743512 & 0.084882 \\ \mathrm{C} & 3.018163 & -2.351943 & 0.030799 \\ \mathrm{~N} & 1.803010 & -1.782116 & -0.015164 \\ \mathrm{H} & 2.173912 & -5.639996 & 0.134047 \\ \mathrm{H} & -0.103163 & -4.561523 & 0.048394 \\ \mathrm{H} & 4.201102 & -4.166411 & 0.119152 \\ \mathrm{C} & -0.609541 & -1.894453 & -0.060830 \\ \mathrm{C} & -1.855753 & 0.022362 & -0.081546\end{array}$




\begin{tabular}{|c|c|c|c|}
\hline $\mathrm{C}$ & -1.875892 & 1.489514 & -0.323849 \\
\hline & -3.010548 & -0.797739 & 0.099258 \\
\hline & -0.831835 & 2.267671 & 0.187507 \\
\hline & -2.871966 & 2.091881 & -1.119546 \\
\hline 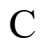 & -4.377563 & -0.314768 & 0.421314 \\
\hline & -0.782182 & 3.647969 & -0.062050 \\
\hline C & -4.579007 & 0.759850 & 1.300290 \\
\hline C & -2.803226 & 3.458487 & -1.379321 \\
\hline $\mathrm{C}$ & -5.484235 & -1.002723 & -0.113507 \\
\hline$C$ & -1.771837 & 4.251146 & -0.852921 \\
\hline $\mathrm{C}$ & -5.884361 & 1.145599 & 1.629028 \\
\hline $\mathrm{C}$ & -6.783928 & -0.600430 & 0.213101 \\
\hline $\mathrm{H}$ & -1.751355 & 5.313139 & -1.065853 \\
\hline $\mathrm{C}$ & -6.985254 & 0.482324 & 1.089005 \\
\hline $\mathrm{H}$ & -8.000576 & 0.776834 & 1.332734 \\
\hline $\mathrm{N}$ & -0.653976 & -0.556714 & -0.086655 \\
\hline $\mathrm{N}$ & -1.690536 & -2.693911 & -0.131505 \\
\hline $\mathrm{N}$ & -2.885195 & -2.133544 & -0.006088 \\
\hline $\mathrm{O}$ & -7.920747 & -1.198685 & -0.265039 \\
\hline $\mathrm{O}$ & 0.273712 & 4.311110 & 0.505730 \\
\hline $\mathrm{C}$ & 0.395785 & 5.711225 & 0.258147 \\
\hline $\mathrm{H}$ & 1.296408 & 6.028200 & 0.785599 \\
\hline $\mathrm{H}$ & 0.510412 & 5.918964 & -0.812893 \\
\hline $\mathrm{H}$ & -0.467837 & 6.263595 & 0.649173 \\
\hline $\mathrm{C}$ & -7.768540 & -2.323413 & -1.131744 \\
\hline $\mathrm{H}$ & -7.242289 & -2.048771 & -2.054295 \\
\hline $\mathrm{H}$ & -7.232470 & -3.140829 & -0.634791 \\
\hline $\mathrm{H}$ & -8.780736 & -2.648772 & -1.376293 \\
\hline $\mathrm{H}$ & -5.299417 & -1.847471 & -0.763441 \\
\hline $\mathrm{H}$ & -3.734647 & 1.284240 & 1.731635 \\
\hline $\mathrm{H}$ & -6.044271 & 1.971695 & 2.315678 \\
\hline $\mathrm{H}$ & -3.678272 & 1.499700 & -1.535028 \\
\hline $\mathrm{H}$ & -0.048706 & 1.810154 & 0.780313 \\
\hline $\mathrm{H}$ & -3.560975 & 3.925479 & -2.001811 \\
\hline $\mathrm{C}$ & 4.145746 & -1.413224 & 0.015186 \\
\hline $\mathrm{C}$ & 5.525984 & -1.555103 & 0.065079 \\
\hline $\mathrm{H}$ & 2.998054 & 0.359558 & -0.120272 \\
\hline $\mathrm{C}$ & 6.025499 & -0.230981 & 0.007820 \\
\hline $\mathrm{H}$ & 6.111075 & -2.458514 & 0.133768 \\
\hline $\mathrm{N}$ & 3.916519 & -0.065922 & -0.065593 \\
\hline $\mathrm{N}$ & 5.030856 & 0.673382 & -0.072740 \\
\hline $\mathrm{C}$ & 7.460116 & 0.139540 & 0.031882 \\
\hline $\mathrm{O}$ & 8.360596 & -0.686715 & 0.104548 \\
\hline $\mathrm{O}$ & 7.663297 & 1.472872 & -0.034327 \\
\hline $\mathrm{C}$ & 9.045981 & 1.881362 & -0.014050 \\
\hline $\mathrm{H}$ & 9.026244 & 2.969824 & -0.073640 \\
\hline
\end{tabular}




$$
\begin{array}{rrrr}
\mathrm{H} & 9.529089 & 1.554017 & 0.910150 \\
\mathrm{H} & 9.583567 & 1.457785 & -0.866271
\end{array}
$$

\begin{tabular}{|c|c|c|c|}
\hline $\mathrm{C}$ & 1.709837 & -2.342527 & 0.020206 \\
\hline $\mathrm{C}$ & 1.905624 & -3.731496 & -0.024505 \\
\hline $\mathrm{C}$ & 3.217222 & -4.212716 & -0.071360 \\
\hline $\mathrm{C}$ & 4.276643 & -3.305941 & -0.074388 \\
\hline $\mathrm{C}$ & 3.981536 & -1.931741 & -0.030467 \\
\hline $\mathrm{N}$ & 2.722027 & -1.465560 & 0.015761 \\
\hline $\mathrm{H}$ & 3.408167 & -5.281400 & -0.105805 \\
\hline $\mathrm{H}$ & 1.049429 & -4.393535 & -0.021489 \\
\hline $\mathrm{H}$ & 5.305681 & -3.646126 & -0.108544 \\
\hline $\mathrm{C}$ & 0.327253 & -1.776983 & 0.070362 \\
\hline $\mathrm{C}$ & -1.074025 & 0.030306 & 0.086285 \\
\hline $\mathrm{C}$ & -1.216476 & 1.490735 & 0.329154 \\
\hline $\mathrm{C}$ & -2.156203 & -0.882067 & -0.098263 \\
\hline $\mathrm{C}$ & -0.234514 & 2.352289 & $-0.1^{\prime}$ \\
\hline $\mathrm{C}$ & -2.266550 & 2.009037 & 1.114660 \\
\hline $\mathrm{C}$ & -3.557076 & -0.514051 & -0.4 \\
\hline $\mathrm{C}$ & -0.301295 & 3.731845 & 0.078053 \\
\hline $\mathrm{C}$ & -3.842055 & 0.535454 & -1.3 \\
\hline $\mathrm{C}$ & -2.313353 & 3.376513 & 1.374442 \\
\hline $\mathrm{C}$ & -4.606241 & -1.285745 & 842 \\
\hline $\mathrm{C}$ & -1.345325 & 4.251501 & 0.858187 \\
\hline $\mathrm{C}$ & -5.173270 & 0.812830 & -1.647792 \\
\hline $\mathrm{C}$ & -5.933165 & -0.991691 & -0.223687 \\
\hline $\mathrm{H}$ & -1.414481 & 5.311528 & 1.070727 \\
\hline $\mathrm{C}$ & -6.218779 & 0.066035 & -1.106569 \\
\hline $\mathrm{H}$ & -7.253827 & 0.276193 & -1.354629 \\
\hline $\mathrm{N}$ & 0.171390 & -0.447566 & 0.095494 \\
\hline $\mathrm{N}$ & -0.685253 & -2.662616 & 0.140617 \\
\hline $\mathrm{N}$ & -1.921437 & -2.202750 & 0.010412 \\
\hline $\mathrm{O}$ & -7.019591 & -1.677236 & 0.255379 \\
\hline $\mathrm{O}$ & 0.702263 & 4.480329 & -0.479057 \\
\hline $\mathrm{C}$ & 0.705861 & 5.885138 & -0.229930 \\
\hline $\mathrm{H}$ & 1.582767 & 6.276005 & -0.747759 \\
\hline $\mathrm{H}$ & -0.196216 & 6.365093 & -0.629816 \\
\hline $\mathrm{H}$ & 0.791616 & 6.100622 & 0.842340 \\
\hline $\mathrm{C}$ & -6.779177 & -2.780557 & 1.129358 \\
\hline $\mathrm{H}$ & -6.177256 & -3.554928 & 0.638867 \\
\hline $\mathrm{H}$ & -6.279329 & -2.458706 & 2.051353 \\
\hline $\mathrm{H}$ & -7.762356 & -3.185416 & 1.373774 \\
\hline $\mathrm{H}$ & -4.355701 & -2.108868 & 0.764535 \\
\hline 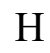 & -5.397216 & 1.619449 & -2.339713 \\
\hline
\end{tabular}

\section{Unbound 2bm}




$\begin{array}{lrrr}\mathrm{H} & 0.590314 & 1.960312 & -0.754645 \\ \mathrm{H} & -3.113286 & 3.779312 & 1.988984 \\ \mathrm{C} & 5.031273 & -0.908159 & -0.026913 \\ \mathrm{C} & 6.422651 & -0.949586 & -0.083519 \\ \mathrm{H} & 3.762685 & 0.775387 & 0.102878 \\ \mathrm{C} & 6.839572 & 0.405746 & -0.038860 \\ \mathrm{H} & 7.050951 & -1.825472 & -0.149573 \\ \mathrm{~N} & 4.705518 & 0.412329 & 0.045135 \\ \mathrm{~N} & 5.780075 & 1.228754 & 0.040643 \\ \mathrm{C} & 8.236583 & 0.957048 & -0.069724 \\ \mathrm{H} & 8.757592 & 0.668077 & -0.988851 \\ \mathrm{H} & 8.202366 & 2.047270 & -0.019415 \\ \mathrm{H} & 8.827816 & 0.588851 & 0.775630 \\ \mathrm{H} & -3.041199 & 1.123744 & -1.745525 \\ \mathrm{H} & -3.025452 & 1.352428 & 1.522506\end{array}$

\section{Unbound 2bp}

$\begin{array}{lrrr}\mathrm{C} & 0.309141 & -2.576128 & -0.026398 \\ \mathrm{C} & 0.386852 & -3.976671 & 0.022247 \\ \mathrm{C} & 1.652625 & -4.567726 & 0.064698 \\ \mathrm{C} & 2.785953 & -3.754698 & 0.059481 \\ \mathrm{C} & 2.607456 & -2.361287 & 0.011945 \\ \mathrm{~N} & 1.392515 & -1.789115 & -0.029861 \\ \mathrm{H} & 1.751877 & -5.648633 & 0.102193 \\ \mathrm{H} & -0.522640 & -4.563362 & 0.025399 \\ \mathrm{H} & 3.782135 & -4.181753 & 0.090061 \\ \mathrm{C} & -1.020243 & -1.894723 & -0.072216 \\ \mathrm{C} & -2.262136 & 0.025209 & -0.087055 \\ \mathrm{C} & -2.280202 & 1.492335 & -0.330613 \\ \mathrm{C} & -3.417926 & -0.791549 & 0.100805 \\ \mathrm{C} & -1.230505 & 2.268366 & 0.172365 \\ \mathrm{C} & -3.280927 & 2.096638 & -1.119002 \\ \mathrm{C} & -4.781892 & -0.305258 & 0.431072 \\ \mathrm{C} & -1.180189 & 3.648520 & -0.077867 \\ \mathrm{C} & -4.975702 & 0.769048 & 1.312115 \\ \mathrm{C} & -3.211518 & 3.462995 & -1.379654 \\ \mathrm{C} & -5.893431 & -0.989559 & -0.098290 \\ \mathrm{C} & -2.174600 & 4.253670 & -0.861154 \\ \mathrm{C} & -6.278170 & 1.158201 & 1.648225 \\ \mathrm{C} & -7.190194 & -0.584093 & 0.235877 \\ \mathrm{H} & -2.153646 & 5.315590 & -1.074416 \\ \mathrm{C} & -7.383891 & 0.498428 & 1.113723 \\ \mathrm{H} & -8.397053 & 0.795506 & 1.363256 \\ \mathrm{~N} & -1.061914 & -0.556861 & -0.098565 \\ \mathrm{~N} & -2.104231 & -2.691145 & -0.137681\end{array}$




$\begin{array}{cccc}\mathrm{N} & -3.296597 & -2.127653 & -0.005592 \\ \mathrm{O} & -8.331324 & -1.179065 & -0.236601 \\ \mathrm{O} & -0.118683 & 4.310135 & 0.481760 \\ \mathrm{C} & 0.002564 & 5.710126 & 0.234103 \\ \mathrm{H} & 0.907244 & 6.026298 & 0.755127 \\ \mathrm{H} & 0.109309 & 5.918608 & -0.837649 \\ \mathrm{H} & -0.857669 & 6.263062 & 0.631808 \\ \mathrm{C} & -8.186557 & -2.303307 & -1.105092 \\ \mathrm{H} & -7.664597 & -2.029177 & -2.030243 \\ \mathrm{H} & -7.649758 & -3.122508 & -0.611857 \\ \mathrm{H} & -9.200854 & -2.626014 & -1.344486 \\ \mathrm{H} & -5.714397 & -1.834199 & -0.749982 \\ \mathrm{H} & -4.127492 & 1.290710 & 1.739224 \\ \mathrm{H} & -6.432000 & 1.984208 & 2.336386 \\ \mathrm{H} & -4.091543 & 1.505988 & -1.528213 \\ \mathrm{H} & -0.443480 & 1.808956 & 0.758538 \\ \mathrm{H} & -3.973008 & 3.931375 & -1.996528 \\ \mathrm{C} & 3.738124 & -1.428080 & -0.000633 \\ \mathrm{C} & 5.119052 & -1.582664 & 0.048084 \\ \mathrm{H} & 2.608292 & 0.352669 & -0.128313 \\ \mathrm{C} & 5.647186 & -0.264358 & -0.002606 \\ \mathrm{H} & 5.662858 & -2.512197 & 0.114049 \\ \mathrm{~N} & 3.520130 & -0.084310 & -0.074613 \\ \mathrm{~N} & 4.650789 & 0.641194 & -0.078589 \\ \mathrm{C} & 7.058873 & 0.163389 & 0.018740 \\ \mathrm{C} & 8.101182 & -0.779455 & 0.082000 \\ \mathrm{C} & 7.390917 & 1.531232 & -0.024114 \\ \mathrm{C} & 9.438087 & -0.368692 & 0.102124 \\ \mathrm{H} & 7.872774 & -1.840061 & 0.115003 \\ \mathrm{C} & 8.726295 & 1.940851 & -0.004080 \\ \mathrm{H} & 6.590817 & 2.261357 & -0.072901 \\ \mathrm{C} & 9.758382 & 0.993822 & 0.059243 \\ \mathrm{H} & 10.229532 & -1.111159 & 0.150946 \\ \mathrm{H} & 8.964819 & 3.000306 & -0.037648 \\ \mathrm{H} & 10.796072 & 1.313612 & 0.074837\end{array}$

\section{Unbound 1i}
$\begin{array}{llll}\text { C } & 0.015135 & -3.222059 & 0.000000\end{array}$
C $\quad-1.412162 \quad-3.498224 \quad 0.000000$
C $\quad-1.873304 \quad-4.839343 \quad 0.000000$
$\begin{array}{llll}\text { C } & -0.944429 & -5.876140 & 0.000000\end{array}$
C $\quad 0.456683 \quad-5.605176 \quad 0.000000$
C $\quad 0.936752 \quad-4.298692 \quad 0.000000$
$\begin{array}{llll}\text { C } & -0.951003 & -1.289447 & 0.000000\end{array}$
$\begin{array}{llll}\text { C } & -2.025400 & -2.223443 & 0.000000\end{array}$ 


$\begin{array}{lrrl}\mathrm{H} & -2.939449 & -5.062053 & 0.000000 \\ \mathrm{H} & -1.284571 & -6.909983 & 0.000000 \\ \mathrm{H} & 1.156508 & -6.438493 & 0.000000 \\ \mathrm{H} & 2.003853 & -4.091210 & 0.000000 \\ \mathrm{H} & -3.088892 & -2.019820 & 0.000000 \\ \mathrm{C} & -1.099417 & 0.166710 & 0.000000 \\ \mathrm{C} & -2.399118 & 0.748377 & 0.000000 \\ \mathrm{C} & -2.545833 & 2.127984 & 0.000000 \\ \mathrm{H} & -3.270117 & 0.104196 & 0.000000 \\ \mathrm{C} & -0.156305 & 2.284623 & 0.000000 \\ \mathrm{C} & -1.399268 & 2.936024 & 0.000000 \\ \mathrm{H} & -3.536356 & 2.576899 & 0.000000 \\ \mathrm{H} & -1.451721 & 4.016557 & 0.000000 \\ \mathrm{C} & 1.084794 & 3.119727 & 0.000000 \\ \mathrm{C} & 2.036784 & 5.185239 & 0.000000 \\ \mathrm{C} & 3.289799 & 4.562828 & 0.000000 \\ \mathrm{H} & 1.940254 & 6.270850 & 0.000000 \\ \mathrm{H} & 4.222030 & 5.121590 & 0.000000 \\ \mathrm{~N} & 0.279407 & -1.888473 & 0.000000 \\ \mathrm{~N} & 0.000000 & 0.953970 & 0.000000 \\ \mathrm{~N} & 0.922745 & 4.466686 & 0.000000 \\ \mathrm{~N} & 2.284863 & 2.491096 & 0.000000 \\ \mathrm{~N} & 3.393870 & 3.227800 & 0.000000\end{array}$

\section{Unbound 1ai}

$\begin{array}{lrrr}\mathrm{C} & 4.530202 & -1.084658 & 0.019465 \\ \mathrm{C} & 5.534785 & -0.034135 & 0.020881 \\ \mathrm{C} & 6.911552 & -0.372844 & 0.033441 \\ \mathrm{C} & 7.280648 & -1.715421 & 0.044194 \\ \mathrm{C} & 6.294760 & -2.746490 & 0.042701 \\ \mathrm{C} & 4.936112 & -2.442027 & 0.030518 \\ \mathrm{C} & 3.429190 & 0.775924 & 0.000025 \\ \mathrm{C} & 4.794908 & 1.172235 & 0.008043 \\ \mathrm{H} & 7.675967 & 0.402956 & 0.034686 \\ \mathrm{H} & 8.333977 & -1.988969 & 0.053854 \\ \mathrm{H} & 6.616512 & -3.785985 & 0.051211 \\ \mathrm{H} & 4.184278 & -3.227404 & 0.029276 \\ \mathrm{H} & 5.198050 & 2.177289 & 0.005378 \\ \mathrm{C} & 2.281951 & 1.687361 & -0.013588 \\ \mathrm{C} & 2.480575 & 3.095946 & -0.020945 \\ \mathrm{C} & 1.387095 & 3.952146 & -0.031218 \\ \mathrm{H} & 3.488793 & 3.493016 & -0.017896 \\ \mathrm{C} & -0.014601 & 2.014003 & -0.028853 \\ \mathrm{C} & 0.092661 & 3.411566 & -0.034351 \\ \mathrm{H} & 1.532293 & 5.029991 & -0.036269\end{array}$




$\begin{array}{lrrr}\mathrm{H} & -0.796330 & 4.028730 & -0.040495 \\ \mathrm{C} & -1.365901 & 1.371902 & -0.032227 \\ \mathrm{C} & -2.647330 & -0.518593 & -0.041658 \\ \mathrm{C} & -3.793488 & 0.305793 & 0.026716 \\ \mathrm{~N} & 3.265430 & -0.583797 & 0.006906 \\ \mathrm{~N} & 1.031318 & 1.176963 & -0.019089 \\ \mathrm{~N} & -1.438499 & 0.032145 & -0.055125 \\ \mathrm{~N} & -2.443640 & 2.188728 & -0.021011 \\ \mathrm{~N} & -3.653042 & 1.640940 & 0.014448 \\ \mathrm{C} & -2.702234 & -2.045851 & -0.077365 \\ \mathrm{C} & -4.143836 & -2.517068 & -0.367549 \\ \mathrm{H} & -4.342465 & -2.423560 & -1.442087 \\ \mathrm{H} & -4.220634 & -3.586055 & -0.135548 \\ \mathrm{C} & -5.202702 & -1.735387 & 0.419100 \\ \mathrm{C} & -5.225738 & -0.227669 & 0.078575 \\ \mathrm{H} & -5.019901 & -1.855079 & 1.493663 \\ \mathrm{H} & -6.198264 & -2.155080 & 0.228711 \\ \mathrm{C} & -1.746604 & -2.566940 & -1.170874 \\ \mathrm{H} & -0.723680 & -2.236559 & -0.981614 \\ \mathrm{H} & -1.771075 & -3.662588 & -1.192770 \\ \mathrm{H} & -2.044247 & -2.200541 & -2.159769 \\ \mathrm{C} & -2.207803 & -2.565063 & 1.294853 \\ \mathrm{H} & -2.178713 & -3.660361 & 1.291059 \\ \mathrm{H} & -1.200079 & -2.191018 & 1.491486 \\ \mathrm{H} & -2.857262 & -2.242933 & 2.115506 \\ \mathrm{C} & -5.891553 & 0.015825 & -1.296906 \\ \mathrm{H} & -6.936345 & -0.315712 & -1.277755 \\ \mathrm{H} & -5.868279 & 1.081722 & -1.539703 \\ \mathrm{H} & -5.377867 & -0.521225 & -2.099981 \\ \mathrm{C} & -6.032672 & 0.524463 & 1.157169 \\ \mathrm{H} & -6.076271 & 1.592990 & 0.937013 \\ \mathrm{H} & -7.054208 & 0.128733 & 1.203569 \\ \mathrm{H} & -5.575077 & 0.402671 & 2.144665\end{array}$

Unbound 1bi
$\begin{array}{llll}\text { C } & -5.511095 & 0.498794 & 0.526290\end{array}$
$\begin{array}{llll}\text { C } & -6.541490 & -0.515392 & 0.375859\end{array}$
$\begin{array}{llll}\text { C } & -7.905037 & -0.169394 & 0.553984\end{array}$
$\begin{array}{llll}\text { C } & -8.235860 & 1.144784 & 0.873216\end{array}$
$\begin{array}{llll}\text { C } & -7.224325 & 2.139943 & 1.021677\end{array}$
$\begin{array}{llll}\text { C } & -5.878162 & 1.827981 & 0.851879\end{array}$
$\begin{array}{llll}\text { C } & -4.464486 & -1.328637 & 0.039467\end{array}$
$\begin{array}{llll}\text { C } & -5.837054 & -1.701182 & 0.059239\end{array}$
$\mathrm{H} \quad-8.688560 \quad-0.917842 \quad 0.444166$
$\begin{array}{llll}\mathrm{H} & -9.278526 & 1.423601 & 1.012978\end{array}$ 


$\begin{array}{lrrr}\mathrm{H} & -7.516731 & 3.157841 & 1.271885 \\ \mathrm{H} & -5.106213 & 2.585210 & 0.964234 \\ \mathrm{H} & -6.266482 & -2.677300 & -0.129009 \\ \mathrm{C} & -3.345284 & -2.229565 & -0.242272 \\ \mathrm{C} & -3.577489 & -3.609816 & -0.499869 \\ \mathrm{C} & -2.509202 & -4.463406 & -0.742867 \\ \mathrm{H} & -4.592651 & -3.988756 & -0.497164 \\ \mathrm{C} & -1.066158 & -2.574724 & -0.490469 \\ \mathrm{C} & -1.204388 & -3.948073 & -0.733034 \\ \mathrm{H} & -2.681581 & -5.519900 & -0.934387 \\ \mathrm{H} & -0.331676 & -4.565917 & -0.901039 \\ \mathrm{C} & 0.291475 & -1.956704 & -0.475076 \\ \mathrm{C} & 1.602112 & -0.079601 & -0.356004 \\ \mathrm{C} & 2.701763 & -0.933633 & -0.062034 \\ \mathrm{~N} & -4.264010 & -0.003702 & 0.320473 \\ \mathrm{~N} & -2.086372 & -1.739445 & -0.254791 \\ \mathrm{~N} & 0.394206 & -0.622380 & -0.491301 \\ \mathrm{~N} & 1.364591 & -2.785493 & -0.488798 \\ \mathrm{~N} & 2.552571 & -2.262370 & -0.231679 \\ \mathrm{C} & 1.680709 & 1.388565 & -0.595763 \\ \mathrm{C} & 2.822859 & 1.993419 & -1.162640 \\ \mathrm{C} & 0.549034 & 2.164576 & -0.317487 \\ \mathrm{C} & 2.815218 & 3.360727 & -1.425249 \\ \mathrm{H} & 3.695358 & 1.399715 & -1.406692 \\ \mathrm{H} & 9.877159 & -1.391047 & 1.585112 \\ \mathrm{C} & 0.560468 & 3.546293 & -0.567313 \\ \mathrm{H} & -0.350245 & 1.697789 & 0.070800 \\ \mathrm{C} & 1.696012 & 4.153480 & -1.125189 \\ \mathrm{H} & 3.688114 & 3.827723 & -1.873606 \\ \mathrm{H} & 1.720249 & 5.216697 & -1.333358 \\ \mathrm{C} & 4.031489 & -0.505964 & 0.444899 \\ \mathrm{C} & 4.142313 & 0.512103 & 1.415401 \\ \mathrm{C} & 5.186633 & -1.167297 & 0.011244 \\ \mathrm{C} & 5.395204 & 0.851982 & 1.918758 \\ \mathrm{H} & 3.254993 & 1.021847 & 1.772463 \\ \mathrm{C} & 6.445838 & -0.810869 & 0.516710 \\ \mathrm{H} & 5.114112 & -1.969905 & -0.713152 \\ \mathrm{C} & 6.560149 & 0.204496 & 1.476904 \\ \mathrm{H} & 5.478114 & 1.631332 & 2.671364 \\ \mathrm{H} & 7.521935 & 0.493526 & 1.883398 \\ \mathrm{H} & -0.5871511 & 4.214961 & -0.233281 \\ \mathrm{H} & -1.519743 & 0.005911 \\ \mathrm{H} & -1.212440 & 0.504005 \\ \mathrm{H} & -0.00166 & -0.541221\end{array}$




$\begin{array}{crcc}\mathrm{H} & -1.667505 & 5.914917 & -0.229071 \\ \mathrm{H} & 0.082581 & 6.182442 & 0.007665 \\ \mathrm{H} & -0.554242 & 5.780427 & -1.618146\end{array}$

\section{Unbound 2i}

$\begin{array}{lrrc}\mathrm{C} & 0.857006 & 0.700660 & 0.000073 \\ \mathrm{C} & 0.869709 & 2.104604 & 0.000006 \\ \mathrm{C} & -0.375551 & 2.752499 & -0.000075 \\ \mathrm{C} & -1.534171 & 1.991333 & -0.000078 \\ \mathrm{C} & -1.460410 & 0.565244 & 0.000007 \\ \mathrm{H} & 1.806129 & 2.645985 & 0.000024 \\ \mathrm{H} & -0.431360 & 3.838882 & -0.000135 \\ \mathrm{H} & -2.506464 & 2.470575 & -0.000146 \\ \mathrm{C} & 2.168363 & -0.020032 & 0.000164 \\ \mathrm{C} & 4.441060 & 0.080598 & 0.000039 \\ \mathrm{C} & 4.462695 & -1.318076 & -0.000105 \\ \mathrm{H} & 5.361673 & 0.664251 & 0.000084 \\ \mathrm{H} & 5.386801 & -1.890337 & -0.000172 \\ \mathrm{C} & -2.683365 & -0.218750 & 0.000012 \\ \mathrm{C} & -4.021558 & 0.269251 & -0.000025 \\ \mathrm{C} & -4.784547 & -0.897620 & -0.000012 \\ \mathrm{H} & -4.378636 & 1.290972 & -0.000044 \\ \mathrm{H} & -5.864641 & -1.005802 & -0.000033 \\ \mathrm{~N} & 3.291680 & 0.741236 & 0.000156 \\ \mathrm{~N} & 2.160572 & -1.375025 & -0.000080 \\ \mathrm{~N} & 3.323880 & -2.022630 & -0.000179 \\ \mathrm{~N} & -0.252039 & -0.049144 & 0.000067 \\ \mathrm{~N} & -2.694469 & -1.588767 & 0.000056 \\ \mathrm{~N} & -3.973751 & -2.001784 & 0.000036\end{array}$

\section{Unbound 2aei}

$\begin{array}{cccc}\mathrm{C} & -2.192974 & 1.085006 & -0.245055 \\ \mathrm{C} & -2.238999 & 2.499354 & -0.394582 \\ \mathrm{C} & -1.061399 & 3.224853 & -0.513354 \\ \mathrm{H} & -3.198538 & 3.003444 & -0.401876 \\ \mathrm{C} & 0.120216 & 1.149954 & -0.358607 \\ \mathrm{C} & 0.164936 & 2.545674 & -0.483459 \\ \mathrm{H} & -1.090710 & 4.306434 & -0.623176 \\ \mathrm{H} & 1.113535 & 3.062429 & -0.556467 \\ \mathrm{C} & 1.405711 & 0.385542 & -0.348292 \\ \mathrm{C} & 3.651067 & 0.340103 & 0.108377 \\ \mathrm{C} & 3.642729 & -1.028296 & -0.230496 \\ \mathrm{~N} & -1.006522 & 0.435833 & -0.246408 \\ \mathrm{~N} & 2.514589 & 1.034330 & 0.051416\end{array}$




$\begin{array}{lrrr}\mathrm{N} & 1.387686 & -0.898356 & -0.770868 \\ \mathrm{~N} & 2.516618 & -1.589940 & -0.702037 \\ \mathrm{C} & 4.905593 & 1.088051 & 0.563825 \\ \mathrm{C} & 6.160855 & 0.235807 & 0.272970 \\ \mathrm{H} & 6.407500 & 0.313736 & -0.792770 \\ \mathrm{H} & 7.012356 & 0.663596 & 0.815993 \\ \mathrm{C} & 5.985883 & -1.239485 & 0.650429 \\ \mathrm{C} & 4.866795 & -1.941289 & -0.151193 \\ \mathrm{H} & 5.763422 & -1.318845 & 1.721099 \\ \mathrm{H} & 6.926880 & -1.780227 & 0.492727 \\ \mathrm{C} & 5.012205 & 2.431957 & -0.184980 \\ \mathrm{H} & 4.145054 & 3.062371 & 0.021385 \\ \mathrm{H} & 5.917896 & 2.963097 & 0.129750 \\ \mathrm{H} & 5.067420 & 2.276537 & -1.267770 \\ \mathrm{C} & 4.769518 & 1.374007 & 2.078612 \\ \mathrm{H} & 5.625983 & 1.960825 & 2.429573 \\ \mathrm{H} & 3.854901 & 1.940366 & 2.272538 \\ \mathrm{H} & 4.722584 & 0.452716 & 2.666909 \\ \mathrm{C} & 5.337190 & -2.261734 & -1.589830 \\ \mathrm{H} & 6.179264 & -2.963008 & -1.566211 \\ \mathrm{H} & 4.520068 & -2.716045 & -2.155996 \\ \mathrm{H} & 5.656675 & -1.362505 & -2.125999 \\ \mathrm{C} & 4.487154 & -3.262213 & 0.550412 \\ \mathrm{H} & 3.701978 & -3.782765 & -0.001141 \\ \mathrm{H} & 5.365633 & -3.914455 & 0.620889 \\ \mathrm{H} & 4.117850 & -3.076382 & 1.564450 \\ \mathrm{C} & -3.432069 & 0.330494 & -0.081960 \\ \mathrm{C} & -4.749182 & 0.822077 & -0.130107 \\ \mathrm{C} & -5.532433 & -0.319283 & 0.099751 \\ \mathrm{H} & -5.114404 & 1.823167 & -0.307941 \\ \mathrm{~N} & -3.455419 & -1.028236 & 0.166993 \\ \mathrm{~N} & -4.720398 & -1.419882 & 0.278661 \\ \mathrm{C} & -6.987937 & -0.358681 & 0.147365 \\ \mathrm{O} & -7.740202 & 0.609532 & -0.007832 \\ \mathrm{O} & -7.494257 & -1.613693 & 0.389708 \\ \mathrm{C} & -8.919878 & -1.681533 & 0.439972 \\ \mathrm{H} & -9.367206 & -1.363040 & -0.507905 \\ \mathrm{H} & -9.157295 & -2.730195 & 0.636516 \\ \mathrm{H} & -9.320935 & -1.046385 & 1.237355\end{array}$

\section{Unbound 2ami}
$\begin{array}{llll}\text { C } & -3.241500 & 0.690348 & -0.180171\end{array}$
$\begin{array}{llll}\text { C } & -3.399984 & 2.093294 & -0.390110\end{array}$
C $\quad-2.289746 \quad 2.906195 \quad-0.564353$
$\mathrm{H} \quad-4.397544 \quad 2.517391 \quad-0.398661$ 


\begin{tabular}{|c|c|c|c|}
\hline C & -0.940542 & 0.943007 & -0.352529 \\
\hline C & -1.008805 & 2.332779 & -0.533455 \\
\hline H & -2.410801 & 3.976336 & -0.718683 \\
\hline & -0.107420 & 2.921389 & -0.647635 \\
\hline $\mathrm{C}$ & 0.403371 & 0.287112 & -0.343179 \\
\hline C & 2.653091 & 0.438859 & 0.073076 \\
\hline$c$ & 2.751427 & -0.937039 & -0.214483 \\
\hline $\mathrm{N}$ & -1.999359 & 0.143006 & -0.186106 \\
\hline $\mathrm{N}$ & 1.463599 & 1.036841 & 0.011096 \\
\hline $\mathbf{N}$ & 0.485683 & -1.009651 & -0.721209 \\
\hline $\mathrm{N}$ & 1.668001 & -1.604185 & -0.647668 \\
\hline $\mathrm{C}$ & 3.849676 & 1.303320 & 0.476626 \\
\hline $\mathrm{C}$ & 5.165755 & 0.543653 & 0.198244 \\
\hline $\mathrm{H}$ & 5.390932 & 0.598494 & 3712 \\
\hline $\mathrm{H}$ & 5.987402 & 1.059407 & 0.710207 \\
\hline $\mathrm{C}$ & 5.115239 & -0.924892 & 730 \\
\hline $\mathrm{C}$ & 4.046436 & -1.744997 & -0.121957 \\
\hline $\mathrm{H}$ & 4.912382 & -0.979092 & 1.710892 \\
\hline $\mathrm{H}$ & 6.095012 & -1.394312 & 0.483902 \\
\hline $\mathrm{C}$ & 3.835907 & 2.619329 & -0.327155 \\
\hline $\mathrm{H}$ & 2.921242 & 3.183048 & 3373 \\
\hline $\mathrm{H}$ & 4.697935 & 3.236421 & 8136 \\
\hline $\mathrm{H}$ & 3.890666 & 2.423944 & 3520 \\
\hline $\mathrm{C}$ & 3.712948 & 1.640206 & 1.980716 \\
\hline $\mathrm{H}$ & 4.522918 & 2.309605 & 2.292508 \\
\hline $\mathrm{H}$ & 2.757230 & 2.136696 & 2.167716 \\
\hline $\mathrm{H}$ & 3.751006 & 0.743348 & 2.606344 \\
\hline $\mathrm{C}$ & 4.522645 & -2.081917 & -1.554805 \\
\hline $\mathrm{H}$ & 5.418930 & -2.712119 & -1.519164 \\
\hline $\mathrm{H}$ & 3.737056 & -2.621260 & -2.090186 \\
\hline $\mathrm{H}$ & 4.761048 & -1.181039 & -2.129072 \\
\hline $\mathrm{C}$ & 3.784992 & -3.064302 & 4468 \\
\hline $\mathrm{H}$ & 3.036136 & -3.666194 & 0.116085 \\
\hline $\mathrm{H}$ & 4.713997 & -3.641404 & 0.713954 \\
\hline $\mathrm{H}$ & 3.416009 & -2.869761 & 1.646999 \\
\hline $\mathrm{C}$ & -4.408520 & -0.144253 & 0.044161 \\
\hline $\mathrm{C}$ & -5.777732 & 0.254517 & 0.026584 \\
\hline $\mathrm{C}$ & -6.466467 & -0.922974 & 0.312772 \\
\hline $\mathrm{H}$ & -6.202467 & 1.231031 & -0.169478 \\
\hline $\mathrm{N}$ & -4.328254 & -1.479673 & 0.330108 \\
\hline $\mathrm{N}$ & -5.577598 & -1.950651 & 0.494938 \\
\hline $\mathrm{C}$ & -7.950474 & -1.157811 & 0.425388 \\
\hline $\mathrm{H}$ & -8.306019 & -1.856736 & -0.343214 \\
\hline-7 & -8.210854 & -1.591951 & 1.399120 \\
\hline $\mathrm{H}$ & -8.505608 & -0.219655 & 0.31158 \\
\hline
\end{tabular}




\section{Unbound 2api}

$\begin{array}{rrrr}\mathrm{C} & -1.721092 & 1.077400 & -0.258200 \\ \mathrm{C} & -1.766836 & 2.493495 & -0.402266 \\ \mathrm{C} & -0.590346 & 3.221645 & -0.513818 \\ \mathrm{H} & -2.726525 & 2.997220 & -0.410606 \\ \mathrm{C} & 0.593632 & 1.148219 & -0.364908 \\ \mathrm{C} & 0.637762 & 2.545212 & -0.483138 \\ \mathrm{H} & -0.621460 & 4.303754 & -0.618974 \\ \mathrm{H} & 1.585654 & 3.063916 & -0.550491 \\ \mathrm{C} & 1.880363 & 0.385778 & -0.354441 \\ \mathrm{C} & 4.122840 & 0.338423 & 0.117065 \\ \mathrm{C} & 4.118467 & -1.026832 & -0.233665 \\ \mathrm{~N} & -0.530993 & 0.431371 & -0.259687 \\ \mathrm{~N} & 2.986020 & 1.032022 & 0.058208 \\ \mathrm{~N} & 1.867177 & -0.894390 & -0.789196 \\ \mathrm{~N} & 2.996405 & -1.585243 & -0.718711 \\ \mathrm{C} & 5.373416 & 1.084028 & 0.587283 \\ \mathrm{C} & 6.631594 & 0.235454 & 0.298242 \\ \mathrm{H} & 6.885622 & 0.322422 & -0.765073 \\ \mathrm{H} & 7.478883 & 0.659495 & 0.850744 \\ \mathrm{C} & 6.455456 & -1.243117 & 0.662168 \\ \mathrm{C} & 5.342854 & -1.939348 & -0.153264 \\ \mathrm{H} & 6.225312 & -1.331530 & 1.730509 \\ \mathrm{H} & 7.398163 & -1.781604 & 0.506845 \\ \mathrm{C} & 5.483463 & 2.434004 & -0.150034 \\ \mathrm{H} & 4.613631 & 3.061195 & 0.054858 \\ \mathrm{H} & 6.385930 & 2.964198 & 0.175451 \\ \mathrm{H} & 5.546813 & 2.287160 & -1.233585 \\ \mathrm{C} & 5.226532 & 1.357666 & 2.103322 \\ \mathrm{H} & 6.079631 & 1.942908 & 2.465029 \\ \mathrm{H} & 4.309650 & 1.921006 & 2.295335 \\ \mathrm{H} & 5.176891 & 0.431582 & 2.683837 \\ \mathrm{C} & 5.823916 & -2.247522 & -1.591039 \\ \mathrm{H} & 6.666413 & -2.948320 & -1.567333 \\ \mathrm{H} & 5.011183 & -2.697649 & -2.166791 \\ \mathrm{H} & 6.146411 & -1.343561 & -2.117367 \\ \mathrm{C} & 4.959450 & -3.266346 & 0.534701 \\ \mathrm{H} & 4.178543 & -3.782790 & -0.026709 \\ \mathrm{H} & 5.837871 & -3.918609 & 0.606027 \\ \mathrm{H} & 4.582780 & -3.089128 & 1.547573 \\ \mathrm{C} & -2.956569 & 0.320772 & -0.101968 \\ \mathrm{C} & -4.281674 & 0.813166 & -0.144522 \\ \mathrm{C} & -5.069417 & -0.325652 & 0.074237 \\ \mathrm{H} & -4.616853 & 1.827181 & -0.316218 \\ \mathrm{~N} & -2.977755 & -1.032986 & 0.132794 \\ & & & \end{array}$




$\begin{array}{lccc}\mathrm{N} & -4.250472 & -1.420571 & 0.240775 \\ \mathrm{C} & -6.525900 & -0.456823 & 0.137939 \\ \mathrm{C} & -7.389856 & 0.650803 & -0.025032 \\ \mathrm{C} & -7.124347 & -1.718356 & 0.368529 \\ \mathrm{C} & -8.779349 & 0.506715 & 0.038872 \\ \mathrm{H} & -6.964391 & 1.633904 & -0.203613 \\ \mathrm{C} & -8.512146 & -1.860687 & 0.432216 \\ \mathrm{H} & -6.465754 & -2.570898 & 0.493728 \\ \mathrm{C} & -9.357363 & -0.750639 & 0.268345 \\ \mathrm{H} & -9.416409 & 1.379182 & -0.090901 \\ \mathrm{H} & -8.942567 & -2.844055 & 0.610704 \\ \mathrm{H} & -10.437185 & -0.863145 & 0.317990\end{array}$

\section{Unbound 2bei}

$\begin{array}{lrrr}\mathrm{C} & 0.757790 & -2.425386 & -0.450128 \\ \mathrm{C} & 0.898534 & -3.798286 & -0.693611 \\ \mathrm{C} & 2.204981 & -4.307076 & -0.731673 \\ \mathrm{C} & 3.274685 & -3.448488 & -0.514515 \\ \mathrm{C} & 3.039271 & -2.069042 & -0.255004 \\ \mathrm{~N} & 1.778768 & -1.585009 & -0.238990 \\ \mathrm{H} & 2.378599 & -5.363050 & -0.924691 \\ \mathrm{H} & 0.025925 & -4.421347 & -0.841295 \\ \mathrm{H} & 4.292331 & -3.821696 & -0.533238 \\ \mathrm{C} & -0.603288 & -1.814387 & -0.405682 \\ \mathrm{C} & -1.922872 & 0.055281 & -0.262609 \\ \mathrm{C} & -2.014909 & 1.521401 & -0.508429 \\ \mathrm{C} & -3.012067 & -0.806130 & 0.053287 \\ \mathrm{C} & -0.888227 & 2.308046 & -0.241637 \\ \mathrm{C} & -3.165179 & 2.112982 & -1.073195 \\ \mathrm{C} & -4.337165 & -0.392315 & 0.583803 \\ \mathrm{C} & -0.912026 & 3.688401 & -0.499934 \\ \mathrm{C} & -4.455405 & 0.649494 & 1.516431 \\ \mathrm{C} & -3.169815 & 3.478384 & -1.345015 \\ \mathrm{C} & -5.484537 & -1.110044 & 0.192786 \\ \mathrm{C} & -2.055415 & 4.282194 & -1.056140 \\ \mathrm{C} & -5.713946 & 0.973356 & 2.037313 \\ \mathrm{C} & -6.737109 & -0.773807 & 0.715603 \\ \mathrm{H} & -2.089434 & 5.343856 & -1.270746 \\ \mathrm{C} & -6.856663 & 0.276964 & 1.642002 \\ \mathrm{H} & -7.837073 & 0.521544 & 2.037323 \\ \mathrm{~N} & -0.714452 & -0.481010 & -0.417739 \\ \mathrm{~N} & -1.670488 & -2.649576 & -0.403205 \\ \mathrm{~N} & -2.856442 & -2.132999 & -0.123001 \\ \mathrm{O} & -7.909693 & -1.415436 & 0.384219 \\ \mathrm{O} & 0.232786 & 4.366763 & -0.175456\end{array}$




$\begin{array}{rrrr}\mathrm{C} & 0.305468 & 5.750419 & -0.493273 \\ \mathrm{H} & 1.302597 & 6.071708 & -0.188197 \\ \mathrm{H} & 0.182958 & 5.922304 & -1.570833 \\ \mathrm{H} & -0.447901 & 6.332176 & 0.055547 \\ \mathrm{C} & -7.826096 & -2.511324 & -0.524350 \\ \mathrm{H} & -7.446957 & -2.193165 & -1.503728 \\ \mathrm{H} & -7.185242 & -3.310189 & -0.131731 \\ \mathrm{H} & -8.845768 & -2.885175 & -0.635700 \\ \mathrm{H} & -5.358421 & -1.929335 & -0.502293 \\ \mathrm{H} & -3.577120 & 1.197177 & 1.837355 \\ \mathrm{H} & -5.804152 & 1.776605 & 2.763232 \\ \mathrm{H} & -4.035131 & 1.511077 & -1.306079 \\ \mathrm{H} & 0.017545 & 1.852903 & 0.145119 \\ \mathrm{H} & -4.049114 & 3.935449 & -1.791008 \\ \mathrm{C} & 4.159052 & -1.167468 & -0.003353 \\ \mathrm{C} & 5.531543 & -1.473961 & -0.010289 \\ \mathrm{C} & 6.141424 & -0.247572 & 0.295435 \\ \mathrm{H} & 6.036384 & -2.409595 & -0.202432 \\ \mathrm{~N} & 3.986235 & 0.170824 & 0.293561 \\ \mathrm{~N} & 5.180479 & 0.725314 & 0.474539 \\ \mathrm{C} & 7.575058 & -0.014045 & 0.411662 \\ \mathrm{O} & 8.457622 & -0.864727 & 0.256407 \\ \mathrm{O} & 7.894613 & 1.286368 & 0.722410 \\ \mathrm{C} & 9.294518 & 1.543181 & 0.843144 \\ \mathrm{H} & 9.378216 & 2.604747 & 1.089542 \\ \mathrm{H} & 9.744085 & 0.933897 & 1.634706 \\ \mathrm{H} & 9.820708 & 1.328924 & -0.093420\end{array}$

Unbound 2bmi
$\begin{array}{llll}\text { C } & -1.722517 & -2.239657 & -0.392557\end{array}$
C $\quad-1.951943 \quad-3.597530 \quad-0.657826$
C $\quad-3.289587-4.023836 \quad-0.656963$
$\begin{array}{llll}\text { C } & -4.294931 & -3.107484 & -0.382852\end{array}$
$\begin{array}{llll}\text { C } & -3.972023 & -1.745769 & -0.102421\end{array}$
$\mathrm{N} \quad-2.679018 \quad-1.342365-0.127120$
$\mathrm{H} \quad-3.535168 \quad-5.062983 \quad-0.864764$
$\mathrm{H} \quad-1.124886 \quad-4.268539 \quad-0.849829$
$\mathrm{H} \quad-5.333464 \quad-3.418308 \quad-0.371273$
C $\quad-0.326236 \quad-1.714114-0.386376$
$\begin{array}{llll}\text { C } & 1.111507 & 0.067981 & -0.246601\end{array}$
$\begin{array}{llll}\text { C } & 1.285780 & 1.531196 & -0.466633\end{array}$
$\begin{array}{llll}\text { C } & 2.154518 & -0.863887 & 0.017710\end{array}$
$\begin{array}{llll}\text { C } & 0.217187 & 2.378682 & -0.151254\end{array}$
$\begin{array}{llll}\text { C } & 2.453571 & 2.064390 & -1.053205\end{array}$
$\begin{array}{llll}\text { C } & 3.517256 & -0.545239 & 0.517370\end{array}$ 


$\begin{array}{rrrr}\mathrm{C} & 0.318863 & 3.760317 & -0.382367 \\ \mathrm{C} & 3.728925 & 0.469568 & 1.463440 \\ \mathrm{C} & 2.534757 & 3.432579 & -1.297350 \\ \mathrm{C} & 4.605325 & -1.327303 & 0.082069 \\ \mathrm{C} & 1.480338 & 4.296122 & -0.959469 \\ \mathrm{C} & 5.019696 & 0.703009 & 1.952753 \\ \mathrm{C} & 5.890780 & -1.081714 & 0.574214 \\ \mathrm{H} & 1.573389 & 5.358275 & -1.153297 \\ \mathrm{C} & 6.104057 & -0.057785 & 1.513615 \\ \mathrm{H} & 7.108767 & 0.116254 & 1.884565 \\ \mathrm{~N} & -0.131614 & -0.389758 & -0.375607 \\ \mathrm{~N} & 0.689674 & -2.611638 & -0.438683 \\ \mathrm{~N} & 1.912310 & -2.174674 & -0.184641 \\ \mathrm{O} & 7.010150 & -1.791795 & 0.198577 \\ \mathrm{O} & -0.772797 & 4.500689 & -0.010929 \\ \mathrm{C} & -0.768322 & 5.891997 & -0.299634 \\ \mathrm{H} & -1.734730 & 6.267711 & 0.040468 \\ \mathrm{H} & 0.034656 & 6.415252 & 0.237897 \\ \mathrm{H} & -0.665333 & 6.079141 & -1.376815 \\ \mathrm{C} & 6.829460 & -2.864126 & -0.723559 \\ \mathrm{H} & 6.148431 & -3.625988 & -0.325009 \\ \mathrm{H} & 6.444837 & -2.505556 & -1.686747 \\ \mathrm{H} & 7.818868 & -3.301970 & -0.870015 \\ \mathrm{H} & 4.406825 & -2.124010 & -0.622268 \\ \mathrm{H} & 5.181493 & 1.485651 & 2.688777 \\ \mathrm{H} & -0.703775 & 1.970042 & 0.251689 \\ \mathrm{H} & 3.427645 & 3.845003 & -1.759707 \\ \mathrm{C} & -5.024470 & -0.794067 & 0.209094 \\ \mathrm{C} & -6.428010 & -1.033636 & 0.255322 \\ \mathrm{C} & -6.961771 & 0.207366 & 0.604569 \\ \mathrm{H} & -6.968755 & -1.952174 & 0.064486 \\ \mathrm{~N} & -4.773645 & 0.514812 & 0.517691 \\ \mathrm{~N} & -5.951042 & 1.120841 & 0.758196 \\ \mathrm{C} & -8.396905 & 0.617125 & 0.812252 \\ \mathrm{H} & -8.880622 & 0.045803 & 1.616438 \\ \mathrm{H} & -8.426301 & 1.677161 & 1.083833 \\ \mathrm{H} & -9.003915 & 0.480584 & -0.093319 \\ \mathrm{H} & 2.896864 & 1.066101 & 1.818572 \\ \mathrm{H} & 3.277871 & 1.415746 & -1.323744\end{array}$

\section{Unbound 2bpi}
$\begin{array}{llll}\text { C } & 0.348749 & -2.421694 & -0.479797\end{array}$
$\begin{array}{llll}\text { C } & 0.487872 & -3.794508 & -0.728317\end{array}$
$\begin{array}{llll}\text { C } & 1.795141 & -4.300702 & -0.778407\end{array}$
$\begin{array}{llll}\text { C } & 2.865275 & -3.441414 & -0.567420\end{array}$ 


\begin{tabular}{|c|c|c|c|}
\hline $\mathrm{C}$ & 2.632417 & -2.061567 & -0.3 \\
\hline V & 1.369167 & -1.580444 & -0.274884 \\
\hline & 1.968770 & -5.355955 & -0.975938 \\
\hline & -0.385116 & -4.418221 & -0.870311 \\
\hline [ & 3.882657 & -3.814677 & -0.595459 \\
\hline & -1.012642 & -1.812437 & -0.422875 \\
\hline$C$ & -2.333665 & 0.055634 & -0.269009 \\
\hline $\mathrm{C}$ & -2.431140 & 1.520908 & -0.5 \\
\hline$c$ & -3.417599 & -0.806390 & 0.0 \\
\hline $\mathrm{C}$ & -1.302538 & 2.310406 & -0.26 \\
\hline $\mathrm{C}$ & -3.589529 & 2.108817 & -1.070193 \\
\hline $\mathrm{C}$ & -4.736688 & -0.393498 & 0.608272 \\
\hline $\mathrm{C}$ & -1.332264 & 3.689853 & -0.530744 \\
\hline$C$ & -4.845283 & 0.650503 & 1.5 \\
\hline $\mathrm{C}$ & -3.600277 & 3.473362 & -1.34 \\
\hline $\mathrm{C}$ & -5.887678 & -1.114093 & 0.2 \\
\hline $\mathrm{C}$ & -2.483728 & 4.280023 & -1.073929 \\
\hline $\mathrm{C}$ & -6.097833 & 0.973678 & \\
\hline $\mathrm{C}$ & -7.134219 & -0.778668 & 0.77 \\
\hline $\mathrm{H}$ & -2.522491 & 5.340951 & -1.2 \\
\hline $\mathrm{C}$ & -7.244207 & 0.274334 & 923 \\
\hline $\mathrm{H}$ & -8.220063 & 0.518270 & \\
\hline $\mathrm{N}$ & -1.126314 & -0.479156 & -0.4 \\
\hline $\mathrm{N}$ & -2.078944 & -2.648948 & -0.4 \\
\hline $\mathrm{N}$ & -3.262188 & -2.133455 & -0.1 \\
\hline $\mathrm{O}$ & -8.309756 & -1.423293 & 0.45 \\
\hline $\mathrm{O}$ & -0.184467 & 4.371785 & -0.22 \\
\hline $\mathrm{C}$ & -0.120319 & 5.754983 & -0.54 \\
\hline $\mathrm{H}$ & 0.879572 & 6.080258 & -0.253029 \\
\hline $\mathrm{H}$ & -0.257228 & 5.924581 & -1.620859 \\
\hline $\mathrm{H}$ & -0.868392 & 6.335464 & 693 \\
\hline $\mathrm{C}$ & -8.235290 & -2.521617 & -0.4 \\
\hline $\mathrm{H}$ & -7.868914 & -2.205614 & -1.435547 \\
\hline $\mathrm{H}$ & -7.588037 & -3.318119 & -0.063731 \\
\hline $\mathrm{H}$ & -9.255541 & -2.897753 & -0.548264 \\
\hline $\mathrm{H}$ & -5.768707 & -1.934982 & -0.461057 \\
\hline $\mathrm{H}$ & -3.963991 & 1.200376 & 1.848391 \\
\hline $\mathrm{H}$ & -6.180402 & 1.778670 & 2.800109 \\
\hline $\mathrm{H}$ & -4.461258 & 1.504611 & -1.290107 \\
\hline $\mathrm{H}$ & -0.391263 & 1.857745 & 0.108294 \\
\hline $\mathrm{H}$ & -4.486090 & 3.927486 & -1.782036 \\
\hline $\mathrm{C}$ & 3.750578 & -1.160841 & -0.055233 \\
\hline $\mathrm{C}$ & 5.130784 & -1.466967 & -0.073151 \\
\hline $\mathrm{C}$ & 5.748558 & -0.246107 & 0.232815 \\
\hline $\mathrm{H}$ & 5.605605 & -2.417102 & -0.277643 \\
\hline $\mathrm{N}$ & 3.579296 & 0.168775 & 0.247100 \\
\hline
\end{tabular}




$\begin{array}{cccc}\mathrm{N} & 4.783431 & 0.718131 & 0.421344 \\ \mathrm{C} & 7.171059 & 0.076007 & 0.359730 \\ \mathrm{C} & 8.182507 & -0.892916 & 0.166047 \\ \mathrm{C} & 7.584032 & 1.389581 & 0.685772 \\ \mathrm{C} & 9.536692 & -0.567487 & 0.291661 \\ \mathrm{H} & 7.901014 & -1.911081 & -0.085842 \\ \mathrm{C} & 8.936823 & 1.713168 & 0.810902 \\ \mathrm{H} & 6.811714 & 2.136185 & 0.835204 \\ \mathrm{C} & 9.930153 & 0.739340 & 0.615620 \\ \mathrm{H} & 10.290588 & -1.336404 & 0.136200 \\ \mathrm{H} & 9.223340 & 2.732235 & 1.062914 \\ \mathrm{H} & 10.982451 & 0.992677 & 0.713446\end{array}$

\section{$\left[\mathrm{M}\left(\mathrm{H}_{2} \mathrm{O}\right){ }_{9}\right]^{3+}$}

$\mathrm{M}=\mathrm{Eu}$

$\begin{array}{lrrr}\text { EU } & -0.000037 & -0.006359 & 0.000222 \\ \mathrm{O} & -1.806107 & -1.698552 & 0.279507 \\ \mathrm{H} & -2.688036 & -1.709881 & -0.134614 \\ \mathrm{H} & -1.794427 & -2.435483 & 0.916838 \\ \mathrm{O} & -1.964056 & 0.851340 & -1.294969 \\ \mathrm{H} & -2.141350 & 0.665392 & -2.234765 \\ \mathrm{H} & -2.725163 & 1.369606 & -0.976524 \\ \mathrm{O} & -1.555409 & 0.913785 & 1.711992 \\ \mathrm{H} & -1.554727 & 1.837563 & 2.021664 \\ \mathrm{H} & -2.320794 & 0.486561 & 2.137433 \\ \mathrm{O} & 0.295502 & -1.270845 & 2.154950 \\ \mathrm{H} & 0.863958 & -2.050361 & 2.290225 \\ \mathrm{H} & -0.112150 & -1.078575 & 3.018747 \\ \mathrm{O} & -0.295675 & -1.343179 & -2.111204 \\ \mathrm{H} & -0.866681 & -2.124962 & -2.220088 \\ \mathrm{H} & 0.112369 & -1.181492 & -2.981073 \\ \mathrm{O} & 1.556626 & 0.856719 & -1.740051 \\ \mathrm{H} & 1.555670 & 1.769262 & -2.081446 \\ \mathrm{H} & 2.321826 & 0.415206 & -2.150990 \\ \mathrm{O} & 1.966573 & 0.890907 & 1.263651 \\ \mathrm{H} & 2.727189 & 1.398007 & 0.926653 \\ \mathrm{H} & 2.145698 & 0.735902 & 2.208705 \\ \mathrm{O} & 1.802860 & -1.709518 & -0.224284 \\ \mathrm{H} & 1.788927 & -2.466086 & -0.838105 \\ \mathrm{H} & 2.684872 & -1.710175 & 0.189818 \\ \mathrm{O} & 0.000158 & 2.538151 & -0.040356 \\ \mathrm{H} & -0.592953 & 3.116967 & -0.552290 \\ \mathrm{H} & 0.594330 & 3.132709 & 0.451934\end{array}$




$\begin{array}{cccc}\mathrm{M}=\mathrm{Gd} & & & \\ \mathrm{O} & 0.000000 & 2.532717 & 0.000195 \\ \mathrm{H} & -0.566164 & 3.120719 & -0.530559 \\ \mathrm{O} & -2.193397 & -1.266358 & 0.000195 \\ \mathrm{H} & -2.419540 & -2.050672 & -0.530559 \\ \mathrm{O} & 2.193397 & -1.266358 & 0.000195 \\ \mathrm{H} & 2.985704 & -1.070047 & -0.530559 \\ \mathrm{H} & 2.419423 & -2.051237 & 0.530174 \\ \mathrm{H} & 0.566712 & 3.120900 & 0.530174 \\ \mathrm{H} & -2.986135 & -1.069663 & 0.530174 \\ \mathrm{O} & -0.003541 & -1.741029 & -1.791818 \\ \mathrm{H} & -0.542328 & -1.770067 & -2.602278 \\ \mathrm{O} & 1.509546 & 0.867448 & -1.791818 \\ \mathrm{H} & 1.877360 & 1.767719 & -1.843357 \\ \mathrm{O} & -1.506005 & 0.873581 & -1.791818 \\ \mathrm{H} & -1.261759 & 1.354704 & -2.602278 \\ \mathrm{H} & 0.592210 & -2.509701 & -1.843357 \\ \mathrm{H} & -2.469570 & 0.741981 & -1.843357 \\ \mathrm{H} & 1.804088 & 0.415363 & -2.602278 \\ \mathrm{O} & 0.002026 & -1.741134 & 1.791515 \\ \mathrm{H} & 0.540573 & -1.771380 & 2.602092 \\ \mathrm{O} & -1.508880 & 0.868813 & 1.791515 \\ \mathrm{H} & -1.804346 & 0.417540 & 2.602092 \\ \mathrm{O} & 1.506854 & 0.872322 & 1.791515 \\ \mathrm{H} & 1.263774 & 1.353839 & 2.602092 \\ \mathrm{H} & 2.470224 & 0.739148 & 1.842545 \\ \mathrm{H} & -1.875233 & 1.769702 & 1.842545 \\ \mathrm{H} & -0.594991 & -2.508851 & 1.842545 \\ \mathrm{GD} & 0.000000 & 0.000000 & 0.000105\end{array}$

$\mathrm{M}=\mathrm{Am}$

$\begin{array}{lrrr}\text { AM } & -0.000031 & -0.005259 & 0.000184 \\ \mathrm{O} & -1.806102 & -1.697451 & 0.279469 \\ \mathrm{H} & -2.688031 & -1.708779 & -0.134652 \\ \mathrm{H} & -1.794423 & -2.434382 & 0.916800 \\ \mathrm{O} & -1.964049 & 0.852442 & -1.295007 \\ \mathrm{H} & -2.141343 & 0.666494 & -2.234803 \\ \mathrm{H} & -2.725155 & 1.370708 & -0.976562 \\ \mathrm{O} & -1.555402 & 0.914887 & 1.711954 \\ \mathrm{H} & -1.554719 & 1.838665 & 2.021626 \\ \mathrm{H} & -2.320788 & 0.487663 & 2.137395 \\ \mathrm{O} & 0.295507 & -1.269746 & 2.154912 \\ \mathrm{H} & 0.863962 & -2.049262 & 2.290187 \\ \mathrm{H} & -0.112145 & -1.077475 & 3.018709\end{array}$




$\begin{array}{rrrr}\mathrm{O} & -0.295670 & -1.342079 & -2.111242 \\ \mathrm{H} & -0.866677 & -2.123861 & -2.220126 \\ \mathrm{H} & 0.112374 & -1.180392 & -2.981111 \\ \mathrm{O} & 1.556633 & 0.857818 & -1.740089 \\ \mathrm{H} & 1.555678 & 1.770361 & -2.081484 \\ \mathrm{H} & 2.321833 & 0.416303 & -2.151028 \\ \mathrm{O} & 1.966580 & 0.892005 & 1.263613 \\ \mathrm{H} & 2.727197 & 1.399104 & 0.926615 \\ \mathrm{H} & 2.145705 & 0.737000 & 2.208667 \\ \mathrm{O} & 1.802865 & -1.708420 & -0.224322 \\ \mathrm{H} & 1.788931 & -2.464988 & -0.838143 \\ \mathrm{H} & 2.684877 & -1.709077 & 0.189780 \\ \mathrm{O} & 0.000166 & 2.539251 & -0.040394 \\ \mathrm{H} & -0.592943 & 3.118068 & -0.552328 \\ \mathrm{H} & 0.594340 & 3.133809 & 0.451896\end{array}$

$\mathrm{M}=\mathrm{Cm}$

$\begin{array}{lrrc}\mathrm{CM} & 0.000000 & 0.000000 & 0.000318 \\ \mathrm{O} & 0.000000 & 2.570555 & 0.000401 \\ \mathrm{H} & -0.562171 & 3.156976 & -0.536199 \\ \mathrm{O} & -2.226166 & -1.285278 & 0.000401 \\ \mathrm{H} & -2.452936 & -2.065342 & -0.536199 \\ \mathrm{O} & 2.226166 & -1.285278 & 0.000401 \\ \mathrm{H} & 3.015106 & -1.091634 & -0.536199 \\ \mathrm{H} & 2.453874 & -2.066920 & 0.534330 \\ \mathrm{H} & 0.563068 & 3.158577 & 0.534330 \\ \mathrm{H} & -3.016942 & -1.091657 & 0.534330 \\ \mathrm{O} & -0.006167 & -1.767596 & -1.838656 \\ \mathrm{H} & -0.549492 & -1.790418 & -2.646284 \\ \mathrm{O} & 1.533867 & 0.878457 & -1.838656 \\ \mathrm{H} & 1.907056 & 1.776171 & -1.895323 \\ \mathrm{O} & -1.527699 & 0.889139 & -1.838656 \\ \mathrm{H} & -1.275802 & 1.371083 & -2.646284 \\ \mathrm{H} & 0.584681 & -2.539645 & -1.895323 \\ \mathrm{H} & -2.491737 & 0.763474 & -1.895323 \\ \mathrm{H} & 1.825293 & 0.419335 & -2.646284 \\ \mathrm{O} & 0.002580 & -1.768108 & 1.837620 \\ \mathrm{H} & 0.545279 & -1.794687 & 2.645552 \\ \mathrm{O} & -1.532517 & 0.881819 & 1.837620 \\ \mathrm{H} & -1.826884 & 0.425118 & 2.645552 \\ \mathrm{O} & 1.529936 & 0.886289 & 1.837620 \\ \mathrm{H} & 1.281605 & 1.369569 & 2.645552 \\ \mathrm{H} & 2.493398 & 0.755752 & 1.892819 \\ \mathrm{H} & -1.901200 & 1.781470 & 1.892819 \\ \mathrm{H} & -0.592198 & -2.537222 & 1.892819\end{array}$




\section{$\mathbf{L}=$ Core 1}

\section{$\left[\mathrm{ML}\left(\mathrm{H}_{2} \mathrm{O}\right)_{6}\right]^{3+}$}

$\begin{array}{lrcc}\mathrm{M}=\mathrm{Eu} & & & \\ \mathrm{EU} & -0.889368 & -1.274364 & -0.168296 \\ \mathrm{~N} & -0.166181 & 1.663636 & 0.157846 \\ \mathrm{C} & 1.042036 & 2.286551 & 0.125808 \\ \mathrm{C} & -1.254167 & 2.466126 & 0.270369 \\ \mathrm{C} & 1.191938 & 3.686324 & 0.198971 \\ \mathrm{C} & 2.297459 & 1.520469 & 0.032968 \\ \mathrm{C} & -1.179560 & 3.864448 & 0.395058 \\ \mathrm{C} & -2.631132 & 1.876061 & 0.201520 \\ \mathrm{C} & 0.065622 & 4.488141 & 0.357839 \\ \mathrm{H} & 2.179345 & 4.132170 & 0.175132 \\ \mathrm{C} & 3.492467 & 1.951789 & -0.636184 \\ \mathrm{~N} & 2.550803 & 0.333174 & 0.633705 \\ \mathrm{H} & -2.093516 & 4.434349 & 0.502034 \\ \mathrm{~N} & -3.658696 & 2.732065 & 0.391846 \\ \mathrm{~N} & -2.777875 & 0.576626 & -0.078310 \\ \mathrm{H} & 0.154384 & 5.566641 & 0.445934 \\ \mathrm{C} & 4.480505 & 0.987113 & -0.402293 \\ \mathrm{H} & 3.587849 & 2.853412 & -1.226834 \\ \mathrm{C} & 3.895007 & -0.027688 & 0.418552 \\ \mathrm{H} & 1.914951 & -0.152837 & 1.268627 \\ \mathrm{C} & -4.877045 & 2.241704 & 0.259099 \\ \mathrm{~N} & -4.020100 & 0.082052 & -0.252666 \\ \mathrm{C} & 5.855330 & 0.891192 & -0.782701 \\ \mathrm{C} & 4.627704 & -1.096508 & 0.892665 \\ \mathrm{C} & -5.063965 & 0.883908 & -0.100451 \\ \mathrm{H} & -5.722143 & 2.907050 & 0.424782 \\ \mathrm{C} & 6.597492 & -0.193023 & -0.315811 \\ \mathrm{H} & 6.311618 & 1.653750 & -1.406803 \\ \mathrm{C} & 6.000704 & -1.163807 & 0.509646 \\ \mathrm{H} & 4.211554 & -1.856782 & 1.545725 \\ \mathrm{H} & -6.048462 & 0.454928 & -0.261674 \\ \mathrm{H} & 7.646174 & -0.287545 & -0.577399 \\ \mathrm{H} & 6.602076 & -1.990815 & 0.875873 \\ \mathrm{O} & 0.534091 & -1.164944 & 2.174741 \\ \mathrm{H} & 0.418743 & -0.772737 & 3.056514 \\ \mathrm{H} & 0.637943 & -2.127230 & 2.309854 \\ \mathrm{O} & -3.024744 & -2.359244 & -1.100620 \\ \mathrm{H} & -3.400575 & -3.100587 & -1.600079 \\ \mathrm{H} & -3.728791 & -1.680298 & -0.968060\end{array}$




$\begin{array}{lrrr}\mathrm{O} & -0.966001 & -0.511907 & -2.792066 \\ \mathrm{H} & -0.750146 & 0.332444 & -3.220045 \\ \mathrm{H} & -1.632992 & -0.920408 & -3.369010 \\ \mathrm{O} & -0.163295 & -3.634065 & 1.042551 \\ \mathrm{H} & 0.281607 & -4.465194 & 0.808370 \\ \mathrm{H} & -0.958209 & -3.888051 & 1.545274 \\ \mathrm{O} & -2.523350 & -2.295387 & 1.826437 \\ \mathrm{H} & -2.716683 & -2.090994 & 2.755959 \\ \mathrm{H} & -3.347901 & -2.666380 & 1.470122 \\ \mathrm{O} & 1.035871 & -2.160924 & -1.672325 \\ \mathrm{H} & 1.707056 & -2.859780 & -1.709191 \\ \mathrm{H} & 0.897732 & -1.868046 & -2.589499\end{array}$

$\mathrm{M}=\mathrm{Gd}$

$\begin{array}{lrrr}\mathrm{C} & 3.275045 & 0.208809 & 0.257660 \\ \mathrm{C} & 3.791917 & 1.333175 & -0.422245 \\ \mathrm{C} & 5.114567 & 1.326511 & -0.899280 \\ \mathrm{C} & 5.897638 & 0.194314 & -0.660234 \\ \mathrm{C} & 5.382953 & -0.905469 & 0.052844 \\ \mathrm{C} & 4.058107 & -0.914428 & 0.526252 \\ \mathrm{C} & 1.653956 & 1.837825 & 0.193217 \\ \mathrm{C} & 2.754031 & 2.341588 & -0.434665 \\ \mathrm{H} & 5.525907 & 2.184475 & -1.421617 \\ \mathrm{H} & 6.925991 & 0.167254 & -1.006010 \\ \mathrm{H} & 6.027286 & -1.754457 & 0.258610 \\ \mathrm{H} & 3.709767 & -1.741141 & 1.138947 \\ \mathrm{H} & 2.825581 & 3.313702 & -0.907256 \\ \mathrm{C} & 0.311417 & 2.394924 & 0.303645 \\ \mathrm{C} & 0.093177 & 3.783812 & 0.438060 \\ \mathrm{C} & -1.207977 & 4.270625 & 0.479404 \\ \mathrm{H} & 0.939590 & 4.455522 & 0.530187 \\ \mathrm{C} & -1.991292 & 2.016901 & 0.204234 \\ \mathrm{C} & -2.280713 & 3.369852 & 0.345947 \\ \mathrm{H} & -1.396325 & 5.333513 & 0.600603 \\ \mathrm{H} & -3.310840 & 3.706276 & 0.331005 \\ \mathrm{C} & -3.060078 & 1.039960 & -0.107069 \\ \mathrm{C} & -5.233747 & 0.579573 & -0.561332 \\ \mathrm{C} & -4.835673 & -0.735859 & -0.931495 \\ \mathrm{H} & -6.277717 & 0.885422 & -0.603869 \\ \mathrm{H} & -5.539561 & -1.471559 & -1.309312 \\ \mathrm{~N} & 1.894496 & 0.463717 & 0.623697 \\ \mathrm{~N} & -0.722377 & 1.519380 & 0.219474 \\ \mathrm{~N} & -4.337623 & 1.465585 & -0.164710 \\ \mathrm{~N} & -2.665649 & -0.213971 & -0.379752 \\ \mathrm{~N} & -3.570587 & -1.107429 & -0.819991\end{array}$




$\begin{array}{lrrr}\mathrm{O} & 0.855782 & -2.693785 & 1.479449 \\ \mathrm{H} & 1.702330 & -3.162240 & 1.400441 \\ \mathrm{O} & -0.331982 & -0.240594 & 2.546379 \\ \mathrm{H} & -0.011820 & -0.759729 & 3.303727 \\ \mathrm{O} & -1.425148 & -2.673157 & -1.230920 \\ \mathrm{H} & -1.254669 & -3.382321 & -1.870914 \\ \mathrm{O} & -1.845959 & -2.432115 & 1.554136 \\ \mathrm{H} & -2.352252 & -3.175717 & 1.185086 \\ \mathrm{O} & 1.655273 & -1.990135 & -1.244950 \\ \mathrm{H} & 1.767068 & -2.827892 & -1.724380 \\ \mathrm{O} & 0.002776 & 0.008637 & -2.205697 \\ \mathrm{H} & 0.585171 & -0.387387 & -2.874742 \\ \mathrm{H} & 0.259965 & -3.277447 & 1.980159 \\ \mathrm{H} & -2.320273 & -2.159433 & 2.356955 \\ \mathrm{H} & 2.559888 & -1.643313 & -1.084939 \\ \mathrm{H} & -2.381460 & -2.405843 & -1.309844 \\ \mathrm{H} & -0.396910 & 0.793168 & -2.613623 \\ \mathrm{H} & 1.781136 & 0.397714 & 1.639768 \\ \mathrm{H} & -0.680840 & 0.586058 & 2.919889 \\ \mathrm{GD} & -0.257824 & -0.957017 & 0.044270\end{array}$

$\mathrm{M}=\mathrm{Am}$

$\begin{array}{lrrr}\text { AM } & -0.257287 & -0.869658 & 0.032244 \\ \text { N } & -0.674325 & 1.634515 & 0.221206 \\ \text { C } & 0.376288 & 2.491248 & 0.303863 \\ \text { C } & -1.934369 & 2.155101 & 0.207597 \\ \text { C } & 0.180710 & 3.883714 & 0.438314 \\ \text { C } & 1.714800 & 1.924334 & 0.194040 \\ \text { C } & -2.198491 & 3.512362 & 0.351479 \\ \text { C } & -3.026551 & 1.204631 & -0.100752 \\ \text { C } & -1.110313 & 4.394287 & 0.483036 \\ \text { H } & 1.039384 & 4.539761 & 0.529018 \\ \text { C } & 2.815561 & 2.425432 & -0.438223 \\ \text { N } & 1.958729 & 0.558607 & 0.632179 \\ \text { H } & -3.222588 & 3.866625 & 0.340767 \\ \text { N } & -4.294211 & 1.660255 & -0.143058 \\ \text { N } & -2.666375 & -0.057238 & -0.383992 \\ \text { H } & -1.279366 & 5.460191 & 0.605539 \\ \text { C } & 3.853236 & 1.417895 & -0.417184 \\ \text { H } & 2.886237 & 3.392979 & -0.920122 \\ \text { C } & 3.334358 & 0.298576 & 0.270264 \\ \text { H } & 1.827869 & 0.482988 & 1.644826 \\ \text { C } & -5.215847 & 0.798468 & -0.534203 \\ \text { N } & -3.597494 & -0.928270 & -0.815727 \\ \text { C } & 5.176781 & 1.404697 & -0.893312\end{array}$




$\begin{array}{crrr}\mathrm{C} & 4.112681 & -0.826619 & 0.544759 \\ \mathrm{C} & -4.853896 & -0.524907 & -0.911722 \\ \mathrm{H} & -6.252156 & 1.130461 & -0.564856 \\ \mathrm{C} & 5.956250 & 0.272779 & -0.645127 \\ \mathrm{H} & 5.590714 & 2.257395 & -1.422095 \\ \mathrm{C} & 5.437504 & -0.822579 & 0.073549 \\ \mathrm{H} & 3.754847 & -1.650884 & 1.155854 \\ \mathrm{H} & -5.579619 & -1.242675 & -1.282614 \\ \mathrm{H} & 6.985127 & 0.240857 & -0.988872 \\ \mathrm{H} & 6.079684 & -1.672166 & 0.283460 \\ \mathrm{O} & -0.198506 & -0.184981 & 2.623040 \\ \mathrm{H} & -0.520268 & 0.630388 & 3.043579 \\ \mathrm{H} & 0.127700 & -0.744400 & 3.348766 \\ \mathrm{O} & -1.511717 & -2.595093 & -1.277132 \\ \mathrm{H} & -1.366970 & -3.302910 & -1.925154 \\ \mathrm{H} & -2.456024 & -2.297838 & -1.347409 \\ \mathrm{O} & 0.057262 & 0.101713 & -2.275167 \\ \mathrm{H} & -0.359184 & 0.851700 & -2.729383 \\ \mathrm{H} & 0.706613 & -0.273200 & -2.892884 \\ \mathrm{O} & 0.818637 & -2.782324 & 1.388850 \\ \mathrm{H} & 1.634000 & -3.291240 & 1.250167 \\ \mathrm{H} & 0.234337 & -3.339872 & 1.930326 \\ \mathrm{O} & -1.889969 & -2.280765 & 1.584213 \\ \mathrm{H} & -2.311672 & -1.997855 & 2.412342 \\ \mathrm{H} & -2.449334 & -2.990368 & 1.225100 \\ \mathrm{O} & 1.735639 & -1.914711 & -1.291298 \\ \mathrm{H} & 1.845329 & -2.728097 & -1.811624 \\ \mathrm{H} & 2.640408 & -1.586611 & -1.100473\end{array}$

$\mathrm{M}=\mathrm{Cm}$

$\begin{array}{lrrr}\mathrm{C} & 3.319269 & 0.308675 & 0.255043 \\ \mathrm{C} & 3.838042 & 1.431200 & -0.426108 \\ \mathrm{C} & 5.159495 & 1.418760 & -0.906706 \\ \mathrm{C} & 5.938020 & 0.283272 & -0.669777 \\ \mathrm{C} & 5.420359 & -0.815389 & 0.043624 \\ \mathrm{C} & 4.096994 & -0.819319 & 0.519739 \\ \mathrm{C} & 1.703299 & 1.942270 & 0.196212 \\ \mathrm{C} & 2.802784 & 2.442797 & -0.435873 \\ \mathrm{H} & 5.573406 & 2.274569 & -1.430484 \\ \mathrm{H} & 6.965488 & 0.252031 & -1.017822 \\ \mathrm{H} & 6.061656 & -1.667407 & 0.246338 \\ \mathrm{H} & 3.742533 & -1.645186 & 1.130548 \\ \mathrm{H} & 2.874852 & 3.413650 & -0.910998 \\ \mathrm{C} & 0.363933 & 2.507821 & 0.312321 \\ \mathrm{C} & 0.160922 & 3.897718 & 0.456434\end{array}$




$\begin{array}{lccc}\mathrm{C} & -1.134572 & 4.398586 & 0.502651 \\ \mathrm{H} & 1.014605 & 4.559539 & 0.552612 \\ \mathrm{C} & -1.942950 & 2.155462 & 0.211242 \\ \mathrm{C} & -2.216793 & 3.510615 & 0.362953 \\ \mathrm{H} & -1.311218 & 5.462483 & 0.631972 \\ \mathrm{H} & -3.242838 & 3.859078 & 0.351236 \\ \mathrm{C} & -3.028326 & 1.197964 & -0.107261 \\ \mathrm{C} & -5.213045 & 0.783616 & -0.556276 \\ \mathrm{C} & -4.842464 & -0.535471 & -0.940111 \\ \mathrm{H} & -6.250855 & 1.110495 & -0.591225 \\ \mathrm{H} & -5.562434 & -1.254243 & -1.320186 \\ \mathrm{~N} & 1.943664 & 0.570084 & 0.626391 \\ \mathrm{~N} & -0.679775 & 1.644882 & 0.223187 \\ \mathrm{~N} & -4.298253 & 1.647897 & -0.154316 \\ \mathrm{~N} & -2.660087 & -0.060508 & -0.395339 \\ \mathrm{~N} & -3.584685 & -0.933166 & -0.838547 \\ \mathrm{CM} & -0.237543 & -0.868689 & 0.035056 \\ \mathrm{O} & 0.857515 & -2.703543 & 1.466347 \\ \mathrm{H} & 1.689661 & -3.195132 & 1.372865 \\ \mathrm{O} & -0.239458 & -0.177882 & 2.604739 \\ \mathrm{H} & 0.078431 & -0.732225 & 3.337895 \\ \mathrm{O} & -1.496024 & -2.599582 & -1.247786 \\ \mathrm{H} & -1.350041 & -3.308411 & -1.894250 \\ \mathrm{O} & -1.867924 & -2.329103 & 1.571755 \\ \mathrm{H} & -2.395244 & -3.052389 & 1.192072 \\ \mathrm{O} & 1.712009 & -1.918143 & -1.284474 \\ \mathrm{H} & 1.813565 & -2.748609 & -1.778793 \\ \mathrm{O} & 0.022680 & 0.086301 & -2.275221 \\ \mathrm{H} & 0.642441 & -0.293511 & -2.919712 \\ \mathrm{H} & 0.252032 & -3.276393 & 1.967509 \\ \mathrm{H} & -2.323627 & -2.062935 & 2.387389 \\ \mathrm{H} & 2.619336 & -1.588623 & -1.107307 \\ \mathrm{H} & -2.436904 & -2.288826 & -1.331884 \\ \mathrm{H} & -0.404909 & 0.841671 & -2.709808 \\ \mathrm{H} & 1.825850 & 0.498013 & 1.641455 \\ \mathrm{H} & -0.577926 & 0.636367 & 3.014015\end{array}$

\section{$\left[\mathrm{ML}\left(\mathrm{H}_{2} \mathrm{O}\right)_{5}\right]^{3+}$}

$\mathrm{M}=\mathrm{Eu}$

$$
\begin{array}{llll}
\text { EU } & -0.936387 & -1.335731 & 0.330804 \\
\mathrm{O} & -2.435185 & -1.487792 & 2.473346 \\
\mathrm{H} & -3.207816 & -2.078022 & 2.476713 \\
\mathrm{O} & -2.952122 & -2.567991 & -0.545024 \\
\mathrm{H} & -3.356086 & -3.437182 & -0.689299
\end{array}
$$




\begin{tabular}{rrrr}
$\mathrm{O}$ & 0.074927 & -3.713106 & -0.103956 \\
$\mathrm{H}$ & -0.297487 & -4.430152 & -0.643616 \\
$\mathrm{O}$ & 0.649344 & -1.697938 & 2.400454 \\
$\mathrm{H}$ & 0.245841 & -2.086565 & 3.195192 \\
$\mathrm{O}$ & 0.138144 & -1.124568 & -2.154757 \\
$\mathrm{H}$ & 0.424065 & -1.931640 & -2.616566 \\
$\mathrm{H}$ & 0.724045 & -4.147915 & 0.473633 \\
$\mathrm{H}$ & -0.290392 & -0.584938 & -2.841707 \\
$\mathrm{H}$ & -2.517124 & -0.963493 & 3.286988 \\
$\mathrm{H}$ & -3.582931 & -1.880952 & -0.879546 \\
$\mathrm{H}$ & 1.576870 & -1.543709 & 2.640589 \\
$\mathrm{C}$ & 3.759483 & 0.041686 & -0.747284 \\
$\mathrm{C}$ & 4.454364 & 0.856737 & 0.203746 \\
$\mathrm{C}$ & 5.868662 & 0.711432 & 0.370294 \\
$\mathrm{C}$ & 6.535718 & -0.217763 & -0.423629 \\
$\mathrm{C}$ & 5.828383 & -0.991618 & -1.364937 \\
$\mathrm{C}$ & 4.417988 & -0.874352 & -1.542260 \\
$\mathrm{C}$ & 2.239816 & 1.429640 & 0.188401 \\
$\mathrm{C}$ & 3.514226 & 1.717886 & 0.781510 \\
$\mathrm{H}$ & 6.406917 & 1.324283 & 1.087210 \\
$\mathrm{H}$ & 7.609381 & -0.343304 & -0.330455 \\
$\mathrm{H}$ & 6.371920 & -1.699236 & -1.984443 \\
$\mathrm{H}$ & 3.916679 & -1.478879 & -2.291005 \\
$\mathrm{H}$ & 1.684771 & 0.079022 & -1.340058 \\
$\mathrm{H}$ & 3.701809 & 2.463328 & 1.542624 \\
$\mathrm{C}$ & 0.980577 & 2.150215 & 0.390975 \\
$\mathrm{C}$ & 1.054824 & 3.470864 & 0.876749 \\
$\mathrm{C}$ & -0.102270 & 4.246200 & 0.926139 \\
$\mathrm{H}$ & 2.006799 & 3.900876 & 1.163659 \\
$\mathrm{C}$ & -1.293857 & 2.344127 & 0.038297 \\
$\mathrm{C}$ & -1.293187 & 3.682544 & 0.470578 \\
$\mathrm{H}$ & -0.070713 & 5.271427 & 1.282290 \\
$\mathrm{H}$ & -2.214155 & 4.251654 & 0.440219 \\
$\mathrm{C}$ & -2.591974 & 1.777635 & -0.446928 \\
$\mathrm{C}$ & -4.699994 & 2.171982 & -1.197385 \\
$\mathrm{C}$ & -4.853585 & 0.773322 & -1.368303 \\
$\mathrm{H}$ & -5.504239 & 2.864650 & -1.437711 \\
$\mathrm{H}$ & -5.767172 & 0.330610 & -1.753804 \\
& 2.401645 & 0.409683 & -0.696191 \\
$\mathrm{~N}$ & -0.189118 & 1.564206 & 0.017591 \\
$\mathrm{~N}$ & -36699 & 2.666182 & -0.729511 \\
& & -0.450934 & -0.570978 \\
\hline
\end{tabular}

$\mathrm{M}=\mathrm{Gd}$ 


\begin{tabular}{|c|c|c|c|}
\hline GD & -0.257366 & -0.942636 & 36723 \\
\hline $\mathrm{O}$ & -1.306673 & -1.382463 & 2.426417 \\
\hline $\mathrm{H}$ & -1.900217 & -2.133342 & 2.600316 \\
\hline J & -1.566158 & -2.963946 & 0.031345 \\
\hline $\mathrm{H}$ & -1.474015 & -3.926418 & -0.056446 \\
\hline ) & 1.538031 & -2.588131 & 0.032043 \\
\hline $\mathrm{H}$ & 1.598463 & -3.546306 & 0.188611 \\
\hline J & 1.177044 & -0.215976 & 2.105015 \\
\hline $\mathrm{H}$ & 1.448041 & -0.713198 & 2.895416 \\
\hline $\mathrm{O}$ & -0.311615 & -1.234372 & -2.250379 \\
\hline $\mathrm{H}$ & 0.018401 & -2.024242 & -2.712746 \\
\hline $\mathrm{H}$ & 2.460458 & -2.272881 & -0.089722 \\
\hline $\mathrm{H}$ & -0.891654 & -0.787960 & -2.890534 \\
\hline $\mathrm{H}$ & -1.289442 & -0.852850 & 3.242150 \\
\hline $\mathrm{H}$ & -2.512936 & -2.716341 & -0.182728 \\
\hline $\mathrm{H}$ & 1.79 & 0.53 & 2.019701 \\
\hline $\mathrm{C}$ & 3.160371 & 0.154065 & -0.656467 \\
\hline $\mathrm{C}$ & 3.798899 & 1.13 & 0.13 \\
\hline $\mathrm{C}$ & 5.175642 & 1.031447 & 0.414609 \\
\hline $\mathrm{C}$ & 5.880679 & -0.040082 & -0.136700 \\
\hline $\mathrm{C}$ & 5.238678 & -0.983769 & -0.964329 \\
\hline $\mathrm{C}$ & 3.862461 & -0.90 & -1.242049 \\
\hline $\mathrm{C}$ & 1.616415 & 1.764426 & -0.100837 \\
\hline $\mathrm{C}$ & 2.805757 & 2.13 & 0.46 \\
\hline $\mathrm{H}$ & 5.684064 & 1.777017 & 1.017920 \\
\hline $\mathrm{H}$ & 6.946172 & -0.135002 & 0.046491 \\
\hline $\mathrm{H}$ & 5.825166 & -1.776629 & -1.418265 \\
\hline $\mathrm{H}$ & 3.411644 & -1.582421 & -1.959297 \\
\hline $\mathrm{H}$ & 1.452377 & 0.523530 & -1.741945 \\
\hline $\mathrm{H}$ & 2.972840 & 3.024661 & 1.063558 \\
\hline $\mathrm{C}$ & 0.280440 & 2.347377 & -0.049233 \\
\hline $\mathrm{C}$ & 0.055089 & 3.734931 & 0.041420 \\
\hline $\mathrm{C}$ & -1.251773 & 4.212112 & 0.028722 \\
\hline $\mathrm{H}$ & 0.894920 & 4.420064 & 0.081633 \\
\hline $\mathrm{C}$ & -2.021508 & 1.944188 & -0.154450 \\
\hline $\mathrm{C}$ & -2.317774 & 3.300278 & -0.086325 \\
\hline $\mathrm{H}$ & -1.448599 & 5.279058 & 0.083458 \\
\hline $\mathrm{H}$ & -3.349192 & 3.631134 & -0.125201 \\
\hline $\mathrm{C}$ & -3.088902 & 0.924567 & -0.266999 \\
\hline $\mathrm{C}$ & -5.273014 & 0.372357 & -0.520778 \\
\hline $\mathrm{C}$ & -4.888276 & -0.998375 & -0.508012 \\
\hline $\mathrm{H}$ & -6.316735 & 0.662800 & -0.628640 \\
\hline $\mathrm{H}$ & -5.607401 & -1.805611 & -0.611840 \\
\hline $\mathrm{N}$ & 1.758145 & 0.480208 & -0.766040 \\
\hline $\mathrm{N}$ & -0.747901 & 1.461595 & -0.123120 \\
\hline $\mathrm{N}$ & -4.367414 & 1.327046 & -0.397154 \\
\hline
\end{tabular}




$$
\begin{array}{lrrr}
\mathrm{N} & -2.695983 & -0.359638 & -0.234722 \\
\mathrm{~N} & -3.617353 & -1.333407 & -0.355446 \\
\end{array}
$$

$\begin{array}{lrrc}\text { AM } & -0.245905 & -0.856780 & 0.196818 \\ \mathrm{O} & -1.346329 & -1.564943 & 2.354023 \\ \mathrm{H} & -1.858649 & -2.389427 & 2.420760 \\ \mathrm{O} & -1.610029 & -2.939437 & -0.136775 \\ \mathrm{H} & -1.526213 & -3.874772 & -0.383594 \\ \mathrm{O} & 1.652303 & -2.507803 & 0.053468 \\ \mathrm{H} & 1.733515 & -3.447632 & 0.291646 \\ \mathrm{O} & 1.079151 & -0.080924 & 2.185075 \\ \mathrm{H} & 1.313981 & -0.564000 & 2.995558 \\ \mathrm{O} & -0.280593 & -1.108150 & -2.368582 \\ \mathrm{H} & 0.045910 & -1.887430 & -2.851532 \\ \mathrm{H} & 2.564599 & -2.189699 & -0.121333 \\ \mathrm{H} & -0.848523 & -0.636644 & -3.002073 \\ \mathrm{H} & -1.452905 & -1.105071 & 3.204446 \\ \mathrm{H} & -2.543086 & -2.648724 & -0.323394 \\ \mathrm{H} & 1.678148 & 0.687811 & 2.134004 \\ \mathrm{C} & 3.209193 & 0.258994 & -0.682205 \\ \mathrm{C} & 3.851545 & 1.208451 & 0.145718 \\ \mathrm{C} & 5.225110 & 1.083879 & 0.428318 \\ \mathrm{C} & 5.923233 & 0.022137 & -0.149597 \\ \mathrm{C} & 5.277843 & -0.890652 & -1.009311 \\ \mathrm{C} & 3.904985 & -0.786317 & -1.292716 \\ \mathrm{C} & 1.677449 & 1.866504 & -0.090008 \\ \mathrm{C} & 2.866940 & 2.212627 & 0.491703 \\ \mathrm{H} & 5.736517 & 1.805871 & 1.057186 \\ \mathrm{H} & 6.986344 & -0.089271 & 0.038120 \\ \mathrm{H} & 5.859572 & -1.676164 & -1.481739 \\ \mathrm{H} & 3.449290 & -1.445254 & -2.027801 \\ \mathrm{H} & 1.509479 & 0.672019 & -1.766813 \\ \mathrm{H} & 3.040169 & 3.082268 & 1.115401 \\ \mathrm{C} & 0.349605 & 2.466870 & -0.033815 \\ \mathrm{C} & 0.145401 & 3.856157 & 0.079279 \\ \mathrm{C} & -1.153339 & 4.354514 & 0.071701 \\ \mathrm{H} & 0.996177 & 4.526774 & 0.132002 \\ \mathrm{C} & -1.958357 & 2.102254 & -0.149074 \\ \mathrm{C} & -2.233036 & 3.461507 & -0.059593 \\ \mathrm{H} & -1.333340 & 5.423362 & 0.143487 \\ \mathrm{H} & -3.259097 & 3.809080 & -0.094039 \\ & -3.043620 & 1.104120 & -0.276107 \\ \mathrm{C} & -237279 & 0.595279 & -0.536187 \\ & -0.781663 & -0.551897\end{array}$




$\begin{array}{crrr}\mathrm{H} & -6.275838 & 0.906452 & -0.635350 \\ \mathrm{H} & -5.610330 & -1.572987 & -0.673574 \\ \mathrm{~N} & 1.813233 & 0.602826 & -0.792014 \\ \mathrm{~N} & -0.692551 & 1.599984 & -0.122343 \\ \mathrm{~N} & -4.314577 & 1.531412 & -0.397600 \\ \mathrm{~N} & -2.675775 & -0.187740 & -0.264476 \\ \mathrm{~N} & -3.612607 & -1.145102 & -0.406990\end{array}$

$\mathrm{M}=\mathrm{Cm}$

$\begin{array}{lrrc}\mathrm{CM} & -0.233320 & -0.856706 & 0.196310 \\ \mathrm{O} & -1.282413 & -1.388440 & 2.423635 \\ \mathrm{H} & -1.869639 & -2.150969 & 2.564875 \\ \mathrm{O} & -1.631126 & -2.883976 & -0.048464 \\ \mathrm{H} & -1.565143 & -3.843191 & -0.182461 \\ \mathrm{O} & 1.591113 & -2.551944 & -0.073354 \\ \mathrm{H} & 1.637573 & -3.515515 & 0.051678 \\ \mathrm{O} & 1.242718 & -0.184486 & 2.116854 \\ \mathrm{H} & 1.503660 & -0.704600 & 2.895832 \\ \mathrm{O} & -0.280840 & -1.109056 & -2.349030 \\ \mathrm{H} & 0.062237 & -1.884948 & -2.825843 \\ \mathrm{H} & 2.515786 & -2.244494 & -0.186508 \\ \mathrm{H} & -0.873613 & -0.662593 & -2.977918 \\ \mathrm{H} & -1.269364 & -0.892672 & 3.260369 \\ \mathrm{H} & -2.567631 & -2.598508 & -0.250173 \\ \mathrm{H} & 1.875144 & 0.556005 & 2.049408 \\ \mathrm{C} & 3.204067 & 0.274082 & -0.681183 \\ \mathrm{C} & 3.837919 & 1.229398 & 0.146584 \\ \mathrm{C} & 5.212618 & 1.116567 & 0.430025 \\ \mathrm{C} & 5.919713 & 0.060480 & -0.146862 \\ \mathrm{C} & 5.282378 & -0.858122 & -1.006474 \\ \mathrm{C} & 3.908877 & -0.765603 & -1.290432 \\ \mathrm{C} & 1.658641 & 1.871586 & -0.093901 \\ \mathrm{C} & 2.844368 & 2.226387 & 0.490121 \\ \mathrm{H} & 5.717671 & 1.843361 & 1.058524 \\ \mathrm{H} & 6.983767 & -0.041608 & 0.040850 \\ \mathrm{H} & 5.871153 & -1.638616 & -1.478533 \\ \mathrm{H} & 3.460043 & -1.426681 & -2.027872 \\ \mathrm{H} & 1.502485 & 0.672887 & -1.768846 \\ \mathrm{H} & 3.008337 & 3.096395 & 1.115789 \\ \mathrm{C} & 0.326218 & 2.463924 & -0.038393 \\ \mathrm{C} & 0.115019 & 3.851917 & 0.073840 \\ \mathrm{C} & -1.186646 & 4.343236 & 0.063901 \\ \mathrm{H} & 0.961918 & 4.527376 & 0.127255 \\ \mathrm{C} & -1.980385 & 2.086531 & -0.155405 \\ \mathrm{C} & -2.261748 & 3.444794 & -0.067919\end{array}$




$\begin{array}{rrrr}\mathrm{H} & -1.372200 & 5.411237 & 0.134604 \\ \mathrm{H} & -3.289231 & 3.787750 & -0.103376 \\ \mathrm{C} & -3.063804 & 1.083672 & -0.278840 \\ \mathrm{C} & -5.258873 & 0.576266 & -0.536440 \\ \mathrm{C} & -4.900557 & -0.801169 & -0.539179 \\ \mathrm{H} & -6.296748 & 0.888321 & -0.639826 \\ \mathrm{H} & -5.635193 & -1.593049 & -0.652138 \\ \mathrm{~N} & 1.805240 & 0.607627 & -0.793356 \\ \mathrm{~N} & -0.711976 & 1.591605 & -0.127767 \\ \mathrm{~N} & -4.334724 & 1.511825 & -0.403999 \\ \mathrm{~N} & -2.696573 & -0.208207 & -0.258650 \\ \mathrm{~N} & -3.636927 & -1.163212 & -0.391264\end{array}$

\section{$\left[\mathrm{ML}_{2}\left(\mathrm{H}_{2} \mathrm{O}\right)_{2}\right]^{3+}$}

$\mathrm{M}=\mathrm{Eu}$

$\begin{array}{lrrr}\mathrm{C} & 3.425091 & -0.744447 & 1.518920 \\ \mathrm{C} & 4.320308 & -0.815237 & 2.591801 \\ \mathrm{C} & 3.897325 & -0.375019 & 3.852166 \\ \mathrm{C} & 2.604993 & 0.122582 & 3.988197 \\ \mathrm{C} & 1.771207 & 0.182819 & 2.852353 \\ \mathrm{~N} & 2.171907 & -0.248288 & 1.630967 \\ \mathrm{H} & 4.567739 & -0.416753 & 4.705280 \\ \mathrm{H} & 5.313946 & -1.215910 & 2.432942 \\ \mathrm{H} & 2.252954 & 0.494317 & 4.943837 \\ \mathrm{C} & 3.833152 & -1.283876 & 0.193379 \\ \mathrm{C} & 5.437023 & -2.211780 & -1.118213 \\ \mathrm{C} & 4.480538 & -2.289292 & -2.160875 \\ \mathrm{H} & 6.457370 & -2.562476 & -1.259457 \\ \mathrm{H} & 4.714203 & -2.701622 & -3.137516 \\ \mathrm{~N} & 2.906591 & -1.336648 & -0.774138 \\ \mathrm{~N} & 3.245722 & -1.849920 & -1.968277 \\ \mathrm{~N} & 5.105661 & -1.709105 & 0.058242 \\ \mathrm{C} & 0.425430 & 0.734794 & 2.955281 \\ \mathrm{C} & -0.444219 & 0.736145 & 4.036087 \\ \mathrm{H} & -0.253317 & 0.285136 & 5.001641 \\ \mathrm{~N} & -0.201884 & 1.324224 & 1.826275 \\ \mathrm{C} & -2.562142 & 0.855588 & -1.841874 \\ \mathrm{C} & -0.862011 & 2.414906 & -2.142475 \\ \mathrm{C} & -3.506516 & 1.734670 & -2.412249 \\ \mathrm{C} & -1.732334 & 3.330095 & -2.736857 \\ \mathrm{C} & -3.085073 & 2.979870 & -2.867019 \\ \mathrm{H} & -4.537791 & 1.420594 & -2.528595 \\ \mathrm{H} & -1.352477 & 4.281847 & -3.088145 \\ \mathrm{H} & -3.787818 & 3.665413 & -3.331225\end{array}$




$\begin{array}{lrrr}\mathrm{C} & 0.571453 & 2.766589 & -1.951268 \\ \mathrm{C} & 2.300857 & 4.184145 & -2.308840 \\ \mathrm{C} & 3.122963 & 3.298990 & -1.569310 \\ \mathrm{H} & 2.697654 & 5.103105 & -2.735886 \\ \mathrm{H} & 4.178148 & 3.494420 & -1.402692 \\ \mathrm{C} & -4.142834 & -0.906218 & -0.841200 \\ \mathrm{H} & -5.010599 & -0.289885 & -0.644712 \\ \mathrm{C} & -2.955756 & -0.475622 & -1.388270 \\ \mathrm{~N} & -1.256938 & 1.194212 & -1.703477 \\ \mathrm{~N} & 1.324739 & 1.918635 & -1.229521 \\ \mathrm{~N} & 2.628944 & 2.187096 & -1.036866 \\ \mathrm{~N} & 1.018974 & 3.912831 & -2.497641 \\ \mathrm{~N} & -2.000999 & -1.543905 & -1.391955 \\ \mathrm{C} & -2.702899 & -2.694199 & -0.926064 \\ \mathrm{C} & -4.009137 & -2.301394 & -0.528631 \\ \mathrm{C} & -4.899554 & -3.254832 & 0.014135 \\ \mathrm{C} & -4.470562 & -4.575238 & 0.112806 \\ \mathrm{C} & -2.271783 & -4.017982 & -0.846850 \\ \mathrm{C} & -3.179824 & -4.955427 & -0.321557 \\ \mathrm{H} & -5.899673 & -2.970508 & 0.325147 \\ \mathrm{H} & -5.138585 & -5.333222 & 0.508500 \\ \mathrm{H} & -2.888185 & -5.999461 & -0.262789 \\ \mathrm{H} & -1.303845 & -4.340764 & -1.219850 \\ \mathrm{C} & -1.470245 & 1.805560 & 2.286243 \\ \mathrm{C} & -1.641955 & 1.397995 & 3.637233 \\ \mathrm{C} & -2.425036 & 2.558263 & 1.622988 \\ \mathrm{C} & -2.835629 & 1.718133 & 4.334355 \\ \mathrm{C} & -3.595123 & 2.893407 & 2.341086 \\ \mathrm{C} & -3.800611 & 2.470630 & 3.671401 \\ \mathrm{H} & -2.979109 & 1.406683 & 5.364181 \\ \mathrm{H} & -4.715441 & 2.751660 & 4.182622 \\ \mathrm{H} & -4.355183 & 3.499211 & 1.857302 \\ \mathrm{H} & -2.293082 & 2.902056 & 0.602631 \\ \mathrm{H} & 0.373187 & 2.013511 & 1.339991 \\ \mathrm{H} & -1.508708 & -1.678161 & -2.276535 \\ \mathrm{O} & 0.785282 & -1.203857 & -2.792254 \\ \mathrm{H} & 1.705462 & -1.586122 & -2.828574 \\ \mathrm{O} & -0.196027 & -2.408127 & 1.040998 \\ \mathrm{H} & 0.244439 & -2.811678 & 1.805045 \\ \mathrm{H} & 0.554183 & -0.934302 & -3.694148 \\ \mathrm{H} & -0.958207 & -2.983217 & 0.833550 \\ \mathrm{EU} & 0.429002 & -0.400788 & -0.415223 \\ & & & \end{array}$

$\mathrm{M}=\mathrm{Gd}$

$\begin{array}{llll}\text { C } & 3.186539 & -1.293424 & 1.374580\end{array}$ 


\begin{tabular}{|c|c|c|c|}
\hline $\mathrm{C}$ & 3.958297 & -1.760051 & 2.433497 \\
\hline & 3.392877 & -1.766237 & 3.720703 \\
\hline$C$ & 2.092994 & -1.306878 & 3.888949 \\
\hline $\mathrm{C}$ & 1.376019 & -0.834812 & 2.767967 \\
\hline $\mathrm{N}$ & 1.918860 & -0.826759 & 1.525860 \\
\hline$\theta$ & 3.968407 & -2.119219 & 4.571312 \\
\hline $\mathrm{H}$ & 4.965489 & -2.114206 & 2.250799 \\
\hline $\mathrm{H}$ & 1.637263 & -1.276477 & 4.872223 \\
\hline $\mathrm{C}$ & 3.701817 & -1.347004 & -0.009853 \\
\hline C & 5.386927 & -1.811318 & -1.458615 \\
\hline$C$ & 4.513997 & -1.464521 & -2.523732 \\
\hline $\mathrm{H}$ & 6.408853 & -2.133694 & -1.649055 \\
\hline $\mathrm{H}$ & 4.817499 & -1.504106 & -3.565258 \\
\hline $\mathrm{N}$ & 2.851098 & -1.013778 & -0.994309 \\
\hline $\mathrm{N}$ & 3.277460 & -1.072821 & -2.267066 \\
\hline $\mathrm{N}$ & 4.974025 & -1.748386 & -0.206119 \\
\hline $\mathrm{C}$ & 0.018945 & -0.326239 & 2.886149 \\
\hline$C$ & -0.988650 & -0.665655 & 3.739845 \\
\hline $\mathrm{H}$ & -0.932839 & -1.413776 & 4.521170 \\
\hline $\mathbf{N}$ & -0.445930 & 0.651015 & 1.909788 \\
\hline $\mathrm{C}$ & -2.278465 & 1.492746 & -1.559429 \\
\hline $\mathrm{C}$ & -0.510225 & 2.981502 & -1.222050 \\
\hline $\mathrm{C}$ & -3.134670 & 2.558301 & -1.907075 \\
\hline $\mathrm{C}$ & -1.293879 & 4.079389 & -1.562914 \\
\hline $\mathrm{C}$ & -2.637859 & 3.856796 & -1.911349 \\
\hline $\mathrm{H}$ & -4.158395 & 2.353381 & -2.199742 \\
\hline $\mathrm{H}$ & -0.861488 & 5.072783 & -1.556088 \\
\hline $\mathrm{H}$ & -3.275256 & 4.689925 & -2.192784 \\
\hline $\mathrm{C}$ & 0.903199 & 3.152457 & -0.808520 \\
\hline $\mathrm{C}$ & 2.704264 & 4.480264 & -0.467887 \\
\hline $\mathrm{C}$ & 3.417752 & 3.331193 & -0.040342 \\
\hline $\mathrm{H}$ & 3.172932 & 5.462365 & -0.489655 \\
\hline $\mathrm{H}$ & 4.454448 & 3.382090 & 0.279121 \\
\hline $\mathrm{C}$ & -3.941772 & -0.433873 & -1.226475 \\
\hline $\mathrm{H}$ & -4.820754 & 0.117129 & -0.916653 \\
\hline $\mathrm{C}$ & -2.733170 & 0.108399 & -1.552264 \\
\hline $\mathrm{N}$ & -0.982339 & 1.706285 & -1.221805 \\
\hline $\mathrm{N}$ & 1.555651 & 2.048991 & -0.397634 \\
\hline $\mathrm{N}$ & 2.841028 & 2.137271 & -0.009371 \\
\hline $\mathrm{N}$ & 1.441994 & 4.384190 & -0.853441 \\
\hline $\mathrm{N}$ & -1.760488 & -0.940546 & -1.805325 \\
\hline $\mathrm{C}$ & -2.511067 & -2.168398 & -1.715929 \\
\hline $\mathrm{C}$ & -3.831600 & -1.874250 & -1.309843 \\
\hline $\mathrm{C}$ & -4.756567 & -2.915751 & -1.117879 \\
\hline 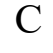 & -4.338001 & -4.225867 & -1.362705 \\
\hline$C$ & -2.088481 & -3.470724 & -1.990190 \\
\hline
\end{tabular}




$\begin{array}{lrrr}\mathrm{C} & -3.028648 & -4.499989 & -1.804115 \\ \mathrm{H} & -5.776132 & -2.709266 & -0.808450 \\ \mathrm{H} & -5.036437 & -5.046683 & -1.236159 \\ \mathrm{H} & -2.745365 & -5.524119 & -2.025440 \\ \mathrm{H} & -1.105764 & -3.694971 & -2.396963 \\ \mathrm{C} & -1.802696 & 0.958724 & 2.326474 \\ \mathrm{C} & -2.152992 & 0.122905 & 3.409501 \\ \mathrm{C} & -2.657058 & 1.951307 & 1.857658 \\ \mathrm{C} & -3.424055 & 0.224154 & 4.003246 \\ \mathrm{C} & -3.912351 & 2.060989 & 2.473092 \\ \mathrm{C} & -4.297144 & 1.199450 & 3.520221 \\ \mathrm{H} & -3.706884 & -0.414148 & 4.834092 \\ \mathrm{H} & -5.276322 & 1.318216 & 3.972820 \\ \mathrm{H} & -4.599047 & 2.836220 & 2.147916 \\ \mathrm{H} & -2.371253 & 2.642958 & 1.073759 \\ \mathrm{H} & 0.134626 & 1.493170 & 1.962574 \\ \mathrm{H} & -1.323291 & -0.841875 & -2.725036 \\ \mathrm{O} & 0.941229 & -0.092531 & -2.824408 \\ \mathrm{H} & 1.861738 & -0.455363 & -3.000285 \\ \mathrm{O} & -0.155853 & -2.487401 & 0.178944 \\ \mathrm{H} & 0.223364 & -3.063910 & 0.861350 \\ \mathrm{H} & 0.701450 & 0.496218 & -3.556505 \\ \mathrm{H} & -0.904542 & -2.977875 & -0.228357 \\ \mathrm{GD} & 0.446243 & -0.212111 & -0.445396\end{array}$

$\mathrm{M}=\mathrm{Am}$

$\begin{array}{llll}\text { C } & 3.267857 & -1.267041 & 1.318284\end{array}$

C $\quad 4.078668-1.766296 \quad 2.332555$

C $\quad 3.554057 \quad-1.837732 \quad 3.634660$

C $\quad 2.257536 \quad-1.395350 \quad 3.865826$

$\begin{array}{llll}\text { C } & 1.501863 & -0.882254 & 2.790739\end{array}$

$\begin{array}{llll}\mathrm{N} & 1.999644 & -0.829787 & 1.530503\end{array}$

$\mathrm{H} \quad 4.160286 \quad-2.221628 \quad 4.449764$

$\mathrm{H} \quad 5.086183 \quad-2.092575 \quad 2.105404$

H $\quad 1.835640 \quad-1.407139 \quad 4.864576$

$\begin{array}{llll}\text { C } & 3.750299 & -1.232652 & -0.079673\end{array}$

C $\quad 5.412250 \quad-1.586889 \quad-1.585430$

$\begin{array}{llll}\text { C } & 4.512219 & -1.193834 & -2.610188\end{array}$

$\mathrm{H} \quad 6.434796-1.881272 \quad-1.813603$

$\mathrm{H} \quad 4.792951 \quad-1.173577 \quad-3.658640$

N $\quad 2.876845 \quad-0.848530 \quad-1.024313$

$\mathrm{N} \quad 3.276015 \quad-0.835191 \quad-2.307856$

N $\quad 5.022591 \quad-1.606347 \quad-0.323905$

$\begin{array}{llll}\mathrm{C} & 0.151535 & -0.371919 & 2.975207\end{array}$

$\begin{array}{llll}\text { C } & -0.842647 & -0.754510 & 3.826438\end{array}$ 


$\begin{array}{lrrr}\mathrm{H} & -0.778200 & -1.547068 & 4.561885 \\ \mathrm{~N} & -0.325544 & 0.663439 & 2.068916 \\ \mathrm{C} & -2.487982 & 1.383914 & -1.494248 \\ \mathrm{C} & -0.823950 & 2.997818 & -1.219971 \\ \mathrm{C} & -3.432048 & 2.385071 & -1.806437 \\ \mathrm{C} & -1.694415 & 4.035052 & -1.537381 \\ \mathrm{C} & -3.031422 & 3.715282 & -1.833603 \\ \mathrm{H} & -4.448852 & 2.106077 & -2.059004 \\ \mathrm{H} & -1.334636 & 5.056961 & -1.549030 \\ \mathrm{H} & -3.737469 & 4.498776 & -2.092476 \\ \mathrm{C} & 0.578339 & 3.274992 & -0.833505 \\ \mathrm{C} & 2.295337 & 4.720753 & -0.539966 \\ \mathrm{C} & 3.082463 & 3.631925 & -0.083333 \\ \mathrm{H} & 2.701495 & 5.729151 & -0.592557 \\ \mathrm{H} & 4.114227 & 3.756855 & 0.231091 \\ \mathrm{C} & -4.012343 & -0.651874 & -1.153233 \\ \mathrm{H} & -4.919738 & -0.164152 & -0.820239 \\ \mathrm{C} & -2.844522 & -0.028360 & -1.487586 \\ \mathrm{~N} & -1.200827 & 1.691175 & -1.201427 \\ \mathrm{~N} & 1.304212 & 2.229358 & -0.398836 \\ \mathrm{~N} & 2.581280 & 2.406195 & -0.018066 \\ \mathrm{~N} & 1.039250 & 4.536165 & -0.914344 \\ \mathrm{~N} & -1.816462 & -1.007511 & -1.774138 \\ \mathrm{C} & -2.482484 & -2.279243 & -1.702836 \\ \mathrm{C} & -3.812582 & -2.079577 & -1.269212 \\ \mathrm{H} & -4.665950 & -3.182799 & -1.087974 \\ \mathrm{C} & -4.169320 & -4.456577 & -1.372198 \\ \mathrm{C} & -1.982402 & -3.546061 & -2.012683 \\ \mathrm{C} & -2.852195 & -4.636135 & -1.839674 \\ \mathrm{H} & -5.691045 & -3.049526 & -0.757536 \\ \mathrm{H} & -4.811976 & -5.323261 & -1.256219 \\ \mathrm{H} & -2.508355 & -5.634728 & -2.089894 \\ \mathrm{H} & -0.991646 & -3.696082 & -2.433891 \\ \mathrm{C} & -1.676823 & 0.941811 & 2.510752 \\ \mathrm{C} & -2.011432 & 0.051850 & 3.555517 \\ \mathrm{C} & -2.545425 & 1.943131 & 2.087039 \\ \mathrm{C} & -3.276339 & 0.119514 & 4.165916 \\ \mathrm{C} & -3.794583 & 2.016027 & 2.718281 \\ \mathrm{H} & -4.160167 & 1.109000 & 3.734120 \\ \mathrm{H} & -5.135405 & -0.557470 & 4.969274 \\ \mathrm{H} & -2.201171 & 4.201216 \\ \mathrm{H} & -0.859004 & -2.683118 \\ \mathrm{H} & -0.004891 & -2.848524\end{array}$




$\begin{array}{lrrr}\mathrm{H} & 1.800618 & -0.291512 & -3.024521 \\ \mathrm{O} & -0.138695 & -2.512964 & 0.218629 \\ \mathrm{H} & 0.253113 & -3.093214 & 0.890191 \\ \mathrm{H} & 0.580723 & 0.580515 & -3.570288 \\ \mathrm{H} & -0.861230 & -3.020169 & -0.213113 \\ \mathrm{AM} & 0.408212 & -0.143034 & -0.376605\end{array}$

\section{$\mathrm{M}=\mathrm{Cm}$}

$\begin{array}{lccc}\mathrm{C} & 3.210023 & -1.249774 & 1.397061 \\ \mathrm{C} & 4.004510 & -1.701009 & 2.446239 \\ \mathrm{C} & 3.460263 & -1.706789 & 3.742211 \\ \mathrm{C} & 2.158941 & -1.258842 & 3.930199 \\ \mathrm{C} & 1.418996 & -0.799925 & 2.819358 \\ \mathrm{~N} & 1.940443 & -0.798069 & 1.568551 \\ \mathrm{H} & 4.053594 & -2.049183 & 4.584857 \\ \mathrm{H} & 5.013133 & -2.043434 & 2.250115 \\ \mathrm{H} & 1.720452 & -1.226492 & 4.921246 \\ \mathrm{C} & 3.710293 & -1.299857 & 0.005550 \\ \mathrm{C} & 5.389966 & -1.748236 & -1.455631 \\ \mathrm{C} & 4.505898 & -1.412058 & -2.514427 \\ \mathrm{H} & 6.413810 & -2.060294 & -1.652677 \\ \mathrm{H} & 4.802209 & -1.450323 & -3.558107 \\ \mathrm{~N} & 2.849759 & -0.976704 & -0.973604 \\ \mathrm{~N} & 3.267240 & -1.033387 & -2.250213 \\ \mathrm{~N} & 4.985283 & -1.688639 & -0.200300 \\ \mathrm{C} & 0.059049 & -0.301133 & 2.960037 \\ \mathrm{C} & -0.932495 & -0.654842 & 3.826778 \\ \mathrm{H} & -0.858228 & -1.407060 & 4.602600 \\ \mathrm{~N} & -0.430913 & 0.676724 & 1.998197 \\ \mathrm{CM} & 0.403148 & -0.195689 & -0.408193 \\ \mathrm{C} & -2.380491 & 1.477819 & -1.527259 \\ \mathrm{C} & -0.641883 & 3.007582 & -1.221345 \\ \mathrm{C} & -3.265364 & 2.521890 & -1.867131 \\ \mathrm{C} & -1.454503 & 4.085662 & -1.558263 \\ \mathrm{C} & -2.798044 & 3.831114 & -1.885241 \\ \mathrm{H} & -4.288304 & 2.293044 & -2.144413 \\ \mathrm{H} & -1.045117 & 5.088649 & -1.564142 \\ \mathrm{H} & -3.458099 & 4.648119 & -2.161510 \\ \mathrm{C} & 0.770907 & 3.217384 & -0.821594 \\ \mathrm{C} & 2.539672 & 4.596311 & -0.512100 \\ \mathrm{C} & 3.285529 & 3.473257 & -0.071385 \\ \mathrm{H} & 2.982335 & 5.589829 & -0.551881 \\ \mathrm{H} & 4.322103 & 3.555816 & 0.241497 \\ \mathrm{C} & -4.001149 & -0.480073 & -1.171470 \\ \mathrm{H} & -4.885029 & 0.055055 & -0.847970\end{array}$




$\begin{array}{lrrl}\mathrm{C} & -2.806179 & 0.083580 & -1.512188 \\ \mathrm{~N} & -1.086267 & 1.723345 & -1.207123 \\ \mathrm{~N} & 1.455542 & 2.138347 & -0.399160 \\ \mathrm{~N} & 2.740525 & 2.265842 & -0.019202 \\ \mathrm{~N} & 1.277759 & 4.462027 & -0.887557 \\ \mathrm{~N} & -1.822108 & -0.948635 & -1.782733 \\ \mathrm{C} & -2.548361 & -2.188523 & -1.685799 \\ \mathrm{C} & -3.868375 & -1.918157 & -1.262226 \\ \mathrm{C} & -4.773580 & -2.976111 & -1.064864 \\ \mathrm{C} & -4.336225 & -4.277207 & -1.322572 \\ \mathrm{C} & -2.106779 & -3.482357 & -1.969873 \\ \mathrm{C} & -3.027269 & -4.527409 & -1.780139 \\ \mathrm{H} & -5.792557 & -2.788646 & -0.741849 \\ \mathrm{H} & -5.019433 & -5.110345 & -1.193153 \\ \mathrm{H} & -2.729524 & -5.545677 & -2.009432 \\ \mathrm{H} & -1.122937 & -3.686601 & -2.384589 \\ \mathrm{C} & -1.785809 & 0.963208 & 2.429408 \\ \mathrm{C} & -2.111261 & 0.120805 & 3.514773 \\ \mathrm{C} & -2.661885 & 1.939600 & 1.966160 \\ \mathrm{C} & -3.376542 & 0.203589 & 4.122815 \\ \mathrm{C} & -3.911486 & 2.030266 & 2.595372 \\ \mathrm{C} & -4.269922 & 1.164749 & 3.648761 \\ \mathrm{H} & -3.641043 & -0.438917 & 4.956410 \\ \mathrm{H} & -5.245653 & 1.268715 & 4.112320 \\ \mathrm{H} & -4.615008 & 2.792533 & 2.275646 \\ \mathrm{H} & -2.395216 & 2.631733 & 1.175432 \\ \mathrm{H} & 0.141476 & 1.524616 & 2.040995 \\ \mathrm{H} & -1.391638 & -0.839034 & -2.704117 \\ \mathrm{O} & 0.901312 & -0.105405 & -2.849340 \\ \mathrm{H} & 1.831189 & -0.448822 & -3.004082 \\ \mathrm{O} & -0.198080 & -2.528958 & 0.251517 \\ \mathrm{H} & 0.171282 & -3.100440 & 0.943379 \\ \mathrm{H} & 0.666522 & 0.477979 & -3.587483 \\ \mathrm{H} & -0.937908 & -3.022780 & -0.165274\end{array}$

\section{$\left[\mathrm{ML}_{2}\right]^{3+}$}

$\mathrm{M}=\mathrm{Eu}$
$\begin{array}{llll}\text { C } & -3.490199 & 0.843037 & -1.776610\end{array}$
$\begin{array}{llll}\text { C } & -4.236134 & -0.098028 & -2.542265\end{array}$
$\begin{array}{llll}\text { C } & -4.969570 & 0.328691 & -3.682224\end{array}$
$\begin{array}{llll}\text { C } & -4.962254 & 1.682509 & -3.998223\end{array}$
$\begin{array}{llll}\text { C } & -4.239862 & 2.603795 & -3.207804\end{array}$
$\begin{array}{llll}\text { C } & -3.486348 & 2.194727 & -2.083197\end{array}$
C $\quad-3.261683 \quad-1.200080 \quad-0.808750$ 


$\begin{array}{lrrr}\mathrm{C} & -4.086207 & -1.367265 & -1.914409 \\ \mathrm{H} & -5.534134 & -0.381832 & -4.277661 \\ \mathrm{H} & -5.522614 & 2.043996 & -4.854035 \\ \mathrm{H} & -4.263119 & 3.657043 & -3.470347 \\ \mathrm{H} & -2.945702 & 2.929840 & -1.495212 \\ \mathrm{H} & -2.887791 & 0.564632 & 0.215137 \\ \mathrm{H} & -4.505851 & -2.305307 & -2.255347 \\ \mathrm{C} & -2.788415 & -2.191474 & 0.152906 \\ \mathrm{C} & -3.579383 & -3.309246 & 0.489340 \\ \mathrm{C} & -3.109290 & -4.208857 & 1.442293 \\ \mathrm{H} & -4.555293 & -3.442884 & 0.036151 \\ \mathrm{C} & -1.112183 & -2.877707 & 1.603857 \\ \mathrm{C} & -1.851221 & -3.988928 & 2.019769 \\ \mathrm{H} & -3.707728 & -5.066113 & 1.735616 \\ \mathrm{H} & -1.438615 & -4.662720 & 2.760955 \\ \mathrm{C} & 0.273480 & -2.677630 & 2.106288 \\ \mathrm{C} & 1.967083 & -3.301878 & 3.478526 \\ \mathrm{C} & 2.786532 & -2.336524 & 2.839666 \\ \mathrm{H} & 2.349870 & -3.922486 & 4.286439 \\ \mathrm{H} & 3.829207 & -2.192948 & 3.106338 \\ \mathrm{~N} & -2.818733 & 0.144144 & -0.725841 \\ \mathrm{~N} & -1.566597 & -1.980172 & 0.699891 \\ \mathrm{C} & 0.714541 & -3.481476 & 3.093822 \\ \mathrm{H} & 1.850637 & 3.987981 & 2.021758 \\ \mathrm{~N} & 1.012843 & -1.726909 & 1.511637 \\ \mathrm{~N} & 2.300301 & -1.573000 & 1.870381 \\ \mathrm{C} & 3.491331 & -0.842247 & -1.776045 \\ \mathrm{C} & 4.237135 & 0.099356 & -2.541243 \\ \mathrm{C} & 4.971046 & -0.326761 & -3.681184 \\ \mathrm{C} & 4.964334 & -1.680475 & -3.997592 \\ \mathrm{C} & 4.242085 & -2.602258 & -3.207618 \\ \mathrm{C} & 3.488094 & -2.193824 & -2.083051 \\ \mathrm{C} & 3.261777 & 1.200384 & -0.807600 \\ \mathrm{C} & 4.086597 & 1.368271 & -1.913074 \\ \mathrm{H} & 5.535485 & 0.384172 & -4.276253 \\ \mathrm{H} & 5.525046 & -2.041502 & -4.853368 \\ \mathrm{H} & 4.265799 & -3.655423 & -3.470462 \\ \mathrm{H} & 2.947560 & -2.929338 & -1.495468 \\ \mathrm{H} & 2.887330 & -0.564787 & 0.215563 \\ \mathrm{H} & 2.505966 & 2.306596 & -2.253572 \\ \mathrm{H} & 5.065420 & 1.738298\end{array}$




$\begin{array}{llll}\mathrm{H} & 1.437874 & 4.661438 & 2.763163 \\ \mathrm{C} & -0.274033 & 2.676627 & 2.107530 \\ \mathrm{C} & -1.967678 & 3.300333 & 3.479952 \\ \mathrm{C} & -2.787119 & 2.335279 & 2.840633 \\ \mathrm{H} & -2.350526 & 3.920700 & 4.288020 \\ \mathrm{H} & -3.829828 & 2.191656 & 3.107150 \\ \mathrm{~N} & 2.819388 & -0.143886 & -0.725322 \\ \mathrm{~N} & 1.566263 & 1.979720 & 0.701036 \\ \mathrm{~N} & -0.715115 & 3.480077 & 3.095369 \\ \mathrm{~N} & -1.013374 & 1.726170 & 1.512465 \\ \mathrm{~N} & -2.300859 & 1.572126 & 1.871068 \\ \mathrm{EU} & -0.000518 & -0.000008 & -0.181961\end{array}$

\section{$\mathrm{M}=\mathrm{Gd}$}

$\begin{array}{lrrr}\mathrm{C} & 1.917426 & 0.741395 & -2.587364 \\ \mathrm{C} & 3.032224 & -0.068621 & -2.894129 \\ \mathrm{C} & 4.244388 & 0.525001 & -3.285983 \\ \mathrm{C} & 4.292327 & 1.918159 & -3.380966 \\ \mathrm{C} & 3.161513 & 2.707729 & -3.093512 \\ \mathrm{C} & 1.947966 & 2.127397 & -2.688881 \\ \mathrm{C} & 1.312230 & -1.481910 & -2.375996 \\ \mathrm{C} & 2.620841 & -1.449802 & -2.754213 \\ \mathrm{H} & 5.113168 & -0.078856 & -3.527506 \\ \mathrm{H} & 5.210204 & 2.403813 & -3.696191 \\ \mathrm{H} & 3.227264 & 3.786019 & -3.197290 \\ \mathrm{H} & 1.080009 & 2.751661 & -2.496188 \\ \mathrm{H} & 0.025376 & 0.024572 & -2.884519 \\ \mathrm{H} & 3.259167 & -2.314798 & -2.889895 \\ \mathrm{C} & 0.429688 & -2.572336 & -1.983336 \\ \mathrm{C} & 0.508571 & -3.878003 & -2.510941 \\ \mathrm{C} & -0.403450 & -4.836692 & -2.080673 \\ \mathrm{H} & 1.250307 & -4.116987 & -3.265124 \\ \mathrm{C} & -1.379804 & -3.192994 & -0.634112 \\ \mathrm{C} & -1.377934 & -4.492729 & -1.122183 \\ \mathrm{H} & -0.372439 & -5.843147 & -2.487856 \\ \mathrm{H} & -2.105598 & -5.211493 & -0.763207 \\ \mathrm{C} & -2.304821 & -2.737368 & 0.425793 \\ \mathrm{C} & -4.025634 & -3.059464 & 1.856214 \\ \mathrm{C} & -3.816480 & -1.744285 & 2.356168 \\ \mathrm{H} & -4.815955 & -3.692357 & 2.256145 \\ \mathrm{H} & -4.424318 & -1.324012 & 3.152059 \\ \mathrm{~N} & 0.796028 & -0.113824 & -2.218728 \\ \mathrm{~N} & -0.501251 & -2.245527 & -1.055677 \\ \mathrm{~N} & -3.261758 & -3.555043 & 0.893329 \\ \mathrm{~N} & -2.095317 & -1.485991 & 0.881185\end{array}$




$\begin{array}{lrrr}\mathrm{N} & -2.854021 & -0.975297 & 1.864892 \\ \mathrm{C} & 1.917859 & -0.739835 & 2.587397 \\ \mathrm{C} & 3.031952 & 0.071069 & 2.894366 \\ \mathrm{C} & 4.244569 & -0.521607 & 3.286245 \\ \mathrm{C} & 4.293652 & -1.914740 & 3.381044 \\ \mathrm{C} & 3.163520 & -2.705212 & 3.093388 \\ \mathrm{C} & 1.949532 & -2.125825 & 2.688722 \\ \mathrm{C} & 1.310818 & 1.482991 & 2.376284 \\ \mathrm{C} & 2.619422 & 1.451930 & 2.754600 \\ \mathrm{H} & 5.112833 & 0.082928 & 3.527928 \\ \mathrm{H} & 5.211903 & -2.399671 & 3.696289 \\ \mathrm{H} & 3.230157 & -3.783460 & 3.197029 \\ \mathrm{H} & 1.082099 & -2.750768 & 2.495867 \\ \mathrm{H} & 0.025181 & -0.024616 & 2.884491 \\ \mathrm{H} & 3.257009 & 2.317443 & 2.890452 \\ \mathrm{C} & 0.427396 & 2.572688 & 1.983574 \\ \mathrm{C} & 0.505130 & 3.878411 & 2.511200 \\ \mathrm{C} & -0.407612 & 4.836356 & 2.080794 \\ \mathrm{H} & 1.246563 & 4.118004 & 3.265489 \\ \mathrm{C} & -1.382381 & 3.191868 & 0.634064 \\ \mathrm{C} & -1.381647 & 4.491608 & 1.122136 \\ \mathrm{H} & -0.377489 & 5.842832 & 2.487992 \\ \mathrm{H} & -2.109818 & 5.209787 & 0.763021 \\ \mathrm{C} & -2.306858 & 2.735531 & -0.426008 \\ \mathrm{C} & -4.027712 & 3.056314 & -1.856683 \\ \mathrm{C} & -3.817498 & 1.741290 & -2.356590 \\ \mathrm{H} & -4.818329 & 3.688679 & -2.256864 \\ \mathrm{H} & -4.424855 & 1.320572 & -3.152613 \\ \mathrm{~N} & 0.795779 & 0.114496 & 2.218783 \\ \mathrm{~N} & -0.503148 & 2.245109 & 1.055789 \\ \mathrm{~N} & -3.264321 & 3.552491 & -0.893721 \\ \mathrm{~N} & -2.096372 & 1.484292 & -0.881335 \\ \mathrm{~N} & -2.854553 & 0.973020 & -1.865135 \\ \mathrm{GD} & -0.403204 & -0.000189 & 0.000036\end{array}$
$\mathrm{M}=\mathrm{Am}$
$\begin{array}{llll}\text { C } & -0.983364 & 1.857250 & -2.656672\end{array}$
$\begin{array}{llll}\text { C } & -0.238134 & 3.014847 & -2.974835\end{array}$
$\begin{array}{llll}\text { C } & -0.902477 & 4.202165 & -3.328467\end{array}$
C $\quad-2.298033 \quad 4.183251 \quad-3.375870$
C $\quad-3.022870 \quad 3.011428 \quad-3.078633$
$\begin{array}{llll}\text { C } & -2.373145 & 1.823919 & -2.709982\end{array}$
$\begin{array}{llll}\text { C } & 1.265300 & 1.353680 & -2.532812\end{array}$
C $\quad 1.164310 \quad 2.665984 \quad-2.891016$
$\mathrm{H} \quad-0.349701 \quad 5.101997 \quad-3.578056$ 


\begin{tabular}{|c|c|c|c|}
\hline $\mathrm{H}$ & -2.838133 & 5.079981 & -3.662151 \\
\hline 1 & -4.105873 & 3.026938 & -3.146614 \\
\hline $\mathrm{H}$ & -2.945817 & 0.922750 & -2.509287 \\
\hline $\mathrm{H}$ & -0.202846 & -0.014742 & -2.965011 \\
\hline 日 & 1.994770 & 3.344361 & -3.045952 \\
\hline & 2.406375 & 0.511048 & -2.202669 \\
\hline & 3.670312 & 0.630662 & -2.815448 \\
\hline & 4.681895 & -0.255272 & -2.459559 \\
\hline $\mathrm{H}$ & 3.833343 & 1.382165 & -3.580123 \\
\hline & 3.169722 & -1.287206 & -0.910206 \\
\hline & 4.430061 & -1.246333 & -1.490497 \\
\hline $\mathrm{H}$ & 5.656597 & -0.193589 & -2.934691 \\
\hline $\mathrm{H}$ & 5.189165 & -1.960273 & -1.192173 \\
\hline $\mathrm{C}$ & 2.820609 & -2.238224 & 0.166201 \\
\hline C & 3.292908 & -3.972165 & 1.537088 \\
\hline $\mathrm{C}$ & 2.018020 & -3.798845 & 2.142706 \\
\hline $\mathrm{H}$ & 3.972023 & -4.754195 & 1.871938 \\
\hline $\mathrm{H}$ & 1.674719 & -4.426899 & 2.959324 \\
\hline$N$ & -0.066627 & 0.780882 & -2.331385 \\
\hline $\mathrm{N}$ & 2.172907 & -0.428924 & -1.254780 \\
\hline$V$ & 3.694306 & -3.182176 & 0.551488 \\
\hline $\mathrm{N}$ & 1.606696 & -2.063996 & 0.720259 \\
\hline $\mathrm{N}$ & 1.193345 & -2.846461 & 1.729340 \\
\hline 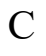 & 0.983633 & 1.857277 & 2.656576 \\
\hline $\mathrm{C}$ & 0.238538 & 3.014962 & 2.974732 \\
\hline $\mathrm{C}$ & 0.903020 & 4.202220 & 3.328303 \\
\hline C & 2.298576 & 4.183159 & 3.375656 \\
\hline $\mathrm{C}$ & 3.023278 & 3.011251 & 3.078428 \\
\hline $\mathrm{C}$ & 2.373413 & 1.823799 & 2.709837 \\
\hline $\mathrm{C}$ & -1.265089 & 1.353942 & 2.532809 \\
\hline $\mathrm{C}$ & -1.163947 & 2.666245 & 2.890972 \\
\hline $\mathrm{H}$ & 0.350348 & 5.102118 & 3.577886 \\
\hline $\mathrm{H}$ & 2.838781 & 5.079841 & 3.661890 \\
\hline $\mathrm{H}$ & 4.106284 & 3.026648 & 3.146369 \\
\hline 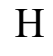 & 2.945982 & 0.922563 & 2.509149 \\
\hline $\mathrm{H}$ & 0.202923 & -0.014614 & 2.965013 \\
\hline I & -1.994328 & 3.344716 & 3.045916 \\
\hline 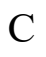 & -2.406269 & 0.511432 & 2.202720 \\
\hline $\mathrm{C}$ & -3.670170 & 0.631201 & 2.815544 \\
\hline $\mathrm{C}$ & -4.681876 & -0.254606 & 2.459691 \\
\hline $\mathrm{H}$ & -3.833079 & 1.382726 & 3.580223 \\
\hline $\mathrm{C}$ & -3.169886 & -1.286728 & 0.910285 \\
\hline , & -4.430200 & -1.245695 & 1.490618 \\
\hline $\mathrm{H}$ & -5.656554 & -0.192801 & 2.934858 \\
\hline $\mathrm{H}$ & -5.189406 & -1.959536 & 1.192315 \\
\hline $\mathrm{C}$ & -2.820936 & -2.237787 & -0.166137 \\
\hline
\end{tabular}




$\begin{array}{llll}\mathrm{C} & -3.293520 & -3.971651 & -1.537023 \\ \mathrm{C} & -2.018627 & -3.798503 & -2.142682 \\ \mathrm{H} & -3.972753 & -4.753586 & -1.871858 \\ \mathrm{H} & -1.675441 & -4.426596 & -2.959318 \\ \mathrm{~N} & 0.066770 & 0.780995 & 2.331354 \\ \mathrm{~N} & -2.172947 & -0.428574 & 1.254828 \\ \mathrm{~N} & -3.694776 & -3.181617 & -0.551404 \\ \mathrm{~N} & -1.607017 & -2.063725 & -0.720232 \\ \mathrm{~N} & -1.193806 & -2.846239 & -1.729332 \\ \mathrm{AM} & -0.000016 & -0.338541 & 0.000015\end{array}$

$\mathrm{M}=\mathrm{Cm}$

$\begin{array}{lrcc}\text { CM } & 0.000289 & -0.355518 & 0.000083 \\ \mathrm{C} & 0.617630 & 1.940548 & 2.686106 \\ \mathrm{C} & -0.205443 & 3.051238 & 2.972373 \\ \mathrm{C} & 0.370409 & 4.259823 & 3.400183 \\ \mathrm{C} & 1.758446 & 4.307874 & 3.550013 \\ \mathrm{C} & 2.560704 & 3.181354 & 3.281171 \\ \mathrm{C} & 1.999004 & 1.972722 & 2.840383 \\ \mathrm{C} & -1.592366 & 1.334103 & 2.378707 \\ \mathrm{C} & -1.579295 & 2.638748 & 2.772930 \\ \mathrm{H} & -0.243652 & 5.125422 & 3.626544 \\ \mathrm{H} & 2.230345 & 5.222640 & 3.893994 \\ \mathrm{H} & 3.634034 & 3.247781 & 3.427247 \\ \mathrm{H} & 2.630327 & 1.106621 & 2.661532 \\ \mathrm{H} & -0.103221 & 0.040757 & 2.926113 \\ \mathrm{H} & -2.450385 & 3.274188 & 2.879984 \\ \mathrm{C} & -2.668453 & 0.453959 & 1.941620 \\ \mathrm{C} & -3.988744 & 0.529245 & 2.431830 \\ \mathrm{C} & -4.935412 & -0.377729 & 1.966267 \\ \mathrm{H} & -4.248861 & 1.264071 & 3.185771 \\ \mathrm{C} & -3.250698 & -1.343037 & 0.559937 \\ \mathrm{C} & -4.564340 & -1.344172 & 1.010437 \\ \mathrm{H} & -5.953211 & -0.349245 & 2.344304 \\ \mathrm{H} & -5.272953 & -2.068526 & 0.625883 \\ \mathrm{C} & -2.771243 & -2.264694 & -0.492981 \\ \mathrm{C} & -3.076371 & -3.980775 & -1.934988 \\ \mathrm{C} & -1.749914 & -3.779738 & -2.407245 \\ \mathrm{H} & -3.706916 & -4.765456 & -2.349404 \\ \mathrm{H} & -1.316858 & -4.388289 & -3.195557 \\ \mathrm{~N} & -0.219330 & 0.824452 & 2.272230 \\ \mathrm{~N} & -2.316850 & -0.468046 & 1.014874 \\ \mathrm{~N} & -3.585455 & -3.215240 & -0.980942 \\ \mathrm{~N} & -1.509513 & -2.063282 & -0.921969 \\ \mathrm{~N} & -0.985325 & -2.824473 & -1.897984\end{array}$




$\begin{array}{rrrr}\mathrm{C} & -0.620520 & 1.938163 & -2.686850 \\ \mathrm{C} & 0.200827 & 3.050000 & -2.973620 \\ \mathrm{C} & -0.376911 & 4.257524 & -3.401883 \\ \mathrm{C} & -1.765031 & 4.303383 & -3.551629 \\ \mathrm{C} & -2.565540 & 3.175744 & -3.282263 \\ \mathrm{C} & -2.001953 & 1.968155 & -2.841027 \\ \mathrm{C} & 1.590425 & 1.335243 & -2.379337 \\ \mathrm{C} & 1.575327 & 2.639699 & -2.774110 \\ \mathrm{H} & 0.235806 & 5.123971 & -3.628641 \\ \mathrm{H} & -2.238361 & 5.217282 & -3.895950 \\ \mathrm{H} & -3.638982 & 3.240464 & -3.428282 \\ \mathrm{H} & -2.631933 & 1.101162 & -2.661763 \\ \mathrm{H} & 0.103246 & 0.039380 & -2.926155 \\ \mathrm{H} & 2.445433 & 3.276436 & -2.881462 \\ \mathrm{C} & 2.667860 & 0.456949 & -1.941856 \\ \mathrm{C} & 3.988063 & 0.534048 & -2.432019 \\ \mathrm{C} & 4.936081 & -0.371294 & -1.966019 \\ \mathrm{H} & 4.247106 & 1.268965 & -3.186241 \\ \mathrm{C} & 3.252745 & -1.338597 & -0.559409 \\ \mathrm{C} & 4.566417 & -1.337913 & -1.009818 \\ \mathrm{H} & 5.953859 & -0.341419 & -2.344003 \\ \mathrm{H} & 5.276105 & -2.061033 & -0.624926 \\ \mathrm{C} & 2.774599 & -2.260554 & 0.493843 \\ \mathrm{C} & 3.082177 & -3.975685 & 1.936459 \\ \mathrm{C} & 1.755439 & -3.776368 & 2.408654 \\ \mathrm{H} & 3.713833 & -4.759335 & 2.351134 \\ \mathrm{H} & 1.323257 & -4.385246 & 3.197193 \\ \mathrm{~N} & 0.218182 & 0.823515 & -2.272593 \\ \mathrm{~N} & 2.317604 & -0.465213 & -1.014764 \\ \mathrm{~N} & 3.590165 & -3.209768 & 0.982137 \\ \mathrm{~N} & 1.512579 & -2.060792 & 0.922759 \\ \mathrm{~N} & 0.989482 & -2.822387 & 1.899044 \\ & & & \\ \mathbf{L}=\mathbf{1 a} & & & \\ & & & \end{array}$

\section{$\left[\mathrm{ML}\left(\mathrm{H}_{2} \mathrm{O}\right)_{6}\right]^{3+}$}

$\mathrm{M}=\mathrm{Eu}$

$\begin{array}{crcc}\mathrm{O} & -2.398922 & -1.483968 & 2.707392 \\ \mathrm{H} & -3.358066 & -1.629581 & 2.688803 \\ \mathrm{O} & -2.559996 & -2.493791 & -0.504959 \\ \mathrm{H} & -3.166884 & -3.247920 & -0.457766 \\ \mathrm{O} & 0.710304 & -1.430516 & 3.138743 \\ \mathrm{H} & 0.962615 & -2.270275 & 3.557233 \\ \mathrm{O} & -1.529782 & -1.143495 & -2.633466\end{array}$




$\begin{array}{lccc}\mathrm{H} & -1.649974 & -1.032511 & -3.590669 \\ \mathrm{O} & -0.164561 & -4.028844 & 1.844018 \\ \mathrm{H} & -0.792509 & -4.519515 & 2.399809 \\ \mathrm{O} & 0.670902 & -2.561722 & -1.256973 \\ \mathrm{H} & 0.823420 & -3.439629 & -1.639944 \\ \mathrm{H} & 1.178641 & -0.741970 & 3.637093 \\ \mathrm{H} & -0.632141 & -1.515398 & -2.520802 \\ \mathrm{H} & -2.470454 & -2.245391 & -1.451296 \\ \mathrm{H} & 1.556525 & -2.090696 & -1.206550 \\ \mathrm{H} & -2.176540 & -1.332356 & 3.640540 \\ \mathrm{H} & 0.486233 & -4.692271 & 1.561034 \\ \mathrm{C} & 0.356188 & 1.923873 & 0.749247 \\ \mathrm{C} & 0.508761 & 3.157408 & 1.407563 \\ \mathrm{C} & -0.630175 & 3.880844 & 1.759501 \\ \mathrm{C} & -1.878150 & 3.381542 & 1.382452 \\ \mathrm{C} & -1.941899 & 2.156464 & 0.692509 \\ \mathrm{~N} & -0.845861 & 1.400979 & 0.427756 \\ \mathrm{H} & -0.548360 & 4.829804 & 2.280631 \\ \mathrm{H} & 1.505480 & 3.525228 & 1.617889 \\ \mathrm{H} & -2.775419 & 3.958148 & 1.573514 \\ \mathrm{EU} & -0.563989 & -1.601040 & 0.843600 \\ \mathrm{C} & -3.220096 & 1.735110 & 0.119798 \\ \mathrm{C} & -4.538040 & 2.182871 & 0.472599 \\ \mathrm{~N} & -3.321953 & 0.890630 & -0.935783 \\ \mathrm{C} & -5.436489 & 1.586541 & -0.420259 \\ \mathrm{H} & -4.779238 & 2.853253 & 1.286481 \\ \mathrm{C} & -4.668077 & 0.779793 & -1.322074 \\ \mathrm{H} & -2.533424 & 0.489097 & -1.441719 \\ \mathrm{C} & -6.854615 & 1.678660 & -0.577497 \\ \mathrm{C} & -5.254529 & 0.095232 & -2.367154 \\ \mathrm{C} & -7.449895 & 0.983595 & -1.626684 \\ \mathrm{H} & -7.447561 & 2.288175 & 0.097652 \\ \mathrm{C} & -6.666967 & 0.210698 & -2.507479 \\ \mathrm{H} & -4.687070 & -0.499397 & -3.075020 \\ \mathrm{H} & -8.522354 & 1.041473 & -1.779644 \\ \mathrm{H} & -7.152429 & -0.311784 & -3.326601 \\ \mathrm{C} & 1.577764 & 1.178533 & 0.314445 \\ \mathrm{~N} & 2.738354 & 1.848055 & 0.286285 \\ \mathrm{~N} & 1.432993 & -0.094799 & -0.045855 \\ \mathrm{~N} & 3.807625 & 1.236290 & -0.218210 \\ \mathrm{C} & 3.653528 & -0.713994 & -0.621938 \\ \mathrm{C} & 5.147364 & -0.092790 & -0.770780 \\ \mathrm{C} & 1.941678 & -0.133099 \\ \mathrm{H} & -0.800298 & -1.548311 \\ \mathrm{H} & 1.307400 & -1.112575 \\ \mathrm{H} & 3.446974 & -0.440749\end{array}$




$\begin{array}{rrrr}\mathrm{C} & 5.628354 & 1.774069 & 1.339775 \\ \mathrm{C} & 6.124480 & -0.222735 & -1.128523 \\ \mathrm{C} & 4.481423 & -0.534258 & -3.056312 \\ \mathrm{C} & 4.740392 & -2.321022 & -1.294847 \\ \mathrm{H} & 5.983482 & 1.698324 & -2.119403 \\ \mathrm{H} & 7.162988 & 1.645128 & -0.834007 \\ \mathrm{H} & 4.353695 & 3.948915 & 0.286796 \\ \mathrm{H} & 5.979953 & 3.916930 & -0.406765 \\ \mathrm{H} & 4.580506 & 3.612043 & -1.440454 \\ \mathrm{H} & 6.578848 & 2.300284 & 1.459143 \\ \mathrm{H} & 4.908750 & 2.212157 & 2.036979 \\ \mathrm{H} & 5.787369 & 0.727323 & 1.614171 \\ \mathrm{H} & 6.396398 & -0.618984 & -0.144074 \\ \mathrm{H} & 6.879086 & -0.599897 & -1.824486 \\ \mathrm{H} & 5.259556 & -1.020082 & -3.650982 \\ \mathrm{H} & 3.514995 & -0.948966 & -3.360225 \\ \mathrm{H} & 4.485947 & 0.529878 & -3.304646 \\ \mathrm{H} & 3.842972 & -2.803316 & -1.692494 \\ \mathrm{H} & 5.598424 & -2.772266 & -1.799489 \\ \mathrm{H} & 4.823118 & -2.554689 & -0.228818\end{array}$

$\mathrm{M}=\mathrm{Gd}$

$\begin{array}{lccc}\text { GD } & -0.977940 & -0.848897 & 0.143078 \\ \mathrm{O} & 0.569733 & -2.371730 & 1.526127 \\ \mathrm{H} & 1.500841 & -2.384822 & 1.230774 \\ \mathrm{O} & -0.686786 & -0.144211 & 2.554655 \\ \mathrm{H} & -0.062422 & -0.701550 & 3.050639 \\ \mathrm{O} & -2.790477 & -2.171802 & -0.983907 \\ \mathrm{H} & -2.811644 & -2.512409 & -1.893422 \\ \mathrm{O} & -2.266743 & -2.407329 & 1.710432 \\ \mathrm{H} & -2.746706 & -3.196723 & 1.408990 \\ \mathrm{O} & 0.270651 & -2.351502 & -1.399542 \\ \mathrm{H} & 0.163145 & -3.244888 & -1.763091 \\ \mathrm{O} & -1.098008 & -0.035200 & -2.211807 \\ \mathrm{H} & -0.613224 & -0.475560 & -2.928673 \\ \mathrm{H} & 0.372268 & -3.255882 & 1.875733 \\ \mathrm{H} & -2.375638 & -2.365232 & 2.674798 \\ \mathrm{H} & 1.230683 & -2.220365 & -1.204719 \\ \mathrm{H} & -3.716097 & -1.920676 & -0.774124 \\ \mathrm{H} & -1.490097 & 0.768669 & -2.588688 \\ \mathrm{H} & -0.695409 & 0.719997 & 2.997442 \\ \mathrm{C} & -4.547637 & 0.145280 & 0.237494 \\ \mathrm{C} & -5.098701 & 1.133268 & -0.606927 \\ \mathrm{C} & -6.398252 & 0.980294 & -1.120779 \\ \mathrm{C} & -7.124511 & -0.155861 & -0.754961\end{array}$




\begin{tabular}{|c|c|c|c|}
\hline $\mathrm{C}$ & -6.575971 & -1.116723 & 0.115891 \\
\hline & -5.273433 & -0.980406 & 0.628954 \\
\hline $\mathrm{C}$ & -3.017854 & 1.846061 & -0.001770 \\
\hline $\mathrm{C}$ & -4.116525 & 2.190908 & -0.730295 \\
\hline $\mathrm{H}$ & -6.836295 & 1.732881 & -1.768690 \\
\hline Н & -8.134965 & -0.292328 & -1.126497 \\
\hline $\mathrm{H}$ & -7.177516 & -1.970128 & 0.412704 \\
\hline H & -4.895467 & -1.695619 & 1.352259 \\
\hline $\mathrm{H}$ & -3.120891 & 0.597739 & 1.623648 \\
\hline $\mathrm{H}$ & -4.222683 & 3.084898 & -1.332910 \\
\hline & -1.708435 & 2.484460 & 0.099795 \\
\hline & -1.549814 & 3.883193 & 0.079650 \\
\hline$C$ & -0.266034 & 4.419284 & 0.126315 \\
\hline $\mathrm{H}$ & -2.421893 & 4.527046 & 0.050763 \\
\hline & 0.605075 & 2.179526 & 0.174857 \\
\hline$C$ & 0.837569 & 3.551686 & 0.166089 \\
\hline $\mathrm{H}$ & -0.118545 & 5.495340 & 0.126563 \\
\hline $\mathrm{H}$ & 1.855592 & 3.921198 & 0.175772 \\
\hline$C$ & 1.727419 & 1.210857 & 0.096008 \\
\hline $\mathrm{C}$ & 3.981733 & 0.797634 & -0.019138 \\
\hline $\mathrm{C}$ & 3.660488 & -0.604074 & -0.237455 \\
\hline$N$ & -3.197992 & 0.531742 & 0.604069 \\
\hline $\mathrm{N}$ & -0.644810 & 1.645863 & 0.171009 \\
\hline $\mathrm{N}$ & 2.984839 & 1.667937 & 0.121182 \\
\hline $\mathrm{N}$ & 1.398436 & -0.077799 & -0.031409 \\
\hline $\mathrm{N}$ & 2.386701 & -0.982951 & -0.216943 \\
\hline $\mathrm{C}$ & 5.400246 & 1.306041 & 0.116720 \\
\hline $\mathrm{C}$ & 6.412423 & 0.269144 & -0.420680 \\
\hline $\mathrm{H}$ & 6.468856 & 0.347802 & -1.510903 \\
\hline $\mathrm{H}$ & 7.405266 & 0.538430 & -0.051263 \\
\hline $\mathrm{C}$ & 6.089314 & -1.169512 & -0.010751 \\
\hline $\mathrm{C}$ & 4.716814 & -1.660304 & -0.531638 \\
\hline $\mathrm{H}$ & 6.119553 & -1.269045 & 1.079725 \\
\hline $\mathrm{H}$ & 6.859047 & -1.843562 & -0.396551 \\
\hline $\mathrm{C}$ & 5.570164 & 2.647890 & -0.631489 \\
\hline $\mathrm{H}$ & 4.937318 & 3.431228 & -0.211601 \\
\hline $\mathrm{H}$ & 6.610998 & 2.969226 & -0.542489 \\
\hline $\mathrm{H}$ & 5.343950 & 2.545705 & -1.697251 \\
\hline $\mathrm{C}$ & 5.620805 & 1.550640 & 1.642841 \\
\hline $\mathrm{H}$ & 6.624802 & 1.958612 & 1.783867 \\
\hline $\mathrm{H}$ & 4.900373 & 2.275955 & 2.029374 \\
\hline $\mathrm{H}$ & 5.545135 & 0.632855 & 2.232753 \\
\hline $\mathrm{C}$ & 4.753474 & -1.852414 & -2.074373 \\
\hline . & 5.516105 & -2.594345 & -2.324805 \\
\hline $\mathrm{H}$ & 3.792030 & -2.218482 & -2.449682 \\
\hline $\mathrm{H}$ & 4.996042 & -0.931177 & -2.609334 \\
\hline
\end{tabular}

S-114 


$$
\begin{array}{lrrr}
\mathrm{C} & 4.368978 & -3.005770 & 0.138167 \\
\mathrm{H} & 3.462167 & -3.457925 & -0.275682 \\
\mathrm{H} & 5.183734 & -3.713344 & -0.033917 \\
\mathrm{H} & 4.258533 & -2.900056 & 1.223287
\end{array}
$$

$\mathrm{M}=\mathrm{Am}$

$\begin{array}{lrrc}\mathrm{AM} & 0.931620 & -0.776534 & 0.229043 \\ \mathrm{O} & -0.655784 & -2.612234 & -0.373192 \\ \mathrm{H} & -1.610084 & -2.265053 & -0.310259 \\ \mathrm{O} & 0.598285 & -0.994871 & -2.331285 \\ \mathrm{H} & -0.097864 & -1.645962 & -2.525749 \\ \mathrm{O} & 3.088389 & -0.948911 & 1.615810 \\ \mathrm{H} & 3.184262 & -0.521927 & 2.483399 \\ \mathrm{O} & 2.353662 & -2.746103 & -0.640477 \\ \mathrm{H} & 3.002401 & -3.288373 & -0.162770 \\ \mathrm{O} & 0.795072 & -2.555165 & 2.237919 \\ \mathrm{H} & 1.575822 & -2.879916 & 2.716966 \\ \mathrm{O} & 0.492325 & 0.188894 & 2.563021 \\ \mathrm{H} & 0.259969 & -0.413184 & 3.289813 \\ \mathrm{H} & -0.647589 & -3.580507 & -0.397279 \\ \mathrm{H} & 2.325838 & -3.093220 & -1.546861 \\ \mathrm{H} & 0.108462 & -3.230411 & 2.364738 \\ \mathrm{H} & 3.947652 & -0.833219 & 1.166020 \\ \mathrm{H} & 0.289984 & 1.089273 & 2.864549 \\ \mathrm{H} & 0.689076 & -0.452521 & -3.131918 \\ \mathrm{C} & 4.338854 & 0.343509 & -0.869698 \\ \mathrm{C} & 5.035459 & 1.296634 & -0.089282 \\ \mathrm{C} & 6.427182 & 1.185751 & 0.086098 \\ \mathrm{C} & 7.088930 & 0.136659 & -0.554501 \\ \mathrm{C} & 6.385895 & -0.785287 & -1.357729 \\ \mathrm{C} & 4.996059 & -0.697180 & -1.525506 \\ \mathrm{C} & 2.851215 & 1.944813 & -0.159762 \\ \mathrm{C} & 4.072016 & 2.290050 & 0.338160 \\ \mathrm{H} & 6.976921 & 1.909867 & 0.678895 \\ \mathrm{H} & 8.164874 & 0.037138 & -0.453088 \\ \mathrm{H} & 6.934620 & -1.571379 & -1.866592 \\ \mathrm{H} & 4.475401 & -1.396754 & -2.171051 \\ \mathrm{H} & 2.602756 & 0.806847 & -1.849384 \\ \mathrm{H} & 4.283054 & 3.146829 & 0.966432 \\ \mathrm{C} & 1.539766 & 2.563879 & -0.017367 \\ \mathrm{C} & 1.375310 & 3.955000 & 0.110674 \\ \mathrm{C} & 0.088675 & 4.478583 & 0.195428 \\ \mathrm{H} & 2.241958 & 4.606503 & 0.104534 \\ \mathrm{C} & -0.773696 & 2.240758 & 0.026414 \\ \mathrm{C} & -1.010919 & 3.606939 & 0.140399\end{array}$




$\begin{array}{lrrr}\mathrm{H} & -0.064595 & 5.550375 & 0.281323 \\ \mathrm{H} & -2.030559 & 3.969733 & 0.178840 \\ \mathrm{C} & -1.893557 & 1.269302 & -0.027411 \\ \mathrm{C} & -4.149653 & 0.862073 & -0.137140 \\ \mathrm{C} & -3.837748 & -0.553423 & -0.189509 \\ \mathrm{~N} & 2.932974 & 0.688063 & -0.889183 \\ \mathrm{~N} & 0.478588 & 1.717200 & -0.040109 \\ \mathrm{~N} & -3.146389 & 1.734755 & -0.063707 \\ \mathrm{~N} & -1.566249 & -0.026289 & -0.048686 \\ \mathrm{~N} & -2.564433 & -0.927890 & -0.142765 \\ \mathrm{C} & -5.560220 & 1.403524 & -0.222112 \\ \mathrm{C} & -6.594623 & 0.277373 & -0.000914 \\ \mathrm{H} & -6.709291 & 0.092940 & 1.072066 \\ \mathrm{H} & -7.567936 & 0.634178 & -0.347360 \\ \mathrm{C} & -6.239306 & -1.022915 & -0.725281 \\ \mathrm{C} & -4.902362 & -1.641273 & -0.250232 \\ \mathrm{H} & -6.196544 & -0.854417 & -1.806748 \\ \mathrm{H} & -7.029660 & -1.761562 & -0.566298 \\ \mathrm{C} & -5.765778 & 2.524213 & 0.823548 \\ \mathrm{H} & -5.106662 & 3.374929 & 0.642695 \\ \mathrm{H} & -6.798472 & 2.876722 & 0.761621 \\ \mathrm{H} & -5.600506 & 2.159745 & 1.842253 \\ \mathrm{C} & -5.708100 & 2.014822 & -1.649793 \\ \mathrm{H} & -6.703609 & 2.457764 & -1.733878 \\ \mathrm{H} & -4.968137 & 2.801544 & -1.815915 \\ \mathrm{H} & -5.604810 & 1.266565 & -2.440375 \\ \mathrm{C} & -5.047698 & -2.225781 & 1.182561 \\ \mathrm{H} & -5.807275 & -3.011710 & 1.173403 \\ \mathrm{H} & -4.106118 & -2.669167 & 1.522496 \\ \mathrm{H} & -5.353549 & -1.474994 & 1.915267 \\ \mathrm{C} & -4.492144 & -2.770679 & -1.218899 \\ \mathrm{H} & -3.627256 & -3.336549 & -0.859259 \\ \mathrm{H} & -5.319233 & -3.479087 & -1.310442 \\ \mathrm{H} & -4.275582 & -2.388117 & -2.221267\end{array}$

$\mathrm{M}=\mathrm{Cm}$

$\begin{array}{lccc}\mathrm{CM} & -0.907992 & -0.786336 & 0.105087 \\ \mathrm{O} & 0.667681 & -2.347178 & 1.497819 \\ \mathrm{H} & 1.596444 & -2.343736 & 1.194216 \\ \mathrm{O} & -0.624851 & -0.145806 & 2.590469 \\ \mathrm{H} & 0.002719 & -0.724802 & 3.056963 \\ \mathrm{O} & -2.796982 & -2.072401 & -1.064950 \\ \mathrm{H} & -2.834442 & -2.378224 & -1.986165 \\ \mathrm{O} & -2.217269 & -2.434580 & 1.650551 \\ \mathrm{H} & -2.710294 & -3.201950 & 1.315108\end{array}$




$\begin{array}{lrrr}\mathrm{O} & 0.388112 & -2.293722 & -1.487949 \\ \mathrm{H} & 0.283857 & -3.179468 & -1.871035 \\ \mathrm{O} & -1.001262 & 0.038443 & -2.302709 \\ \mathrm{H} & -0.487029 & -0.399035 & -3.000829 \\ \mathrm{H} & 0.474490 & -3.246335 & 1.809824 \\ \mathrm{H} & -2.332749 & -2.428258 & 2.615016 \\ \mathrm{H} & 1.342414 & -2.170271 & -1.271235 \\ \mathrm{H} & -3.713464 & -1.811287 & -0.833457 \\ \mathrm{H} & -1.394791 & 0.833696 & -2.696632 \\ \mathrm{H} & -0.633427 & 0.696870 & 3.073435 \\ \mathrm{C} & -4.476838 & 0.290669 & 0.251500 \\ \mathrm{C} & -5.012898 & 1.291829 & -0.586771 \\ \mathrm{C} & -6.318285 & 1.165581 & -1.093299 \\ \mathrm{C} & -7.063912 & 0.042937 & -0.725794 \\ \mathrm{C} & -6.528396 & -0.932241 & 0.137938 \\ \mathrm{C} & -5.220508 & -0.823412 & 0.642263 \\ \mathrm{C} & -2.914884 & 1.961590 & 0.010246 \\ \mathrm{C} & -4.009955 & 2.329633 & -0.712908 \\ \mathrm{H} & -6.745633 & 1.928000 & -1.736789 \\ \mathrm{H} & -8.079337 & -0.072677 & -1.090838 \\ \mathrm{H} & -7.144214 & -1.775580 & 0.434251 \\ \mathrm{H} & -4.847229 & -1.550870 & 1.356208 \\ \mathrm{C} & 6.191653 & -1.114537 & 0.015413 \\ \mathrm{H} & -3.035100 & 0.709950 & 1.634316 \\ \mathrm{H} & -4.100172 & 3.225673 & -1.315038 \\ \mathrm{C} & -1.594891 & 2.580559 & 0.106503 \\ \mathrm{C} & -1.422287 & 3.977499 & 0.095999 \\ \mathrm{C} & -0.133241 & 4.500902 & 0.139899 \\ \mathrm{H} & -2.287962 & 4.630272 & 0.077896 \\ \mathrm{C} & 0.717102 & 2.252796 & 0.168491 \\ \mathrm{C} & 0.961943 & 3.622633 & 0.169433 \\ \mathrm{H} & 0.024422 & 5.575434 & 0.147497 \\ \mathrm{H} & 1.983066 & 3.983189 & 0.180057 \\ \mathrm{C} & 1.835313 & 1.277871 & 0.087021 \\ \mathrm{C} & 4.089491 & 0.857356 & -0.014451 \\ \mathrm{C} & 3.765779 & -0.543282 & -0.232834 \\ \mathrm{~N} & -3.121275 & 0.651939 & 0.615289 \\ \mathrm{~N} & -0.538279 & 1.732257 & 0.163209 \\ \mathrm{~N} & 3.094322 & 1.730730 & 0.121775 \\ \mathrm{H} & 1.504408 & -0.009497 & -0.049179 \\ \mathrm{H} & -506778 & -0.918515 & -0.225327 \\ \mathrm{H} & 1.363308 & 0.125198 \\ \mathrm{H} & 0.320724 & -0.401471 \\ \mathrm{H} & -1.605206 & -0.511239\end{array}$




$\begin{array}{lccc}\mathrm{H} & 6.214415 & -1.206946 & 1.106725 \\ \mathrm{H} & 6.962353 & -1.792852 & -0.360866 \\ \mathrm{C} & 5.684520 & 2.699682 & -0.631634 \\ \mathrm{H} & 5.051538 & 3.487130 & -0.219654 \\ \mathrm{H} & 6.725608 & 3.019716 & -0.540806 \\ \mathrm{H} & 5.462326 & 2.590614 & -1.697600 \\ \mathrm{C} & 5.723902 & 1.617716 & 1.650280 \\ \mathrm{H} & 6.727838 & 2.025292 & 1.792909 \\ \mathrm{H} & 5.002718 & 2.346265 & 2.029251 \\ \mathrm{H} & 5.644514 & 0.703866 & 2.245797 \\ \mathrm{C} & 4.869003 & -1.811605 & -2.051579 \\ \mathrm{H} & 5.629042 & -2.560199 & -2.289780 \\ \mathrm{H} & 3.908290 & -2.175371 & -2.431285 \\ \mathrm{H} & 5.121011 & -0.896577 & -2.592811 \\ \mathrm{C} & 4.464200 & -2.943464 & 0.168413 \\ \mathrm{H} & 3.560061 & -3.397409 & -0.249696 \\ \mathrm{H} & 5.278621 & -3.654727 & 0.010404 \\ \mathrm{H} & 4.344105 & -2.826945 & 1.251394\end{array}$

\section{$\left[\mathrm{ML}\left(\mathrm{H}_{2} \mathrm{O}\right)_{5}\right]^{3+}$}

$\mathrm{M}=\mathrm{Eu}$

$\begin{array}{lccc}\text { EU } & -2.961539 & -1.863085 & -0.316037 \\ \mathrm{O} & -2.897679 & -1.683364 & -2.904722 \\ \mathrm{H} & -2.528445 & -2.295598 & -3.562131 \\ \mathrm{O} & -2.178795 & -4.334562 & -0.637484 \\ \mathrm{H} & -2.868751 & -5.000025 & -0.799547 \\ \mathrm{O} & -5.131519 & -3.264039 & -0.782011 \\ \mathrm{H} & -5.561496 & -3.367310 & -1.647324 \\ \mathrm{O} & -4.416016 & 0.111455 & -0.232487 \\ \mathrm{H} & -3.781731 & 0.877116 & -0.099887 \\ \mathrm{O} & -3.519441 & -2.373420 & 2.182591 \\ \mathrm{H} & -3.477017 & -3.200774 & 2.689713 \\ \mathrm{H} & -5.803165 & -3.537404 & -0.135256 \\ \mathrm{H} & -3.967914 & -1.741008 & 2.769029 \\ \mathrm{H} & -3.264063 & -0.946891 & -3.421850 \\ \mathrm{H} & -1.340015 & -4.821593 & -0.674324 \\ \mathrm{H} & -5.317899 & 0.451463 & -0.321481 \\ \mathrm{C} & 6.112689 & -0.239791 & -0.554450 \\ \mathrm{C} & 6.605023 & -1.455798 & 0.023162 \\ \mathrm{C} & 7.992447 & -1.780694 & -0.087779 \\ \mathrm{C} & 8.830110 & -0.892319 & -0.761388 \\ \mathrm{C} & 8.316009 & 0.294235 & -1.316592 \\ \mathrm{C} & 6.936163 & 0.643028 & -1.221329 \\ \mathrm{C} & 4.363446 & -1.280250 & 0.411029\end{array}$




\begin{tabular}{crrr}
$\mathrm{C}$ & 5.517957 & -2.105257 & 0.624588 \\
$\mathrm{H}$ & 8.382754 & -2.696562 & 0.345386 \\
$\mathrm{H}$ & 9.887962 & -1.111232 & -0.859817 \\
$\mathrm{H}$ & 8.987401 & 0.972077 & -1.835290 \\
$\mathrm{H}$ & 6.575967 & 1.567706 & -1.660293 \\
$\mathrm{H}$ & 4.082884 & 0.544609 & -0.538475 \\
$\mathrm{H}$ & 5.535771 & -3.047487 & 1.155220 \\
$\mathrm{C}$ & 2.973862 & -1.458099 & 0.839794 \\
$\mathrm{C}$ & 2.578957 & -2.553966 & 1.628041 \\
$\mathrm{C}$ & 1.246797 & -2.622038 & 2.039195 \\
$\mathrm{H}$ & 3.289411 & -3.312068 & 1.937006 \\
$\mathrm{C}$ & 0.849050 & -0.558070 & 0.847262 \\
$\mathrm{C}$ & 0.363762 & -1.610490 & 1.646480 \\
$\mathrm{H}$ & 0.916115 & -3.429004 & 2.685866 \\
$\mathrm{H}$ & -0.653174 & -1.590636 & 2.025975 \\
$\mathrm{C}$ & -0.032936 & 0.598617 & 0.479022 \\
$\mathrm{C}$ & -0.206441 & 2.872076 & 0.220568 \\
$\mathrm{C}$ & -1.638524 & 2.701894 & 0.160880 \\
$\mathrm{~N}$ & 4.738919 & -0.189345 & -0.288232 \\
$\mathrm{~N}$ & 2.125811 & -0.484333 & 0.458164 \\
$\mathrm{~N}$ & 0.556172 & 1.799982 & 0.401009 \\
$\mathrm{~N}$ & -1.339131 & 0.378807 & 0.274794 \\
$\mathrm{~N}$ & -2.135186 & 1.468155 & 0.132476 \\
$\mathrm{C}$ & 0.482065 & 4.210568 & 0.016436 \\
$\mathrm{C}$ & -0.509899 & 5.377562 & 0.218088 \\
$\mathrm{H}$ & -0.617959 & 5.580367 & 1.288018 \\
$\mathrm{H}$ & -0.071257 & 6.281244 & -0.213993 \\
$\mathrm{C}$ & -1.883563 & 5.127450 & -0.407863 \\
$\mathrm{C}$ & -2.602538 & 3.882404 & 0.165456 \\
$\mathrm{H}$ & -1.793323 & 5.022832 & -1.494947 \\
$\mathrm{H}$ & -2.525373 & 5.996972 & -0.239896 \\
$\mathrm{C}$ & 1.670337 & 4.360675 & 0.990330 \\
$\mathrm{H}$ & 2.423467 & 3.587196 & 0.830442 \\
$\mathrm{H}$ & 2.136368 & 5.337350 & 0.834838 \\
$\mathrm{H}$ & 1.342047 & 4.310713 & 2.032878 \\
$\mathrm{C}$ & 1.021337 & 4.198083 & -1.443829 \\
$\mathrm{H}$ & 1.574834 & 5.123413 & -1.623459 \\
$\mathrm{H}$ & 1.700151 & 3.354833 & -1.599397 \\
$\mathrm{H}$ & 0.220517 & 4.136797 & -2.186089 \\
$\mathrm{C}$ & -3.015315 & 4.119002 & 1.645679 \\
$\mathrm{H}$ & -3.697694 & 4.971758 & 1.697321 \\
$\mathrm{H}$ & -3.533820 & 3.244611 & 2.051211 \\
$\mathrm{H}$ & -2.161922 & 4.334197 & 2.293105 \\
$\mathrm{C}$ & -3.869099 & 3.609180 & -0.668695 \\
$\mathrm{H}$ & -4.530881 & 2.880800 & -0.191636 \\
$\mathrm{H}$ & -4.441959 & 4.535660 & -0.758022 \\
& & & \\
\hline
\end{tabular}




$$
\begin{aligned}
& \text { H } \quad-3.629511 \quad 3.270821 \quad-1.681647 \\
& \mathrm{M}=\mathrm{Gd} \\
& \text { GD } \quad \begin{array}{llll}
1.003282 & -0.765274 & 0.592617
\end{array} \\
& \begin{array}{llll}
\mathrm{O} & 2.738168 & -2.466220 & 0.167963
\end{array} \\
& \mathrm{H} \quad 3.580099 \quad-2.253436 \quad-0.289850 \\
& \begin{array}{llll}
\text { O } & 2.895848 & -0.099824 & 2.109432
\end{array} \\
& \begin{array}{llll}
\mathrm{H} & 3.413547 & -0.678894 & 2.694481
\end{array} \\
& \begin{array}{llll}
\text { O } & 0.416368 & -2.586675 & 2.181702
\end{array} \\
& \mathrm{H} \quad 0.063677 \quad-3.459119 \quad 1.938344 \\
& \begin{array}{llll}
\mathrm{O} & -0.122080 & -2.417720 & -0.696679
\end{array} \\
& \mathrm{H} \quad-1.113700 \quad-2.240805 \quad-0.679670 \\
& \begin{array}{llll}
\mathrm{O} & 0.216391 & 0.189835 & 2.768158
\end{array} \\
& \begin{array}{llll}
\mathrm{H} & 0.825684 & 0.675630 & 3.349443
\end{array} \\
& \mathrm{H} \quad 0.334640 \quad-2.520533 \quad 3.148000 \\
& \mathrm{H} \quad-0.677153 \quad 0.332272 \quad 3.121304 \\
& \begin{array}{llll}
\mathrm{H} & 2.804234 & -3.390779 & 0.458622
\end{array} \\
& \begin{array}{llll}
\mathrm{H} & 3.507276 & 0.601927 & 1.813027
\end{array} \\
& \mathrm{H} \quad 0.075573 \quad-3.130960 \quad-1.323844 \\
& \begin{array}{llll}
\text { C } & 4.195775 & -0.059584 & -1.209059
\end{array} \\
& \begin{array}{llll}
\text { C } & 5.080018 & 0.863511 & -0.604741
\end{array} \\
& \begin{array}{llll}
\text { C } & 6.468051 & 0.635761 & -0.640075
\end{array} \\
& \begin{array}{llll}
\text { C } & 6.933494 & -0.502611 & -1.301960
\end{array} \\
& \begin{array}{llll}
\text { C } & 6.041413 & -1.391805 & -1.934568
\end{array} \\
& \begin{array}{llll}
\text { C } & 4.651017 & -1.184040 & -1.899925
\end{array} \\
& \begin{array}{llll}
\text { C } & 2.965814 & 1.697884 & -0.378136
\end{array} \\
& \begin{array}{llll}
\text { C } & 4.277566 & 1.961437 & -0.100071
\end{array} \\
& \mathrm{H} \quad 7.163423 \quad 1.336565 \quad-0.188850 \\
& \text { H } \quad 8.000259 \quad-0.693894 \quad-1.358447 \\
& \mathrm{H} \quad 6.437563 \quad-2.241510 \quad-2.481850 \\
& \text { H } \quad 3.987294 \quad-1.834418 \quad-2.464217 \\
& \mathrm{H} \quad 2.334541 \quad 0.469926 \quad-1.903427 \\
& \mathrm{H} \quad 4.653382 \quad 2.842272 \quad 0.407907 \\
& \text { C } \quad 1.718914 \quad 2.412040 \quad-0.119300 \\
& \begin{array}{llll}
\text { C } & 1.605694 & 3.810478 & -0.036942
\end{array} \\
& \begin{array}{llll}
\text { C } & 0.338011 & 4.370499 & 0.117984
\end{array} \\
& \text { H } \quad 2.482937 \quad 4.440305 \quad-0.136462 \\
& \begin{array}{llll}
\text { C } & -0.600300 & 2.160798 & 0.079314
\end{array} \\
& \begin{array}{llll}
\text { C } & -0.793196 & 3.535400 & 0.155889
\end{array} \\
& \begin{array}{llll}
\mathrm{H} & 0.221104 & 5.449061 & 0.172609
\end{array} \\
& \mathrm{H} \quad-1.796895 \quad 3.937694 \quad 0.225648 \\
& \begin{array}{llll}
\text { C } & -1.718674 & 1.184932 & 0.036271
\end{array} \\
& \begin{array}{llll}
\text { C } & -3.940602 & 0.707841 & -0.251669
\end{array} \\
& \begin{array}{llll}
\mathrm{C} & -3.570783 & -0.691705 & -0.381048
\end{array} \\
& \begin{array}{llll}
\mathrm{N} & 2.838537 & 0.392350 & -1.014540
\end{array}
\end{aligned}
$$




$\begin{array}{lrrr}\mathrm{N} & 0.633266 & 1.606404 & -0.026573 \\ \mathrm{~N} & -2.975603 & 1.614711 & -0.081698 \\ \mathrm{~N} & -1.360036 & -0.105724 & 0.053664 \\ \mathrm{~N} & -2.299358 & -1.037724 & -0.204131 \\ \mathrm{C} & -5.364565 & 1.201908 & -0.366876 \\ \mathrm{C} & -6.359318 & 0.020002 & -0.351129 \\ \mathrm{H} & -6.539947 & -0.293816 & 0.682048 \\ \mathrm{H} & -7.321497 & 0.377867 & -0.726031 \\ \mathrm{C} & -5.891773 & -1.171026 & -1.191118 \\ \mathrm{C} & -4.575385 & -1.798522 & -0.674177 \\ \mathrm{H} & -5.765249 & -0.870274 & -2.236716 \\ \mathrm{H} & -6.660839 & -1.948071 & -1.191899 \\ \mathrm{C} & -5.674989 & 2.177077 & 0.794783 \\ \mathrm{H} & -5.033759 & 3.059888 & 0.765930 \\ \mathrm{H} & -6.712587 & 2.508504 & 0.705336 \\ \mathrm{H} & -5.566282 & 1.690710 & 1.769416 \\ \mathrm{C} & -5.458570 & 1.981926 & -1.715094 \\ \mathrm{H} & -6.467106 & 2.393221 & -1.803428 \\ \mathrm{H} & -4.746289 & 2.809695 & -1.738371 \\ \mathrm{H} & -5.278097 & 1.341854 & -2.582745 \\ \mathrm{C} & -4.820283 & -2.571150 & 0.651677 \\ \mathrm{H} & -5.535050 & -3.377389 & 0.468229 \\ \mathrm{H} & -3.892203 & -3.018506 & 1.020791 \\ \mathrm{H} & -5.230996 & -1.935402 & 1.440063 \\ \mathrm{C} & -4.020258 & -2.775163 & -1.734060 \\ \mathrm{H} & -3.166040 & -3.348793 & -1.361117 \\ \mathrm{H} & -4.798307 & -3.496703 & -1.995487 \\ \mathrm{H} & -3.730932 & -2.257147 & -2.653731\end{array}$

$\mathrm{M}=\mathrm{Am}$

$\begin{array}{lccc}\text { AM } & 0.913790 & -0.742563 & 0.519692 \\ \mathrm{O} & 2.779778 & -2.361951 & 0.008980 \\ \mathrm{H} & 3.600463 & -2.115067 & -0.468435 \\ \mathrm{O} & 2.785779 & 0.015740 & 2.141554 \\ \mathrm{H} & 3.296148 & -0.506764 & 2.783466 \\ \mathrm{O} & 0.477615 & -2.851155 & 1.916953 \\ \mathrm{H} & 0.074701 & -3.651338 & 1.539622 \\ \mathrm{O} & -0.255386 & -2.388197 & -0.863826 \\ \mathrm{H} & -1.238316 & -2.185454 & -0.843947 \\ \mathrm{O} & 0.024828 & -0.047184 & 2.800519 \\ \mathrm{H} & 0.567345 & 0.473041 & 3.417196 \\ \mathrm{H} & 0.511780 & -2.990858 & 2.878244 \\ \mathrm{H} & -0.860023 & -0.111525 & 3.196486 \\ \mathrm{H} & 2.901733 & -3.271102 & 0.328486 \\ \mathrm{H} & 3.382708 & 0.726925 & 1.838667\end{array}$




\begin{tabular}{|c|c|c|c|}
\hline $\mathrm{H}$ & -0.064879 & -3.028350 & -1.567677 \\
\hline & 4.131004 & 0.140185 & -1.299407 \\
\hline & 4.999849 & 1.046021 & -0.647812 \\
\hline C & 6.392002 & 0.845912 & -0.697953 \\
\hline $\mathrm{C}$ & 6.875993 & -0.245098 & -1.422515 \\
\hline C & 5.998336 & -1.115522 & -2.100821 \\
\hline $\mathrm{C}$ & 4.605149 & -0.936882 & -2.050769 \\
\hline$C$ & 2.870430 & 1.821745 & -0.371338 \\
\hline $\mathrm{C}$ & 4.178388 & 2.098352 & -0.082905 \\
\hline $\mathrm{H}$ & 7.075732 & 1.533416 & -0.210048 \\
\hline $\mathrm{H}$ & 7.945883 & -0.413211 & -1.491914 \\
\hline $\mathrm{H}$ & 6.408492 & -1.927077 & -2.693729 \\
\hline $\mathrm{H}$ & 3.950132 & -1.571179 & -2.642946 \\
\hline $\mathrm{H}$ & 2.249620 & 0.656995 & -1.952242 \\
\hline $\mathrm{H}$ & 4.538808 & 2.958644 & 0.469438 \\
\hline $\mathrm{C}$ & 1.614729 & 2.503621 & 213 \\
\hline $\mathrm{C}$ & 1.490297 & 3.895867 & 0.072686 \\
\hline $\mathrm{C}$ & 0.220044 & 4.440647 & 0.253012 \\
\hline $\mathrm{H}$ & 2.363572 & 4.534838 & 0.000979 \\
\hline $\mathrm{C}$ & -0.702928 & 2.228856 & 0.111926 \\
\hline $\mathrm{C}$ & -0.904932 & 3.596888 & 0.250703 \\
\hline $\mathrm{H}$ & 0.096093 & 5.514662 & 0.357675 \\
\hline $\mathrm{H}$ & -1.911783 & 3.987693 & 7595 \\
\hline $\mathrm{C}$ & -1.818044 & 1.254946 & 0.022966 \\
\hline $\mathrm{C}$ & -4.042454 & 0.787558 & -0.269445 \\
\hline $\mathrm{C}$ & -3.674412 & -0.606462 & -0.449518 \\
\hline $\mathrm{N}$ & 2.769661 & 0.554043 & -1.076256 \\
\hline $\mathrm{N}$ & 0.534668 & 1.686217 & -0.014265 \\
\hline $\mathrm{N}$ & -3.076526 & 1.686368 & -0.066605 \\
\hline $\mathrm{N}$ & -1.459100 & -0.034489 & -0.026306 \\
\hline $\mathrm{N}$ & -2.400322 & -0.957158 & -0.303488 \\
\hline $\mathrm{C}$ & -5.466086 & 1.287201 & -0.366295 \\
\hline $\mathrm{C}$ & -6.463463 & 0.107426 & -0.379905 \\
\hline $\mathrm{H}$ & -6.641683 & -0.233764 & 0.644963 \\
\hline $\mathrm{H}$ & -7.425924 & 0.477664 & -0.741878 \\
\hline $\mathrm{C}$ & -6.002167 & -1.061644 & -1.253471 \\
\hline $\mathrm{C}$ & -4.683271 & -1.704076 & -0.761436 \\
\hline $\mathrm{H}$ & -5.881514 & -0.733975 & -2.291651 \\
\hline $\mathrm{H}$ & -6.772140 & -1.837638 & -1.269751 \\
\hline $\mathrm{C}$ & -5.772535 & 2.231814 & 0.821084 \\
\hline $\mathrm{H}$ & -5.131241 & 3.114948 & 0.813459 \\
\hline $\mathrm{H}$ & -6.810359 & 2.565602 & 0.743777 \\
\hline $\mathrm{H}$ & -5.660477 & 1.720315 & 1.782361 \\
\hline $\mathrm{C}$ & -5.560690 & 2.102489 & -1.693637 \\
\hline $\mathrm{H}$ & -6.568565 & 2.517914 & -1.769589 \\
\hline $\mathrm{H}$ & -4.846926 & 2.929380 & -1.696233 \\
\hline
\end{tabular}




$\begin{array}{lrrr}\mathrm{H} & -5.382765 & 1.485216 & -2.578213 \\ \mathrm{C} & -4.919522 & -2.506945 & 0.547999 \\ \mathrm{H} & -5.637555 & -3.307271 & 0.351778 \\ \mathrm{H} & -3.989442 & -2.965078 & 0.898913 \\ \mathrm{H} & -5.322351 & -1.888981 & 1.354407 \\ \mathrm{C} & -4.139727 & -2.657301 & -1.848156 \\ \mathrm{H} & -3.287065 & -3.245250 & -1.494228 \\ \mathrm{H} & -4.923175 & -3.367981 & -2.122865 \\ \mathrm{H} & -3.852641 & -2.118410 & -2.756528\end{array}$

$\mathrm{M}=\mathrm{Cm}$

$\begin{array}{lrrc}\mathrm{CM} & 0.929174 & -0.735850 & 0.490790 \\ \mathrm{O} & 2.684756 & -2.437214 & -0.117615 \\ \mathrm{H} & 3.529736 & -2.182203 & -0.545487 \\ \mathrm{O} & 2.898003 & -0.171343 & 2.053442 \\ \mathrm{H} & 3.428014 & -0.799683 & 2.573232 \\ \mathrm{O} & 0.372503 & -2.660402 & 2.056833 \\ \mathrm{H} & 0.024235 & -3.522727 & 1.774414 \\ \mathrm{O} & -0.280008 & -2.401800 & -0.806315 \\ \mathrm{H} & -1.264041 & -2.188935 & -0.765686 \\ \mathrm{O} & 0.198817 & 0.135841 & 2.764907 \\ \mathrm{H} & 0.839905 & 0.554430 & 3.364179 \\ \mathrm{H} & 0.314039 & -2.646423 & 3.026794 \\ \mathrm{H} & -0.682189 & 0.291768 & 3.143620 \\ \mathrm{H} & 2.743157 & -3.388224 & 0.071584 \\ \mathrm{H} & 3.506027 & 0.548460 & 1.798188 \\ \mathrm{H} & -0.115652 & -3.070351 & -1.489678 \\ \mathrm{C} & 4.127110 & 0.141210 & -1.279632 \\ \mathrm{C} & 4.987707 & 1.041922 & -0.610897 \\ \mathrm{C} & 6.380107 & 0.838616 & -0.641308 \\ \mathrm{C} & 6.872489 & -0.250174 & -1.363747 \\ \mathrm{C} & 6.003314 & -1.113894 & -2.061127 \\ \mathrm{C} & 4.609863 & -0.931619 & -2.031420 \\ \mathrm{C} & 2.856391 & 1.826879 & -0.366246 \\ \mathrm{C} & 4.160124 & 2.096282 & -0.056137 \\ \mathrm{H} & 7.058239 & 1.522783 & -0.140942 \\ \mathrm{H} & 7.942971 & -0.420143 & -1.418252 \\ \mathrm{H} & 6.420664 & -1.921618 & -2.654310 \\ \mathrm{H} & 3.963383 & -1.555271 & -2.644174 \\ \mathrm{H} & 2.260332 & 0.670746 & -1.963055 \\ \mathrm{H} & 4.514224 & 2.953084 & 0.505670 \\ \mathrm{C} & 1.596727 & 2.512681 & -0.088671 \\ \mathrm{C} & 1.468716 & 3.904976 & 0.050562 \\ \mathrm{C} & 0.194519 & 4.446151 & 0.218762 \\ \mathrm{H} & 2.340320 & 4.546699 & -0.017142\end{array}$




$\begin{array}{lrrr}\mathrm{C} & -0.720569 & 2.229923 & 0.088662 \\ \mathrm{C} & -0.927702 & 3.598856 & 0.217774 \\ \mathrm{H} & 0.066331 & 5.520404 & 0.315867 \\ \mathrm{H} & -1.935637 & 3.987732 & 0.300106 \\ \mathrm{C} & -1.834212 & 1.249318 & 0.015664 \\ \mathrm{C} & -4.059476 & 0.778892 & -0.263836 \\ \mathrm{C} & -3.692128 & -0.617870 & -0.423433 \\ \mathrm{~N} & 2.762276 & 0.559551 & -1.077140 \\ \mathrm{~N} & 0.518665 & 1.693521 & -0.034236 \\ \mathrm{~N} & -3.092969 & 1.681057 & -0.079642 \\ \mathrm{~N} & -1.474923 & -0.040711 & -0.008680 \\ \mathrm{~N} & -2.418800 & -0.967143 & -0.272651 \\ \mathrm{C} & -5.483580 & 1.276784 & -0.361981 \\ \mathrm{C} & -6.480629 & 0.096653 & -0.355290 \\ \mathrm{H} & -6.654191 & -0.230794 & 0.674869 \\ \mathrm{H} & -7.444795 & 0.461609 & -0.718056 \\ \mathrm{C} & -6.022382 & -1.083972 & -1.214801 \\ \mathrm{C} & -4.701868 & -1.719558 & -0.718626 \\ \mathrm{H} & -5.905434 & -0.770122 & -2.257700 \\ \mathrm{H} & -6.792437 & -1.860046 & -1.218043 \\ \mathrm{C} & -5.785343 & 2.237032 & 0.814063 \\ \mathrm{H} & -5.144809 & 3.120493 & 0.791484 \\ \mathrm{H} & -6.823776 & 2.569035 & 0.737144 \\ \mathrm{H} & -5.668468 & 1.738484 & 1.781583 \\ \mathrm{C} & -5.584642 & 2.074271 & -1.699489 \\ \mathrm{H} & -6.592902 & 2.488575 & -1.776374 \\ \mathrm{H} & -4.870922 & 2.901024 & -1.716556 \\ \mathrm{H} & -5.410717 & 1.445150 & -2.576493 \\ \mathrm{C} & -4.934055 & -2.505976 & 0.601486 \\ \mathrm{H} & -5.652316 & -3.308930 & 0.417178 \\ \mathrm{H} & -4.002783 & -2.958922 & 0.955734 \\ \mathrm{H} & -5.334807 & -1.878034 & 1.401180 \\ \mathrm{C} & -4.160684 & -2.686178 & -1.794669 \\ \mathrm{H} & -3.306427 & -3.268724 & -1.435696 \\ \mathrm{H} & -4.944442 & -3.400829 & -2.057939 \\ \mathrm{H} & -3.876589 & -2.158691 & -2.710667\end{array}$

$\left[\mathrm{ML}_{2}\left(\mathrm{H}_{2} \mathrm{O}\right)_{2}\right]^{3+}$

$\mathrm{M}=\mathrm{Eu}$

$\begin{array}{lrrr}\text { EU } & 0.000004 & 0.180189 & -0.000022 \\ \mathrm{O} & 0.545244 & -1.404150 & -1.850558 \\ \mathrm{H} & 1.408546 & -1.854794 & -1.605887 \\ \mathrm{O} & -0.545208 & -1.404268 & 1.850417 \\ \mathrm{H} & -0.081129 & -1.954031 & 2.497951\end{array}$




\begin{tabular}{|c|c|c|c|}
\hline $\mathrm{H}$ & 0.081183 & -1.953932 & -2.498088 \\
\hline & -1.408376 & -1.855078 & 1.605586 \\
\hline & 2.343009 & 2.511003 & -2.072474 \\
\hline & 2.093331 & 3.899695 & -2.223504 \\
\hline & 3.172044 & 4.814105 & -2.262943 \\
\hline & 4.467063 & 4.307087 & -2.188333 \\
\hline & 4.694431 & 2.918938 & -2.073591 \\
\hline & 3.631795 & 1.997869 & -2.007974 \\
\hline 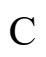 & 0.095069 & 2.811576 & -2.292182 \\
\hline$C$ & 0.677629 & 4.062183 & -2.363782 \\
\hline H & 2.996255 & 5.878990 & -2.377233 \\
\hline & 5.315826 & 4.981124 & -2.238186 \\
\hline & 5.715863 & 2.552814 & -2.044588 \\
\hline & 3.828377 & 0.933303 & -1.935724 \\
\hline त & 0.149119 & 4.999680 & -2.479435 \\
\hline & -1.306711 & 2.421845 & -2.384158 \\
\hline 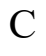 & -2.220246 & 3.173602 & -3.148699 \\
\hline$C$ & -3.533166 & 2.726282 & -3.259906 \\
\hline $\mathrm{H}$ & -1.889610 & 4.061409 & -3.675454 \\
\hline & -2.951662 & 0.873171 & -1.838015 \\
\hline$C$ & -3.907012 & 1.547564 & -2.601336 \\
\hline $\mathrm{H}$ & -4.253421 & 3.274234 & -3.859744 \\
\hline H & -4.913051 & 1.152729 & -2.664729 \\
\hline $\mathrm{C}$ & -3.335317 & -0.343981 & -1.069987 \\
\hline $\mathrm{C}$ & -4.892056 & -1.962984 & -0.602238 \\
\hline $\mathrm{C}$ & -3.989721 & -2.465515 & 0.409290 \\
\hline $\mathrm{N}$ & 1.089624 & 1.826645 & -2.033887 \\
\hline $\mathrm{N}$ & -1.670370 & 1.293299 & -1.727084 \\
\hline $\mathrm{N}$ & -4.538261 & -0.887511 & -1.301261 \\
\hline 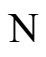 & -2.454737 & -0.811753 & -0.181012 \\
\hline 4 & -2.812388 & -1.869149 & 0.571715 \\
\hline $\mathrm{C}$ & -6.208720 & -2.634421 & -0.944079 \\
\hline $\mathrm{C}$ & -6.635879 & -3.601208 & 0.182906 \\
\hline $\mathrm{H}$ & -7.095413 & -3.030143 & 0.996385 \\
\hline $\mathrm{H}$ & -7.422711 & -4.253858 & -0.204906 \\
\hline $\mathrm{C}$ & -5.484653 & -4.452897 & 0.723023 \\
\hline 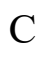 & -4.341584 & -3.616290 & 1.345141 \\
\hline $\mathrm{H}$ & -5.077339 & -5.084716 & -0.073644 \\
\hline $\mathrm{H}$ & -5.861031 & -5.137648 & 1.488277 \\
\hline $\mathrm{C}$ & -7.311799 & -1.579284 & -1.176557 \\
\hline 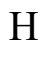 & -7.081449 & -0.931027 & -2.023592 \\
\hline 2 & -8.253835 & -2.091840 & -1.388102 \\
\hline $\mathrm{H}$ & -7.465018 & -0.956368 & -0.289512 \\
\hline- & -5.967651 & -3.409737 & -2.273651 \\
\hline $\mathrm{H}$ & -6.904727 & -3.882813 & -2.578380 \\
\hline $\mathrm{H}$ & -5.654581 & -2.728306 & -3.068924 \\
\hline
\end{tabular}




$\begin{array}{lrrr}\mathrm{H} & -5.212591 & -4.194236 & -2.171811 \\ \mathrm{C} & -4.790570 & -2.993978 & 2.695651 \\ \mathrm{H} & -5.045619 & -3.794333 & 3.395288 \\ \mathrm{H} & -3.985409 & -2.400749 & 3.140835 \\ \mathrm{H} & -5.668641 & -2.351481 & 2.590381 \\ \mathrm{C} & -3.122601 & -4.529574 & 1.591268 \\ \mathrm{H} & -2.329195 & -4.023340 & 2.147941 \\ \mathrm{H} & -3.436718 & -5.390984 & 2.186400 \\ \mathrm{H} & -2.705555 & -4.908811 & 0.653284 \\ \mathrm{C} & -2.343037 & 2.510869 & 2.072519 \\ \mathrm{C} & -2.093388 & 3.899560 & 2.223595 \\ \mathrm{C} & -3.172120 & 4.813946 & 2.263068 \\ \mathrm{C} & -4.467129 & 4.306902 & 2.188444 \\ \mathrm{C} & -4.694467 & 2.918752 & 2.073655 \\ \mathrm{C} & -3.631812 & 1.997709 & 2.008003 \\ \mathrm{C} & -0.095102 & 2.811484 & 2.292232 \\ \mathrm{C} & -0.677688 & 4.062074 & 2.363875 \\ \mathrm{H} & -2.996355 & 5.878830 & 2.377395 \\ \mathrm{H} & -5.315907 & 4.980918 & 2.238321 \\ \mathrm{H} & -5.715891 & 2.552606 & 2.044640 \\ \mathrm{H} & -3.828371 & 0.933140 & 1.935717 \\ \mathrm{H} & -0.149199 & 4.999580 & 2.479558 \\ \mathrm{C} & 1.306687 & 2.421780 & 2.384187 \\ \mathrm{C} & 2.220210 & 3.173527 & 3.148754 \\ \mathrm{H} & 5.077357 & -5.084722 & 0.073681 \\ \mathrm{C} & 3.533139 & 2.726230 & 3.259940 \\ \mathrm{H} & 1.889557 & 4.061308 & 3.675544 \\ \mathrm{C} & 2.951669 & 0.873161 & 1.837982 \\ \mathrm{C} & 3.907007 & 1.547543 & 2.601327 \\ \mathrm{H} & 4.253384 & 3.274173 & 3.859799 \\ \mathrm{H} & 4.913052 & 1.152722 & 2.664708 \\ \mathrm{C} & 3.335342 & -0.343968 & 1.069927 \\ \mathrm{C} & 4.892087 & -1.962973 & 0.602199 \\ \mathrm{C} & 3.989747 & -2.465527 & -0.409312 \\ \mathrm{~N} & -1.089636 & 1.826538 & 2.033906 \\ \mathrm{~N} & 1.670368 & 1.293267 & 1.727069 \\ \mathrm{~N} & 4.538286 & -0.887496 & 1.301212 \\ \mathrm{H} & 2.454766 & -0.811741 & 0.180949 \\ \mathrm{H} & 2.812413 & -1.869164 & -0.571742 \\ \mathrm{H} & -635901 & -2.634411 & 0.944058 \\ \mathrm{H} & -3.601225 & -0.182905 \\ \mathrm{H} & -3.137692 & -1.488240\end{array}$




$\begin{array}{rrrr}\mathrm{C} & 7.311832 & -1.579276 & 1.176516 \\ \mathrm{H} & 7.081485 & -0.931001 & 2.023538 \\ \mathrm{H} & 8.253864 & -2.091835 & 1.388072 \\ \mathrm{H} & 7.465056 & -0.956379 & 0.289459 \\ \mathrm{C} & 5.967669 & -3.409698 & 2.273646 \\ \mathrm{H} & 6.904741 & -3.882772 & 2.578388 \\ \mathrm{H} & 5.654601 & -2.728248 & 3.068904 \\ \mathrm{H} & 5.212605 & -4.194194 & 2.171820 \\ \mathrm{C} & 4.790589 & -2.994047 & -2.695662 \\ \mathrm{H} & 5.045635 & -3.794420 & -3.395280 \\ \mathrm{H} & 3.985428 & -2.400827 & -3.140859 \\ \mathrm{H} & 5.668662 & -2.351550 & -2.590410 \\ \mathrm{C} & 3.122617 & -4.529612 & -1.591240 \\ \mathrm{H} & 2.329216 & -4.023392 & -2.147931 \\ \mathrm{H} & 3.436733 & -5.391041 & -2.186344 \\ \mathrm{H} & 2.705567 & -4.908818 & -0.653245 \\ \mathrm{H} & 1.029719 & 0.987640 & -2.614459 \\ \mathrm{H} & -1.029713 & 0.987521 & 2.614461\end{array}$

$\mathrm{M}=\mathrm{Gd}$

$\begin{array}{lrrr}\text { GD } & 0.000020 & -0.238318 & 0.000030 \\ \mathrm{O} & -0.383636 & 1.405643 & -1.700567 \\ \mathrm{H} & -1.261313 & 1.874766 & -1.516330 \\ \mathrm{O} & 0.383655 & 1.405789 & 1.700500 \\ \mathrm{H} & -0.135307 & 1.917890 & 2.337023 \\ \mathrm{H} & 0.135321 & 1.917689 & -2.337137 \\ \mathrm{H} & 1.261337 & 1.874890 & 1.516240 \\ \mathrm{C} & -2.437363 & -2.451864 & -1.779745 \\ \mathrm{C} & -2.230924 & -3.846781 & -1.861976 \\ \mathrm{C} & -3.327988 & -4.726550 & -1.829091 \\ \mathrm{C} & -4.608592 & -4.177923 & -1.753449 \\ \mathrm{C} & -4.798573 & -2.781143 & -1.716424 \\ \mathrm{C} & -3.712331 & -1.895510 & -1.726281 \\ \mathrm{C} & -0.195664 & -2.844817 & -2.068604 \\ \mathrm{C} & -0.812910 & -4.060414 & -2.047198 \\ \mathrm{H} & -3.186702 & -5.800699 & -1.892611 \\ \mathrm{H} & -5.475159 & -4.831118 & -1.749166 \\ \mathrm{H} & -5.809215 & -2.386224 & -1.694089 \\ \mathrm{H} & -3.875923 & -0.823084 & -1.728980 \\ \mathrm{H} & -0.321250 & -5.021331 & -2.132972 \\ \mathrm{C} & 1.205709 & -2.477719 & -2.220079 \\ \mathrm{C} & 2.105143 & -3.245758 & -2.983733 \\ \mathrm{C} & 3.413712 & -2.800524 & -3.135368 \\ \mathrm{H} & 1.763343 & -4.148786 & -3.476421 \\ \mathrm{C} & 2.871390 & -0.909783 & -1.758401\end{array}$




\begin{tabular}{|c|c|c|c|}
\hline $\mathrm{C}$ & 3.806691 & -1.601146 & -2.519941 \\
\hline H & 4.120239 & -3.365440 & -3.735987 \\
\hline $\mathrm{H}$ & 4.811675 & -1.210708 & -2.617656 \\
\hline $\mathrm{C}$ & 3.243735 & 0.321741 & -1.020005 \\
\hline $\mathrm{C}$ & 4.777017 & 1.959658 & -0.543489 \\
\hline$C$ & 3.851550 & 2.468293 & 0.449121 \\
\hline $\mathrm{N}$ & -1.158644 & -1.784006 & -1.828936 \\
\hline $\mathrm{N}$ & 1.589583 & -1.330955 & -1.608842 \\
\hline $\mathrm{N}$ & 4.444636 & 0.873337 & -1.236026 \\
\hline $\mathrm{N}$ & 2.339852 & 0.802158 & -0.159764 \\
\hline $\mathrm{N}$ & 2.672550 & 1.873074 & 0.586083 \\
\hline $\mathrm{C}$ & 6.088143 & 2.643703 & -0.874728 \\
\hline $\mathrm{C}$ & 6.490074 & 3.631018 & 0.243811 \\
\hline $\mathrm{H}$ & 6.953576 & 3.077761 & 1.067003 \\
\hline $\mathrm{H}$ & 7.268633 & 4.291833 & -0.146593 \\
\hline $\mathrm{C}$ & 5.321820 & 4.470676 & 0.766075 \\
\hline $\mathrm{C}$ & 4.185751 & 3.622461 & 1.385673 \\
\hline $\mathrm{H}$ & 4.912207 & 5.090755 & -0.038688 \\
\hline $\mathrm{H}$ & 5.681664 & 5.166186 & 1.529488 \\
\hline $\mathrm{C}$ & 7.207977 & 1.601002 & -1.084384 \\
\hline $\mathrm{H}$ & 6.994965 & 0.939403 & -1.925468 \\
\hline $\mathrm{H}$ & 8.144193 & 2.125106 & -1.293119 \\
\hline $\mathrm{H}$ & 7.361673 & 0.991560 & -0.188256 \\
\hline $\mathrm{C}$ & 5.849225 & 3.400041 & -2.217109 \\
\hline $\mathrm{H}$ & 6.783601 & 3.881875 & -2.516115 \\
\hline $\mathrm{H}$ & 5.555069 & 2.704999 & -3.007710 \\
\hline $\mathrm{H}$ & 5.083107 & 4.175875 & -2.132310 \\
\hline $\mathrm{C}$ & 4.638968 & 3.001151 & 2.736156 \\
\hline $\mathrm{H}$ & 4.889912 & 3.803425 & 3.435014 \\
\hline $\mathrm{H}$ & 3.837080 & 2.403947 & 3.181836 \\
\hline $\mathrm{H}$ & 5.520203 & 2.363159 & 2.631575 \\
\hline $\mathrm{C}$ & 2.956402 & 4.521074 & 1.631751 \\
\hline $\mathrm{H}$ & 2.169334 & 4.006323 & 2.190124 \\
\hline $\mathrm{H}$ & 3.260610 & 5.385189 & 2.227892 \\
\hline $\mathrm{H}$ & 2.535237 & 4.897243 & 0.694296 \\
\hline $\mathrm{C}$ & 2.437436 & -2.451888 & 1.779679 \\
\hline $\mathrm{C}$ & 2.230962 & -3.846798 & 1.861935 \\
\hline $\mathrm{C}$ & 3.327996 & -4.726601 & 1.828942 \\
\hline $\mathrm{C}$ & 4.608609 & -4.178013 & 1.753168 \\
\hline $\mathrm{C}$ & 4.798629 & -2.781238 & 1.716117 \\
\hline $\mathrm{C}$ & 3.712415 & -1.895572 & 1.726082 \\
\hline $\mathrm{C}$ & 0.195741 & -2.844775 & 2.068714 \\
\hline $\mathrm{C}$ & 0.812958 & -4.060387 & 2.047293 \\
\hline $\mathrm{H}$ & 3.186683 & -5.800745 & 1.892477 \\
\hline $\mathrm{H}$ & 5.475156 & -4.831234 & 1.748799 \\
\hline $\mathrm{H}$ & 5.809280 & -2.386351 & 1.693679 \\
\hline
\end{tabular}




$\begin{array}{lrrr}\mathrm{H} & 3.876039 & -0.823151 & 1.728761 \\ \mathrm{H} & 0.321277 & -5.021291 & 2.133101 \\ \mathrm{C} & -1.205617 & -2.477644 & 2.220248 \\ \mathrm{C} & -2.105030 & -3.245664 & 2.983947 \\ \mathrm{C} & -3.413595 & -2.800429 & 3.135606 \\ \mathrm{H} & -1.763217 & -4.148681 & 3.476645 \\ \mathrm{C} & -2.871322 & -0.909740 & 1.758549 \\ \mathrm{C} & -3.806599 & -1.601078 & 2.520140 \\ \mathrm{H} & -4.120105 & -3.365331 & 3.736256 \\ \mathrm{H} & -4.811586 & -1.210650 & 2.617858 \\ \mathrm{C} & -3.243715 & 0.321730 & 1.020088 \\ \mathrm{C} & -4.777064 & 1.959566 & 0.543504 \\ \mathrm{C} & -3.851641 & 2.468162 & -0.449166 \\ \mathrm{~N} & 1.158742 & -1.783992 & 1.829011 \\ \mathrm{~N} & -1.589512 & -1.330899 & 1.608984 \\ \mathrm{~N} & -4.444627 & 0.873302 & 1.236104 \\ \mathrm{~N} & -2.339870 & 0.802109 & 0.159784 \\ \mathrm{~N} & -2.672627 & 1.872967 & -0.586120 \\ \mathrm{C} & -6.088199 & 2.643597 & 0.874739 \\ \mathrm{C} & -6.490193 & 3.630826 & -0.243853 \\ \mathrm{H} & -6.953707 & 3.077502 & -1.066992 \\ \mathrm{H} & -7.268756 & 4.291647 & 0.146533 \\ \mathrm{C} & -5.321978 & 4.470480 & -0.766212 \\ \mathrm{C} & -4.185906 & 3.622254 & -1.385789 \\ \mathrm{H} & -4.912356 & 5.090626 & 0.038495 \\ \mathrm{H} & -5.681866 & 5.165927 & -1.529661 \\ \mathrm{C} & -7.207997 & 1.600879 & 1.084500 \\ \mathrm{H} & -6.994939 & 0.939341 & 1.925621 \\ \mathrm{H} & -8.144220 & 2.124971 & 1.293232 \\ \mathrm{H} & -7.361706 & 0.991374 & 0.188417 \\ \mathrm{C} & -5.849258 & 3.400031 & 2.217062 \\ \mathrm{H} & -6.783638 & 3.881859 & 2.516066 \\ \mathrm{H} & -5.555057 & 2.705050 & 3.007700 \\ \mathrm{H} & -5.083165 & 4.175881 & 2.132187 \\ \mathrm{C} & -4.639150 & 3.000834 & -2.736212 \\ \mathrm{H} & -4.890142 & 3.803052 & -3.435118 \\ \mathrm{H} & -3.837259 & 2.403623 & -3.181877 \\ \mathrm{C} & -2.520362 & 2.362823 & -2.631557 \\ \mathrm{H} & -2.169527 & 4.006117 & -2.190337 \\ \mathrm{H} & -350393 & 5.384949 & -2.228162 \\ \mathrm{H} & -1.897131 & -0.694558 \\ \mathrm{H} & -1.083766 & -2.575911 \\ \mathrm{H} & -1.083770 & 2.576007\end{array}$

$\mathrm{M}=\mathrm{Am}$

S-129 


\begin{tabular}{|c|c|c|c|}
\hline M & -0.0000 & 7225 & 0000 \\
\hline $\mathrm{O}$ & -0.407947 & -1.392579 & 1.768470 \\
\hline $\mathrm{H}$ & -1.291720 & -1.853775 & 1.592518 \\
\hline $\mathrm{O}$ & 0.407950 & -1.392570 & -1.768476 \\
\hline $\mathrm{H}$ & -0.114659 & -1.910483 & -2.397399 \\
\hline $\mathrm{H}$ & 0.114664 & -1.910500 & 2.397387 \\
\hline $\mathrm{H}$ & 1.291720 & -1.853770 & -1.592522 \\
\hline$\gamma$ & -2.293429 & 2.611214 & 1.801415 \\
\hline $\mathrm{C}$ & -1.992799 & 900 & 1.949357 \\
\hline $\mathrm{C}$ & -3.021427 & 4.940099 & 1.898020 \\
\hline $\mathrm{C}$ & -4.331724 & 4.489033 & 1.734102 \\
\hline $\mathrm{C}$ & -4.617905 & 3.112635 & 1.626500 \\
\hline $\mathrm{C}$ & -3.598968 & 2.151231 & 1.655195 \\
\hline $\mathrm{C}$ & -0.045106 & 2.827819 & 2.202601 \\
\hline $\mathrm{C}$ & -0.572411 & 4.085 & 2.203017 \\
\hline $\mathrm{H}$ & -2.808596 & 5.998097 & 2.01 \\
\hline $\mathrm{H}$ & -5.148442 & 5.203270 & 1.71 \\
\hline $\mathrm{H}$ & -5.650 & 2.79 & 1.5 \\
\hline $\mathrm{H}$ & -3.834983 & 1.093707 & 1.597213 \\
\hline $\mathrm{H}$ & -0.016969 & 5.004805 & 2.34 \\
\hline $\mathrm{C}$ & 1.326616 & 2.365719 & 2.370508 \\
\hline $\mathrm{C}$ & 2.243499 & 3.046463 & 3.19 \\
\hline $\mathrm{C}$ & 3.527908 & 2.536200 & 3.341852 \\
\hline $\mathrm{H}$ & 1.931897 & 3.934943 & 3.73 \\
\hline $\mathrm{C}$ & 2.930860 & 0.757398 & 1.842230 \\
\hline $\mathrm{C}$ & 3.881360 & 1.362887 & $2.65^{\circ}$ \\
\hline $\mathrm{H}$ & 4.246578 & 3.032608 & 3.986840 \\
\hline $\mathrm{H}$ & 4.868821 & 0.927517 & 2.741792 \\
\hline $\mathrm{C}$ & 3.278886 & -0.434433 & 1.029287 \\
\hline $\mathrm{C}$ & 4.783851 & -2.077006 & 0.476274 \\
\hline $\mathrm{C}$ & 3.857641 & -2.510881 & -0.549107 \\
\hline $\mathrm{N}$ & -1.070657 & 1.851864 & 1.887227 \\
\hline $\mathrm{N}$ & 1.669309 & 1.237383 & 1.702363 \\
\hline $\mathrm{N}$ & 4.462414 & -1.029080 & 1.230153 \\
\hline $\mathrm{N}$ & 2.382070 & -0.833663 & 0.121836 \\
\hline $\mathrm{N}$ & 2.698557 & -1.875793 & -0.671352 \\
\hline $\mathrm{C}$ & 6.084522 & -2.796560 & 0.772802 \\
\hline $\mathrm{C}$ & 6.469777 & -3.734444 & -0.393131 \\
\hline $\mathrm{H}$ & 6.941295 & -3.149332 & -1.189372 \\
\hline $\mathrm{H}$ & 7.237695 & -4.426158 & -0.036716 \\
\hline $\mathrm{C}$ & 5.286889 & -4.527769 & -0.953304 \\
\hline $\mathrm{C}$ & 4.168153 & -3.630835 & -1.534636 \\
\hline $\mathrm{H}$ & 4.864633 & -5.175262 & -0.177093 \\
\hline $\mathrm{H}$ & 5.634385 & -5.195118 & -1.746958 \\
\hline $\mathrm{C}$ & 7.219152 & -1.779493 & 1.027041 \\
\hline
\end{tabular}




\begin{tabular}{|c|c|c|c|}
\hline $\mathrm{H}$ & 7.018155 & -1.156824 & 1.900266 \\
\hline 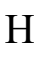 & 8.149275 & -2.325058 & 1.206043 \\
\hline & 7.377332 & -1.129448 & 0.160733 \\
\hline C & 5.839873 & -3.612190 & 2.078397 \\
\hline & 6.769165 & -4.118016 & 2.352567 \\
\hline 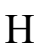 & 5.554605 & -2.951870 & 2.901330 \\
\hline & 5.064879 & -4.374498 & 1.958867 \\
\hline & 4.632113 & -2.963970 & -2.859216 \\
\hline $\mathrm{H}$ & 4.862318 & -3.741625 & -3.592226 \\
\hline 1 & 3.843549 & -2.329384 & -3.275963 \\
\hline 11 & 5.528233 & -2.351670 & -2.730803 \\
\hline $\mathrm{C}$ & 2.920058 & -4.493451 & -1.814517 \\
\hline $\mathrm{H}$ & 2.145045 & -3.941453 & -2.354022 \\
\hline $\mathrm{H}$ & 3.206383 & -5.340777 & -2.442785 \\
\hline H & 2.489922 & -4.895693 & -0.892011 \\
\hline $\mathrm{C}$ & 2.293433 & 2.611222 & -1.801411 \\
\hline $\mathrm{C}$ & 1.992800 & 3.982909 & -1.949354 \\
\hline $\mathrm{C}$ & 3.021426 & 4.940109 & -1.898016 \\
\hline $\mathrm{C}$ & 4.331723 & 4.489046 & -1.734096 \\
\hline $\mathrm{C}$ & 4.617907 & 3.112648 & -1.626493 \\
\hline $\mathrm{C}$ & 3.598972 & 2.151242 & -1.655189 \\
\hline $\mathrm{C}$ & 0.045109 & 2.827823 & -2.202600 \\
\hline $\mathrm{C}$ & 0.572412 & 4.085622 & -2.203015 \\
\hline $\mathrm{H}$ & 2.808593 & 5.998107 & -2.011894 \\
\hline $\mathrm{H}$ & 5.148440 & 5.203284 & -1.712141 \\
\hline $\mathrm{H}$ & 5.650792 & 2.793450 & -1.531297 \\
\hline $\mathrm{H}$ & 3.834989 & 1.093719 & -1.597207 \\
\hline $\mathrm{H}$ & 0.016969 & 5.004809 & -2.340434 \\
\hline $\mathrm{C}$ & -1.326612 & 2.365722 & -2.370508 \\
\hline $\mathrm{C}$ & -2.243494 & 3.046466 & -3.193717 \\
\hline $\mathrm{C}$ & -3.527903 & 2.536203 & -3.341853 \\
\hline $\mathrm{H}$ & -1.931892 & 3.934945 & -3.730752 \\
\hline $\mathrm{C}$ & -2.930857 & 0.757402 & -1.842231 \\
\hline $\mathrm{C}$ & -3.881356 & 1.362891 & -2.657087 \\
\hline $\mathrm{H}$ & -4.246572 & 3.032611 & -3.986842 \\
\hline $\mathrm{H}$ & -4.868818 & 0.927521 & -2.741793 \\
\hline $\mathrm{C}$ & -3.278885 & -0.434428 & -1.029287 \\
\hline $\mathrm{C}$ & -4.783852 & -2.077001 & -0.476276 \\
\hline $\mathrm{C}$ & -3.857643 & -2.510876 & 0.549106 \\
\hline $\mathrm{N}$ & 1.070661 & 1.851871 & -1.887224 \\
\hline $\mathrm{N}$ & -1.669306 & 1.237386 & -1.702363 \\
\hline $\mathrm{N}$ & -4.462414 & -1.029076 & -1.230155 \\
\hline $\mathrm{N}$ & -2.382071 & -0.833659 & -0.121835 \\
\hline $\mathrm{N}$ & -2.698560 & -1.875789 & 0.671353 \\
\hline $\mathrm{C}$ & -6.084523 & -2.796554 & -0.772806 \\
\hline I & -6.469781 & -3.734437 & 0.393126 \\
\hline
\end{tabular}




$\begin{array}{crrr}\mathrm{H} & -6.941299 & -3.149326 & 1.189367 \\ \mathrm{H} & -7.237698 & -4.426150 & 0.036710 \\ \mathrm{C} & -5.286893 & -4.527763 & 0.953301 \\ \mathrm{C} & -4.168158 & -3.630830 & 1.534635 \\ \mathrm{H} & -4.864637 & -5.175257 & 0.177091 \\ \mathrm{H} & -5.634392 & -5.195112 & 1.746955 \\ \mathrm{C} & -7.219152 & -1.779486 & -1.027046 \\ \mathrm{H} & -7.018154 & -1.156817 & -1.900271 \\ \mathrm{H} & -8.149276 & -2.325050 & -1.206050 \\ \mathrm{H} & -7.377333 & -1.129441 & -0.160739 \\ \mathrm{C} & -5.839873 & -3.612184 & -2.078401 \\ \mathrm{H} & -6.769165 & -4.118009 & -2.352572 \\ \mathrm{H} & -5.554603 & -2.951863 & -2.901333 \\ \mathrm{H} & -5.064880 & -4.374492 & -1.958870 \\ \mathrm{C} & -4.632120 & -2.963964 & 2.859214 \\ \mathrm{H} & -4.862326 & -3.741620 & 3.592224 \\ \mathrm{H} & -3.843555 & -2.329380 & 3.275963 \\ \mathrm{H} & -5.528238 & -2.351664 & 2.730800 \\ \mathrm{C} & -2.920064 & -4.493447 & 1.814518 \\ \mathrm{H} & -2.145052 & -3.941450 & 2.354025 \\ \mathrm{H} & -3.206390 & -5.340773 & 2.442784 \\ \mathrm{H} & -2.489926 & -4.895689 & 0.892012 \\ \mathrm{H} & -1.125650 & 1.120779 & 2.601988 \\ \mathrm{H} & 1.125657 & 1.120785 & -2.601984\end{array}$

$\mathrm{M}=\mathrm{Cm}$

$\begin{array}{lrrr}\mathrm{CM} & -0.000011 & -0.237860 & -0.000028 \\ \mathrm{O} & -0.411690 & 1.440555 & -1.740289 \\ \mathrm{H} & -1.290504 & 1.899940 & -1.543096 \\ \mathrm{O} & 0.411709 & 1.440497 & 1.740272 \\ \mathrm{H} & -0.100768 & 1.966397 & 2.370987 \\ \mathrm{H} & 0.100805 & 1.966465 & -2.370979 \\ \mathrm{H} & 1.290534 & 1.899866 & 1.543091 \\ \mathrm{C} & -2.378928 & -2.490972 & -1.835719 \\ \mathrm{C} & -2.139645 & -3.879423 & -1.931836 \\ \mathrm{C} & -3.214662 & -4.785417 & -1.892582 \\ \mathrm{C} & -4.506777 & -4.268499 & -1.795470 \\ \mathrm{C} & -4.730147 & -2.876982 & -1.742139 \\ \mathrm{C} & -3.665945 & -1.965808 & -1.757949 \\ \mathrm{C} & -0.130760 & -2.826247 & -2.146822 \\ \mathrm{C} & -0.718120 & -4.057015 & -2.130032 \\ \mathrm{H} & -3.048638 & -5.855327 & -1.966373 \\ \mathrm{H} & -5.357318 & -4.942406 & -1.785635 \\ \mathrm{H} & -5.749591 & -2.506911 & -1.700933 \\ \mathrm{H} & -3.853231 & -0.897041 & -1.744870\end{array}$




\begin{tabular}{|c|c|c|c|}
\hline $\mathrm{H}$ & -0.203581 & -5.005169 & -2.223207 \\
\hline & 1.264464 & -2.430416 & -2.294255 \\
\hline $\mathrm{C}$ & 2.172118 & -3.167646 & -3.077715 \\
\hline $\mathrm{C}$ & 3.475568 & -2.703851 & -3.217637 \\
\hline $\mathrm{H}$ & 1.840842 & -4.061654 & -3.593505 \\
\hline C & 2.911904 & -0.854839 & -1.792404 \\
\hline $\mathrm{C}$ & 3.854993 & -1.516945 & -2.570900 \\
\hline $\mathrm{H}$ & 4.188564 & -3.245091 & -3.832237 \\
\hline $\mathrm{H}$ & 4.855526 & -1.113202 & -2.658940 \\
\hline $\mathrm{C}$ & 3.275897 & 0.364653 & -1.027725 \\
\hline $\mathrm{C}$ & 4.805926 & 1.999666 & -0.525619 \\
\hline $\mathrm{C}$ & 3.877021 & 2.494376 & 0.469843 \\
\hline $\mathrm{N}$ & -1.118868 & -1.793279 & -1.894837 \\
\hline$N$ & 1.636289 & -1.296045 & -1.653454 \\
\hline $\mathrm{N}$ & 4.475624 & 0.923393 & -1.234615 \\
\hline $\mathrm{N}$ & 2.372490 & 0.828223 & -0.157869 \\
\hline $\mathrm{N}$ & 2.701197 & 1.892287 & 0.600179 \\
\hline $\mathrm{C}$ & 6.120173 & 2.685674 & -0.840889 \\
\hline $\mathrm{C}$ & 6.514712 & 3.660903 & 0.290804 \\
\hline $\mathrm{H}$ & 6.970938 & 3.098577 & 1.111980 \\
\hline $\mathrm{H}$ & 7.297097 & 4.324719 & -0.086608 \\
\hline$C^{\prime}$ & 5.343164 & 4.496302 & 0.812262 \\
\hline $\mathrm{C}$ & 4.202755 & 3.643017 & 1.416775 \\
\hline $\mathrm{H}$ & 4.939149 & 5.123097 & 0.009815 \\
\hline $\mathrm{H}$ & 5.697767 & 5.185400 & 1.583887 \\
\hline $\mathrm{C}$ & 7.239952 & 1.642880 & -1.051318 \\
\hline $\mathrm{H}$ & 7.033197 & 0.990566 & -1.901209 \\
\hline $\mathrm{H}$ & 8.179055 & 2.167154 & -1.246281 \\
\hline $\mathrm{H}$ & 7.384472 & 1.023735 & -0.160311 \\
\hline $\mathrm{C}$ & 5.893775 & 3.455516 & -2.177479 \\
\hline $\mathrm{H}$ & 6.831512 & 3.937916 & -2.464844 \\
\hline $\mathrm{H}$ & 5.603715 & 2.768943 & -2.976958 \\
\hline $\mathrm{H}$ & 5.128865 & 4.232368 & -2.091005 \\
\hline $\mathrm{C}$ & 4.644391 & 3.015012 & 2.767761 \\
\hline $\mathrm{H}$ & 4.885566 & 3.813634 & 3.474227 \\
\hline $\mathrm{H}$ & 3.840222 & 2.412069 & 3.201535 \\
\hline $\mathrm{H}$ & 5.528787 & 2.380619 & 2.668003 \\
\hline $\mathrm{C}$ & 2.970332 & 4.539442 & 1.656483 \\
\hline $\mathrm{H}$ & 2.179772 & 4.021992 & 2.207527 \\
\hline $\mathrm{H}$ & 3.268962 & 5.402082 & 2.257580 \\
\hline $\mathrm{H}$ & 2.555574 & 4.918002 & 0.717077 \\
\hline $\mathrm{C}$ & 2.378893 & -2.490807 & 1.835820 \\
\hline $\mathrm{C}$ & 2.139668 & -3.879269 & 1.931932 \\
\hline $\mathrm{C}$ & 3.214728 & -4.785214 & 1.892752 \\
\hline $\mathrm{C}$ & 4.506826 & -4.268238 & 1.795719 \\
\hline $\mathrm{C}$ & 4.730135 & -2.876711 & 1.742394 \\
\hline
\end{tabular}




$\begin{array}{rrrr}\mathrm{C} & 3.665890 & -1.965585 & 1.758130 \\ \mathrm{C} & 0.130727 & -2.826183 & 2.146809 \\ \mathrm{C} & 0.718138 & -4.056926 & 2.130039 \\ \mathrm{H} & 3.048748 & -5.855131 & 1.966541 \\ \mathrm{H} & 5.357398 & -4.942105 & 1.785943 \\ \mathrm{H} & 5.749565 & -2.506593 & 1.701249 \\ \mathrm{H} & 3.853129 & -0.896809 & 1.745056 \\ \mathrm{H} & 0.203638 & -5.005102 & 2.223192 \\ \mathrm{C} & -1.264516 & -2.430405 & 2.294182 \\ \mathrm{C} & -2.172178 & -3.167640 & 3.077627 \\ \mathrm{C} & -3.475634 & -2.703852 & 3.217523 \\ \mathrm{H} & -1.840903 & -4.061638 & 3.593435 \\ \mathrm{C} & -2.911949 & -0.854831 & 1.792308 \\ \mathrm{C} & -3.855050 & -1.516941 & 2.570788 \\ \mathrm{H} & -4.188637 & -3.245090 & 3.832117 \\ \mathrm{H} & -4.855582 & -1.113193 & 2.658823 \\ \mathrm{C} & -3.275919 & 0.364685 & 1.027656 \\ \mathrm{C} & -4.805905 & 1.999752 & 0.525599 \\ \mathrm{C} & -3.876985 & 2.494471 & -0.469846 \\ \mathrm{~N} & 1.118798 & -1.793170 & 1.894851 \\ \mathrm{~N} & -1.636337 & -1.296042 & 1.653367 \\ \mathrm{~N} & -4.475634 & 0.923447 & 1.234559 \\ \mathrm{~N} & -2.372493 & 0.828269 & 0.157828 \\ \mathrm{~N} & -2.701172 & 1.892363 & -0.600191 \\ \mathrm{C} & -6.120144 & 2.685773 & 0.840875 \\ \mathrm{C} & -6.514657 & 3.661041 & -0.290794 \\ \mathrm{H} & -6.970888 & 3.098746 & -1.111989 \\ \mathrm{H} & -7.297032 & 4.324861 & 0.086630 \\ \mathrm{C} & -5.343090 & 4.496432 & -0.812221 \\ \mathrm{C} & -4.202693 & 3.643142 & -1.416750 \\ \mathrm{H} & -4.939068 & 5.123197 & -0.009754 \\ \mathrm{H} & -5.697675 & 5.185558 & -1.583829 \\ \mathrm{C} & -7.239943 & 1.642993 & 1.051265 \\ \mathrm{H} & -7.033206 & 0.990651 & 1.901140 \\ \mathrm{H} & -8.179039 & 2.167277 & 1.246235 \\ \mathrm{H} & -7.384465 & 1.023875 & 0.160239 \\ \mathrm{C} & -5.893745 & 3.455575 & 2.177489 \\ \mathrm{H} & -6.831476 & 3.937983 & 2.464858 \\ \mathrm{H} & -5.603705 & 2.768974 & 2.976951 \\ \mathrm{H} & -5.128820 & 4.232415 & 2.091043 \\ \mathrm{C} & -4.644336 & 3.015179 & -2.767753 \\ \mathrm{H} & -4.885495 & 3.813823 & -3.474200 \\ \mathrm{H} & -3.840177 & 2.412233 & -3.201540 \\ \mathrm{H} & -5.528744 & 2.380800 & -2.668015 \\ \mathrm{C} & -2.970253 & 4.539550 & -1.656431 \\ \mathrm{H} & -2.179702 & 4.022101 & -2.207487 \\ & & & \end{array}$




$$
\begin{array}{lrrr}
\mathrm{H} & -3.268866 & 5.402213 & -2.257506 \\
\mathrm{H} & -2.555491 & 4.918078 & -0.717014 \\
\mathrm{H} & -1.113702 & -1.080098 & -2.629287 \\
\mathrm{H} & 1.113561 & -1.079988 & 2.629299
\end{array}
$$

\section{$\left[\mathrm{ML}_{2}\right]^{3+}$}

$\mathrm{M}=\mathrm{Eu}$

$\begin{array}{lrrr}\text { EU } & 0.000012 & 0.735509 & -0.000020 \\ \mathrm{C} & -2.000600 & 3.700402 & -1.500520 \\ \mathrm{C} & -3.046541 & 3.434723 & -2.425148 \\ \mathrm{C} & -4.245511 & 4.186063 & -2.377076 \\ \mathrm{C} & -4.346023 & 5.202036 & -1.432444 \\ \mathrm{C} & -3.280941 & 5.473786 & -0.544384 \\ \mathrm{C} & -2.090060 & 4.720752 & -0.564401 \\ \mathrm{C} & -1.314627 & 2.038911 & -2.915349 \\ \mathrm{C} & -2.589242 & 2.397992 & -3.300125 \\ \mathrm{H} & -5.054404 & 3.988577 & -3.073139 \\ \mathrm{H} & -5.244834 & 5.807614 & -1.380373 \\ \mathrm{H} & -3.381176 & 6.286844 & 0.167854 \\ \mathrm{H} & -1.283736 & 4.967003 & 0.120124 \\ \mathrm{H} & -0.017623 & 3.227055 & -1.858312 \\ \mathrm{H} & -3.154360 & 1.946833 & -4.105847 \\ \mathrm{C} & -0.404466 & 1.034325 & -3.455898 \\ \mathrm{C} & -0.413354 & 0.662120 & -4.812219 \\ \mathrm{C} & 0.516357 & -0.279967 & -5.252689 \\ \mathrm{H} & -1.107745 & 1.123785 & -5.505299 \\ \mathrm{C} & 1.343923 & -0.433897 & -2.998905 \\ \mathrm{C} & 1.416484 & -0.837629 & -4.334927 \\ \mathrm{H} & 0.547060 & -0.572815 & -6.297866 \\ \mathrm{H} & 2.157793 & -1.569326 & -4.632416 \\ \mathrm{C} & 2.221489 & -1.032617 & -1.955526 \\ \mathrm{C} & 3.974834 & -2.373041 & -1.360291 \\ \mathrm{C} & 3.709629 & -2.024142 & 0.014410 \\ \mathrm{~N} & -0.927571 & 2.775702 & -1.742172 \\ \mathrm{~N} & 0.461234 & 0.492551 & -2.567423 \\ \mathrm{~N} & 3.209904 & -1.848938 & -2.321973 \\ \mathrm{~N} & 1.934101 & -0.716360 & -0.684605 \\ \mathrm{~N} & 2.687836 & -1.216353 & 0.304801 \\ \mathrm{C} & 5.113819 & -3.281043 & -1.783471 \\ \mathrm{C} & 5.681523 & -4.042763 & -0.565144 \\ \mathrm{H} & 5.033939 & -4.895721 & -0.336299 \\ \mathrm{H} & 6.648668 & -4.468214 & -0.846481 \\ \mathrm{C} & 5.847682 & -3.161286 & 0.674967 \\ \mathrm{C} & 4.512351 & -2.574346 & 1.187959\end{array}$




$\begin{array}{lrrr}\mathrm{H} & 6.545084 & -2.343602 & 0.462666 \\ \mathrm{H} & 6.300791 & -3.742265 & 1.483335 \\ \mathrm{C} & 4.623748 & -4.287553 & -2.849090 \\ \mathrm{H} & 4.290319 & -3.784603 & -3.758421 \\ \mathrm{H} & 5.449340 & -4.953866 & -3.112616 \\ \mathrm{H} & 3.804558 & -4.906872 & -2.470284 \\ \mathrm{C} & 6.200721 & -2.365617 & -2.419506 \\ \mathrm{H} & 7.021777 & -2.992419 & -2.776894 \\ \mathrm{H} & 5.794972 & -1.814782 & -3.271760 \\ \mathrm{H} & 6.611787 & -1.645749 & -1.706413 \\ \mathrm{C} & 3.652278 & -3.673645 & 1.866879 \\ \mathrm{H} & 4.195144 & -4.080653 & 2.724253 \\ \mathrm{H} & 2.706302 & -3.257211 & 2.225697 \\ \mathrm{H} & 3.424562 & -4.502482 & 1.191526 \\ \mathrm{C} & 4.802984 & -1.457498 & 2.212704 \\ \mathrm{H} & 3.881566 & -1.058781 & 2.644282 \\ \mathrm{H} & 5.412969 & -1.864617 & 3.023744 \\ \mathrm{H} & 5.362132 & -0.634046 & 1.756676 \\ \mathrm{C} & 2.000509 & 3.700561 & 1.500377 \\ \mathrm{C} & 3.046446 & 3.434965 & 2.425034 \\ \mathrm{C} & 4.245388 & 4.186350 & 2.376947 \\ \mathrm{C} & 4.345875 & 5.202283 & 1.432270 \\ \mathrm{C} & 3.280797 & 5.473951 & 0.544181 \\ \mathrm{C} & 2.089944 & 4.720871 & 0.564213 \\ \mathrm{C} & 1.314578 & 2.039108 & 2.915270 \\ \mathrm{C} & 2.589174 & 2.398257 & 3.300051 \\ \mathrm{H} & 5.054277 & 3.988927 & 3.073031 \\ \mathrm{~N} & -0.461226 & 0.492670 & 2.567397 \\ \mathrm{H} & 5.244663 & 5.807895 & 1.380186 \\ \mathrm{H} & 3.381010 & 6.286980 & -0.168093 \\ \mathrm{H} & 1.283622 & 4.967058 & -0.120338 \\ \mathrm{H} & 0.017543 & 3.227146 & 1.858150 \\ \mathrm{H} & 3.154297 & 1.947157 & 4.105803 \\ \mathrm{C} & 0.404448 & 1.034514 & 3.455855 \\ \mathrm{C} & 0.413337 & 0.662372 & 4.812193 \\ \mathrm{C} & -0.516347 & -0.279724 & 5.252699 \\ \mathrm{H} & 1.107706 & 1.124092 & 5.505257 \\ \mathrm{C} & -1.343889 & -0.433786 & 2.998915 \\ \mathrm{C} & -1.416448 & -0.837458 & 4.334955 \\ \mathrm{H} & -0.547050 & -0.572524 & 6.297889 \\ \mathrm{C} & -3.974737 & -1.569164 & 4.632471 \\ \mathrm{~N} & -1.032581 & 1.955558 \\ \mathrm{H} & -2.373113 & 1.360377 \\ \mathrm{H} & -1.848920 & 2.322039\end{array}$




$\begin{array}{lrrr}\mathrm{N} & -1.934039 & -0.716383 & 0.684624 \\ \mathrm{~N} & -2.687754 & -1.216446 & -0.304762 \\ \mathrm{C} & -5.113768 & -3.281004 & 1.783603 \\ \mathrm{C} & -5.681530 & -4.042734 & 0.565311 \\ \mathrm{H} & -5.033998 & -4.895736 & 0.336485 \\ \mathrm{H} & -6.648695 & -4.468120 & 0.846676 \\ \mathrm{C} & -5.847660 & -3.161286 & -0.674825 \\ \mathrm{C} & -4.512310 & -2.574424 & -1.187857 \\ \mathrm{H} & -6.545017 & -2.343560 & -0.462535 \\ \mathrm{H} & -6.300814 & -3.742265 & -1.483169 \\ \mathrm{C} & -4.623780 & -4.287500 & 2.849272 \\ \mathrm{H} & -4.290333 & -3.784535 & 3.758587 \\ \mathrm{H} & -5.449421 & -4.953746 & 3.112812 \\ \mathrm{H} & -3.804625 & -4.906889 & 2.470505 \\ \mathrm{C} & -6.200603 & -2.365462 & 2.419588 \\ \mathrm{H} & -7.021704 & -2.992181 & 2.777018 \\ \mathrm{H} & -5.794810 & -1.814604 & 3.271807 \\ \mathrm{H} & -6.611620 & -1.645606 & 1.706453 \\ \mathrm{C} & -3.652314 & -3.673771 & -1.866798 \\ \mathrm{H} & -4.195233 & -4.080762 & -2.724145 \\ \mathrm{H} & -2.706333 & -3.257384 & -2.225658 \\ \mathrm{H} & -3.424610 & -4.502612 & -1.191445 \\ \mathrm{C} & -4.802910 & -1.457566 & -2.212599 \\ \mathrm{H} & -3.881481 & -1.058889 & -2.644191 \\ \mathrm{H} & -5.412926 & -1.864657 & -3.023630 \\ \mathrm{H} & -5.362016 & -0.634089 & -1.756563\end{array}$

\section{$\mathrm{M}=\mathrm{Gd}$}

\begin{tabular}{|c|c|c|c|}
\hline GD & 0.000203 & 0.796821 & -0.000236 \\
\hline $\mathrm{C}$ & -2.110745 & 3.521080 & -1.014345 \\
\hline $\mathrm{C}$ & -3.201214 & 3.316675 & 6975 \\
\hline $\mathrm{C}$ & -4.400697 & 4.021656 & -1.688694 \\
\hline $\mathrm{C}$ & -4.461553 & 4.934807 & -0.633368 \\
\hline $\mathrm{C}$ & -3.351595 & 5.151966 & 0.206122 \\
\hline $\mathrm{C}$ & -2.152734 & 4.445244 & 0.0 \\
\hline $\mathrm{C}$ & -1.486487 & 2.017910 & -2.654686 \\
\hline $\mathrm{C}$ & -2.775809 & 2.375119 & -2.903125 \\
\hline $\mathrm{H}$ & -5.249748 & 3.879969 & -2.349593 \\
\hline $\mathrm{H}$ & -5.370381 & 5.503711 & -0.465868 \\
\hline $\mathrm{H}$ & -3.421170 & 5.889192 & 0.999368 \\
\hline $\mathrm{H}$ & -1.298009 & 4.664403 & 0.659653 \\
\hline $\mathrm{H}$ & -0.184654 & 3.241075 & -1.659795 \\
\hline $\mathrm{H}$ & -3.391288 & 1.992593 & -3.707988 \\
\hline $\mathrm{C}$ & -0.587163 & 1.056926 & -3.283262 \\
\hline $\mathrm{C}$ & -0.604253 & 0.735519 & -4.652027 \\
\hline
\end{tabular}




\begin{tabular}{|c|c|c|c|}
\hline $\mathrm{C}$ & 0.329137 & -0.178462 & -5.137876 \\
\hline 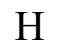 & -1.310394 & 1.217245 & -5.319052 \\
\hline $\mathrm{C}$ & 1.204602 & -0.406828 & -2.917912 \\
\hline $\mathrm{C}$ & 1.259635 & -0.762525 & -4.259559 \\
\hline $\mathrm{H}$ & 0.346304 & -0.430275 & -6.194201 \\
\hline$\theta$ & 2.001643 & -1.473932 & -4.601488 \\
\hline $\mathrm{C}$ & 2.088970 & -0.994205 & -1.882155 \\
\hline C & 3.829299 & -2.327687 & -1.239264 \\
\hline $\mathrm{C}$ & 3.544378 & -1.962492 & 0.133507 \\
\hline$N$ & -1.007128 & 2.672126 & -1.432031 \\
\hline$N$ & 0.304406 & 0.486819 & -2.439411 \\
\hline $\mathrm{N}$ & 3.073366 & -1.822806 & -2.219934 \\
\hline $\mathrm{N}$ & 1.808750 & -0.638717 & -0.616385 \\
\hline $\mathrm{N}$ & 2.539099 & -1.130622 & 0.397973 \\
\hline C & 4.982376 & -3.225135 & -1.634663 \\
\hline 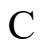 & 5.534167 & -3.983141 & -0.406865 \\
\hline $\mathrm{H}$ & 4.894062 & -4.845997 & -0.195718 \\
\hline $\mathrm{H}$ & 6.512543 & -4.394024 & -0.669873 \\
\hline $\mathrm{C}$ & 5.663456 & -3.105209 & 0.839852 \\
\hline $\mathrm{C}$ & 4.312587 & -2.527888 & 1.322242 \\
\hline $\mathrm{H}$ & 6.361612 & -2.282751 & 0.649889 \\
\hline $\mathrm{H}$ & 6.098345 & -3.687321 & 1.657239 \\
\hline $\mathrm{C}$ & 4.532296 & -4.232299 & -2.717723 \\
\hline $\mathrm{H}$ & 4.216192 & -3.730191 & -3.633365 \\
\hline $\mathrm{H}$ & 5.373939 & -4.885880 & -2.961162 \\
\hline $\mathrm{H}$ & 3.712404 & -4.864306 & -2.362403 \\
\hline $\mathrm{C}$ & 6.072103 & -2.289209 & -2.242379 \\
\hline $\mathrm{H}$ & 6.909318 & -2.906195 & -2.578566 \\
\hline $\mathrm{H}$ & 5.680404 & -1.744141 & -3.104708 \\
\hline $\mathrm{H}$ & 6.455333 & -1.565330 & -1.518086 \\
\hline$C$ & 3.431158 & -3.640092 & 1.952801 \\
\hline $\mathrm{H}$ & 3.950537 & -4.067189 & 2.814822 \\
\hline 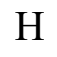 & 2.477473 & -3.228571 & 2.297145 \\
\hline $\mathrm{H}$ & 3.218754 & -4.453761 & 1.254433 \\
\hline $\mathrm{C}$ & 4.569751 & -1.430534 & 2.375792 \\
\hline $\mathrm{H}$ & 3.636100 & -1.043932 & 2.791210 \\
\hline $\mathrm{H}$ & 5.159125 & -1.852188 & 3.194401 \\
\hline $\mathrm{H}$ & 5.137928 & -0.596419 & 1.951566 \\
\hline $\mathrm{C}$ & 2.110948 & 3.521968 & 1.011777 \\
\hline $\mathrm{C}$ & 3.201112 & 3.318416 & 1.884988 \\
\hline $\mathrm{C}$ & 4.400697 & 4.023132 & 1.686377 \\
\hline $\mathrm{C}$ & 4.461955 & 4.935170 & 0.630112 \\
\hline $\mathrm{C}$ & 3.352300 & 5.151492 & -0.209994 \\
\hline $\mathrm{C}$ & 2.153342 & 4.445018 & -0.029051 \\
\hline C & 1.486067 & 2.020511 & 2.653446 \\
\hline $\mathrm{C}$ & 2.775322 & 2.377921 & 2.901958 \\
\hline
\end{tabular}




$\begin{array}{lrrr}\mathrm{H} & 5.249518 & 3.882092 & 2.347709 \\ \mathrm{H} & 5.370869 & 5.503853 & 0.462324 \\ \mathrm{H} & 3.422190 & 5.887865 & -1.004004 \\ \mathrm{H} & 1.298858 & 4.663505 & -0.663750 \\ \mathrm{H} & 0.184614 & 3.242704 & 1.656857 \\ \mathrm{H} & 3.390516 & 1.996190 & 3.707418 \\ \mathrm{C} & 0.586489 & 1.060206 & 3.282693 \\ \mathrm{C} & 0.603113 & 0.740184 & 4.651787 \\ \mathrm{C} & -0.330477 & -0.173264 & 5.138254 \\ \mathrm{H} & 1.309057 & 1.222554 & 5.318556 \\ \mathrm{C} & -1.205216 & -0.403847 & 2.918229 \\ \mathrm{C} & -1.260708 & -0.758177 & 4.260220 \\ \mathrm{H} & -0.348001 & -0.424009 & 6.194826 \\ \mathrm{H} & -2.002859 & -1.469206 & 4.602622 \\ \mathrm{C} & -2.089263 & -0.992261 & 1.882788 \\ \mathrm{C} & -3.829422 & -2.326399 & 1.240792 \\ \mathrm{C} & -3.544025 & -1.962717 & -0.132278 \\ \mathrm{~N} & 1.007151 & 2.673500 & 1.429965 \\ \mathrm{~N} & -0.304826 & 0.489277 & 2.439120 \\ \mathrm{~N} & -3.073787 & -1.820474 & 2.221149 \\ \mathrm{~N} & -1.808644 & -0.638106 & 0.616730 \\ \mathrm{~N} & -2.538677 & -1.131120 & -0.397326 \\ \mathrm{C} & -4.982701 & -3.223317 & 1.636807 \\ \mathrm{C} & -5.534168 & -3.982637 & 0.409677 \\ \mathrm{H} & -3.5 \\ \mathrm{H} & -4.894104 & -4.845813 & 0.199721 \\ \mathrm{H} & -6.512687 & -4.393097 & 0.672811 \\ \mathrm{C} & -5.662917 & -3.106102 & -0.838078 \\ \mathrm{C} & -4.311817 & -2.529464 & -1.320639 \\ \mathrm{H} & -6.361053 & -2.283355 & -0.649294 \\ \mathrm{H} & -6.097576 & -3.689095 & -1.654960 \\ \mathrm{C} & -4.533071 & -4.229312 & 2.721137 \\ \mathrm{H} & -4.217221 & -3.726212 & 3.636322 \\ \mathrm{H} & -5.374855 & -4.882543 & 2.965030 \\ \mathrm{H} & -3.713122 & -4.861791 & 2.366792 \\ \mathrm{C} & -6.072547 & -2.286614 & 2.243119 \\ \mathrm{H} & -6.909925 & -2.903149 & 2.579727 \\ \mathrm{H} & -5.681081 & -1.740610 & 3.104962 \\ & -6.455481 & -1.563517 & 1.517888 \\ \mathrm{H} & -3.4763920 & -3.642487 & -1.949517 \\ \mathrm{H} & -4.070621 & -2.811199 \\ \mathrm{H} & -3.231433 & -2.294023 \\ \mathrm{H} & -0.598706 & -1.952604\end{array}$


$\mathrm{M}=\mathrm{Am}$

\begin{tabular}{|c|c|c|c|}
\hline AM & -0.000002 & 0.676354 & 0.000006 \\
\hline $\mathrm{C}$ & -2.172984 & 3.360948 & -1.128270 \\
\hline $\mathrm{C}$ & -3.166867 & 3.136945 & -2.105811 \\
\hline C & -4.420186 & 3.761912 & -1.989736 \\
\hline $\mathrm{C}$ & -4.631862 & 4.616120 & -0.905530 \\
\hline $\mathrm{C}$ & -3.618904 & 4.850812 & 0.045183 \\
\hline $\mathrm{C}$ & -2.369433 & 4.222237 & -0.052911 \\
\hline $\mathrm{C}$ & -1.313342 & 1.977461 & -2.760257 \\
\hline $\mathrm{C}$ & -2.595195 & 2.269014 & -3.115179 \\
\hline $\mathrm{H}$ & -5.195466 & 3.605312 & -2.732700 \\
\hline $\mathrm{H}$ & -5.584379 & 5.125141 & -0.799267 \\
\hline $\mathrm{H}$ & -3.806463 & 5.539370 & 0.862626 \\
\hline $\mathrm{H}$ & -1.593059 & 4.446808 & 0.673543 \\
\hline $\mathrm{H}$ & -0.183379 & 3.227121 & -1.601251 \\
\hline $\mathrm{H}$ & -3.112273 & 1.883987 & -3.985408 \\
\hline $\mathrm{C}$ & -0.311100 & 1.093861 & -3.342720 \\
\hline $\mathrm{C}$ & -0.191629 & 0.856237 & -4.723413 \\
\hline $\mathrm{C}$ & 0.821737 & 0.015673 & -5.177453 \\
\hline $\mathrm{H}$ & -0.859763 & 1.349540 & -5.420333 \\
\hline $\mathrm{C}$ & 1.507335 & -0.316438 & -2.903047 \\
\hline $\mathrm{C}$ & 1.696140 & -0.581769 & -4.252976 \\
\hline $\mathrm{H}$ & 0.943287 & -0.169144 & -6.240666 \\
\hline $\mathrm{H}$ & 2.498429 & -1.239516 & -4.565038 \\
\hline $\mathrm{C}$ & 2.325569 & -0.944702 & -1.839048 \\
\hline $\mathrm{C}$ & 4.044386 & -2.270143 & -1.128760 \\
\hline $\mathrm{C}$ & 3.623337 & -2.010538 & 0.233471 \\
\hline $\mathrm{N}$ & -0.987725 & 2.603950 & -1.480262 \\
\hline $\mathrm{N}$ & 0.525924 & 0.507711 & -2.452855 \\
\hline $\mathrm{N}$ & 3.365549 & -1.718566 & -2.140209 \\
\hline $\mathrm{N}$ & 1.922798 & -0.687855 & -0.586971 \\
\hline $\mathrm{N}$ & 2.571697 & -1.225247 & 0.455681 \\
\hline $\mathrm{C}$ & 5.257721 & -3.108138 & -1.472891 \\
\hline C & 5.715366 & -3.937547 & -0.252401 \\
\hline $\mathrm{H}$ & 5.083755 & -4.827300 & -0.161384 \\
\hline $\mathrm{H}$ & 6.725405 & -4.306822 & -0.449081 \\
\hline $\mathrm{C}$ & 5.702925 & -3.146680 & 1.057630 \\
\hline $\mathrm{C}$ & 4.296576 & -2.636535 & 1.448619 \\
\hline $\mathrm{H}$ & 6.390767 & -2.296765 & 0.990530 \\
\hline $\mathrm{H}$ & 6.077475 & -3.774507 & 1.871015 \\
\hline $\mathrm{C}$ & 4.941442 & -4.047686 & -2.659141 \\
\hline $\mathrm{H}$ & 4.697516 & -3.490444 & -3.564943 \\
\hline $\mathrm{H}$ & 5.821219 & -4.662926 & -2.864821 \\
\hline $\mathrm{H}$ & 4.111097 & -4.721900 & -2.427072 \\
\hline
\end{tabular}




\begin{tabular}{|c|c|c|c|}
\hline $\mathrm{C}$ & 6.369717 & -2.106034 & -1.909286 \\
\hline $\mathrm{H}$ & 7.253097 & -2.676620 & -2.207131 \\
\hline $\mathrm{H}$ & 6.042683 & -1.510038 & -2.764910 \\
\hline $\mathrm{H}$ & 6.662233 & -1.426833 & -1.103914 \\
\hline $\mathrm{C}$ & 3.395743 & -3.810348 & 1.920467 \\
\hline $\mathrm{H}$ & 3.846720 & -4.280844 & 2.798236 \\
\hline H & 2.402024 & -3.447314 & 2.199941 \\
\hline H & 3.274098 & -4.580539 & 1.154370 \\
\hline $\mathrm{C}$ & 4.422249 & -1.606980 & 2.591017 \\
\hline $\mathrm{H}$ & 3.443411 & -1.273674 & 2.943878 \\
\hline $\mathrm{H}$ & 4.948470 & -2.068089 & 3.431096 \\
\hline $\mathrm{H}$ & 4.999619 & -0.731634 & 2.276284 \\
\hline $\mathrm{C}$ & 2.173065 & 3.360843 & 1.128371 \\
\hline $\mathrm{C}$ & 3.166932 & 3.136797 & 2.105918 \\
\hline $\mathrm{C}$ & 4.420268 & 3.761734 & 1.989867 \\
\hline $\mathrm{C}$ & 4.631978 & 4.615955 & 0.905678 \\
\hline $\mathrm{C}$ & 3.619036 & 4.850687 & -0.045044 \\
\hline $\mathrm{C}$ & 2.369549 & 4.222142 & 0.053026 \\
\hline $\mathrm{C}$ & 1.313373 & 1.977342 & 2.760319 \\
\hline $\mathrm{C}$ & 2.595229 & 2.268858 & 3.115261 \\
\hline $\mathrm{H}$ & 5.195535 & 3.605102 & 2.732837 \\
\hline $\mathrm{H}$ & 5.584509 & 5.124953 & 0.799433 \\
\hline $\mathrm{H}$ & 3.806623 & 5.539252 & -0.862476 \\
\hline $\mathrm{H}$ & 1.593192 & 4.446739 & -0.673438 \\
\hline $\mathrm{H}$ & 0.183453 & 3.227060 & 1.601335 \\
\hline $\mathrm{H}$ & 3.112290 & 1.883798 & 3.985486 \\
\hline $\mathrm{C}$ & 0.311110 & 1.093745 & 3.342748 \\
\hline $\mathrm{C}$ & 0.191625 & 0.856084 & 4.723434 \\
\hline $\mathrm{C}$ & -0.821752 & 0.015518 & 5.177445 \\
\hline $\mathrm{H}$ & 0.859761 & 1.349360 & 5.420372 \\
\hline $\mathrm{C}$ & -1.507340 & -0.316522 & 2.903023 \\
\hline $\mathrm{C}$ & -1.696155 & -0.581889 & 4.252945 \\
\hline $\mathrm{H}$ & -0.943312 & -0.169327 & 6.240651 \\
\hline $\mathrm{H}$ & -2.498452 & -1.239637 & 4.564982 \\
\hline $\mathrm{C}$ & -2.325582 & -0.944747 & 1.839006 \\
\hline $\mathrm{C}$ & -4.044411 & -2.270160 & 1.128691 \\
\hline $\mathrm{C}$ & -3.623386 & -2.010497 & -0.233535 \\
\hline $\mathrm{N}$ & 0.987783 & 2.603869 & 1.480336 \\
\hline $\mathrm{N}$ & -0.525917 & 0.507630 & 2.452862 \\
\hline $\mathrm{N}$ & -3.365561 & -1.718619 & 2.140151 \\
\hline $\mathrm{N}$ & -1.922820 & -0.687865 & 0.586932 \\
\hline $\mathrm{N}$ & -2.571738 & -1.225212 & -0.455732 \\
\hline $\mathrm{C}$ & -5.257734 & -3.108177 & 1.472815 \\
\hline $\mathrm{C}$ & -5.715442 & -3.937495 & 0.252287 \\
\hline $\mathrm{H}$ & -5.083862 & -4.827261 & 0.161192 \\
\hline $\mathrm{H}$ & -6.725486 & -4.306753 & 0.448977 \\
\hline
\end{tabular}




$\begin{array}{llll}\mathrm{C} & -5.703019 & -3.146547 & -1.057694 \\ \mathrm{C} & -4.296665 & -2.636425 & -1.448696 \\ \mathrm{H} & -6.390830 & -2.296612 & -0.990518 \\ \mathrm{H} & -6.077616 & -3.774311 & -1.871107 \\ \mathrm{C} & -4.941395 & -4.047813 & 2.658980 \\ \mathrm{H} & -4.697416 & -3.490638 & 3.564809 \\ \mathrm{H} & -5.821165 & -4.663063 & 2.864663 \\ \mathrm{H} & -4.111067 & -4.722015 & 2.426817 \\ \mathrm{C} & -6.369708 & -2.106105 & 1.909340 \\ \mathrm{H} & -7.253071 & -2.676713 & 2.207192 \\ \mathrm{H} & -6.042629 & -1.510168 & 2.764988 \\ \mathrm{H} & -6.662269 & -1.426848 & 1.104031 \\ \mathrm{C} & -3.395873 & -3.810239 & -1.920618 \\ \mathrm{H} & -3.846886 & -4.280691 & -2.798391 \\ \mathrm{H} & -2.402154 & -3.447217 & -2.200106 \\ \mathrm{H} & -3.274222 & -4.580462 & -1.154554 \\ \mathrm{C} & -4.422340 & -1.606816 & -2.591046 \\ \mathrm{H} & -3.443501 & -1.273519 & -2.943914 \\ \mathrm{H} & -4.948591 & -2.067875 & -3.431133 \\ \mathrm{H} & -4.999682 & -0.731471 & -2.276261\end{array}$

$\mathrm{M}=\mathrm{Cm}$

$\begin{array}{lccc}\text { CM } & -0.000037 & 0.745412 & -0.000067 \\ \mathrm{C} & 2.211672 & 3.386844 & 1.115780 \\ \mathrm{C} & 3.233718 & 3.168548 & 2.063794 \\ \mathrm{C} & 4.473764 & 3.813176 & 1.920370 \\ \mathrm{C} & 4.644358 & 4.679479 & 0.837907 \\ \mathrm{C} & 3.603919 & 4.906391 & -0.083968 \\ \mathrm{C} & 2.366161 & 4.258496 & 0.042664 \\ \mathrm{C} & 1.417561 & 1.969472 & 2.758081 \\ \mathrm{C} & 2.702976 & 2.280101 & 3.078723 \\ \mathrm{H} & 5.271122 & 3.661377 & 2.640643 \\ \mathrm{H} & 5.586537 & 5.202781 & 0.710811 \\ \mathrm{H} & 3.759902 & 5.603034 & -0.901230 \\ \mathrm{H} & 1.567311 & 4.475848 & -0.661469 \\ \mathrm{H} & 0.245805 & 3.232880 & 1.662463 \\ \mathrm{H} & 3.250189 & 1.895321 & 3.930522 \\ \mathrm{C} & 0.450349 & 1.056614 & 3.358334 \\ \mathrm{C} & 0.384936 & 0.780529 & 4.735641 \\ \mathrm{C} & -0.593756 & -0.096406 & 5.199159 \\ \mathrm{H} & 1.065269 & 1.268460 & 5.424573 \\ \mathrm{C} & -1.351144 & -0.379112 & 2.941889 \\ \mathrm{C} & -1.486590 & -0.689610 & 4.289418 \\ \mathrm{H} & -0.673682 & -0.313293 & 6.260282 \\ \mathrm{H} & -2.261169 & -1.374845 & 4.611695\end{array}$




\begin{tabular}{|c|c|c|c|}
\hline $\mathrm{C}$ & -2.196461 & -0.988274 & 1.885559 \\
\hline & -3.926432 & -2.322729 & 1.213499 \\
\hline & -3.578863 & -2.008989 & -0.157427 \\
\hline & 1.042933 & 2.610206 & 1.493126 \\
\hline & -0.406477 & 0.478922 & 2.484864 \\
\hline & -3.207681 & -1.791473 & 2.207872 \\
\hline$N$ & -1.856834 & -0.684649 & 0.621927 \\
\hline V & -2.551850 & -1.200427 & -0.405518 \\
\hline $\mathrm{C}$ & -5.105554 & -3.194667 & 1.589187 \\
\hline$C$ & -5.615599 & -3.986017 & 0.364293 \\
\hline $\mathrm{H}$ & -4.978061 & -4.862247 & 0.207561 \\
\hline $\mathrm{H}$ & -6.609014 & -4.377318 & 0.599224 \\
\hline $\mathrm{C}$ & -5.682016 & -3.147936 & -0.914369 \\
\hline $\mathrm{C}$ & -4.304781 & -2.603130 & -1.358606 \\
\hline $\mathrm{H}$ & -6.376165 & -2.311167 & -0.780036 \\
\hline $\mathrm{H}$ & -6.090785 & -3.751196 & -1.729881 \\
\hline $\mathrm{C}$ & -4.711219 & -4.171404 & 2.720843 \\
\hline $\mathrm{H}$ & -4.426973 & -3.643552 & 3.632479 \\
\hline $\mathrm{H}$ & -5.569219 & -4.808645 & 2.950155 \\
\hline $\mathrm{H}$ & -3.884620 & -4.822417 & 2.419380 \\
\hline $\mathrm{C}$ & -6.208365 & -2.229094 & 2.121857 \\
\hline $\mathrm{H}$ & -7.065284 & -2.826218 & 2.444004 \\
\hline $\mathrm{H}$ & -5.845355 & -1.659582 & 2.980957 \\
\hline $\mathrm{H}$ & -6.554437 & -1.525815 & 1.359486 \\
\hline $\mathrm{C}$ & -3.413365 & -3.745513 & -1.917028 \\
\hline $\mathrm{H}$ & -3.902341 & -4.192864 & -2.786547 \\
\hline $\mathrm{H}$ & -2.440659 & -3.357026 & -2.233757 \\
\hline $\mathrm{H}$ & -3.241316 & -4.539545 & -1.185690 \\
\hline $\mathrm{C}$ & -4.503319 & -1.536674 & -2.455798 \\
\hline $\mathrm{H}$ & -3.548345 & -1.175575 & -2.844822 \\
\hline $\mathrm{H}$ & -5.064878 & -1.976766 & -3.284231 \\
\hline $\mathrm{H}$ & -5.076340 & -0.682103 & -2.081630 \\
\hline $\mathrm{C}$ & -2.211647 & 3.386796 & -1.116182 \\
\hline $\mathrm{C}$ & -3.233600 & 3.168509 & -2.064300 \\
\hline $\mathrm{C}$ & -4.473637 & 3.813186 & -1.921027 \\
\hline $\mathrm{C}$ & -4.644317 & 4.679525 & -0.838606 \\
\hline 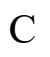 & -3.603969 & 4.906426 & 0.083375 \\
\hline $\mathrm{C}$ & -2.366221 & 4.258483 & -0.043107 \\
\hline $\mathrm{C}$ & -1.417405 & 1.969363 & -2.758366 \\
\hline $\mathrm{C}$ & -2.702782 & 2.280012 & -3.079144 \\
\hline I & -5.270924 & 3.661395 & -2.641381 \\
\hline 11 & -5.586492 & 5.202863 & -0.711626 \\
\hline $\mathrm{H}$ & -3.760015 & 5.603097 & 0.900600 \\
\hline te & -1.567438 & 4.475828 & 0.661104 \\
\hline $\mathrm{H}$ & -0.245726 & 3.232749 & -1.662643 \\
\hline $\mathrm{H}$ & -3.249916 & 1.895228 & -3.930992 \\
\hline
\end{tabular}




$\begin{array}{crrr}\mathrm{C} & -0.450153 & 1.056470 & -3.358503 \\ \mathrm{C} & -0.384616 & 0.780346 & -4.735796 \\ \mathrm{C} & 0.594103 & -0.096619 & -5.199199 \\ \mathrm{H} & -1.064876 & 1.268272 & -5.424805 \\ \mathrm{C} & 1.351278 & -0.379273 & -2.941850 \\ \mathrm{C} & 1.486843 & -0.689811 & -4.289358 \\ \mathrm{H} & 0.674126 & -0.313535 & -6.260308 \\ \mathrm{H} & 2.261443 & -1.375065 & -4.611544 \\ \mathrm{C} & 2.196497 & -0.988409 & -1.885426 \\ \mathrm{C} & 3.926401 & -2.322847 & -1.213160 \\ \mathrm{C} & 3.578733 & -2.009025 & 0.157722 \\ \mathrm{~N} & -1.042895 & 2.610107 & -1.493381 \\ \mathrm{~N} & 0.406581 & 0.478788 & -2.484936 \\ \mathrm{~N} & 3.207733 & -1.791635 & -2.207618 \\ \mathrm{~N} & 1.856775 & -0.684715 & -0.621837 \\ \mathrm{~N} & 2.551708 & -1.200440 & 0.405690 \\ \mathrm{C} & 5.105540 & -3.194822 & -1.588712 \\ \mathrm{C} & 5.615488 & -3.986101 & -0.363733 \\ \mathrm{H} & 4.977929 & -4.862313 & -0.206991 \\ \mathrm{H} & 6.608915 & -4.377429 & -0.598570 \\ \mathrm{C} & 5.681826 & -3.147940 & 0.914881 \\ \mathrm{C} & 4.304566 & -2.603092 & 1.358989 \\ \mathrm{H} & 6.375992 & -2.311186 & 0.780542 \\ \mathrm{H} & 6.090533 & -3.751153 & 1.730460 \\ \mathrm{C} & 4.711271 & -4.171625 & -2.720335 \\ \mathrm{H} & 4.427092 & -3.643825 & -3.632022 \\ \mathrm{H} & 5.569279 & -4.808889 & -2.949548 \\ \mathrm{H} & 3.884644 & -4.822610 & -2.418887 \\ \mathrm{C} & 6.208400 & -2.229296 & -2.121365 \\ \mathrm{H} & 7.065333 & -2.826451 & -2.443417 \\ \mathrm{H} & 5.845456 & -1.659830 & -2.980523 \\ \mathrm{H} & 6.554430 & -1.525975 & -1.359012 \\ \mathrm{C} & 3.413104 & -3.745428 & 1.917433 \\ \mathrm{H} & 3.902017 & -4.192719 & 2.787018 \\ \mathrm{H} & 2.440379 & -3.356910 & 2.234069 \\ \mathrm{H} & 3.241098 & -4.539511 & 1.186141 \\ \mathrm{C} & 4.503041 & -1.536560 & 2.456119 \\ \mathrm{H} & 3.548045 & -1.175424 & 2.845055 \\ \mathrm{H} & 5.064541 & -1.976598 & 3.284621 \\ & 5.076096 & -0.682020 & 2.081928\end{array}$

$L=1 b$

$\left[\mathrm{ML}\left(\mathrm{H}_{2} \mathrm{O}\right)_{6}\right]^{3+}$

$\mathrm{M}=\mathrm{Eu}$ 


$\begin{array}{lrrr}\mathrm{EU} & 2.080187 & 0.893599 & 0.435915 \\ \mathrm{O} & 1.320365 & 0.051000 & 2.798114 \\ \mathrm{H} & 0.857378 & -0.691203 & 3.214405 \\ \mathrm{O} & 4.194163 & 0.356607 & 1.952376 \\ \mathrm{H} & 4.088439 & -0.214373 & 2.729552 \\ \mathrm{O} & 3.931838 & 2.508522 & -0.480875 \\ \mathrm{H} & 4.085839 & 3.442397 & -0.268676 \\ \mathrm{O} & 2.529993 & 2.597876 & 2.484001 \\ \mathrm{H} & 2.139856 & 3.443628 & 2.753825 \\ \mathrm{O} & 0.413674 & 2.811930 & 0.298794 \\ \mathrm{H} & 0.355550 & 3.771707 & 0.194040 \\ \mathrm{O} & 1.885154 & 1.153607 & -2.200953 \\ \mathrm{H} & 2.300339 & 1.941573 & -2.587504 \\ \mathrm{H} & 1.358580 & 0.764855 & 3.455944 \\ \mathrm{H} & 3.429547 & 2.576313 & 2.849914 \\ \mathrm{H} & -0.500901 & 2.438629 & 0.206851 \\ \mathrm{H} & 4.799753 & 2.152369 & -0.755855 \\ \mathrm{H} & 1.166323 & 0.909681 & -2.804443 \\ \mathrm{H} & 5.071308 & 0.140748 & 1.590623 \\ \mathrm{C} & 5.414452 & -0.416452 & -1.129158 \\ \mathrm{C} & 6.132534 & -1.354793 & -0.343144 \\ \mathrm{C} & 7.532167 & -1.231936 & -0.211950 \\ \mathrm{C} & 8.175402 & -0.200242 & -0.893274 \\ \mathrm{C} & 7.452309 & 0.690877 & -1.717449 \\ \mathrm{C} & 6.060899 & 0.595928 & -1.851331 \\ \mathrm{C} & 3.938174 & -1.956733 & -0.335077 \\ \mathrm{C} & 5.174770 & -2.329253 & 0.126891 \\ \mathrm{H} & 8.101048 & -1.940337 & 0.382141 \\ \mathrm{H} & 4.038274 & -0.727413 & -1.045965 \\ \mathrm{H} & 9.253018 & -0.096416 & -0.820620 \\ \mathrm{H} & 7.990913 & 1.447670 & -2.278969 \\ \mathrm{H} & 5.534974 & 1.229573 & -2.561164 \\ \mathrm{H} & 5.388152 & -3.179473 & 0.761806 \\ \mathrm{C} & 2.619793 & -2.551747 & -0.125892 \\ \mathrm{C} & 2.458079 & -3.946416 & 0.001735 \\ \mathrm{C} & 1.175898 & -4.468098 & 0.128559 \\ \mathrm{H} & 3.323414 & -4.598121 & -0.041965 \\ \mathrm{C} & 0.321481 & -2.224190 & 0.002892 \\ \mathrm{C} & 0.079088 & -3.592956 & 0.109505 \\ \mathrm{H} & 1.023199 & -5.539795 & 0.211961 \\ \mathrm{H} & -0.938347 & -3.958037 & 0.163483 \\ \mathrm{H} & -1.700946 & -0.097077\end{array}$




$\begin{array}{lrrr}\mathrm{N} & -2.061238 & -1.739186 & -0.098125 \\ \mathrm{~N} & -0.509659 & 0.049173 & 0.003028 \\ \mathrm{~N} & -1.517000 & 0.929643 & 0.058437 \\ \mathrm{C} & -4.419579 & -1.434769 & -0.405686 \\ \mathrm{C} & -5.314269 & -0.810035 & -1.306332 \\ \mathrm{C} & -4.768394 & -2.657862 & 0.167085 \\ \mathrm{C} & -6.543660 & -1.418324 & -1.612495 \\ \mathrm{H} & -5.055252 & 0.128733 & -1.782227 \\ \mathrm{C} & -6.029438 & -3.251476 & -0.121889 \\ \mathrm{H} & -4.101849 & -3.178448 & 0.844889 \\ \mathrm{C} & -6.920432 & -2.622437 & -1.027334 \\ \mathrm{H} & -7.214155 & -0.938194 & -2.318253 \\ \mathrm{H} & -7.878141 & -3.067898 & -1.268577 \\ \mathrm{C} & -3.816923 & 1.587392 & 0.223747 \\ \mathrm{C} & -4.755965 & 1.476060 & 1.269988 \\ \mathrm{C} & -3.812153 & 2.722863 & -0.590386 \\ \mathrm{C} & -5.678942 & 2.508562 & 1.479629 \\ \mathrm{H} & -4.765312 & 0.606150 & 1.918176 \\ \mathrm{C} & -4.765616 & 3.752023 & -0.385739 \\ \mathrm{H} & -3.110288 & 2.834305 & -1.410136 \\ \mathrm{C} & -5.703041 & 3.640270 & 0.662655 \\ \mathrm{H} & -6.393741 & 2.429146 & 2.292832 \\ \mathrm{H} & -6.436009 & 4.417506 & 0.841506 \\ \mathrm{O} & -6.262033 & -4.405059 & 0.507675 \\ \mathrm{O} & -4.679640 & 4.785407 & -1.242991 \\ \mathrm{C} & -5.624405 & 5.876980 & -1.142463 \\ \mathrm{H} & -5.357488 & 6.562691 & -1.944667 \\ \mathrm{H} & -6.645775 & 5.513065 & -1.288115 \\ \mathrm{H} & -5.529029 & 6.378907 & -0.174884 \\ \mathrm{C} & -7.507314 & -5.122562 & 0.298953 \\ \mathrm{H} & -7.432133 & -6.008003 & 0.926855 \\ \mathrm{H} & -8.353625 & -4.506260 & 0.614723 \\ \mathrm{H} & -7.603107 & -5.411097 & -0.751498 \\ \mathrm{H} & 3.474629 & -0.621822 & -1.887411\end{array}$

$\mathrm{M}=\mathrm{Gd}$

$\begin{array}{lccc}\text { GD } & 1.938615 & 0.751182 & 0.380122 \\ \mathrm{O} & 1.151410 & -0.047562 & 2.653216 \\ \mathrm{H} & 0.645910 & -0.837490 & 2.904373 \\ \mathrm{O} & 3.873118 & 0.268805 & 1.920820 \\ \mathrm{H} & 3.725945 & -0.218970 & 2.747445 \\ \mathrm{O} & 3.618174 & 2.367405 & -0.461586 \\ \mathrm{H} & 3.691128 & 3.309106 & -0.236584 \\ \mathrm{O} & 2.227736 & 2.499780 & 2.268882 \\ \mathrm{H} & 1.657142 & 3.274122 & 2.402437\end{array}$




\begin{tabular}{|c|c|c|c|}
\hline & 0.442703 & 2.618292 & 44000 \\
\hline & 0.420879 & 3.540886 & -0.149463 \\
\hline & 1.631369 & 0.850886 & -2.127404 \\
\hline & 1.921776 & 1.603612 & -2.668679 \\
\hline & 1.000049 & 0.611647 & 3.350977 \\
\hline & 3.022148 & 2.630236 & 2.812508 \\
\hline & -0.507603 & 2.226459 & 0.084795 \\
\hline & 4.510272 & 2.084820 & -0.756445 \\
\hline F & 0.847408 & 0.488352 & -2.57 \\
\hline & 4.783093 & 0.063220 & 1.641905 \\
\hline & 5.295328 & -0.302402 & -1.071258 \\
\hline C & 6.084519 & -1.207527 & -0.32 \\
\hline $\mathrm{C}$ & 7.480373 & -1.0 & -0.25 \\
\hline $\mathrm{C}$ & 8.051078 & 0.029902 & -0.9 \\
\hline$C$ & 7.258311 & 0.887458 & -1.74 \\
\hline $\mathrm{C}$ & 5.864653 & 0.7 & -1.8 \\
\hline $\mathrm{C}$ & 3.926699 & -1.931946 & -0.2 \\
\hline $\mathrm{C}$ & 5.193482 & -2.2 & 0.1 \\
\hline $\mathrm{H}$ & 8.103234 & -1.717168 & 0.3 \\
\hline $\mathrm{H}$ & 9.125770 & 0.177793 & -0.9 \\
\hline $\mathrm{H}$ & 7.739109 & 1.664831 & -2.331972 \\
\hline H & 5.28 & 1.3 & -2.5 \\
\hline $\mathrm{H}$ & 5.479214 & -3.0 & $0 . ?$ \\
\hline $\mathrm{C}$ & 2.637499 & -2.565883 & 0. \\
\hline$C$ & 2.491106 & -3.9 & 0.1 \\
\hline . & 1.212311 & -4.487699 & 0.3 \\
\hline H & 3.360905 & -4.601934 & 240 \\
\hline $\mathrm{C}$ & 0.324758 & -2.260103 & 0.15 \\
\hline $\mathrm{C}$ & 0.102954 & -3.627763 & 0.28 \\
\hline $\mathrm{H}$ & 1.072151 & -5.559828 & 0.41 \\
\hline $\mathrm{H}$ & -0.912117 & -4.000504 & 0.3 \\
\hline $\mathrm{C}$ & -0.796662 & -1.288157 & 0.0 \\
\hline $\mathrm{C}$ & -3.053274 & -0.853192 & -0.073011 \\
\hline $\mathrm{C}$ & -2.721103 & 0.569486 & 0.03 \\
\hline $\mathrm{N}$ & 3.918970 & -0.678623 & -0.9 \\
\hline $\mathrm{N}$ & 1.570689 & -1.726468 & 0.046183 \\
\hline $\mathrm{N}$ & -2.046208 & -1.738006 & 0.056363 \\
\hline $\mathrm{N}$ & -0.444856 & 0.004299 & 0.012359 \\
\hline $\mathrm{N}$ & -1.438793 & 0.921266 & 0.037573 \\
\hline$C^{\prime}$ & -4.377191 & -1.388002 & -0.350206 \\
\hline $\mathrm{C}$ & -5.353228 & -0.642952 & -1.067782 \\
\hline $\mathrm{C}$ & -4.648178 & -2.724576 & 0.013878 \\
\hline $\mathrm{C}$ & -6.557369 & -1.252936 & -1.399639 \\
\hline $\mathrm{H}$ & -5.161978 & 0.370903 & -1.390475 \\
\hline $\mathrm{C}$ & -5.882823 & -3.314540 & -0.286421 \\
\hline $\mathrm{H}$ & -3.916235 & -3.309490 & 0.555772 \\
\hline
\end{tabular}




$\begin{array}{cccc}\mathrm{C} & -6.842056 & -2.568958 & -1.007085 \\ \mathrm{H} & -7.298984 & -0.702774 & -1.970056 \\ \mathrm{H} & -7.801507 & -3.002824 & -1.263690 \\ \mathrm{C} & -3.688241 & 1.670622 & 0.209344 \\ \mathrm{C} & -4.753283 & 1.546979 & 1.127424 \\ \mathrm{C} & -3.487435 & 2.876639 & -0.478824 \\ \mathrm{C} & -5.588527 & 2.643616 & 1.339887 \\ \mathrm{H} & -4.919790 & 0.625462 & 1.672442 \\ \mathrm{C} & -4.353679 & 3.966831 & -0.279205 \\ \mathrm{H} & -2.704325 & 2.978923 & -1.222687 \\ \mathrm{C} & -5.409688 & 3.846072 & 0.644286 \\ \mathrm{H} & -6.402395 & 2.565549 & 2.054105 \\ \mathrm{H} & -6.092799 & 4.668458 & 0.819198 \\ \mathrm{O} & -6.051126 & -4.583154 & 0.144014 \\ \mathrm{O} & -4.082573 & 5.070940 & -1.016032 \\ \mathrm{C} & -4.977113 & 6.200173 & -0.923789 \\ \mathrm{H} & -4.585599 & 6.938645 & -1.622105 \\ \mathrm{H} & -5.991613 & 5.917091 & -1.220896 \\ \mathrm{H} & -4.978469 & 6.616345 & 0.088741 \\ \mathrm{C} & -7.301821 & -5.252503 & -0.123837 \\ \mathrm{H} & -7.200910 & -6.240783 & 0.322142 \\ \mathrm{H} & -8.135796 & -4.721984 & 0.346492 \\ \mathrm{H} & -7.467918 & -5.351734 & -1.201268 \\ \mathrm{H} & 3.417186 & -0.719863 & -1.835405\end{array}$

$\mathrm{M}=\mathrm{Am}$

$\begin{array}{lccc}\text { AM } & 1.833273 & 0.732508 & 0.339993 \\ \mathrm{O} & 0.957820 & 0.041296 & 2.700387 \\ \mathrm{H} & 0.430599 & -0.712560 & 3.009265 \\ \mathrm{O} & 3.765277 & 0.178542 & 1.985057 \\ \mathrm{H} & 3.584167 & -0.251728 & 2.836075 \\ \mathrm{O} & 3.692957 & 2.301874 & -0.483439 \\ \mathrm{H} & 3.833507 & 3.226368 & -0.223221 \\ \mathrm{O} & 2.121411 & 2.593077 & 2.193767 \\ \mathrm{H} & 1.550751 & 3.376954 & 2.246927 \\ \mathrm{O} & 0.262192 & 2.667993 & 0.077476 \\ \mathrm{H} & 0.242749 & 3.530382 & -0.363291 \\ \mathrm{O} & 1.628029 & 0.900871 & -2.271404 \\ \mathrm{H} & 2.014740 & 1.629839 & -2.783913 \\ \mathrm{H} & 0.845716 & 0.745868 & 3.359610 \\ \mathrm{H} & 2.894666 & 2.759904 & 2.757010 \\ \mathrm{H} & -0.664712 & 2.262974 & 0.028818 \\ \mathrm{H} & 4.566137 & 1.962588 & -0.771732 \\ \mathrm{H} & 0.870834 & 0.583749 & -2.790367 \\ \mathrm{H} & 4.670937 & -0.077206 & 1.738273\end{array}$




\begin{tabular}{|c|c|c|c|}
\hline $\mathrm{C}$ & 5.218453 & -0.487044 & -1.096368 \\
\hline & 5.955072 & -1.406740 & -0.310263 \\
\hline $\mathrm{C}$ & 7.353609 & -1.272461 & -0.198782 \\
\hline $\mathrm{C}$ & 7.979218 & -0.242532 & -0.901718 \\
\hline $\mathrm{C}$ & 7.238461 & 0.629647 & -1.727075 \\
\hline C & 5.844344 & 0.519190 & -1.840737 \\
\hline $\mathrm{C}$ & 3.771496 & -2.052530 & -0.276346 \\
\hline C & 5.015513 & -2.395833 & 0.175890 \\
\hline $\mathrm{H}$ & 7.936477 & -1.969655 & 0.394900 \\
\hline $\mathrm{H}$ & 9.056870 & -0.128958 & -0.844787 \\
\hline $\mathrm{H}$ & 7.761625 & 1.383669 & -2.306656 \\
\hline $\mathrm{H}$ & 5.306746 & 1.134796 & -2.558350 \\
\hline $\mathrm{H}$ & 5.251917 & -3.240713 & 0.810463 \\
\hline $\mathrm{C}$ & 2.460587 & -2.655389 & -0.060073 \\
\hline $\mathrm{C}$ & 2.291426 & -4.045017 & 0.078462 \\
\hline $\mathrm{C}$ & 1.004388 & -4.559687 & 0.201688 \\
\hline $\mathrm{H}$ & 3.153104 & -4.702124 & 0.044117 \\
\hline $\mathrm{C}$ & 0.153983 & -2.317260 & 0.047469 \\
\hline $\mathrm{C}$ & -0.090799 & -3.682446 & 0.166013 \\
\hline $\mathrm{H}$ & 0.847144 & -5.630184 & 0.293738 \\
\hline $\mathrm{H}$ & -1.111218 & -4.040959 & 0.215660 \\
\hline $\mathrm{C}$ & -0.960805 & -1.336022 & 0.000180 \\
\hline $\mathrm{C}$ & -3.218111 & -0.902392 & -0.127384 \\
\hline $\mathrm{C}$ & -2.890752 & 0.512962 & -0.005001 \\
\hline $\mathrm{N}$ & 3.834128 & -0.815535 & -1.003815 \\
\hline $\mathrm{N}$ & 1.406762 & -1.801263 & -0.043961 \\
\hline $\mathrm{N}$ & -2.214319 & -1.787578 & -0.040854 \\
\hline $\mathrm{N}$ & -0.617179 & -0.040797 & -0.047226 \\
\hline $\mathrm{N}$ & -1.609634 & 0.872701 & -0.005997 \\
\hline $\mathrm{C}$ & -4.559275 & -1.434547 & -0.370188 \\
\hline $\mathrm{C}$ & -5.530019 & -0.700923 & -1.106157 \\
\hline $\mathrm{C}$ & -4.850121 & -2.741765 & 0.053851 \\
\hline $\mathrm{C}$ & -6.757381 & -1.294880 & -1.394946 \\
\hline $\mathrm{H}$ & -5.317190 & 0.290799 & -1.481385 \\
\hline $\mathrm{C}$ & -6.105780 & -3.317144 & -0.207727 \\
\hline $\mathrm{H}$ & -4.124069 & -3.322007 & 0.609254 \\
\hline $\mathrm{C}$ & -7.064597 & -2.583539 & -0.945669 \\
\hline $\mathrm{H}$ & -7.493024 & -0.750201 & -1.978154 \\
\hline $\mathrm{H}$ & -8.035063 & -3.009946 & -1.171051 \\
\hline $\mathrm{C}$ & -3.871924 & 1.604697 & 0.169788 \\
\hline $\mathrm{C}$ & -4.932363 & 1.467127 & 1.093263 \\
\hline $\mathrm{C}$ & -3.701626 & 2.805829 & -0.529330 \\
\hline $\mathrm{C}$ & -5.794633 & 2.545953 & 1.298972 \\
\hline $\mathrm{H}$ & -5.071277 & 0.549968 & 1.653314 \\
\hline $\mathrm{C}$ & -4.593537 & 3.879606 & -0.334564 \\
\hline $\mathrm{H}$ & -2.921254 & 2.921763 & -1.273943 \\
\hline
\end{tabular}




$\begin{array}{lrrr}\mathrm{C} & -5.645821 & 3.744815 & 0.593349 \\ \mathrm{H} & -6.603140 & 2.454779 & 2.017693 \\ \mathrm{H} & -6.344860 & 4.554638 & 0.763789 \\ \mathrm{O} & -6.291188 & -4.559717 & 0.275745 \\ \mathrm{O} & -4.349392 & 4.980080 & -1.080356 \\ \mathrm{C} & -5.256432 & 6.101008 & -0.988636 \\ \mathrm{H} & -4.876242 & 6.839188 & -1.693187 \\ \mathrm{H} & -6.268841 & 5.803730 & -1.278271 \\ \mathrm{H} & -5.254975 & 6.520699 & 0.022189 \\ \mathrm{C} & -7.554549 & -5.227023 & 0.055364 \\ \mathrm{H} & -7.455464 & -6.195950 & 0.541796 \\ \mathrm{H} & -8.373349 & -4.665436 & 0.515365 \\ \mathrm{H} & -7.735652 & -5.367950 & -1.014608 \\ \mathrm{H} & 3.327395 & -0.814126 & -1.889539\end{array}$

$\mathrm{M}=\mathrm{Cm}$

$\begin{array}{lccc}\mathrm{CM} & 1.811508 & 0.690783 & 0.333063 \\ \mathrm{O} & 1.042182 & -0.089077 & 2.668420 \\ \mathrm{H} & 0.533965 & -0.869438 & 2.943086 \\ \mathrm{O} & 3.806659 & 0.235133 & 1.902528 \\ \mathrm{H} & 3.673199 & -0.246891 & 2.734948 \\ \mathrm{O} & 3.532855 & 2.324073 & -0.576529 \\ \mathrm{H} & 3.611838 & 3.271232 & -0.377799 \\ \mathrm{O} & 2.119597 & 2.482549 & 2.236102 \\ \mathrm{H} & 1.554721 & 3.264070 & 2.350887 \\ \mathrm{O} & 0.279385 & 2.601631 & 0.106915 \\ \mathrm{H} & 0.249738 & 3.513970 & -0.216797 \\ \mathrm{O} & 1.493385 & 0.788499 & -2.226319 \\ \mathrm{H} & 1.806627 & 1.532127 & -2.767707 \\ \mathrm{H} & 0.913538 & 0.584571 & 3.356831 \\ \mathrm{H} & 2.923914 & 2.627756 & 2.760992 \\ \mathrm{H} & -0.662956 & 2.198510 & 0.052604 \\ \mathrm{H} & 4.422715 & 2.025169 & -0.858119 \\ \mathrm{H} & 0.701883 & 0.445597 & -2.673599 \\ \mathrm{H} & 4.709272 & 0.021191 & 1.606484 \\ \mathrm{C} & 5.144914 & -0.455189 & -1.113592 \\ \mathrm{C} & 5.914260 & -1.361104 & -0.344593 \\ \mathrm{C} & 7.312671 & -1.205823 & -0.267597 \\ \mathrm{C} & 7.905050 & -0.167778 & -0.988169 \\ \mathrm{C} & 7.131359 & 0.689343 & -1.798146 \\ \mathrm{C} & 5.736199 & 0.556440 & -1.877329 \\ \mathrm{C} & 3.744400 & -2.050626 & -0.257651 \\ \mathrm{C} & 5.003652 & -2.368398 & 0.163720 \\ \mathrm{H} & 7.920656 & -1.893281 & 0.312139 \\ \mathrm{H} & 8.981967 & -0.037675 & -0.957905\end{array}$




\begin{tabular}{|c|c|c|c|}
\hline $\mathrm{H}$ & 7.628479 & 1.448553 & -2.393741 \\
\hline $\mathrm{H}$ & 5.173362 & 1.156961 & -2.588643 \\
\hline $\mathrm{H}$ & 5.271858 & -3.209113 & 0.791466 \\
\hline & 2.445008 & -2.666634 & -0.009975 \\
\hline$C$ & 2.279042 & -4.053692 & 0.141722 \\
\hline C & 0.992115 & -4.566090 & 0.290304 \\
\hline $\mathrm{H}$ & 3.139123 & -4.712487 & 0.098618 \\
\hline $\mathrm{C}$ & 0.136070 & -2.326548 & 0.126367 \\
\hline $\mathrm{C}$ & -0.104942 & -3.690843 & 0.260202 \\
\hline $\mathrm{H}$ & 0.836660 & -5.635837 & 0.394835 \\
\hline $\mathrm{H}$ & -1.124841 & -4.049595 & 0.322927 \\
\hline$C$ & -0.973845 & -1.339901 & 0.065785 \\
\hline $\mathrm{C}$ & -3.227799 & -0.884613 & -0.085603 \\
\hline $\mathrm{C}$ & -2.882089 & 0.534720 & 0.020015 \\
\hline $\mathrm{N}$ & 3.762881 & -0.809281 & -0.993730 \\
\hline $\mathrm{N}$ & 1.389473 & -1.813823 & 0.017172 \\
\hline $\mathrm{N}$ & -2.228024 & -1.778165 & 0.038478 \\
\hline $\mathrm{N}$ & -0.611752 & -0.050726 & -0.014611 \\
\hline $\mathrm{N}$ & -1.597237 & 0.875898 & 0.014036 \\
\hline $\mathrm{C}$ & -4.558657 & -1.408234 & -0.352373 \\
\hline $\mathrm{C}$ & -5.531715 & -0.657453 & -1.067702 \\
\hline $\mathrm{C}$ & -4.840811 & -2.739814 & 0.020874 \\
\hline$c$ & -6.743896 & -1.257150 & -1.388909 \\
\hline $\mathrm{H}$ & -5.332344 & 0.352685 & -1.397136 \\
\hline $\mathrm{C}$ & -6.083014 & -3.319199 & -0.268835 \\
\hline $\mathrm{H}$ & -4.111623 & -3.329033 & 0.561911 \\
\hline $\mathrm{C}$ & -7.039254 & -2.568149 & -0.987589 \\
\hline $\mathrm{H}$ & -7.483519 & -0.702624 & -1.957711 \\
\hline $\mathrm{H}$ & -8.004491 & -2.993820 & -1.236007 \\
\hline $\mathrm{C}$ & -3.838804 & 1.645574 & 0.190272 \\
\hline $\mathrm{C}$ & -4.898270 & 1.538438 & 1.116578 \\
\hline $\mathrm{C}$ & -3.632828 & 2.844036 & -0.509345 \\
\hline $\mathrm{C}$ & -5.722902 & 2.643740 & 1.325666 \\
\hline $\mathrm{H}$ & -5.068629 & 0.622738 & 1.670325 \\
\hline $\mathrm{C}$ & -4.488295 & 3.943190 & -0.312488 \\
\hline $\mathrm{H}$ & -2.854244 & 2.933264 & -1.259849 \\
\hline $\mathrm{C}$ & -5.538788 & 3.838971 & 0.619088 \\
\hline $\mathrm{H}$ & -6.532416 & 2.578339 & 2.046115 \\
\hline $\mathrm{H}$ & -6.213683 & 4.668518 & 0.792021 \\
\hline $\mathrm{O}$ & -6.261028 & -4.583939 & 0.169475 \\
\hline $\mathrm{O}$ & -4.212735 & 5.039249 & -1.059983 \\
\hline 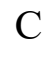 & -5.097229 & 6.176526 & -0.970884 \\
\hline $\mathrm{H}$ & -4.704327 & 6.906189 & -1.677624 \\
\hline & -6.116001 & 5.899528 & -1.259076 \\
\hline $\mathrm{H}$ & -5.088426 & 6.600741 & 0.038282 \\
\hline & -7.519910 & -5.242099 & -0.086974 \\
\hline
\end{tabular}




$$
\begin{array}{lrrr}
H & -7.426051 & -6.229055 & 0.363458 \\
H & -8.345575 & -4.700870 & 0.385855 \\
H & -7.693910 & -5.345199 & -1.162806 \\
H & 3.264785 & -0.854096 & -1.884598
\end{array}
$$

\section{$\left[\mathrm{ML}\left(\mathrm{H}_{2} \mathrm{O}\right)_{5}\right]^{3+}$}

$\mathrm{M}=\mathrm{Eu}$

$\begin{array}{lccc}\mathrm{EU} & 2.124467 & 0.919652 & 0.397984 \\ \mathrm{O} & 1.233295 & 1.298506 & 2.785244 \\ \mathrm{H} & 1.398744 & 0.829623 & 3.617973 \\ \mathrm{O} & 4.023533 & 2.637044 & -0.011430 \\ \mathrm{H} & 4.146790 & 3.576554 & 0.197934 \\ \mathrm{O} & 3.843977 & 0.099042 & 2.157909 \\ \mathrm{H} & 4.249231 & 0.570892 & 2.901993 \\ \mathrm{O} & 0.473330 & 2.884810 & 0.427263 \\ \mathrm{H} & 0.422964 & 3.842861 & 0.297229 \\ \mathrm{O} & 2.063332 & 1.366848 & -2.210891 \\ \mathrm{H} & 2.505309 & 2.144079 & -2.589429 \\ \mathrm{H} & 0.639105 & 2.036311 & 2.994745 \\ \mathrm{H} & 4.444509 & -0.638804 & 1.945538 \\ \mathrm{H} & -0.432183 & 2.508677 & 0.286766 \\ \mathrm{H} & 4.916605 & 2.286640 & -0.198486 \\ \mathrm{H} & 1.403636 & 1.098990 & -2.869935 \\ \mathrm{C} & 5.547331 & -0.260494 & -0.912692 \\ \mathrm{C} & 6.238494 & -1.210925 & -0.121004 \\ \mathrm{C} & 7.623353 & -1.068070 & 0.097860 \\ \mathrm{C} & 8.281120 & 0.003964 & -0.502604 \\ \mathrm{C} & 7.585090 & 0.919422 & -1.322852 \\ \mathrm{C} & 6.205612 & 0.802655 & -1.541708 \\ \mathrm{C} & 4.055586 & -1.855786 & -0.253105 \\ \mathrm{C} & 5.272771 & -2.212612 & 0.273377 \\ \mathrm{H} & 8.171331 & -1.786257 & 0.699496 \\ \mathrm{H} & 9.350130 & 0.126828 & -0.363111 \\ \mathrm{H} & 8.135912 & 1.717005 & -1.811398 \\ \mathrm{H} & 5.700839 & 1.471783 & -2.233157 \\ \mathrm{H} & 5.467299 & -3.080716 & 0.891033 \\ \mathrm{C} & 2.738258 & -2.482353 & -0.129541 \\ \mathrm{C} & 2.594212 & -3.881656 & -0.053958 \\ \mathrm{C} & 1.315790 & -4.424782 & 0.016675 \\ \mathrm{H} & 3.469855 & -4.520027 & -0.088445 \\ \mathrm{C} & 0.430793 & -2.190984 & -0.056477 \\ \mathrm{C} & 0.206732 & -3.565488 & 0.000290 \\ \mathrm{H} & 1.177016 & -5.500682 & 0.061184 \\ \mathrm{H} & -0.805995 & -3.946569 & 0.023884\end{array}$




$\begin{array}{lrrr}\mathrm{C} & -0.711135 & -1.236711 & -0.053597 \\ \mathrm{C} & -2.974499 & -0.867886 & -0.144726 \\ \mathrm{C} & -2.704925 & 0.533510 & 0.058097 \\ \mathrm{~N} & 4.170197 & -0.603747 & -0.928827 \\ \mathrm{~N} & 1.671497 & -1.649324 & -0.111539 \\ \mathrm{~N} & -1.958559 & -1.726980 & -0.136295 \\ \mathrm{~N} & -0.423450 & 0.072922 & -0.008276 \\ \mathrm{~N} & -1.436097 & 0.945532 & 0.082070 \\ \mathrm{C} & -4.323279 & -1.433382 & -0.404839 \\ \mathrm{C} & -5.229687 & -0.801356 & -1.288426 \\ \mathrm{C} & -4.661150 & -2.664600 & 0.156406 \\ \mathrm{C} & -6.461017 & -1.410236 & -1.589107 \\ \mathrm{H} & -4.978433 & 0.143411 & -1.756777 \\ \mathrm{C} & -5.924343 & -3.259374 & -0.126990 \\ \mathrm{H} & -3.986164 & -3.191107 & 0.821380 \\ \mathrm{C} & -6.827603 & -2.622376 & -1.015265 \\ \mathrm{H} & -7.140175 & -0.923694 & -2.282106 \\ \mathrm{H} & -7.786139 & -3.068621 & -1.251861 \\ \mathrm{C} & -3.741629 & 1.572175 & 0.298370 \\ \mathrm{C} & -4.647768 & 1.430628 & 1.369775 \\ \mathrm{C} & -3.779136 & 2.718484 & -0.499067 \\ \mathrm{C} & -5.581855 & 2.444610 & 1.621182 \\ \mathrm{H} & -4.623401 & 0.552005 & 2.005853 \\ \mathrm{C} & -4.743649 & 3.729159 & -0.251271 \\ \mathrm{H} & -3.103537 & 2.853939 & -1.337147 \\ \mathrm{C} & -5.648521 & 3.586974 & 0.822364 \\ \mathrm{H} & -6.271002 & 2.341275 & 2.453635 \\ \mathrm{H} & -6.388207 & 4.349575 & 1.033716 \\ \mathrm{O} & -6.145099 & -4.420244 & 0.490429 \\ \mathrm{O} & -4.699034 & 4.774707 & -1.094818 \\ \mathrm{C} & -5.655179 & 5.852576 & -0.951589 \\ \mathrm{H} & -5.420312 & 6.552394 & -1.751537 \\ \mathrm{H} & -6.675162 & 5.476208 & -1.072720 \\ \mathrm{H} & -5.537540 & 6.341827 & 0.019926 \\ \mathrm{C} & -7.389863 & -5.142523 & 0.289274 \\ \mathrm{H} & -7.301646 & -6.034147 & 0.906549 \\ \mathrm{H} & -8.234687 & -4.533518 & 0.622487 \\ \mathrm{H} & -7.496486 & -5.419498 & -0.763183 \\ \mathrm{H} & 3.689138 & -0.525200 & -1.823722\end{array}$

$\mathrm{M}=\mathrm{Gd}$

$\begin{array}{lclc}\text { GD } & 1.984665 & 0.736718 & 0.208734 \\ \mathrm{O} & 1.196877 & 0.791451 & 2.574173 \\ \mathrm{H} & 1.365227 & 0.177186 & 3.308029 \\ \mathrm{O} & 3.464586 & 2.524996 & -0.676615\end{array}$




$\begin{array}{lrrr}\mathrm{H} & 3.312052 & 3.475182 & -0.810582 \\ \mathrm{O} & 3.876072 & 0.740069 & 1.818428 \\ \mathrm{H} & 3.930883 & 1.211219 & 2.666078 \\ \mathrm{O} & 0.533020 & 2.609054 & 0.315416 \\ \mathrm{H} & 0.494945 & 3.573970 & 0.397665 \\ \mathrm{O} & 1.599036 & 0.772081 & -2.243427 \\ \mathrm{H} & 1.960023 & 1.419000 & -2.871975 \\ \mathrm{H} & 0.455591 & 1.354518 & 2.854337 \\ \mathrm{H} & 4.763143 & 0.373260 & 1.644956 \\ \mathrm{H} & -0.423001 & 2.234999 & 0.205463 \\ \mathrm{H} & 4.431987 & 2.392188 & -0.719172 \\ \mathrm{H} & 0.825566 & 0.375995 & -2.678302 \\ \mathrm{C} & 5.385782 & -0.237216 & -0.846470 \\ \mathrm{C} & 6.132770 & -1.049159 & 0.039077 \\ \mathrm{C} & 7.508606 & -0.807606 & 0.222854 \\ \mathrm{C} & 8.102559 & 0.221476 & -0.509514 \\ \mathrm{C} & 7.353953 & 0.987450 & -1.427383 \\ \mathrm{C} & 5.979591 & 0.768270 & -1.613097 \\ \mathrm{C} & 4.003135 & -1.864723 & 0.001318 \\ \mathrm{C} & 5.236870 & -2.073630 & 0.542577 \\ \mathrm{H} & 8.100117 & -1.422776 & 0.893700 \\ \mathrm{H} & 9.164167 & 0.417372 & -0.398674 \\ \mathrm{H} & 7.856972 & 1.745165 & -2.019941 \\ \mathrm{H} & 5.441517 & 1.308882 & -2.387497 \\ \mathrm{H} & 5.495351 & -2.850159 & 1.252129 \\ \mathrm{C} & 2.716192 & -2.523755 & 0.207944 \\ \mathrm{C} & 2.584750 & -3.903211 & 0.432809 \\ \mathrm{C} & 1.305983 & -4.445685 & 0.554425 \\ \mathrm{H} & 3.464448 & -4.535982 & 0.470688 \\ \mathrm{C} & 0.390155 & -2.248355 & 0.234678 \\ \mathrm{C} & 0.184567 & -3.609088 & 0.436091 \\ \mathrm{H} & 1.177573 & -5.512296 & 0.713977 \\ \mathrm{H} & -0.825748 & -3.995461 & 0.491841 \\ \mathrm{C} & -0.732040 & -1.283209 & 0.117793 \\ \mathrm{C} & -2.984573 & -0.835625 & -0.038942 \\ \mathrm{C} & -2.646384 & 0.586267 & 0.096368 \\ \mathrm{~N} & 4.012517 & -0.670649 & -0.826000 \\ \mathrm{~N} & 1.633045 & -1.708015 & 0.133812 \\ \mathrm{~N} & -1.982532 & -1.725762 & 0.099598 \\ \mathrm{C} & -1.363545 & 0.006700 & -0.003657 \\ \mathrm{C} & -533211 & 0.058950 \\ \mathrm{C} & -1.1749303 & -1.357097 & -0.345224 \\ \mathrm{H} & -0.444913 & -1.319083\end{array}$




$\begin{array}{lrrr}\mathrm{C} & -5.813061 & -3.282691 & -0.371584 \\ \mathrm{H} & -3.854633 & -3.313497 & 0.489421 \\ \mathrm{C} & -6.765382 & -2.505836 & -1.069352 \\ \mathrm{H} & -7.213507 & -0.601007 & -1.958626 \\ \mathrm{H} & -7.723616 & -2.927227 & -1.350419 \\ \mathrm{C} & -3.605369 & 1.680050 & 0.336043 \\ \mathrm{C} & -4.664392 & 1.508218 & 1.254165 \\ \mathrm{C} & -3.401923 & 2.924740 & -0.280433 \\ \mathrm{C} & -5.490668 & 2.595306 & 1.539150 \\ \mathrm{H} & -4.832168 & 0.557389 & 1.745724 \\ \mathrm{C} & -4.259352 & 4.006056 & -0.008021 \\ \mathrm{H} & -2.624656 & 3.066912 & -1.023794 \\ \mathrm{C} & -5.309039 & 3.836063 & 0.915869 \\ \mathrm{H} & -6.299153 & 2.479536 & 2.254364 \\ \mathrm{H} & -5.985121 & 4.650714 & 1.145771 \\ \mathrm{O} & -5.987395 & -4.566493 & 0.004969 \\ \mathrm{O} & -3.988026 & 5.150281 & -0.678988 \\ \mathrm{C} & -4.872515 & 6.279131 & -0.509336 \\ \mathrm{H} & -4.480756 & 7.055561 & -1.164949 \\ \mathrm{H} & -5.891812 & 6.022520 & -0.813789 \\ \mathrm{H} & -4.860847 & 6.632446 & 0.526662 \\ \mathrm{C} & -7.237975 & -5.222360 & -0.297245 \\ \mathrm{H} & -7.141237 & -6.227626 & 0.109865 \\ \mathrm{H} & -8.073685 & -4.709206 & 0.188873 \\ \mathrm{H} & -7.396998 & -5.278436 & -1.378802 \\ \mathrm{H} & 3.637830 & -0.845985 & -1.761791\end{array}$

$\mathrm{M}=\mathrm{Am}$

$\begin{array}{lccc}\text { AM } & 1.908426 & 0.723289 & 0.173702 \\ \mathrm{O} & 1.317088 & 0.610837 & 2.667606 \\ \mathrm{H} & 1.579056 & -0.014978 & 3.362658 \\ \mathrm{O} & 3.142919 & 2.776324 & -0.826432 \\ \mathrm{H} & 2.773148 & 3.594146 & -1.197811 \\ \mathrm{O} & 4.043948 & 1.059504 & 1.550424 \\ \mathrm{H} & 4.147045 & 1.451012 & 2.433079 \\ \mathrm{O} & 0.329369 & 2.587766 & 0.524205 \\ \mathrm{H} & 0.291295 & 3.535726 & 0.720470 \\ \mathrm{O} & 1.517405 & 0.742875 & -2.373630 \\ \mathrm{H} & 1.947114 & 1.317453 & -3.028411 \\ \mathrm{H} & 0.619164 & 1.166526 & 3.052410 \\ \mathrm{H} & 4.913726 & 0.695939 & 1.298468 \\ \mathrm{H} & -0.607691 & 2.236064 & 0.357916 \\ \mathrm{H} & 4.067651 & 2.978432 & -0.604737 \\ \mathrm{H} & 0.764316 & 0.333775 & -2.831150 \\ \mathrm{C} & 5.290596 & -0.452778 & -0.827622\end{array}$




\begin{tabular}{|c|c|c|c|}
\hline $\mathrm{C}$ & 5.985610 & -1.306413 & 0.061845 \\
\hline & 7.368157 & -1.131374 & 0.267346 \\
\hline $\mathrm{C}$ & 8.018354 & -0.126226 & -0.449663 \\
\hline C & 7.316132 & 0.692411 & -1.360393 \\
\hline $\mathrm{C}$ & 5.937124 & 0.543308 & -1.561220 \\
\hline $\mathrm{C}$ & 3.818693 & -2.010645 & -0.005587 \\
\hline$C$ & 5.032486 & -2.281471 & 0.554170 \\
\hline $\mathrm{H}$ & 7.920122 & -1.777147 & 0.942854 \\
\hline $\mathrm{H}$ & 9.086760 & 0.017799 & -0.325182 \\
\hline $\mathrm{H}$ & 7.859404 & 1.442511 & -1.926187 \\
\hline $\mathrm{H}$ & 5.416877 & 1.157832 & -2.290297 \\
\hline $\mathrm{H}$ & 5.241559 & -3.068363 & 1.268180 \\
\hline$C$ & 2.506708 & -2.630036 & 0.166274 \\
\hline $\mathrm{C}$ & 2.341636 & -4.009678 & 0.373783 \\
\hline $\mathrm{C}$ & 1.051361 & -4.527332 & 0.462298 \\
\hline $\mathrm{H}$ & 3.207728 & -4.660127 & 0.421975 \\
\hline $\mathrm{C}$ & 0.192749 & -2.304285 & 0.156527 \\
\hline $\mathrm{C}$ & -0.047362 & -3.663654 & 0.334270 \\
\hline $\mathrm{H}$ & 0.896741 & -5.592628 & 0.605462 \\
\hline $\mathrm{H}$ & -1.066413 & -4.028114 & 0.366632 \\
\hline $\mathrm{C}$ & -0.918314 & -1.325211 & 0.052485 \\
\hline $\mathrm{C}$ & -3.172069 & -0.880434 & -0.082472 \\
\hline $\mathrm{C}$ & -2.838981 & 0.531464 & 0.083041 \\
\hline $\mathrm{N}$ & 3.901128 & -0.824267 & -0.834962 \\
\hline $\mathrm{N}$ & 1.445622 & -1.788764 & 0.083408 \\
\hline $\mathrm{N}$ & -2.174269 & -1.769994 & 0.009937 \\
\hline $\mathrm{N}$ & -0.569820 & -0.032552 & -0.021411 \\
\hline $\mathrm{N}$ & -1.557024 & 0.885089 & 0.059718 \\
\hline $\mathrm{C}$ & -4.509953 & -1.396251 & -0.369436 \\
\hline $\mathrm{C}$ & -5.469531 & -0.627716 & -1.079923 \\
\hline $\mathrm{C}$ & -4.809522 & -2.721699 & -0.008136 \\
\hline $\mathrm{C}$ & -6.695692 & -1.204889 & -1.408172 \\
\hline $\mathrm{H}$ & -5.252485 & 0.381078 & -1.404219 \\
\hline $\mathrm{C}$ & -6.064323 & -3.281526 & -0.310835 \\
\hline $\mathrm{H}$ & -4.092519 & -3.327529 & 0.531374 \\
\hline $\mathrm{C}$ & -7.012078 & -2.512457 & -1.023451 \\
\hline $\mathrm{H}$ & -7.424016 & -0.631119 & -1.972480 \\
\hline $\mathrm{H}$ & -7.981686 & -2.923821 & -1.278353 \\
\hline $\mathrm{C}$ & -3.810622 & 1.616834 & 0.329998 \\
\hline $\mathrm{C}$ & -4.871988 & 1.427729 & 1.243361 \\
\hline $\mathrm{C}$ & -3.630847 & 2.860525 & -0.289535 \\
\hline $\mathrm{C}$ & -5.726844 & 2.497002 & 1.519025 \\
\hline $\mathrm{H}$ & -5.017608 & 0.477553 & 1.743378 \\
\hline 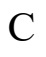 & -4.515601 & 3.925526 & -0.024293 \\
\hline $\mathrm{H}$ & -2.848037 & 3.019524 & -1.023475 \\
\hline $\mathrm{C}$ & -5.569477 & 3.737985 & 0.892964 \\
\hline
\end{tabular}




$\begin{array}{rrrr}\mathrm{H} & -6.535686 & 2.364984 & 2.230985 \\ \mathrm{H} & -6.262661 & 4.539996 & 1.116161 \\ \mathrm{O} & -6.254824 & -4.544832 & 0.113319 \\ \mathrm{O} & -4.263706 & 5.070367 & -0.696244 \\ \mathrm{C} & -5.162336 & 6.190013 & -0.531806 \\ \mathrm{H} & -4.775881 & 6.969498 & -1.186665 \\ \mathrm{H} & -6.176717 & 5.919807 & -0.840426 \\ \mathrm{H} & -5.158334 & 6.542818 & 0.504246 \\ \mathrm{C} & -7.516431 & -5.199217 & -0.150396 \\ \mathrm{H} & -7.423759 & -6.189771 & 0.291675 \\ \mathrm{H} & -8.339065 & -4.657535 & 0.326483 \\ \mathrm{H} & -7.686796 & -5.289668 & -1.227651 \\ \mathrm{H} & 3.534308 & -0.980440 & -1.776586\end{array}$

$\mathrm{M}=\mathrm{Cm}$

$\begin{array}{lccc}\mathrm{CM} & 1.847006 & 0.683794 & 0.199230 \\ \mathrm{O} & 1.050182 & 0.889375 & 2.602833 \\ \mathrm{H} & 1.169007 & 0.305060 & 3.370113 \\ \mathrm{O} & 3.412526 & 2.487498 & -0.676948 \\ \mathrm{H} & 3.303611 & 3.448754 & -0.768080 \\ \mathrm{O} & 3.764619 & 0.601879 & 1.855897 \\ \mathrm{H} & 3.848144 & 1.093208 & 2.689551 \\ \mathrm{O} & 0.352539 & 2.601771 & 0.280682 \\ \mathrm{H} & 0.307117 & 3.569778 & 0.289140 \\ \mathrm{O} & 1.480605 & 0.761109 & -2.309052 \\ \mathrm{H} & 1.850154 & 1.428503 & -2.911212 \\ \mathrm{H} & 0.342148 & 1.512661 & 2.837978 \\ \mathrm{H} & 4.626606 & 0.176084 & 1.693344 \\ \mathrm{H} & -0.594060 & 2.213433 & 0.178261 \\ \mathrm{H} & 4.371990 & 2.312269 & -0.734172 \\ \mathrm{H} & 0.708905 & 0.384085 & -2.764148 \\ \mathrm{C} & 5.240925 & -0.387370 & -0.880586 \\ \mathrm{C} & 5.967922 & -1.214913 & 0.007161 \\ \mathrm{C} & 7.347649 & -1.000773 & 0.196905 \\ \mathrm{C} & 7.964397 & 0.017325 & -0.531588 \\ \mathrm{C} & 7.234476 & 0.800045 & -1.450763 \\ \mathrm{C} & 5.857131 & 0.608782 & -1.641373 \\ \mathrm{C} & 3.821552 & -1.986816 & -0.041547 \\ \mathrm{C} & 5.048936 & -2.221151 & 0.505920 \\ \mathrm{H} & 7.924324 & -1.628146 & 0.869320 \\ \mathrm{H} & 9.029317 & 0.191898 & -0.416842 \\ \mathrm{H} & 7.754615 & 1.549283 & -2.039352 \\ \mathrm{H} & 5.330361 & 1.163112 & -2.414111 \\ \mathrm{H} & 5.287349 & -3.003121 & 1.216561 \\ \mathrm{C} & 2.522253 & -2.624651 & 0.160541\end{array}$




\begin{tabular}{|c|c|c|c|}
\hline $\mathrm{C}$ & 2.369837 & -4.003605 & 0.372523 \\
\hline & 1.083201 & -4.527369 & 0.493706 \\
\hline $\mathrm{H}$ & 3.239604 & -4.650484 & 0.400007 \\
\hline $\mathrm{C}$ & 0.200531 & -2.312502 & 0.201583 \\
\hline $\mathrm{C}$ & -0.025124 & -3.672188 & 0.389038 \\
\hline $\mathrm{H}$ & 0.938783 & -5.593396 & 0.643010 \\
\hline & -1.040991 & -4.043380 & 0.445123 \\
\hline & -0.912461 & -1.333658 & 0.099270 \\
\hline C & -3.163659 & -0.872204 & -0.047815 \\
\hline & -2.816337 & 0.547014 & 0.084099 \\
\hline $\mathrm{N}$ & 3.861773 & -0.794877 & -0.867836 \\
\hline $\mathbf{N}$ & 1.451272 & -1.791552 & 0.101831 \\
\hline $\mathrm{N}$ & -2.165998 & -1.768499 & 0.081566 \\
\hline $\mathrm{N}$ & -0.550306 & -0.045054 & -0.010329 \\
\hline $\mathrm{N}$ & -1.532067 & 0.887491 & 0.050101 \\
\hline $\mathrm{C}$ & -4.489388 & -1.386746 & -0.342864 \\
\hline $\mathrm{C}$ & -5.458104 & -0.609349 & -1.037696 \\
\hline $\mathrm{C}$ & -4.773470 & -2.732389 & -0.022230 \\
\hline $\mathrm{C}$ & -6.666583 & -1.197016 & -1.391374 \\
\hline $\mathrm{H}$ & -5.257290 & 0.413097 & -1.325848 \\
\hline $\mathrm{C}$ & -6.012148 & -3.301277 & -0.344915 \\
\hline H & -4.048919 & -3.339892 & 0.504403 \\
\hline $\mathrm{C}$ & -6.963174 & -2.523092 & -1.042710 \\
\hline H & -7.402731 & -0.621966 & -1.944056 \\
\hline $\mathrm{H}$ & -7.926122 & -2.939634 & -1.314665 \\
\hline 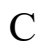 & -3.769178 & 1.648813 & 0.315079 \\
\hline $\mathrm{C}$ & -4.825166 & 1.494017 & 1.239336 \\
\hline 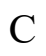 & -3.561861 & 2.884406 & -0.317869 \\
\hline$C$ & -5.644863 & 2.588859 & 1.513654 \\
\hline $\mathrm{H}$ & -4.995767 & 0.550193 & 1.743464 \\
\hline$C$ & -4.412548 & 3.973588 & -0.055713 \\
\hline $\mathrm{H}$ & -2.787082 & 3.012835 & -1.066574 \\
\hline , & -5.459396 & 3.820759 & 0.874120 \\
\hline $\mathrm{H}$ & -6.451121 & 2.486213 & 2.233408 \\
\hline 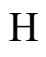 & -6.130384 & 4.641711 & 1.096373 \\
\hline $\mathrm{O}$ & -6.193263 & -4.580975 & 0.042841 \\
\hline $\mathrm{O}$ & -4.137466 & 5.108193 & -0.741834 \\
\hline $\mathrm{C}$ & -5.016083 & 6.243216 & -0.583811 \\
\hline $\mathrm{H}$ & -4.622889 & 7.009417 & -1.250502 \\
\hline $\mathrm{H}$ & -6.037549 & 5.987511 & -0.881769 \\
\hline $\mathrm{H}$ & -4.999471 & 6.609685 & 0.447559 \\
\hline $\mathrm{C}$ & -7.450603 & -5.229721 & -0.245915 \\
\hline $\mathrm{H}$ & -7.358707 & -6.232504 & 0.168387 \\
\hline 4 & -8.279221 & -4.706527 & 0.241687 \\
\hline $\mathrm{H}$ & -7.617337 & -5.293028 & -1.325922 \\
\hline $\mathrm{H}$ & 3.482403 & -0.954533 & -1.804233 \\
\hline
\end{tabular}




\section{$\left[\mathrm{ML}_{2}\left(\mathrm{H}_{2} \mathrm{O}\right)_{2}\right]^{3+}$}

$\mathrm{M}=\mathrm{Eu}$

\begin{tabular}{|c|c|c|c|}
\hline EU & .000003 & 2156 & \\
\hline $\mathrm{O}$ & -0.447721 & 0.855033 & -1.733746 \\
\hline $\mathrm{H}$ & -1.322052 & 1.273424 & -1.506539 \\
\hline$U$ & 0.447707 & 0.855051 & 1.733729 \\
\hline H & -0.046224 & 1.469899 & 2.293610 \\
\hline 11 & 0.046207 & 1.469880 & -2.293630 \\
\hline $\mathrm{H}$ & 1.322043 & 1.273439 & 1.506530 \\
\hline $\mathrm{C}$ & -2.337983 & -3.043606 & -2.189219 \\
\hline $\mathrm{C}$ & -2.178112 & -4.448192 & -2.244380 \\
\hline $\mathrm{C}$ & -3.310628 & -5.283607 & -2.285605 \\
\hline $\mathrm{C}$ & -4.570213 & -4.686792 & -2.310202 \\
\hline $\mathrm{C}$ & -4.710163 & -3.281799 & -2.295237 \\
\hline $\mathrm{C}$ & -3.594917 & -2.439353 & -2.23 \\
\hline $\mathrm{C}$ & -0.104571 & -3.509772 & -2.270487 \\
\hline $\mathrm{C}$ & -0.759022 & -4.71 & -2.25 \\
\hline $\mathrm{H}$ & -3.207247 & -6.363262 & -2.324779 \\
\hline $\mathrm{H}$ & -5.459100 & -5.307032 & -2.3 \\
\hline $\mathrm{H}$ & -5.704365 & -2.849356 & -2.346060 \\
\hline $\mathrm{H}$ & -3.712748 & -1.360611 & -2.239965 \\
\hline $\mathrm{H}$ & -0.291543 & -5.686278 & -2.324614 \\
\hline $\mathrm{C}$ & 1.324394 & -3.20 & -2.29 \\
\hline $\mathrm{C}$ & 2.235988 & -4.034316 & -2.982311 \\
\hline $\mathrm{C}$ & 3.579436 & -3.6 & -3.0 \\
\hline $\mathrm{H}$ & 1.880342 & -4.914134 & -3.506006 \\
\hline $\mathrm{C}$ & 3.032017 & -1.750245 & -1.687758 \\
\hline $\mathrm{C}$ & 3.990418 & -2.507129 & -2.359071 \\
\hline $\mathrm{H}$ & 4.299652 & -4.292130 & -3.543859 \\
\hline $\mathrm{H}$ & 5.024550 & -2.188169 & -2.356318 \\
\hline $\mathrm{C}$ & 3.430778 & -0.536211 & -0.927751 \\
\hline $\mathrm{C}$ & 5.058497 & 0.979463 & -0.348266 \\
\hline $\mathrm{C}$ & 4.062706 & 1.660917 & 0.44 \\
\hline $\mathrm{N}$ & -1.048574 & -2.438672 & -2.116898 \\
\hline $\mathrm{N}$ & 1.721284 & -2.087254 & -1.650887 \\
\hline $\mathrm{N}$ & 4.688560 & -0.092434 & -1.050300 \\
\hline $\mathrm{N}$ & 2.515099 & 0.010531 & -0.115876 \\
\hline $\mathrm{N}$ & 2.846443 & 1.124168 & 0.553687 \\
\hline $\mathrm{C}$ & 6.481602 & 1.367186 & -0.424691 \\
\hline $\mathrm{C}$ & 7.171322 & 1.895342 & 0.696164 \\
\hline $\mathrm{C}$ & 7.173822 & 1.131817 & -1.616613 \\
\hline $\mathrm{C}$ & 8.535951 & 2.178643 & 0.591038 \\
\hline 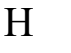 & 6.667234 & 2.045850 & 1.641842 \\
\hline
\end{tabular}




$\begin{array}{lccc}\mathrm{C} & 8.544094 & 1.449872 & -1.722913 \\ \mathrm{H} & 6.671331 & 0.717533 & -2.482346 \\ \mathrm{C} & 9.229564 & 1.975282 & -0.603866 \\ \mathrm{H} & 9.070754 & 2.563025 & 1.453806 \\ \mathrm{H} & 10.284293 & 2.216448 & -0.660150 \\ \mathrm{C} & 4.273566 & 2.947911 & 1.152848 \\ \mathrm{C} & 4.878545 & 4.035805 & 0.483831 \\ \mathrm{C} & 3.826529 & 3.098216 & 2.467943 \\ \mathrm{C} & 5.020065 & 5.253991 & 1.153221 \\ \mathrm{H} & 5.212750 & 3.941138 & -0.542651 \\ \mathrm{C} & 3.993118 & 4.325825 & 3.143093 \\ \mathrm{H} & 3.383635 & 2.272088 & 3.013558 \\ \mathrm{C} & 4.593511 & 5.412232 & 2.475307 \\ \mathrm{H} & 5.472706 & 6.096976 & 0.640374 \\ \mathrm{H} & 4.731163 & 6.364957 & 2.971927 \\ \mathrm{O} & 9.101205 & 1.209758 & -2.924980 \\ \mathrm{O} & 3.544271 & 4.351172 & 4.418571 \\ \mathrm{C} & 3.731210 & 5.548555 & 5.200615 \\ \mathrm{H} & 3.322898 & 5.319270 & 6.183917 \\ \mathrm{H} & 4.794711 & 5.790328 & 5.291509 \\ \mathrm{H} & 3.185543 & 6.389914 & 4.761507 \\ \mathrm{C} & 10.500116 & 1.502204 & -3.131355 \\ \mathrm{H} & 10.701093 & 1.229369 & -4.166052 \\ \mathrm{H} & 10.697214 & 2.568672 & -2.984999 \\ \mathrm{H} & -4.299654 & -4.292135 & 3.543852 \\ \mathrm{H} & 11.123104 & 0.900640 & -2.462248 \\ \mathrm{C} & 2.337982 & -3.043598 & 2.189231 \\ \mathrm{C} & 2.178114 & -4.448185 & 2.244387 \\ \mathrm{C} & 3.310631 & -5.283597 & 2.285612 \\ \mathrm{C} & 4.570216 & -4.686779 & 2.310215 \\ \mathrm{C} & 4.710162 & -3.281786 & 2.295255 \\ \mathrm{C} & 3.594914 & -2.439342 & 2.230151 \\ \mathrm{C} & 0.104571 & -3.509770 & 2.270492 \\ \mathrm{C} & 0.759024 & -4.710534 & 2.299707 \\ \mathrm{H} & 3.207253 & -6.363253 & 2.324782 \\ \mathrm{H} & 5.459104 & -5.307017 & 2.363232 \\ \mathrm{H} & 5.704363 & -2.849341 & 2.346082 \\ \mathrm{H} & 3.712743 & -1.360600 & 2.239986 \\ \mathrm{C} & -1.3291548 & -5.686275 & 2.324611 \\ \mathrm{C} & -3.579394 & -3.207176 & 2.296266 \\ \mathrm{H} & -4.034318 & 2.982309 \\ \mathrm{H} & -3.678330 & 3.011730 \\ \mathrm{H} & -2.188172 & 2.356314\end{array}$




$\begin{array}{cccc}\mathrm{C} & -3.430777 & -0.536212 & 0.927751 \\ \mathrm{C} & -5.058496 & 0.979461 & 0.348264 \\ \mathrm{C} & -4.062706 & 1.660914 & -0.448109 \\ \mathrm{~N} & 1.048572 & -2.438667 & 2.116909 \\ \mathrm{~N} & -1.721283 & -2.087254 & 1.650889 \\ \mathrm{~N} & -4.688559 & -0.092435 & 1.050299 \\ \mathrm{~N} & -2.515099 & 0.010529 & 0.115875 \\ \mathrm{~N} & -2.846443 & 1.124164 & -0.553690 \\ \mathrm{C} & -6.481601 & 1.367184 & 0.424690 \\ \mathrm{C} & -7.171324 & 1.895332 & -0.696167 \\ \mathrm{C} & -7.173818 & 1.131825 & 1.616616 \\ \mathrm{C} & -8.535953 & 2.178634 & -0.591041 \\ \mathrm{H} & -6.667239 & 2.045831 & -1.641848 \\ \mathrm{C} & -8.544091 & 1.449881 & 1.722916 \\ \mathrm{H} & -6.671326 & 0.717547 & 2.482351 \\ \mathrm{C} & -9.229563 & 1.975282 & 0.603867 \\ \mathrm{H} & -9.070758 & 2.563008 & -1.453810 \\ \mathrm{H} & -10.284292 & 2.216448 & 0.660152 \\ \mathrm{C} & -4.273564 & 2.947907 & -1.152853 \\ \mathrm{C} & -4.878526 & 4.035809 & -0.483832 \\ \mathrm{C} & -3.826541 & 3.098205 & -2.467953 \\ \mathrm{C} & -5.020045 & 5.253993 & -1.153225 \\ \mathrm{H} & -5.212719 & 3.941148 & 0.542654 \\ \mathrm{C} & -3.993129 & 4.325813 & -3.143105 \\ \mathrm{H} & -3.383659 & 2.272072 & -3.013570 \\ \mathrm{C} & -4.593505 & 5.412226 & -2.475316 \\ \mathrm{H} & -5.472673 & 6.096984 & -0.640376 \\ \mathrm{H} & -4.731155 & 6.364951 & -2.971938 \\ \mathrm{O} & -9.101198 & 1.209776 & 2.924987 \\ \mathrm{O} & -3.544296 & 4.351151 & -4.418589 \\ \mathrm{C} & -3.731234 & 5.548533 & -5.200635 \\ \mathrm{H} & -3.322935 & 5.319241 & -6.183940 \\ \mathrm{H} & -4.794734 & 5.790314 & -5.291518 \\ \mathrm{H} & -3.185555 & 6.389889 & -4.761536 \\ \mathrm{C} & -10.500109 & 1.502224 & 3.131363 \\ \mathrm{H} & -10.701083 & 1.229397 & 4.166063 \\ \mathrm{H} & -10.697206 & 2.568691 & 2.984999 \\ \mathrm{H} & -11.123098 & 0.900655 & 2.462262 \\ \mathrm{H} & 0.907677 & -1.655016 & 2.755995 \\ \mathrm{H} & -0.907682 & -1.655017 & -2.755981\end{array}$

$\mathrm{M}=\mathrm{Gd}$

$\begin{array}{llll}\text { GD } & -0.000045 & 1.001439 & -0.000009\end{array}$

$\begin{array}{llll}\mathrm{O} & -0.301711 & -0.686044 & 1.673307\end{array}$

H $\quad-1.177263 \quad-1.161923 \quad 1.488495$ 


\begin{tabular}{|c|c|c|c|}
\hline 0 & 0.301401 & -0.686294 & -1.673079 \\
\hline $\mathrm{H}$ & -0.262363 & -1.249047 & -2.222845 \\
\hline & 0.262001 & -1.248796 & 2.223128 \\
\hline $\mathrm{H}$ & 1.176945 & -1.162204 & -1.488266 \\
\hline 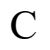 & -2.410001 & 3.158062 & 1.897563 \\
\hline $\mathrm{C}$ & -2.221875 & 4.555632 & 1.982325 \\
\hline $\mathrm{C}$ & -3.332779 & 5.418435 & 1.984889 \\
\hline $\mathrm{C}$ & -4.606574 & 4.850905 & 1.941960 \\
\hline $\mathrm{C}$ & -4.776988 & 3.451556 & 1.903006 \\
\hline$C$ & -3.677981 & 2.583028 & 1.877977 \\
\hline$C$ & -0.167970 & 3.581751 & 2.120567 \\
\hline $\mathrm{C}$ & -0.801896 & 4.788987 & 2.125399 \\
\hline П & -3.205617 & 6.494305 & 2.048899 \\
\hline $\mathrm{H}$ & -5.482465 & 5.491193 & 1.963673 \\
\hline $\mathrm{H}$ & -5.781152 & 3.039908 & 1.903743 \\
\hline $\mathrm{H}$ & -3.825645 & 1.508688 & 1.875626 \\
\hline $\mathrm{H}$ & -0.320417 & 5.755824 & 2.199972 \\
\hline $\mathrm{C}$ & 1.243132 & 3.232951 & 2.223754 \\
\hline $\mathrm{C}$ & 2.155259 & 4.001027 & 2.970076 \\
\hline $\mathrm{C}$ & 3.476192 & 3.57 & 3.065735 \\
\hline $\mathrm{H}$ & 1.816727 & 4.889804 & 3.490036 \\
\hline $\mathrm{C}$ & 2.913861 & 1.698066 & 1.677415 \\
\hline $\mathrm{C}$ & 3.866604 & 2.395239 & 2.413383 \\
\hline $\mathrm{H}$ & 4.195050 & 4.14 & 3.649130 \\
\hline $\mathrm{H}$ & 4.882880 & 2.024735 & 2.456908 \\
\hline $\mathrm{C}$ & 3.275925 & 0.487337 & 0.900502 \\
\hline $\mathrm{C}$ & 4.841185 & -1.081762 & 0.275860 \\
\hline $\mathrm{C}$ & 3.798506 & -1.710865 & -0.528280 \\
\hline $\mathrm{N}$ & -1.121633 & 2.511729 & 1.900040 \\
\hline $\mathrm{N}$ & 1.622219 & 2.101936 & 1.581577 \\
\hline $\mathrm{N}$ & 4.503039 & -0.017334 & 1.019050 \\
\hline $\mathrm{N}$ & 2.340069 & 0.017643 & 0.064750 \\
\hline $\mathrm{N}$ & 2.616651 & -1.107749 & -0.622895 \\
\hline $\mathrm{C}$ & 6.244122 & -1.494446 & 0.309059 \\
\hline $\mathrm{C}$ & 6.877429 & -2.096749 & -0.808119 \\
\hline $\mathrm{C}$ & 6.998294 & -1.188615 & 1.458644 \\
\hline $\mathrm{C}$ & 8.239617 & -2.371988 & -0.743926 \\
\hline $\mathrm{H}$ & 6.329780 & -2.315499 & -1.714586 \\
\hline $\mathrm{C}$ & 8.361632 & -1.509005 & 1.527926 \\
\hline $\mathrm{H}$ & 6.532491 & -0.723751 & 2.318541 \\
\hline $\mathrm{C}$ & 8.986680 & -2.100756 & 0.411203 \\
\hline $\mathrm{H}$ & 8.739176 & -2.811177 & -1.601704 \\
\hline $\mathrm{H}$ & 10.040969 & -2.350142 & 0.432461 \\
\hline $\mathrm{C}$ & 3.916827 & -3.004236 & -1.234920 \\
\hline $\mathrm{C}$ & 4.452802 & -4.129607 & -0.574976 \\
\hline$C$ & 3.418225 & -3.123326 & -2.539342 \\
\hline
\end{tabular}




\begin{tabular}{|c|c|c|c|}
\hline & 4.471204 & 54621 & \\
\hline & 4.838389 & -4.054484 & 0.434932 \\
\hline & 3.466869 & -4.357890 & -3.212060 \\
\hline & 3.033803 & -2.263806 & -3.0 \\
\hline & 3.994336 & -5.482415 & -2.5 \\
\hline & 912 & -6.230398 & -0 \\
\hline & 4.044648 & -6.4 & 5119 \\
\hline & 8.97 & 390 & 776 \\
\hline & 2.9 & -4.3 & -4.4 \\
\hline & 3.070022 & -5.5 & -5.2 \\
\hline & 2.6 & -5.3 & -6. \\
\hline & 4.1 & -5.88 & -5.3 \\
\hline & 2.4 & -6.3 & -4.8 \\
\hline & 284 & -1.5 & 366 \\
\hline & 42 & -1 & 875 \\
\hline & 911 & -2.5 & 695 \\
\hline & & -0.5 & 2.1 \\
\hline 4 & 2.4 & 3.1 & -1.8 \\
\hline & 2.2 & 4.5 & -1.9 \\
\hline $\mathrm{C}$ & 3.3 & 5.4 & -1.9 \\
\hline & 4.6 & 67 & -1.9 \\
\hline & 4.7 & 3.4 & -1.9 \\
\hline C & $3.6^{\circ}$ & 2.5 & -1.8 \\
\hline & 0.1 & 3.5 & -2.1 \\
\hline C & 0.8 & 4.7 & -2.1 \\
\hline & 3.2 & 6.4 & $-2 .($ \\
\hline & 5.4 & 5.4 & -1.5 \\
\hline & 5.7 & 3.0 & -1.9 \\
\hline $\mathrm{H}$ & 3.8 & 1.5 & -1.8 \\
\hline & 0.3 & 5.7 & -2.2 \\
\hline $\mathrm{C}$ & -1.2 & 3.2 & -2.2 \\
\hline & -2.1 & 4.0 & -2.9 \\
\hline C & -3.4 & 3.5 & -3.0 \\
\hline $\mathrm{H}$ & -1.8 & 4.8 & -3. \\
\hline $\mathrm{C}$ & -2.9 & 1.6 & -1.6 \\
\hline $\mathrm{C}$ & -3.8 & 2.3 & -2.4 \\
\hline & -4.1 & 4.14 & -3.6 \\
\hline 11 & -4.8 & 2.024717 & -2.4 \\
\hline & -3.275995 & 0.487396 & -0.9 \\
\hline $\mathrm{C}$ & -4.8 & -1.081527 & $-0.2^{\prime}$ \\
\hline & -3.798609 & -1.710572 & 3712 \\
\hline & 1.121604 & 2.511489 & -1.90 \\
\hline & -1.622257 & 2.101873 & -1.581670 \\
\hline & -4.50 & -0.0 & -1.0 \\
\hline & -2.340149 & 0.017790 & -0.064612 \\
\hline & -2.616727 & -1.107493 & 0.623207 \\
\hline
\end{tabular}




$\begin{array}{cccc}\mathrm{C} & -6.244179 & -1.494385 & -0.308877 \\ \mathrm{C} & -6.877621 & -2.096684 & 0.808227 \\ \mathrm{C} & -6.998174 & -1.188726 & -1.458622 \\ \mathrm{C} & -8.239770 & -2.372067 & 0.743806 \\ \mathrm{H} & -6.330118 & -2.315308 & 1.714810 \\ \mathrm{C} & -8.361466 & -1.509265 & -1.528130 \\ \mathrm{H} & -6.532264 & -0.723873 & -2.318468 \\ \mathrm{C} & -8.986653 & -2.101000 & -0.411478 \\ \mathrm{H} & -8.739439 & -2.811244 & 1.601527 \\ \mathrm{H} & -10.040912 & -2.350499 & -0.432908 \\ \mathrm{C} & -3.916874 & -3.003972 & 1.235308 \\ \mathrm{C} & -4.452891 & -4.129317 & 0.575356 \\ \mathrm{C} & -3.418206 & -3.123106 & 2.539701 \\ \mathrm{C} & -4.471272 & -5.354351 & 1.241137 \\ \mathrm{H} & -4.838542 & -4.054152 & -0.434527 \\ \mathrm{C} & -3.466824 & -4.357692 & 3.212380 \\ \mathrm{H} & -3.033752 & -2.263605 & 3.078691 \\ \mathrm{C} & -3.994334 & -5.482192 & 2.552241 \\ \mathrm{H} & -4.871019 & -6.230108 & 0.739260 \\ \mathrm{H} & -4.044627 & -6.445310 & 3.045402 \\ \mathrm{O} & -8.978579 & -1.205801 & -2.694116 \\ \mathrm{O} & -2.981077 & -4.352029 & 4.479868 \\ \mathrm{C} & -3.069879 & -5.563254 & 5.254526 \\ \mathrm{H} & -2.660097 & -5.314496 & 6.232780 \\ \mathrm{H} & -4.111797 & -5.880617 & 5.364666 \\ \mathrm{H} & -2.476217 & -6.364001 & 4.801015 \\ \mathrm{C} & -10.377877 & -1.516798 & -2.838940 \\ \mathrm{H} & -10.643284 & -1.196380 & -3.845520 \\ \mathrm{H} & -10.551407 & -2.593387 & -2.740223 \\ \mathrm{H} & -10.979338 & -0.965294 & -2.108734 \\ \mathrm{H} & 1.057898 & 1.791752 & -2.625699 \\ \mathrm{H} & -1.057968 & 1.792015 & 2.625561\end{array}$

$\mathrm{M}=\mathrm{Am}$

$\begin{array}{lrrr}\text { AM } & -0.000019 & -0.983838 & -0.000022 \\ \mathrm{O} & 0.340722 & 0.737784 & 1.720857 \\ \mathrm{H} & 1.229173 & 1.190974 & 1.539152 \\ \mathrm{O} & -0.340749 & 0.737744 & -1.720962 \\ \mathrm{H} & 0.218800 & 1.323083 & -2.251313 \\ \mathrm{H} & -0.218840 & 1.323154 & 2.251160 \\ \mathrm{H} & -1.229187 & 1.190948 & -1.539244 \\ \mathrm{C} & 2.324537 & -3.224655 & 1.922872 \\ \mathrm{C} & 2.061629 & -4.604064 & 2.074404 \\ \mathrm{C} & 3.119921 & -5.529764 & 2.057092 \\ \mathrm{C} & 4.419823 & -5.040587 & 1.924766\end{array}$




\begin{tabular}{|c|c|c|c|}
\hline $\mathrm{C}$ & 4.667462 & -3.656675 & 1.815808 \\
\hline C & 3.620018 & -2.726863 & 1.810123 \\
\hline C & 0.075355 & -3.505615 & 2.263504 \\
\hline $\mathrm{C}$ & 0.638543 & -4.747592 & 2.289842 \\
\hline H & 2.935455 & -6.592993 & 2.171625 \\
\hline H & 5.257721 & -5.730174 & 1.928158 \\
\hline $\mathrm{H}$ & 5.691910 & -3.305656 & 1.744709 \\
\hline H & 3.826083 & -1.663723 & 1.749371 \\
\hline $\mathrm{H}$ & 0.106007 & -5.681278 & 2.418785 \\
\hline $\mathrm{C}$ & -1.314038 & -3.082829 & 2.391210 \\
\hline $\mathrm{C}$ & -2.230164 & -3.775515 & 3.203403 \\
\hline $\mathrm{C}$ & -3.534507 & -3.303313 & 3.304605 \\
\hline $\mathrm{H}$ & -1.905971 & -4.643676 & 3.765491 \\
\hline $\mathrm{C}$ & -2.949926 & -1.533255 & 1.790460 \\
\hline $\mathrm{C}$ & -3.905716 & -2.157038 & 2.586548 \\
\hline $\mathrm{H}$ & -4.255669 & -3.811682 & 3.937271 \\
\hline $\mathrm{H}$ & -4.910855 & -1.757056 & 2.625089 \\
\hline $\mathrm{C}$ & -3.306353 & -0.367772 & 0.944210 \\
\hline $\mathrm{C}$ & -4.864195 & 1.188928 & 0.266636 \\
\hline $\mathrm{C}$ & -3.828563 & 1.760651 & -0.586801 \\
\hline $\mathrm{N}$ & 1.078088 & -2.505269 & 1.962890 \\
\hline $\mathrm{N}$ & -1.672199 & -1.977340 & 1.694689 \\
\hline $\mathrm{N}$ & -4.522211 & 0.165129 & 1.062271 \\
\hline $\mathrm{N}$ & -2.386961 & 0.033067 & 0.056038 \\
\hline $\mathrm{N}$ & -2.661494 & 1.130480 & -0.678077 \\
\hline $\mathrm{C}$ & -6.262153 & 1.617427 & 0.298421 \\
\hline $\mathrm{C}$ & -6.904606 & 2.166342 & -0.840837 \\
\hline $\mathrm{C}$ & -7.003470 & 1.381278 & 1.472381 \\
\hline $\mathrm{C}$ & -8.263150 & 2.458131 & -0.774132 \\
\hline $\mathrm{H}$ & -6.366861 & 2.330953 & -1.764569 \\
\hline $\mathrm{C}$ & -8.362846 & 1.717940 & 1.541794 \\
\hline $\mathrm{H}$ & -6.530411 & 0.958949 & 2.350094 \\
\hline $\mathrm{C}$ & -8.997288 & 2.255651 & 0.403183 \\
\hline $\mathrm{H}$ & -8.769988 & 2.856249 & -1.647545 \\
\hline $\mathrm{H}$ & -10.048924 & 2.515940 & 0.424583 \\
\hline $\mathrm{C}$ & -3.938459 & 3.023691 & -1.347622 \\
\hline $\mathrm{C}$ & -4.452215 & 4.183606 & -0.731161 \\
\hline $\mathrm{C}$ & -3.454864 & 3.079594 & -2.662044 \\
\hline $\mathrm{C}$ & -4.464106 & 5.378690 & -1.449452 \\
\hline $\mathrm{H}$ & -4.825956 & 4.157470 & 0.285659 \\
\hline $\mathrm{C}$ & -3.496473 & 4.284420 & -3.386998 \\
\hline $\mathrm{H}$ & -3.088365 & 2.192344 & -3.167653 \\
\hline $\mathrm{C}$ & -4.001973 & 5.443266 & -2.770428 \\
\hline $\mathrm{H}$ & -4.846887 & 6.280449 & -0.981516 \\
\hline $\mathrm{H}$ & -4.046668 & 6.384539 & -3.304606 \\
\hline $\mathrm{O}$ & -8.967420 & 1.482840 & 2.729938 \\
\hline
\end{tabular}




\begin{tabular}{|c|c|c|c|}
\hline $\mathrm{O}$ & -3.026473 & 4.217761 & -4.658746 \\
\hline & -3.111208 & 5.394944 & -5.484614 \\
\hline H & -2.716809 & 5.098768 & -6.455953 \\
\hline 1 & -4.150745 & 5.719679 & -5.595840 \\
\hline $\mathrm{H}$ & -2.502683 & 6.207596 & -5.073970 \\
\hline $\mathrm{C}$ & -10.361962 & 1.814162 & 2.875434 \\
\hline $\mathrm{H}$ & -10.617132 & 1.550001 & 3.900818 \\
\hline$H$ & -10.527353 & 2.885608 & 2.721875 \\
\hline $\mathrm{H}$ & -10.977572 & 1.230403 & 2.183081 \\
\hline $\mathrm{C}$ & -2.324494 & -3.224729 & -1.922840 \\
\hline $\mathrm{C}$ & -2.061578 & -4.604137 & -2.074371 \\
\hline $\mathrm{C}$ & -3.119860 & -5.529845 & -2.057049 \\
\hline $\mathrm{C}$ & -4.419767 & -5.040679 & -1.924716 \\
\hline $\mathrm{C}$ & -4.667415 & -3.656770 & -1.815763 \\
\hline $\mathrm{C}$ & -3.619978 & -2.726949 & -1.810086 \\
\hline $\mathrm{C}$ & -0.075311 & -3.505678 & -2.2 \\
\hline $\mathrm{C}$ & -0.638493 & -4.747656 & -2.289826 \\
\hline $\mathrm{H}$ & -2.935386 & -6.593073 & -2.1 \\
\hline $\mathrm{H}$ & -5.257659 & -5.730274 & -1.928101 \\
\hline $\mathrm{H}$ & -5.691866 & -3.305758 & -1.744662 \\
\hline $\mathrm{H}$ & -3.826054 & -1.663811 & -1.749340 \\
\hline $\mathrm{H}$ & -0.105954 & -5.681339 & -2.418774 \\
\hline $\mathrm{C}$ & 1.314078 & -3.082883 & -2.391203 \\
\hline $\mathrm{C}$ & 2.230214 & -3.775557 & -3.203394 \\
\hline $\mathrm{C}$ & 3.534555 & -3.303342 & -3.304582 \\
\hline $\mathrm{H}$ & 1.906034 & -4.643719 & -3.765487 \\
\hline $\mathrm{C}$ & 2.949944 & -1.533290 & -1.790441 \\
\hline $\mathrm{C}$ & 3.905746 & -2.157065 & -2.586521 \\
\hline $\mathrm{H}$ & 4.255727 & -3.811703 & -3.937243 \\
\hline $\mathrm{H}$ & 4.910882 & -1.757071 & -2.625055 \\
\hline $\mathrm{C}$ & 3.306350 & -0.367788 & -0.944203 \\
\hline $\mathrm{C}$ & 4.864186 & 1.188920 & -0.266633 \\
\hline $\mathrm{C}$ & 3.828548 & 1.760650 & 0.586790 \\
\hline $\mathrm{N}$ & -1.078047 & -2.505331 & -1.962877 \\
\hline $\mathrm{N}$ & 1.672222 & -1.977393 & -1.694678 \\
\hline $\mathrm{N}$ & 4.522213 & 0.165107 & -1.062253 \\
\hline $\mathrm{N}$ & 2.386940 & 0.033072 & -0.056058 \\
\hline $\mathrm{N}$ & 2.661474 & 1.130484 & 0.678055 \\
\hline $\mathrm{C}$ & 6.262141 & 1.617432 & -0.298420 \\
\hline $\mathrm{C}$ & 6.904593 & 2.166341 & 0.840840 \\
\hline $\mathrm{C}$ & 7.003455 & 1.381300 & -1.472384 \\
\hline $\mathrm{C}$ & 8.263135 & 2.458144 & 0.774132 \\
\hline $\mathrm{H}$ & 6.366851 & 2.330936 & 1.764577 \\
\hline $\mathrm{C}$ & 8.362827 & 1.717979 & -1.541802 \\
\hline $\mathrm{H}$ & 6.530397 & 0.958975 & -2.350100 \\
\hline $\mathrm{C}$ & 8.997268 & 2.255685 & -0.403188 \\
\hline
\end{tabular}




$\begin{array}{cccl}\mathrm{H} & 8.769972 & 2.856258 & 1.647548 \\ \mathrm{H} & 10.048902 & 2.515984 & -0.424590 \\ \mathrm{C} & 3.938443 & 3.023683 & 1.347623 \\ \mathrm{C} & 4.452203 & 4.183605 & 0.731178 \\ \mathrm{C} & 3.454846 & 3.079570 & 2.662045 \\ \mathrm{C} & 4.464096 & 5.378679 & 1.449485 \\ \mathrm{H} & 4.825946 & 4.157481 & -0.285642 \\ \mathrm{C} & 3.496457 & 4.284386 & 3.387016 \\ \mathrm{H} & 3.088343 & 2.192313 & 3.167641 \\ \mathrm{C} & 4.001962 & 5.443239 & 2.770462 \\ \mathrm{H} & 4.846880 & 6.280443 & 0.981561 \\ \mathrm{H} & 4.046659 & 6.384504 & 3.304652 \\ \mathrm{O} & 8.967397 & 1.482899 & -2.729951 \\ \mathrm{O} & 3.026456 & 4.217710 & 4.658762 \\ \mathrm{C} & 3.111193 & 5.394882 & 5.484646 \\ \mathrm{H} & 2.716793 & 5.098693 & 6.455981 \\ \mathrm{H} & 4.150731 & 5.719612 & 5.595878 \\ \mathrm{H} & 2.502671 & 6.207541 & 5.074013 \\ \mathrm{C} & 10.361933 & 1.814242 & -2.875451 \\ \mathrm{H} & 10.617102 & 1.550096 & -3.900841 \\ \mathrm{H} & 10.527311 & 2.885688 & -2.721881 \\ \mathrm{H} & 10.977556 & 1.230483 & -2.183109 \\ \mathrm{H} & -1.086315 & -1.749935 & -2.653433 \\ \mathrm{H} & 1.086338 & -1.749851 & 2.653421\end{array}$

$\mathrm{M}=\mathrm{Cm}$

$\begin{array}{lrrc}\mathrm{CM} & -0.000004 & 0.967293 & 0.000003 \\ \mathrm{O} & -0.330583 & -0.761870 & 1.706467 \\ \mathrm{H} & -1.209711 & -1.223580 & 1.508393 \\ \mathrm{O} & 0.330526 & -0.762015 & -1.706304 \\ \mathrm{H} & -0.227107 & -1.344435 & -2.241929 \\ \mathrm{H} & 0.227091 & -1.344221 & 2.242125 \\ \mathrm{H} & 1.209719 & -1.223633 & -1.508246 \\ \mathrm{C} & -2.366068 & 3.146396 & 1.954914 \\ \mathrm{C} & -2.148059 & 4.537605 & 2.064743 \\ \mathrm{C} & -3.239275 & 5.424857 & 2.061900 \\ \mathrm{C} & -4.524230 & 4.887008 & 1.987063 \\ \mathrm{C} & -4.725386 & 3.492592 & 1.920670 \\ \mathrm{C} & -3.645960 & 2.600389 & 1.900469 \\ \mathrm{C} & -0.118085 & 3.515273 & 2.213566 \\ \mathrm{C} & -0.724942 & 4.736649 & 2.229183 \\ \mathrm{H} & -3.089509 & 6.496509 & 2.144570 \\ \mathrm{H} & -5.385934 & 5.546439 & 2.003629 \\ \mathrm{H} & -5.738413 & 3.104025 & 1.894877 \\ \mathrm{H} & -3.815537 & 1.529288 & 1.874262\end{array}$




\begin{tabular}{|c|c|c|c|}
\hline $\mathrm{H}$ & -0.222772 & 5.691425 & 2.320628 \\
\hline & 1.287504 & 3.140159 & 2.316841 \\
\hline$C$ & 2.203380 & 3.874536 & 3.091493 \\
\hline C & 3.519675 & 3.432154 & 3.179211 \\
\hline $\mathrm{H}$ & 1.871573 & 4.749991 & 3.637727 \\
\hline & 2.945129 & 1.605329 & 1.730243 \\
\hline & 3.901397 & 2.270675 & 2.491331 \\
\hline $\mathrm{H}$ & 4.241627 & 3.973645 & 3.782938 \\
\hline $\mathrm{H}$ & 4.913831 & 1.889303 & 2.528197 \\
\hline $\mathrm{C}$ & 3.303762 & 0.411732 & 0.923529 \\
\hline $\mathrm{C}$ & 4.868986 & -1.150172 & 0.276991 \\
\hline $\mathrm{C}$ & 3.827842 & -1.763859 & -0.540053 \\
\hline $\mathrm{N}$ & -1.094090 & 2.472389 & 1.968602 \\
\hline $\mathrm{N}$ & 1.659251 & 2.026752 & 1.640958 \\
\hline $\mathrm{N}$ & 4.529411 & -0.098951 & 1.037705 \\
\hline $\mathrm{N}$ & 2.372450 & -0.039295 & 0.072762 \\
\hline $\mathrm{N}$ & 2.648880 & -1.155377 & -0.630825 \\
\hline $\mathrm{C}$ & 6.271475 & -1.564876 & 0.306216 \\
\hline $\mathrm{C}$ & 6.906217 & -2.147067 & -0.820620 \\
\hline $\mathrm{C}$ & 7.023517 & -1.282328 & 1.462959 \\
\hline $\mathrm{C}$ & 8.267927 & -2.425173 & -0.759062 \\
\hline $\mathrm{H}$ & 6.360011 & -2.347886 & -1.732161 \\
\hline $\mathrm{C}$ & 8.386442 & -1.605273 & 1.528768 \\
\hline $\mathrm{H}$ & 6.556530 & -0.833687 & 2.330856 \\
\hline $\mathrm{C}$ & 9.013070 & -2.176558 & 0.402378 \\
\hline $\mathrm{H}$ & 8.768642 & -2.848790 & -1.623990 \\
\hline $\mathrm{H}$ & 10.067037 & -2.427441 & 0.420964 \\
\hline $\mathrm{C}$ & 3.944465 & -3.047731 & -1.264421 \\
\hline $\mathrm{C}$ & 4.476935 & -4.183447 & -0.619674 \\
\hline $\mathrm{C}$ & 3.448061 & -3.147318 & -2.571364 \\
\hline $\mathrm{C}$ & 4.494067 & -5.398988 & -1.302740 \\
\hline $\mathrm{H}$ & 4.860940 & -4.123507 & 0.391924 \\
\hline $\mathrm{C}$ & 3.495003 & -4.372380 & -3.261184 \\
\hline $\mathrm{H}$ & 3.066779 & -2.279233 & -3.098976 \\
\hline $\mathrm{C}$ & 4.019077 & -5.507238 & -2.616291 \\
\hline $\mathrm{H}$ & 4.891200 & -6.282587 & -0.812624 \\
\hline $\mathrm{H}$ & 4.068188 & -6.463357 & -3.122993 \\
\hline $\mathrm{O}$ & 9.001739 & -1.324274 & 2.701406 \\
\hline $\mathrm{O}$ & 3.011015 & -4.347962 & -4.529268 \\
\hline $\mathrm{C}$ & 3.099445 & -5.548068 & -5.321066 \\
\hline $\mathrm{H}$ & 2.691813 & -5.284721 & -6.296384 \\
\hline $\mathrm{H}$ & 4.141135 & -5.865292 & -5.433911 \\
\hline $\mathrm{H}$ & 2.503788 & -6.354381 & -4.880175 \\
\hline . & 10.400472 & -1.639162 & 2.842771 \\
\hline $\mathrm{H}$ & 10.664489 & -1.337755 & 3.855567 \\
\hline $\mathrm{H}$ & 10.573200 & -2.713912 & 2.724356 \\
\hline
\end{tabular}




\begin{tabular}{|c|c|c|c|}
\hline $\mathrm{H}$ & 11.003663 & -1.074730 & 3955 \\
\hline & 2.366092 & 3.146374 & -1.954928 \\
\hline & 2.148083 & 4.537583 & -2.064764 \\
\hline & 3.239297 & 5.424837 & -2.061919 \\
\hline & 4.524254 & 4.886992 & -1.987072 \\
\hline $\mathrm{C}$ & 4.725411 & 3.492577 & -1.920671 \\
\hline & 3.645986 & 2.600372 & -1.900473 \\
\hline & 0.118111 & 3.515247 & -2.213603 \\
\hline & 0.724969 & 4.736622 & -2.229230 \\
\hline & 3.089528 & 6.496488 & -2.144596 \\
\hline & 5.385956 & 5.546425 & -2.003636 \\
\hline $\mathrm{H}$ & 5.738438 & 3.104011 & -1.894871 \\
\hline & 3.815569 & 1.529271 & -1.874260 \\
\hline 11 & 0.222801 & 5.691399 & -2.320684 \\
\hline 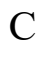 & -1.287475 & 3.140124 & -2.316899 \\
\hline & -2.203348 & 3.87 & -3.091574 \\
\hline $\mathrm{C}$ & -3.519636 & 3.432080 & -3.179304 \\
\hline $\mathrm{H}$ & -1.871542 & 4.749931 & -3.63 \\
\hline$C$ & -2.945091 & 1.605286 & -1.730294 \\
\hline & -3.901354 & 2.270609 & -2.491409 \\
\hline $\mathrm{H}$ & -4.241585 & 3.973554 & -3.783050 \\
\hline $\mathrm{H}$ & -4.913783 & 1.889225 & -2.528279 \\
\hline $\mathrm{C}$ & -3.303736 & 0.411706 & -0.923562 \\
\hline $\mathrm{C}$ & -4.868975 & -1.150180 & -0.277011 \\
\hline$C$ & -3.827844 & -1.763853 & 0056 \\
\hline N & 1.094118 & 2.472365 & -1.968630 \\
\hline N & -1.659217 & 2.026725 & -1.640999 \\
\hline $\mathrm{N}$ & -4.529382 & -0.098973 & -1.037741 \\
\hline $\mathrm{N}$ & -2.372440 & -0.039305 & -0.072763 \\
\hline $\mathrm{N}$ & -2.648882 & -1.155370 & 0.630837 \\
\hline 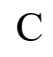 & -6.271469 & -1.564863 & -0.306231 \\
\hline $\mathrm{C}$ & -6.906218 & -2.147043 & 0.820607 \\
\hline 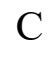 & -7.023511 & -1.282309 & -1.462973 \\
\hline 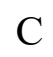 & -8.267931 & -2.425134 & 0.759051 \\
\hline $\mathrm{H}$ & -6.360014 & -2.347865 & 1.732148 \\
\hline $\mathrm{C}$ & -8.386440 & -1.605236 & -1.528780 \\
\hline 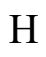 & -6.556520 & -0.833680 & -2.330873 \\
\hline 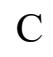 & -9.013073 & -2.176513 & -0.402387 \\
\hline $\mathrm{H}$ & -8.768648 & -2.848745 & 1.623981 \\
\hline 11 & -10.067043 & -2.427386 & -0.420972 \\
\hline $\mathrm{C}$ & -3.944476 & -3.047714 & 1.264444 \\
\hline 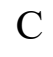 & -4.476921 & -4.183444 & 0.619702 \\
\hline $\mathrm{C}$ & -3.448110 & -3.147275 & 2.571402 \\
\hline 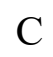 & -4.494065 & -5.398973 & 1.302788 \\
\hline $\mathrm{H}$ & -4.860900 & -4.123523 & -0.391908 \\
\hline $\mathrm{C}$ & -3.495063 & -4.372326 & 3.261242 \\
\hline
\end{tabular}




$\begin{array}{llll}\mathrm{H} & -3.066849 & -2.279178 & 3.099010 \\ \mathrm{C} & -4.019111 & -5.507198 & 2.616355 \\ \mathrm{H} & -4.891180 & -6.282583 & 0.812675 \\ \mathrm{H} & -4.068229 & -6.463309 & 3.123071 \\ \mathrm{O} & -9.001736 & -1.324232 & -2.701416 \\ \mathrm{O} & -3.011110 & -4.347882 & 4.529340 \\ \mathrm{C} & -3.099558 & -5.547974 & 5.321157 \\ \mathrm{H} & -2.691957 & -5.284607 & 6.296483 \\ \mathrm{H} & -4.141250 & -5.865202 & 5.433976 \\ \mathrm{H} & -2.503883 & -6.354291 & 4.880300 \\ \mathrm{C} & -10.400472 & -1.639107 & -2.842779 \\ \mathrm{H} & -10.664488 & -1.337699 & -3.855575 \\ \mathrm{H} & -10.573211 & -2.713855 & -2.724361 \\ \mathrm{H} & -11.003657 & -1.074668 & -2.123962 \\ \mathrm{H} & 1.054048 & 1.734540 & -2.676807 \\ \mathrm{H} & -1.054012 & 1.734556 & 2.676770\end{array}$

\section{$\left[\mathrm{ML}_{2}\right]^{3+}$}

$\mathrm{M}=\mathrm{Eu}$

$\begin{array}{lccc}\text { EU } & 0.092646 & -1.499916 & -0.385408 \\ \mathrm{C} & -2.755769 & -3.509645 & 0.900291 \\ \mathrm{C} & -2.600370 & -4.712853 & 1.628077 \\ \mathrm{C} & -3.451965 & -5.804115 & 1.370230 \\ \mathrm{C} & -4.450857 & -5.648994 & 0.409368 \\ \mathrm{C} & -4.607100 & -4.432834 & -0.290137 \\ \mathrm{C} & -3.759057 & -3.343948 & -0.055962 \\ \mathrm{C} & -1.034387 & -3.237744 & 2.377628 \\ \mathrm{C} & -1.510134 & -4.508138 & 2.555023 \\ \mathrm{H} & -3.344545 & -6.737906 & 1.912771 \\ \mathrm{H} & -5.126759 & -6.471253 & 0.198044 \\ \mathrm{H} & -5.402439 & -4.342547 & -1.023110 \\ \mathrm{H} & -3.893369 & -2.411337 & -0.595267 \\ \mathrm{H} & -1.100672 & -5.249338 & 3.229304 \\ \mathrm{C} & 0.126866 & -2.575237 & 2.971410 \\ \mathrm{C} & 0.551966 & -2.849693 & 4.286275 \\ \mathrm{C} & 1.674762 & -2.193999 & 4.781360 \\ \mathrm{H} & -0.006628 & -3.543546 & 4.904095 \\ \mathrm{C} & 1.882155 & -1.076527 & 2.666017 \\ \mathrm{C} & 2.356767 & -1.283451 & 3.960289 \\ \mathrm{H} & 2.016410 & -2.379763 & 5.795023 \\ \mathrm{H} & 3.231971 & -0.748626 & 4.305893 \\ \mathrm{C} & 2.598558 & -0.175656 & 1.722648 \\ \mathrm{C} & 4.313786 & 1.283408 & 1.300594 \\ \mathrm{C} & 3.941040 & 1.235073 & -0.091017\end{array}$




\begin{tabular}{|c|c|c|c|}
\hline $\mathrm{N}$ & -1.744905 & -2.588237 & 1.311612 \\
\hline $\mathrm{N}$ & 0.784749 & -1.699669 & 2.179507 \\
\hline $\mathrm{N}$ & 3.655319 & 0.512405 & 2.167249 \\
\hline $\mathrm{N}$ & 2.124776 & -0.093611 & 0.465291 \\
\hline $\mathrm{N}$ & 2.826603 & 0.587924 & -0.447621 \\
\hline $\mathrm{C}$ & 5.373719 & 2.155666 & 1.852599 \\
\hline $\mathrm{C}$ & 5.612547 & 3.451125 & 1.323755 \\
\hline $\mathrm{C}$ & 6.107106 & 1.712689 & 2.953464 \\
\hline $\mathrm{C}$ & 6.589489 & 4.265593 & 1.908207 \\
\hline H & 5.018517 & 3.834789 & 0.504214 \\
\hline $\mathrm{C}$ & 7.109192 & 2.531822 & 3.521787 \\
\hline $\mathrm{H}$ & 5.937533 & 0.732334 & 3.381979 \\
\hline $\mathrm{C}$ & 7.348216 & 3.822055 & 2.991246 \\
\hline $\mathrm{H}$ & 6.758458 & 5.263714 & 1.516659 \\
\hline $\mathrm{H}$ & 8.105339 & 4.468036 & 3.419247 \\
\hline C & 4.732320 & 1.838237 & -1.190776 \\
\hline $\mathrm{C}$ & 6.145095 & 1.726538 & -1.195476 \\
\hline $\mathrm{C}$ & 4.084653 & 2.477699 & -2.246588 \\
\hline $\mathrm{C}$ & 6.876357 & 2.269235 & -2.257639 \\
\hline $\mathrm{H}$ & 6.661758 & 1.195095 & -0.405323 \\
\hline $\mathrm{C}$ & 4.832250 & 3.039570 & -3.305724 \\
\hline $\mathrm{H}$ & 3.005437 & 2.573667 & -2.267533 \\
\hline $\mathrm{C}$ & 6.240997 & 2.932531 & -3.308321 \\
\hline $\mathrm{H}$ & 7.957318 & 2.170939 & -2.269276 \\
\hline $\mathrm{H}$ & 6.831269 & 3.352716 & -4.113459 \\
\hline $\mathrm{O}$ & 7.770371 & 1.993743 & 4.559716 \\
\hline $\mathrm{O}$ & 4.107040 & 3.654661 & -4.263047 \\
\hline $\mathrm{C}$ & 4.789812 & 4.294794 & -5.362106 \\
\hline $\mathrm{H}$ & 4.003426 & 4.731060 & -5.976232 \\
\hline $\mathrm{H}$ & 5.453570 & 5.084639 & -4.997651 \\
\hline $\mathrm{H}$ & 5.353413 & 3.562216 & -5.948132 \\
\hline $\mathrm{C}$ & 8.819168 & 2.745875 & 5.210929 \\
\hline $\mathrm{H}$ & 9.191118 & 2.094240 & 5.999682 \\
\hline $\mathrm{H}$ & 9.624444 & 2.971820 & 4.505585 \\
\hline $\mathrm{H}$ & 8.418058 & 3.665656 & 5.647123 \\
\hline $\mathrm{H}$ & -2.098629 & -1.650390 & 1.536754 \\
\hline $\mathrm{C}$ & 1.358198 & -4.342230 & -2.474853 \\
\hline $\mathrm{C}$ & 2.272458 & -4.053846 & -3.514271 \\
\hline $\mathrm{C}$ & 3.381086 & -4.895357 & -3.724760 \\
\hline $\mathrm{C}$ & 3.521809 & -6.016217 & -2.907017 \\
\hline $\mathrm{C}$ & 2.582515 & -6.302739 & -1.892859 \\
\hline $\mathrm{C}$ & 1.484600 & -5.465732 & -1.658482 \\
\hline $\mathrm{C}$ & 0.633556 & -2.468911 & -3.578136 \\
\hline $\mathrm{C}$ & 1.786730 & -2.872970 & -4.192006 \\
\hline $\mathrm{H}$ & 4.096665 & -4.691370 & -4.514754 \\
\hline $\mathrm{H}$ & 4.358054 & -6.691078 & -3.058053 \\
\hline
\end{tabular}




\begin{tabular}{|c|c|c|c|}
\hline & & 219 & \\
\hline & & -5.705228 & \\
\hline & 88 & 96 & \\
\hline & 272655 & -2.368597 & -5.017396 \\
\hline & .232479 & -1.315817 & -3.8 \\
\hline & 634 & -0.745477 & -5.0 \\
\hline & -1.27 & & \\
\hline & 2 & -1.1 & -5.9 \\
\hline & -1.7 & & \\
\hline & 1.95 & 0.8 & -4 \\
\hline & 0 & & -6 \\
\hline & -2.6 & 1.6 & -4 \\
\hline & -2.4 & & -1. \\
\hline & -4.0 & & -0. \\
\hline & 3.7 & 1.1 & \\
\hline & 0.3 & -3.3 & -2 \\
\hline & 0.8 & -0.8 & -2.7 \\
\hline & -3.3 & & -1.7 \\
\hline & -1.9 & & -0.4 \\
\hline & -2.7 & & \\
\hline & -4.9 & & -0.6 \\
\hline & -5.1 & & \\
\hline & -5.6 & & -1.8 \\
\hline & -5.9 & & \\
\hline $\mathrm{H}$ & -4.6 & & \\
\hline & -6.4 & & $-2 .($ \\
\hline $\mathrm{H}$ & -5.4 & & -2 \\
\hline & -6.6 & 5.2 & -0.9 \\
\hline $\mathrm{H}$ & -6.1 & & \\
\hline $\mathrm{H}$ & -7.3 & & -1.0 \\
\hline C & -4.58 & & \\
\hline C & -5.99 & 1.2 & \\
\hline C & $-3.9^{\prime}$ & 1.1 & \\
\hline $\mathrm{C}$ & -6.76 & & \\
\hline $\mathrm{H}$ & -6.48 & & \\
\hline C & -4.76 & 1.2 & 4.2 \\
\hline $\mathrm{H}$ & -2.89 & 1.1 & \\
\hline $\mathrm{C}$ & -6.16 & 1.2 & 74 \\
\hline 11 & -7.84 & 1.2 & 2.8 \\
\hline $\mathrm{H}$ & -6.78 & 1.2 & 5.0 \\
\hline $\mathrm{O}$ & -7.08 & 4.5 & -3.2 \\
\hline$\Omega$ & -4.06 & 1.19 & \\
\hline $\mathrm{C}$ & -4.792930 & 1.24 & 6.660464 \\
\hline & -4.030467 & 1.249935 & \\
\hline $\mathrm{H}$ & -5.394686 & 2.153997 & 6.726343 \\
\hline & -5.427205 & 0.357544 & 6.773799 \\
\hline
\end{tabular}




$\begin{array}{llll}\mathrm{C} & -8.003230 & 5.627871 & -3.444125 \\ \mathrm{H} & -8.350373 & 5.503660 & -4.468533 \\ \mathrm{H} & -8.851194 & 5.562863 & -2.755523 \\ \mathrm{H} & -7.495083 & 6.591414 & -3.339252\end{array}$

$\mathrm{M}=\mathrm{Gd}$

$\begin{array}{lccc}\text { GD } & -0.032070 & -1.541333 & -0.409681 \\ \mathrm{C} & -2.934722 & -3.561212 & -0.182356 \\ \mathrm{C} & -3.031877 & -4.791608 & 0.504781 \\ \mathrm{C} & -3.805540 & -5.834941 & -0.033912 \\ \mathrm{C} & -4.474794 & -5.604392 & -1.237935 \\ \mathrm{C} & -4.384565 & -4.361349 & -1.896660 \\ \mathrm{C} & -3.609610 & -3.314811 & -1.375473 \\ \mathrm{C} & -1.710173 & -3.418221 & 1.758630 \\ \mathrm{C} & -2.254276 & -4.667797 & 1.721514 \\ \mathrm{H} & -3.894294 & -6.788623 & 0.476332 \\ \mathrm{H} & -5.086504 & -6.389060 & -1.671215 \\ \mathrm{H} & -4.932669 & -4.209987 & -2.820998 \\ \mathrm{H} & -3.572348 & -2.352630 & -1.878254 \\ \mathrm{H} & -2.090383 & -5.450724 & 2.451556 \\ \mathrm{C} & -0.726563 & -2.810513 & 2.649172 \\ \mathrm{C} & -0.606256 & -3.118242 & 4.015526 \\ \mathrm{C} & 0.381097 & -2.480178 & 4.763767 \\ \mathrm{H} & -1.288898 & -3.821780 & 4.478419 \\ \mathrm{C} & 1.069328 & -1.312988 & 2.785952 \\ \mathrm{C} & 1.237384 & -1.553855 & 4.144238 \\ \mathrm{H} & 0.484638 & -2.692633 & 5.823631 \\ \mathrm{H} & 2.014702 & -1.035839 & 4.692520 \\ \mathrm{C} & 1.951066 & -0.412036 & 2.005710 \\ \mathrm{C} & 3.702617 & 1.054526 & 1.822725 \\ \mathrm{C} & 3.620285 & 0.877651 & 0.372882 \\ \mathrm{~N} & -2.074354 & -2.673273 & 0.563859 \\ \mathrm{~N} & 0.102294 & -1.919901 & 2.053105 \\ \mathrm{~N} & 2.915843 & 0.279039 & 2.591715 \\ \mathrm{~N} & 1.681197 & -0.347811 & 0.686697 \\ \mathrm{~N} & 2.567404 & 0.244296 & -0.137318 \\ \mathrm{C} & 4.537958 & 2.034944 & 2.506372 \\ \mathrm{C} & 4.941295 & 3.240790 & 1.874814 \\ \mathrm{C} & 4.863093 & 1.812002 & 3.859855 \\ \mathrm{C} & 5.650849 & 4.182746 & 2.610800 \\ \mathrm{H} & 4.681828 & 3.448137 & 0.845452 \\ \mathrm{C} & 5.613753 & 2.751106 & 4.580560 \\ \mathrm{H} & 4.560815 & 0.899430 & 4.357317 \\ \mathrm{H} & 6.004609 & 3.949588 & 3.948357 \\ & 5.945742 & 5.117840 & 2.145165\end{array}$




\begin{tabular}{|c|c|c|c|}
\hline & 6.578365 & 4.697152 & 58 \\
\hline & 4.649446 & 1.308725 & -0.597786 \\
\hline & 6.020043 & 1.179659 & -0.289482 \\
\hline & 4.255950 & 1.769655 & -1.862312 \\
\hline & 6.966313 & 1.520079 & -1.254945 \\
\hline & 6.343502 & 0.813453 & 0.677497 \\
\hline & 5.218023 & 2.130969 & -2.820167 \\
\hline & 3.207141 & 1.884686 & 0148 \\
\hline & 6.58 & 2.004248 & 2939 \\
\hline I & 8.023189 & 1.416071 & -1.029683 \\
\hline & 7.347282 & 2.278907 & -3.231047 \\
\hline $\mathrm{O}$ & 5.900779 & 2.418464 & 5.860259 \\
\hline C & 4.726264 & 2.583017 & 8748 \\
\hline $\mathrm{C}$ & 5.661749 & 3.082324 & 3828 \\
\hline $\mathrm{H}$ & 5.056766 & 3.440114 & -5.8 \\
\hline $\mathrm{H}$ & 6.2 & 66 & 555 \\
\hline $\mathrm{H}$ & 6.330666 & 504 & 2953 \\
\hline $\mathrm{C}$ & 6.68 & 3.3 & 6. \\
\hline $\mathrm{H}$ & 6.789616 & 2.849284 & 6915 \\
\hline $\mathrm{H}$ & 7.67 & 3.4 & 700 \\
\hline $\mathrm{H}$ & 6.161045 & 4.287281 & 3509 \\
\hline $\mathrm{H}$ & -2.5 & -1.78 & 689 \\
\hline $\mathrm{C}$ & 1.79 & -4.0 & 7605 \\
\hline $\mathrm{C}$ & 3.047703 & -3.7 & -2. \\
\hline $\mathrm{C}$ & 4.11 & -4.6 & -2. \\
\hline$C$ & 3.881048 & -5.875220 & 2453 \\
\hline$C$ & 2.614859 & -6.18 & 6229 \\
\hline$C$ & 1.544554 & -5.281459 & -1.435492 \\
\hline$C$ & 1.641807 & -2.016885 & -3.120882 \\
\hline $\mathrm{C}$ & 2.917746 & -2.462673 & 8860 \\
\hline $\mathrm{H}$ & 5.086784 & -4.4 & -2.9 \\
\hline $\mathrm{H}$ & 4.682619 & -6.601626 & -1.796258 \\
\hline $\mathrm{H}$ & 2.463055 & -7.143928 & -0.862654 \\
\hline $\mathrm{H}$ & 0.567617 & -5.542273 & -1.037937 \\
\hline $\mathrm{H}$ & 0.052407 & -3.294369 & -2.830934 \\
\hline $\mathrm{H}$ & 3.712879 & -1.916792 & -3.781113 \\
\hline $\mathrm{C}$ & 0.988492 & -0.751223 & -3.442213 \\
\hline $\mathrm{C}$ & 1.306479 & 0.056216 & -4.547183 \\
\hline $\mathrm{C}$ & 0.589955 & 1.236858 & -4.739846 \\
\hline $\mathrm{H}$ & 2.077111 & -0.247931 & -5.246085 \\
\hline $\mathrm{C}$ & -0.680266 & 0.753536 & -2.765943 \\
\hline $\mathrm{C}$ & -0.427460 & 1.599325 & -3.839285 \\
\hline $\mathrm{H}$ & 0.812309 & 1.873211 & -5.591008 \\
\hline $\mathrm{H}$ & -1.001290 & 2.510154 & -3.959061 \\
\hline $\mathrm{C}$ & -1.695866 & 1.025885 & -1.718771 \\
\hline${ }_{1}$ & -3.422015 & 2.264772 & -0.853443 \\
\hline
\end{tabular}




$\begin{array}{rrrr}\mathrm{C} & -3.634370 & 1.181675 & 0.107996 \\ \mathrm{~N} & 0.878443 & -2.974312 & -2.313761 \\ \mathrm{~N} & 0.013454 & -0.393067 & -2.575536 \\ \mathrm{~N} & -2.508345 & 2.067455 & -1.820808 \\ \mathrm{~N} & -1.692985 & 0.171182 & -0.676359 \\ \mathrm{~N} & -2.723036 & 0.216755 & 0.197695 \\ \mathrm{C} & -4.097087 & 3.555652 & -0.828461 \\ \mathrm{C} & -4.615201 & 4.104856 & 0.374513 \\ \mathrm{C} & -4.144480 & 4.310340 & -2.018891 \\ \mathrm{C} & -5.158862 & 5.384002 & 0.352346 \\ \mathrm{H} & -4.567688 & 3.558448 & 1.306561 \\ \mathrm{C} & -4.731747 & 5.582513 & -2.037660 \\ \mathrm{H} & -3.753832 & 3.906733 & -2.944228 \\ \mathrm{C} & -5.237651 & 6.123727 & -0.837101 \\ \mathrm{H} & -5.538545 & 5.822551 & 1.269756 \\ \mathrm{H} & -5.690794 & 7.107974 & -0.820462 \\ \mathrm{C} & -4.823553 & 1.032537 & 0.971411 \\ \mathrm{C} & -6.111310 & 1.296719 & 0.458093 \\ \mathrm{C} & -4.673015 & 0.544695 & 2.277351 \\ \mathrm{C} & -7.221621 & 1.060678 & 1.267395 \\ \mathrm{H} & -6.246479 & 1.664886 & -0.551999 \\ \mathrm{C} & -5.798060 & 0.336244 & 3.094214 \\ \mathrm{H} & -3.690496 & 0.358010 & 2.696063 \\ \mathrm{C} & -7.082303 & 0.593222 & 2.580608 \\ \mathrm{H} & -8.217719 & 1.247321 & 0.878183 \\ \mathrm{H} & -7.966689 & 0.440011 & 3.186975 \\ \mathrm{O} & -4.757803 & 6.202137 & -3.240043 \\ \mathrm{O} & -5.536283 & -0.112837 & 4.349560 \\ \mathrm{C} & -6.640322 & -0.284005 & 5.258604 \\ \mathrm{H} & -6.197333 & -0.612307 & 6.198263 \\ \mathrm{H} & -7.168138 & 0.662234 & 5.415302 \\ \mathrm{H} & -7.334799 & -1.048337 & 4.894301 \\ \mathrm{C} & -5.367327 & 7.504361 & -3.337207 \\ \mathrm{H} & -5.282530 & 7.786087 & -4.385848 \\ \mathrm{H} & -6.424193 & 7.463184 & -3.054142 \\ \mathrm{H} & -4.834301 & 8.233416 & -2.717968 \\ & & & \end{array}$

$\mathrm{M}=\mathrm{Am}$
AM $\quad 0.034678-1.434005 \quad-0.408798$
$\begin{array}{llll}\text { C } & -2.793422 & -3.542038 & 0.098637\end{array}$
$\begin{array}{llll}\text { C } & -2.746350 & -4.827398 & 0.683595\end{array}$
$\begin{array}{llll}\text { C } & -3.541497 & -5.863708 & 0.163858\end{array}$
$\begin{array}{llll}\text { C } & -4.375799 & -5.573578 & -0.917572\end{array}$
$\begin{array}{llll}\text { C } & -4.425194 & -4.279445 & -1.474242\end{array}$
$\begin{array}{llll}\text { C } & -3.630933 & -3.239341 & -0.972776\end{array}$ 


\begin{tabular}{|c|c|c|c|}
\hline $\mathrm{C}$ & -1.326235 & -3.491016 & 1.865512 \\
\hline$C$ & -1.816772 & -4.761270 & 1.793480 \\
\hline $\mathrm{H}$ & -3.521613 & -6.857877 & 0.598376 \\
\hline H & -5.008570 & -6.351797 & -1.331903 \\
\hline $\mathrm{H}$ & -5.097941 & -4.084584 & -2.303158 \\
\hline $\mathrm{H}$ & -3.695762 & -2.240881 & -1.394239 \\
\hline $\mathrm{H}$ & -1.520600 & -5.590849 & 2.423364 \\
\hline $\mathrm{C}$ & -0.255093 & -2.907381 & 2.665940 \\
\hline $\mathrm{C}$ & 0.039996 & -3.300174 & 3.982536 \\
\hline $\mathrm{C}$ & 1.085782 & -2.671057 & 4.654582 \\
\hline $\mathrm{H}$ & -0.558459 & -4.061146 & 4.470337 \\
\hline $\mathrm{C}$ & 1.483181 & -1.338318 & 2.700899 \\
\hline $\mathrm{C}$ & 1.821039 & -1.663306 & 4.008965 \\
\hline $\mathrm{H}$ & 1.324039 & -2.949592 & 5.676669 \\
\hline $\mathrm{H}$ & 2.633328 & -1.141280 & 4.499997 \\
\hline $\mathrm{C}$ & 2.217131 & -0.327505 & 1.904506 \\
\hline $\mathrm{C}$ & 3.853822 & 1.249781 & 1.624080 \\
\hline $\mathrm{C}$ & 3.570087 & 1.204524 & 0.188402 \\
\hline $\mathrm{N}$ & -1.878947 & -2.676566 & 0.799480 \\
\hline $\mathrm{N}$ & 0.465327 & -1.946574 & 2.039323 \\
\hline $\mathrm{N}$ & 3.221756 & 0.365478 & 2.418413 \\
\hline $\mathrm{N}$ & 1.767294 & -0.167545 & 0.648772 \\
\hline $\mathrm{N}$ & 2.491069 & 0.547242 & -0.230198 \\
\hline $\mathrm{C}$ & 4.742053 & 2.206525 & 2.274924 \\
\hline $\mathrm{C}$ & 4.986656 & 3.491208 & 1.723070 \\
\hline $\mathrm{C}$ & 5.285674 & 1.870488 & 3.531091 \\
\hline $\mathrm{C}$ & 5.759517 & 4.397245 & 2.440298 \\
\hline $\mathrm{H}$ & 4.558934 & 3.784129 & 0.773798 \\
\hline $\mathrm{C}$ & 6.097416 & 2.777387 & 4.226471 \\
\hline $\mathrm{H}$ & 5.106666 & 0.896433 & 3.968139 \\
\hline $\mathrm{C}$ & 6.329573 & 4.054494 & 3.675497 \\
\hline $\mathrm{H}$ & 5.934424 & 5.390414 & 2.038791 \\
\hline $\mathrm{H}$ & 6.945753 & 4.778949 & 4.194841 \\
\hline $\mathrm{C}$ & 4.422460 & 1.796562 & -0.863830 \\
\hline $\mathrm{C}$ & 5.828285 & 1.715300 & -0.771456 \\
\hline $\mathrm{C}$ & 3.825116 & 2.371144 & -1.994502 \\
\hline $\mathrm{C}$ & 6.604534 & 2.216277 & -1.814947 \\
\hline $\mathrm{H}$ & 6.306852 & 1.264086 & 0.089507 \\
\hline $\mathrm{C}$ & 4.617919 & 2.896597 & -3.028935 \\
\hline $\mathrm{H}$ & 2.747131 & 2.451198 & -2.075811 \\
\hline $\mathrm{C}$ & 6.018823 & 2.815900 & -2.937752 \\
\hline $\mathrm{H}$ & 7.686619 & 2.149866 & -1.757837 \\
\hline $\mathrm{H}$ & 6.653888 & 3.214383 & -3.719593 \\
\hline $\mathrm{O}$ & 6.596908 & 2.336933 & 5.404557 \\
\hline $\mathrm{O}$ & 3.936407 & 3.452885 & -4.068276 \\
\hline $\mathrm{C}$ & 4.692308 & 4.103639 & -5.106419 \\
\hline
\end{tabular}




\begin{tabular}{|c|c|c|c|}
\hline $\mathrm{H}$ & 3.953703 & 4.515892 & -5.793341 \\
\hline & 5.301140 & 4.916015 & -4.696660 \\
\hline & 5.328635 & 3.388896 & -5.639304 \\
\hline & 7.448784 & 3.213013 & 6.167727 \\
\hline & 7.729517 & 2.644764 & 7.053472 \\
\hline & 8.348408 & 3.474840 & 5.601080 \\
\hline r & 6.910684 & 4.117971 & 6.468795 \\
\hline H & -2.339729 & -1.819622 & 1.145224 \\
\hline $\mathrm{C}$ & 1.705933 & -4.034407 & -2.236687 \\
\hline $\mathrm{C}$ & 2.817323 & -3.697331 & -3.040592 \\
\hline$C$ & 3.948858 & -4.531346 & -3.053587 \\
\hline $\mathrm{C}$ & 3.918199 & -5.691706 & -2.277955 \\
\hline $\mathrm{C}$ & 2.788966 & -6.022295 & -1.501151 \\
\hline $\mathrm{C}$ & 1.659976 & -5.192400 & -1.465648 \\
\hline $\mathrm{C}$ & 1.229140 & -2.092869 & -3.382668 \\
\hline $\mathrm{C}$ & 2.486294 & -2.476274 & -3.745976 \\
\hline $\mathrm{H}$ & 4.814818 & -4.292390 & -3.662128 \\
\hline $\mathrm{H}$ & 4.771447 & -6.362221 & -2.280537 \\
\hline $\mathrm{H}$ & 2.792666 & -6.941858 & -0.925034 \\
\hline $\mathrm{H}$ & 0.787655 & -5.467539 & -0.879261 \\
\hline $\mathrm{H}$ & -0.198842 & -3.414875 & -2.699811 \\
\hline $\mathrm{H}$ & 3.143311 & -1.930746 & -4.411699 \\
\hline $\mathrm{C}$ & 0.440499 & -0.901545 & -3.682557 \\
\hline $\mathrm{C}$ & 0.491783 & -0.205106 & -4.901846 \\
\hline $\mathrm{C}$ & -0.326950 & 0.909702 & -5.072749 \\
\hline $\mathrm{H}$ & 1.136379 & -0.551573 & -5.701609 \\
\hline $\mathrm{C}$ & -1.176242 & 0.584526 & -2.854453 \\
\hline $\mathrm{C}$ & -1.183867 & 1.316409 & -4.035373 \\
\hline $\mathrm{H}$ & -0.311771 & 1.457073 & -6.010332 \\
\hline $\mathrm{H}$ & -1.834353 & 2.176991 & -4.133107 \\
\hline $\mathrm{C}$ & -2.008189 & 0.923583 & -1.674757 \\
\hline $\mathrm{C}$ & -3.623457 & 2.169358 & -0.626721 \\
\hline $\mathrm{C}$ & -3.589161 & 1.186700 & 0.457967 \\
\hline $\mathrm{N}$ & 0.692441 & -3.016440 & -2.388149 \\
\hline $\mathrm{N}$ & -0.377373 & -0.497033 & -2.682390 \\
\hline $\mathrm{N}$ & -2.888835 & 1.912940 & -1.724239 \\
\hline $\mathrm{N}$ & -1.767510 & 0.186728 & -0.575432 \\
\hline $\mathrm{N}$ & -2.618239 & 0.276519 & 0.468179 \\
\hline $\mathrm{C}$ & -4.364900 & 3.423998 & -0.600533 \\
\hline $\mathrm{C}$ & -4.678668 & 4.079722 & 0.619195 \\
\hline $\mathrm{C}$ & -4.688483 & 4.038096 & -1.827708 \\
\hline $\mathrm{C}$ & -5.299021 & 5.323003 & 0.576253 \\
\hline $\mathrm{H}$ & -4.417659 & 3.643285 & 1.573717 \\
\hline $\mathrm{C}$ & -5.350825 & 5.272868 & -1.858252 \\
\hline $\mathrm{H}$ & -4.455915 & 3.552459 & -2.766850 \\
\hline $\mathrm{C}$ & -5.652241 & 5.921383 & -0.642422 \\
\hline
\end{tabular}




$\begin{array}{crrr}\mathrm{H} & -5.523907 & 5.843626 & 1.501744 \\ \mathrm{H} & -6.156944 & 6.880296 & -0.635864 \\ \mathrm{C} & -4.589994 & 1.078419 & 1.538841 \\ \mathrm{C} & -5.963073 & 1.241472 & 1.256402 \\ \mathrm{C} & -4.174621 & 0.727390 & 2.831477 \\ \mathrm{C} & -6.890233 & 1.045991 & 2.278872 \\ \mathrm{H} & -6.302696 & 1.502180 & 0.261072 \\ \mathrm{C} & -5.116344 & 0.559649 & 3.861538 \\ \mathrm{H} & -3.122864 & 0.618844 & 3.071618 \\ \mathrm{C} & -6.485508 & 0.717069 & 3.579032 \\ \mathrm{H} & -7.949784 & 1.155929 & 2.069534 \\ \mathrm{H} & -7.232942 & 0.592478 & 4.353082 \\ \mathrm{O} & -5.646936 & 5.752510 & -3.088252 \\ \mathrm{O} & -4.603305 & 0.246743 & 5.080206 \\ \mathrm{C} & -5.509081 & 0.128863 & 6.193748 \\ \mathrm{H} & -4.882807 & -0.088024 & 7.058452 \\ \mathrm{H} & -6.048293 & 1.066998 & 6.360218 \\ \mathrm{H} & -6.217472 & -0.691907 & 6.039471 \\ \mathrm{C} & -6.346068 & 7.008131 & -3.193991 \\ \mathrm{H} & -6.481489 & 7.175030 & -4.261708 \\ \mathrm{H} & -7.324489 & 6.952869 & -2.705658 \\ \mathrm{H} & -5.752455 & 7.823922 & -2.768310\end{array}$

$\mathrm{M}=\mathrm{Cm}$

$\begin{array}{lrrr}\text { CM } & -0.019640 & -1.489223 & -0.349663 \\ \text { C } & -2.933850 & -3.525610 & 0.011718 \\ \text { C } & -3.011179 & -4.719695 & 0.762189 \\ \text { C } & -3.763183 & -5.804361 & 0.277646 \\ \text { C } & -4.432547 & -5.650020 & -0.938102 \\ \text { C } & -4.362755 & -4.442146 & -1.661394 \\ \text { C } & -3.608476 & -3.356469 & -1.195220 \\ \text { C } & -1.719939 & -3.257231 & 1.944429 \\ \text { C } & -2.240588 & -4.517212 & 1.972739 \\ \text { H } & -3.835474 & -6.731356 & 0.837188 \\ \text { H } & -5.028567 & -6.467533 & -1.330744 \\ \text { H } & -4.910326 & -4.350070 & -2.593831 \\ \text { H } & -3.585327 & -2.421836 & -1.748415 \\ \text { H } & -2.063931 & -5.257739 & 2.742893 \\ \text { C } & -0.751525 & -2.589998 & 2.809815 \\ \text { C } & -0.651720 & -2.817679 & 4.193488 \\ \mathrm{C} & 0.319327 & -2.131114 & 4.919740 \\ \text { H } & -1.338131 & -3.497512 & 4.685281 \\ \text { C } & 1.032932 & -1.075727 & 2.888821 \\ \text { C } & 1.180054 & -1.236703 & 4.261577 \\ \text { H } & 0.406593 & -2.281398 & 5.991596\end{array}$




\begin{tabular}{|c|c|c|c|}
\hline $\mathrm{H}$ & 1.945023 & -0.682725 & 4.791615 \\
\hline $\mathrm{C}$ & 1.928218 & -0.216687 & 2.076758 \\
\hline $\mathrm{C}$ & 3.688616 & 1.235674 & 1.855612 \\
\hline$C$ & 3.644192 & 0.975285 & 0.417016 \\
\hline $\mathrm{N}$ & -2.093141 & -2.586223 & 0.711437 \\
\hline $\mathbf{N}$ & 0.082365 & -1.730710 & 2.177868 \\
\hline $\mathrm{N}$ & 2.880417 & 0.506114 & 2.646162 \\
\hline $\mathrm{N}$ & 1.690442 & -0.222527 & 0.750240 \\
\hline $\mathrm{N}$ & 2.601004 & 0.319122 & -0.082523 \\
\hline $\mathrm{C}$ & 4.508031 & 2.253565 & 2.502803 \\
\hline $\mathrm{C}$ & 4.925191 & 3.422287 & 1.813479 \\
\hline $\mathrm{C}$ & 4.804234 & 2.106948 & 3.872972 \\
\hline $\mathrm{C}$ & 5.619024 & 4.404832 & 2.510344 \\
\hline $\mathrm{H}$ & 4.687499 & 3.571389 & 0.768774 \\
\hline $\mathrm{C}$ & 5.539357 & 3.085897 & 4.555878 \\
\hline $\mathrm{H}$ & 4.491938 & 1.223108 & 4.414349 \\
\hline $\mathrm{C}$ & 5.944020 & 4.247403 & 3.866113 \\
\hline $\mathrm{H}$ & 5.923969 & 5.312648 & 1.999358 \\
\hline $\mathrm{H}$ & 6.506311 & 5.024335 & 4.370530 \\
\hline $\mathrm{C}$ & 4.702866 & 1.341394 & -0.548745 \\
\hline $\mathrm{C}$ & 6.063397 & 1.234279 & -0.191424 \\
\hline $\mathrm{C}$ & 4.348511 & 1.714968 & -1.853169 \\
\hline $\mathrm{C}$ & 7.038869 & 1.509213 & -1.148634 \\
\hline $\mathrm{H}$ & 6.357205 & 0.934259 & 0.807300 \\
\hline $\mathrm{C}$ & 5.339535 & 2.010232 & -2.803856 \\
\hline $\mathrm{H}$ & 3.307782 & 1.812071 & -2.139846 \\
\hline $\mathrm{C}$ & 6.695716 & 1.906104 & -2.447620 \\
\hline $\mathrm{H}$ & 8.088309 & 1.421370 & -0.884924 \\
\hline $\mathrm{H}$ & 7.480526 & 2.131741 & -3.159348 \\
\hline $\mathrm{O}$ & 5.798794 & 2.825673 & 5.858092 \\
\hline $\mathrm{O}$ & 4.884676 & 2.378218 & -4.035652 \\
\hline $\mathrm{C}$ & 5.849767 & 2.813196 & -5.012821 \\
\hline $\mathrm{H}$ & 5.270804 & 3.111896 & -5.886331 \\
\hline $\mathrm{H}$ & 6.419791 & 3.671718 & -4.643743 \\
\hline $\mathrm{H}$ & 6.529990 & 1.999606 & -5.286455 \\
\hline $\mathrm{C}$ & 6.561855 & 3.782616 & 6.618302 \\
\hline $\mathrm{H}$ & 6.649404 & 3.355841 & 7.616510 \\
\hline $\mathrm{H}$ & 7.560219 & 3.916071 & 6.188895 \\
\hline $\mathrm{H}$ & 6.039383 & 4.743291 & 6.675429 \\
\hline $\mathrm{H}$ & -2.577527 & -1.686032 & 0.880916 \\
\hline $\mathrm{C}$ & 1.941733 & -3.971653 & -2.018485 \\
\hline $\mathrm{C}$ & 3.186158 & -3.609086 & -2.577906 \\
\hline $\mathrm{C}$ & 4.287910 & -4.471458 & -2.446733 \\
\hline $\mathrm{C}$ & 4.098828 & -5.682750 & -1.777803 \\
\hline $\mathrm{C}$ & 2.841717 & -6.036191 & -1.247377 \\
\hline $\mathrm{C}$ & 1.737011 & -5.179555 & -1.358508 \\
\hline
\end{tabular}




\begin{tabular}{|c|c|c|c|}
\hline $\mathrm{C}$ & 1.713352 & -1.938278 & -3.086413 \\
\hline C & 3.008561 & -2.331933 & -3239112 \\
\hline H & 5.254524 & -4.214283 & -2.867253 \\
\hline & 4.928557 & -6.374484 & -1.674252 \\
\hline H & 2.725270 & -6.993667 & -0.750159 \\
\hline & 0.767615 & -5.474270 & -0.965561 \\
\hline $\mathrm{H}$ & 0.174148 & -3.275026 & -2.794845 \\
\hline A & 3.785304 & -1.757415 & -3.72791 \\
\hline $\mathrm{C}$ & 1.017922 & -0.701554 & -3.431445 \\
\hline $\mathrm{C}$ & 1.316857 & 0.089191 & -4.553907 \\
\hline $\mathrm{C}$ & 0.567303 & 1.242862 & -4.778799 \\
\hline $\mathrm{H}$ & 2.098816 & -0.209751 & -5.242372 \\
\hline C & -0.695674 & 0.769229 & -2.797739 \\
\hline $\mathrm{C}$ & -0.463931 & 1.595617 & -3.890954 \\
\hline $\mathrm{H}$ & 0.773965 & 1.864520 & -5.644634 \\
\hline $\mathrm{H}$ & -1.064454 & 2.485394 & -4.03 \\
\hline C & -1.726335 & 1.045064 & -1.766269 \\
\hline $\mathrm{C}$ & -3.481057 & 2.280587 & -0.951208 \\
\hline $\mathrm{C}$ & -3.678957 & 1.226886 & 0.044821 \\
\hline $\mathrm{N}$ & 0.984303 & -2.917090 & -2.278332 \\
\hline $\mathrm{N}$ & 0.031203 & -0.350447 & -2.575228 \\
\hline $\mathrm{N}$ & -2.555505 & 2.069942 & -1.904 \\
\hline $\mathrm{N}$ & -1.719045 & 0.221315 & -0.699704 \\
\hline $\mathrm{N}$ & -2.753944 & 0.279758 & 0.168496 \\
\hline $\mathrm{C}$ & -4.182855 & 3.557329 & -0.975793 \\
\hline $\mathrm{C}$ & -4.715188 & 4.140160 & 0.204820 \\
\hline $\mathrm{C}$ & -4.244773 & 4.265090 & -2.193883 \\
\hline $\mathrm{C}$ & -5.286257 & 5.405504 & 0.133873 \\
\hline $\mathrm{H}$ & -4.657097 & 3.630719 & 1.157047 \\
\hline $\mathrm{C}$ & -4.859437 & 5.522651 & -2.261406 \\
\hline $\mathrm{H}$ & -3.844272 & 3.835498 & -3.103238 \\
\hline $\mathrm{C}$ & -5.379089 & 6.097828 & -1.082760 \\
\hline $\mathrm{H}$ & -5.676738 & 5.870143 & 1.033763 \\
\hline $\mathrm{H}$ & -5.853317 & 7.071989 & -1.103819 \\
\hline $\mathrm{C}$ & -4.868171 & 1.087247 & 0.910314 \\
\hline $\mathrm{C}$ & -6.158914 & 1.309506 & 0.385118 \\
\hline $\mathrm{C}$ & -4.712537 & 0.649041 & 2.233145 \\
\hline $\mathrm{C}$ & -7.267045 & 1.082459 & 1.200009 \\
\hline $\mathrm{H}$ & -6.298029 & 1.638496 & -0.637930 \\
\hline $\mathrm{C}$ & -5.835885 & 0.449532 & 3.054418 \\
\hline $\mathrm{H}$ & -3.727896 & 0.496342 & 2.660935 \\
\hline $\mathrm{C}$ & -7.123072 & 0.664815 & 2.529322 \\
\hline $\mathrm{H}$ & -8.265241 & 1.236953 & 0.802125 \\
\hline $\mathrm{H}$ & -8.006273 & 0.517338 & 3.138822 \\
\hline $\mathrm{O}$ & -4.896804 & 6.095447 & -3.486497 \\
\hline $\mathrm{O}$ & -5.569748 & 0.050151 & 4.325685 \\
\hline
\end{tabular}




$\begin{array}{crrr}\mathrm{C} & -6.673106 & -0.106821 & 5.238186 \\ \mathrm{H} & -6.227064 & -0.393287 & 6.189997 \\ \mathrm{H} & -7.217214 & 0.835395 & 5.359479 \\ \mathrm{H} & -7.353555 & -0.895600 & 4.900480 \\ \mathrm{C} & -5.534180 & 7.379526 & -3.633671 \\ \mathrm{H} & -5.453551 & 7.623029 & -4.692159 \\ \mathrm{H} & -6.590431 & 7.326114 & -3.350312 \\ \mathrm{H} & -5.018178 & 8.142933 & -3.042028\end{array}$

\section{$\mathbf{L}=$ Core 2}

\section{$\left[\mathrm{ML}\left(\mathrm{H}_{2} \mathrm{O}\right)_{6}\right]^{3+}$}

$\mathrm{M}=\mathrm{Eu}$

$\begin{array}{lccc}\mathrm{C} & 1.377639 & 2.101508 & 0.124758 \\ \mathrm{C} & 1.629219 & 3.471997 & 0.313593 \\ \mathrm{C} & 0.540501 & 4.346718 & 0.409157 \\ \mathrm{C} & -0.746506 & 3.828365 & 0.277544 \\ \mathrm{C} & -0.913533 & 2.439756 & 0.082522 \\ \mathrm{H} & 2.652654 & 3.825643 & 0.364874 \\ \mathrm{H} & 0.697149 & 5.410591 & 0.561668 \\ \mathrm{H} & -1.609210 & 4.483886 & 0.317515 \\ \mathrm{C} & 2.507954 & 1.154254 & -0.058487 \\ \mathrm{C} & 4.733478 & 0.788017 & -0.296978 \\ \mathrm{C} & 4.436881 & -0.580850 & -0.529893 \\ \mathrm{H} & 5.758305 & 1.154777 & -0.304966 \\ \mathrm{H} & 5.207744 & -1.314263 & -0.747838 \\ \mathrm{C} & -2.231633 & 1.852949 & -0.136567 \\ \mathrm{C} & -3.515134 & 2.449535 & -0.176532 \\ \mathrm{C} & -4.384565 & 1.413648 & -0.472231 \\ \mathrm{H} & -3.786943 & 3.483337 & -0.023321 \\ \mathrm{H} & -5.457179 & 1.400524 & -0.615654 \\ \mathrm{~N} & 3.759240 & 1.652757 & -0.067221 \\ \mathrm{~N} & 2.196331 & -0.138713 & -0.231852 \\ \mathrm{~N} & 3.184339 & -1.014420 & -0.480990 \\ \mathrm{~N} & 0.137860 & 1.582985 & 0.038862 \\ \mathrm{~N} & -2.317224 & 0.514838 & -0.397969 \\ \mathrm{~N} & -3.627570 & 0.285404 & -0.587780 \\ \mathrm{EU} & -0.309036 & -1.031828 & 0.044742 \\ \mathrm{O} & -1.468874 & -0.470609 & 2.274269 \\ \mathrm{H} & -2.275363 & 0.008267 & 2.523725 \\ \mathrm{O} & -2.095473 & -2.394905 & -1.238024 \\ \mathrm{H} & -2.471133 & -3.251286 & -0.974195 \\ \mathrm{O} & 1.095214 & -1.529451 & 2.226295 \\ \mathrm{H} & 1.036208 & -2.436521 & 2.570087\end{array}$




$\begin{array}{rrrr}\mathrm{O} & -0.158651 & -0.611838 & -2.487506 \\ \mathrm{H} & -0.490149 & 0.147494 & -2.994197 \\ \mathrm{O} & -1.065630 & -3.246981 & 1.367631 \\ \mathrm{H} & -1.719362 & -3.228695 & 2.086968 \\ \mathrm{O} & 1.201038 & -2.784093 & -0.839711 \\ \mathrm{H} & 1.198331 & -3.689101 & -1.187230 \\ \mathrm{H} & 1.908654 & -1.159122 & 2.605480 \\ \mathrm{H} & 0.483128 & -1.056870 & -3.065507 \\ \mathrm{H} & -2.100080 & -2.382247 & -2.210410 \\ \mathrm{H} & 2.144966 & -2.476389 & -0.781201 \\ \mathrm{H} & -0.937400 & -0.556010 & 3.083637 \\ \mathrm{H} & -0.830316 & -4.183107 & 1.254367 \\ \mathrm{H} & -3.938348 & -0.648102 & -0.838831\end{array}$

$\mathrm{M}=\mathrm{Gd}$

$\begin{array}{lccc}\mathrm{C} & 1.393938 & 2.052175 & 0.096257 \\ \mathrm{C} & 1.649485 & 3.415537 & 0.244434 \\ \mathrm{C} & 0.560094 & 4.296903 & 0.295588 \\ \mathrm{C} & -0.730484 & 3.784191 & 0.169517 \\ \mathrm{C} & -0.904732 & 2.398521 & 0.021627 \\ \mathrm{H} & 2.672560 & 3.768303 & 0.302531 \\ \mathrm{H} & 0.720784 & 5.364844 & 0.411776 \\ \mathrm{H} & -1.588115 & 4.447333 & 0.174378 \\ \mathrm{C} & 2.507797 & 1.084454 & -0.049316 \\ \mathrm{C} & 4.731430 & 0.668919 & -0.231024 \\ \mathrm{C} & 4.412472 & -0.688654 & -0.504452 \\ \mathrm{H} & 5.764113 & 1.011759 & -0.198311 \\ \mathrm{H} & 5.171428 & -1.433032 & -0.726490 \\ \mathrm{C} & -2.227006 & 1.790399 & -0.181325 \\ \mathrm{C} & -3.509651 & 2.368647 & -0.238404 \\ \mathrm{C} & -4.370134 & 1.310771 & -0.503995 \\ \mathrm{H} & -3.793090 & 3.403345 & -0.116594 \\ \mathrm{H} & -5.442502 & 1.286028 & -0.647302 \\ \mathrm{~N} & 3.770615 & 1.551780 & -0.019888 \\ \mathrm{~N} & 2.176107 & -0.201444 & -0.241386 \\ \mathrm{~N} & 3.151383 & -1.091850 & -0.496842 \\ \mathrm{~N} & 0.140732 & 1.538959 & 0.010709 \\ \mathrm{~N} & -2.290137 & 0.452417 & -0.397265 \\ \mathrm{~N} & -3.609888 & 0.191662 & -0.581676 \\ \mathrm{GD} & -0.293034 & -0.975821 & 0.055136 \\ \mathrm{O} & -2.025749 & -1.397704 & 1.957292 \\ \mathrm{H} & -2.980992 & -1.571707 & 1.934201 \\ \mathrm{O} & -1.984751 & -2.605775 & -0.892887 \\ \mathrm{H} & -2.272407 & -3.462447 & -0.533152 \\ \mathrm{O} & 0.495981 & -0.263039 & 2.388594\end{array}$




\begin{tabular}{|c|c|c|c|}
\hline $\mathrm{H}$ & 0.969079 & -0.879546 & 2.973257 \\
\hline $\mathrm{O}$ & -0.377365 & -0.616324 & -2.401729 \\
\hline $\mathrm{H}$ & 0.271846 & -0.979657 & -3.027261 \\
\hline $\mathrm{O}$ & 0.187492 & -2.974791 & 1.552986 \\
\hline $\mathrm{H}$ & -0.406972 & -3.275374 & 2.260812 \\
\hline $\mathrm{O}$ & 1.117701 & -2.638506 & -1.091548 \\
\hline $\mathrm{H}$ & 1.033913 & -3.517086 & -1.493482 \\
\hline $\mathrm{H}$ & 0.648841 & 0.624584 & 2.753341 \\
\hline $\mathrm{H}$ & -0.831206 & 0.109771 & -2.861198 \\
\hline $\mathrm{H}$ & -2.082603 & -2.676824 & -1.858267 \\
\hline $\mathrm{H}$ & 2.085589 & -2.407725 & -1.009692 \\
\hline $\mathrm{H}$ & -1.865389 & -0.943356 & 2.801677 \\
\hline $\mathrm{H}$ & 0.837408 & -3.683410 & 1.413587 \\
\hline $\mathrm{H}$ & -3.915517 & -0.746016 & -0.813209 \\
\hline \multicolumn{4}{|c|}{$\mathrm{M}=\mathrm{Am}$} \\
\hline $\mathrm{AM}$ & -0.248691 & $1-0.883063$ & 0.036961 \\
\hline $\mathrm{O}$ & -1.782020 & -2.325847 & 1.588926 \\
\hline $\mathrm{H}$ & -2.301569 & -3.145418 & 1.540106 \\
\hline $\mathrm{O}$ & -1.899708 & -2.365495 & -1.382516 \\
\hline $\mathrm{H}$ & -2.292340 & -3.253163 & -1.336584 \\
\hline $\mathrm{O}$ & -0.394192 & -0.042400 & 2.492291 \\
\hline $\mathrm{H}$ & 0.271522 & -0.330176 & 3.140169 \\
\hline $\mathrm{O}$ & -0.237781 & -0.310957 & -2.497258 \\
\hline $\mathrm{H}$ & -0.572708 & 0.481984 & -2.948483 \\
\hline $\mathrm{O}$ & 1.188099 & -2.244847 & 1.733894 \\
\hline $\mathrm{H}$ & 0.850410 & -3.007970 & 2.232697 \\
\hline $\mathrm{O}$ & 1.166992 & -2.536469 & -1.306342 \\
\hline $\mathrm{H}$ & 1.046318 & -3.411379 & -1.709044 \\
\hline $\mathrm{H}$ & -0.787116 & 0.772342 & 2.847554 \\
\hline $\mathrm{H}$ & 0.423224 & -0.705208 & -3.091444 \\
\hline $\mathrm{H}$ & -1.926336 & -2.112537 & -2.321665 \\
\hline $\mathrm{H}$ & 2.121263 & -2.426154 & -1.101083 \\
\hline $\mathrm{H}$ & -1.972144 & -1.940069 & 2.461427 \\
\hline $\mathrm{H}$ & 2.143872 & -2.392718 & 1.632768 \\
\hline $\mathrm{C}$ & 1.375237 & 2.206611 & 0.037438 \\
\hline $\mathrm{C}$ & 1.612041 & 3.579168 & 0.111476 \\
\hline $\mathrm{C}$ & 0.510653 & 4.445146 & 0.143435 \\
\hline $\mathrm{C}$ & -0.773196 & 3.905292 & 0.087053 \\
\hline $\mathrm{C}$ & -0.929773 & 2.511456 & 0.013487 \\
\hline $\mathrm{N}$ & 0.130506 & 1.670386 & 0.001352 \\
\hline $\mathrm{H}$ & 0.655846 & 5.519932 & 0.202223 \\
\hline $\mathrm{H}$ & 2.630157 & 3.949403 & 0.136637 \\
\hline $\mathrm{H}$ & -1.641819 & 4.553898 & 0.095189 \\
\hline $\mathrm{C}$ & -2.253773 & 1.881217 & -0.077973 \\
\hline
\end{tabular}




$\begin{array}{cccc}\mathrm{C} & -3.540361 & 2.448159 & -0.122845 \\ \mathrm{~N} & -2.320511 & 0.528571 & -0.167110 \\ \mathrm{C} & -4.406310 & 1.366980 & -0.248766 \\ \mathrm{H} & -3.826610 & 3.488301 & -0.079011 \\ \mathrm{~N} & -3.644608 & 0.250275 & -0.270533 \\ \mathrm{H} & -5.484971 & 1.326616 & -0.324619 \\ \mathrm{H} & -3.955848 & -0.708117 & -0.373419 \\ \mathrm{C} & 2.505496 & 1.252451 & -0.038679 \\ \mathrm{~N} & 3.760817 & 1.742200 & -0.032499 \\ \mathrm{~N} & 2.199094 & -0.050918 & -0.129634 \\ \mathrm{C} & 4.737968 & 0.859955 & -0.141090 \\ \mathrm{~N} & 3.192093 & -0.953566 & -0.257768 \\ \mathrm{C} & 4.445845 & -0.525939 & -0.269729 \\ \mathrm{H} & 5.764310 & 1.222967 & -0.133114 \\ \mathrm{H} & 5.224343 & -1.275015 & -0.383049\end{array}$

$\mathrm{M}=\mathrm{Cm}$

$\begin{array}{lccc}\mathrm{C} & 1.528796 & 2.118824 & 0.100595 \\ \mathrm{C} & 1.844733 & 3.468681 & 0.256102 \\ \mathrm{C} & 0.795918 & 4.397388 & 0.312366 \\ \mathrm{C} & -0.516089 & 3.943833 & 0.183048 \\ \mathrm{C} & -0.753103 & 2.568450 & 0.028203 \\ \mathrm{H} & 2.882230 & 3.775908 & 0.315616 \\ \mathrm{H} & 1.004168 & 5.456399 & 0.434705 \\ \mathrm{H} & -1.342418 & 4.645442 & 0.191190 \\ \mathrm{C} & 2.603145 & 1.106702 & -0.050879 \\ \mathrm{C} & 4.809956 & 0.608066 & -0.234349 \\ \mathrm{C} & 4.440328 & -0.734813 & -0.514641 \\ \mathrm{H} & 5.854655 & 0.911959 & -0.199684 \\ \mathrm{H} & 5.171059 & -1.506002 & -0.739800 \\ \mathrm{C} & -2.104580 & 2.027746 & -0.178223 \\ \mathrm{C} & -3.352444 & 2.677170 & -0.239150 \\ \mathrm{C} & -4.270404 & 1.669992 & -0.509422 \\ \mathrm{H} & -3.578099 & 3.725885 & -0.116922 \\ \mathrm{H} & -5.342022 & 1.706398 & -0.655295 \\ \mathrm{~N} & 3.883081 & 1.525483 & -0.018244 \\ \mathrm{~N} & 2.224424 & -0.165063 & -0.250124 \\ \mathrm{~N} & 3.165445 & -1.091178 & -0.509123 \\ \mathrm{~N} & 0.253547 & 1.664006 & 0.014767 \\ \mathrm{~N} & -2.243409 & 0.695947 & -0.394849 \\ \mathrm{~N} & -3.574863 & 0.510649 & -0.586249 \\ \mathrm{CM} & -0.300743 & -0.860911 & 0.044357 \\ \mathrm{O} & -2.071969 & -1.240214 & 1.983252 \\ \mathrm{H} & -3.033622 & -1.376085 & 1.965742 \\ \mathrm{O} & -2.115863 & -2.421780 & -0.947552\end{array}$




$\begin{array}{crrr}\mathrm{H} & -2.444815 & -3.266483 & -0.594576 \\ \mathrm{O} & 0.530649 & -0.210166 & 2.433569 \\ \mathrm{H} & 0.970794 & -0.862569 & 3.004862 \\ \mathrm{O} & -0.378240 & -0.498096 & -2.466545 \\ \mathrm{H} & 0.251135 & -0.901095 & -3.088223 \\ \mathrm{O} & 0.100172 & -2.932931 & 1.560190 \\ \mathrm{H} & -0.519574 & -3.219408 & 2.252047 \\ \mathrm{O} & 1.086620 & -2.598460 & -1.133078 \\ \mathrm{H} & 0.988539 & -3.473803 & -1.538913 \\ \mathrm{H} & 0.729935 & 0.661287 & 2.814692 \\ \mathrm{H} & -0.790256 & 0.249158 & -2.931848 \\ \mathrm{H} & -2.210278 & -2.484360 & -1.913926 \\ \mathrm{H} & 2.056579 & -2.387783 & -1.041748 \\ \mathrm{H} & -1.885753 & -0.806192 & 2.833013 \\ \mathrm{H} & 0.715567 & -3.670466 & 1.413847 \\ \mathrm{H} & -3.932609 & -0.408644 & -0.816909\end{array}$

\section{$\left[\mathrm{ML}\left(\mathrm{H}_{2} \mathrm{O}\right)_{5}\right]^{3+}$}

$\mathrm{M}=\mathrm{Eu}$

$\begin{array}{lrrr}\text { EU } & 0.264673 & -1.096278 & 0.042354 \\ \mathrm{O} & 0.307100 & -3.101398 & 1.654127 \\ \mathrm{H} & -0.299784 & -3.853540 & 1.544970 \\ \mathrm{O} & -1.343035 & -2.809868 & -0.753411 \\ \mathrm{H} & -1.377951 & -3.664658 & -1.212093 \\ \mathrm{O} & 2.075002 & -2.727830 & -0.774244 \\ \mathrm{H} & 2.370542 & -2.809992 & -1.697486 \\ \mathrm{O} & 0.306302 & -0.352717 & 2.476037 \\ \mathrm{H} & 0.684101 & 0.463185 & 2.844435 \\ \mathrm{O} & 0.306031 & -0.791264 & -2.462196 \\ \mathrm{H} & -0.272838 & -1.264540 & -3.083516 \\ \mathrm{H} & 2.276056 & -3.583156 & -0.356662 \\ \mathrm{H} & 0.764468 & -0.119447 & -2.994058 \\ \mathrm{H} & 0.808969 & -3.283708 & 2.466982 \\ \mathrm{H} & -2.274147 & -2.494469 & -0.604784 \\ \mathrm{H} & -0.130621 & -0.795256 & 3.223405 \\ \mathrm{C} & -1.260858 & 2.093981 & 0.012027 \\ \mathrm{C} & -1.456722 & 3.486751 & 0.037452 \\ \mathrm{C} & -0.334477 & 4.320905 & 0.012747 \\ \mathrm{C} & 0.933067 & 3.738600 & -0.028248 \\ \mathrm{C} & 1.044909 & 2.331314 & -0.043171 \\ \mathrm{H} & -2.465107 & 3.884225 & 0.059728 \\ \mathrm{H} & -0.447271 & 5.401170 & 0.025409 \\ \mathrm{H} & 1.821835 & 4.359660 & -0.038100 \\ \mathrm{C} & -2.431210 & 1.178349 & 0.004992\end{array}$




$\begin{array}{lrrc}\mathrm{C} & -4.681211 & 0.878541 & -0.000519 \\ \mathrm{C} & -4.451818 & -0.517790 & -0.124679 \\ \mathrm{H} & -5.689977 & 1.284920 & 0.048862 \\ \mathrm{H} & -5.261469 & -1.236564 & -0.211476 \\ \mathrm{C} & 2.345592 & 1.665547 & -0.052747 \\ \mathrm{C} & 3.653164 & 2.203046 & -0.042303 \\ \mathrm{C} & 4.495704 & 1.103226 & -0.041189 \\ \mathrm{H} & 3.960224 & 3.238298 & -0.033803 \\ \mathrm{H} & 5.575723 & 1.031847 & -0.038756 \\ \mathrm{~N} & -3.662077 & 1.720403 & 0.038994 \\ \mathrm{~N} & -2.181853 & -0.139891 & -0.044849 \\ \mathrm{~N} & -3.213827 & -0.992262 & -0.143592 \\ \mathrm{~N} & -0.041888 & 1.521776 & -0.032226 \\ \mathrm{~N} & 2.388465 & 0.298346 & -0.061445 \\ \mathrm{~N} & 3.701972 & -0.001383 & -0.051764 \\ \mathrm{H} & 3.999252 & -0.971614 & -0.075833\end{array}$

$\mathrm{M}=\mathrm{Gd}$

$\begin{array}{lrrc}\text { GD } & 0.224709 & -1.021657 & 0.100516 \\ \mathrm{O} & -1.053836 & -1.699639 & 2.185132 \\ \mathrm{H} & -1.657825 & -2.462424 & 2.182593 \\ \mathrm{O} & -1.308627 & -2.778695 & -0.540158 \\ \mathrm{H} & -1.313404 & -3.725715 & -0.754066 \\ \mathrm{O} & 1.766623 & -2.960645 & -0.347667 \\ \mathrm{H} & 1.831721 & -3.454147 & -1.184025 \\ \mathrm{O} & 1.629258 & -1.136447 & 2.148254 \\ \mathrm{H} & 1.417286 & -1.587972 & 2.983357 \\ \mathrm{O} & 0.314953 & -1.013919 & -2.342668 \\ \mathrm{H} & -0.313247 & -1.435585 & -2.953773 \\ \mathrm{H} & 2.198655 & -3.520418 & 0.321302 \\ \mathrm{H} & 0.882255 & -0.442387 & -2.887940 \\ \mathrm{H} & -1.234250 & -1.227232 & 3.016358 \\ \mathrm{H} & -2.241983 & -2.420095 & -0.607617 \\ \mathrm{H} & 2.481564 & -0.690352 & 2.289040 \\ \mathrm{C} & -1.205960 & 2.088913 & 0.103235 \\ \mathrm{C} & -1.349941 & 3.467412 & 0.246684 \\ \mathrm{C} & -0.191368 & 4.254653 & 0.317660 \\ \mathrm{C} & 1.054388 & 3.637520 & 0.203872 \\ \mathrm{C} & 1.117038 & 2.243693 & 0.055052 \\ \mathrm{H} & -2.340961 & 3.904437 & 0.287296 \\ \mathrm{H} & -0.264254 & 5.332004 & 0.435878 \\ \mathrm{H} & 1.962702 & 4.229180 & 0.218200 \\ \mathrm{C} & -2.389137 & 1.211931 & -0.060537 \\ \mathrm{C} & -4.629910 & 0.953284 & -0.291451 \\ \mathrm{C} & -4.407748 & -0.437703 & -0.493362\end{array}$




$\begin{array}{crcc}\mathrm{H} & -5.634882 & 1.371761 & -0.307863 \\ \mathrm{H} & -5.217685 & -1.134142 & -0.689671 \\ \mathrm{C} & 2.386714 & 1.532528 & -0.152706 \\ \mathrm{C} & 3.706367 & 2.011484 & -0.241609 \\ \mathrm{C} & 4.482419 & 0.887977 & -0.505671 \\ \mathrm{H} & 4.068135 & 3.024192 & -0.143692 \\ \mathrm{H} & 5.547982 & 0.782575 & -0.664582 \\ \mathrm{~N} & -3.614043 & 1.771111 & -0.077293 \\ \mathrm{~N} & -2.148998 & -0.098677 & -0.214677 \\ \mathrm{~N} & -3.181362 & -0.932209 & -0.437709 \\ \mathrm{~N} & 0.002661 & 1.472332 & 0.040050 \\ \mathrm{~N} & 2.347333 & 0.186758 & -0.347728 \\ \mathrm{H} & 3.880709 & -1.136828 & -0.757032 \\ \mathrm{~N} & 3.643259 & -0.173058 & -0.552200\end{array}$

$\mathrm{M}=\mathrm{Am}$

$\begin{array}{lrrr}\text { AM } & 0.305728 & -0.908146 & 0.030348 \\ \mathrm{O} & 0.858435 & -2.896409 & 1.625457 \\ \mathrm{H} & 0.300631 & -3.692920 & 1.665716 \\ \mathrm{O} & -1.183697 & -2.796499 & -0.539872 \\ \mathrm{H} & -1.160525 & -3.678085 & -0.946073 \\ \mathrm{O} & 2.170635 & -2.373653 & -0.980911 \\ \mathrm{H} & 2.454987 & -2.341440 & -1.911107 \\ \mathrm{O} & 0.055920 & -0.251310 & 2.451258 \\ \mathrm{H} & 0.066403 & 0.647065 & 2.822815 \\ \mathrm{O} & 0.178621 & -0.608125 & -2.488218 \\ \mathrm{H} & -0.352744 & -1.141454 & -3.104440 \\ \mathrm{H} & 2.442511 & -3.246179 & -0.647597 \\ \mathrm{H} & 0.501926 & 0.148727 & -3.006909 \\ \mathrm{H} & 1.536408 & -3.015307 & 2.313591 \\ \mathrm{H} & -2.139491 & -2.511861 & -0.431633 \\ \mathrm{H} & -0.084399 & -0.849842 & 3.204585 \\ \mathrm{C} & -1.460911 & 2.111654 & 0.003292 \\ \mathrm{C} & -1.752417 & 3.475159 & 0.028614 \\ \mathrm{C} & -0.686630 & 4.385757 & 0.031422 \\ \mathrm{C} & 0.619404 & 3.897689 & 0.013659 \\ \mathrm{C} & 0.832454 & 2.510367 & -0.008656 \\ \mathrm{H} & -2.784598 & 3.805042 & 0.043651 \\ \mathrm{H} & -0.875933 & 5.455237 & 0.048187 \\ \mathrm{H} & 1.460311 & 4.581862 & 0.017412 \\ \mathrm{C} & -2.552382 & 1.109351 & -0.013460 \\ \mathrm{C} & -4.770136 & 0.625386 & -0.029937 \\ \mathrm{C} & -4.427792 & -0.752476 & -0.112384 \\ \mathrm{H} & -5.809282 & 0.948807 & -0.003184 \\ \mathrm{H} & -5.176105 & -1.537432 & -0.169922\end{array}$




$\begin{array}{rrrr}\mathrm{C} & 2.181848 & 1.929523 & -0.022766 \\ \mathrm{C} & 3.443195 & 2.547132 & -0.026247 \\ \mathrm{C} & 4.359440 & 1.499606 & -0.047710 \\ \mathrm{H} & 3.684144 & 3.599614 & -0.018539 \\ \mathrm{H} & 5.441679 & 1.503726 & -0.060142 \\ \mathrm{~N} & -3.825526 & 1.548552 & 0.006744 \\ \mathrm{~N} & -2.196373 & -0.183224 & -0.059167 \\ \mathrm{~N} & -3.158206 & -1.122815 & -0.127643 \\ \mathrm{~N} & -0.193620 & 1.625998 & -0.016827 \\ \mathrm{~N} & 2.307801 & 0.575661 & -0.040439 \\ \mathrm{~N} & 3.649421 & 0.351076 & -0.055616 \\ \mathrm{H} & 4.009723 & -0.595347 & -0.085467\end{array}$

$\mathrm{M}=\mathrm{Cm}$

$\begin{array}{lrcc}\mathrm{CM} & 0.223565 & -0.904033 & 0.079866 \\ \mathrm{O} & -1.059146 & -1.699104 & 2.187307 \\ \mathrm{H} & -1.637360 & -2.481155 & 2.163156 \\ \mathrm{O} & -1.318095 & -2.712306 & -0.620692 \\ \mathrm{H} & -1.317220 & -3.651246 & -0.867577 \\ \mathrm{O} & 1.868350 & -2.819929 & -0.431500 \\ \mathrm{H} & 1.954870 & -3.280711 & -1.284328 \\ \mathrm{O} & 1.650083 & -1.066482 & 2.171093 \\ \mathrm{H} & 1.430883 & -1.554955 & 2.983128 \\ \mathrm{O} & 0.338910 & -0.889846 & -2.415730 \\ \mathrm{H} & -0.276443 & -1.334252 & -3.024339 \\ \mathrm{H} & 2.300043 & -3.396717 & 0.223063 \\ \mathrm{H} & 0.890059 & -0.305344 & -2.964425 \\ \mathrm{H} & -1.259687 & -1.251873 & 3.027831 \\ \mathrm{H} & -2.252698 & -2.361057 & -0.662028 \\ \mathrm{H} & 2.487478 & -0.605272 & 2.347915 \\ \mathrm{C} & -1.297304 & 2.199932 & 0.104314 \\ \mathrm{C} & -1.479893 & 3.573522 & 0.251307 \\ \mathrm{C} & -0.344541 & 4.393641 & 0.321325 \\ \mathrm{C} & 0.917966 & 3.812776 & 0.205605 \\ \mathrm{C} & 1.021581 & 2.421464 & 0.054924 \\ \mathrm{H} & -2.482580 & 3.982377 & 0.296208 \\ \mathrm{H} & -0.448256 & 5.468182 & 0.441941 \\ \mathrm{H} & 1.808559 & 4.430568 & 0.221881 \\ \mathrm{C} & -2.461047 & 1.294774 & -0.055567 \\ \mathrm{C} & -4.698009 & 0.992463 & -0.275461 \\ \mathrm{C} & -4.449261 & -0.392173 & -0.486656 \\ \mathrm{H} & -5.710912 & 1.391465 & -0.283715 \\ \mathrm{H} & -5.246273 & -1.102826 & -0.684894 \\ \mathrm{C} & 2.316543 & 1.753831 & -0.146175 \\ \mathrm{C} & 3.615366 & 2.286550 & -0.236061\end{array}$




$\begin{array}{lrrr}\mathrm{C} & 4.438895 & 1.194423 & -0.486675 \\ \mathrm{H} & 3.934632 & 3.314147 & -0.146624 \\ \mathrm{H} & 5.508622 & 1.132369 & -0.639569 \\ \mathrm{~N} & -3.697172 & 1.829407 & -0.064078 \\ \mathrm{~N} & -2.197186 & -0.010806 & -0.213522 \\ \mathrm{~N} & -3.213844 & -0.863822 & -0.439470 \\ \mathrm{~N} & -0.070867 & 1.619727 & 0.038037 \\ \mathrm{~N} & 2.335057 & 0.406510 & -0.327068 \\ \mathrm{H} & 3.923065 & -0.856115 & -0.717959 \\ \mathrm{~N} & 3.645214 & 0.099519 & -0.526171\end{array}$

\section{$\left[\mathrm{ML}_{2}\left(\mathrm{H}_{2} \mathrm{O}\right)_{2}\right]^{3+}$}

$\mathrm{M}=\mathrm{Eu}$

$\begin{array}{lrrr}\text { EU } & 0.000114 & -0.444774 & 0.000500 \\ \mathrm{O} & 0.444878 & -2.074707 & -1.741831 \\ \mathrm{H} & -0.399691 & -2.469196 & -2.093368 \\ \mathrm{O} & -0.444129 & -2.071444 & 1.745993 \\ \mathrm{H} & 0.400564 & -2.465101 & 2.098214 \\ \mathrm{H} & 1.190583 & -2.457579 & -2.227250 \\ \mathrm{H} & -1.189729 & -2.453568 & 2.232159 \\ \mathrm{C} & 3.435082 & -0.017011 & -0.544752 \\ \mathrm{C} & 4.638690 & 0.413540 & -1.104331 \\ \mathrm{C} & 4.594602 & 1.402450 & -2.096349 \\ \mathrm{C} & 3.358442 & 1.914977 & -2.485066 \\ \mathrm{C} & 2.189509 & 1.430417 & -1.872719 \\ \mathrm{H} & 5.573706 & -0.020229 & -0.770436 \\ \mathrm{H} & 5.509965 & 1.760640 & -2.558073 \\ \mathrm{H} & 3.298962 & 2.674596 & -3.255682 \\ \mathrm{C} & 3.425868 & -1.072198 & 0.501158 \\ \mathrm{C} & 4.552874 & -2.528734 & 1.825677 \\ \mathrm{C} & 3.304313 & -2.952626 & 2.351566 \\ \mathrm{H} & 5.488256 & -2.966376 & 2.169310 \\ \mathrm{H} & 3.223444 & -3.724840 & 3.110500 \\ \mathrm{C} & 0.860223 & 1.934289 & -2.250674 \\ \mathrm{C} & 0.511294 & 2.953467 & -3.158066 \\ \mathrm{C} & -0.874661 & 3.020088 & -3.112676 \\ \mathrm{H} & 1.156178 & 3.568184 & -3.767187 \\ \mathrm{H} & -1.573791 & 3.654847 & -3.640014 \\ \mathrm{~N} & 4.606131 & -1.586226 & 0.900002 \\ \mathrm{~N} & 2.230414 & -1.447845 & 0.980980 \\ \mathrm{~N} & 2.177876 & -2.406374 & 1.921394 \\ \mathrm{~N} & 2.227999 & 0.478488 & -0.913608 \\ \mathrm{~N} & -0.249302 & 1.396648 & -1.682526 \\ \mathrm{~N} & -1.283823 & 2.082972 & -2.225376\end{array}$




$\begin{array}{lrrc}\mathrm{C} & -3.435066 & -0.016398 & 0.544756 \\ \mathrm{C} & -4.638850 & 0.415107 & 1.103315 \\ \mathrm{C} & -4.595081 & 1.406126 & 2.093215 \\ \mathrm{C} & -3.359053 & 1.919741 & 2.480954 \\ \mathrm{C} & -2.189955 & 1.434089 & 1.869763 \\ \mathrm{H} & -5.573737 & -0.019561 & 0.770227 \\ \mathrm{H} & -5.510563 & 1.765114 & 2.554083 \\ \mathrm{H} & -3.299805 & 2.681007 & 3.249963 \\ \mathrm{C} & -3.425581 & -1.073737 & -0.499000 \\ \mathrm{C} & -4.552237 & -2.533121 & -1.820667 \\ \mathrm{C} & -3.303569 & -2.957803 & -2.345649 \\ \mathrm{H} & -5.487515 & -2.971632 & -2.163470 \\ \mathrm{H} & -3.222512 & -3.731484 & -3.103068 \\ \mathrm{C} & -0.860840 & 1.939016 & 2.246791 \\ \mathrm{C} & -0.512178 & 2.960182 & 3.152010 \\ \mathrm{C} & 0.873775 & 3.026917 & 3.106643 \\ \mathrm{H} & -1.157219 & 3.576136 & 3.759714 \\ \mathrm{H} & 1.572750 & 3.662920 & 3.632692 \\ \mathrm{~N} & -4.605722 & -1.588775 & -0.896870 \\ \mathrm{~N} & -2.230031 & -1.450127 & -0.977978 \\ \mathrm{~N} & -2.177247 & -2.410496 & -1.916489 \\ \mathrm{~N} & -2.228143 & 0.480093 & 0.912686 \\ \mathrm{~N} & 0.248917 & 1.400263 & 1.679927 \\ \mathrm{~N} & 1.283199 & 2.087911 & 2.221407 \\ \mathrm{H} & 2.234799 & 1.881077 & 1.947837 \\ \mathrm{H} & -2.235342 & 1.876631 & -1.951185\end{array}$

$\mathrm{M}=\mathrm{Gd}$

$\begin{array}{lrrr}\text { GD } & -0.000045 & -0.708330 & 0.000734 \\ \text { O } & -0.645731 & -2.264686 & 1.948354 \\ \text { H } & -1.462358 & -2.789706 & 1.891551 \\ \text { O } & 0.646840 & -2.268165 & -1.944330 \\ \text { H } & 1.463181 & -2.793420 & -1.885699 \\ \text { H } & -0.539734 & -2.055937 & 2.892050 \\ \text { H } & 0.541920 & -2.061248 & -2.888545 \\ \mathrm{C} & -2.151596 & 1.357600 & 1.719779 \\ \mathrm{C} & -3.312892 & 2.000093 & 2.149253 \\ \mathrm{C} & -4.543098 & 1.542261 & 1.658991 \\ \mathrm{C} & -4.562288 & 0.463959 & 0.774301 \\ \mathrm{C} & -3.348286 & -0.127317 & 0.391082 \\ \mathrm{H} & -3.245386 & 2.825577 & 2.847829 \\ \mathrm{H} & -5.469656 & 2.015500 & 1.970213 \\ \mathrm{H} & -5.502799 & 0.085367 & 0.390886 \\ \mathrm{C} & -0.817082 & 1.771293 & 2.216863 \\ \mathrm{C} & 0.470695 & 3.082719 & 3.536320\end{array}$




$\begin{array}{rrrr}\mathrm{C} & 1.603155 & 2.370657 & 3.066164 \\ \mathrm{H} & 0.569357 & 3.892844 & 4.256481 \\ \mathrm{H} & 2.608745 & 2.594714 & 3.409520 \\ \mathrm{C} & -3.289582 & -1.284557 & -0.513426 \\ \mathrm{C} & -4.318374 & -2.001716 & -1.152298 \\ \mathrm{C} & -3.672220 & -3.004075 & -1.866145 \\ \mathrm{H} & -5.384060 & -1.834323 & -1.114639 \\ \mathrm{H} & -4.062714 & -3.790988 & -2.497418 \\ \mathrm{~N} & -0.743521 & 2.776551 & 3.106197 \\ \mathrm{~N} & 0.243435 & 1.091768 & 1.742428 \\ \mathrm{~N} & 1.479918 & 1.395638 & 2.175278 \\ \mathrm{~N} & -2.160287 & 0.318843 & 0.853793 \\ \mathrm{~N} & -2.076232 & -1.815502 & -0.814449 \\ \mathrm{H} & -1.587962 & -3.429483 & -1.994379 \\ \mathrm{~N} & -2.346231 & -2.857314 & -1.642694 \\ \mathrm{C} & 2.151389 & 1.354917 & -1.721721 \\ \mathrm{C} & 3.312573 & 1.997253 & -2.151758 \\ \mathrm{C} & 4.542818 & 1.540502 & -1.660599 \\ \mathrm{C} & 4.562180 & 0.463335 & -0.774527 \\ \mathrm{C} & 3.348286 & -0.127836 & -0.390817 \\ \mathrm{H} & 3.244959 & 2.821768 & -2.851468 \\ \mathrm{H} & 5.469280 & 2.013680 & -1.972199 \\ \mathrm{H} & 5.502731 & 0.085553 & -0.390412 \\ \mathrm{C} & 0.816873 & 1.767384 & -2.219809 \\ \mathrm{C} & -0.470967 & 3.076257 & -3.541740 \\ \mathrm{C} & -1.603300 & 2.364439 & -3.070914 \\ \mathrm{H} & -0.569708 & 3.885252 & -4.263159 \\ \mathrm{H} & -2.608855 & 2.587537 & -3.414995 \\ \mathrm{C} & 3.289701 & -1.283874 & 0.515260 \\ \mathrm{C} & 4.318553 & -2.000276 & 1.154875 \\ \mathrm{C} & 3.672412 & -3.001529 & 1.870303 \\ \mathrm{H} & 5.384265 & -1.833195 & 1.116559 \\ \mathrm{H} & 4.062958 & -3.787589 & 2.502607 \\ \mathrm{~N} & 0.743217 & 2.771264 & -3.110695 \\ \mathrm{~N} & -0.243539 & 1.088194 & -1.744668 \\ \mathrm{~N} & -1.479990 & 1.390899 & -2.178419 \\ \mathrm{~N} & 2.160243 & 0.317338 & -0.854338 \\ \mathrm{~N} & 2.076342 & -1.814109 & 0.817464 \\ \mathrm{H} & 1.588096 & -3.426223 & 2.000070 \\ \mathrm{~N} & 2.346370 & -2.854807 & 1.647150 \\ & & & \\ \mathrm{M}=\mathrm{A} \mathrm{m} & & & \end{array}$
$\begin{array}{llll}\text { AM } & -0.000008 & -0.396772 & 0.000100\end{array}$
O $\quad 0.450856 \quad-2.043388-1.780101$
$\mathrm{H} \quad-0.390140 \quad-2.473311-2.094630$ 


\begin{tabular}{|c|c|c|c|}
\hline $\mathrm{O}$ & -0.450526 & -2.043514 & 1.780332 \\
\hline $\mathrm{H}$ & 0.390548 & -2.473219 & 2.094961 \\
\hline $\mathrm{H}$ & 1.181165 & -2.329364 & -2.348754 \\
\hline $\mathrm{H}$ & -1.180859 & -2.329746 & 2.348823 \\
\hline $\mathrm{C}$ & 3.475288 & 0.031522 & -0.479850 \\
\hline $\mathrm{C}$ & 4.695338 & 0.475114 & -0.990410 \\
\hline $\mathrm{C}$ & 4.683503 & 1.490671 & -1.955829 \\
\hline $\mathrm{C}$ & 3.460532 & 2.010244 & -2.373257 \\
\hline $\mathrm{C}$ & 2.272850 & 1.511323 & -1.812117 \\
\hline $\mathrm{H}$ & 5.619243 & 0.029498 & -0.641994 \\
\hline $\mathrm{H}$ & 5.613416 & 1.860586 & -2.377437 \\
\hline $\mathrm{H}$ & 3.425321 & 2.786823 & -3.128244 \\
\hline $\mathrm{C}$ & 3.440290 & -1.058320 & 0.528450 \\
\hline $\mathrm{C}$ & 4.542180 & -2.562677 & 1.821733 \\
\hline $\mathrm{C}$ & 3.283877 & -3.003221 & 2.308884 \\
\hline $\mathrm{H}$ & 5.471086 & -3.013046 & 2.166357 \\
\hline $\mathrm{H}$ & 3.188163 & -3.800270 & 3.039884 \\
\hline $\mathrm{C}$ & 0.957850 & 2.013699 & -2.235742 \\
\hline $\mathrm{C}$ & 0.640020 & 3.042306 & -3.144119 \\
\hline $\mathrm{C}$ & -0.746847 & 3.090209 & -3.165007 \\
\hline $\mathrm{H}$ & 1.304468 & 3.675102 & -3.712279 \\
\hline $\mathrm{H}$ & -1.428399 & 3.724217 & -3.715487 \\
\hline $\mathrm{N}$ & 4.612586 & -1.586249 & 0.933686 \\
\hline $\mathrm{N}$ & 2.236222 & -1.452153 & 0.969150 \\
\hline $\mathrm{N}$ & 2.166560 & -2.440543 & 1.878311 \\
\hline $\mathrm{N}$ & 2.280100 & 0.540237 & -0.870658 \\
\hline $\mathrm{N}$ & -0.167835 & 1.456694 & -1.726904 \\
\hline $\mathrm{N}$ & -1.185575 & 2.135707 & -2.312263 \\
\hline $\mathrm{C}$ & -3.475280 & 0.031386 & 0.479764 \\
\hline $\mathrm{C}$ & -4.695400 & 0.475010 & 0.990128 \\
\hline $\mathrm{C}$ & -4.683710 & 1.490817 & 1.955287 \\
\hline $\mathrm{C}$ & -3.460809 & 2.010586 & 2.372674 \\
\hline $\mathrm{C}$ & -2.273047 & 1.511605 & 1.811758 \\
\hline $\mathrm{H}$ & -5.619247 & 0.029235 & 0.641761 \\
\hline $\mathrm{H}$ & -5.613681 & 1.860772 & 2.376731 \\
\hline $\mathrm{H}$ & -3.425711 & 2.787363 & 3.127462 \\
\hline $\mathrm{C}$ & -3.440119 & -1.058685 & -0.528285 \\
\hline $\mathrm{C}$ & -4.541788 & -2.563406 & -1.821336 \\
\hline $\mathrm{C}$ & -3.283417 & -3.003886 & -2.308366 \\
\hline $\mathrm{H}$ & -5.470629 & -3.013949 & -2.165908 \\
\hline $\mathrm{H}$ & -3.187583 & -3.801037 & -3.039240 \\
\hline $\mathrm{C}$ & -0.958105 & 2.014153 & 2.235360 \\
\hline $\mathrm{C}$ & -0.640389 & 3.042905 & 3.143612 \\
\hline $\mathrm{C}$ & 0.746474 & 3.090884 & 3.164585 \\
\hline $\mathrm{H}$ & -1.304908 & 3.675743 & 3.711643 \\
\hline $\mathrm{H}$ & 1.427956 & 3.725004 & 3.715021 \\
\hline
\end{tabular}




$\begin{array}{rrrr}\mathrm{N} & -4.612341 & -1.586815 & -0.933478 \\ \mathrm{~N} & -2.235989 & -1.452479 & -0.968846 \\ \mathrm{~N} & -2.166182 & -2.441005 & -1.877845 \\ \mathrm{~N} & -2.280158 & 0.540285 & 0.870537 \\ \mathrm{~N} & 0.167644 & 1.457136 & 1.726675 \\ \mathrm{~N} & 1.185307 & 2.136282 & 2.312006 \\ \mathrm{H} & 2.146317 & 1.912821 & 2.089482 \\ \mathrm{H} & -2.146561 & 1.912239 & -2.089639\end{array}$

$\mathrm{M}=\mathrm{Cm}$

$\begin{array}{lrrc}\mathrm{CM} & -0.000257 & -0.637625 & -0.001296 \\ \mathrm{O} & -0.702127 & -2.288521 & 1.959155 \\ \mathrm{H} & -1.478735 & -2.861975 & 1.841977 \\ \mathrm{O} & 0.702992 & -2.280954 & -1.965569 \\ \mathrm{H} & 1.485497 & -2.847280 & -1.852789 \\ \mathrm{H} & -0.697783 & -2.057552 & 2.903661 \\ \mathrm{H} & 0.690925 & -2.050504 & -2.910136 \\ \mathrm{C} & -2.254774 & 1.401796 & 1.693299 \\ \mathrm{C} & -3.435723 & 2.021481 & 2.102072 \\ \mathrm{C} & -4.646544 & 1.551449 & 1.576415 \\ \mathrm{C} & -4.627809 & 0.485584 & 0.677526 \\ \mathrm{C} & -3.396727 & -0.084645 & 0.317315 \\ \mathrm{H} & -3.398697 & 2.840318 & 2.810555 \\ \mathrm{H} & -5.587377 & 2.007365 & 1.870167 \\ \mathrm{H} & -5.553263 & 0.100374 & 0.265316 \\ \mathrm{C} & -0.940255 & 1.838979 & 2.224364 \\ \mathrm{C} & 0.287154 & 3.173985 & 3.578249 \\ \mathrm{C} & 1.447481 & 2.495953 & 3.126125 \\ \mathrm{H} & 0.349862 & 3.980776 & 4.306105 \\ \mathrm{H} & 2.440025 & 2.745315 & 3.489161 \\ \mathrm{C} & -3.307068 & -1.224639 & -0.607084 \\ \mathrm{C} & -4.319972 & -1.934331 & -1.279330 \\ \mathrm{C} & -3.655299 & -2.916700 & -2.003548 \\ \mathrm{H} & -5.387244 & -1.774898 & -1.256779 \\ \mathrm{H} & -4.029962 & -3.690863 & -2.659555 \\ \mathrm{~N} & -0.909997 & 2.839935 & 3.121569 \\ \mathrm{~N} & 0.147354 & 1.189293 & 1.770866 \\ \mathrm{~N} & 1.367340 & 1.522524 & 2.229272 \\ \mathrm{~N} & -2.228054 & 0.372897 & 0.815829 \\ \mathrm{~N} & -2.086422 & -1.741416 & -0.899719 \\ \mathrm{H} & -1.564560 & -3.319849 & -2.110100 \\ \mathrm{~N} & -2.335055 & -2.767027 & -1.753672 \\ \mathrm{C} & 2.255990 & 1.405971 & -1.689118 \\ \mathrm{C} & 3.437394 & 2.025917 & -2.096213 \\ \mathrm{C} & 4.647903 & 1.553346 & -1.572113\end{array}$




$\begin{array}{rrrr}\mathrm{C} & 4.628441 & 0.484879 & -0.676315 \\ \mathrm{C} & 3.396927 & -0.085310 & -0.317550 \\ \mathrm{H} & 3.400950 & 2.846874 & -2.802270 \\ \mathrm{H} & 5.589067 & 2.009341 & -1.864681 \\ \mathrm{H} & 5.553630 & 0.097680 & -0.265363 \\ \mathrm{C} & 0.941725 & 1.845677 & -2.218705 \\ \mathrm{C} & -0.284983 & 3.185707 & -3.568256 \\ \mathrm{C} & -1.445716 & 2.507069 & -3.118088 \\ \mathrm{H} & -0.347238 & 3.994751 & -4.293646 \\ \mathrm{H} & -2.438137 & 2.758230 & -3.480215 \\ \mathrm{C} & 3.306090 & -1.227774 & 0.603660 \\ \mathrm{C} & 4.317856 & -1.940534 & 1.274351 \\ \mathrm{C} & 3.651615 & -2.923839 & 1.995925 \\ \mathrm{H} & 5.385350 & -1.782458 & 1.252520 \\ \mathrm{H} & 4.025072 & -3.700069 & 2.650171 \\ \mathrm{~N} & 0.912012 & 2.849426 & -3.112795 \\ \mathrm{~N} & -0.146279 & 1.195309 & -1.767110 \\ \mathrm{~N} & -1.366102 & 1.530778 & -2.224292 \\ \mathrm{~N} & 2.228563 & 0.374592 & -0.814626 \\ \mathrm{~N} & 2.084736 & -1.743739 & 0.894650 \\ \mathrm{H} & 1.559807 & -3.323017 & 2.102029 \\ \mathrm{~N} & 2.331666 & -2.771843 & 1.745992 \\ & & & \\ {[\mathrm{ML}} & \end{array}$

$\mathrm{M}=\mathrm{Eu}$

$\begin{array}{lccc}\text { EU } & -0.000031 & 0.235066 & -0.000045 \\ \text { C } & -3.167813 & -0.798806 & -0.840323 \\ \text { C } & -4.553761 & -0.930717 & -0.863124 \\ \text { C } & -5.309408 & -0.106937 & -0.015111 \\ \text { C } & -4.654208 & 0.804886 & 0.812371 \\ \text { C } & -3.251366 & 0.880297 & 0.776555 \\ \text { H } & -5.017015 & -1.655959 & -1.522765 \\ \text { H } & -6.393029 & -0.179682 & -0.001833 \\ \text { H } & -5.221469 & 1.447447 & 1.475805 \\ \text { C } & -2.289137 & -1.631299 & -1.692759 \\ \text { C } & -1.943379 & -3.225749 & -3.260227 \\ \text { C } & -0.544825 & -3.008697 & -3.128723 \\ \text { H } & -2.334333 & -3.966380 & -3.955946 \\ \text { H } & 0.186952 & -3.562497 & -3.709352 \\ \text { C } & -2.492318 & 1.817677 & 1.619764 \\ \text { C } & -2.954505 & 2.764540 & 2.550016 \\ \text { C } & -1.809044 & 3.372897 & 3.049930 \\ \text { H } & -3.970195 & 2.993296 & 2.834920 \\ \text { H } & -1.683624 & 4.157384 & 3.784516\end{array}$




$\begin{array}{lrrr}\mathrm{N} & -2.810817 & -2.531907 & -2.537077 \\ \mathrm{~N} & -0.967563 & -1.414619 & -1.553455 \\ \mathrm{~N} & -0.081664 & -2.105310 & -2.272845 \\ \mathrm{~N} & -2.524921 & 0.088914 & -0.042263 \\ \mathrm{~N} & -1.131221 & 1.836343 & 1.546759 \\ \mathrm{~N} & -0.753640 & 2.797450 & 2.432591 \\ \mathrm{C} & 3.167873 & -0.798426 & 0.840386 \\ \mathrm{C} & 4.553826 & -0.930402 & 0.863041 \\ \mathrm{C} & 5.309397 & -0.106941 & 0.014654 \\ \mathrm{C} & 4.654131 & 0.804654 & -0.813017 \\ \mathrm{C} & 3.251292 & 0.880154 & -0.777026 \\ \mathrm{H} & 5.017137 & -1.655441 & 1.522867 \\ \mathrm{H} & 6.393012 & -0.179745 & 0.001248 \\ \mathrm{H} & 5.221335 & 1.446978 & -1.476730 \\ \mathrm{C} & 2.289277 & -1.630559 & 1.693238 \\ \mathrm{C} & 1.943642 & -3.224389 & 3.261375 \\ \mathrm{C} & 0.545085 & -3.007292 & 3.130000 \\ \mathrm{H} & 2.334653 & -3.964775 & 3.957322 \\ \mathrm{H} & -0.186648 & -3.560814 & 3.710952 \\ \mathrm{C} & 2.492186 & 1.817347 & -1.620348 \\ \mathrm{C} & 2.954307 & 2.764015 & -2.550838 \\ \mathrm{C} & 1.808803 & 3.372314 & -3.050717 \\ \mathrm{H} & 3.969970 & 2.992675 & -2.835914 \\ \mathrm{H} & 1.683323 & 4.156676 & -3.785427 \\ \mathrm{~N} & 2.811010 & -2.530878 & 2.537825 \\ \mathrm{~N} & 0.967698 & -1.413853 & 1.554047 \\ \mathrm{~N} & 0.081875 & -2.104199 & 2.273835 \\ \mathrm{~N} & 2.524908 & 0.089058 & 0.042126 \\ \mathrm{~N} & 1.131122 & 1.836084 & -1.547150 \\ \mathrm{~N} & 0.753462 & 2.797033 & -2.433121 \\ \mathrm{H} & -0.224693 & 3.020538 & -2.572873 \\ \mathrm{H} & 0.224504 & 3.020942 & 2.572436\end{array}$

$\mathrm{M}=\mathrm{Gd}$

$\begin{array}{lccc}\text { GD } & -0.000003 & -0.162034 & -0.000019 \\ \mathrm{C} & -3.206024 & 0.741829 & 0.727545 \\ \mathrm{C} & -4.595072 & 0.833934 & 0.693886 \\ \mathrm{C} & -5.289694 & -0.000852 & -0.195429 \\ \mathrm{C} & -4.575137 & -0.884043 & -1.007084 \\ \mathrm{C} & -3.175245 & -0.916986 & -0.910595 \\ \mathrm{H} & -5.108596 & 1.536633 & 1.340311 \\ \mathrm{H} & -6.373453 & 0.041330 & -0.253275 \\ \mathrm{H} & -5.096111 & -1.532814 & -1.701919 \\ \mathrm{C} & -2.376543 & 1.586116 & 1.619287 \\ \mathrm{C} & -2.122518 & 3.177769 & 3.202001\end{array}$




$\begin{array}{crrr}\mathrm{C} & -0.715045 & 2.999815 & 3.110742 \\ \mathrm{H} & -2.553125 & 3.902475 & 3.890791 \\ \mathrm{H} & -0.018334 & 3.573542 & 3.714874 \\ \mathrm{C} & -2.335391 & -1.811500 & -1.722400 \\ \mathrm{C} & -2.694094 & -2.769518 & -2.683397 \\ \mathrm{C} & -1.491812 & -3.315537 & -3.121064 \\ \mathrm{H} & -3.679705 & -3.044572 & -3.027443 \\ \mathrm{H} & -1.286280 & -4.085298 & -3.853418 \\ \mathrm{~N} & -2.952831 & 2.466984 & 2.450321 \\ \mathrm{~N} & -1.047377 & 1.399660 & 1.521372 \\ \mathrm{~N} & -0.194360 & 2.113298 & 2.271522 \\ \mathrm{~N} & -2.505656 & -0.116349 & -0.053930 \\ \mathrm{~N} & -0.979331 & -1.763496 & -1.570882 \\ \mathrm{~N} & -0.502612 & -2.696773 & -2.441087 \\ \mathrm{C} & 3.206060 & 0.741718 & -0.727531 \\ \mathrm{C} & 4.595110 & 0.833788 & -0.693838 \\ \mathrm{C} & 5.289687 & -0.000988 & 0.195521 \\ \mathrm{C} & 4.575086 & -0.884136 & 1.007185 \\ \mathrm{C} & 3.175196 & -0.917048 & 0.910657 \\ \mathrm{H} & 5.108669 & 1.536455 & -1.340271 \\ \mathrm{H} & 6.373445 & 0.041170 & 0.253397 \\ \mathrm{H} & 5.096024 & -1.532898 & 1.702055 \\ \mathrm{C} & 2.376625 & 1.585998 & -1.619322 \\ \mathrm{C} & 2.122682 & 3.177610 & -3.202090 \\ \mathrm{C} & 0.715202 & 2.999693 & -3.110865 \\ \mathrm{H} & 2.553326 & 3.902281 & -3.890894 \\ \mathrm{H} & 0.018521 & 3.573416 & -3.715037 \\ \mathrm{C} & 2.335297 & -1.811519 & 1.722464 \\ \mathrm{C} & 2.693948 & -2.769510 & 2.683506 \\ \mathrm{C} & 1.491644 & -3.315535 & 3.121105 \\ \mathrm{H} & 3.679542 & -3.044573 & 3.027594 \\ \mathrm{H} & 1.286073 & -4.085294 & 3.853448 \\ \mathrm{~N} & 2.952958 & 2.466827 & -2.450367 \\ \mathrm{~N} & 1.047452 & 1.399578 & -1.521437 \\ \mathrm{~N} & 0.194472 & 2.113215 & -2.271631 \\ \mathrm{~N} & 2.505650 & -0.116419 & 0.053951 \\ \mathrm{~N} & 0.979242 & -1.763474 & 1.570915 \\ \mathrm{~N} & 0.502473 & -2.696701 & 2.441147 \\ \mathrm{H} & 0.491625 & -2.871425 & -2.526522 \\ \mathrm{H} & -0.491773 & -2.871298 & 2.526586 \\ & & & \end{array}$

$\mathrm{M}=\mathrm{Am}$
AM $\quad 0.000000 \quad 0.181114 \quad-0.000003$
$\begin{array}{llll}\text { C } & -3.206660 & -0.795139 & -0.797700\end{array}$
$\begin{array}{llll}\text { C } & -4.593850 & -0.911423 & -0.799763\end{array}$ 


$\begin{array}{rrrr}\mathrm{C} & -5.328260 & -0.085266 & 0.064011 \\ \mathrm{C} & -4.650580 & 0.814721 & 0.886349 \\ \mathrm{C} & -3.249271 & 0.874748 & 0.829498 \\ \mathrm{H} & -5.075267 & -1.627417 & -1.456144 \\ \mathrm{H} & -6.412204 & -0.146641 & 0.092969 \\ \mathrm{H} & -5.200716 & 1.459687 & 1.561736 \\ \mathrm{C} & -2.351139 & -1.632273 & -1.668995 \\ \mathrm{C} & -2.046332 & -3.224481 & -3.241777 \\ \mathrm{C} & -0.643740 & -3.023249 & -3.127042 \\ \mathrm{H} & -2.453716 & -3.958204 & -3.935005 \\ \mathrm{H} & 0.072459 & -3.586205 & -3.718034 \\ \mathrm{C} & -2.466336 & 1.798109 & 1.663327 \\ \mathrm{C} & -2.893067 & 2.746454 & 2.607693 \\ \mathrm{C} & -1.727074 & 3.334554 & 3.084752 \\ \mathrm{H} & -3.898387 & 2.989185 & 2.917083 \\ \mathrm{H} & -1.573493 & 4.112986 & 3.820432 \\ \mathrm{~N} & -2.900207 & -2.524644 & -2.506732 \\ \mathrm{~N} & -1.029692 & -1.426814 & -1.547616 \\ \mathrm{~N} & -0.153129 & -2.127729 & -2.280612 \\ \mathrm{~N} & -2.539958 & 0.080396 & -0.003012 \\ \mathrm{~N} & -1.109011 & 1.796961 & 1.559950 \\ \mathrm{~N} & -0.694420 & 2.747246 & 2.442000 \\ \mathrm{C} & 3.206656 & -0.795151 & 0.797702 \\ \mathrm{C} & 4.593845 & -0.911439 & 0.799768 \\ \mathrm{C} & 5.328261 & -0.085286 & -0.064004 \\ \mathrm{C} & 4.650585 & 0.814703 & -0.886344 \\ \mathrm{C} & 3.249276 & 0.874735 & -0.829497 \\ \mathrm{H} & 5.075258 & -1.627435 & 1.456151 \\ \mathrm{H} & 6.412204 & -0.146665 & -0.092959 \\ \mathrm{H} & 5.200726 & 1.459667 & -1.561730 \\ \mathrm{C} & 2.351130 & -1.632280 & 1.668997 \\ \mathrm{C} & 2.046313 & -3.224486 & 3.241779 \\ \mathrm{C} & 0.643723 & -3.023247 & 3.127044 \\ \mathrm{H} & 2.453693 & -3.958210 & 3.935009 \\ \mathrm{H} & -0.072479 & -3.586199 & 3.718035 \\ \mathrm{C} & 2.466347 & 1.798099 & -1.663328 \\ \mathrm{C} & 2.893084 & 2.746453 & -2.607682 \\ \mathrm{C} & 1.727095 & 3.334559 & -3.084741 \\ \mathrm{H} & 3.898406 & 2.989186 & -2.917065 \\ \mathrm{H} & 1.573519 & 4.112999 & -3.820415 \\ \mathrm{~N} & 2.900192 & -2.524653 & 2.506735 \\ \mathrm{~N} & 1.029684 & -1.426815 & 1.547616 \\ \mathrm{~N} & 0.153117 & -2.127725 & 2.280612 \\ \mathrm{~N} & 2.539958 & 0.080386 & 0.003012 \\ \mathrm{~N} & 1.109022 & 1.796952 & -1.559958 \\ \mathrm{~N} & 0.694437 & 2.747248 & -2.442000 \\ & & & \end{array}$




$$
\begin{array}{crrc}
\mathrm{H} & 0.289816 & 2.955660 & 2.560063 \\
\mathrm{H} & -0.289798 & 2.955663 & -2.560068
\end{array}
$$

$\mathrm{M}=\mathrm{Cm}$

$\begin{array}{lrrr}\mathrm{CM} & 0.000047 & -0.155790 & -0.000284 \\ \mathrm{C} & 3.248660 & 0.768593 & -0.731256 \\ \mathrm{C} & 4.637722 & 0.868097 & -0.699615 \\ \mathrm{C} & 5.338437 & 0.035696 & 0.186453 \\ \mathrm{C} & 4.630005 & -0.853524 & 0.996324 \\ \mathrm{C} & 3.230139 & -0.893979 & 0.902256 \\ \mathrm{H} & 5.146799 & 1.574383 & -1.345460 \\ \mathrm{H} & 6.422026 & 0.083800 & 0.242523 \\ \mathrm{H} & 5.156150 & -1.501753 & 1.687679 \\ \mathrm{C} & 2.419615 & 1.611367 & -1.625520 \\ \mathrm{C} & 2.181283 & 3.205822 & -3.209870 \\ \mathrm{C} & 0.773218 & 3.028454 & -3.131545 \\ \mathrm{H} & 2.619328 & 3.930828 & -3.893559 \\ \mathrm{H} & 0.081647 & 3.602581 & -3.740969 \\ \mathrm{C} & 2.402182 & -1.799875 & 1.714353 \\ \mathrm{C} & 2.779059 & -2.754189 & 2.672260 \\ \mathrm{C} & 1.587450 & -3.318562 & 3.114972 \\ \mathrm{H} & 3.769963 & -3.015500 & 3.011607 \\ \mathrm{H} & 1.397305 & -4.092560 & 3.846907 \\ \mathrm{~N} & 3.003301 & 2.493662 & -2.450911 \\ \mathrm{~N} & 1.090041 & 1.425680 & -1.539879 \\ \mathrm{~N} & 0.245298 & 2.142057 & -2.298241 \\ \mathrm{~N} & 2.555385 & -0.094255 & 0.049924 \\ \mathrm{~N} & 1.045654 & -1.772516 & 1.569765 \\ \mathrm{~N} & 0.586273 & -2.713578 & 2.441373 \\ \mathrm{C} & -3.248421 & 0.768834 & 0.732692 \\ \mathrm{C} & -4.637469 & 0.868691 & 0.701663 \\ \mathrm{C} & -5.338664 & 0.037487 & -0.185156 \\ \mathrm{C} & -4.630701 & -0.850953 & -0.996305 \\ \mathrm{C} & -3.230821 & -0.891894 & -0.902705 \\ \mathrm{H} & -5.146163 & 1.574317 & 1.348528 \\ \mathrm{H} & -6.422260 & 0.085909 & -0.240822 \\ \mathrm{H} & -5.157222 & -1.498246 & -1.688250 \\ \mathrm{C} & -2.418776 & 1.610478 & 1.627433 \\ \mathrm{C} & -2.179209 & 3.203072 & 3.213435 \\ \mathrm{C} & -0.771220 & 3.025561 & 3.134010 \\ \mathrm{H} & -2.616702 & 3.927374 & 3.898224 \\ \mathrm{C} & -0.079171 & 3.598859 & 3.743672 \\ \mathrm{C} & -2.403332 & -1.797081 & -1.716076 \\ & -1.589507 & -3.314469 & -3.118633\end{array}$




$\begin{array}{lrrl}\mathrm{H} & -3.771879 & -3.010762 & -3.014341 \\ \mathrm{H} & -1.399830 & -4.087719 & -3.851480 \\ \mathrm{~N} & -3.001825 & 2.491904 & 2.454201 \\ \mathrm{~N} & -1.089290 & 1.424696 & 1.540685 \\ \mathrm{~N} & -0.243955 & 2.140057 & 2.299341 \\ \mathrm{~N} & -2.555616 & -0.093295 & -0.049686 \\ \mathrm{~N} & -1.046744 & -1.770381 & -1.571796 \\ \mathrm{~N} & -0.587941 & -2.710639 & -2.444578 \\ \mathrm{H} & -0.404742 & -2.903398 & 2.530351 \\ \mathrm{H} & 0.402978 & -2.900754 & -2.533992\end{array}$

$L=\mathbf{2 a e}$

$\left[\mathrm{ML}\left(\mathrm{H}_{2} \mathrm{O}\right)_{6}\right]^{3+}$

$\mathrm{M}=\mathrm{Eu}$

$\begin{array}{lccc}\text { EU } & 0.749762 & -1.095597 & -0.060637 \\ \mathrm{O} & -0.801445 & -2.361346 & -1.687276 \\ \mathrm{H} & -1.759030 & -2.387664 & -1.514075 \\ \mathrm{O} & 0.944270 & -0.248492 & -2.515588 \\ \mathrm{H} & 0.247339 & -0.459851 & -3.158584 \\ \mathrm{O} & 2.238630 & -2.685274 & 1.354579 \\ \mathrm{H} & 2.347518 & -2.380316 & 2.271232 \\ \mathrm{O} & 2.162247 & -2.624337 & -1.618019 \\ \mathrm{H} & 2.616945 & -3.481587 & -1.609361 \\ \mathrm{O} & -0.784690 & -2.538538 & 1.364946 \\ \mathrm{H} & -0.690190 & -3.404939 & 1.790703 \\ \mathrm{O} & 0.891772 & -0.451343 & 2.452524 \\ \mathrm{H} & 0.200691 & -0.743768 & 3.069457 \\ \mathrm{H} & -0.589346 & -3.152541 & -2.208373 \\ \mathrm{H} & 2.339358 & -2.232038 & -2.489618 \\ \mathrm{H} & -1.728738 & -2.415834 & 1.137841 \\ \mathrm{H} & 2.651803 & -3.562142 & 1.310334 \\ \mathrm{H} & 1.316245 & 0.318395 & 2.865105 \\ \mathrm{H} & 1.403050 & 0.534809 & -2.860373 \\ \mathrm{C} & 1.654993 & 2.269462 & 0.015787 \\ \mathrm{C} & 1.594057 & 3.673643 & 0.016897 \\ \mathrm{C} & 0.349240 & 4.300190 & 0.012922 \\ \mathrm{H} & 2.505037 & 4.260995 & 0.021990 \\ \mathrm{C} & -0.662638 & 2.122151 & 0.010841 \\ \mathrm{C} & -0.806397 & 3.509559 & 0.010492 \\ \mathrm{H} & 0.277294 & 5.383781 & 0.013453 \\ \mathrm{H} & -1.797956 & 3.945904 & 0.010112 \\ \mathrm{C} & -1.854212 & 1.241646 & 0.021093\end{array}$




\begin{tabular}{|c|c|c|c|}
\hline $\mathrm{C}$ & -4.148530 & 0.999192 & 0.030757 \\
\hline & -3.950371 & -0.441686 & 0.077264 \\
\hline $\mathrm{N}$ & 0.540076 & 1.504463 & 0.011254 \\
\hline $\mathrm{N}$ & -3.077285 & 1.777024 & 0.009684 \\
\hline N & -1.647333 & -0.083588 & 0.046467 \\
\hline J & -2.701015 & -0.898845 & 0.082738 \\
\hline c & -5.522578 & 1.640736 & -0.044894 \\
\hline C & -6.625412 & 0.621456 & 0.310851 \\
\hline $\mathrm{H}$ & -6.708504 & 0.537566 & 1.398840 \\
\hline H & -7.583726 & 1.021912 & -0.031277 \\
\hline C & -6.404362 & -0.759660 & -0.312967 \\
\hline C & -5.095137 & -1.438292 & 0.161229 \\
\hline $\mathrm{H}$ & -6.399791 & -0.686418 & -1.405618 \\
\hline H & -7.239805 & -1.416662 & -0.057082 \\
\hline $\mathrm{C}$ & -5.589100 & 2.852520 & 0.913928 \\
\hline H & -4.871790 & 3.626814 & 4651 \\
\hline $\mathrm{H}$ & -6.592501 & 3.282837 & 0.864527 \\
\hline $\mathrm{H}$ & -5.404263 & 2.558596 & 1.951550 \\
\hline $\mathrm{C}$ & -5.681108 & 2.141900 & -1.513697 \\
\hline H & -6.643780 & 2.652495 & -1.598323 \\
\hline $\mathrm{H}$ & -4.892249 & 2.853249 & -1.770639 \\
\hline $\mathrm{H}$ & -5.667701 & 1.326623 & -2.242059 \\
\hline $\mathrm{C}$ & -5.216259 & -1.887152 & 1.644157 \\
\hline H & -6.037832 & -2.602103 & 1.735916 \\
\hline $\mathrm{H}$ & -4.300528 & -2.383617 & 1.982464 \\
\hline $\mathrm{H}$ & -5.419439 & -1.055276 & 2.322601 \\
\hline $\mathrm{C}$ & -4.813441 & -2.671324 & -0.724902 \\
\hline $\mathrm{H}$ & -3.952914 & -3.245970 & -0.366457 \\
\hline $\mathrm{H}$ & -5.678269 & -3.338669 & -0.699333 \\
\hline $\mathrm{H}$ & -4.651338 & -2.389068 & -1.770661 \\
\hline $\mathrm{C}$ & 2.940960 & 1.556220 & 0.025513 \\
\hline $\mathrm{C}$ & 4.255455 & 2.057380 & 0.050115 \\
\hline $\mathrm{C}$ & 5.068524 & 0.930131 & 0.060681 \\
\hline $\mathrm{H}$ & 4.609624 & 3.077427 & 0.062100 \\
\hline $\mathrm{N}$ & 2.942272 & 0.197606 & 0.019811 \\
\hline $\mathrm{N}$ & 4.247681 & -0.149428 & 0.042255 \\
\hline $\mathrm{H}$ & 4.538055 & -1.120512 & 0.050418 \\
\hline $\mathrm{C}$ & 6.564058 & 0.850219 & 0.089015 \\
\hline $\mathrm{O}$ & 7.252156 & 1.845788 & 0.106604 \\
\hline $\mathrm{O}$ & 6.971224 & -0.428358 & 0.091567 \\
\hline $\mathrm{C}$ & 8.428572 & -0.626267 & 0.119867 \\
\hline $\mathrm{H}$ & 8.837420 & -0.175151 & 1.024579 \\
\hline 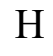 & 8.569109 & -1.705225 & 0.117829 \\
\hline $\mathrm{H}$ & 8.87 & -0.167023 & -0.763 \\
\hline
\end{tabular}

$\mathrm{M}=\mathrm{Gd}$ 


$\begin{array}{lrrc}\text { GD } & 0.741034 & -1.021085 & -0.052973 \\ \mathrm{~N} & 2.901910 & 0.200103 & 0.016262 \\ \mathrm{~N} & 4.200390 & -0.180277 & 0.025646 \\ \mathrm{C} & 2.933701 & 1.560234 & 0.038497 \\ \mathrm{C} & 5.044011 & 0.879569 & 0.052365 \\ \mathrm{H} & 4.468657 & -1.157630 & 0.021146 \\ \mathrm{C} & 4.258008 & 2.027644 & 0.060688 \\ \mathrm{C} & 1.657186 & 2.287330 & 0.041013 \\ \mathrm{C} & 6.538856 & 0.765459 & 0.070063 \\ \mathrm{H} & 4.635714 & 3.039242 & 0.082162 \\ \mathrm{C} & 1.592730 & 3.688146 & 0.058707 \\ \mathrm{~N} & 0.544904 & 1.515425 & 0.027662 \\ \mathrm{O} & 6.915896 & -0.521803 & 0.057764 \\ \mathrm{O} & 7.246969 & 1.746140 & 0.092273 \\ \mathrm{C} & 0.342359 & 4.307633 & 0.061125 \\ \mathrm{H} & 2.501092 & 4.279709 & 0.070623 \\ \mathrm{C} & -0.663759 & 2.125603 & 0.031076 \\ \mathrm{C} & 8.369466 & -0.753459 & 0.074248 \\ \mathrm{C} & -0.810281 & 3.512649 & 0.046649 \\ \mathrm{H} & 0.265117 & 5.390821 & 0.074816 \\ \mathrm{C} & -1.847777 & 1.229445 & 0.026644 \\ \mathrm{H} & 8.818004 & -0.296320 & -0.808317 \\ \mathrm{H} & 8.793965 & -0.319731 & 0.980206 \\ \mathrm{H} & 8.485040 & -1.835258 & 0.061690 \\ \mathrm{H} & -1.803760 & 3.943909 & 0.049310 \\ \mathrm{~N} & -3.070011 & 1.772617 & 0.013555 \\ \mathrm{H} & -1.604374 & -0.083907 & 0.037466 \\ \mathrm{C} & -4.126625 & 0.963049 & 0.022588 \\ \mathrm{~N} & -2.657485 & -0.932648 & 0.072196 \\ \mathrm{C} & -5.502750 & 1.583467 & -0.074831 \\ \mathrm{C} & -3.904591 & -0.472583 & 0.071964 \\ \mathrm{C} & -6.598828 & 0.553460 & 0.279676 \\ \mathrm{C} & -5.608413 & 2.811373 & 0.858843 \\ \mathrm{C} & -5.654754 & 2.061857 & -1.553001 \\ \mathrm{C} & -5.037968 & -1.485535 & 0.168297 \\ \mathrm{C} & -6.351507 & -0.830921 & -0.323804 \\ \mathrm{H} & -7.557826 & 0.939618 & -0.075069 \\ \mathrm{H} & -6.691295 & 0.480377 & 1.367865 \\ \mathrm{H} & -6.620518 & 3.217936 & 0.789250 \\ & -5.431103 & 2.538934 & 1.903787 \\ \mathrm{H} & -4.907361 & 3.598630 & 0.577362 \\ \mathrm{H} & -6.621326 & 1.236007 & -2.269045 \\ \mathrm{H} & 2.781361 & -1.812337 \\ \mathrm{H} & -2.737778 & -0.683602\end{array}$




$\begin{array}{rrrr}\mathrm{C} & -5.160326 & -1.900972 & 1.661360 \\ \mathrm{H} & -7.179394 & -1.497836 & -0.067985 \\ \mathrm{H} & -6.338825 & -0.770857 & -1.417490 \\ \mathrm{H} & -3.887286 & -3.307995 & -0.305957 \\ \mathrm{H} & -4.569758 & -2.479811 & -1.734332 \\ \mathrm{H} & -5.607126 & -3.404806 & -0.653483 \\ \mathrm{H} & -5.977541 & -2.618981 & 1.767761 \\ \mathrm{H} & -4.242567 & -2.383586 & 2.014134 \\ \mathrm{H} & -5.371618 & -1.055166 & 2.319901 \\ \mathrm{O} & 0.847367 & -0.190890 & -2.447685 \\ \mathrm{H} & 1.238427 & 0.625752 & -2.799392 \\ \mathrm{H} & 0.144838 & -0.451674 & -3.066912 \\ \mathrm{O} & -0.774615 & -2.312353 & -1.632890 \\ \mathrm{H} & -0.614451 & -3.131706 & -2.128313 \\ \mathrm{H} & -1.723870 & -2.295542 & -1.402620 \\ \mathrm{O} & 0.833701 & -0.401009 & 2.393861 \\ \mathrm{H} & 0.137905 & -0.729302 & 2.988100 \\ \mathrm{H} & 1.205525 & 0.392547 & 2.812857 \\ \mathrm{O} & -0.752121 & -2.469444 & 1.322778 \\ \mathrm{H} & -0.685732 & -3.355962 & 1.710511 \\ \mathrm{H} & -1.689578 & -2.313713 & 1.059666 \\ \mathrm{O} & 2.215747 & -2.600479 & 1.326171 \\ \mathrm{H} & 2.578218 & -3.499406 & 1.272162 \\ \mathrm{H} & 2.345333 & -2.312609 & 2.246058 \\ \mathrm{O} & 2.154331 & -2.505683 & -1.588987 \\ \mathrm{H} & 2.588574 & -3.373764 & -1.579030 \\ \mathrm{H} & 2.320443 & -2.129653 & -2.470259\end{array}$

$\mathrm{M}=\mathrm{Am}$

$\begin{array}{lccc}\mathrm{AM} & -0.675065 & -0.957272 & 0.109544 \\ \mathrm{O} & 0.899535 & -2.146006 & 1.792991 \\ \mathrm{H} & 1.847873 & -2.172532 & 1.569250 \\ \mathrm{O} & -0.897500 & -0.099643 & 2.561121 \\ \mathrm{H} & -0.178390 & -0.290767 & 3.186866 \\ \mathrm{O} & -2.226878 & -2.566305 & -1.280720 \\ \mathrm{H} & -2.583443 & -3.468112 & -1.232518 \\ \mathrm{O} & -2.084566 & -2.491518 & 1.693538 \\ \mathrm{H} & -2.544895 & -3.346148 & 1.672809 \\ \mathrm{O} & 0.846426 & -2.487977 & -1.240319 \\ \mathrm{H} & 0.818792 & -3.382340 & -1.614122 \\ \mathrm{O} & -0.774899 & -0.419746 & -2.445341 \\ \mathrm{H} & -0.066580 & -0.751145 & -3.022667 \\ \mathrm{H} & 0.710323 & -2.947651 & 2.307853 \\ \mathrm{H} & -2.265586 & -2.106502 & 2.567948 \\ \mathrm{H} & 1.779294 & -2.275032 & -0.994105\end{array}$




$\begin{array}{lrrr}\mathrm{H} & -2.280298 & -2.304745 & -2.216029 \\ \mathrm{H} & -1.154338 & 0.354392 & -2.893230 \\ \mathrm{H} & -1.350172 & 0.692003 & 2.896192 \\ \mathrm{C} & -1.584200 & 2.380425 & 0.008161 \\ \mathrm{C} & -1.513148 & 3.780936 & 0.023024 \\ \mathrm{C} & -0.261842 & 4.396881 & 0.038323 \\ \mathrm{H} & -2.419189 & 4.375945 & 0.018695 \\ \mathrm{C} & 0.737316 & 2.212376 & 0.014036 \\ \mathrm{C} & 0.888032 & 3.598350 & 0.029450 \\ \mathrm{H} & -0.181599 & 5.479834 & 0.050618 \\ \mathrm{H} & 1.882706 & 4.026716 & 0.029833 \\ \mathrm{C} & 1.921260 & 1.318010 & -0.022125 \\ \mathrm{C} & 4.200276 & 1.051440 & -0.065951 \\ \mathrm{C} & 3.977554 & -0.382098 & -0.147090 \\ \mathrm{~N} & -0.473835 & 1.605132 & 0.012159 \\ \mathrm{~N} & 3.143646 & 1.860095 & -0.013247 \\ \mathrm{~N} & 1.679652 & 0.004808 & -0.070439 \\ \mathrm{~N} & 2.730272 & -0.841910 & -0.142747 \\ \mathrm{C} & 5.578283 & 1.670422 & 0.013837 \\ \mathrm{C} & 6.663942 & 0.648905 & -0.393294 \\ \mathrm{H} & 6.724796 & 0.598349 & -1.485062 \\ \mathrm{H} & 7.632717 & 1.028312 & -0.058421 \\ \mathrm{C} & 6.433847 & -0.747556 & 0.188692 \\ \mathrm{C} & 5.108164 & -1.394435 & -0.280782 \\ \mathrm{H} & -4.989208 & 1.025884 & -0.127478 \\ \mathrm{H} & 6.450690 & -0.708714 & 1.283262 \\ \mathrm{H} & 7.255254 & -1.408096 & -0.102097 \\ \mathrm{C} & 5.660793 & 2.919909 & -0.893294 \\ \mathrm{H} & 4.967611 & 3.700375 & -0.575655 \\ \mathrm{H} & 6.674504 & 3.324955 & -0.840080 \\ \mathrm{H} & 5.456779 & 2.672033 & -1.939474 \\ \mathrm{C} & 5.767405 & 2.113908 & 1.498389 \\ \mathrm{H} & 6.738690 & 2.606599 & 1.588840 \\ \mathrm{H} & 4.993789 & 2.826993 & 1.793926 \\ \mathrm{H} & 5.751371 & 1.271621 & 2.195597 \\ \mathrm{C} & 5.196547 & -1.795357 & -1.779951 \\ \mathrm{H} & 6.005488 & -2.518647 & -1.910816 \\ \mathrm{H} & 4.267619 & -2.265625 & -2.119606 \\ \mathrm{H} & 5.401892 & -0.943707 & -2.432876 \\ \mathrm{H} & 3.961521 & -3.216729 & 0.208007 \\ \mathrm{H} & -2.177118 & -0.059723\end{array}$




$\begin{array}{lrrr}\mathrm{N} & -2.859970 & 0.310664 & -0.063283 \\ \mathrm{~N} & -4.163204 & -0.047594 & -0.122647 \\ \mathrm{C} & -6.484322 & 0.938894 & -0.191183 \\ \mathrm{O} & -7.175463 & 1.932045 & -0.189963 \\ \mathrm{O} & -6.882765 & -0.340597 & -0.245875 \\ \mathrm{C} & -8.338450 & -0.546201 & -0.314778 \\ \mathrm{H} & -8.728779 & -0.066830 & -1.213084 \\ \mathrm{H} & -8.471420 & -1.625415 & -0.352674 \\ \mathrm{H} & -8.805982 & -0.119773 & 0.573303 \\ \mathrm{H} & -4.444162 & -1.020245 & -0.173448\end{array}$

$\mathrm{M}=\mathrm{Cm}$

$\begin{array}{lrcc}\mathrm{CM} & 0.684423 & -0.956122 & 0.205678 \\ \mathrm{O} & 2.172462 & -2.453889 & 1.814334 \\ \mathrm{H} & 3.119192 & -2.607464 & 1.967397 \\ \mathrm{O} & 0.918330 & 0.037205 & 2.603071 \\ \mathrm{H} & 1.580455 & -0.318412 & 3.218465 \\ \mathrm{O} & -0.890130 & -2.611663 & -0.787974 \\ \mathrm{H} & -0.917347 & -3.443583 & -1.283701 \\ \mathrm{O} & -0.611304 & -2.274947 & 2.054276 \\ \mathrm{H} & -1.272427 & -2.960061 & 1.862319 \\ \mathrm{O} & 2.228125 & -2.596089 & -1.085983 \\ \mathrm{H} & 2.500985 & -3.492991 & -0.831558 \\ \mathrm{O} & 0.679008 & -0.505331 & -2.325816 \\ \mathrm{H} & 1.124777 & 0.236003 & -2.768357 \\ \mathrm{H} & 1.696703 & -3.085181 & 2.380568 \\ \mathrm{H} & -0.847288 & -1.892192 & 2.915567 \\ \mathrm{H} & 2.260079 & -2.561186 & -2.056949 \\ \mathrm{H} & -1.818670 & -2.230421 & -0.701426 \\ \mathrm{H} & -0.037748 & -0.784702 & -2.919165 \\ \mathrm{H} & 0.721377 & 0.937420 & 2.909165 \\ \mathrm{C} & 1.561581 & 2.377329 & 0.134456 \\ \mathrm{C} & 1.487663 & 3.772858 & 0.247736 \\ \mathrm{C} & 0.234112 & 4.379695 & 0.339766 \\ \mathrm{H} & 2.390705 & 4.372404 & 0.257146 \\ \mathrm{C} & -0.761863 & 2.198813 & 0.183010 \\ \mathrm{C} & -0.915011 & 3.580509 & 0.298189 \\ \mathrm{H} & 0.151513 & 5.458871 & 0.429973 \\ \mathrm{H} & -1.910050 & 4.005705 & 0.343821 \\ \mathrm{C} & -1.943676 & 1.302663 & 0.075569 \\ \mathrm{C} & -4.216655 & 1.043712 & -0.095184 \\ \mathrm{C} & -3.986492 & -0.373984 & -0.301015 \\ \mathrm{~N} & 0.451971 & 1.600775 & 0.119023 \\ \mathrm{~N} & -3.164521 & 1.845746 & 0.065407 \\ \mathrm{~N} & -1.697949 & -0.006340 & -0.042547\end{array}$




$\begin{array}{lrrr}\mathrm{N} & -2.740807 & -0.834723 & -0.257405 \\ \mathrm{C} & -5.592629 & 1.673351 & -0.112975 \\ \mathrm{C} & -6.693123 & 0.590475 & -0.054708 \\ \mathrm{H} & -6.838642 & 0.272114 & 0.982589 \\ \mathrm{H} & -7.638112 & 1.045855 & -0.361502 \\ \mathrm{C} & -6.395930 & -0.620279 & -0.942037 \\ \mathrm{C} & -5.111063 & -1.377301 & -0.528629 \\ \mathrm{H} & -6.313140 & -0.310526 & -1.989475 \\ \mathrm{H} & -7.232349 & -1.323229 & -0.900747 \\ \mathrm{C} & -5.742780 & 2.647400 & 1.079854 \\ \mathrm{H} & -5.029287 & 3.471318 & 1.023906 \\ \mathrm{H} & -6.750677 & 3.069755 & 1.062753 \\ \mathrm{H} & -5.614932 & 2.133966 & 2.038009 \\ \mathrm{C} & -5.690750 & 2.485790 & -1.440806 \\ \mathrm{H} & -6.657487 & 2.994831 & -1.462776 \\ \mathrm{H} & -4.904080 & 3.242018 & -1.495315 \\ \mathrm{H} & -5.624947 & 1.849745 & -2.327744 \\ \mathrm{C} & -5.332542 & -2.141599 & 0.805797 \\ \mathrm{H} & -6.140259 & -2.866237 & 0.675048 \\ \mathrm{H} & -4.430914 & -2.691666 & 1.095065 \\ \mathrm{H} & -5.608348 & -1.480183 & 1.630792 \\ \mathrm{C} & -4.737827 & -2.388115 & -1.634167 \\ \mathrm{H} & -3.920749 & -3.051430 & -1.333470 \\ \mathrm{H} & -5.601923 & -3.024004 & -1.842259 \\ \mathrm{H} & -4.466748 & -1.887482 & -2.568984 \\ \mathrm{C} & 2.843697 & 1.673380 & -0.013075 \\ \mathrm{C} & 4.153893 & 2.174664 & -0.094734 \\ \mathrm{C} & 4.956269 & 1.055927 & -0.292113 \\ \mathrm{H} & 4.511442 & 3.192026 & -0.036640 \\ \mathrm{~N} & 2.836919 & 0.319842 & -0.145630 \\ \mathrm{~N} & 4.136106 & -0.022566 & -0.312899 \\ \mathrm{H} & 4.412216 & -0.981043 & -0.494384 \\ \mathrm{C} & 6.443244 & 0.985753 & -0.467588 \\ \mathrm{O} & 7.131517 & 1.980241 & -0.436801 \\ \mathrm{O} & 6.838682 & -0.283074 & -0.651417 \\ \mathrm{C} & 8.285700 & -0.471761 & -0.844731 \\ \mathrm{H} & 8.417094 & -1.543531 & -0.978456 \\ \mathrm{H} & 8.606714 & 0.080169 & -1.728687 \\ & 8.817780 & -0.113418 & 0.037075\end{array}$

\section{$\left[\mathrm{ML}\left(\mathrm{H}_{2} \mathrm{O}\right)_{5}\right]^{3+}$}

$\mathrm{M}=\mathrm{Eu}$

$\begin{array}{llll}\text { EU } & 0.762148 & -1.127455 & 0.067519\end{array}$

$\begin{array}{llll}\mathrm{N} & 2.958316 & 0.146897 & 0.014197\end{array}$ 


\begin{tabular}{|c|c|c|c|}
\hline $\mathrm{C}$ & 2.959098 & 1.508024 & -0.022935 \\
\hline N & 4.265948 & -0.202236 & -0.003611 \\
\hline $\mathrm{C}$ & 4.273788 & 2.004532 & -0.062925 \\
\hline $\mathrm{C}$ & 1.675252 & 2.226759 & -0.011454 \\
\hline $\mathrm{C}$ & 5.086059 & 0.875743 & -0.049038 \\
\hline H & 4.629628 & 3.023457 & -0.100503 \\
\hline $\mathrm{C}$ & 1.619821 & 3.630701 & 0.002722 \\
\hline $\mathrm{N}$ & 0.557881 & 1.465918 & -0.003841 \\
\hline $\mathrm{C}$ & 6.582679 & 0.794527 & -0.075581 \\
\hline $\mathrm{C}$ & 0.377093 & 4.261302 & 0.033747 \\
\hline $\mathrm{H}$ & 2.532256 & 4.215744 & -0.005798 \\
\hline $\mathrm{C}$ & -0.642313 & 2.087302 & 0.029047 \\
\hline $\mathrm{O}$ & 6.988148 & -0.483176 & -0.062289 \\
\hline $\mathrm{O}$ & 7.269125 & 1.791009 & -0.103456 \\
\hline $\mathrm{C}$ & -0.781443 & 3.475004 & 0.050993 \\
\hline $\mathrm{H}$ & 0.309161 & 5.345088 & 0.045816 \\
\hline $\mathrm{C}$ & -1.835885 & 1.209968 & 0.026696 \\
\hline $\mathrm{C}$ & 8.445937 & -0.685004 & -0.080317 \\
\hline $\mathrm{H}$ & -1.770537 & 3.916260 & 0.076269 \\
\hline $\mathrm{N}$ & -3.058682 & 1.742439 & 0.032834 \\
\hline $\mathrm{N}$ & -1.637205 & -0.119129 & -0.004024 \\
\hline $\mathrm{H}$ & 8.860167 & -0.245043 & -0.988052 \\
\hline $\mathrm{H}$ & 8.886107 & -0.216787 & 0.800647 \\
\hline $\mathrm{H}$ & 8.583110 & -1.764214 & -0.064916 \\
\hline $\mathrm{C}$ & -4.133347 & 0.971861 & 0.012537 \\
\hline $\mathrm{N}$ & -2.692624 & -0.924788 & -0.067896 \\
\hline $\mathrm{C}$ & -5.506004 & 1.623211 & -0.012029 \\
\hline $\mathrm{C}$ & -3.941496 & -0.470916 & -0.052913 \\
\hline $\mathrm{C}$ & -6.617688 & 0.582805 & 0.233465 \\
\hline $\mathrm{C}$ & -5.567659 & 2.734176 & 1.063911 \\
\hline $\mathrm{C}$ & -5.649544 & 2.267321 & -1.425639 \\
\hline $\mathrm{C}$ & -5.091813 & -1.462020 & -0.066917 \\
\hline $\mathrm{C}$ & -6.389733 & -0.740156 & -0.505423 \\
\hline $\mathrm{H}$ & -7.568285 & 1.015196 & -0.091411 \\
\hline $\mathrm{H}$ & -6.722617 & 0.403946 & 1.307779 \\
\hline $\mathrm{H}$ & -6.566062 & 3.178486 & 1.049282 \\
\hline $\mathrm{H}$ & -5.395631 & 2.336429 & 2.068565 \\
\hline $\mathrm{H}$ & -4.838313 & 3.522952 & 0.867384 \\
\hline $\mathrm{H}$ & -6.607541 & 2.792007 & -1.464659 \\
\hline $\mathrm{H}$ & -5.638286 & 1.526584 & -2.229519 \\
\hline $\mathrm{H}$ & -4.852447 & 2.992383 & -1.607386 \\
\hline $\mathrm{C}$ & -4.803742 & -2.625209 & -1.041456 \\
\hline $\mathrm{C}$ & -5.231631 & -2.024287 & 1.375865 \\
\hline $\mathrm{H}$ & -7.231823 & -1.412208 & -0.320721 \\
\hline $\mathrm{H}$ & -6.365173 & -0.573281 & -1.587466 \\
\hline $\mathrm{H}$ & -3.975459 & -3.250253 & -0.691683 \\
\hline
\end{tabular}




$\begin{array}{crrr}\mathrm{H} & -4.587984 & -2.267689 & -2.053010 \\ \mathrm{H} & -5.684934 & -3.268501 & -1.100494 \\ \mathrm{H} & -6.056296 & -2.741283 & 1.399910 \\ \mathrm{H} & -4.318518 & -2.544672 & 1.680909 \\ \mathrm{H} & -5.443092 & -1.247201 & 2.114190 \\ \mathrm{O} & 0.987839 & -0.786216 & -2.431501 \\ \mathrm{H} & 0.409266 & -1.159322 & -3.116594 \\ \mathrm{H} & 1.533935 & -0.120185 & -2.880805 \\ \mathrm{O} & -0.874266 & -2.762618 & -0.899127 \\ \mathrm{H} & -0.914898 & -3.571482 & -1.432686 \\ \mathrm{H} & -1.797799 & -2.457452 & -0.717795 \\ \mathrm{O} & 0.535925 & -3.110445 & 1.669583 \\ \mathrm{H} & 0.926341 & -3.242108 & 2.549601 \\ \mathrm{H} & -0.036639 & -3.878902 & 1.510121 \\ \mathrm{O} & 1.070782 & -0.427250 & 2.520856 \\ \mathrm{H} & 0.486742 & -0.542922 & 3.288527 \\ \mathrm{H} & 1.758232 & 0.195377 & 2.810662 \\ \mathrm{H} & 2.658730 & -3.734266 & -0.243723 \\ \mathrm{O} & 2.481738 & -2.883109 & -0.678366 \\ \mathrm{H} & 2.833627 & -2.965609 & -1.580739 \\ \mathrm{H} & 4.555415 & -1.174003 & 0.021240\end{array}$

\section{$\mathrm{M}=\mathrm{Gd}$}

$\begin{array}{lrrl}\text { GD } & 0.755525 & -1.037183 & 0.086613 \\ \mathrm{O} & 1.449006 & -2.898245 & 1.707341 \\ \mathrm{H} & 0.897042 & -3.680436 & 1.880060 \\ \mathrm{O} & -0.831796 & -2.766498 & -0.302986 \\ \mathrm{H} & -0.903140 & -3.675893 & -0.631178 \\ \mathrm{O} & 2.262039 & -2.694287 & -1.085418 \\ \mathrm{H} & 2.450461 & -2.657378 & -2.038672 \\ \mathrm{O} & 0.547566 & -0.322911 & 2.440196 \\ \mathrm{H} & 0.446802 & 0.587118 & 2.765018 \\ \mathrm{O} & 0.625214 & -0.646998 & -2.367775 \\ \mathrm{H} & -0.015969 & -1.051558 & -2.976193 \\ \mathrm{H} & 2.517073 & -3.584433 & -0.791129 \\ \mathrm{H} & 1.007139 & 0.106649 & -2.848439 \\ \mathrm{H} & 2.215187 & -2.981114 & 2.301098 \\ \mathrm{H} & -1.766799 & -2.352156 & -0.235571 \\ \mathrm{H} & 0.510229 & -0.895785 & 3.223952 \\ \mathrm{C} & 1.676292 & 2.232161 & 0.091326 \\ \mathrm{C} & 1.614670 & 3.631700 & 0.141647 \\ \mathrm{C} & 0.364960 & 4.253710 & 0.159372 \\ \mathrm{H} & 2.523768 & 4.221785 & 0.163132 \\ \mathrm{C} & -0.652196 & 2.078480 & 0.075659 \\ \mathrm{C} & -0.792258 & 3.464781 & 0.122139\end{array}$




$\begin{array}{lrrc}\mathrm{H} & 0.291576 & 5.336697 & 0.197521 \\ \mathrm{H} & -1.783638 & 3.901243 & 0.127168 \\ \mathrm{C} & -1.836970 & 1.182862 & 0.026275 \\ \mathrm{C} & -4.113917 & 0.910135 & -0.038749 \\ \mathrm{C} & -3.890737 & -0.525981 & -0.063098 \\ \mathrm{~N} & 0.558325 & 1.466238 & 0.063881 \\ \mathrm{~N} & -3.058588 & 1.722976 & 0.006193 \\ \mathrm{~N} & -1.591599 & -0.130907 & -0.011497 \\ \mathrm{~N} & -2.641474 & -0.976026 & -0.064171 \\ \mathrm{C} & -5.488509 & 1.532760 & -0.132856 \\ \mathrm{C} & -6.592060 & 0.484024 & 0.132281 \\ \mathrm{H} & -6.717896 & 0.352867 & 1.211527 \\ \mathrm{H} & -7.540492 & 0.888034 & -0.230845 \\ \mathrm{C} & -6.323468 & -0.866567 & -0.535584 \\ \mathrm{C} & -5.021935 & -1.542858 & -0.042230 \\ \mathrm{H} & -6.282009 & -0.751253 & -1.624146 \\ \mathrm{H} & -7.155317 & -1.547376 & -0.335591 \\ \mathrm{C} & -5.618660 & 2.704432 & 0.868182 \\ \mathrm{H} & -4.912178 & 3.506962 & 0.650286 \\ \mathrm{H} & -6.629411 & 3.114034 & 0.797097 \\ \mathrm{H} & -5.467466 & 2.371299 & 1.899559 \\ \mathrm{C} & -5.604903 & 2.096890 & -1.584393 \\ \mathrm{H} & -6.570845 & 2.598960 & -1.679800 \\ \mathrm{H} & -4.817935 & 2.828368 & -1.783862 \\ \mathrm{H} & -5.555993 & 1.313281 & -2.345445 \\ \mathrm{C} & -5.174164 & -2.020719 & 1.430513 \\ \mathrm{H} & 8.501923 \\ \mathrm{H} & -5.990387 & -2.745637 & 1.486215 \\ \mathrm{H} & -4.260307 & -2.511747 & 1.779465 \\ \mathrm{H} & -5.405785 & -1.204328 & 2.118774 \\ \mathrm{C} & -4.704598 & -2.759050 & -0.936808 \\ \mathrm{H} & -3.878543 & -3.360426 & -0.544861 \\ \mathrm{H} & -5.580434 & -3.411547 & -0.972368 \\ \mathrm{H} & -4.475940 & -2.460852 & -1.964835 \\ \mathrm{C} & 2.950049 & 1.501038 & 0.044105 \\ \mathrm{C} & 4.271808 & 1.970443 & 0.035320 \\ \mathrm{C} & 5.060290 & 0.826934 & -0.058884 \\ \mathrm{H} & 4.648222 & 2.981732 & 0.082152 \\ \mathrm{~N} & 2.919308 & 0.139944 & -0.036369 \\ & 4.220903 & -0.234123 & -0.099421 \\ \mathrm{C} & 7.259500 & 1.702553 & -0.074668 \\ \mathrm{H} & -0.83485 & -0.562721 & -0.214561 \\ \mathrm{H} & -0.286177 & -1.157507\end{array}$




$$
\text { H } \quad 4.494493 \quad-1.205873 \quad-0.195104
$$

$\mathrm{M}=\mathrm{Am}$

$\begin{array}{lrrc}\text { AM } & 0.706855 & -0.985995 & 0.050023 \\ \text { N } & 2.866186 & 0.285783 & -0.029974 \\ \mathrm{C} & 2.875289 & 1.646816 & 0.006266 \\ \mathrm{~N} & 4.174192 & -0.072334 & -0.057604 \\ \mathrm{C} & 4.190048 & 2.135635 & 0.001967 \\ \mathrm{C} & 1.590966 & 2.358727 & 0.036408 \\ \mathrm{C} & 4.996779 & 1.001572 & -0.039868 \\ \mathrm{H} & 4.551700 & 3.153105 & 0.021676 \\ \mathrm{C} & 1.516294 & 3.757573 & 0.074909 \\ \mathrm{~N} & 0.482230 & 1.579272 & 0.024431 \\ \mathrm{C} & 6.494322 & 0.915885 & -0.065479 \\ \mathrm{C} & 0.261675 & 4.368006 & 0.103374 \\ \mathrm{H} & 2.419777 & 4.356454 & 0.082499 \\ \mathrm{C} & -0.732431 & 2.181068 & 0.052085 \\ \mathrm{O} & 6.893664 & -0.362605 & -0.115152 \\ \mathrm{O} & 7.182166 & 1.910711 & -0.041876 \\ \mathrm{C} & -0.886251 & 3.566270 & 0.092441 \\ \mathrm{H} & 0.177619 & 5.450406 & 0.133263 \\ \mathrm{C} & -1.914205 & 1.282066 & 0.025654 \\ \mathrm{C} & 8.351421 & -0.569579 & -0.141336 \\ \mathrm{H} & -1.881897 & 3.992012 & 0.112364 \\ \mathrm{~N} & -3.136083 & 1.823158 & 0.023728 \\ \mathrm{~N} & -1.671437 & -0.031260 & -0.018473 \\ \mathrm{H} & 8.768245 & -0.087148 & -1.025969 \\ \mathrm{H} & 8.791717 & -0.146793 & 0.762220 \\ \mathrm{H} & 8.484009 & -1.648796 & -0.178939 \\ \mathrm{C} & -4.193848 & 1.013600 & -0.008851 \\ \mathrm{~N} & -2.724726 & -0.872956 & -0.076389 \\ \mathrm{C} & -5.568668 & 1.641013 & -0.067447 \\ \mathrm{C} & -3.972876 & -0.421369 & -0.057129 \\ \mathrm{C} & -6.670321 & 0.587944 & 0.188297 \\ \mathrm{C} & -5.679146 & 2.786296 & 0.966442 \\ \mathrm{C} & -5.707470 & 2.242854 & -1.501360 \\ \mathrm{C} & -5.105858 & -1.437121 & -0.046582 \\ \mathrm{C} & -6.410912 & -0.747996 & -0.512128 \\ \mathrm{H} & -7.622589 & 1.000458 & -0.154568 \\ \mathrm{H} & -6.783565 & 0.433098 & 1.265809 \\ & -6.689486 & 3.200768 & 0.922553 \\ \mathrm{H} & -5.512490 & 2.425594 & 1.986109 \\ \mathrm{H} & -673389 & 3.592142 & 0.758390 \\ \mathrm{H} & 2.751112 & -1.567728 \\ \mathrm{H} & 1.478591 & -2.282684\end{array}$




$\begin{array}{crrr}\mathrm{H} & -4.920569 & 2.975652 & -1.695824 \\ \mathrm{C} & -4.800114 & -2.633902 & -0.971048 \\ \mathrm{C} & -5.244472 & -1.947430 & 1.416300 \\ \mathrm{H} & -7.242139 & -1.431667 & -0.319452 \\ \mathrm{H} & -6.379524 & -0.608264 & -1.598232 \\ \mathrm{H} & -3.975697 & -3.248818 & -0.596581 \\ \mathrm{H} & -4.576020 & -2.313193 & -1.993410 \\ \mathrm{H} & -5.679369 & -3.281173 & -1.016701 \\ \mathrm{H} & -6.061530 & -2.671945 & 1.464707 \\ \mathrm{H} & -4.327804 & -2.447508 & 1.744632 \\ \mathrm{H} & -5.467186 & -1.146072 & 2.124847 \\ \mathrm{O} & 0.662561 & -0.640715 & -2.474957 \\ \mathrm{H} & 0.046580 & -1.059453 & -3.099894 \\ \mathrm{H} & 1.077653 & 0.090723 & -2.962977 \\ \mathrm{O} & -0.967817 & -2.691250 & -0.493172 \\ \mathrm{H} & -1.065705 & -3.536145 & -0.958793 \\ \mathrm{H} & -1.885170 & -2.255602 & -0.372799 \\ \mathrm{O} & 1.065798 & -3.037587 & 1.628715 \\ \mathrm{H} & 1.725425 & -3.253820 & 2.309971 \\ \mathrm{H} & 0.415677 & -3.760879 & 1.645705 \\ \mathrm{O} & 0.590149 & -0.320293 & 2.483153 \\ \mathrm{H} & 0.405648 & -0.899401 & 3.241153 \\ \mathrm{H} & 0.671534 & 0.578303 & 2.844048 \\ \mathrm{H} & 2.597075 & -3.528928 & -0.670740 \\ \mathrm{O} & 2.409087 & -2.630453 & -0.990759 \\ \mathrm{H} & 2.688275 & -2.610832 & -1.922244 \\ \mathrm{H} & 4.460643 & -1.044115 & -0.099738\end{array}$

$\mathrm{M}=\mathrm{Cm}$

$\begin{array}{lccc}\mathrm{CM} & 0.697824 & -0.969035 & 0.089135 \\ \mathrm{O} & 1.260111 & -2.918266 & 1.744459 \\ \mathrm{H} & 0.662363 & -3.677271 & 1.857772 \\ \mathrm{O} & -0.940859 & -2.723380 & -0.377381 \\ \mathrm{H} & -1.028986 & -3.613193 & -0.752029 \\ \mathrm{O} & 2.290476 & -2.661016 & -1.042246 \\ \mathrm{H} & 2.498507 & -2.651187 & -1.992110 \\ \mathrm{O} & 0.492414 & -0.258811 & 2.495847 \\ \mathrm{H} & 0.430062 & 0.647558 & 2.840338 \\ \mathrm{O} & 0.618765 & -0.601108 & -2.421292 \\ \mathrm{H} & -0.015887 & -1.006994 & -3.036103 \\ \mathrm{H} & 2.512519 & -3.552419 & -0.725322 \\ \mathrm{H} & 1.020562 & 0.141012 & -2.904215 \\ \mathrm{H} & 1.995353 & -3.065291 & 2.364155 \\ \mathrm{H} & -1.861560 & -2.290331 & -0.307111 \\ \mathrm{H} & 0.431015 & -0.847893 & 3.266055\end{array}$




\begin{tabular}{|c|c|c|c|}
\hline $\mathrm{C}$ & 1.596572 & 2.340820 & 0.08 \\
\hline C & 1.524975 & 3.739611 & 0.145038 \\
\hline $\mathrm{C}$ & 0.271492 & 4.352969 & 0.173752 \\
\hline $\boldsymbol{H}$ & 2.429597 & 4.336584 & 0.161818 \\
\hline $\mathrm{C}$ & -0.731367 & 2.171245 & 0.085577 \\
\hline $\mathrm{C}$ & -0.880282 & 3.556399 & 0.138878 \\
\hline $\mathrm{H}$ & 0.190988 & 5.435260 & 0.217022 \\
\hline $\mathrm{H}$ & -1.874210 & 3.986678 & 0.149171 \\
\hline $\mathrm{C}$ & -1.915146 & 1.273318 & 0.028436 \\
\hline $\mathrm{C}$ & -4.193265 & 1.005676 & -0.043329 \\
\hline $\mathrm{C}$ & -3.972653 & -0.429604 & -0.091348 \\
\hline $\mathrm{N}$ & 0.483481 & 1.568182 & 0.068107 \\
\hline $\mathrm{N}$ & -3.136170 & 1.815592 & 0.014611 \\
\hline $\mathrm{N}$ & -1.673416 & -0.040492 & -0.027156 \\
\hline $\mathrm{N}$ & -2.725032 & -0.883414 & -0.096173 \\
\hline $\mathrm{C}$ & -5.566569 & 1.633545 & -0.125679 \\
\hline $\mathrm{C}$ & -6.672517 & 0.582282 & 0.118854 \\
\hline $\mathrm{H}$ & -6.799302 & 0.430832 & 1.195372 \\
\hline $\mathrm{H}$ & -7.619906 & 0.994951 & -0.237124 \\
\hline $\mathrm{C}$ & -6.405940 & -0.755914 & -0.574294 \\
\hline $\mathrm{C}$ & -5.106555 & -1.444453 & -0.092374 \\
\hline $\mathrm{H}$ & -6.362650 & -0.619770 & -1.660426 \\
\hline $\mathrm{H}$ & -7.239681 & -1.438461 & -0.388627 \\
\hline $\mathrm{C}$ & -5.693542 & 2.784883 & 0.899215 \\
\hline $\mathrm{H}$ & -4.985451 & 3.590185 & 0.697227 \\
\hline $\mathrm{H}$ & -6.703435 & 3.198154 & 0.837529 \\
\hline $\mathrm{H}$ & -5.542183 & 2.430399 & 1.923455 \\
\hline $\mathrm{C}$ & -5.682187 & 2.226913 & -1.565361 \\
\hline $\mathrm{H}$ & -6.646689 & 2.733568 & -1.650650 \\
\hline $\mathrm{H}$ & -4.893093 & 2.959807 & -1.750771 \\
\hline $\mathrm{H}$ & -5.635635 & 1.458396 & -2.341804 \\
\hline $\mathrm{C}$ & -5.262474 & -1.952207 & 1.369720 \\
\hline $\mathrm{H}$ & -6.079314 & -2.677496 & 1.409330 \\
\hline $\mathrm{H}$ & -4.349544 & -2.450827 & 1.710467 \\
\hline $\mathrm{H}$ & -5.494846 & -1.149714 & 2.073936 \\
\hline $\mathrm{C}$ & -4.790706 & -2.642828 & -1.011353 \\
\hline $\mathrm{H}$ & -3.969029 & -3.256011 & -0.628410 \\
\hline $\mathrm{H}$ & -5.669082 & -3.290710 & -1.064442 \\
\hline $\mathrm{H}$ & -4.556225 & -2.323914 & -2.031880 \\
\hline $\mathrm{C}$ & 2.879310 & 1.625115 & 0.030244 \\
\hline $\mathrm{C}$ & 4.193439 & 2.115771 & 0.019495 \\
\hline $\mathrm{C}$ & 5.000609 & 0.985879 & -0.080567 \\
\hline $\mathrm{H}$ & 4.554005 & 3.132524 & 0.069927 \\
\hline $\mathrm{N}$ & 2.871603 & 0.264491 & -0.055552 \\
\hline $\mathrm{N}$ & 4.179046 & -0.088085 & -0.123010 \\
\hline$C$ & 6.497458 & 0.904936 & -0.139976 \\
\hline
\end{tabular}




$\begin{array}{cccc}\mathrm{O} & 7.183889 & 1.900051 & -0.095490 \\ \mathrm{O} & 6.897771 & -0.369944 & -0.243475 \\ \mathrm{C} & 8.354879 & -0.572259 & -0.310180 \\ \mathrm{H} & 8.814997 & -0.180707 & 0.597574 \\ \mathrm{H} & 8.488328 & -1.649118 & -0.389326 \\ \mathrm{H} & 8.750492 & -0.057676 & -1.186393 \\ \mathrm{H} & 4.466556 & -1.056267 & -0.214458\end{array}$

\section{$\left[\mathrm{ML}_{2}\left(\mathrm{H}_{2} \mathrm{O}\right)_{2}\right]^{3+}$}

$\mathrm{M}=\mathrm{Eu}$

$\begin{array}{lrrr}\text { EU } & -0.010890 & -0.036643 & 0.009096 \\ \mathrm{O} & 0.508829 & -1.686139 & -1.698127 \\ \mathrm{H} & 1.428986 & -2.051761 & -1.528536 \\ \mathrm{O} & -0.550492 & -1.626497 & 1.766370 \\ \mathrm{H} & -0.174917 & -2.007869 & 2.572006 \\ \mathrm{H} & 0.155313 & -2.072799 & -2.510980 \\ \mathrm{H} & -1.462721 & -2.006085 & 1.608893 \\ \mathrm{C} & 0.915031 & 1.895304 & 2.719456 \\ \mathrm{C} & 1.610303 & 2.383673 & 3.837698 \\ \mathrm{C} & 2.865281 & 1.857991 & 4.138374 \\ \mathrm{H} & 1.174278 & 3.155702 & 4.460523 \\ \mathrm{C} & 2.646676 & 0.421153 & 2.224435 \\ \mathrm{C} & 3.397208 & 0.855877 & 3.317619 \\ \mathrm{H} & 3.420815 & 2.218127 & 4.999039 \\ \mathrm{H} & 4.365546 & 0.411365 & 3.510208 \\ \mathrm{C} & 3.164801 & -0.647516 & 1.326779 \\ \mathrm{C} & 4.833440 & -2.121924 & 0.777635 \\ \mathrm{C} & 4.020860 & -2.543847 & -0.342980 \\ \mathrm{~N} & 1.427880 & 0.928897 & 1.923311 \\ \mathrm{~N} & 4.369294 & -1.170564 & 1.584724 \\ \mathrm{~N} & 2.380669 & -1.023309 & 0.311216 \\ \mathrm{~N} & 2.829887 & -1.981032 & -0.519072 \\ \mathrm{C} & 6.169583 & -2.752896 & 1.116644 \\ \mathrm{C} & 6.704290 & -3.574436 & -0.077479 \\ \mathrm{H} & 7.172289 & -2.900135 & -0.802081 \\ \mathrm{H} & 7.504587 & -4.225012 & 0.285222 \\ \mathrm{C} & 5.628496 & -4.419311 & -0.763704 \\ \mathrm{C} & 4.479347 & -3.576031 & -1.365211 \\ \mathrm{H} & 5.212420 & -5.146756 & -0.058266 \\ \mathrm{H} & 6.078801 & -5.004598 & -1.570293 \\ \mathrm{C} & 7.193936 & -1.663168 & 1.505428 \\ \mathrm{H} & 6.885804 & -1.115851 & 2.397843 \\ \mathrm{H} & 8.154853 & -2.140448 & 1.714388 \\ \mathrm{H} & 7.348358 & -0.948388 & 0.690978\end{array}$




\begin{tabular}{|c|c|c|c|}
\hline $\mathrm{C}$ & 5.920058 & -3.671561 & 2.350057 \\
\hline $\mathrm{H}$ & 6.872063 & -4.114726 & 2.653143 \\
\hline & 5.528079 & -3.095215 & 3.191954 \\
\hline & 5.223618 & -4.486082 & 2.132739 \\
\hline$C$ & 4.967409 & -2.797377 & -2.618295 \\
\hline 1 & 5.298052 & -3.510779 & -3.377792 \\
\hline $\mathrm{H}$ & 4.158762 & -2.196426 & -3.045592 \\
\hline $\mathrm{H}$ & 5.805373 & -2.130888 & -2.398922 \\
\hline $\mathrm{C}$ & 3.322031 & -4.512418 & -1.771192 \\
\hline $\mathrm{H}$ & 2.539357 & -3.989460 & -2.327622 \\
\hline $\mathrm{H}$ & 3.712091 & -5.297106 & -2.424536 \\
\hline $\mathrm{H}$ & 2.869891 & -4.999294 & -0.901708 \\
\hline $\mathrm{C}$ & -0.412287 & 2.414335 & 2.361160 \\
\hline $\mathrm{C}$ & -1.151275 & 3.459989 & 2.947046 \\
\hline $\mathrm{C}$ & -2.319041 & 3.535761 & 2.201845 \\
\hline $\mathrm{H}$ & -0.906523 & 4.096015 & 3.784122 \\
\hline $\mathrm{N}$ & -1.089630 & 1.873685 & 1.315533 \\
\hline $\mathrm{N}$ & -2.238725 & 2.575554 & 1.244773 \\
\hline $\mathrm{C}$ & -3.475084 & 4.468364 & 2.360602 \\
\hline $\mathrm{O}$ & -3.505514 & 5.312133 & 3.228456 \\
\hline $\mathrm{O}$ & -4.417151 & 4.226093 & 1.430825 \\
\hline $\mathrm{C}$ & -5.596576 & 5.095951 & 1.49 \\
\hline $\mathrm{H}$ & -5.291802 & 6.134332 & 1.360470 \\
\hline $\mathrm{H}$ & -6.241193 & 4.765645 & 0.683969 \\
\hline $\mathrm{H}$ & -6.086080 & 4.974684 & 2.463392 \\
\hline $\mathrm{C}$ & -0.903379 & 1.836125 & -2.757525 \\
\hline $\mathrm{C}$ & -1.590143 & 2.306394 & -3.888486 \\
\hline $\mathrm{C}$ & -2.846071 & 1.781135 & -4.187190 \\
\hline $\mathrm{H}$ & -1.146409 & 3.064623 & -4.522844 \\
\hline $\mathrm{C}$ & -2.644402 & 0.381354 & -2.246506 \\
\hline $\mathrm{C}$ & -3.387376 & 0.796958 & -3.351601 \\
\hline $\mathrm{H}$ & -3.394380 & 2.127720 & -5.057985 \\
\hline $\mathrm{H}$ & -4.356125 & 0.352147 & -3.542096 \\
\hline $\mathrm{C}$ & -3.167714 & -0.665844 & -1.331267 \\
\hline $\mathrm{C}$ & -4.837771 & -2.137019 & -0.761687 \\
\hline $\mathrm{C}$ & -4.041212 & -2.521220 & 0.384674 \\
\hline $\mathrm{N}$ & -1.426097 & 0.888886 & -1.947278 \\
\hline $\mathrm{N}$ & -4.365011 & -1.205091 & -1.583715 \\
\hline $\mathrm{N}$ & -2.395994 & -1.018629 & -0.295553 \\
\hline $\mathrm{N}$ & -2.853414 & -1.948871 & 0.552931 \\
\hline $\mathrm{C}$ & -6.161903 & -2.791126 & -1.106480 \\
\hline $\mathrm{C}$ & -6.713085 & -3.579069 & 0.102368 \\
\hline $\mathrm{H}$ & -7.203903 & -2.887088 & 0.794266 \\
\hline $\mathrm{H}$ & -7.498368 & -4.250106 & -0.256052 \\
\hline $\mathrm{C}$ & -5.644554 & -4.390555 & 0.838824 \\
\hline$C$ & -4.514521 & -3.516717 & 1.434257 \\
\hline
\end{tabular}




$\begin{array}{lrrr}\mathrm{H} & -5.207988 & -5.138277 & 0.167908 \\ \mathrm{H} & -6.106648 & -4.951100 & 1.656153 \\ \mathrm{C} & -7.186853 & -1.723844 & -1.551582 \\ \mathrm{H} & -6.864397 & -1.203510 & -2.455115 \\ \mathrm{H} & -8.138980 & -2.216638 & -1.764521 \\ \mathrm{H} & -7.364377 & -0.984202 & -0.764609 \\ \mathrm{C} & -5.875725 & -3.746432 & -2.304082 \\ \mathrm{H} & -6.816648 & -4.209785 & -2.611589 \\ \mathrm{H} & -5.472775 & -3.193168 & -3.156238 \\ \mathrm{H} & -5.175480 & -4.545611 & -2.046033 \\ \mathrm{C} & -5.035684 & -2.694052 & 2.645423 \\ \mathrm{H} & -5.380542 & -3.380510 & 3.423170 \\ \mathrm{H} & -4.239859 & -2.073330 & 3.068581 \\ \mathrm{H} & -5.871322 & -2.040822 & 2.381932 \\ \mathrm{C} & -3.360658 & -4.428614 & 1.901045 \\ \mathrm{H} & -2.596759 & -3.878803 & 2.458034 \\ \mathrm{H} & -3.760441 & -5.192257 & 2.573068 \\ \mathrm{H} & -2.883314 & -4.942587 & 1.061223 \\ \mathrm{C} & 0.425780 & 2.351902 & -2.399769 \\ \mathrm{C} & 1.183940 & 3.372812 & -3.003320 \\ \mathrm{C} & 2.346542 & 3.449520 & -2.249093 \\ \mathrm{H} & 0.955872 & 3.991757 & -3.857749 \\ \mathrm{~N} & 1.084924 & 1.827266 & -1.336815 \\ \mathrm{~N} & 2.244614 & 2.514026 & -1.271119 \\ \mathrm{C} & 3.517085 & 4.361703 & -2.419952 \\ \mathrm{O} & 3.566451 & 5.184290 & -3.307156 \\ \mathrm{O} & 4.448265 & 4.128470 & -1.477132 \\ \mathrm{C} & 5.640572 & 4.979575 & -1.553602 \\ \mathrm{H} & 5.349910 & 6.025141 & -1.444642 \\ \mathrm{H} & 6.274092 & 4.659318 & -0.728626 \\ \mathrm{H} & 6.135728 & 4.828510 & -2.513605 \\ \mathrm{H} & 2.932654 & 2.328262 & -0.551724 \\ \mathrm{H} & -2.935569 & 2.384700 & 0.535176\end{array}$

$\mathrm{M}=\mathrm{Gd}$

$\begin{array}{lrrr}\text { GD } & -0.000036 & -0.026846 & 0.000043 \\ \text { O } & -0.530527 & -1.614616 & 1.709880 \\ \text { H } & -1.453871 & -1.986067 & 1.553147 \\ \text { O } & 0.530167 & -1.615147 & -1.709435 \\ \text { H } & 0.155722 & -1.998869 & -2.514376 \\ \text { H } & -0.156119 & -1.998300 & 2.514856 \\ \text { H } & 1.453469 & -1.986684 & -1.552638 \\ \mathrm{C} & -0.855040 & 1.864777 & -2.729624 \\ \mathrm{C} & -1.533574 & 2.351870 & -3.856952 \\ \mathrm{C} & -2.792433 & 1.837279 & -4.164475\end{array}$




\begin{tabular}{|c|c|c|c|}
\hline $\mathrm{H}$ & -1.082951 & 3.113936 & -4.481867 \\
\hline & -2.608289 & 0.415231 & -2.237233 \\
\hline$C$ & -3.343728 & 0.848712 & -3.340554 \\
\hline $\mathrm{H}$ & -3.335762 & 2.196412 & -5.033334 \\
\hline$H$ & -4.315577 & 0.414015 & -3.538016 \\
\hline & -3.142087 & -0.636997 & -1.330521 \\
\hline & -4.816253 & -2.103501 & -0.779092 \\
\hline C & -4.022669 & -2.498307 & 0.365573 \\
\hline $\mathrm{N}$ & -1.385835 & 0.911570 & -1.930809 \\
\hline N & -4.341822 & -1.166296 & -1.597225 \\
\hline N & -2.371354 & -0.994564 & -0.298918 \\
\hline$N$ & -2.833567 & -1.934115 & 0.546212 \\
\hline & -6.141204 & -2.749943 & -1.130528 \\
\hline$\tau$ & -6.697550 & -3.547063 & 0.070461 \\
\hline H & -7.187858 & -2.859503 & 0.767193 \\
\hline $\mathrm{H}$ & -7.484059 & -4.212560 & -0.295205 \\
\hline $\mathrm{C}$ & -5.632422 & -4.366741 & 0.802499 \\
\hline $\mathrm{C}$ & -4.502294 & -3.500627 & 1.407356 \\
\hline $\mathrm{H}$ & -5.196068 & -5.109803 & 0.126170 \\
\hline- & -6.097569 & -4.933460 & 1.613909 \\
\hline$C$ & -7.163642 & -1.677872 & -1.569419 \\
\hline H & -6.839518 & -1.150904 & -2.468352 \\
\hline H & -8.116410 & -2.167207 & -1.787489 \\
\hline $\mathrm{H}$ & -7.341030 & -0.944110 & -0.776831 \\
\hline $\mathrm{C}$ & -5.856926 & -3.696950 & -2.335373 \\
\hline $\mathrm{H}$ & -6.798860 & -4.154580 & -2.648255 \\
\hline $\mathrm{H}$ & -5.450473 & -3.138304 & -3.182321 \\
\hline $\mathrm{H}$ & -5.159910 & -4.500637 & -2.082413 \\
\hline $\mathrm{C}$ & -5.025247 & -2.684415 & 2.622079 \\
\hline $\mathrm{H}$ & -5.376307 & -3.374721 & 3.393646 \\
\hline $\mathrm{H}$ & -4.228694 & -2.069995 & 3.052969 \\
\hline $\mathrm{H}$ & -5.857157 & -2.025968 & 2.359675 \\
\hline 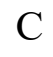 & -3.352588 & -4.418092 & 1.873261 \\
\hline $\mathrm{H}$ & -2.588880 & -3.874496 & 2.436420 \\
\hline 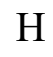 & -3.757263 & -5.184843 & 2.538843 \\
\hline $\mathrm{H}$ & -2.873887 & -4.928636 & 1.032017 \\
\hline $\mathrm{C}$ & 0.475651 & 2.363418 & -2.354807 \\
\hline $\mathrm{C}$ & 1.254888 & 3.379454 & -2.937349 \\
\hline $\mathrm{C}$ & 2.408205 & 3.433614 & -2.166130 \\
\hline $\mathrm{H}$ & 1.046168 & 4.009359 & -3.788767 \\
\hline $\mathrm{N}$ & 1.113837 & 1.819859 & -1.287602 \\
\hline $\mathrm{N}$ & 2.281922 & 2.490469 & -1.199117 \\
\hline $\mathrm{C}$ & 3.592126 & 4.333417 & -2.312260 \\
\hline 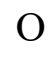 & 3.663177 & 5.162633 & -3.191566 \\
\hline $\mathrm{O}$ & 4.506605 & 4.080852 & -1.358357 \\
\hline $\mathrm{C}$ & 5.709480 & 4.919421 & -1.409474 \\
\hline
\end{tabular}




\begin{tabular}{|c|c|c|c|}
\hline & 5.428539 & 5.967080 & 95410 \\
\hline & 6.326975 & 4.584859 & -0.578071 \\
\hline & 6.217059 & 4.771284 & -2.363414 \\
\hline & 0.855248 & 1.865183 & 2.729331 \\
\hline & 1.533875 & 2.352443 & 3.856531 \\
\hline & 2.792733 & 1.837854 & 4.164060 \\
\hline & 1.083325 & 3.114636 & 4.481343 \\
\hline & 2.608401 & 0.415472 & 2.237082 \\
\hline C & 3.343936 & 0.849126 & 0271 \\
\hline F & 3.336134 & 2.197114 & 5.0 \\
\hline 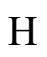 & 4.31 & 0.4 & 735 \\
\hline $\mathrm{C}$ & 3.142090 & -0.636951 & 530 \\
\hline C & 4.816232 & -2.103507 & 166 \\
\hline $\mathrm{C}$ & 4.022353 & -2.498833 & 5109 \\
\hline $\mathrm{N}$ & 1.385945 & 0.91 & \\
\hline $\mathrm{N}$ & 4.341914 & -1.166093 & 1.597129 \\
\hline & & -0.95 & \\
\hline $\mathrm{T}$ & 2.83 & -1.9 & -0 . \\
\hline & 6.141451 & -2.749535 & 1.1 \\
\hline $\mathrm{C}$ & 6.65 & -3.5 & -0. \\
\hline $\mathrm{H}$ & 7.187268 & -2.859560 & 7806 \\
\hline 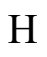 & 7.484346 & -4.212106 & 005 \\
\hline 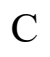 & 5.632234 & -4.367255 & -0.8 \\
\hline y & 4.501634 & -3.501699 & -1. \\
\hline $\mathrm{H}$ & 5.196357 & -5.1 & -0.1 \\
\hline П & & -4.93 & -1 \\
\hline$y$ & 7.163824 & -1.6 & 1.5 \\
\hline $\mathrm{H}$ & 6.839948 & -1.149773 & 2.4 \\
\hline $\mathrm{H}$ & 8.11 & -2.16 & 258 \\
\hline $\mathrm{H}$ & 7.340723 & -0.943570 & 0.7 \\
\hline 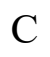 & 5.857907 & -3.696114 & 692 \\
\hline $\mathrm{H}$ & 6.800083 & -4.153386 & 2.6 \\
\hline $\mathrm{H}$ & 5.451669 & -3.137222 & 3.1 \\
\hline $\mathrm{H}$ & 5.160981 & -4.500072 & 2.0 \\
\hline C & 5.023798 & -2.686167 & -2.6 \\
\hline $\mathrm{H}$ & 5.374451 & -3.376899 & -3.3 \\
\hline $\mathrm{H}$ & 4.226952 & -2.072051 & -3.052833 \\
\hline $\mathrm{H}$ & 5.855817 & -2.027510 & -2.360520 \\
\hline $\mathrm{C}$ & 3.351838 & -4.419676 & -1.871233 \\
\hline $\mathrm{H}$ & 2.587678 & -3.876589 & -2.434266 \\
\hline $\mathrm{H}$ & 3.756288 & -5.186749 & -2.536580 \\
\hline $\mathrm{H}$ & 2.873730 & -4.929806 & -1.029401 \\
\hline C & -0.475442 & 2.363824 & 2.354504 \\
\hline $\mathrm{C}$ & -1.254596 & 3.379994 & 2.936921 \\
\hline C & -2.407956 & 3.434078 & 2.165762 \\
\hline $\mathrm{H}$ & -1.045801 & 4.010026 & 3.788226 \\
\hline
\end{tabular}




$\begin{array}{lrrr}\mathrm{N} & -1.113712 & 1.820121 & 1.287423 \\ \mathrm{~N} & -2.281772 & 2.490767 & 1.198897 \\ \mathrm{C} & -3.591827 & 4.333960 & 2.311816 \\ \mathrm{O} & -3.662786 & 5.163321 & 3.190992 \\ \mathrm{O} & -4.506374 & 4.081282 & 1.358008 \\ \mathrm{C} & -5.709207 & 4.919916 & 1.409062 \\ \mathrm{H} & -5.428224 & 5.967542 & 1.294805 \\ \mathrm{H} & -6.326770 & 4.585243 & 0.577754 \\ \mathrm{H} & -6.216732 & 4.771963 & 2.363059 \\ \mathrm{H} & -2.956699 & 2.290991 & 0.470904 \\ \mathrm{H} & 2.956797 & 2.290785 & -0.471050\end{array}$

$\mathrm{M}=\mathrm{Am}$

$\begin{array}{lrcc}\text { AM } & 0.000000 & 0.042011 & 0.000000 \\ \mathrm{O} & -0.597617 & 1.697540 & -1.709990 \\ \mathrm{H} & -1.537897 & 2.020084 & -1.551091 \\ \mathrm{O} & 0.597614 & 1.697545 & 1.709983 \\ \mathrm{H} & 0.218770 & 2.153630 & 2.474303 \\ \mathrm{H} & -0.218771 & 2.153628 & -2.474306 \\ \mathrm{H} & 1.537894 & 2.020090 & 1.551086 \\ \mathrm{C} & -0.873416 & -1.791321 & 2.824828 \\ \mathrm{C} & -1.539346 & -2.238151 & 3.975466 \\ \mathrm{C} & -2.791773 & -1.708684 & 4.282154 \\ \mathrm{H} & -1.085869 & -2.983811 & 4.617740 \\ \mathrm{C} & -2.627605 & -0.352885 & 2.305829 \\ \mathrm{C} & -3.351612 & -0.749583 & 3.430484 \\ \mathrm{H} & -3.325722 & -2.037054 & 5.168758 \\ \mathrm{H} & -4.322520 & -0.310623 & 3.622111 \\ \mathrm{C} & -3.181985 & 0.663061 & 1.370208 \\ \mathrm{C} & -4.884656 & 2.090886 & 0.799517 \\ \mathrm{C} & -4.111541 & 2.463593 & -0.365428 \\ \mathrm{~N} & -1.407614 & -0.857509 & 2.004945 \\ \mathrm{~N} & -4.383694 & 1.187734 & 1.639514 \\ \mathrm{~N} & -2.433001 & 0.995523 & 0.314880 \\ \mathrm{~N} & -2.918613 & 1.908856 & -0.547009 \\ \mathrm{C} & -6.216635 & 2.724678 & 1.148733 \\ \mathrm{C} & -6.796224 & 3.485221 & -0.064966 \\ \mathrm{H} & -7.284161 & 2.774781 & -0.740061 \\ \mathrm{H} & -7.587894 & 4.148798 & 0.292930 \\ \mathrm{C} & -5.749686 & 4.300981 & -0.827522 \\ \mathrm{C} & -4.615707 & 3.434929 & -1.425356 \\ \mathrm{H} & -5.314974 & 5.064324 & -0.172980 \\ \mathrm{H} & -6.230797 & 4.843504 & -1.646126 \\ \mathrm{C} & -7.217145 & 1.645415 & 1.619942 \\ \mathrm{H} & -6.876603 & 1.144356 & 2.527612\end{array}$




\begin{tabular}{|c|c|c|c|}
\hline $\mathrm{H}$ & -8.176535 & 2.122976 & 1.835184 \\
\hline & -7.388144 & 0.891059 & 0.845490 \\
\hline C & -5.938623 & 3.702994 & 2.329467 \\
\hline $\mathrm{H}$ & -6.885499 & 4.150864 & 2.641555 \\
\hline & -5.513981 & 3.170772 & 3.184434 \\
\hline & -5.258536 & 4.513045 & 2.051879 \\
\hline & -5.141586 & 2.584616 & -2.615013 \\
\hline & -5.509556 & 3.252308 & -3.398538 \\
\hline & -4.341874 & 1.970211 & -3.040080 \\
\hline & -5.962345 & 1.922339 & -2.328270 \\
\hline & -3.483289 & 4.355769 & -1.925814 \\
\hline & -2.723180 & 3.809276 & -2.491266 \\
\hline 7 & -3.906131 & 5.105235 & -2.599746 \\
\hline & -2.997488 & 4.887669 & -1.101968 \\
\hline & 0.441634 & -2.326122 & 2.444529 \\
\hline $\mathrm{C}$ & 1.216593 & -3.327092 & 3.057885 \\
\hline $\mathrm{C}$ & 2.347647 & -3.444958 & 2.260967 \\
\hline H & 1.019971 & -3.908774 & 3.945637 \\
\hline $\mathrm{N}$ & 1.061472 & -1.851861 & 1.335433 \\
\hline $\mathrm{N}$ & 2.214506 & -2.550128 & 1.250819 \\
\hline 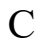 & 3.515686 & -4.362586 & 2.421795 \\
\hline $\mathrm{U}$ & 3.593684 & -5.146834 & 3.340955 \\
\hline $\mathrm{O}$ & 4.407869 & -4.180680 & 1.431562 \\
\hline C & 5.591882 & -5.044957 & 1.490990 \\
\hline $\mathrm{H}$ & 5.283421 & -6.089754 & 1.438243 \\
\hline $\mathrm{H}$ & 6.191817 & -4.767815 & 0.626267 \\
\hline $\mathrm{H}$ & 6.130918 & -4.861832 & 2.421318 \\
\hline $\mathrm{C}$ & 0.873419 & -1.791327 & -2.824823 \\
\hline $\mathrm{C}$ & 1.539350 & -2.238160 & -3.975459 \\
\hline $\mathrm{C}$ & 2.791778 & -1.708693 & -4.282147 \\
\hline $\mathrm{H}$ & 1.085874 & -2.983820 & -4.617732 \\
\hline $\mathrm{C}$ & 2.627608 & -0.352890 & -2.305825 \\
\hline $\mathrm{C}$ & 3.351616 & -0.749590 & -3.430479 \\
\hline $\mathrm{H}$ & 3.325728 & -2.037065 & -5.168750 \\
\hline $\mathrm{H}$ & 4.322524 & -0.310631 & -3.622106 \\
\hline $\mathrm{C}$ & 3.181986 & 0.663058 & -1.370207 \\
\hline $\mathrm{C}$ & 4.884656 & 2.090886 & -0.799518 \\
\hline $\mathrm{C}$ & 4.111539 & 2.463596 & 0.365425 \\
\hline $\mathrm{N}$ & 1.407617 & -0.857514 & -2.004942 \\
\hline $\mathrm{N}$ & 4.383695 & 1.187731 & -1.639513 \\
\hline $\mathrm{N}$ & 2.433000 & 0.995523 & -0.314881 \\
\hline $\mathrm{N}$ & 2.918612 & 1.908860 & 0.547006 \\
\hline $\mathrm{C}$ & 6.216635 & 2.724678 & -1.148735 \\
\hline $\mathrm{C}$ & 6.796223 & 3.485224 & 0.064962 \\
\hline $\mathrm{H}$ & 7.284159 & 2.774786 & 0.740060 \\
\hline U & 7.587892 & 4.148802 & -0.29293 \\
\hline
\end{tabular}




$\begin{array}{lrrr}\mathrm{C} & 5.749683 & 4.300986 & 0.827515 \\ \mathrm{C} & 4.615704 & 3.434935 & 1.425351 \\ \mathrm{H} & 5.314971 & 5.064328 & 0.172971 \\ \mathrm{H} & 6.230793 & 4.843511 & 1.646119 \\ \mathrm{C} & 7.217146 & 1.645416 & -1.619941 \\ \mathrm{H} & 6.876604 & 1.144353 & -2.527610 \\ \mathrm{H} & 8.176535 & 2.122976 & -1.835183 \\ \mathrm{H} & 7.388145 & 0.891061 & -0.845487 \\ \mathrm{C} & 5.938623 & 3.702991 & -2.329471 \\ \mathrm{H} & 6.885499 & 4.150861 & -2.641560 \\ \mathrm{H} & 5.513981 & 3.170767 & -3.184437 \\ \mathrm{H} & 5.258535 & 4.513043 & -2.051886 \\ \mathrm{C} & 5.141583 & 2.584625 & 2.615010 \\ \mathrm{H} & 5.509552 & 3.252319 & 3.398534 \\ \mathrm{H} & 4.341870 & 1.970221 & 3.040078 \\ \mathrm{H} & 5.962341 & 1.922348 & 2.328270 \\ \mathrm{C} & 3.483285 & 4.355776 & 1.925805 \\ \mathrm{H} & 2.723176 & 3.809284 & 2.491258 \\ \mathrm{H} & 3.906127 & 5.105244 & 2.599736 \\ \mathrm{H} & 2.997485 & 4.887674 & 1.101958 \\ \mathrm{C} & -0.441632 & -2.326126 & -2.444525 \\ \mathrm{C} & -1.216590 & -3.327098 & -3.057880 \\ \mathrm{C} & -2.347646 & -3.444961 & -2.260964 \\ \mathrm{H} & -1.019965 & -3.908784 & -3.945630 \\ \mathrm{~N} & -1.061473 & -1.851861 & -1.335433 \\ \mathrm{~N} & -2.214507 & -2.550128 & -1.250819 \\ \mathrm{C} & -3.515684 & -4.362589 & -2.421792 \\ \mathrm{O} & -3.593680 & -5.146841 & -3.340949 \\ \mathrm{O} & -4.407869 & -4.180680 & -1.431562 \\ \mathrm{C} & -5.591883 & -5.044958 & -1.490989 \\ \mathrm{H} & -5.283421 & -6.089754 & -1.438238 \\ \mathrm{H} & -6.191820 & -4.767813 & -0.626269 \\ \mathrm{H} & -6.130916 & -4.861836 & -2.421319 \\ \mathrm{H} & -2.870597 & -2.404325 & -0.493397 \\ \mathrm{H} & 2.870595 & -2.404328 & 0.493395\end{array}$

$\mathrm{M}=\mathrm{Cm}$
$\begin{array}{llll}\text { CM } & 0.000026 & -0.031977 & -0.000077\end{array}$
O $\quad 0.563446 \quad-1.658998 \quad-1.745492$
$\mathrm{H} \quad 1.485378 \quad-2.020456 \quad-1.570019$
$\begin{array}{llll}\mathrm{O} & -0.562987 & -1.659716 & 1.744958\end{array}$
$\mathrm{H} \quad-0.207966-2.046791 \quad 2.557251$
$\mathrm{H} \quad 0.208233 \quad-2.046263 \quad-2.557606$
$\mathrm{H} \quad-1.484999 \quad-2.020998 \quad 1.569556$
$\begin{array}{llll}\text { C } & 0.905099 & 1.855900 & 2.760950\end{array}$ 


\begin{tabular}{|c|c|c|c|}
\hline & 1.593814 & 2.329703 & 70 \\
\hline & 2.849420 & 1.802653 & 4.186089 \\
\hline & 1.154050 & 3.092268 & 4.519542 \\
\hline & 2.643781 & 0.393414 & 2.251340 \\
\hline & 3.388349 & 0.815128 & 3.353324 \\
\hline I & 3.400219 & 2.152054 & 5.054219 \\
\hline & 4.357990 & 0.372407 & 3.543018 \\
\hline & 3.172053 & -0.658113 & 9006 \\
\hline$C$ & 4.84 & -2.121700 & 3166 \\
\hline $\mathrm{C}$ & 4.052716 & -2.519604 & -0.358026 \\
\hline $\mathrm{N}$ & 1.423973 & 0.901898 & 1.955292 \\
\hline $\mathrm{N}$ & 4.373439 & -1.186038 & 1.602620 \\
\hline & 2.40 & -1.016462 & 0.307711 \\
\hline $\mathrm{N}$ & 2.86 & -1.956289 & -0.5 \\
\hline $\mathrm{C}$ & 6.17 & -2.760010 & 3680 \\
\hline $\mathrm{C}$ & 6.73 & -3.5 & $-0 .($ \\
\hline $\mathrm{H}$ & 7.213456 & -2.865357 & -0.776138 \\
\hline 1 & 7.52 & -4.214615 & 0.286402 \\
\hline $\mathrm{C}$ & 5.66 & -4.383468 & -0.797596 \\
\hline $\mathrm{C}$ & 4.52 & -3.526146 & -1.3 \\
\hline $\mathrm{H}$ & 5.240737 & -5.126838 & -0.115986 \\
\hline $\mathrm{H}$ & 6.13 & -4.950190 & -1. \\
\hline . & $7.1 \mathrm{~S}$ & -1.68 & 594 \\
\hline 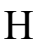 & 6.8 & -1.154089 & 2.459002 \\
\hline $\mathrm{H}$ & 8.1 & -2.162592 & 1.770645 \\
\hline $\mathrm{H}$ & 7.36 & -0.946525 & 0.763657 \\
\hline 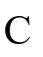 & 5.90 & -3.706366 & 5938 \\
\hline 1 & 6.8 & -4.157219 & 2.645262 \\
\hline 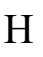 & 5.50 & -3.148762 & 5158 \\
\hline $\mathrm{H}$ & 5.21 & -4.515108 & 2.089835 \\
\hline $\mathrm{C}$ & 5.03 & -2.716480 & -2.622924 \\
\hline $\mathrm{H}$ & 5.38 & -3.410474 & -3.394233 \\
\hline $\mathrm{H}$ & 4.23 & -2.105782 & -3.049133 \\
\hline $\mathrm{H}$ & 5.87 & -2.055064 & -2.372965 \\
\hline C & 3.379619 & -4.452721 & -1.846864 \\
\hline $\mathrm{H}$ & 2.608462 & -3.917433 & -2.407903 \\
\hline $\mathrm{H}$ & 3.782209 & -5.223162 & -2.509461 \\
\hline $\mathrm{H}$ & 2.91 & -4.958326 & -0.997404 \\
\hline $\mathrm{C}$ & -0.421926 & 2.376197 & 2.399656 \\
\hline $\mathrm{C}$ & $-1.1^{\prime}$ & 3.397493 & 3.003086 \\
\hline $\mathrm{C}$ & -2.338225 & 3.482094 & 2.244737 \\
\hline $\mathrm{H}$ & -0.951047 & 4.012658 & 3.860378 \\
\hline $\mathrm{N}$ & -1.080701 & 1.858443 & 1.331737 \\
\hline 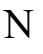 & -2.238156 & 2.550653 & 1.264516 \\
\hline $\mathrm{C}$ & -3.504171 & 4.400476 & 2.416002 \\
\hline $\mathrm{O}$ & -3.550790 & 5.218767 & 3.307205 \\
\hline
\end{tabular}




\begin{tabular}{|c|c|c|c|}
\hline $\mathrm{O}$ & -4.433211 & 4.177147 & 1.469148 \\
\hline $\mathrm{C}$ & -5.620733 & 5.035454 & 1.544409 \\
\hline H & -5.322939 & 6.079561 & 1.440983 \\
\hline $\mathrm{H}$ & -6.252626 & 4.722482 & 0.715403 \\
\hline $\mathrm{H}$ & -6.120631 & 4.883244 & 2.501762 \\
\hline C & -0.905242 & 1.856221 & -2.760811 \\
\hline $\mathrm{C}$ & -1.593974 & 2.330030 & -3.887521 \\
\hline$C$ & -2.849544 & 1.802918 & -4.185980 \\
\hline $\mathrm{H}$ & -1.154252 & 3.092654 & -4.519350 \\
\hline $\mathrm{C}$ & -2.643838 & 0.393596 & -2.251304 \\
\hline $\mathrm{C}$ & -3.388428 & 0.815324 & -3.353266 \\
\hline $\mathrm{H}$ & -3.400352 & 2.152328 & -5.054101 \\
\hline $\mathrm{H}$ & -4.358046 & 0.372565 & -3.542986 \\
\hline $\mathrm{C}$ & -3.172039 & -0.658018 & -1.339035 \\
\hline $\mathrm{C}$ & -4.848521 & -2.121706 & -0.783216 \\
\hline $\mathrm{C}$ & -4.052489 & -2.519751 & 0.357839 \\
\hline $\mathrm{N}$ & -1.424064 & 0.902137 & -1.955217 \\
\hline $\mathrm{N}$ & -4.373442 & -1.185928 & -1.602596 \\
\hline $\mathrm{N}$ & -2.401225 & -1.016488 & -0.307858 \\
\hline $\mathrm{N}$ & -2.863206 & -1.956431 & 0.53 \\
\hline $\mathrm{C}$ & -6.179274 & -2.759996 & -1.128681 \\
\hline $\mathrm{C}$ & -6.732781 & -3.555534 & 0.074663 \\
\hline $\mathrm{H}$ & -7.213184 & -2.865761 & 0.776223 \\
\hline $\mathrm{H}$ & -7.526525 & -4.214845 & -0.286533 \\
\hline $\mathrm{C}$ & -5.667946 & -4.383769 & 0.797254 \\
\hline $\mathrm{C}$ & -4.528670 & -3.526468 & 1.397714 \\
\hline $\mathrm{H}$ & -5.240367 & -5.126986 & 0.115471 \\
\hline $\mathrm{H}$ & -6.131157 & -4.950671 & 1.609632 \\
\hline $\mathrm{C}$ & -7.197693 & -1.680247 & -1.558254 \\
\hline $\mathrm{H}$ & -6.876529 & -1.153826 & -2.458593 \\
\hline $\mathrm{H}$ & -8.155439 & -2.162508 & -1.770285 \\
\hline $\mathrm{H}$ & -7.364271 & -0.946621 & -0.763148 \\
\hline $\mathrm{C}$ & -5.909126 & -3.706108 & -2.337158 \\
\hline $\mathrm{H}$ & -6.855864 & -4.156912 & -2.645459 \\
\hline $\mathrm{H}$ & -5.503962 & -3.148333 & -3.185317 \\
\hline $\mathrm{H}$ & -5.215827 & -4.514891 & -2.090292 \\
\hline $\mathrm{C}$ & -5.037164 & -2.717018 & 2.622790 \\
\hline $\mathrm{H}$ & -5.381383 & -3.411150 & 3.394017 \\
\hline $\mathrm{H}$ & -4.235141 & -2.106342 & 3.049037 \\
\hline $\mathrm{H}$ & -5.870658 & -2.055610 & 2.372995 \\
\hline $\mathrm{C}$ & -3.379159 & -4.453027 & 1.846348 \\
\hline $\mathrm{H}$ & -2.607982 & -3.917756 & 2.407381 \\
\hline $\mathrm{H}$ & -3.781643 & -5.223566 & 2.508895 \\
\hline $\mathrm{H}$ & -2.909781 & -4.958506 & 0.996786 \\
\hline $\mathrm{C}$ & 0.421726 & 2.376610 & -2.399449 \\
\hline S & 1.177944 & 3.398041 & $-3.0027^{\prime}$ \\
\hline
\end{tabular}




$\begin{array}{cccc}\mathrm{C} & 2.337911 & 3.482681 & -2.244409 \\ \mathrm{H} & 0.950693 & 4.013270 & -3.860004 \\ \mathrm{~N} & 1.080547 & 1.858811 & -1.331578 \\ \mathrm{~N} & 2.237925 & 2.551137 & -1.264278 \\ \mathrm{C} & 3.503766 & 4.401195 & -2.415579 \\ \mathrm{O} & 3.550315 & 5.219568 & -3.306711 \\ \mathrm{O} & 4.432816 & 4.177879 & -1.468733 \\ \mathrm{C} & 5.620257 & 5.036302 & -1.543913 \\ \mathrm{H} & 5.322362 & 6.080375 & -1.440426 \\ \mathrm{H} & 6.252163 & 4.723335 & -0.714916 \\ \mathrm{H} & 6.120188 & 4.884202 & -2.501266 \\ \mathrm{H} & 2.923191 & 2.372267 & -0.540540 \\ \mathrm{H} & -2.923405 & 2.371789 & 0.540760\end{array}$

$\left[\mathrm{ML}_{2}\right]^{3+}$

$\mathrm{M}=\mathrm{Eu}$

$\begin{array}{lrrc}\text { EU } & 0.000001 & 0.614704 & -0.000001 \\ \mathrm{~N} & -1.726876 & -0.975961 & 0.741703 \\ \mathrm{C} & -2.076393 & -1.166757 & 2.024447 \\ \mathrm{~N} & -2.338605 & -1.657651 & -0.222794 \\ \mathrm{C} & -1.356116 & -0.336248 & 3.021389 \\ \mathrm{~N} & -3.010856 & -2.034103 & 2.403841 \\ \mathrm{C} & -3.297972 & -2.533429 & 0.075519 \\ \mathrm{C} & -1.601902 & -0.445657 & 4.388168 \\ \mathrm{~N} & -0.454178 & 0.532265 & 2.508174 \\ \mathrm{C} & -3.640810 & -2.744885 & 1.467473 \\ \mathrm{C} & -3.946019 & -3.292036 & -1.073808 \\ \mathrm{C} & -0.879888 & 0.380263 & 5.259660 \\ \mathrm{H} & -2.336584 & -1.156670 & 4.746883 \\ \mathrm{C} & 0.240060 & 1.331101 & 3.346987 \\ \mathrm{C} & -4.719246 & -3.713322 & 1.913672 \\ \mathrm{C} & -4.257860 & -2.330416 & -2.241138 \\ \mathrm{C} & -5.256798 & -3.953371 & -0.587029 \\ \mathrm{C} & -2.931538 & -4.364579 & -1.554269 \\ \mathrm{C} & 0.050531 & 1.279185 & 4.736343 \\ \mathrm{H} & -1.042923 & 0.323462 & 6.331769 \\ \mathrm{C} & 1.194902 & 2.260192 & 2.721059 \\ \mathrm{C} & -5.109078 & -4.664051 & 0.760858 \\ \mathrm{C} & -4.223329 & -4.531814 & 3.128133 \\ \mathrm{C} & -5.936091 & -2.844405 & 2.352720 \\ \mathrm{H} & -4.758372 & -2.885874 & -3.038557 \\ \mathrm{H} & -4.927950 & -1.523672 & -1.927979 \\ \mathrm{H} & -3.347320 & -1.889037 & -2.653616 \\ \mathrm{H} & -5.582261 & -4.668500 & -1.347524\end{array}$




\begin{tabular}{|c|c|c|c|}
\hline $\mathrm{H}$ & -6.044976 & -3.195287 & -0.528345 \\
\hline & -2.679887 & -5.084292 & -0.770827 \\
\hline $\mathrm{H}$ & -2.005486 & -3.893559 & -1.897451 \\
\hline $\mathrm{H}$ & -3.363746 & -4.918449 & -2.391748 \\
\hline $\mathrm{H}$ & 0.616911 & 1.928166 & 5.393980 \\
\hline & 2.035625 & 3.214331 & 3.317860 \\
\hline $\mathbf{N}$ & 1.340302 & 2.269145 & 1.365696 \\
\hline & -6.052150 & -5.151229 & 1.023241 \\
\hline $\mathrm{H}$ & -4.367965 & -5.466559 & 0.685343 \\
\hline & -5.003226 & -5.241412 & 3.416157 \\
\hline $\mathrm{H}$ & -3.323837 & -5.106385 & 2.886055 \\
\hline $\mathrm{H}$ & -4.010237 & -3.892767 & 3.986931 \\
\hline $\mathrm{H}$ & -6.721687 & -3.509416 & 2.720531 \\
\hline $\mathrm{H}$ & -6.350565 & -2.255630 & 1.530050 \\
\hline $\mathrm{H}$ & -5.657249 & -2.163902 & 3.161087 \\
\hline & 2.708235 & 3.815848 & 2.261008 \\
\hline $\mathrm{H}$ & 2.165166 & 3.465414 & 4.359802 \\
\hline$N$ & 2.267383 & 3.227015 & 1.123435 \\
\hline 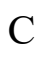 & 3.729896 & 4.909492 & 2.295147 \\
\hline $\mathrm{H}$ & 2.571811 & 3.459098 & 0.184415 \\
\hline 0 & 4.133661 & 5.218805 & 1.052798 \\
\hline $\mathrm{O}$ & 4.098729 & 5.405842 & 3.335914 \\
\hline 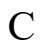 & 5.136378 & 6.288082 & 0.962729 \\
\hline $\mathrm{H}$ & 4.726963 & 7.20 & \\
\hline $\mathrm{H}$ & 6.033504 & 5.991133 & 1.507152 \\
\hline H & 5.338263 & 6.400060 & -0.100635 \\
\hline $\mathrm{N}$ & 1.726875 & -0.975965 & -0.741699 \\
\hline & 2.076385 & -1.166775 & -2.024443 \\
\hline $\mathrm{N}$ & 2.338610 & -1.657645 & 0.222801 \\
\hline $\mathrm{C}$ & 1.356105 & -0.336275 & -3.021389 \\
\hline $\mathrm{N}$ & 3.010845 & -2.034127 & -2.403833 \\
\hline $\mathrm{C}$ & 3.297976 & -2.533426 & -0.075507 \\
\hline $\mathrm{C}$ & 1.601885 & -0.445695 & -4.388168 \\
\hline $\mathrm{N}$ & 0.454171 & 0.532245 & -2.508177 \\
\hline , & 3.640804 & -2.744899 & -1.467461 \\
\hline 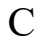 & 3.946033 & -3.292017 & 1.073825 \\
\hline $\mathrm{C}$ & 0.879869 & 0.380220 & -5.259664 \\
\hline $\mathrm{H}$ & 2.336564 & -1.156713 & -4.746880 \\
\hline $\mathrm{C}$ & -0.240068 & 1.331076 & -3.346994 \\
\hline $\mathrm{C}$ & 4.719235 & -3.713343 & -1.913656 \\
\hline 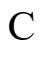 & 4.257878 & -2.330381 & 2.241141 \\
\hline $\mathrm{C}$ & 5.256812 & -3.953351 & 0.587044 \\
\hline $\mathrm{C}$ & 2.931560 & -4.364559 & 1.554304 \\
\hline 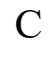 & -0.050545 & 1.279149 & -4.736351 \\
\hline $\mathrm{H}$ & 1.042900 & 0.323410 & -6.331774 \\
\hline $\mathrm{C}$ & -1.194904 & 2.260176 & -2.721070 \\
\hline
\end{tabular}




$\begin{array}{lrrr}\mathrm{C} & 5.109084 & -4.664052 & -0.760831 \\ \mathrm{C} & 4.223302 & -4.531857 & -3.128097 \\ \mathrm{C} & 5.936074 & -2.844434 & -2.352736 \\ \mathrm{H} & 4.758392 & -2.885828 & 3.038565 \\ \mathrm{H} & 4.927966 & -1.523640 & 1.927969 \\ \mathrm{H} & 3.347339 & -1.888998 & 2.653617 \\ \mathrm{H} & 5.582286 & -4.668466 & 1.347546 \\ \mathrm{H} & 6.044985 & -3.195262 & 0.528341 \\ \mathrm{H} & 2.679904 & -5.084279 & 0.770871 \\ \mathrm{H} & 2.005509 & -3.893538 & 1.897490 \\ \mathrm{H} & 3.363776 & -4.918419 & 2.391785 \\ \mathrm{H} & -0.616926 & 1.928127 & -5.393990 \\ \mathrm{C} & -2.035627 & 3.214312 & -3.317874 \\ \mathrm{~N} & -1.340299 & 2.269140 & -1.365706 \\ \mathrm{H} & 6.052156 & -5.151228 & -1.023215 \\ \mathrm{H} & 4.367977 & -5.466564 & -0.685297 \\ \mathrm{H} & 5.003195 & -5.241460 & -3.416118 \\ \mathrm{H} & 3.323813 & -5.106423 & -2.885997 \\ \mathrm{H} & 4.010199 & -3.892824 & -3.986903 \\ \mathrm{H} & 6.721664 & -3.509452 & -2.720549 \\ \mathrm{H} & 6.350561 & -2.255647 & -1.530081 \\ \mathrm{H} & 5.657221 & -2.163943 & -3.161109 \\ \mathrm{C} & -2.708231 & 3.815840 & -2.261024 \\ \mathrm{H} & -2.165172 & 3.465388 & -4.359817 \\ \mathrm{~N} & -2.267376 & 3.227014 & -1.123449 \\ \mathrm{C} & -3.729888 & 4.909487 & -2.295167 \\ \mathrm{H} & -2.571799 & 3.459105 & -0.184428 \\ \mathrm{O} & -4.133648 & 5.218811 & -1.052819 \\ \mathrm{O} & -4.098724 & 5.405830 & -3.335936 \\ \mathrm{C} & -5.136361 & 6.288091 & -0.962753 \\ \mathrm{H} & -4.726945 & 7.205822 & -1.386474 \\ \mathrm{H} & -6.033489 & 5.991140 & -1.507171 \\ \mathrm{H} & -5.338241 & 6.400077 & 0.100610\end{array}$

$\mathrm{M}=\mathrm{Gd}$

$\begin{array}{llll}\text { GD } & -0.000068 & 0.510060 & -0.000010 \\ \mathrm{~N} & 1.787414 & -0.947885 & -0.608767 \\ \mathrm{C} & 2.304593 & -1.062651 & -1.840931 \\ \mathrm{~N} & 2.267213 & -1.691288 & 0.398834 \\ \mathrm{C} & 1.690869 & -0.182335 & -2.867543 \\ \mathrm{~N} & 3.294050 & -1.894020 & -2.155980 \\ \mathrm{C} & 3.263370 & -2.543980 & 0.161239 \\ \mathrm{C} & 2.088782 & -0.190488 & -4.202276 \\ \mathrm{~N} & 0.708932 & 0.627725 & -2.405651 \\ \mathrm{C} & 3.798990 & -2.658526 & -1.180587\end{array}$




\begin{tabular}{|c|c|c|c|}
\hline $\mathrm{C}$ & 3.750988 & -3.388592 & 745 \\
\hline$C$ & 1.439378 & 0.675720 & -5.092599 \\
\hline $\mathrm{H}$ & 2.879479 & -0.857575 & -4.524367 \\
\hline 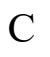 & 0.082838 & 1.461226 & -3.263911 \\
\hline $\mathrm{C}$ & 4.947864 & -3.578166 & -1.535564 \\
\hline$C$ & 3.869590 & -2.529276 & 2.608483 \\
\hline C & 5.129780 & -4.000297 & 0.991891 \\
\hline $\mathrm{C}$ & 2.696028 & -4.503795 & 1.566678 \\
\hline $\mathrm{C}$ & 0.423980 & 1.512224 & -4.621926 \\
\hline $\mathrm{H}$ & 1.721480 & 0.696351 & -6.141080 \\
\hline $\mathrm{C}$ & -0.969219 & 2.298138 & -2.667558 \\
\hline $\mathrm{C}$ & 5.191437 & -4.608953 & -0.410778 \\
\hline $\mathrm{C}$ & 4.655968 & -4.309238 & -2.866410 \\
\hline $\mathrm{C}$ & 6.196763 & -2.664833 & -1.728620 \\
\hline $\mathrm{H}$ & 4.263704 & -3.147462 & 3.419385 \\
\hline $\mathrm{H}$ & 4.560343 & -1.692273 & 117 \\
\hline $\mathrm{H}$ & 2.901492 & -2.133987 & 2.924226 \\
\hline $\mathrm{H}$ & 5.356505 & -4.767460 & 1.737515 \\
\hline $\mathrm{H}$ & 5.903715 & -3.233297 & 1.103677 \\
\hline $\mathrm{H}$ & 2.573037 & -5.155099 & 0.697291 \\
\hline $\mathrm{H}$ & 1.721846 & -4.068926 & 1.809526 \\
\hline $\mathrm{H}$ & 3.011667 & -5.125426 & 2.40 \\
\hline $\mathrm{H}$ & -0.090501 & 2.186552 & -5.296799 \\
\hline $\mathrm{C}$ & -1.793415 & 3.272134 & -3.249489 \\
\hline $\mathrm{N}$ & -1.242789 & 2.166516 & -1.336651 \\
\hline $\mathrm{H}$ & 6.172011 & -5.064978 & -0.571317 \\
\hline $\mathrm{H}$ & 4.464352 & -5.422694 & -0.501241 \\
\hline $\mathrm{H}$ & 5.485056 & -4.987675 & -3.083426 \\
\hline $\mathrm{H}$ & 3.743060 & -4.909582 & -2.802873 \\
\hline $\mathrm{H}$ & 4.559570 & -3.612632 & -3.700687 \\
\hline $\mathrm{H}$ & 7.041104 & -3.291582 & -2.026684 \\
\hline $\mathrm{H}$ & 6.475630 & -2.136200 & -0.813089 \\
\hline $\mathrm{H}$ & 6.022451 & -1.928281 & -2.516926 \\
\hline $\mathrm{C}$ & -2.591850 & 3.739245 & -2.210513 \\
\hline $\mathrm{H}$ & -1.835281 & 3.618853 & -4.271207 \\
\hline $\mathrm{N}$ & -2.235135 & 3.059542 & -1.095681 \\
\hline $\mathrm{C}$ & -3.657769 & 4.791462 & -2.243852 \\
\hline $\mathrm{H}$ & -2.639907 & 3.184884 & -0.174351 \\
\hline $\mathrm{O}$ & -4.195930 & 4.958450 & -1.026096 \\
\hline $\mathrm{O}$ & -3.943846 & 5.373889 & -3.265471 \\
\hline $\mathrm{C}$ & -5.254255 & 5.974192 & -0.937548 \\
\hline $\mathrm{H}$ & -4.849845 & 6.944702 & -1.227150 \\
\hline $\mathrm{H}$ & -6.077483 & 5.698125 & -1.597401 \\
\hline $\mathrm{H}$ & -5.564963 & 5.970926 & 0.105231 \\
\hline $\mathrm{N}$ & -1.787419 & -0.947986 & 0.608832 \\
\hline $\mathrm{C}$ & -2.304725 & -1.062568 & 1.840957 \\
\hline
\end{tabular}




\begin{tabular}{|c|c|c|c|}
\hline $\mathrm{N}$ & -2.266992 & -1.691667 & -0.398670 \\
\hline & -1.691125 & -0.182072 & 2.867484 \\
\hline 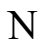 & -3.294192 & -1.893915 & 2.156037 \\
\hline C & -3.263073 & -2.544432 & -0.161022 \\
\hline C & -2.089157 & -0.190037 & 4.202182 \\
\hline $\mathrm{N}$ & -0.709154 & 0.627932 & 2.405558 \\
\hline $\mathrm{C}$ & -3.798949 & -2.658652 & 1.180732 \\
\hline C & -3.750292 & -3.389493 & -1.331370 \\
\hline $\mathrm{C}$ & -1.439841 & 0.676301 & 5.092443 \\
\hline $\mathrm{H}$ & -2.879875 & -0.857090 & 4.524296 \\
\hline $\mathrm{C}$ & -0.083142 & 1.461552 & 3.263764 \\
\hline $\mathrm{C}$ & -4.947919 & -3.578180 & 1.535678 \\
\hline $\mathrm{C}$ & -3.868690 & -2.530630 & -2.608431 \\
\hline $\mathrm{C}$ & -5.129075 & -4.001306 & -0.991672 \\
\hline $\mathrm{C}$ & -2.695100 & -4.504618 & -1.565646 \\
\hline $\mathrm{C}$ & -0.424403 & 1.512739 & 4.621741 \\
\hline $\mathrm{H}$ & -1.722037 & 0.697078 & 6.140895 \\
\hline $\mathrm{C}$ & 0.968974 & 2.298375 & 2.667388 \\
\hline $\mathrm{C}$ & -5.191039 & -4.609430 & 0.411217 \\
\hline $\mathrm{C}$ & -4.656521 & -4.308704 & 2.866927 \\
\hline $\mathrm{C}$ & -6.196906 & -2.664786 & 1.727881 \\
\hline $\mathrm{H}$ & -4.262531 & -3.149143 & -3.419216 \\
\hline $\mathrm{H}$ & -4.559580 & -1.693662 & -2.465520 \\
\hline $\mathrm{H}$ & -2.900565 & -2.135328 & -2.924075 \\
\hline $\mathrm{H}$ & -5.355448 & -4.768802 & -1.737062 \\
\hline $\mathrm{H}$ & -5.903114 & -3.234490 & -1.103985 \\
\hline $\mathrm{H}$ & -2.572253 & -5.155618 & -0.696010 \\
\hline $\mathrm{H}$ & -1.720914 & -4.069685 & -1.808367 \\
\hline $\mathrm{H}$ & -3.010416 & -5.126571 & -2.407539 \\
\hline $\mathrm{H}$ & 0.090018 & 2.187164 & 5.296564 \\
\hline $\mathrm{C}$ & 1.793180 & 3.272394 & 3.249265 \\
\hline $\mathrm{N}$ & 1.242616 & 2.166598 & 1.336513 \\
\hline $\mathrm{H}$ & -6.171599 & -5.065522 & 0.571655 \\
\hline $\mathrm{H}$ & -4.463873 & -5.423042 & 0.502204 \\
\hline $\mathrm{H}$ & -5.485672 & -4.987081 & 3.083892 \\
\hline $\mathrm{H}$ & -3.743570 & -4.909043 & 2.803989 \\
\hline $\mathrm{H}$ & -4.560471 & -3.611765 & 3.700966 \\
\hline $\mathrm{H}$ & -7.041357 & -3.291429 & 2.025857 \\
\hline $\mathrm{H}$ & -6.475417 & -2.136513 & 0.812035 \\
\hline $\mathrm{H}$ & -6.022913 & -1.927925 & 2.515969 \\
\hline $\mathrm{C}$ & 2.591700 & 3.739355 & 2.210288 \\
\hline $\mathrm{H}$ & 1.835008 & 3.619212 & 4.270952 \\
\hline $\mathrm{N}$ & 2.235017 & 3.059553 & 1.095504 \\
\hline 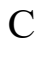 & 3.657684 & 4.791507 & 2.243588 \\
\hline $\mathrm{H}$ & 2.639846 & 3.184778 & 0.174184 \\
\hline $\mathrm{O}$ & 4.195948 & 4.958326 & 1.025855 \\
\hline
\end{tabular}




$\begin{array}{lrrr}\mathrm{O} & 3.943725 & 5.374024 & 3.265166 \\ \mathrm{C} & 5.254352 & 5.973983 & 0.937277 \\ \mathrm{H} & 4.849989 & 6.944554 & 1.226742 \\ \mathrm{H} & 6.077509 & 5.697931 & 1.597226 \\ \mathrm{H} & 5.565142 & 5.970580 & -0.105477\end{array}$

$\mathrm{M}=\mathrm{Am}$

$\begin{array}{lrrl}\text { AM } & 0.000042 & 0.564106 & 0.000008 \\ \mathrm{C} & 0.266608 & 1.298176 & 3.345345 \\ \mathrm{C} & 0.081488 & 1.249884 & 4.733551 \\ \mathrm{C} & -0.852772 & 0.356984 & 5.261407 \\ \mathrm{H} & 0.653958 & 1.896687 & 5.388092 \\ \mathrm{C} & -1.341828 & -0.361662 & 3.026315 \\ \mathrm{C} & -1.582371 & -0.465967 & 4.393741 \\ \mathrm{H} & -1.012697 & 0.302869 & 6.334092 \\ \mathrm{H} & -2.319639 & -1.172456 & 4.755847 \\ \mathrm{C} & -2.065911 & -1.187852 & 2.029646 \\ \mathrm{C} & -3.617415 & -2.762152 & 1.455212 \\ \mathrm{C} & -3.259243 & -2.544813 & 0.068148 \\ \mathrm{~N} & -0.434293 & 0.501637 & 2.507856 \\ \mathrm{~N} & -2.999412 & -2.056913 & 2.409420 \\ \mathrm{~N} & -1.708827 & -0.983854 & 0.756075 \\ \mathrm{~N} & -2.306222 & -1.663756 & -0.231242 \\ \mathrm{C} & -4.700866 & -3.727493 & 1.887860 \\ \mathrm{C} & -5.080950 & -4.677872 & 0.730565 \\ \mathrm{H} & -4.341670 & -5.482978 & 0.664751 \\ \mathrm{H} & -6.028386 & -5.161774 & 0.982344 \\ \mathrm{C} & -5.207916 & -3.967702 & -0.618978 \\ \mathrm{C} & -3.889699 & -3.309930 & -1.088816 \\ \mathrm{H} & -5.994939 & -3.207351 & -0.571413 \\ \mathrm{H} & -5.525262 & -4.681935 & -1.383873 \\ \mathrm{C} & -4.226526 & -4.548230 & 3.109482 \\ \mathrm{H} & -4.026697 & -3.912584 & 3.973586 \\ \mathrm{H} & -5.011955 & -5.257447 & 3.383184 \\ \mathrm{H} & -3.324100 & -5.123740 & 2.880612 \\ \mathrm{C} & -5.922254 & -2.856497 & 2.312086 \\ \mathrm{H} & -6.712967 & -3.519733 & 2.671924 \\ \mathrm{H} & -5.651968 & -2.175181 & 3.122645 \\ \mathrm{H} & -6.326437 & -2.268629 & 1.483537 \\ \mathrm{C} & -2.867612 & -4.387013 & -1.543345 \\ \mathrm{H} & -3.286101 & -4.948851 & -2.382559 \\ \mathrm{H} & -1.936019 & -3.919386 & -1.876103 \\ \mathrm{H} & -2.628301 & -5.099693 & -0.749646 \\ \mathrm{C} & -4.181358 & -2.360617 & -2.270591 \\ \mathrm{H} & -3.265590 & -1.927348 & -2.679227\end{array}$




\begin{tabular}{|c|c|c|c|}
\hline $\mathrm{H}$ & -4.674923 & -2.923372 & -3.067348 \\
\hline $\mathrm{H}$ & -4.852482 & -1.547878 & -1.975018 \\
\hline $\mathrm{C}$ & 1.221903 & 2.216536 & 2.709649 \\
\hline $\mathrm{C}$ & 2.080388 & 3.166690 & 3.283964 \\
\hline $\mathrm{C}$ & 2.743246 & 3.751112 & 2.210365 \\
\hline $\mathrm{H}$ & 2.229491 & 3.425870 & 4.321394 \\
\hline $1 \mathrm{~s}$ & 1.346398 & 2.211709 & 1.353466 \\
\hline N & 2.280489 & 3.157495 & 1.085283 \\
\hline $\mathrm{C}$ & 3.777293 & 4.834504 & 2.220387 \\
\hline $\mathrm{O}$ & 4.164078 & 5.335049 & 3.252339 \\
\hline $\mathrm{O}$ & 4.167085 & 5.127736 & 0.970347 \\
\hline $\mathrm{C}$ & 5.180852 & 6.185115 & 0.856025 \\
\hline $\mathrm{H}$ & 6.081899 & 5.882663 & 1.390800 \\
\hline $\mathrm{H}$ & 5.368854 & 6.284453 & -0.211103 \\
\hline $\mathrm{H}$ & 4.787365 & 7.111183 & 1.276619 \\
\hline $\mathrm{C}$ & -0.266183 & 1.298462 & -3.345300 \\
\hline $\mathrm{C}$ & -0.081049 & 1.250183 & -4.733505 \\
\hline $\mathrm{C}$ & 0.852896 & 0.356972 & -5.261392 \\
\hline Н & -0.653269 & 1.897233 & -5.388021 \\
\hline $\mathrm{C}$ & 1.341643 & -0.361979 & -3.026331 \\
\hline $\mathrm{C}$ & 1.582178 & -0.466293 & -4.393758 \\
\hline $\mathrm{H}$ & 1.012824 & 0.302861 & -6.334077 \\
\hline $\mathrm{H}$ & 2.319199 & -1.173026 & -4.755889 \\
\hline $\mathrm{C}$ & 2.065427 & -1.188472 & -2.029695 \\
\hline $\mathrm{C}$ & 3.616362 & -2.763356 & -1.455325 \\
\hline $\mathrm{C}$ & 3.258275 & -2.545939 & -0.068252 \\
\hline $\mathrm{N}$ & 0.434409 & 0.501617 & -2.507842 \\
\hline $\mathrm{N}$ & 2.998612 & -2.057856 & -2.409505 \\
\hline $\mathrm{N}$ & 1.708419 & -0.984395 & -0.756116 \\
\hline $\mathrm{N}$ & 2.305573 & -1.664549 & 0.231174 \\
\hline $\mathrm{C}$ & 4.699459 & -3.729076 & -1.888015 \\
\hline $\mathrm{C}$ & 5.079209 & -4.679632 & -0.730756 \\
\hline $\mathrm{H}$ & 4.339640 & -5.484474 & -0.664964 \\
\hline $\mathrm{H}$ & 6.026469 & -5.163865 & -0.982558 \\
\hline $\mathrm{C}$ & 5.206439 & -3.969553 & 0.618811 \\
\hline $\mathrm{C}$ & 3.888461 & -3.311326 & 1.088680 \\
\hline $\mathrm{H}$ & 5.993734 & -3.209484 & 0.571266 \\
\hline $\mathrm{H}$ & 5.523534 & -4.683927 & 1.383679 \\
\hline $\mathrm{C}$ & 4.224808 & -4.549601 & -3.109659 \\
\hline $\mathrm{H}$ & 4.025199 & -3.913855 & -3.973740 \\
\hline $\mathrm{H}$ & 5.009976 & -5.259094 & -3.383394 \\
\hline $\mathrm{H}$ & 3.322175 & -5.124792 & -2.880798 \\
\hline $\mathrm{C}$ & 5.921158 & -2.858510 & -2.312225 \\
\hline 1. & 6.711627 & -3.522021 & -2.672092 \\
\hline $\mathrm{H}$ & 5.651112 & -2.177070 & -3.122760 \\
\hline $\mathrm{H}$ & 6.325562 & -2.270816 & -1.483661 \\
\hline
\end{tabular}




$\begin{array}{lrrr}\mathrm{C} & 2.865989 & -4.388058 & 1.543176 \\ \mathrm{H} & 3.284281 & -4.950077 & 2.382365 \\ \mathrm{H} & 1.934566 & -3.920108 & 1.875956 \\ \mathrm{H} & 2.626417 & -5.100622 & 0.749451 \\ \mathrm{C} & 4.180467 & -2.362161 & 2.270490 \\ \mathrm{H} & 3.264858 & -1.928580 & 2.679148 \\ \mathrm{H} & 4.673836 & -2.925124 & 3.067222 \\ \mathrm{H} & 4.851882 & -1.549652 & 1.974944 \\ \mathrm{C} & -1.221140 & 2.217148 & -2.709569 \\ \mathrm{C} & -2.079121 & 3.167789 & -3.283831 \\ \mathrm{C} & -2.741736 & 3.752440 & -2.210205 \\ \mathrm{H} & -2.228044 & 3.427147 & -4.321243 \\ \mathrm{~N} & -1.345698 & 2.212254 & -1.353392 \\ \mathrm{~N} & -2.279316 & 3.158493 & -1.085158 \\ \mathrm{C} & -3.775245 & 4.836345 & -2.220171 \\ \mathrm{O} & -4.161733 & 5.337181 & -3.252092 \\ \mathrm{O} & -4.164950 & 5.129649 & -0.970121 \\ \mathrm{C} & -5.178207 & 6.187511 & -0.855744 \\ \mathrm{H} & -6.079374 & 5.885551 & -1.390593 \\ \mathrm{H} & -5.366214 & 6.286835 & 0.211384 \\ \mathrm{H} & -4.784247 & 7.113428 & -1.276228 \\ \mathrm{H} & -2.572406 & 3.378245 & -0.139643 \\ \mathrm{H} & 2.573622 & 3.377214 & 0.139774\end{array}$

$\mathrm{M}=\mathrm{Cm}$

$\begin{array}{lrrc}\mathrm{CM} & 0.000000 & 0.509638 & 0.000000 \\ \mathrm{~N} & -1.793498 & -0.989137 & 0.656360 \\ \mathrm{C} & -2.273801 & -1.126802 & 1.900514 \\ \mathrm{~N} & -2.299792 & -1.720591 & -0.347984 \\ \mathrm{C} & -1.641490 & -0.262729 & 2.930171 \\ \mathrm{~N} & -3.249939 & -1.969606 & 2.229626 \\ \mathrm{C} & -3.283319 & -2.582407 & -0.096310 \\ \mathrm{C} & -2.013194 & -0.305013 & 4.272247 \\ \mathrm{~N} & -0.677050 & 0.567039 & 2.468849 \\ \mathrm{C} & -3.779555 & -2.721181 & 1.257718 \\ \mathrm{C} & -3.798863 & -3.411538 & -1.266315 \\ \mathrm{C} & -1.355515 & 0.547241 & 5.169334 \\ \mathrm{H} & -2.791231 & -0.986635 & 4.594367 \\ \mathrm{C} & -0.044296 & 1.388802 & 3.332435 \\ \mathrm{C} & -4.913022 & -3.652778 & 1.630704 \\ \mathrm{C} & -3.961837 & -2.531784 & -2.524167 \\ \mathrm{C} & -5.162425 & -4.040138 & -0.896713 \\ \mathrm{C} & -2.743128 & -4.514152 & -1.551342 \\ \mathrm{C} & -0.359165 & 1.405404 & 4.697730 \\ \mathrm{H} & -1.617315 & 0.541264 & 6.223242\end{array}$




\begin{tabular}{|c|c|c|c|}
\hline $\mathrm{C}$ & 0.985036 & 2.256823 & 2.739877 \\
\hline $\mathrm{C}$ & -5.179686 & -4.669357 & 0.498128 \\
\hline $\mathrm{C}$ & -4.581202 & -4.400551 & 2.942642 \\
\hline $\mathrm{C}$ & -6.161805 & -2.750386 & 1.869580 \\
\hline H & -4.377045 & -3.138796 & -3.333024 \\
\hline $\mathrm{H}$ & -4.652798 & -1.701706 & -2.345443 \\
\hline $\mathrm{H}$ & -3.006144 & -2.125072 & -2.862578 \\
\hline $\mathrm{H}$ & -5.403739 & -4.798469 & -1.646784 \\
\hline $\mathrm{H}$ & -5.945552 & -3.278370 & -0.975578 \\
\hline $\mathrm{H}$ & -2.591340 & -5.180588 & -0.698028 \\
\hline $\mathrm{H}$ & -1.779121 & -4.067498 & -1.812963 \\
\hline $\mathrm{H}$ & -3.077625 & -5.122605 & -2.395720 \\
\hline $\mathrm{H}$ & 0.160056 & 2.070844 & 5.377699 \\
\hline $\mathrm{C}$ & 1.804912 & 3.224747 & 3.338063 \\
\hline $\mathrm{N}$ & 1.237911 & 2.172240 & 1.401382 \\
\hline $\mathrm{H}$ & -6.151523 & -5.136230 & 0.679235 \\
\hline $\mathrm{H}$ & -4.443413 & -5.477852 & 0.556356 \\
\hline $\mathrm{H}$ & -5.399135 & -5.088525 & 3.171703 \\
\hline $\mathrm{H}$ & -3.665751 & -4.992734 & 2.846685 \\
\hline $\mathrm{H}$ & -4.468113 & -3.715222 & 3.784157 \\
\hline $\mathrm{H}$ & -6.994404 & -3.386207 & 2.181235 \\
\hline $\mathrm{H}$ & -6.468030 & -2.210796 & 0.96 \\
\hline $\mathrm{H}$ & -5.970797 & -2.023540 & 2.663047 \\
\hline $\mathrm{C}$ & 2.578650 & 3.736713 & 2.301674 \\
\hline $\mathrm{H}$ & 1.859664 & 3.539956 & 4.369245 \\
\hline $\mathrm{N}$ & 2.213333 & 3.087607 & \\
\hline $\mathrm{C}$ & 3.629146 & 4.803355 & 2.351719 \\
\hline $\mathrm{H}$ & 2.600098 & 3.248482 & 0.249018 \\
\hline $\mathrm{O}$ & 4.143797 & 5.018143 & 1.131311 \\
\hline $\mathrm{O}$ & 3.924266 & 5.356579 & 3.386959 \\
\hline $\mathrm{C}$ & 5.185610 & 6.051876 & 1.057992 \\
\hline $\mathrm{H}$ & 4.772530 & 7.006287 & 1.386300 \\
\hline $\mathrm{H}$ & 6.024350 & 5.766720 & 1.694027 \\
\hline $\mathrm{H}$ & 5.477703 & 6.087209 & 0.010419 \\
\hline $\mathrm{N}$ & 1.793496 & -0.989140 & -0.656360 \\
\hline $\mathrm{C}$ & 2.273799 & -1.126804 & -1.900515 \\
\hline $\mathrm{N}$ & 2.299788 & -1.720596 & 0.347983 \\
\hline $\mathrm{C}$ & 1.641491 & -0.262729 & -2.930170 \\
\hline $\mathrm{N}$ & 3.249936 & -1.969609 & -2.229627 \\
\hline $\mathrm{C}$ & 3.283313 & -2.582414 & 0.096308 \\
\hline $\mathrm{C}$ & 2.013195 & -0.305012 & -4.272247 \\
\hline $\mathrm{N}$ & 0.677051 & 0.567040 & -2.468848 \\
\hline $\mathrm{C}$ & 3.779551 & -2.721186 & -1.257720 \\
\hline $\mathrm{C}$ & 3.798855 & -3.411548 & 1.266312 \\
\hline $\mathrm{C}$ & 1.355519 & 0.547245 & -5.169333 \\
\hline $\mathrm{H}$ & 2.791231 & -0.986634 & -4.594367 \\
\hline
\end{tabular}




$\begin{array}{lrrr}\mathrm{C} & 0.044299 & 1.388806 & -3.332434 \\ \mathrm{C} & 4.913017 & -3.652783 & -1.630706 \\ \mathrm{C} & 3.961827 & -2.531797 & 2.524167 \\ \mathrm{C} & 5.162418 & -4.040147 & 0.896711 \\ \mathrm{C} & 2.743118 & -4.514162 & 1.551334 \\ \mathrm{C} & 0.359170 & 1.405409 & -4.697728 \\ \mathrm{H} & 1.617319 & 0.541268 & -6.223241 \\ \mathrm{C} & -0.985031 & 2.256828 & -2.739875 \\ \mathrm{C} & 5.179680 & -4.669364 & -0.498131 \\ \mathrm{C} & 4.581197 & -4.400555 & -2.942645 \\ \mathrm{C} & 6.161801 & -2.750392 & -1.869580 \\ \mathrm{H} & 4.377033 & -3.138811 & 3.333023 \\ \mathrm{H} & 4.652789 & -1.701719 & 2.345446 \\ \mathrm{H} & 3.006133 & -2.125085 & 2.862577 \\ \mathrm{H} & 5.403731 & -4.798478 & 1.646781 \\ \mathrm{H} & 5.945544 & -3.278379 & 0.975578 \\ \mathrm{H} & 2.591332 & -5.180595 & 0.698018 \\ \mathrm{H} & 1.779112 & -4.067508 & 1.812956 \\ \mathrm{H} & 3.077614 & -5.122617 & 2.395711 \\ \mathrm{H} & -0.160051 & 2.070850 & -5.377697 \\ \mathrm{C} & -1.804906 & 3.224754 & -3.338060 \\ \mathrm{~N} & -1.237907 & 2.172243 & -1.401380 \\ \mathrm{H} & 6.151517 & -5.136237 & -0.679238 \\ \mathrm{H} & 4.443407 & -5.477859 & -0.556361 \\ \mathrm{H} & 5.399130 & -5.088530 & -3.171706 \\ \mathrm{H} & 3.665745 & -4.992737 & -2.846688 \\ \mathrm{H} & 4.468109 & -3.715225 & -3.784160 \\ \mathrm{H} & 6.994399 & -3.386214 & -2.181236 \\ \mathrm{H} & 6.468026 & -2.210804 & -0.969312 \\ \mathrm{H} & 5.970794 & -2.023546 & -2.663047 \\ \mathrm{C} & -2.578643 & 3.736720 & -2.301672 \\ \mathrm{H} & -1.859656 & 3.539964 & -4.369242 \\ \mathrm{H} & -2.213327 & 3.087612 & -1.172397 \\ \mathrm{C} & -3.629137 & 4.803364 & -2.351716 \\ \mathrm{H} & -2.600093 & 3.248486 & -0.249016 \\ \mathrm{O} & -4.143789 & 5.018152 & -1.131308 \\ \mathrm{C} & -3.924256 & 5.356590 & -3.386955 \\ \mathrm{H} & -4.185600 & 6.051886 & -1.057988 \\ & -6.024340 & 5.766733 & -1.694024 \\ \mathrm{H} & & \\ \mathrm{H} & & \\ \mathrm{H} & & \end{array}$

$\mathbf{L}=\mathbf{2} \mathbf{a m}$

\section{$\left[\mathrm{ML}\left(\mathrm{H}_{2} \mathrm{O}\right)_{6}\right]^{3+}$}




\begin{tabular}{|c|c|c|c|}
\hline EU & -1.317406 & -1.064697 & -0.038807 \\
\hline $\mathrm{O}$ & 0.238495 & -2.532089 & 1.369684 \\
\hline $\mathrm{H}$ & 1.180041 & -2.413991 & 1.127860 \\
\hline $\mathrm{O}$ & -1.321752 & -0.372475 & 2.463492 \\
\hline $\mathrm{H}$ & -0.610781 & -0.684823 & 3.047087 \\
\hline $\mathrm{O}$ & -2.757816 & -2.667256 & -1.493781 \\
\hline $\mathrm{H}$ & -2.955 & -2.314016 & 450 \\
\hline $\mathrm{O}$ & -2.809354 & -2.569991 & 1.474300 \\
\hline $\mathrm{H}$ & -3.208698 & -3.454302 & 1.484159 \\
\hline $\mathrm{O}$ & 0.203108 & -2.341265 & -1.671780 \\
\hline $\mathrm{H}$ & 0.016 & -3.16 & 606 \\
\hline $\mathrm{O}$ & -1.593808 & -0.3 & 000 \\
\hline $\mathrm{H}$ & -0.8 & -0.5 & 897 \\
\hline $\mathrm{H}$ & 0.1 & -3.3 & \\
\hline $\mathrm{H}$ & -2.8 & -2.2 & 004 \\
\hline $\mathrm{H}$ & 1.1 & -2.3 & -1.4 \\
\hline $\mathrm{H}$ & -3.18 & -3.5 & 225 \\
\hline $\mathrm{H}$ & -2.0 & & -2.8 \\
\hline $\mathrm{H}$ & -1.6 & 0.4 & 120 \\
\hline $\mathrm{C}$ & & & \\
\hline $\mathrm{C}$ & -2.1 & 3.7 & -0 \\
\hline $\mathrm{C}$ & -0.8 & 4.3 & -0.2 \\
\hline $\mathrm{H}$ & -3.0 & 4.3 & -0 . \\
\hline $\mathrm{C}$ & 0.1 & 2.1 & -0.0 \\
\hline $\mathrm{C}$ & 0.2 & 3.5 & -0.1 \\
\hline $\mathrm{H}$ & -0.7 & 5.3 & -0.2 \\
\hline $\mathrm{H}$ & 1.2 & 3.9 & -0.2 \\
\hline $\mathrm{C}$ & 1.3 & 1.2 & -0.0 \\
\hline $\mathrm{C}$ & 3.6 & 0.9 & 0.0 \\
\hline $\mathrm{C}$ & 3.391289 & -0.4 & 0.0 \\
\hline $\mathrm{N}$ & -1.0 & 1.5 & -0 \\
\hline $\mathrm{N}$ & 2.5 & 1.7 & -0.0 \\
\hline $\mathrm{N}$ & 1.09 & -0.0 & -0. \\
\hline $\mathrm{N}$ & 2.1 & -0.9 & 468 \\
\hline $\mathrm{C}$ & 4.98 & 1.60 & 0.1 \\
\hline $\mathrm{C}$ & 6.08 & 0.5 & -0.1 \\
\hline $\mathrm{H}$ & 6.210847 & 0.426037 & -1.2 \\
\hline $\mathrm{H}$ & 7.03 & 0.9 & 431 \\
\hline $\mathrm{C}$ & 5.827503 & $-0.7 \varepsilon$ & 258 \\
\hline $\mathrm{C}$ & 4.528669 & -1.473514 & 0.020741 \\
\hline $\mathrm{H}$ & 5.783792 & -0.665446 & 1.598732 \\
\hline $\mathrm{H}$ & 6.663925 & -1.464279 & 0.316104 \\
\hline $\mathrm{C}$ & 5.096083 & 2.768399 & -0.913440 \\
\hline $\mathrm{H}$ & 4.380464 & 3.563873 & -0.697098 \\
\hline
\end{tabular}




$\begin{array}{lrrr}\mathrm{H} & 6.102810 & 3.189359 & -0.852041 \\ \mathrm{H} & 4.941469 & 2.425338 & -1.940947 \\ \mathrm{C} & 5.098606 & 2.178975 & 1.546759 \\ \mathrm{H} & 6.062316 & 2.686287 & 1.638312 \\ \mathrm{H} & 4.308019 & 2.907721 & 1.742524 \\ \mathrm{H} & 5.054057 & 1.400743 & 2.313514 \\ \mathrm{C} & 4.690354 & -1.971220 & -1.442470 \\ \mathrm{H} & 5.516424 & -2.685356 & -1.490003 \\ \mathrm{H} & 3.785929 & -2.486335 & -1.784796 \\ \mathrm{H} & 4.906150 & -1.162925 & -2.145102 \\ \mathrm{C} & 4.213089 & -2.677448 & 0.934255 \\ \mathrm{H} & 3.372904 & -3.269841 & 0.556935 \\ \mathrm{H} & 5.081079 & -3.340448 & 0.966920 \\ \mathrm{H} & 4.002757 & -2.363271 & 1.961657 \\ \mathrm{C} & -3.469869 & 1.604040 & 0.018308 \\ \mathrm{C} & -4.778770 & 2.106488 & 0.076791 \\ \mathrm{C} & -5.612793 & 0.987344 & 0.191590 \\ \mathrm{H} & -5.108657 & 3.134179 & 0.048027 \\ \mathrm{~N} & -3.469693 & 0.246568 & 0.087926 \\ \mathrm{~N} & -4.781705 & -0.087928 & 0.195226 \\ \mathrm{C} & -7.099316 & 0.874879 & 0.291723 \\ \mathrm{H} & -7.573526 & 1.281500 & -0.606670 \\ \mathrm{H} & -7.422562 & -0.161317 & 0.412497 \\ \mathrm{H} & -7.467356 & 1.452737 & 1.144503 \\ \mathrm{H} & -5.047756 & -1.062074 & 0.271905\end{array}$

$$
\begin{array}{lrrc}
\mathrm{M}=\mathrm{Gd} & & & \\
\mathrm{GD} & 1.293162 & -1.010898 & -0.044159 \\
\mathrm{O} & -0.222832 & -2.300080 & -1.638301 \\
\mathrm{H} & -1.172157 & -2.285190 & -1.408998 \\
\mathrm{O} & 1.408250 & -0.185245 & -2.439834 \\
\mathrm{H} & 0.703859 & -0.437028 & -3.060558 \\
\mathrm{O} & 2.762168 & -2.598005 & 1.339684 \\
\mathrm{H} & 2.876141 & -2.310422 & 2.261685 \\
\mathrm{O} & 2.705713 & -2.505782 & -1.575319 \\
\mathrm{H} & 3.124722 & -3.381264 & -1.571156 \\
\mathrm{O} & -0.210092 & -2.470271 & 1.318010 \\
\mathrm{H} & -0.149842 & -3.358023 & 1.703571 \\
\mathrm{O} & 1.364946 & -0.403643 & 2.406668 \\
\mathrm{H} & 0.661857 & -0.726268 & 2.995261 \\
\mathrm{H} & -0.061628 & -3.118706 & -2.134390 \\
\mathrm{H} & 2.873103 & -2.128407 & -2.455681 \\
\mathrm{H} & -1.145262 & -2.310852 & 1.048454 \\
\mathrm{H} & 3.103243 & -3.505789 & 1.296623 \\
\mathrm{H} & 1.737397 & 0.389643 & 2.825355
\end{array}
$$




\begin{tabular}{|c|c|c|c|}
\hline $\mathrm{H}$ & 1.806186 & 0.630489 & -2.785538 \\
\hline & 2.196879 & 2.294472 & 0.055499 \\
\hline T & 2.129486 & 3.695231 & 0.071022 \\
\hline 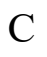 & 0.878897 & 4.313841 & 0.066765 \\
\hline 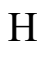 & 3.037010 & 4.287729 & 0.086511 \\
\hline & -0.124892 & 2.131414 & 0.034843 \\
\hline 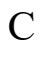 & -0.273337 & 3.518102 & 0.048136 \\
\hline त & 0.800536 & 5.396937 & 0.078686 \\
\hline $\mathrm{H}$ & -1.267139 & 3.948539 & 0.045913 \\
\hline C & -1.307115 & 1.233103 & 0.026438 \\
\hline 0 & -3.585297 & 0.961622 & 0.014139 \\
\hline $\mathrm{C}$ & -3.360277 & -0.473166 & 0.064617 \\
\hline $\mathrm{N}$ & 1.084416 & 1.522832 & 0.037651 \\
\hline $\mathbf{N}$ & -2.530626 & 1.773637 & 0.008405 \\
\hline $\mathbf{N}$ & -1.060726 & -0.079647 & 0.039184 \\
\hline $\mathbf{N}$ & -2.112084 & -0.930342 & 106 \\
\hline $\mathrm{C}$ & -4.962711 & 1.579102 & -0.087696 \\
\hline $\mathrm{C}$ & -6.057282 & 0.546438 & 0.263705 \\
\hline $\mathrm{H}$ & -6.152190 & 0.472648 & 1.351652 \\
\hline $\mathrm{H}$ & -7.016344 & 0.930458 & -0.093217 \\
\hline $\mathrm{C}$ & -5.805135 & -0.837123 & -0.339662 \\
\hline $\mathrm{C}$ & -4.491614 & -1.489059 & 0.155985 \\
\hline $\mathrm{H}$ & -5.789294 & -0.776379 & -1.433271 \\
\hline $\mathrm{H}$ & -6.632352 & -1.505975 & -0.0 \\
\hline $\mathrm{C}$ & -5.073865 & 2.806387 & 0.846068 \\
\hline $\mathrm{H}$ & -4.373506 & 3.595126 & 0.566993 \\
\hline $\mathrm{H}$ & -6.086590 & 3.210950 & 0.773730 \\
\hline $\mathrm{H}$ & -4.898985 & 2.533915 & 1.891420 \\
\hline $\mathrm{C}$ & -5.111662 & 2.057365 & -1.565984 \\
\hline $\mathrm{H}$ & -6.081303 & 2.550218 & -1.671793 \\
\hline $\mathrm{H}$ & -4.331866 & 2.778614 & -1.822939 \\
\hline $\mathrm{H}$ & -5.074099 & 1.231708 & -2.282054 \\
\hline $\mathrm{C}$ & -4.618055 & -1.907169 & 1.647866 \\
\hline $\mathrm{H}$ & -5.433313 & -2.627971 & 1.750373 \\
\hline $\mathrm{H}$ & -3.699977 & -2.387185 & 2.003276 \\
\hline $\mathrm{H}$ & -4.834452 & -1.062932 & 2.306778 \\
\hline $\mathrm{C}$ & -4.189695 & -2.739238 & -0.696868 \\
\hline $\mathrm{H}$ & -3.334550 & -3.307625 & -0.317382 \\
\hline $\mathrm{H}$ & -5.053074 & -3.408631 & -0.670606 \\
\hline $\mathrm{H}$ & -4.014628 & -2.479144 & -1.746615 \\
\hline $\mathrm{C}$ & 3.472331 & 1.565140 & 0.060882 \\
\hline $\mathrm{C}$ & 4.796105 & 2.026804 & 0.090425 \\
\hline $\mathrm{C}$ & 5.600101 & 0.880911 & 0.089547 \\
\hline $\mathrm{H}$ & 5.152985 & 3.045651 & 0.112728 \\
\hline $\mathrm{N}$ & 3.433493 & 0.206863 & 0.040557 \\
\hline 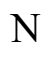 & 4.741454 & -0.169943 & 0.058748 \\
\hline
\end{tabular}




$\begin{array}{lrrr}\text { C } & 7.086786 & 0.723332 & 0.115921 \\ \mathrm{H} & 4.983886 & -1.152860 & 0.060002 \\ \mathrm{H} & 7.385053 & -0.327379 & 0.118325 \\ \mathrm{H} & 7.535715 & 1.206598 & -0.756576 \\ \mathrm{H} & 7.503884 & 1.201633 & 1.006637\end{array}$

$\mathrm{M}=\mathrm{Am}$

$\begin{array}{lccc}\text { AM } & -1.209154 & -0.931305 & 0.046382 \\ \text { N } & -3.330889 & 0.388425 & -0.047961 \\ \text { N } & -4.651337 & 0.057077 & -0.085424 \\ \mathrm{C} & -3.322433 & 1.747986 & -0.050222 \\ \mathrm{C} & -5.472403 & 1.136667 & -0.105983 \\ \mathrm{H} & -4.927137 & -0.916993 & -0.097912 \\ \mathrm{C} & -4.629014 & 2.254146 & -0.083764 \\ \mathrm{C} & -2.026938 & 2.441469 & -0.033675 \\ \mathrm{C} & -6.963117 & 1.031573 & -0.141569 \\ \mathrm{H} & -4.951839 & 3.284422 & -0.094339 \\ \mathrm{C} & -1.929207 & 3.840446 & -0.039120 \\ \mathrm{~N} & -0.931763 & 1.646404 & -0.021422 \\ \mathrm{H} & -7.360652 & 1.563496 & -1.010489 \\ \mathrm{H} & -7.397905 & 1.490929 & 0.751008 \\ \mathrm{H} & -7.297211 & -0.007086 & -0.191309 \\ \mathrm{C} & -0.666068 & 4.432014 & -0.034184 \\ \mathrm{H} & -2.823074 & 4.453285 & -0.048911 \\ \mathrm{C} & 0.290760 & 2.228309 & -0.020143 \\ \mathrm{C} & 0.468500 & 3.611695 & -0.025869 \\ \mathrm{H} & -0.564549 & 5.513194 & -0.038690 \\ \mathrm{C} & 1.459098 & 1.310365 & -0.018470 \\ \mathrm{H} & 1.470811 & 4.021652 & -0.024988 \\ \mathrm{~N} & 2.690673 & 1.834136 & -0.010889 \\ \mathrm{~N} & 1.195954 & 0.001233 & -0.020876 \\ \mathrm{C} & 3.734093 & 1.007582 & -0.021518 \\ \mathrm{~N} & 2.235032 & -0.864709 & -0.046136 \\ \mathrm{C} & 5.120736 & 1.608037 & 0.063595 \\ \mathrm{C} & 3.489242 & -0.424135 & -0.056374 \\ \mathrm{C} & 6.199272 & 0.556348 & -0.280905 \\ \mathrm{C} & 5.241173 & 2.820346 & -0.888582 \\ \mathrm{C} & 5.286896 & 2.104803 & 1.533594 \\ \mathrm{C} & 4.606614 & -1.456132 & -0.143146 \\ \mathrm{C} & 5.931002 & -0.816524 & 0.339729 \\ \mathrm{H} & 7.165269 & 0.931057 & 0.067081 \\ \mathrm{H} & 6.288132 & 0.468437 & -1.368327 \\ \mathrm{H} & 6.259506 & 3.212842 & -0.829416 \\ \mathrm{H} & 5.055083 & 2.535315 & -1.928662 \\ \mathrm{H} & 4.553004 & 3.621988 & -0.615904\end{array}$




$\begin{array}{crrr}\mathrm{H} & 6.262800 & 2.587944 & 1.625687 \\ \mathrm{H} & 5.245313 & 1.289318 & 2.261015 \\ \mathrm{H} & 4.517240 & 2.838150 & 1.786791 \\ \mathrm{C} & 4.293027 & -2.694323 & 0.722745 \\ \mathrm{C} & 4.720689 & -1.890070 & -1.631362 \\ \mathrm{H} & 6.748177 & -1.499410 & 0.091664 \\ \mathrm{H} & 5.919945 & -0.742725 & 1.432609 \\ \mathrm{H} & 3.431652 & -3.257710 & 0.349384 \\ \mathrm{H} & 4.121399 & -2.422325 & 1.769830 \\ \mathrm{H} & 5.149141 & -3.373189 & 0.701363 \\ \mathrm{H} & 5.526870 & -2.621332 & -1.731673 \\ \mathrm{H} & 3.795212 & -2.363575 & -1.976881 \\ \mathrm{H} & 4.942464 & -1.055111 & -2.300188 \\ \mathrm{O} & 0.301065 & -2.378971 & -1.461512 \\ \mathrm{H} & 0.224530 & -3.259287 & -1.862392 \\ \mathrm{H} & 1.236047 & -2.253555 & -1.190003 \\ \mathrm{O} & 0.371500 & -2.273958 & 1.554368 \\ \mathrm{H} & 0.256257 & -3.122193 & 2.011723 \\ \mathrm{H} & 1.307732 & -2.212569 & 1.272582 \\ \mathrm{O} & -1.287242 & -0.136392 & 2.536460 \\ \mathrm{H} & -1.671764 & 0.674354 & 2.908726 \\ \mathrm{H} & -0.569608 & -0.400563 & 3.136623 \\ \mathrm{O} & -1.310458 & -0.295167 & -2.479367 \\ \mathrm{H} & -1.667656 & 0.505510 & -2.897438 \\ \mathrm{H} & -0.607352 & -0.624580 & -3.064220 \\ \mathrm{O} & -2.610773 & -2.449889 & 1.624361 \\ \mathrm{H} & -3.033785 & -3.323653 & 1.623880 \\ \mathrm{H} & -2.729600 & -2.088676 & 2.519365 \\ \mathrm{O} & -2.770874 & -2.463455 & -1.363232 \\ \mathrm{H} & -3.135312 & -3.362564 & -1.326035 \\ \mathrm{H} & -2.860491 & -2.169784 & -2.286176\end{array}$

$\mathrm{M}=\mathrm{Cm}$

$\begin{array}{lccc}\mathrm{CM} & 1.201353 & -0.906532 & 0.122143 \\ \mathrm{O} & 2.752819 & -2.375304 & 1.693050 \\ \mathrm{H} & 3.703767 & -2.521281 & 1.824541 \\ \mathrm{O} & 1.472661 & 0.097524 & 2.512985 \\ \mathrm{H} & 2.164098 & -0.239071 & 3.106314 \\ \mathrm{O} & -0.376712 & -2.603658 & -0.810666 \\ \mathrm{H} & -0.407859 & -3.435915 & -1.305449 \\ \mathrm{O} & -0.013481 & -2.252249 & 2.020902 \\ \mathrm{H} & -0.667549 & -2.949277 & 1.849040 \\ \mathrm{O} & 2.734536 & -2.532398 & -1.211018 \\ \mathrm{H} & 3.014146 & -3.429067 & -0.963069 \\ \mathrm{O} & 1.095146 & -0.481238 & -2.411156\end{array}$




\begin{tabular}{|c|c|c|c|}
\hline $\mathrm{H}$ & 1.520011 & 0.264758 & -2.866033 \\
\hline $\mathrm{H}$ & 2.293633 & -3.005768 & 2.273735 \\
\hline$U$ & -0.237630 & -1.865511 & 2.883522 \\
\hline $\mathrm{H}$ & 2.715032 & -2.507018 & -2.182625 \\
\hline & -1.307907 & -2.239708 & -0.691256 \\
\hline & 0.358354 & -0.762946 & -2.978163 \\
\hline & 1.271853 & 0.997808 & 2.816042 \\
\hline 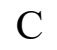 & 2.002374 & 2.437851 & 0.004945 \\
\hline $\mathrm{C}$ & 1.904094 & 3.832048 & 0.117151 \\
\hline C & 0.643594 & 4.415095 & 0.254253 \\
\hline & 2.794799 & 4.449039 & 0.091070 \\
\hline & -0.314910 & 2.215430 & 0.141609 \\
\hline $\mathrm{C}$ & -0.491014 & 3.594077 & 0.258189 \\
\hline $\mathrm{H}$ & 0.543386 & 5.492759 & 0.344324 \\
\hline $\mathrm{H}$ & -1.491620 & 4.000381 & 0.339684 \\
\hline $\mathrm{C}$ & -1.481121 & 1.294888 & 0.081035 \\
\hline $\mathrm{C}$ & -3.752748 & 0.987198 & -0.001875 \\
\hline $\mathrm{C}$ & -3.500527 & -0.425330 & -0.214931 \\
\hline $\mathrm{N}$ & 0.907239 & 1.641338 & 0.034199 \\
\hline $\mathrm{N}$ & -2.712805 & 1.812023 & 0.116831 \\
\hline $\mathrm{N}$ & -1.212349 & -0.008996 & -0.043578 \\
\hline $\mathrm{N}$ & -2.244531 & -0.859702 & -0.217237 \\
\hline 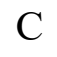 & -5.141850 & 1.587018 & 0.034561 \\
\hline $\mathrm{C}$ & -6.214712 & 0.480239 & 0.139289 \\
\hline $\mathrm{H}$ & -6.309250 & 0.159898 & 1.181899 \\
\hline $\mathrm{H}$ & -7.181643 & 0.914229 & -0.127581 \\
\hline $\mathrm{C}$ & -5.928144 & -0.724609 & -0.759473 \\
\hline $\mathrm{C}$ & -4.611060 & -1.453098 & -0.399586 \\
\hline I & -5.895540 & -0.413998 & -1.809402 \\
\hline H & -6.746654 & -1.445555 & -0.683740 \\
\hline $\mathrm{C}$ & -5.265041 & 2.560107 & 1.231150 \\
\hline $\mathrm{H}$ & -4.572257 & 3.399015 & 1.145512 \\
\hline $\mathrm{H}$ & -6.281695 & 2.960643 & 1.254281 \\
\hline $\mathrm{H}$ & -5.087552 & 2.051560 & 2.184002 \\
\hline $\mathrm{C}$ & -5.311435 & 2.393920 & -1.289179 \\
\hline $\mathrm{H}$ & -6.289325 & 2.881457 & -1.273257 \\
\hline $\mathrm{H}$ & -4.544524 & 3.167216 & -1.376325 \\
\hline $\mathrm{H}$ & -5.266993 & 1.757538 & -2.177194 \\
\hline $\mathrm{C}$ & -4.762236 & -2.224645 & 0.940316 \\
\hline $\mathrm{H}$ & -5.557069 & -2.968061 & 0.839422 \\
\hline $\mathrm{H}$ & -3.837288 & -2.753672 & 1.192910 \\
\hline $\mathrm{H}$ & -5.021228 & -1.571149 & 1.777022 \\
\hline $\mathrm{C}$ & -4.259817 & -2.453193 & -1.522029 \\
\hline . & -3.416459 & -3.098227 & -1.256239 \\
\hline $\mathrm{H}$ & -5.117033 & -3.108029 & -1.697282 \\
\hline $\mathrm{H}$ & -4.037571 & -1.944668 & -2.465422 \\
\hline
\end{tabular}




$\begin{array}{lrrr}\mathrm{C} & 3.289625 & 1.754469 & -0.189583 \\ \mathrm{C} & 4.586026 & 2.273405 & -0.325210 \\ \mathrm{C} & 5.417720 & 1.171769 & -0.553291 \\ \mathrm{H} & 4.906121 & 3.303671 & -0.282607 \\ \mathrm{~N} & 3.295285 & 0.402012 & -0.315583 \\ \mathrm{~N} & 4.602610 & 0.086159 & -0.532261 \\ \mathrm{H} & 4.861740 & -0.873496 & -0.726404 \\ \mathrm{C} & 6.891501 & 1.084767 & -0.790821 \\ \mathrm{H} & 7.170631 & 1.674994 & -1.668227 \\ \mathrm{H} & 7.439470 & 1.489927 & 0.064706 \\ \mathrm{H} & 7.217942 & 0.054916 & -0.951970\end{array}$

\section{$\left[\mathrm{ML}\left(\mathrm{H}_{2} \mathrm{O}\right)_{5}\right]^{3+}$}

$\mathrm{M}=\mathrm{Eu}$

$\begin{array}{lrrr}\text { EU } & 1.362688 & -1.099112 & 0.039095 \\ \mathrm{O} & 1.691314 & -3.130492 & 1.646279 \\ \mathrm{H} & 1.066755 & -3.875239 & 1.653433 \\ \mathrm{O} & -0.300966 & -2.819187 & -0.596005 \\ \mathrm{H} & -0.373650 & -3.673509 & -1.048803 \\ \mathrm{O} & 3.029441 & -2.768069 & -0.986723 \\ \mathrm{H} & 3.306378 & -2.752560 & -1.918309 \\ \mathrm{O} & 1.211876 & -0.396486 & 2.463992 \\ \mathrm{H} & 1.328600 & 0.499661 & 2.819334 \\ \mathrm{O} & 1.322036 & -0.719873 & -2.470841 \\ \mathrm{H} & 0.739078 & -1.150850 & -3.117188 \\ \mathrm{H} & 3.229226 & -3.661386 & -0.661179 \\ \mathrm{H} & 1.750282 & 0.009779 & -2.948128 \\ \mathrm{H} & 2.338181 & -3.323895 & 2.345685 \\ \mathrm{H} & -1.217547 & -2.450055 & -0.457382 \\ \mathrm{H} & 1.013138 & -0.961913 & 3.227914 \\ \mathrm{C} & 2.229598 & 2.257091 & 0.000811 \\ \mathrm{C} & 2.157283 & 3.659449 & 0.018834 \\ \mathrm{C} & 0.906783 & 4.275551 & 0.041407 \\ \mathrm{H} & 3.062609 & 4.255211 & 0.015114 \\ \mathrm{C} & -0.090535 & 2.090858 & 0.024683 \\ \mathrm{C} & -0.243781 & 3.477016 & 0.045509 \\ \mathrm{H} & 0.826352 & 5.358476 & 0.054869 \\ \mathrm{H} & -1.237579 & 3.907722 & 0.061801 \\ \mathrm{C} & -1.275570 & 1.199152 & 0.016513 \\ \mathrm{C} & -3.568636 & 0.942409 & 0.009393 \\ \mathrm{C} & -3.363522 & -0.497214 & -0.037744 \\ \mathrm{~N} & 1.118939 & 1.483953 & 0.002453 \\ \mathrm{~N} & -2.501758 & 1.726380 & 0.023556 \\ \mathrm{~N} & -1.061121 & -0.124812 & -0.016656\end{array}$




$\begin{array}{lrrr}\mathrm{N} & -2.111353 & -0.942885 & -0.059043 \\ \mathrm{C} & -4.946346 & 1.581233 & -0.021324 \\ \mathrm{C} & -6.047264 & 0.536203 & 0.254350 \\ \mathrm{H} & -6.141392 & 0.379053 & 1.333151 \\ \mathrm{H} & -7.004350 & 0.953738 & -0.070772 \\ \mathrm{C} & -5.813189 & -0.799640 & -0.458255 \\ \mathrm{C} & -4.504111 & -1.500148 & -0.018972 \\ \mathrm{H} & -5.801313 & -0.655480 & -1.543797 \\ \mathrm{H} & -6.646713 & -1.475913 & -0.251118 \\ \mathrm{C} & -5.016924 & 2.718165 & 1.025033 \\ \mathrm{H} & -4.298297 & 3.510761 & 0.806011 \\ \mathrm{H} & -6.020307 & 3.150843 & 1.004584 \\ \mathrm{H} & -4.835368 & 2.348037 & 2.038590 \\ \mathrm{C} & -5.103307 & 2.188289 & -1.450165 \\ \mathrm{H} & -6.066630 & 2.702411 & -1.498133 \\ \mathrm{H} & -4.314328 & 2.916574 & -1.653519 \\ \mathrm{H} & -5.087974 & 1.427853 & -2.235408 \\ \mathrm{C} & -4.623669 & -2.033033 & 1.436759 \\ \mathrm{H} & -5.440759 & -2.757470 & 1.484685 \\ \mathrm{H} & -3.702760 & -2.538220 & 1.744109 \\ \mathrm{H} & -4.835358 & -1.242322 & 2.160448 \\ \mathrm{C} & -4.217487 & -2.681888 & -0.971271 \\ \mathrm{H} & -3.382212 & -3.295532 & -0.619040 \\ \mathrm{H} & -5.095724 & -3.330885 & -1.008272 \\ \mathrm{H} & -4.013141 & -2.344324 & -1.991934 \\ \mathrm{C} & 3.517476 & 1.545968 & -0.020082 \\ \mathrm{C} & 4.827731 & 2.045087 & -0.005096 \\ \mathrm{C} & 5.666317 & 0.922367 & -0.037471 \\ \mathrm{H} & 5.157552 & 3.072843 & 0.022579 \\ \mathrm{~N} & 3.517733 & 0.186640 & -0.060080 \\ \mathrm{~N} & 4.836936 & -0.151177 & -0.066683 \\ \mathrm{C} & 7.155906 & 0.809195 & -0.047567 \\ \mathrm{H} & 7.578505 & 1.292996 & 0.838038 \\ \mathrm{H} & 7.485760 & -0.231800 & -0.061631 \\ \mathrm{H} & 7.570051 & 1.315081 & -0.924847 \\ \mathrm{H} & 5.107792 & -1.126138 & -0.114395\end{array}$

$\mathrm{M}=\mathrm{Gd}$

$\begin{array}{lrrc}\text { GD } & 1.325001 & -1.032699 & 0.059886 \\ \mathrm{O} & 2.005591 & -2.904565 & 1.676599 \\ \mathrm{H} & 1.446363 & -3.682540 & 1.844439 \\ \mathrm{O} & -0.271065 & -2.763931 & -0.328055 \\ \mathrm{H} & -0.348256 & -3.670316 & -0.662870 \\ \mathrm{O} & 2.818923 & -2.706852 & -1.117624 \\ \mathrm{H} & 2.974256 & -2.684381 & -2.077241\end{array}$




\begin{tabular}{|c|c|c|c|}
\hline O & 1.123445 & -0.323129 & 2.418639 \\
\hline $\mathrm{H}$ & 1.037872 & 0.587997 & 2.744416 \\
\hline $\mathrm{O}$ & 1.163012 & -0.660486 & -2.395629 \\
\hline $\mathrm{H}$ & 0.495403 & -1.043005 & -2.989503 \\
\hline $\mathrm{H}$ & 3.056536 & -3.601902 & -0.823708 \\
\hline $\mathrm{H}$ & 1.560832 & 0.079465 & -2.884354 \\
\hline $\mathrm{H}$ & 2.767308 & -2.993696 & 2.274970 \\
\hline $\mathrm{H}$ & -1.203599 & -2.349099 & -0.248943 \\
\hline $\mathrm{H}$ & 1.076029 & -0.896463 & 3.201358 \\
\hline $\mathrm{C}$ & 2.244101 & 2.230691 & 0.055849 \\
\hline $\mathrm{C}$ & 2.184799 & 3.630094 & 0.112080 \\
\hline $\mathrm{C}$ & 0.937030 & 4.254862 & 0.148358 \\
\hline $\mathrm{H}$ & 3.095095 & 4.218354 & 0.123317 \\
\hline $\mathrm{C}$ & -0.085636 & 2.082631 & 0.069984 \\
\hline $\mathrm{C}$ & -0.222664 & 3.468882 & 0.122845 \\
\hline $\mathrm{H}$ & 0.866386 & 5.337817 & 0.191264 \\
\hline $\mathrm{H}$ & -1.212854 & 3.907610 & 0.141381 \\
\hline $\mathrm{C}$ & -1.271690 & 1.188362 & 0.030570 \\
\hline $\mathrm{C}$ & -3.549242 & 0.916949 & -0.010831 \\
\hline $\mathrm{C}$ & -3.326986 & -0.518700 & -0.044743 \\
\hline $\mathrm{N}$ & 1.123363 & 1.468603 & 0.041311 \\
\hline $\mathrm{N}$ & -2.493247 & 1.729271 & 0.026524 \\
\hline $\mathrm{N}$ & -1.027379 & -0.125319 & -0.015922 \\
\hline $\mathrm{N}$ & -2.078010 & -0.969579 & -0.061048 \\
\hline $\mathrm{C}$ & -4.924725 & 1.540902 & -0.086478 \\
\hline $\mathrm{C}$ & -6.025826 & 0.491044 & 0.184484 \\
\hline $\mathrm{H}$ & -6.140347 & 0.353897 & 1.264262 \\
\hline $\mathrm{H}$ & -6.977928 & 0.897274 & -0.166384 \\
\hline $\mathrm{C}$ & -5.764673 & -0.855971 & -0.493569 \\
\hline $\mathrm{C}$ & -4.458419 & -1.535379 & -0.017503 \\
\hline $\mathrm{H}$ & -5.734289 & -0.734515 & -1.581842 \\
\hline $\mathrm{H}$ & -6.594785 & -1.537535 & -0.288930 \\
\hline $\mathrm{C}$ & -5.043206 & 2.706258 & 0.923273 \\
\hline $\mathrm{H}$ & -4.338469 & 3.509611 & 0.702720 \\
\hline $\mathrm{H}$ & -6.054369 & 3.117040 & 0.866039 \\
\hline $\mathrm{H}$ & -4.880816 & 2.366499 & 1.950792 \\
\hline $\mathrm{C}$ & -5.056929 & 2.113895 & -1.532922 \\
\hline $\mathrm{H}$ & -6.023319 & 2.617493 & -1.614835 \\
\hline $\mathrm{H}$ & -4.271400 & 2.845712 & -1.736813 \\
\hline $\mathrm{H}$ & -5.017202 & 1.334802 & -2.299143 \\
\hline $\mathrm{C}$ & -4.595537 & -2.021780 & 1.453784 \\
\hline $\mathrm{H}$ & -5.411321 & -2.746836 & 1.514048 \\
\hline $\mathrm{H}$ & -3.678171 & -2.514950 & 1.790306 \\
\hline $\mathrm{H}$ & -4.819596 & -1.209240 & 2.149077 \\
\hline $\mathrm{C}$ & -4.151011 & -2.746512 & -0.922371 \\
\hline $\mathrm{H}$ & -3.320929 & -3.350177 & -0.542708 \\
\hline
\end{tabular}




$\begin{array}{cccc}\mathrm{H} & -5.027354 & -3.398619 & -0.952505 \\ \mathrm{H} & -3.933078 & -2.442390 & -1.950998 \\ \mathrm{C} & 3.513204 & 1.492734 & -0.013403 \\ \mathrm{C} & 4.835976 & 1.950191 & -0.038275 \\ \mathrm{C} & 5.636274 & 0.805699 & -0.153042 \\ \mathrm{H} & 5.197090 & 2.966650 & 0.011087 \\ \mathrm{~N} & 3.467907 & 0.133879 & -0.102720 \\ \mathrm{~N} & 4.776299 & -0.242276 & -0.186712 \\ \mathrm{C} & 7.120646 & 0.650400 & -0.232623 \\ \mathrm{H} & 7.591487 & 1.042768 & 0.673535 \\ \mathrm{H} & 7.415918 & -0.394569 & -0.349362 \\ \mathrm{H} & 7.516343 & 1.217783 & -1.079770 \\ \mathrm{H} & 5.016443 & -1.219694 & -0.300086\end{array}$

$\mathrm{M}=\mathrm{Am}$

$\begin{array}{lrrc}\text { AM } & 1.234175 & -0.948071 & 0.038465 \\ \mathrm{O} & 1.601271 & -3.000420 & 1.616551 \\ \mathrm{H} & 0.958261 & -3.730120 & 1.620009 \\ \mathrm{O} & -0.420570 & -2.682197 & -0.509249 \\ \mathrm{H} & -0.510011 & -3.521944 & -0.985608 \\ \mathrm{O} & 2.956324 & -2.585898 & -0.997502 \\ \mathrm{H} & 3.208205 & -2.580504 & -1.936864 \\ \mathrm{O} & 1.113964 & -0.284158 & 2.474784 \\ \mathrm{H} & 1.211127 & 0.613158 & 2.834679 \\ \mathrm{O} & 1.169908 & -0.626180 & -2.489070 \\ \mathrm{H} & 0.537835 & -1.033589 & -3.105190 \\ \mathrm{H} & 3.141846 & -3.483236 & -0.673005 \\ \mathrm{H} & 1.591136 & 0.098559 & -2.981557 \\ \mathrm{H} & 2.249324 & -3.209664 & 2.310804 \\ \mathrm{H} & -1.342259 & -2.260617 & -0.381623 \\ \mathrm{H} & 0.909880 & -0.857773 & 3.231821 \\ \mathrm{C} & 2.062840 & 2.405037 & 0.012021 \\ \mathrm{C} & 1.967578 & 3.802612 & 0.049632 \\ \mathrm{C} & 0.704988 & 4.395647 & 0.086190 \\ \mathrm{H} & 2.862359 & 4.414214 & 0.050078 \\ \mathrm{C} & -0.258451 & 2.195401 & 0.043789 \\ \mathrm{C} & -0.431954 & 3.578212 & 0.083901 \\ \mathrm{H} & 0.605860 & 5.476749 & 0.115530 \\ \mathrm{H} & -1.433232 & 3.990121 & 0.110106 \\ \mathrm{C} & -1.426660 & 1.278720 & 0.025356 \\ \mathrm{C} & -3.701829 & 0.974765 & 0.006447 \\ \mathrm{C} & -3.458874 & -0.456103 & -0.046589 \\ \mathrm{~N} & 0.964265 & 1.611396 & 0.008648 \\ \mathrm{~N} & -2.656840 & 1.800910 & 0.032678 \\ \mathrm{~N} & -1.163755 & -0.030588 & -0.021590\end{array}$




$\begin{array}{crrr}\mathrm{N} & -2.203959 & -0.888461 & -0.074164 \\ \mathrm{C} & -5.086926 & 1.580952 & -0.039642 \\ \mathrm{C} & -6.169667 & 0.509872 & 0.221887 \\ \mathrm{H} & -6.271252 & 0.349683 & 1.299802 \\ \mathrm{H} & -7.131248 & 0.908341 & -0.111508 \\ \mathrm{C} & -5.894988 & -0.819468 & -0.485191 \\ \mathrm{C} & -4.575813 & -1.489722 & -0.032164 \\ \mathrm{H} & -5.874094 & -0.675404 & -1.570986 \\ \mathrm{H} & -6.714019 & -1.516658 & -0.288723 \\ \mathrm{C} & -5.206860 & 2.720887 & 0.999016 \\ \mathrm{H} & -4.515089 & 3.538073 & 0.788212 \\ \mathrm{H} & -6.223741 & 3.120004 & 0.964688 \\ \mathrm{H} & -5.026483 & 2.359362 & 2.016069 \\ \mathrm{C} & -5.247031 & 2.184961 & -1.470128 \\ \mathrm{H} & -6.220389 & 2.678442 & -1.527279 \\ \mathrm{H} & -4.473101 & 2.930372 & -1.668702 \\ \mathrm{H} & -5.208824 & 1.423708 & -2.254146 \\ \mathrm{C} & -4.695850 & -2.008974 & 1.429053 \\ \mathrm{H} & -5.500688 & -2.746872 & 1.480034 \\ \mathrm{H} & -3.768858 & -2.495560 & 1.748571 \\ \mathrm{H} & -4.926364 & -1.214449 & 2.142798 \\ \mathrm{C} & -4.258030 & -2.677269 & -0.964509 \\ \mathrm{H} & -3.421016 & -3.280486 & -0.599137 \\ \mathrm{H} & -5.127164 & -3.338311 & -1.006769 \\ \mathrm{H} & -4.046666 & -2.348246 & -1.986944 \\ \mathrm{C} & 3.354599 & 1.706464 & -0.026164 \\ \mathrm{C} & 4.662971 & 2.204171 & -0.032771 \\ \mathrm{C} & 5.500802 & 1.081787 & -0.080535 \\ \mathrm{H} & 4.992252 & 3.232262 & -0.010557 \\ \mathrm{~N} & 3.353612 & 0.346814 & -0.066908 \\ \mathrm{~N} & 4.675095 & 0.007172 & -0.098177 \\ \mathrm{C} & 6.990864 & 0.970824 & -0.112421 \\ \mathrm{H} & 7.424282 & 1.440954 & 0.775078 \\ \mathrm{H} & 7.321789 & -0.069384 & -0.147190 \\ \mathrm{H} & 7.391559 & 1.490536 & -0.987540 \\ \mathrm{H} & 4.945852 & -0.967456 & -0.149748\end{array}$

$\mathrm{M}=\mathrm{Cm}$

$\begin{array}{lrrl}\mathrm{CM} & 1.223663 & -0.932155 & 0.062315 \\ \mathrm{O} & 1.804614 & -2.879946 & 1.715700 \\ \mathrm{H} & 1.213340 & -3.644789 & 1.822862 \\ \mathrm{O} & -0.397159 & -2.715405 & -0.397805 \\ \mathrm{H} & -0.478290 & -3.602938 & -0.779176 \\ \mathrm{O} & 2.831497 & -2.617045 & -1.072968 \\ \mathrm{H} & 3.005472 & -2.621548 & -2.029664\end{array}$




\begin{tabular}{|c|c|c|c|}
\hline D & 1.020592 & -0.224681 & 2.473177 \\
\hline & 0.963526 & 0.682125 & 2.817107 \\
\hline $\mathrm{O}$ & 1.106721 & -0.588521 & -2.450361 \\
\hline $\mathrm{H}$ & 0.451697 & -0.982910 & -3.050949 \\
\hline $\mathrm{H}$ & 3.053210 & -3.507510 & -0.753177 \\
\hline T & 1.512669 & 0.145631 & -2.941674 \\
\hline $\mathrm{H}$ & 2.535439 & -3.019576 & 2.342118 \\
\hline $\mathrm{H}$ & -1.321827 & -2.295888 & -0.315452 \\
\hline $\mathrm{H}$ & 0.954071 & -0.813148 & 3.243276 \\
\hline $\mathrm{C}$ & 2.069647 & 2.385304 & 0.046355 \\
\hline $\mathrm{C}$ & 1.978716 & 3.782881 & 0.104337 \\
\hline $\mathrm{C}$ & 0.717891 & 4.379506 & 0.151341 \\
\hline $\mathrm{H}$ & 2.875124 & 4.392084 & 0.108434 \\
\hline $\mathrm{C}$ & -0.256605 & 2.185135 & 0.075350 \\
\hline$C$ & -0.423882 & 3.567943 & 0.131731 \\
\hline H & 0.623394 & 5.460548 & 0.196600 \\
\hline H & -1.423148 & 3.985051 & 0.155798 \\
\hline $\mathrm{C}$ & -1.427700 & 1.270063 & 0.032178 \\
\hline $\mathrm{C}$ & -3.702074 & 0.968033 & -0.010932 \\
\hline $\mathrm{C}$ & -3.460368 & -0.463164 & -0.067030 \\
\hline $\mathrm{N}$ & 0.965878 & 1.599190 & 0.041082 \\
\hline $\mathrm{N}$ & -2.656909 & 1.793935 & 0.035765 \\
\hline $\mathrm{N}$ & -1.166836 & -0.039809 & -0.029785 \\
\hline N & -2.206136 & -0.898285 & -0.088237 \\
\hline $\mathrm{C}$ & -5.085954 & 1.575469 & -0.072095 \\
\hline $\mathrm{C}$ & -6.172258 & 0.506323 & 0.182663 \\
\hline $\mathrm{H}$ & -6.281898 & 0.348064 & 1.260106 \\
\hline $\mathrm{H}$ & -7.130696 & 0.905908 & -0.158395 \\
\hline $\mathrm{C}$ & -5.894603 & -0.824477 & -0.520281 \\
\hline x & -4.578727 & -1.495346 & -0.058746 \\
\hline $\mathrm{H}$ & -5.867551 & -0.682559 & -1.606208 \\
\hline $\mathrm{H}$ & -6.715458 & -1.520460 & -0.327174 \\
\hline $\mathrm{C}$ & -5.216289 & 2.719785 & 0.960141 \\
\hline $\mathrm{H}$ & -4.522892 & 3.536426 & 0.752734 \\
\hline $\mathrm{H}$ & -6.232934 & 3.118314 & 0.914210 \\
\hline $\mathrm{H}$ & -5.045792 & 2.362652 & 1.980461 \\
\hline , & -5.230466 & 2.173582 & -1.506921 \\
\hline $\mathrm{H}$ & -6.203434 & 2.666223 & -1.576817 \\
\hline $\mathrm{H}$ & -4.454882 & 2.918899 & -1.699709 \\
\hline $\mathrm{H}$ & -5.183115 & 1.409370 & -2.287565 \\
\hline $\mathrm{C}$ & -4.708101 & -2.013441 & 1.402157 \\
\hline $\mathrm{H}$ & -5.513060 & -2.751517 & 1.448345 \\
\hline $\mathrm{H}$ & -3.783237 & -2.499622 & 1.728404 \\
\hline 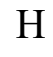 & -4.943630 & -1.218346 & 2.113688 \\
\hline $\mathrm{C}$ & -4.256585 & -2.683744 & -0.988480 \\
\hline $\mathrm{H}$ & -3.420463 & -3.286002 & -0.619804 \\
\hline
\end{tabular}




$\begin{array}{lrrr}\mathrm{H} & -5.125470 & -3.344897 & -1.033801 \\ \mathrm{H} & -4.040398 & -2.355657 & -2.010140 \\ \mathrm{C} & 3.358685 & 1.682413 & -0.033100 \\ \mathrm{C} & 4.666592 & 2.181303 & -0.061943 \\ \mathrm{C} & 5.502570 & 1.062916 & -0.178389 \\ \mathrm{H} & 4.996081 & 3.208326 & -0.012513 \\ \mathrm{~N} & 3.357279 & 0.323367 & -0.122666 \\ \mathrm{~N} & 4.676721 & -0.011321 & -0.210413 \\ \mathrm{C} & 6.991036 & 0.955277 & -0.260311 \\ \mathrm{H} & 7.450960 & 1.370572 & 0.641178 \\ \mathrm{H} & 7.319601 & -0.080637 & -0.368619 \\ \mathrm{H} & 7.366344 & 1.527599 & -1.113453 \\ \mathrm{H} & 4.946334 & -0.982220 & -0.313624\end{array}$

$\left[\mathrm{ML}_{2}\left(\mathrm{H}_{2} \mathrm{O}\right)_{2}\right]^{3+}$

$\mathrm{M}=\mathrm{Eu}$

$\begin{array}{lrrr}\text { EU } & 0.003544 & 0.464989 & 0.001209 \\ \mathrm{O} & -0.402158 & -1.139908 & 1.758361 \\ \mathrm{H} & -1.332535 & -1.513965 & 1.672363 \\ \mathrm{O} & 0.374655 & -1.182395 & -1.737946 \\ \mathrm{H} & -0.057491 & -1.569043 & -2.511808 \\ \mathrm{H} & 0.012631 & -1.478228 & 2.563800 \\ \mathrm{H} & 1.307163 & -1.547364 & -1.657294 \\ \mathrm{C} & -1.123583 & 2.319856 & -2.669560 \\ \mathrm{C} & -1.908637 & 2.805662 & -3.726295 \\ \mathrm{C} & -3.195198 & 2.299635 & -3.905074 \\ \mathrm{H} & -1.516530 & 3.560713 & -4.397215 \\ \mathrm{C} & -2.828613 & 0.883566 & -1.999313 \\ \mathrm{C} & -3.667276 & 1.317370 & -3.026701 \\ \mathrm{H} & -3.820092 & 2.658884 & -4.717164 \\ \mathrm{H} & -4.655830 & 0.886727 & -3.125211 \\ \mathrm{C} & -3.277808 & -0.167324 & -1.045939 \\ \mathrm{C} & -4.894410 & -1.636047 & -0.347569 \\ \mathrm{C} & -3.993442 & -2.044474 & 0.707736 \\ \mathrm{~N} & -1.580353 & 1.375296 & -1.815895 \\ \mathrm{~N} & -4.498878 & -0.693205 & -1.200364 \\ \mathrm{~N} & -2.415820 & -0.526171 & -0.090462 \\ \mathrm{~N} & -2.795639 & -1.473661 & 0.784483 \\ \mathrm{C} & -6.253895 & -2.269945 & -0.568553 \\ \mathrm{C} & -6.686212 & -3.081100 & 0.673320 \\ \mathrm{H} & -7.092638 & -2.400534 & 1.428610 \\ \mathrm{H} & -7.513493 & -3.734956 & 0.384635 \\ \mathrm{C} & -5.555800 & -3.919457 & 1.274524 \\ \mathrm{C} & -4.362287 & -3.070232 & 1.772225\end{array}$




\begin{tabular}{|c|c|c|c|}
\hline $\mathrm{H}$ & -5.198315 & -4.651539 & 0.542313 \\
\hline & -5.936637 & -4.499407 & 2.119861 \\
\hline$C$ & -7.307956 & -1.184051 & -0.880302 \\
\hline & -7.074880 & -0.643772 & -1.799371 \\
\hline & -8.282428 & -1.663085 & -1.005818 \\
\hline & -7.395900 & -0.462681 & -0.061736 \\
\hline & -6.107212 & -3.199541 & -1.810179 \\
\hline & -7.080329 & -3.646705 & -2.028537 \\
\hline 7 & -5.788195 & -2.630245 & -2.686946 \\
\hline & -5.393275 & -4.011181 & -1.645027 \\
\hline & -4.744616 & -2.286032 & 3.057684 \\
\hline & -5.006560 & -2.995631 & 3.846942 \\
\hline & -3.904735 & -1.679879 & 3.411165 \\
\hline H & -5.600867 & -1.623731 & 2.906601 \\
\hline $\mathcal{C}$ & -3.172137 & -4.001908 & 2.083854 \\
\hline $\mathrm{H}$ & -2.345569 & -3.473875 & 2.567163 \\
\hline H & -3.502917 & -4.783041 & 2.773207 \\
\hline $\mathrm{H}$ & -2.795014 & -4.493605 & 1.181947 \\
\hline $\mathrm{C}$ & 0.243558 & 2.805933 & -2.436886 \\
\hline$C$ & 0.981812 & 3.787130 & -3.120504 \\
\hline $\mathrm{C}$ & 2.220235 & 3.847260 & -2.479374 \\
\hline $\mathrm{H}$ & 0.680441 & 4.388301 & -3.964791 \\
\hline $\mathbf{N}$ & 0.970021 & 2.275685 & -1.424070 \\
\hline$N$ & 2.160915 & 2.926045 & -1.482444 \\
\hline C & 3.421945 & 4.701477 & -2.731946 \\
\hline $\mathrm{C}$ & 1.124244 & 2.342350 & 2.656280 \\
\hline $\mathrm{C}$ & 1.908832 & 2.830408 & 3.712743 \\
\hline $\mathrm{C}$ & 3.194046 & 2.322414 & 3.895430 \\
\hline $\mathrm{H}$ & 1.518303 & 3.589378 & 4.380082 \\
\hline $\mathrm{C}$ & 2.829140 & 0.899777 & 1.995120 \\
\hline $\mathrm{C}$ & 3.667359 & 1.336293 & 3.021232 \\
\hline $\mathrm{H}$ & 3.818000 & 2.683703 & 4.707344 \\
\hline П & 4.655398 & 0.905543 & 3.123850 \\
\hline $\mathrm{C}$ & 3.275863 & -0.156244 & 1.045161 \\
\hline $\mathrm{C}$ & 4.889312 & -1.634137 & 0.357377 \\
\hline $\mathrm{C}$ & 3.987133 & -2.049628 & -0.694395 \\
\hline $\mathrm{N}$ & 1.581202 & 1.392139 & 1.809345 \\
\hline $\mathrm{N}$ & 4.494997 & -0.685076 & 1.203790 \\
\hline $\mathrm{N}$ & 2.414405 & -0.519027 & 0.089068 \\
\hline $\mathrm{N}$ & 2.791194 & -1.476221 & -0.777177 \\
\hline $\mathrm{C}$ & 6.248336 & -2.267336 & 0.582284 \\
\hline $\mathrm{C}$ & 6.678137 & -3.091304 & -0.651973 \\
\hline $\mathrm{H}$ & 7.085434 & -2.418970 & -1.414112 \\
\hline . & 7.504270 & -3.744028 & -0.357533 \\
\hline $\mathrm{C}$ & 5.545482 & -3.933037 & -1.244164 \\
\hline & 4.353749 & -3.085956 & -1.749496 \\
\hline
\end{tabular}




$\begin{array}{lrrr}\mathrm{H} & 5.186794 & -4.657072 & -0.504565 \\ \mathrm{H} & 5.924524 & -4.522105 & -2.083980 \\ \mathrm{C} & 7.303946 & -1.179702 & 0.882485 \\ \mathrm{H} & 7.072120 & -0.629942 & 1.796251 \\ \mathrm{H} & 8.277888 & -1.658685 & 1.012193 \\ \mathrm{H} & 7.392316 & -0.466724 & 0.056640 \\ \mathrm{C} & 6.101855 & -3.184864 & 1.833155 \\ \mathrm{H} & 7.074817 & -3.630973 & 2.054361 \\ \mathrm{H} & 5.784572 & -2.606759 & 2.704733 \\ \mathrm{H} & 5.386791 & -3.997181 & 1.676565 \\ \mathrm{C} & 4.737265 & -2.314349 & -3.042211 \\ \mathrm{H} & 4.997910 & -3.031709 & -3.824859 \\ \mathrm{H} & 3.898266 & -1.710170 & -3.401010 \\ \mathrm{H} & 5.594733 & -1.652204 & -2.897425 \\ \mathrm{C} & 3.161505 & -4.017808 & -2.052534 \\ \mathrm{H} & 2.337425 & -3.492422 & -2.542980 \\ \mathrm{H} & 3.490999 & -4.807056 & -2.733201 \\ \mathrm{H} & 2.781851 & -4.498935 & -1.145996 \\ \mathrm{C} & -0.239548 & 2.837397 & 2.414800 \\ \mathrm{C} & -0.960656 & 3.843325 & 3.082021 \\ \mathrm{C} & -2.196711 & 3.917126 & 2.437328 \\ \mathrm{H} & -0.648814 & 4.453458 & 3.916010 \\ \mathrm{~N} & -0.974095 & 2.304905 & 1.409028 \\ \mathrm{~N} & -2.150761 & 2.981694 & 1.453595 \\ \mathrm{C} & -3.387497 & 4.788718 & 2.682222 \\ \mathrm{H} & -2.879279 & 2.774725 & 0.783016 \\ \mathrm{H} & 2.884128 & 2.721222 & -0.805507 \\ \mathrm{H} & 3.182424 & 5.756411 & -2.569995 \\ \mathrm{H} & 4.253611 & 4.434796 & -2.075656 \\ \mathrm{H} & 3.754714 & 4.594585 & -3.767844 \\ \mathrm{H} & -3.796068 & 4.606148 & 3.680261 \\ \mathrm{H} & -3.106021 & 5.843904 & 2.629675 \\ \mathrm{H} & -4.178223 & 4.608847 & 1.950158\end{array}$

$\mathrm{M}=\mathrm{Gd}$

$\begin{array}{lrrr}\text { GD } & 0.000001 & 0.455899 & -0.000005 \\ \mathrm{O} & -0.365439 & -1.162674 & 1.734804 \\ \mathrm{H} & -1.297174 & -1.534055 & 1.659297 \\ \mathrm{O} & 0.365440 & -1.162690 & -1.734799 \\ \mathrm{H} & -0.077628 & -1.547313 & -2.503409 \\ \mathrm{H} & 0.077627 & -1.547289 & 2.503419 \\ \mathrm{H} & 1.297174 & -1.534071 & -1.659290 \\ \mathrm{C} & -1.091888 & 2.331509 & -2.650141 \\ \mathrm{C} & -1.869920 & 2.821850 & -3.710098 \\ \mathrm{C} & -3.154632 & 2.315237 & -3.900523\end{array}$




\begin{tabular}{|c|c|c|c|}
\hline $\mathrm{H}$ & -1.474157 & 3.581055 & -4.3741 \\
\hline $\mathrm{C}$ & -2.801291 & 0.890278 & -1.999838 \\
\hline $\mathrm{C}$ & -3.633425 & 1.328369 & -3.030140 \\
\hline $\mathrm{H}$ & -3.773817 & 2.677991 & -4.715435 \\
\hline $\mathrm{H}$ & -4.621264 & 0.898417 & -3.138356 \\
\hline $\mathrm{C}$ & -3.252021 & -0.163764 & -1.050957 \\
\hline $\mathrm{C}$ & -4.868808 & -1.633973 & -0.356479 \\
\hline $\mathrm{C}$ & -3.969052 & -2.043632 & 0.69 \\
\hline $\mathrm{N}$ & -1.553953 & 1.381104 & -1.806486 \\
\hline $\mathrm{N}$ & -4.472589 & -0.689793 & -1.207699 \\
\hline $\mathrm{N}$ & -2.390489 & -0.525768 & -0.0 \\
\hline $\mathrm{N}$ & -2.770415 & -1.475380 & 0.77 \\
\hline $\mathrm{C}$ & -6.226722 & -2.269280 & -0.5 \\
\hline $\mathrm{C}$ & -6.661331 & -3.083612 & 0.65 \\
\hline $\mathrm{H}$ & -7.072399 & -2.405406 & 415 \\
\hline $\mathrm{H}$ & -7.485799 & -3.739151 & 738 \\
\hline $\mathrm{C}$ & -5.531067 & -3.920024 & 1.2 \\
\hline $\mathrm{C}$ & -4.341213 & -3.068468 & 1.76 \\
\hline $\mathrm{H}$ & -5.169460 & -4.65 & 0.5 \\
\hline $\mathrm{H}$ & -5.913490 & -4.5 & 2.1 \\
\hline $\mathrm{C}$ & -7.281703 & -1.1 & -0.8 \\
\hline $\mathrm{H}$ & -7.046979 & -0.6 & -1 \\
\hline $\mathrm{H}$ & -8.254953 & -1.665194 & -1.0 \\
\hline $\mathrm{H}$ & -7.373246 & -0.464738 & -0.0 \\
\hline $\mathrm{C}$ & -6.074874 & -3.196633 & -1.8 \\
\hline $\mathrm{H}$ & -7.046819 & -3.644635 & -2.0 \\
\hline $\mathrm{H}$ & -5.754167 & -2.625415 & -2.6 \\
\hline $\mathrm{H}$ & -5.360434 & -4.007658 & -1.6 \\
\hline $\mathrm{C}$ & -4.730967 & -2.282063 & 160 \\
\hline $\mathrm{H}$ & -4.997288 & -2.990490 & 3.8 \\
\hline $\mathrm{H}$ & -3.893024 & -1.675391 & 3.4 \\
\hline $\mathrm{H}$ & -5.586461 & -1.620137 & 2.8 \\
\hline $\mathrm{C}$ & -3.151407 & -3.997624 & 2.083961 \\
\hline $\mathrm{H}$ & -2.329706 & -3.467625 & 2.573501 \\
\hline $\mathrm{H}$ & -3.485240 & -4.779153 & 2.771368 \\
\hline $\mathrm{H}$ & -2.767090 & -4.489001 & 1.184901 \\
\hline $\mathrm{C}$ & 0.271546 & 2.819103 & -2.3 \\
\hline $\mathrm{C}$ & 1.006250 & 3.824250 & -3.050755 \\
\hline $\mathrm{C}$ & 2.237031 & 3.881236 & -2.395564 \\
\hline $\mathrm{H}$ & 0.706585 & 4.442857 & -3.882963 \\
\hline $\mathrm{N}$ & 0.993303 & 2.270148 & -1.392231 \\
\hline $\mathrm{N}$ & 2.175747 & 2.937275 & -1.420321 \\
\hline $\mathrm{C}$ & 3.439567 & 4.740940 & -2.625957 \\
\hline $\mathrm{C}$ & 1.091887 & 2.331519 & 2.650124 \\
\hline $\mathrm{C}$ & 1.869921 & 2.821870 & 3.710076 \\
\hline 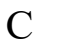 & 3.154636 & 2.315264 & 3.90049 \\
\hline
\end{tabular}




\begin{tabular}{|c|c|c|c|}
\hline $\mathrm{H}$ & 1.474157 & 3.581077 & 4.374156 \\
\hline $\mathrm{C}$ & 2.801295 & 0.890292 & 1.999823 \\
\hline C & 3.633430 & 1.328393 & 3.030120 \\
\hline 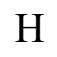 & 3.773823 & 2.678026 & 4.715406 \\
\hline $\mathrm{H}$ & 4.621271 & 0.898445 & 3.138336 \\
\hline $\mathrm{C}$ & 3.252025 & -0.163756 & 1.050949 \\
\hline $\mathrm{C}$ & 4.868812 & -1.633968 & 0.356481 \\
\hline $\mathrm{C}$ & 3.969054 & -2.043639 & -0.699971 \\
\hline $\mathrm{N}$ & 1.553954 & 1.381112 & 1.806471 \\
\hline $\mathrm{N}$ & 4.472594 & -0.689781 & 1.207693 \\
\hline $\mathrm{N}$ & 2.390491 & -0.525769 & 0.095323 \\
\hline $\mathrm{N}$ & 2.770417 & -1.475388 & -0.778128 \\
\hline $\mathrm{C}$ & 6.226727 & -2.269272 & 0.581460 \\
\hline $\mathrm{C}$ & 6.661334 & -3.083618 & -0.657548 \\
\hline $\mathrm{H}$ & 7.072400 & -2.405422 & -1.412410 \\
\hline $\mathrm{H}$ & 7.485801 & -3.739154 & -0.364717 \\
\hline $\mathrm{C}$ & 5.531068 & -3.920037 & -1.261730 \\
\hline $\mathrm{C}$ & 4.341213 & -3.068486 & -1.764100 \\
\hline $\mathrm{H}$ & 5.169462 & -4.650841 & -0.530231 \\
\hline $\mathrm{H}$ & 5.913489 & -4.501362 & -2.105397 \\
\hline $\mathrm{C}$ & 7.281708 & -1.184599 & 0.894592 \\
\hline $\mathrm{H}$ & 7.046986 & -0.642515 & 1.812155 \\
\hline $\mathrm{H}$ & 8.254959 & -1.665179 & 1.023555 \\
\hline $\mathrm{H}$ & 7.373249 & -0.464735 & 0.075101 \\
\hline $\mathrm{C}$ & 6.074883 & -3.196610 & 1.824441 \\
\hline $\mathrm{H}$ & 7.046829 & -3.644609 & 2.046227 \\
\hline $\mathrm{H}$ & 5.754178 & -2.625383 & 2.699317 \\
\hline $\mathrm{H}$ & 5.360444 & -4.007638 & 1.658424 \\
\hline $\mathrm{C}$ & 4.730966 & -2.282094 & -3.046150 \\
\hline $\mathrm{H}$ & 4.997287 & -2.990529 & -3.834993 \\
\hline $\mathbf{H}$ & 3.893022 & -1.675426 & -3.403254 \\
\hline $\mathrm{H}$ & 5.586459 & -1.620165 & -2.889318 \\
\hline $\mathrm{C}$ & 3.151407 & -3.997645 & -2.083931 \\
\hline $\mathrm{H}$ & 2.329705 & -3.467650 & -2.573475 \\
\hline $\mathrm{H}$ & 3.485238 & -4.779181 & -2.771331 \\
\hline $\mathrm{H}$ & 2.767091 & -4.489012 & -1.184865 \\
\hline $\mathrm{C}$ & -0.271550 & 2.819106 & 2.398274 \\
\hline $\mathrm{C}$ & -1.006265 & 3.824245 & 3.050757 \\
\hline $\mathrm{C}$ & -2.237041 & 3.881230 & 2.395574 \\
\hline $\mathrm{H}$ & -0.706607 & 4.442845 & 3.882972 \\
\hline $\mathrm{N}$ & -0.993304 & 2.270162 & 1.392218 \\
\hline $\mathrm{N}$ & -2.175756 & 2.937277 & 1.420312 \\
\hline $\mathrm{C}$ & -3.439591 & 4.740909 & 2.625989 \\
\hline $\mathrm{H}$ & -2.896542 & 2.719717 & 0.744869 \\
\hline $\mathrm{H}$ & 2.896544 & 2.719711 & -0.744891 \\
\hline $\mathrm{H}$ & 3.890315 & 4.516069 & -3.597035 \\
\hline
\end{tabular}




$\begin{array}{rrrr}\mathrm{H} & 3.158563 & 5.797219 & -2.629780 \\ \mathrm{H} & 4.197750 & 4.591743 & -1.853600 \\ \mathrm{H} & -3.158485 & 5.797154 & 2.630553 \\ \mathrm{H} & -4.197469 & 4.592245 & 1.853226 \\ \mathrm{H} & -3.890761 & 4.515494 & 3.596745\end{array}$

$\mathrm{M}=\mathrm{Am}$

$\begin{array}{lrrc}\text { AM } & -0.000001 & 0.412973 & 0.000001 \\ \mathrm{O} & 0.433728 & -1.272058 & -1.742177 \\ \mathrm{H} & 1.382892 & -1.593795 & -1.667154 \\ \mathrm{O} & -0.433743 & -1.272028 & 1.742205 \\ \mathrm{H} & 0.013009 & -1.735550 & 2.463960 \\ \mathrm{H} & -0.013027 & -1.735587 & -2.463926 \\ \mathrm{H} & -1.382908 & -1.593762 & 1.667184 \\ \mathrm{C} & 1.118047 & 2.229532 & 2.744132 \\ \mathrm{C} & 1.884658 & 2.677733 & 3.830029 \\ \mathrm{C} & 3.162207 & 2.154781 & 4.021605 \\ \mathrm{H} & 1.487347 & 3.420157 & 4.511818 \\ \mathrm{C} & 2.825401 & 0.798450 & 2.068222 \\ \mathrm{C} & 3.647185 & 1.197986 & 3.122438 \\ \mathrm{H} & 3.772965 & 2.485301 & 4.856284 \\ \mathrm{H} & 4.633145 & 0.762986 & 3.225709 \\ \mathrm{C} & 3.295059 & -0.217805 & 1.087493 \\ \mathrm{C} & 4.941803 & -1.643553 & 0.367218 \\ \mathrm{C} & 4.062393 & -2.029083 & -0.714176 \\ \mathrm{~N} & 1.581720 & 1.298809 & 1.878900 \\ \mathrm{~N} & 4.518767 & -0.737268 & 1.245836 \\ \mathrm{~N} & 2.453636 & -0.554607 & 0.105579 \\ \mathrm{~N} & 2.857864 & -1.474183 & -0.790232 \\ \mathrm{C} & 6.307387 & -2.264221 & 0.588401 \\ \mathrm{C} & 6.768638 & -3.032561 & -0.670148 \\ \mathrm{H} & 7.178450 & -2.325014 & -1.398303 \\ \mathrm{H} & 7.599135 & -3.685214 & -0.388129 \\ \mathrm{C} & 5.657898 & -3.865402 & -1.314249 \\ \mathrm{C} & 4.462329 & -3.015041 & -1.805156 \\ \mathrm{H} & 5.297693 & -4.623501 & -0.610254 \\ \mathrm{H} & 6.058900 & -4.414943 & -2.170503 \\ \mathrm{C} & 7.340327 & -1.171628 & 0.945287 \\ \mathrm{H} & 7.087136 & -0.662129 & 1.876536 \\ \mathrm{H} & 8.320705 & -1.638856 & 1.069446 \\ \mathrm{H} & 7.426993 & -0.425316 & 0.149255 \\ \mathrm{C} & 6.159042 & -3.231415 & 1.800694 \\ \mathrm{H} & 7.136364 & -3.668596 & 2.020440 \\ \mathrm{H} & 5.817854 & -2.693142 & 2.688595 \\ \mathrm{H} & 5.461440 & -4.049633 & 1.601625\end{array}$




$\begin{array}{lrrr}\mathrm{C} & 4.856575 & -2.183639 & -3.056964 \\ \mathrm{H} & 5.142368 & -2.862980 & -3.864394 \\ \mathrm{H} & 4.014306 & -1.577581 & -3.404883 \\ \mathrm{H} & 5.700757 & -1.515412 & -2.868644 \\ \mathrm{C} & 3.290468 & -3.950571 & -2.169642 \\ \mathrm{H} & 2.471099 & -3.417937 & -2.660505 \\ \mathrm{H} & 3.645939 & -4.709217 & -2.871691 \\ \mathrm{H} & 2.897342 & -4.470783 & -1.290767 \\ \mathrm{C} & -0.229652 & 2.754935 & 2.483526 \\ \mathrm{C} & -0.955733 & 3.748860 & 3.162369 \\ \mathrm{C} & -2.166196 & 3.870042 & 2.478611 \\ \mathrm{H} & -0.664125 & 4.321101 & 4.029796 \\ \mathrm{~N} & -0.937568 & 2.273935 & 1.435099 \\ \mathrm{~N} & -2.103654 & 2.971198 & 1.462483 \\ \mathrm{C} & -3.353058 & 4.747862 & 2.720962 \\ \mathrm{C} & -1.118034 & 2.229497 & -2.744158 \\ \mathrm{C} & -1.884640 & 2.677686 & -3.830064 \\ \mathrm{C} & -3.162189 & 2.154734 & -4.021639 \\ \mathrm{H} & -1.487324 & 3.420099 & -4.511861 \\ \mathrm{C} & -2.825394 & 0.798428 & -2.068235 \\ \mathrm{C} & -3.647172 & 1.197952 & -3.122461 \\ \mathrm{H} & -3.772942 & 2.485243 & -4.856325 \\ \mathrm{H} & -4.633132 & 0.762952 & -3.225730 \\ \mathrm{C} & -3.295058 & -0.217812 & -1.087495 \\ \mathrm{H} & -5.817833 & -2.693183 & -2.688575 \\ \mathrm{C} & -4.941807 & -1.643550 & -0.367209 \\ \mathrm{C} & -4.062405 & -2.029061 & 0.714199 \\ \mathrm{~N} & -1.581712 & 1.298787 & -1.878915 \\ \mathrm{~N} & -4.518765 & -0.737278 & -1.245838 \\ \mathrm{~N} & -2.453641 & -0.554600 & -0.105570 \\ \mathrm{~N} & -2.857875 & -1.474161 & 0.790253 \\ \mathrm{C} & -6.307387 & -2.264225 & -0.588393 \\ \mathrm{C} & -6.768649 & -3.032543 & 0.670165 \\ \mathrm{H} & -7.178470 & -2.324983 & 1.398303 \\ \mathrm{H} & -7.599141 & -3.685203 & 0.388150 \\ \mathrm{C} & -5.657913 & -3.865370 & 1.314293 \\ \mathrm{C} & -4.462351 & -3.014997 & 1.805195 \\ \mathrm{H} & -5.297701 & -4.623481 & 0.610316 \\ \mathrm{H} & -6.058922 & -4.414895 & 2.170553 \\ \mathrm{H} & -7.087128 & -0.662158 & -1.876565 \\ \mathrm{H} & -136340 & -1.638874 & -1.069470 \\ \mathrm{H} & -0.425314 & -0.149293 \\ \mathrm{H} & -3.231441 & -1.800667 \\ \mathrm{H} & -3.668628 & -2.020414 \\ \mathrm{H} & -1.04963 & -1.601576\end{array}$




$\begin{array}{lrrr}\mathrm{C} & -4.856610 & -2.183570 & 3.056982 \\ \mathrm{H} & -5.142411 & -2.862895 & 3.864423 \\ \mathrm{H} & -4.014345 & -1.577505 & 3.404897 \\ \mathrm{H} & -5.700790 & -1.515347 & 2.868640 \\ \mathrm{C} & -3.290492 & -3.950518 & 2.169712 \\ \mathrm{H} & -2.471129 & -3.417873 & 2.660573 \\ \mathrm{H} & -3.645969 & -4.709151 & 2.871771 \\ \mathrm{H} & -2.897355 & -4.470747 & 1.290851 \\ \mathrm{C} & 0.229666 & 2.754900 & -2.483554 \\ \mathrm{C} & 0.955751 & 3.748814 & -3.162406 \\ \mathrm{C} & 2.166213 & 3.870001 & -2.478646 \\ \mathrm{H} & 0.664149 & 4.321045 & -4.029842 \\ \mathrm{~N} & 0.937576 & 2.273911 & -1.435119 \\ \mathrm{~N} & 2.103665 & 2.971169 & -1.462507 \\ \mathrm{C} & 3.353076 & 4.747819 & -2.721001 \\ \mathrm{H} & 2.808338 & 2.807240 & -0.755639 \\ \mathrm{H} & -2.808329 & 2.807263 & 0.755618 \\ \mathrm{H} & 3.036545 & 5.781927 & -2.876754 \\ \mathrm{H} & 4.050363 & 4.727010 & -1.880066 \\ \mathrm{H} & 3.889335 & 4.427764 & -3.619600 \\ \mathrm{H} & -4.050311 & 4.727104 & 1.879999 \\ \mathrm{H} & -3.889356 & 4.427767 & 3.619524 \\ \mathrm{H} & -3.036522 & 5.781958 & 2.876781\end{array}$

$\mathrm{M}=\mathrm{Cm}$

$\begin{array}{lccc}\mathrm{CM} & 0.000001 & 0.426709 & -0.000004 \\ \mathrm{O} & 0.388646 & -1.233278 & -1.774063 \\ \mathrm{H} & 1.321879 & -1.592480 & -1.683486 \\ \mathrm{O} & -0.388655 & -1.233236 & 1.774095 \\ \mathrm{H} & 0.037730 & -1.622590 & 2.549946 \\ \mathrm{H} & -0.037744 & -1.622650 & -2.549903 \\ \mathrm{H} & -1.321889 & -1.592438 & 1.683522 \\ \mathrm{C} & 1.152573 & 2.300593 & 2.671975 \\ \mathrm{C} & 1.944363 & 2.779009 & 3.727110 \\ \mathrm{C} & 3.226093 & 2.260899 & 3.904368 \\ \mathrm{H} & 1.561936 & 3.538872 & 4.398105 \\ \mathrm{C} & 2.844455 & 0.846970 & 2.000655 \\ \mathrm{C} & 3.689111 & 1.274603 & 3.025373 \\ \mathrm{H} & 3.855472 & 2.614948 & 4.715297 \\ \mathrm{H} & 4.674684 & 0.837239 & 3.122868 \\ \mathrm{C} & 3.286229 & -0.206753 & 1.045727 \\ \mathrm{C} & 4.902283 & -1.675043 & 0.342549 \\ \mathrm{C} & 3.998388 & -2.085804 & -0.709160 \\ \mathrm{~N} & 1.599688 & 1.349007 & 1.821559 \\ \mathrm{~N} & 4.508112 & -0.732391 & 1.196354\end{array}$




\begin{tabular}{|c|c|c|c|}
\hline I & (1) & -0.569198 & \\
\hline $\mathrm{N}$ & 799347 & -1.518600 & \\
\hline & 6.264185 & -2.305312 & \\
\hline & 6.693667 & -3.117149 & -0.68 \\
\hline & .095839 & -2.436628 & \\
\hline & 7.523376 & -3.7 & \\
\hline & 36 & -3.9 & \\
\hline$C$ & 792 & -3.1 & \\
\hline & & & \\
\hline & 5.94 & -4.5 & -2 . \\
\hline & 7.3 & -1.2 & \\
\hline & 7.08 & -0.6 & \\
\hline & 8.2 & -1.6 & \\
\hline & 7.3 & -0.4 & \\
\hline & 6.12 & -3.2 & \\
\hline & 7.1 & -3.6 & \\
\hline & 5.8 & -2.6 & \\
\hline & 5.4 & -4.0 & \\
\hline & 4.7 & -2.3 & -3 \\
\hline & 5.0 & -3.0 & \\
\hline $\mathrm{H}$ & 3.8 & -1.7 & -3. \\
\hline & 5.5 & -1.6 & -2 \\
\hline & $3.1^{\prime}$ & -4.0 & -2 . \\
\hline & 2.3 & -3.5 & -2 \\
\hline $\mathrm{H}$ & 3.5 & -4.8 & -2 . \\
\hline & 2.80 & -4.5 & -1 . \\
\hline & -0.20 & 2.8 & \\
\hline & -0.9 & 3.8 & \\
\hline $\mathrm{C}$ & -2.1 & 3.9 & \\
\hline $\mathrm{H}$ & -0.5 & 4.4 & \\
\hline $\mathbf{N}$ & -0.9 & 2.2 & \\
\hline 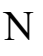 & -2.1 & 2.97 & \\
\hline $\mathrm{C}$ & -3.3 & $4.7^{\prime}$ & \\
\hline 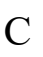 & -1.1 & 2.3 & -2. \\
\hline & -1.9 & 2.77 & -3.7 \\
\hline 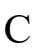 & -3.22 & 2.26 & -3. \\
\hline $\mathrm{H}$ & -1.56 & 3.53 & -4 \\
\hline 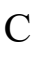 & -2.8 & 0.8 & $-2 .($ \\
\hline 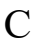 & -3.68 & 1.274541 & -3.0 \\
\hline $\mathrm{H}$ & -3.8 & 2.6 & -4 \\
\hline 11 & -4.6 & 0.83 & -3. \\
\hline $\mathrm{C}$ & -3.28 & -0.20 & -1.0 \\
\hline$C$ & -4.902284 & -1.675038 & -0.3 \\
\hline 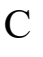 & -3.998396 & -2.085777 & 0.70 \\
\hline $\mathrm{N}$ & -1.599677 & 1.348978 & -1.82 \\
\hline & -4.508106 & -0.732406 & -1.1963 \\
\hline
\end{tabular}




$\begin{array}{crrr}\mathrm{N} & -2.422015 & -0.569190 & -0.092788 \\ \mathrm{~N} & -2.799356 & -1.518573 & 0.782835 \\ \mathrm{C} & -6.264187 & -2.305308 & -0.559090 \\ \mathrm{C} & -6.693677 & -3.117117 & 0.683373 \\ \mathrm{H} & -7.095852 & -2.436579 & 1.440985 \\ \mathrm{H} & -7.523386 & -3.768860 & 0.396957 \\ \mathrm{C} & -5.562851 & -3.958479 & 1.279416 \\ \mathrm{C} & -4.365808 & -3.112304 & 1.773987 \\ \mathrm{H} & -5.209392 & -4.690291 & 0.544907 \\ \mathrm{H} & -5.941880 & -4.538830 & 2.125278 \\ \mathrm{C} & -7.316650 & -1.216135 & -0.865023 \\ \mathrm{H} & -7.086431 & -0.675773 & -1.784761 \\ \mathrm{H} & -8.293150 & -1.692159 & -0.986213 \\ \mathrm{H} & -7.398518 & -0.495131 & -0.045471 \\ \mathrm{C} & -6.124848 & -3.233604 & -1.802604 \\ \mathrm{H} & -7.100021 & -3.677710 & -2.018037 \\ \mathrm{H} & -5.807322 & -2.664025 & -2.679737 \\ \mathrm{H} & -5.412652 & -4.047521 & -1.641104 \\ \mathrm{C} & -4.741794 & -2.329096 & 3.061893 \\ \mathrm{H} & -5.001580 & -3.039091 & 3.851528 \\ \mathrm{H} & -3.899509 & -1.724524 & 3.412520 \\ \mathrm{H} & -5.597758 & -1.665424 & 2.915068 \\ \mathrm{C} & -3.176794 & -4.047227 & 2.080261 \\ \mathrm{H} & -2.349421 & -3.522651 & 2.566184 \\ \mathrm{H} & -3.508115 & -4.831079 & 2.766254 \\ \mathrm{H} & -2.800837 & -4.535297 & 1.175838 \\ \mathrm{C} & 0.207583 & 2.808249 & -2.438182 \\ \mathrm{C} & 0.915414 & 3.820661 & -3.109679 \\ \mathrm{C} & 2.154351 & 3.905384 & -2.473681 \\ \mathrm{H} & 0.593518 & 4.427481 & -3.942101 \\ \mathrm{~N} & 0.954198 & 2.282103 & -1.437801 \\ \mathrm{~N} & 2.124432 & 2.970331 & -1.489324 \\ \mathrm{C} & 3.340765 & 4.777969 & -2.736218 \\ \mathrm{H} & 2.858162 & 2.771103 & -0.822250 \\ \mathrm{H} & -2.858177 & 2.771077 & 0.822256 \\ \mathrm{H} & -3.025795 & 5.812259 & 2.892079 \\ \mathrm{H} & -4.049777 & 4.758123 & 1.905030 \\ \mathrm{H} & -3.863517 & 4.451847 & 3.640849 \\ \mathrm{H} & 3.862684 & 4.452864 & -3.641629 \\ \mathrm{H} & 3.025846 & 5.812546 & -2.890573 \\ \mathrm{H} & 4.050430 & 4.757044 & -1.905609 \\ & & & \\ {[\mathrm{ML} 2]^{3+}} & & \\ & & & \end{array}$

$\mathrm{M}=\mathrm{Eu}$ 


\begin{tabular}{|c|c|c|c|}
\hline EU & 0.024069 & 1.014935 & 32039 \\
\hline$N$ & -2.009131 & -0.351959 & 0.188731 \\
\hline $\mathrm{N}$ & 1.929698 & -0.507863 & -0.277052 \\
\hline $\mathrm{C}$ & -2.791911 & -0.445802 & 1.272596 \\
\hline $\mathrm{N}$ & -2.316935 & -1.034868 & -0.921350 \\
\hline N & -0.726223 & 2.882890 & -1.461012 \\
\hline$N$ & 1.045850 & 2.492852 & 1.775178 \\
\hline N & 1.490372 & 1.399179 & -2.045661 \\
\hline N & -1.235749 & 1.088469 & 2.262405 \\
\hline 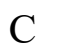 & 2.801725 & -0.455379 & -1.299843 \\
\hline N & 2.068539 & -1.419348 & 0.671024 \\
\hline $\mathrm{C}$ & -2.357413 & 0.353576 & 2.448009 \\
\hline N & -3.891814 & -1.195109 & 1.333190 \\
\hline $\mathrm{C}$ & -3.406917 & -1.802858 & -0.940218 \\
\hline$c$ & -0.018243 & 3.176942 & -2.585404 \\
\hline $\mathrm{N}$ & -1.745608 & 3.786825 & -1.461624 \\
\hline$C$ & 0.459267 & 2.604036 & 2.998854 \\
\hline $\mathrm{N}$ & 2.124963 & 3.322297 & 1.844441 \\
\hline $\mathrm{C}$ & 2.555398 & 0.606104 & -2.304497 \\
\hline $\mathrm{C}$ & 1.170741 & 2.376444 & -2.919529 \\
\hline $\mathrm{C}$ & -0.765833 & 1.838961 & 3.281869 \\
\hline $\mathrm{N}$ & 3.818896 & -1.303976 & -1.415623 \\
\hline $\mathrm{C}$ & 3.064947 & -2.303087 & 0.630610 \\
\hline $\mathrm{C}$ & -3.056646 & 0.340534 & 3.653392 \\
\hline $\mathrm{C}$ & -4.230947 & -1.894092 & 0.245725 \\
\hline $\mathrm{C}$ & -3.690445 & -2.579113 & -2.220416 \\
\hline $\mathrm{C}$ & -0.596681 & 4.254324 & -3.272381 \\
\hline $\mathrm{C}$ & -1.714844 & 4.631487 & -2.523025 \\
\hline $\mathrm{H}$ & -2.430223 & 3.788172 & -0.715565 \\
\hline $\mathrm{C}$ & 1.173794 & 3.492320 & 3.815790 \\
\hline $\mathrm{C}$ & 2.247548 & 3.944926 & 3.044512 \\
\hline $\mathrm{H}$ & 2.738183 & 3.432675 & 1.046755 \\
\hline $\mathrm{C}$ & 3.354857 & 0.759653 & -3.434396 \\
\hline $\mathrm{C}$ & 1.927361 & 2.596185 & -4.082005 \\
\hline $\mathrm{C}$ & -1.412290 & 1.879187 & 4.525705 \\
\hline $\mathrm{C}$ & 3.986848 & -2.245734 & -0.488789 \\
\hline $\mathrm{C}$ & 3.148063 & -3.340868 & 1.737928 \\
\hline $\mathrm{C}$ & -2.570235 & 1.121501 & 4.710252 \\
\hline $\mathrm{H}$ & -3.949420 & -0.265231 & 3.750894 \\
\hline $\mathrm{C}$ & -5.500607 & -2.720301 & 0.308717 \\
\hline $\mathrm{C}$ & -3.462679 & -1.683994 & -3.457430 \\
\hline $\mathrm{C}$ & -5.153019 & -3.080743 & -2.210960 \\
\hline $\mathrm{C}$ & -2.698572 & -3.772380 & -2.268588 \\
\hline $\mathrm{H}$ & -0.270580 & 4.717027 & -4.191521 \\
\hline $\mathrm{C}$ & -2.730536 & 5.707282 & -2.740497 \\
\hline $\mathrm{H}$ & 0.960202 & 3.787424 & 4.831919 \\
\hline
\end{tabular}




\begin{tabular}{|c|c|c|c|}
\hline $\mathrm{C}$ & 3.352670 & 4.902137 & 3.358644 \\
\hline & 3.030710 & 1.781563 & -4.337816 \\
\hline $\mathrm{H}$ & 4.196330 & 0.096413 & -3.596145 \\
\hline $\mathrm{H}$ & 1.654864 & 3.383742 & -4.774706 \\
\hline H & -1.018993 & 2.486210 & 5.332611 \\
\hline $\mathrm{C}$ & 5.168004 & -3.188384 & -0.628752 \\
\hline $\mathrm{C}$ & 2.894783 & -2.679517 & 3.110133 \\
\hline 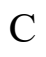 & 4.549082 & -3.997353 & 1.731063 \\
\hline $\mathrm{C}$ & 2.041370 & -4.396393 & 1.466894 \\
\hline H & -3.087640 & 1.136326 & 5.664807 \\
\hline $\mathrm{C}$ & -5.567992 & -3.707334 & -0.877714 \\
\hline $\mathrm{C}$ & -5.564883 & -3.497601 & 1.643245 \\
\hline $\mathrm{C}$ & -6.686422 & -1.711123 & 0.257267 \\
\hline $\mathrm{H}$ & -3.714926 & -2.248679 & -4.358926 \\
\hline $\mathrm{H}$ & -4.103358 & -0.796752 & -3.432487 \\
\hline $\mathrm{H}$ & -2.422310 & -1.361342 & -3.539183 \\
\hline $\mathrm{H}$ & -5.269419 & -3.812659 & -3.015186 \\
\hline $\mathrm{H}$ & -5.822132 & -2.250082 & -2.459956 \\
\hline $\mathrm{H}$ & -2.820244 & -4.452596 & -1.421368 \\
\hline $\mathrm{H}$ & -1.664594 & -3.414505 & -2.274890 \\
\hline $\mathrm{H}$ & -2.867038 & -4.344781 & -3.184624 \\
\hline H & -3.460991 & 5.745369 & -1.929284 \\
\hline $\mathrm{H}$ & -3.266995 & 5.539363 & -3.678794 \\
\hline $\mathrm{H}$ & -2.242528 & 6.683309 & -2.809984 \\
\hline $\mathrm{H}$ & 4.020472 & 5.045162 & 2.506126 \\
\hline $\mathrm{H}$ & 3.944926 & 4.536602 & 4.202348 \\
\hline $\mathrm{H}$ & 2.943439 & 5.875975 & 3.641615 \\
\hline $\mathrm{H}$ & 3.628574 & 1.933905 & -5.231414 \\
\hline $\mathrm{C}$ & 5.022777 & -4.390634 & 0.329117 \\
\hline $\mathrm{C}$ & 5.271374 & -3.685852 & -2.089527 \\
\hline $\mathrm{C}$ & 6.438128 & -2.353200 & -0.285925 \\
\hline $\mathrm{H}$ & 2.995016 & -3.433710 & 3.894883 \\
\hline $\mathrm{H}$ & 3.622636 & -1.888231 & 3.314932 \\
\hline $\mathrm{H}$ & 1.889357 & -2.255656 & 3.172643 \\
\hline $\mathrm{H}$ & 4.514372 & -4.883577 & 2.370480 \\
\hline $\mathrm{H}$ & 5.270382 & -3.316985 & 2.195932 \\
\hline 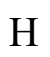 & 2.173745 & -4.907434 & 0.509720 \\
\hline 11 & 1.052233 & -3.928817 & 1.471574 \\
\hline $\mathrm{H}$ & 2.066294 & -5.151648 & 2.256721 \\
\hline $\mathrm{H}$ & -6.591490 & -4.084853 & -0.951538 \\
\hline $\mathrm{H}$ & -4.941997 & -4.579096 & -0.660115 \\
\hline $\mathrm{H}$ & -6.471181 & -4.108705 & 1.652024 \\
\hline $\mathrm{H}$ & -4.709103 & -4.170299 & 1.757737 \\
\hline 11 & -5.598919 & -2.826314 & 2.502891 \\
\hline $\mathrm{H}$ & -7.622679 & -2.268731 & 0.342200 \\
\hline $\mathrm{H}$ & -6.715159 & -1.144902 & -0.677708 \\
\hline
\end{tabular}




$\begin{array}{lrrr}\mathrm{H} & -6.632514 & -1.004874 & 1.089612 \\ \mathrm{H} & 5.992702 & -4.890816 & 0.398607 \\ \mathrm{H} & 4.338078 & -5.123871 & -0.109266 \\ \mathrm{H} & 6.108037 & -4.385290 & -2.163427 \\ \mathrm{H} & 4.365878 & -4.216203 & -2.399817 \\ \mathrm{H} & 5.451529 & -2.863514 & -2.784369 \\ \mathrm{H} & 7.316289 & -2.990508 & -0.417668 \\ \mathrm{H} & 6.436802 & -1.990188 & 0.745320 \\ \mathrm{H} & 6.533748 & -1.495973 & -0.957049\end{array}$

$\mathrm{M}=\mathrm{Gd}$

$\begin{array}{lrrc}\text { GD } & 0.000006 & 1.088506 & 0.000001 \\ \mathrm{~N} & 1.865885 & -0.384298 & -0.288457 \\ \mathrm{~N} & -1.865893 & -0.384280 & 0.288447 \\ \mathrm{C} & 2.592543 & -0.495000 & -1.410282 \\ \mathrm{~N} & 2.154503 & -1.140343 & 0.780534 \\ \mathrm{~N} & -0.984037 & 2.725979 & -1.529465 \\ \mathrm{~N} & 0.984095 & 2.725931 & 1.529491 \\ \mathrm{~N} & 1.127609 & 1.203508 & -2.241484 \\ \mathrm{~N} & -1.127600 & 1.203513 & 2.241480 \\ \mathrm{C} & -2.592556 & -0.494973 & 1.410270 \\ \mathrm{~N} & -2.154530 & -1.140312 & -0.780549 \\ \mathrm{C} & 2.175067 & 0.393883 & -2.524462 \\ \mathrm{~N} & 3.617463 & -1.331537 & -1.552244 \\ \mathrm{C} & 3.170464 & -2.000360 & 0.714918 \\ \mathrm{C} & -0.481843 & 2.871757 & -2.788266 \\ \mathrm{~N} & -2.012945 & 3.620528 & -1.471843 \\ \mathrm{C} & 0.481888 & 2.871720 & 2.788285 \\ \mathrm{~N} & 2.013024 & 3.620456 & 1.471882 \\ \mathrm{C} & 0.662882 & 2.041318 & -3.193075 \\ \mathrm{C} & -2.175075 & 0.393906 & 2.524450 \\ \mathrm{C} & -0.662865 & 2.041312 & 3.193076 \\ \mathrm{~N} & -3.617481 & -1.331502 & 1.552233 \\ \mathrm{C} & -3.170505 & -2.000312 & -0.714935 \\ \mathrm{C} & 2.805273 & 0.391388 & -3.766510 \\ \mathrm{C} & 3.935789 & -2.107934 & -0.510156 \\ \mathrm{C} & 3.433979 & -2.860276 & 1.944987 \\ \mathrm{C} & -1.194457 & 3.845561 & -3.498460 \\ \mathrm{C} & -2.180658 & 4.315381 & -2.623991 \\ \mathrm{H} & -2.562732 & 3.719318 & -0.627278 \\ \mathrm{C} & 1.194514 & 3.845509 & 3.498490 \\ \mathrm{C} & 2.180746 & 4.315299 & 2.624032 \\ \mathrm{H} & 2.562826 & 3.719228 & 0.627324 \\ \mathrm{C} & 1.242257 & 2.097750 & -4.467662 \\ \mathrm{C} & -2.805293 & 0.391424 & 3.766492\end{array}$




\begin{tabular}{|c|c|c|c|}
\hline $\mathrm{C}$ & -1.242254 & 2.097758 & 4.467657 \\
\hline & -3.935817 & -2.107895 & 0.510146 \\
\hline $\mathrm{C}$ & -3.434053 & -2.860196 & -1.945020 \\
\hline $\mathrm{C}$ & 2.325676 & 1.263415 & -4.753665 \\
\hline 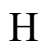 & 3.639888 & -0.275720 & -3.945969 \\
\hline & 5.123737 & -3.034425 & -0.663581 \\
\hline $\mathrm{C}$ & 3.331454 & -2.012795 & 3.230977 \\
\hline & 4.845365 & -3.484519 & 1.850254 \\
\hline$C$ & 2.343657 & -3.965460 & 1.977348 \\
\hline H & -1.037429 & 4.184415 & -4.511388 \\
\hline $\mathrm{C}$ & -3.243035 & 5.351749 & -2.804880 \\
\hline $\mathrm{H}$ & 1.037473 & 4.184371 & 4.511413 \\
\hline $\mathrm{C}$ & 3.243215 & 5.351580 & 2.804961 \\
\hline $\mathrm{H}$ & 0.856154 & 2.774961 & -5.220575 \\
\hline $\mathrm{C}$ & -2.325693 & 1.263446 & 4.753649 \\
\hline $\mathrm{H}$ & -3.639920 & -0.275671 & 3.945945 \\
\hline $\mathrm{H}$ & -0.856144 & 2.774963 & 5.220573 \\
\hline $\mathrm{C}$ & -5.123758 & -3.034393 & 0.663581 \\
\hline $\mathrm{C}$ & -3.331548 & -2.012682 & -3.230990 \\
\hline $\mathrm{C}$ & -4.845445 & -3.484423 & -1.850271 \\
\hline $\mathrm{C}$ & -2.343746 & -3.965393 & -1.977432 \\
\hline $\mathrm{H}$ & 2.790735 & 1.289056 & -5.734642 \\
\hline $\mathrm{C}$ & 5.151816 & -4.079468 & 0.474041 \\
\hline $\mathrm{C}$ & 5.071209 & -3.748778 & -2.033703 \\
\hline $\mathrm{C}$ & 6.393778 & -2.131761 & -0.616920 \\
\hline $\mathrm{H}$ & 3.568651 & -2.641855 & 4.093042 \\
\hline $\mathrm{H}$ & 4.044928 & -1.182630 & 3.220811 \\
\hline $\mathrm{H}$ & 2.326683 & -1.608542 & 3.372689 \\
\hline $\mathrm{H}$ & 4.927595 & -4.261798 & 2.615133 \\
\hline $\mathrm{H}$ & 5.594082 & -2.727702 & 2.107935 \\
\hline $\mathrm{H}$ & 2.372498 & -4.609084 & 1.094077 \\
\hline $\mathrm{H}$ & 1.345879 & -3.521654 & 2.045274 \\
\hline $\mathrm{H}$ & 2.497067 & -4.596649 & 2.856641 \\
\hline $\mathrm{H}$ & -3.841846 & 5.482082 & -1.900774 \\
\hline $\mathrm{H}$ & -2.793880 & 6.315011 & -3.062492 \\
\hline $\mathrm{H}$ & -3.911570 & 5.070915 & -3.623678 \\
\hline 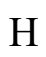 & 3.911563 & 5.070759 & 3.623932 \\
\hline HI & 3.842215 & 5.481677 & 1.900951 \\
\hline $\mathrm{H}$ & 2.794162 & 6.314942 & 3.062359 \\
\hline $\mathrm{H}$ & -2.790763 & 1.289099 & 5.734620 \\
\hline $\mathrm{C}$ & -5.151870 & -4.079406 & -0.474067 \\
\hline $\mathrm{C}$ & -5.071184 & -3.748785 & 2.033682 \\
\hline $\mathrm{C}$ & -6.393802 & -2.131730 & 0.616985 \\
\hline 11 & -3.568768 & -2.641719 & -4.093067 \\
\hline $\mathrm{H}$ & -4.045016 & -1.182512 & -3.220789 \\
\hline $\mathrm{H}$ & -2.326778 & -1.608433 & -3.372713 \\
\hline
\end{tabular}




$\begin{array}{lrrr}\mathrm{H} & -4.927706 & -4.261678 & -2.615171 \\ \mathrm{H} & -5.594159 & -2.727587 & -2.107910 \\ \mathrm{H} & -2.372565 & -4.609028 & -1.094170 \\ \mathrm{H} & -1.345965 & -3.521595 & -2.045384 \\ \mathrm{H} & -2.497192 & -4.596566 & -2.856730 \\ \mathrm{H} & 6.140832 & -4.545331 & 0.486329 \\ \mathrm{H} & 4.444767 & -4.883625 & 0.244919 \\ \mathrm{H} & 5.920150 & -4.433537 & -2.105888 \\ \mathrm{H} & 4.156774 & -4.340111 & -2.143351 \\ \mathrm{H} & 5.132658 & -3.042611 & -2.863242 \\ \mathrm{H} & 7.273516 & -2.762829 & -0.766644 \\ \mathrm{H} & 6.507402 & -1.616472 & 0.340696 \\ \mathrm{H} & 6.369689 & -1.384264 & -1.413830 \\ \mathrm{H} & -6.140887 & -4.545264 & -0.486344 \\ \mathrm{H} & -4.444819 & -4.883572 & -0.244982 \\ \mathrm{H} & -5.920126 & -4.433541 & 2.105877 \\ \mathrm{H} & -4.156749 & -4.340127 & 2.143279 \\ \mathrm{H} & -5.132599 & -3.042640 & 2.863243 \\ \mathrm{H} & -7.273537 & -2.762807 & 0.766700 \\ \mathrm{H} & -6.507447 & -1.616399 & -0.340605 \\ \mathrm{H} & -6.369697 & -1.384268 & 1.413927\end{array}$

$\mathrm{M}=\mathrm{Am}$

$\begin{array}{lrrr}\text { AM } & -0.000029 & 1.105153 & -0.000043 \\ \text { N } & -1.834114 & -0.449301 & 0.384774 \\ \text { N } & 1.834155 & -0.449242 & -0.384721 \\ \text { C } & -2.454349 & -0.643416 & 1.554699 \\ \text { N } & -2.204318 & -1.143847 & -0.698913 \\ \text { N } & -1.029080 & 2.737161 & -1.596128 \\ \text { N } & 1.028809 & 2.737513 & 1.595838 \\ \text { N } & -0.961781 & 1.051213 & 2.358085 \\ \text { N } & 0.961637 & 1.050951 & -2.358206 \\ \mathrm{C} & 2.454376 & -0.643446 & -1.554638 \\ \text { N } & 2.204467 & -1.143605 & 0.699048 \\ \mathrm{C} & -1.960766 & 0.192485 & 2.676432 \\ \mathrm{~N} & -3.446074 & -1.512706 & 1.735670 \\ \mathrm{C} & -3.195750 & -2.027820 & -0.599700 \\ \mathrm{C} & -0.622103 & 2.761361 & -2.893396 \\ \mathrm{~N} & -2.011036 & 3.682045 & -1.532225 \\ \mathrm{C} & 0.621784 & 2.761848 & 2.893089 \\ \mathrm{~N} & 2.010669 & 3.682492 & 1.531842 \\ \mathrm{C} & -0.452606 & 1.853625 & 3.319426 \\ \mathrm{C} & 1.960685 & 0.192264 & -2.676466 \\ \mathrm{C} & 0.452360 & 1.853183 & -3.319642 \\ \mathrm{~N} & 3.446184 & -1.512659 & -1.735527\end{array}$




\begin{tabular}{|c|c|c|c|}
\hline $\mathrm{C}$ & 3.195987 & -2.027489 & 0.599920 \\
\hline & -2.489286 & 0.099198 & 3.961172 \\
\hline$C$ & -3.843500 & -2.230818 & 0.679525 \\
\hline $\mathrm{C}$ & -3.557940 & -2.811300 & -1.855517 \\
\hline $\mathrm{C}$ & -1.345677 & 3.712687 & -3.625010 \\
\hline $\mathrm{C}$ & -2.238665 & 4.295313 & -2.719945 \\
\hline $\mathrm{H}$ & -2.486934 & 3.872006 & -0.658963 \\
\hline $\mathrm{C}$ & 1.345233 & 3.713349 & 3.624599 \\
\hline $\mathrm{C}$ & 2.238193 & 4.295943 & 2.719488 \\
\hline $\mathrm{H}$ & 2.486578 & 3.872384 & 0.658572 \\
\hline $\mathrm{C}$ & -0.931925 & 1.815921 & 4.635752 \\
\hline $\mathrm{C}$ & 2.489173 & 0.098848 & -3.961211 \\
\hline$C$ & 0.931640 & 1.815341 & -4.635977 \\
\hline $\mathrm{C}$ & 3.843715 & -2.230593 & -0.679299 \\
\hline $\mathrm{C}$ & 3.558299 & -2.810764 & 1.855829 \\
\hline $\mathrm{C}$ & -1.960334 & 0.929068 & 4.958255 \\
\hline $\mathrm{H}$ & -3.288259 & -0.604146 & 4.162758 \\
\hline $\mathrm{C}$ & -4.993842 & -3.195645 & 0.879936 \\
\hline $\mathrm{C}$ & -3.591476 & -1.878225 & -3.084742 \\
\hline $\mathrm{C}$ & -4.943389 & -3.473305 & -1.673433 \\
\hline $\mathrm{C}$ & -2.456784 & -3.885900 & -2.064348 \\
\hline $\mathrm{H}$ & -1.255101 & 3.966500 & -4.670338 \\
\hline $\mathrm{C}$ & -3.264946 & 5.367258 & -2.901805 \\
\hline $\mathrm{H}$ & 1.254594 & 3.967295 & 4.669890 \\
\hline $\mathrm{C}$ & 3.264364 & 5.368011 & 2.901241 \\
\hline $\mathrm{H}$ & -0.510652 & 2.466692 & 5.392867 \\
\hline $\mathrm{C}$ & 1.960119 & 0.928536 & -4.958390 \\
\hline $\mathrm{H}$ & 3.288200 & -0.604455 & -4.162725 \\
\hline $\mathrm{H}$ & 0.510286 & 2.465971 & -5.393169 \\
\hline $\mathrm{C}$ & 4.994149 & -3.195329 & -0.879620 \\
\hline $\mathrm{C}$ & 3.591777 & -1.877523 & 3.084929 \\
\hline $\mathrm{C}$ & 4.943811 & -3.472649 & 1.673788 \\
\hline $\mathrm{C}$ & 2.457262 & -3.885452 & 2.064839 \\
\hline $\mathrm{H}$ & -2.346650 & 0.883904 & 5.972065 \\
\hline $\mathrm{C}$ & -5.109227 & -4.164297 & -0.318135 \\
\hline $\mathrm{C}$ & -4.796507 & -3.996878 & 2.187362 \\
\hline $\mathrm{C}$ & -6.279995 & -2.325422 & 1.013764 \\
\hline $\mathrm{H}$ & -3.897934 & -2.454014 & -3.962100 \\
\hline $\mathrm{H}$ & -4.314772 & -1.067344 & -2.951703 \\
\hline $\mathrm{H}$ & -2.611259 & -1.442277 & -3.290603 \\
\hline $\mathrm{H}$ & -5.083737 & -4.200234 & -2.478324 \\
\hline $\mathrm{H}$ & -5.725722 & -2.718701 & -1.808825 \\
\hline $\mathrm{H}$ & -2.392920 & -4.588442 & -1.229146 \\
\hline 1 & -1.477259 & -3.415133 & -2.191523 \\
\hline $\mathrm{H}$ & -2.679790 & -4.459516 & -2.967875 \\
\hline $\mathrm{H}$ & -4.000306 & 5.065675 & -3.653058 \\
\hline
\end{tabular}




$\begin{array}{cccc}\mathrm{H} & -3.793690 & 5.585446 & -1.971284 \\ \mathrm{H} & -2.793439 & 6.289083 & -3.253936 \\ \mathrm{H} & 3.999800 & 5.066540 & 3.652466 \\ \mathrm{H} & 2.792776 & 6.289798 & 3.253358 \\ \mathrm{H} & 3.793033 & 5.586217 & 1.970681 \\ \mathrm{H} & 2.346409 & 0.883267 & -5.972206 \\ \mathrm{C} & 5.109677 & -4.163807 & 0.318578 \\ \mathrm{C} & 4.796850 & -3.996758 & -2.186930 \\ \mathrm{C} & 6.280208 & -2.324991 & -1.013611 \\ \mathrm{H} & 3.898324 & -2.453164 & 3.962354 \\ \mathrm{H} & 4.314984 & -1.066584 & 2.951760 \\ \mathrm{H} & 2.611521 & -1.441651 & 3.290766 \\ \mathrm{H} & 5.084263 & -4.199454 & 2.478773 \\ \mathrm{H} & 5.726070 & -2.717944 & 1.809052 \\ \mathrm{H} & 2.393443 & -4.588111 & 1.229731 \\ \mathrm{H} & 1.477692 & -3.414771 & 2.191984 \\ \mathrm{H} & 2.680358 & -4.458926 & 2.968433 \\ \mathrm{H} & -6.086464 & -4.652187 & -0.270897 \\ \mathrm{H} & -4.369399 & -4.964348 & -0.209971 \\ \mathrm{H} & -5.621101 & -4.706581 & 2.293267 \\ \mathrm{H} & -3.864464 & -4.570433 & 2.169900 \\ \mathrm{H} & -4.791748 & -3.348283 & 3.064830 \\ \mathrm{H} & -7.129457 & -2.987087 & 1.201505 \\ \mathrm{H} & -6.493939 & -1.750853 & 0.108440 \\ \mathrm{H} & -6.194891 & -1.631530 & 1.853760 \\ \mathrm{H} & 6.086963 & -4.651600 & 0.271373 \\ \mathrm{H} & 4.369929 & -4.963950 & 0.210547 \\ \mathrm{H} & 5.621513 & -4.706391 & -2.292770 \\ \mathrm{H} & 3.864866 & -4.570406 & -2.169358 \\ \mathrm{H} & 4.791994 & -3.348283 & -3.064486 \\ \mathrm{H} & 7.129732 & -2.986594 & -1.201292 \\ \mathrm{H} & 6.494125 & -1.750278 & -0.108372 \\ \mathrm{H} & 6.195003 & -1.631222 & -1.853697\end{array}$

$\mathrm{M}=\mathrm{Cm}$

$\begin{array}{lrrc}\mathrm{CM} & -0.000008 & 1.043201 & -0.000014 \\ \mathrm{~N} & -1.892776 & -0.463186 & 0.294550 \\ \mathrm{C} & -2.610097 & -0.593776 & 1.419650 \\ \mathrm{~N} & -2.188241 & -1.205520 & -0.783022 \\ \mathrm{C} & -2.196666 & 0.278847 & 2.548603 \\ \mathrm{~N} & -3.630027 & -1.438418 & 1.556261 \\ \mathrm{C} & -3.199458 & -2.070142 & -0.723338 \\ \mathrm{C} & -2.828949 & 0.244966 & 3.789629 \\ \mathrm{~N} & -1.159040 & 1.105747 & 2.283946 \\ \mathrm{C} & -3.953783 & -2.200475 & 0.505683\end{array}$




\begin{tabular}{|c|c|c|c|}
\hline $\mathrm{C}$ & -3.469795 & -2.911044 & -1.965314 \\
\hline & -2.362072 & 1.103397 & 4.794091 \\
\hline & -3.656150 & -0.434793 & 3.954745 \\
\hline 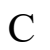 & -0.707853 & 1.932462 & 3.250715 \\
\hline$C$ & -5.135432 & -3.135716 & 0.655303 \\
\hline $\mathrm{C}$ & -3.383964 & -2.041486 & -3.237737 \\
\hline C & -4.877143 & -3.544128 & -1.867851 \\
\hline C & -2.374398 & -4.009869 & -2.026892 \\
\hline $\mathrm{C}$ & -1.289803 & 1.957173 & 4.525236 \\
\hline $\mathrm{H}$ & -2.829039 & 1.104512 & 5.774486 \\
\hline $\mathrm{C}$ & 0.423467 & 2.791927 & 2.867864 \\
\hline $\mathrm{C}$ & -5.168166 & -4.162625 & -0.498673 \\
\hline $\mathrm{C}$ & -5.065780 & -3.871671 & 2.013147 \\
\hline $\mathrm{C}$ & -6.410857 & -2.239899 & 0.634922 \\
\hline $\mathrm{H}$ & -3.627515 & -2.656782 & -4.107963 \\
\hline $\mathrm{H}$ & -4.100614 & -1.214513 & -3.206042 \\
\hline $\mathrm{H}$ & -2.382202 & -1.630819 & -3.382666 \\
\hline $\mathrm{H}$ & -4.962478 & -4.309425 & -2.644385 \\
\hline $\mathrm{H}$ & -5.631950 & -2.787052 & -2.106523 \\
\hline $\mathrm{H}$ & -2.392520 & -4.669540 & -1.155219 \\
\hline $\mathrm{H}$ & -1.379419 & -3.559749 & -2.095124 \\
\hline $\mathrm{H}$ & -2.531964 & -4.625999 & -2.916107 \\
\hline $\mathrm{H}$ & -0.915008 & 2.625944 & 5.291229 \\
\hline $\mathrm{C}$ & 1.114748 & 3.760096 & 3.60 \\
\hline $\mathrm{N}$ & 0.933399 & 2.690698 & 1.608065 \\
\hline $\mathrm{H}$ & -6.154695 & -4.633727 & -0.509767 \\
\hline $\mathrm{H}$ & -4.454650 & -4.966377 & -0.288786 \\
\hline $\mathrm{H}$ & -5.909507 & -4.563172 & 2.082374 \\
\hline $\mathrm{H}$ & -4.146490 & -4.458576 & 2.104969 \\
\hline $\mathrm{H}$ & -5.124123 & -3.179256 & 2.854457 \\
\hline $\mathrm{H}$ & -7.285842 & -2.877890 & 0.783260 \\
\hline $\mathrm{H}$ & -6.536537 & -1.710445 & -0.313432 \\
\hline $\mathrm{H}$ & -6.383000 & -1.504494 & 1.442897 \\
\hline $\mathrm{C}$ & 2.095026 & 4.272368 & 2.749600 \\
\hline $\mathrm{H}$ & 0.947663 & 4.068841 & 4.627361 \\
\hline $\mathrm{N}$ & 1.945745 & 3.606221 & 1.579046 \\
\hline $\mathrm{H}$ & 2.496293 & 3.738916 & 0.739800 \\
\hline $\mathrm{N}$ & 1.892797 & -0.463151 & -0.294528 \\
\hline $\mathrm{C}$ & 2.610099 & -0.593784 & -1.419636 \\
\hline $\mathrm{N}$ & 2.188301 & -1.205418 & 0.783079 \\
\hline $\mathrm{C}$ & 2.196625 & 0.278768 & -2.548628 \\
\hline $\mathrm{N}$ & 3.630045 & -1.438411 & -1.556221 \\
\hline $\mathrm{C}$ & 3.199539 & -2.070019 & 0.723421 \\
\hline $\mathrm{C}$ & 2.828886 & 0.244835 & -3.789664 \\
\hline $\mathrm{N}$ & 1.158985 & 1.105658 & -2.283995 \\
\hline$C$ & 3.953841 & -2.200402 & -0.505608 \\
\hline
\end{tabular}




\begin{tabular}{|c|c|c|c|}
\hline $\mathrm{C}$ & 3.469924 & -2.910845 & 1.965438 \\
\hline $\mathrm{C}$ & 2.361969 & 1.103202 & -4.794163 \\
\hline H & 3.656099 & -0.434913 & -3.954759 \\
\hline $\mathrm{C}$ & 0.707761 & 1.932312 & -3.250800 \\
\hline $\mathrm{C}$ & 5.135507 & -3.135624 & -0.655203 \\
\hline C & 3.384092 & -2.041220 & 3.237815 \\
\hline $\mathrm{C}$ & 4.877289 & -3.543890 & 1.867982 \\
\hline $\mathrm{C}$ & 2.374561 & -4.009699 & 2.027099 \\
\hline $\mathrm{C}$ & 1.289686 & 1.956967 & -4.525333 \\
\hline $\mathrm{H}$ & 2.828918 & 1.104275 & -5.774566 \\
\hline $\mathrm{C}$ & -0.423569 & 2.791773 & -2.867973 \\
\hline $\mathrm{C}$ & 5.168300 & -4.162462 & 0.498835 \\
\hline $\mathrm{C}$ & 5.065833 & -3.871665 & -2.013000 \\
\hline $\mathrm{C}$ & 6.410912 & -2.239776 & -0.634914 \\
\hline $\mathrm{H}$ & 3.627677 & -2.656461 & 4.108070 \\
\hline $\mathrm{H}$ & 4.100718 & -1.214227 & 3.206062 \\
\hline H & 2.382321 & 0573 & 3.382741 \\
\hline $\mathrm{H}$ & 4.962666 & 137 & 2.64 \\
\hline $\mathrm{H}$ & 5.632079 & -2.786776 & 2.106590 \\
\hline $\mathrm{H}$ & 2.392685 & -4.669417 & 1.155461 \\
\hline $\mathrm{H}$ & 1.379570 & -3.559604 & 2.095327 \\
\hline $\mathrm{H}$ & 2.532164 & -4.625776 & 2.916344 \\
\hline $\mathrm{H}$ & 0.914863 & 2.625691 & -5.291354 \\
\hline $\mathrm{C}$ & -1.114905 & 3.759868 & -3.600 \\
\hline $\mathrm{N}$ & -0.933467 & 2.690609 & -1.608155 \\
\hline $\mathrm{H}$ & 6.154843 & -4.633533 & 0.509935 \\
\hline $\mathrm{H}$ & 4.454804 & -4.966249 & 0.289014 \\
\hline $\mathrm{H}$ & 5.909575 & -4.563150 & -2.082209 \\
\hline $\mathrm{H}$ & 4.146556 & -4.458597 & -2.104759 \\
\hline $\mathrm{H}$ & 5.124136 & -3.179300 & -2.854354 \\
\hline $\mathrm{H}$ & 7.285908 & -2.877755 & -0.783241 \\
\hline $\mathrm{H}$ & 6.536608 & -1.710263 & 0.313405 \\
\hline $\mathrm{H}$ & 6.383014 & -1.504420 & -1.442932 \\
\hline $\mathrm{C}$ & -2.095173 & 4.272168 & -2.749763 \\
\hline $\mathrm{H}$ & -0.947866 & 4.068543 & -4.627545 \\
\hline $\mathrm{N}$ & -1.945845 & 3.606097 & -1.579170 \\
\hline $\mathrm{H}$ & -2.496376 & 3.738826 & -0.739919 \\
\hline $\mathrm{C}$ & -3.135831 & 5.323830 & -2.963974 \\
\hline $\mathrm{H}$ & -3.806393 & 5.034022 & -3.778024 \\
\hline $\mathrm{H}$ & -3.735927 & 5.490634 & -2.066687 \\
\hline $\mathrm{H}$ & -2.666645 & 6.270742 & -3.245497 \\
\hline $\mathrm{C}$ & 3.135735 & 5.323976 & 2.963814 \\
\hline 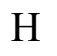 & 3.735441 & 5.491182 & 2.066344 \\
\hline F & 2.666669 & 6.270753 & 3.24597 \\
\hline $\mathrm{H}$ & 3.806657 & 5.033809 & 3.77745 \\
\hline
\end{tabular}




\section{$\mathbf{L}=\mathbf{2 a p}$}

\section{$\left[\mathrm{ML}\left(\mathrm{H}_{2} \mathrm{O}\right)_{6}\right]^{3+}$}

$\mathrm{M}=\mathrm{Eu}$

$\begin{array}{llll}\text { EU } & 0.423726 & -1.223689 & 0.274926\end{array}$

$\begin{array}{llll}\mathrm{O} & 1.573157 & -2.973412 & 1.899517\end{array}$

$\begin{array}{llll}\mathrm{H} & 2.388080 & -3.471920 & 2.064408\end{array}$

$\begin{array}{llll}\mathrm{O} & 0.798725 & -0.251881 & 2.715694\end{array}$

$\begin{array}{llll}\mathrm{H} & 1.400450 & -0.713496 & 3.321488\end{array}$

$\begin{array}{lllll}\mathrm{O} & -1.274204 & -2.777706 & -0.783509\end{array}$

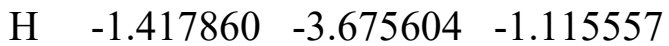

$\begin{array}{llll}\mathrm{O} & -1.100385 & -2.340235 & 2.183575\end{array}$

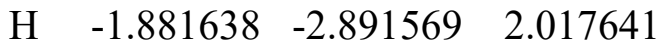

$\begin{array}{llll}\mathrm{O} & 2.083866 & -2.791068 & -1.063908\end{array}$

$\mathrm{H} \quad 2.223830 \quad-3.748564 \quad-0.988513$

$\begin{array}{lllll}\mathrm{O} & 0.426780 & -0.860490 & -2.349391\end{array}$

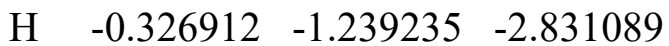

$\begin{array}{llll}\mathrm{H} & 0.874719 & -3.398960 & 2.426332\end{array}$

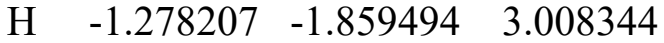

$\mathrm{H} \quad \begin{array}{llll}\mathrm{H} & 1.981755 & -2.604826 & -2.013409\end{array}$

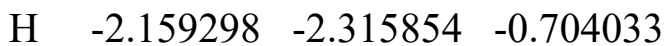

$\begin{array}{llll}\mathrm{H} & 0.710158 & -0.088041 & -2.864052\end{array}$

$\begin{array}{llll}\mathrm{H} & 0.702165 & 0.646502 & 3.068216\end{array}$

$\begin{array}{llll}\text { C } & 1.446158 & 2.164462 & 0.222675\end{array}$

$\begin{array}{llll}\text { C } & 1.433364 & 3.557928 & 0.372076\end{array}$

$\begin{array}{llll}\text { C } & 0.204909 & 4.216084 & 0.460035\end{array}$

$\begin{array}{llll}\mathrm{H} & 2.358822 & 4.120332 & 0.413744\end{array}$

$\begin{array}{llll}\mathrm{C} & -0.874291 & 2.080021 & 0.228670\end{array}$

$\begin{array}{llll}\mathrm{C} & -0.972387 & 3.467172 & 0.378267\end{array}$

$\begin{array}{llll}\mathrm{H} & 0.165324 & 5.294730 & 0.578103\end{array}$

$\begin{array}{llll}\mathrm{H} & -1.950006 & 3.930859 & 0.419259\end{array}$

$\begin{array}{llll}\mathrm{C} & -2.103918 & 1.247992 & 0.081991\end{array}$

$\begin{array}{llll}\text { C } & -4.384968 & 1.135634 & -0.124738\end{array}$

$\begin{array}{llll}\text { C } & -4.240147 & -0.284226 & -0.353222\end{array}$

$\begin{array}{llll}\mathrm{N} & 0.310001 & 1.433539 & 0.168658\end{array}$

$\begin{array}{llll}\mathrm{N} & -3.289300 & 1.868605 & 0.065154\end{array}$

$\begin{array}{llll}\mathrm{N} & -1.937025 & -0.069975 & -0.053888\end{array}$

$\begin{array}{llll}\mathrm{N} & -3.024977 & -0.824951 & -0.293959\end{array}$

$\begin{array}{llll}\mathrm{C} & -5.722442 & 1.850172 & -0.139622\end{array}$

$\begin{array}{llll}C & -6.882840 & 0.831226 & -0.098910\end{array}$

$\begin{array}{llll}\mathrm{H} & -7.040282 & 0.497512 & 0.932105\end{array}$

$\begin{array}{llll}\mathrm{H} & -7.802519 & 1.345797 & -0.389440\end{array}$

$\begin{array}{llll}\text { C } & -6.657705 & -0.374063 & -1.014381\end{array}$

$\begin{array}{llll}\text { C } & -5.418876 & -1.214135 & -0.622279\end{array}$ 


$\begin{array}{cccc}\mathrm{H} & -6.556681 & -0.043675 & -2.053797 \\ \mathrm{H} & -7.534331 & -1.027267 & -0.989545 \\ \mathrm{C} & -5.820710 & 2.808669 & 1.069647 \\ \mathrm{H} & -5.057852 & 3.588324 & 1.031797 \\ \mathrm{H} & -6.801071 & 3.291956 & 1.058641 \\ \mathrm{H} & -5.726758 & 2.270990 & 2.018498 \\ \mathrm{C} & -5.770437 & 2.688099 & -1.451066 \\ \mathrm{H} & -6.705115 & 3.254181 & -1.470421 \\ \mathrm{H} & -4.940008 & 3.397257 & -1.490641 \\ \mathrm{H} & -5.736166 & 2.064576 & -2.348665 \\ \mathrm{C} & -5.693697 & -2.017331 & 0.677408 \\ \mathrm{H} & -6.534909 & -2.695612 & 0.512949 \\ \mathrm{H} & -4.823531 & -2.622325 & 0.953081 \\ \mathrm{H} & -5.944210 & -1.373786 & 1.524494 \\ \mathrm{C} & -5.093950 & -2.199127 & -1.765992 \\ \mathrm{H} & -4.309021 & -2.910310 & -1.492150 \\ \mathrm{H} & -5.988114 & -2.782546 & -2.000140 \\ \mathrm{H} & -4.794128 & -1.675677 & -2.679109 \\ \mathrm{C} & 2.706798 & 1.413308 & 0.075028 \\ \mathrm{C} & 4.028744 & 1.865781 & 0.005917 \\ \mathrm{C} & 4.825711 & 0.720042 & -0.201114 \\ \mathrm{H} & 4.381579 & 2.882616 & 0.075060 \\ \mathrm{~N} & 2.660569 & 0.060955 & -0.068245 \\ \mathrm{~N} & 3.939499 & -0.327990 & -0.232154 \\ \mathrm{C} & 6.257874 & 0.590938 & -0.364474 \\ \mathrm{C} & 7.079566 & 1.752341 & -0.261404 \\ \mathrm{C} & 6.871853 & -0.666165 & -0.627542 \\ \mathrm{C} & 8.454258 & 1.656307 & -0.413807 \\ \mathrm{H} & 6.635571 & 2.720272 & -0.058725 \\ \mathrm{C} & 8.246360 & -0.757246 & -0.780633 \\ \mathrm{H} & 6.279371 & -1.571192 & -0.720154 \\ \mathrm{C} & 9.047178 & 0.403869 & -0.674328 \\ \mathrm{H} & 9.076142 & 2.541812 & -0.333283 \\ \mathrm{H} & 8.713404 & -1.715308 & -0.984458 \\ \mathrm{H} & 10.123935 & 0.328809 & -0.795203 \\ \mathrm{H} & 4.125283 & -1.308308 & -0.406097\end{array}$

$\mathrm{M}=\mathrm{Gd}$

$\begin{array}{lccc}\text { GD } & 0.433414 & -1.076566 & -0.039911 \\ \mathrm{O} & -1.141261 & -2.343628 & -1.603173 \\ \mathrm{H} & -2.088277 & -2.304266 & -1.369728 \\ \mathrm{O} & 0.567911 & -0.310522 & -2.457646 \\ \mathrm{H} & -0.151779 & -0.531157 & -3.072398 \\ \mathrm{O} & 1.860929 & -2.684041 & 1.367920 \\ \mathrm{H} & 2.000702 & -2.369671 & 2.277484\end{array}$




$\begin{array}{lrrr}\mathrm{O} & 1.765066 & -2.662986 & -1.551627 \\ \mathrm{H} & 2.170882 & -3.543994 & -1.527782 \\ \mathrm{O} & -1.107590 & -2.462079 & 1.359953 \\ \mathrm{H} & -1.074701 & -3.341291 & 1.767188 \\ \mathrm{O} & 0.545185 & -0.421613 & 2.398080 \\ \mathrm{H} & -0.162609 & -0.697649 & 3.004145 \\ \mathrm{H} & -0.999925 & -3.174557 & -2.084367 \\ \mathrm{H} & 1.948676 & -2.300527 & -2.434891 \\ \mathrm{H} & -2.039017 & -2.275047 & 1.094554 \\ \mathrm{H} & 2.171069 & -3.603454 & 1.349490 \\ \mathrm{H} & 0.957994 & 0.365578 & 2.789350 \\ \mathrm{H} & 1.009426 & 0.477323 & -2.814845 \\ \mathrm{C} & 1.433846 & 2.194286 & -0.021913 \\ \mathrm{C} & 1.411965 & 3.596953 & -0.042429 \\ \mathrm{C} & 0.182683 & 4.255671 & -0.058695 \\ \mathrm{H} & 2.338618 & 4.159031 & -0.045702 \\ \mathrm{C} & -0.892611 & 2.108239 & -0.028523 \\ \mathrm{C} & -0.995738 & 3.498419 & -0.051459 \\ \mathrm{H} & 0.139805 & 5.340635 & -0.075468 \\ \mathrm{H} & -1.974709 & 3.961379 & -0.060652 \\ \mathrm{C} & -2.102290 & 1.248184 & -0.004564 \\ \mathrm{C} & -4.387595 & 1.047686 & 0.007856 \\ \mathrm{C} & -4.206940 & -0.390631 & 0.100884 \\ \mathrm{~N} & 0.296210 & 1.460702 & -0.015630 \\ \mathrm{~N} & -3.308848 & 1.826035 & -0.029889 \\ \mathrm{~N} & -1.896897 & -0.070784 & 0.044109 \\ \mathrm{~N} & -2.973625 & -0.886433 & 0.109359 \\ \mathrm{C} & -5.746406 & 1.704773 & -0.103769 \\ \mathrm{C} & -6.869451 & 0.718644 & 0.288959 \\ \mathrm{H} & -6.957017 & 0.682474 & 1.379435 \\ \mathrm{H} & -7.819266 & 1.120863 & -0.072709 \\ \mathrm{C} & -6.665548 & -0.690788 & -0.271325 \\ \mathrm{C} & -5.368473 & -1.367148 & 0.234452 \\ \mathrm{H} & -6.657649 & -0.665548 & -1.366443 \\ \mathrm{H} & -7.510844 & -1.325007 & 0.009639 \\ \mathrm{C} & -5.811546 & 2.963626 & 0.791252 \\ \mathrm{H} & -5.088868 & 3.720435 & 0.482285 \\ \mathrm{H} & -6.811599 & 3.397718 & 0.713655 \\ \mathrm{H} & -5.636430 & 2.718781 & 1.843389 \\ \mathrm{H} & -6.847730 & 2.659856 & -1.595000 \\ \mathrm{H} & -5.1 .70989 & -2.228930 & 2.103009\end{array}$




$\begin{array}{cccc}\mathrm{H} & -5.678420 & -0.861575 & 2.372562 \\ \mathrm{C} & -5.113992 & -2.652995 & -0.579941 \\ \mathrm{H} & -4.272883 & -3.235107 & -0.190281 \\ \mathrm{H} & -5.997449 & -3.293802 & -0.524273 \\ \mathrm{H} & -4.941340 & -2.432281 & -1.639090 \\ \mathrm{C} & 2.682683 & 1.422374 & -0.000711 \\ \mathrm{C} & 4.015769 & 1.841348 & 0.012368 \\ \mathrm{C} & 4.792058 & 0.667771 & 0.023536 \\ \mathrm{H} & 4.397280 & 2.850119 & -0.015732 \\ \mathrm{~N} & 2.595711 & 0.064170 & 0.004314 \\ \mathrm{~N} & 3.893552 & -0.357419 & 0.017596 \\ \mathrm{H} & 4.102091 & -1.344125 & 0.089873 \\ \mathrm{C} & 6.239150 & 0.479743 & 0.040138 \\ \mathrm{C} & 6.826504 & -0.720262 & -0.414664 \\ \mathrm{C} & 7.066868 & 1.516405 & 0.520058 \\ \mathrm{C} & 8.211949 & -0.881598 & -0.380816 \\ \mathrm{H} & 6.217953 & -1.514656 & -0.840062 \\ \mathrm{C} & 8.451726 & 1.348368 & 0.553977 \\ \mathrm{H} & 6.633773 & 2.440448 & 0.889513 \\ \mathrm{C} & 9.026967 & 0.151421 & 0.106057 \\ \mathrm{H} & 8.661481 & -1.799642 & -0.745196 \\ \mathrm{H} & 9.083805 & 2.145865 & 0.930731 \\ \mathrm{H} & 10.104797 & 0.025621 & 0.129198\end{array}$

$\mathrm{M}=\mathrm{Am}$

$\begin{array}{lrrr}\text { AM } & -0.410870 & -1.039570 & 0.031807 \\ \mathrm{O} & 1.193715 & -2.279302 & 1.699873 \\ \mathrm{H} & 2.143395 & -2.247287 & 1.483741 \\ \mathrm{O} & -0.567306 & -0.241602 & 2.534906 \\ \mathrm{H} & 0.162962 & -0.468045 & 3.134789 \\ \mathrm{O} & -1.816055 & -2.698993 & -1.408869 \\ \mathrm{H} & -2.107811 & -3.624469 & -1.387512 \\ \mathrm{O} & -1.795215 & -2.597130 & 1.597928 \\ \mathrm{H} & -2.214726 & -3.472047 & 1.594508 \\ \mathrm{O} & 1.228209 & -2.418294 & -1.326881 \\ \mathrm{H} & 1.245069 & -3.324680 & -1.670426 \\ \mathrm{O} & -0.504313 & -0.438532 & -2.509301 \\ \mathrm{H} & 0.229222 & -0.722798 & -3.080099 \\ \mathrm{H} & 1.046008 & -3.107055 & 2.185232 \\ \mathrm{H} & -1.949812 & -2.218201 & 2.479893 \\ \mathrm{H} & 2.142668 & -2.170365 & -1.039411 \\ \mathrm{H} & -1.902009 & -2.407244 & -2.332666 \\ \mathrm{H} & -0.906246 & 0.333890 & -2.939600 \\ \mathrm{H} & -0.987986 & 0.554459 & 2.898837 \\ \mathrm{C} & -1.393388 & 2.285940 & -0.004527\end{array}$




\begin{tabular}{|c|c|c|c|}
\hline $\mathrm{C}$ & -1.371449 & 3.688366 & 0.012414 \\
\hline C & -0.142356 & 4.346815 & 0.034494 \\
\hline H & -2.296887 & 4.252212 & 0.009089 \\
\hline$c$ & 0.932211 & 2.198640 & 0.014640 \\
\hline $\mathrm{C}$ & 1.035133 & 3.589315 & 0.036269 \\
\hline $\mathrm{H}$ & -0.099306 & 5.431744 & 0.048872 \\
\hline $\mathrm{H}$ & 2.013667 & 4.052832 & 0.050360 \\
\hline $\mathrm{C}$ & 2.148481 & 1.345130 & -0.005345 \\
\hline $\mathrm{C}$ & 4.436162 & 1.165260 & -0.001834 \\
\hline $\mathrm{C}$ & 4.269756 & -0.272235 & -0.113975 \\
\hline $\mathrm{N}$ & -0.256907 & 1.552299 & -0.003460 \\
\hline $\mathbf{N}$ & 3.350079 & 1.933800 & 0.035969 \\
\hline $\mathrm{N}$ & 1.956561 & 0.025430 & -0.071195 \\
\hline $\mathbf{N}$ & 3.040720 & -0.778138 & -0.140849 \\
\hline$c$ & 5.788942 & 1.833493 & 0.124622 \\
\hline $\mathrm{C}$ & 6.920979 & 0.862563 & -0.280260 \\
\hline $\mathrm{H}$ & 7.007724 & 0.839872 & -1.371246 \\
\hline $\mathrm{H}$ & 7.867368 & 1.269322 & 0.085362 \\
\hline $\mathrm{C}$ & 6.730531 & -0.555148 & 0.263662 \\
\hline $\mathrm{C}$ & 5.440166 & -1.238352 & -0.249847 \\
\hline $\mathrm{H}$ & 6.722233 & -0.541882 & 1.358988 \\
\hline $\mathrm{H}$ & 7.582213 & -1.177770 & -0.023955 \\
\hline $\mathrm{C}$ & 5.846060 & 3.105218 & -0.752150 \\
\hline $\mathrm{H}$ & 5.116888 & 3.851927 & -0.433910 \\
\hline $\mathrm{H}$ & 6.842432 & 3.546322 & -0.666793 \\
\hline $\mathrm{H}$ & 5.674450 & 2.874034 & -1.807959 \\
\hline $\mathrm{C}$ & 5.928193 & 2.248406 & 1.621903 \\
\hline $\mathrm{H}$ & 6.877756 & 2.774568 & 1.747941 \\
\hline $\mathrm{H}$ & 5.121380 & 2.924794 & 1.915224 \\
\hline $\mathrm{H}$ & 5.927256 & 1.389761 & 2.299165 \\
\hline $\mathrm{C}$ & 5.573420 & -1.596806 & -1.756147 \\
\hline $\mathrm{H}$ & 6.411360 & -2.285997 & -1.889021 \\
\hline $\mathrm{H}$ & 4.669437 & -2.091782 & -2.126386 \\
\hline $\mathrm{H}$ & 5.759086 & -0.721176 & -2.382741 \\
\hline $\mathrm{C}$ & 5.193080 & -2.529575 & 0.558755 \\
\hline $\mathrm{H}$ & 4.355311 & -3.114616 & 0.166346 \\
\hline $\mathrm{H}$ & 6.080420 & -3.164874 & 0.501095 \\
\hline $\mathrm{H}$ & 5.018409 & -2.313885 & 1.618699 \\
\hline $\mathrm{C}$ & -2.648843 & 1.522964 & -0.025241 \\
\hline $\mathrm{C}$ & -3.974352 & 1.961006 & -0.030933 \\
\hline $\mathrm{C}$ & -4.770592 & 0.799244 & -0.034434 \\
\hline $\mathrm{H}$ & -4.339918 & 2.975554 & -0.004231 \\
\hline $\mathrm{N}$ & -2.584175 & 0.161907 & -0.029976 \\
\hline $\mathrm{N}$ & -3.887824 & -0.239602 & -0.028698 \\
\hline $\mathrm{H}$ & -4.109282 & -1.223317 & -0.103042 \\
\hline$C$ & -6.218556 & 0.638096 & -0.044755 \\
\hline
\end{tabular}




$\begin{array}{cccc}\text { C } & -6.826094 & -0.568934 & 0.367263 \\ \text { C } & -7.032293 & 1.708834 & -0.476549 \\ \text { C } & -8.213468 & -0.702637 & 0.340376 \\ \text { H } & -6.229910 & -1.392887 & 0.751670 \\ \mathrm{C} & -8.419343 & 1.568554 & -0.504340 \\ \mathrm{H} & -6.585416 & 2.638694 & -0.813070 \\ \mathrm{C} & -9.013251 & 0.365012 & -0.098025 \\ \mathrm{H} & -8.677828 & -1.626037 & 0.670995 \\ \mathrm{H} & -9.039728 & 2.391506 & -0.843858 \\ \mathrm{H} & -10.093459 & 0.260006 & -0.116505\end{array}$

$\mathrm{M}=\mathrm{Cm}$

$\begin{array}{lrrr}\mathrm{CM} & 0.394765 & -1.010833 & 0.233614 \\ \mathrm{O} & 1.888638 & -2.422662 & 1.916070 \\ \mathrm{H} & 2.839869 & -2.501698 & 2.094640 \\ \mathrm{O} & 0.501432 & 0.006705 & 2.638411 \\ \mathrm{H} & 1.173498 & -0.316658 & 3.260438 \\ \mathrm{O} & -1.234269 & -2.629995 & -0.775271 \\ \mathrm{H} & -1.285560 & -3.442797 & -1.299506 \\ \mathrm{O} & -0.916556 & -2.358518 & 2.051528 \\ \mathrm{H} & -1.565549 & -3.048516 & 1.838025 \\ \mathrm{O} & 1.877728 & -2.763171 & -0.991638 \\ \mathrm{H} & 2.128425 & -3.654833 & -0.699556 \\ \mathrm{O} & 0.452411 & -0.618499 & -2.306282 \\ \mathrm{H} & 0.980674 & 0.078464 & -2.729522 \\ \mathrm{H} & 1.446270 & -3.084322 & 2.474154 \\ \mathrm{H} & -1.177526 & -1.981454 & 2.907844 \\ \mathrm{H} & 1.890452 & -2.774020 & -1.963355 \\ \mathrm{H} & -2.147514 & -2.216725 & -0.695039 \\ \mathrm{H} & -0.275313 & -0.820346 & -2.917051 \\ \mathrm{H} & 0.279226 & 0.907298 & 2.924815 \\ \mathrm{C} & 1.379630 & 2.276691 & 0.135605 \\ \mathrm{C} & 1.355586 & 3.675711 & 0.232266 \\ \mathrm{C} & 0.125475 & 4.330774 & 0.295985 \\ \mathrm{H} & 2.280561 & 4.240143 & 0.250077 \\ \mathrm{C} & -0.950874 & 2.188788 & 0.151179 \\ \mathrm{C} & -1.053655 & 3.576070 & 0.247190 \\ \mathrm{H} & 0.082589 & 5.413308 & 0.371325 \\ \mathrm{H} & -2.032034 & 4.039628 & 0.273655 \\ \mathrm{C} & -2.162331 & 1.333555 & 0.044457 \\ \mathrm{C} & -4.441170 & 1.149777 & -0.139853 \\ \mathrm{C} & -4.258730 & -0.277175 & -0.321377 \\ \mathrm{~N} & 0.240350 & 1.545661 & 0.110524 \\ \mathrm{~N} & -3.363853 & 1.918288 & 0.015557 \\ \mathrm{~N} & -1.961333 & 0.014821 & -0.051057\end{array}$




\begin{tabular}{lrrr}
$\mathrm{N}$ & -3.030082 & -0.780192 & -0.261669 \\
$\mathrm{C}$ & -5.795156 & 1.826106 & -0.177128 \\
$\mathrm{C}$ & -6.931827 & 0.782179 & -0.106241 \\
$\mathrm{H}$ & -7.091676 & 0.485614 & 0.935445 \\
$\mathrm{H}$ & -7.859869 & 1.264050 & -0.424301 \\
$\mathrm{C}$ & -6.672245 & -0.452269 & -0.972530 \\
$\mathrm{C}$ & -5.415482 & -1.245448 & -0.541179 \\
$\mathrm{H}$ & -6.574658 & -0.162298 & -2.024373 \\
$\mathrm{H}$ & -7.532303 & -1.125667 & -0.923958 \\
$\mathrm{C}$ & -5.918366 & 2.824402 & 0.998328 \\
$\mathrm{H}$ & -5.176489 & 3.622147 & 0.932850 \\
$\mathrm{H}$ & -6.911087 & 3.280727 & 0.968847 \\
$\mathrm{H}$ & -5.812747 & 2.322943 & 1.965523 \\
$\mathrm{C}$ & -5.858982 & 2.618444 & -1.518447 \\
$\mathrm{H}$ & -6.807469 & 3.159971 & -1.555360 \\
$\mathrm{H}$ & -5.046364 & 3.346092 & -1.581176 \\
$\mathrm{H}$ & -5.809928 & 1.965445 & -2.394097 \\
$\mathrm{C}$ & -5.669075 & -1.983408 & 0.802048 \\
$\mathrm{H}$ & -6.498316 & -2.684326 & 0.676572 \\
$\mathrm{H}$ & -4.786524 & -2.556216 & 1.105163 \\
$\mathrm{H}$ & -5.928836 & -1.301589 & 1.615579 \\
$\mathrm{C}$ & -5.070537 & -2.283529 & -1.630500 \\
$\mathrm{H}$ & -4.277798 & -2.969195 & -1.315414 \\
$\mathrm{H}$ & -5.954379 & -2.892857 & -1.835291 \\
$\mathrm{H}$ & -4.777126 & -1.805202 & -2.570267 \\
$\mathrm{C}$ & 2.631839 & 1.516484 & 0.019864 \\
$\mathrm{C}$ & 3.957829 & 1.955951 & -0.036674 \\
$\mathrm{C}$ & 4.742656 & 0.804854 & -0.230250 \\
$\mathrm{H}$ & 4.325850 & 2.969250 & 0.002909 \\
$\mathrm{~N}$ & 2.559170 & 0.164610 & -0.113947 \\
$\mathrm{H}$ & 3.857857 & -0.232049 & -0.257864 \\
$\mathrm{C}$ & 6.185239 & 0.646348 & -0.385063 \\
$\mathrm{C}$ & 7.049562 & 1.638516 & 0.123338 \\
$\mathrm{C}$ & 6.732349 & -0.481338 & -1.033860 \\
$\mathrm{C}$ & 8.431801 & 1.496960 & -0.005909 \\
$\mathrm{H}$ & 6.649138 & 2.505540 & 0.639089 \\
$\mathrm{C}$ & 8.115101 & -0.616208 & -1.162682 \\
& 6.090843 & -1.235133 & -1.484639 \\
$\mathrm{H}$ & 9.967503 & 0.371370 & -0.646515 \\
$\mathrm{H}$ & 8.531733 & -1.476648 & -1.676272 \\
\hline & 0.042842 & 0.266800 & -0.750343 \\
& -1.207158 & -0.422593
\end{tabular}

\section{$\left[\mathrm{ML}\left(\mathrm{H}_{2} \mathrm{O}\right)_{5}\right]^{3+}$}




$\begin{array}{lccc}\mathrm{M}=\mathrm{Eu} & & & \\ \mathrm{EU} & 0.425129 & -1.248240 & 0.084092 \\ \mathrm{O} & 0.607728 & -3.334815 & 1.708664 \\ \mathrm{H} & -0.129991 & -3.965893 & 1.666587 \\ \mathrm{O} & -1.377960 & -2.887565 & -0.483632 \\ \mathrm{H} & -1.570451 & -3.737133 & -0.906758 \\ \mathrm{O} & 2.181800 & -2.957640 & -0.906646 \\ \mathrm{H} & 2.283407 & -3.865099 & -0.575187 \\ \mathrm{O} & 0.384592 & -0.524161 & 2.539002 \\ \mathrm{H} & 0.425721 & 0.374264 & 2.903144 \\ \mathrm{O} & 0.390350 & -1.008534 & -2.489035 \\ \mathrm{H} & 0.772935 & -0.299383 & -3.030307 \\ \mathrm{H} & 2.296014 & -3.014030 & -1.870153 \\ \mathrm{H} & -0.289868 & -1.421292 & -3.045813 \\ \mathrm{H} & 1.191034 & -3.656600 & 2.415012 \\ \mathrm{H} & -2.243976 & -2.379399 & -0.381393 \\ \mathrm{H} & 0.183571 & -1.105685 & 3.289482 \\ \mathrm{C} & 1.463601 & 2.133983 & 0.055723 \\ \mathrm{C} & 1.450880 & 3.533654 & 0.109076 \\ \mathrm{C} & 0.222241 & 4.196307 & 0.149829 \\ \mathrm{H} & 2.376177 & 4.097686 & 0.115619 \\ \mathrm{C} & -0.857466 & 2.048733 & 0.075467 \\ \mathrm{C} & -0.954340 & 3.442844 & 0.130358 \\ \mathrm{H} & 0.182429 & 5.280570 & 0.191781 \\ \mathrm{H} & -1.932167 & 3.907274 & 0.153153 \\ \mathrm{C} & -2.091539 & 1.211742 & 0.033320 \\ \mathrm{C} & -4.382210 & 1.093334 & -0.011769 \\ \mathrm{C} & -4.254346 & -0.345570 & -0.088851 \\ \mathrm{~N} & 0.327759 & 1.399965 & 0.042943 \\ \mathrm{H} & -3.276304 & 1.833647 & 0.038130 \\ \mathrm{~N} & -1.933885 & -0.112908 & -0.027357 \\ \mathrm{~N} & -3.036800 & -0.881107 & -0.101918 \\ \mathrm{C} & -5.716437 & 1.812149 & -0.049185 \\ \mathrm{C} & -6.878413 & 0.823780 & 0.196038 \\ \mathrm{H} & -6.983495 & 0.644405 & 1.270836 \\ \mathrm{H} & -7.808755 & 1.303992 & -0.118487 \\ \mathrm{C} & -6.711806 & -0.504791 & -0.545069 \\ \mathrm{C} & -5.449872 & -1.289287 & -0.114225 \\ \mathrm{H} & -6.679853 & -0.333222 & -1.626579 \\ \mathrm{H} & -7.584397 & -1.138953 & -0.365451 \\ \mathrm{H} & -4.990362 & 3.696860 & 0.820390 \\ \mathrm{H} & -6.728160 & 3.416600 & 0.988440 \\ \mathrm{H} & & 2.538029 & 2.022026 \\ \mathrm{H} & 2.454259 & -1.464239\end{array}$




$\begin{array}{cccc}\mathrm{H} & -6.762269 & 3.023550 & -1.514332 \\ \mathrm{H} & -5.000307 & 3.140241 & -1.649445 \\ \mathrm{H} & -5.849074 & 1.707886 & -2.263218 \\ \mathrm{C} & -5.619692 & -1.857040 & 1.322328 \\ \mathrm{H} & -6.472185 & -2.541160 & 1.339512 \\ \mathrm{H} & -4.729892 & -2.415341 & 1.629543 \\ \mathrm{H} & -5.803112 & -1.076283 & 2.064560 \\ \mathrm{C} & -5.219537 & -2.459037 & -1.093925 \\ \mathrm{H} & -4.430480 & -3.135821 & -0.753038 \\ \mathrm{H} & -6.136437 & -3.049570 & -1.165495 \\ \mathrm{H} & -4.976484 & -2.104969 & -2.100673 \\ \mathrm{C} & 2.727219 & 1.374391 & -0.001029 \\ \mathrm{C} & 4.053150 & 1.820641 & 0.030934 \\ \mathrm{C} & 4.858551 & 0.665095 & -0.053712 \\ \mathrm{H} & 4.404857 & 2.836512 & 0.119165 \\ \mathrm{~N} & 2.686293 & 0.018803 & -0.108300 \\ \mathrm{~N} & 3.974711 & -0.381569 & -0.126141 \\ \mathrm{C} & 6.299059 & 0.528200 & -0.071122 \\ \mathrm{C} & 7.109968 & 1.698809 & -0.173066 \\ \mathrm{C} & 6.931116 & -0.745372 & 0.011268 \\ \mathrm{C} & 8.491743 & 1.595366 & -0.195696 \\ \mathrm{H} & 6.649641 & 2.677470 & -0.247728 \\ \mathrm{C} & 8.312846 & -0.843635 & -0.008707 \\ \mathrm{H} & 6.346393 & -1.654310 & 0.113944 \\ \mathrm{C} & 9.103115 & 0.326524 & -0.114209 \\ \mathrm{H} & 9.105814 & 2.486153 & -0.278189 \\ \mathrm{H} & 8.795674 & -1.812894 & 0.062311 \\ \mathrm{H} & 10.186167 & 0.245171 & -0.130294 \\ \mathrm{H} & 4.173181 & -1.365205 & -0.264359\end{array}$

$\mathrm{M}=\mathrm{Gd}$

$\begin{array}{lccc}\text { GD } & 0.440448 & -1.088542 & 0.124115 \\ \mathrm{O} & 1.112792 & -2.918022 & 1.795900 \\ \mathrm{H} & 0.556477 & -3.687982 & 2.004205 \\ \mathrm{O} & -1.202079 & -2.793149 & -0.213548 \\ \mathrm{H} & -1.299318 & -3.709326 & -0.514099 \\ \mathrm{O} & 1.873728 & -2.839677 & -1.015631 \\ \mathrm{H} & 2.025970 & -2.839224 & -1.975714 \\ \mathrm{O} & 0.188117 & -0.329240 & 2.465241 \\ \mathrm{H} & 0.100777 & 0.588951 & 2.769363 \\ \mathrm{O} & 0.311535 & -0.766235 & -2.343790 \\ \mathrm{H} & -0.374936 & -1.110862 & -2.939060 \\ \mathrm{H} & 2.096678 & -3.731543 & -0.702355 \\ \mathrm{H} & 0.761847 & -0.059662 & -2.836238 \\ \mathrm{H} & 1.883338 & -2.981633 & 2.385987\end{array}$




\begin{tabular}{|c|c|c|c|}
\hline $\mathrm{H}$ & -2.122399 & -2.351238 & -0.168298 \\
\hline $\mathrm{H}$ & 0.140668 & -0.884591 & 3.260524 \\
\hline & -0.891623 & 2.061632 & 0.043438 \\
\hline & -0.988576 & 3.451540 & 0.065611 \\
\hline $\mathrm{C}$ & 0.194039 & 4.203001 & 0.100835 \\
\hline$C$ & 1.422721 & 3.541705 & 0.103901 \\
\hline $\mathrm{C}$ & 1.442044 & 2.139749 & 0.075166 \\
\hline $\mathrm{H}$ & -1.965161 & 3.919854 & 0.054131 \\
\hline $\mathrm{H}$ & 0.154705 & 5.288147 & 0.120676 \\
\hline $\mathrm{H}$ & 2.349776 & 4.102705 & 0.123077 \\
\hline $\mathrm{N}$ & 0.299148 & 1.412418 & 0.052099 \\
\hline & 2.687315 & 1.361670 & 0.044473 \\
\hline $\mathrm{C}$ & 4.017394 & 1.779825 & 0.036755 \\
\hline $\mathrm{N}$ & 2.598962 & 0.001578 & -0.036629 \\
\hline $\mathrm{C}$ & 4.796077 & 0.609573 & -0.065372 \\
\hline $\mathrm{H}$ & 4.397303 & 2.789398 & 0.056099 \\
\hline $\mathrm{N}$ & 3.899947 & -0.415365 & -0.102174 \\
\hline C & 6.241337 & 0.430875 & -0.129394 \\
\hline $\mathrm{H}$ & 4.113174 & -1.401702 & -0.169003 \\
\hline & 7.086280 & 1.446511 & 0.366950 \\
\hline $\mathrm{C}$ & 6.812264 & -0.738900 & -0.676314 \\
\hline $\mathrm{C}$ & 8.471667 & 1.286848 & 0.326638 \\
\hline $\mathrm{H}$ & 6.667276 & 2.345974 & 0.806515 \\
\hline $\mathrm{C}$ & 8.198039 & -0.891154 & -0.717153 \\
\hline $\mathrm{H}$ & 6.189471 & -1.514846 & -1.115111 \\
\hline $\mathrm{C}$ & 9.030269 & 0.120226 & -0.213174 \\
\hline $\mathrm{H}$ & 9.117318 & 2.067027 & 0.716346 \\
\hline $\mathrm{H}$ & 8.634254 & -1.784479 & -1.152208 \\
\hline $\mathrm{H}$ & 10.108588 & 0.001236 & -0.248131 \\
\hline $\mathrm{C}$ & -2.101279 & 1.200222 & 0.000278 \\
\hline $\mathrm{N}$ & -3.307391 & 1.774269 & -0.038330 \\
\hline $\mathrm{N}$ & -1.893130 & -0.120505 & -0.010844 \\
\hline $\mathrm{C}$ & -4.384172 & 0.990157 & -0.074619 \\
\hline $\mathrm{N}$ & -2.965649 & -0.936314 & -0.050435 \\
\hline $\mathrm{C}$ & -4.201611 & -0.450685 & -0.067191 \\
\hline $\mathrm{C}$ & -5.740818 & 1.649678 & -0.190491 \\
\hline $\mathrm{C}$ & -5.361210 & -1.435329 & -0.032220 \\
\hline $\mathrm{C}$ & -6.874447 & 0.638039 & 0.091294 \\
\hline $\mathrm{C}$ & -5.842934 & 2.844761 & 0.785408 \\
\hline $\mathrm{C}$ & -5.834643 & 2.185844 & -1.653411 \\
\hline $\mathrm{C}$ & -6.640709 & -0.733388 & -0.546589 \\
\hline $\mathrm{C}$ & -5.534971 & -1.880490 & 1.447939 \\
\hline $\mathrm{C}$ & -5.073419 & -2.676830 & -0.901689 \\
\hline $\mathrm{H}$ & -7.008080 & 0.533024 & 1.172505 \\
\hline $\mathrm{H}$ & -7.809850 & 1.060499 & -0.284554 \\
\hline $\mathrm{H}$ & -5.112231 & 3.621821 & 0.555360 \\
\hline
\end{tabular}




$\begin{array}{llll}\mathrm{H} & -6.841076 & 3.281840 & 0.700581 \\ \mathrm{H} & -5.706252 & 2.528695 & 1.824190 \\ \mathrm{H} & -6.785399 & 2.712829 & -1.765757 \\ \mathrm{H} & -5.026139 & 2.890272 & -1.863973 \\ \mathrm{H} & -5.803596 & 1.385149 & -2.397488 \\ \mathrm{H} & -6.590414 & -0.641817 & -1.637056 \\ \mathrm{H} & -7.492581 & -1.386163 & -0.337379 \\ \mathrm{H} & -6.369649 & -2.583327 & 1.512803 \\ \mathrm{H} & -4.635957 & -2.387254 & 1.812560 \\ \mathrm{H} & -5.749736 & -1.044878 & 2.118427 \\ \mathrm{H} & -4.265942 & -3.292704 & -0.494133 \\ \mathrm{H} & -5.966847 & -3.305462 & -0.930047 \\ \mathrm{H} & -4.830873 & -2.404526 & -1.933710\end{array}$

$\mathrm{M}=\mathrm{Am}$

$\begin{array}{lrrr}\text { AM } & 0.415065 & -1.044192 & 0.069304 \\ \mathrm{O} & 0.615007 & -3.096816 & 1.685347 \\ \mathrm{H} & -0.071531 & -3.785213 & 1.670712 \\ \mathrm{O} & -1.326998 & -2.707711 & -0.489495 \\ \mathrm{H} & -1.456304 & -3.532357 & -0.982370 \\ \mathrm{O} & 2.056503 & -2.808518 & -0.908730 \\ \mathrm{H} & 2.307203 & -2.843254 & -1.847461 \\ \mathrm{O} & 0.352448 & -0.331152 & 2.499398 \\ \mathrm{H} & 0.550172 & 0.555630 & 2.843426 \\ \mathrm{O} & 0.391792 & -0.779153 & -2.467216 \\ \mathrm{H} & 0.880678 & -0.100072 & -2.961837 \\ \mathrm{H} & 2.181922 & -3.707178 & -0.560830 \\ \mathrm{H} & -0.269810 & -1.134538 & -3.084012 \\ \mathrm{H} & 1.223653 & -3.336440 & 2.404584 \\ \mathrm{H} & -2.224495 & -2.241962 & -0.365934 \\ \mathrm{H} & 0.078063 & -0.862616 & 3.264651 \\ \mathrm{C} & 1.397506 & 2.261219 & -0.023367 \\ \mathrm{C} & 1.372586 & 3.662643 & -0.016543 \\ \mathrm{C} & 0.141413 & 4.318478 & 0.002472 \\ \mathrm{H} & 2.296850 & 4.228373 & -0.027360 \\ \mathrm{C} & -0.931240 & 2.169486 & 0.004580 \\ \mathrm{C} & -1.035482 & 3.559585 & 0.014230 \\ \mathrm{H} & 0.096400 & 5.403485 & 0.007246 \\ \mathrm{H} & -2.014697 & 4.021850 & 0.027916 \\ \mathrm{C} & -2.143118 & 1.311177 & 0.000833 \\ \mathrm{C} & -4.430035 & 1.118928 & -0.019630 \\ \mathrm{C} & -4.257646 & -0.321722 & -0.050452 \\ \mathrm{~N} & 0.260601 & 1.525213 & -0.013632 \\ \mathrm{~N} & -3.346423 & 1.893569 & -0.004428 \\ \mathrm{~N} & -1.944983 & -0.010148 & -0.022119\end{array}$




$\begin{array}{crrr}\mathrm{N} & -3.025532 & -0.816415 & -0.065586 \\ \mathrm{C} & -5.784236 & 1.792309 & -0.076804 \\ \mathrm{C} & -6.918432 & 0.778768 & 0.195628 \\ \mathrm{H} & -7.029314 & 0.637078 & 1.275249 \\ \mathrm{H} & -7.859016 & 1.219290 & -0.144812 \\ \mathrm{C} & -6.707311 & -0.571257 & -0.493965 \\ \mathrm{C} & -5.424095 & -1.299523 & -0.027901 \\ \mathrm{H} & -6.675699 & -0.441501 & -1.581331 \\ \mathrm{H} & -7.560412 & -1.224826 & -0.292341 \\ \mathrm{C} & -5.849263 & 2.948214 & 0.948805 \\ \mathrm{H} & -5.116572 & 3.726961 & 0.730768 \\ \mathrm{H} & -6.844694 & 3.397696 & 0.907816 \\ \mathrm{H} & -5.688879 & 2.589473 & 1.970214 \\ \mathrm{C} & -5.913237 & 2.386699 & -1.513681 \\ \mathrm{H} & -6.860873 & 2.927034 & -1.579049 \\ \mathrm{H} & -5.103025 & 3.090355 & -1.719755 \\ \mathrm{H} & -5.911311 & 1.615289 & -2.288690 \\ \mathrm{C} & -5.574825 & -1.796454 & 1.437830 \\ \mathrm{H} & -6.413501 & -2.495335 & 1.493482 \\ \mathrm{H} & -4.672841 & -2.322007 & 1.766988 \\ \mathrm{H} & -5.770620 & -0.983933 & 2.141658 \\ \mathrm{C} & -5.161450 & -2.511384 & -0.946059 \\ \mathrm{H} & -4.356226 & -3.150387 & -0.570433 \\ \mathrm{H} & -6.061835 & -3.129442 & -0.985486 \\ \mathrm{H} & -4.929754 & -2.203996 & -1.970840 \\ \mathrm{C} & 2.650082 & 1.494697 & -0.038206 \\ \mathrm{C} & 3.976329 & 1.923413 & -0.019242 \\ \mathrm{C} & 4.767756 & 0.756240 & -0.054564 \\ \mathrm{H} & 4.346388 & 2.936609 & -0.015629 \\ \mathrm{~N} & 2.575676 & 0.134339 & -0.080079 \\ \mathrm{~N} & 3.880645 & -0.276225 & -0.084628 \\ \mathrm{C} & 6.215076 & 0.591860 & -0.067162 \\ \mathrm{C} & 7.037622 & 1.669511 & 0.329310 \\ \mathrm{C} & 6.814706 & -0.623767 & -0.464924 \\ \mathrm{C} & 8.424807 & 1.527526 & 0.337593 \\ \mathrm{H} & 6.599242 & 2.607806 & 0.653031 \\ \mathrm{C} & 8.201962 & -0.759265 & -0.458381 \\ \mathrm{H} & 6.213683 & -1.457932 & -0.818773 \\ \mathrm{C} & 9.010331 & 0.315612 & -0.054697 \\ \mathrm{H} & 9.051530 & 2.356228 & 0.650354 \\ \mathrm{H} & 8.659258 & -1.690428 & -0.776759 \\ \mathrm{H} & 10.090551 & 0.209156 & -0.052179 \\ \mathrm{H} & 4.095910 & -1.264140 & -0.101431 \\ & & & \\ \mathrm{M}=\mathrm{Cm} & & & \\ & & & \end{array}$




$\begin{array}{lccc}\mathrm{CM} & 0.406361 & -1.024100 & 0.121769 \\ \mathrm{O} & 0.917611 & -2.954001 & 1.823125 \\ \mathrm{H} & 0.302700 & -3.695113 & 1.958531 \\ \mathrm{O} & -1.296258 & -2.746741 & -0.305752 \\ \mathrm{H} & -1.414290 & -3.639026 & -0.665276 \\ \mathrm{O} & 1.920340 & -2.813474 & -0.978613 \\ \mathrm{H} & 2.096112 & -2.836767 & -1.934426 \\ \mathrm{O} & 0.161518 & -0.271286 & 2.517514 \\ \mathrm{H} & 0.126708 & 0.642651 & 2.844573 \\ \mathrm{O} & 0.336850 & -0.717526 & -2.400881 \\ \mathrm{H} & -0.341045 & -1.059783 & -3.007712 \\ \mathrm{H} & 2.102186 & -3.707757 & -0.645631 \\ \mathrm{H} & 0.807451 & -0.020707 & -2.888729 \\ \mathrm{H} & 1.649149 & -3.097320 & 2.447666 \\ \mathrm{H} & -2.199201 & -2.281058 & -0.255769 \\ \mathrm{H} & 0.079991 & -0.844291 & 3.297473 \\ \mathrm{C} & -0.930664 & 2.157774 & 0.055812 \\ \mathrm{C} & -1.029832 & 3.547367 & 0.087459 \\ \mathrm{C} & 0.151267 & 4.300846 & 0.121090 \\ \mathrm{C} & 1.380947 & 3.641970 & 0.111569 \\ \mathrm{C} & 1.403544 & 2.240313 & 0.075213 \\ \mathrm{H} & -2.007000 & 4.014355 & 0.082471 \\ \mathrm{H} & 0.110009 & 5.385776 & 0.147953 \\ \mathrm{H} & 2.306481 & 4.205493 & 0.126795 \\ \mathrm{~N} & 0.261676 & 1.511743 & 0.057432 \\ \mathrm{C} & 2.654830 & 1.471234 & 0.032288 \\ \mathrm{C} & 3.980286 & 1.904708 & 0.020531 \\ \mathrm{~N} & 2.583300 & 0.110866 & -0.050510 \\ \mathrm{C} & 4.772515 & 0.743964 & -0.084755 \\ \mathrm{H} & 4.348903 & 2.918302 & 0.041265 \\ \mathrm{~N} & -3.346227 & 1.881929 & -0.027628 \\ \mathrm{~N} & 3.888849 & -0.290829 & -0.121370 \\ \mathrm{C} & 6.219697 & 0.582541 & -0.150936 \\ \mathrm{H} & 4.112210 & -1.275676 & -0.176285 \\ \mathrm{C} & 7.053828 & 1.609945 & 0.339260 \\ \mathrm{C} & 6.803269 & -0.582815 & -0.693726 \\ \mathrm{C} & 8.440907 & 1.466475 & 0.296514 \\ \mathrm{H} & 6.625365 & 2.506432 & 0.775854 \\ \mathrm{C} & 8.190616 & -0.719192 & -0.736892 \\ \mathrm{H} & 6.188543 & -1.368518 & -1.126674 \\ & 9.012050 & 0.304106 & -0.239369 \\ \mathrm{H} & 8.636275 & -1.609585 & -1.168437 \\ \mathrm{H} & -10.091606 & 0.197561 & -0.275996 \\ \mathrm{H} & -0.021992 & -0.030315\end{array}$




$\begin{array}{rrrr}\mathrm{C} & -4.428219 & 1.105731 & -0.079729 \\ \mathrm{~N} & -3.022813 & -0.830719 & -0.089827 \\ \mathrm{C} & -4.254783 & -0.335495 & -0.101435 \\ \mathrm{C} & -5.780375 & 1.777398 & -0.181456 \\ \mathrm{C} & -5.421471 & -1.313064 & -0.092910 \\ \mathrm{C} & -6.921224 & 0.767014 & 0.074702 \\ \mathrm{C} & -5.874929 & 2.948570 & 0.823903 \\ \mathrm{C} & -5.869545 & 2.349963 & -1.630611 \\ \mathrm{C} & -6.694763 & -0.590755 & -0.594253 \\ \mathrm{C} & -5.603038 & -1.792982 & 1.375195 \\ \mathrm{C} & -5.139615 & -2.535126 & -0.991523 \\ \mathrm{H} & -7.057770 & 0.637791 & 1.152963 \\ \mathrm{H} & -7.853102 & 1.204075 & -0.293061 \\ \mathrm{H} & -5.138973 & 3.726238 & 0.613355 \\ \mathrm{H} & -6.870096 & 3.394379 & 0.750025 \\ \mathrm{H} & -5.740557 & 2.605852 & 1.854533 \\ \mathrm{H} & -6.816181 & 2.886756 & -1.730704 \\ \mathrm{H} & -5.055497 & 3.052986 & -1.823796 \\ \mathrm{H} & -5.843999 & 1.567360 & -2.393903 \\ \mathrm{H} & -6.640530 & -0.474014 & -1.682176 \\ \mathrm{H} & -7.551692 & -1.242370 & -0.402841 \\ \mathrm{H} & -6.441709 & -2.492603 & 1.420566 \\ \mathrm{H} & -4.707903 & -2.313247 & 1.730419 \\ \mathrm{H} & -5.815537 & -0.972573 & 2.064948 \\ \mathrm{H} & -4.340404 & -3.168341 & -0.594194 \\ \mathrm{H} & -6.038398 & -3.154767 & -1.040887 \\ \mathrm{H} & -4.888116 & -2.239453 & -2.014993\end{array}$

$\left[\mathrm{ML}_{2}\left(\mathrm{H}_{2} \mathrm{O}\right)_{2}\right]^{3+}$

$\mathrm{M}=\mathrm{Eu}$

$\begin{array}{lccc}\text { EU } & -0.000005 & -0.293377 & 0.000004 \\ \mathrm{O} & -0.679415 & -1.950351 & 1.682577 \\ \mathrm{H} & -1.592014 & -2.292600 & 1.456010 \\ \mathrm{O} & 0.679412 & -1.950299 & -1.682628 \\ \mathrm{H} & 0.366917 & -2.385075 & -2.487239 \\ \mathrm{H} & -0.366980 & -2.385063 & 2.487246 \\ \mathrm{H} & 1.592041 & -2.292503 & -1.456114 \\ \mathrm{C} & -0.745009 & 1.541508 & -2.875173 \\ \mathrm{C} & -1.339987 & 1.975560 & -4.069747 \\ \mathrm{C} & -2.564288 & 1.430732 & -4.454504 \\ \mathrm{H} & -0.851699 & 2.719181 & -4.688041 \\ \mathrm{C} & -2.508506 & 0.083240 & -2.466652 \\ \mathrm{C} & -3.164402 & 0.465934 & -3.638674 \\ \mathrm{H} & -3.042834 & 1.747951 & -5.376029\end{array}$




\begin{tabular}{|c|c|c|c|}
\hline & 12505 & 72 & \\
\hline & 104491 & -0.949920 & \\
\hline & 35 & -2.4 & \\
\hline & 1.104620 & -2.791471 & \\
\hline & 1.321750 & 0.608532 & \\
\hline & 826 & -1.4 & \\
\hline & -2.4 & -1.28 & -0 . \\
\hline & -2.9 & -2.2 & 0. \\
\hline & -6.1 & -3.0 & \\
\hline & -6.7 & -3.8 & \\
\hline & $-7.2^{\prime}$ & -3.1 & \\
\hline & -7.52 & -4.5 & -0 . \\
\hline & -5.7 & -4.6 & \\
\hline & -4.6 & -3.7 & \\
\hline (1) & -5.2 & -5.4 & \\
\hline & -6.2 & -5.2 & \\
\hline 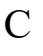 & -7.1 & -1.9 & -2 \\
\hline $\mathrm{H}$ & -6.7 & -1.4 & \\
\hline & -8.0 & -2.4 & -2 . \\
\hline & -7.3 & -1.2 & \\
\hline & $-5.7^{\prime}$ & -4.0 & -2 \\
\hline & -6.6 & -4.4 & \\
\hline & -5.3 & -3.4 & \\
\hline & -5.0 & -4.8 & -2 \\
\hline & -5.2 & -2.9 & \\
\hline $\mathrm{H}$ & -5.6 & -3.6 & \\
\hline $\mathrm{H}$ & -4.4 & -2.3 & \\
\hline & -6.0 & -2.3 & \\
\hline & -3.5 & -4.7 & \\
\hline & -2.7 & -4.1 & \\
\hline & -3.9 & -5.4 & \\
\hline $\mathrm{H}$ & -2.99 & -5.2 & \\
\hline & 0.5 & 2.0 & -2.4 \\
\hline 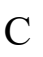 & 1.3 & 3.1 & -2. \\
\hline $\mathrm{C}$ & 2.42 & 3.26 & -2.1 \\
\hline $\mathrm{H}$ & 1.0 & 3.7 & -3. \\
\hline $\mathrm{N}$ & 1.13 & 1.58 & -1. \\
\hline $\mathrm{N}$ & 2.2 & 2.3 & -1 . \\
\hline $\mathrm{C}$ & 0.74 & 1.54 & 2.8 \\
\hline $\mathrm{C}$ & 1.33 & & \\
\hline $\mathrm{C}$ & 2.564215 & 1.43 & 4.4 \\
\hline $\mathrm{H}$ & 0.85 & 2.7 & \\
\hline $\mathrm{C}$ & 2.508466 & 0.08 & 2.4 \\
\hline $\mathrm{C}$ & 3.10 & 0.4 & 3.6 \\
\hline $\mathrm{H}$ & 3.042745 & 1.747773 & 5.376155 \\
\hline & 4.112435 & 0.009239 & 3.892839 \\
\hline
\end{tabular}




\begin{tabular}{|c|c|c|c|}
\hline $\mathrm{C}$ & 3.104470 & -0.949951 & 1.572869 \\
\hline & 4.814220 & -2.410798 & 1.124585 \\
\hline $\mathrm{C}$ & 4.104674 & -2.791356 & -0.073621 \\
\hline $\mathrm{N}$ & 1.321720 & 0.608477 & 2.086434 \\
\hline $\mathrm{N}$ & 4.280783 & -1.487625 & 1.921210 \\
\hline$N$ & 2.416194 & -1.282800 & 0.477062 \\
\hline $\mathrm{N}$ & 2.935852 & -2.215542 & -0.339243 \\
\hline $\mathrm{C}$ & 6.118865 & -3.054126 & 1.557769 \\
\hline $\mathrm{C}$ & 6.753511 & -3.839224 & 0.388240 \\
\hline H & 7.279136 & -3.143332 & -0.273853 \\
\hline $\mathrm{H}$ & 7.521717 & -4.501776 & 0.796202 \\
\hline $\mathrm{C}$ & 5.739653 & -4.660301 & -0.411891 \\
\hline $\mathrm{C}$ & 4.646808 & -3.795988 & -1.083642 \\
\hline $\mathrm{H}$ & 5.264153 & -5.405643 & 0.234955 \\
\hline $\mathrm{H}$ & 6.256650 & -5.224440 & -1.193343 \\
\hline $\mathrm{C}$ & 7.104933 & -1.977404 & 2.062261 \\
\hline $\mathrm{H}$ & 6.720076 & -1.454435 & 2.939435 \\
\hline $\mathrm{H}$ & 8.045841 & -2.459978 & 2.339497 \\
\hline $\mathrm{H}$ & 7.326252 & -1.239942 & 1.284160 \\
\hline $\mathrm{C}$ & 5.770043 & -4.009121 & 2.736720 \\
\hline $\mathrm{H}$ & 6.692984 & -4.463317 & 3.106394 \\
\hline $\mathrm{H}$ & 5.306852 & -3.458072 & 3.559206 \\
\hline $\mathrm{H}$ & 5.094748 & -4.815400 & 2.437174 \\
\hline $\mathrm{C}$ & 5.238047 & -2.987063 & -2.270247 \\
\hline $\mathrm{H}$ & 5.628370 & -3.680092 & -3.020363 \\
\hline $\mathrm{H}$ & 4.468266 & -2.370535 & -2.744391 \\
\hline $\mathrm{H}$ & 6.056403 & -2.330531 & -1.963706 \\
\hline $\mathrm{C}$ & 3.526317 & -4.716991 & -1.610414 \\
\hline $\mathrm{H}$ & 2.796072 & -4.175696 & -2.217972 \\
\hline $\mathrm{H}$ & 3.968478 & -5.487648 & -2.247294 \\
\hline $\mathrm{H}$ & 2.999570 & -5.222138 & -0.795030 \\
\hline $\mathrm{C}$ & -0.545297 & 2.085446 & 2.420537 \\
\hline $\mathrm{C}$ & -1.313381 & 3.127277 & 2.964025 \\
\hline $\mathrm{C}$ & -2.424544 & 3.266638 & 2.121768 \\
\hline $\mathrm{H}$ & -1.092865 & 3.738439 & 3.824960 \\
\hline $\mathrm{N}$ & -1.134967 & 1.580239 & 1.310878 \\
\hline $\mathrm{N}$ & -2.258842 & 2.322019 & 1.149428 \\
\hline $\mathrm{H}$ & -2.908234 & 2.094850 & 0.408922 \\
\hline $\mathrm{H}$ & 2.908273 & 2.094816 & -0.408938 \\
\hline $\mathrm{C}$ & -3.561239 & 4.180698 & 2.182190 \\
\hline $\mathrm{C}$ & -3.926327 & 4.754487 & 3.421383 \\
\hline $\mathrm{C}$ & -4.303713 & 4.506779 & 1.025070 \\
\hline $\mathrm{C}$ & -5.011083 & 5.625698 & 3.499456 \\
\hline $\mathrm{H}$ & -3.378555 & 4.500277 & 4.322846 \\
\hline $\mathrm{C}$ & -5.386962 & 5.379980 & 1.107931 \\
\hline $\mathrm{H}$ & -4.013605 & 4.119282 & 0.052048 \\
\hline
\end{tabular}




$\begin{array}{lccc}\mathrm{C} & -5.745703 & 5.940735 & 2.345652 \\ \mathrm{H} & -5.290906 & 6.058383 & 4.454429 \\ \mathrm{H} & -5.945774 & 5.640588 & 0.214873 \\ \mathrm{H} & -6.588008 & 6.622526 & 2.407908 \\ \mathrm{C} & 3.561238 & 4.180719 & -2.182150 \\ \mathrm{C} & 4.303721 & 4.506786 & -1.025033 \\ \mathrm{C} & 3.926320 & 4.754514 & -3.421340 \\ \mathrm{C} & 5.386975 & 5.379980 & -1.107894 \\ \mathrm{H} & 4.013614 & 4.119284 & -0.052012 \\ \mathrm{C} & 5.011082 & 5.625719 & -3.499414 \\ \mathrm{H} & 3.378541 & 4.500313 & -4.322802 \\ \mathrm{C} & 5.745712 & 5.940743 & -2.345613 \\ \mathrm{H} & 5.945794 & 5.640578 & -0.214838 \\ \mathrm{H} & 5.290901 & 6.058409 & -4.454386 \\ \mathrm{H} & 6.588021 & 6.622528 & -2.407869\end{array}$

$\mathrm{M}=\mathrm{Gd}$

$\begin{array}{lccc}\text { GD } & -0.000004 & 0.248013 & -0.000005 \\ \mathrm{O} & -0.620352 & 1.872670 & -1.662785 \\ \mathrm{H} & -1.527531 & 2.246643 & -1.446719 \\ \mathrm{O} & 0.620332 & 1.872663 & 1.662789 \\ \mathrm{H} & 0.312186 & 2.232182 & 2.505718 \\ \mathrm{H} & -0.312210 & 2.232203 & -2.505710 \\ \mathrm{H} & 1.527510 & 2.246641 & 1.446729 \\ \mathrm{C} & -0.684438 & -1.627896 & 2.775666 \\ \mathrm{C} & -1.295683 & -2.122919 & 3.938412 \\ \mathrm{C} & -2.532077 & -1.610247 & 4.326530 \\ \mathrm{H} & -0.808473 & -2.890189 & 4.528079 \\ \mathrm{C} & -2.464540 & -0.172524 & 2.404607 \\ \mathrm{C} & -3.131891 & -0.613241 & 3.547033 \\ \mathrm{H} & -3.021995 & -1.976080 & 5.223798 \\ \mathrm{H} & -4.088442 & -0.178650 & 3.808545 \\ \mathrm{C} & -3.048177 & 0.888841 & 1.540542 \\ \mathrm{C} & -4.738109 & 2.377645 & 1.111152 \\ \mathrm{C} & -4.016439 & 2.774895 & -0.077367 \\ \mathrm{~N} & -1.264591 & -0.668628 & 2.019969 \\ \mathrm{~N} & -4.222719 & 1.428325 & 1.889205 \\ \mathrm{~N} & -2.344618 & 1.245273 & 0.461467 \\ \mathrm{~N} & -2.849798 & 2.196861 & -0.342850 \\ \mathrm{C} & -6.032018 & 3.033802 & 1.552968 \\ \mathrm{C} & -6.654460 & 3.848408 & 0.397021 \\ \mathrm{H} & -7.192724 & 3.172467 & -0.275367 \\ \mathrm{H} & -7.411009 & 4.516608 & 0.817164 \\ \mathrm{C} & -5.628822 & 4.666481 & -0.391118 \\ \mathrm{C} & -4.547570 & 3.796782 & -1.074906\end{array}$




$\begin{array}{lrrr}\mathrm{H} & -5.143512 & 5.396762 & 0.265485 \\ \mathrm{H} & -6.137798 & 5.247760 & -1.165138 \\ \mathrm{C} & -7.035666 & 1.967010 & 2.043937 \\ \mathrm{H} & -6.659473 & 1.425079 & 2.913214 \\ \mathrm{H} & -7.967358 & 2.462425 & 2.329225 \\ \mathrm{H} & -7.271473 & 1.245121 & 1.255573 \\ \mathrm{C} & -5.663880 & 3.964956 & 2.746501 \\ \mathrm{H} & -6.578775 & 4.430064 & 3.122401 \\ \mathrm{H} & -5.211595 & 3.393079 & 3.560765 \\ \mathrm{H} & -4.974285 & 4.763322 & 2.458648 \\ \mathrm{C} & -5.151833 & 3.005388 & -2.267494 \\ \mathrm{H} & -5.537510 & 3.710554 & -3.008539 \\ \mathrm{H} & -4.390804 & 2.385824 & -2.751776 \\ \mathrm{H} & -5.976265 & 2.354611 & -1.965131 \\ \mathrm{C} & -3.417502 & 4.709122 & -1.595931 \\ \mathrm{H} & -2.694594 & 4.165694 & -2.210508 \\ \mathrm{H} & -3.852370 & 5.490057 & -2.225103 \\ \mathrm{H} & -2.883553 & 5.201522 & -0.777442 \\ \mathrm{C} & 0.620392 & -2.120149 & 2.314359 \\ \mathrm{C} & 1.435684 & -3.132693 & 2.840388 \\ \mathrm{C} & 2.564590 & -3.185907 & 2.013066 \\ \mathrm{H} & 1.267478 & -3.736277 & 3.718340 \\ \mathrm{~N} & 1.188258 & -1.558866 & 1.219153 \\ \mathrm{~N} & 2.363136 & -2.225404 & 1.066538 \\ \mathrm{C} & 0.684451 & -1.627874 & -2.775686 \\ \mathrm{C} & 1.295699 & -2.122881 & -3.938437 \\ \mathrm{C} & 2.532087 & -1.610192 & -4.326553 \\ \mathrm{H} & 0.808497 & -2.890151 & -4.528109 \\ \mathrm{C} & 2.464537 & -0.172486 & -2.404618 \\ \mathrm{C} & 3.131891 & -0.613186 & -3.547049 \\ \mathrm{H} & 3.022007 & -1.976013 & -5.223825 \\ \mathrm{H} & 4.088437 & -0.178583 & -3.808559 \\ \mathrm{C} & 3.048167 & 0.888877 & -1.540543 \\ \mathrm{C} & 4.738089 & 2.377686 & -1.111137 \\ \mathrm{C} & 4.016418 & 2.774917 & 0.077387 \\ \mathrm{~N} & 1.264594 & -0.668605 & -2.019983 \\ \mathrm{~N} & 4.222705 & 1.428371 & -1.889201 \\ \mathrm{~N} & 2.344604 & 1.245294 & -0.461466 \\ \mathrm{~N} & 2.849779 & 2.196876 & 0.342862 \\ \mathrm{C} & 6.031993 & 3.033858 & -1.552947 \\ \mathrm{C} & 6.654432 & 3.848453 & -0.396991 \\ \mathrm{H} & 7.192702 & 3.172507 & 0.275387 \\ \mathrm{H} & 7.410975 & 4.516663 & -0.817126 \\ \mathrm{C} & 5.628790 & 4.666508 & 0.391162 \\ \mathrm{C} & 4.547546 & 3.796792 & 1.074940 \\ \mathrm{H} & 5.143474 & 5.396795 & -0.265430 \\ & & & \end{array}$




$\begin{array}{llll}\mathrm{H} & 6.137764 & 5.247779 & 1.165189 \\ \mathrm{C} & 7.035647 & 1.967079 & -2.043933 \\ \mathrm{H} & 6.659457 & 1.425158 & -2.913217 \\ \mathrm{H} & 7.967335 & 2.462505 & -2.329216 \\ \mathrm{H} & 7.271461 & 1.245181 & -1.255580 \\ \mathrm{C} & 5.663846 & 3.965025 & -2.746466 \\ \mathrm{H} & 6.578736 & 4.430145 & -3.122362 \\ \mathrm{H} & 5.211563 & 3.393157 & -3.560738 \\ \mathrm{H} & 4.974245 & 4.763382 & -2.458601 \\ \mathrm{C} & 5.151816 & 3.005383 & 2.267513 \\ \mathrm{H} & 5.537493 & 3.710540 & 3.008568 \\ \mathrm{H} & 4.390791 & 2.385809 & 2.751789 \\ \mathrm{H} & 5.976249 & 2.354613 & 1.965138 \\ \mathrm{C} & 3.417474 & 4.709118 & 1.595983 \\ \mathrm{H} & 2.694572 & 4.165676 & 2.210554 \\ \mathrm{H} & 3.852340 & 5.490046 & 2.225165 \\ \mathrm{H} & 2.883519 & 5.201528 & 0.777503 \\ \mathrm{C} & -0.620374 & -2.120144 & -2.314382 \\ \mathrm{C} & -1.435652 & -3.132700 & -2.840413 \\ \mathrm{C} & -2.564559 & -3.185924 & -2.013096 \\ \mathrm{H} & -1.267441 & -3.736286 & -3.718364 \\ \mathrm{~N} & -1.188252 & -1.558866 & -1.219180 \\ \mathrm{~N} & -2.363122 & -2.225416 & -1.066571 \\ \mathrm{H} & -2.950945 & -2.039537 & -0.265755 \\ \mathrm{H} & -4.717721 & -7.122320 & -3.167317 \\ \mathrm{H} & 2.950953 & -2.039503 & 0.265725 \\ \mathrm{C} & 3.751192 & -4.041369 & 2.058157 \\ \mathrm{C} & 4.978703 & -3.615910 & 1.511151 \\ \mathrm{C} & 3.668038 & -5.312233 & 2.661077 \\ \mathrm{C} & 6.097554 & -4.450290 & 1.558849 \\ \mathrm{H} & 5.082771 & -2.619196 & 1.089430 \\ \mathrm{C} & 4.789484 & -6.142553 & 2.706267 \\ \mathrm{H} & 2.726800 & -5.662357 & 3.072706 \\ \mathrm{C} & 6.004915 & -5.715928 & 2.154747 \\ \mathrm{H} & 7.044480 & -4.113223 & 1.149421 \\ \mathrm{H} & 4.717810 & -7.122203 & 3.167561 \\ \mathrm{H} & 6.876097 & -6.361920 & 2.195242 \\ \mathrm{C} & -3.751143 & -4.041378 & -2.058178 \\ \mathrm{H} & -4.667960 & -5.312307 & -2.660959 \\ \mathrm{H} & -2.7266966 & -3.615844 & -1.511301 \\ \mathrm{H} & -5.662478 & -3.072490 \\ \mathrm{H} & -4.450218 & -1.558983 \\ \mathrm{H} & -2.113096 & -1.149658\end{array}$




$$
\begin{array}{llll}
\mathrm{H} & -6.876062 & -6.361908 & -2.195222
\end{array}
$$

$\mathrm{M}=\mathrm{Am}$

$\begin{array}{lrcc}\text { AM } & -0.000004 & 0.245702 & -0.000004 \\ \mathrm{O} & -0.686143 & 1.936166 & -1.662581 \\ \mathrm{H} & -1.608319 & 2.265908 & -1.441735 \\ \mathrm{O} & 0.686117 & 1.936189 & 1.662558 \\ \mathrm{H} & 0.369118 & 2.366502 & 2.468381 \\ \mathrm{H} & -0.369154 & 2.366460 & -2.468417 \\ \mathrm{H} & 1.608293 & 2.265931 & 1.441714 \\ \mathrm{C} & -0.698454 & -1.563573 & 2.877309 \\ \mathrm{C} & -1.293561 & -2.011637 & 4.066450 \\ \mathrm{C} & -2.519946 & -1.477159 & 4.455678 \\ \mathrm{H} & -0.803622 & -2.762489 & 4.674589 \\ \mathrm{C} & -2.475831 & -0.112451 & 2.480296 \\ \mathrm{C} & -3.128304 & -0.509595 & 3.647276 \\ \mathrm{H} & -2.997729 & -1.806892 & 5.373203 \\ \mathrm{H} & -4.081416 & -0.065386 & 3.904424 \\ \mathrm{C} & -3.080607 & 0.912668 & 1.587034 \\ \mathrm{C} & -4.797494 & 2.366511 & 1.138914 \\ \mathrm{C} & -4.098382 & 2.737654 & -0.070436 \\ \mathrm{~N} & -1.281642 & -0.623676 & 2.099041 \\ \mathrm{~N} & -4.255004 & 1.451480 & 1.938924 \\ \mathrm{~N} & -2.401362 & 1.239646 & 0.483782 \\ \mathrm{~N} & -2.929806 & 2.165085 & -0.337305 \\ \mathrm{C} & -6.097105 & 3.013582 & 1.578463 \\ \mathrm{C} & -6.743472 & 3.790170 & 0.409548 \\ \mathrm{H} & -7.279473 & 3.090252 & -0.239723 \\ \mathrm{H} & -7.504557 & 4.458517 & 0.821145 \\ \mathrm{C} & -5.737578 & 4.601518 & -0.410286 \\ \mathrm{C} & -4.654010 & 3.728562 & -1.086273 \\ \mathrm{H} & -5.253357 & 5.352915 & 0.222992 \\ \mathrm{H} & -6.262787 & 5.158113 & -1.191570 \\ \mathrm{C} & -7.078383 & 1.941907 & 2.103444 \\ \mathrm{H} & -6.685239 & 1.427097 & 2.981701 \\ \mathrm{H} & -8.015935 & 2.427998 & 2.385656 \\ \mathrm{H} & -7.308642 & 1.197613 & 1.334517 \\ \mathrm{C} & -5.734074 & 3.978458 & 2.746096 \\ \mathrm{H} & -6.653168 & 4.435848 & 3.121239 \\ \mathrm{H} & -5.262727 & 3.434022 & 3.568286 \\ \mathrm{H} & -5.062139 & 4.782120 & 2.432330 \\ \mathrm{C} & -5.262150 & 2.902191 & -2.252725 \\ \mathrm{H} & -5.664484 & 3.584823 & -3.005953 \\ \mathrm{H} & -4.499001 & 2.280181 & -2.730529 \\ \mathrm{H} & -6.075335 & 2.249224 & -1.925623 \\ & & & \end{array}$




\begin{tabular}{|c|c|c|c|}
\hline $\mathrm{C}$ & -3.541638 & 4.642041 & -1.642381 \\
\hline 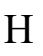 & -2.823517 & 4.093586 & -2.258298 \\
\hline H & -3.994075 & 5.405874 & -2.280115 \\
\hline & -3.000264 & 5.156183 & -0.842270 \\
\hline$C$ & 0.586574 & -2.099253 & 2.408492 \\
\hline $\mathrm{C}$ & 1.396211 & -3.100759 & 2.963409 \\
\hline$C$ & 2.497994 & -3.224165 & 2.106927 \\
\hline $\mathrm{H}$ & 1.243353 & -3.653571 & 3.876795 \\
\hline $\mathrm{N}$ & 1.132516 & -1.610879 & 1.269353 \\
\hline $\mathrm{N}$ & 2.288914 & -2.311002 & 1.117171 \\
\hline $\mathrm{C}$ & 0.698466 & -1.563595 & -2.877299 \\
\hline $\mathrm{C}$ & 1.293580 & -2.011666 & -4.066435 \\
\hline $\mathrm{C}$ & 2.519963 & -1.477184 & -4.455664 \\
\hline $\mathrm{H}$ & 0.803647 & -2.762526 & -4.674568 \\
\hline $\mathrm{C}$ & 2.475833 & -0.112459 & -2.480293 \\
\hline $\mathrm{C}$ & 3.128312 & -0.509609 & -3.647267 \\
\hline $\mathrm{H}$ & 2.997750 & -1.806921 & -5.373184 \\
\hline $\mathrm{H}$ & 4.081423 & -0.065398 & -3.904415 \\
\hline $\mathrm{C}$ & 3.080601 & 0.912669 & -1.587037 \\
\hline $\mathrm{C}$ & 4.797483 & 2.366520 & -1.138918 \\
\hline $\mathrm{C}$ & 4.098364 & 2.737670 & 0.070425 \\
\hline $\mathrm{N}$ & 1.281646 & -0.623687 & -2.099039 \\
\hline $\mathrm{N}$ & 4.254999 & 1.451482 & -1.938924 \\
\hline $\mathrm{N}$ & 2.401350 & 1.239654 & -0.483790 \\
\hline $\mathrm{N}$ & 2.929787 & 2.165100 & 0.337292 \\
\hline $\mathrm{C}$ & 6.097095 & 3.013589 & -1.578464 \\
\hline $\mathrm{C}$ & 6.743454 & 3.790186 & -0.409551 \\
\hline $\mathrm{H}$ & 7.279453 & 3.090272 & 0.239728 \\
\hline $\mathrm{H}$ & 7.504542 & 4.458530 & -0.821148 \\
\hline $\mathrm{C}$ & 5.737556 & 4.601538 & 0.410272 \\
\hline $\mathrm{C}$ & 4.653984 & 3.728585 & 1.086259 \\
\hline $\mathrm{H}$ & 5.253338 & 5.352931 & -0.223014 \\
\hline $\mathrm{H}$ & 6.262760 & 5.158138 & 1.191555 \\
\hline $\mathrm{C}$ & 7.078378 & 1.941912 & -2.103433 \\
\hline $\mathrm{H}$ & 6.685238 & 1.427096 & -2.981690 \\
\hline $\mathrm{H}$ & 8.015930 & 2.428003 & -2.385644 \\
\hline $\mathrm{H}$ & 7.308633 & 1.197623 & -1.334501 \\
\hline $\mathrm{C}$ & 5.734068 & 3.978458 & -2.746106 \\
\hline $\mathrm{H}$ & 6.653164 & 4.435847 & -3.121246 \\
\hline $\mathrm{H}$ & 5.262727 & 3.434016 & -3.568295 \\
\hline $\mathrm{H}$ & 5.062131 & 4.782120 & -2.432348 \\
\hline $\mathrm{C}$ & 5.262118 & 2.902224 & 2.252720 \\
\hline $\mathrm{H}$ & 5.664447 & 3.584862 & 3.005946 \\
\hline $\mathrm{H}$ & 4.498967 & 2.280216 & 2.730523 \\
\hline $\mathrm{H}$ & 6.075306 & 2.249255 & 1.925628 \\
\hline $\mathrm{C}$ & 3.541608 & 4.642067 & 1.642353 \\
\hline
\end{tabular}




$\begin{array}{lrrr}\mathrm{H} & 2.823484 & 4.093616 & 2.258271 \\ \mathrm{H} & 3.994040 & 5.405906 & 2.280084 \\ \mathrm{H} & 3.000237 & 5.156202 & 0.842235 \\ \mathrm{C} & -0.586560 & -2.099280 & -2.408483 \\ \mathrm{C} & -1.396186 & -3.100799 & -2.963392 \\ \mathrm{C} & -2.497975 & -3.224201 & -2.106917 \\ \mathrm{H} & -1.243324 & -3.653616 & -3.876775 \\ \mathrm{~N} & -1.132513 & -1.610896 & -1.269353 \\ \mathrm{~N} & -2.288908 & -2.311024 & -1.117170 \\ \mathrm{H} & -2.852262 & -2.183989 & -0.287806 \\ \mathrm{H} & 2.852267 & -2.183965 & 0.287806 \\ \mathrm{C} & -3.665876 & -4.104132 & -2.162689 \\ \mathrm{C} & -4.882708 & -3.741471 & -1.550439 \\ \mathrm{C} & -3.575250 & -5.336039 & -2.840788 \\ \mathrm{C} & -5.983270 & -4.599101 & -1.608492 \\ \mathrm{H} & -4.994354 & -2.773988 & -1.066988 \\ \mathrm{C} & -4.678405 & -6.189842 & -2.896218 \\ \mathrm{H} & -2.641342 & -5.638938 & -3.303431 \\ \mathrm{C} & -5.883009 & -5.825750 & -2.279913 \\ \mathrm{H} & -6.922314 & -4.309954 & -1.147469 \\ \mathrm{H} & -4.600617 & -7.139504 & -3.415557 \\ \mathrm{H} & -6.740004 & -6.489929 & -2.328023 \\ \mathrm{C} & 3.665901 & -4.104088 & 2.162702 \\ \mathrm{C} & 4.882686 & -3.741486 & 1.550321 \\ \mathrm{C} & 3.575332 & -5.335924 & 2.840937 \\ \mathrm{C} & 5.983255 & -4.599106 & 1.608382 \\ \mathrm{H} & 4.994286 & -2.774061 & 1.066745 \\ \mathrm{C} & 4.678495 & -6.189717 & 2.896374 \\ \mathrm{H} & 2.641463 & -5.638776 & 3.303688 \\ \mathrm{C} & 5.883051 & -5.825683 & 2.279940 \\ \mathrm{H} & 6.922262 & -4.310005 & 1.147253 \\ \mathrm{H} & 4.600751 & -7.139323 & 3.415820 \\ \mathrm{H} & 6.740053 & -6.489854 & 2.328055\end{array}$

$\mathrm{M}=\mathrm{Cm}$

$\begin{array}{lrcc}\mathrm{CM} & -0.000007 & 0.242172 & -0.000008 \\ \mathrm{O} & -0.657201 & 1.908763 & -1.695835 \\ \mathrm{H} & -1.562017 & 2.270980 & -1.459142 \\ \mathrm{O} & 0.657164 & 1.908742 & 1.695849 \\ \mathrm{H} & 0.374435 & 2.268195 & 2.547881 \\ \mathrm{H} & -0.374478 & 2.268236 & -2.547860 \\ \mathrm{H} & 1.561977 & 2.270972 & 1.459166 \\ \mathrm{C} & -0.727023 & -1.631246 & 2.810416 \\ \mathrm{C} & -1.346328 & -2.113704 & 3.974060 \\ \mathrm{C} & -2.579310 & -1.588628 & 4.355590\end{array}$




\begin{tabular}{|c|c|c|c|}
\hline $\mathrm{H}$ & -0.868463 & -2.881795 & 4.570146 \\
\hline & -2.494246 & -0.162466 & 2.425497 \\
\hline & -3.168623 & -0.591950 & 3.568304 \\
\hline & -3.075031 & -1.945229 & 5.253399 \\
\hline $\mathrm{H}$ & -4.122744 & -0.149052 & 3.824225 \\
\hline & -3.073978 & 0.899034 & 1.557294 \\
\hline $\mathrm{C}$ & -4.765961 & 2.386955 & 1.128360 \\
\hline$C$ & -4.044709 & 2.786043 & -0.059126 \\
\hline $\mathrm{N}$ & -1.297244 & -0.670851 & 2.048614 \\
\hline $\mathrm{N}$ & -4.248775 & 1.438516 & 1.906269 \\
\hline $\mathrm{N}$ & -2.372730 & 1.255626 & 0.476850 \\
\hline $\mathrm{N}$ & -2.878917 & 2.207971 & -0.326774 \\
\hline $\mathrm{C}$ & -6.063532 & 3.037473 & 1.568567 \\
\hline $\mathrm{C}$ & -6.686233 & 3.850559 & 0.411697 \\
\hline $\mathrm{H}$ & -7.218471 & 3.172664 & -0.263625 \\
\hline $\mathrm{H}$ & -7.447752 & 4.514219 & 0.830041 \\
\hline $\mathrm{C}$ & -5.661839 & 4.674863 & -0.371370 \\
\hline $\mathrm{C}$ & -4.574671 & 3.811647 & -1.054194 \\
\hline $\mathrm{H}$ & -5.181612 & 5.405378 & 0.288742 \\
\hline $\mathrm{H}$ & -6.170911 & 5.256173 & -1.145298 \\
\hline $\mathrm{C}$ & -7.063863 & 1.965291 & 2.054669 \\
\hline $\mathrm{H}$ & -6.688255 & 1.424248 & 2.924778 \\
\hline $\mathrm{H}$ & -7.999126 & 2.455658 & 2.337042 \\
\hline $\mathrm{H}$ & -7.293083 & 1.242986 & 1.264706 \\
\hline $\mathrm{C}$ & -5.703171 & 3.968376 & 2.764410 \\
\hline $\mathrm{H}$ & -6.621023 & 4.428908 & 3.138779 \\
\hline $\mathrm{H}$ & -5.250294 & 3.397296 & 3.578929 \\
\hline $\mathrm{H}$ & -5.016294 & 4.770203 & 2.479682 \\
\hline $\mathrm{C}$ & -5.170631 & 3.025915 & -2.254445 \\
\hline $\mathrm{H}$ & -5.551996 & 3.734218 & -2.994747 \\
\hline $\mathrm{H}$ & -4.406219 & 2.408882 & -2.736799 \\
\hline $\mathrm{H}$ & -5.996632 & 2.373277 & -1.960364 \\
\hline $\mathrm{C}$ & -3.444624 & 4.730788 & -1.563617 \\
\hline $\mathrm{H}$ & -2.717282 & 4.193958 & -2.178823 \\
\hline $\mathrm{H}$ & -3.878736 & 5.515230 & -2.188959 \\
\hline $\mathrm{H}$ & -2.915477 & 5.218424 & -0.739136 \\
\hline $\mathrm{C}$ & 0.574630 & -2.144300 & 2.360200 \\
\hline $\mathrm{C}$ & 1.370439 & -3.161896 & 2.906275 \\
\hline $\mathrm{C}$ & 2.505282 & -3.244129 & 2.089396 \\
\hline $\mathrm{H}$ & 1.186508 & -3.751307 & 3.790519 \\
\hline $\mathrm{N}$ & 1.160756 & -1.607410 & 1.261969 \\
\hline $\mathrm{N}$ & 2.326774 & -2.294479 & 1.128642 \\
\hline $\mathrm{C}$ & 0.727043 & -1.631193 & -2.810459 \\
\hline $\mathrm{C}$ & 1.346353 & -2.113620 & -3.974113 \\
\hline $\mathrm{C}$ & 2.579326 & -1.588515 & -4.355636 \\
\hline $\mathrm{H}$ & 0.868501 & -2.881708 & -4.570212 \\
\hline
\end{tabular}




\begin{tabular}{|c|c|c|c|}
\hline $\mathrm{C}$ & 2.494242 & -0.162390 & -2.425517 \\
\hline & 3.168624 & -0.591842 & -3.568333 \\
\hline $\mathrm{H}$ & 3.075051 & -1.945092 & -5.253453 \\
\hline $\mathrm{H}$ & 4.122737 & -0.148923 & -3.824247 \\
\hline C & 3.073958 & 0.899102 & -1.557294 \\
\hline C & 4.765924 & 2.387034 & -1.128330 \\
\hline C & 4.044668 & 2.786088 & 0.059166 \\
\hline $\mathbf{N}$ & 1.297248 & -0.670801 & -2.048642 \\
\hline $\mathrm{N}$ & 4.248749 & 1.438605 & -1.906258 \\
\hline$N$ & 2.372706 & 1.255665 & -0.476844 \\
\hline $\mathbf{N}$ & 2.878882 & 2.207998 & 0.326801 \\
\hline $\mathrm{C}$ & 6.063484 & 3.037581 & -1.568525 \\
\hline $\mathrm{C}$ & 6.686177 & 3.850649 & -0.411639 \\
\hline $\mathrm{H}$ & 7.218429 & 3.172746 & 0.263665 \\
\hline $\mathrm{H}$ & 7.447685 & 4.514330 & -0.829971 \\
\hline $\mathrm{C}$ & 5.661775 & 4.674920 & 0.371451 \\
\hline $\mathrm{C}$ & 4.574622 & 3.811671 & 1.054258 \\
\hline $\mathrm{H}$ & 5.181535 & 5.405443 & -0.288642 \\
\hline $\mathrm{H}$ & 6.170841 & 5.256218 & 1.145391 \\
\hline $\mathrm{C}$ & 7.063828 & 1.965425 & -2.054657 \\
\hline $\mathrm{H}$ & 6.688225 & 1.424397 & -2.924777 \\
\hline $\mathrm{H}$ & 7.999084 & 2.455811 & -2.337021 \\
\hline $\mathrm{H}$ & 7.293061 & 1.243104 & -1.264711 \\
\hline $\mathrm{C}$ & 5.703106 & 3.968507 & -2.764346 \\
\hline $\mathrm{H}$ & 6.620950 & 4.429060 & -3.138707 \\
\hline $\mathrm{H}$ & 5.250234 & 3.397439 & -3.578876 \\
\hline $\mathrm{H}$ & 5.016219 & 4.770318 & -2.479596 \\
\hline $\mathrm{C}$ & 5.170598 & 3.025914 & 2.254484 \\
\hline $\mathrm{H}$ & 5.551962 & 3.734202 & 2.994802 \\
\hline $\mathrm{H}$ & 4.406196 & 2.408862 & 2.736827 \\
\hline $\mathrm{H}$ & 5.996603 & 2.373291 & 1.960381 \\
\hline $\mathrm{C}$ & 3.444566 & 4.730784 & 1.563713 \\
\hline $\mathrm{H}$ & 2.717235 & 4.193929 & 2.178910 \\
\hline $\mathrm{H}$ & 3.878672 & 5.515216 & 2.189073 \\
\hline $\mathrm{H}$ & 2.915407 & 5.218435 & 0.739248 \\
\hline $\mathrm{C}$ & -0.574600 & -2.144278 & -2.360249 \\
\hline $\mathrm{C}$ & -1.370383 & -3.161891 & -2.906332 \\
\hline $\mathrm{C}$ & -2.505229 & -3.244152 & -2.089463 \\
\hline $\mathrm{H}$ & -1.186435 & -3.751296 & -3.790576 \\
\hline $\mathrm{N}$ & -1.160744 & -1.607406 & -1.262019 \\
\hline $\mathrm{N}$ & -2.326747 & -2.294500 & -1.128703 \\
\hline $\mathrm{H}$ & -2.924185 & -2.127343 & -0.330949 \\
\hline $\mathrm{H}$ & 2.924209 & -2.127280 & 0.330895 \\
\hline $\mathrm{C}$ & 3.677583 & -4.117406 & 2.157083 \\
\hline C & 4.915512 & -3.720435 & 1.612164 \\
\hline $\mathrm{C}$ & 3.570053 & -5.377109 & 2.779260 \\
\hline
\end{tabular}




$\begin{array}{llll}\mathrm{C} & 6.020566 & -4.571496 & 1.680989 \\ \mathrm{H} & 5.038534 & -2.732429 & 1.175045 \\ \mathrm{C} & 4.677766 & -6.224216 & 2.845797 \\ \mathrm{H} & 2.620506 & -5.705801 & 3.189586 \\ \mathrm{C} & 5.903663 & -5.825784 & 2.296304 \\ \mathrm{H} & 6.975488 & -4.256013 & 1.272838 \\ \mathrm{H} & 4.587209 & -7.195134 & 3.321983 \\ \mathrm{H} & 6.764091 & -6.484801 & 2.353281 \\ \mathrm{C} & -3.677480 & -4.117409 & -2.157126 \\ \mathrm{C} & -4.915449 & -3.720340 & -1.612367 \\ \mathrm{C} & -3.569922 & -5.377202 & -2.779117 \\ \mathrm{C} & -6.020511 & -4.571394 & -1.681154 \\ \mathrm{H} & -5.038477 & -2.732259 & -1.175416 \\ \mathrm{C} & -4.677642 & -6.224302 & -2.845618 \\ \mathrm{H} & -2.620348 & -5.705964 & -3.189327 \\ \mathrm{C} & -5.903577 & -5.825773 & -2.296278 \\ \mathrm{H} & -6.975463 & -4.255836 & -1.273130 \\ \mathrm{H} & -4.587064 & -7.195289 & -3.321659 \\ \mathrm{H} & -6.764010 & -6.484785 & -2.353229\end{array}$

\section{$\left[\mathrm{ML}_{2}\right]^{3+}$}

$\mathrm{M}=\mathrm{Eu}$

$\begin{array}{lrrr}\text { EU } & -0.000004 & 0.338467 & 0.000002 \\ \mathrm{~N} & 1.698680 & -1.206449 & -0.971851 \\ \mathrm{~N} & -1.698702 & -1.206446 & 0.971835 \\ \mathrm{C} & 1.936782 & -1.337286 & -2.284032 \\ \mathrm{~N} & 2.384149 & -1.952563 & -0.096262 \\ \mathrm{~N} & 1.541119 & 1.960402 & 1.250176 \\ \mathrm{~N} & -1.541093 & 1.960453 & -1.250151 \\ \mathrm{~N} & -0.251634 & 0.357035 & 2.579078 \\ \mathrm{~N} & 0.251655 & 0.357094 & -2.579072 \\ \mathrm{C} & -1.936789 & -1.337314 & 2.284016 \\ \mathrm{~N} & -2.384197 & -1.952524 & 0.096235 \\ \mathrm{C} & 1.133769 & -0.467586 & -3.186639 \\ \mathrm{~N} & 2.824913 & -2.186097 & -2.802597 \\ \mathrm{C} & 3.294394 & -2.821171 & -0.539670 \\ \mathrm{C} & 1.475627 & 2.019172 & 2.608528 \\ \mathrm{~N} & 2.527040 & 2.834301 & 0.915991 \\ \mathrm{C} & -1.475584 & 2.019255 & -2.608500 \\ \mathrm{~N} & -2.527008 & 2.834355 & -0.915956 \\ \mathrm{C} & -1.133751 & -0.467649 & 3.186635 \\ \mathrm{C} & 0.521433 & 1.163080 & 3.336484 \\ \mathrm{C} & -0.521392 & 1.163170 & -3.336466 \\ \mathrm{~N} & -2.824925 & -2.186125 & 2.802570\end{array}$




\begin{tabular}{|c|c|c|c|}
\hline $\mathrm{C}$ & -3.294452 & -2.821128 & 0.539632 \\
\hline & 1.286490 & -0.515637 & -4.572600 \\
\hline C & 3.518246 & -2.955018 & -1.958606 \\
\hline $\mathrm{C}$ & 4.020007 & -3.658191 & 0.507936 \\
\hline C & 2.409655 & 2.933723 & 3.111342 \\
\hline C & 3.085194 & 3.455125 & 1.996885 \\
\hline $\mathrm{H}$ & 2.732546 & 3.016782 & -0.057149 \\
\hline $\mathrm{C}$ & -2.409595 & 2.933830 & -3.111303 \\
\hline $\mathrm{C}$ & -3.085142 & 3.455212 & -1.996842 \\
\hline $\mathrm{H}$ & -2.732524 & 3.016815 & 0.057186 \\
\hline $\mathrm{C}$ & -1.286456 & -0.515734 & 4.572597 \\
\hline $\mathrm{C}$ & 0.426469 & 1.175352 & 4.735117 \\
\hline $\mathrm{C}$ & -0.426410 & 1.175476 & -4.735097 \\
\hline $\mathrm{C}$ & -3.518283 & -2.955012 & 1.958569 \\
\hline $\mathrm{C}$ & -4.020098 & -3.658103 & -0.507986 \\
\hline $\mathrm{C}$ & 0.490119 & 0.325779 & -5.357456 \\
\hline $\mathrm{H}$ & 2.007018 & -1.196525 & -5.008734 \\
\hline $\mathrm{C}$ & 4.540653 & -3.906603 & -2.552101 \\
\hline $\mathrm{C}$ & 4.445169 & -2.777462 & 1.702118 \\
\hline $\mathrm{C}$ & 5.272704 & -4.308400 & -0.122962 \\
\hline $\mathrm{C}$ & 3.028125 & -4.742438 & 1.006949 \\
\hline $\mathrm{H}$ & 2.610931 & 3.173213 & 4.143430 \\
\hline $\mathrm{H}$ & -2.610856 & 3.173347 & -4.143387 \\
\hline $\mathrm{C}$ & -0.490063 & 0.325651 & 5.357465 \\
\hline $\mathrm{H}$ & -2.006987 & -1.196624 & 5.008722 \\
\hline $\mathrm{H}$ & 1.056065 & 1.828944 & 5.326926 \\
\hline $\mathrm{H}$ & -1.055990 & 1.829092 & -5.326898 \\
\hline $\mathrm{C}$ & -4.540694 & -3.906599 & 2.552053 \\
\hline $\mathrm{C}$ & -4.445263 & -2.777331 & -1.702135 \\
\hline $\mathrm{C}$ & -5.272798 & -4.308304 & 0.122914 \\
\hline $\mathrm{C}$ & -3.028247 & -4.742355 & -1.007047 \\
\hline $\mathrm{H}$ & 0.580361 & 0.315552 & -6.439411 \\
\hline $\mathrm{C}$ & 5.003150 & -4.932971 & -1.494006 \\
\hline $\mathrm{C}$ & 3.936181 & -4.644640 & -3.767901 \\
\hline $\mathrm{C}$ & 5.735294 & -3.034823 & -3.036513 \\
\hline $\mathrm{H}$ & 4.999176 & -3.389057 & 2.419480 \\
\hline $\mathrm{H}$ & 5.103107 & -1.962687 & 1.382981 \\
\hline $\mathrm{H}$ & 3.582307 & -2.347624 & 2.215471 \\
\hline $\mathrm{H}$ & 5.646179 & -5.072798 & 0.564460 \\
\hline $\mathrm{H}$ & 6.068097 & -3.559305 & -0.202316 \\
\hline $\mathrm{H}$ & 2.700280 & -5.409777 & 0.205355 \\
\hline $\mathrm{H}$ & 2.141580 & -4.278820 & 1.449559 \\
\hline $\mathrm{H}$ & 3.513867 & -5.352435 & 1.773356 \\
\hline $\mathrm{H}$ & -0.580292 & 0.315396 & 6.439420 \\
\hline $\mathrm{C}$ & -5.003233 & -4.932924 & 1.493934 \\
\hline$C$ & -3.936208 & -4.644686 & 3.767815 \\
\hline
\end{tabular}




\begin{tabular}{|c|c|c|c|}
\hline $\mathrm{C}$ & -5.735309 & -3.034815 & 3.036520 \\
\hline & -4.999294 & -3.388895 & -2.419506 \\
\hline & -5.103180 & -1.962552 & -1.382964 \\
\hline & -3.582402 & -2.347495 & -2.215490 \\
\hline & -5.646302 & -5.072673 & -0.564524 \\
\hline & -6.068174 & -3.559193 & 0.202307 \\
\hline & -2.700400 & -5.409723 & -0.205477 \\
\hline & -2.141700 & -4.278742 & -1.449659 \\
\hline & -3.514015 & -5.352322 & -1.773461 \\
\hline & 5.910181 & -5.420492 & -1.861977 \\
\hline & 4.251988 & -5.724937 & -1.404881 \\
\hline & 4.675802 & -5.348412 & -4.158810 \\
\hline 7 & 3.046930 & -5.217968 & -3.487579 \\
\hline & 3.667004 & -3.953888 & -4.568765 \\
\hline & 6.475521 & -3.684441 & -3.510758 \\
\hline $\mathrm{H}$ & 6.227612 & -2.506346 & -2.215438 \\
\hline 7 & 5.404982 & -2.298343 & -3.773525 \\
\hline $\mathrm{H}$ & -5.910268 & -5.420436 & 1.861907 \\
\hline H & -4.252090 & -5.724903 & 1.404770 \\
\hline $\mathrm{H}$ & -4.675833 & -5.348458 & 4.158718 \\
\hline $\mathrm{H}$ & -3.046974 & -5.218022 & 3.487454 \\
\hline $\mathrm{H}$ & -3.667000 & -3.953965 & 4.568696 \\
\hline $\mathrm{H}$ & -6.475538 & -3.684435 & 3.510759 \\
\hline $\mathrm{H}$ & -6.227636 & -2.506301 & \\
\hline $\mathrm{H}$ & -5.404969 & -2.298365 & 3.773550 \\
\hline $\mathrm{C}$ & 4.155996 & 4.439871 & 1.908270 \\
\hline $\mathrm{C}$ & 4.406618 & 5.293751 & 3.010243 \\
\hline $\mathrm{C}$ & 4.952768 & 4.562538 & 0.745009 \\
\hline O & 5.418617 & 6.246780 & 2.944302 \\
\hline $\mathrm{H}$ & 3.796651 & 5.225290 & 3.904620 \\
\hline $\mathrm{C}$ & 5.965313 & 5.515526 & 0.684328 \\
\hline $\mathrm{H}$ & 4.814590 & 3.893558 & -0.099930 \\
\hline $\mathrm{C}$ & 6.201136 & 6.363240 & 1.783005 \\
\hline $\mathrm{H}$ & 5.602270 & 6.903057 & 3.788635 \\
\hline$U$ & 6.582576 & 5.599150 & -0.204216 \\
\hline $\mathrm{H}$ & 6.992475 & 7.104750 & 1.734177 \\
\hline 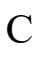 & -4.155934 & 4.439969 & -1.908215 \\
\hline $\mathrm{C}$ & -4.406528 & 5.293883 & -3.010168 \\
\hline $\mathrm{C}$ & -4.952723 & 4.562610 & -0.744963 \\
\hline $\mathrm{C}$ & -5.418517 & 6.246922 & -2.944215 \\
\hline $\mathrm{H}$ & -3.796548 & 5.225441 & -3.904536 \\
\hline $\mathrm{C}$ & -5.965258 & 5.515608 & -0.684271 \\
\hline $\mathrm{H}$ & -4.814566 & 3.893604 & 0.099958 \\
\hline 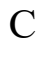 & -6.201054 & 6.363357 & -1.782927 \\
\hline $\mathrm{H}$ & -5.602149 & 6.903226 & -3.788531 \\
\hline & -6.582534 & 5.599214 & 0.204266 \\
\hline
\end{tabular}




$$
\begin{aligned}
& \text { H } \quad-6.992386 \quad 7.104874 \quad-1.734090 \\
& \mathrm{M}=\mathrm{Gd} \\
& \text { GD } \quad-0.275404 \quad 0.004762 \quad-0.000141 \\
& \begin{array}{llll}
\mathrm{N} & 1.257781 & 1.659195 & -0.828428
\end{array} \\
& \begin{array}{llll}
\mathrm{N} & 1.202756 & -1.698010 & 0.829979
\end{array} \\
& \begin{array}{llll}
\text { C } & 1.409149 & 1.984862 & -2.120662
\end{array} \\
& \begin{array}{llll}
\mathrm{N} & 2.000162 & 2.262822 & 0.110137
\end{array} \\
& \begin{array}{llll}
\mathrm{N} & -1.919641 & -1.353465 & -1.168042
\end{array} \\
& \begin{array}{llll}
\mathrm{N} & -1.877855 & 1.413858 & 1.166061
\end{array} \\
& \mathrm{~N} \quad-0.316214 \quad 0.369721 \quad-2.484322 \\
& \mathrm{~N} \quad-0.331732 \quad-0.359803 \quad 2.484153 \\
& \begin{array}{llll}
\text { C } & 1.341579 & -2.029267 & 2.122183
\end{array} \\
& \text { N } \quad \begin{array}{llll}
\text { C } & 1.927542 & -2.323701 & -0.107877
\end{array} \\
& \begin{array}{llll}
\text { C } & 0.530391 & 1.250701 & -3.066285
\end{array} \\
& \text { N } \quad 2.276305 \quad 2.893166 \quad-2.561988 \\
& \text { C } \quad 2.886258 \quad 3.188813 \quad-0.255284 \\
& \begin{array}{llll}
\text { C } & -2.029461 & -1.282244 & -2.526331
\end{array} \\
& \begin{array}{llll}
\mathrm{N} & -2.846593 & -2.290004 & -0.804317
\end{array} \\
& \begin{array}{llll}
\mathrm{C} & -1.991504 & 1.345811 & 2.524234
\end{array} \\
& \begin{array}{llll}
\mathrm{N} & -2.774208 & 2.379486 & 0.801568
\end{array} \\
& \text { C } \quad-1.152320 \quad-0.355864 \quad-3.256837 \\
& \begin{array}{llll}
\text { C } & 0.485343 & -1.267763 & 3.066948
\end{array} \\
& \begin{array}{llll}
\text { C } & -1.145317 & 0.391840 & 3.255693
\end{array} \\
& \begin{array}{llll}
\mathrm{N} & 2.178286 & -2.965499 & 2.564026
\end{array} \\
& \begin{array}{llll}
\text { C } & 2.783205 & -3.277616 & 0.258108
\end{array} \\
& \begin{array}{llll}
\text { C } & 0.575466 & 1.446956 & -4.444060
\end{array} \\
& \begin{array}{llll}
\text { C } & 3.039715 & 3.515168 & -1.656890
\end{array} \\
& \begin{array}{llll}
\text { C } & 3.724502 & 3.821643 & 0.849099
\end{array} \\
& \text { C } \quad-3.010262 \quad-2.157644 \quad-2.995524 \\
& \text { C } \quad-3.530722 \quad-2.806116-1.862022 \\
& \begin{array}{llll}
\mathrm{H} & -3.020490 & -2.488722 & 0.172064
\end{array} \\
& \begin{array}{llll}
\text { C } & -2.944595 & 2.251737 & 2.992548
\end{array} \\
& \begin{array}{llll}
\text { C } & -3.442968 & 2.916564 & 1.858643
\end{array} \\
& \text { H } \quad-2.941089 \quad 2.583485-0.174965 \\
& \text { C } \quad-1.166900 \quad-0.216850 \quad-4.651593 \\
& \begin{array}{llll}
\text { C } & 0.522014 & -1.465950 & 4.444697
\end{array} \\
& \begin{array}{llll}
\text { C } & -1.166371 & 0.252866 & 4.650393
\end{array} \\
& \begin{array}{llll}
\text { C } & 2.922915 & -3.610776 & 1.659571
\end{array} \\
& \begin{array}{llll}
\text { C } & 3.603667 & -3.934626 & -0.845494
\end{array} \\
& \begin{array}{llll}
\text { C } & -0.293163 & 0.695022 & -5.247640
\end{array} \\
& \text { H } \quad 1.271055 \quad 2.163364 \quad-4.864215 \\
& \begin{array}{llll}
\text { C } & 4.003232 & 4.570840 & -2.159745
\end{array} \\
& \begin{array}{llll}
\text { C } & 2.844116 & 4.157883 & 2.071539
\end{array} \\
& \begin{array}{llll}
\text { C } & 4.388205 & 5.114389 & 0.321173
\end{array}
\end{aligned}
$$




\begin{tabular}{|c|c|c|c|}
\hline $\mathrm{C}$ & 4.798616 & 2.781926 & 1.268178 \\
\hline$\pi$ & -3.300420 & -2.342090 & -4.017968 \\
\hline 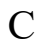 & -4.573752 & -3.820458 & -1.734821 \\
\hline $\mathrm{H}$ & -3.229909 & 2.445238 & 4.014691 \\
\hline $\mathrm{C}$ & -4.453193 & 3.963444 & 1.730754 \\
\hline H & -1.843136 & -0.807951 & -5.257916 \\
\hline C & -0.323182 & -0.686762 & 5.247320 \\
\hline $\mathrm{H}$ & 1.193570 & -2.204525 & 4.865565 \\
\hline $\mathrm{H}$ & -1.824308 & 0.864979 & 5.255998 \\
\hline $\mathrm{C}$ & 3.850571 & -4.698009 & 2.162548 \\
\hline $\mathrm{C}$ & 2.715972 & -4.240733 & -2.070586 \\
\hline $\mathrm{C}$ & 4.225421 & -5.248407 & -0.318437 \\
\hline $\mathrm{C}$ & 4.710790 & -2.928370 & -1.260310 \\
\hline $\mathrm{H}$ & -0.285804 & 0.819212 & -6.326366 \\
\hline C & 5.022584 & 4.946854 & -1.061396 \\
\hline $\mathrm{C}$ & 4.747105 & 4.059731 & -3.414844 \\
\hline $\mathrm{C}$ & 3.137924 & 5.804319 & -2.556903 \\
\hline $\mathrm{H}$ & 3.458574 & 4.650251 & 2.830011 \\
\hline $\mathrm{H}$ & 2.034153 & 4.844163 & 1.804710 \\
\hline $\mathrm{H}$ & 2.408581 & 3.260966 & 2.517422 \\
\hline $\mathrm{H}$ & 5.149450 & 5.427107 & 1.041423 \\
\hline $\mathrm{H}$ & 3.645550 & 5.919247 & 0.29 \\
\hline $\mathrm{H}$ & 5.461500 & 2.508289 & 0.443002 \\
\hline $\mathrm{H}$ & 4.326194 & 1.869656 & 1.644517 \\
\hline $\mathrm{H}$ & 5.414719 & 3.202109 & 2.067598 \\
\hline $\mathrm{C}$ & -4.626348 & -4.678457 & -0.616354 \\
\hline $\mathrm{C}$ & -5.546491 & -3.944381 & -2.748118 \\
\hline $\mathrm{C}$ & -4.474200 & 4.826776 & 0.615392 \\
\hline $\mathrm{C}$ & -5.425744 & 4.113961 & 2.740617 \\
\hline $\mathrm{H}$ & -0.321399 & -0.811518 & 6.326006 \\
\hline $\mathrm{C}$ & 4.860877 & -5.103084 & 1.066116 \\
\hline $\mathrm{C}$ & 4.606294 & -4.214474 & 3.421409 \\
\hline $\mathrm{C}$ & 2.944866 & -5.904176 & 2.553424 \\
\hline $\mathrm{H}$ & 3.316423 & -4.750860 & -2.828551 \\
\hline $\mathrm{H}$ & 1.884171 & -4.901605 & -1.806825 \\
\hline $\mathrm{H}$ & 2.309983 & -3.329689 & -2.515746 \\
\hline $\mathrm{H}$ & 4.978499 & -5.583316 & -1.037291 \\
\hline $\mathrm{H}$ & 3.458080 & -6.029804 & -0.299434 \\
\hline $\mathrm{H}$ & 5.381409 & -2.678496 & -0.433799 \\
\hline $\mathrm{H}$ & 4.267955 & -2.000376 & -1.634202 \\
\hline $\mathrm{H}$ & 5.313846 & -3.365532 & -2.060541 \\
\hline $\mathrm{H}$ & 5.515190 & 5.877518 & -1.355760 \\
\hline $\mathrm{H}$ & 5.811907 & 4.188740 & -1.024485 \\
\hline $\mathrm{H}$ & 5.457691 & 4.824578 & -3.738848 \\
\hline $\mathrm{H}$ & 5.313923 & 3.147943 & -3.201971 \\
\hline $\mathrm{H}$ & 4.061905 & 3.860447 & -4.240322 \\
\hline
\end{tabular}




$\begin{array}{lrrc}\mathrm{H} & 3.796919 & 6.575051 & -2.964808 \\ \mathrm{H} & 2.604022 & 6.233642 & -1.704760 \\ \mathrm{H} & 2.408278 & 5.536482 & -3.325223 \\ \mathrm{C} & -5.637926 & -5.634046 & -0.510918 \\ \mathrm{H} & -3.859755 & -4.640180 & 0.153548 \\ \mathrm{C} & -6.556886 & -4.900506 & -2.636355 \\ \mathrm{H} & -5.531522 & -3.282471 & -3.607927 \\ \mathrm{C} & -5.454933 & 5.814008 & 0.509692 \\ \mathrm{H} & -3.705776 & 4.767395 & -0.151333 \\ \mathrm{C} & -6.405290 & 5.101615 & 2.628512 \\ \mathrm{H} & -5.435157 & 3.448471 & 3.597741 \\ \mathrm{H} & 5.324078 & -6.048915 & 1.359949 \\ \mathrm{H} & 5.673148 & -4.369388 & 1.032845 \\ \mathrm{H} & 5.290448 & -5.002811 & 3.746033 \\ \mathrm{H} & 5.203272 & -3.321160 & 3.212709 \\ \mathrm{H} & 3.925002 & -3.994801 & 4.244962 \\ \mathrm{H} & 3.577474 & -6.696959 & 2.960844 \\ \mathrm{H} & 2.399485 & -6.313462 & 1.698684 \\ \mathrm{H} & 2.222225 & -5.615067 & 3.320653 \\ \mathrm{C} & -6.606428 & -5.745309 & -1.519294 \\ \mathrm{H} & -5.667419 & -6.301248 & 0.344336 \\ \mathrm{H} & -7.307156 & -4.987219 & -3.415382 \\ \mathrm{C} & -6.423649 & 5.951779 & 1.514581 \\ \mathrm{H} & -5.459908 & 6.485108 & -0.343002 \\ \mathrm{H} & -7.155735 & 5.208820 & 3.404818 \\ \mathrm{H} & -7.390954 & -6.490716 & -1.437287 \\ \mathrm{H} & -7.184045 & 6.721760 & 1.432318 \\ & & & \\ \mathrm{M}=\mathrm{Am} & & & \\ & & & \end{array}$

$\begin{array}{lrrr}\text { AM } & -0.311949 & 0.000000 & 0.000000 \\ \mathrm{~N} & 1.259280 & 1.608364 & -0.952690 \\ \mathrm{~N} & 1.259285 & -1.608358 & 0.952691 \\ \mathrm{C} & 1.460690 & 1.812579 & -2.259955 \\ \mathrm{~N} & 1.952166 & 2.309264 & -0.046381 \\ \mathrm{~N} & -1.944735 & 1.463949 & 1.176062 \\ \mathrm{~N} & -1.944726 & -1.463957 & -1.176064 \\ \mathrm{~N} & -0.240095 & 0.148400 & -2.541938 \\ \mathrm{~N} & -0.240098 & -0.148402 & 2.541938 \\ \mathrm{C} & 1.460695 & -1.812573 & 2.259956 \\ \mathrm{~N} & 1.952176 & -2.309254 & 0.046382 \\ \mathrm{C} & 0.627558 & 0.982670 & -3.164167 \\ \mathrm{~N} & 2.335537 & 2.688630 & -2.750306 \\ \mathrm{C} & 2.840382 & 3.211892 & -0.459349 \\ \mathrm{C} & -1.962988 & 1.508203 & 2.536274 \\ \mathrm{~N} & -2.894068 & 2.370144 & 0.795591\end{array}$




\begin{tabular}{|c|c|c|c|}
\hline $\mathrm{C}$ & -1.962977 & -1.508213 & -2.536276 \\
\hline J & -2.894055 & -2.370158 & -0.795593 \\
\hline $\mathrm{C}$ & -1.042316 & -0.643788 & -3.286958 \\
\hline $\mathrm{C}$ & 0.627558 & -0.982668 & 3.164168 \\
\hline $\mathrm{C}$ & -1.042323 & 0.643782 & 3.286957 \\
\hline $\mathrm{N}$ & 2.335546 & -2.688620 & 2.750308 \\
\hline $\mathrm{C}$ & 2.840396 & -3.211878 & 0.459350 \\
\hline $\mathrm{C}$ & 0.731601 & 1.058997 & -4.550150 \\
\hline $\mathrm{C}$ & 3.050747 & 3.406525 & -1.877831 \\
\hline $\mathrm{C}$ & 3.619838 & 3.961334 & 0.614744 \\
\hline $\mathrm{C}$ & -2.912512 & 2.424882 & 2.995178 \\
\hline $\mathrm{C}$ & -3.508089 & 2.976651 & 1.848460 \\
\hline $\mathrm{H}$ & -3.133909 & 2.483500 & -0.180383 \\
\hline $\mathrm{C}$ & -2.912496 & -2.424898 & -2.995180 \\
\hline $\mathrm{C}$ & -3.508071 & -2.976669 & -1.848462 \\
\hline $\mathrm{H}$ & -3.133898 & -2.483512 & 0.180381 \\
\hline $\mathrm{C}$ & -0.993817 & -0.624139 & -4.687891 \\
\hline $\mathrm{C}$ & 0.731599 & -1.058996 & 4.550150 \\
\hline $\mathrm{C}$ & -0.993827 & 0.624132 & 4.687890 \\
\hline $\mathrm{C}$ & 3.050760 & -3.406510 & 1.877832 \\
\hline $\mathrm{C}$ & 3.619857 & -3.961315 & -0.614742 \\
\hline $\mathrm{C}$ & -0.097215 & 0.235367 & -5.323595 \\
\hline $\mathrm{H}$ & 1.441841 & 1.743325 & -4.998195 \\
\hline $\mathrm{C}$ & 4.022357 & 4.425991 & -2.437434 \\
\hline $\mathrm{C}$ & 2.679952 & 4.398821 & 1.758421 \\
\hline $\mathrm{C}$ & 4.291555 & 5.208161 & -0.005445 \\
\hline $\mathrm{C}$ & 4.686227 & 2.985042 & 1.180309 \\
\hline $\mathrm{H}$ & -3.134843 & 2.698281 & 4.014637 \\
\hline $\mathrm{C}$ & -4.560012 & 3.979843 & 1.703965 \\
\hline $\mathrm{H}$ & -3.134824 & -2.698299 & -4.014639 \\
\hline $\mathrm{C}$ & -4.559989 & -3.979865 & -1.703967 \\
\hline $\mathrm{H}$ & -1.644274 & -1.267200 & -5.268722 \\
\hline $\mathrm{C}$ & -0.097221 & -0.235370 & 5.323595 \\
\hline $\mathrm{H}$ & 1.441842 & -1.743320 & 4.998196 \\
\hline $\mathrm{H}$ & -1.644287 & 1.267190 & 5.268721 \\
\hline $\mathrm{C}$ & 4.022375 & -4.425972 & 2.437436 \\
\hline $\mathrm{C}$ & 2.679975 & -4.398807 & -1.758420 \\
\hline $\mathrm{C}$ & 4.291580 & -5.208139 & 0.005447 \\
\hline $\mathrm{C}$ & 4.686242 & -2.985017 & -1.180306 \\
\hline $\mathrm{H}$ & -0.043224 & 0.266075 & -6.407619 \\
\hline $\mathrm{C}$ & 4.988227 & 4.919203 & -1.337024 \\
\hline $\mathrm{C}$ & 4.826484 & 3.810974 & -3.605620 \\
\hline $\mathrm{C}$ & 3.160792 & 5.602719 & -2.985552 \\
\hline $\mathrm{H}$ & 3.252412 & 4.973051 & 2.491808 \\
\hline $\mathrm{H}$ & 1.873944 & 5.041526 & 1.390236 \\
\hline $\mathrm{H}$ & 2.236499 & 3.541435 & 2.269643 \\
\hline
\end{tabular}




\begin{tabular}{|c|c|c|c|}
\hline $\mathrm{H}$ & 5.016530 & 5.599984 & 0.7135 \\
\hline H & 3.541537 & 5.995532 & -0.137009 \\
\hline & 5.394048 & 2.649722 & 0.417471 \\
\hline & 4.208550 & 2.102212 & 1.615791 \\
\hline & 5.255067 & 3.488272 & 1.966691 \\
\hline & -5.472861 & 4.183640 & 2.759146 \\
\hline & -4.680172 & 4.748038 & 0.527015 \\
\hline 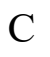 & -5.472854 & -4.183647 & -2.759138 \\
\hline$C$ & -4.680128 & -4.748080 & -0.527028 \\
\hline $\mathrm{H}$ & -0.043232 & -0.266079 & 6.407619 \\
\hline G & 4.988249 & -4.919178 & 1.337028 \\
\hline $\mathrm{C}$ & 4.826498 & -3.810951 & 3.605624 \\
\hline $\mathrm{C}$ & 3.160816 & -5.602705 & 2.985553 \\
\hline $\mathrm{H}$ & 3.252438 & -4.973034 & -2.491807 \\
\hline $\mathrm{H}$ & 1.873970 & -5.041516 & -1.390236 \\
\hline $\mathrm{H}$ & 2.236518 & -3.541423 & -2.269642 \\
\hline $\mathrm{H}$ & 5.016558 & -5.599958 & -0.713552 \\
\hline $\mathrm{H}$ & 3.541566 & -5.995514 & 0.137010 \\
\hline $\mathrm{H}$ & 5.394060 & -2.649694 & -0.417467 \\
\hline $\mathrm{H}$ & 4.208560 & -2.102190 & -1.615788 \\
\hline $\mathrm{H}$ & 5.255085 & -3.488245 & -1.966687 \\
\hline $\mathrm{H}$ & 5.484209 & 5.824527 & -1.697302 \\
\hline $\mathrm{H}$ & 5.782499 & 4.179009 & -1.193778 \\
\hline $\mathrm{H}$ & 5.541783 & 4.552706 & -3.970468 \\
\hline $\mathrm{H}$ & 5.39 & 2.932182 & -3.283440 \\
\hline $\mathrm{H}$ & 4.180393 & 3.524145 & -4.436879 \\
\hline $\mathrm{H}$ & 3.827266 & 6.342212 & -3.436859 \\
\hline $\mathrm{H}$ & 2.585226 & 6.101771 & -2.201219 \\
\hline $\mathrm{H}$ & 2.468082 & 5.252162 & -3.754756 \\
\hline $\mathrm{C}$ & -6.490815 & 5.129862 & 2.632327 \\
\hline $\mathrm{H}$ & -5.406210 & 3.590013 & 3.665282 \\
\hline $\mathrm{C}$ & -5.699314 & 5.693933 & 0.406376 \\
\hline $\mathrm{H}$ & -3.959043 & 4.648961 & -0.280630 \\
\hline $\mathrm{C}$ & -6.490804 & -5.129875 & -2.632318 \\
\hline $\mathrm{H}$ & -5.406219 & -3.590004 & -3.665265 \\
\hline $\mathrm{C}$ & -5.699266 & -5.693980 & -0.406389 \\
\hline $\mathrm{H}$ & -3.958984 & -4.649015 & 0.280605 \\
\hline $\mathrm{H}$ & 5.484235 & -5.824500 & 1.697306 \\
\hline $\mathrm{H}$ & 5.782517 & -4.178980 & 1.193783 \\
\hline $\mathrm{H}$ & 5.541800 & -4.552680 & 3.970472 \\
\hline $\mathrm{H}$ & 5.393887 & -2.932156 & 3.283445 \\
\hline $\mathrm{H}$ & 4.180404 & -3.524126 & 4.436882 \\
\hline $\mathrm{H}$ & 3.827292 & -6.342195 & 3.436860 \\
\hline $\mathrm{H}$ & 2.585253 & -6.101759 & 2.201219 \\
\hline $\mathrm{H}$ & 2.468103 & -5.252152 & 3.754756 \\
\hline$\Omega^{\prime}$ & -6.607828 & 5.885061 & 1.457586 \\
\hline
\end{tabular}




$\begin{array}{rrrr}H & -7.194937 & 5.278011 & 3.444590 \\ H & -5.780489 & 6.292335 & -0.495314 \\ \mathrm{C} & -6.607795 & -5.885093 & -1.457587 \\ \mathrm{H} & -7.194938 & -5.278013 & -3.444572 \\ \mathrm{H} & -5.780424 & -6.292397 & 0.495293 \\ \mathrm{H} & -7.398217 & 6.622909 & 1.363455 \\ \mathrm{H} & -7.398182 & -6.622945 & -1.363455\end{array}$

$\mathrm{M}=\mathrm{Cm}$

$\begin{array}{lrrr}\mathrm{CM} & -0.271666 & 0.000000 & 0.000000 \\ \mathrm{~N} & 1.260873 & -1.685246 & 0.889747 \\ \mathrm{C} & 1.423039 & -1.970976 & 2.189596 \\ \mathrm{~N} & 1.979318 & -2.335996 & -0.036692 \\ \mathrm{C} & 0.570174 & -1.197248 & 3.127957 \\ \mathrm{~N} & 2.281673 & -2.879314 & 2.649209 \\ \mathrm{C} & 2.851342 & -3.266714 & 0.346970 \\ \mathrm{C} & 0.638115 & -1.361708 & 4.509383 \\ \mathrm{~N} & -0.276464 & -0.320432 & 2.541519 \\ \mathrm{C} & 3.021095 & -3.545846 & 1.756299 \\ \mathrm{C} & 3.656370 & -3.956964 & -0.748042 \\ \mathrm{C} & -0.207194 & -0.581794 & 5.310475 \\ \mathrm{H} & 1.332598 & -2.076443 & 4.933941 \\ \mathrm{C} & -1.092389 & 0.429953 & 3.310684 \\ \mathrm{C} & 3.976295 & -4.597922 & 2.282242 \\ \mathrm{C} & 2.744651 & -4.324807 & -1.938175 \\ \mathrm{C} & 4.307696 & -5.240216 & -0.182681 \\ \mathrm{C} & 4.739879 & -2.955116 & -1.229969 \\ \mathrm{C} & -1.082918 & 0.323895 & 4.708466 \\ \mathrm{H} & -0.181487 & -0.680787 & 6.391518 \\ \mathrm{C} & -1.981043 & 1.345746 & 2.579669 \\ \mathrm{C} & 4.969637 & -5.031179 & 1.181129 \\ \mathrm{C} & 4.750629 & -4.051531 & 3.503600 \\ \mathrm{C} & 3.099400 & -5.801255 & 2.741168 \\ \mathrm{H} & 3.334005 & -4.858989 & -2.688275 \\ \mathrm{H} & 1.927747 & -4.984050 & -1.627581 \\ \mathrm{H} & 2.316716 & -3.438053 & -2.411073 \\ \mathrm{H} & 5.050299 & -5.593575 & -0.903606 \\ \mathrm{H} & 3.552032 & -6.030461 & -0.116257 \\ \mathrm{H} & 5.428183 & -2.665916 & -0.431256 \\ \mathrm{H} & 4.276305 & -2.047375 & -1.627771 \\ \mathrm{H} & 5.327887 & -3.416019 & -2.028107 \\ \mathrm{H} & -1.743229 & 0.934420 & 5.313027 \\ \mathrm{C} & -2.942346 & 2.238470 & 3.056965 \\ \mathrm{~N} & -1.911586 & 1.386256 & 1.217794 \\ \mathrm{H} & 5.453573 & -5.957717 & 1.501667\end{array}$




\begin{tabular}{|c|c|c|c|}
\hline $\mathrm{H}$ & 5.769370 & -4.287289 & 1.101533 \\
\hline & 5.454742 & -4.814829 & 3.844986 \\
\hline & 5.327958 & -3.158069 & 3.245778 \\
\hline & 4.083414 & -3.809279 & 4.332369 \\
\hline & 3.753282 & -6.567049 & 3.166255 \\
\hline & 2.542959 & -6.253377 & 1.915615 \\
\hline $\mathrm{H}$ & 2.388189 & -5.492661 & 3.511467 \\
\hline & -3.491992 & 2.865417 & 1.925143 \\
\hline $\mathrm{H}$ & -3.201097 & 2.448463 & 4.082830 \\
\hline & -2.842400 & 2.322228 & 0.860144 \\
\hline H & -3.045697 & 2.497518 & -0.114901 \\
\hline $1 \mathbf{x}$ & 1.260873 & 1.685246 & -0.889747 \\
\hline 0 & 1.423039 & 1.970976 & -2.189596 \\
\hline $\mathrm{N}$ & 1.979318 & 2.335996 & 0.03 \\
\hline $\mathrm{C}$ & 0.570174 & 1.197248 & -3.127957 \\
\hline 10 & 2.281673 & 2.879314 & -2.649209 \\
\hline $\mathrm{C}$ & 2.851342 & 3.266714 & -0.346970 \\
\hline 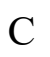 & 0.638115 & 1.361708 & -4.509383 \\
\hline $\mathrm{N}$ & -0.276464 & 0.320432 & -2.541519 \\
\hline $\mathrm{C}$ & 3.021095 & 3.545846 & -1.756299 \\
\hline $\mathrm{C}$ & 3.656370 & 3.956964 & 0.748042 \\
\hline $\mathrm{C}$ & -0.207194 & 0.581794 & -5.310475 \\
\hline $\mathrm{H}$ & 1.332598 & 2.076444 & -4.933941 \\
\hline $\mathrm{C}$ & -1.092389 & -0.429953 & -3.310684 \\
\hline $\mathrm{C}$ & 3.976295 & 4.597922 & -2.282242 \\
\hline $\mathrm{C}$ & 2.744651 & 4.324807 & 1.938175 \\
\hline $\mathrm{C}$ & 4.307696 & 5.240216 & 0.182681 \\
\hline $\mathrm{C}$ & 4.739879 & 2.955116 & 1.229969 \\
\hline $\mathrm{C}$ & -1.082918 & -0.323895 & -4.708466 \\
\hline $\mathrm{H}$ & -0.181487 & 0.680787 & -6.391518 \\
\hline $\mathrm{C}$ & -1.981043 & -1.345746 & -2.579669 \\
\hline $\mathrm{C}$ & 4.969637 & 5.031179 & -1.181129 \\
\hline $\mathrm{C}$ & 4.750628 & 4.051531 & -3.503600 \\
\hline $\mathrm{C}$ & 3.099400 & 5.801255 & -2.741168 \\
\hline $\mathrm{H}$ & 3.334005 & 4.858989 & 2.688275 \\
\hline $\mathrm{H}$ & 1.927747 & 4.984050 & 1.627581 \\
\hline $\mathrm{H}$ & 2.316716 & 3.438052 & 2.411073 \\
\hline $\mathrm{H}$ & 5.050299 & 5.593575 & 0.903606 \\
\hline $\mathrm{H}$ & 3.552032 & 6.030461 & 0.116257 \\
\hline $\mathrm{H}$ & 5.428183 & 2.665916 & 0.431256 \\
\hline $\mathrm{H}$ & 4.276305 & 2.047374 & 1.627771 \\
\hline $\mathrm{H}$ & 5.327887 & 3.416019 & 2.028107 \\
\hline $\mathrm{H}$ & -1.743229 & -0.934420 & -5.313027 \\
\hline . & -2.942346 & -2.238470 & -3.056965 \\
\hline $\mathrm{N}$ & -1.911586 & -1.386256 & -1.217794 \\
\hline I & 5.453573 & 5.957717 & -1.501667 \\
\hline
\end{tabular}




$\begin{array}{lrrr}\mathrm{H} & 5.769370 & 4.287289 & -1.101533 \\ \mathrm{H} & 5.454742 & 4.814829 & -3.844986 \\ \mathrm{H} & 5.327958 & 3.158069 & -3.245778 \\ \mathrm{H} & 4.083414 & 3.809279 & -4.332369 \\ \mathrm{H} & 3.753282 & 6.567049 & -3.166255 \\ \mathrm{H} & 2.542959 & 6.253377 & -1.915615 \\ \mathrm{H} & 2.388189 & 5.492661 & -3.511467 \\ \mathrm{C} & -3.491992 & -2.865417 & -1.925143 \\ \mathrm{H} & -3.201098 & -2.448463 & -4.082830 \\ \mathrm{~N} & -2.842400 & -2.322228 & -0.860144 \\ \mathrm{H} & -3.045697 & -2.497518 & 0.114901 \\ \mathrm{C} & -4.532554 & 3.883158 & 1.806947 \\ \mathrm{C} & -4.612654 & 4.718487 & 0.672977 \\ \mathrm{C} & -5.475498 & 4.033582 & 2.844640 \\ \mathrm{C} & -5.621745 & 5.677641 & 0.576649 \\ \mathrm{H} & -3.868354 & 4.660250 & -0.117533 \\ \mathrm{C} & -6.483358 & 4.993390 & 2.742212 \\ \mathrm{H} & -5.439704 & 3.389031 & 3.717094 \\ \mathrm{C} & -6.560317 & 5.815430 & 1.609786 \\ \mathrm{H} & -5.672092 & 6.327408 & -0.291112 \\ \mathrm{H} & -7.210536 & 5.100476 & 3.540482 \\ \mathrm{H} & -7.342870 & 6.563758 & 1.534820 \\ \mathrm{C} & -4.532554 & -3.883158 & -1.806947 \\ \mathrm{C} & -4.612654 & -4.718487 & -0.672977 \\ \mathrm{C} & -5.475498 & -4.033582 & -2.844640 \\ \mathrm{C} & -5.621745 & -5.677641 & -0.576649 \\ \mathrm{H} & -3.868354 & -4.660250 & 0.117533 \\ \mathrm{C} & -6.483358 & -4.993390 & -2.742212 \\ \mathrm{H} & -5.439704 & -3.389031 & -3.717094 \\ \mathrm{C} & -6.560317 & -5.815431 & -1.609786 \\ \mathrm{H} & -5.672092 & -6.327408 & 0.291112 \\ \mathrm{H} & -7.210536 & -5.100476 & -3.540482 \\ \mathrm{H} & -7.342870 & -6.563758 & -1.534820\end{array}$

$L=2 b e$

\section{$\left[\mathrm{ML}\left(\mathrm{H}_{2} \mathrm{O}\right)_{6}\right]^{3+}$}

$\mathrm{M}=\mathrm{Eu}$

$\begin{array}{lccc}\text { EU } & 1.834540 & -1.090755 & 0.332230 \\ \mathrm{O} & 0.772406 & -2.613160 & 2.226309 \\ \mathrm{O} & 2.090628 & -1.218513 & -2.308100 \\ \mathrm{H} & 0.359362 & -3.487836 & 2.158665 \\ \mathrm{H} & 0.416941 & -2.199842 & 3.028900 \\ \mathrm{O} & 0.200267 & -2.942406 & -0.643160\end{array}$




\begin{tabular}{|c|c|c|c|}
\hline 0 & 1.508054 & 0.129418 & 2.671851 \\
\hline 1 & 2.747570 & -1.815436 & -2.700272 \\
\hline & 1.977307 & -0.499176 & -2.948897 \\
\hline & -0.684467 & -2.582985 & -0.400297 \\
\hline $\mathrm{H}$ & 0.195977 & -3.006454 & -1.611236 \\
\hline & 2.285131 & -0.116348 & 3.202384 \\
\hline $\mathrm{H}$ & 1.210315 & 0.992080 & 2.997232 \\
\hline $\mathbf{N}$ & -1.722323 & -0.974100 & -0.067921 \\
\hline $\mathrm{C}$ & -2.973825 & -0.507042 & -0.048228 \\
\hline $\mathrm{N}$ & -0.678206 & -0.136359 & -0.141129 \\
\hline $\mathrm{C}$ & -3.195464 & 0.911366 & -0.180886 \\
\hline $\mathrm{C}$ & -4.062722 & -1.494712 & 0.157343 \\
\hline $\mathrm{C}$ & -0.916993 & 1.182750 & -0.194902 \\
\hline $\mathrm{C}$ & -4.535158 & 1.533053 & -0.291848 \\
\hline $\mathrm{N}$ & -2.143490 & 1.725915 & -0.225669 \\
\hline $\mathrm{C}$ & -4.102600 & -2.681192 & -0.585144 \\
\hline $\mathrm{C}$ & -5.045682 & -1.234496 & 1.143315 \\
\hline $\mathrm{C}$ & 0.257448 & 2.095609 & -0.279865 \\
\hline $\mathrm{C}$ & -4.740105 & 2.797685 & 0.251240 \\
\hline $\mathrm{C}$ & -5.596028 & 0.887495 & -0.988573 \\
\hline $\mathrm{C}$ & -5.143256 & -3.608930 & -0.353785 \\
\hline $\mathrm{H}$ & -3.363942 & -2.865903 & -1.355205 \\
\hline $\mathrm{C}$ & -6.058076 & -2.177943 & 1.386384 \\
\hline $\mathrm{H}$ & -4.995134 & -0.335842 & 1.747111 \\
\hline $\mathrm{C}$ & 0.059545 & 3.470595 & -0.426056 \\
\hline $\mathrm{N}$ & 1.484007 & 1.526265 & -0.238356 \\
\hline $\mathrm{C}$ & -6.007604 & 3.426351 & 0.144733 \\
\hline $\mathrm{H}$ & -3.950403 & 3.321525 & 0.776512 \\
\hline $\mathrm{C}$ & -6.842417 & 1.522644 & -1.104643 \\
\hline $\mathrm{H}$ & -5.437229 & -0.058257 & -1.490030 \\
\hline $\mathrm{C}$ & -6.118066 & -3.350442 & 0.648991 \\
\hline $\mathrm{O}$ & -5.311684 & -4.757952 & -1.020234 \\
\hline $\mathrm{H}$ & -6.797870 & -1.988999 & 2.157636 \\
\hline $\mathrm{C}$ & 1.182392 & 4.298470 & -0.534729 \\
\hline $\mathrm{H}$ & -0.946062 & 3.868648 & -0.463996 \\
\hline $\mathrm{C}$ & 2.564518 & 2.327537 & -0.345939 \\
\hline $\mathrm{C}$ & -7.067300 & 2.774690 & -0.542386 \\
\hline $\mathrm{O}$ & -6.097506 & 4.625807 & 0.720581 \\
\hline $\mathrm{H}$ & -7.641396 & 1.035412 & -1.654508 \\
\hline $\mathrm{H}$ & -6.897541 & -4.087992 & 0.810454 \\
\hline $\mathrm{C}$ & -4.415813 & -5.127480 & -2.085930 \\
\hline $\mathrm{C}$ & 2.448679 & 3.721768 & -0.496250 \\
\hline $\mathrm{H}$ & 1.069081 & 5.371823 & -0.651713 \\
\hline 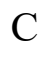 & 3.894297 & 1.691874 & -0.308777 \\
\hline $\mathrm{H}$ & -8.037760 & 3.246537 & -0.641714 \\
\hline$C$ & -7.341867 & 5.374295 & 0.680037 \\
\hline
\end{tabular}




$\begin{array}{lrrr}\mathrm{H} & -4.443105 & -4.382241 & -2.887515 \\ \mathrm{H} & -3.396969 & -5.253778 & -1.704446 \\ \mathrm{H} & -4.789183 & -6.080224 & -2.457638 \\ \mathrm{H} & 3.334182 & 4.340222 & -0.579988 \\ \mathrm{C} & 5.158693 & 2.292090 & -0.493980 \\ \mathrm{~N} & 4.020615 & 0.360845 & -0.086983 \\ \mathrm{H} & -8.135621 & 4.815885 & 1.183566 \\ \mathrm{H} & -7.614131 & 5.598140 & -0.354973 \\ \mathrm{H} & -7.133850 & 6.296198 & 1.219383 \\ \mathrm{C} & 6.070611 & 1.255383 & -0.377302 \\ \mathrm{H} & 5.414600 & 3.321319 & -0.693694 \\ \mathrm{~N} & 5.349907 & 0.128653 & -0.132125 \\ \mathrm{O} & 3.623797 & -1.713888 & 2.435032 \\ \mathrm{H} & 3.415130 & -2.543923 & 2.894263 \\ \mathrm{H} & 4.529718 & -1.488109 & 2.699196 \\ \mathrm{O} & 3.032602 & -3.377938 & -0.339352 \\ \mathrm{H} & 2.395411 & -4.097715 & -0.477420 \\ \mathrm{H} & 3.893207 & -3.808148 & -0.220793 \\ \mathrm{H} & 5.732845 & -0.802601 & -0.026793 \\ \mathrm{C} & 7.558890 & 1.286353 & -0.489457 \\ \mathrm{O} & 8.169889 & 2.307754 & -0.713923 \\ \mathrm{O} & 8.075225 & 0.056034 & -0.308951 \\ \mathrm{C} & 9.536269 & -0.031264 & -0.404385 \\ \mathrm{H} & 9.990208 & 0.604282 & 0.356936 \\ \mathrm{H} & 9.772062 & -1.079984 & -0.233842 \\ \mathrm{H} & 9.856423 & 0.288432 & -1.396784\end{array}$

$\mathrm{M}=\mathrm{Gd}$

$\begin{array}{lrrr}\text { GD } & -1.718333 & -0.913436 & 0.250403 \\ \mathrm{~N} & -1.442333 & 1.585581 & -0.113066 \\ \mathrm{~N} & -3.838185 & 0.354744 & -0.072357 \\ \mathrm{C} & -0.211699 & 2.146884 & -0.136107 \\ \mathrm{C} & -2.525679 & 2.392861 & -0.213875 \\ \mathrm{~N} & 0.632107 & -0.091851 & 0.087100 \\ \mathrm{~N} & -5.145202 & 0.009978 & -0.109353 \\ \mathrm{C} & -3.825752 & 1.708357 & -0.198696 \\ \mathrm{C} & -0.014626 & 3.524541 & -0.247214 \\ \mathrm{C} & 0.935012 & 1.207447 & -0.052088 \\ \mathrm{C} & -2.409431 & 3.783471 & -0.335610 \\ \mathrm{~N} & 1.646313 & -0.987827 & -0.061573 \\ \mathrm{C} & -5.954147 & 1.087990 & -0.253208 \\ \mathrm{H} & -5.438104 & -0.958881 & -0.058261 \\ \mathrm{C} & -5.133603 & 2.209687 & -0.312548 \\ \mathrm{C} & -1.135262 & 4.355452 & -0.349629 \\ \mathrm{H} & 0.994066 & 3.918445 & -0.251347\end{array}$




\begin{tabular}{|c|c|c|c|}
\hline $\mathrm{N}$ & 2.170031 & 1.694282 & -0.094139 \\
\hline 1 & -3.294197 & 4.404353 & -0.417859 \\
\hline 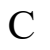 & 2.906474 & -0.585056 & -0.216596 \\
\hline C & -7.448254 & 1.013029 & -0.331896 \\
\hline H & -5.477505 & 3.226769 & -0.428581 \\
\hline & -1.017488 & 5.431171 & -0.440141 \\
\hline $\mathrm{C}$ & 3.207645 & 0.841994 & -0.050763 \\
\hline C & 3.887359 & -1.606888 & -0.623469 \\
\hline $\mathrm{O}$ & -7.864919 & -0.260101 & -0.246303 \\
\hline 0 & -8.127840 & 2.006605 & -0.456186 \\
\hline $\mathrm{C}$ & 4.528298 & 1.397886 & 0.192310 \\
\hline $\mathrm{C}$ & 4.782380 & -1.304468 & -1.663901 \\
\hline $\mathrm{C}$ & 3.862701 & -2.899740 & -0.050956 \\
\hline $\mathrm{C}$ & -9.321231 & -0.452130 & -0.3 \\
\hline $\mathrm{C}$ & 4.730821 & 2.773774 & -0.05 \\
\hline $\mathrm{C}$ & 5.578373 & 0.62 & 0.7 \\
\hline $\mathrm{C}$ & 5.634387 & -2.306917 & -2.146776 \\
\hline $\mathrm{H}$ & 4.808066 & -0.316215 & -2.10 \\
\hline $\mathrm{C}$ & 4.756992 & -3.877717 & -0.510515 \\
\hline $\mathrm{H}$ & 3.196651 & -3.111160 & 0.776794 \\
\hline $\mathrm{H}$ & -9.690901 & -0.073296 & -1.269654 \\
\hline $\mathrm{H}$ & -9.796545 & 0.079093 & 0.5 \\
\hline $\mathrm{H}$ & -9.470981 & -1.526676 & -0.233240 \\
\hline $\mathrm{C}$ & 5.963911 & 3.378933 & 0.224272 \\
\hline $\mathrm{H}$ & 3.945696 & 3.379064 & -0.4 \\
\hline $\mathrm{C}$ & 6.784202 & 1.242042 & 1.066063 \\
\hline $\mathrm{H}$ & 5.446963 & -0.427016 & 0.980454 \\
\hline $\mathrm{C}$ & 5.633262 & -3.575933 & -1.578125 \\
\hline $\mathrm{H}$ & 6.314487 & -2.088072 & -2.963841 \\
\hline $\mathrm{O}$ & 4.867081 & -5.130949 & -0.010330 \\
\hline $\mathrm{C}$ & 6.996666 & 2.601932 & 0.794818 \\
\hline $\mathrm{O}$ & 6.059789 & 4.689519 & -0.082338 \\
\hline $\mathrm{H}$ & 7.585015 & 0.665585 & 1.518257 \\
\hline $\mathrm{H}$ & 6.310593 & -4.350189 & -1.923559 \\
\hline $\mathrm{C}$ & 4.100461 & -5.499268 & 1.139031 \\
\hline $\mathrm{H}$ & 7.958948 & 3.044214 & 1.025255 \\
\hline $\mathrm{C}$ & 7.307265 & 5.376041 & 0.158098 \\
\hline $\mathrm{H}$ & 4.327952 & -4.847202 & 1.990727 \\
\hline $\mathrm{H}$ & 3.024497 & -5.479735 & 0.919957 \\
\hline $\mathrm{H}$ & 4.398153 & -6.519965 & 1.376710 \\
\hline $\mathrm{H}$ & 8.117119 & 4.926665 & -0.425193 \\
\hline $\mathrm{H}$ & 7.553854 & 5.373919 & 1.224597 \\
\hline $\mathrm{H}$ & 7.141752 & 6.399083 & -0.176070 \\
\hline $\mathrm{O}$ & -1.725084 & -0.616227 & -2.261078 \\
\hline $\mathrm{H}$ & -2.014143 & 0.153368 & -2.778161 \\
\hline $\mathrm{U}$ & -1.019758 & -1.046699 & -2.773061 \\
\hline
\end{tabular}




$\begin{array}{rrrr}\mathrm{O} & -1.950065 & 0.221328 & 2.530626 \\ \mathrm{H} & -2.337523 & 1.084799 & 2.748260 \\ \mathrm{H} & -1.247342 & 0.060174 & 3.182710 \\ \mathrm{O} & -0.316691 & -1.968285 & 2.119664 \\ \mathrm{H} & -0.567957 & -2.724132 & 2.674797 \\ \mathrm{H} & 0.645272 & -2.024821 & 1.987914 \\ \mathrm{O} & -0.283500 & -2.597692 & -0.812058 \\ \mathrm{H} & -0.305914 & -3.522970 & -1.097370 \\ \mathrm{H} & 0.665896 & -2.329221 & -0.625813 \\ \mathrm{O} & -3.285769 & -2.561587 & -0.964700 \\ \mathrm{H} & -3.602039 & -3.472488 & -0.854268 \\ \mathrm{H} & -3.332600 & -2.374667 & -1.918084 \\ \mathrm{O} & -3.196978 & -2.175230 & 1.926717 \\ \mathrm{H} & -3.729226 & -2.984589 & 1.981455 \\ \mathrm{H} & -3.385936 & -1.666088 & 2.733328\end{array}$

$\mathrm{M}=\mathrm{Am}$

$\begin{array}{lrrc}\text { AM } & -1.614904 & -0.877565 & 0.371824 \\ \text { N } & -1.295593 & 1.669141 & 0.049937 \\ \text { N } & 0.780011 & -0.033484 & 0.072611 \\ \mathrm{C} & -0.060077 & 2.220920 & 0.089674 \\ \mathrm{C} & -2.368535 & 2.491613 & -0.027251 \\ \mathrm{~N} & -3.724358 & 0.483494 & -0.248798 \\ \mathrm{C} & 1.082592 & 1.272736 & 0.056412 \\ \mathrm{~N} & 1.781890 & -0.912466 & -0.163588 \\ \mathrm{C} & 0.150319 & 3.599719 & 0.116375 \\ \mathrm{C} & -2.237731 & 3.886836 & -0.008280 \\ \mathrm{C} & -3.676239 & 1.838075 & -0.185579 \\ \mathrm{~N} & -5.028227 & 0.185177 & -0.443355 \\ \mathrm{~N} & 2.320859 & 1.757690 & 0.016397 \\ \mathrm{C} & 3.040579 & -0.505214 & -0.310543 \\ \mathrm{C} & -0.962662 & 4.446544 & 0.079361 \\ \mathrm{H} & 1.161539 & 3.984430 & 0.159331 \\ \mathrm{H} & -3.114061 & 4.521546 & -0.070355 \\ \mathrm{C} & -4.961932 & 2.389593 & -0.341686 \\ \mathrm{C} & -5.804148 & 1.296007 & -0.508295 \\ \mathrm{H} & -5.333724 & -0.775834 & -0.549651 \\ \mathrm{C} & 3.351979 & 0.903038 & -0.067707 \\ \mathrm{C} & 4.012439 & -1.512627 & -0.778851 \\ \mathrm{H} & -0.836216 & 5.524761 & 0.101393 \\ \mathrm{H} & -5.276663 & 3.422478 & -0.350864 \\ \mathrm{C} & -7.284711 & 1.276610 & -0.729175 \\ \mathrm{C} & 4.693264 & 1.445682 & 0.119973 \\ \mathrm{C} & 4.866881 & -1.184008 & -1.846464 \\ \mathrm{C} & 4.025524 & -2.808624 & -0.219653\end{array}$




\begin{tabular}{|c|c|c|c|}
\hline & 7.728551 & 0.016867 & \\
\hline & -7.935610 & 2.296530 & \\
\hline & 323 & 2.821142 & \\
\hline & 5.765610 & 0.647502 & 0.605940 \\
\hline & 20041 & -2.166240 & \\
\hline & 4.859092 & -0.190887 & -2.280805 \\
\hline & 4.919680 & -3.767998 & -0.722157 \\
\hline & 3.386695 & -3.038528 & 0.624742 \\
\hline & -9.1 & -0.1 & \\
\hline & 4160 & 791 & \\
\hline & 613 & 3.4 & -0. \\
\hline & 6.998445 & 1.2 & \\
\hline & 5.6 & -0.4 & \\
\hline & 5.7 & -3.4 & -1. \\
\hline & 6.36 & -1.9 & -3 . \\
\hline ) & 5.0 & -5.0 & -0 . \\
\hline & -9.4 & 169 & -2 \\
\hline & -9.7 & 0.3 & -0.2 \\
\hline $\mathrm{H}$ & -9.347389 & -1.15 & -1.1 \\
\hline & 7.212194 & 2.60 & \\
\hline $\mathrm{O}$ & 6.2 & 4.7 & -0.17 \\
\hline & 7.8 & 0.6 & \\
\hline $\mathrm{H}$ & 6.4 & -4.2 & -2 \\
\hline & 4.336039 & -5.4 & 0.9 \\
\hline $\mathrm{H}$ & 8.1 & & \\
\hline & 7.51 & 5.3 & 0.0 \\
\hline $\mathrm{H}$ & 4.5 & -4.7 & 1.7 \\
\hline & 3.254346 & -5.4 & 0.73 \\
\hline $\mathrm{H}$ & 4.654328 & -6.4 & 1.13 \\
\hline & 8.279453 & 426 & -0.634 \\
\hline & 7.821300 & 5.3 & \\
\hline & 7.33 & 6.4 & -0.29 \\
\hline $\mathrm{O}$ & -0.100738 & -2.699778 & -0.40 \\
\hline $\mathrm{H}$ & -0.086333 & -3.55 & -0.84 \\
\hline $\mathrm{H}$ & 0.832813 & -2.314363 & -0.38 \\
\hline $\mathrm{O}$ & -1.585610 & -0.682828 & -2.23 \\
\hline H & -1.974214 & 0.059019 & -2.726 \\
\hline $\mathrm{H}$ & -0.866186 & -1.025766 & -2.79 \\
\hline 0 & -2.833169 & -0.072140 & 2.518587 \\
\hline $\mathrm{H}$ & -3.627733 & 0.478069 & 2.60 \\
\hline $\mathrm{H}$ & -2.327025 & 0.029055 & 3.341612 \\
\hline & -0.274924 & -1.136171 & 2.630541 \\
\hline 11 & -0.376319 & -1.962365 & 3.130381 \\
\hline & 0.599354 & -0.782132 & 2.858295 \\
\hline $\mathrm{O}$ & -2.366103 & -2.971718 & 1.941229 \\
\hline & -2.120896 & -3.910950 & 1.913061 \\
\hline
\end{tabular}




$$
\begin{array}{lrrr}
\mathrm{H} & -3.067543 & -2.897230 & 2.609601 \\
\mathrm{O} & -3.353334 & -2.470348 & -0.812813 \\
\mathrm{H} & -3.694235 & -3.334395 & -0.531743 \\
\mathrm{H} & -3.346060 & -2.475370 & -1.784781
\end{array}
$$

$\mathrm{M}=\mathrm{Cm}$

$\begin{array}{lrrc}\mathrm{CM} & -1.601917 & -0.857813 & 0.254110 \\ \mathrm{~N} & -1.293377 & 1.664695 & -0.121925 \\ \mathrm{~N} & 0.782041 & -0.033325 & 0.076960 \\ \mathrm{C} & -0.056066 & 2.213019 & -0.134266 \\ \mathrm{C} & -2.368327 & 2.482020 & -0.227397 \\ \mathrm{~N} & -3.725706 & 0.465344 & -0.111479 \\ \mathrm{C} & 1.086309 & 1.266403 & -0.055227 \\ \mathrm{~N} & 1.791766 & -0.930848 & -0.087387 \\ \mathrm{C} & 0.154588 & 3.589300 & -0.234673 \\ \mathrm{C} & -2.236472 & 3.872089 & -0.339119 \\ \mathrm{C} & -3.680064 & 1.818555 & -0.231636 \\ \mathrm{~N} & -5.039558 & 0.150657 & -0.171025 \\ \mathrm{~N} & 2.323178 & 1.749477 & -0.097748 \\ \mathrm{C} & 3.051991 & -0.530243 & -0.244975 \\ \mathrm{C} & -0.957119 & 4.431712 & -0.339003 \\ \mathrm{H} & 1.166660 & 3.974194 & -0.230241 \\ \mathrm{H} & -3.113826 & 4.502752 & -0.425146 \\ \mathrm{C} & -4.974577 & 2.349357 & -0.364158 \\ \mathrm{C} & -5.821265 & 1.246578 & -0.323027 \\ \mathrm{H} & -5.354728 & -0.811661 & -0.128283 \\ \mathrm{C} & 3.358281 & 0.893556 & -0.065389 \\ \mathrm{C} & 4.027463 & -1.551576 & -0.666771 \\ \mathrm{H} & -0.828278 & 5.506833 & -0.421219 \\ \mathrm{H} & -5.294124 & 3.374018 & -0.482191 \\ \mathrm{C} & -7.314991 & 1.206753 & -0.426482 \\ \mathrm{C} & 4.681624 & 1.442829 & 0.179774 \\ \mathrm{C} & 4.921070 & -1.242496 & -1.706243 \\ \mathrm{C} & 3.999161 & -2.849816 & -0.106779 \\ \mathrm{O} & -7.762437 & -0.056553 & -0.354154 \\ \mathrm{O} & -7.969309 & 2.216496 & -0.556866 \\ \mathrm{C} & 4.890060 & 2.819313 & -0.054788 \\ \mathrm{C} & 5.729202 & 0.659082 & 0.738675 \\ \mathrm{C} & 5.768425 & -2.243354 & -2.200551 \\ \mathrm{H} & 4.949401 & -0.250079 & -2.140979 \\ \mathrm{C} & 4.888526 & -3.826652 & -0.578030 \\ \mathrm{H} & 3.333389 & -3.066640 & 0.719918 \\ \mathrm{C} & -9.221224 & -0.215020 & -0.448950 \\ \mathrm{C} & 6.126382 & 3.416844 & 0.223820 \\ \mathrm{H} & 4.107238 & 3.431558 & -0.483169\end{array}$




$\begin{array}{crrc}\mathrm{C} & 6.938471 & 1.270108 & 1.047648 \\ \mathrm{H} & 5.593344 & -0.392233 & 0.951526 \\ \mathrm{C} & 5.763751 & -3.517889 & -1.644308 \\ \mathrm{H} & 6.447568 & -2.019148 & -3.016984 \\ \mathrm{O} & 4.994011 & -5.085551 & -0.090530 \\ \mathrm{H} & -9.566405 & 0.176360 & -1.406496 \\ \mathrm{H} & -9.698025 & 0.323099 & 0.371007 \\ \mathrm{H} & -9.396505 & -1.286279 & -0.373683 \\ \mathrm{C} & 7.156675 & 2.631048 & 0.786397 \\ \mathrm{O} & 6.227385 & 4.729442 & -0.073041 \\ \mathrm{H} & 7.737566 & 0.686486 & 1.493686 \\ \mathrm{H} & 6.437276 & -4.291328 & -1.998881 \\ \mathrm{C} & 4.230602 & -5.460749 & 1.058568 \\ \mathrm{H} & 8.121381 & 3.067175 & 1.018320 \\ \mathrm{C} & 7.478489 & 5.408329 & 0.169623 \\ \mathrm{H} & 4.464695 & -4.817484 & 1.915211 \\ \mathrm{H} & 3.153639 & -5.434085 & 0.844633 \\ \mathrm{H} & 4.524351 & -6.484975 & 1.285671 \\ \mathrm{H} & 8.284935 & 4.959625 & -0.418919 \\ \mathrm{H} & 7.727591 & 5.397047 & 1.235495 \\ \mathrm{H} & 7.316994 & 6.434627 & -0.156436 \\ \mathrm{O} & -0.124447 & -2.583407 & -0.802394 \\ \mathrm{H} & -0.127223 & -3.517777 & -1.057721 \\ \mathrm{H} & 0.818216 & -2.289576 & -0.619084 \\ \mathrm{O} & -1.588123 & -0.616152 & -2.317026 \\ \mathrm{H} & -1.859225 & 0.143849 & -2.857911 \\ \mathrm{H} & -0.876182 & -1.065358 & -2.803419 \\ \mathrm{O} & -1.889496 & 0.296796 & 2.583897 \\ \mathrm{H} & -2.288830 & 1.156614 & 2.795238 \\ \mathrm{H} & -1.189877 & 0.146567 & 3.241893 \\ \mathrm{O} & -0.191472 & -1.890388 & 2.200502 \\ \mathrm{H} & -0.458244 & -2.642010 & 2.754364 \\ \mathrm{H} & 0.774207 & -1.944238 & 2.104891 \\ \mathrm{O} & -3.110680 & -2.139891 & 1.972224 \\ \mathrm{H} & -3.637743 & -2.952492 & 2.032793 \\ \mathrm{H} & -3.310971 & -1.620579 & 2.769399 \\ \mathrm{O} & -3.210647 & -2.520288 & -0.986611 \\ \mathrm{H} & -3.544907 & -3.422446 & -0.857716 \\ \mathrm{H} & -3.221780 & -2.362958 & -1.946259\end{array}$

\section{$\left[\mathrm{ML}\left(\mathrm{H}_{2} \mathrm{O}\right)_{5}\right]^{3+}$}

$\mathrm{M}=\mathrm{Eu}$

$\begin{array}{llll}\text { EU } & 1.903132 & -1.096703 & 0.528634\end{array}$

$\begin{array}{llll}\text { O } & 0.618172 & -1.253549 & 2.856383\end{array}$ 


\begin{tabular}{|c|c|c|c|}
\hline $\mathrm{H}$ & -0.000269 & -1.984687 & 3.011387 \\
\hline J & 0.178244 & -3.002973 & 0.389961 \\
\hline & 0.100932 & -3.967295 & 0.411425 \\
\hline & 3.645507 & -3.069952 & 0.382307 \\
\hline & 3.741539 & -3.676345 & -0.369213 \\
\hline & 3.489228 & -0.831411 & 2.617068 \\
\hline$\theta$ & 3.316996 & -1.133393 & 3.522629 \\
\hline & 2.093769 & -1.676064 & -2.000714 \\
\hline H & 2.668709 & -1.185936 & -2.609719 \\
\hline H & 4.125651 & -3.481990 & 1.118253 \\
\hline $\mathrm{H}$ & 1.513125 & -2.214024 & -2.560459 \\
\hline H & 0.528854 & -0.662616 & 3.620230 \\
\hline $\mathrm{H}$ & -0.720708 & -2.614030 & 0.247701 \\
\hline $\mathrm{H}$ & 4.317599 & -0.328354 & 2.657998 \\
\hline$C$ & 0.299978 & 2.043657 & -0.159531 \\
\hline $\mathrm{C}$ & 0.099599 & 3.417815 & -0.309328 \\
\hline $\mathrm{C}$ & 1.219643 & 4.248170 & -0.425818 \\
\hline $\mathrm{C}$ & 2.487340 & 3.672516 & -0.416741 \\
\hline $\mathrm{C}$ & 2.605395 & 2.279713 & -0.268895 \\
\hline $\mathrm{N}$ & 1.528277 & 1.478971 & -0.117612 \\
\hline $\mathrm{H}$ & 1.102699 & 5.321462 & -0.539507 \\
\hline $\mathrm{H}$ & -0.906647 & 3.813871 & -0.347614 \\
\hline $\mathrm{H}$ & 3.370799 & 4.289267 & -0.531165 \\
\hline $\mathrm{C}$ & -0.872585 & 1.126667 & -0.094950 \\
\hline $\mathrm{C}$ & -3.150878 & 0.854574 & -0.165204 \\
\hline $\mathrm{C}$ & -4.486755 & 1.476559 & -0.321926 \\
\hline $\mathrm{C}$ & -2.934692 & -0.562706 & -0.021979 \\
\hline $\mathrm{C}$ & -4.711604 & 2.739080 & 0.216685 \\
\hline $\mathrm{C}$ & -5.522685 & 0.832397 & -1.056921 \\
\hline $\mathrm{C}$ & -4.030171 & -1.552836 & 0.125777 \\
\hline $\mathrm{C}$ & -5.976220 & 3.367076 & 0.067729 \\
\hline $\mathrm{C}$ & -5.053187 & -1.310369 & 1.074624 \\
\hline $\mathrm{C}$ & -6.766194 & 1.465993 & -1.213469 \\
\hline $\mathrm{C}$ & -4.040643 & -2.722157 & -0.645203 \\
\hline $\mathrm{C}$ & -7.011885 & 2.715973 & -0.656643 \\
\hline $\mathrm{C}$ & -6.075973 & -2.256927 & 1.255116 \\
\hline $\mathrm{C}$ & -5.093444 & -3.650630 & -0.479331 \\
\hline $\mathrm{H}$ & -7.978795 & 3.187363 & -0.787876 \\
\hline $\mathrm{C}$ & -6.107070 & -3.412614 & 0.489846 \\
\hline $\mathrm{H}$ & -6.893908 & -4.151460 & 0.602466 \\
\hline $\mathrm{N}$ & -2.098632 & 1.668631 & -0.163843 \\
\hline $\mathrm{N}$ & -0.635623 & -0.192125 & -0.019043 \\
\hline $\mathrm{N}$ & -1.682958 & -1.025804 & 0.032808 \\
\hline $\mathrm{O}$ & -5.240135 & -4.781349 & -1.180908 \\
\hline $\mathrm{O}$ & -6.086354 & 4.564061 & 0.642617 \\
\hline $\mathrm{C}$ & -7.328943 & 5.313810 & 0.563921 \\
\hline
\end{tabular}




$\begin{array}{cccc}\mathrm{H} & -7.137674 & 6.233677 & 1.112765 \\ \mathrm{H} & -7.566505 & 5.540655 & -0.478894 \\ \mathrm{H} & -8.138457 & 4.753718 & 1.039581 \\ \mathrm{C} & -4.314163 & -5.121028 & -2.230731 \\ \mathrm{H} & -4.314017 & -4.350201 & -3.008087 \\ \mathrm{H} & -3.307341 & -5.264357 & -1.824114 \\ \mathrm{H} & -4.679628 & -6.059755 & -2.643648 \\ \mathrm{H} & -3.271236 & -2.888515 & -1.389296 \\ \mathrm{H} & -5.026830 & -0.423947 & 1.697935 \\ \mathrm{H} & -6.846871 & -2.083514 & 1.999096 \\ \mathrm{H} & -5.344938 & -0.110179 & -1.557979 \\ \mathrm{H} & -3.941214 & 3.262835 & 0.770095 \\ \mathrm{H} & -7.544837 & 0.978995 & -1.791976 \\ \mathrm{C} & 3.928008 & 1.629768 & -0.312023 \\ \mathrm{C} & 5.203428 & 2.208483 & -0.482575 \\ \mathrm{C} & 6.086768 & 1.138380 & -0.488275 \\ \mathrm{H} & 5.485247 & 3.244272 & -0.595505 \\ \mathrm{~N} & 4.021744 & 0.280999 & -0.216722 \\ \mathrm{~N} & 5.341146 & 0.013697 & -0.322076 \\ \mathrm{C} & 7.572216 & 1.142959 & -0.648070 \\ \mathrm{O} & 8.201802 & 2.167615 & -0.792866 \\ \mathrm{O} & 8.059186 & -0.110035 & -0.605293 \\ \mathrm{C} & 9.512994 & -0.225286 & -0.762893 \\ \mathrm{H} & 9.722965 & -1.291544 & -0.704732 \\ \mathrm{H} & 9.807771 & 0.182503 & -1.730555 \\ \mathrm{H} & 10.011338 & 0.319916 & 0.039619 \\ \mathrm{H} & 5.685649 & -0.939642 & -0.306954\end{array}$

$\mathrm{M}=\mathrm{Gd}$

$\begin{array}{lccc}\text { GD } & 1.752949 & -0.948225 & 0.127821 \\ \mathrm{O} & 2.761557 & -2.613352 & 1.815815 \\ \mathrm{H} & 2.310461 & -3.419973 & 2.117905 \\ \mathrm{O} & 0.225062 & -2.754580 & 0.077695 \\ \mathrm{H} & 0.157104 & -3.711357 & -0.056427 \\ \mathrm{O} & 3.231956 & -2.618910 & -1.054848 \\ \mathrm{H} & 3.297793 & -2.650381 & -2.024186 \\ \mathrm{O} & 1.481162 & -0.175911 & 2.458890 \\ \mathrm{H} & 1.227419 & 0.715693 & 2.748115 \\ \mathrm{O} & 1.630884 & -0.633556 & -2.353933 \\ \mathrm{H} & 0.879802 & -0.892076 & -2.914233 \\ \mathrm{H} & 3.564064 & -3.470736 & -0.727685 \\ \mathrm{H} & 2.099771 & 0.060196 & -2.847526 \\ \mathrm{H} & 3.570244 & -2.548542 & 2.351855 \\ \mathrm{H} & -0.724356 & -2.337622 & 0.096223 \\ \mathrm{H} & 1.520347 & -0.721118 & 3.261491\end{array}$




\begin{tabular}{|c|c|c|c|}
\hline C & 0.266168 & 2.115286 & 0.037650 \\
\hline $\mathrm{C}$ & 0.083732 & 3.498593 & 0.045052 \\
\hline $\mathrm{C}$ & 1.215013 & 4.322569 & 0.062181 \\
\hline $\mathrm{C}$ & 2.485109 & 3.740204 & 0.058895 \\
\hline $\mathrm{C}$ & 2.589406 & 2.343844 & 0.042576 \\
\hline $\mathrm{H}$ & -0.920991 & 3.902905 & 0.031516 \\
\hline $\mathrm{H}$ & 1.108330 & 5.403295 & 0.070880 \\
\hline $\mathrm{H}$ & 3.374959 & 4.359129 & 0.063064 \\
\hline $\mathrm{N}$ & 1.495261 & 1.544137 & 0.038699 \\
\hline $\mathrm{C}$ & 3.883979 & 1.648708 & 0.001694 \\
\hline $\mathrm{C}$ & 5.192037 & 2.156605 & -0.028082 \\
\hline $\mathrm{N}$ & 3.893303 & 0.287005 & -0.055898 \\
\hline $\mathrm{C}$ & 6.012751 & 1.036176 & -0.112555 \\
\hline $\mathrm{H}$ & 5.537612 & 3.179410 & -0.001677 \\
\hline $\mathrm{N}$ & 5.204332 & -0.050374 & -0.125881 \\
\hline $\mathrm{C}$ & 7.508628 & 0.970292 & -0.187093 \\
\hline $\mathrm{H}$ & 5.503873 & -1.014007 & -0.223533 \\
\hline $\mathrm{O}$ & 8.187757 & 1.971456 & -0.171187 \\
\hline $\mathrm{O}$ & 7.922177 & -0.303211 & -0.269146 \\
\hline $\mathrm{C}$ & 9.379452 & -0.489800 & -0.351086 \\
\hline $\mathrm{H}$ & 9.525225 & -1.566388 & -0.410544 \\
\hline $\mathrm{H}$ & 9.758209 & 0.011348 & -1.242446 \\
\hline $\mathrm{H}$ & 9.847521 & -0.074758 & 0.542104 \\
\hline $\mathrm{C}$ & -0.886400 & 1.177127 & 0.014795 \\
\hline $\mathrm{N}$ & -2.118548 & 1.668256 & 0.019424 \\
\hline $\mathrm{N}$ & -0.582041 & -0.128934 & -0.046179 \\
\hline $\mathrm{C}$ & -3.161746 & 0.816264 & -0.018804 \\
\hline $\mathrm{N}$ & -1.604942 & -1.013405 & 0.052020 \\
\hline $\mathrm{C}$ & -4.480174 & 1.387677 & -0.233198 \\
\hline $\mathrm{C}$ & -2.870932 & -0.614806 & 0.123484 \\
\hline $\mathrm{C}$ & -4.670010 & 2.755585 & 0.064542 \\
\hline $\mathrm{C}$ & -5.541544 & 0.644049 & -0.822208 \\
\hline $\mathrm{C}$ & -3.870754 & -1.661076 & 0.407422 \\
\hline $\mathrm{C}$ & -5.900182 & 3.380284 & -0.176211 \\
\hline $\mathrm{H}$ & -3.876197 & 3.338654 & 0.512872 \\
\hline $\mathrm{C}$ & -6.743834 & 1.284642 & -1.095750 \\
\hline $\mathrm{H}$ & -5.419696 & -0.395882 & -1.089844 \\
\hline $\mathrm{C}$ & -4.785215 & -1.459684 & 1.454085 \\
\hline $\mathrm{C}$ & -3.843848 & -2.881462 & -0.304832 \\
\hline $\mathrm{C}$ & -6.943627 & 2.634089 & -0.768837 \\
\hline $\mathrm{O}$ & -5.983617 & 4.678504 & 0.182394 \\
\hline $\mathrm{H}$ & -7.551562 & 0.733144 & -1.566342 \\
\hline $\mathrm{C}$ & -5.657447 & -2.498969 & 1.805003 \\
\hline $\mathrm{H}$ & -4.811645 & -0.523898 & 2.000601 \\
\hline $\mathrm{C}$ & -4.759917 & -3.892453 & 0.024280 \\
\hline $\mathrm{H}$ & -3.163323 & -3.003637 & -1.139332 \\
\hline
\end{tabular}




$\begin{array}{lrrr}\mathrm{H} & -7.903790 & 3.092759 & -0.974997 \\ \mathrm{C} & -7.226572 & 5.384280 & -0.024561 \\ \mathrm{C} & -5.655756 & -3.698283 & 1.100045 \\ \mathrm{H} & -6.354178 & -2.363133 & 2.626085 \\ \mathrm{O} & -4.871421 & -5.080480 & -0.614955 \\ \mathrm{H} & -7.050373 & 6.392332 & 0.347529 \\ \mathrm{H} & -7.478730 & 5.425103 & -1.088945 \\ \mathrm{H} & -8.037106 & 4.919802 & 0.545777 \\ \mathrm{H} & -6.348616 & -4.496950 & 1.344170 \\ \mathrm{C} & -4.088846 & -5.323292 & -1.787649 \\ \mathrm{H} & -4.293667 & -4.574170 & -2.561311 \\ \mathrm{H} & -3.016611 & -5.341933 & -1.551565 \\ \mathrm{H} & -4.393122 & -6.305977 & -2.146245\end{array}$

$\mathrm{M}=\mathrm{Am}$

$\begin{array}{lrrr}\text { AM } & 1.679671 & -0.937412 & 0.185877 \\ \mathrm{O} & 2.246190 & -2.719664 & 2.075992 \\ \mathrm{H} & 1.629710 & -3.447620 & 2.261590 \\ \mathrm{O} & 0.046212 & -2.813700 & -0.012459 \\ \mathrm{H} & -0.038795 & -3.753308 & -0.230890 \\ \mathrm{O} & 3.481073 & -2.633869 & -0.664780 \\ \mathrm{H} & 3.699390 & -2.734535 & -1.606416 \\ \mathrm{O} & 1.452718 & 0.045465 & 2.531255 \\ \mathrm{H} & 1.408975 & 0.982866 & 2.779838 \\ \mathrm{O} & 1.710661 & -0.919232 & -2.405487 \\ \mathrm{H} & 1.089472 & -1.381560 & -2.991983 \\ \mathrm{H} & 3.718468 & -3.474128 & -0.239576 \\ \mathrm{H} & 2.119586 & -0.226482 & -2.950397 \\ \mathrm{H} & 2.964220 & -2.807480 & 2.724859 \\ \mathrm{H} & -0.873496 & -2.390121 & 0.008702 \\ \mathrm{H} & 1.393783 & -0.458095 & 3.359060 \\ \mathrm{C} & 0.121558 & 2.173809 & -0.180764 \\ \mathrm{C} & -0.087734 & 3.548640 & -0.294929 \\ \mathrm{C} & 1.027223 & 4.391612 & -0.365693 \\ \mathrm{C} & 2.304914 & 3.832973 & -0.324195 \\ \mathrm{C} & 2.434836 & 2.441634 & -0.210636 \\ \mathrm{H} & -1.098967 & 3.933466 & -0.334570 \\ \mathrm{H} & 0.900668 & 5.466247 & -0.456358 \\ \mathrm{H} & 3.183719 & 4.464633 & -0.382117 \\ \mathrm{~N} & 1.358202 & 1.624194 & -0.137651 \\ \mathrm{C} & -1.026508 & 1.230240 & -0.119240 \\ \mathrm{~N} & -2.261227 & 1.731199 & -0.127849 \\ \mathrm{~N} & -0.736244 & -0.078257 & -0.099191 \\ \mathrm{C} & -3.302407 & 0.887572 & -0.090899 \\ \mathrm{~N} & -1.762158 & -0.950061 & 0.011327\end{array}$




\begin{tabular}{|c|c|c|c|}
\hline $\mathrm{C}$ & -4.638800 & 1.469750 & -0.232730 \\
\hline & -3.024943 & -0.534449 & 0061370 \\
\hline $\mathrm{C}$ & -4.834703 & 2.799966 & 0.170442 \\
\hline C & -5.708194 & 0.755412 & -0.842165 \\
\hline $\mathrm{C}$ & -4.050018 & -1.568348 & 0.325247 \\
\hline $\mathrm{C}$ & -6.088263 & 3.419187 & 0.014286 \\
\hline $\mathrm{H}$ & -4.035848 & 3.366330 & 0.63 \\
\hline $\mathrm{C}$ & -6.936247 & 1.389672 & -1.026586 \\
\hline $\mathrm{H}$ & -5.573121 & -0.254666 & -1.203622 \\
\hline $\mathrm{C}$ & -4.956389 & -1.374154 & 1.383 \\
\hline $\mathrm{C}$ & -4.071752 & -2.755729 & -0.433061 \\
\hline $\mathrm{C}$ & -7.146427 & 2.703134 & -0.596399 \\
\hline $\mathrm{O}$ & -6.175244 & 4.681686 & 0.468000 \\
\hline $\mathrm{H}$ & -7.747617 & 0.856865 & -1.5 \\
\hline $\mathrm{C}$ & -5.871693 & -2.389889 & 1.695820 \\
\hline $\mathrm{H}$ & -4.939007 & -0.463318 & \\
\hline $\mathrm{C}$ & -5.027323 & -3.745270 & -0.138207 \\
\hline $\mathrm{H}$ & -3.394389 & -2.874990 & -1.270 \\
\hline $\mathrm{H}$ & -8.117574 & 3.162933 & -0.737762 \\
\hline $\mathrm{C}$ & -7.427916 & 5.396997 & 0.357076 \\
\hline $\mathrm{C}$ & -5.917377 & -3.559482 & 0.946281 \\
\hline $\mathrm{H}$ & -6.560530 & -2.258094 & 2.52 \\
\hline $\mathrm{O}$ & -5.183056 & -4.900441 & -0.8 \\
\hline $\mathrm{H}$ & -7.238740 & 6.374464 & 0.797 \\
\hline $\mathrm{H}$ & -7.713572 & 5.513143 & -0.692741 \\
\hline $\mathrm{H}$ & -8.214878 & 4.884724 & 0.918625 \\
\hline $\mathrm{H}$ & -6.638103 & -4.341709 & 1.161045 \\
\hline $\mathrm{C}$ & -4.399960 & -5.145421 & -1.993935 \\
\hline $\mathrm{H}$ & -4.567811 & -4.367232 & -2.746955 \\
\hline $\mathrm{H}$ & -3.332933 & -5.215059 & -1.747631 \\
\hline $\mathrm{H}$ & -4.743435 & -6.104342 & -2.379767 \\
\hline $\mathrm{C}$ & 3.750478 & 1.786101 & -0.172821 \\
\hline $\mathrm{C}$ & 5.041899 & 2.336970 & -0.233967 \\
\hline $\mathrm{N}$ & 3.809402 & 0.431860 & -0.078466 \\
\hline $\mathrm{C}$ & 5.902240 & 1.246030 & -0.173730 \\
\hline $\mathrm{H}$ & 5.352474 & 3.367932 & -0.314005 \\
\hline $\mathrm{N}$ & 5.130052 & 0.136786 & -0.082151 \\
\hline $\mathrm{C}$ & 7.399046 & 1.227628 & -0.202943 \\
\hline $\mathrm{H}$ & 5.457132 & -0.821760 & -0.038848 \\
\hline $\mathrm{O}$ & 8.046450 & 2.247356 & -0.281741 \\
\hline $\mathrm{O}$ & 7.859660 & -0.031270 & -0.131470 \\
\hline $\mathrm{C}$ & 9.322658 & -0.169437 & -0.150875 \\
\hline $\mathrm{H}$ & 9.508367 & -1.239611 & -0.085484 \\
\hline-7 & 9.713551 & 0.244111 & -1.081193 \\
\hline H & 9.747909 & 0.358999 & 0.70306 \\
\hline
\end{tabular}




\begin{tabular}{|c|c|c|c|}
\hline & 1.634003 & -0.886730 & \\
\hline $\mathrm{O}$ & 2.459236 & -2.630466 & 1.952307 \\
\hline $\mathrm{H}$ & 1.913943 & -3.394088 & 2.207372 \\
\hline $\mathrm{O}$ & 0.061880 & -2.742000 & 0.0 \\
\hline $\mathrm{H}$ & -0.018485 & -3.690069 & -0.1 \\
\hline $\mathrm{O}$ & 3.240720 & -2.602377 & -0.9 \\
\hline $\mathrm{H}$ & 3.362041 & -2.67 & -1.8 \\
\hline $\mathrm{O}$ & 1.368900 & $-0.03 \mathrm{C}$ & 2.5 \\
\hline $\mathrm{H}$ & 1.161505 & 0.866613 & 2.7 \\
\hline $\mathrm{O}$ & 1.574401 & -0.67 & -2.3 \\
\hline $\mathrm{H}$ & 0.85 & -0.9 & -2.5 \\
\hline $\mathrm{H}$ & 3.5 & -3.4 & -0. \\
\hline $\mathrm{H}$ & 2.02 & 0.0 & -2.8 \\
\hline $\mathrm{H}$ & 3.2 & -2.6 & \\
\hline $\mathrm{H}$ & -0.87 & -2.3 & 0.0 \\
\hline $\mathrm{H}$ & & -0.5 & \\
\hline $\mathrm{C}$ & 0.10 & 2.1 & -0.0 \\
\hline $\mathrm{C}$ & -0.0 & 3.5 & $-0 .($ \\
\hline $\mathrm{C}$ & 1.0 & 4.4 & $-0 .($ \\
\hline $\mathrm{C}$ & & & \\
\hline $\mathrm{C}$ & 2.4 & 2.4 & -0. \\
\hline $\mathrm{H}$ & -1.10 & 3.9 & \\
\hline $\mathrm{H}$ & 0.9 & 5.4 & -0. \\
\hline $\mathrm{H}$ & 3.18 & 4.4 & -0. \\
\hline $\mathrm{N}$ & 1.3 & 1.6 & -0. \\
\hline $\mathrm{C}$ & 3.73 & 1.7 & -0.0 \\
\hline $\mathrm{C}$ & 5.0 & 2.3 & -0.1 \\
\hline $\mathrm{N}$ & & 0.4 & \\
\hline $\mathrm{C}$ & & & \\
\hline $\mathrm{H}$ & & 3.3 & -0. \\
\hline $\mathrm{N}$ & 5.09 & 0.1 & \\
\hline $\mathrm{C}$ & 7.3 & 1.1 & -0.2 \\
\hline $\mathrm{H}$ & 5.41 & -0.8 & \\
\hline $\mathrm{O}$ & 8.0 & 2.1 & -0.2 \\
\hline $\mathrm{O}$ & & -0.0 & -0.2 \\
\hline $\mathrm{C}$ & $9.2^{\prime}$ & -0.2 & -0.3 \\
\hline $\mathrm{H}$ & 9.447064 & -1.32 & -0.403258 \\
\hline $\mathrm{H}$ & 9.64 & 0.23 & -1.27 \\
\hline $\mathrm{H}$ & 9.73 & 0.19 & 0.51 \\
\hline $\mathrm{C}$ & -1.0 & 1.2 & -0.0 \\
\hline $\mathrm{N}$ & -2.271551 & 1.727626 & -0.004357 \\
\hline $\mathrm{N}$ & -0.729195 & -0.06 & -0.0 \\
\hline $\mathrm{C}$ & -3.312646 & 0.872426 & -0.034199 \\
\hline $\mathrm{N}$ & -1.749416 & -0.953063 & 0.032383 \\
\hline
\end{tabular}




$\begin{array}{lrrr}\mathrm{C} & -4.635161 & 1.442154 & -0.230236 \\ \mathrm{C} & -3.016279 & -0.557567 & 0.097814 \\ \mathrm{C} & -4.827113 & 2.805044 & 0.087921 \\ \mathrm{C} & -5.699651 & 0.702710 & -0.818478 \\ \mathrm{C} & -4.013830 & -1.612033 & 0.364508 \\ \mathrm{C} & -6.061838 & 3.428378 & -0.132136 \\ \mathrm{H} & -4.031177 & 3.385187 & 0.536455 \\ \mathrm{C} & -6.906806 & 1.342521 & -1.071800 \\ \mathrm{H} & -5.576487 & -0.332831 & -1.101983 \\ \mathrm{C} & -4.921349 & -1.437627 & 1.421478 \\ \mathrm{C} & -3.991208 & -2.813379 & -0.379083 \\ \mathrm{C} & -7.108364 & 2.686588 & -0.724619 \\ \mathrm{O} & -6.146272 & 4.721477 & 0.245033 \\ \mathrm{H} & -7.716968 & 0.794452 & -1.542235 \\ \mathrm{C} & -5.791650 & -2.485766 & 1.750675 \\ \mathrm{H} & -4.944809 & -0.515736 & 1.991498 \\ \mathrm{C} & -4.905065 & -3.833005 & -0.070215 \\ \mathrm{H} & -3.315988 & -2.913552 & -1.220977 \\ \mathrm{H} & -8.072062 & 3.144465 & -0.915363 \\ \mathrm{C} & -7.393716 & 5.425180 & 0.059948 \\ \mathrm{C} & -5.794259 & -3.666740 & 1.015345 \\ \mathrm{H} & -6.483629 & -2.371005 & 2.579003 \\ \mathrm{O} & -5.019271 & -5.004711 & -0.738994 \\ \mathrm{H} & -7.217637 & 6.428767 & 0.443982 \\ \mathrm{H} & -7.656599 & 5.479526 & -1.001241 \\ \mathrm{H} & -8.196900 & 4.949897 & 0.631826 \\ \mathrm{H} & -6.485661 & -4.471442 & 1.243171 \\ \mathrm{C} & -4.247045 & -5.214771 & -1.924726 \\ \mathrm{H} & -4.459170 & -4.445107 & -2.675954 \\ \mathrm{H} & -3.172575 & -5.238786 & -1.699037 \\ \mathrm{H} & -4.553651 & -6.187663 & -2.307203\end{array}$

\section{$\left[\mathrm{ML}_{2}\left(\mathrm{H}_{2} \mathrm{O}\right)_{2}\right]^{3+}$}

$\mathrm{M}=\mathrm{Eu}$

$\begin{array}{lrrr}\text { EU } & -0.000021 & -0.649373 & 0.000019 \\ \mathrm{O} & -0.465006 & 1.082809 & 1.756236 \\ \mathrm{H} & -1.393645 & 1.415433 & 1.628165 \\ \mathrm{O} & 0.464947 & 1.083335 & -1.755625 \\ \mathrm{H} & 1.393738 & 1.415592 & -1.627693 \\ \mathrm{H} & -0.032077 & 1.626369 & 2.427532 \\ \mathrm{H} & 0.032492 & 1.626641 & -2.427426 \\ \mathrm{C} & 2.854699 & -1.105044 & 2.113001 \\ \mathrm{C} & 3.675910 & -1.519704 & 3.164426 \\ \mathrm{C} & 3.192287 & -2.493065 & 4.044539\end{array}$




$\begin{array}{lccc}\mathrm{C} & 1.917720 & -3.016368 & 3.837961 \\ \mathrm{C} & 1.155636 & -2.551010 & 2.753486 \\ \mathrm{~N} & 1.617106 & -1.607589 & 1.905291 \\ \mathrm{H} & 3.800785 & -2.837634 & 4.874970 \\ \mathrm{H} & 4.662419 & -1.088285 & 3.274538 \\ \mathrm{H} & 1.519104 & -3.771009 & 4.505343 \\ \mathrm{C} & 3.335903 & -0.071277 & 1.152453 \\ \mathrm{C} & 5.008653 & 1.354330 & 0.476967 \\ \mathrm{C} & 6.407993 & 1.790098 & 0.628692 \\ \mathrm{C} & 4.100192 & 1.839249 & -0.541086 \\ \mathrm{C} & 6.979189 & 1.771543 & 1.907226 \\ \mathrm{C} & 7.201461 & 2.151602 & -0.490188 \\ \mathrm{C} & 4.366263 & 2.995486 & -1.428350 \\ \mathrm{C} & 8.323814 & 2.145231 & 2.096164 \\ \mathrm{C} & 4.808973 & 4.209076 & -0.871079 \\ \mathrm{C} & 8.541867 & 2.490042 & -0.297178 \\ \mathrm{C} & 4.122754 & 2.888159 & -2.810004 \\ \mathrm{C} & 9.111232 & 2.503926 & 0.979343 \\ \mathrm{C} & 4.991833 & 5.321698 & -1.704896 \\ \mathrm{C} & 4.345855 & 4.001285 & -3.639849 \\ \mathrm{H} & 10.150393 & 2.786205 & 1.099054 \\ \mathrm{C} & 4.771454 & 5.226160 & -3.074202 \\ \mathrm{H} & 4.929014 & 6.072740 & -3.734193 \\ \mathrm{~N} & 4.561671 & 0.434192 & 1.335184 \\ \mathrm{~N} & 2.521002 & 0.264020 & 0.143684 \\ \mathrm{C} & -0.880799 & -4.120173 & 3.164756 \\ \mathrm{H} & 2.912746 & 1.250468 & -0.679771 \\ \mathrm{O} & 4.184949 & 4.009753 & -4.982414 \\ \mathrm{O} & 8.759177 & 2.122069 & 3.372186 \\ \mathrm{C} & 10.122874 & 2.497047 & 3.660136 \\ \mathrm{H} & 10.224746 & 2.405600 & 4.740367 \\ \mathrm{H} & 10.824121 & 1.818375 & 3.164518 \\ \mathrm{H} & 10.311878 & 3.531878 & 3.358074 \\ \mathrm{C} & 3.835060 & 2.795633 & -5.658601 \\ \mathrm{H} & 4.591757 & 2.021048 & -5.490603 \\ \mathrm{H} & 2.848802 & 2.437312 & -5.339754 \\ \mathrm{H} & 3.803511 & 3.049366 & -6.717518 \\ \mathrm{H} & 3.803288 & 1.940817 & -3.226975 \\ \mathrm{H} & 4.989155 & 4.296699 & 0.194239 \\ \mathrm{H} & 6.316828 & 6.266034 & -1.279971 \\ \mathrm{H} & -0.159296 & 2.134020 & -1.492813 \\ \mathrm{H} & -4.727568 & 4.001635\end{array}$




\begin{tabular}{|c|c|c|c|}
\hline $\mathrm{N}$ & -0.942616 & -2.587736 & 186 \\
\hline & -2.086607 & -3.297721 & 1.514380 \\
\hline & -3.226758 & -5.162427 & 2.763896 \\
\hline ) & -3.207185 & -5.978338 & 3.660102 \\
\hline D & -4.227206 & -4.962528 & 1.882177 \\
\hline C & -5.385017 & -5.841564 & 2.044798 \\
\hline 1 & -6.081852 & -5.546311 & 1.262306 \\
\hline $\mathrm{H}$ & -5.076654 & -6.880987 & 1.924132 \\
\hline $\mathrm{H}$ & -5.820276 & -5.697292 & 671 \\
\hline C & -2.854728 & -1.105003 & -2.113040 \\
\hline $\mathrm{C}$ & -3.675967 & -1.519662 & -3.164444 \\
\hline C & -3.192380 & -2.493037 & -4.044555 \\
\hline $\mathrm{C}$ & -1.917817 & -3.016348 & -3.8 \\
\hline$C$ & -1.155707 & -2.550983 & -2.753543 \\
\hline $\mathrm{N}$ & -1.617131 & -1.607554 & -1.9 \\
\hline Н & -3.800898 & -2.83 & -4.8 \\
\hline H & -4.662474 & -1.088231 & -3.274539 \\
\hline $\mathrm{H}$ & -1.519219 & -3.77 & -4.50 \\
\hline $\mathrm{C}$ & -3.335914 & -0.071242 & -1.152491 \\
\hline $\mathrm{C}$ & -5.008638 & 1.35 & -0.476982 \\
\hline $\mathrm{C}$ & -6.407973 & 1.790176 & -0.628700 \\
\hline $\mathrm{C}$ & -4.100172 & 1.839263 & 0.54 \\
\hline $\mathrm{C}$ & -6.979160 & 1.771681 & -1.90 \\
\hline $\mathrm{C}$ & -7.201443 & 2.151641 & 0.4 \\
\hline $\mathrm{C}$ & -4.366223 & 2.995 & 1.42 \\
\hline T & -8.323780 & 2.145395 & -2.096169 \\
\hline $\mathrm{C}$ & -4.809012 & 4.209065 & 0.871125 \\
\hline $\mathrm{C}$ & -8.541844 & 2.490106 & 0.297186 \\
\hline $\mathrm{C}$ & -4.122610 & 2.888172 & 2.810002 \\
\hline 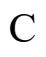 & -9.111201 & 2.504053 & -0.979338 \\
\hline $\mathrm{C}$ & -4.991844 & 5.321684 & 1.704952 \\
\hline $\mathrm{C}$ & -4.345681 & 4.001294 & 3.63 \\
\hline $\mathrm{H}$ & -10.150357 & 2.786349 & -1.099044 \\
\hline $\mathrm{C}$ & -4.771363 & 5.226156 & 3.074242 \\
\hline $\mathrm{H}$ & -4.928898 & 6.072733 & 3.734242 \\
\hline $\mathrm{N}$ & -4.561675 & 0.434249 & -1.335213 \\
\hline $\mathrm{N}$ & -2.521011 & 0.264022 & -0.143722 \\
\hline $\mathrm{N}$ & -2.912738 & 1.250450 & 0.679760 \\
\hline $\mathrm{O}$ & -4.184674 & 4.009773 & 4.982409 \\
\hline $\mathrm{O}$ & -8.759135 & 2.122293 & -3.372195 \\
\hline $\mathrm{C}$ & -10.122824 & 2.497302 & -3.660138 \\
\hline . & -10.224689 & 2.405903 & -4.740374 \\
\hline $\mathrm{H}$ & -10.824084 & 1.818618 & -3.164555 \\
\hline 1 & -10.311816 & 3.532122 & -3.358033 \\
\hline $\mathrm{C}$ & -3.834655 & 2.795674 & 5.658573 \\
\hline $\mathrm{H}$ & -4.591331 & 2.021051 & 5.490652 \\
\hline
\end{tabular}




$\begin{array}{lrrr}\mathrm{H} & -2.848411 & 2.437402 & 5.339631 \\ \mathrm{H} & -3.803019 & 3.049418 & 6.717484 \\ \mathrm{H} & -3.803080 & 1.940843 & 3.226954 \\ \mathrm{H} & -4.989268 & 4.296682 & -0.194180 \\ \mathrm{H} & -5.316898 & 6.266009 & 1.280047 \\ \mathrm{H} & -6.795285 & 2.134007 & 1.492817 \\ \mathrm{H} & -6.394954 & 1.491334 & -2.775109 \\ \mathrm{H} & -9.157805 & 2.748301 & 1.152784 \\ \mathrm{C} & 0.192316 & -3.086346 & -2.495533 \\ \mathrm{C} & 0.880654 & -4.120220 & -3.164766 \\ \mathrm{C} & 2.094861 & -4.229284 & -2.504116 \\ \mathrm{H} & 0.572258 & -4.727708 & -4.001557 \\ \mathrm{~N} & 0.942575 & -2.587579 & -1.485379 \\ \mathrm{~N} & 2.086554 & -3.297590 & -1.514560 \\ \mathrm{C} & 3.226626 & -5.162444 & -2.763924 \\ \mathrm{O} & 3.206994 & -5.978464 & -3.660029 \\ \mathrm{O} & 4.227130 & -4.962439 & -1.882293 \\ \mathrm{C} & 5.384935 & -5.841490 & -2.044887 \\ \mathrm{H} & 6.081821 & -5.546139 & -1.262478 \\ \mathrm{H} & 5.076585 & -6.880900 & -1.924077 \\ \mathrm{H} & 5.820126 & -5.697333 & -3.034807 \\ \mathrm{H} & 2.826294 & -3.130724 & -0.843954 \\ \mathrm{H} & -2.826298 & -3.130944 & 0.843697\end{array}$

$\mathrm{M}=\mathrm{Gd}$

$\begin{array}{lrrr}\text { GD } & -0.000002 & 0.677392 & 0.000094 \\ \mathrm{O} & -0.396096 & -0.978563 & -1.685738 \\ \mathrm{H} & -1.326079 & -1.352351 & -1.560039 \\ \mathrm{O} & 0.395701 & -0.979810 & 1.684775 \\ \mathrm{H} & 1.325736 & -1.353543 & 1.559155 \\ \mathrm{H} & 0.083766 & -1.511746 & -2.333991 \\ \mathrm{H} & -0.084123 & -1.512700 & 2.333296 \\ \mathrm{C} & 2.724097 & 1.149811 & -2.085169 \\ \mathrm{C} & 3.523309 & 1.593032 & -3.140437 \\ \mathrm{C} & 3.011372 & 2.569741 & -4.001238 \\ \mathrm{C} & 1.728008 & 3.068457 & -3.776195 \\ \mathrm{C} & 0.987895 & 2.575200 & -2.692587 \\ \mathrm{~N} & 1.479367 & 1.630738 & -1.859466 \\ \mathrm{H} & 3.604217 & 2.935479 & -4.834112 \\ \mathrm{H} & 4.514956 & 1.177300 & -3.267735 \\ \mathrm{H} & 1.307729 & 3.823667 & -4.429861 \\ \mathrm{C} & 3.213397 & 0.112334 & -1.137497 \\ \mathrm{C} & 4.882111 & -1.319018 & -0.455095 \\ \mathrm{C} & 6.286278 & -1.709416 & -0.566360 \\ \mathrm{C} & 3.940106 & -1.838573 & 0.531588\end{array}$




\begin{tabular}{|c|c|c|c|}
\hline $\mathrm{C}$ & 6.927507 & -1.537999 & -1.809233 \\
\hline & 7.032631 & -2.162547 & 0.551986 \\
\hline 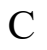 & 4.157134 & -3.035687 & 1.370578 \\
\hline $\mathrm{C}$ & 8.286164 & -1.846238 & -1.964719 \\
\hline $\mathrm{C}$ & 4.592614 & -4.227185 & 0.770962 \\
\hline $\mathrm{C}$ & 8.389331 & -2.427000 & 0.396122 \\
\hline $\mathrm{C}$ & 3.847329 & -2.991907 & 2.747341 \\
\hline $\mathrm{C}$ & 9.023024 & -2.289155 & -0.847062 \\
\hline $\mathrm{C}$ & 4.697542 & -5.384493 & 1.553992 \\
\hline $\mathrm{C}$ & 4.000252 & -4.148180 & 3.526989 \\
\hline $\mathrm{H}$ & 10.076388 & -2.527539 & -0.935424 \\
\hline $\mathrm{C}$ & 4.414065 & -5.351689 & 2.916162 \\
\hline $\mathrm{H}$ & 4.518771 & -6.236268 & 3.535647 \\
\hline $\mathrm{N}$ & 4.435257 & -0.388618 & -1.312840 \\
\hline $\mathrm{N}$ & 2.388845 & -0.220921 & -0.136208 \\
\hline $\mathrm{N}$ & 2.762807 & -1.235693 & 0.670467 \\
\hline $\mathrm{O}$ & 3.777196 & -4.218953 & 4.863633 \\
\hline $\mathrm{O}$ & 8.788697 & -1.680222 & -3.210661 \\
\hline $\mathrm{C}$ & 10.175101 & -1.994849 & -3.446332 \\
\hline $\mathrm{H}$ & 10.340993 & -1.798291 & -4.504697 \\
\hline $\mathrm{H}$ & 10.829690 & -1.352705 & -2.847830 \\
\hline $\mathrm{H}$ & 10.377999 & -3.049636 & -3.234134 \\
\hline $\mathrm{C}$ & 3.458040 & -3.022965 & 5.579489 \\
\hline $\mathrm{H}$ & 4.252413 & -2.274734 & 5.473902 \\
\hline $\mathrm{H}$ & 2.499714 & -2.603800 & 5.246316 \\
\hline $\mathrm{H}$ & 3.376565 & -3.318400 & 6.625136 \\
\hline $\mathrm{H}$ & 3.541681 & -2.055568 & 3.198683 \\
\hline $\mathrm{H}$ & 4.834004 & -4.264135 & -0.285165 \\
\hline $\mathrm{H}$ & 5.016691 & -6.316165 & 1.097668 \\
\hline $\mathrm{H}$ & 6.573838 & -2.279585 & 1.524066 \\
\hline $\mathrm{H}$ & 6.375112 & -1.191910 & -2.673569 \\
\hline $\mathrm{H}$ & 8.973685 & -2.754402 & 1.250256 \\
\hline $\mathrm{C}$ & -0.371095 & 3.053098 & -2.401068 \\
\hline $\mathrm{C}$ & -1.138589 & 4.045801 & -3.037964 \\
\hline $\mathrm{C}$ & -2.337034 & 4.076286 & -2.337467 \\
\hline $\mathrm{H}$ & -0.893841 & 4.673622 & -3.881124 \\
\hline $\mathrm{N}$ & -1.058420 & 2.503397 & -1.369592 \\
\hline $\mathrm{N}$ & -2.245621 & 3.143507 & -1.356297 \\
\hline $\mathrm{C}$ & -3.533070 & 4.941395 & -2.560637 \\
\hline $\mathrm{O}$ & -3.580156 & 5.760191 & -3.452007 \\
\hline $\mathrm{O}$ & -4.493290 & 4.673395 & -1.656319 \\
\hline $\mathrm{C}$ & -5.712838 & 5.475675 & -1.783753 \\
\hline $\mathrm{H}$ & -6.367952 & 5.129071 & -0.986692 \\
\hline 14 & -5.469531 & 6.532026 & -1.662547 \\
\hline $\mathrm{H}$ & -6.160748 & 5.307168 & -2.763930 \\
\hline $\mathrm{C}$ & -2.723757 & 1.148906 & 2.085964 \\
\hline
\end{tabular}




\begin{tabular}{|c|c|c|c|}
\hline $\mathrm{C}$ & -3.522775 & 1.591593 & 3.141603 \\
\hline & -3.010682 & 2.567863 & 4.002806 \\
\hline & -1.727369 & 3.066714 & 3.777771 \\
\hline & -0.987453 & 2.574001 & 2.693783 \\
\hline & -1.479055 & 1.629933 & 1.860294 \\
\hline & -3.603378 & 2.933180 & 4.835971 \\
\hline H & -4.514407 & 1.175811 & 3.268861 \\
\hline 1 & -1.306983 & 3.821617 & 4.431724 \\
\hline $\mathrm{C}$ & -3.213261 & 0.111976 & 1.137799 \\
\hline $\mathrm{C}$ & -4.882119 & -1.318967 & 0.454906 \\
\hline C & -6.286280 & -1.709383 & 0.566188 \\
\hline $\mathrm{C}$ & -3.940301 & -1.837978 & -0.532242 \\
\hline C & -6.927305 & -1.538616 & 1.809256 \\
\hline $\mathrm{C}$ & -7.032826 & -2.161891 & -0.552282 \\
\hline C & -4.157484 & -3.034635 & -1.371843 \\
\hline $\mathrm{C}$ & -8.285948 & -1.846891 & 1.964792 \\
\hline $\mathrm{C}$ & -4.592883 & -4.226454 & -0.772807 \\
\hline $\mathrm{C}$ & -8.389509 & -2.426390 & -0.396342 \\
\hline $\mathrm{C}$ & -3.847900 & -2.990109 & -2.748632 \\
\hline $\mathrm{C}$ & -9.023000 & -2.289191 & 0.847016 \\
\hline $\mathrm{C}$ & -4.697954 & -5.383333 & -1.556452 \\
\hline $\mathrm{C}$ & -4.000962 & -4.14 & -3.528887 \\
\hline $\mathrm{H}$ & -10.076357 & -2.527589 & 0.935418 \\
\hline $\mathrm{C}$ & -4.414694 & -5.349791 & -2.918650 \\
\hline $\mathrm{H}$ & -4.519512 & -6.234030 & -3.538600 \\
\hline $\mathrm{N}$ & -4.435082 & -0.389076 & 1.313109 \\
\hline $\mathrm{N}$ & -2.388928 & -0.220682 & 0.136134 \\
\hline $\mathrm{N}$ & -2.763033 & -1.235015 & -0.671026 \\
\hline $\mathrm{O}$ & -3.778117 & -4.216000 & -4.865604 \\
\hline $\mathrm{O}$ & -8.788282 & -1.681519 & 3.210901 \\
\hline $\mathrm{C}$ & -10.174663 & -1.996210 & 3.446616 \\
\hline $\mathrm{H}$ & -10.340388 & -1.800201 & 4.505109 \\
\hline $\mathrm{H}$ & -10.829314 & -1.353723 & 2.848549 \\
\hline $\mathrm{H}$ & -10.377639 & -3.050877 & 3.233895 \\
\hline S & -3.459059 & -3.019625 & -5.580857 \\
\hline $\mathrm{H}$ & -4.253411 & -2.271446 & -5.474744 \\
\hline $\mathrm{H}$ & -2.500681 & -2.600646 & -5.247598 \\
\hline $\mathrm{H}$ & -3.377743 & -3.314491 & -6.626676 \\
\hline $\mathrm{H}$ & -3.542310 & -2.053530 & -3.199513 \\
\hline $\mathrm{H}$ & -4.834105 & -4.263978 & 0.283338 \\
\hline $\mathrm{H}$ & -5.017044 & -6.315249 & -1.100585 \\
\hline $\mathrm{H}$ & -6.574191 & -2.278427 & -1.524496 \\
\hline $\mathrm{H}$ & -6.374763 & -1.193004 & 2.673689 \\
\hline $\mathrm{H}$ & -8.974008 & -2.753321 & -1.250558 \\
\hline $\mathrm{C}$ & 0.371443 & 3.052089 & 2.402190 \\
\hline$C$ & 1.139013 & 4.044608 & 3.039277 \\
\hline
\end{tabular}




$\begin{array}{cccc}\mathrm{C} & 2.337291 & 4.075442 & 2.338509 \\ \mathrm{H} & 0.894414 & 4.672099 & 3.882726 \\ \mathrm{~N} & 1.058560 & 2.502825 & 1.370348 \\ \mathrm{~N} & 2.245714 & 3.143027 & 1.357009 \\ \mathrm{C} & 3.533319 & 4.940551 & 2.561726 \\ \mathrm{O} & 3.580552 & 5.759021 & 3.453388 \\ \mathrm{O} & 4.493352 & 4.672949 & 1.657091 \\ \mathrm{C} & 5.712880 & 5.475258 & 1.784552 \\ \mathrm{H} & 6.367845 & 5.128976 & 0.987228 \\ \mathrm{H} & 5.469483 & 6.531637 & 1.663772 \\ \mathrm{H} & 6.161008 & 5.306428 & 2.764574 \\ \mathrm{H} & -2.958806 & 2.925053 & -0.671391 \\ \mathrm{H} & 2.958755 & 2.924872 & 0.671857\end{array}$

$\mathrm{M}=\mathrm{Am}$

$\begin{array}{lrrc}\text { AM } & 0.000005 & 0.593836 & 0.000008 \\ \text { O } & -0.476040 & -1.135206 & -1.683143 \\ \text { H } & -1.426399 & -1.448096 & -1.551377 \\ \text { O } & 0.476067 & -1.135136 & 1.683181 \\ \text { H } & 1.426429 & -1.448027 & 1.551433 \\ \text { H } & -0.005170 & -1.759280 & -2.252751 \\ \text { H } & 0.005196 & -1.759191 & 2.252810 \\ \mathrm{C} & 2.733679 & 1.048239 & -2.163341 \\ \mathrm{C} & 3.516525 & 1.464357 & -3.241667 \\ \mathrm{C} & 2.986189 & 2.407705 & -4.127458 \\ \mathrm{C} & 1.704546 & 2.908027 & -3.898623 \\ \mathrm{C} & 0.982477 & 2.445825 & -2.789919 \\ \mathrm{~N} & 1.487245 & 1.524120 & -1.939143 \\ \mathrm{H} & 3.565573 & 2.749945 & -4.979515 \\ \mathrm{H} & 4.510948 & 1.055096 & -3.366866 \\ \mathrm{H} & 1.273713 & 3.643858 & -4.567243 \\ \mathrm{C} & 3.252679 & 0.051442 & -1.188256 \\ \mathrm{C} & 4.960530 & -1.328246 & -0.492454 \\ \mathrm{C} & 6.372119 & -1.688944 & -0.610177 \\ \mathrm{C} & 4.043036 & -1.840247 & 0.520217 \\ \mathrm{C} & 6.995335 & -1.539891 & -1.864839 \\ \mathrm{C} & 7.140903 & -2.091828 & 0.512150 \\ \mathrm{C} & 4.291814 & -3.015196 & 1.381457 \\ \mathrm{C} & 8.359190 & -1.820796 & -2.026898 \\ \mathrm{C} & 4.751799 & -4.208599 & 0.804085 \\ \mathrm{C} & 8.501605 & -2.329493 & 0.348528 \\ \mathrm{C} & 3.987074 & -2.950936 & 2.758688 \\ \mathrm{C} & 9.118344 & -2.213526 & -0.905418 \\ \mathrm{C} & 4.887235 & -5.346927 & 1.609903 \\ \mathrm{C} & 4.169582 & -4.087394 & 3.560653\end{array}$




\begin{tabular}{|c|c|c|c|}
\hline & 5966 & -2.430008 & \\
\hline & 4.608886 & -5.293124 & 2.972463 \\
\hline & 4.736766 & -6.162306 & 3.609166 \\
\hline & 4.480276 & -0.434376 & -1.369840 \\
\hline & 2.453670 & -0.263492 & -0.160891 \\
\hline & 2.858773 & -1.253005 & 0.6 \\
\hline & 3.952929 & -4.1 & \\
\hline & 8.8 & -1.6 & -3.2 \\
\hline & 10.2 & -1.9 & \\
\hline & 629 & -1.7 & -4 \\
\hline & 10.8 & -1.2 & \\
\hline & 10.4 & -3.0 & -3. \\
\hline & 3.6 & -2.9 & \\
\hline & 4.3 & -2.1 & 5. \\
\hline & 2.64 & -2.5 & 5.2 \\
\hline & & -3.2 & \\
\hline & 3.6 & -2.0 & 3.1 \\
\hline & & -4.2 & -0.2 \\
\hline & 5.2 & -6.2 & 1.1 \\
\hline & 6.6 & -2.19 & \\
\hline & 6.4 & -1.2 & -2.7 \\
\hline & & -2.6 & \\
\hline & -0.3 & 2.9 & -2. \\
\hline & -1.1 & 3.9 & -3. \\
\hline & -2.3 & 4.0 & -2. \\
\hline & -0.9 & 4.5 & -4.0 \\
\hline & -1.0 & 2.4 & -1 \\
\hline & -2.2 & 3.1 & -1.3 \\
\hline & -3.5 & 4.8 & -2.6 \\
\hline $\mathrm{O}$ & -3.5 & 5.6 & -3.5 \\
\hline 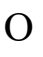 & -4.4 & 4.6 & -1.7 \\
\hline & -5.6 & 5.4 & -1.8 \\
\hline & -6.2 & 5.1 & -0.9 \\
\hline H & -5.3 & 6.54 & -1.76 \\
\hline & -6.1 & 5.28 & -2.787 \\
\hline & -2.7 & 1.0 & 2.16 \\
\hline & -3.5 & 1.4 & 3.24 \\
\hline $\mathrm{C}$ & -2.9 & 2.4 & 4.1 \\
\hline $\mathrm{C}$ & -1.704582 & 2.90 & 3.898548 \\
\hline $\mathrm{C}$ & -0.9 & 2.4 & 2.78 \\
\hline & -1.4 & 1.52 & 1.939117 \\
\hline & -3.56 & 2.75 & 4.979434 \\
\hline $\mathrm{H}$ & -4.510961 & 1.055163 & 3.366834 \\
\hline & -1.273760 & 3.643997 & 4.567147 \\
\hline $\mathrm{C}$ & -3.252670 & 0.051450 & 1.188265 \\
\hline & -4.960517 & -1.328252 & 0.492480 \\
\hline
\end{tabular}




\begin{tabular}{|c|c|c|c|}
\hline $\mathrm{C}$ & -6.372109 & -1.688942 & 0.610195 \\
\hline & -4.043012 & -1.840284 & -0.520165 \\
\hline & -6.995338 & -1.539853 & 1.864846 \\
\hline & -7.140882 & -2.091853 & -0.512130 \\
\hline & -4.291786 & -3.015254 & -1.381379 \\
\hline & -8.359196 & -1.820751 & 2.026896 \\
\hline & -4.751782 & -4.208641 & -0.803983 \\
\hline & -8.501586 & -2.329510 & -0.348518 \\
\hline C & -3.987033 & -2.951028 & -2.758610 \\
\hline$C$ & -9.118339 & -2.213508 & 0.905418 \\
\hline $\mathrm{C}$ & -4.887215 & -5.346987 & -1.609776 \\
\hline $\mathrm{C}$ & -4.169537 & -4.087504 & -3.560549 \\
\hline $\mathrm{H}$ & -10.175962 & -2.429985 & 0.998980 \\
\hline $\mathrm{C}$ & -4.608852 & -5.293218 & -2.972335 \\
\hline $\mathrm{H}$ & -4.736728 & -6.162415 & -3.609018 \\
\hline $\mathrm{N}$ & -4.480272 & -0.434358 & 1.3 \\
\hline$N$ & -2.453645 & -0.263522 & 0.160923 \\
\hline $\mathrm{N}$ & -2.858741 & -1.253056 & -0.66 \\
\hline $\mathrm{O}$ & -3.952871 & -4.136218 & -4.899275 \\
\hline 0 & -8.844172 & -1.679732 & 3.282841 \\
\hline $\mathrm{C}$ & -10.234907 & -1.968850 & 3.525265 \\
\hline $\mathrm{H}$ & -10.384664 & -1.799362 & 4.5 \\
\hline $\mathrm{H}$ & -10.880662 & -1.294557 & 2.95 \\
\hline $\mathrm{H}$ & -10.464826 & -3.012048 & 3.28 \\
\hline $\mathrm{C}$ & -3.608591 & -2.933460 & -5.591898 \\
\hline $\mathrm{H}$ & -4.385773 & -2.169966 & -5.468907 \\
\hline $\mathrm{H}$ & -2.640336 & -2.542532 & -5.253121 \\
\hline $\mathrm{H}$ & -3.536475 & -3.209612 & -6.643480 \\
\hline $\mathrm{H}$ & -3.661058 & -2.013145 & -3.192258 \\
\hline $\mathrm{H}$ & -4.988998 & -4.261851 & 0.252400 \\
\hline $\mathrm{H}$ & -5.225990 & -6.280094 & -1.170824 \\
\hline $\mathrm{H}$ & -6.695198 & -2.190944 & -1.492340 \\
\hline $\mathrm{H}$ & -6.425478 & -1.232841 & 2.732628 \\
\hline $\mathrm{H}$ & -9.102678 & -2.618382 & -1.204941 \\
\hline $\mathrm{C}$ & 0.365679 & 2.946528 & 2.486566 \\
\hline $\mathrm{C}$ & 1.137590 & 3.919550 & 3.147884 \\
\hline $\mathrm{C}$ & 2.315292 & 4.001249 & 2.416780 \\
\hline $\mathrm{H}$ & 0.909542 & 4.504008 & 4.026096 \\
\hline $\mathrm{N}$ & 1.031053 & 2.456509 & 1.412572 \\
\hline 14 & 2.209396 & 3.114358 & 1.396182 \\
\hline $\mathrm{C}$ & 3.503685 & 4.874730 & 2.646610 \\
\hline $\mathrm{O}$ & 3.564671 & 5.650630 & 3.574830 \\
\hline $\mathrm{O}$ & 4.440448 & 4.667071 & 1.702724 \\
\hline 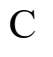 & 5.648994 & 5.485544 & 1.830679 \\
\hline $\mathrm{H}$ & 6.284689 & 5.189021 & 0.998450 \\
\hline U & 5.383479 & 6.541565 & 1.766730 \\
\hline
\end{tabular}




$\begin{array}{cccc}\mathrm{H} & 6.130344 & 5.280259 & 2.787733 \\ \mathrm{H} & 2.903352 & 2.941151 & 0.679455 \\ \mathrm{H} & -2.903360 & 2.941109 & -0.679492\end{array}$

$\mathrm{M}=\mathrm{Cm}$

$\begin{array}{lccc}\mathrm{CM} & -0.000017 & 0.640999 & 0.000026 \\ \mathrm{O} & -0.422223 & -1.064279 & -1.716708 \\ \mathrm{H} & -1.352962 & -1.423948 & -1.573643 \\ \mathrm{O} & 0.422102 & -1.064842 & 1.716437 \\ \mathrm{H} & 1.352884 & -1.424377 & 1.573332 \\ \mathrm{H} & 0.048299 & -1.622813 & -2.350612 \\ \mathrm{H} & -0.048491 & -1.623756 & 2.349954 \\ \mathrm{C} & 2.758541 & 1.098748 & -2.098528 \\ \mathrm{C} & 3.566740 & 1.531742 & -3.151315 \\ \mathrm{C} & 3.066136 & 2.506244 & -4.020831 \\ \mathrm{C} & 1.785038 & 3.014511 & -3.806018 \\ \mathrm{C} & 1.034973 & 2.533186 & -2.723897 \\ \mathrm{~N} & 1.515672 & 1.589260 & -1.884049 \\ \mathrm{H} & 3.666380 & 2.863309 & -4.852181 \\ \mathrm{H} & 4.556748 & 1.109993 & -3.270391 \\ \mathrm{H} & 1.374781 & 3.769007 & -4.466722 \\ \mathrm{C} & 3.242757 & 0.062415 & -1.145522 \\ \mathrm{C} & 4.911519 & -1.369954 & -0.462526 \\ \mathrm{C} & 6.315300 & -1.762397 & -0.575758 \\ \mathrm{C} & 3.971160 & -1.886244 & 0.526626 \\ \mathrm{C} & 6.952798 & -1.601338 & -1.821711 \\ \mathrm{C} & 7.064283 & -2.208499 & 0.543451 \\ \mathrm{C} & 4.189596 & -3.080642 & 1.369611 \\ \mathrm{C} & 8.310711 & -1.912151 & -1.978962 \\ \mathrm{C} & 4.623034 & -4.274960 & 0.774309 \\ \mathrm{C} & 8.420224 & -2.475727 & 0.385599 \\ \mathrm{C} & 3.883717 & -3.030641 & 2.747022 \\ \mathrm{C} & 9.050418 & -2.347723 & -0.860411 \\ \mathrm{C} & 4.730097 & -5.428692 & 1.562380 \\ \mathrm{C} & 4.038312 & -4.183440 & 3.531456 \\ \mathrm{H} & 10.103239 & -2.587898 & -0.950129 \\ \mathrm{C} & 4.450341 & -5.389725 & 2.925163 \\ \mathrm{H} & 4.556602 & -6.271505 & 3.548362 \\ \mathrm{~N} & 4.464306 & -0.440476 & -1.320775 \\ \mathrm{~N} & 2.419723 & -0.270000 & -0.143023 \\ \mathrm{~N} & 2.793980 & -1.283576 & 0.665641 \\ \mathrm{O} & 3.818156 & -4.247849 & 4.869070 \\ \mathrm{O} & 8.809681 & -1.755676 & -3.227699 \\ \mathrm{C} & 10.195017 & -2.073292 & -3.465063 \\ \mathrm{H} & 10.358120 & -1.884428 & -4.525262\end{array}$




$\begin{array}{lccc}\mathrm{H} & 10.851952 & -1.427564 & -2.873004 \\ \mathrm{H} & 10.397526 & -3.126763 & -3.245951 \\ \mathrm{C} & 3.503411 & -3.048028 & 5.580348 \\ \mathrm{H} & 4.298757 & -2.301662 & 5.468697 \\ \mathrm{H} & 2.544745 & -2.628506 & 5.248329 \\ \mathrm{H} & 3.424726 & -3.338424 & 6.627600 \\ \mathrm{H} & 3.579462 & -2.092113 & 3.194977 \\ \mathrm{H} & 4.861592 & -4.316870 & -0.282352 \\ \mathrm{H} & 5.047949 & -6.362472 & 1.109414 \\ \mathrm{H} & 6.608105 & -2.317695 & 1.517732 \\ \mathrm{H} & 6.398253 & -1.261135 & -2.687089 \\ \mathrm{H} & 9.006706 & -2.797613 & 1.240387 \\ \mathrm{C} & -0.321091 & 3.030121 & -2.446825 \\ \mathrm{C} & -1.065111 & 4.028419 & -3.102707 \\ \mathrm{C} & -2.270601 & 4.087384 & -2.416340 \\ \mathrm{H} & -0.801217 & 4.643081 & -3.949638 \\ \mathrm{~N} & -1.029870 & 2.503731 & -1.417197 \\ \mathrm{~N} & -2.206211 & 3.164917 & -1.424438 \\ \mathrm{C} & -3.448210 & 4.970839 & -2.663451 \\ \mathrm{O} & -3.469856 & 5.780317 & -3.564336 \\ \mathrm{O} & -4.423764 & 4.730067 & -1.768152 \\ \mathrm{C} & -5.627469 & 5.552000 & -1.918798 \\ \mathrm{H} & -6.297771 & 5.225476 & -1.125881 \\ \mathrm{C} & -5.367131 & 6.605217 & -1.805966 \\ \mathrm{C} & -3.883998 & -3.029703 & -2.747673 \\ \mathrm{H} & -6.066710 & 5.380497 & -2.902376 \\ \mathrm{C} & -2.758423 & 1.098338 & 2.098890 \\ \mathrm{C} & -3.566538 & 1.531122 & 3.151826 \\ \mathrm{C} & -3.065875 & 2.505478 & 4.021473 \\ \mathrm{C} & -1.784808 & 3.013813 & 3.806637 \\ \mathrm{C} & -1.034830 & 2.532696 & 2.724363 \\ \mathrm{~N} & -1.515581 & 1.588910 & 1.884390 \\ \mathrm{H} & -3.666052 & 2.862380 & 4.852942 \\ \mathrm{H} & -4.556529 & 1.109333 & 3.270913 \\ \mathrm{H} & -1.374508 & 3.768200 & 4.467438 \\ \mathrm{C} & -3.242698 & 0.062184 & 1.145720 \\ \mathrm{C} & -4.911527 & -1.369962 & 0.462435 \\ \mathrm{C} & -6.315306 & -1.762416 & 0.575657 \\ \mathrm{C} & -3.971235 & -1.886012 & -0.526907 \\ \mathrm{C} & -7.064380 & -2.208191 & -0.543621 \\ \mathrm{C} & -2.34779 & -3.080135 & -1.370256 \\ \mathrm{C} & -1.912553 & 1.978973 \\ \mathrm{C} & -4.274627 & -0.775306 \\ \mathrm{C} & -2.860354\end{array}$




$\begin{array}{cccc}\mathrm{C} & -4.730383 & -5.428102 & -1.563742 \\ \mathrm{C} & -4.038695 & -4.182243 & -3.532467 \\ \mathrm{H} & -10.103224 & -2.587989 & 0.950084 \\ \mathrm{C} & -4.450725 & -5.388707 & -2.926533 \\ \mathrm{H} & -4.557064 & -6.270283 & -3.550008 \\ \mathrm{~N} & -4.464255 & -0.440709 & 1.320899 \\ \mathrm{~N} & -2.419692 & -0.270049 & 0.143141 \\ \mathrm{~N} & -2.794010 & -1.283395 & -0.665771 \\ \mathrm{O} & -3.818636 & -4.246231 & -4.870117 \\ \mathrm{O} & -8.809484 & -1.756433 & 3.227794 \\ \mathrm{C} & -10.194800 & -2.074121 & 3.465176 \\ \mathrm{H} & -10.357819 & -1.885565 & 4.525442 \\ \mathrm{H} & -10.851783 & -1.428223 & 2.873356 \\ \mathrm{H} & -10.397323 & -3.127529 & 3.245774 \\ \mathrm{C} & -3.503879 & -3.046198 & -5.581032 \\ \mathrm{H} & -4.299183 & -2.299829 & -5.469097 \\ \mathrm{H} & -2.545172 & -2.626828 & -5.248938 \\ \mathrm{H} & -3.425270 & -3.336264 & -6.628382 \\ \mathrm{H} & -3.579739 & -2.091043 & -3.195348 \\ \mathrm{H} & -4.861703 & -4.316868 & 0.281358 \\ \mathrm{H} & -5.048237 & -6.362016 & -1.111053 \\ \mathrm{H} & -6.608280 & -2.317110 & -1.517969 \\ \mathrm{H} & -6.398094 & -1.261751 & 2.687136 \\ \mathrm{H} & -9.006864 & -2.797080 & -1.240577 \\ \mathrm{C} & 0.321207 & 3.029687 & 2.447257 \\ \mathrm{C} & 1.065325 & 4.027777 & 3.103341 \\ \mathrm{C} & 2.270773 & 4.086844 & 2.416909 \\ \mathrm{H} & 0.801522 & 4.642236 & 3.950447 \\ \mathrm{~N} & 1.029883 & 2.503517 & 1.417445 \\ \mathrm{~N} & 2.206267 & 3.164625 & 1.424784 \\ \mathrm{C} & 3.448451 & 4.970168 & 2.664160 \\ \mathrm{O} & 3.470210 & 5.779418 & 3.565248 \\ \mathrm{O} & 4.423927 & 4.729565 & 1.768730 \\ \mathrm{C} & 5.627688 & 5.551396 & 1.919490 \\ \mathrm{H} & 6.297912 & 5.225033 & 1.126442 \\ \mathrm{H} & 5.367396 & 6.604655 & 1.806939 \\ \mathrm{H} & 6.066992 & 5.379626 & 2.902992 \\ \mathrm{H} & 2.930259 & 2.965806 & 0.745319 \\ \mathrm{H} & -2.930264 & 2.965961 & -0.745077\end{array}$

\section{$\left[\mathrm{ML}_{2}\right]^{3+}$}

$\mathrm{M}=\mathrm{Eu}$

$\begin{array}{llll}\text { EU } & -0.000007 & 1.287068 & -0.000012\end{array}$

$\mathrm{N} \quad-0.767146 \quad 3.098166 \quad-1.751078$ 


\begin{tabular}{|c|c|c|c|}
\hline $\mathrm{N}$ & 0.767077 & 3.098280 & 0951 \\
\hline & -0.014064 & 3.314251 & -2.859179 \\
\hline $\mathrm{N}$ & -1.791531 & 3.971381 & -1.851481 \\
\hline 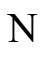 & -1.548294 & 1.628100 & 2.147436 \\
\hline & 1.548236 & 1.628006 & -2.147533 \\
\hline$\checkmark$ & -2.171161 & -0.134606 & 0.182363 \\
\hline$N$ & 2.171242 & -0.134481 & -0.182317 \\
\hline C & 0.013952 & 3.314430 & 2.859010 \\
\hline $\mathrm{N}$ & 1.791442 & 3.971520 & 1.851325 \\
\hline $\mathrm{C}$ & -0.578758 & 4.331611 & -3.655364 \\
\hline $\mathrm{C}$ & 1.216414 & 2.534406 & -3.089580 \\
\hline $\mathrm{C}$ & -1.719662 & 4.730806 & -2.975141 \\
\hline $\mathrm{H}$ & -2.511128 & 4.029363 & -1.140927 \\
\hline $\mathrm{C}$ & -2.670932 & 0.896125 & 2.316254 \\
\hline $\mathrm{C}$ & -1.216517 & 2.534574 & 3.089428 \\
\hline $\mathrm{C}$ & 2.670890 & 0.896049 & -2.3 \\
\hline $\mathrm{C}$ & -2.993942 & -0.087270 & 1.244280 \\
\hline $\mathrm{N}$ & -2.360497 & -1.086302 & -0.740884 \\
\hline $\mathrm{C}$ & 2.993956 & -0.087252 & -1.244288 \\
\hline $\mathrm{N}$ & 2.360610 & -1.086107 & 0.740995 \\
\hline $\mathrm{C}$ & 0.578601 & 4.331857 & 3.655141 \\
\hline $\mathrm{C}$ & 1.719520 & 4.731024 & \\
\hline $\mathrm{H}$ & 2.511064 & 4.029461 & 1.140793 \\
\hline $\mathrm{H}$ & -0.236052 & 4.746770 & -4.590562 \\
\hline $\mathrm{C}$ & 2.001088 & 2.735632 & -4.236505 \\
\hline $\mathrm{C}$ & -2.715144 & 5.780136 & -3.337630 \\
\hline $\mathrm{C}$ & -3.507729 & 1.040239 & 3.425439 \\
\hline $\mathrm{C}$ & -2.001227 & 2.735862 & 4.236319 \\
\hline $\mathrm{C}$ & 3.507653 & 1.040104 & -3.425546 \\
\hline $\mathrm{N}$ & -4.095095 & -0.832570 & 1.371997 \\
\hline $\mathrm{C}$ & -3.397119 & -1.924575 & -0.635098 \\
\hline $\mathrm{N}$ & 4.095096 & -0.832572 & -1.371998 \\
\hline $\mathrm{C}$ & 3.397218 & -1.924403 & 0.635225 \\
\hline $\mathrm{H}$ & 0.235856 & 4.747078 & 4.590298 \\
\hline $\mathrm{C}$ & 2.714971 & 5.780399 & 3.337376 \\
\hline $\mathrm{C}$ & 3.159944 & 1.978104 & -4.403252 \\
\hline $\mathrm{H}$ & 1.713096 & 3.469193 & -4.980049 \\
\hline $\mathrm{O}$ & -3.675464 & 5.873090 & -2.397983 \\
\hline $\mathrm{O}$ & -2.628378 & 6.436297 & -4.353146 \\
\hline $\mathrm{C}$ & -3.160070 & 1.978319 & 4.403087 \\
\hline $\mathrm{H}$ & -4.402451 & 0.436107 & 3.504758 \\
\hline $\mathrm{H}$ & -1.713272 & 3.469482 & 4.979819 \\
\hline $\mathrm{H}$ & 4.402389 & 0.435989 & -3.504845 \\
\hline $\mathrm{C}$ & -4.370292 & -1.719112 & 0.411921 \\
\hline $\mathrm{C}$ & -3.440910 & -3.044217 & -1.604884 \\
\hline$C$ & 4.370340 & -1.719031 & -0.411858 \\
\hline
\end{tabular}




\begin{tabular}{|c|c|c|c|}
\hline $\mathrm{C}$ & 3.441041 & -3.043972 & 1.605089 \\
\hline $\mathrm{O}$ & 3.675324 & 5.873301 & 2.397757 \\
\hline 0 & 2.628156 & 6.436633 & 4.352840 \\
\hline $\mathrm{H}$ & 3.785347 & 2.117976 & -5.279581 \\
\hline $\mathrm{C}$ & -4.702955 & 6.884124 & -2.650356 \\
\hline $\mathrm{H}$ & -3.785500 & 2.118238 & 5.279389 \\
\hline $\mathrm{C}$ & -5.677312 & -2.402357 & 0.486329 \\
\hline $\mathrm{C}$ & -3.737514 & -4.347306 & -1.151616 \\
\hline $\mathrm{C}$ & -3.139984 & -2.814037 & -2.956314 \\
\hline $\mathrm{C}$ & 5.677361 & -2.402278 & -0.486268 \\
\hline $\mathrm{C}$ & 3.737639 & -4.347093 & 1.151908 \\
\hline $\mathrm{C}$ & 3.140148 & -2.813696 & 2.956512 \\
\hline $\mathrm{C}$ & 4.702787 & 6.884371 & 2.650093 \\
\hline $\mathrm{H}$ & -4.239940 & 7.870053 & -2.709645 \\
\hline $\mathrm{H}$ & -5.217545 & 6.658716 & -3.585454 \\
\hline $\mathrm{H}$ & -5.382281 & 6.820055 & -1.802302 \\
\hline $\mathrm{C}$ & -6.241997 & -2.643995 & 1.741390 \\
\hline $\mathrm{C}$ & -6.396133 & -2.749872 & -0.687067 \\
\hline $\mathrm{C}$ & -3.726949 & -5.416179 & -2.059805 \\
\hline $\mathrm{H}$ & -3.945811 & -4.533609 & -0.104588 \\
\hline $\mathrm{C}$ & -3.161642 & -3.889659 & -3.863194 \\
\hline $\mathrm{H}$ & -2.911548 & -1.809378 & -3.288008 \\
\hline $\mathrm{C}$ & 6.241984 & -2.644026 & -1.741335 \\
\hline $\mathrm{C}$ & 6.396243 & -2.749677 & 0.687123 \\
\hline $\mathrm{C}$ & 3.727095 & -5.415901 & 2.060174 \\
\hline $\mathrm{H}$ & 3.945911 & -4.533471 & 0.104889 \\
\hline $\mathrm{C}$ & 3.161831 & -3.889252 & 3.863467 \\
\hline $\mathrm{H}$ & 2.911718 & -1.809013 & 3.288139 \\
\hline $\mathrm{H}$ & 4.239753 & 7.870296 & 2.709291 \\
\hline $\mathrm{H}$ & 5.217347 & 6.659041 & 3.585227 \\
\hline $\mathrm{H}$ & 5.382146 & 6.820251 & 1.802069 \\
\hline $\mathrm{C}$ & -7.505055 & -3.263484 & 1.849988 \\
\hline $\mathrm{H}$ & -5.717179 & -2.378539 & 2.650998 \\
\hline $\mathrm{C}$ & -7.657986 & -3.339457 & -0.570539 \\
\hline $\mathrm{H}$ & -6.000574 & -2.526107 & -1.669301 \\
\hline $\mathrm{C}$ & -3.450990 & -5.198666 & -3.403780 \\
\hline $\mathrm{H}$ & -3.940550 & -6.421798 & -1.712069 \\
\hline $\mathrm{O}$ & -2.922542 & -3.786627 & -5.187362 \\
\hline $\mathrm{C}$ & 7.505043 & -3.263514 & -1.849941 \\
\hline $\mathrm{H}$ & 5.717118 & -2.378657 & -2.650941 \\
\hline 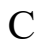 & 7.658095 & -3.339261 & 0.570584 \\
\hline $\mathrm{H}$ & 6.000731 & -2.525828 & 1.669356 \\
\hline $\mathrm{C}$ & 3.451168 & -5.198293 & 3.404140 \\
\hline $\mathrm{H}$ & 3.940690 & -6.421545 & 1.712505 \\
\hline $\mathrm{O}$ & 2.922767 & -3.786124 & 5.187635 \\
\hline$C$ & -8.218192 & -3.611110 & 0.6792 \\
\hline
\end{tabular}




$\begin{array}{cccc}\mathrm{O} & -7.939382 & -3.473533 & 3.106382 \\ \mathrm{H} & -8.217997 & -3.588152 & -1.466449 \\ \mathrm{H} & -3.455265 & -6.009883 & -4.124213 \\ \mathrm{C} & -2.674834 & -2.496728 & -5.764834 \\ \mathrm{C} & 8.218241 & -3.611023 & -0.679248 \\ \mathrm{O} & 7.939306 & -3.473675 & -3.106339 \\ \mathrm{H} & 8.218155 & -3.587868 & 1.466488 \\ \mathrm{H} & 3.455462 & -6.009457 & 4.124632 \\ \mathrm{C} & 2.675095 & -2.496181 & 5.765023 \\ \mathrm{H} & -9.193576 & -4.078727 & 0.740355 \\ \mathrm{C} & -9.222116 & -4.102234 & 3.320717 \\ \mathrm{H} & -3.530212 & -1.829985 & -5.610168 \\ \mathrm{H} & -1.764264 & -2.051099 & -5.348128 \\ \mathrm{H} & -2.540072 & -2.676198 & -6.830716 \\ \mathrm{H} & 9.193626 & -4.078637 & -0.740320 \\ \mathrm{C} & 9.222037 & -4.102378 & -3.320679 \\ \mathrm{H} & 3.530476 & -1.829460 & 5.610277 \\ \mathrm{H} & 1.764515 & -2.050570 & 5.348319 \\ \mathrm{H} & 2.540369 & -2.675572 & 6.830923 \\ \mathrm{H} & -9.234571 & -5.109195 & 2.892576 \\ \mathrm{H} & -10.025875 & -3.493180 & 2.895858 \\ \mathrm{H} & -9.336245 & -4.160400 & 4.401906 \\ \mathrm{H} & 9.234527 & -5.109300 & -2.892445 \\ \mathrm{H} & 10.025809 & -3.493274 & -2.895915 \\ \mathrm{H} & 9.336114 & -4.160643 & -4.401868\end{array}$

\section{$\mathrm{M}=\mathrm{Gd}$}

$\begin{array}{lrrc}\text { GD } & 0.000120 & 1.387052 & -0.000064 \\ \mathrm{~N} & 0.932867 & 3.075967 & 1.553520 \\ \mathrm{~N} & -0.932662 & 3.075904 & -1.553729 \\ \mathrm{C} & 0.344204 & 3.276338 & 2.766526 \\ \mathrm{~N} & 1.973630 & 3.943045 & 1.522347 \\ \mathrm{~N} & -1.237146 & 1.596663 & 2.178212 \\ \mathrm{~N} & 1.237216 & 1.596465 & -2.178429 \\ \mathrm{~N} & -1.901553 & 0.001418 & 0.208073 \\ \mathrm{~N} & 1.901567 & 0.001429 & -0.208162 \\ \mathrm{C} & -0.344077 & 3.276159 & -2.766792 \\ \mathrm{~N} & -1.973387 & 3.943026 & -1.522551 \\ \mathrm{C} & 1.022510 & 4.270470 & 3.488555 \\ \mathrm{C} & -0.834850 & 2.472625 & 3.124158 \\ \mathrm{C} & 2.062409 & 4.674640 & 2.658521 \\ \mathrm{H} & 2.598893 & 4.007169 & 0.726848 \\ \mathrm{C} & -2.306193 & 0.803033 & 2.419934 \\ \mathrm{C} & 2.306209 & 0.802758 & -2.420122 \\ \mathrm{C} & 0.834920 & 2.472364 & -3.124429\end{array}$




\begin{tabular}{|c|c|c|c|}
\hline C & -2.655602 & -0.123543 & 1.314367 \\
\hline J & -2.006494 & -0.914671 & -0.773882 \\
\hline $\mathrm{C}$ & 2.655586 & -0.123717 & -1.314464 \\
\hline V & 2.006469 & -0.914552 & 0.773903 \\
\hline & -1.022391 & 4.270262 & -3.488851 \\
\hline C & -2.062216 & 4.674537 & -2.658776 \\
\hline $\mathrm{H}$ & -2.598594 & 4.007233 & -0.727015 \\
\hline$H$ & 0.819541 & 4.667082 & 4.471916 \\
\hline $\mathrm{C}$ & -1.499060 & 2.587984 & 4.350906 \\
\hline $\mathrm{C}$ & 3.113799 & 5.710741 & 2.904623 \\
\hline $\mathrm{C}$ & -3.022000 & 0.859148 & 3.615354 \\
\hline $\mathrm{C}$ & 3.021969 & 0.858723 & -3.615575 \\
\hline $\mathrm{C}$ & 1.499083 & 2.587577 & -4.351217 \\
\hline $\mathrm{N}$ & -3.667270 & -0.969227 & 1.428638 \\
\hline $\mathrm{C}$ & -2.936435 & -1.865416 & -0.684743 \\
\hline $\mathrm{N}$ & 3.667188 & -0.969485 & -1.428656 \\
\hline $\mathrm{C}$ & 2.936341 & -1.865370 & 0.684855 \\
\hline $\mathrm{H}$ & -0.819473 & 4.666790 & -4.472257 \\
\hline $\mathrm{C}$ & -3.113582 & 5.710661 & -2.904885 \\
\hline $\mathrm{C}$ & -2.606457 & 1.769429 & 4.594597 \\
\hline $\mathrm{H}$ & -1.162443 & 3.296881 & 5.098510 \\
\hline $\mathrm{O}$ & 3.938102 & 5.809894 & 1.849295 \\
\hline $\mathrm{O}$ & 3.160549 & 6.341020 & 3.937414 \\
\hline $\mathrm{H}$ & -3.876323 & 0.208847 & 3.760153 \\
\hline $\mathrm{C}$ & 2.606427 & 1.768940 & -4.594881 \\
\hline $\mathrm{H}$ & 3.876252 & 0.208363 & -3.760355 \\
\hline $\mathrm{H}$ & 1.162472 & 3.296424 & -5.098871 \\
\hline $\mathrm{C}$ & -3.925240 & -1.791732 & 0.393460 \\
\hline $\mathrm{C}$ & -2.857103 & -2.958486 & -1.673617 \\
\hline $\mathrm{C}$ & 3.925126 & -1.791886 & -0.393383 \\
\hline $\mathrm{C}$ & 2.856958 & -2.958315 & 1.673865 \\
\hline $\mathrm{O}$ & -3.937809 & 5.809929 & -1.849507 \\
\hline $\mathrm{O}$ & -3.160379 & 6.340862 & -3.937722 \\
\hline $\mathrm{H}$ & -3.139875 & 1.840932 & 5.537729 \\
\hline $\mathrm{C}$ & 5.012198 & 6.801658 & 1.979350 \\
\hline $\mathrm{H}$ & 3.139807 & 1.840330 & -5.538043 \\
\hline $\mathrm{C}$ & -5.196941 & -2.505596 & 0.419260 \\
\hline $\mathrm{C}$ & -2.997610 & -4.288021 & -1.243543 \\
\hline $\mathrm{C}$ & -2.564104 & -2.666887 & -3.022929 \\
\hline $\mathrm{C}$ & 5.196773 & -2.505841 & -0.419132 \\
\hline $\mathrm{C}$ & 2.997328 & -4.287913 & 1.243942 \\
\hline $\mathrm{C}$ & 2.564047 & -2.666529 & 3.023155 \\
\hline $\mathrm{C}$ & -5.011874 & 6.801725 & -1.979566 \\
\hline 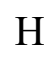 & 4.577236 & 7.792106 & 2.118336 \\
\hline $\mathrm{H}$ & 5.641707 & 6.545729 & 2.832411 \\
\hline $\mathrm{H}$ & 5.568860 & 6.742629 & 1.046201 \\
\hline
\end{tabular}




\begin{tabular}{|c|c|c|c|}
\hline$C$ & -5.834052 & -2.692065 & 1.663542 \\
\hline & -5.847642 & -2.922088 & -0.772318 \\
\hline C & -2.829915 & -5.326008 & -2.168679 \\
\hline & -3.219957 & -4.518457 & -0.208075 \\
\hline C & -2.441059 & -3.714787 & -3.945396 \\
\hline & -2.465417 & -1.634850 & -3.334435 \\
\hline $\mathrm{C}$ & 5.833858 & -2.692467 & -1.663405 \\
\hline $\mathrm{C}$ & 5.847461 & -2.922274 & 0.772477 \\
\hline$c$ & 2.829584 & -5.325775 & 2.169210 \\
\hline $\mathrm{H}$ & 3.219607 & -4.518492 & 0.208491 \\
\hline $\mathrm{C}$ & 2.440953 & -3.714308 & 3.945753 \\
\hline H & 2.465467 & -1.634446 & 3.334543 \\
\hline $\mathrm{H}$ & -4.576883 & 7.792145 & -2.118661 \\
\hline $\mathrm{H}$ & -5.641452 & 6.545754 & -2.832564 \\
\hline $\mathrm{H}$ & -5.568474 & 6.742792 & -1.046374 \\
\hline C & -7.086256 & -3.316424 & 1.742186 \\
\hline $\mathrm{H}$ & -5.353770 & -2.380164 & 2.582001 \\
\hline $\mathrm{C}$ & -7.106958 & -3.504218 & -0.685512 \\
\hline $\mathrm{H}$ & -5.393155 & -2.771326 & -1.741816 \\
\hline $\mathrm{C}$ & -2.564059 & -5.050667 & -3.507141 \\
\hline $\mathrm{H}$ & -2.922085 & -6.357566 & -1.843899 \\
\hline $\mathrm{O}$ & -2.201589 & -3.556456 & -5.273484 \\
\hline $\mathrm{C}$ & 016 & -3.316922 & -1.742008 \\
\hline $\mathrm{H}$ & 5.353587 & -2.380613 & -2.581886 \\
\hline $\mathrm{C}$ & 7.106734 & -3.504500 & 0.685708 \\
\hline $\mathrm{H}$ & 5.392998 & -2.771391 & 1.741968 \\
\hline $\mathrm{C}$ & 2.563815 & -5.050250 & 3.507651 \\
\hline $\mathrm{H}$ & 2.921648 & -6.357380 & 1.844549 \\
\hline $\mathrm{O}$ & 2.201560 & -3.555798 & 5.273832 \\
\hline $\mathrm{C}$ & -7.728987 & -3.719661 & 0.553360 \\
\hline $\mathrm{O}$ & -7.587416 & -3.476977 & 2.9 \\
\hline $\mathrm{H}$ & -7.622146 & -3.807249 & -1.591555 \\
\hline $\mathrm{H}$ & -2.460234 & -5.846480 & -4.237313 \\
\hline $\mathrm{C}$ & -2.169581 & -2.235381 & -5.817023 \\
\hline S & 7.728732 & -3.720098 & -0.553153 \\
\hline $\mathrm{O}$ & 7.587150 & -3.477622 & -2.988761 \\
\hline $\mathrm{H}$ & 7.621912 & -3.807486 & 1.591772 \\
\hline $\mathrm{H}$ & 2.459954 & -5.845967 & 4.237923 \\
\hline $\mathrm{C}$ & 2.169698 & -2.234655 & 5.817218 \\
\hline $\mathrm{H}$ & -8.700915 & -4.197977 & 0.582899 \\
\hline $\mathrm{C}$ & -8.866398 & -4.122584 & 3.144576 \\
\hline $\mathrm{H}$ & -3.118015 & -1.713076 & -5.643733 \\
\hline $\mathrm{H}$ & -1.338526 & -1.653572 & -5.397205 \\
\hline 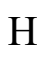 & -2.017082 & -2.361178 & -6.888763 \\
\hline $\mathrm{H}$ & 8.700626 & -4.198485 & -0.582660 \\
\hline $\mathrm{C}$ & 8.866085 & -4.123334 & -3.144347 \\
\hline
\end{tabular}




$\begin{array}{lrrr}\mathrm{H} & 3.118171 & -1.712456 & 5.643819 \\ \mathrm{H} & 1.338676 & -1.652820 & 5.397373 \\ \mathrm{H} & 2.017241 & -2.360312 & 6.888981 \\ \mathrm{H} & -8.837330 & -5.146032 & 2.756596 \\ \mathrm{H} & -9.657194 & -3.549157 & 2.649766 \\ \mathrm{H} & -9.050523 & -4.145545 & 4.217800 \\ \mathrm{H} & 8.836949 & -5.146745 & -2.756276 \\ \mathrm{H} & 9.656928 & -3.549918 & -2.649599 \\ \mathrm{H} & 9.050195 & -4.146403 & -4.217572\end{array}$

$\mathrm{M}=\mathrm{Am}$

$\begin{array}{lrcc}\text { AM } & -0.000660 & 1.446568 & -0.000069 \\ \mathrm{~N} & 0.989539 & 3.122051 & 1.621498 \\ \mathrm{~N} & -0.993186 & 3.119974 & -1.622276 \\ \mathrm{C} & 0.532488 & 3.162212 & 2.902065 \\ \mathrm{~N} & 1.959248 & 4.066629 & 1.565033 \\ \mathrm{~N} & 1.000613 & 1.416059 & -2.343390 \\ \mathrm{~N} & -1.002217 & 1.415878 & 2.343110 \\ \mathrm{~N} & 1.841491 & -0.059456 & -0.342077 \\ \mathrm{~N} & -1.841234 & -0.061161 & 0.342218 \\ \mathrm{C} & -0.536198 & 3.160360 & -2.902854 \\ \mathrm{~N} & -1.964074 & 4.063352 & -1.566049 \\ \mathrm{C} & 1.220731 & 4.135879 & 3.644208 \\ \mathrm{C} & -0.543255 & 2.245473 & 3.306671 \\ \mathrm{C} & 2.128800 & 4.695069 & 2.752593 \\ \mathrm{H} & 2.481479 & 4.254483 & 0.716663 \\ \mathrm{C} & 1.993645 & 0.544645 & -2.641493 \\ \mathrm{C} & 0.540639 & 2.244801 & -3.307206 \\ \mathrm{C} & -1.994283 & 0.543439 & 2.641430 \\ \mathrm{C} & 2.437733 & -0.312874 & -1.516766 \\ \mathrm{~N} & 2.036800 & -0.893652 & 0.695017 \\ \mathrm{C} & -2.437336 & -0.314886 & 1.516915 \\ \mathrm{~N} & -2.035517 & -0.895861 & -0.694658 \\ \mathrm{C} & -1.225665 & 4.132966 & -3.645253 \\ \mathrm{C} & -2.134423 & 4.691259 & -2.753778 \\ \mathrm{H} & -2.486545 & 4.250761 & -0.717729 \\ \mathrm{H} & 1.106375 & 4.424555 & 4.678086 \\ \mathrm{C} & -1.066862 & 2.225947 & 4.604839 \\ \mathrm{C} & 3.129277 & 5.782675 & 2.986583 \\ \mathrm{C} & 2.566240 & 0.467639 & -3.910034 \\ \mathrm{C} & 1.064214 & 2.225481 & -4.605389 \\ \mathrm{C} & -2.566850 & 0.466170 & 3.909965 \\ \mathrm{~N} & 3.384937 & -1.222490 & -1.686933 \\ \mathrm{C} & 2.907302 & -1.894934 & 0.575344 \\ \mathrm{~N} & -3.383597 & -1.225452 & 1.687217\end{array}$




$\begin{array}{lrrr}\mathrm{C} & -2.904965 & -1.898035 & -0.574810 \\ \mathrm{H} & -1.111681 & 4.421505 & -4.679211 \\ \mathrm{C} & -3.136258 & 5.777554 & -2.988046 \\ \mathrm{C} & -2.090211 & 1.323917 & 4.907324 \\ \mathrm{H} & -0.686908 & 2.901209 & 5.362532 \\ \mathrm{O} & 3.815218 & 6.045268 & 1.862611 \\ \mathrm{O} & 3.254860 & 6.314470 & 4.067236 \\ \mathrm{C} & 2.088593 & 1.324541 & -4.907635 \\ \mathrm{H} & 3.364024 & -0.241871 & -4.093607 \\ \mathrm{H} & 0.683438 & 2.900061 & -5.363277 \\ \mathrm{H} & -3.363841 & -0.244182 & 4.093721 \\ \mathrm{C} & 3.739589 & -1.973102 & -0.626559 \\ \mathrm{C} & 2.919374 & -2.888347 & 1.668478 \\ \mathrm{C} & -3.737339 & -1.976727 & 0.627005 \\ \mathrm{C} & -2.915830 & -2.891786 & -1.667647 \\ \mathrm{O} & -3.822508 & 6.039597 & -1.864133 \\ \mathrm{O} & -3.262520 & 6.308902 & -4.068839 \\ \mathrm{H} & -2.513387 & 1.292737 & 5.906788 \\ \mathrm{C} & 4.828257 & 7.101424 & 1.973086 \\ \mathrm{H} & 2.511770 & 1.293541 & -5.907104 \\ \mathrm{C} & 4.954047 & -2.770942 & -0.759003 \\ \mathrm{C} & 2.920283 & -4.257363 & 1.356649 \\ \mathrm{C} & 2.854270 & -2.456955 & 3.010221 \\ \mathrm{C} & -4.950995 & -2.775769 & 0.759506 \\ \mathrm{C} & -2.915330 & -4.260708 & -1.355407 \\ \mathrm{H} & -5.281623 & 7.166791 & -0.984375 \\ \mathrm{C} & -2.851009 & -2.460728 & -3.009513 \\ \mathrm{C} & -4.836860 & 7.094462 & -1.974877 \\ \mathrm{H} & 4.347506 & 8.037310 & 2.260311 \\ \mathrm{H} & 5.570261 & 6.816538 & 2.719931 \\ \mathrm{H} & 5.272948 & 7.174036 & 0.982573 \\ \mathrm{C} & 5.393258 & -3.110514 & -2.054958 \\ \mathrm{C} & 5.746146 & -3.123251 & 0.365385 \\ \mathrm{C} & 2.841494 & -5.193793 & 2.395173 \\ \mathrm{H} & 2.970141 & -4.594436 & 0.327653 \\ \mathrm{C} & 2.818792 & -3.406593 & 4.040554 \\ \mathrm{H} & 2.861960 & -1.396440 & 3.228433 \\ \mathrm{C} & -5.390076 & -3.115362 & 2.055502 \\ \mathrm{C} & -5.742545 & -3.129261 & -0.364898 \\ \mathrm{H} & -2.835416 & -5.197364 & -2.393640 \\ \mathrm{H} & -2.964966 & -4.597525 & -0.326316 \\ \mathrm{H} & -3.822759 & -2.245283\end{array}$




$\begin{array}{crrr}\mathrm{H} & 4.803668 & -2.849295 & -2.924346 \\ \mathrm{C} & 6.946268 & -3.794780 & 0.162177 \\ \mathrm{H} & 5.446333 & -2.855138 & 1.369119 \\ \mathrm{C} & 2.799957 & -4.781597 & 3.724295 \\ \mathrm{H} & 2.828089 & -6.254396 & 2.164719 \\ \mathrm{O} & 2.796126 & -3.112073 & 5.367295 \\ \mathrm{C} & -6.581364 & -3.828762 & 2.245866 \\ \mathrm{H} & -4.800899 & -2.853251 & 2.924901 \\ \mathrm{C} & -6.942011 & -3.801951 & -0.161665 \\ \mathrm{H} & -5.442837 & -2.861182 & -1.368672 \\ \mathrm{C} & -2.794149 & -4.785523 & -3.722881 \\ \mathrm{H} & -2.820921 & -6.257883 & -2.162866 \\ \mathrm{O} & -2.791878 & -3.116489 & -5.366383 \\ \mathrm{C} & 7.370328 & -4.161194 & -1.123784 \\ \mathrm{O} & 6.891297 & -4.127074 & -3.528056 \\ \mathrm{H} & 7.569866 & -4.049548 & 1.013293 \\ \mathrm{H} & 2.767746 & -5.499469 & 4.537230 \\ \mathrm{C} & 2.939263 & -1.750187 & 5.774672 \\ \mathrm{C} & -7.365909 & -4.168372 & 1.124348 \\ \mathrm{O} & -6.887320 & -4.132964 & 3.528690 \\ \mathrm{H} & -7.565205 & -4.057643 & -1.012799 \\ \mathrm{H} & -2.761079 & -5.503605 & -4.535596 \\ \mathrm{C} & -2.936418 & -1.754880 & -5.774184 \\ \mathrm{H} & 8.300751 & -4.704158 & -1.241080 \\ \mathrm{C} & 8.100006 & -4.864359 & -3.796252 \\ \mathrm{H} & 3.880576 & -1.324082 & 5.407769 \\ \mathrm{H} & 2.092972 & -1.141196 & 5.429953 \\ \mathrm{H} & 2.951155 & -1.767881 & 6.864306 \\ \mathrm{H} & -8.295796 & -4.712250 & 1.241668 \\ \mathrm{C} & -8.095320 & -4.871395 & 3.796925 \\ \mathrm{H} & -3.878227 & -1.329665 & -5.407517 \\ \mathrm{H} & -2.090815 & -1.144883 & -5.429552 \\ \mathrm{H} & -2.948167 & -1.772912 & -6.863815 \\ \mathrm{H} & 8.075337 & -5.845442 & -3.310699 \\ \mathrm{H} & 8.981878 & -4.301078 & -3.473719 \\ \mathrm{H} & 8.126321 & -4.994113 & -4.877327 \\ \mathrm{H} & -8.069564 & -5.852616 & 3.311708 \\ \mathrm{H} & -8.977713 & -4.309126 & 3.474050 \\ \mathrm{H} & -8.121689 & -5.000811 & 4.878039\end{array}$

$\mathrm{M}=\mathrm{Cm}$
$\begin{array}{llll}\mathrm{CM} & 0.000073 & 1.372276 & -0.000021\end{array}$
$\begin{array}{llll}\mathrm{N} & 0.889627 & 3.065559 & 1.634120\end{array}$
$\mathrm{N} \quad-0.889446 \quad 3.065573 \quad-1.634185$
C $\quad 0.305932 \quad 3.205982 \quad 2.857824$ 


$\begin{array}{rrrr}\mathrm{N} & 1.903793 & 3.965179 & 1.624294 \\ \mathrm{~N} & 1.236896 & 1.495782 & -2.241466 \\ \mathrm{~N} & -1.236822 & 1.495881 & 2.241388 \\ \mathrm{~N} & 1.903966 & -0.075779 & -0.232296 \\ \mathrm{~N} & -1.903968 & -0.075730 & 0.232258 \\ \mathrm{C} & -0.305782 & 3.205940 & -2.857910 \\ \mathrm{~N} & -1.903569 & 3.965240 & -1.624351 \\ \mathrm{C} & 0.960673 & 4.195837 & 3.607126 \\ \mathrm{C} & -0.846562 & 2.358748 & 3.203124 \\ \mathrm{C} & 1.980251 & 4.659840 & 2.783374 \\ \mathrm{H} & 2.518873 & 4.076820 & 0.826270 \\ \mathrm{C} & 2.284035 & 0.672026 & -2.473049 \\ \mathrm{C} & 0.846662 & 2.358641 & -3.203217 \\ \mathrm{C} & -2.284009 & 0.672187 & 2.472980 \\ \mathrm{C} & 2.631643 & -0.236034 & -1.351087 \\ \mathrm{~N} & 2.016399 & -0.974605 & 0.765494 \\ \mathrm{C} & -2.631659 & -0.235897 & 1.351049 \\ \mathrm{~N} & -2.016450 & -0.974586 & -0.765497 \\ \mathrm{C} & -0.960498 & 4.195807 & -3.607216 \\ \mathrm{C} & -1.980030 & 4.659878 & -2.783445 \\ \mathrm{H} & -2.518621 & 4.076929 & -0.826311 \\ \mathrm{H} & 0.755057 & 4.553039 & 4.604857 \\ \mathrm{C} & -1.500426 & 2.428163 & 4.438997 \\ \mathrm{C} & 3.001180 & 5.719029 & 3.057006 \\ \mathrm{C} & 2.988917 & 0.682117 & -3.676621 \\ \mathrm{C} & 1.500509 & 2.427985 & -4.439104 \\ \mathrm{C} & -2.988910 & 0.682352 & 3.676542 \\ \mathrm{C} & 3.625182 & -1.103585 & -1.468916 \\ \mathrm{C} & 2.927287 & -1.942594 & 0.676991 \\ \mathrm{~N} & -3.625250 & -1.103386 & 1.468909 \\ \mathrm{C} & -2.927395 & -1.942519 & -0.676961 \\ \mathrm{H} & -0.754895 & 4.552975 & -4.604963 \\ \mathrm{C} & -3.000918 & 5.719107 & -3.057072 \\ \mathrm{C} & -2.584997 & 1.577534 & 4.673909 \\ \mathrm{H} & -1.174454 & 3.127523 & 5.200129 \\ \mathrm{O} & 3.812441 & 5.880160 & 1.999308 \\ \mathrm{O} & 3.037758 & 6.314426 & 4.110735 \\ \mathrm{C} & 2.585031 & 1.577291 & -4.674009 \\ \mathrm{H} & 3.826940 & 0.009419 & -3.813339 \\ \mathrm{C} & -3.826970 & 0.009702 & 3.813264 \\ \mathrm{C} & 2.851615 & -3.011982 & 1.692446 \\ \mathrm{C} & -3.011947 & -1.692378 \\ \mathrm{H} & 5.880301 & -1.999353\end{array}$




\begin{tabular}{|c|c|c|c|}
\hline$D$ & -3.037499 & 6.314480 & -4.110814 \\
\hline & -3.110513 & 1.613499 & 5.623475 \\
\hline$C$ & 4.856960 & 6.899479 & 2.154620 \\
\hline I & 3.110533 & 1.613201 & -5.623585 \\
\hline $\mathrm{C}$ & 5.147226 & -2.651505 & -0.465446 \\
\hline & 2.957015 & -4.353272 & 1.290060 \\
\hline$C$ & 2.597813 & -2.684391 & 3.041354 \\
\hline $\mathrm{C}$ & -5.147376 & -2.651265 & 0.465498 \\
\hline $\mathrm{C}$ & -2.957268 & -4.353217 & -1.289946 \\
\hline $\mathrm{C}$ & -2.597955 & -2.684418 & -3.041296 \\
\hline $\mathrm{C}$ & -4.856616 & 6.899665 & -2.154659 \\
\hline H & 4.393295 & 7.870759 & 2.331077 \\
\hline $\mathrm{H}$ & 5.501821 & 6.634035 & 2.993186 \\
\hline $\mathrm{H}$ & 5.406469 & 6.889353 & 1.215426 \\
\hline C & 5.745753 & -2.885539 & -1.720451 \\
\hline $\mathrm{C}$ & 5.821055 & -3.050069 & 0.719124 \\
\hline $\mathrm{C}$ & 2.794282 & -5.366604 & 2.243019 \\
\hline $\mathrm{H}$ & 3.149316 & -4.611322 & 0.255034 \\
\hline $\mathrm{C}$ & 2.478916 & -3.708583 & 3.990636 \\
\hline $\mathrm{H}$ & 2.525801 & -1.643695 & 3.331125 \\
\hline $\mathrm{C}$ & -5.745909 & -2.885232 & 1.720511 \\
\hline $\mathrm{C}$ & -5.821231 & -3.049825 & -0.719058 \\
\hline $\mathrm{C}$ & -2.794593 & -5.366592 & -2.242870 \\
\hline $\mathrm{H}$ & -3.149591 & -4.611220 & -0.254913 \\
\hline $\mathrm{C}$ & -2.479116 & -3.708650 & -3.990542 \\
\hline $\mathrm{H}$ & -2.525877 & -1.643737 & -3.331102 \\
\hline $\mathrm{H}$ & -4.392911 & 7.870919 & -2.331154 \\
\hline $\mathrm{H}$ & -5.501515 & 6.634230 & -2.993200 \\
\hline $\mathrm{H}$ & -5.406098 & 6.889588 & -1.215449 \\
\hline $\mathrm{C}$ & 6.981984 & -3.538958 & -1.815320 \\
\hline $\mathrm{H}$ & 5.247349 & -2.588377 & -2.634228 \\
\hline $\mathrm{C}$ & 7.065084 & -3.661559 & 0.614949 \\
\hline $\mathrm{H}$ & 5.396761 & -2.862603 & 1.695974 \\
\hline $\mathrm{C}$ & 2.566983 & -5.056065 & 3.580854 \\
\hline $\mathrm{H}$ & 2.860058 & -6.406845 & 1.940163 \\
\hline $\mathrm{O}$ & 2.275096 & -3.515266 & 5.320298 \\
\hline $\mathrm{C}$ & -6.982176 & -3.538583 & 1.815404 \\
\hline $\mathrm{H}$ & -5.247486 & -2.588072 & 2.634278 \\
\hline $\mathrm{C}$ & -7.065293 & -3.661247 & -0.614861 \\
\hline $\mathrm{H}$ & -5.396931 & -2.862409 & -1.695915 \\
\hline $\mathrm{C}$ & -2.567268 & -5.056113 & -3.580715 \\
\hline $\mathrm{H}$ & -2.860435 & -6.406818 & -1.939979 \\
\hline $\mathrm{O}$ & -2.275277 & -3.515391 & -5.320211 \\
\hline $\mathrm{C}$ & 7.648392 & -3.923954 & -0.633628 \\
\hline $\mathrm{O}$ & 7.445233 & -3.743933 & -3.070344 \\
\hline $\mathrm{H}$ & 7.598381 & -3.950887 & 1.514996 \\
\hline
\end{tabular}




$\begin{array}{lrrr}\mathrm{H} & 2.467427 & -5.832956 & 4.331713 \\ \mathrm{C} & 2.286159 & -2.182168 & 5.834187 \\ \mathrm{C} & -7.648610 & -3.923576 & 0.633726 \\ \mathrm{O} & -7.445430 & -3.743498 & 3.070435 \\ \mathrm{H} & -7.598608 & -3.950571 & -1.514898 \\ \mathrm{H} & -2.467756 & -5.833036 & -4.331547 \\ \mathrm{C} & -2.286255 & -2.182310 & -5.834144 \\ \mathrm{H} & 8.608963 & -4.423724 & -0.675975 \\ \mathrm{C} & 8.706042 & -4.420213 & -3.242298 \\ \mathrm{H} & 3.240922 & -1.685129 & 5.624856 \\ \mathrm{H} & 1.457423 & -1.591067 & 5.422570 \\ \mathrm{H} & 2.158893 & -2.280590 & 6.912064 \\ \mathrm{H} & -8.609207 & -4.423293 & 0.676090 \\ \mathrm{C} & -8.706274 & -4.419706 & 3.242414 \\ \mathrm{H} & -3.240988 & -1.685205 & -5.624835 \\ \mathrm{H} & -1.457484 & -1.591246 & -5.422542 \\ \mathrm{H} & -2.158988 & -2.280777 & -6.912017 \\ \mathrm{H} & 8.666820 & -5.432019 & -2.825661 \\ \mathrm{H} & 9.521556 & -3.850443 & -2.784774 \\ \mathrm{H} & 8.860336 & -4.475963 & -4.319019 \\ \mathrm{H} & -8.667108 & -5.431525 & 2.825804 \\ \mathrm{H} & -9.521760 & -3.849906 & 2.784877 \\ \mathrm{H} & -8.860566 & -4.475419 & 4.319136\end{array}$

$\mathbf{L}=\mathbf{2 b m}$

\section{$\left[\mathrm{ML}\left(\mathrm{H}_{2} \mathrm{O}\right)_{6}\right]^{3+}$}

$\mathrm{M}=\mathrm{Eu}$

$\begin{array}{lccc}\text { EU } & 2.417897 & -0.948090 & 0.273716 \\ \mathrm{O} & 1.423610 & -2.494821 & 2.191491 \\ \mathrm{O} & 2.605650 & -1.101932 & -2.377147 \\ \mathrm{H} & 1.046107 & -3.386834 & 2.148047 \\ \mathrm{H} & 1.051588 & -2.074362 & 2.982845 \\ \mathrm{O} & 0.842296 & -2.865577 & -0.680010 \\ \mathrm{O} & 2.036235 & 0.272157 & 2.608961 \\ \mathrm{H} & 3.289135 & -1.662488 & -2.777599 \\ \mathrm{H} & 2.458436 & -0.380858 & -3.009117 \\ \mathrm{H} & -0.051368 & -2.547233 & -0.414513 \\ \mathrm{H} & 0.827658 & -2.894083 & -1.649918 \\ \mathrm{H} & 2.828084 & 0.071590 & 3.136467 \\ \mathrm{H} & 1.705502 & 1.128383 & 2.919169 \\ \mathrm{~N} & -1.147278 & -0.975384 & -0.068165 \\ \mathrm{C} & -2.415028 & -0.555741 & -0.030168 \\ \mathrm{~N} & -0.137161 & -0.099301 & -0.164956\end{array}$




$\begin{array}{lrcc}\mathrm{C} & -2.692568 & 0.852327 & -0.169531 \\ \mathrm{C} & -3.461240 & -1.582909 & 0.201647 \\ \mathrm{C} & -0.426550 & 1.209492 & -0.222366 \\ \mathrm{C} & -4.056301 & 1.421781 & -0.264790 \\ \mathrm{~N} & -1.672961 & 1.705886 & -0.236387 \\ \mathrm{C} & -3.466414 & -2.776731 & -0.530416 \\ \mathrm{C} & -4.436782 & -1.353163 & 1.202087 \\ \mathrm{C} & 0.712072 & 2.164002 & -0.331639 \\ \mathrm{C} & -4.300842 & 2.682596 & 0.271419 \\ \mathrm{C} & -5.101943 & 0.730861 & -0.940245 \\ \mathrm{C} & -4.465113 & -3.742783 & -0.273766 \\ \mathrm{H} & -2.733735 & -2.938945 & -1.311177 \\ \mathrm{C} & -5.406608 & -2.333725 & 1.469981 \\ \mathrm{H} & -4.412466 & -0.447437 & 1.796866 \\ \mathrm{C} & 0.463366 & 3.530365 & -0.478438 \\ \mathrm{~N} & 1.958517 & 1.638187 & -0.310810 \\ \mathrm{C} & -5.592296 & 3.261981 & 0.179393 \\ \mathrm{H} & -3.523596 & 3.240025 & 0.780412 \\ \mathrm{C} & -6.372591 & 1.317811 & -1.042730 \\ \mathrm{H} & -4.915279 & -0.213159 & -1.435325 \\ \mathrm{C} & -5.432354 & -3.514213 & 0.743218 \\ \mathrm{O} & -4.598609 & -4.903824 & -0.927907 \\ \mathrm{H} & -6.140517 & -2.167358 & 2.251978 \\ \mathrm{C} & 1.555375 & 4.395883 & -0.609445 \\ \mathrm{H} & -0.555977 & 3.893177 & -0.499699 \\ \mathrm{C} & 3.010067 & 2.474429 & -0.440997 \\ \mathrm{C} & -6.636270 & 2.565306 & -0.486668 \\ \mathrm{H} & -5.719215 & 4.462348 & 0.747654 \\ \mathrm{H} & -6.812226 & 6.095293 & 1.248920 \\ \mathrm{H} & -7.160780 & 0.796348 & -1.576526 \\ \mathrm{H} & -6.179269 & -4.280416 & 0.923934 \\ \mathrm{C} & -3.706315 & -5.246047 & -2.005406 \\ \mathrm{C} & 2.841190 & 3.863382 & -0.592490 \\ \mathrm{H} & 1.402688 & 5.464282 & -0.727014 \\ \mathrm{C} & 4.360177 & 1.882566 & -0.428603 \\ \mathrm{H} & -7.625312 & 2.999205 & -0.574942 \\ \mathrm{C} & -6.991848 & 5.161502 & 0.719874 \\ \mathrm{H} & -3.776964 & -4.509602 & -2.812489 \\ \mathrm{H} & -2.676885 & -5.327621 & -1.640441 \\ \mathrm{H} & -4.046690 & -6.216340 & -2.363173 \\ \mathrm{H} & 5.601924 & 2.520033 & -0.646909 \\ \mathrm{H} & -7.56895 & 0.561619 & -0.200618 \\ \mathrm{H} & -5.523610 & -0.548894\end{array}$




$\begin{array}{llll}\mathrm{H} & 5.797063 & 3.559919 & -0.858912 \\ \mathrm{~N} & 5.875992 & 0.379192 & -0.276223 \\ \mathrm{C} & 8.054801 & 1.564081 & -0.699628 \\ \mathrm{H} & 8.388687 & 2.594067 & -0.828279 \\ \mathrm{H} & 8.379402 & 0.993534 & -1.575669 \\ \mathrm{H} & 8.557806 & 1.153737 & 0.181260 \\ \mathrm{O} & 4.224700 & -1.483711 & 2.361455 \\ \mathrm{H} & 4.055094 & -2.314151 & 2.835761 \\ \mathrm{H} & 5.124080 & -1.216981 & 2.608414 \\ \mathrm{O} & 3.662669 & -3.208942 & -0.390590 \\ \mathrm{H} & 3.022652 & -3.927621 & -0.522694 \\ \mathrm{H} & 4.523781 & -3.639038 & -0.276543 \\ \mathrm{H} & 6.267599 & -0.547812 & -0.175541\end{array}$

$\mathrm{M}=\mathrm{Gd}$

$\begin{array}{lrrr}\text { GD } & -2.269480 & -0.844624 & 0.203161 \\ \mathrm{O} & -3.778871 & -2.097875 & 1.861224 \\ \mathrm{H} & -4.310420 & -2.907634 & 1.915297 \\ \mathrm{O} & -3.851189 & -2.469217 & -1.033936 \\ \mathrm{H} & -4.160581 & -3.384091 & -0.937810 \\ \mathrm{O} & -2.523590 & 0.293143 & 2.478978 \\ \mathrm{H} & -1.829544 & 0.135829 & 3.141122 \\ \mathrm{O} & -2.222515 & -0.564269 & -2.311513 \\ \mathrm{H} & -2.493052 & 0.211382 & -2.829421 \\ \mathrm{O} & -0.901967 & -1.906888 & 2.103026 \\ \mathrm{H} & -1.171163 & -2.658285 & 2.655628 \\ \mathrm{O} & -0.848696 & -2.569187 & -0.823182 \\ \mathrm{H} & -0.880021 & -3.494318 & -1.107739 \\ \mathrm{H} & -2.911837 & 1.159498 & 2.682771 \\ \mathrm{H} & -1.512222 & -1.000021 & -2.811850 \\ \mathrm{H} & -3.864967 & -2.279512 & -1.987868 \\ \mathrm{H} & 0.102370 & -2.313776 & -0.627870 \\ \mathrm{H} & -3.974133 & -1.584770 & 2.663716 \\ \mathrm{H} & 0.060421 & -1.978481 & 1.983348 \\ \mathrm{C} & -0.691920 & 2.183664 & -0.166329 \\ \mathrm{C} & -0.467864 & 3.557300 & -0.273379 \\ \mathrm{C} & -1.572297 & 4.408003 & -0.390742 \\ \mathrm{C} & -2.856281 & 3.858763 & -0.395852 \\ \mathrm{C} & -3.000884 & 2.470423 & -0.277387 \\ \mathrm{~N} & -1.932750 & 1.645097 & -0.161115 \\ \mathrm{H} & -1.433869 & 5.481479 & -0.478342 \\ \mathrm{H} & 0.547655 & 3.933090 & -0.263064 \\ \mathrm{H} & -3.728216 & 4.495593 & -0.490501 \\ \mathrm{C} & 0.435163 & 1.222300 & -0.067647 \\ \mathrm{~N} & 1.680324 & 1.684556 & -0.093609\end{array}$




\begin{tabular}{|c|c|c|c|}
\hline & 4666 & -0.070521 & \\
\hline $\mathrm{C}$ & 2.699825 & 0.811724 & 0037508 \\
\hline & 1.102501 & -0.986256 & 6590 \\
\hline & 4.028921 & 1.34 & \\
\hline & 2.372435 & -0.6 & \\
\hline & 4.262511 & 2.7 & \\
\hline & & & \\
\hline 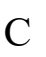 & 3.338025 & -1.6 & \\
\hline & 5.50 & & \\
\hline & 3.495 & 06 & -0. \\
\hline $\mathrm{C}$ & 6.2 & 54 & \\
\hline & 4.900145 & -0. & \\
\hline & 4.251 & -1.3 & $-1 .($ \\
\hline$C$ & 3.28 & -2 & -0. \\
\hline $\mathrm{C}$ & 6.5 & & \\
\hline & & & -0. \\
\hline H & 7.0 & & \\
\hline & 5.0 & -2.3 & \\
\hline $\mathrm{H}$ & 4.30 & -0 . & -2 \\
\hline & 4.1 & & -0. \\
\hline $\mathrm{H}$ & 2.6 & & \\
\hline & 7.4 & & \\
\hline $\mathrm{C}$ & & & \\
\hline & 5.0 & -3.6 & -1.5 \\
\hline $\mathrm{H}$ & 5.7 & -2 . & -2 \\
\hline $\mathrm{O}$ & 4.2 & -5 & \\
\hline $\mathrm{H}$ & 6.7 & & -0.1 \\
\hline 11 & 7.1225 & & \\
\hline $\mathrm{H}$ & 7.65 & 4.7 & -0.3 \\
\hline $\mathrm{H}$ & 5.72 & -4.4 & -1. \\
\hline $\mathrm{C}$ & & & \\
\hline H & 3.68 & & \\
\hline $\mathrm{H}$ & 2.3793 & -5. & \\
\hline $\mathrm{H}$ & 3.72 & -6 & 96 \\
\hline $\mathrm{C}$ & -4.311503 & & -0.2 \\
\hline $\mathrm{C}$ & -5.60 & 2.3 & -0. \\
\hline $\mathrm{N}$ & -4.341459 & 0.4 & -0 . \\
\hline $\mathrm{C}$ & -6.4 & 1.2 & -0.3 \\
\hline $\mathrm{H}$ & -5.912788 & 234 & -0.5 \\
\hline $\mathrm{N}$ & -5.662788 & 80 & -0.2 \\
\hline$c$ & -7.955470 & 1.124709 & -0.4 \\
\hline $\mathrm{H}$ & -5.947223 & -0.835514 & -0.177566 \\
\hline 11 & -8.428064 & 1.694771 & 0.327996 \\
\hline $\mathrm{H}$ & & 1.547320 & -1.424 \\
\hline & -8.302843 & 0.090992 & -0.415 \\
\hline
\end{tabular}


$\mathrm{M}=\mathrm{Am}$

$\begin{array}{lrrr}\text { AM } & -2.127413 & -0.763452 & 0.226619 \\ \mathrm{~N} & -4.168119 & 0.627249 & -0.297623 \\ \mathrm{~N} & 0.301614 & -0.010638 & 0.069322 \\ \mathrm{~N} & -5.492124 & 0.355105 & -0.446149 \\ \mathrm{C} & -4.087873 & 1.978966 & -0.364000 \\ \mathrm{~N} & -1.714404 & 1.753767 & -0.141688 \\ \mathrm{C} & 0.647535 & 1.281476 & -0.026595 \\ \mathrm{~N} & 1.282101 & -0.935391 & -0.089372 \\ \mathrm{C} & -6.251401 & 1.469309 & -0.603363 \\ \mathrm{H} & -5.804755 & -0.608014 & -0.463868 \\ \mathrm{C} & -5.359176 & 2.545336 & -0.549787 \\ \mathrm{C} & -2.760428 & 2.603826 & -0.275267 \\ \mathrm{C} & -0.462039 & 2.264883 & -0.106248 \\ \mathrm{~N} & 1.901734 & 1.724727 & -0.038006 \\ \mathrm{C} & 2.556941 & -0.572791 & -0.223765 \\ \mathrm{C} & -7.734067 & 1.428754 & -0.795946 \\ \mathrm{H} & -5.624538 & 3.587418 & -0.646067 \\ \mathrm{C} & -2.581423 & 3.991708 & -0.349810 \\ \mathrm{C} & -0.205785 & 3.635165 & -0.169191 \\ \mathrm{C} & 2.905230 & 0.834955 & -0.024322 \\ \mathrm{C} & 3.509180 & -1.622152 & -0.634287 \\ \mathrm{H} & -8.235712 & 2.012554 & -0.019268 \\ \mathrm{H} & -8.004737 & 1.865225 & -1.761647 \\ \mathrm{H} & -8.120023 & 0.407535 & -0.761044 \\ \mathrm{C} & -1.288410 & 4.513089 & -0.288747 \\ \mathrm{H} & -3.435842 & 4.649683 & -0.457371 \\ \mathrm{H} & 0.816676 & 3.988876 & -0.127045 \\ \mathrm{C} & 4.251023 & 1.339423 & 0.221949 \\ \mathrm{C} & 3.438048 & -2.917515 & -0.074133 \\ \mathrm{C} & 4.427913 & -1.337569 & -1.659329 \\ \mathrm{H} & -1.125235 & 5.585338 & -0.340723 \\ \mathrm{C} & 4.516451 & 2.698166 & -0.036148 \\ \mathrm{C} & 5.262340 & 0.523413 & 0.800769 \\ \mathrm{C} & 4.309966 & -3.918122 & -0.530413 \\ \mathrm{H} & 2.750460 & -3.117163 & 0.738890 \\ \mathrm{C} & 5.258552 & -2.360039 & -2.138139 \\ \mathrm{H} & 4.486817 & -0.347448 & -2.096227 \\ \mathrm{C} & 5.778217 & 3.247644 & 0.238642 \\ \mathrm{H} & 3.762317 & 3.336290 & -0.478440 \\ & 6.497622 & 1.087028 & 1.104761 \\ \mathrm{H} & 5.079344 & -0.516409 & 1.034723 \\ \mathrm{H} & -3.633289 & -1.581383 \\ \mathrm{H} & -5.178444 & -0.041580 \\ \mathrm{H} & -2.154170 & -2.943429\end{array}$




$\begin{array}{rrrc}\mathrm{C} & 6.774542 & 2.430756 & 0.820775 \\ \mathrm{O} & 5.934676 & 4.547612 & -0.081047 \\ \mathrm{H} & 7.268077 & 0.477030 & 1.565574 \\ \mathrm{H} & 5.870488 & -4.424605 & -1.924270 \\ \mathrm{C} & 3.575092 & -5.536437 & 1.090057 \\ \mathrm{H} & 7.754957 & 2.831611 & 1.050267 \\ \mathrm{C} & 7.209693 & 5.184500 & 0.155938 \\ \mathrm{H} & 3.808847 & -4.902474 & 1.953543 \\ \mathrm{H} & 2.504457 & -5.479005 & 0.853095 \\ \mathrm{H} & 3.836020 & -6.569059 & 1.319045 \\ \mathrm{H} & 8.000768 & 4.694023 & -0.419694 \\ \mathrm{H} & 7.451813 & 5.183087 & 1.223312 \\ \mathrm{H} & 7.087404 & 6.209497 & -0.190301 \\ \mathrm{O} & -0.671747 & -2.592835 & -0.761196 \\ \mathrm{H} & -0.686960 & -3.524012 & -1.026633 \\ \mathrm{H} & 0.272830 & -2.315966 & -0.584677 \\ \mathrm{O} & -3.718277 & -2.022547 & 1.902234 \\ \mathrm{H} & -4.278959 & -2.813518 & 1.941915 \\ \mathrm{H} & -3.938400 & -1.488157 & 2.684046 \\ \mathrm{O} & -2.523648 & 0.418032 & 2.545241 \\ \mathrm{H} & -2.940272 & 1.276705 & 2.724154 \\ \mathrm{H} & -1.849872 & 0.288256 & 3.233534 \\ \mathrm{O} & -0.781863 & -1.761588 & 2.258147 \\ \mathrm{H} & -1.097953 & -2.504434 & 2.797975 \\ \mathrm{H} & 0.185723 & -1.837961 & 2.226948 \\ \mathrm{O} & -3.785103 & -2.380474 & -1.082878 \\ \mathrm{H} & -4.137760 & -3.280390 & -0.994328 \\ \mathrm{H} & -3.684490 & -2.223026 & -2.037569 \\ \mathrm{O} & -2.009282 & -0.586051 & -2.390495 \\ \mathrm{H} & -2.253753 & 0.170518 & -2.948144 \\ \mathrm{H} & -1.287083 & -1.046122 & -2.850006 \\ & & & \end{array}$

$\mathrm{M}=\mathrm{Cm}$

$\begin{array}{lrrr}\mathrm{CM} & 2.111443 & 0.756980 & 0.196661 \\ \mathrm{O} & 3.671418 & 2.011163 & 1.892252 \\ \mathrm{H} & 4.209159 & 2.816845 & 1.949938 \\ \mathrm{O} & 3.750474 & 2.376161 & -1.071071 \\ \mathrm{H} & 4.086581 & 3.279593 & -0.956632 \\ \mathrm{O} & 2.416779 & -0.407474 & 2.517601 \\ \mathrm{H} & 1.730205 & -0.254864 & 3.188585 \\ \mathrm{O} & 2.031248 & 0.537574 & -2.376640 \\ \mathrm{H} & 2.270697 & -0.230769 & -2.920524 \\ \mathrm{O} & 0.754213 & 1.809584 & 2.180249 \\ \mathrm{H} & 1.048530 & 2.553251 & 2.730723 \\ \mathrm{O} & 0.665561 & 2.542178 & -0.816289\end{array}$




\begin{tabular}{|c|c|c|c|}
\hline $\mathrm{H}$ & 0.686928 & 3.477091 & -1.068386 \\
\hline $\mathrm{H}$ & 2.807664 & -1.275134 & 2.711392 \\
\hline & 1.319554 & 1.003078 & -2.847675 \\
\hline 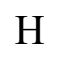 & 3.722780 & 2.218137 & -2.030336 \\
\hline & -0.281281 & 2.271932 & -0.619679 \\
\hline & 3.873487 & 1.485713 & 2.684845 \\
\hline & -0.211026 & 1.888604 & 2.100093 \\
\hline & 0.458097 & -2.261758 & -0.172093 \\
\hline & 0.204345 & -3.630776 & -0.269319 \\
\hline$y$ & 1.289102 & -4.505340 & -0.393574 \\
\hline $\mathrm{C}$ & 2.583940 & -3.983562 & -0.416728 \\
\hline$C$ & 2.760471 & -2.598171 & -0.307243 \\
\hline $\mathrm{N}$ & 1.711179 & -1.750836 & -0.181388 \\
\hline $\mathrm{H}$ & 1.126984 & -5.576091 & -0.473619 \\
\hline $\mathrm{H}$ & -0.818385 & -3.985708 & -0.247255 \\
\hline $\mathrm{H}$ & 3.440321 & -4.639877 & -0.519000 \\
\hline $\mathrm{C}$ & -0.652838 & -1.280413 & -0.072713 \\
\hline $\mathrm{C}$ & -2.911682 & -0.836009 & -0.044893 \\
\hline $\mathrm{C}$ & -4.248467 & -1.344181 & 0.218330 \\
\hline $\mathrm{C}$ & -2.563583 & 0.577758 & -0.224479 \\
\hline $\mathrm{C}$ & -4.504821 & -2.711515 & -0.020999 \\
\hline$r$ & -5.261104 & -0.530806 & 0.798251 \\
\hline $\mathrm{C}$ & -3.513270 & 1.631894 & -0.624698 \\
\hline $\mathrm{C}$ & -5.755388 & -3.270632 & 0.273606 \\
\hline $\mathrm{C}$ & -4.432466 & 1.357913 & -1.651485 \\
\hline $\mathrm{C}$ & -6.484614 & -1.104493 & 1.122714 \\
\hline $\mathrm{C}$ & -3.435615 & 2.924637 & -0.056956 \\
\hline 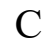 & -6.750828 & -2.455936 & 0.857003 \\
\hline $\mathrm{C}$ & -5.256224 & 2.387950 & -2.125334 \\
\hline G & -4.301436 & 3.931954 & -0.507494 \\
\hline $\mathrm{H}$ & -7.725357 & -2.862207 & 1.101655 \\
\hline $\mathrm{C}$ & -5.202967 & 3.657906 & -1.561126 \\
\hline $\mathrm{H}$ & -5.857688 & 4.454278 & -1.899766 \\
\hline $\mathrm{N}$ & -1.905156 & -1.724206 & -0.095192 \\
\hline $\mathrm{N}$ & -0.305471 & 0.008606 & 0.056174 \\
\hline $\mathrm{N}$ & -1.288730 & 0.937722 & -0.087671 \\
\hline $\mathrm{O}$ & -4.359134 & 5.190380 & -0.010463 \\
\hline $\mathrm{O}$ & -5.903260 & -4.577635 & -0.029459 \\
\hline 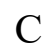 & -7.171633 & -5.217027 & 0.229172 \\
\hline $\mathrm{H}$ & -7.048954 & -6.245939 & -0.105503 \\
\hline $\mathrm{H}$ & -7.403460 & -5.204559 & 1.298943 \\
\hline $\mathrm{H}$ & -7.972389 & -4.738627 & -0.343578 \\
\hline $\mathrm{C}$ & -3.565913 & 5.533227 & 1.128472 \\
\hline $\mathrm{H}$ & -3.806611 & 4.891832 & 1.984689 \\
\hline $\mathrm{H}$ & -2.493884 & 5.473807 & 0.897064 \\
\hline $\mathrm{H}$ & -3.823199 & 6.564683 & 1.366840 \\
\hline
\end{tabular}




$\begin{array}{lrrr}\mathrm{H} & -2.749890 & 3.115046 & 0.759878 \\ \mathrm{H} & -4.498732 & 0.369812 & -2.091915 \\ \mathrm{H} & -5.955162 & 2.190546 & -2.931925 \\ \mathrm{H} & -5.088036 & 0.514243 & 1.014986 \\ \mathrm{H} & -3.748804 & -3.345945 & -0.465008 \\ \mathrm{H} & -7.257298 & -0.498199 & 1.584764 \\ \mathrm{C} & 4.089356 & -1.969852 & -0.336632 \\ \mathrm{C} & 5.365977 & -2.530968 & -0.494347 \\ \mathrm{C} & 6.260812 & -1.455838 & -0.473316 \\ \mathrm{H} & 5.633439 & -3.569619 & -0.617772 \\ \mathrm{~N} & 4.168004 & -0.619903 & -0.217335 \\ \mathrm{~N} & 5.498028 & -0.346341 & -0.303995 \\ \mathrm{C} & 7.749738 & -1.412692 & -0.607019 \\ \mathrm{H} & 8.219172 & -2.035296 & 0.159573 \\ \mathrm{H} & 8.055985 & -1.804437 & -1.581310 \\ \mathrm{H} & 8.137163 & -0.396167 & -0.508683 \\ \mathrm{H} & 5.815675 & 0.614498 & -0.271035\end{array}$

\section{$\left[\mathrm{ML}\left(\mathrm{H}_{2} \mathrm{O}\right)_{5}\right]^{3+}$}

$\mathrm{M}=\mathrm{Eu}$

$\begin{array}{lccc}\text { EU } & 2.494713 & -0.985491 & 0.423905 \\ \mathrm{O} & 1.271216 & -1.177702 & 2.776257 \\ \mathrm{H} & 0.673570 & -1.923900 & 2.940465 \\ \mathrm{O} & 0.820011 & -2.942264 & 0.342793 \\ \mathrm{H} & 0.769657 & -3.908276 & 0.365948 \\ \mathrm{O} & 4.270433 & -2.929799 & 0.259184 \\ \mathrm{H} & 4.349846 & -3.540431 & -0.490850 \\ \mathrm{O} & 4.118309 & -0.632981 & 2.464300 \\ \mathrm{H} & 4.014841 & -0.929212 & 3.382031 \\ \mathrm{O} & 2.643717 & -1.584646 & -2.100041 \\ \mathrm{H} & 3.194756 & -1.069581 & -2.710517 \\ \mathrm{H} & 4.765983 & -3.338290 & 0.986815 \\ \mathrm{H} & 2.065688 & -2.128203 & -2.656983 \\ \mathrm{H} & 1.195254 & -0.598923 & 3.550644 \\ \mathrm{H} & -0.092376 & -2.578310 & 0.219539 \\ \mathrm{H} & 4.915073 & -0.080065 & 2.449814 \\ \mathrm{C} & 0.789177 & 2.097368 & -0.249275 \\ \mathrm{C} & 0.549585 & 3.464056 & -0.407558 \\ \mathrm{C} & 1.645368 & 4.320245 & -0.563448 \\ \mathrm{C} & 2.926722 & 3.776217 & -0.583266 \\ \mathrm{C} & 3.085758 & 2.388606 & -0.424320 \\ \mathrm{~N} & 2.032134 & 1.564421 & -0.235259 \\ \mathrm{H} & 1.498318 & 5.388951 & -0.685067 \\ \mathrm{H} & -0.467024 & 3.834429 & -0.422199\end{array}$




\begin{tabular}{|c|c|c|c|}
\hline $\mathrm{H}$ & 3.790789 & 4.413401 & -0.728558 \\
\hline & -0.356089 & 1.150501 & -0.143702 \\
\hline $\mathrm{C}$ & -2.627115 & 0.815430 & -0.146466 \\
\hline$C$ & -3.983415 & 1.399288 & -0.268881 \\
\hline 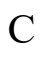 & -2.367607 & -0.594376 & 0.000543 \\
\hline $\mathrm{C}$ & -4.226966 & 2.659661 & 0.267432 \\
\hline$C$ & -5.021797 & 0.721804 & -0.969094 \\
\hline $\mathrm{C}$ & -3.429776 & -1.613855 & 0.186850 \\
\hline$C$ & -5.511583 & 3.251947 & 0.151136 \\
\hline & -4.429470 & -1.395054 & 1.165283 \\
\hline$C$ & -6.285493 & 1.320754 & -1.094418 \\
\hline & -3.429912 & -2.787936 & -0.577338 \\
\hline & -6.549011 & 2.567967 & -0.538883 \\
\hline$C$ & -5.418227 & -2.369568 & 1.382079 \\
\hline $\mathrm{C}$ & -4.449585 & -3.745167 & -0.374383 \\
\hline $\mathrm{H}$ & -7.531828 & 3.011873 & -0.645305 \\
\hline $\mathrm{C}$ & -5.439286 & -3.530457 & 0.624124 \\
\hline $\mathrm{H}$ & -6.200777 & -4.290729 & 0.764754 \\
\hline $\mathrm{N}$ & -1.598027 & 1.658099 & -0.181411 \\
\hline $\mathrm{N}$ & -0.080562 & -0.160545 & -0.064601 \\
\hline $\mathrm{N}$ & -1.102532 & -1.022258 & 0.022962 \\
\hline 0 & -4.584662 & -4.884344 & -1.065439 \\
\hline $\mathrm{O}$ & -5.638057 & 4.450155 & 0.721611 \\
\hline $\mathrm{C}$ & -6.902883 & 5.163572 & 0.673803 \\
\hline $\mathrm{H}$ & -6.722683 & 6.092495 & 1.211069 \\
\hline $\mathrm{H}$ & -7.176817 & 5.376322 & -0.363089 \\
\hline $\mathrm{H}$ & -7.682522 & 4.584450 & 1.175935 \\
\hline$C$ & -3.681731 & -5.202193 & -2.141455 \\
\hline $\mathrm{H}$ & -3.727893 & -4.435983 & -2.922053 \\
\hline $\mathrm{H}$ & -2.659002 & -5.313657 & -1.765583 \\
\hline $\mathrm{H}$ & -4.031565 & -6.153496 & -2.538885 \\
\hline $\mathrm{H}$ & -2.678954 & -2.936528 & -1.343705 \\
\hline $\mathrm{H}$ & -4.410505 & -0.503729 & 1.781840 \\
\hline $\mathrm{H}$ & -6.170920 & -2.213790 & 2.148267 \\
\hline $\mathrm{H}$ & -4.833426 & -0.220402 & -1.466945 \\
\hline $\mathrm{H}$ & -3.455317 & 3.207944 & 0.794694 \\
\hline $\mathrm{H}$ & -7.067022 & 0.808747 & -1.646842 \\
\hline $\mathrm{C}$ & 4.421314 & 1.768318 & -0.495937 \\
\hline 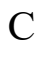 & 5.680322 & 2.371384 & -0.700314 \\
\hline $\mathrm{C}$ & 6.604237 & 1.328489 & -0.721747 \\
\hline 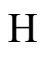 & 5.913810 & 3.417655 & -0.825433 \\
\hline $\mathrm{N}$ & 4.543150 & 0.425719 & -0.389729 \\
\hline $\mathrm{N}$ & 5.875947 & 0.194163 & -0.523785 \\
\hline 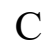 & 8.085004 & 1.321159 & -0.940693 \\
\hline $\mathrm{H}$ & 8.315911 & 1.282585 & -2.010263 \\
\hline & 8.532528 & 2.231572 & -0.537985 \\
\hline
\end{tabular}




$$
\begin{array}{rrrr}
\mathrm{H} & 8.561311 & 0.463518 & -0.458705 \\
\mathrm{H} & 6.220642 & -0.758003 & -0.505858
\end{array}
$$

\section{$\mathrm{M}=\mathrm{Gd}$}

$\begin{array}{lrrr}\mathrm{O} & 3.344659 & -2.534316 & 1.789969 \\ \mathrm{H} & 2.899179 & -3.343412 & 2.093506 \\ \mathrm{O} & 0.821686 & -2.723243 & 0.050697 \\ \mathrm{H} & 0.767659 & -3.680456 & -0.086064 \\ \mathrm{O} & 3.825012 & -2.546665 & -1.080408 \\ \mathrm{H} & 3.869928 & -2.590363 & -2.050464 \\ \mathrm{O} & 2.040173 & -0.104956 & 2.426809 \\ \mathrm{H} & 1.785407 & 0.787907 & 2.710909 \\ \mathrm{O} & 2.160531 & -0.608253 & -2.387373 \\ \mathrm{H} & 2.613402 & 0.089596 & -2.889815 \\ \mathrm{H} & 4.151319 & -3.399613 & -0.750333 \\ \mathrm{H} & 1.404973 & -0.879569 & -2.935271 \\ \mathrm{H} & 4.149093 & -2.458316 & 2.330672 \\ \mathrm{H} & -0.133016 & -2.323818 & 0.079809 \\ \mathrm{H} & 2.077774 & -0.646273 & 3.231985 \\ \mathrm{C} & 0.773290 & 2.150664 & 0.005698 \\ \mathrm{C} & 0.567862 & 3.530577 & 0.010243 \\ \mathrm{C} & 1.686206 & 4.372531 & 0.010564 \\ \mathrm{C} & 2.965246 & 3.810749 & -0.006796 \\ \mathrm{C} & 3.093549 & 2.416312 & -0.019843 \\ \mathrm{~N} & 2.011580 & 1.600332 & -0.006224 \\ \mathrm{H} & 1.561945 & 5.451370 & 0.016825 \\ \mathrm{H} & -0.443314 & 3.918647 & 0.007286 \\ \mathrm{H} & 3.844592 & 4.444222 & -0.016341 \\ \mathrm{C} & -0.362736 & 1.192325 & -0.001187 \\ \mathrm{C} & -2.631310 & 0.790742 & -0.009453 \\ \mathrm{C} & -3.962871 & 1.338286 & -0.208099 \\ \mathrm{C} & -2.313233 & -0.634322 & 0.130316 \\ \mathrm{C} & -4.174318 & 2.701824 & 0.094117 \\ \mathrm{C} & -5.016973 & 0.576167 & -0.785697 \\ \mathrm{C} & -3.291341 & -1.698820 & 0.423745 \\ \mathrm{C} & -5.418599 & 3.304046 & -0.131237 \\ \mathrm{C} & -4.196602 & -1.516222 & 1.481603 \\ \mathrm{C} & -6.234132 & 1.194830 & -1.044018 \\ \mathrm{C} & -3.252078 & -2.916333 & -0.292626 \\ \mathrm{C} & -6.454999 & 2.539843 & -0.712693 \\ \mathrm{C} & -5.047100 & -2.571172 & 1.839155 \\ \mathrm{H} & -4.146785 & -3.943891 & 0.044002 \\ & -5.725783 & 2.980996 & -0.906880 \\ & & -3.768246 & 1.130491 \\ & -4.579299 & 1.380138\end{array}$




$\begin{array}{lrrc}\mathrm{N} & -1.603604 & 1.661489 & 0.015407 \\ \mathrm{~N} & -0.035664 & -0.108042 & -0.062029 \\ \mathrm{~N} & -1.041033 & -1.010448 & 0.047079 \\ \mathrm{O} & -4.245012 & -5.132015 & -0.597606 \\ \mathrm{O} & -5.521535 & 4.600318 & 0.230469 \\ \mathrm{C} & -6.779522 & 5.283020 & 0.038908 \\ \mathrm{H} & -6.617921 & 6.293772 & 0.410350 \\ \mathrm{H} & -7.044846 & 5.320431 & -1.022420 \\ \mathrm{H} & -7.574762 & 4.802906 & 0.617805 \\ \mathrm{C} & -3.472043 & -5.357489 & -1.780009 \\ \mathrm{H} & -3.698856 & -4.609723 & -2.548848 \\ \mathrm{H} & -2.396942 & -5.358024 & -1.556524 \\ \mathrm{H} & -3.763210 & -6.344265 & -2.138283 \\ \mathrm{H} & -2.579130 & -3.024454 & -1.135170 \\ \mathrm{H} & -4.232681 & -0.582505 & 2.031125 \\ \mathrm{H} & -5.736565 & -2.449579 & 2.668564 \\ \mathrm{H} & -4.879200 & -0.461060 & -1.056154 \\ \mathrm{H} & -3.386027 & 3.298866 & 0.533758 \\ \mathrm{H} & -7.037010 & 0.629056 & -1.505888 \\ \mathrm{C} & 4.396513 & 1.737598 & -0.076852 \\ \mathrm{C} & 5.696428 & 2.257349 & -0.126024 \\ \mathrm{C} & 6.549187 & 1.151050 & -0.222400 \\ \mathrm{H} & 6.007665 & 3.291029 & -0.105031 \\ \mathrm{~N} & 4.416480 & 0.377327 & -0.132640 \\ \mathrm{~N} & 5.740384 & 0.061721 & -0.220280 \\ \mathrm{C} & 8.038699 & 1.064204 & -0.315738 \\ \mathrm{H} & 8.399985 & 1.643722 & -1.169788 \\ \mathrm{H} & 8.500104 & 1.482419 & 0.583693 \\ \mathrm{H} & 8.380406 & 0.033132 & -0.430029 \\ \mathrm{GD} & 2.320707 & -0.883602 & 0.095770 \\ \mathrm{H} & 6.024593 & -0.904154 & -0.329063 \\ & & & \\ \mathrm{M}=\mathrm{Am} & & & \\ & & & \\ & & \\ & & \end{array}$

$\begin{array}{lrrc}\text { AM } & 2.204980 & -0.822267 & 0.160756 \\ \mathrm{O} & 2.806729 & -2.596860 & 2.043546 \\ \mathrm{H} & 2.205330 & -3.340999 & 2.213941 \\ \mathrm{O} & 0.633868 & -2.752630 & -0.042460 \\ \mathrm{H} & 0.576417 & -3.689733 & -0.279815 \\ \mathrm{O} & 4.054482 & -2.474768 & -0.685168 \\ \mathrm{H} & 4.250118 & -2.588555 & -1.630332 \\ \mathrm{O} & 1.945861 & 0.147303 & 2.507267 \\ \mathrm{H} & 1.889102 & 1.084614 & 2.753501 \\ \mathrm{O} & 2.213549 & -0.827259 & -2.425604 \\ \mathrm{H} & 2.617590 & -0.133678 & -2.973034 \\ \mathrm{H} & 4.300735 & -3.309790 & -0.254523\end{array}$




$\begin{array}{lrrr}\mathrm{H} & 1.581917 & -1.285209 & -3.004307 \\ \mathrm{H} & 3.511866 & -2.665717 & 2.708570 \\ \mathrm{H} & -0.299282 & -2.357502 & -0.009375 \\ \mathrm{H} & 1.878294 & -0.355833 & 3.334617 \\ \mathrm{C} & 0.541362 & 2.231118 & -0.196249 \\ \mathrm{C} & 0.288421 & 3.598513 & -0.309103 \\ \mathrm{C} & 1.376794 & 4.475013 & -0.388618 \\ \mathrm{C} & 2.671334 & 3.955873 & -0.356976 \\ \mathrm{C} & 2.846355 & 2.569601 & -0.244104 \\ \mathrm{~N} & 1.794774 & 1.720653 & -0.162397 \\ \mathrm{H} & 1.216384 & 5.545169 & -0.478574 \\ \mathrm{H} & -0.734491 & 3.951968 & -0.341068 \\ \mathrm{H} & 3.529601 & 4.614298 & -0.422147 \\ \mathrm{C} & -0.574314 & 1.250436 & -0.126293 \\ \mathrm{C} & -2.837071 & 0.829717 & -0.081154 \\ \mathrm{C} & -4.192499 & 1.365541 & -0.216370 \\ \mathrm{C} & -2.509045 & -0.582278 & 0.070603 \\ \mathrm{C} & -4.428296 & 2.692953 & 0.177485 \\ \mathrm{C} & -5.242858 & 0.612018 & -0.811083 \\ \mathrm{C} & -3.493779 & -1.651534 & 0.346070 \\ \mathrm{C} & -5.701437 & 3.270323 & 0.026487 \\ \mathrm{C} & -4.393893 & -1.489292 & 1.413980 \\ \mathrm{C} & -6.491178 & 1.205446 & -0.991185 \\ \mathrm{C} & -3.480465 & -2.840354 & -0.410946 \\ \mathrm{H} & -4.404538 & -0.576928 & 1.999524 \\ \mathrm{C} & -6.739971 & 2.515589 & -0.569939 \\ \mathrm{C} & -5.267038 & -2.537866 & 1.738139 \\ \mathrm{C} & -4.394974 & -3.863941 & -0.104193 \\ \mathrm{H} & -7.726628 & 2.942387 & -0.707262 \\ \mathrm{C} & -5.278141 & -3.709578 & 0.990278 \\ \mathrm{H} & -5.967215 & -4.517315 & 1.214250 \\ \mathrm{~N} & -1.825076 & 1.708676 & -0.125210 \\ \mathrm{~N} & -0.238597 & -0.047125 & -0.109781 \\ \mathrm{~N} & -1.233202 & -0.953770 & 0.009459 \\ \mathrm{O} & -4.515623 & -5.025603 & -0.782561 \\ \mathrm{O} & -5.825831 & 4.534025 & 0.470828 \\ \mathrm{C} & -7.102289 & 5.205354 & 0.363180 \\ \mathrm{H} & -6.943494 & 6.192642 & 0.793527 \\ \mathrm{H} & -7.399840 & 5.302842 & -0.685305 \\ \mathrm{H} & -3.739362 & -5.240282 & -1.967288 \\ \mathrm{H} & -2.4304939 & -4.468898 & -2.717745 \\ \mathrm{H} & -5.269559 & -1.735351 \\ \mathrm{H} & -6.211441 & -2.349624 \\ \mathrm{H} & -574039\end{array}$




$\begin{array}{lrrr}\mathrm{H} & -5.079000 & -0.396985 & -1.163355 \\ \mathrm{H} & -3.644240 & 3.288090 & 0.628471 \\ \mathrm{H} & -7.289119 & 0.643134 & -1.465578 \\ \mathrm{C} & 4.179185 & 1.949217 & -0.215924 \\ \mathrm{C} & 5.455096 & 2.528795 & -0.281808 \\ \mathrm{C} & 6.361910 & 1.464770 & -0.229501 \\ \mathrm{H} & 5.716521 & 3.573235 & -0.360955 \\ \mathrm{~N} & 4.267362 & 0.597884 & -0.125809 \\ \mathrm{~N} & 5.605228 & 0.342613 & -0.136700 \\ \mathrm{C} & 7.856842 & 1.443494 & -0.261338 \\ \mathrm{H} & 8.225568 & 1.926123 & -1.170668 \\ \mathrm{H} & 8.263058 & 1.994605 & 0.591686 \\ \mathrm{H} & 8.249261 & 0.424649 & -0.229564 \\ \mathrm{H} & 5.933482 & -0.614845 & -0.102363\end{array}$

$\mathrm{M}=\mathrm{Cm}$

$\begin{array}{lrrr}\mathrm{O} & 3.014411 & -2.506442 & 1.928780 \\ \mathrm{H} & 2.482811 & -3.281241 & 2.178755 \\ \mathrm{O} & 0.637829 & -2.697354 & 0.010790 \\ \mathrm{H} & 0.581636 & -3.645996 & -0.176387 \\ \mathrm{O} & 3.813059 & -2.474522 & -0.938568 \\ \mathrm{H} & 3.910787 & -2.560226 & -1.901991 \\ \mathrm{O} & 1.875433 & 0.068478 & 2.480001 \\ \mathrm{H} & 1.659670 & 0.974898 & 2.753847 \\ \mathrm{O} & 2.058063 & -0.619775 & -2.417200 \\ \mathrm{H} & 1.337441 & -0.957851 & -2.975258 \\ \mathrm{H} & 4.097063 & -3.322098 & -0.558485 \\ \mathrm{H} & 2.489946 & 0.079938 & -2.935578 \\ \mathrm{H} & 3.794156 & -2.519984 & 2.509297 \\ \mathrm{H} & -0.308816 & -2.295374 & 0.037839 \\ \mathrm{H} & 1.907424 & -0.463766 & 3.291605 \\ \mathrm{C} & 0.533844 & 2.238270 & -0.046998 \\ \mathrm{C} & 0.294333 & 3.612268 & -0.076869 \\ \mathrm{C} & 1.391150 & 4.481237 & -0.110841 \\ \mathrm{C} & 2.683230 & 3.950887 & -0.127535 \\ \mathrm{C} & 2.847051 & 2.560368 & -0.102476 \\ \mathrm{H} & -0.725963 & 3.975463 & -0.081698 \\ \mathrm{H} & 1.240042 & 5.556451 & -0.132753 \\ \mathrm{H} & 3.545811 & 4.605900 & -0.165658 \\ \mathrm{~N} & 1.785626 & 1.719454 & -0.053056 \\ \mathrm{C} & -0.583286 & 1.256731 & -0.029450 \\ \mathrm{~N} & -1.831638 & 1.706113 & -0.010143 \\ \mathrm{~N} & -0.236544 & -0.038808 & -0.077478 \\ \mathrm{C} & -2.846325 & 0.819672 & -0.023330 \\ \mathrm{~N} & -1.227834 & -0.957538 & 0.029331\end{array}$




$\begin{array}{lrrr}\mathrm{C} & -4.188632 & 1.348790 & -0.201848 \\ \mathrm{C} & -2.505251 & -0.599956 & 0.107888 \\ \mathrm{C} & -4.417818 & 2.705037 & 0.119162 \\ \mathrm{C} & -5.237707 & 0.577037 & -0.775389 \\ \mathrm{C} & -3.467486 & -1.684024 & 0.387246 \\ \mathrm{C} & -5.674056 & 3.290138 & -0.083800 \\ \mathrm{H} & -3.633793 & 3.309483 & 0.556484 \\ \mathrm{C} & -6.467418 & 1.179443 & -1.011898 \\ \mathrm{H} & -5.086822 & -0.454426 & -1.060423 \\ \mathrm{C} & -4.364973 & -1.537908 & 1.456805 \\ \mathrm{C} & -3.420076 & -2.882886 & -0.358962 \\ \mathrm{C} & -6.705388 & 2.516729 & -0.661847 \\ \mathrm{O} & -5.792739 & 4.580443 & 0.294784 \\ \mathrm{H} & -7.266766 & 0.606546 & -1.471123 \\ \mathrm{C} & -5.199998 & -2.611435 & 1.795540 \\ \mathrm{H} & -4.407660 & -0.617842 & 2.028685 \\ \mathrm{C} & -4.299409 & -3.929356 & -0.039655 \\ \mathrm{H} & -2.753538 & -2.962007 & -1.209966 \\ \mathrm{H} & -7.685191 & 2.944764 & -0.839259 \\ \mathrm{C} & -7.063536 & 5.245163 & 0.126794 \\ \mathrm{C} & -5.178240 & -3.790873 & 1.058024 \\ \mathrm{H} & -5.883825 & -2.518137 & 2.633283 \\ \mathrm{O} & -4.388043 & -5.103072 & -0.709128 \\ \mathrm{H} & -6.913418 & 6.253902 & 0.508400 \\ \mathrm{H} & -7.342585 & 5.290955 & -0.930688 \\ \mathrm{H} & -7.843916 & 4.745585 & 0.709477 \\ \mathrm{H} & -5.842722 & -4.615742 & 1.293645 \\ \mathrm{C} & -3.626323 & -5.288079 & -1.905707 \\ \mathrm{H} & -3.871358 & -4.523711 & -2.652331 \\ \mathrm{H} & -2.548590 & -5.280643 & -1.694890 \\ \mathrm{H} & -3.909213 & -6.268951 & -2.286097 \\ \mathrm{C} & 4.169677 & 1.919019 & -0.152354 \\ \mathrm{C} & 5.451788 & 2.479661 & -0.221269 \\ \mathrm{H} & 4.235712 & 0.559676 & -0.168163 \\ \mathrm{C} & 6.340747 & 1.399800 & -0.286033 \\ \mathrm{H} & 5.729352 & 3.522952 & -0.230841 \\ \mathrm{~N} & 5.569063 & 0.285542 & -0.250439 \\ \mathrm{C} & 7.832403 & 1.360185 & -0.377143 \\ \mathrm{H} & 5.883900 & -0.674925 & -0.314321 \\ \mathrm{H} & 2.15737014 & 1.926800 & -1.247394 \\ \mathrm{H} & -0.787357 & 0.125848\end{array}$

\section{$\left[\mathrm{ML}_{2}\left(\mathrm{H}_{2} \mathrm{O}\right)_{2}\right]^{3+}$}




$\begin{array}{lccc}\mathrm{M}=\mathrm{Eu} & & & \\ \mathrm{EU} & -0.000001 & 1.120478 & -0.000002 \\ \mathrm{O} & -0.354514 & -0.635405 & -1.757248 \\ \mathrm{H} & -1.287092 & -0.972152 & -1.678932 \\ \mathrm{O} & 0.354524 & -0.635374 & 1.757273 \\ \mathrm{H} & 1.287100 & -0.972124 & 1.678956 \\ \mathrm{H} & 0.121452 & -1.187395 & -2.391361 \\ \mathrm{H} & -0.121437 & -1.187348 & 2.391403 \\ \mathrm{C} & 2.960979 & 1.567830 & -1.954266 \\ \mathrm{C} & 3.838884 & 1.989752 & -2.955526 \\ \mathrm{C} & 3.399990 & 2.963449 & -3.858908 \\ \mathrm{C} & 2.112627 & 3.478382 & -3.724057 \\ \mathrm{C} & 1.291240 & 3.007177 & -2.685975 \\ \mathrm{~N} & 1.711309 & 2.064036 & -1.815682 \\ \mathrm{H} & 4.052917 & 3.313629 & -4.652444 \\ \mathrm{H} & 4.832291 & 1.563689 & -3.010988 \\ \mathrm{H} & 1.747765 & 4.231752 & -4.411739 \\ \mathrm{C} & 3.388466 & 0.531212 & -0.972077 \\ \mathrm{C} & 5.018990 & -0.899676 & -0.209597 \\ \mathrm{C} & 6.426820 & -1.328226 & -0.276485 \\ \mathrm{C} & 4.049534 & -1.396532 & 0.744944 \\ \mathrm{C} & 7.080163 & -1.286858 & -1.514926 \\ \mathrm{C} & 7.147607 & -1.703894 & 0.885882 \\ \mathrm{C} & 4.257471 & -2.567494 & 1.628072 \\ \mathrm{C} & 8.435927 & -1.650953 & -1.621780 \\ \mathrm{C} & 4.734952 & -3.771828 & 1.080413 \\ \mathrm{C} & 8.499361 & -2.032555 & 0.775194 \\ \mathrm{H} & 3.446470 & -2.439296 & 5.815751 \\ \mathrm{C} & 3.922930 & -2.483883 & 2.992579 \\ \mathrm{C} & 9.150780 & -2.023254 & -0.461859 \\ \mathrm{C} & 4.861271 & -4.898847 & 1.905107 \\ \mathrm{C} & 4.089358 & -3.611316 & 3.815661 \\ \mathrm{H} & 10.197137 & -2.298707 & -0.517717 \\ \mathrm{C} & 4.550640 & -4.826632 & 3.258397 \\ \mathrm{H} & 4.663650 & -5.684901 & 3.912385 \\ \mathrm{~N} & 4.623152 & 0.027512 & -1.085411 \\ \mathrm{~N} & 2.517174 & 0.191625 & -0.012914 \\ \mathrm{~N} & 2.858147 & -0.804375 & 0.821586 \\ \mathrm{O} & 3.839031 & -3.642649 & 5.144926 \\ \mathrm{O} & 8.953540 & -1.605670 & -2.866768 \\ \mathrm{H} & 10.335184 & -1.969046 & -3.069433 \\ \mathrm{H} & 10.998362 & -1.294537 & -2.518682 \\ \mathrm{H} & & -1.663565 & 5.711458\end{array}$




\begin{tabular}{|c|c|c|c|}
\hline & 132 & -2.073004 & 10 \\
\hline & 343890 & -2.709880 & 6866019 \\
\hline & 3.576810 & -1.543335 & 3.403577 \\
\hline & .985958 & -3.841225 & 0.028181 \\
\hline & 5.213189 & -5.836305 & 428 \\
\hline & 6.676469 & -1.706120 & \\
\hline & & -0.9 & 328 \\
\hline & 9.059962 & 831 & 770 \\
\hline & 20 & & \\
\hline & 299 & 612 & \\
\hline & 71 & & \\
\hline & -0.3 & 770 & -4 \\
\hline & -0.8 & $3 .($ & \\
\hline & -2.0 & 3.7 & -1 . \\
\hline & -3.1 & 725 & -2 \\
\hline & -2.9 & & \\
\hline & -3.8 & 75 & 2. \\
\hline & -3.3 & & \\
\hline & -2.1 & 13 & 3.7 \\
\hline & -1.2 & & \\
\hline $\mathrm{N}$ & -1.7 & & \\
\hline & & & \\
\hline & -4.8 & 1.5 & \\
\hline & -1.7 & 4.2 & \\
\hline $\mathrm{C}$ & -3.3 & & \\
\hline & -5.0 & -0.8 & \\
\hline & -6.4 & -1.3 & \\
\hline & -4.0 & -1.3 & -0. \\
\hline C & -7.0 & -1.2 & 1.5 \\
\hline $\mathrm{C}$ & -7.1 & -1.7 & -0 . \\
\hline $\mathrm{C}$ & -4.2 & -2.5 & -1. \\
\hline$c$ & -8.4 & -1.6 & \\
\hline $\mathrm{C}$ & -4.7 & -3.7 & -1 . \\
\hline C & -8.4 & -2.0 & -0. \\
\hline $\mathrm{C}$ & -3.92 & -2.4 & -2 \\
\hline 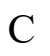 & -9.1 & -2.0 & 0. \\
\hline $\mathrm{C}$ & -4.86 & -4.898869 & -1. \\
\hline $\mathrm{C}$ & -4.0 & -3.6 & -3.8 \\
\hline $\mathrm{H}$ & -10.1 & -2.298705 & 7719 \\
\hline $\mathrm{C}$ & -4.5 & -4.826667 & -3.2 \\
\hline 11 & -4.66 & -5.684942 & -3.912333 \\
\hline IN & -4.62 & 0.027519 & 1.0 \\
\hline $\mathrm{N}$ & -2.51 & 0.191619 & 0.012917 \\
\hline & -2.85 & -0.804388 & -0.821 \\
\hline $\mathrm{O}$ & -3.839011 & -3.642703 & -5.144890 \\
\hline $\mathrm{O}$ & -8.953547 & -1.605648 & 2.86676 \\
\hline
\end{tabular}




$\begin{array}{llll}\mathrm{C} & -10.335191 & -1.969023 & 3.069432 \\ \mathrm{H} & -10.507807 & -1.860665 & 4.139098 \\ \mathrm{H} & -10.998368 & -1.294519 & 2.518674 \\ \mathrm{H} & -10.510651 & -3.007373 & 2.771090 \\ \mathrm{C} & -3.446446 & -2.439356 & -5.815725 \\ \mathrm{H} & -4.213506 & -1.663624 & -5.711443 \\ \mathrm{H} & -2.484110 & -2.073062 & -5.437943 \\ \mathrm{H} & -3.343862 & -2.709950 & -6.865990 \\ \mathrm{H} & -3.576796 & -1.543373 & -3.403560 \\ \mathrm{H} & -4.985958 & -3.841229 & -0.028148 \\ \mathrm{H} & -5.213186 & -5.836323 & -1.486377 \\ \mathrm{H} & -6.676462 & -1.706139 & -1.859823 \\ \mathrm{H} & -6.551790 & -0.995453 & 2.414330 \\ \mathrm{H} & -9.059956 & -2.301848 & -1.664764 \\ \mathrm{C} & 0.072914 & 3.530656 & 2.501797 \\ \mathrm{C} & 0.737297 & 4.559632 & 3.205107 \\ \mathrm{C} & 1.994965 & 4.667490 & 2.621802 \\ \mathrm{H} & 0.370630 & 5.160791 & 4.022726 \\ \mathrm{~N} & 0.867203 & 3.020744 & 1.538075 \\ \mathrm{~N} & 2.020321 & 3.727036 & 1.636386 \\ \mathrm{C} & 3.147012 & 5.578808 & 2.909905 \\ \mathrm{H} & 2.780549 & 3.534605 & 0.997916 \\ \mathrm{H} & -2.780550 & 3.534598 & -0.997932 \\ \mathrm{H} & -2.933651 & 6.182380 & -3.792679 \\ \mathrm{H} & -4.065071 & 5.014423 & -3.100387 \\ \mathrm{H} & -3.331535 & 6.260024 & -2.073273 \\ \mathrm{H} & 4.065296 & 5.014619 & 3.099343 \\ \mathrm{H} & 3.330802 & 6.260744 & 2.073554 \\ \mathrm{H} & 2.933984 & 6.181794 & 3.793142\end{array}$

$\mathrm{M}=\mathrm{Gd}$

$\begin{array}{lccc}\text { GD } & 0.000000 & 1.113213 & -0.000002 \\ \mathrm{O} & 0.299697 & -0.572239 & 1.688519 \\ \mathrm{H} & 1.232631 & -0.945778 & 1.609626 \\ \mathrm{O} & -0.299697 & -0.572244 & -1.688516 \\ \mathrm{H} & -1.232631 & -0.945783 & -1.609623 \\ \mathrm{H} & -0.218062 & -1.119215 & 2.294508 \\ \mathrm{H} & 0.218062 & -1.119223 & -2.294503 \\ \mathrm{C} & -2.833112 & 1.584375 & 1.942170 \\ \mathrm{C} & -3.687276 & 2.034796 & 2.950169 \\ \mathrm{C} & -3.216306 & 3.009214 & 3.837011 \\ \mathrm{C} & -1.918598 & 3.497057 & 3.683509 \\ \mathrm{C} & -1.121589 & 2.997982 & 2.643346 \\ \mathrm{~N} & -1.574756 & 2.056539 & 1.785484 \\ \mathrm{H} & -3.852074 & 3.380538 & 4.635012\end{array}$




\begin{tabular}{|c|c|c|c|}
\hline $\mathrm{H}$ & -4.687420 & 1.626454 & 3.023115 \\
\hline & -1.529412 & 4.249320 & 4.359252 \\
\hline & -3.273904 & 0.546145 & 0.971788 \\
\hline & -4.907400 & -0.882440 & 0.203969 \\
\hline & -6.319565 & -1.261012 & 0.231438 \\
\hline & -3.910702 & -1.417294 & -0.717927 \\
\hline 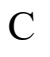 & -7.035954 & -1.070073 & 1.429333 \\
\hline C & -6.998031 & -1.721013 & 6340 \\
\hline C & -4.081461 & -2.626352 & -1.550676 \\
\hline $\mathrm{C}$ & -8.404660 & -1.364530 & 1.502123 \\
\hline C & -4.561601 & -3.805859 & -0.961651 \\
\hline $\mathrm{C}$ & -8.364212 & -1.972582 & 355 \\
\hline $\mathrm{C}$ & -3.684588 & -2.606579 & -2.9 \\
\hline $\mathrm{C}$ & -9.073815 & -1.814376 & 65 \\
\hline $\mathrm{C}$ & -4.624237 & -4.974978 & -1.731520 \\
\hline C & -3.794356 & -3.774479 & 731 \\
\hline $\mathrm{H}$ & -10.132850 & -2.042441 & 0.369922 \\
\hline $\mathrm{C}$ & -4.254157 & -4.965739 & -3.073116 \\
\hline $\mathrm{H}$ & -4.324576 & -5.859629 & -3.684001 \\
\hline $\mathbf{N}$ & -4.507178 & 0.052890 & 618 \\
\hline $\mathrm{N}$ & -2.396053 & 0.203888 & 018 \\
\hline $\mathrm{N}$ & -2.726049 & -0.817471 & \\
\hline $\mathrm{O}$ & -3.486080 & -3.867983 & -4.9 \\
\hline $\mathrm{O}$ & -8.983076 & -1.179094 & 2.7 \\
\hline $\mathrm{C}$ & -10.384967 & -1.476066 & 341 \\
\hline $\mathrm{H}$ & -10.615948 & -1.264498 & 3.905517 \\
\hline $\mathrm{H}$ & -10.992734 & -0.834672 & 2.215567 \\
\hline $\mathrm{H}$ & -10.585966 & -2.531241 & 2.650096 \\
\hline C & -3.111512 & -2.685781 & -5.704607 \\
\hline $\mathrm{H}$ & -3.905449 & -1.930730 & -5.663153 \\
\hline $\mathrm{H}$ & -2.174158 & -2.267445 & -5.31 \\
\hline $\mathrm{H}$ & -2.963514 & -2.998148 & -6.737996 \\
\hline $\mathrm{H}$ & -3.344134 & -1.679404 & -3.350629 \\
\hline $\mathrm{H}$ & -4.869875 & -3.824572 & 0.077412 \\
\hline $\mathrm{H}$ & -4.977900 & -5.897395 & -1.281886 \\
\hline $\mathrm{H}$ & -6.479770 & -1.854121 & -1.865974 \\
\hline $\mathrm{H}$ & -6.535934 & -0.718266 & 2.322748 \\
\hline $\mathrm{H}$ & -8.896474 & -2.305502 & -1.738837 \\
\hline $\mathrm{C}$ & 0.255969 & 3.462196 & 2.426199 \\
\hline $\mathrm{C}$ & 1.002389 & 4.440979 & 3.106686 \\
\hline $\mathrm{C}$ & 2.248755 & 4.470435 & 2.480949 \\
\hline $\mathrm{H}$ & 0.700239 & 5.057292 & 3.939598 \\
\hline $\mathrm{N}$ & 0.986268 & 2.905075 & 1.432903 \\
\hline 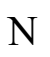 & 2.185553 & 3.537435 & 1.495075 \\
\hline$C$ & 3.460397 & 5.312181 & 2.730741 \\
\hline & 2.833112 & 1.584372 & -1.942174 \\
\hline
\end{tabular}




\begin{tabular}{|c|c|c|c|}
\hline $\mathrm{C}$ & 3.687277 & 2.034792 & -2.950172 \\
\hline & 3.216308 & 3.009210 & -3.837015 \\
\hline$C$ & 1.918601 & 3.497054 & -3.683513 \\
\hline $\mathrm{C}$ & 1.121591 & 2.997980 & -2.643350 \\
\hline $\mathrm{N}$ & 1.574756 & 2.056537 & -1.785488 \\
\hline $\mathrm{H}$ & 3.852077 & 3.380533 & -4.635016 \\
\hline H & 4.687420 & 1.626449 & -3.023117 \\
\hline & 1.529415 & 4.249317 & -4.359256 \\
\hline $\mathrm{C}$ & 3.273903 & 0.546143 & -0.971791 \\
\hline $\mathrm{C}$ & 4.907399 & -0.882442 & -0.203969 \\
\hline $\mathrm{C}$ & 6.319563 & -1.261015 & -0.231438 \\
\hline $\mathrm{C}$ & 3.910701 & -1.417293 & 0.717928 \\
\hline $\mathrm{C}$ & 7.035952 & -1.070078 & -1.429334 \\
\hline $\mathrm{C}$ & 6.998030 & -1.721014 & 0.926340 \\
\hline $\mathrm{C}$ & 4.081460 & -2.626349 & 1.550680 \\
\hline $\mathrm{C}$ & 8.404658 & -1.364535 & -1.502123 \\
\hline $\mathrm{C}$ & 4.561599 & -3.805858 & 0.961658 \\
\hline $\mathrm{C}$ & 8.364211 & -1.972583 & 0.853355 \\
\hline $\mathrm{C}$ & 3.684588 & -2.606572 & 2.905405 \\
\hline $\mathrm{C}$ & 9.073814 & -1.814380 & -0.345566 \\
\hline $\mathrm{C}$ & 4.624235 & -4.974975 & 1.731530 \\
\hline $\mathrm{C}$ & 3.794356 & -3.774470 & 3.674739 \\
\hline $\mathrm{H}$ & 10.132848 & -2.042445 & -0.369922 \\
\hline $\mathrm{C}$ & 4.254156 & -4.965732 & 3.073127 \\
\hline $\mathrm{H}$ & 4.324575 & -5.859620 & 3.684015 \\
\hline $\mathrm{N}$ & 4.507177 & 0.052886 & -1.078620 \\
\hline $\mathrm{N}$ & 2.396052 & 0.203888 & -0.020019 \\
\hline $\mathrm{N}$ & 2.726048 & -0.817470 & 0.796804 \\
\hline $\mathrm{O}$ & 3.486082 & -3.867970 & 4.993306 \\
\hline $\mathrm{O}$ & 8.983074 & -1.179101 & -2.712118 \\
\hline $\mathrm{C}$ & 10.384964 & -1.476073 & -2.862342 \\
\hline $\mathrm{H}$ & 10.615945 & -1.264507 & -3.905519 \\
\hline $\mathrm{H}$ & 10.992732 & -0.834678 & -2.215570 \\
\hline $\mathrm{H}$ & 10.585963 & -2.531248 & -2.650096 \\
\hline $\mathrm{C}$ & 3.111514 & -2.685766 & 5.704612 \\
\hline $\mathrm{H}$ & 3.905452 & -1.930716 & 5.663156 \\
\hline $\mathrm{H}$ & 2.174161 & -2.267431 & 5.315376 \\
\hline $\mathrm{H}$ & 2.963518 & -2.998130 & 6.738002 \\
\hline $\mathrm{H}$ & 3.344135 & -1.679396 & 3.350631 \\
\hline $\mathrm{H}$ & 4.869871 & -3.824574 & -0.077405 \\
\hline $\mathrm{H}$ & 4.977897 & -5.897394 & 1.281899 \\
\hline $\mathrm{H}$ & 6.479769 & -1.854121 & 1.865975 \\
\hline $\mathrm{H}$ & 6.535932 & -0.718271 & -2.322749 \\
\hline $\mathrm{H}$ & 8.896473 & -2.305502 & 1.738838 \\
\hline $\mathrm{C}$ & -0.255967 & 3.462197 & -2.426202 \\
\hline $\mathrm{C}$ & -1.002382 & 4.440984 & -3.106683 \\
\hline
\end{tabular}




$\begin{array}{lrrr}\mathrm{C} & -2.248750 & 4.470440 & -2.480944 \\ \mathrm{H} & -0.700229 & 5.057300 & -3.939593 \\ \mathrm{~N} & -0.986266 & 2.905073 & -1.432906 \\ \mathrm{~N} & -2.185548 & 3.537438 & -1.495076 \\ \mathrm{C} & -3.460399 & 5.312171 & -2.730751 \\ \mathrm{H} & 2.918746 & 3.295486 & 0.841568 \\ \mathrm{H} & -2.918741 & 3.295496 & -0.841567 \\ \mathrm{H} & 3.663991 & 5.378089 & 3.801843 \\ \mathrm{H} & 4.345672 & 4.901836 & 2.238912 \\ \mathrm{H} & 3.303902 & 6.330041 & 2.360184 \\ \mathrm{H} & -3.303628 & 6.330243 & -2.360900 \\ \mathrm{H} & -3.664439 & 5.377439 & -3.801813 \\ \mathrm{H} & -4.345515 & 4.902241 & -2.238293\end{array}$

$\mathrm{M}=\mathrm{Am}$

$\begin{array}{lrrr}\text { AM } & -0.000227 & 1.014726 & -0.000750 \\ \mathrm{O} & -0.372146 & -0.744764 & -1.691750 \\ \mathrm{H} & -1.325135 & -1.060181 & -1.608447 \\ \mathrm{O} & 0.372303 & -0.741958 & 1.692938 \\ \mathrm{H} & 1.325223 & -1.057649 & 1.609958 \\ \mathrm{H} & 0.135508 & -1.385862 & -2.208181 \\ \mathrm{H} & -0.135011 & -1.381332 & 2.211828 \\ \mathrm{C} & 2.853403 & 1.462785 & -2.012338 \\ \mathrm{C} & 3.696901 & 1.886013 & -3.040946 \\ \mathrm{C} & 3.214918 & 2.831021 & -3.952582 \\ \mathrm{C} & 1.919826 & 3.324252 & -3.797488 \\ \mathrm{C} & 1.134862 & 2.856250 & -2.734503 \\ \mathrm{~N} & 1.594710 & 1.933889 & -1.859201 \\ \mathrm{H} & 3.841820 & 3.178727 & -4.767987 \\ \mathrm{H} & 4.698443 & 1.480868 & -3.110024 \\ \mathrm{H} & 1.524947 & 4.059461 & -4.488436 \\ \mathrm{C} & 3.316406 & 0.461426 & -1.013985 \\ \mathrm{C} & 4.980895 & -0.924026 & -0.230406 \\ \mathrm{C} & 6.398750 & -1.280287 & -0.264251 \\ \mathrm{C} & 4.004283 & -1.447412 & 0.718433 \\ \mathrm{C} & 7.098216 & -1.115420 & -1.475724 \\ \mathrm{C} & 7.097415 & -1.693804 & 0.898964 \\ \mathrm{C} & 4.199637 & -2.635232 & 1.576058 \\ \mathrm{C} & 8.470705 & -1.390033 & -1.555454 \\ \mathrm{C} & 4.697479 & -3.819399 & 1.011339 \\ \mathrm{C} & 8.466557 & -1.925889 & 0.817844 \\ \mathrm{C} & 3.807811 & -2.592531 & 2.931861 \\ \mathrm{C} & 9.160026 & -1.793340 & -0.393617 \\ \mathrm{C} & 4.783827 & -4.969723 & 1.806787 \\ \mathrm{C} & 3.940369 & -3.741047 & 3.726249\end{array}$




\begin{tabular}{|c|c|c|c|}
\hline $\mathrm{H}$ & 10.222271 & -2.005204 & -0.423384 \\
\hline & 4.418865 & -4.937167 & 3.149430 \\
\hline & 4.507333 & -5.815900 & 3.779668 \\
\hline N & 4.553557 & -0.022171 & -1.126212 \\
\hline & 2.459995 & 0.140001 & -0.036100 \\
\hline N & 2.814840 & -0.858305 & 0.800178 \\
\hline & 3.637815 & -3.810429 & 5.047680 \\
\hline D & 9.032372 & -1.232827 & -2.777303 \\
\hline & 10.436970 & -1.512366 & -2.934975 \\
\hline & 10.652658 & -1.329465 & -3.986809 \\
\hline & 11.041782 & -0.841946 & -2.315431 \\
\hline & 10.657187 & -2.557251 & -2.692919 \\
\hline & 3.245385 & -2.619048 & 5.733759 \\
\hline H & 4.026755 & -1.852234 & 5.673358 \\
\hline & 2.300396 & -2.224723 & 5.337976 \\
\hline 1 & 3.105199 & -2.910979 & $6.7^{\prime}$ \\
\hline & 3.452296 & -1.661863 & 3.357687 \\
\hline $\mathrm{H}$ & 5.001669 & -3.856267 & -0.028440 \\
\hline 1 & 5.151874 & -5.895620 & 1.376215 \\
\hline & 6.591642 & -1.806161 & 1.848137 \\
\hline $\mathrm{H}$ & 6.582428 & -0.799885 & -2.373742 \\
\hline & 9.014050 & -2.223097 & 1.706747 \\
\hline C & -0.232126 & 3.34 & -2.507755 \\
\hline 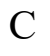 & -0.971994 & 4.319389 & -3.203756 \\
\hline $\mathrm{C}$ & -2.202500 & 4.399393 & -2.551857 \\
\hline$\theta$ & -0.675591 & 4.902999 & -4.061844 \\
\hline $\mathrm{N}$ & -0.950811 & 2.842486 & -1.479494 \\
\hline $\mathrm{N}$ & -2.137548 & 3.500715 & -1.535375 \\
\hline 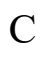 & -3.414314 & 5.232494 & -2.827820 \\
\hline C & -2.853202 & 1.463182 & 2.011536 \\
\hline $\mathrm{C}$ & -3.696053 & 1.885997 & 3.040847 \\
\hline 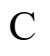 & -3.213377 & 2.830387 & 3.952769 \\
\hline ( & -1.918232 & 3.323380 & 3.797333 \\
\hline 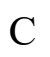 & -1.133838 & 2.855625 & 2.733797 \\
\hline 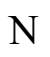 & -1.594483 & 1.934099 & 1.858016 \\
\hline 11 & -3.839862 & 3.177943 & 4.768561 \\
\hline 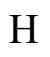 & -4.697654 & 1.481046 & 3.110206 \\
\hline 11 & -1.523093 & 4.058620 & 4.488101 \\
\hline$O$ & -3.316652 & 0.461832 & 1.013381 \\
\hline $\mathrm{C}$ & -4.981381 & -0.923735 & 0.230619 \\
\hline ( & -6.399440 & -1.279196 & 0.264069 \\
\hline 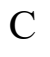 & -4.004569 & -1.448538 & -0.717244 \\
\hline $\mathrm{C}$ & -7.099546 & -1.112554 & 1.474921 \\
\hline $\mathrm{C}$ & -7.097619 & -1.693695 & -0.899081 \\
\hline 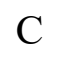 & -4.199706 & -2.637770 & -1.572948 \\
\hline $\mathrm{C}$ & -8.472235 & -1.386323 & 1.554134 \\
\hline
\end{tabular}




$\begin{array}{cccc}\mathrm{C} & -4.698716 & -3.820643 & -1.006533 \\ \mathrm{C} & -8.466927 & -1.924976 & -0.818524 \\ \mathrm{C} & -3.806363 & -2.597894 & -2.928407 \\ \mathrm{C} & -9.161065 & -1.790631 & 0.392358 \\ \mathrm{C} & -4.784749 & -4.972454 & -1.799856 \\ \mathrm{C} & -3.938539 & -3.747884 & -3.720707 \\ \mathrm{H} & -10.223439 & -2.001896 & 0.421730 \\ \mathrm{C} & -4.418269 & -4.942664 & -3.142144 \\ \mathrm{H} & -4.506429 & -5.822569 & -3.770787 \\ \mathrm{~N} & -4.553945 & -0.021337 & 1.125799 \\ \mathrm{~N} & -2.460287 & 0.139602 & 0.035730 \\ \mathrm{~N} & -2.815099 & -0.859543 & -0.799548 \\ \mathrm{O} & -3.634478 & -3.820004 & -5.041665 \\ \mathrm{O} & -9.034559 & -1.227370 & 2.775456 \\ \mathrm{C} & -10.439409 & -1.505934 & 2.932592 \\ \mathrm{H} & -10.655646 & -1.321658 & 3.984075 \\ \mathrm{H} & -11.043461 & -0.835916 & 2.311874 \\ \mathrm{H} & -10.660062 & -2.550984 & 2.691647 \\ \mathrm{C} & -3.240468 & -2.630233 & -5.729562 \\ \mathrm{H} & -4.021494 & -1.862860 & -5.671699 \\ \mathrm{H} & -2.295771 & -2.235654 & -5.333327 \\ \mathrm{H} & -3.099087 & -2.924282 & -6.769231 \\ \mathrm{H} & -3.449879 & -1.668235 & -3.355617 \\ \mathrm{H} & -5.004026 & -3.855401 & 0.032988 \\ \mathrm{H} & -5.153708 & -5.897344 & -1.367902 \\ \mathrm{H} & -6.591310 & -1.807443 & -1.847805 \\ \mathrm{H} & -6.584134 & -0.796252 & 2.372882 \\ \mathrm{H} & -9.014040 & -2.222951 & -1.707404 \\ \mathrm{C} & 0.233131 & 3.345557 & 2.506673 \\ \mathrm{C} & 0.978379 & 4.309104 & 3.210492 \\ \mathrm{C} & 2.207720 & 4.390501 & 2.557125 \\ \mathrm{H} & 0.687078 & 4.883791 & 4.076303 \\ \mathrm{~N} & 0.949139 & 2.846219 & 1.474551 \\ \mathrm{~N} & 2.138764 & 3.498886 & 1.534353 \\ \mathrm{C} & 3.405342 & 5.251122 & 2.809353 \\ \mathrm{H} & 2.857455 & 3.301015 & 0.850724 \\ \mathrm{H} & -2.856437 & 3.303562 & -0.851730 \\ \mathrm{H} & -3.121303 & 6.237686 & -3.137625 \\ \mathrm{H} & -4.006142 & 4.794846 & -3.638112 \\ \mathrm{H} & -4.053647 & 5.319885 & -1.945825 \\ \mathrm{H} & 4.322022 & 4.786600 & 2.437072 \\ \mathrm{H} & 3.291097 & 6.223535 & 2.319306 \\ \mathrm{H} & 3.523781 & 5.431051 & 3.879411 \\ & & & \\ \mathrm{M}=\mathrm{Cm} & & & \\ & & & \end{array}$




$\begin{array}{lccc}\mathrm{CM} & 0.000002 & 1.053644 & 0.000012 \\ \mathrm{O} & 0.322980 & -0.684915 & 1.718926 \\ \mathrm{H} & 1.258726 & -1.041626 & 1.623294 \\ \mathrm{O} & -0.322985 & -0.684866 & -1.718953 \\ \mathrm{H} & -1.258729 & -1.041583 & -1.623324 \\ \mathrm{H} & -0.186165 & -1.264941 & 2.301418 \\ \mathrm{H} & 0.186156 & -1.264867 & -2.301473 \\ \mathrm{C} & -2.869640 & 1.515546 & 1.950291 \\ \mathrm{C} & -3.733327 & 1.958163 & 2.953727 \\ \mathrm{C} & -3.273337 & 2.929527 & 3.849220 \\ \mathrm{C} & -1.976789 & 3.423478 & 3.708103 \\ \mathrm{C} & -1.169232 & 2.933901 & 2.671543 \\ \mathrm{~N} & -1.612305 & 1.994151 & 1.806642 \\ \mathrm{H} & -3.916987 & 3.294099 & 4.644022 \\ \mathrm{H} & -4.732538 & 1.546228 & 3.016995 \\ \mathrm{H} & -1.597234 & 4.174215 & 4.390879 \\ \mathrm{C} & -3.305731 & 0.478983 & 0.974611 \\ \mathrm{C} & -4.940483 & -0.948187 & 0.204451 \\ \mathrm{C} & -6.353154 & -1.326110 & 0.231585 \\ \mathrm{C} & -3.944601 & -1.482437 & -0.717889 \\ \mathrm{C} & -7.067991 & -1.143477 & 1.431476 \\ \mathrm{C} & -7.032796 & -1.778589 & -0.928274 \\ \mathrm{C} & -4.117065 & -2.689425 & -1.553730 \\ \mathrm{C} & -8.436731 & -1.438122 & 1.503801 \\ \mathrm{C} & -4.598776 & -3.870168 & -0.968608 \\ \mathrm{C} & -8.398944 & -2.030499 & -0.855570 \\ \mathrm{C} & -3.720769 & -2.665821 & -2.908559 \\ \mathrm{C} & -9.107251 & -1.880176 & 0.345134 \\ \mathrm{C} & -4.663802 & -5.036537 & -1.742508 \\ \mathrm{C} & -3.832510 & -3.830965 & -3.681756 \\ \mathrm{H} & -10.166274 & -2.108239 & 0.369128 \\ \mathrm{C} & -4.294183 & -5.023433 & -3.084205 \\ \mathrm{H} & -4.366330 & -5.915131 & -3.698089 \\ \mathrm{~N} & -4.539712 & -0.014017 & 1.079754 \\ \mathrm{~N} & -2.428512 & 0.135638 & 0.022978 \\ \mathrm{~N} & -2.758958 & -0.884781 & -0.795472 \\ \mathrm{O} & -3.524126 & -3.920271 & -5.000736 \\ \mathrm{O} & -9.013754 & -1.260520 & 2.715762 \\ \mathrm{C} & -10.415364 & -1.558591 & 2.865610 \\ \mathrm{H} & -10.645240 & -1.353869 & 3.910396 \\ \mathrm{H} & -11.023966 & -0.913081 & 2.223718 \\ \mathrm{H} & -10.616495 & -2.612403 & 2.646707 \\ \mathrm{C} & -3.150079 & -2.735732 & -5.708363 \\ \mathrm{H} & -3.943942 & -1.980740 & -5.663649 \\ \mathrm{H} & -2.212349 & -2.318573 & -5.318564 \\ \mathrm{H} & -3.002963 & -3.044610 & -6.742906\end{array}$




\begin{tabular}{|c|c|c|c|}
\hline $\mathrm{H}$ & -3.378844 & -1.737645 & -3.350786 \\
\hline $\mathrm{U}$ & -4.906782 & -3.892024 & 0.070545 \\
\hline & -5.018948 & -5.959871 & -1.295877 \\
\hline & -6.515412 & -1.905389 & -1.869327 \\
\hline & -6.566955 & -0.797922 & 2.326840 \\
\hline & -8.932185 & -2.357542 & -1.742668 \\
\hline & 0.206668 & 3.412944 & 2.471482 \\
\hline & 0.931612 & 4.393990 & 3.172842 \\
\hline & 2.185216 & 4.448061 & 2.564703 \\
\hline & 0.611385 & 4.996825 & 4.008697 \\
\hline & 0.958715 & 2.877397 & 1.482412 \\
\hline & 2.148768 & 3.525927 & 1.567787 \\
\hline & 3.378606 & 5.308470 & 2.836818 \\
\hline & 2.869643 & 1.515580 & -1.950258 \\
\hline & 3.733331 & 1.958215 & -2.953686 \\
\hline & 3.273339 & 2.929591 & -3.849166 \\
\hline & 1.976788 & 3.423534 & -3.708045 \\
\hline$C$ & 1.169231 & 2.933938 & -2.671493 \\
\hline $\mathrm{N}$ & 1.612307 & 1.994178 & -1.806604 \\
\hline 1 & 3.916989 & 3.294178 & -4.643961 \\
\hline & 4.732543 & 1.546284 & -3.016959 \\
\hline 7 & 1.597232 & 4.174281 & -4.390809 \\
\hline & 3.305736 & 0.479000 & -0.974595 \\
\hline & 4.940488 & -0.948181 & -0.204457 \\
\hline$C$ & 6.353160 & -1.326100 & -0.231593 \\
\hline C & 3.944603 & -1.482453 & 0.717866 \\
\hline $\mathrm{C}$ & 7.068001 & -1.143445 & -1.431477 \\
\hline $\mathrm{C}$ & 7.032797 & -1.778599 & 0.928262 \\
\hline $\mathrm{C}$ & 4.117066 & -2.689460 & 1.553680 \\
\hline $\mathrm{C}$ & 8.436742 & -1.438087 & -1.503801 \\
\hline $\mathrm{C}$ & 4.598784 & -3.870188 & 0.968533 \\
\hline $\mathrm{C}$ & 8.398946 & -2.030506 & 0.855558 \\
\hline $\mathrm{C}$ & 3.720760 & -2.665890 & 2.908507 \\
\hline$C$ & 9.107258 & -1.880161 & -0.345139 \\
\hline$C$ & 4.663808 & -5.036575 & 1.742406 \\
\hline 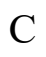 & 3.832498 & -3.831051 & 3.681677 \\
\hline 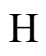 & 10.166281 & -2.108222 & -0.369133 \\
\hline 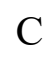 & 4.294179 & -5.023504 & 3.084101 \\
\hline- & 4.366324 & -5.915216 & 3.697964 \\
\hline $\mathrm{N}$ & 4.539719 & -0.013994 & -1.079744 \\
\hline 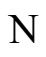 & 2.428514 & 0.135634 & -0.022973 \\
\hline $\mathrm{N}$ & 2.758958 & -0.884802 & 0.795458 \\
\hline $\mathrm{O}$ & 3.524106 & -3.920390 & 5.000653 \\
\hline $\mathrm{O}$ & 9.013770 & -1.260463 & -2.715757 \\
\hline $\mathrm{C}$ & 10.415381 & -1.558531 & -2.865604 \\
\hline 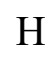 & 10.645260 & -1.353790 & -3.910386 \\
\hline
\end{tabular}




$\begin{array}{llll}\mathrm{H} & 11.023980 & -0.913032 & -2.223699 \\ \mathrm{H} & 10.616511 & -2.612346 & -2.646719 \\ \mathrm{C} & 3.150050 & -2.735868 & 5.708305 \\ \mathrm{H} & 3.943911 & -1.980873 & 5.663614 \\ \mathrm{H} & 2.212321 & -2.318704 & 5.318509 \\ \mathrm{H} & 3.002927 & -3.044772 & 6.742840 \\ \mathrm{H} & 3.378829 & -1.737725 & 3.350754 \\ \mathrm{H} & 4.906797 & -3.892018 & -0.070618 \\ \mathrm{H} & 5.018960 & -5.959897 & 1.295756 \\ \mathrm{H} & 6.515409 & -1.905416 & 1.869310 \\ \mathrm{H} & 6.566968 & -0.797875 & -2.326837 \\ \mathrm{H} & 8.932183 & -2.357563 & 1.742653 \\ \mathrm{C} & -0.206672 & 3.412971 & -2.471434 \\ \mathrm{C} & -0.931638 & 4.394007 & -3.172811 \\ \mathrm{C} & -2.185232 & 4.448074 & -2.564689 \\ \mathrm{H} & -0.611422 & 4.996838 & -4.008673 \\ \mathrm{~N} & -0.958721 & 2.877428 & -1.482377 \\ \mathrm{~N} & -2.148786 & 3.525936 & -1.567754 \\ \mathrm{C} & -3.378591 & 5.308540 & -2.836753 \\ \mathrm{H} & -2.893311 & 3.300293 & -0.921372 \\ \mathrm{H} & 2.893298 & 3.300317 & 0.921398 \\ \mathrm{H} & 3.451747 & 5.527969 & 3.903510 \\ \mathrm{H} & 4.306332 & 4.822869 & 2.523348 \\ \mathrm{H} & 3.295260 & 6.262445 & 2.305947 \\ \mathrm{H} & -4.306757 & 4.820952 & -2.527669 \\ \mathrm{H} & -3.297518 & 6.260566 & -2.302030 \\ \mathrm{H} & -3.448998 & 5.531992 & -3.902788\end{array}$

$\left[\mathrm{ML}_{2}\right]^{3+}$

$\mathrm{M}=\mathrm{Eu}$

$\begin{array}{lrrr}\text { EU } & 0.000001 & 1.828879 & 0.000007 \\ \mathrm{~N} & -0.608818 & 3.612885 & -1.802409 \\ \mathrm{~N} & 0.608807 & 3.612887 & 1.802397 \\ \mathrm{C} & 0.249683 & 3.865084 & -2.816824 \\ \mathrm{~N} & -1.637022 & 4.477657 & -2.006125 \\ \mathrm{~N} & -1.752807 & 2.190310 & 1.967436 \\ \mathrm{~N} & 1.752904 & 2.190455 & -1.967313 \\ \mathrm{~N} & -2.173407 & 0.402889 & -0.023315 \\ \mathrm{~N} & 2.173401 & 0.402880 & 0.023313 \\ \mathrm{C} & -0.249530 & 3.864848 & 2.817023 \\ \mathrm{~N} & 1.637141 & 4.477464 & 2.006291 \\ \mathrm{C} & -0.248590 & 4.888512 & -3.650761 \\ \mathrm{C} & 1.510143 & 3.107800 & -2.926351 \\ \mathrm{C} & -1.469839 & 5.267472 & -3.102525\end{array}$




\begin{tabular}{|c|c|c|c|}
\hline $\mathrm{H}$ & -2.419467 & 4.490758 & -1.364908 \\
\hline & -2.894777 & 1.471405 & 2.025776 \\
\hline & -1.509979 & 3.107546 & 2.926561 \\
\hline$\tau$ & 2.894875 & 1.471554 & -2.025657 \\
\hline$C$ & -3.106862 & 0.471750 & 0.941701 \\
\hline & -2.260853 & -0.570787 & -0.938837 \\
\hline $\mathrm{C}$ & 3.106895 & 0.471798 & -0.941661 \\
\hline $\mathbf{N}$ & 2.260808 & -0.570847 & 0.938784 \\
\hline $\mathrm{C}$ & 0.249023 & 4.887837 & 3.651310 \\
\hline $\mathrm{C}$ & 1.470215 & 5.266900 & 3.102983 \\
\hline $\mathrm{H}$ & 2.419607 & 4.490571 & 1.365098 \\
\hline $\mathrm{H}$ & 0.201623 & 5.313237 & -4.534651 \\
\hline $\mathrm{C}$ & 2.411933 & 3.333790 & -3.978956 \\
\hline $\mathrm{C}$ & -3.843948 & 1.641042 & 3.036182 \\
\hline $\mathrm{C}$ & -2.411701 & 3.333426 & 3.979247 \\
\hline $\mathrm{C}$ & 3.844115 & 1.641300 & -3.035979 \\
\hline $\mathrm{N}$ & -4.219241 & -0.267069 & 0.960621 \\
\hline $\mathrm{C}$ & -3.303661 & -1.407970 & -0.928130 \\
\hline $\mathrm{N}$ & 4.219259 & -0.267044 & -0.960601 \\
\hline $\mathrm{C}$ & 3.303611 & -1.408038 & 0.928064 \\
\hline $\mathrm{H}$ & -0.200912 & 5.312141 & 4.535545 \\
\hline $\mathrm{C}$ & 3.591411 & 2.591828 & -4.031033 \\
\hline $\mathrm{H}$ & 2.195650 & 559 & -4.739381 \\
\hline $\mathrm{C}$ & -3.591176 & 2.591460 & 4.031323 \\
\hline $\mathrm{H}$ & -4.748714 & 1.046752 & 3.028769 \\
\hline $\mathrm{H}$ & -2.195383 & 4.074138 & 4.739718 \\
\hline $\mathrm{H}$ & 4.748877 & 1.047005 & -3.028573 \\
\hline $\mathrm{C}$ & -4.390043 & -1.173436 & -0.005393 \\
\hline $\mathrm{C}$ & -3.236729 & -2.555764 & -1.862624 \\
\hline $\mathrm{C}$ & 4.390012 & -1.173480 & 0.005357 \\
\hline $\mathrm{C}$ & 3.236652 & -2.555862 & 1.862519 \\
\hline $\mathrm{H}$ & 4.305362 & 2.751843 & -4.833117 \\
\hline $\mathrm{H}$ & -4.305078 & 2.751396 & 4.833467 \\
\hline $\mathrm{C}$ & -5.703061 & -1.845452 & -0.068311 \\
\hline $\mathrm{C}$ & -3.593639 & -3.843642 & -1.410446 \\
\hline $\mathrm{C}$ & -2.770090 & -2.367557 & -3.173261 \\
\hline $\mathrm{C}$ & 5.703003 & -1.845556 & 0.068246 \\
\hline $\mathrm{C}$ & 3.593515 & -3.843738 & 1.410297 \\
\hline $\mathrm{C}$ & 2.770043 & -2.367679 & 3.173169 \\
\hline $\mathrm{C}$ & -6.415213 & -2.047291 & 1.117351 \\
\hline $\mathrm{C}$ & -6.281128 & -2.221203 & -1.308607 \\
\hline $\mathrm{C}$ & -3.477203 & -4.939453 & -2.277955 \\
\hline $\mathrm{H}$ & -3.931154 & -3.997585 & -0.392243 \\
\hline $\mathrm{C}$ & -2.685250 & -3.469984 & -4.042767 \\
\hline $\mathrm{H}$ & -2.496369 & -1.373873 & -3.503660 \\
\hline $\mathrm{C}$ & 6.415144 & -2.047373 & -1.117425 \\
\hline
\end{tabular}




$\begin{array}{lccc}\mathrm{C} & 6.281052 & -2.221388 & 1.308526 \\ \mathrm{C} & 3.477058 & -4.939572 & 2.277775 \\ \mathrm{H} & 3.931010 & -3.997660 & 0.392083 \\ \mathrm{C} & 2.685183 & -3.470129 & 4.042644 \\ \mathrm{H} & 2.496362 & -1.373995 & 3.503604 \\ \mathrm{C} & -7.688059 & -2.654465 & 1.092507 \\ \mathrm{H} & -5.998682 & -1.759737 & 2.074970 \\ \mathrm{C} & -7.553649 & -2.798025 & -1.326192 \\ \mathrm{H} & -5.768668 & -2.030365 & -2.242586 \\ \mathrm{C} & -3.036392 & -4.763481 & -3.583679 \\ \mathrm{H} & -3.737685 & -5.933653 & -1.929327 \\ \mathrm{O} & -2.282721 & -3.407705 & -5.330204 \\ \mathrm{C} & 7.687963 & -2.654609 & -1.092608 \\ \mathrm{H} & 5.998627 & -1.759757 & -2.075031 \\ \mathrm{C} & 7.553547 & -2.798270 & 1.326085 \\ \mathrm{H} & 5.768602 & -2.030566 & 2.242513 \\ \mathrm{C} & 3.036275 & -4.763624 & 3.583512 \\ \mathrm{H} & 3.737503 & -5.933769 & 1.929112 \\ \mathrm{O} & 2.282682 & -3.407875 & 5.330090 \\ \mathrm{C} & -8.260784 & -3.030018 & -0.144302 \\ \mathrm{O} & -8.270532 & -2.825985 & 2.294427 \\ \mathrm{H} & -8.006250 & -3.068826 & -2.274848 \\ \mathrm{H} & -2.956358 & -5.596409 & -4.274273 \\ \mathrm{C} & -1.956715 & -2.136383 & -5.908698 \\ \mathrm{C} & 8.260670 & -3.030244 & 0.144185 \\ \mathrm{O} & 8.270426 & -2.826105 & -2.294536 \\ \mathrm{H} & 9.818245 & -3.467962 & -3.431640 \\ \mathrm{H} & 8.006135 & -3.069133 & 2.274729 \\ \mathrm{H} & 2.956225 & -5.596570 & 4.274082 \\ \mathrm{C} & 1.956738 & -2.136558 & 5.908632 \\ \mathrm{H} & -9.241138 & -3.489197 & -0.186832 \\ \mathrm{C} & -9.575134 & -3.440369 & 2.370583 \\ \mathrm{H} & -2.820234 & -1.462637 & -5.881568 \\ \mathrm{H} & -1.102575 & -1.680752 & -5.394508 \\ \mathrm{H} & -1.690902 & -2.347125 & -6.943844 \\ \mathrm{H} & 9.241003 & -3.489472 & 0.186694 \\ \mathrm{C} & 9.574998 & -3.440551 & -2.370720 \\ \mathrm{H} & 2.820280 & -1.462843 & 5.881501 \\ \mathrm{H} & 1.102602 & -1.680880 & 5.394477 \\ \mathrm{H} & 1.690943 & -2.347322 & 6.943778 \\ \mathrm{H} & -10.317028 & -2.838774 & 1.836454 \\ \mathrm{H} & -5.301044 & 3.522584\end{array}$




$\begin{array}{llll}\mathrm{H} & 2.154540 & 6.763408 & 4.459083 \\ \mathrm{H} & 3.457512 & 5.860416 & 3.676906 \\ \mathrm{H} & 2.558755 & 7.090994 & 2.770382 \\ \mathrm{C} & -2.468182 & 6.300542 & -3.523016 \\ \mathrm{H} & -2.141775 & 6.780942 & -4.445840 \\ \mathrm{H} & -3.450971 & 5.854130 & -3.703132 \\ \mathrm{H} & -2.580021 & 7.076968 & -2.759713\end{array}$

$\mathrm{M}=\mathrm{Gd}$

$\begin{array}{lccc}\text { GD } & 0.000000 & 1.933558 & 0.000002 \\ \mathrm{~N} & 0.748343 & 3.600076 & 1.644722 \\ \mathrm{~N} & -0.748346 & 3.600075 & -1.644720 \\ \mathrm{C} & 0.029383 & 3.814666 & 2.780144 \\ \mathrm{~N} & 1.795883 & 4.467435 & 1.738465 \\ \mathrm{~N} & -1.482536 & 2.140636 & 2.020971 \\ \mathrm{~N} & 1.482538 & 2.140641 & -2.020966 \\ \mathrm{~N} & -1.914007 & 0.532978 & -0.004719 \\ \mathrm{~N} & 1.914005 & 0.532976 & 0.004720 \\ \mathrm{C} & -0.029377 & 3.814679 & -2.780132 \\ \mathrm{~N} & -1.795870 & 4.467457 & -1.738447 \\ \mathrm{C} & 0.628506 & 4.806905 & 3.568109 \\ \mathrm{C} & -1.188306 & 3.019515 & 3.003333 \\ \mathrm{C} & 1.771383 & 5.212223 & 2.871671 \\ \mathrm{H} & 2.498329 & 4.504202 & 1.010296 \\ \mathrm{C} & -2.573515 & 1.349642 & 2.140262 \\ \mathrm{C} & 2.573515 & 1.349646 & -2.140258 \\ \mathrm{C} & 1.188311 & 3.019526 & -3.003324 \\ \mathrm{C} & -2.791768 & 0.416281 & 1.007009 \\ \mathrm{~N} & -1.904458 & -0.392112 & -0.983156 \\ \mathrm{C} & 2.791766 & 0.416281 & -1.007009 \\ \mathrm{~N} & 1.904455 & -0.392116 & 0.983155 \\ \mathrm{C} & -0.628474 & 4.806952 & -3.568074 \\ \mathrm{C} & -1.771350 & 5.212270 & -2.871637 \\ \mathrm{H} & -2.498312 & 4.504228 & -1.010275 \\ \mathrm{H} & 0.298276 & 5.196008 & 4.519341 \\ \mathrm{C} & -1.991144 & 3.140730 & 4.143758 \\ \mathrm{C} & -3.423589 & 1.412323 & 3.243849 \\ \mathrm{C} & 3.423592 & 1.412332 & -3.243843 \\ \mathrm{C} & 1.991151 & 3.140745 & -4.143747 \\ \mathrm{~N} & -3.811024 & -0.428905 & 1.009323 \\ \mathrm{C} & -2.837467 & -1.344299 & -0.993336 \\ \mathrm{~N} & 3.811023 & -0.428905 & -1.009324 \\ \mathrm{C} & 2.837464 & -1.344303 & 0.993333 \\ \mathrm{H} & -0.298221 & 5.196086 & -4.519286 \\ \mathrm{C} & -3.121921 & 2.326605 & 4.260558\end{array}$




\begin{tabular}{|c|c|c|c|}
\hline $\mathrm{H}$ & -1.741200 & 3.851218 & 4.923015 \\
\hline $\mathrm{H}$ & -4.290228 & 0.764040 & 3.291742 \\
\hline & 3.121927 & 2.326620 & -4.260548 \\
\hline & 4.290231 & 0.764049 & -3.291737 \\
\hline & 1.741208 & 3.851237 & -4.923001 \\
\hline & -3.945435 & -1.261613 & -0.040158 \\
\hline & -2.640659 & -2.447733 & -1.954287 \\
\hline & 3.945433 & -1.261616 & 0.040154 \\
\hline & 2.640656 & -2.447738 & 1.954282 \\
\hline & -3.761174 & 2.403570 & 5.134942 \\
\hline $\mathrm{H}$ & 3.761181 & 2.403587 & -5.134931 \\
\hline & -5.211857 & -1.977556 & -0.156947 \\
\hline & -2.833617 & -3.772867 & -1.531281 \\
\hline & -2.185515 & -2.169992 & -3.260830 \\
\hline & 5.211854 & -1.977560 & 0.156942 \\
\hline$C$ & 2.833612 & -3.772871 & 1.531274 \\
\hline$C$ & 2.185515 & -2.169999 & 3.260827 \\
\hline $\mathrm{C}$ & -5.987593 & -2.158257 & 1.006394 \\
\hline$C$ & -5.719967 & -2.401856 & -1.412857 \\
\hline$c$ & -2.556334 & -4.820168 & -2.418779 \\
\hline H & -3.179785 & -3.992861 & -0.528069 \\
\hline & -1.951511 & -3.227143 & -4.150516 \\
\hline $\mathrm{H}$ & -2.047457 & -1.141111 & -3.567694 \\
\hline & 5.987589 & -2.158260 & -1.006400 \\
\hline $\mathrm{C}$ & 5.719963 & -2.401864 & 1.412851 \\
\hline $\mathrm{C}$ & 2.556330 & -4.820174 & 2.418771 \\
\hline $\mathrm{H}$ & 3.179778 & -3.992865 & 0.528061 \\
\hline & 1.951512 & -3.227150 & 4.150511 \\
\hline $\mathrm{H}$ & 2.047460 & -1.141118 & 3.567692 \\
\hline & -7.239728 & -2.784869 & 0.943642 \\
\hline $\mathrm{H}$ & -5.616978 & -1.839830 & 1.972226 \\
\hline $\mathrm{C}$ & -6.980077 & -2.986426 & -1.468572 \\
\hline $\mathrm{H}$ & -5.156504 & -2.255854 & -2.324221 \\
\hline $\mathrm{C}$ & -2.129021 & -4.558465 & -3.717594 \\
\hline $\mathrm{H}$ & -2.688580 & -5.848374 & -2.097222 \\
\hline U & -1.550475 & -3.081963 & -5.441042 \\
\hline 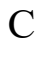 & 7.239724 & -2.784873 & -0.943650 \\
\hline $\mathrm{H}$ & 5.616974 & -1.839830 & -1.972231 \\
\hline & 6.980074 & -2.986435 & 1.468564 \\
\hline 11 & 5.156501 & -2.255863 & 2.324215 \\
\hline O & 2.129019 & -4.558472 & 3.717588 \\
\hline 11 & 2.688573 & -5.848380 & 2.097212 \\
\hline 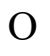 & 1.550479 & -3.081972 & 5.441038 \\
\hline . & -7.740637 & -3.196173 & -0.308620 \\
\hline 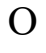 & -7.881098 & -2.939348 & 2.125632 \\
\hline & -7.386730 & -3.295779 & -2.4262 \\
\hline
\end{tabular}




$\begin{array}{crcc}\mathrm{H} & -1.937729 & -5.361622 & -4.421566 \\ \mathrm{C} & -1.446706 & -1.766122 & -5.987524 \\ \mathrm{C} & 7.740633 & -3.196180 & 0.308611 \\ \mathrm{O} & 7.881093 & -2.939349 & -2.125640 \\ \mathrm{H} & 7.386726 & -3.295791 & 2.426225 \\ \mathrm{H} & 1.937728 & -5.361630 & 4.421558 \\ \mathrm{C} & 1.446714 & -1.766131 & 5.987524 \\ \mathrm{H} & -8.708829 & -3.676229 & -0.388555 \\ \mathrm{C} & -9.168381 & -3.586551 & 2.136091 \\ \mathrm{H} & -2.407613 & -1.240066 & -5.937965 \\ \mathrm{H} & -0.672515 & -1.182260 & -5.472584 \\ \mathrm{H} & -1.162547 & -1.901771 & -7.030910 \\ \mathrm{H} & 8.708825 & -3.676237 & 0.388545 \\ \mathrm{C} & 9.168376 & -3.586553 & -2.136101 \\ \mathrm{H} & 2.407622 & -1.240078 & 5.937962 \\ \mathrm{H} & 0.672522 & -1.182267 & 5.472586 \\ \mathrm{H} & 1.162558 & -1.901782 & 7.030909 \\ \mathrm{H} & -9.093457 & -4.611973 & 1.759548 \\ \mathrm{H} & -9.897646 & -3.017440 & 1.550116 \\ \mathrm{H} & -9.475310 & -3.604311 & 3.180971 \\ \mathrm{H} & 9.093450 & -4.611976 & -1.759560 \\ \mathrm{H} & 9.897641 & -3.017444 & -1.550125 \\ \mathrm{H} & 9.475304 & -3.604311 & -3.180982 \\ \mathrm{C} & -2.816271 & 6.230396 & -3.200685 \\ \mathrm{H} & -2.359297 & 7.214453 & -3.336768 \\ \mathrm{H} & -3.321058 & 5.968994 & -4.135019 \\ \mathrm{H} & -3.569506 & 6.307176 & -2.413393 \\ \mathrm{C} & 2.816236 & 6.230437 & 3.200656 \\ \mathrm{H} & 2.359352 & 7.214730 & 3.335400 \\ \mathrm{H} & 3.320160 & 5.969830 & 4.135671 \\ \mathrm{H} & 3.570164 & 6.306307 & 2.413939 \\ & & & \\ \mathrm{M}=\mathrm{Am} & & & \\ & & & \\ & & \end{array}$

$\begin{array}{lrrr}\text { AM } & -0.000062 & 1.979366 & -0.000056 \\ \text { N } & -0.699849 & 3.643130 & -1.751638 \\ \text { N } & 0.699493 & 3.643462 & 1.751322 \\ \text { N } & -1.671545 & 4.593280 & -1.859233 \\ \mathrm{C} & -0.036106 & 3.702353 & -2.934972 \\ \mathrm{~N} & -1.385367 & 1.952832 & 2.140066 \\ \mathrm{~N} & 1.385167 & 1.952688 & -2.140234 \\ \mathrm{~N} & -1.867131 & 0.451852 & 0.038550 \\ \mathrm{~N} & 1.867080 & 0.451930 & -0.038585 \\ \mathrm{~N} & 1.671076 & 4.593736 & 1.858839 \\ \mathrm{C} & 0.035723 & 3.702727 & 2.934640 \\ \mathrm{C} & -1.650592 & 5.244073 & -3.048972\end{array}$




\begin{tabular}{|c|c|c|c|}
\hline $\mathrm{H}$ & -2.320903 & 4.752487 & -1.099067 \\
\hline & -0.592317 & 4.683054 & -3.769424 \\
\hline & 1.095407 & 2.790864 & -3.160614 \\
\hline C & -2.412896 & 1.081033 & 2.271982 \\
\hline $\mathrm{C}$ & -1.095702 & 2.791146 & 3.160359 \\
\hline $\mathrm{C}$ & 2.412759 & 1.080954 & -2.272084 \\
\hline $\mathrm{C}$ & -2.655422 & 0.210579 & 1.096797 \\
\hline $\mathrm{N}$ & -1.879923 & -0.397786 & -1.003876 \\
\hline $\mathrm{C}$ & 2.655373 & 0.210626 & -1.096822 \\
\hline $\mathrm{N}$ & 1.879975 & -0.397602 & 1.003929 \\
\hline $\mathrm{C}$ & 1.650030 & 5.244645 & 3.048512 \\
\hline $\mathrm{H}$ & 2.320426 & 4.752944 & 1.098666 \\
\hline $\mathrm{C}$ & 0.591808 & 4.683576 & 3.769003 \\
\hline $\mathrm{C}$ & -2.620460 & 6.325832 & -3.403642 \\
\hline $\mathrm{H}$ & -0.287607 & 4.968090 & -4.764943 \\
\hline $\mathrm{C}$ & 1.833570 & 2.780328 & -4.350182 \\
\hline $\mathrm{C}$ & -3.193911 & 1.013296 & 3.424567 \\
\hline $\mathrm{C}$ & -1.833888 & 2.780672 & 4.349913 \\
\hline $\mathrm{C}$ & 3.193756 & 1.013160 & -3.424678 \\
\hline $\mathrm{N}$ & -3.617891 & -0.699637 & 1.113124 \\
\hline $\mathrm{C}$ & -2.755043 & -1.402400 & -1.020434 \\
\hline $\mathrm{N}$ & 3.617920 & -0.699510 & -1.113085 \\
\hline $\mathrm{C}$ & 2.755184 & -1.402139 & 1.020563 \\
\hline $\mathrm{C}$ & 2.619763 & 6.326556 & 3.403086 \\
\hline $\mathrm{H}$ & 0.287049 & 4.968678 & 4.764488 \\
\hline $\mathrm{H}$ & -2.087839 & 7.244808 & -3.663094 \\
\hline $\mathrm{H}$ & -3.216415 & 6.033007 & -4.272773 \\
\hline $\mathrm{H}$ & -3.302170 & 6.545242 & -2.578844 \\
\hline $\mathrm{C}$ & 2.893955 & 1.880212 & -4.481224 \\
\hline $\mathrm{H}$ & 1.587762 & 3.461519 & -5.156248 \\
\hline $\mathrm{C}$ & -2.894199 & 1.880480 & 4.481030 \\
\hline $\mathrm{H}$ & -4.010365 & 0.303221 & 3.476080 \\
\hline $\mathrm{H}$ & -1.588157 & 3.461971 & 5.155911 \\
\hline $\mathrm{H}$ & 4.010264 & 0.303144 & -3.476135 \\
\hline $\mathrm{C}$ & -3.783121 & -1.465397 & 0.018725 \\
\hline $\mathrm{C}$ & -2.573609 & -2.413833 & -2.081701 \\
\hline $\mathrm{C}$ & 3.783237 & -1.465154 & -0.018618 \\
\hline $\mathrm{C}$ & 2.573870 & -2.413475 & 2.081943 \\
\hline $\mathrm{H}$ & 2.087031 & 7.245520 & 3.662355 \\
\hline $\mathrm{H}$ & 3.215681 & 6.033926 & 4.272307 \\
\hline $\mathrm{H}$ & 3.301513 & 6.545906 & 2.578305 \\
\hline $\mathrm{H}$ & 3.481573 & 1.856792 & -5.393970 \\
\hline $\mathrm{H}$ & -3.481831 & 1.857105 & 5.393768 \\
\hline $\mathrm{C}$ & -5.003787 & -2.263242 & -0.051485 \\
\hline $\mathrm{C}$ & -2.638950 & -3.777657 & -1.754344 \\
\hline$C$ & -2.261394 & -2.004962 & -3.395484 \\
\hline
\end{tabular}




\begin{tabular}{|c|c|c|c|}
\hline $\mathrm{C}$ & 5.003969 & -2.262896 & 0.051635 \\
\hline $\mathrm{C}$ & 2.639313 & -3.777328 & 1.754728 \\
\hline $\mathrm{C}$ & 2.261671 & -2.004491 & 3.395695 \\
\hline $\mathrm{C}$ & -5.658818 & -2.591497 & 1.152506 \\
\hline$C$ & -5.591182 & -2.625423 & -1.291741 \\
\hline $\mathrm{C}$ & -2.377462 & -4.731207 & -2.746250 \\
\hline $\mathrm{H}$ & -2.877282 & -4.097888 & -0.746649 \\
\hline $\mathrm{C}$ & -2.042694 & -2.971337 & -4.386640 \\
\hline $\mathrm{H}$ & -2.221674 & -0.948113 & -3.627351 \\
\hline $\mathrm{C}$ & 5.658987 & -2.591221 & -1.152345 \\
\hline $\mathrm{C}$ & 5.591434 & -2.624902 & 1.291909 \\
\hline $\mathrm{C}$ & 2.377943 & -4.730795 & 2.746745 \\
\hline $\mathrm{H}$ & 2.877635 & -4.097646 & 0.747058 \\
\hline $\mathrm{C}$ & 2.043090 & -2.970779 & 4.386961 \\
\hline $\mathrm{H}$ & 2.221871 & -0.947622 & 3.627452 \\
\hline $\mathrm{C}$ & -6.866861 & -3.302386 & 1.141490 \\
\hline $\mathrm{H}$ & -5.226871 & -2.322115 & 2.107826 \\
\hline $\mathrm{C}$ & -6.809271 & -3.295673 & -1.291870 \\
\hline $\mathrm{H}$ & -5.122564 & -2.366303 & -2.231283 \\
\hline $\mathrm{C}$ & -2.090737 & -4.340986 & -4.051512 \\
\hline $\mathrm{H}$ & -2.412694 & -5.787914 & -2.500701 \\
\hline $\mathrm{O}$ & -1.774201 & -2.698363 & -5.691310 \\
\hline $\mathrm{C}$ & 6.867088 & -3.302013 & -1.141295 \\
\hline $\mathrm{H}$ & 5.226988 & -2.321972 & -2.107678 \\
\hline $\mathrm{C}$ & 6.809577 & -3.295053 & 1.292066 \\
\hline $\mathrm{H}$ & 5.122826 & -2.365723 & 2.231439 \\
\hline $\mathrm{C}$ & 2.091235 & -4.340459 & 4.051977 \\
\hline $\mathrm{H}$ & 2.413254 & -5.787525 & 2.501307 \\
\hline $\mathrm{O}$ & 1.774623 & -2.697690 & 5.691613 \\
\hline $\mathrm{C}$ & -7.448307 & -3.650910 & -0.094757 \\
\hline $\mathrm{O}$ & -7.388889 & -3.595381 & 2.355740 \\
\hline $\mathrm{H}$ & -7.277657 & -3.558250 & -2.235200 \\
\hline $\mathrm{H}$ & -1.914165 & -5.072100 & -4.833509 \\
\hline $\mathrm{C}$ & -1.826942 & -1.342397 & -6.137058 \\
\hline $\mathrm{C}$ & 7.448602 & -3.650362 & 0.094969 \\
\hline $\mathrm{O}$ & 7.389099 & -3.595091 & -2.355533 \\
\hline $\mathrm{H}$ & 7.278015 & -3.557496 & 2.235408 \\
\hline $\mathrm{H}$ & 1.914755 & -5.071505 & 4.834058 \\
\hline $\mathrm{C}$ & 1.827264 & -1.341671 & 6.137214 \\
\hline $\mathrm{H}$ & -8.385741 & -4.192982 & -0.134182 \\
\hline $\mathrm{C}$ & -8.626573 & -4.330172 & 2.418601 \\
\hline $\mathrm{H}$ & -2.816192 & -0.904707 & -5.957415 \\
\hline $\mathrm{H}$ & -1.054105 & -0.733250 & -5.649603 \\
\hline $\mathrm{H}$ & -1.636455 & -1.376857 & -7.209626 \\
\hline $\mathrm{H}$ & 8.386080 & -4.192355 & 0.134418 \\
\hline $\mathrm{C}$ & 8.626841 & -4.329787 & -2.418357 \\
\hline
\end{tabular}




$\begin{array}{lrrr}\mathrm{H} & 2.816469 & -0.903915 & 5.957486 \\ \mathrm{H} & 1.054355 & -0.732644 & 5.649723 \\ \mathrm{H} & 1.636821 & -1.376032 & 7.209793 \\ \mathrm{H} & -8.520498 & -5.315500 & 1.952947 \\ \mathrm{H} & -9.439179 & -3.769891 & 1.944421 \\ \mathrm{H} & -8.838592 & -4.450538 & 3.480143 \\ \mathrm{H} & 8.520861 & -5.315076 & -1.952598 \\ \mathrm{H} & 9.439417 & -3.769391 & -1.944261 \\ \mathrm{H} & 8.838836 & -4.450245 & -3.479894\end{array}$

$\mathrm{M}=\mathrm{Cm}$

$\begin{array}{lrcc}\mathrm{CM} & 0.000000 & 1.884506 & -0.000002 \\ \mathrm{~N} & 0.669366 & 3.562174 & 1.722916 \\ \mathrm{~N} & -0.669367 & 3.562167 & -1.722922 \\ \mathrm{C} & -0.064215 & 3.722003 & 2.857985 \\ \mathrm{~N} & 1.687028 & 4.461925 & 1.847237 \\ \mathrm{~N} & 1.524438 & 2.016737 & -2.057805 \\ \mathrm{~N} & -1.524425 & 2.016725 & 2.057811 \\ \mathrm{~N} & 1.923834 & 0.427570 & 0.009084 \\ \mathrm{~N} & -1.923835 & 0.427570 & -0.009086 \\ \mathrm{C} & 0.064235 & 3.722023 & -2.857974 \\ \mathrm{~N} & -1.687013 & 4.461939 & -1.847229 \\ \mathrm{C} & 0.496361 & 4.713081 & 3.675377 \\ \mathrm{C} & -1.258769 & 2.885442 & 3.056176 \\ \mathrm{C} & 1.629498 & 5.174842 & 2.998612 \\ \mathrm{H} & 2.391863 & 4.543046 & 1.125175 \\ \mathrm{C} & 2.595802 & 1.197882 & -2.154969 \\ \mathrm{C} & 1.258790 & 2.885465 & -3.056164 \\ \mathrm{C} & -2.595790 & 1.197870 & 2.154975 \\ \mathrm{C} & 2.793527 & 0.279885 & -1.004940 \\ \mathrm{~N} & 1.905023 & -0.483335 & 1.001406 \\ \mathrm{C} & -2.793524 & 0.279882 & 1.004941 \\ \mathrm{~N} & -1.905028 & -0.483333 & -1.001410 \\ \mathrm{C} & -0.496312 & 4.713137 & -3.675341 \\ \mathrm{C} & -1.629458 & 5.174886 & -2.998583 \\ \mathrm{H} & -2.391867 & 4.543038 & -1.125184 \\ \mathrm{H} & 0.147004 & 5.066472 & 4.633619 \\ \mathrm{C} & -2.070736 & 2.965659 & 4.193889 \\ \mathrm{C} & 3.453888 & 1.219593 & -3.254357 \\ \mathrm{C} & 2.070766 & 2.965692 & -4.193870 \\ \mathrm{C} & -3.453868 & 1.219572 & 3.254370 \\ \mathrm{~N} & 3.796554 & -0.585560 & -0.999401 \\ \mathrm{C} & 2.820272 & -1.451350 & 1.022003 \\ \mathrm{~N} & -3.796554 & -0.585560 & 0.999401 \\ \mathrm{C} & -2.820279 & -1.451347 & -1.022006\end{array}$




\begin{tabular}{|c|c|c|c|}
\hline $\mathrm{H}$ & -0.146925 & 5.066563 & -4.633561 \\
\hline & -3.180982 & 2.121503 & 4.289582 \\
\hline $\mathrm{H}$ & -1.844450 & 3.668822 & 4.986855 \\
\hline C & 3.181012 & 2.121534 & -4.289562 \\
\hline $\mathrm{H}$ & 4.305288 & 0.550550 & -3.284571 \\
\hline $\mathrm{H}$ & 1.844487 & 3.668861 & -4.986832 \\
\hline $\mathrm{H}$ & -4.305268 & 0.550531 & 3.284584 \\
\hline C & 3.922048 & -1.405648 & 0.060447 \\
\hline 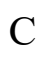 & 2.609635 & -2.534351 & 2.003808 \\
\hline C & -3.922054 & -1.405643 & -0.060450 \\
\hline & -2.609643 & -2.534350 & -2.003810 \\
\hline & -3.827234 & 2.166694 & 5.161029 \\
\hline 7 & 3.827270 & 2.166732 & -5.161004 \\
\hline c & 5.174056 & -2.146673 & 0.178183 \\
\hline 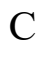 & 2.771094 & -3.870267 & 1.602419 \\
\hline 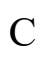 & 2.173672 & -2.224558 & 3.309559 \\
\hline C & -5.174066 & -2.146660 & -0.178188 \\
\hline$C$ & -2.771113 & -3.870264 & -1.602421 \\
\hline C & -2.173672 & -2.224561 & -3.309559 \\
\hline$C$ & 5.933199 & -2.368012 & -0.988733 \\
\hline C & 5.685502 & -2.557428 & 1.437004 \\
\hline$C$ & 2.481694 & -4.895936 & 2.511101 \\
\hline $\mathrm{H}$ & 3.103130 & -4.114800 & 0.600025 \\
\hline 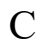 & 1.927218 & -3.260980 & 4.220079 \\
\hline $\mathrm{H}$ & 2.060096 & -1.187672 & 3.599566 \\
\hline $\mathrm{C}$ & -5.933212 & -2.367996 & 0.988727 \\
\hline $\mathrm{C}$ & -5.685513 & -2.557408 & -1.437010 \\
\hline $\mathrm{C}$ & -2.481715 & -4.895936 & -2.511100 \\
\hline $\mathrm{H}$ & -3.103154 & -4.114795 & -0.600027 \\
\hline $\mathrm{C}$ & -1.927219 & -3.260986 & -4.220077 \\
\hline $\mathrm{H}$ & -2.060088 & -1.187676 & -3.599567 \\
\hline $\mathrm{C}$ & 7.171939 & -3.020819 & -0.925851 \\
\hline$\Pi$ & 5.559807 & -2.060958 & -1.957260 \\
\hline 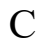 & 6.932935 & -3.168709 & 1.492109 \\
\hline $\mathrm{H}$ & 5.135188 & -2.380132 & 2.350927 \\
\hline $\mathrm{C}$ & 2.072927 & -4.602947 & 3.809207 \\
\hline $\mathrm{H}$ & 2.590026 & -5.932129 & 2.206596 \\
\hline $\mathrm{O}$ & 1.542282 & -3.084533 & 5.511878 \\
\hline $\mathrm{C}$ & -7.171957 & -3.020794 & 0.925842 \\
\hline $\mathrm{H}$ & -5.559819 & -2.060947 & 1.957255 \\
\hline 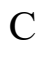 & -6.932951 & -3.168681 & -1.492117 \\
\hline $\mathrm{H}$ & -5.135197 & -2.380115 & -2.350932 \\
\hline $\mathrm{C}$ & -2.072939 & -4.602952 & -3.809204 \\
\hline 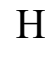 & -2.590055 & -5.932128 & -2.206595 \\
\hline $\mathrm{O}$ & -1.542275 & -3.084542 & -5.511874 \\
\hline $\mathrm{C}$ & 7.676739 & -3.418249 & 0.329218 \\
\hline
\end{tabular}




$\begin{array}{cccc}\mathrm{O} & 7.797390 & -3.212826 & -2.111025 \\ \mathrm{H} & 7.342553 & -3.467752 & 2.451801 \\ \mathrm{H} & 1.872643 & -5.389565 & 4.529181 \\ \mathrm{C} & 1.478724 & -1.757863 & 6.037701 \\ \mathrm{C} & -7.676757 & -3.418217 & -0.329228 \\ \mathrm{O} & -7.797410 & -3.212799 & 2.111015 \\ \mathrm{H} & -7.342569 & -3.467720 & -2.451810 \\ \mathrm{H} & -1.872656 & -5.389570 & -4.529176 \\ \mathrm{C} & -1.478703 & -1.757874 & -6.037697 \\ \mathrm{H} & 8.635009 & -3.917761 & 0.409191 \\ \mathrm{C} & 9.070412 & -3.887455 & -2.121195 \\ \mathrm{H} & 2.451986 & -1.257392 & 5.967815 \\ \mathrm{H} & 0.713319 & -1.162534 & 5.522547 \\ \mathrm{H} & 1.204198 & -1.869184 & 7.086525 \\ \mathrm{H} & -8.635031 & -3.917723 & -0.409203 \\ \mathrm{C} & -9.070437 & -3.887418 & 2.121182 \\ \mathrm{H} & -2.451962 & -1.257394 & -5.967817 \\ \mathrm{H} & -0.713296 & -1.162550 & -5.522539 \\ \mathrm{H} & -1.204171 & -1.869196 & -7.086519 \\ \mathrm{H} & 8.977652 & -4.903444 & -1.723569 \\ \mathrm{H} & 9.817547 & -3.322660 & -1.553839 \\ \mathrm{H} & 9.366255 & -3.932383 & -3.168456 \\ \mathrm{H} & -8.977684 & -4.903407 & 1.723555 \\ \mathrm{H} & -9.817567 & -3.322617 & 1.553827 \\ \mathrm{H} & -9.366282 & -3.932346 & 3.168443 \\ \mathrm{C} & -2.637334 & 6.217597 & -3.363438 \\ \mathrm{H} & -2.144134 & 7.176077 & -3.546856 \\ \mathrm{H} & -3.161575 & 5.935428 & -4.281055 \\ \mathrm{H} & -3.379105 & 6.358320 & -2.574030 \\ \mathrm{C} & 2.637295 & 6.217651 & 3.363399 \\ \mathrm{H} & 3.379202 & 6.358226 & 2.574089 \\ \mathrm{H} & 2.144008 & 7.176157 & 3.546490 \\ \mathrm{H} & 3.161387 & 5.935735 & 4.281167\end{array}$

$\mathbf{L}=\mathbf{2 b p}$

\section{$\left[\mathrm{ML}\left(\mathrm{H}_{2} \mathrm{O}\right)_{6}\right]^{3+}$}

$\mathrm{M}=\mathrm{Eu}$

$\begin{array}{lccc}\text { EU } & 1.518655 & -1.193093 & 0.404101 \\ \text { O } & 0.371630 & -2.643501 & 2.291008 \\ \text { O } & 1.725792 & -1.368184 & -2.257109 \\ \text { H } & -0.061408 & -3.510291 & 2.260276 \\ \text { H } & 0.033195 & -2.190404 & 3.079344 \\ \text { O } & -0.158885 & -2.982314 & -0.603328\end{array}$




\begin{tabular}{|c|c|c|c|}
\hline O & 1.164070 & 0.062984 & 33911 \\
\hline $\mathrm{H}$ & 2.397523 & -1.955020 & -2.639554 \\
\hline & 1.645641 & -0.628280 & -2.879459 \\
\hline A & -1.036691 & -2.609099 & -0.357326 \\
\hline H & -0.137956 & -2.972307 & -1.573760 \\
\hline $\mathbf{H}$ & 1.934025 & -0.163103 & 3.282385 \\
\hline $\mathrm{H}$ & 0.863420 & 0.936306 & 3.026750 \\
\hline $\mathbf{N}$ & -2.028552 & -0.960600 & -0.039845 \\
\hline$c$ & -3.263737 & -0.450940 & -0.052220 \\
\hline $\mathrm{N}$ & -0.955267 & -0.159476 & -0.096996 \\
\hline C & -3.434136 & 0.973843 & -0.196576 \\
\hline $\mathrm{C}$ & -4.387856 & -1.400921 & 0.136102 \\
\hline C & -1.147611 & 1.166577 & -0.165938 \\
\hline $\mathrm{C}$ & -4.748193 & 1.640916 & -0.339991 \\
\hline $\mathrm{N}$ & -2.353539 & 1.751494 & -0.222340 \\
\hline $\mathrm{C}$ & -4.450955 & -2.589660 & -0.6 \\
\hline $\mathrm{C}$ & -5.379371 & -1.105608 & 1.102631 \\
\hline $\mathrm{C}$ & 0.060142 & 2.035591 & -0.236656 \\
\hline $\mathrm{C}$ & -4.918986 & 2.916479 & 0.191435 \\
\hline $\mathrm{C}$ & -5.815439 & 1.029480 & -1.056022 \\
\hline $\mathrm{C}$ & -5.523373 & -3.483013 & -0.386720 \\
\hline $\mathrm{H}$ & -3.703767 & -2.800679 & -1.3 \\
\hline $\mathrm{C}$ & -6.424574 & -2.015886 & 1.330512 \\
\hline $\mathrm{H}$ & -5.313430 & -0.204524 & 1.7 \\
\hline $\mathrm{C}$ & -0.082084 & 3.417375 & -0.379994 \\
\hline $\mathrm{N}$ & 1.262950 & 1.418587 & -0.186050 \\
\hline $\mathrm{C}$ & -6.159293 & 3.589156 & 0.054900 \\
\hline $\mathrm{H}$ & -4.121708 & 3.414326 & 0.730297 \\
\hline $\mathrm{C}$ & -7.033718 & 1.708969 & -1.203263 \\
\hline $\mathrm{H}$ & -5.681183 & 0.073784 & -1.545622 \\
\hline $\mathrm{C}$ & -6.507531 & -3.189531 & 0.596521 \\
\hline $\mathrm{O}$ & -5.715054 & -4.630436 & -1.051842 \\
\hline $\mathrm{H}$ & -7.172598 & -1.800468 & 2.086722 \\
\hline $\mathrm{C}$ & 1.074956 & 4.199462 & -0.473266 \\
\hline $\mathrm{H}$ & -1.070614 & 3.855226 & -0.427981 \\
\hline $\mathrm{C}$ & 2.377384 & 2.173947 & -0.281815 \\
\hline $\mathrm{C}$ & -7.225339 & 2.972256 & -0.651832 \\
\hline $\mathrm{O}$ & -6.219014 & 4.795724 & 0.624202 \\
\hline $\mathrm{H}$ & -7.838043 & 1.248151 & -1.767887 \\
\hline $\mathrm{H}$ & -7.312784 & -3.901339 & 0.746438 \\
\hline $\mathrm{C}$ & -4.810480 & -5.029645 & -2.098517 \\
\hline $\mathrm{C}$ & 2.316682 & 3.572617 & -0.425374 \\
\hline $\mathrm{H}$ & 1.005445 & 5.276906 & -0.586755 \\
\hline $\mathrm{C}$ & 3.676355 & 1.479294 & -0.240268 \\
\hline $\mathrm{H}$ & -8.176105 & 3.477380 & -0.774639 \\
\hline $\mathrm{C}$ & -7.436241 & 5.582961 & 0.552509 \\
\hline
\end{tabular}




$\begin{array}{cccc}\mathrm{H} & -4.800171 & -4.286985 & -2.903020 \\ \mathrm{H} & -3.802899 & -5.184255 & -1.697859 \\ \mathrm{H} & -5.204121 & -5.972438 & -2.474783 \\ \mathrm{H} & 3.226972 & 4.155112 & -0.498267 \\ \mathrm{C} & 4.965647 & 2.020204 & -0.404632 \\ \mathrm{~N} & 3.731140 & 0.140092 & -0.048721 \\ \mathrm{H} & -8.259467 & 5.053965 & 1.040515 \\ \mathrm{H} & -7.679212 & 5.810602 & -0.489078 \\ \mathrm{H} & -7.211332 & 6.500890 & 1.092015 \\ \mathrm{C} & 5.850395 & 0.942194 & -0.316991 \\ \mathrm{H} & 5.241291 & 3.042709 & -0.608918 \\ \mathrm{~N} & 5.059005 & -0.150012 & -0.098003 \\ \mathrm{O} & 3.271329 & -1.809089 & 2.486082 \\ \mathrm{H} & 3.105339 & -2.621737 & 2.991087 \\ \mathrm{H} & 4.178219 & -1.541865 & 2.704042 \\ \mathrm{O} & 2.601067 & -3.536706 & -0.238698 \\ \mathrm{H} & 1.905470 & -4.197409 & -0.391688 \\ \mathrm{H} & 3.418263 & -4.038135 & -0.097320 \\ \mathrm{H} & 5.377845 & -1.101889 & 0.019370 \\ \mathrm{C} & 7.309490 & 0.873686 & -0.418227 \\ \mathrm{C} & 7.954703 & -0.297918 & -0.864363 \\ \mathrm{C} & 8.084560 & 1.996579 & -0.065282 \\ \mathrm{C} & 9.348017 & -0.347151 & -0.945636 \\ \mathrm{H} & 7.379012 & -1.158304 & -1.196910 \\ \mathrm{C} & 9.477008 & 1.942274 & -0.148304 \\ \mathrm{H} & 7.604429 & 2.900721 & 0.295428 \\ \mathrm{C} & 10.112168 & 0.771923 & -0.585665 \\ \mathrm{H} & 9.839315 & -1.246269 & -1.303516 \\ \mathrm{H} & 10.068904 & 2.808099 & 0.130442 \\ \mathrm{H} & 11.194750 & 0.733983 & -0.652522\end{array}$

\section{$\mathrm{M}=\mathrm{Gd}$}

$\begin{array}{lrrr}\text { GD } & -1.424923 & -1.002256 & 0.277168 \\ \mathrm{~N} & -1.213580 & 1.499489 & -0.084051 \\ \mathrm{~N} & -3.552142 & 0.180334 & -0.046162 \\ \mathrm{C} & -0.002513 & 2.101244 & -0.114620 \\ \mathrm{C} & -2.325613 & 2.267889 & -0.171291 \\ \mathrm{~N} & 0.911540 & -0.109946 & 0.095375 \\ \mathrm{~N} & -4.858341 & -0.208060 & -0.083902 \\ \mathrm{C} & -3.598457 & 1.535426 & -0.148382 \\ \mathrm{C} & 0.148323 & 3.484374 & -0.220994 \\ \mathrm{C} & 1.173363 & 1.198047 & -0.043157 \\ \mathrm{C} & -2.254933 & 3.662765 & -0.286321 \\ \mathrm{~N} & 1.950984 & -0.973383 & -0.058941 \\ \mathrm{C} & -5.725668 & 0.836176 & -0.206425\end{array}$




\begin{tabular}{|c|c|c|c|}
\hline $\mathrm{H}$ & -5.093224 & -1.188881 & -0.011091 \\
\hline & -4.918734 & 1.987061 & -0.243555 \\
\hline C & -1.001521 & 4.277077 & -0.309151 \\
\hline $\mathrm{H}$ & 1.142952 & 3.912275 & -0.232362 \\
\hline $\mathrm{N}$ & 2.393288 & 1.722560 & -0.094679 \\
\hline 1 & -3.160597 & 4.253714 & -0.357790 \\
\hline $\mathrm{C}$ & 3.197184 & -0.532798 & -0.221715 \\
\hline H & -5.268851 & 2.999842 & -0.368601 \\
\hline $\mathrm{H}$ & -0.920478 & 5.356453 & -0.395694 \\
\hline 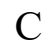 & 3.455925 & 0.902289 & -0.063207 \\
\hline $\mathrm{C}$ & 4.206297 & -1.527699 & -0.629350 \\
\hline $\mathrm{C}$ & 4.763334 & 1.499663 & 0.160422 \\
\hline $\mathrm{C}$ & 5.079704 & -1.209398 & -1.682830 \\
\hline $\mathrm{C}$ & 4.230255 & -2.812819 & -0.040482 \\
\hline C & 4.922207 & 2.877850 & -0.099563 \\
\hline$C$ & 5.841569 & 0.762102 & 0.722534 \\
\hline$C$ & 5.959854 & -2.189239 & -2.161665 \\
\hline $\mathrm{H}$ & 5.068381 & -0.226262 & -2.138846 \\
\hline $\mathrm{C}$ & 5.151143 & -3.767031 & -0.497618 \\
\hline 11 & 3.579129 & -3.035315 & 0.796181 \\
\hline $\mathrm{C}$ & 6.140135 & 3.521660 & 0.156381 \\
\hline $\mathrm{H}$ & 4.114246 & 3.455477 & -0.529348 \\
\hline$C$ & 7.032384 & 1.419180 & 1.008711 \\
\hline $\mathrm{H}$ & 5.743659 & -0.289255 & 0.954995 \\
\hline $\mathrm{C}$ & 6.006303 & -3.450443 & -1.577498 \\
\hline $\mathrm{H}$ & 6.624360 & -1.958480 & -2.988232 \\
\hline $\mathrm{O}$ & 5.306068 & -5.010303 & 0.016841 \\
\hline $\mathrm{C}$ & 7.201771 & 2.781812 & 0.722013 \\
\hline $\mathrm{O}$ & 6.193270 & 4.832145 & -0.164113 \\
\hline $\mathrm{H}$ & 7.854869 & 0.870785 & 1.456904 \\
\hline $\mathrm{H}$ & 6.705163 & -4.206352 & -1.920570 \\
\hline$C$ & 4.562282 & -5.387558 & 1.178055 \\
\hline UT & 8.153091 & 3.254454 & 0.936963 \\
\hline 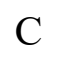 & 7.422187 & 5.556612 & 0.056191 \\
\hline U & 4.776872 & -4.717796 & 2.019332 \\
\hline 11 & 3.484173 & -5.404501 & 0.969588 \\
\hline $\mathrm{H}$ & 4.894109 & -6.395293 & 1.425761 \\
\hline $\mathrm{H}$ & 8.238779 & 5.125738 & -0.531769 \\
\hline $\mathrm{H}$ & 7.680710 & 5.571596 & 1.119825 \\
\hline $\mathrm{H}$ & 7.223568 & 6.571401 & -0.285190 \\
\hline $\mathrm{O}$ & -1.445126 & -0.718915 & -2.238523 \\
\hline 2 & -1.786193 & 0.040001 & -2.739289 \\
\hline $\mathrm{H}$ & -0.721022 & -1.098277 & -2.764045 \\
\hline 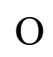 & -1.698292 & 0.119281 & 2.562757 \\
\hline $\mathrm{H}$ & -2.136682 & 0.960953 & 2.768104 \\
\hline $\mathrm{H}$ & -0.984967 & 0.009385 & 3.213669 \\
\hline
\end{tabular}




$\begin{array}{cccc}\mathrm{O} & 0.025205 & -1.996059 & 2.155498 \\ \mathrm{H} & -0.210533 & -2.756965 & 2.710293 \\ \mathrm{H} & 0.987984 & -2.031441 & 2.025688 \\ \mathrm{O} & 0.066628 & -2.655247 & -0.774369 \\ \mathrm{H} & 0.077356 & -3.578066 & -1.067227 \\ \mathrm{H} & 1.006781 & -2.352344 & -0.597946 \\ \mathrm{O} & -2.935341 & -2.715412 & -0.928051 \\ \mathrm{H} & -3.177487 & -3.650428 & -0.834828 \\ \mathrm{H} & -2.982595 & -2.517584 & -1.879179 \\ \mathrm{O} & -2.832919 & -2.330609 & 1.966405 \\ \mathrm{H} & -3.353660 & -3.147330 & 2.017948 \\ \mathrm{H} & -3.046647 & -1.815092 & 2.762642 \\ \mathrm{C} & -7.176384 & 0.682049 & -0.278130 \\ \mathrm{C} & -8.006678 & 1.758321 & 0.097320 \\ \mathrm{C} & -7.762930 & -0.523844 & -0.716629 \\ \mathrm{C} & -9.394833 & 1.623773 & 0.045416 \\ \mathrm{H} & -7.574296 & 2.688478 & 0.452072 \\ \mathrm{C} & -9.151647 & -0.651875 & -0.768870 \\ \mathrm{H} & -7.148085 & -1.350535 & -1.064252 \\ \mathrm{C} & -9.970188 & 0.420697 & -0.385371 \\ \mathrm{H} & -10.029468 & 2.452546 & 0.341868 \\ \mathrm{H} & -9.599199 & -1.575564 & -1.121275 \\ \mathrm{H} & -11.050053 & 0.320834 & -0.429370 \\ & & & \\ \mathrm{M}=\mathrm{Am} & & & \end{array}$

$\begin{array}{lrrc}\text { AM } & -1.322337 & -0.950139 & 0.424846 \\ \text { N } & -1.096706 & 1.582309 & 0.078695 \\ \text { N } & 1.028901 & -0.040067 & 0.091437 \\ \text { C } & 0.116928 & 2.182030 & 0.086001 \\ \text { C } & -2.205345 & 2.357314 & 0.010380 \\ \text { N } & -3.456325 & 0.285756 & -0.180618 \\ \text { C } & 1.290696 & 1.274544 & 0.047545 \\ \text { N } & 2.053802 & -0.891762 & -0.153451 \\ \mathrm{C} & 0.272657 & 3.567628 & 0.087550 \\ \mathrm{C} & -2.128283 & 3.756643 & 0.007238 \\ \mathrm{C} & -3.482832 & 1.641415 & -0.113344 \\ \mathrm{~N} & -4.759609 & -0.072778 & -0.356149 \\ \mathrm{~N} & 2.511117 & 1.796804 & -0.020950 \\ \mathrm{C} & 3.295616 & -0.448150 & -0.331542 \\ \mathrm{C} & -0.875135 & 4.367746 & 0.060191 \\ \mathrm{H} & 1.268320 & 3.992943 & 0.104299 \\ \mathrm{H} & -3.030238 & 4.354781 & -0.047236 \\ \mathrm{C} & -4.791439 & 2.124951 & -0.242395 \\ \mathrm{C} & -5.608107 & 0.993205 & -0.408139 \\ \mathrm{H} & -5.000379 & -1.052794 & -0.428727\end{array}$




\begin{tabular}{|c|c|c|c|}
\hline $\mathrm{C}$ & 3.568684 & 0.973033 & -0.107076 \\
\hline & 4.284627 & -1.432447 & -0.811697 \\
\hline H & -0.791508 & 5.450326 & 0.062959 \\
\hline & -5.123688 & 3.151041 & -0.268173 \\
\hline $\mathrm{C}$ & 4.891901 & 1.557543 & 0.064518 \\
\hline $\mathrm{C}$ & 5.109246 & -1.091076 & -1.896884 \\
\hline C & 4.336983 & -2.726175 & -0.246650 \\
\hline $\mathrm{C}$ & 5.043486 & 2.942961 & -0.152218 \\
\hline $\mathrm{C}$ & 5.997409 & 0.794990 & 0.531473 \\
\hline $\mathrm{C}$ & 5.971702 & -2.058318 & -2.430605 \\
\hline $\mathrm{H}$ & 5.074226 & -0.099572 & -2.333540 \\
\hline $\mathrm{C}$ & 5.240294 & -3.668659 & -0.761703 \\
\hline $\mathrm{H}$ & 3.720673 & -2.964504 & 0.612070 \\
\hline $\mathrm{C}$ & 6.279826 & 3.571348 & 308 \\
\hline $\mathrm{H}$ & 4.214945 & 3.540846 & -0.509249 \\
\hline $\mathrm{C}$ & 7.208514 & 1.435430 & 0.76 \\
\hline $\mathrm{H}$ & 5.906478 & -0.263592 & 0.731670 \\
\hline $\mathrm{C}$ & 6.047234 & -3.329669 & -1.871723 \\
\hline $\mathrm{H}$ & 6.598836 & -1.810350 & -3.281052 \\
\hline $\mathrm{O}$ & 5.419346 & -4.920508 & -0.277768 \\
\hline $\mathrm{C}$ & 7.369636 & 2.806703 & 0.523334 \\
\hline $\mathrm{O}$ & 6.32 & 4.8 & -0.221775 \\
\hline $\mathrm{H}$ & 8.052694 & 0.866397 & 839 \\
\hline $\mathrm{H}$ & 6.731939 & -4.077113 & -2.258997 \\
\hline $\mathrm{C}$ & 4.728248 & -5.320439 & 0.908859 \\
\hline $\mathrm{H}$ & 8.335311 & 3.266907 & 0.697140 \\
\hline $\mathrm{C}$ & 7.565364 & 5.604287 & -0.050967 \\
\hline $\mathrm{H}$ & 4.980749 & -4.666163 & 1.751591 \\
\hline $\mathrm{H}$ & 3.641972 & -5.332428 & 0.749565 \\
\hline $\mathrm{H}$ & 5.070720 & -6.332540 & 1.121661 \\
\hline $\mathrm{H}$ & 8.341639 & 5.192839 & -0.703848 \\
\hline $\mathrm{H}$ & 7.888815 & 5.578253 & 0.994516 \\
\hline $\mathrm{H}$ & 7.351649 & 6.631772 & -0.341385 \\
\hline $\mathrm{O}$ & 0.231170 & -2.740524 & -0.342237 \\
\hline $\mathrm{H}$ & 0.268267 & -3.601277 & -0.783455 \\
\hline $\mathrm{H}$ & 1.152143 & -2.323594 & -0.344687 \\
\hline $\mathrm{O}$ & -1.305195 & -0.778951 & -2.187795 \\
\hline $\mathrm{H}$ & -1.747099 & -0.055956 & -2.662531 \\
\hline $\mathrm{H}$ & -0.563692 & -1.058244 & -2.749542 \\
\hline $\mathrm{O}$ & -2.470706 & -0.115626 & 2.580845 \\
\hline $\mathrm{H}$ & -3.262607 & 0.442576 & 2.642218 \\
\hline $\mathrm{H}$ & -1.960618 & 0.023786 & 3.395730 \\
\hline $\mathrm{O}$ & 0.078274 & -1.206837 & 2.628825 \\
\hline $\mathrm{H}$ & -0.021942 & -2.018549 & 3.151961 \\
\hline $\mathrm{H}$ & 0.974909 & -0.876985 & 2.798379 \\
\hline O & -2.066741 & -3.009804 & 2.040069 \\
\hline
\end{tabular}




$\begin{array}{cccc}\mathrm{H} & -1.841553 & -3.954397 & 2.037915 \\ \mathrm{H} & -2.756863 & -2.899794 & 2.715279 \\ \mathrm{O} & -2.966111 & -2.637879 & -0.761647 \\ \mathrm{H} & -3.262336 & -3.523254 & -0.497607 \\ \mathrm{H} & -2.931145 & -2.630564 & -1.733054 \\ \mathrm{C} & -7.051025 & 0.873217 & -0.604062 \\ \mathrm{C} & -7.611589 & -0.260005 & -1.229921 \\ \mathrm{C} & -7.899690 & 1.908927 & -0.161694 \\ \mathrm{C} & -8.993321 & -0.357568 & -1.400867 \\ \mathrm{H} & -6.978462 & -1.048672 & -1.629219 \\ \mathrm{C} & -9.280786 & 1.805263 & -0.333383 \\ \mathrm{H} & -7.488577 & 2.782196 & 0.334818 \\ \mathrm{C} & -9.830736 & 0.673554 & -0.950662 \\ \mathrm{H} & -9.419345 & -1.223971 & -1.896392 \\ \mathrm{H} & -9.929877 & 2.602426 & 0.014092 \\ \mathrm{H} & -10.904809 & 0.597983 & -1.087200\end{array}$

$\mathrm{M}=\mathrm{Cm}$

$\begin{array}{lrrr}\mathrm{CM} & -1.329632 & -0.951530 & 0.283429 \\ \mathrm{~N} & -1.096331 & 1.576121 & -0.086184 \\ \mathrm{~N} & 1.036508 & -0.046352 & 0.084912 \\ \mathrm{C} & 0.119696 & 2.169591 & -0.107592 \\ \mathrm{C} & -2.203446 & 2.350877 & -0.175718 \\ \mathrm{~N} & -3.467461 & 0.278324 & -0.075215 \\ \mathrm{C} & 1.294839 & 1.263265 & -0.044651 \\ \mathrm{~N} & 2.074159 & -0.907540 & -0.088420 \\ \mathrm{C} & 0.278916 & 3.552498 & -0.201756 \\ \mathrm{C} & -2.122442 & 3.746107 & -0.279005 \\ \mathrm{C} & -3.486208 & 1.634187 & -0.171181 \\ \mathrm{~N} & -4.780009 & -0.085266 & -0.134422 \\ \mathrm{~N} & 2.514727 & 1.788601 & -0.097736 \\ \mathrm{C} & 3.318610 & -0.464285 & -0.255305 \\ \mathrm{C} & -0.865545 & 4.352879 & -0.288875 \\ \mathrm{H} & 1.275753 & 3.975159 & -0.205785 \\ \mathrm{H} & -3.023399 & 4.343880 & -0.352024 \\ \mathrm{C} & -4.796711 & 2.110484 & -0.283445 \\ \mathrm{C} & -5.625460 & 0.974949 & -0.264225 \\ \mathrm{H} & -5.033926 & -1.061888 & -0.069017 \\ \mathrm{C} & 3.577796 & 0.968372 & -0.080750 \\ \mathrm{C} & 4.325014 & -1.454331 & -0.681783 \\ \mathrm{H} & -0.777489 & 5.432437 & -0.365806 \\ \mathrm{H} & -5.126679 & 3.129783 & -0.409469 \\ \mathrm{C} & 4.886374 & 1.563489 & 0.143883 \\ \mathrm{C} & 5.194071 & -1.123606 & -1.734844 \\ \mathrm{C} & 4.350811 & -2.746547 & -0.108735\end{array}$




\begin{tabular}{|c|c|c|c|}
\hline $\mathrm{C}$ & 5.045884 & 2.943579 & -0.104252 \\
\hline & 5.965862 & 0.819660 & 0.694716 \\
\hline $\mathrm{C}$ & 6.072075 & -2.097788 & -2.228991 \\
\hline $\mathrm{H}$ & 5.181185 & -0.134988 & -2.178949 \\
\hline C & 5.269272 & -3.695445 & -0.581384 \\
\hline $\mathrm{H}$ & 3.702176 & -2.978915 & 0.727288 \\
\hline $\mathrm{C}$ & 6.265428 & 3.583793 & 0.153316 \\
\hline $\mathrm{H}$ & 4.237282 & 3.526145 & -0.526205 \\
\hline $\mathrm{C}$ & 7.158515 & 1.472719 & 0.982562 \\
\hline $\mathrm{H}$ & 5.867578 & -0.233854 & 0.917421 \\
\hline $\mathrm{C}$ & 6.120374 & -3.366096 & -1.660482 \\
\hline $\mathrm{H}$ & 6.733342 & -1.857217 & -3.055385 \\
\hline $\mathrm{O}$ & 5.424874 & -4.945430 & -0.082979 \\
\hline $\mathrm{C}$ & 7.328370 & 2.837794 & 0.707991 \\
\hline $\mathrm{O}$ & 6.318526 & 4.897305 & -0.155184 \\
\hline $\mathrm{H}$ & 7.982131 & 0.919202 & 1.422341 \\
\hline $\mathrm{H}$ & 6.817424 & -4.118061 & -2.015676 \\
\hline $\mathrm{C}$ & 4.687637 & -5.335122 & 1.078134 \\
\hline $\mathrm{H}$ & 8.280986 & 3.307398 & 0.923746 \\
\hline $\mathrm{C}$ & 7.549126 & 5.618260 & 0.066626 \\
\hline $\mathrm{H}$ & 4.908039 & -4.675267 & 1.925772 \\
\hline $\mathrm{H}$ & 3.608100 & -5.348264 & 0.876290 \\
\hline $\mathrm{H}$ & 5.019530 & -6.346062 & 1.312251 \\
\hline $\mathrm{H}$ & 8.362759 & 5.191897 & -0.528714 \\
\hline $\mathrm{H}$ & 7.812193 & 5.623130 & 1.129252 \\
\hline $\mathrm{H}$ & 7.350327 & 6.636403 & -0.264515 \\
\hline $\mathrm{O}$ & 0.210132 & -2.636826 & -0.770934 \\
\hline $\mathrm{H}$ & 0.244120 & -3.567905 & -1.034902 \\
\hline $\mathrm{H}$ & 1.141648 & -2.305987 & -0.598388 \\
\hline $\mathrm{O}$ & -1.339367 & -0.719963 & -2.291446 \\
\hline $\mathrm{H}$ & -1.665730 & 0.030766 & -2.814315 \\
\hline $\mathrm{H}$ & -0.606984 & -1.114648 & -2.794068 \\
\hline $\mathrm{O}$ & -1.657641 & 0.183021 & 2.620892 \\
\hline $\mathrm{H}$ & -2.107162 & 1.020289 & 2.820947 \\
\hline $\mathrm{H}$ & -0.945721 & 0.084632 & 3.275206 \\
\hline $\mathrm{O}$ & 0.135011 & -1.921976 & 2.234921 \\
\hline $\mathrm{H}$ & -0.112689 & -2.680868 & 2.787487 \\
\hline $\mathrm{H}$ & 1.101389 & -1.951100 & 2.139432 \\
\hline $\mathrm{O}$ & -2.758920 & -2.306018 & 2.017544 \\
\hline $\mathrm{H}$ & -3.273045 & -3.126713 & 2.076243 \\
\hline $\mathrm{H}$ & -2.982300 & -1.781331 & 2.804950 \\
\hline $\mathrm{O}$ & -2.877383 & -2.685231 & -0.944408 \\
\hline $\mathrm{H}$ & -3.132138 & -3.614870 & -0.831506 \\
\hline $\mathrm{H}$ & -2.888903 & -2.515313 & -1.901890 \\
\hline $\mathrm{C}$ & -7.077472 & 0.848382 & -0.358615 \\
\hline $\mathrm{C}$ & -7.893731 & 1.937873 & 0.009242 \\
\hline
\end{tabular}




$\begin{array}{lrrr}\mathrm{C} & -7.679206 & -0.344602 & -0.811480 \\ \mathrm{C} & -9.283149 & 1.829098 & -0.064575 \\ \mathrm{H} & -7.449929 & 2.858456 & 0.374857 \\ \mathrm{C} & -9.069046 & -0.447063 & -0.885452 \\ \mathrm{H} & -7.074238 & -1.181145 & -1.153106 \\ \mathrm{C} & -9.873701 & 0.638625 & -0.509636 \\ \mathrm{H} & -9.906995 & 2.668081 & 0.226007 \\ \mathrm{H} & -9.527866 & -1.361011 & -1.248682 \\ \mathrm{H} & -10.954401 & 0.558753 & -0.570541\end{array}$

\section{$\left[\mathrm{ML}\left(\mathrm{H}_{2} \mathrm{O}\right)_{5}\right]^{3+}$}

$\mathrm{M}=\mathrm{Eu}$

$\begin{array}{lrcc}\text { EU } & 1.569947 & -1.243531 & 0.349131 \\ \mathrm{O} & 2.174589 & -2.840764 & 2.470908 \\ \mathrm{H} & 1.599032 & -3.558922 & 2.778751 \\ \mathrm{O} & -0.226563 & -3.059876 & 0.267769 \\ \mathrm{H} & -0.362476 & -4.016775 & 0.229350 \\ \mathrm{O} & 3.312189 & -3.093340 & -0.381555 \\ \mathrm{H} & 3.453238 & -3.250826 & -1.328959 \\ \mathrm{O} & 1.284764 & -0.042854 & 2.635846 \\ \mathrm{H} & 1.288581 & 0.904698 & 2.840141 \\ \mathrm{O} & 1.697467 & -1.403133 & -2.284752 \\ \mathrm{H} & 1.100953 & -1.831170 & -2.918409 \\ \mathrm{H} & 3.561181 & -3.914996 & 0.069662 \\ \mathrm{H} & 2.202600 & -0.753175 & -2.798985 \\ \mathrm{H} & 2.957430 & -2.875089 & 3.043890 \\ \mathrm{H} & -1.112404 & -2.617067 & 0.214721 \\ \mathrm{H} & 1.312616 & -0.503405 & 3.488710 \\ \mathrm{C} & 0.083171 & 1.974096 & -0.268309 \\ \mathrm{C} & -0.067384 & 3.349467 & -0.459632 \\ \mathrm{C} & 1.084256 & 4.138772 & -0.560310 \\ \mathrm{C} & 2.331363 & 3.525998 & -0.474280 \\ \mathrm{C} & 2.400916 & 2.133687 & -0.286299 \\ \mathrm{H} & -1.058311 & 3.777658 & -0.535324 \\ \mathrm{H} & 1.006576 & 5.211206 & -0.710180 \\ \mathrm{H} & 3.238230 & 4.112904 & -0.556761 \\ \mathrm{~N} & 1.290426 & 1.371694 & -0.179809 \\ \mathrm{C} & -1.120138 & 1.100455 & -0.175306 \\ \mathrm{~N} & -2.326510 & 1.685205 & -0.229084 \\ \mathrm{~N} & -0.930247 & -0.224724 & -0.074205 \\ \mathrm{C} & -3.409019 & 0.913212 & -0.168363 \\ \mathrm{~N} & -2.006873 & -1.015286 & 0.034079 \\ \mathrm{C} & -4.724072 & 1.580456 & -0.303529 \\ \mathrm{C} & -3.240752 & -0.506172 & 0.016883\end{array}$




\begin{tabular}{|c|c|c|c|}
\hline $\mathrm{C}$ & -4.878845 & 2.871780 & 0.192899 \\
\hline $\mathcal{C}$ & -5.810701 & 0.951098 & -0.973406 \\
\hline . & -4.363749 & -1.448893 & 0.244861 \\
\hline $\mathrm{C}$ & -6.121264 & 3.543992 & 0.066413 \\
\hline $\mathrm{H}$ & -4.067861 & 3.382989 & 0.697747 \\
\hline C & -7.031530 & 1.629222 & -1.110595 \\
\hline $\mathrm{H}$ & -5.691312 & -0.019348 & -1.437035 \\
\hline $\mathrm{C}$ & -5.326908 & -1.142127 & 1.235245 \\
\hline $\mathrm{C}$ & -4.454340 & -2.638566 & -0.489536 \\
\hline $\mathrm{C}$ & -7.206679 & 2.909086 & -0.594081 \\
\hline $\mathrm{O}$ & -6.163364 & 4.766858 & 0.599441 \\
\hline $\mathrm{H}$ & -7.850722 & 1.153193 & -1.640134 \\
\hline $\mathrm{C}$ & -6.370959 & -2.045398 & 1.495046 \\
\hline $\mathrm{H}$ & -5.238905 & -0.238427 & 1.827350 \\
\hline $\mathrm{C}$ & -5.528726 & -3.522368 & -0.243901 \\
\hline $\mathrm{H}$ & -3.729271 & -2.853810 & -1.264978 \\
\hline $\mathrm{H}$ & -8.159102 & 3.413162 & -0.708172 \\
\hline $\mathrm{C}$ & -7.379829 & 5.556917 & 0.536280 \\
\hline $\mathrm{C}$ & -6.481828 & -3.220442 & 0.766895 \\
\hline $\mathrm{H}$ & -7.096316 & -1.823137 & 2.271096 \\
\hline $\mathrm{O}$ & -5.750082 & -4.667527 & -0.904153 \\
\hline $\mathrm{H}$ & -7.137322 & 6.489480 & 1.041924 \\
\hline $\mathrm{H}$ & -7.649091 & 5.753911 & -0.505049 \\
\hline $\mathrm{H}$ & -8.191175 & 5.045665 & 1.061560 \\
\hline $\mathrm{H}$ & -7.287552 & -3.926188 & 0.940993 \\
\hline $\mathrm{C}$ & -4.890877 & -5.065504 & -1.988363 \\
\hline $\mathrm{H}$ & -4.904479 & -4.316129 & -2.786464 \\
\hline $\mathrm{H}$ & -3.869350 & -5.232149 & -1.629719 \\
\hline $\mathrm{H}$ & -5.306726 & -6.001924 & -2.356593 \\
\hline $\mathrm{C}$ & 3.699638 & 1.441895 & -0.212358 \\
\hline $\mathrm{C}$ & 4.998616 & 1.972735 & -0.291498 \\
\hline $\mathrm{N}$ & 3.735076 & 0.094069 & -0.076705 \\
\hline $\mathrm{C}$ & 5.868093 & 0.878086 & -0.204648 \\
\hline $\mathrm{H}$ & 5.294153 & 3.000272 & -0.433770 \\
\hline $\mathrm{N}$ & 5.057793 & -0.212409 & -0.077286 \\
\hline $\mathrm{C}$ & 7.329287 & 0.802943 & -0.234965 \\
\hline $\mathrm{H}$ & 5.344943 & -1.176110 & 0.034500 \\
\hline $\mathrm{C}$ & 7.991511 & -0.368472 & -0.657129 \\
\hline $\mathrm{C}$ & 8.091064 & 1.920316 & 0.163995 \\
\hline $\mathrm{C}$ & 9.386335 & -0.422687 & -0.671044 \\
\hline $\mathrm{H}$ & 7.429695 & -1.226149 & -1.018363 \\
\hline $\mathrm{C}$ & 9.485230 & 1.861041 & 0.149069 \\
\hline $\mathrm{H}$ & 7.598008 & 2.823761 & 0.508383 \\
\hline . & 10.136520 & 0.691124 & -0.266085 \\
\hline $\mathrm{H}$ & 9.891288 & -1.321715 & -1.009531 \\
\hline $\mathrm{H}$ & 10.066177 & 2.721926 & 0.463713 \\
\hline
\end{tabular}


H $\quad 11.220933 \quad 0.648910 \quad-0.279967$

$\begin{array}{lccc}\mathrm{M}=\mathrm{Gd} & & & \\ \mathrm{GD} & 1.451173 & -1.036429 & 0.144440 \\ \mathrm{O} & 2.499012 & -2.670024 & 1.835529 \\ \mathrm{H} & 2.090902 & -3.486696 & 2.169042 \\ \mathrm{O} & -0.136016 & -2.807137 & 0.158722 \\ \mathrm{H} & -0.234052 & -3.765818 & 0.064242 \\ \mathrm{O} & 2.825142 & -2.786546 & -1.056459 \\ \mathrm{H} & 2.833333 & -2.841721 & -2.026673 \\ \mathrm{O} & 1.129720 & -0.268298 & 2.478428 \\ \mathrm{H} & 0.889989 & 0.629068 & 2.760779 \\ \mathrm{O} & 1.323078 & -0.730657 & -2.340803 \\ \mathrm{H} & 0.538352 & -0.883863 & -2.893222 \\ \mathrm{H} & 3.149775 & -3.639999 & -0.727130 \\ \mathrm{H} & 1.869729 & -0.091940 & -2.828470 \\ \mathrm{H} & 3.301931 & -2.540372 & 2.368185 \\ \mathrm{H} & -1.068456 & -2.365473 & 0.154362 \\ \mathrm{H} & 1.129598 & -0.814626 & 3.280891 \\ \mathrm{C} & 0.045835 & 2.066356 & 0.038747 \\ \mathrm{C} & -0.090673 & 3.454255 & 0.042372 \\ \mathrm{C} & 1.068826 & 4.238827 & 0.071055 \\ \mathrm{C} & 2.317867 & 3.614241 & 0.080855 \\ \mathrm{C} & 2.377196 & 2.214614 & 0.064915 \\ \mathrm{H} & -1.080577 & 3.892966 & 0.017613 \\ \mathrm{H} & 0.998383 & 5.322463 & 0.077719 \\ \mathrm{H} & 3.227806 & 4.202671 & 0.092745 \\ \mathrm{~N} & 1.255331 & 1.455360 & 0.052599 \\ \mathrm{C} & 3.643724 & 1.470215 & 0.030670 \\ \mathrm{C} & 4.963049 & 1.925265 & 0.014702 \\ \mathrm{~N} & 3.593479 & 0.109435 & -0.051901 \\ \mathrm{C} & 5.771684 & 0.778430 & -0.095938 \\ \mathrm{H} & 5.314891 & 2.944944 & 0.032612 \\ \mathrm{~N} & 4.904347 & -0.271702 & -0.125541 \\ \mathrm{C} & 7.221769 & 0.637153 & -0.174154 \\ \mathrm{H} & 5.144414 & -1.249882 & -0.216339 \\ \mathrm{C} & 8.045191 & 1.660643 & 0.340305 \\ \mathrm{C} & 7.816285 & -0.504376 & -0.753444 \\ \mathrm{C} & 9.433932 & 1.536053 & 0.285908 \\ \mathrm{H} & 7.606887 & 2.538381 & 0.804368 \\ \mathrm{C} & 9.205415 & -0.621740 & -0.807935 \\ \mathrm{H} & 7.208471 & -1.283470 & -1.207425 \\ \mathrm{C} & 10.016744 & 0.396890 & -0.285821 \\ \mathrm{H} & 10.063289 & 2.322434 & 0.689604 \\ \mathrm{H} & 9.659420 & -1.493379 & -1.268104\end{array}$




$\begin{array}{cccc}\mathrm{H} & 11.097307 & 0.305336 & -0.331478 \\ \mathrm{C} & -1.134990 & 1.164523 & 0.008412 \\ \mathrm{~N} & -2.352509 & 1.693019 & 0.002742 \\ \mathrm{~N} & -0.871057 & -0.150552 & -0.044625 \\ \mathrm{C} & -3.419423 & 0.872486 & -0.034824 \\ \mathrm{~N} & -1.919422 & -1.002296 & 0.06111 \\ \mathrm{C} & -4.720372 & 1.480686 & -0.263499 \\ \mathrm{C} & -3.172666 & -0.564002 & 0.124428 \\ \mathrm{C} & -4.873335 & 2.854781 & 0.023948 \\ \mathrm{C} & -5.797422 & 0.763492 & -0.854770 \\ \mathrm{C} & -4.204818 & -1.576625 & 0.417889 \\ \mathrm{C} & -6.083806 & 3.512213 & -0.230146 \\ \mathrm{H} & -4.066131 & 3.418265 & 0.473501 \\ \mathrm{C} & -6.979651 & 1.435678 & -1.140882 \\ \mathrm{H} & -5.703161 & -0.281649 & -1.113483 \\ \mathrm{C} & -5.117174 & -1.336353 & 1.457783 \\ \mathrm{C} & -4.212283 & -2.804689 & -0.281057 \\ \mathrm{C} & -7.143693 & 2.792381 & -0.824831 \\ \mathrm{O} & -6.132442 & 4.815562 & 0.119220 \\ \mathrm{H} & -7.799427 & 0.903535 & -1.612941 \\ \mathrm{C} & -6.023190 & -2.344221 & 1.814698 \\ \mathrm{H} & -5.117438 & -0.394241 & 1.993999 \\ \mathrm{C} & -5.159889 & -3.783893 & 0.054563 \\ \mathrm{H} & -3.530427 & -2.956995 & -1.109421 \\ \mathrm{H} & -8.089035 & 3.276439 & -1.040913 \\ \mathrm{C} & -7.353182 & 5.553703 & -0.102113 \\ \mathrm{C} & -6.054947 & -3.550782 & 1.122795 \\ \mathrm{H} & -6.719626 & -2.178047 & 2.630433 \\ \mathrm{O} & -5.302951 & -4.975839 & -0.572192 \\ \mathrm{H} & -7.152080 & 6.559392 & 0.263848 \\ \mathrm{H} & -7.596782 & 5.593579 & -1.168598 \\ \mathrm{H} & -8.180825 & 5.116333 & 0.465213 \\ \mathrm{H} & -6.773049 & -4.325161 & 1.372025 \\ \mathrm{C} & -4.520196 & -5.254361 & -1.736584 \\ \mathrm{H} & -4.698068 & -4.508499 & -2.520043 \\ \mathrm{H} & -3.450441 & -5.301014 & -1.493337 \\ \mathrm{H} & -4.850373 & -6.231891 & -2.086346 \\ & & & \end{array}$

$\mathrm{M}=\mathrm{Am}$

$\begin{array}{lrrr}\mathrm{AM} & 1.390239 & -1.013844 & 0.240779 \\ \mathrm{O} & 1.629081 & -2.801890 & 2.158039 \\ \mathrm{H} & 0.949516 & -3.491831 & 2.239641 \\ \mathrm{O} & -0.294966 & -2.832233 & -0.053338 \\ \mathrm{H} & -0.404047 & -3.745487 & -0.356474 \\ \mathrm{O} & 3.136028 & -2.843280 & -0.428052\end{array}$




$\begin{array}{lrrr}\mathrm{H} & 3.376879 & -3.035839 & -1.349562 \\ \mathrm{O} & 1.326744 & 0.058081 & 2.563737 \\ \mathrm{H} & 1.543565 & 0.982547 & 2.766855 \\ \mathrm{O} & 1.452980 & -1.126490 & -2.326651 \\ \mathrm{H} & 1.947980 & -0.506640 & -2.887792 \\ \mathrm{H} & 3.289351 & -3.662834 & 0.070358 \\ \mathrm{H} & 0.796914 & -1.545809 & -2.907311 \\ \mathrm{H} & 2.207134 & -2.896285 & 2.933176 \\ \mathrm{H} & -1.203531 & -2.380621 & -0.003961 \\ \mathrm{H} & 1.016977 & -0.335674 & 3.395266 \\ \mathrm{C} & -0.064094 & 2.124325 & -0.216150 \\ \mathrm{C} & -0.221448 & 3.501050 & -0.375356 \\ \mathrm{C} & 0.925054 & 4.295287 & -0.491623 \\ \mathrm{C} & 2.180619 & 3.688362 & -0.445193 \\ \mathrm{C} & 2.258870 & 2.298432 & -0.283139 \\ \mathrm{~N} & 1.150800 & 1.528489 & -0.170768 \\ \mathrm{H} & 0.839095 & 5.370087 & -0.619840 \\ \mathrm{H} & -1.217673 & 3.923456 & -0.415054 \\ \mathrm{H} & 3.082631 & 4.282132 & -0.535208 \\ \mathrm{C} & -1.242792 & 1.225252 & -0.113919 \\ \mathrm{C} & -3.530671 & 0.951537 & -0.086024 \\ \mathrm{C} & -4.845663 & 1.575203 & -0.220922 \\ \mathrm{C} & -3.292206 & -0.479670 & 0.072869 \\ \mathrm{H} & -8.235388 & 5.182616 & 0.902502 \\ \mathrm{C} & -4.974632 & 2.930871 & 0.138592 \\ \mathrm{C} & -5.960536 & 0.888310 & -0.771057 \\ \mathrm{C} & -4.341487 & -1.494605 & 0.323338 \\ \mathrm{C} & -6.201654 & 3.599497 & -0.003367 \\ \mathrm{C} & -5.201068 & -1.326867 & 1.421497 \\ \mathrm{C} & -7.161875 & 1.571731 & -0.943204 \\ \mathrm{C} & -4.428360 & -2.638661 & -0.494783 \\ \mathrm{C} & -7.303352 & 2.909898 & -0.555717 \\ \mathrm{C} & -6.139907 & -2.327377 & 1.712544 \\ \mathrm{C} & -5.405249 & -3.611783 & -0.216920 \\ \mathrm{H} & -8.259080 & 3.403885 & -0.685809 \\ \mathrm{C} & -6.250472 & -3.454478 & 0.905927 \\ \mathrm{H} & -6.989918 & -4.222892 & 1.106138 \\ \mathrm{~N} & -2.460542 & 1.761605 & -0.134978 \\ \mathrm{~N} & -0.988989 & -0.088861 & -0.051422 \\ \mathrm{H} & -2.041675 & -0.929225 & 0.052903 \\ \mathrm{H} & -4.920526 & -4.726340 & -0.950478 \\ \mathrm{H} & 4.883881 & 0.407562 \\ \mathrm{H} & 5.640802 & 0.301449 \\ \mathrm{H} & -2.75676 & 6.627240 & 0.697446 \\ \mathrm{H} & -2.166386\end{array}$




$\begin{array}{cccc}\mathrm{H} & -5.062708 & -4.103161 & -2.868791 \\ \mathrm{H} & -3.817041 & -5.039605 & -1.967788 \\ \mathrm{H} & -5.276537 & -5.852379 & -2.591009 \\ \mathrm{H} & -3.785649 & -2.733332 & -1.362365 \\ \mathrm{H} & -5.137318 & -0.444902 & 2.049138 \\ \mathrm{H} & -6.797065 & -2.216461 & 2.569229 \\ \mathrm{H} & -5.884562 & -0.140210 & -1.094344 \\ \mathrm{H} & -4.137887 & 3.476469 & 0.556016 \\ \mathrm{H} & -8.010791 & 1.059731 & -1.385126 \\ \mathrm{C} & 3.541940 & 1.585079 & -0.220140 \\ \mathrm{C} & 4.851971 & 2.065823 & -0.291433 \\ \mathrm{C} & 5.687567 & 0.938511 & -0.187789 \\ \mathrm{H} & 5.180859 & 3.082770 & -0.437320 \\ \mathrm{~N} & 3.525964 & 0.232845 & -0.075343 \\ \mathrm{~N} & 4.844618 & -0.123303 & -0.059324 \\ \mathrm{C} & 7.142720 & 0.824175 & -0.206173 \\ \mathrm{C} & 7.777972 & -0.389822 & -0.543591 \\ \mathrm{C} & 7.930112 & 1.947870 & 0.121228 \\ \mathrm{C} & 9.170344 & -0.478646 & -0.544763 \\ \mathrm{H} & 7.199326 & -1.258189 & -0.849181 \\ \mathrm{C} & 9.322221 & 1.852838 & 0.121041 \\ \mathrm{H} & 7.460815 & 2.885961 & 0.399729 \\ \mathrm{C} & 9.945263 & 0.641883 & -0.210042 \\ \mathrm{H} & 9.655192 & -1.410209 & -0.818209 \\ \mathrm{H} & 9.922971 & 2.718319 & 0.380868 \\ \mathrm{H} & 11.028385 & 0.572152 & -0.213700 \\ \mathrm{H} & 5.102640 & -1.092702 & 0.073621\end{array}$

$\mathrm{M}=\mathrm{Cm}$

$\begin{array}{lccc}\mathrm{CM} & 1.355520 & -0.977647 & 0.186240 \\ \mathrm{O} & 2.153136 & -2.717530 & 1.998248 \\ \mathrm{H} & 1.601771 & -3.469084 & 2.274318 \\ \mathrm{O} & -0.285016 & -2.793542 & 0.094561 \\ \mathrm{H} & -0.399556 & -3.741003 & -0.069840 \\ \mathrm{O} & 2.873163 & -2.780324 & -0.886550 \\ \mathrm{H} & 2.956773 & -2.868097 & -1.850876 \\ \mathrm{O} & 1.049794 & -0.119937 & 2.539015 \\ \mathrm{H} & 0.860902 & 0.792803 & 2.811179 \\ \mathrm{O} & 1.300180 & -0.790096 & -2.360216 \\ \mathrm{H} & 1.815244 & -0.132105 & -2.856766 \\ \mathrm{H} & 3.114376 & -3.642023 & -0.509473 \\ \mathrm{H} & 0.553516 & -1.032454 & -2.933368 \\ \mathrm{H} & 2.942370 & -2.743437 & 2.565229 \\ \mathrm{H} & -1.202452 & -2.333481 & 0.093102 \\ \mathrm{H} & 1.064888 & -0.651862 & 3.351087\end{array}$




$\begin{array}{lrrr}\mathrm{C} & -0.076417 & 2.143339 & -0.009698 \\ \mathrm{C} & -0.225000 & 3.529550 & -0.040430 \\ \mathrm{C} & 0.927627 & 4.324495 & -0.045350 \\ \mathrm{C} & 2.181849 & 3.711071 & -0.033955 \\ \mathrm{C} & 2.254259 & 2.312166 & -0.011637 \\ \mathrm{~N} & 1.138776 & 1.544061 & 0.010725 \\ \mathrm{H} & 0.847666 & 5.407290 & -0.066884 \\ \mathrm{H} & -1.218717 & 3.959220 & -0.067810 \\ \mathrm{H} & 3.086111 & 4.308026 & -0.049701 \\ \mathrm{C} & -1.254095 & 1.235553 & -0.017403 \\ \mathrm{C} & -3.539621 & 0.943153 & -0.053559 \\ \mathrm{C} & -4.842928 & 1.554670 & -0.262476 \\ \mathrm{C} & -3.292054 & -0.493612 & 0.092744 \\ \mathrm{C} & -4.993772 & 2.923596 & 0.049130 \\ \mathrm{C} & -5.925247 & 0.847046 & -0.855233 \\ \mathrm{C} & -4.326037 & -1.512393 & 0.363183 \\ \mathrm{C} & -6.206728 & 3.584665 & -0.182680 \\ \mathrm{C} & -5.232260 & -1.300832 & 1.414047 \\ \mathrm{C} & -7.110190 & 1.523444 & -1.119506 \\ \mathrm{C} & -4.341025 & -2.718002 & -0.373165 \\ \mathrm{C} & -7.271851 & 2.874558 & -0.779445 \\ \mathrm{C} & -6.140540 & -2.316059 & 1.743855 \\ \mathrm{C} & -5.290562 & -3.704081 & -0.063164 \\ \mathrm{H} & -8.219180 & 3.361769 & -0.979002 \\ \mathrm{C} & -6.179838 & -3.500831 & 1.015584 \\ \mathrm{H} & -7.933 \\ \mathrm{H} & -6.899671 & -4.279896 & 1.244311 \\ \mathrm{~N} & -2.472078 & 1.763538 & -0.023584 \\ \mathrm{~N} & -0.990299 & -0.079562 & -0.057262 \\ \mathrm{~N} & -2.038981 & -0.932458 & 0.038295 \\ \mathrm{O} & -5.439669 & -4.876202 & -0.725512 \\ \mathrm{O} & -6.252331 & 4.882202 & 0.188851 \\ \mathrm{C} & -7.475196 & 5.623257 & -0.009017 \\ \mathrm{H} & -7.271154 & 6.622864 & 0.371695 \\ \mathrm{H} & -7.728647 & 5.680714 & -1.072411 \\ \mathrm{H} & -8.297511 & 5.176150 & 0.558517 \\ \mathrm{C} & -4.666457 & -5.118989 & -1.904079 \\ \mathrm{H} & -4.847646 & -4.347608 & -2.661665 \\ \mathrm{H} & -3.594917 & -5.176610 & -1.670707 \\ \mathrm{H} & -5.002066 & -6.083736 & -2.282911 \\ \mathrm{H} & -5.227012 & -0.375109 & 1.978320 \\ \mathrm{H} & -532936 & -2.172380 & 2.567309 \\ \mathrm{H} & -0.193348 & -1.132907 \\ \mathrm{H} & -3.480190 & 0.500498 \\ \mathrm{H} & -1.584142 & -0.036792\end{array}$




$\begin{array}{cccc}\mathrm{C} & 4.842392 & 2.060721 & -0.076354 \\ \mathrm{C} & 5.670335 & 0.924649 & -0.150947 \\ \mathrm{H} & 5.177204 & 3.086011 & -0.094194 \\ \mathrm{~N} & 3.505039 & 0.221251 & -0.072599 \\ \mathrm{~N} & 4.821645 & -0.139721 & -0.142038 \\ \mathrm{C} & 7.122487 & 0.806303 & -0.228391 \\ \mathrm{C} & 7.929295 & 1.863958 & 0.241183 \\ \mathrm{C} & 7.735582 & -0.347264 & -0.762456 \\ \mathrm{C} & 9.319854 & 1.761712 & 0.186965 \\ \mathrm{H} & 7.477018 & 2.752157 & 0.670730 \\ \mathrm{C} & 9.126371 & -0.442614 & -0.816968 \\ \mathrm{H} & 7.140105 & -1.155394 & -1.180735 \\ \mathrm{C} & 9.921128 & 0.610553 & -0.339869 \\ \mathrm{H} & 9.936315 & 2.574799 & 0.556191 \\ \mathrm{H} & 9.594350 & -1.324591 & -1.242174 \\ \mathrm{H} & 11.003002 & 0.536088 & -0.385347 \\ \mathrm{H} & 5.076321 & -1.117759 & -0.178721\end{array}$

$\left[\mathrm{ML}_{2}\left(\mathrm{H}_{2} \mathrm{O}\right)_{2}\right]^{3+}$

$\mathrm{M}=\mathrm{Eu}$

$\begin{array}{lccc}\text { EU } & -0.003351 & 0.448454 & -0.002347 \\ \mathrm{O} & -0.523403 & -1.297825 & -1.726050 \\ \mathrm{H} & -1.442125 & -1.640029 & -1.559418 \\ \mathrm{O} & 0.511423 & -1.310397 & 1.710929 \\ \mathrm{H} & 1.427431 & -1.658278 & 1.539720 \\ \mathrm{H} & -0.115410 & -1.829704 & -2.421659 \\ \mathrm{H} & 0.110287 & -1.829447 & 2.420009 \\ \mathrm{C} & 2.766966 & 0.897949 & -2.214787 \\ \mathrm{C} & 3.550834 & 1.329335 & -3.287217 \\ \mathrm{C} & 3.033303 & 2.313298 & -4.136245 \\ \mathrm{C} & 1.763606 & 2.826096 & -3.881099 \\ \mathrm{C} & 1.038571 & 2.344966 & -2.777755 \\ \mathrm{~N} & 1.536316 & 1.394983 & -1.957042 \\ \mathrm{H} & 3.612114 & 2.671454 & -4.982026 \\ \mathrm{H} & 4.533563 & 0.901496 & -3.437800 \\ \mathrm{H} & 1.337507 & 3.584711 & -4.526335 \\ \mathrm{C} & 3.277656 & -0.152887 & -1.289761 \\ \mathrm{C} & 4.964576 & -1.597214 & -0.693945 \\ \mathrm{C} & 6.356067 & -2.037492 & -0.899043 \\ \mathrm{C} & 4.086083 & -2.096641 & 0.343446 \\ \mathrm{C} & 6.883259 & -1.997007 & -2.196765 \\ \mathrm{C} & 7.183955 & -2.426340 & 0.182830 \\ \mathrm{C} & 4.371605 & -3.269986 & 1.202410 \\ \mathrm{C} & 8.217673 & -2.374981 & -2.440184\end{array}$




\begin{tabular}{|c|c|c|c|}
\hline $\mathrm{C}$ & 4.773891 & -4.480499 & 0.611352 \\
\hline & 8.514325 & -2.768552 & -0.064263 \\
\hline $\mathrm{C}$ & 4.184733 & -3.178981 & 2.594267 \\
\hline $\mathrm{C}$ & 9.039889 & -2.760300 & -1.360147 \\
\hline & 4.973707 & -5.607035 & 1.422122 \\
\hline & 4.423702 & -4.306585 & 3.399067 \\
\hline $\mathrm{H}$ & 10.072257 & -3.046975 & -1.520685 \\
\hline & 4.808763 & -5.528318 & 2.800548 \\
\hline $\mathrm{H}$ & 4.980103 & -6.386603 & 3.441662 \\
\hline$N$ & 4.495879 & -0.658320 & -1.519481 \\
\hline $\mathbf{N}$ & 2.493557 & -0.504390 & -0.263280 \\
\hline$N$ & 2.906574 & -1.505700 & 0.530320 \\
\hline 0 & 4.314441 & -4.331262 & 4.748029 \\
\hline $\mathrm{O}$ & 8.607816 & -2.327929 & -3.732053 \\
\hline $\mathrm{C}$ & 9.958064 & -2.703915 & -4.071462 \\
\hline $\mathrm{H}$ & 10.026110 & -2.591850 & -5.152521 \\
\hline $\mathrm{H}$ & 10.679896 & -2.039503 & -3.585788 \\
\hline $\mathrm{H}$ & 10.151695 & -3.745515 & -3.796158 \\
\hline $\mathrm{C}$ & 4.009821 & -3.120733 & 5.450446 \\
\hline H & 4.770567 & -2.354789 & 5.261659 \\
\hline $\mathrm{H}$ & 3.017408 & -2.743559 & 5.174885 \\
\hline H & 4.015703 & -3.385958 & 6.507094 \\
\hline $\mathrm{H}$ & 3.896260 & -2.232932 & 3.036117 \\
\hline $\mathrm{H}$ & 4.913266 & -4.554302 & -0.461160 \\
\hline $\mathrm{H}$ & 5.268771 & -6.549470 & 0.971858 \\
\hline 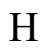 & 6.812378 & -2.429922 & 1.198937 \\
\hline $\mathrm{H}$ & 6.271000 & -1.695126 & -3.037674 \\
\hline Н & 9.157870 & -3.048081 & 0.763940 \\
\hline $\mathrm{C}$ & -0.306337 & 2.859415 & -2.472016 \\
\hline $\mathrm{C}$ & -1.028194 & 3.889033 & -3.105629 \\
\hline $\mathrm{C}$ & -2.234386 & 3.993722 & -2.409550 \\
\hline $\mathrm{H}$ & -0.718205 & 4.516347 & -3.926385 \\
\hline $\mathrm{N}$ & -1.011210 & 2.337736 & -1.444188 \\
\hline $\mathrm{N}$ & -2.168475 & 3.044109 & -1.432105 \\
\hline 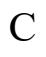 & -2.765670 & 0.887960 & 2.223619 \\
\hline $\mathrm{C}$ & -3.544890 & 1.309991 & 3.303028 \\
\hline , & -3.022033 & 2.284424 & 4.160090 \\
\hline $\mathrm{C}$ & -1.752445 & 2.797287 & 3.905354 \\
\hline $\mathrm{C}$ & -1.032116 & 2.325105 & 2.794759 \\
\hline $\mathrm{N}$ & -1.534837 & 1.384270 & 1.967081 \\
\hline $\mathrm{H}$ & -3.597112 & 2.635434 & 5.011391 \\
\hline 11 & -4.528024 & 0.882966 & 3.453128 \\
\hline $\mathrm{H}$ & -1.322818 & 3.549323 & 4.555943 \\
\hline 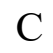 & -3.281514 & -0.151706 & 1.288664 \\
\hline $\mathrm{C}$ & -4.968481 & -1.594199 & 0.690105 \\
\hline $\mathrm{C}$ & -6.358890 & -2.035850 & 0.896847 \\
\hline
\end{tabular}




$\begin{array}{lccc}\mathrm{C} & -4.095138 & -2.084328 & -0.355438 \\ \mathrm{C} & -6.882289 & -2.010866 & 2.195599 \\ \mathrm{C} & -7.191124 & -2.408302 & -0.189418 \\ \mathrm{C} & -4.382875 & -3.253858 & -1.218422 \\ \mathrm{C} & -8.217057 & -2.388379 & 2.436480 \\ \mathrm{C} & -4.799852 & -4.462530 & -0.632773 \\ \mathrm{C} & -8.522041 & -2.750013 & 0.055139 \\ \mathrm{C} & -4.181502 & -3.163324 & -2.608348 \\ \mathrm{C} & -9.043709 & -2.757272 & 1.352110 \\ \mathrm{C} & -4.999232 & -5.586988 & -1.446541 \\ \mathrm{C} & -4.420787 & -4.288330 & -3.416612 \\ \mathrm{H} & -10.076623 & -3.042523 & 1.511966 \\ \mathrm{C} & -4.820362 & -5.508069 & -2.823130 \\ \mathrm{H} & -4.991565 & -6.364427 & -3.466869 \\ \mathrm{~N} & -4.496783 & -0.662053 & 1.521691 \\ \mathrm{~N} & -2.505475 & -0.487895 & 0.249831 \\ \mathrm{~N} & -2.920870 & -1.484904 & -0.548362 \\ \mathrm{O} & -4.299336 & -4.312446 & -4.764235 \\ \mathrm{O} & -8.605631 & -2.358393 & 3.728223 \\ \mathrm{C} & -9.956140 & -2.736369 & 4.066890 \\ \mathrm{H} & -10.019910 & -2.638928 & 5.149576 \\ \mathrm{H} & -10.677779 & -2.063495 & 3.592953 \\ \mathrm{H} & -10.152433 & -3.773689 & 3.778048 \\ \mathrm{C} & -3.977241 & -3.104017 & -5.462734 \\ \mathrm{H} & -3.289192 & 6.106704 & -1.697289 \\ \mathrm{H} & -4.733305 & -2.331774 & -5.281096 \\ \mathrm{H} & -2.984475 & -2.735698 & -5.176722 \\ \mathrm{H} & -3.974657 & -3.368614 & -6.519534 \\ \mathrm{H} & -3.881353 & -2.219187 & -3.046386 \\ \mathrm{H} & -4.948069 & -4.537394 & 0.438404 \\ \mathrm{H} & -5.304767 & -6.527892 & -1.000079 \\ \mathrm{H} & -6.821196 & -2.397892 & -1.206115 \\ \mathrm{H} & -6.267253 & -1.721944 & 3.039012 \\ \mathrm{H} & -9.168096 & -3.016792 & -0.775257 \\ \mathrm{C} & 0.312090 & 2.840519 & 2.487736 \\ \mathrm{C} & 1.037688 & 3.864326 & 3.126563 \\ \mathrm{C} & 2.240137 & 3.974777 & 2.424973 \\ \mathrm{H} & 0.732226 & 4.484484 & 3.954426 \\ \mathrm{~N} & 1.011288 & 2.327451 & 1.451793 \\ \mathrm{H} & 2.888969 & 2.033745 & 1.439587 \\ \mathrm{C} & -2.808790 & 0.767377 \\ \mathrm{C} & -3.931623 & 2.813504 & -0.765659 \\ \mathrm{H} & 4.884844 & -2.592736 \\ \mathrm{H} & -0.495368\end{array}$




$\begin{array}{llll}\mathrm{C} & -4.775184 & 6.231278 & -4.064681 \\ \mathrm{H} & -3.075343 & 5.091822 & -4.727625 \\ \mathrm{C} & -5.582381 & 6.593701 & -2.978166 \\ \mathrm{H} & -5.901736 & 6.403346 & -0.851758 \\ \mathrm{H} & -5.000749 & 6.608538 & -5.056989 \\ \mathrm{H} & -6.428423 & 7.256982 & -3.127003 \\ \mathrm{C} & 3.391574 & 4.863456 & 2.609825 \\ \mathrm{C} & 4.197180 & 5.246444 & 1.519409 \\ \mathrm{C} & 3.696881 & 5.349651 & 3.895794 \\ \mathrm{C} & 5.292400 & 6.091952 & 1.714832 \\ \mathrm{H} & 3.949328 & 4.928488 & 0.509874 \\ \mathrm{C} & 4.791484 & 6.195809 & 4.085995 \\ \mathrm{H} & 3.094608 & 5.051555 & 4.748172 \\ \mathrm{C} & 5.592967 & 6.567345 & 2.998339 \\ \mathrm{H} & 5.900583 & 6.395554 & 0.868627 \\ \mathrm{H} & 5.022786 & 6.564045 & 5.080370 \\ \mathrm{H} & 6.440350 & 7.228628 & 3.148425\end{array}$

$\mathrm{M}=\mathrm{Gd}$

$\begin{array}{lrrr}\text { GD } & 0.000003 & 0.466733 & 0.000009 \\ \mathrm{O} & -0.456746 & -1.226147 & -1.652341 \\ \mathrm{H} & -1.378716 & -1.596664 & -1.488515 \\ \mathrm{O} & 0.456748 & -1.226177 & 1.652331 \\ \mathrm{H} & 1.378718 & -1.596692 & 1.488496 \\ \mathrm{H} & -0.001419 & -1.770281 & -2.308709 \\ \mathrm{H} & 0.001416 & -1.770333 & 2.308677 \\ \mathrm{C} & 2.632187 & 0.924061 & -2.210268 \\ \mathrm{C} & 3.382657 & 1.369647 & -3.299173 \\ \mathrm{C} & 2.826234 & 2.341648 & -4.138310 \\ \mathrm{C} & 1.550799 & 2.831243 & -3.859006 \\ \mathrm{C} & 0.860042 & 2.337093 & -2.742595 \\ \mathrm{~N} & 1.396228 & 1.398533 & -1.931229 \\ \mathrm{H} & 3.379819 & 2.709052 & -4.997041 \\ \mathrm{H} & 4.370070 & 0.959466 & -3.469662 \\ \mathrm{H} & 1.096298 & 3.580652 & -4.495897 \\ \mathrm{C} & 3.164618 & -0.112428 & -1.285343 \\ \mathrm{C} & 4.862469 & -1.542453 & -0.678077 \\ \mathrm{C} & 6.262546 & -1.931587 & -0.849034 \\ \mathrm{C} & 3.963683 & -2.067437 & 0.343332 \\ \mathrm{C} & 6.848479 & -1.765198 & -2.118828 \\ \mathrm{C} & 7.056481 & -2.379169 & 0.237336 \\ \mathrm{C} & 4.217313 & -3.268400 & 1.167508 \\ \mathrm{C} & 8.199631 & -2.072906 & -2.331476 \\ \mathrm{C} & 4.629906 & -4.456732 & 0.546344 \\ \mathrm{C} & 8.405456 & -2.643931 & 0.024030\end{array}$




\begin{tabular}{|c|c|c|c|}
\hline $\mathrm{C}$ & 3.965235 & -3.230247 & 2.555869 \\
\hline & 8.984763 & -2.510720 & -1.245813 \\
\hline & 4.771076 & -5.616219 & 1.320375 \\
\hline C & 4.152502 & -4.388850 & 3.324278 \\
\hline & 10.033528 & -2.748462 & -1.378744 \\
\hline & 4.544205 & -5.588961 & 2.693312 \\
\hline त & 4.676441 & -6.475415 & 3.304749 \\
\hline & 4.380442 & -0.609550 & -1.512328 \\
\hline $\mathrm{N}$ & 2.383833 & -0.451093 & -0.251525 \\
\hline & 2.791983 & -1.467482 & 0.534299 \\
\hline$J$ & 3.983497 & -4.464309 & 4.669337 \\
\hline 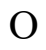 & 8.647673 & -1.910979 & -3.599548 \\
\hline$C$ & 10.022921 & -2.223420 & -3.892074 \\
\hline $\mathrm{H}$ & 10.144148 & -2.030420 & -4.957202 \\
\hline H & 10.701010 & -1.578052 & -3.323799 \\
\hline H & 10.237449 & -3.276989 & -3.6 \\
\hline $\mathrm{C}$ & 3.686678 & -3.271392 & 5.399164 \\
\hline H & 4.472623 & -2.518888 & 5.264333 \\
\hline H & 2.714389 & -2.855878 & 5.104095 \\
\hline H & 3.647063 & -3.569027 & 6.446673 \\
\hline $\mathrm{H}$ & 3.674908 & -2.296349 & 3.022054 \\
\hline $\mathrm{H}$ & 4.827085 & -4.489293 & 9071 \\
\hline $\mathrm{H}$ & 5.073592 & -6.545409 & 0.847930 \\
\hline $\mathrm{H}$ & 6.639750 & -2.492466 & 1.228727 \\
\hline $\mathrm{H}$ & 6.258767 & -1.422230 & -2.959497 \\
\hline 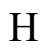 & 9.026311 & -2.967530 & 0.853514 \\
\hline $\mathrm{C}$ & -0.488919 & 2.801671 & -2.392763 \\
\hline $\mathrm{C}$ & -1.289152 & 3.785158 & -2.993733 \\
\hline $\mathrm{C}$ & -2.469474 & 3.830362 & -2.242216 \\
\hline $\mathrm{H}$ & -1.049448 & 4.420017 & -3.832123 \\
\hline $\mathrm{N}$ & -1.118102 & 2.248310 & -1.329060 \\
\hline $\mathrm{N}$ & -2.311871 & 2.893060 & -1.265217 \\
\hline $\mathrm{C}$ & -2.632187 & 0.924026 & 2.210291 \\
\hline $\mathrm{C}$ & -3.382658 & 1.369597 & 3.299200 \\
\hline $\mathrm{C}$ & -2.826237 & 2.341586 & 4.138352 \\
\hline $\mathrm{C}$ & -1.550800 & 2.831183 & 3.859059 \\
\hline 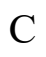 & -0.860040 & 2.337045 & 2.742643 \\
\hline 10 & -1.396226 & 1.398499 & 1.931261 \\
\hline 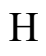 & -3.379823 & 2.708980 & 4.997086 \\
\hline 11 & -4.370072 & 0.959415 & 3.469681 \\
\hline $\mathrm{H}$ & -1.096299 & 3.580582 & 4.495961 \\
\hline $\mathrm{C}$ & -3.164616 & -0.112449 & 1.285349 \\
\hline $\mathrm{C}$ & -4.862468 & -1.542462 & 0.678058 \\
\hline $\mathrm{C}$ & -6.262543 & -1.931605 & 0.849016 \\
\hline $\mathrm{C}$ & -3.963685 & -2.067425 & -0.343364 \\
\hline $\mathrm{C}$ & -6.848468 & -1.765244 & 2.118817 \\
\hline
\end{tabular}




\begin{tabular}{|c|c|c|c|}
\hline $\mathrm{C}$ & -7.056484 & -2.379167 & -0.237359 \\
\hline 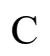 & -4.217319 & -3.268366 & -1.167571 \\
\hline & -8.199617 & -2.072963 & 469 \\
\hline $\mathcal{C}$ & -4.629908 & -4.456715 & -0.546438 \\
\hline $\mathrm{C}$ & -8.405457 & -2.643940 & -0.024047 \\
\hline( & -3.965250 & -3.230174 & -2.555932 \\
\hline$C$ & -8.984755 & -2.510759 & 803 \\
\hline$C$ & -4.771085 & -5.6 & 501 \\
\hline $\mathrm{C}$ & -4.152523 & -4.38 & 372 \\
\hline $\mathrm{H}$ & -10.033518 & -2.748508 & 1.378736 \\
\hline $\mathrm{C}$ & -4.544223 & -5.588883 & -2.693438 \\
\hline $\mathrm{H}$ & -4.676465 & -6.475320 & -3.304900 \\
\hline $\mathrm{N}$ & -4.380441 & -0.6 & 325 \\
\hline $\mathrm{N}$ & -2.383829 & -0.4 & 528 \\
\hline $\mathbf{N}$ & -2.791982 & -1.4 & -0.5 \\
\hline $\mathrm{O}$ & -3.983 & -4.4 & -4 \\
\hline $\mathrm{O}$ & -8.647650 & -1.9 & 548 \\
\hline $\mathrm{C}$ & -10.022894 & -2.2 & 2077 \\
\hline $\mathrm{H}$ & -10.144114 & -2.0 & 4.957211 \\
\hline $\mathrm{H}$ & -10.700991 & -1.5 & 322 \\
\hline $\mathrm{H}$ & -10.237418 & -3.277085 & 3.684826 \\
\hline C & -3.686714 & -3.271237 & -5.35 \\
\hline $\mathrm{H}$ & -4.472656 & -2.5 & 4372 \\
\hline $\mathrm{H}$ & -2.714422 & -2.8 & -5 \\
\hline $\mathrm{H}$ & -3.647107 & -3.5 & -6.446748 \\
\hline $\mathrm{H}$ & -3.674926 & -2.296263 & -3.022092 \\
\hline $\mathrm{H}$ & -4.827081 & $-4.4 \varepsilon$ & 978 \\
\hline $\mathrm{H}$ & -5.073599 & -6.5 & -0.848080 \\
\hline $\mathrm{H}$ & -6.639760 & -2.492441 & -1.228755 \\
\hline H & -6.258751 & -1.422292 & 2.959489 \\
\hline $\mathrm{H}$ & -9.026317 & -2.967525 & -0.853534 \\
\hline $\mathrm{C}$ & 0.488925 & 2.80 & 2.3 \\
\hline 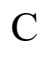 & 1.289156 & 3.78 & 2.9 \\
\hline $\mathrm{C}$ & 2.469476 & 3.83 & 2.242301 \\
\hline $\mathrm{H}$ & 1.049466 & 4.41 & 3.832209 \\
\hline $\mathrm{N}$ & 1.118114 & 2.248274 & 1.329121 \\
\hline $\mathrm{N}$ & 2.311881 & 2.893024 & 1.265289 \\
\hline $\mathrm{H}$ & -2.997193 & 2.622843 & -0.573211 \\
\hline $\mathrm{H}$ & 2.997230 & 2.622809 & 0.573305 \\
\hline $\mathrm{C}$ & -3.668843 & 4.65 & -2.381384 \\
\hline 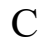 & -4.471386 & 4.972400 & -1.266122 \\
\hline 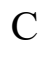 & -4.025291 & 5.157327 & -3.649993 \\
\hline $\mathrm{C}$ & -5.613383 & 5.761743 & -1.420361 \\
\hline - & -4.187439 & 4.645672 & -0.268903 \\
\hline $\mathrm{C}$ & -5.167706 & 5.946087 & -3.798808 \\
\hline $3-$ & -3.426550 & 4.912194 & -4.521475 \\
\hline
\end{tabular}




$\begin{array}{llll}\mathrm{C} & -5.964923 & 6.248750 & -2.686872 \\ \mathrm{H} & -6.219903 & 6.012988 & -0.556092 \\ \mathrm{H} & -5.439449 & 6.323290 & -4.779421 \\ \mathrm{H} & -6.849637 & 6.866231 & -2.804815 \\ \mathrm{C} & 3.668847 & 4.658918 & 2.381459 \\ \mathrm{C} & 4.471303 & 4.972410 & 1.266155 \\ \mathrm{C} & 4.025362 & 5.157200 & 3.650076 \\ \mathrm{C} & 5.613304 & 5.761756 & 1.420365 \\ \mathrm{H} & 4.187269 & 4.645713 & 0.268950 \\ \mathrm{C} & 5.167783 & 5.945960 & 3.798858 \\ \mathrm{H} & 3.426658 & 4.912017 & 4.521569 \\ \mathrm{C} & 5.964922 & 6.248690 & 2.686882 \\ \mathrm{H} & 6.219766 & 6.013058 & 0.556072 \\ \mathrm{H} & 5.439589 & 6.323116 & 4.779471 \\ \mathrm{H} & 6.849639 & 6.866172 & 2.804802\end{array}$

$\mathrm{M}=\mathrm{Am}$

$\begin{array}{lrrc}\text { AM } & 0.000001 & 0.381890 & 0.000035 \\ \mathrm{O} & 0.517491 & -1.360137 & 1.704935 \\ \mathrm{H} & 1.449660 & -1.679167 & 1.522986 \\ \mathrm{O} & -0.517509 & -1.360122 & -1.704818 \\ \mathrm{H} & -1.449632 & -1.679273 & -1.522814 \\ \mathrm{H} & 0.121342 & -1.903150 & 2.399940 \\ \mathrm{H} & -0.121363 & -1.902978 & -2.399947 \\ \mathrm{C} & -2.630713 & 0.904505 & 2.252618 \\ \mathrm{C} & -3.374039 & 1.363380 & 3.340471 \\ \mathrm{C} & -2.800567 & 2.324563 & 4.180255 \\ \mathrm{C} & -1.517716 & 2.792141 & 3.900302 \\ \mathrm{C} & -0.833479 & 2.285280 & 2.785458 \\ \mathrm{~N} & -1.384711 & 1.353442 & 1.976703 \\ \mathrm{H} & -3.348420 & 2.702569 & 5.037967 \\ \mathrm{H} & -4.369884 & 0.973837 & 3.509494 \\ \mathrm{H} & -1.053018 & 3.536298 & 4.535833 \\ \mathrm{C} & -3.189273 & -0.112694 & 1.322527 \\ \mathrm{C} & -4.915543 & -1.515043 & 0.726892 \\ \mathrm{C} & -6.318377 & -1.886088 & 0.915347 \\ \mathrm{C} & -4.039646 & -2.041863 & -0.312993 \\ \mathrm{C} & -6.883507 & -1.722545 & 2.194902 \\ \mathrm{C} & -7.133929 & -2.315605 & -0.162460 \\ \mathrm{C} & -4.321576 & -3.232432 & -1.143577 \\ \mathrm{C} & -8.235301 & -2.014751 & 2.425254 \\ \mathrm{C} & -4.736346 & -4.422002 & -0.526469 \\ \mathrm{C} & -8.482802 & -2.565282 & 0.068778 \\ \mathrm{C} & -4.094719 & -3.183407 & -2.536012 \\ \mathrm{C} & -9.041753 & -2.434459 & 1.348029\end{array}$




\begin{tabular}{|c|c|c|c|}
\hline $\mathrm{C}$ & -4.905630 & -5.572006 & -1.309086 \\
\hline & -4.309480 & -4.332195 & -3.312085 \\
\hline & -10.091218 & -2.660674 & 1.494829 \\
\hline 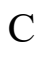 & -4.703750 & -5.533835 & -2.685618 \\
\hline $\mathrm{H}$ & -4.857465 & -6.412654 & -3.303034 \\
\hline $\mathrm{N}$ & -4.407992 & -0.596796 & 1.562025 \\
\hline $\mathbf{N}$ & -2.431697 & -0.450393 & 0.270674 \\
\hline $\mathbf{v}$ & -2.864530 & -1.454665 & -0.519589 \\
\hline U & -4.165666 & -4.396243 & -4.660570 \\
\hline 0 & -8.662405 & -1.857053 & 3.700810 \\
\hline $\mathrm{C}$ & -10.036646 & -2.155821 & 4.012158 \\
\hline $\mathrm{H}$ & -10.139248 & -1.969341 & 5.080379 \\
\hline $\mathrm{H}$ & -10.715732 & -1.498392 & 3.459107 \\
\hline $\mathrm{H}$ & -10.266436 & -3.205293 & 3.800573 \\
\hline $\mathrm{C}$ & -3.868777 & -3.199689 & -5.384549 \\
\hline $\mathrm{H}$ & -4.643847 & -2.440009 & -5.22 \\
\hline $\mathrm{H}$ & -2.886858 & -2.797392 & -5.103243 \\
\hline $\mathrm{H}$ & -3.851119 & -3.487760 & -6.435299 \\
\hline $\mathrm{H}$ & -3.802041 & -2.248260 & -2.998476 \\
\hline $\mathrm{H}$ & -4.913710 & -4.463073 & 0.542192 \\
\hline $\mathrm{H}$ & -5.210158 & -6.502328 & -0.840135 \\
\hline $\mathrm{H}$ & -6.732983 & -2.427809 & -1.160456 \\
\hline $\mathrm{H}$ & -6.277075 & -1.394422 & 3.029609 \\
\hline $\mathrm{H}$ & -9.119620 & -2.875794 & -0.753602 \\
\hline $\mathrm{C}$ & 0.519499 & 2.738336 & 2.436093 \\
\hline $\mathrm{C}$ & 1.327752 & 3.708387 & 3.049334 \\
\hline $\mathrm{C}$ & 2.519406 & 3.734011 & 2.315604 \\
\hline $\mathrm{H}$ & 1.113282 & 4.300490 & 3.924918 \\
\hline $\mathrm{N}$ & 1.151558 & 2.180733 & 1.377265 \\
\hline $\mathrm{N}$ & 2.359132 & 2.801701 & 1.334804 \\
\hline $\mathrm{C}$ & 2.630614 & 0.904307 & -2.252761 \\
\hline $\mathrm{C}$ & 3.373861 & 1.363055 & -3.340720 \\
\hline $\mathrm{C}$ & 2.800307 & 2.324107 & -4.180601 \\
\hline $\mathrm{C}$ & 1.517465 & 2.791694 & -3.900630 \\
\hline $\mathrm{C}$ & 0.833308 & 2.284968 & -2.785673 \\
\hline $\mathrm{N}$ & 1.384612 & 1.353245 & -1.976836 \\
\hline $\mathrm{H}$ & 3.348098 & 2.702012 & -5.038398 \\
\hline $\mathrm{H}$ & 4.369709 & 0.973524 & -3.509749 \\
\hline $\mathrm{H}$ & 1.052713 & 3.535759 & -4.536230 \\
\hline $\mathrm{C}$ & 3.189272 & -0.112746 & -1.322557 \\
\hline $\mathrm{C}$ & 4.915592 & -1.514999 & -0.726859 \\
\hline $\mathrm{C}$ & 6.318428 & -1.886023 & -0.915329 \\
\hline $\mathrm{C}$ & 4.039760 & -2.041713 & 0.313138 \\
\hline $\mathrm{C}$ & 6.883507 & -1.722599 & -2.194923 \\
\hline $\mathrm{C}$ & 7.134032 & -2.315400 & 0.162495 \\
\hline $\mathrm{C}$ & 4.321732 & -3.232217 & 1.143800 \\
\hline
\end{tabular}




\begin{tabular}{|c|c|c|c|}
\hline $\mathrm{C}$ & 8.235302 & -2.014788 & -2.425290 \\
\hline & 4.736518 & -4.421822 & 0.526769 \\
\hline$C$ & 8.482905 & -2.565061 & -0.068764 \\
\hline $\mathrm{C}$ & 4.094892 & -3.183102 & 2.536235 \\
\hline $\mathrm{C}$ & 9.041805 & -2.434357 & -1.348049 \\
\hline & 4.905836 & -5.571770 & 1.309462 \\
\hline$C$ & 4.309684 & -4.331832 & 3.312383 \\
\hline $\mathrm{H}$ & 10.091272 & -2.660556 & -1.494862 \\
\hline $\mathrm{C}$ & 4.703971 & -5.533507 & 2.685995 \\
\hline H & 4.857712 & -6.412281 & 3.303469 \\
\hline $\mathrm{N}$ & 4.407972 & -0.596876 & -1.562089 \\
\hline N & 2.431796 & -0.450281 & -0.270579 \\
\hline $\mathbf{N}$ & 2.864670 & -1.454475 & 0.519769 \\
\hline $\mathrm{O}$ & 4.165886 & -4.395791 & 4.660875 \\
\hline $\mathrm{O}$ & 8.662357 & -1.857213 & -3.700878 \\
\hline $\mathrm{C}$ & 10.036597 & 5969 & -4.012242 \\
\hline $\mathrm{H}$ & 10.139156 & -1.969598 & -5.080487 \\
\hline $\mathrm{H}$ & 10.715682 & -1.498461 & -3.45 \\
\hline $\mathrm{H}$ & 10.266428 & -3.205412 & -3.800555 \\
\hline $\mathrm{C}$ & 3.868976 & -3.199195 & 5.384774 \\
\hline $\mathrm{H}$ & 4.644028 & -2.439508 & 5.228856 \\
\hline $\mathrm{H}$ & 2.887047 & -2.796937 & 3447 \\
\hline $\mathrm{H}$ & 3.851331 & -3.487195 & 6.435543 \\
\hline $\mathrm{H}$ & 3.802196 & -2.247931 & 2.998637 \\
\hline $\mathrm{H}$ & 4.913868 & -4.462965 & -0.541891 \\
\hline $\mathrm{H}$ & 5.210377 & -6.502117 & 0.840572 \\
\hline $\mathrm{H}$ & 6.733124 & -2.427511 & 1.160517 \\
\hline $\mathrm{H}$ & 6.277036 & -1.394585 & -3.029642 \\
\hline $\mathrm{H}$ & 9.119761 & -2.875468 & 0.753626 \\
\hline $\mathrm{C}$ & -0.519646 & 2.738073 & -2.436270 \\
\hline $\mathrm{C}$ & -1.327921 & 3.708061 & -3.049591 \\
\hline $\mathrm{C}$ & -2.519513 & 3.733829 & -2.315770 \\
\hline $\mathrm{H}$ & -1.113500 & 4.300035 & -3.925274 \\
\hline $\mathrm{N}$ & -1.151639 & 2.180642 & -1.377311 \\
\hline $\mathrm{N}$ & -2.359188 & 2.801655 & -1.334848 \\
\hline $\mathrm{H}$ & -3.002948 & 2.602097 & -0.581948 \\
\hline 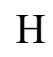 & 3.002950 & 2.601999 & 0.581992 \\
\hline $\mathrm{C}$ & 3.730700 & 4.542000 & 2.472305 \\
\hline $\mathrm{C}$ & 4.982301 & 4.073646 & 2.024884 \\
\hline $\mathrm{C}$ & 3.646618 & 5.809529 & 3.081339 \\
\hline $\mathrm{C}$ & 6.124843 & 4.862798 & 2.176239 \\
\hline $\mathrm{H}$ & 5.082328 & 3.078548 & 1.598469 \\
\hline $\mathrm{C}$ & 4.791670 & 6.594274 & 3.231244 \\
\hline 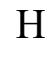 & 2.687744 & 6.192537 & 3.415831 \\
\hline $\mathrm{C}$ & 6.031905 & 6.125232 & 2.778224 \\
\hline $\mathrm{H}$ & 7.088451 & 4.492123 & 1.841463 \\
\hline
\end{tabular}




$\begin{array}{lrrr}\mathrm{H} & 4.718937 & 7.571998 & 3.696507 \\ \mathrm{H} & 6.920682 & 6.736294 & 2.898890 \\ \mathrm{C} & -3.730800 & 4.541829 & -2.472482 \\ \mathrm{C} & -4.982371 & 4.073565 & -2.024882 \\ \mathrm{C} & -3.646745 & 5.809267 & -3.081706 \\ \mathrm{C} & -6.124911 & 4.862719 & -2.176249 \\ \mathrm{H} & -5.082372 & 3.078532 & -1.598307 \\ \mathrm{C} & -4.791794 & 6.594015 & -3.231621 \\ \mathrm{H} & -2.687893 & 6.192203 & -3.416346 \\ \mathrm{C} & -6.031999 & 6.125064 & -2.778423 \\ \mathrm{H} & -7.088496 & 4.492113 & -1.841333 \\ \mathrm{H} & -4.719082 & 7.571671 & -3.697031 \\ \mathrm{H} & -6.920773 & 6.736129 & -2.899097\end{array}$

$\mathrm{M}=\mathrm{Cm}$

$\begin{array}{lrrr}\mathrm{CM} & 0.000011 & 0.439050 & 0.000008 \\ \mathrm{O} & -0.487525 & -1.307309 & -1.679988 \\ \mathrm{H} & -1.410068 & -1.661015 & -1.496401 \\ \mathrm{O} & 0.487602 & -1.307168 & 1.680134 \\ \mathrm{H} & 1.410146 & -1.660876 & 1.496560 \\ \mathrm{H} & -0.039933 & -1.886009 & -2.312034 \\ \mathrm{H} & 0.040039 & -1.885805 & 2.312258 \\ \mathrm{C} & 2.660702 & 0.885674 & -2.230818 \\ \mathrm{C} & 3.417309 & 1.322729 & -3.319049 \\ \mathrm{C} & 2.867797 & 2.290742 & -4.166853 \\ \mathrm{C} & 1.593060 & 2.786299 & -3.896085 \\ \mathrm{C} & 0.895445 & 2.302494 & -2.779472 \\ \mathrm{~N} & 1.425226 & 1.366423 & -1.961197 \\ \mathrm{H} & 3.426502 & 2.650806 & -5.025387 \\ \mathrm{H} & 4.404326 & 0.909130 & -3.482745 \\ \mathrm{H} & 1.145096 & 3.533424 & -4.540130 \\ \mathrm{C} & 3.192216 & -0.148188 & -1.300974 \\ \mathrm{C} & 4.893678 & -1.575945 & -0.695642 \\ \mathrm{C} & 6.294145 & -1.963615 & -0.869510 \\ \mathrm{C} & 3.998540 & -2.100551 & 0.328443 \\ \mathrm{C} & 6.875308 & -1.805361 & -2.142311 \\ \mathrm{C} & 7.092251 & -2.402910 & 0.216979 \\ \mathrm{C} & 4.256415 & -3.299670 & 1.154380 \\ \mathrm{C} & 8.226322 & -2.112229 & -2.357423 \\ \mathrm{C} & 4.670365 & -4.488649 & 0.535453 \\ \mathrm{C} & 8.440935 & -2.667084 & 0.001015 \\ \mathrm{C} & 4.007414 & -3.258699 & 2.543218 \\ \mathrm{C} & 9.015811 & -2.541503 & -1.271619 \\ \mathrm{C} & 4.816207 & -5.645788 & 1.312188 \\ \mathrm{C} & 4.198869 & -4.414930 & 3.314122\end{array}$




\begin{tabular}{|c|c|c|c|}
\hline $\mathrm{H}$ & 10.064486 & -2.778469 & -1.406476 \\
\hline & 4.592235 & -5.615644 & 2.685544 \\
\hline & 4.727941 & -6.500219 & 3.298943 \\
\hline & 4.408475 & -0.644698 & -1.529532 \\
\hline & 2.415176 & -0.487530 & -0.264861 \\
\hline J & 2.826283 & -1.502710 & 0.521637 \\
\hline & 4.032214 & -4.487141 & 4.659800 \\
\hline ) & 8.669807 & -1.957946 & -3.628163 \\
\hline & 10.044488 & -2.270156 & -3.923183 \\
\hline & 10.161952 & -2.083898 & -4.989932 \\
\hline & 10.723473 & -1.620093 & -3.361347 \\
\hline & 10.261332 & -3.322049 & -3.709825 \\
\hline & 3.735986 & -3.292586 & 5.387115 \\
\hline 1 & 4.520847 & -2.539630 & 5.248271 \\
\hline H & 2.762546 & -2.878652 & 5.093343 \\
\hline 1 & 3.699223 & -3.587411 & 6.435504 \\
\hline 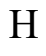 & 3.715761 & -2.324261 & 3.007697 \\
\hline $\mathrm{H}$ & 4.865322 & -4.523609 & -0.530367 \\
\hline 1 & 5.120044 & -6.575435 & 0.841436 \\
\hline & 6.678848 & -2.510071 & 1.210511 \\
\hline $\mathrm{H}$ & 6.282221 & -1.469231 & -2.983456 \\
\hline & 9.065039 & -2.984244 & 0.830567 \\
\hline $\mathcal{C}$ & -0.452656 & 2.781676 & -2.442529 \\
\hline $\mathrm{C}$ & -1.235063 & 3.767574 & -3.062916 \\
\hline C & -2.422343 & 3.836934 & -2.324178 \\
\hline$\theta$ & -0.979749 & 4.389724 & -3.906069 \\
\hline $\mathrm{N}$ & -1.100373 & 2.249089 & -1.378752 \\
\hline $\mathrm{N}$ & -2.286602 & 2.910631 & -1.334728 \\
\hline 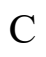 & -2.660731 & 0.885829 & 2.230740 \\
\hline C & -3.417373 & 1.322977 & 3.318908 \\
\hline $\mathrm{C}$ & -2.867896 & 2.291075 & 4.166639 \\
\hline $\mathrm{C}$ & -1.593155 & 2.786617 & 3.895864 \\
\hline $\mathrm{C}$ & -0.895500 & 2.302711 & 2.779318 \\
\hline 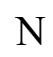 & -1.425248 & 1.366562 & 1.961114 \\
\hline 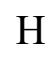 & -3.426630 & 2.651214 & 5.025122 \\
\hline $\mathrm{H}$ & -4.404390 & 0.909383 & 3.482615 \\
\hline 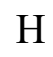 & -1.145217 & 3.533809 & 4.539851 \\
\hline $\mathrm{C}$ & -3.192211 & -0.148116 & 1.300970 \\
\hline f & -4.893655 & -1.575924 & 0.695700 \\
\hline $\mathrm{C}$ & -6.294125 & -1.963589 & 0.869565 \\
\hline $\mathrm{C}$ & -3.998489 & -2.100604 & -0.328322 \\
\hline 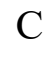 & -6.875314 & -1.805252 & 2.142343 \\
\hline $\mathrm{C}$ & -7.092206 & -2.402959 & -0.216911 \\
\hline . & -4.256349 & -3.299772 & -1.154194 \\
\hline $\mathrm{C}$ & -8.226331 & -2.112114 & 2.357449 \\
\hline & -4.670314 & -4.488716 & -0.535210 \\
\hline
\end{tabular}




\begin{tabular}{|c|c|c|c|}
\hline $\mathrm{C}$ & -8.440894 & -2.667126 & -0.000957 \\
\hline & -4.007320 & -3.258878 & -2.543030 \\
\hline & -9.015796 & -2.541464 & 1.271657 \\
\hline 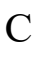 & -4.816142 & -5.645898 & -1.311884 \\
\hline$C$ & -4.198760 & -4.415152 & -3.313873 \\
\hline 1 & -10.064472 & -2.778426 & 1.406509 \\
\hline $\mathrm{C}$ & -4.592141 & -5.615831 & -2.685237 \\
\hline $\mathrm{H}$ & -4.727837 & -6.500439 & -3.298590 \\
\hline $\mathrm{N}$ & -4.408477 & -0.644608 & 1.529529 \\
\hline $\mathrm{N}$ & -2.415137 & -0.487547 & 0.264912 \\
\hline $\mathrm{N}$ & -2.826223 & -1.502785 & -0.521522 \\
\hline $\mathrm{O}$ & -4.032077 & -4.487437 & -4.659544 \\
\hline J & -8.669843 & -1.957748 & 3.628170 \\
\hline $\mathrm{C}$ & -10.044527 & -2.269949 & 182 \\
\hline $\mathrm{H}$ & -10.162014 & -2.083622 & 9917 \\
\hline $\mathrm{H}$ & -10.723507 & -1.619930 & 290 \\
\hline $\mathrm{H}$ & -10.261357 & -3.321859 & 3.709890 \\
\hline $\mathrm{C}$ & -3.735833 & -3.292922 & -5.3 \\
\hline $\mathrm{H}$ & -4.520697 & -2.539959 & -5.248134 \\
\hline $\mathrm{H}$ & -2.762400 & -2.878972 & -5.0 \\
\hline $\mathrm{H}$ & -3.699046 & -3.587804 & 5290 \\
\hline $\mathrm{H}$ & -3.715655 & -2.324467 & -3. \\
\hline $\mathrm{H}$ & -4.865293 & -4.523616 & 609 \\
\hline $\mathrm{H}$ & -5.119990 & -6.575518 & -0.8 \\
\hline $\mathrm{H}$ & -6.678782 & -2.510185 & -1.2 \\
\hline $\mathrm{H}$ & -6.282246 & -1.469065 & 478 \\
\hline $\mathrm{H}$ & -9.064979 & -2.984344 & -0.830501 \\
\hline $\mathrm{C}$ & 0.452609 & 2.781875 & 2.442382 \\
\hline $\mathrm{C}$ & 1.234978 & 3.767851 & 3.062696 \\
\hline $\mathrm{C}$ & 2.422277 & 3.837124 & 2.323998 \\
\hline $\mathrm{H}$ & 0.979677 & 4.390122 & 3.905769 \\
\hline $\mathrm{N}$ & 1.100380 & 2.249185 & 1.3 \\
\hline $\mathrm{N}$ & 2.286603 & 2.910727 & 1.334639 \\
\hline $\mathrm{H}$ & 2.982006 & 2.656748 & 0.646671 \\
\hline 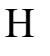 & -2.981932 & 2.656755 & -0.646654 \\
\hline 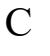 & -3.609140 & 4.679004 & -2.486303 \\
\hline O & -4.420409 & 5.014633 & -1.383877 \\
\hline $\mathrm{C}$ & -3.945219 & 5.167487 & -3.764274 \\
\hline $\mathrm{C}$ & -5.550853 & 5.815923 & -1.559747 \\
\hline $\mathrm{H}$ & -4.152012 & 4.695459 & -0.379819 \\
\hline $\mathrm{C}$ & -5.076023 & 5.968455 & -3.934810 \\
\hline $\mathrm{H}$ & -3.339884 & 4.905305 & -4.626241 \\
\hline $\mathrm{C}$ & -5.882029 & 6.293101 & -2.835462 \\
\hline . & -6.164029 & 6.083944 & -0.705223 \\
\hline $\mathrm{H}$ & -5.332038 & 6.337885 & -4.922578 \\
\hline 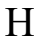 & -6.757746 & 6.919846 & -2.970348 \\
\hline
\end{tabular}




$\begin{array}{llll}\mathrm{C} & 3.609094 & 4.679318 & 2.486090 \\ \mathrm{C} & 4.420316 & 5.014956 & 1.383644 \\ \mathrm{C} & 3.945103 & 5.167844 & 3.764059 \\ \mathrm{C} & 5.550716 & 5.816318 & 1.559512 \\ \mathrm{H} & 4.151873 & 4.695777 & 0.379601 \\ \mathrm{C} & 5.075866 & 5.968878 & 3.934577 \\ \mathrm{H} & 3.339725 & 4.905646 & 4.625997 \\ \mathrm{C} & 5.881858 & 6.293532 & 2.835220 \\ \mathrm{H} & 6.163875 & 6.084377 & 0.704987 \\ \mathrm{H} & 5.331854 & 6.338359 & 4.922334 \\ \mathrm{H} & 6.757539 & 6.920329 & 2.970097\end{array}$

\section{$\left[\mathrm{ML}_{2}\right]^{3+}$}

$\mathrm{M}=\mathrm{Eu}$

$\begin{array}{lrrr}\mathrm{EU} & 0.000003 & 1.077459 & -0.000002 \\ \mathrm{~N} & -0.892202 & 2.843079 & -1.674355 \\ \mathrm{~N} & 0.892229 & 2.843066 & 1.674352 \\ \mathrm{C} & -0.243426 & 3.053230 & -2.845315 \\ \mathrm{~N} & -1.923579 & 3.728496 & -1.696887 \\ \mathrm{~N} & -1.352161 & 1.351685 & 2.264850 \\ \mathrm{~N} & 1.352174 & 1.351678 & -2.264852 \\ \mathrm{~N} & -2.107481 & -0.392772 & 0.343049 \\ \mathrm{~N} & 2.107478 & -0.392785 & -0.343051 \\ \mathrm{C} & 0.243457 & 3.053221 & 2.845314 \\ \mathrm{~N} & 1.923615 & 3.728474 & 1.696885 \\ \mathrm{C} & -0.867722 & 4.069367 & -3.590601 \\ \mathrm{C} & 0.949814 & 2.256053 & -3.181333 \\ \mathrm{C} & -1.957215 & 4.494162 & -2.824844 \\ \mathrm{H} & -2.530916 & 3.819334 & -0.893591 \\ \mathrm{C} & -2.444143 & 0.599959 & 2.523154 \\ \mathrm{C} & -0.949790 & 2.256054 & 3.181332 \\ \mathrm{C} & 2.444150 & 0.599943 & -2.523155 \\ \mathrm{C} & -2.839434 & -0.376562 & 1.470345 \\ \mathrm{~N} & -2.350338 & -1.338964 & -0.572860 \\ \mathrm{C} & 2.839430 & -0.376582 & -1.470348 \\ \mathrm{~N} & 2.350325 & -1.338980 & 0.572857 \\ \mathrm{C} & 0.867763 & 4.069351 & 3.590600 \\ \mathrm{C} & 1.957259 & 4.494138 & 2.824843 \\ \mathrm{H} & 2.530955 & 3.819302 & 0.893591 \\ \mathrm{H} & -0.602279 & 4.438779 & -4.568505 \\ \mathrm{C} & 1.635683 & 2.433435 & -4.394131 \\ \mathrm{C} & -3.182573 & 0.720124 & 3.701960 \\ \mathrm{C} & -1.635656 & 2.433439 & 4.394132 \\ \mathrm{C} & 3.182584 & 0.720104 & -3.701960\end{array}$




\begin{tabular}{|c|c|c|c|}
\hline $\mathrm{N}$ & -3.910814 & -1.146245 & 1.677941 \\
\hline & -3.356027 & -2.201614 & -0.392849 \\
\hline & 3.910802 & -1.146278 & -1.677944 \\
\hline & 3.356005 & -2.201640 & 0.392846 \\
\hline 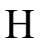 & 0.602321 & 4.438766 & 4.568504 \\
\hline & 2.763497 & 1.656079 & -4.654127 \\
\hline $\mathrm{H}$ & 1.294429 & 3.165012 & -5.116578 \\
\hline 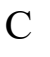 & -2.763476 & 1.656094 & 4.654129 \\
\hline $\mathrm{H}$ & -4.057477 & 0.100946 & 3.853714 \\
\hline H & -1.294392 & 3.165012 & 5.116580 \\
\hline $\mathrm{H}$ & 4.057483 & 0.100919 & -3.853713 \\
\hline $\mathrm{C}$ & -4.246258 & -2.027077 & 0.731376 \\
\hline $\mathrm{C}$ & -3.450414 & -3.313359 & -1.367910 \\
\hline $\mathrm{C}$ & 4.246237 & -2.027112 & -0.731380 \\
\hline $\mathrm{C}$ & 3.450381 & -3.313387 & 1.367907 \\
\hline $\mathrm{H}$ & 3.311536 & 1.778160 & -5.583324 \\
\hline $\mathrm{H}$ & -3.311511 & 1.778177 & 5.583327 \\
\hline $\mathrm{C}$ & -5.530677 & -2.734701 & 0.901383 \\
\hline $\mathrm{C}$ & -3.681245 & -4.626672 & -0.908351 \\
\hline $\mathrm{C}$ & -3.257651 & -3.063226 & -2.735975 \\
\hline $\mathrm{C}$ & 5.530651 & -2.734747 & -0.901384 \\
\hline $\mathrm{C}$ & 3.681204 & -4.626701 & 348 \\
\hline $\mathrm{C}$ & 3.257616 & -3.063252 & 2.735972 \\
\hline $\mathrm{C}$ & -5.990383 & -2.995396 & 2.195704 \\
\hline $\mathrm{C}$ & -6.333476 & -3.086021 & -0.214282 \\
\hline $\mathrm{C}$ & -3.714247 & -5.685806 & -1.827040 \\
\hline $\mathrm{H}$ & -3.808035 & -4.827557 & 0.148983 \\
\hline $\mathrm{C}$ & -3.322095 & -4.129700 & -3.650539 \\
\hline $\mathrm{H}$ & -3.077657 & -2.050127 & -3.071757 \\
\hline $\mathrm{C}$ & 5.990354 & -2.995452 & -2.195704 \\
\hline $\mathrm{C}$ & 6.333449 & -3.086063 & 0.214282 \\
\hline $\mathrm{C}$ & 3.714195 & -5.685836 & 1.827037 \\
\hline $\mathrm{H}$ & 3.807994 & -4.827587 & -0.148986 \\
\hline $\mathrm{C}$ & 3.322049 & -4.129726 & 3.650536 \\
\hline $\mathrm{H}$ & 3.077628 & -2.050152 & 3.071752 \\
\hline $\mathrm{C}$ & -7.229111 & -3.637621 & 2.398706 \\
\hline $\mathrm{H}$ & -5.399240 & -2.726872 & 3.062692 \\
\hline $\mathrm{C}$ & -7.571560 & -3.697598 & -0.002908 \\
\hline $\mathrm{H}$ & -6.019038 & -2.851237 & -1.222917 \\
\hline $\mathrm{C}$ & -3.545415 & -5.448928 & -3.185740 \\
\hline $\mathrm{H}$ & -3.878142 & -6.699571 & -1.475946 \\
\hline $\mathrm{O}$ & -3.184772 & -4.007352 & -4.988843 \\
\hline $\mathrm{C}$ & 7.229080 & -3.637682 & -2.398703 \\
\hline $\mathrm{H}$ & 5.399212 & -2.726930 & -3.062693 \\
\hline $\mathrm{C}$ & 7.571531 & -3.697645 & 0.002911 \\
\hline$H$ & 6.019013 & -2.851272 & 1.222916 \\
\hline
\end{tabular}




\begin{tabular}{|c|c|c|c|}
\hline $\mathrm{C}$ & 3.545361 & -5.448957 & 3.185737 \\
\hline H & 3.878083 & -6.699602 & 1.475944 \\
\hline $\mathcal{U}$ & 3.184724 & -4.007377 & 4.988839 \\
\hline C & -8.026195 & -3.988465 & 1.285609 \\
\hline$U$ & -7.559250 & -3.865296 & 3.685126 \\
\hline H & -8.196726 & -3.950194 & -0.853502 \\
\hline $\mathrm{H}$ & -3.585350 & -6.253358 & -3.912629 \\
\hline C & -3.010986 & -2.705423 & -5.564645 \\
\hline $\mathrm{C}$ & 8.026165 & -3.988521 & -1.285605 \\
\hline $\mathrm{O}$ & 7.559217 & -3.865366 & -3.685122 \\
\hline $\mathrm{H}$ & 8.196697 & -3.950238 & 0.853506 \\
\hline $\mathrm{H}$ & 3.585288 & -6.253387 & 3.912626 \\
\hline $\mathrm{C}$ & 3.010949 & -2.705447 & 5.564641 \\
\hline $\mathrm{H}$ & -8.985387 & -4.474138 & 1.419043 \\
\hline $\mathrm{C}$ & -8.809376 & -4.518995 & 3.990756 \\
\hline $\mathrm{H}$ & -3.867397 & -2.060859 & -5.337804 \\
\hline $\mathrm{H}$ & -2.082722 & -2.242175 & -5.210630 \\
\hline $\mathrm{H}$ & -2.951782 & -2.868110 & -6.640138 \\
\hline $\mathrm{H}$ & 8.985354 & -4.474198 & -1.419037 \\
\hline $\mathrm{C}$ & 8.809342 & -4.519068 & -3.990749 \\
\hline $\mathrm{H}$ & 3.867367 & -2.060891 & 5.337800 \\
\hline $\mathrm{H}$ & 2.082690 & -2.242191 & 5.210625 \\
\hline $\mathrm{H}$ & 2.951743 & -2.868133 & 6.640133 \\
\hline $\mathrm{H}$ & -8.837948 & -5.522351 & 3.554645 \\
\hline $\mathrm{H}$ & -9.654943 & -3.921734 & 3.635668 \\
\hline $\mathrm{H}$ & -8.839321 & -4.589366 & 5.076914 \\
\hline $\mathrm{H}$ & 8.837914 & -5.522421 & -3.554631 \\
\hline $\mathrm{H}$ & 9.654910 & -3.921806 & -3.635666 \\
\hline $\mathrm{H}$ & 8.839286 & -4.589446 & -5.076906 \\
\hline $\mathrm{C}$ & 2.972087 & 5.522414 & 3.071572 \\
\hline $\mathrm{C}$ & 2.660995 & 6.624113 & 3.892126 \\
\hline $\mathrm{C}$ & 4.257005 & 5.428880 & 2.501072 \\
\hline $\mathrm{C}$ & 3.615406 & 7.615467 & 4.129093 \\
\hline $\mathrm{H}$ & 1.670007 & 6.719957 & 4.324322 \\
\hline $\mathrm{C}$ & 5.208045 & 6.424022 & 2.739894 \\
\hline $\mathrm{H}$ & 4.537643 & 4.564020 & 1.905322 \\
\hline $\mathrm{C}$ & 4.889117 & 7.520039 & 3.552968 \\
\hline $\mathrm{H}$ & 3.366999 & 8.464730 & 4.757464 \\
\hline $\mathrm{H}$ & 6.199771 & 6.341051 & 2.306741 \\
\hline $\mathrm{H}$ & 5.629447 & 8.291194 & 3.740354 \\
\hline $\mathrm{C}$ & -2.972034 & 5.522447 & -3.071570 \\
\hline $\mathrm{C}$ & -4.256969 & 5.428893 & -2.501112 \\
\hline $\mathrm{C}$ & -2.660915 & 6.624175 & -3.892077 \\
\hline $\mathrm{C}$ & -5.208000 & 6.424046 & -2.739925 \\
\hline $\mathrm{H}$ & -4.537626 & 4.564009 & -1.905407 \\
\hline $\mathrm{C}$ & -3.615320 & 7.615536 & -4.129038 \\
\hline
\end{tabular}




$\begin{array}{llll}\mathrm{H} & -1.669913 & 6.720034 & -4.324236 \\ \mathrm{C} & -4.889047 & 7.520091 & -3.552952 \\ \mathrm{H} & -6.199739 & 6.341062 & -2.306803 \\ \mathrm{H} & -3.366895 & 8.464820 & -4.757374 \\ \mathrm{H} & -5.629371 & 8.291253 & -3.740336\end{array}$

$\mathrm{M}=\mathrm{Gd}$

$\begin{array}{lrcc} & & & \\ \mathrm{GD} & 0.000000 & 1.167674 & 0.000001 \\ \mathrm{~N} & 1.045946 & 2.821125 & 1.465812 \\ \mathrm{~N} & -1.045948 & 2.821125 & -1.465810 \\ \mathrm{C} & 0.572490 & 3.021918 & 2.727391 \\ \mathrm{~N} & 2.084127 & 3.699889 & 1.350220 \\ \mathrm{~N} & -1.040531 & 1.330513 & 2.283291 \\ \mathrm{~N} & 1.040530 & 1.330515 & -2.283289 \\ \mathrm{~N} & -1.863473 & -0.264319 & 0.372145 \\ \mathrm{~N} & 1.863474 & -0.264317 & -0.372144 \\ \mathrm{C} & -0.572493 & 3.021918 & -2.727389 \\ \mathrm{~N} & -2.084129 & 3.699887 & -1.350217 \\ \mathrm{C} & 1.304481 & 4.015259 & 3.383862 \\ \mathrm{C} & -0.558581 & 2.205055 & 3.192073 \\ \mathrm{C} & 2.284814 & 4.442141 & 2.473535 \\ \mathrm{H} & 2.582509 & 3.793137 & 0.475049 \\ \mathrm{C} & -2.072865 & 0.523007 & 2.617244 \\ \mathrm{C} & 2.072865 & 0.523011 & -2.617243 \\ \mathrm{C} & 0.558579 & 2.205057 & -3.192071 \\ \mathrm{C} & -2.511034 & -0.401496 & 1.542024 \\ \mathrm{~N} & -2.052742 & -1.175626 & -0.599826 \\ \mathrm{C} & 2.511035 & -0.401493 & -1.542023 \\ \mathrm{~N} & 2.052744 & -1.175625 & 0.599825 \\ \mathrm{C} & -1.304486 & 4.015258 & -3.383858 \\ \mathrm{C} & -2.284818 & 4.442140 & -2.473531 \\ \mathrm{H} & -2.582513 & 3.793132 & -0.475045 \\ \mathrm{H} & 1.184390 & 4.369136 & 4.395787 \\ \mathrm{C} & -1.108085 & 2.303694 & 4.476484 \\ \mathrm{C} & -2.674937 & 0.562479 & 3.873867 \\ \mathrm{C} & 2.674937 & 0.562484 & -3.873866 \\ \mathrm{C} & 1.108082 & 2.303697 & -4.476482 \\ \mathrm{~N} & -3.499613 & -1.259621 & 1.745725 \\ \mathrm{C} & -2.960077 & -2.137337 & -0.429119 \\ \mathrm{~N} & 3.499615 & -1.259616 & -1.745725 \\ \mathrm{C} & 2.960079 & -2.137336 & 0.429117 \\ \mathrm{H} & -1.184394 & 4.369137 & -4.395784 \\ \mathrm{C} & -2.178644 & 1.471850 & 4.816373 \\ \mathrm{H} & -0.710100 & 3.010987 & 5.194575 \\ \mathrm{H} & -3.504497 & -0.098674 & 4.093424\end{array}$




\begin{tabular}{|c|c|c|c|}
\hline $\mathrm{C}$ & 2.178643 & 1.471855 & -4.816372 \\
\hline & 3.504498 & -0.098667 & -4.093423 \\
\hline $\mathrm{H}$ & 0.710096 & 3.010990 & -5.194573 \\
\hline $\mathrm{C}$ & -3.840121 & -2.083691 & 0.737839 \\
\hline 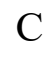 & -2.963715 & -3.221221 & -1.432521 \\
\hline & 3.840124 & -2.083687 & -0.737839 \\
\hline 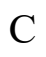 & 2.963717 & -3.221222 & 1.432518 \\
\hline H & -2.622189 & 1.530859 & 5.805728 \\
\hline $\mathrm{H}$ & 2.622188 & 1.530865 & -5.805726 \\
\hline & -5.091328 & -2.823378 & 0.884176 \\
\hline 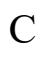 & -3.041947 & -4.556688 & -1.006073 \\
\hline$C$ & -2.811326 & -2.911891 & -2.800615 \\
\hline $\mathrm{C}$ & 5.091332 & -2.823372 & -0.884177 \\
\hline$C$ & 3.041951 & -4.556687 & 1.006066 \\
\hline C & 2.811325 & -2.911894 & 2.800611 \\
\hline$C$ & -5.590705 & -3.040792 & 2.183995 \\
\hline $\mathrm{C}$ & -5.853568 & -3.236522 & -0.239245 \\
\hline $\mathrm{C}$ & -2.954851 & -5.582653 & -1.955427 \\
\hline $\mathrm{H}$ & -3.155959 & -4.800573 & 0.043806 \\
\hline$C$ & -2.766128 & -3.948369 & -3.742794 \\
\hline $\mathrm{H}$ & -2.756464 & -1.875283 & -3.107693 \\
\hline $\mathrm{C}$ & 5.590710 & -3.040783 & -2.183996 \\
\hline $\mathrm{C}$ & 5.853571 & -3.236517 & 0.239244 \\
\hline $\mathrm{C}$ & 2.954854 & -5.582654 & 1.955419 \\
\hline $\mathrm{H}$ & 3.155965 & -4.800570 & -0.043812 \\
\hline$C$ & 2.766126 & -3.948375 & 3.742789 \\
\hline $\mathrm{H}$ & 2.756461 & -1.875287 & 3.107692 \\
\hline $\mathrm{C}$ & -6.815321 & -3.693351 & 2.382080 \\
\hline $\mathrm{H}$ & -5.023847 & -2.730547 & 3.052388 \\
\hline $\mathrm{C}$ & -7.085028 & -3.847814 & -0.031652 \\
\hline $\mathrm{H}$ & -5.505020 & -3.062633 & -1.248087 \\
\hline $\mathrm{C}$ & -2.827714 & -5.290066 & -3.310584 \\
\hline $\mathrm{H}$ & -3.000534 & -6.618687 & -1.635008 \\
\hline $\mathrm{O}$ & -2.660621 & -3.771981 & -5.086699 \\
\hline $\mathrm{C}$ & 6.815328 & -3.693340 & -2.382080 \\
\hline $\mathrm{H}$ & 5.023853 & -2.730537 & -3.052389 \\
\hline 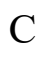 & 7.085033 & -3.847807 & 0.031651 \\
\hline $\mathrm{H}$ & 5.505022 & -3.062630 & 1.248086 \\
\hline $\mathrm{C}$ & 2.827714 & -5.290070 & 3.310576 \\
\hline $\mathrm{H}$ & 3.000539 & -6.618687 & 1.634997 \\
\hline $\mathrm{O}$ & 2.660617 & -3.771989 & 5.086693 \\
\hline$C$ & -7.570301 & -4.094226 & 1.261200 \\
\hline $\mathrm{O}$ & -7.180336 & -3.881647 & 3.672652 \\
\hline 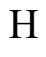 & -7.685167 & -4.149552 & -0.884293 \\
\hline $\mathrm{H}$ & -2.786441 & -6.076844 & -4.056550 \\
\hline $\mathrm{C}$ & -2.693978 & -2.443959 & -5.612307 \\
\hline
\end{tabular}




\begin{tabular}{|c|c|c|c|}
\hline & 7.570307 & -4.094216 & -1.261201 \\
\hline $\mathrm{O}$ & 7.180345 & -3.881633 & -3.672653 \\
\hline & 7.685171 & -4.149546 & 0.884293 \\
\hline & 2.786441 & -6.076850 & 4.056540 \\
\hline & 2.693971 & -2.443968 & 2305 \\
\hline & -8.523896 & -4.594006 & 1.383889 \\
\hline C & -8.422411 & -4.556527 & 3.948749 \\
\hline $\mathrm{F}$ & -3.626156 & -1.934000 & -5.341268 \\
\hline H & -1.832328 & -1.858163 & -5.2 \\
\hline $\mathrm{H}$ & -2.644291 & -2.554211 & -6.695463 \\
\hline $\mathrm{H}$ & 8.523904 & -4.593994 & 3889 \\
\hline $\mathrm{C}$ & 8.422421 & -4.556511 & -3.948749 \\
\hline $\mathrm{H}$ & 3.626149 & -1.934008 & 5.341268 \\
\hline $\mathrm{H}$ & 1.832321 & -1.8 & 296 \\
\hline $\mathrm{H}$ & 2.644282 & -2.554223 & 5460 \\
\hline $\mathrm{H}$ & -8.4 & -5.5 & 3042 \\
\hline $\mathrm{H}$ & -9.271905 & -3.993813 & 7546 \\
\hline $\mathrm{H}$ & -8.494374 & -4.598943 & 766 \\
\hline $\mathrm{H}$ & 8.413761 & -5.573548 & -3.5 \\
\hline $\mathrm{H}$ & 9.27 & -3.9 & -3.5 \\
\hline $\mathrm{H}$ & 8.49 & 925 & 4767 \\
\hline C & -3.335755 & 5.450720 & -2.5 \\
\hline $\mathrm{C}$ & -3.17 & 169 & -3.5 \\
\hline $\mathrm{C}$ & -4.512989 & 5.377210 & -1.825632 \\
\hline $\mathrm{C}$ & -4.1 & 115 & 0488 \\
\hline $\mathrm{H}$ & -2.262838 & 6.595765 & -4.097896 \\
\hline $\mathrm{C}$ & -5.499700 & 6.356435 & -1.954025 \\
\hline $\mathrm{H}$ & -4.689841 & 4.537820 & -1.157823 \\
\hline C & -5.323835 & 7.416797 & -2.854532 \\
\hline $\mathrm{H}$ & -4.023855 & 8.313435 & -4.326662 \\
\hline $\mathrm{H}$ & -6.410424 & 6.288799 & -1.367728 \\
\hline $\mathrm{H}$ & -6.093119 & 8.175742 & -2.9 \\
\hline $\mathrm{C}$ & 3.335750 & 5.450721 & 2.598463 \\
\hline $\mathrm{C}$ & 3.169988 & 6.515195 & 3.507533 \\
\hline $\mathrm{C}$ & 4.513004 & 5.377187 & 1.825668 \\
\hline $\mathrm{C}$ & 4.159283 & 7.492141 & 3.630459 \\
\hline $\mathrm{H}$ & 2.262798 & 6.595809 & 4.097842 \\
\hline $\mathrm{C}$ & 5.499714 & 6.356413 & 1.954060 \\
\hline $\mathrm{H}$ & 4.689870 & 4.537776 & 1.157889 \\
\hline $\mathrm{C}$ & 5.323829 & 7.416799 & 2.854534 \\
\hline H & 4.023814 & 8.313480 & 4.326607 \\
\hline 1 & 6.410453 & 6.288758 & 1.367788 \\
\hline $\mathrm{H}$ & 6.093112 & 8.175745 & 2.955403 \\
\hline
\end{tabular}

$\mathrm{M}=\mathrm{Am}$ 


\begin{tabular}{|c|c|c|c|}
\hline$\Delta M$ & .220036 & 0.010426 & -0.00053 \\
\hline $\mathrm{N}$ & -2.887938 & -1.096153 & -1.499757 \\
\hline $\mathrm{N}$ & -2.879962 & 1.136209 & 1.494169 \\
\hline $\mathrm{N}$ & -3.847882 & -2.054078 & -1.344936 \\
\hline $\mathrm{C}$ & -2.937745 & -0.777230 & -2.820115 \\
\hline $\mathrm{N}$ & -1.164854 & 0.775979 & -2.431666 \\
\hline $\mathrm{N}$ & -1.183181 & -0.758788 & 2.429506 \\
\hline $\mathrm{N}$ & 0.339037 & 1.784007 & -0.528744 \\
\hline $\mathrm{N}$ & 0.311203 & -1.786027 & 0.52 \\
\hline $\mathrm{N}$ & -3.827720 & 2.105943 & 1.337647 \\
\hline $\mathrm{C}$ & -2.936825 & 0.817243 & 2.814251 \\
\hline $\mathrm{C}$ & -4.499942 & -2.349795 & -2.502733 \\
\hline $\mathrm{H}$ & -4.059449 & -2.425419 & -0.428303 \\
\hline $\mathrm{C}$ & -3.920766 & -1.523635 & -3.478573 \\
\hline $\mathrm{C}$ & -2.005767 & 0.233258 & -3.339856 \\
\hline $\mathrm{C}$ & -0.275629 & 1.715550 & -2.8 \\
\hline $\mathrm{C}$ & -0.308031 & -1.710789 & 2.83 \\
\hline $\mathrm{C}$ & -2.019211 & -0.205426 & 3.3 \\
\hline $\mathrm{C}$ & 0.594837 & 2.254076 & -1.758499 \\
\hline $\mathrm{N}$ & 1.181963 & 2.071132 & 0.47 \\
\hline $\mathrm{C}$ & 0.557245 & -2.260780 & 1.759633 \\
\hline $\mathrm{N}$ & 1.152429 & -2.084302 & $-0.4^{\prime}$ \\
\hline $\mathrm{C}$ & -4.478834 & 2.409061 & 2.49 \\
\hline $\mathrm{H}$ & -4.03 & 2.48 & 0.42 \\
\hline $\mathrm{C}$ & -3.912132 & 1.575356 & 3.47 \\
\hline $\mathrm{C}$ & -5.569925 & -3.341852 & -2.596091 \\
\hline $\mathrm{H}$ & -4.173698 & -1.513116 & -4.527093 \\
\hline $\mathrm{C}$ & -1.979674 & 0.621343 & -4.685330 \\
\hline $\mathrm{C}$ & -0.191431 & 2.153507 & -4.151026 \\
\hline $\mathrm{C}$ & -0.233170 & -2.150655 & 0406 \\
\hline $\mathrm{C}$ & -2.001738 & -0.594574 & 100 \\
\hline $\mathrm{N}$ & 1.520090 & 3.164145 & -2.028257 \\
\hline $\mathrm{C}$ & 2.197792 & 2.906777 & 0.265562 \\
\hline $\mathrm{N}$ & 1.468562 & -3.184381 & 2.030735 \\
\hline $\mathrm{C}$ & 2.155482 & -2.934821 & -0.261164 \\
\hline $\mathrm{C}$ & -5.536896 & 3.413998 & 2.585499 \\
\hline $\mathrm{H}$ & -4.167702 & 1.567343 & 4.518697 \\
\hline $\mathrm{C}$ & -6.536134 & -3.226381 & -3.615880 \\
\hline $\mathrm{C}$ & -5.652382 & -4.412941 & -1.682636 \\
\hline $\mathrm{C}$ & -1.061217 & 1.591404 & -5.092574 \\
\hline $\mathrm{H}$ & -2.663421 & 0.176928 & -5.398773 \\
\hline $\mathrm{H}$ & 0.532491 & 2.914054 & -4.417187 \\
\hline $\mathrm{C}$ & -1.097503 & -1.577158 & 5.090116 \\
\hline $\mathrm{H}$ & 0.479511 & -2.921282 & 4.417909 \\
\hline $\mathrm{H}$ & -2.681274 & -0.141428 & 5.393067 \\
\hline $\mathrm{C}$ & 2.284985 & 3.607723 & -1.014405 \\
\hline
\end{tabular}




\begin{tabular}{|c|c|c|c|}
\hline $\mathrm{C}$ & 3.195272 & 3.013903 & 1.350647 \\
\hline 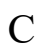 & 2.229283 & -3.638240 & 1.018300 \\
\hline $\mathrm{C}$ & 3.154024 & -3.055417 & -1.343845 \\
\hline C & -6.506503 & 3.309850 & 3.603283 \\
\hline $\mathrm{C}$ & -5.604629 & 4.486267 & 1.672219 \\
\hline $\mathrm{C}$ & -7.569878 & -4.159483 & -3.710784 \\
\hline $\mathrm{H}$ & -6.497245 & -2.398472 & -4.316676 \\
\hline $\mathrm{C}$ & -6.687896 & -5.343907 & -1.783155 \\
\hline $\mathrm{H}$ & -4.890154 & -4.555626 & -0.920654 \\
\hline $\mathrm{H}$ & -1.025091 & 1.908636 & -6.130327 \\
\hline $\mathrm{H}$ & -1.068278 & -1.895367 & 6.127787 \\
\hline $\mathrm{C}$ & 3.110137 & 4.785145 & -1.275042 \\
\hline $\mathrm{C}$ & 4.563452 & 2.962634 & 1.040305 \\
\hline $\mathrm{C}$ & 2.765599 & 3.090856 & 2.692080 \\
\hline $\mathrm{C}$ & 3.036314 & -4.827957 & 1.279780 \\
\hline $\mathrm{C}$ & 4.522014 & -3.024579 & -1.029985 \\
\hline $\mathrm{C}$ & 2.726693 & -3.124772 & -2.686441 \\
\hline $\mathrm{C}$ & -7.529160 & 4.255257 & 3.696396 \\
\hline $\mathrm{H}$ & -6.479012 & 2.481334 & 4.303900 \\
\hline $\mathrm{C}$ & -6.629105 & 5.429562 & 1.770934 \\
\hline $\mathrm{H}$ & -4.839215 & 4.620017 & 0.911811 \\
\hline $\mathrm{C}$ & -7.649706 & -5.217794 & -2.795586 \\
\hline $\mathrm{H}$ & -8.315245 & -4.062064 & -4.493419 \\
\hline $\mathrm{H}$ & -6.740045 & -6.174348 & -1.086429 \\
\hline $\mathrm{C}$ & 3.468115 & 5.069389 & -2.607705 \\
\hline $\mathrm{C}$ & 3.471240 & 5.689072 & -0.242892 \\
\hline $\mathrm{C}$ & 5.500400 & 2.976173 & 2.081236 \\
\hline $\mathrm{H}$ & 4.899319 & 2.902768 & 0.011480 \\
\hline $\mathrm{C}$ & 3.716171 & 3.144481 & 3.720563 \\
\hline $\mathrm{H}$ & 1.705541 & 3.134167 & 2.908191 \\
\hline $\mathrm{C}$ & 3.386488 & -5.118880 & 2.613083 \\
\hline $\mathrm{C}$ & 3.386810 & -5.736021 & 0.247597 \\
\hline $\mathrm{C}$ & 5.461324 & -3.050999 & -2.068534 \\
\hline $\mathrm{H}$ & 4.856108 & -2.970555 & -0.000262 \\
\hline $\mathrm{C}$ & 3.679007 & -3.191479 & -3.712545 \\
\hline $\mathrm{H}$ & 1.666668 & -3.152279 & -2.905275 \\
\hline $\mathrm{C}$ & -7.594420 & 5.314711 & 2.781369 \\
\hline $\mathrm{H}$ & -8.277232 & 4.166565 & 4.477486 \\
\hline $\mathrm{H}$ & -6.669867 & 6.260764 & 1.074358 \\
\hline $\mathrm{H}$ & -8.452622 & -5.943808 & -2.874249 \\
\hline $\mathrm{C}$ & 4.208038 & 6.217744 & -2.922350 \\
\hline $\mathrm{H}$ & 3.199159 & 4.392505 & -3.408580 \\
\hline $\mathrm{C}$ & 4.171119 & 6.844760 & -0.571546 \\
\hline $\mathrm{H}$ & 3.189587 & 5.507716 & 0.785394 \\
\hline $\mathrm{C}$ & 5.090022 & 3.074606 & 3.408010 \\
\hline $\mathrm{H}$ & 6.560308 & 2.924213 & 1.853009 \\
\hline
\end{tabular}




$\begin{array}{lrrr}\mathrm{O} & 3.422526 & 3.258178 & 5.043579 \\ \mathrm{C} & 4.108508 & -6.278374 & 2.928449 \\ \mathrm{H} & 3.125422 & -4.438942 & 3.413980 \\ \mathrm{C} & 4.068640 & -6.902275 & 0.576861 \\ \mathrm{H} & 3.110667 & -5.549425 & -0.781246 \\ \mathrm{C} & 5.052940 & -3.142197 & -3.396435 \\ \mathrm{H} & 6.521293 & -3.014875 & -1.837552 \\ \mathrm{O} & 3.387108 & -3.299614 & -5.036416 \\ \mathrm{H} & -8.388722 & 6.050289 & 2.858617 \\ \mathrm{C} & 4.556080 & 7.115418 & -1.892883 \\ \mathrm{O} & 4.527843 & 6.372305 & -4.229431 \\ \mathrm{H} & 4.433742 & 7.553289 & 0.207713 \\ \mathrm{H} & 5.808714 & 3.113493 & 4.219895 \\ \mathrm{C} & 2.062208 & 3.454725 & 5.432809 \\ \mathrm{C} & 4.445987 & -7.180011 & 1.898927 \\ \mathrm{O} & 4.422477 & -6.439017 & 4.236203 \\ \mathrm{H} & 4.322860 & -7.613786 & -0.202468 \\ \mathrm{H} & 5.773052 & -3.190958 & -4.206527 \\ \mathrm{C} & 2.025032 & -3.475495 & -5.429333 \\ \mathrm{H} & 5.120366 & 8.015158 & -2.107709 \\ \mathrm{C} & 5.293366 & 7.527269 & -4.622117 \\ \mathrm{H} & 1.645848 & 4.359713 & 4.974544 \\ \mathrm{H} & 1.444207 & 2.585399 & 5.171875 \\ \mathrm{H} & 2.079558 & 3.573453 & 6.516095 \\ \mathrm{H} & 4.996294 & -8.088245 & 2.114270 \\ \mathrm{C} & 5.169794 & -7.605578 & 4.629696 \\ \mathrm{H} & 1.594038 & -4.374624 & -4.973067 \\ \mathrm{H} & 1.419383 & -2.597307 & -5.169103 \\ \mathrm{H} & 2.043413 & -3.593412 & -6.512691 \\ \mathrm{H} & 6.270081 & 7.536263 & -4.127099 \\ \mathrm{H} & 4.747870 & 8.451596 & -4.404636 \\ \mathrm{H} & 5.432046 & 7.431296 & -5.698212 \\ \mathrm{H} & 6.147630 & -7.628450 & 4.137346 \\ \mathrm{H} & 4.611320 & -8.521520 & 4.409696 \\ \mathrm{H} & 5.306909 & -7.512815 & 5.706273\end{array}$

$\mathrm{M}=\mathrm{Cm}$

$\begin{array}{lccc}\mathrm{CM} & 0.000036 & 1.155621 & -0.000008 \\ \mathrm{~N} & -1.013861 & 2.825210 & -1.531920 \\ \mathrm{~N} & 1.014018 & 2.825177 & 1.531880 \\ \mathrm{C} & -0.560584 & 2.966514 & -2.808752 \\ \mathrm{~N} & -2.025996 & 3.736414 & -1.428386 \\ \mathrm{~N} & -1.018589 & 1.242197 & 2.351499 \\ \mathrm{~N} & 1.018643 & 1.242090 & -2.351526 \\ \mathrm{~N} & -1.865776 & -0.330491 & 0.412654\end{array}$




\begin{tabular}{|c|c|c|c|}
\hline $\mathrm{N}$ & 1.865764 & -0.330600 & -0.412654 \\
\hline $\mathrm{C}$ & 0.560734 & 2.966538 & 2.808703 \\
\hline $\mathrm{N}$ & 2.026201 & 3.736327 & 1.428336 \\
\hline $\mathrm{C}$ & -1.278523 & 3.956420 & -3.485822 \\
\hline $\mathrm{C}$ & 0.539492 & 2.105967 & -3.270713 \\
\hline $\mathrm{C}$ & -2.228087 & 4.443416 & -2.573068 \\
\hline $\mathrm{H}$ & -2.500941 & 3.877774 & -0.546825 \\
\hline $\mathrm{C}$ & -2.026902 & 0.405658 & 2.684011 \\
\hline $\mathrm{C}$ & -0.539400 & 2.106067 & 3.270671 \\
\hline $\mathrm{C}$ & 2.026905 & 0.405487 & -2.684031 \\
\hline $\mathrm{C}$ & -2.474870 & -0.502052 & 1.597965 \\
\hline $\mathrm{N}$ & -2.071499 & -1.225993 & -0.571328 \\
\hline $\mathrm{C}$ & 2.474835 & -0.502222 & -1.597968 \\
\hline $\mathrm{N}$ & 2.071448 & -1.226092 & 0.571346 \\
\hline $\mathrm{C}$ & 1.278718 & 3.956420 & 3.485755 \\
\hline $\mathrm{C}$ & 2.228319 & 4.443350 & 2.573001 \\
\hline $\mathrm{H}$ & 2.501201 & 3.877588 & 0.546791 \\
\hline $\mathrm{H}$ & -1.169668 & 4.270852 & -4.511860 \\
\hline $\mathrm{C}$ & 1.065691 & 2.161444 & -4.567523 \\
\hline $\mathrm{C}$ & -2.605569 & 0.402046 & 3.952574 \\
\hline $\mathrm{C}$ & -1.065611 & 2.161605 & 4.567473 \\
\hline $\mathrm{C}$ & 2.605557 & 0.401813 & -3.952600 \\
\hline $\mathrm{N}$ & -3.442137 & -1.382519 & 1.812957 \\
\hline $\mathrm{C}$ & -2.957405 & -2.205276 & -0.394458 \\
\hline $\mathrm{N}$ & 3.442051 & -1.382747 & -1.812950 \\
\hline $\mathrm{C}$ & 2.957298 & -2.205428 & 0.394488 \\
\hline $\mathrm{H}$ & 1.169840 & 4.270890 & 4.511778 \\
\hline $\mathrm{C}$ & 2.110581 & 1.298035 & -4.907774 \\
\hline $\mathrm{H}$ & 0.670837 & 2.861006 & -5.294818 \\
\hline $\mathrm{C}$ & -2.110554 & 1.298264 & 4.907732 \\
\hline $\mathrm{H}$ & -3.417460 & -0.280849 & 4.171165 \\
\hline $\mathrm{H}$ & -0.670727 & 2.861162 & 5.294756 \\
\hline $\mathrm{H}$ & 3.417407 & -0.281134 & -4.171185 \\
\hline $\mathrm{C}$ & -3.799871 & -2.192425 & 0.800123 \\
\hline $\mathrm{C}$ & -2.975240 & -3.266303 & -1.422579 \\
\hline $\mathrm{C}$ & 3.799753 & -2.192649 & -0.800102 \\
\hline $\mathrm{C}$ & 2.975084 & -3.266433 & 1.422632 \\
\hline $\mathrm{H}$ & 2.536251 & 1.323610 & -5.906362 \\
\hline $\mathrm{H}$ & -2.536235 & 1.323887 & 5.906315 \\
\hline $\mathrm{C}$ & -5.031343 & -2.959704 & 0.970727 \\
\hline $\mathrm{C}$ & -3.013682 & -4.612483 & -1.025752 \\
\hline $\mathrm{C}$ & -2.876666 & -2.922386 & -2.787236 \\
\hline $\mathrm{C}$ & 5.031181 & -2.959998 & -0.970700 \\
\hline $\mathrm{C}$ & 3.013449 & -4.612624 & 1.025833 \\
\hline $\mathrm{C}$ & 2.876541 & -2.922481 & 2.787282 \\
\hline $\mathrm{C}$ & -5.480969 & -3.220703 & 2.280365 \\
\hline
\end{tabular}




\begin{tabular}{|c|c|c|c|}
\hline $\mathrm{C}$ & -5.823949 & -3.358868 & -0.136372 \\
\hline & -2.940870 & -5.614158 & -2.001926 \\
\hline 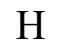 & -3.087172 & -4.882783 & 0.021359 \\
\hline C & -2.845302 & -3.935594 & -3.754985 \\
\hline $\mathrm{H}$ & -2.852017 & -1.877877 & -3.071066 \\
\hline & 5.480782 & -3.221049 & -2.280337 \\
\hline & 5.823776 & -3.359180 & 0.136400 \\
\hline & 2.940591 & -5.614274 & 2.002029 \\
\hline $\mathrm{H}$ & 3.086914 & -4.882951 & -0.021273 \\
\hline & 2.845131 & -3.935667 & 3.755053 \\
\hline 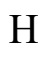 & 2.851953 & -1.877965 & 3.071090 \\
\hline & -6.685736 & -3.901869 & 2.502815 \\
\hline $\mathrm{H}$ & -4.890373 & -2.922138 & 3.137056 \\
\hline & -7.035870 & -3.999353 & 0.096691 \\
\hline $\mathrm{H}$ & -5.514268 & -3.151407 & -1.151592 \\
\hline & -2.866589 & -5.287824 & -3.3 \\
\hline $\mathrm{H}$ & -2.956466 & -6.658094 & -1.705031 \\
\hline 0 & -2.790277 & -3.725386 & -5.097286 \\
\hline C & 6.685511 & -3.902284 & -2.502783 \\
\hline $\mathrm{H}$ & 4.890194 & -2.922472 & -3.137029 \\
\hline$C$ & 7.035662 & -3.999734 & -0.096660 \\
\hline $\mathrm{H}$ & 5.514117 & -3.151680 & 1.151619 \\
\hline$C$ & 2.866339 & -5.287907 & 3.353410 \\
\hline H & 2.956126 & -6.658217 & 1.705157 \\
\hline 0 & 2.790129 & -3.725427 & 5.097350 \\
\hline $\mathrm{C}$ & -7.471535 & -4.288408 & 1.398302 \\
\hline 0 & -7.002212 & -4.130396 & 3.799817 \\
\hline $\mathrm{H}$ & -7.659462 & -4.290439 & -0.742743 \\
\hline $\mathrm{H}$ & -2.837038 & -6.056096 & -4.118875 \\
\hline $\mathrm{C}$ & -2.875882 & -2.386911 & -5.589223 \\
\hline $\mathrm{C}$ & 7.471299 & -4.288841 & -1.398268 \\
\hline $\mathrm{O}$ & 7.001962 & -4.130856 & -3.799783 \\
\hline 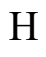 & 7.659246 & -4.290835 & 0.742775 \\
\hline $\mathrm{H}$ & 2.836752 & -6.056160 & 4.118990 \\
\hline $\mathrm{C}$ & 2.875812 & -2.386946 & 5.589257 \\
\hline $\mathrm{H}$ & -8.410970 & -4.809417 & 1.540180 \\
\hline 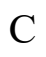 & -8.221832 & -4.835031 & 4.100178 \\
\hline 11 & -3.809139 & -1.906990 & -5.271041 \\
\hline 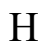 & -2.016227 & -1.787430 & -5.261907 \\
\hline $\mathrm{H}$ & -2.864911 & -2.470784 & -6.675815 \\
\hline $\mathrm{H}$ & 8.410705 & -4.809903 & -1.540144 \\
\hline $\mathrm{C}$ & 8.221543 & -4.835562 & -4.100140 \\
\hline $\mathrm{H}$ & 3.809092 & -1.907083 & 5.271057 \\
\hline & 2.016187 & -1.787426 & 5.261937 \\
\hline 7 & 2.864845 & -2.470795 & 6.675851 \\
\hline $\mathrm{H}$ & -8.209058 & -5.841153 & 3.668147 \\
\hline
\end{tabular}




$\begin{array}{lrrr}\mathrm{H} & -9.094464 & -4.278276 & 3.742694 \\ \mathrm{H} & -8.255771 & -4.906284 & 5.186540 \\ \mathrm{H} & 8.208720 & -5.841674 & -3.668086 \\ \mathrm{H} & 9.094207 & -4.278845 & -3.742676 \\ \mathrm{H} & 8.255468 & -4.906840 & -5.186501 \\ \mathrm{C} & 3.252510 & 5.476643 & 2.714647 \\ \mathrm{C} & 3.077305 & 6.500796 & 3.667250 \\ \mathrm{C} & 4.413560 & 5.467143 & 1.914349 \\ \mathrm{C} & 4.040959 & 7.500906 & 3.806336 \\ \mathrm{H} & 2.181836 & 6.532541 & 4.279775 \\ \mathrm{C} & 5.374641 & 6.469283 & 2.058718 \\ \mathrm{H} & 4.598982 & 4.659341 & 1.210661 \\ \mathrm{C} & 5.189226 & 7.489177 & 3.003007 \\ \mathrm{H} & 3.897954 & 8.290971 & 4.536341 \\ \mathrm{H} & 6.273257 & 6.450668 & 1.450488 \\ \mathrm{H} & 5.938632 & 8.266039 & 3.116280 \\ \mathrm{C} & -3.252229 & 5.476756 & -2.714715 \\ \mathrm{C} & -4.413602 & 5.466903 & -1.914891 \\ \mathrm{C} & -3.076645 & 6.501295 & -3.666833 \\ \mathrm{C} & -5.374636 & 6.469093 & -2.059242 \\ \mathrm{H} & -4.599300 & 4.658773 & -1.211653 \\ \mathrm{C} & -4.040257 & 7.501449 & -3.805899 \\ \mathrm{H} & -2.180914 & 6.533298 & -4.278965 \\ \mathrm{C} & -5.188847 & 7.489376 & -3.003037 \\ \mathrm{H} & -6.273507 & 6.450210 & -1.451397 \\ \mathrm{H} & -3.896967 & 8.291817 & -4.535521 \\ \mathrm{H} & -5.938218 & 8.266275 & -3.116298\end{array}$

$\mathbf{L}=\mathbf{1 i}$

\section{$\left[\mathrm{ML}\left(\mathrm{H}_{2} \mathrm{O}\right)_{6}\right]^{2+}$}

$\mathrm{M}=\mathrm{Eu}$

$\begin{array}{llrr}\text { EU } & -0.243552 & -1.032976 & -0.044325 \\ \mathrm{~N} & 1.854470 & 0.465751 & 0.013565 \\ \mathrm{C} & 3.240722 & 0.234703 & -0.016004 \\ \mathrm{C} & 1.705442 & 1.807665 & 0.020688 \\ \mathrm{C} & 3.924894 & -0.975655 & 0.016583 \\ \mathrm{C} & 3.956400 & 1.473802 & -0.056634 \\ \mathrm{C} & 2.968109 & 2.486811 & -0.025700 \\ \mathrm{C} & 0.377663 & 2.432831 & 0.074247 \\ \mathrm{C} & 5.340500 & -0.946105 & -0.019383 \\ \mathrm{H} & 3.401159 & -1.923272 & 0.103671 \\ \mathrm{C} & 5.366839 & 1.490141 & -0.093723 \\ \mathrm{H} & 3.138421 & 3.555132 & -0.037271\end{array}$




$\begin{array}{lrrr}\mathrm{C} & 0.228912 & 3.833731 & 0.146377 \\ \mathrm{~N} & -0.693517 & 1.609976 & 0.054477 \\ \mathrm{C} & 6.048331 & 0.264000 & -0.079389 \\ \mathrm{H} & 5.891720 & -1.880959 & 0.008613 \\ \mathrm{H} & 5.916220 & 2.426026 & -0.128894 \\ \mathrm{C} & -1.047898 & 4.384600 & 0.200606 \\ \mathrm{H} & 1.099362 & 4.478035 & 0.163364 \\ \mathrm{C} & -1.927367 & 2.155092 & 0.087879 \\ \mathrm{H} & 7.132764 & 0.248158 & -0.105316 \\ \mathrm{C} & -2.157305 & 3.531156 & 0.167310 \\ \mathrm{H} & -1.182527 & 5.459956 & 0.262209 \\ \mathrm{C} & -3.077845 & 1.214697 & -0.001688 \\ \mathrm{H} & -3.171699 & 3.908347 & 0.195034 \\ \mathrm{~N} & -4.323752 & 1.734964 & 0.008954 \\ \mathrm{~N} & -2.799164 & -0.093624 & -0.112870 \\ \mathrm{C} & -5.316759 & 0.871384 & -0.118109 \\ \mathrm{~N} & -3.807643 & -0.965451 & -0.262119 \\ \mathrm{C} & -5.054870 & -0.509960 & -0.271290 \\ \mathrm{H} & -6.334637 & 1.255162 & -0.105902 \\ \mathrm{H} & -5.846732 & -1.240850 & -0.401912 \\ \mathrm{O} & -1.843979 & -2.901097 & -0.979847 \\ \mathrm{H} & -1.917466 & -3.538849 & -1.703611 \\ \mathrm{H} & -2.744379 & -2.538595 & -0.828138 \\ \mathrm{O} & -0.505707 & -0.259672 & -2.538452 \\ \mathrm{H} & -0.825112 & 0.516361 & -3.020092 \\ \mathrm{H} & 0.048557 & -0.765267 & -3.152846 \\ \mathrm{O} & 1.401380 & -2.235687 & -1.914827 \\ \mathrm{H} & 1.460753 & -3.142187 & -2.253601 \\ \mathrm{H} & 2.296199 & -1.866113 & -1.997139 \\ \mathrm{O} & 0.298966 & -0.542678 & 2.562140 \\ \mathrm{H} & -0.459560 & -0.795458 & 3.114862 \\ \mathrm{H} & 0.746610 & 0.196313 & 3.000092 \\ \mathrm{O} & 1.016459 & -2.967531 & 1.361009 \\ \mathrm{H} & 1.466135 & -3.822812 & 1.297335 \\ \mathrm{H} & 1.325036 & -2.540475 & 2.178272 \\ \mathrm{O} & -1.752248 & -2.240354 & 2.003589 \\ \mathrm{H} & -2.712376 & -2.360797 & 2.056210 \\ \mathrm{H} & -1.371011 & -3.128893 & 2.093953\end{array}$

$\mathrm{M}=\mathrm{Gd}$

$\begin{array}{lrrr}\mathrm{C} & 3.117116 & 0.176338 & 0.032132 \\ \mathrm{C} & 3.825767 & 1.415899 & -0.107639 \\ \mathrm{C} & 5.234151 & 1.431836 & -0.233444 \\ \mathrm{C} & 5.920923 & 0.225082 & -0.217028 \\ \mathrm{C} & 5.226494 & -0.998093 & -0.051176\end{array}$




$\begin{array}{lccc}\mathrm{C} & 3.837038 & -1.039218 & 0.079861 \\ \mathrm{C} & 1.612434 & 1.802329 & 0.058013 \\ \mathrm{C} & 2.842678 & 2.442391 & -0.072852 \\ \mathrm{H} & 5.769035 & 2.370889 & -0.337182 \\ \mathrm{H} & 7.001571 & 0.212295 & -0.312336 \\ \mathrm{H} & 5.794060 & -1.922536 & -0.004237 \\ \mathrm{H} & 3.351735 & -1.987120 & 0.293176 \\ \mathrm{H} & 3.022845 & 3.505886 & -0.149357 \\ \mathrm{C} & 0.293032 & 2.386938 & 0.099193 \\ \mathrm{C} & 0.072474 & 3.788702 & 0.156441 \\ \mathrm{C} & -1.219307 & 4.283507 & 0.190355 \\ \mathrm{H} & 0.920676 & 4.462261 & 0.180655 \\ \mathrm{C} & -2.022175 & 2.027214 & 0.086078 \\ \mathrm{C} & -2.305400 & 3.383644 & 0.148776 \\ \mathrm{H} & -1.398302 & 5.352944 & 0.241654 \\ \mathrm{H} & -3.333330 & 3.723576 & 0.155195 \\ \mathrm{C} & -3.100996 & 1.027911 & -0.026812 \\ \mathrm{C} & -5.299361 & 0.500138 & -0.196887 \\ \mathrm{C} & -4.922122 & -0.860995 & -0.340502 \\ \mathrm{H} & -6.346018 & 0.797111 & -0.211079 \\ \mathrm{H} & -5.649833 & -1.653218 & -0.486240 \\ \mathrm{~N} & 1.749498 & 0.405760 & 0.115891 \\ \mathrm{~N} & -0.757115 & 1.525188 & 0.076594 \\ \mathrm{~N} & -4.387071 & 1.441759 & -0.045702 \\ \mathrm{H} & -2.716257 & -0.256442 & -0.132576 \\ \mathrm{H} & -2.386795 & -2.614061 & -0.962310 \\ \mathrm{~N} & -3.645565 & -1.212883 & -0.300547 \\ \mathrm{GD} & -0.197873 & -0.902508 & 0.018942 \\ \mathrm{O} & 1.048169 & -2.734942 & 1.378360 \\ \mathrm{H} & 1.497608 & -3.560159 & 1.139018 \\ \mathrm{O} & 0.190767 & -0.279519 & 2.451979 \\ \mathrm{H} & -0.429711 & -0.291157 & 3.197719 \\ \mathrm{O} & -1.433880 & -2.751835 & -1.161778 \\ \mathrm{H} & -1.389407 & -3.019457 & -2.092320 \\ \mathrm{O} & -1.650694 & -2.232385 & 1.718046 \\ \mathrm{H} & -1.201661 & -3.007174 & 2.092671 \\ \mathrm{O} & 1.455906 & -2.016916 & -1.623582 \\ \mathrm{H} & 1.549673 & -2.902905 & -2.006606 \\ \mathrm{O} & -0.397375 & -0.138967 & -2.375486 \\ \mathrm{H} & 0.343730 & -0.439414 & -2.926524 \\ \mathrm{H} & 0.821323 & 0.444646 & 2.599373 \\ \mathrm{H} & -2.367325 & -2.390521 & 2.168911 \\ \mathrm{H} & -2.449512 & 1.668546 \\ \mathrm{H} & -1.672959 & -1.504442 \\ \mathrm{H} & & -2.679561\end{array}$


$\mathrm{M}=\mathrm{Am}$

$\begin{array}{lccc}\text { AM } & -0.189928 & -0.822606 & 0.014419 \\ \mathrm{~N} & 1.785978 & 0.521889 & 0.138996 \\ \mathrm{C} & 3.147494 & 0.277812 & 0.045674 \\ \mathrm{C} & 1.658183 & 1.914531 & 0.072701 \\ \mathrm{C} & 3.853905 & -0.945057 & 0.100864 \\ \mathrm{C} & 3.866105 & 1.509921 & -0.107021 \\ \mathrm{C} & 2.892377 & 2.545488 & -0.071406 \\ \mathrm{C} & 0.341883 & 2.499749 & 0.115820 \\ \mathrm{C} & 5.242318 & -0.919225 & -0.038572 \\ \mathrm{H} & 3.356192 & -1.884652 & 0.325880 \\ \mathrm{C} & 5.274038 & 1.510103 & -0.239970 \\ \mathrm{H} & 3.081473 & 3.606706 & -0.156524 \\ \mathrm{C} & 0.131475 & 3.902283 & 0.179099 \\ \mathrm{~N} & -0.714403 & 1.642904 & 0.089634 \\ \mathrm{C} & 5.947893 & 0.296438 & -0.218445 \\ \mathrm{H} & 5.801455 & -1.848427 & 0.013854 \\ \mathrm{H} & 5.818600 & 2.442540 & -0.352491 \\ \mathrm{C} & -1.154792 & 4.408206 & 0.217316 \\ \mathrm{H} & 0.986230 & 4.567320 & 0.205953 \\ \mathrm{C} & -1.976371 & 2.157623 & 0.101712 \\ \mathrm{H} & 7.027849 & 0.271899 & -0.319153 \\ \mathrm{C} & -2.246515 & 3.515875 & 0.172647 \\ \mathrm{H} & -1.325491 & 5.478601 & 0.274653 \\ \mathrm{C} & -3.071445 & 1.178506 & -0.016167 \\ \mathrm{H} & -3.271846 & 3.863153 & 0.183224 \\ \mathrm{H} & -4.350413 & 1.614097 & -0.028394 \\ \mathrm{~N} & -2.709489 & -0.110340 & -0.132071 \\ \mathrm{C} & -5.278511 & 0.689073 & -0.185507 \\ \mathrm{~N} & -3.653857 & -1.050682 & -0.307984 \\ \mathrm{C} & -4.924013 & -0.676640 & -0.342587 \\ \mathrm{H} & -6.320053 & 1.003597 & -0.193944 \\ \mathrm{H} & -5.665067 & -1.455076 & -0.494972 \\ \mathrm{O} & -1.501420 & -2.677517 & -1.227345 \\ \mathrm{H} & -1.474641 & -2.927024 & -2.163750 \\ \mathrm{H} & -2.445078 & -2.506064 & -1.016115 \\ \mathrm{O} & -0.370774 & -0.016870 & -2.445061 \\ \mathrm{H} & -0.595673 & 0.868688 & -2.768684 \\ \mathrm{H} & 0.398852 & -0.313414 & -2.958241 \\ \mathrm{H} & 1.525910 & -1.896929 & -1.698656 \\ \mathrm{H} & 2.622383 & -2.766064 & -2.118148 \\ \mathrm{H} & 0.312623 & -0.295056 & 2.522989 \\ \mathrm{H} & -0.282928 & 3.294311 \\ \mathrm{H} & 0.400775 & 2.648130\end{array}$




$\begin{array}{lrrr}\mathrm{O} & 1.006456 & -2.809029 & 1.327285 \\ \mathrm{H} & 1.440422 & -3.638789 & 1.074121 \\ \mathrm{H} & 1.431669 & -2.507648 & 2.148006 \\ \mathrm{O} & -1.693814 & -2.161950 & 1.740244 \\ \mathrm{H} & -2.646172 & -2.336051 & 1.686499 \\ \mathrm{H} & -1.278618 & -2.976891 & 2.065507\end{array}$

$\mathrm{M}=\mathrm{Cm}$

$\begin{array}{lccc}\mathrm{C} & 3.153582 & 0.272629 & 0.011474 \\ \mathrm{C} & 3.865258 & 1.510511 & -0.119135 \\ \mathrm{C} & 5.273280 & 1.522168 & -0.248010 \\ \mathrm{C} & 5.955040 & 0.312569 & -0.241841 \\ \mathrm{C} & 5.256536 & -0.909632 & -0.082995 \\ \mathrm{C} & 3.867615 & -0.946185 & 0.050213 \\ \mathrm{C} & 1.652414 & 1.901566 & 0.055921 \\ \mathrm{C} & 2.884397 & 2.539297 & -0.072248 \\ \mathrm{H} & 5.811924 & 2.459663 & -0.345961 \\ \mathrm{H} & 7.035455 & 0.296336 & -0.339550 \\ \mathrm{H} & 5.821036 & -1.836263 & -0.043203 \\ \mathrm{H} & 3.376283 & -1.892953 & 0.258532 \\ \mathrm{H} & 3.068167 & 3.602691 & -0.140252 \\ \mathrm{C} & 0.335452 & 2.492805 & 0.107808 \\ \mathrm{C} & 0.127676 & 3.895528 & 0.180752 \\ \mathrm{C} & -1.159171 & 4.402041 & 0.223190 \\ \mathrm{H} & 0.981774 & 4.561311 & 0.210110 \\ \mathrm{C} & -1.984913 & 2.155087 & 0.094756 \\ \mathrm{C} & -2.254068 & 3.513484 & 0.172877 \\ \mathrm{H} & -1.327617 & 5.472511 & 0.286801 \\ \mathrm{H} & -3.278186 & 3.864406 & 0.183593 \\ \mathrm{C} & -3.077705 & 1.171362 & -0.033864 \\ \mathrm{C} & -5.283355 & 0.680609 & -0.222624 \\ \mathrm{C} & -4.926972 & -0.682727 & -0.391763 \\ \mathrm{H} & -6.325117 & 0.994330 & -0.234619 \\ \mathrm{H} & -5.665845 & -1.460143 & -0.559090 \\ \mathrm{~N} & 1.788949 & 0.505461 & 0.099087 \\ \mathrm{~N} & -0.724144 & 1.642610 & 0.079314 \\ \mathrm{~N} & -4.357099 & 1.605361 & -0.050712 \\ \mathrm{~N} & -2.714238 & -0.117410 & -0.157026 \\ \mathrm{~N} & -3.656437 & -1.055605 & -0.350572 \\ \mathrm{CM} & -0.181762 & -0.820526 & 0.014992 \\ \mathrm{O} & 1.042389 & -2.720928 & 1.412834 \\ \mathrm{H} & 1.477006 & -3.555859 & 1.178768 \\ \mathrm{O} & 0.297655 & -0.211228 & 2.495496 \\ \mathrm{H} & -0.318991 & -0.205569 & 3.244696 \\ \mathrm{O} & -1.511816 & -2.724131 & -1.118903\end{array}$




$\begin{array}{lrrr}\mathrm{H} & -1.469805 & -3.151804 & -1.987216 \\ \mathrm{O} & -1.666894 & -2.086227 & 1.827634 \\ \mathrm{H} & -1.218858 & -2.880322 & 2.161622 \\ \mathrm{O} & 1.486498 & -1.946392 & -1.680093 \\ \mathrm{H} & 1.581635 & -2.827554 & -2.073696 \\ \mathrm{O} & -0.403811 & -0.050893 & -2.422052 \\ \mathrm{H} & 0.311052 & -0.387409 & -2.986702 \\ \mathrm{H} & 0.936508 & 0.508326 & 2.628552 \\ \mathrm{H} & 1.499285 & -2.377143 & 2.198962 \\ \mathrm{H} & -2.612817 & -2.295938 & 1.794132 \\ \mathrm{H} & 2.396581 & -1.601651 & -1.557759 \\ \mathrm{H} & -2.456979 & -2.498647 & -0.962365 \\ \mathrm{H} & -0.595110 & 0.851025 & -2.721610\end{array}$

$\left[\mathrm{ML}\left(\mathrm{H}_{2} \mathrm{O}\right)_{5}\right]^{2+}$

$\mathrm{M}=\mathrm{Eu}$

$\begin{array}{lrrr}\text { EU } & -0.266567 & -1.089401 & 0.096753 \\ \mathrm{O} & -1.444341 & -2.473643 & 2.004159 \\ \mathrm{H} & -2.118595 & -3.168793 & 1.993891 \\ \mathrm{O} & -1.813857 & -2.920839 & -0.984140 \\ \mathrm{H} & -1.862548 & -3.840891 & -1.279714 \\ \mathrm{O} & 1.555379 & -2.604128 & 1.267750 \\ \mathrm{H} & 1.355412 & -3.432317 & 1.731407 \\ \mathrm{O} & 0.116776 & -0.227343 & 2.663112 \\ \mathrm{H} & 0.955067 & -0.519731 & 3.054437 \\ \mathrm{O} & 0.366620 & -1.385153 & -2.377730 \\ \mathrm{H} & -0.114837 & -1.921432 & -3.025981 \\ \mathrm{H} & 2.521487 & -2.560831 & 1.185763 \\ \mathrm{H} & 1.017052 & -0.863566 & -2.872281 \\ \mathrm{H} & -1.413143 & -2.115597 & 2.905136 \\ \mathrm{H} & -2.729821 & -2.555504 & -0.975214 \\ \mathrm{H} & -0.081494 & 0.626307 & 3.077600 \\ \mathrm{C} & 3.205033 & 0.129744 & -0.342801 \\ \mathrm{C} & 3.950826 & 1.331876 & -0.122907 \\ \mathrm{C} & 5.360415 & 1.326893 & -0.193239 \\ \mathrm{C} & 6.008806 & 0.120242 & -0.497379 \\ \mathrm{C} & 5.269322 & -1.047512 & -0.738767 \\ \mathrm{C} & 3.853846 & -1.056618 & -0.668053 \\ \mathrm{C} & 1.708311 & 1.701575 & 0.010806 \\ \mathrm{C} & 2.987002 & 2.345492 & 0.098489 \\ \mathrm{H} & 5.933749 & 2.233567 & -0.025170 \\ \mathrm{H} & 7.091288 & 0.090036 & -0.562199 \\ \mathrm{H} & 5.792589 & -1.962566 & -0.998394 \\ \mathrm{H} & 3.305535 & -1.962603 & -0.913813\end{array}$




$\begin{array}{lrrr}\mathrm{H} & 3.182108 & 3.394109 & 0.280615 \\ \mathrm{C} & 0.388951 & 2.338869 & 0.107897 \\ \mathrm{C} & 0.247760 & 3.731186 & 0.277646 \\ \mathrm{C} & -1.027107 & 4.290495 & 0.303252 \\ \mathrm{H} & 1.121492 & 4.364208 & 0.374619 \\ \mathrm{C} & -1.918373 & 2.085476 & -0.010642 \\ \mathrm{C} & -2.140607 & 3.455808 & 0.145401 \\ \mathrm{H} & -1.156401 & 5.360924 & 0.429263 \\ \mathrm{H} & -3.151225 & 3.844033 & 0.133307 \\ \mathrm{C} & -3.064862 & 1.160358 & -0.226519 \\ \mathrm{C} & -5.286149 & 0.843114 & -0.549700 \\ \mathrm{C} & -5.020052 & -0.533068 & -0.738568 \\ \mathrm{H} & -6.299060 & 1.235538 & -0.608352 \\ \mathrm{H} & -5.800743 & -1.249759 & -0.972718 \\ \mathrm{~N} & 1.826079 & 0.378542 & -0.232369 \\ \mathrm{~N} & -0.688384 & 1.531350 & -0.014094 \\ \mathrm{~N} & -4.302674 & 1.691698 & -0.301214 \\ \mathrm{~N} & -2.786258 & -0.146421 & -0.355903 \\ \mathrm{~N} & -3.782698 & -1.000538 & -0.631038\end{array}$

$\mathrm{M}=\mathrm{Gd}$

$\begin{array}{lrrc}\text { GD } & -0.199571 & -0.923139 & 0.137550 \\ \mathrm{O} & -1.323136 & -1.925837 & 2.154377 \\ \mathrm{H} & -1.925719 & -2.678342 & 2.253165 \\ \mathrm{O} & -1.440227 & -2.959309 & -0.561276 \\ \mathrm{H} & -1.284926 & -3.853635 & -0.898853 \\ \mathrm{O} & 1.620743 & -2.379863 & 0.947230 \\ \mathrm{H} & 1.660718 & -3.252935 & 1.367913 \\ \mathrm{O} & 0.502503 & 0.010934 & 2.452197 \\ \mathrm{H} & 1.352725 & -0.336091 & 2.770054 \\ \mathrm{O} & 0.193410 & -1.152580 & -2.259269 \\ \mathrm{H} & -0.165488 & -1.620985 & -3.028345 \\ \mathrm{H} & 2.532991 & -2.150071 & 0.655204 \\ \mathrm{H} & 0.874945 & -0.529322 & -2.566319 \\ \mathrm{H} & -1.177633 & -1.541413 & 3.034061 \\ \mathrm{H} & -2.402154 & -2.736973 & -0.660394 \\ \mathrm{H} & 0.546317 & 0.968836 & 2.607918 \\ \mathrm{C} & 3.040669 & 0.088374 & -0.452017 \\ \mathrm{C} & 3.798183 & 1.251035 & -0.090238 \\ \mathrm{C} & 5.211014 & 1.199169 & -0.050957 \\ \mathrm{C} & 5.845814 & 0.005465 & -0.372031 \\ \mathrm{C} & 5.097629 & -1.130910 & -0.766902 \\ \mathrm{C} & 3.700967 & -1.106170 & -0.819513 \\ \mathrm{C} & 1.592826 & 1.720110 & -0.062469 \\ \mathrm{C} & 2.849029 & 2.288787 & 0.138911\end{array}$




$\begin{array}{lrrr}\mathrm{H} & 5.790616 & 2.077701 & 0.215617 \\ \mathrm{H} & 6.928812 & -0.055766 & -0.351748 \\ \mathrm{H} & 5.626281 & -2.030808 & -1.066224 \\ \mathrm{H} & 3.166861 & -1.951690 & -1.248939 \\ \mathrm{H} & 3.067714 & 3.313977 & 0.406251 \\ \mathrm{C} & 0.279958 & 2.317542 & 0.024118 \\ \mathrm{C} & 0.049823 & 3.712776 & 0.127914 \\ \mathrm{C} & -1.248616 & 4.195710 & 0.129299 \\ \mathrm{H} & 0.892229 & 4.392852 & 0.177375 \\ \mathrm{C} & -2.036782 & 1.940429 & -0.064951 \\ \mathrm{C} & -2.328498 & 3.293378 & 0.012947 \\ \mathrm{H} & -1.437095 & 5.262769 & 0.195816 \\ \mathrm{H} & -3.356526 & 3.631406 & -0.024868 \\ \mathrm{C} & -3.094274 & 0.925103 & -0.232873 \\ \mathrm{C} & -5.269705 & 0.361372 & -0.524229 \\ \mathrm{C} & -4.864737 & -0.994075 & -0.642998 \\ \mathrm{H} & -6.318313 & 0.642053 & -0.597866 \\ \mathrm{H} & -5.570407 & -1.797548 & -0.828117 \\ \mathrm{~N} & 1.681008 & 0.363075 & -0.409667 \\ \mathrm{~N} & -0.767855 & 1.451850 & -0.035170 \\ \mathrm{~N} & -4.382103 & 1.318114 & -0.322442 \\ \mathrm{~N} & -2.684833 & -0.355256 & -0.309014 \\ \mathrm{~N} & -3.588440 & -1.324704 & -0.524425 \\ & & & \\ \mathrm{M}=\mathrm{Am} & & & \end{array}$

$\begin{array}{lrrr}\text { AM } & -0.184549 & -0.845762 & 0.126831 \\ \mathrm{O} & -1.402839 & -2.109241 & 2.024678 \\ \mathrm{H} & -1.980465 & -2.886739 & 1.990037 \\ \mathrm{O} & -1.527105 & -2.887955 & -0.799289 \\ \mathrm{H} & -1.452469 & -3.795586 & -1.128412 \\ \mathrm{O} & 1.698694 & -2.247086 & 1.209777 \\ \mathrm{H} & 1.729886 & -3.116075 & 1.639817 \\ \mathrm{O} & 0.241031 & 0.025412 & 2.570392 \\ \mathrm{H} & 1.094618 & -0.275898 & 2.923953 \\ \mathrm{O} & 0.353412 & -1.174710 & -2.301343 \\ \mathrm{H} & -0.034612 & -1.729341 & -2.995517 \\ \mathrm{H} & 2.615156 & -2.026080 & 0.942062 \\ \mathrm{H} & 1.034586 & -0.616185 & -2.710939 \\ \mathrm{H} & -1.375782 & -1.799584 & 2.944129 \\ \mathrm{H} & -2.468824 & -2.597574 & -0.878756 \\ \mathrm{H} & 0.157726 & 0.954170 & 2.840047 \\ \mathrm{C} & 3.091191 & 0.185887 & -0.418252 \\ \mathrm{C} & 3.859336 & 1.365644 & -0.157312 \\ \mathrm{C} & 5.269837 & 1.324118 & -0.201113 \\ \mathrm{C} & 5.893146 & 0.119874 & -0.516062\end{array}$




$\begin{array}{rrrr}\mathrm{C} & 5.131585 & -1.035473 & -0.809418 \\ \mathrm{C} & 3.733417 & -1.019739 & -0.768125 \\ \mathrm{C} & 1.655028 & 1.828365 & -0.009666 \\ \mathrm{C} & 2.916973 & 2.408433 & 0.090079 \\ \mathrm{H} & 5.858443 & 2.213790 & 0.000557 \\ \mathrm{H} & 6.975816 & 0.065599 & -0.560976 \\ \mathrm{H} & 5.646273 & -1.947441 & -1.095666 \\ \mathrm{H} & 3.176853 & -1.897433 & -1.090892 \\ \mathrm{H} & 3.147680 & 3.443988 & 0.300989 \\ \mathrm{C} & 0.346274 & 2.437001 & 0.080074 \\ \mathrm{C} & 0.138526 & 3.832279 & 0.211688 \\ \mathrm{C} & -1.151595 & 4.337616 & 0.210411 \\ \mathrm{H} & 0.990504 & 4.497276 & 0.290556 \\ \mathrm{C} & -1.973281 & 2.100770 & -0.049250 \\ \mathrm{C} & -2.243198 & 3.457010 & 0.059490 \\ \mathrm{H} & -1.322852 & 5.405621 & 0.302342 \\ \mathrm{H} & -3.264793 & 3.813028 & 0.016259 \\ \mathrm{C} & -3.052532 & 1.115782 & -0.268006 \\ \mathrm{C} & -5.236632 & 0.626876 & -0.623171 \\ \mathrm{C} & -4.866405 & -0.732320 & -0.789559 \\ \mathrm{H} & -6.275273 & 0.940385 & -0.704376 \\ \mathrm{H} & -5.589595 & -1.506783 & -1.024099 \\ \mathrm{~N} & 1.734925 & 0.458598 & -0.290221 \\ \mathrm{~N} & -0.713604 & 1.590542 & -0.012425 \\ \mathrm{~N} & -4.326579 & 1.549223 & -0.366834 \\ \mathrm{~N} & -2.678003 & -0.171940 & -0.380263 \\ \mathrm{~N} & -3.603355 & -1.105822 & -0.655207 \\ & & & \\ \mathrm{M}=\mathrm{Cm} & & & \\ & & & \end{array}$

$\begin{array}{lrrc}\mathrm{CM} & -0.187318 & -0.841748 & 0.103814 \\ \mathrm{O} & -1.296377 & -2.000636 & 2.122951 \\ \mathrm{H} & -1.890920 & -2.764264 & 2.177656 \\ \mathrm{O} & -1.526729 & -2.861686 & -0.704630 \\ \mathrm{H} & -1.423831 & -3.756985 & -1.059240 \\ \mathrm{O} & 1.690407 & -2.281374 & 1.018659 \\ \mathrm{H} & 1.729930 & -3.155449 & 1.437457 \\ \mathrm{O} & 0.452133 & 0.056186 & 2.497978 \\ \mathrm{H} & 1.327485 & -0.251906 & 2.786695 \\ \mathrm{O} & 0.283245 & -1.094091 & -2.329105 \\ \mathrm{H} & -0.078607 & -1.586483 & -3.082089 \\ \mathrm{H} & 2.600882 & -2.052062 & 0.726749 \\ \mathrm{H} & 0.971741 & -0.491260 & -2.658724 \\ \mathrm{H} & -1.163242 & -1.662129 & 3.023082 \\ \mathrm{H} & -2.478897 & -2.595380 & -0.769624 \\ \mathrm{H} & 0.425661 & 1.001259 & 2.719752\end{array}$




$\begin{array}{lrrr}\mathrm{C} & 3.086064 & 0.193168 & -0.446929 \\ \mathrm{C} & 3.843574 & 1.360450 & -0.102151 \\ \mathrm{C} & 5.256984 & 1.314314 & -0.077764 \\ \mathrm{C} & 5.892293 & 0.121435 & -0.399240 \\ \mathrm{C} & 5.143474 & -1.020810 & -0.776761 \\ \mathrm{C} & 3.746998 & -1.001853 & -0.811204 \\ \mathrm{C} & 1.637006 & 1.823193 & -0.053065 \\ \mathrm{C} & 2.894115 & 2.396041 & 0.131865 \\ \mathrm{H} & 5.835970 & 2.196444 & 0.177919 \\ \mathrm{H} & 6.975704 & 0.064022 & -0.391225 \\ \mathrm{H} & 5.671809 & -1.921590 & -1.073946 \\ \mathrm{H} & 3.209235 & -1.856571 & -1.217679 \\ \mathrm{H} & 3.114208 & 3.422745 & 0.391704 \\ \mathrm{C} & 0.327776 & 2.427132 & 0.037678 \\ \mathrm{C} & 0.116035 & 3.824424 & 0.155360 \\ \mathrm{C} & -1.174739 & 4.325899 & 0.164130 \\ \mathrm{H} & 0.967478 & 4.492402 & 0.211654 \\ \mathrm{C} & -1.995350 & 2.083956 & -0.053777 \\ \mathrm{C} & -2.267073 & 3.439856 & 0.040300 \\ \mathrm{H} & -1.347936 & 5.394666 & 0.243018 \\ \mathrm{H} & -3.290110 & 3.792985 & 0.008541 \\ \mathrm{C} & -3.074225 & 1.092031 & -0.231820 \\ \mathrm{C} & -5.263847 & 0.584090 & -0.522929 \\ \mathrm{C} & -4.890914 & -0.777612 & -0.668274 \\ \mathrm{H} & -6.305868 & 0.890551 & -0.586290 \\ \mathrm{H} & -5.615731 & -1.560699 & -0.866420 \\ \mathrm{~N} & 1.727512 & 0.464906 & -0.390901 \\ \mathrm{~N} & -0.732711 & 1.577003 & -0.029175 \\ \mathrm{~N} & -4.353222 & 1.516262 & -0.309075 \\ \mathrm{~N} & -2.696042 & -0.196483 & -0.328836 \\ \mathrm{~N} & -3.623086 & -1.140832 & -0.559789\end{array}$

\section{$\left[\mathrm{ML}_{2}\left(\mathrm{H}_{2} \mathrm{O}\right)_{2}\right]^{1+}$}

$\begin{array}{lrrr}\mathrm{M}=\mathrm{Eu} & & & \\ \mathrm{C} & 3.555710 & 0.576405 & -1.139353 \\ \mathrm{C} & 4.731267 & 0.165789 & -1.764889 \\ \mathrm{C} & 4.701627 & -1.028779 & -2.501471 \\ \mathrm{C} & 3.513369 & -1.737962 & -2.587791 \\ \mathrm{C} & 2.354883 & -1.246688 & -1.938655 \\ \mathrm{~N} & 2.391456 & -0.102141 & -1.219521 \\ \mathrm{H} & 5.596424 & -1.389019 & -2.999576 \\ \mathrm{H} & 5.628588 & 0.763277 & -1.673727 \\ \mathrm{H} & 3.464203 & -2.661345 & -3.151633 \\ \mathrm{C} & 3.547459 & 1.822405 & -0.335555\end{array}$




\begin{tabular}{|c|c|c|c|}
\hline $\mathrm{C}$ & 4.627845 & 3.672864 & 0.411910 \\
\hline & 3.461435 & 4.017328 & 1.126524 \\
\hline $\mathrm{H}$ & 5.515857 & 4.300401 & 0.444344 \\
\hline & 3.393903 & 4.908979 & 1.741299 \\
\hline$N$ & 2.419117 & 2.129417 & 0.329776 \\
\hline$\sqrt{ }$ & 2.388689 & 3.238161 & 1.078716 \\
\hline $\mathbf{N}$ & 4.674049 & 2.568937 & -0.312823 \\
\hline & 1.073807 & -1.931743 & -2.040574 \\
\hline $\mathrm{C}$ & 0.777985 & -3.074389 & -2.814015 \\
\hline Н & 1.461800 & -3.650846 & -3.422074 \\
\hline $\mathrm{N}$ & -0.030899 & -1.452802 & -1.378999 \\
\hline $\mathrm{C}$ & -2.665269 & -0.529259 & 1.733556 \\
\hline $\mathrm{C}$ & -0.882281 & -1.783426 & 2.560427 \\
\hline $\mathrm{C}$ & -3.574043 & -1.312325 & 2.485230 \\
\hline $\mathrm{C}$ & -1.714711 & -2.591501 & 3.329674 \\
\hline $\mathrm{C}$ & -3.097235 & -2.345808 & 3.277271 \\
\hline $\mathrm{H}$ & -4.634041 & -1.093419 & 2.443193 \\
\hline $\mathrm{H}$ & -1.291189 & -3.374417 & 3.944759 \\
\hline $\mathrm{H}$ & -3.782963 & -2.953823 & 3.859252 \\
\hline $\mathrm{C}$ & 0.588934 & -1.967559 & 2.598728 \\
\hline $\mathrm{C}$ & 2.412727 & -3.016547 & 3.435736 \\
\hline $\mathrm{C}$ & 3.214213 & -2.152164 & 2.663294 \\
\hline $\mathrm{H}$ & 2.854689 & -3.779646 & 4.072982 \\
\hline $\mathrm{H}$ & 4.298673 & -2.196509 & 2.679939 \\
\hline $\mathrm{C}$ & -4.406974 & 1.033415 & 0.678042 \\
\hline $\mathrm{H}$ & -5.324421 & 0.597420 & 1.048935 \\
\hline $\mathrm{C}$ & -3.099144 & 0.589007 & 0.909659 \\
\hline $\mathrm{N}$ & -1.337738 & -0.786600 & 1.771855 \\
\hline $\mathrm{N}$ & 1.333809 & -1.152112 & 1.826908 \\
\hline $\mathrm{N}$ & 2.667236 & -1.240476 & 1.865149 \\
\hline $\mathrm{N}$ & 1.093267 & -2.922125 & 3.408005 \\
\hline $\mathrm{N}$ & -2.154814 & 1.377102 & 0.267265 \\
\hline $\mathrm{C}$ & -2.879058 & 2.372839 & -0.355828 \\
\hline $\mathrm{C}$ & -4.288977 & 2.184382 & -0.149512 \\
\hline $\mathrm{C}$ & -5.219228 & 3.084927 & -0.715299 \\
\hline $\mathrm{C}$ & -4.745271 & 4.161643 & -1.458394 \\
\hline $\mathrm{C}$ & -2.415705 & 3.491711 & -1.082912 \\
\hline $\mathrm{C}$ & -3.353963 & 4.368753 & -1.629558 \\
\hline $\mathrm{H}$ & -6.286341 & 2.944694 & -0.568898 \\
\hline $\mathrm{H}$ & -5.443756 & 4.865774 & -1.899503 \\
\hline $\mathrm{H}$ & -3.013171 & 5.239063 & -2.182412 \\
\hline $\mathrm{H}$ & -1.355298 & 3.719446 & -1.166390 \\
\hline $\mathrm{C}$ & -1.078459 & -2.282074 & -1.763834 \\
\hline $\mathrm{C}$ & -0.610738 & -3.313353 & -2.643842 \\
\hline $\mathrm{C}$ & -2.437451 & -2.198128 & -1.432602 \\
\hline $\mathrm{C}$ & -1.504555 & -4.277150 & -3.160530 \\
\hline
\end{tabular}




$\begin{array}{lccc}\mathrm{C} & -3.311022 & -3.156124 & -1.963696 \\ \mathrm{C} & -2.852381 & -4.188956 & -2.810848 \\ \mathrm{H} & -1.154128 & -5.066888 & -3.818590 \\ \mathrm{H} & -3.561097 & -4.913849 & -3.198774 \\ \mathrm{H} & -4.368429 & -3.100194 & -1.723663 \\ \mathrm{H} & -2.819973 & -1.402409 & -0.804441 \\ \mathrm{O} & 0.108123 & 2.134835 & 2.135280 \\ \mathrm{H} & 0.744582 & 2.873683 & 2.041127 \\ \mathrm{O} & -0.165513 & 1.627685 & -2.184318 \\ \mathrm{H} & -0.030922 & 1.006413 & -2.915917 \\ \mathrm{H} & -0.779567 & 2.504599 & 2.254344 \\ \mathrm{H} & -1.038553 & 2.036405 & -2.327027 \\ \mathrm{EU} & 0.186131 & 0.534529 & 0.138652\end{array}$

$\mathrm{M}=\mathrm{Gd}$

$\begin{array}{lrrr}\mathrm{C} & 3.481507 & 0.658925 & -1.070305 \\ \mathrm{C} & 4.661930 & 0.297210 & -1.707956 \\ \mathrm{C} & 4.667469 & -0.903327 & -2.444535 \\ \mathrm{C} & 3.508567 & -1.655372 & -2.521237 \\ \mathrm{C} & 2.331389 & -1.207846 & -1.865480 \\ \mathrm{~N} & 2.341161 & -0.064323 & -1.139001 \\ \mathrm{H} & 5.569863 & -1.228971 & -2.952670 \\ \mathrm{H} & 5.537704 & 0.927176 & -1.625829 \\ \mathrm{H} & 3.483872 & -2.576023 & -3.091449 \\ \mathrm{C} & 3.421076 & 1.882824 & -0.247369 \\ \mathrm{C} & 4.400437 & 3.768118 & 0.548870 \\ \mathrm{C} & 3.224809 & 4.020987 & 1.290527 \\ \mathrm{H} & 5.249932 & 4.446354 & 0.591281 \\ \mathrm{H} & 3.117061 & 4.882958 & 1.940792 \\ \mathrm{~N} & 2.280181 & 2.110318 & 0.432267 \\ \mathrm{~N} & 2.197640 & 3.186233 & 1.225273 \\ \mathrm{~N} & 4.503599 & 2.691229 & -0.208472 \\ \mathrm{C} & 1.072047 & -1.907628 & -1.964383 \\ \mathrm{C} & 0.792576 & -3.090527 & -2.651764 \\ \mathrm{H} & 1.491074 & -3.713886 & -3.193214 \\ \mathrm{~N} & -0.071182 & -1.350701 & -1.385647 \\ \mathrm{C} & -2.667747 & -0.533139 & 1.598053 \\ \mathrm{C} & -0.938132 & -1.908421 & 2.355621 \\ \mathrm{C} & -3.612185 & -1.331715 & 2.286063 \\ \mathrm{C} & -1.808142 & -2.735016 & 3.055937 \\ \mathrm{C} & -3.181598 & -2.434380 & 3.006781 \\ \mathrm{H} & -4.662987 & -1.071492 & 2.247155 \\ \mathrm{H} & -1.421044 & -3.574641 & 3.618117 \\ \mathrm{H} & -3.895641 & -3.057178 & 3.536588 \\ \mathrm{C} & 0.523733 & -2.129585 & 2.396044\end{array}$




$\begin{array}{lrrr}\mathrm{C} & 2.322174 & -3.264739 & 3.167779 \\ \mathrm{C} & 3.145060 & -2.348926 & 2.479680 \\ \mathrm{H} & 2.746620 & -4.083353 & 3.745048 \\ \mathrm{H} & 4.228526 & -2.406017 & 2.510277 \\ \mathrm{C} & -4.298314 & 1.184189 & 0.606455 \\ \mathrm{H} & -5.249090 & 0.782997 & 0.929467 \\ \mathrm{C} & -3.031875 & 0.651970 & 0.845091 \\ \mathrm{~N} & -1.350582 & -0.843551 & 1.631761 \\ \mathrm{~N} & 1.289668 & -1.267119 & 1.698315 \\ \mathrm{~N} & 2.621597 & -1.370855 & 1.749008 \\ \mathrm{~N} & 1.004444 & -3.150922 & 3.132437 \\ \mathrm{~N} & -2.019162 & 1.423790 & 0.273329 \\ \mathrm{C} & -2.668369 & 2.489897 & -0.316718 \\ \mathrm{C} & -4.090367 & 2.369843 & -0.153992 \\ \mathrm{C} & -4.954664 & 3.350526 & -0.691630 \\ \mathrm{C} & -4.403928 & 4.432448 & -1.368040 \\ \mathrm{C} & -2.124495 & 3.617078 & -0.974055 \\ \mathrm{C} & -2.998417 & 4.569158 & -1.496919 \\ \mathrm{H} & -6.030855 & 3.264369 & -0.573521 \\ \mathrm{H} & -5.050538 & 5.196213 & -1.788394 \\ \mathrm{H} & -2.596732 & 5.445598 & -1.996592 \\ \mathrm{H} & -1.051855 & 3.793363 & -1.017354 \\ \mathrm{C} & -1.104814 & -2.196901 & -1.751982 \\ \mathrm{C} & -0.606682 & -3.299504 & -2.524780 \\ \mathrm{C} & -2.488516 & -2.073355 & -1.509874 \\ \mathrm{C} & -1.489847 & -4.290700 & -3.016613 \\ \mathrm{C} & -3.337577 & -3.053626 & -2.010055 \\ \mathrm{C} & -2.845027 & -4.162136 & -2.750227 \\ \mathrm{H} & -1.115133 & -5.126643 & -3.600010 \\ \mathrm{H} & -3.545068 & -4.903980 & -3.122160 \\ \mathrm{H} & -4.407322 & -2.966945 & -1.843654 \\ \mathrm{H} & -2.895371 & -1.221005 & -0.978697 \\ \mathrm{O} & 0.122203 & 1.793765 & 2.305460 \\ \mathrm{H} & 0.687317 & 2.593098 & 2.236151 \\ \mathrm{O} & -0.058801 & 1.618498 & -2.075913 \\ \mathrm{H} & -0.059467 & 0.902151 & -2.732600 \\ \mathrm{H} & -0.788223 & 2.090080 & 2.460220 \\ \mathrm{H} & -0.874806 & 2.132585 & -2.223602 \\ \mathrm{GD} & 0.187983 & 0.469194 & 0.150460\end{array}$

$\mathrm{M}=\mathrm{Am}$

$\begin{array}{llll}\text { C } & 3.517829 & 0.567652 & -1.099740\end{array}$

$\begin{array}{llll}\text { C } & 4.703487 & 0.154875 & -1.696562\end{array}$

$\begin{array}{llll}\text { C } & 4.700245 & -1.072557 & -2.385508\end{array}$

$\begin{array}{llll}\text { C } & 3.526297 & -1.800888 & -2.461282\end{array}$ 


\begin{tabular}{|c|c|c|c|}
\hline $\mathrm{C}$ & 2.346732 & -1.303932 & -1.849212 \\
\hline & 2.364691 & -0.136058 & -1.162017 \\
\hline H & 5.606165 & -1.436153 & -2.860381 \\
\hline $\mathrm{H}$ & 5.589784 & 0.770718 & -1.622767 \\
\hline $\mathrm{H}$ & 3.492670 & -2.740701 & -2.998741 \\
\hline & 3.472537 & 1.835751 & -0.343876 \\
\hline 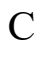 & 4.495471 & 3.731748 & 0.370443 \\
\hline & 3.305022 & 4.073422 & 1.048933 \\
\hline $\mathrm{H}$ & 5.368814 & 4.379469 & 0.403096 \\
\hline $\mathrm{H}$ & 3.205720 & 4.979814 & 1.637133 \\
\hline $\mathbf{N}$ & 2.320027 & 2.143387 & 0.280914 \\
\hline$N$ & 2.251020 & 3.272224 & 0.998816 \\
\hline $\mathrm{N}$ & 4.582815 & 2.606652 & -0.315318 \\
\hline $\mathrm{C}$ & 1.076520 & -1.982603 & -1.955202 \\
\hline$C$ & 0.786696 & -3.182269 & -2.607082 \\
\hline $\mathrm{H}$ & 1.482953 & -3.841382 & -3.107410 \\
\hline $\mathrm{N}$ & -0.066503 & -1.385298 & -1.424534 \\
\hline 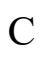 & -2.653651 & -0.670733 & 1.656213 \\
\hline $\mathrm{C}$ & -0.850149 & -1.949562 & 2.404488 \\
\hline $\mathrm{C}$ & -3.550168 & -1.513999 & 2.353600 \\
\hline $\mathrm{C}$ & -1.671239 & -2.817057 & 3.115130 \\
\hline $\mathrm{C}$ & -3.058539 & -2.591153 & 3.073298 \\
\hline $\mathrm{H}$ & -4.613151 & -1.307995 & 2.322714 \\
\hline $\mathrm{H}$ & -1.237107 & -3.630625 & 3.681023 \\
\hline $\mathrm{H}$ & -3.735335 & -3.248633 & 3.609842 \\
\hline $\mathrm{C}$ & 0.621788 & -2.090691 & 2.452359 \\
\hline $\mathrm{C}$ & 2.471748 & -3.128172 & 3.240850 \\
\hline $\mathrm{C}$ & 3.250164 & -2.162345 & 2.569504 \\
\hline $\mathrm{H}$ & 2.934648 & -3.925578 & 3.818251 \\
\hline $\mathrm{H}$ & 4.334482 & -2.157207 & 2.615778 \\
\hline $\mathrm{C}$ & -4.381015 & 0.975289 & 0.705097 \\
\hline $\mathrm{H}$ & -5.306532 & 0.538782 & 1.054390 \\
\hline , & -3.088802 & 0.495117 & 0.911189 \\
\hline $\mathrm{N}$ & -1.322223 & -0.913871 & 1.674608 \\
\hline $\mathrm{N}$ & 1.346070 & -1.183865 & 1.767719 \\
\hline $\mathrm{N}$ & 2.682220 & -1.213278 & 1.835526 \\
\hline $\mathrm{N}$ & 1.150579 & -3.089323 & 3.188516 \\
\hline $\mathrm{N}$ & -2.127554 & 1.304165 & 0.310285 \\
\hline $\mathrm{C}$ & -2.831364 & 2.342531 & -0.265545 \\
\hline $\mathrm{C}$ & -4.241259 & 2.167686 & -0.062197 \\
\hline , & -5.156700 & 3.112182 & -0.578546 \\
\hline $\mathrm{C}$ & -4.666209 & 4.211421 & -1.273735 \\
\hline $\mathrm{C}$ & -2.348402 & 3.481940 & -0.946642 \\
\hline $\mathrm{C}$ & -3.271431 & 4.399084 & -1.446250 \\
\hline $\mathrm{H}$ & -6.225238 & 2.985050 & -0.431584 \\
\hline $\mathrm{H}$ & -5.353159 & 4.948216 & -1.678003 \\
\hline
\end{tabular}




$\begin{array}{lccc}\mathrm{H} & -2.917759 & 5.285106 & -1.964747 \\ \mathrm{H} & -1.283232 & 3.687575 & -1.034009 \\ \mathrm{C} & -1.111789 & -2.220028 & -1.783047 \\ \mathrm{C} & -0.620285 & -3.358180 & -2.505077 \\ \mathrm{C} & -2.495974 & -2.059577 & -1.571859 \\ \mathrm{C} & -1.513459 & -4.348522 & -2.978270 \\ \mathrm{C} & -3.355157 & -3.040993 & -2.052763 \\ \mathrm{C} & -2.870866 & -4.183866 & -2.743639 \\ \mathrm{H} & -1.144690 & -5.213250 & -3.522046 \\ \mathrm{H} & -3.578181 & -4.925277 & -3.102292 \\ \mathrm{H} & -4.425557 & -2.928472 & -1.908298 \\ \mathrm{H} & -2.894136 & -1.184641 & -1.070271 \\ \mathrm{O} & 0.068352 & 2.091779 & 2.099986 \\ \mathrm{H} & 0.676441 & 2.853104 & 1.978023 \\ \mathrm{O} & -0.310113 & 1.509645 & -2.214705 \\ \mathrm{H} & -0.364582 & 0.729073 & -2.791601 \\ \mathrm{H} & -0.834690 & 2.429896 & 2.202774 \\ \mathrm{H} & -1.141122 & 2.004971 & -2.333787 \\ \mathrm{AM} & 0.155794 & 0.482886 & 0.107038\end{array}$

$\mathrm{M}=\mathrm{Cm}$

$\begin{array}{lrrr}\mathrm{C} & 3.523055 & 0.622045 & -1.043775 \\ \mathrm{C} & 4.710675 & 0.260580 & -1.668993 \\ \mathrm{C} & 4.719178 & -0.929436 & -2.421616 \\ \mathrm{C} & 3.557654 & -1.674718 & -2.522420 \\ \mathrm{C} & 2.374729 & -1.230996 & -1.875141 \\ \mathrm{~N} & 2.381388 & -0.095327 & -1.137324 \\ \mathrm{H} & 5.626339 & -1.253365 & -2.922262 \\ \mathrm{H} & 5.589357 & 0.883407 & -1.566980 \\ \mathrm{H} & 3.537073 & -2.588066 & -3.104290 \\ \mathrm{C} & 3.463292 & 1.838083 & -0.206577 \\ \mathrm{C} & 4.456925 & 3.702900 & 0.621345 \\ \mathrm{C} & 3.275328 & 3.964523 & 1.349735 \\ \mathrm{H} & 5.315001 & 4.368897 & 0.681632 \\ \mathrm{H} & 3.169979 & 4.822553 & 2.005637 \\ \mathrm{~N} & 2.318031 & 2.073485 & 0.462975 \\ \mathrm{~N} & 2.238021 & 3.144700 & 1.263260 \\ \mathrm{~N} & 4.555316 & 2.632797 & -0.146225 \\ \mathrm{C} & 1.117554 & -1.934882 & -1.993804 \\ \mathrm{C} & 0.856198 & -3.117391 & -2.688534 \\ \mathrm{H} & 1.565439 & -3.732633 & -3.225185 \\ \mathrm{~N} & -0.038266 & -1.395269 & -1.424772 \\ \mathrm{CM} & 0.172714 & 0.439514 & 0.145145 \\ \mathrm{C} & -2.746206 & -0.537777 & 1.561931 \\ \mathrm{C} & -1.055427 & -1.941265 & 2.356916\end{array}$




$\begin{array}{lrrr}\mathrm{C} & -3.715783 & -1.313022 & 2.241886 \\ \mathrm{C} & -1.952473 & -2.745211 & 3.049494 \\ \mathrm{C} & -3.318563 & -2.417739 & 2.977588 \\ \mathrm{H} & -4.760634 & -1.033179 & 2.185194 \\ \mathrm{H} & -1.591687 & -3.589312 & 3.622142 \\ \mathrm{H} & -4.052871 & -3.021907 & 3.501139 \\ \mathrm{C} & 0.399974 & -2.201655 & 2.419183 \\ \mathrm{C} & 2.152665 & -3.396172 & 3.206970 \\ \mathrm{C} & 3.012532 & -2.506794 & 2.529569 \\ \mathrm{H} & 2.544299 & -4.228846 & 3.787339 \\ \mathrm{H} & 4.093019 & -2.601207 & 2.569489 \\ \mathrm{C} & -4.345081 & 1.184224 & 0.533863 \\ \mathrm{H} & -5.303167 & 0.792622 & 0.846658 \\ \mathrm{C} & -3.085366 & 0.645327 & 0.793701 \\ \mathrm{~N} & -1.435726 & -0.872952 & 1.620208 \\ \mathrm{~N} & 1.202070 & -1.360644 & 1.737070 \\ \mathrm{~N} & 2.530052 & -1.508007 & 1.800155 \\ \mathrm{~N} & 0.839726 & -3.240140 & 3.157984 \\ \mathrm{~N} & -2.062285 & 1.407680 & 0.229958 \\ \mathrm{C} & -2.695712 & 2.472997 & -0.376079 \\ \mathrm{C} & -4.119922 & 2.363763 & -0.230944 \\ \mathrm{C} & -4.970472 & 3.346855 & -0.785898 \\ \mathrm{C} & -4.403186 & 4.420684 & -1.461098 \\ \mathrm{C} & -2.135398 & 3.591055 & -1.034437 \\ \mathrm{C} & -2.995003 & 4.546245 & -1.573170 \\ \mathrm{H} & -0.825523 & 2.179645 & 2.450032 \\ \mathrm{H} & -6.048706 & 3.268542 & -0.681789 \\ \mathrm{H} & -5.038835 & 5.186586 & -1.894264 \\ \mathrm{H} & -2.580676 & 5.416004 & -2.074168 \\ \mathrm{H} & -1.060253 & 3.754751 & -1.069100 \\ \mathrm{C} & -1.058704 & -2.251362 & -1.800617 \\ \mathrm{C} & -0.542032 & -3.344568 & -2.573025 \\ \mathrm{C} & -2.444732 & -2.145324 & -1.565369 \\ \mathrm{C} & -1.409502 & -4.345683 & -3.071428 \\ \mathrm{C} & -3.278515 & -3.135941 & -2.070324 \\ \mathrm{C} & -2.767402 & -4.235858 & -2.810597 \\ \mathrm{H} & -1.021386 & -5.175409 & -3.654875 \\ \mathrm{H} & -3.455691 & -4.986277 & -3.187270 \\ & -4.349978 & -3.064220 & -1.908220 \\ \mathrm{H} & -2.863678 & -1.299016 & -1.032668 \\ \mathrm{H} & -0.075091 & 1.838648 & 2.336725 \\ \mathrm{H} & 2.609387 & 2.255553 \\ \mathrm{H} & -2.082822 & -2.307850\end{array}$




\begin{tabular}{|c|c|c|c|}
\hline \multicolumn{4}{|c|}{$\mathrm{M}=\mathrm{Eu}$} \\
\hline $\mathrm{C}$ & 1.383249 & -2.318320 & 1.839335 \\
\hline $\mathrm{C}$ & 1.048118 & -3.531128 & 2.523266 \\
\hline $\mathrm{C}$ & 1.973522 & -4.130535 & 3.402605 \\
\hline $\mathrm{C}$ & 3.213599 & -3.515096 & 3.587134 \\
\hline $\mathrm{C}$ & 3.536088 & -2.315819 & 2.913596 \\
\hline $\mathrm{C}$ & 2.628960 & -1.705568 & 2.039471 \\
\hline $\mathrm{C}$ & -0.659159 & -2.850171 & 1.206237 \\
\hline $\mathrm{C}$ & -0.274412 & -3.858203 & 2.104373 \\
\hline $\mathrm{H}$ & 1.729918 & -5.048358 & 3.929474 \\
\hline $\mathrm{H}$ & 3.940941 & -3.957199 & 4.260704 \\
\hline $\mathrm{H}$ & 4.504861 & -1.856817 & \\
\hline $\mathrm{H}$ & 2.888798 & -0.772772 & 1.5 \\
\hline $\mathrm{H}$ & -0.856648 & & \\
\hline $\mathrm{C}$ & -1.912554 & -2.721522 & $0.4^{\prime}$ \\
\hline $\mathrm{C}$ & -2.982509 & -3.636720 & \\
\hline $\mathrm{C}$ & -4.143463 & -3.4 & -0 . \\
\hline $\mathrm{H}$ & -2.890619 & -4.471802 & 1.303127 \\
\hline $\mathrm{C}$ & -3.147132 & -1.5 & -1.0 \\
\hline $\mathrm{C}$ & -4.239300 & -2.363762 & -1.001957 \\
\hline $\mathrm{H}$ & -4.971816 & -4.148630 & -0.018059 \\
\hline $\mathrm{H}$ & -5.121987 & -2.182827 & 1607 \\
\hline $\mathrm{C}$ & & & \\
\hline $\mathrm{C}$ & -4.201059 & 0.953444 & -3.5 \\
\hline $\mathrm{C}$ & -3.044352 & 1.759189 & -3.5 \\
\hline $\mathrm{H}$ & -5.072612 & 193 & -4.1 \\
\hline $\mathrm{H}$ & -2.969108 & 2.627054 & -4.246488 \\
\hline $\mathrm{N}$ & 0.334127 & -1.907630 & 1792 \\
\hline $\mathrm{N}$ & -2.015155 & -1.672143 & 1357 \\
\hline $\mathrm{N}$ & -4.261024 & -0.102542 & -2.747229 \\
\hline $\mathrm{N}$ & -2.047531 & 0.422613 & -2.035372 \\
\hline $\mathrm{N}$ & & & \\
\hline $\mathrm{C}$ & -1.383236 & 2.318358 & 1.839262 \\
\hline $\mathrm{C}$ & -1.048115 & 3.531199 & 2.523138 \\
\hline $\mathrm{C}$ & -1.973511 & 4.130623 & 3.402471 \\
\hline $\mathrm{C}$ & -3.213575 & 3.515170 & 3.587049 \\
\hline $\mathrm{C}$ & -3.536054 & 2.315860 & 2.913565 \\
\hline $\mathrm{C}$ & -2.628932 & 1.705591 & 2.039447 \\
\hline $\mathrm{C}$ & 0.659152 & 2.850216 & 1.206109 \\
\hline $\mathrm{C}$ & 0.274400 & 3.858283 & 2.104203 \\
\hline $\mathrm{H}$ & -1.729915 & 5.048473 & 3.929298 \\
\hline $\mathrm{H}$ & -3.940912 & 3.957287 & 4.260615 \\
\hline $\mathrm{H}$ & -4.504815 & 1.856847 & 3.085170 \\
\hline
\end{tabular}




$\begin{array}{cccc}\mathrm{H} & -2.888762 & 0.772769 & 1.545379 \\ \mathrm{H} & 0.856625 & 4.714799 & 2.416011 \\ \mathrm{C} & 1.912538 & 2.721559 & 0.475184 \\ \mathrm{C} & 2.982477 & 3.636784 & 0.618899 \\ \mathrm{C} & 4.143423 & 3.454251 & -0.119354 \\ \mathrm{H} & 2.890583 & 4.471893 & 1.302895 \\ \mathrm{C} & 3.147115 & 1.505641 & -1.088941 \\ \mathrm{C} & 4.239268 & 2.363780 & -1.002121 \\ \mathrm{H} & 4.971765 & 4.148704 & -0.018309 \\ \mathrm{H} & 5.121948 & 2.182837 & -1.601777 \\ \mathrm{C} & 3.160340 & 0.337072 & -2.005516 \\ \mathrm{C} & 4.201047 & -0.953536 & -3.544900 \\ \mathrm{C} & 3.044355 & -1.759307 & -3.598870 \\ \mathrm{H} & 5.072593 & -1.177294 & -4.156401 \\ \mathrm{H} & 2.969117 & -2.627201 & -4.246416 \\ \mathrm{~N} & -0.334122 & 1.907653 & 1.031716 \\ \mathrm{~N} & 2.015145 & 1.672147 & -0.371456 \\ \mathrm{~N} & 4.261006 & 0.102486 & -2.747298 \\ \mathrm{~N} & 2.047536 & -0.422682 & -2.035380 \\ \mathrm{~N} & 1.983699 & -1.484652 & -2.844642 \\ \mathrm{EU} & 0.000008 & -0.000017 & -0.439714\end{array}$

$\begin{array}{lrcc}\mathrm{M}=\mathrm{Gd} & & & \\ \mathrm{C} & 1.430092 & 2.102834 & -1.884736 \\ \mathrm{C} & 1.162233 & 3.347882 & -2.542203 \\ \mathrm{C} & 2.098125 & 3.882421 & -3.459480 \\ \mathrm{C} & 3.266701 & 3.174389 & -3.703840 \\ \mathrm{C} & 3.521549 & 1.937213 & -3.053398 \\ \mathrm{C} & 2.617402 & 1.392869 & -2.147422 \\ \mathrm{C} & -0.539411 & 2.810036 & -1.164793 \\ \mathrm{C} & -0.108451 & 3.781442 & -2.067223 \\ \mathrm{H} & 1.904857 & 4.824255 & -3.964203 \\ \mathrm{H} & 3.998678 & 3.561724 & -4.405657 \\ \mathrm{H} & 4.440900 & 1.404821 & -3.277885 \\ \mathrm{H} & 2.824244 & 0.435382 & -1.675304 \\ \mathrm{H} & -0.632219 & 4.683354 & -2.353612 \\ \mathrm{C} & -1.756697 & 2.736880 & -0.394404 \\ \mathrm{C} & -2.790668 & 3.707007 & -0.445914 \\ \mathrm{C} & -3.924324 & 3.543330 & 0.332784 \\ \mathrm{H} & -2.685509 & 4.566615 & -1.097136 \\ \mathrm{C} & -2.988305 & 1.510607 & 1.179971 \\ \mathrm{C} & -4.038161 & 2.416905 & 1.175989 \\ \mathrm{H} & -4.722630 & 4.278167 & 0.297864 \\ \mathrm{H} & -4.904066 & 2.251298 & 1.804090 \\ \mathrm{C} & -2.990450 & 0.309926 & 2.041880\end{array}$




$\begin{array}{lrrr}\mathrm{C} & -3.961676 & -1.050825 & 3.563108 \\ \mathrm{C} & -2.805750 & -1.864021 & 3.525864 \\ \mathrm{H} & -4.804740 & -1.303209 & 4.202713 \\ \mathrm{H} & -2.706938 & -2.761760 & 4.127743 \\ \mathrm{~N} & 0.389630 & 1.775063 & -1.034255 \\ \mathrm{~N} & -1.879119 & 1.654959 & 0.415777 \\ \mathrm{~N} & -4.054672 & 0.043548 & 2.823354 \\ \mathrm{~N} & -1.881930 & -0.457796 & 1.986267 \\ \mathrm{~N} & -1.780442 & -1.557887 & 2.739561 \\ \mathrm{C} & -1.430070 & -2.102904 & -1.884678 \\ \mathrm{C} & -1.162196 & -3.347969 & -2.542108 \\ \mathrm{C} & -2.098083 & -3.882550 & -3.459367 \\ \mathrm{C} & -3.266668 & -3.174540 & -3.703747 \\ \mathrm{C} & -3.521532 & -1.937347 & -3.053342 \\ \mathrm{C} & -2.617391 & -1.392964 & -2.147383 \\ \mathrm{C} & 0.539433 & -2.810069 & -1.164700 \\ \mathrm{C} & 0.108500 & -3.781492 & -2.067124 \\ \mathrm{H} & -1.904800 & -4.824394 & -3.964064 \\ \mathrm{H} & -3.998639 & -3.561904 & -4.405553 \\ \mathrm{H} & -4.440890 & -1.404975 & -3.277843 \\ \mathrm{H} & -2.824247 & -0.435468 & -1.675291 \\ \mathrm{H} & 0.632282 & -4.683403 & -2.353492 \\ \mathrm{C} & 1.756709 & -2.736886 & -0.394298 \\ \mathrm{C} & 2.790686 & -3.707008 & -0.445768 \\ \mathrm{C} & 3.924332 & -3.543303 & 0.332938 \\ \mathrm{H} & 2.685539 & -4.566636 & -1.096967 \\ \mathrm{C} & 2.988295 & -1.510558 & 1.180053 \\ \mathrm{C} & 4.038154 & -2.416853 & 1.176110 \\ \mathrm{H} & 4.722643 & -4.278137 & 0.298049 \\ \mathrm{H} & 4.904051 & -2.251223 & 1.804216 \\ \mathrm{C} & 2.990424 & -0.309852 & 2.041925 \\ \mathrm{C} & 3.961625 & 1.050950 & 3.563123 \\ \mathrm{C} & 2.805696 & 1.864140 & 3.525841 \\ \mathrm{H} & 4.804679 & 1.303356 & 4.202733 \\ \mathrm{H} & 2.706872 & 2.761896 & 4.127693 \\ \mathrm{~N} & -0.389614 & -1.775097 & -1.034204 \\ \mathrm{~N} & 1.879117 & -1.654939 & 0.415851 \\ \mathrm{~N} & 4.054635 & -0.043445 & 2.823405 \\ \mathrm{~N} & 1.881901 & 0.457864 & 1.986275 \\ \mathrm{~N} & 1.780399 & 1.557978 & 2.739534 \\ \mathrm{GD} & -0.000002 & 0.000006 & 0.377641 \\ & & \end{array}$

$\mathrm{M}=\mathrm{Am}$

$\begin{array}{llll}\text { C } & 1.703255 & -2.059301 & 1.839145\end{array}$

$\begin{array}{llll}\text { C } & 1.557563 & -3.325939 & 2.492391\end{array}$ 


\begin{tabular}{|c|c|c|c|}
\hline $\mathrm{C}$ & 2.567665 & -3.798638 & 552 \\
\hline & 3.691383 & -3.009420 & 3.565528 \\
\hline $\mathrm{C}$ & 3.826652 & -1.751966 & 2.918668 \\
\hline $\mathrm{C}$ & 2.846650 & -1.267668 & 2.059337 \\
\hline $\mathrm{C}$ & -0.236360 & -2.903557 & 1.194396 \\
\hline C & 0.303484 & -3.849154 & 2.065095 \\
\hline $\mathrm{H}$ & 2.465017 & -4.756322 & 3.863861 \\
\hline H & 4.479238 & -3.348009 & 4.231054 \\
\hline $\mathrm{H}$ & 4.714117 & -1.155943 & 3.108584 \\
\hline $\mathrm{H}$ & 2.964070 & -0.293782 & 1.589417 \\
\hline H & -0.135766 & -4.792327 & 2.360271 \\
\hline $\mathrm{C}$ & -1.480247 & -2.929833 & 0.464682 \\
\hline $\mathrm{C}$ & -2.421497 & -3.986998 & 0.554224 \\
\hline $\mathrm{C}$ & -3.589176 & -3.932923 & -0.187456 \\
\hline $\mathrm{H}$ & -2.218268 & -4.828652 & 1.205454 \\
\hline $\mathrm{C}$ & -2.866463 & -1.830638 & -1.074959 \\
\hline $\mathrm{C}$ & -3.828660 & -2.828593 & -1.032232 \\
\hline $\mathrm{H}$ & -4.316661 & -4.735997 & -0.123077 \\
\hline $\mathrm{H}$ & -4.724098 & -2.746589 & -1.634714 \\
\hline $\mathrm{C}$ & -3.012659 & -0.646716 & -1.947338 \\
\hline $\mathrm{C}$ & -4.158484 & 0.588747 & -3.453375 \\
\hline $\mathrm{C}$ & -3.088341 & 1.512308 & -3.459480 \\
\hline $\mathrm{H}$ & -5.040592 & 0.747479 & -4.069905 \\
\hline $\mathrm{H}$ & -3.095940 & 2.406388 & -4.074505 \\
\hline $\mathrm{N}$ & 0.604706 & -1.802001 & 1.040986 \\
\hline $\mathrm{N}$ & -1.724890 & -1.867391 & -0.344514 \\
\hline $\mathrm{N}$ & -4.121090 & -0.498570 & -2.698574 \\
\hline $\mathrm{N}$ & -1.987395 & 0.227238 & -1.931395 \\
\hline $\mathrm{N}$ & -2.017501 & 1.321440 & -2.699462 \\
\hline $\mathrm{C}$ & -1.703241 & 2.059376 & 1.839137 \\
\hline $\mathrm{C}$ & -1.557531 & 3.326037 & 2.492336 \\
\hline $\mathrm{C}$ & -2.567612 & 3.798769 & 3.362503 \\
\hline $\mathrm{C}$ & -3.691327 & 3.009562 & 3.565532 \\
\hline $\mathrm{C}$ & -3.826615 & 1.752086 & 2.918718 \\
\hline $\mathrm{C}$ & -2.846634 & 1.267755 & 2.059382 \\
\hline $\mathrm{C}$ & 0.236363 & 2.903602 & 1.194316 \\
\hline $\mathrm{C}$ & -0.303459 & 3.849232 & 2.064994 \\
\hline $\mathrm{H}$ & -2.464949 & 4.756470 & 3.863777 \\
\hline $\mathrm{H}$ & -4.479166 & 3.348177 & 4.231064 \\
\hline $\mathrm{H}$ & -4.714078 & 1.156073 & 3.108674 \\
\hline $\mathrm{H}$ & -2.964069 & 0.293853 & 1.589497 \\
\hline $\mathrm{H}$ & 0.135800 & 4.792413 & 2.360129 \\
\hline $\mathrm{C}$ & 1.480243 & 2.929848 & 0.464586 \\
\hline 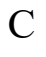 & 2.421493 & 3.987019 & 0.554075 \\
\hline $\mathrm{C}$ & 3.589169 & 3.932913 & -0.187606 \\
\hline $\mathrm{H}$ & 2.218266 & 4.828702 & 1.205269 \\
\hline
\end{tabular}




$\begin{array}{lccc}\mathrm{C} & 2.866458 & 1.830587 & -1.075013 \\ \mathrm{C} & 3.828654 & 2.828545 & -1.032332 \\ \mathrm{H} & 4.316652 & 4.735992 & -0.123266 \\ \mathrm{H} & 4.724092 & 2.746513 & -1.634809 \\ \mathrm{C} & 3.012657 & 0.646621 & -1.947332 \\ \mathrm{C} & 4.158485 & -0.588914 & -3.453307 \\ \mathrm{C} & 3.088343 & -1.512477 & -3.459367 \\ \mathrm{H} & 5.040594 & -0.747676 & -4.069829 \\ \mathrm{H} & 3.095943 & -2.406586 & -4.074350 \\ \mathrm{~N} & -0.604712 & 1.802045 & 1.040962 \\ \mathrm{~N} & 1.724885 & 1.867373 & -0.344569 \\ \mathrm{~N} & 4.121088 & 0.498441 & -2.698561 \\ \mathrm{~N} & 1.987395 & -0.227336 & -1.931343 \\ \mathrm{~N} & 2.017503 & -1.321574 & -2.699358 \\ \mathrm{AM} & -0.000015 & 0.000006 & -0.340870\end{array}$

$\mathrm{M}=\mathrm{Cm}$

$\begin{array}{llll}\text { CM } & -0.000199 & -0.000210 & -0.384606\end{array}$

$\begin{array}{llll}\text { C } & 1.337745 & -2.171860 & 1.909665\end{array}$

$\begin{array}{llll}\text { C } & 1.018301 & -3.398153 & 2.577716\end{array}$

$\begin{array}{llll}\text { C } & 1.934487 & -3.971371 & 3.490483\end{array}$

$\begin{array}{llll}\text { C } & 3.137517 & -3.318737 & 3.721075\end{array}$

$\begin{array}{llll}\text { C } & 3.444672 & -2.099448 & 3.060070\end{array}$

$\begin{array}{llll}\text { C } & 2.560162 & -1.518642 & 2.158074\end{array}$

$\begin{array}{llll}\text { C } & -0.669393 & -2.791061 & 1.210904\end{array}$

$\begin{array}{llll}\text { C } & -0.275488 & -3.774845 & 2.115810\end{array}$

$\begin{array}{llll}\mathrm{H} & 1.700308 & -4.899869 & 4.002423\end{array}$

H $\quad 3.856132 \quad-3.736033 \quad 4.419542$

$\mathrm{H} \quad 4.390080 \quad-1.609686 \quad 3.273099$

H $\quad 2.808609-0.575273 \quad 1.677542$

H $\quad-0.836752 \quad-4.649853 \quad 2.414124$

C $\quad-1.893783 \quad-2.675766 \quad 0.455142$

C $\quad-2.962119 \quad-3.605520 \quad 0.536125$

C $\quad-4.102622 \quad-3.408584 \quad-0.224491$

$\mathrm{H} \quad-2.878517 \quad-4.461063 \quad 1.195660$

C $\quad-3.106552 \quad-1.421809-1.111357$

C $\quad-4.189787 \quad-2.288010 \quad-1.077734$

H $\quad-4.926989-4.112556 \quad-0.166693$

H $\quad-5.060865 \quad-2.096787 \quad-1.691080$

$\begin{array}{llll}\text { C } & -3.086988 & -0.229995 & -1.986437\end{array}$

$\begin{array}{llll}\text { C } & -4.053867 & 1.143392 & -3.500085\end{array}$

C $\quad-2.873590 \quad 1.921241 \quad-3.499496$

$\mathrm{H} \quad-4.904165 \quad 1.414002 \quad-4.122442$

$\mathrm{H} \quad-2.761866 \quad 2.809000 \quad-4.113689$

$\begin{array}{llll}\mathrm{N} & 0.306064 & -1.802060 & 1.066615\end{array}$ 


$\begin{array}{lrrr}\mathrm{N} & -1.990399 & -1.600849 & -0.366143 \\ \mathrm{~N} & -4.161548 & 0.060470 & -2.745876 \\ \mathrm{~N} & -1.955810 & 0.503912 & -1.965797 \\ \mathrm{~N} & -1.840003 & 1.592285 & -2.735052 \\ \mathrm{C} & -1.336778 & 2.175341 & 1.906762 \\ \mathrm{C} & -1.016784 & 3.402596 & 2.572779 \\ \mathrm{C} & -1.932482 & 3.977455 & 3.485004 \\ \mathrm{C} & -3.135579 & 3.325470 & 3.717075 \\ \mathrm{C} & -3.443277 & 2.105224 & 3.058093 \\ \mathrm{C} & -2.559252 & 1.522799 & 2.156665 \\ \mathrm{C} & 0.670240 & 2.792971 & 1.206270 \\ \mathrm{C} & 0.276924 & 3.778251 & 2.109802 \\ \mathrm{H} & -1.697883 & 4.906693 & 3.995408 \\ \mathrm{H} & -3.853825 & 3.744026 & 4.415168 \\ \mathrm{H} & -4.388719 & 1.616018 & 3.272252 \\ \mathrm{H} & -2.808107 & 0.578740 & 1.677704 \\ \mathrm{H} & 0.838520 & 4.653578 & 2.406552 \\ \mathrm{C} & 1.894323 & 2.676181 & 0.450241 \\ \mathrm{C} & 2.962965 & 3.605736 & 0.529450 \\ \mathrm{C} & 4.103149 & 3.407303 & -0.231255 \\ \mathrm{H} & 2.879851 & 4.462295 & 1.187728 \\ \mathrm{C} & 3.106162 & 1.419506 & -1.114797 \\ \mathrm{C} & 4.189680 & 2.285416 & -1.082835 \\ \mathrm{H} & 4.927751 & 4.111108 & -0.174797 \\ \mathrm{H} & 5.060488 & 2.093006 & -1.696192 \\ \mathrm{C} & 3.085932 & 0.226398 & -1.988099 \\ \mathrm{C} & 4.051899 & -1.149559 & -3.499997 \\ \mathrm{C} & 2.871342 & -1.926981 & -3.497941 \\ \mathrm{H} & 4.901928 & -1.421390 & -4.122189 \\ \mathrm{H} & 2.759130 & -2.815602 & -4.110798 \\ \mathrm{~N} & -0.305512 & 1.803987 & 1.063888 \\ \mathrm{~N} & 1.990321 & 1.600006 & -0.369467 \\ \mathrm{~N} & 4.160176 & -0.065567 & -2.747412 \\ \mathrm{~N} & 1.954491 & -0.507063 & -1.966082 \\ \mathrm{~N} & 1.838080 & -1.596522 & -2.733707\end{array}$

\section{$\mathrm{L}=1 \mathrm{ai}$}

\section{$\left[\mathrm{ML}\left(\mathrm{H}_{2} \mathrm{O}\right)_{6}\right]^{2+}$}

$\mathrm{M}=\mathrm{Eu}$

$$
\begin{array}{llll}
\text { EU } & -1.102742 & -1.030110 & -0.011121 \\
\mathrm{~N} & -3.175365 & 0.501361 & 0.046607 \\
\mathrm{C} & -4.562089 & 0.268029 & 0.062049 \\
\mathrm{C} & -3.029581 & 1.840440 & -0.025904
\end{array}
$$




\begin{tabular}{|c|c|c|c|}
\hline $\mathrm{C}$ & -5.240988 & -0.939279 & 0.156712 \\
\hline & -5.280231 & 1.503359 & -0.017435 \\
\hline $\mathrm{C}$ & -4.294518 & 2.516506 & -0.071249 \\
\hline $\mathrm{C}$ & -1.701195 & 2.464422 & -0.044604 \\
\hline $\mathrm{C}$ & -6.656657 & -0.912532 & 0.157304 \\
\hline $\mathrm{H}$ & -4.707901 & -1.879972 & 0.244207 \\
\hline $\mathrm{C}$ & -6.691975 & 1.517944 & -0.017556 \\
\hline H & -4.466173 & 3.582846 & -0.133541 \\
\hline $\mathrm{C}$ & -1.551620 & 3.865117 & -0.080458 \\
\hline $\mathbf{N}$ & -0.633019 & 1.636462 & -0.019406 \\
\hline C & -7.369630 & 0.293273 & 0.068422 \\
\hline H & -7.205166 & -1.846464 & 0.231811 \\
\hline $\mathrm{H}$ & -7.243398 & 2.451174 & -0.080003 \\
\hline $\mathrm{C}$ & -0.272774 & 4.414164 & -0.084632 \\
\hline $\mathrm{H}$ & -2.421553 & 4.509865 & -0.100844 \\
\hline$C$ & 0.602183 & 2.178427 & -0.026909 \\
\hline $\mathrm{H}$ & -8.454334 & 0.274559 & 0.071379 \\
\hline $\mathrm{C}$ & 0.832145 & 3.556602 & -0.056027 \\
\hline $\mathrm{H}$ & -0.134794 & 5.490612 & -0.109525 \\
\hline $\mathrm{C}$ & 1.755689 & 1.234288 & -0.011364 \\
\hline $\mathrm{H}$ & 1.847660 & 3.930095 & -0.057829 \\
\hline $\mathrm{N}$ & 2.994929 & 1.751196 & 0.024734 \\
\hline $\mathrm{N}$ & 1.485001 & -0.073137 & -0.036367 \\
\hline $\mathrm{C}$ & 4.028191 & 0.916458 & 0.029281 \\
\hline $\mathrm{N}$ & 2.518953 & -0.934648 & -0.038959 \\
\hline $\mathrm{C}$ & 5.422677 & 1.516097 & 0.124885 \\
\hline $\mathrm{C}$ & 3.778035 & -0.500786 & -0.008027 \\
\hline $\mathrm{C}$ & 5.556465 & 2.706107 & -0.850287 \\
\hline $\mathrm{C}$ & 6.494497 & 0.452277 & -0.200935 \\
\hline $\mathrm{C}$ & 5.588342 & 2.036627 & 1.580097 \\
\hline $\mathrm{C}$ & 4.888316 & -1.547200 & -0.052089 \\
\hline $\mathrm{H}$ & 6.573523 & 3.103465 & -0.792023 \\
\hline $\mathrm{H}$ & 5.377068 & 2.398548 & -1.885396 \\
\hline $\mathrm{H}$ & 4.861235 & 3.510015 & -0.602605 \\
\hline $\mathrm{C}$ & 6.210078 & -0.909802 & 0.437025 \\
\hline $\mathrm{H}$ & 7.464261 & 0.823203 & 0.142749 \\
\hline $\mathrm{H}$ & 6.582316 & 0.345398 & -1.287231 \\
\hline $\mathrm{H}$ & 6.563755 & 2.520831 & 1.676630 \\
\hline $\mathrm{H}$ & 5.536679 & 1.232748 & 2.320044 \\
\hline $\mathrm{H}$ & 4.815768 & 2.772209 & 1.818044 \\
\hline $\mathrm{C}$ & 4.547772 & -2.754435 & 0.846587 \\
\hline $\mathrm{C}$ & 5.026300 & -2.032353 & -1.519344 \\
\hline $\mathrm{H}$ & 7.027871 & -1.601417 & 0.213918 \\
\hline $\mathrm{H}$ & 6.182318 & -0.814465 & 1.528197 \\
\hline $\mathrm{H}$ & 3.682794 & -3.312666 & 0.476791 \\
\hline $\mathrm{H}$ & 4.356547 & -2.445618 & 1.879690 \\
\hline
\end{tabular}




$\begin{array}{lrrr}\mathrm{H} & 5.396079 & -3.444043 & 0.862213 \\ \mathrm{H} & 5.817278 & -2.784738 & -1.582461 \\ \mathrm{H} & 4.096586 & -2.491724 & -1.870056 \\ \mathrm{H} & 5.278981 & -1.221415 & -2.206944 \\ \mathrm{O} & 0.629816 & -2.471626 & -1.558421 \\ \mathrm{H} & 0.582480 & -3.389422 & -1.864329 \\ \mathrm{H} & 1.518298 & -2.331233 & -1.172568 \\ \mathrm{O} & -2.493934 & -2.494152 & -1.722894 \\ \mathrm{H} & -2.421848 & -2.000677 & -2.557696 \\ \mathrm{H} & -3.282659 & -3.050016 & -1.792125 \\ \mathrm{O} & -0.928704 & -0.430815 & -2.664958 \\ \mathrm{H} & -0.130733 & -0.902680 & -2.958820 \\ \mathrm{H} & -1.011046 & 0.367132 & -3.207772 \\ \mathrm{O} & -1.334947 & -0.514527 & 2.609319 \\ \mathrm{H} & -0.538445 & -0.774211 & 3.099958 \\ \mathrm{H} & -1.708283 & 0.258132 & 3.059604 \\ \mathrm{O} & -2.443318 & -2.844282 & 1.444299 \\ \mathrm{H} & -2.849133 & -3.722871 & 1.455036 \\ \mathrm{H} & -2.585407 & -2.454737 & 2.322686 \\ \mathrm{O} & 0.600766 & -2.362244 & 1.646055 \\ \mathrm{H} & 1.519248 & -2.273537 & 1.330966 \\ \mathrm{H} & 0.505351 & -3.261985 & 1.991745\end{array}$

$\mathrm{M}=\mathrm{Gd}$

$\begin{array}{lrrr}\text { GD } & -1.039847 & -0.833962 & 0.113348 \\ \mathrm{O} & 0.458337 & -1.923808 & 1.932713 \\ \mathrm{H} & 1.407328 & -2.085544 & 1.812465 \\ \mathrm{O} & -1.592576 & -0.126767 & 2.489736 \\ \mathrm{H} & -1.005199 & -0.000555 & 3.251121 \\ \mathrm{O} & -2.496254 & -2.283774 & -1.353196 \\ \mathrm{H} & -2.269873 & -2.199513 & -2.293754 \\ \mathrm{O} & -2.198542 & -2.690861 & 1.479752 \\ \mathrm{H} & -2.604022 & -3.505380 & 1.143005 \\ \mathrm{O} & 0.381783 & -2.535484 & -1.055006 \\ \mathrm{H} & 0.295558 & -3.452118 & -1.352942 \\ \mathrm{O} & -0.926534 & -0.169224 & -2.376293 \\ \mathrm{H} & -0.163756 & -0.247019 & -2.969291 \\ \mathrm{H} & 0.090135 & -2.703466 & 2.377638 \\ \mathrm{H} & -2.712332 & -2.415069 & 2.256500 \\ \mathrm{H} & 1.329343 & -2.348298 & -0.842464 \\ \mathrm{H} & -3.452917 & -2.084387 & -1.295527 \\ \mathrm{H} & -1.438600 & 0.597288 & -2.680912 \\ \mathrm{H} & -2.292926 & 0.545023 & 2.537204 \\ \mathrm{C} & -4.398625 & 0.073487 & -0.052587 \\ \mathrm{C} & -5.171103 & 1.261557 & -0.271443\end{array}$




$\begin{array}{lrrr}\mathrm{C} & -6.573297 & 1.189181 & -0.438280 \\ \mathrm{C} & -7.191065 & -0.053236 & -0.380371 \\ \mathrm{C} & -6.434680 & -1.224588 & -0.131508 \\ \mathrm{C} & -5.050691 & -1.176632 & 0.040156 \\ \mathrm{C} & -2.990416 & 1.784031 & -0.054394 \\ \mathrm{C} & -4.248398 & 2.345285 & -0.254865 \\ \mathrm{H} & -7.157334 & 2.089352 & -0.603649 \\ \mathrm{H} & -8.265777 & -0.133131 & -0.505733 \\ \mathrm{H} & -6.949737 & -2.177105 & -0.052658 \\ \mathrm{H} & -4.524959 & -2.084368 & 0.325294 \\ \mathrm{H} & -4.484934 & 3.392326 & -0.385986 \\ \mathrm{C} & -1.702266 & 2.438584 & 0.009791 \\ \mathrm{C} & -1.551184 & 3.847813 & 0.012316 \\ \mathrm{C} & -0.283253 & 4.401818 & 0.064685 \\ \mathrm{H} & -2.429811 & 4.480777 & -0.019637 \\ \mathrm{C} & 0.624393 & 2.182728 & 0.080328 \\ \mathrm{C} & 0.841355 & 3.552618 & 0.092692 \\ \mathrm{H} & -0.154292 & 5.479676 & 0.075245 \\ \mathrm{H} & 1.852128 & 3.938676 & 0.112047 \\ \mathrm{C} & 1.752828 & 1.226799 & 0.032009 \\ \mathrm{C} & 4.008287 & 0.815346 & -0.018744 \\ \mathrm{C} & 3.700165 & -0.590347 & -0.154439 \\ \mathrm{~N} & -3.050053 & 0.385854 & 0.058937 \\ \mathrm{~N} & -0.614875 & 1.626647 & 0.060791 \\ \mathrm{~N} & 3.012147 & 1.689243 & 0.065429 \\ \mathrm{H} & 1.432945 & -0.068876 & -0.071731 \\ \mathrm{H} & 5.568682 & -2.835078 & -1.973357 \\ \mathrm{~N} & 2.427222 & -0.971582 & -0.174755 \\ \mathrm{C} & 5.428065 & 1.346523 & 0.078235 \\ \mathrm{C} & 6.440347 & 0.276084 & -0.386248 \\ \mathrm{H} & 6.474075 & 0.258974 & -1.480717 \\ \mathrm{H} & 7.438462 & 0.582202 & -0.060727 \\ \mathrm{C} & 6.132324 & -1.123482 & 0.150998 \\ \mathrm{C} & 4.764414 & -1.671566 & -0.319896 \\ \mathrm{H} & 6.162807 & -1.119582 & 1.246103 \\ \mathrm{H} & 6.909672 & -1.822764 & -0.170498 \\ \mathrm{C} & 5.581430 & 2.619127 & -0.783355 \\ \mathrm{H} & 4.931106 & 3.423117 & -0.435259 \\ \mathrm{H} & 6.616498 & 2.966290 & -0.723779 \\ \mathrm{H} & 5.356165 & 2.420531 & -1.835913 \\ \mathrm{H} & 6.662897 & 2.145673 & 1.675939 \\ \mathrm{H} & 5.53146 & 2.465113 & 1.901225 \\ \mathrm{H} & -2.445876 & -2.162554\end{array}$




$\begin{array}{llll}\mathrm{H} & 5.080536 & -1.208513 & -2.461250 \\ \mathrm{C} & 4.411904 & -2.924335 & 0.509538 \\ \mathrm{H} & 3.498908 & -3.412588 & 0.157578 \\ \mathrm{H} & 5.223041 & -3.652525 & 0.426482 \\ \mathrm{H} & 4.298798 & -2.682847 & 1.572165\end{array}$

$\mathrm{M}=\mathrm{Am}$

$\begin{array}{lccc}\text { AM } & -0.992285 & -0.771197 & 0.025729 \\ \text { N } & -2.957610 & 0.548028 & 0.051979 \\ \mathrm{C} & -4.314377 & 0.253135 & 0.026289 \\ \mathrm{C} & -2.879442 & 1.941299 & -0.040445 \\ \mathrm{C} & -4.973578 & -0.989036 & 0.137327 \\ \mathrm{C} & -5.078376 & 1.454922 & -0.127420 \\ \mathrm{C} & -4.137157 & 2.524953 & -0.154974 \\ \mathrm{C} & -1.577004 & 2.567235 & -0.019183 \\ \mathrm{C} & -6.367216 & -1.015916 & 0.053794 \\ \mathrm{H} & -4.437114 & -1.908010 & 0.361610 \\ \mathrm{C} & -6.487666 & 1.404564 & -0.210258 \\ \mathrm{H} & -4.365260 & 3.576908 & -0.258016 \\ \mathrm{C} & -1.401191 & 3.972123 & -0.025088 \\ \mathrm{~N} & -0.505843 & 1.731857 & 0.013717 \\ \mathrm{C} & -7.119319 & 0.168938 & -0.129309 \\ \mathrm{H} & -6.890008 & -1.962712 & 0.147803 \\ \mathrm{H} & -7.067487 & 2.314155 & -0.333229 \\ \mathrm{C} & -0.123352 & 4.503687 & 0.010884 \\ \mathrm{H} & -2.268858 & 4.620292 & -0.049308 \\ \mathrm{C} & 0.743734 & 2.266703 & 0.033763 \\ \mathrm{H} & -8.200755 & 0.106262 & -0.189896 \\ \mathrm{C} & 0.983652 & 3.633233 & 0.040934 \\ \mathrm{H} & 0.025931 & 5.578874 & 0.014159 \\ \mathrm{C} & 1.865252 & 1.300746 & 0.017279 \\ \mathrm{H} & 2.001139 & 4.000597 & 0.063801 \\ \mathrm{~N} & 3.126135 & 1.759327 & 0.068923 \\ \mathrm{~N} & 1.542470 & 0.005625 & -0.066523 \\ \mathrm{C} & 4.120364 & 0.880544 & 0.025534 \\ \mathrm{~N} & 2.535528 & -0.901491 & -0.136830 \\ \mathrm{C} & 5.539999 & 1.407556 & 0.148772 \\ \mathrm{C} & 3.809486 & -0.525133 & -0.094119 \\ \mathrm{C} & 5.719987 & 2.667394 & -0.725971 \\ \mathrm{C} & 6.557974 & 0.326445 & -0.277099 \\ \mathrm{C} & 5.740336 & 1.799017 & 1.640924 \\ \mathrm{C} & 4.872444 & -1.613384 & -0.219704 \\ \mathrm{H} & 6.755088 & 3.010699 & -0.647231 \\ \mathrm{H} & 5.517947 & 2.455693 & -1.780707 \\ \mathrm{H} & 5.065907 & 3.479210 & -0.404019\end{array}$




$\begin{array}{lrrr}\mathrm{C} & 6.232069 & -1.063995 & 0.273245 \\ \mathrm{H} & 7.549866 & 0.633185 & 0.066422 \\ \mathrm{H} & 6.616263 & 0.293303 & -1.370217 \\ \mathrm{H} & 6.740428 & 2.222730 & 1.765029 \\ \mathrm{H} & 5.651572 & 0.942593 & 2.315409 \\ \mathrm{H} & 5.009210 & 2.552677 & 1.944202 \\ \mathrm{C} & 4.496092 & -2.851546 & 0.621171 \\ \mathrm{C} & 4.957641 & -2.021023 & -1.714564 \\ \mathrm{H} & 7.013432 & -1.770936 & -0.020707 \\ \mathrm{H} & 6.238242 & -1.044139 & 1.368576 \\ \mathrm{H} & 3.589225 & -3.341621 & 0.255618 \\ \mathrm{H} & 4.359560 & -2.592548 & 1.676863 \\ \mathrm{H} & 5.305660 & -3.584326 & 0.568250 \\ \mathrm{H} & 5.707902 & -2.806988 & -1.836240 \\ \mathrm{H} & 3.999088 & -2.411492 & -2.071005 \\ \mathrm{H} & 5.240522 & -1.185434 & -2.359751 \\ \mathrm{O} & 0.556209 & -2.465034 & -1.193613 \\ \mathrm{H} & 0.506674 & -3.396007 & -1.454687 \\ \mathrm{H} & 1.475645 & -2.267068 & -0.886783 \\ \mathrm{O} & -2.564912 & -2.073218 & -1.559827 \\ \mathrm{H} & -2.370303 & -1.888242 & -2.493164 \\ \mathrm{H} & -3.514226 & -1.869873 & -1.442447 \\ \mathrm{O} & -0.674734 & -0.169793 & -2.524568 \\ \mathrm{H} & 0.088605 & -0.500769 & -3.023024 \\ \mathrm{H} & -0.931093 & 0.675412 & -2.926536 \\ \mathrm{O} & -1.605520 & -0.316223 & 2.482858 \\ \mathrm{H} & -1.003765 & -0.342529 & 3.243216 \\ \mathrm{H} & -2.279029 & 0.362081 & 2.652992 \\ \mathrm{O} & -2.086134 & -2.898621 & 1.219681 \\ \mathrm{H} & -2.482831 & -3.662931 & 0.772104 \\ \mathrm{H} & -2.594009 & -2.755752 & 2.035037 \\ \mathrm{O} & 0.531668 & -1.988924 & 1.901084 \\ \mathrm{H} & 1.491604 & -2.077675 & 1.789516 \\ \mathrm{H} & 0.202821 & -2.855616 & 2.187668\end{array}$

$\mathrm{M}=\mathrm{Cm}$

$\begin{array}{lccc}\mathrm{CM} & -0.964055 & -0.770124 & 0.086293 \\ \mathrm{O} & 0.548133 & -1.930341 & 1.927191 \\ \mathrm{H} & 1.496177 & -2.091393 & 1.798230 \\ \mathrm{O} & -1.524123 & -0.114189 & 2.525760 \\ \mathrm{H} & -0.929286 & -0.024873 & 3.286693 \\ \mathrm{O} & -2.491186 & -2.197823 & -1.411544 \\ \mathrm{H} & -2.274924 & -2.123083 & -2.355094 \\ \mathrm{O} & -2.139487 & -2.699837 & 1.460170 \\ \mathrm{H} & -2.562206 & -3.495128 & 1.098954\end{array}$




\begin{tabular}{|c|c|c|c|}
\hline $\mathrm{O}$ & 0.507922 & -2.488695 & -1.155764 \\
\hline $\mathrm{H}$ & 0.447675 & -3.408357 & -1.451638 \\
\hline $\mathrm{O}$ & -0.818796 & -0.111213 & -2.455083 \\
\hline $\mathrm{H}$ & -0.053273 & -0.263650 & -3.030268 \\
\hline $\mathrm{H}$ & 0.175170 & -2.731151 & 2.328566 \\
\hline $\mathrm{H}$ & -2.644141 & -2.441751 & 2.248862 \\
\hline $\mathrm{H}$ & 1.443445 & -2.291319 & -0.906820 \\
\hline $\mathrm{H}$ & -3.438171 & -1.961036 & -1.339435 \\
\hline $\mathrm{H}$ & -1.267374 & 0.682015 & -2.789826 \\
\hline $\mathrm{H}$ & -2.208242 & 0.571682 & 2.598714 \\
\hline$C$ & -4.322656 & 0.222294 & -0.044486 \\
\hline $\mathrm{C}$ & -5.073527 & 1.423763 & -0.260670 \\
\hline $\mathrm{C}$ & -6.477160 & 1.376392 & -0.422251 \\
\hline $\mathrm{C}$ & -7.116409 & 0.144995 & -0.361126 \\
\hline$C$ & -6.380211 & -1.039840 & -0.114749 \\
\hline$C$ & -4.995211 & -1.016063 & 0.050948 \\
\hline $\mathrm{C}$ & -2.881707 & 1.905182 & -0.053010 \\
\hline $\mathrm{C}$ & -4.129725 & 2.489911 & -0.248041 \\
\hline $\mathrm{H}$ & -7.045941 & 2.286504 & -0.586189 \\
\hline $\mathrm{H}$ & -8.192901 & 0.084213 & -0.482190 \\
\hline $\mathrm{H}$ & -6.911922 & -1.982936 & -0.033515 \\
\hline $\mathrm{H}$ & -4.480531 & -1.931488 & 0.333337 \\
\hline $\mathrm{H}$ & -4.347864 & 3.540897 & -0.378840 \\
\hline $\mathrm{C}$ & -1.582834 & 2.539362 & 0.006974 \\
\hline $\mathrm{C}$ & -1.415125 & 3.946548 & 0.014391 \\
\hline $\mathrm{C}$ & -0.141240 & 4.486202 & 0.066906 \\
\hline $\mathrm{H}$ & -2.286321 & 4.589839 & -0.012934 \\
\hline $\mathrm{C}$ & 0.742783 & 2.257159 & 0.074118 \\
\hline $\mathrm{C}$ & 0.973855 & 3.624542 & 0.091926 \\
\hline $\mathrm{H}$ & -0.000380 & 5.562488 & 0.081341 \\
\hline $\mathrm{H}$ & 1.988435 & 4.000123 & 0.114089 \\
\hline $\mathrm{C}$ & 1.865739 & 1.293204 & 0.027261 \\
\hline $\mathrm{C}$ & 4.119825 & 0.871455 & -0.010913 \\
\hline $\mathrm{C}$ & 3.806526 & -0.531875 & -0.154207 \\
\hline $\mathrm{N}$ & -2.969883 & 0.509820 & 0.061332 \\
\hline $\mathrm{N}$ & -0.503449 & 1.716063 & 0.051372 \\
\hline $\mathrm{N}$ & 3.127113 & 1.749861 & 0.069910 \\
\hline $\mathrm{N}$ & 1.542069 & -0.000959 & -0.081479 \\
\hline $\mathrm{N}$ & 2.532111 & -0.908034 & -0.183913 \\
\hline $\mathrm{C}$ & 5.541474 & 1.396161 & 0.096368 \\
\hline $\mathrm{C}$ & 6.551627 & 0.323268 & -0.367198 \\
\hline $\mathrm{H}$ & 6.590849 & 0.310469 & -1.461592 \\
\hline $\mathrm{H}$ & 7.549385 & 0.623732 & -0.035350 \\
\hline $\mathrm{C}$ & 6.234866 & -1.077122 & 0.162667 \\
\hline $\mathrm{C}$ & 4.867070 & -1.617420 & -0.317460 \\
\hline $\mathrm{H}$ & 6.259500 & -1.077619 & 1.257956 \\
\hline
\end{tabular}




$\begin{array}{lrrr}\mathrm{H} & 7.011024 & -1.778365 & -0.157480 \\ \mathrm{C} & 5.705285 & 2.671541 & -0.759148 \\ \mathrm{H} & 5.057273 & 3.477298 & -0.410784 \\ \mathrm{H} & 6.741721 & 3.013507 & -0.693358 \\ \mathrm{H} & 5.483943 & 2.478475 & -1.813595 \\ \mathrm{C} & 5.768945 & 1.761390 & 1.591305 \\ \mathrm{H} & 6.770951 & 2.183666 & 1.704250 \\ \mathrm{H} & 5.043213 & 2.509061 & 1.921201 \\ \mathrm{H} & 5.693238 & 0.893004 & 2.251971 \\ \mathrm{C} & 4.926669 & -1.997477 & -1.820833 \\ \mathrm{H} & 5.674410 & -2.781193 & -1.969508 \\ \mathrm{H} & 3.961920 & -2.380965 & -2.167896 \\ \mathrm{H} & 5.199020 & -1.150223 & -2.455283 \\ \mathrm{C} & 4.504432 & -2.870805 & 0.506735 \\ \mathrm{H} & 3.591242 & -3.354006 & 0.148071 \\ \mathrm{H} & 5.312856 & -3.602358 & 0.426596 \\ \mathrm{H} & 4.386092 & -2.631212 & 1.569238\end{array}$

\section{$\left[\mathrm{ML}\left(\mathrm{H}_{2} \mathrm{O}\right)_{5}\right]^{2+}$}

$\mathrm{M}=\mathrm{Eu}$

$\begin{array}{lrrr}\text { EU } & -1.080161 & -1.027389 & 0.081336 \\ \mathrm{O} & -2.876717 & -2.306001 & 1.684929 \\ \mathrm{H} & -3.772423 & -1.930210 & 1.718350 \\ \mathrm{O} & -1.330621 & -3.301972 & -1.335312 \\ \mathrm{H} & -0.547029 & -3.784774 & -1.014912 \\ \mathrm{O} & 0.721634 & -2.995620 & 0.486535 \\ \mathrm{H} & 0.897991 & -3.599948 & 1.222502 \\ \mathrm{O} & -0.806412 & -0.579092 & 2.631668 \\ \mathrm{H} & -0.293400 & 0.016943 & 3.196195 \\ \mathrm{O} & -0.790501 & -0.693011 & -2.469787 \\ \mathrm{H} & -0.838850 & -1.475775 & -3.039726 \\ \mathrm{H} & 1.562441 & -2.475378 & 0.341500 \\ \mathrm{H} & -0.798130 & 0.080503 & -3.052357 \\ \mathrm{H} & -2.973936 & -3.238608 & 1.932246 \\ \mathrm{H} & -1.904874 & -3.942251 & -1.779993 \\ \mathrm{H} & -1.468390 & -1.003904 & 3.198986 \\ \mathrm{C} & -4.580852 & 0.163619 & -0.195029 \\ \mathrm{C} & -5.320161 & 1.387169 & -0.106848 \\ \mathrm{C} & -6.730981 & 1.383209 & -0.168645 \\ \mathrm{C} & -7.387420 & 0.155316 & -0.330267 \\ \mathrm{C} & -6.654680 & -1.037024 & -0.438471 \\ \mathrm{C} & -5.239195 & -1.047137 & -0.375225 \\ \mathrm{C} & -3.074816 & 1.754415 & -0.012220 \\ \mathrm{C} & -4.352402 & 2.411622 & 0.003901\end{array}$




\begin{tabular}{|c|c|c|c|}
\hline $\mathrm{H}$ & -7.297189 & 2.307001 & -0.098718 \\
\hline H & -8.470406 & 0.123663 & -0.384448 \\
\hline & -7.184635 & -1.973066 & -0.585081 \\
\hline $\mathrm{H}$ & -4.699438 & -1.980921 & -0.505921 \\
\hline & -4.540953 & 3.474225 & 0.079250 \\
\hline & -1.757059 & 2.400379 & 0.041600 \\
\hline & -1.624343 & 3.801019 & 0.093208 \\
\hline 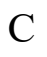 & -0.350025 & 4.363663 & 0.106152 \\
\hline & -2.500674 & 4.437032 & 0.115669 \\
\hline & 0.554167 & 2.140099 & 0.033445 \\
\hline $\mathrm{C}$ & 0.766187 & 3.521112 & 0.071366 \\
\hline $\mathrm{H}$ & -0.225032 & 5.441456 & 0.140417 \\
\hline $\mathrm{H}$ & 1.777046 & 3.907670 & 0.074171 \\
\hline $\mathrm{C}$ & 1.713432 & 1.201636 & 0.017112 \\
\hline $\mathrm{C}$ & 3.981615 & 0.880669 & -0.067008 \\
\hline $\mathrm{C}$ & 3.732753 & -0.536139 & -0.016973 \\
\hline $\mathrm{N}$ & -3.199028 & 0.415482 & -0.11 \\
\hline $\mathrm{N}$ & -0.676430 & 1.588203 & 0.0 \\
\hline $\mathrm{N}$ & 2.949220 & 1.718856 & -0.040179 \\
\hline $\mathrm{N}$ & 1.446199 & -0.106815 & 0.076291 \\
\hline $\mathrm{N}$ & 2.475729 & -0.967363 & 0.065762 \\
\hline $\mathrm{C}$ & 5.378072 & 1.482346 & -0.090233 \\
\hline $\mathrm{C}$ & 6.428866 & 0.404460 & -0.437274 \\
\hline $\mathrm{H}$ & 6.445884 & 0.249448 & -1.521134 \\
\hline $\mathrm{H}$ & 7.417925 & 0.790176 & -0.174181 \\
\hline $\mathrm{C}$ & 6.189773 & -0.928084 & 0.277038 \\
\hline $\mathrm{C}$ & 4.838641 & -1.583746 & -0.091126 \\
\hline $\mathrm{H}$ & 6.238293 & -0.786765 & 1.362552 \\
\hline $\mathrm{H}$ & 6.990538 & -1.630197 & 0.026712 \\
\hline $\mathrm{C}$ & 5.445130 & 2.627344 & -1.124517 \\
\hline $\mathrm{H}$ & 4.764861 & 3.441743 & -0.869509 \\
\hline $\mathrm{H}$ & 6.462819 & 3.026538 & -1.150002 \\
\hline $\mathrm{H}$ & 5.200309 & 2.273031 & -2.130833 \\
\hline $\mathrm{C}$ & 5.637886 & 2.067134 & 1.326422 \\
\hline $\mathrm{H}$ & 6.616376 & 2.554642 & 1.336458 \\
\hline $\mathrm{H}$ & 4.881291 & 2.813273 & 1.582455 \\
\hline $\mathrm{H}$ & 5.637411 & 1.296633 & 2.102686 \\
\hline $\mathrm{C}$ & 4.869162 & -2.128278 & -1.544372 \\
\hline $\mathrm{H}$ & 5.648808 & -2.890228 & -1.630709 \\
\hline $\mathrm{H}$ & 3.912092 & -2.589132 & -1.806444 \\
\hline $\mathrm{H}$ & 5.079970 & -1.347470 & -2.279567 \\
\hline $\mathrm{C}$ & 4.566089 & -2.754304 & 0.876577 \\
\hline $\mathrm{H}$ & 3.701251 & -3.348753 & 0.570562 \\
\hline 1 & 5.431304 & -3.422838 & 0.88202 \\
\hline 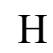 & 4.410956 & -2.404241 & 1.90199 \\
\hline
\end{tabular}




$\begin{array}{lrcc}\mathrm{M}=\mathrm{Gd} & & & \\ \mathrm{GD} & 1.047883 & -0.841473 & -0.013024 \\ \mathrm{O} & 2.448688 & -2.196756 & -1.671032 \\ \mathrm{H} & 3.386554 & -1.928186 & -1.712473 \\ \mathrm{O} & 2.447037 & -2.247072 & 1.600376 \\ \mathrm{H} & 2.394385 & -3.158905 & 1.926765 \\ \mathrm{O} & -0.410792 & -2.802239 & -0.045091 \\ \mathrm{H} & -0.446114 & -3.767935 & -0.087107 \\ \mathrm{O} & 0.552017 & -0.354653 & -2.400498 \\ \mathrm{H} & 0.113768 & 0.406003 & -2.810228 \\ \mathrm{O} & 0.554431 & -0.424375 & 2.388082 \\ \mathrm{H} & 1.154789 & -0.816812 & 3.041429 \\ \mathrm{H} & -1.350527 & -2.444469 & -0.035595 \\ \mathrm{H} & 0.111357 & 0.322027 & 2.818386 \\ \mathrm{H} & 2.402363 & -3.099212 & -2.023401 \\ \mathrm{H} & 3.386267 & -1.984996 & 1.650639 \\ \mathrm{H} & 1.151108 & -0.732107 & -3.063778 \\ \mathrm{C} & 4.413802 & -0.026687 & -0.001266 \\ \mathrm{C} & 5.209618 & 1.165403 & 0.016624 \\ \mathrm{C} & 6.619525 & 1.091442 & 0.016726 \\ \mathrm{C} & 7.226799 & -0.159165 & -0.000979 \\ \mathrm{C} & 6.446455 & -1.337885 & -0.018867 \\ \mathrm{C} & 5.049314 & -1.290006 & -0.019277 \\ \mathrm{C} & 3.020879 & 1.701582 & 0.022667 \\ \mathrm{C} & 4.293455 & 2.256791 & 0.031625 \\ \mathrm{H} & 7.219906 & 1.995915 & 0.030391 \\ \mathrm{H} & 8.308744 & -0.238925 & -0.001246 \\ \mathrm{H} & 6.946258 & -2.301526 & -0.032603 \\ \mathrm{~N} & -2.991719 & 1.633188 & 0.009295 \\ \mathrm{H} & 4.498919 & -2.228621 & -0.033763 \\ \mathrm{H} & 4.549307 & 3.307196 & 0.046957 \\ \mathrm{C} & 1.738944 & 2.371534 & 0.031230 \\ \mathrm{C} & 1.597764 & 3.781371 & 0.050094 \\ \mathrm{C} & 0.332283 & 4.344216 & 0.056355 \\ \mathrm{H} & 2.480349 & 4.409385 & 0.059432 \\ \mathrm{C} & -0.600435 & 2.136280 & 0.025905 \\ \mathrm{C} & -0.803404 & 3.507280 & 0.043660 \\ \mathrm{H} & 0.212788 & 5.423155 & 0.070889 \\ \mathrm{H} & -1.809948 & 3.905329 & 0.048077 \\ \mathrm{C} & -1.731440 & 1.177515 & 0.013283 \\ \mathrm{C} & -3.981474 & 0.744930 & 0.006578 \\ \mathrm{~N} & 3.060979 & -0.665767 & 0.005737 \\ \mathrm{~N} & & -0.121808 & 0.003011\end{array}$




$\begin{array}{lrrr}\mathrm{N} & -2.389726 & -1.036568 & -0.000540 \\ \mathrm{C} & -5.403660 & 1.274779 & -0.050160 \\ \mathrm{C} & -6.416256 & 0.157207 & 0.284332 \\ \mathrm{H} & -6.471561 & 0.030430 & 1.370558 \\ \mathrm{H} & -7.409955 & 0.489041 & -0.029272 \\ \mathrm{C} & -6.086733 & -1.179922 & -0.383211 \\ \mathrm{C} & -4.723364 & -1.762480 & 0.057147 \\ \mathrm{H} & -6.097256 & -1.069186 & -1.473103 \\ \mathrm{H} & -6.863465 & -1.912672 & -0.145945 \\ \mathrm{C} & -5.574308 & 2.448646 & 0.939339 \\ \mathrm{H} & -4.923522 & 3.287470 & 0.687357 \\ \mathrm{H} & -6.610291 & 2.796219 & 0.902926 \\ \mathrm{H} & -5.362340 & 2.140017 & 1.967892 \\ \mathrm{C} & -5.622325 & 1.801417 & -1.497948 \\ \mathrm{H} & -6.624208 & 2.232876 & -1.568991 \\ \mathrm{H} & -4.895863 & 2.581184 & -1.740247 \\ \mathrm{H} & -5.542497 & 1.009764 & -2.248300 \\ \mathrm{C} & -4.792415 & -2.275914 & 1.520711 \\ \mathrm{H} & -5.537914 & -3.072734 & 1.590156 \\ \mathrm{H} & -3.827895 & -2.684235 & 1.837508 \\ \mathrm{H} & -5.074098 & -1.491092 & 2.227327 \\ \mathrm{C} & -4.352306 & -2.936763 & -0.872610 \\ \mathrm{H} & -3.463284 & -3.472641 & -0.529209 \\ \mathrm{H} & -5.176602 & -3.654753 & -0.887999 \\ \mathrm{H} & -4.183282 & -2.602165 & -1.900658\end{array}$

$\mathrm{M}=\mathrm{Am}$

$\begin{array}{lrrc}\text { AM } & -0.992945 & -0.802737 & 0.044410 \\ \mathrm{O} & -2.503796 & -2.073815 & 1.816101 \\ \mathrm{H} & -3.422969 & -1.747370 & 1.840715 \\ \mathrm{O} & -2.432320 & -2.203319 & -1.651376 \\ \mathrm{H} & -2.367686 & -3.110069 & -1.990751 \\ \mathrm{O} & 0.565053 & -2.782181 & 0.125839 \\ \mathrm{H} & 0.627801 & -3.718824 & 0.360269 \\ \mathrm{O} & -0.425269 & -0.348086 & 2.484969 \\ \mathrm{H} & 0.067469 & 0.371037 & 2.908034 \\ \mathrm{O} & -0.478695 & -0.366523 & -2.426812 \\ \mathrm{H} & -1.064303 & -0.775843 & -3.083286 \\ \mathrm{H} & 1.492499 & -2.399142 & 0.079830 \\ \mathrm{H} & -0.062185 & 0.396416 & -2.855442 \\ \mathrm{H} & -2.524860 & -2.972556 & 2.181206 \\ \mathrm{H} & -3.371603 & -1.946556 & -1.717150 \\ \mathrm{H} & -1.060348 & -0.683918 & 3.137566 \\ \mathrm{C} & -4.323327 & 0.139286 & -0.031586 \\ \mathrm{C} & -5.095197 & 1.342956 & -0.095780\end{array}$




$\begin{array}{lrrr}\mathrm{C} & -6.503783 & 1.292959 & -0.152711 \\ \mathrm{C} & -7.132544 & 0.051640 & -0.150078 \\ \mathrm{C} & -6.374145 & -1.138723 & -0.085843 \\ \mathrm{C} & -4.977185 & -1.112512 & -0.024583 \\ \mathrm{C} & -2.899325 & 1.845947 & -0.013308 \\ \mathrm{C} & -4.159672 & 2.420739 & -0.081942 \\ \mathrm{H} & -7.087936 & 2.207046 & -0.195784 \\ \mathrm{H} & -8.214798 & -0.009863 & -0.194313 \\ \mathrm{H} & -6.889888 & -2.093975 & -0.081199 \\ \mathrm{H} & -4.439214 & -2.056150 & 0.035132 \\ \mathrm{H} & -4.398967 & 3.474461 & -0.119719 \\ \mathrm{C} & -1.601628 & 2.486691 & 0.000898 \\ \mathrm{C} & -1.434997 & 3.891804 & -0.001046 \\ \mathrm{C} & -0.158800 & 4.430671 & 0.003535 \\ \mathrm{H} & -2.305591 & 4.536392 & -0.004794 \\ \mathrm{C} & 0.727845 & 2.202117 & 0.010326 \\ \mathrm{C} & 0.957018 & 3.570364 & 0.007443 \\ \mathrm{H} & -0.017511 & 5.506999 & 0.002846 \\ \mathrm{H} & 1.971597 & 3.946949 & 0.006293 \\ \mathrm{C} & 1.851155 & 1.233540 & 0.005336 \\ \mathrm{C} & 4.101575 & 0.799367 & -0.024625 \\ \mathrm{C} & 3.782693 & -0.609564 & -0.036212 \\ \mathrm{~N} & -2.966745 & 0.445677 & 0.026703 \\ \mathrm{~N} & -0.521144 & 1.664271 & 0.009906 \\ \mathrm{~N} & 3.112837 & 1.687850 & -0.001896 \\ \mathrm{H} & 1.523625 & -0.063217 & 0.010418 \\ \mathrm{H} & 5.623872 & -2.993575 & -1.690243 \\ \mathrm{~N} & 2.507124 & -0.978307 & -0.008674 \\ \mathrm{C} & 5.525585 & 1.326626 & 0.019415 \\ \mathrm{C} & 6.531092 & 0.212454 & -0.346621 \\ \mathrm{H} & 6.569771 & 0.101717 & -1.435320 \\ \mathrm{H} & 7.530042 & 0.537872 & -0.043066 \\ \mathrm{C} & 6.209197 & -1.134189 & 0.305424 \\ \mathrm{C} & 4.837749 & -1.707266 & -0.122200 \\ \mathrm{H} & 6.237129 & -1.040314 & 1.396654 \\ \mathrm{H} & 6.980567 & -1.864601 & 0.044546 \\ \mathrm{C} & 5.684128 & 2.514403 & -0.955223 \\ \mathrm{H} & 5.039519 & 3.351036 & -0.680920 \\ \mathrm{H} & 6.721409 & 2.859185 & -0.930109 \\ \mathrm{H} & 5.455134 & 2.221487 & -1.984725 \\ \mathrm{H} & 6.770212 & 2.831315 & 1.471168 \\ \mathrm{H} & 5.260640 & 1.534197 \\ \mathrm{H} & -2.597401 & -1.901909\end{array}$




$\begin{array}{llll}\mathrm{H} & 5.153150 & -1.400539 & -2.293127 \\ \mathrm{C} & 4.480370 & -2.896972 & 0.793038 \\ \mathrm{H} & 3.591229 & -3.431733 & 0.448004 \\ \mathrm{H} & 5.307572 & -3.611798 & 0.789603 \\ \mathrm{H} & 4.319765 & -2.579090 & 1.827807\end{array}$

$\mathrm{M}=\mathrm{Cm}$

$\begin{array}{lrrc}\mathrm{CM} & 0.967438 & -0.782606 & -0.011577 \\ \mathrm{O} & 2.427133 & -2.124673 & -1.722471 \\ \mathrm{H} & 3.358048 & -1.833662 & -1.761016 \\ \mathrm{O} & 2.420257 & -2.174866 & 1.661148 \\ \mathrm{H} & 2.390633 & -3.092237 & 1.975552 \\ \mathrm{O} & -0.538107 & -2.800721 & -0.042015 \\ \mathrm{H} & -0.594592 & -3.765559 & -0.085246 \\ \mathrm{O} & 0.456035 & -0.313486 & -2.453106 \\ \mathrm{H} & 0.024133 & 0.445854 & -2.872761 \\ \mathrm{O} & 0.453590 & -0.377111 & 2.441300 \\ \mathrm{H} & 1.062447 & -0.772246 & 3.085507 \\ \mathrm{H} & -1.466222 & -2.424055 & -0.034994 \\ \mathrm{H} & 0.021408 & 0.372670 & 2.877584 \\ \mathrm{H} & 2.406484 & -3.033318 & -2.061888 \\ \mathrm{H} & 3.352842 & -1.891644 & 1.712706 \\ \mathrm{H} & 1.066976 & -0.693073 & -3.104681 \\ \mathrm{C} & 4.334032 & 0.122147 & 0.002569 \\ \mathrm{C} & 5.107815 & 1.327492 & 0.018256 \\ \mathrm{C} & 6.518724 & 1.278291 & 0.018883 \\ \mathrm{C} & 7.146972 & 0.038087 & 0.003895 \\ \mathrm{C} & 6.386933 & -1.154267 & -0.011648 \\ \mathrm{C} & 4.989621 & -1.129992 & -0.012506 \\ \mathrm{C} & 2.908966 & 1.824602 & 0.022580 \\ \mathrm{C} & 4.171575 & 2.402411 & 0.030792 \\ \mathrm{H} & 7.103588 & 2.192852 & 0.030865 \\ \mathrm{H} & 8.230162 & -0.023292 & 0.004075 \\ \mathrm{H} & 6.903523 & -2.109090 & -0.023075 \\ \mathrm{H} & 4.451561 & -2.075835 & -0.024683 \\ \mathrm{H} & 4.409824 & 3.456897 & 0.044150 \\ \mathrm{C} & 1.615318 & 2.473390 & 0.029275 \\ \mathrm{C} & 1.456098 & 3.880813 & 0.045612 \\ \mathrm{C} & 0.184058 & 4.428300 & 0.050489 \\ \mathrm{H} & 2.330576 & 4.520015 & 0.054167 \\ \mathrm{C} & -0.721866 & 2.208761 & 0.023349 \\ \mathrm{C} & -0.940771 & 3.577369 & 0.038919 \\ \mathrm{H} & 0.051397 & 5.505704 & 0.063125 \\ \mathrm{H} & -1.951993 & 3.963119 & 0.042454 \\ \mathrm{C} & -1.847246 & 1.242067 & 0.011661\end{array}$




$\begin{array}{lrrr}\mathrm{C} & -4.096127 & 0.802670 & 0.007309 \\ \mathrm{C} & -3.775254 & -0.606462 & 0.004900 \\ \mathrm{~N} & 2.977325 & 0.421913 & 0.005208 \\ \mathrm{~N} & 0.524636 & 1.663011 & 0.018847 \\ \mathrm{~N} & -3.109108 & 1.694047 & 0.008866 \\ \mathrm{~N} & -1.519039 & -0.055618 & 0.001674 \\ \mathrm{~N} & -2.499054 & -0.974464 & -0.001825 \\ \mathrm{C} & -5.520232 & 1.328445 & -0.044385 \\ \mathrm{C} & -6.527767 & 0.207282 & 0.293283 \\ \mathrm{H} & -6.576876 & 0.078388 & 1.379617 \\ \mathrm{H} & -7.524133 & 0.536514 & -0.014568 \\ \mathrm{C} & -6.197200 & -1.127459 & -0.378293 \\ \mathrm{C} & -4.830126 & -1.706972 & 0.054686 \\ \mathrm{H} & -6.212849 & -1.014379 & -1.467914 \\ \mathrm{H} & -6.970734 & -1.863022 & -0.139262 \\ \mathrm{C} & -5.691089 & 2.500775 & 0.946884 \\ \mathrm{H} & -5.044467 & 3.342270 & 0.692995 \\ \mathrm{H} & -6.728459 & 2.844725 & 0.915298 \\ \mathrm{H} & -5.473581 & 2.192008 & 1.974273 \\ \mathrm{C} & -5.746205 & 1.855626 & -1.490695 \\ \mathrm{H} & -6.749871 & 2.283585 & -1.558051 \\ \mathrm{H} & -5.023348 & 2.638171 & -1.734937 \\ \mathrm{H} & -5.666043 & 1.064979 & -2.242080 \\ \mathrm{C} & -4.892786 & -2.228329 & 1.515610 \\ \mathrm{H} & -5.633417 & -3.029887 & 1.582931 \\ \mathrm{H} & -3.925058 & -2.632380 & 1.828222 \\ \mathrm{H} & -5.177541 & -1.448640 & 2.226739 \\ \mathrm{C} & -4.458668 & -2.875133 & -0.882700 \\ \mathrm{H} & -3.568211 & -3.411679 & -0.544096 \\ \mathrm{H} & -5.281873 & -3.594336 & -0.901162 \\ \mathrm{H} & -4.291609 & -2.534101 & -1.908994\end{array}$

\section{$\left[\mathrm{ML}_{2}\left(\mathrm{H}_{2} \mathrm{O}\right)_{2}\right]^{1+}$}

$\mathrm{M}=\mathrm{Eu}$

$\begin{array}{lccc}\text { EU } & 0.000004 & 0.358884 & -0.000009 \\ \text { O } & 0.432757 & -1.504834 & -1.739753 \\ \text { H } & 1.385805 & -1.744213 & -1.618068 \\ \text { O } & -0.432721 & -1.504875 & 1.739700 \\ \text { H } & -0.291770 & -1.339074 & 2.681616 \\ \text { H } & 0.291733 & -1.339027 & -2.681657 \\ \text { H } & -1.385732 & -1.744362 & 1.617933 \\ \text { C } & 2.206216 & 2.731385 & -1.548879 \\ \text { C } & 2.293228 & 3.539122 & -2.731564 \\ \text { C } & 3.413836 & 4.369140 & -2.953319\end{array}$




\begin{tabular}{|c|c|c|c|}
\hline $\mathrm{C}$ & 4.424782 & 4.395252 & -1.994814 \\
\hline & 4.328773 & 3.609219 & -0.821715 \\
\hline & 3.231216 & 2.777688 & -0.588849 \\
\hline & 0.371182 & 2.356122 & -2.697966 \\
\hline 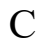 & 1.098950 & 3.285008 & -3.459312 \\
\hline $\mathrm{H}$ & 3.486181 & 4.978829 & -3.849344 \\
\hline$\pi$ & 5.292989 & 5.030794 & -2.139630 \\
\hline & 5.123115 & 3.664338 & -0.083135 \\
\hline $\mathrm{H}$ & 3.165271 & 2.205514 & 0.328975 \\
\hline $\mathrm{H}$ & 0.813069 & 3.729097 & -4.402889 \\
\hline $\mathrm{C}$ & -0.938254 & 1.802900 & -3.004701 \\
\hline $\mathrm{C}$ & -1.633596 & 2.143240 & -4.190990 \\
\hline $\mathrm{C}$ & -2.881519 & 1.593255 & -4.436720 \\
\hline $\mathrm{H}$ & -1.187446 & 2.833291 & -4.896270 \\
\hline $\mathrm{C}$ & -2.697399 & 0.412576 & -2.358945 \\
\hline $\mathrm{C}$ & -3.436597 & 0.703323 & -3.501552 \\
\hline $\mathrm{H}$ & -3.426406 & 1.848395 & -5.340528 \\
\hline $\mathrm{H}$ & -4.409193 & 0.251690 & -3.643163 \\
\hline $\mathrm{C}$ & -3.235641 & -0.520921 & -1.334908 \\
\hline $\mathrm{C}$ & -4.940384 & -1.857921 & -0.590810 \\
\hline $\mathrm{C}$ & -4.117509 & -2.205246 & 0.527382 \\
\hline $\mathrm{N}$ & 1.033910 & 1.994277 & -1.541855 \\
\hline $\mathrm{N}$ & -1.479433 & 0.944601 & -2.107974 \\
\hline $\mathrm{N}$ & -4.464765 & -1.030289 & -1.514367 \\
\hline $\mathrm{N}$ & -2.455090 & -0.798250 & -0.282529 \\
\hline $\mathrm{N}$ & -2.909496 & -1.655925 & 0.634703 \\
\hline $\mathrm{C}$ & -6.339361 & -2.422619 & -0.806246 \\
\hline $\mathrm{C}$ & -6.850795 & -3.090321 & 0.489105 \\
\hline $\mathrm{H}$ & -7.204546 & -2.316266 & 1.178984 \\
\hline $\mathrm{H}$ & -7.726204 & -3.699764 & 0.243607 \\
\hline $\mathrm{C}$ & -5.792879 & -3.955887 & 1.178466 \\
\hline $\mathrm{C}$ & -4.555065 & -3.153500 & 1.641453 \\
\hline $\mathrm{H}$ & -5.471117 & -4.757316 & 0.503852 \\
\hline $\mathrm{H}$ & -6.229186 & -4.450865 & 2.051912 \\
\hline $\mathrm{C}$ & -7.303405 & -1.289950 & -1.219292 \\
\hline $\mathrm{H}$ & -6.999465 & -0.830517 & -2.161531 \\
\hline $\mathrm{H}$ & -8.310591 & -1.699262 & -1.342938 \\
\hline $\mathrm{H}$ & -7.349372 & -0.507564 & -0.455142 \\
\hline $\mathrm{C}$ & -6.249789 & -3.453233 & -1.962028 \\
\hline $\mathrm{H}$ & -7.248030 & -3.845509 & -2.177280 \\
\hline $\mathrm{H}$ & -5.863144 & -2.980176 & -2.868368 \\
\hline $\mathrm{H}$ & -5.599760 & -4.297902 & -1.716338 \\
\hline $\mathrm{C}$ & -4.890938 & -2.301021 & 2.891537 \\
\hline 12 & -5.176951 & -2.957783 & 3.718583 \\
\hline $\mathrm{H}$ & -4.023998 & -1.712506 & 3.204388 \\
\hline $\mathrm{H}$ & -5.715035 & -1.605742 & 2.710600 \\
\hline
\end{tabular}




$\begin{array}{rrrr}\mathrm{C} & -3.422202 & -4.141229 & 1.992922 \\ \mathrm{H} & -2.554383 & -3.637877 & 2.424490 \\ \mathrm{H} & -3.788860 & -4.863166 & 2.728985 \\ \mathrm{H} & -3.089363 & -4.698901 & 1.112009 \\ \mathrm{C} & -2.206242 & 2.731327 & 1.548901 \\ \mathrm{C} & -2.293263 & 3.539047 & 2.731596 \\ \mathrm{C} & -3.413883 & 4.369044 & 2.953366 \\ \mathrm{C} & -4.424834 & 4.395150 & 1.994866 \\ \mathrm{C} & -4.328816 & 3.609134 & 0.821757 \\ \mathrm{C} & -3.231247 & 2.777625 & 0.588876 \\ \mathrm{C} & -0.371197 & 2.356082 & 2.697975 \\ \mathrm{C} & -1.098977 & 3.284946 & 3.459336 \\ \mathrm{H} & -3.486236 & 4.978721 & 3.849400 \\ \mathrm{H} & -5.293051 & 5.030676 & 2.139694 \\ \mathrm{H} & -5.123163 & 3.664248 & 0.083181 \\ \mathrm{H} & -3.165295 & 2.205463 & -0.328955 \\ \mathrm{H} & -0.813099 & 3.729028 & 4.402917 \\ \mathrm{C} & 0.938250 & 1.802879 & 3.004698 \\ \mathrm{C} & 1.633591 & 2.143220 & 4.190987 \\ \mathrm{C} & 2.881525 & 1.593253 & 4.436707 \\ \mathrm{H} & 1.187433 & 2.833255 & 4.896277 \\ \mathrm{C} & 2.697416 & 0.412592 & 2.358921 \\ \mathrm{C} & 3.436613 & 0.703338 & 3.501528 \\ \mathrm{H} & 3.426411 & 1.848393 & 5.340516 \\ \mathrm{H} & 4.409216 & 0.251718 & 3.643132 \\ \mathrm{C} & 3.235665 & -0.520895 & 1.334878 \\ \mathrm{C} & 4.940404 & -1.857908 & 0.590793 \\ \mathrm{C} & 4.117517 & -2.205264 & -0.527379 \\ \mathrm{~N} & -1.033924 & 1.994239 & 1.541863 \\ \mathrm{~N} & 1.479440 & 0.944599 & 2.107960 \\ \mathrm{~N} & 4.464790 & -1.030262 & 1.514340 \\ \mathrm{~N} & 2.455109 & -0.798241 & 0.282508 \\ \mathrm{~N} & 2.909500 & -1.655950 & -0.634699 \\ \mathrm{C} & 6.339382 & -2.422604 & 0.806233 \\ \mathrm{C} & 6.850803 & -3.090339 & -0.489106 \\ \mathrm{H} & 7.204547 & -2.316302 & -1.179009 \\ \mathrm{H} & 7.726214 & -3.699776 & -0.243602 \\ \mathrm{C} & 5.792880 & -3.955923 & -1.178435 \\ \mathrm{C} & 4.555061 & -3.153548 & -1.641430 \\ \mathrm{H} & 5.471125 & -4.757334 & -0.503797 \\ \mathrm{H} & 6.229178 & -4.450923 & -2.051873 \\ \mathrm{C} & 7.303431 & -1.289928 & 1.219243 \\ \mathrm{H} & 6.999502 & -0.830472 & 2.161473 \\ \mathrm{H} & 8.310617 & -1.699239 & 1.342889 \\ \mathrm{H} & 7.349393 & -0.507559 & 0.455074 \\ \mathrm{C} & 6.249816 & -3.453189 & 1.962040 \\ & & & \end{array}$




$\begin{array}{llll}\mathrm{H} & 7.248058 & -3.845463 & 2.177295 \\ \mathrm{H} & 5.863179 & -2.980110 & 2.868372 \\ \mathrm{H} & 5.599784 & -4.297864 & 1.716376 \\ \mathrm{C} & 4.890921 & -2.301101 & -2.891540 \\ \mathrm{H} & 5.176927 & -2.957884 & -3.718571 \\ \mathrm{H} & 4.023979 & -1.712593 & -3.204397 \\ \mathrm{H} & 5.715021 & -1.605816 & -2.710628 \\ \mathrm{C} & 3.422196 & -4.141287 & -1.992863 \\ \mathrm{H} & 2.554377 & -3.637947 & -2.424447 \\ \mathrm{H} & 3.788852 & -4.863249 & -2.728903 \\ \mathrm{H} & 3.089358 & -4.698929 & -1.111931\end{array}$

\section{$\mathrm{M}=\mathrm{Gd}$}

$\begin{array}{lrrc}\text { GD } & -0.000031 & -0.362893 & 0.000069 \\ \mathrm{O} & 0.428288 & 1.497325 & 1.642364 \\ \mathrm{H} & 1.390720 & 1.723842 & 1.547907 \\ \mathrm{O} & -0.428479 & 1.496503 & -1.643245 \\ \mathrm{H} & -0.247081 & 1.362756 & -2.583473 \\ \mathrm{H} & 0.246364 & 1.365067 & 2.582693 \\ \mathrm{H} & -1.390903 & 1.723024 & -1.548657 \\ \mathrm{C} & 2.389497 & -2.562288 & 1.363867 \\ \mathrm{C} & 2.624697 & -3.265244 & 2.594663 \\ \mathrm{C} & 3.810481 & -4.015103 & 2.782438 \\ \mathrm{C} & 4.736456 & -4.066685 & 1.750690 \\ \mathrm{C} & 4.492349 & -3.390381 & 0.525285 \\ \mathrm{C} & 3.336400 & -2.645627 & 0.321477 \\ \mathrm{C} & 0.636825 & -2.213243 & 2.648716 \\ \mathrm{C} & 1.482192 & -3.030039 & 3.403161 \\ \mathrm{H} & 3.985915 & -4.548442 & 3.712301 \\ \mathrm{H} & 5.649735 & -4.642315 & 1.866723 \\ \mathrm{H} & 5.220867 & -3.474605 & -0.276107 \\ \mathrm{H} & 3.156626 & -2.179375 & -0.638661 \\ \mathrm{H} & 1.302549 & -3.420117 & 4.395509 \\ \mathrm{C} & -0.667901 & -1.715169 & 3.017683 \\ \mathrm{C} & -1.289797 & -2.043797 & 4.250177 \\ \mathrm{C} & -2.540714 & -1.532427 & 4.546436 \\ \mathrm{H} & -0.781421 & -2.699892 & 4.945695 \\ \mathrm{C} & -2.516225 & -0.404706 & 2.432830 \\ \mathrm{C} & -3.180085 & -0.686553 & 3.618686 \\ \mathrm{H} & -3.027995 & -1.782146 & 5.483985 \\ \mathrm{H} & -4.159099 & -0.264688 & 3.802055 \\ \mathrm{C} & -3.122673 & 0.482260 & 1.412256 \\ \mathrm{C} & -4.891975 & 1.735411 & 0.678297 \\ \mathrm{C} & -4.110801 & 2.079934 & -0.472938 \\ \mathrm{~N} & 1.176582 & -1.900702 & 1.401953\end{array}$




\begin{tabular}{|c|c|c|c|}
\hline $\mathrm{N}$ & -1.293665 & -0.904492 & 2.128211 \\
\hline $\mathbf{N}$ & -4.361859 & 0.955435 & 1.612980 \\
\hline & -2.378621 & 0.761621 & 0.334260 \\
\hline $\mathbf{N}$ & -2.884489 & 1.579365 & -0.592270 \\
\hline$C$ & -6.302870 & 2.258132 & 0.916206 \\
\hline C & -6.872633 & 2.872084 & -0.381434 \\
\hline $\mathrm{H}$ & -7.222113 & 2.068121 & -1.038241 \\
\hline H & -7.759098 & 3.461109 & -0.126296 \\
\hline $\mathrm{C}$ & -5.863865 & 3.749857 & -1.126718 \\
\hline $\mathrm{C}$ & -4.615114 & 2.973129 & -1.603566 \\
\hline $\mathrm{H}$ & -5.548553 & 4.581225 & -0.486036 \\
\hline $\mathrm{H}$ & -6.341219 & 4.203790 & -2.000913 \\
\hline $\mathrm{C}$ & -7.215081 & 1.105204 & 1.387618 \\
\hline $\mathrm{H}$ & -6.871021 & 0.685429 & 2.334532 \\
\hline $\mathrm{H}$ & -8.232411 & 1.483422 & 1.525991 \\
\hline $\mathrm{H}$ & -7.252546 & 0.299131 & 0.648234 \\
\hline $\mathrm{C}$ & -6.216473 & 3.323687 & 2.040624 \\
\hline $\mathrm{H}$ & -7.221704 & 3.686509 & 2.273893 \\
\hline $\mathrm{H}$ & -5.788065 & 2.890264 & 2.947963 \\
\hline $\mathrm{H}$ & -5.604560 & 4.183418 & 1.752748 \\
\hline $\mathrm{C}$ & -4.961807 & 2.063862 & -2.810424 \\
\hline $\mathrm{H}$ & -5.298795 & 2.680447 & -3.649098 \\
\hline $\mathrm{H}$ & -4.085420 & 1.494542 & -3.132177 \\
\hline $\mathrm{H}$ & -5.753323 & 1.346977 & -2.577122 \\
\hline $\mathrm{C}$ & -3.529009 & 3.983908 & -2.028409 \\
\hline $\mathrm{H}$ & -2.663176 & 3.494189 & -2.479650 \\
\hline $\mathrm{H}$ & -3.946342 & 4.669506 & -2.772032 \\
\hline $\mathrm{H}$ & -3.180949 & 4.580357 & -1.179357 \\
\hline $\mathrm{C}$ & -2.389518 & -2.562494 & -1.363314 \\
\hline $\mathrm{C}$ & -2.624681 & -3.265811 & -2.593907 \\
\hline $\mathrm{C}$ & -3.810498 & -4.015650 & -2.781524 \\
\hline $\mathrm{C}$ & -4.736537 & -4.066864 & -1.749809 \\
\hline $\mathrm{C}$ & -4.492459 & -3.390212 & -0.524594 \\
\hline $\mathrm{C}$ & -3.336475 & -2.645463 & -0.320946 \\
\hline $\mathrm{C}$ & -0.636716 & -2.213992 & -2.648139 \\
\hline $\mathrm{C}$ & -1.482086 & -3.030952 & -3.402391 \\
\hline $\mathrm{H}$ & -3.985916 & -4.549264 & -3.711232 \\
\hline $\mathrm{H}$ & -5.649839 & -4.642480 & -1.865724 \\
\hline $\mathrm{H}$ & -5.221019 & -3.474163 & 0.276789 \\
\hline $\mathrm{H}$ & -3.156708 & -2.178944 & 0.639067 \\
\hline $\mathrm{H}$ & -1.302399 & -3.421352 & -4.394605 \\
\hline $\mathrm{C}$ & 0.668093 & -1.716127 & -3.017127 \\
\hline $\mathrm{C}$ & 1.290196 & -2.045381 & -4.249344 \\
\hline 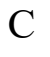 & 2.541193 & -1.534209 & -4.545619 \\
\hline $\mathrm{H}$ & 0.781922 & -2.701802 & -4.944628 \\
\hline$C$ & 2.516377 & -0.405493 & -2.432547 \\
\hline
\end{tabular}




$\begin{array}{lrrr}\mathrm{C} & 3.180434 & -0.687931 & -3.618152 \\ \mathrm{H} & 3.028639 & -1.784405 & -5.482954 \\ \mathrm{H} & 4.159500 & -0.266196 & -3.801540 \\ \mathrm{C} & 3.122727 & 0.481867 & -1.412253 \\ \mathrm{C} & 4.891955 & 1.735366 & -0.678699 \\ \mathrm{C} & 4.110712 & 2.080287 & 0.472373 \\ \mathrm{~N} & -1.176548 & -1.901007 & -1.401517 \\ \mathrm{~N} & 1.293734 & -0.905067 & -2.127916 \\ \mathrm{~N} & 4.361906 & 0.955018 & -1.613107 \\ \mathrm{~N} & 2.378625 & 0.761574 & -0.334393 \\ \mathrm{~N} & 2.884427 & 1.579703 & 0.591852 \\ \mathrm{C} & 6.302872 & 2.257979 & -0.916712 \\ \mathrm{C} & 6.872524 & 2.872525 & 0.380695 \\ \mathrm{H} & 7.222001 & 2.068866 & 1.037877 \\ \mathrm{H} & 7.758976 & 3.461481 & 0.125358 \\ \mathrm{C} & 5.863658 & 3.750568 & 1.125531 \\ \mathrm{C} & 4.614934 & 2.973969 & 1.602658 \\ \mathrm{H} & 5.548327 & 4.581624 & 0.484455 \\ \mathrm{H} & 6.340930 & 4.204929 & 1.999549 \\ \mathrm{C} & 7.215115 & 1.104823 & -1.387513 \\ \mathrm{H} & 6.871134 & 0.684621 & -2.334268 \\ \mathrm{H} & 8.232461 & 1.482966 & -1.525968 \\ \mathrm{H} & 7.252505 & 0.299086 & -0.647759 \\ \mathrm{C} & 6.216592 & 3.323018 & -2.041630 \\ \mathrm{H} & 7.221850 & 3.685724 & -2.274961 \\ \mathrm{H} & 5.788269 & 2.889180 & -2.948809 \\ \mathrm{H} & 5.604655 & 4.182883 & -1.754206 \\ \mathrm{C} & 4.961622 & 2.065221 & 2.809909 \\ \mathrm{H} & 5.298568 & 2.682168 & 3.648333 \\ \mathrm{H} & 4.085242 & 1.496012 & 3.131876 \\ \mathrm{H} & 5.753167 & 1.348263 & 2.576931 \\ \mathrm{C} & 3.528754 & 3.984863 & 2.027041 \\ \mathrm{H} & 2.662941 & 3.495277 & 2.478467 \\ \mathrm{H} & 3.946020 & 4.670795 & 2.770391 \\ \mathrm{H} & 3.180679 & 4.580934 & 1.177731\end{array}$

$\mathrm{M}=\mathrm{Am}$
AM $\quad 0.373988-0.348769-0.067183$
$\begin{array}{llll}\mathrm{O} & -0.679625 & 0.700406 & -2.156301\end{array}$
$\mathrm{H} \quad-1.594359 \quad 0.985946 \quad-1.912516$
$\begin{array}{llll}\text { O } & 1.177536 & 0.875294 & 2.173033\end{array}$
$\mathrm{H} \quad 1.575874 \quad-0.007661 \quad 2.374633$
$\mathrm{H} \quad-0.760439 \quad 0.004706 \quad-2.827641$
$\mathrm{H} \quad 0.699625 \quad 1.159005 \quad 2.964834$
C $\quad-1.118475 \quad-3.152493 \quad-1.589406$ 


\begin{tabular}{|c|c|c|c|}
\hline $\mathrm{C}$ & -0.722273 & -4.218647 & -2.461588 \\
\hline 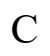 & -1.616225 & -5.269290 & -2.765551 \\
\hline $\mathrm{C}$ & -2.889058 & -5.245344 & -2.209397 \\
\hline $\mathrm{C}$ & -3.282389 & -4.185668 & -1.353694 \\
\hline $\mathrm{C}$ & -2.413925 & -3.144690 & -1.038686 \\
\hline $\mathrm{C}$ & 0.953951 & -2.732218 & -2.236148 \\
\hline$C$ & 0.612466 & -3.925619 & -2.862671 \\
\hline $\mathrm{H}$ & -1.313537 & -6.079904 & -3.421834 \\
\hline $\mathrm{H}$ & -3.593676 & -6.041652 & -2.428400 \\
\hline $\mathrm{H}$ & -4.283683 & -4.192327 & -0.932890 \\
\hline $\mathrm{H}$ & -2.739916 & -2.350657 & -0.378511 \\
\hline $\mathrm{H}$ & 1.228589 & -4.514703 & -3.527590 \\
\hline $\mathrm{C}$ & 2.182594 & -1.973222 & -2.362300 \\
\hline $\mathrm{C}$ & 3.265414 & -2.406965 & -3.155399 \\
\hline $\mathrm{C}$ & 4.394990 & -1.610265 & -3.260093 \\
\hline $\mathrm{H}$ & 3.205457 & -3.355613 & -3.673872 \\
\hline $\mathrm{C}$ & 3.338639 & -0.013197 & -1.816122 \\
\hline $\mathrm{C}$ & 4.440159 & -0.382447 & -2.581925 \\
\hline $\mathrm{H}$ & 5.238186 & -1.929943 & -3.864507 \\
\hline $\mathrm{H}$ & 5.299834 & 0.271484 & -2.633880 \\
\hline $\mathrm{C}$ & 3.328266 & 1.302301 & -1.119167 \\
\hline $\mathrm{C}$ & 2.210014 & 3.117538 & -0.279640 \\
\hline $\mathrm{C}$ & 3.476757 & 3.664837 & 0.047875 \\
\hline $\mathrm{N}$ & -0.083886 & -2.240753 & -1.442330 \\
\hline $\mathrm{N}$ & 2.241051 & -0.791535 & -1.696842 \\
\hline $\mathrm{N}$ & 2.152704 & 1.854693 & -0.746978 \\
\hline $\mathrm{N}$ & 4.529973 & 1.882355 & -0.972924 \\
\hline $\mathrm{N}$ & 4.599822 & 3.027386 & -0.318189 \\
\hline $\mathrm{C}$ & 0.933159 & 3.963559 & -0.246040 \\
\hline $\mathrm{C}$ & 1.275458 & 5.417263 & 0.166769 \\
\hline $\mathrm{H}$ & 1.649840 & 5.961301 & -0.706421 \\
\hline $\mathrm{H}$ & 0.348938 & 5.920643 & 0.461294 \\
\hline $\mathrm{C}$ & 2.307987 & 5.492196 & 1.291768 \\
\hline $\mathrm{C}$ & 3.680574 & 4.954869 & 0.838693 \\
\hline $\mathrm{H}$ & 1.958887 & 4.920612 & 2.160502 \\
\hline $\mathrm{H}$ & 2.423970 & 6.526099 & 1.631308 \\
\hline $\mathrm{C}$ & 0.353003 & 3.983791 & -1.681856 \\
\hline $\mathrm{H}$ & 0.069234 & 2.987251 & -2.021406 \\
\hline $\mathrm{H}$ & -0.527961 & 4.633255 & -1.706147 \\
\hline $\mathrm{H}$ & 1.082478 & 4.388776 & -2.390160 \\
\hline $\mathrm{C}$ & -0.119508 & 3.393479 & 0.724057 \\
\hline $\mathrm{H}$ & -1.019552 & 4.014026 & 0.681244 \\
\hline $\mathrm{H}$ & -0.419814 & 2.379040 & 0.454233 \\
\hline $\mathrm{H}$ & 0.241082 & 3.381568 & 1.754755 \\
\hline $\mathrm{C}$ & 4.418410 & 5.987147 & -0.046505 \\
\hline $\mathrm{H}$ & 4.619782 & 6.893467 & 0.532590 \\
\hline
\end{tabular}




\begin{tabular}{|c|c|c|c|}
\hline $\mathrm{H}$ & 5.370573 & 5.578404 & -0.391660 \\
\hline & 3.835123 & 6.270941 & -0.927530 \\
\hline $\mathrm{C}$ & 4.553843 & 4.642832 & 2.075172 \\
\hline $\mathrm{H}$ & 5.539975 & 4.280356 & 1.778450 \\
\hline & 4.683126 & 5.551967 & 2.670871 \\
\hline & 4.086255 & 3.884324 & 2.711713 \\
\hline & 3.072269 & -2.137968 & 1.577419 \\
\hline & 3.176605 & -3.358568 & 2.321543 \\
\hline$C$ & 4.432633 & -3.978265 & 2.521644 \\
\hline$C$ & 5.564580 & -3.365492 & 2.005307 \\
\hline $\mathrm{C}$ & 5.463656 & -2.135659 & 1.303022 \\
\hline$C$ & 4.237630 & -1.518254 & 1.086714 \\
\hline $\mathrm{C}$ & 1.037833 & -2.655608 & 2.270113 \\
\hline $\mathrm{C}$ & 1.861671 & -3.665812 & 2.761310 \\
\hline $\mathrm{H}$ & 4.508053 & -4.907673 & 3.078253 \\
\hline H & 6.541931 & -3.815447 & 2.149807 \\
\hline $\mathrm{H}$ & 6.368727 & -1.662823 & 0.933655 \\
\hline $\mathrm{H}$ & 4.202018 & -0.567238 & 0.571438 \\
\hline $\mathrm{H}$ & 1.566042 & -4.519108 & 3.356001 \\
\hline $\mathrm{C}$ & -0.375343 & -2.479652 & 2.507405 \\
\hline$C$ & -1.075518 & -3.263184 & 3.461223 \\
\hline $\mathrm{C}$ & -2.403650 & -2.993609 & 3.732470 \\
\hline $\mathrm{H}$ & -0.553882 & -4.053028 & 3.986881 \\
\hline $\mathrm{C}$ & -2.316065 & -1.251736 & 2.089342 \\
\hline $\mathrm{C}$ & -3.046582 & -1.948056 & 3.042171 \\
\hline $\mathrm{H}$ & -2.944794 & -3.576985 & 4.470758 \\
\hline $\mathrm{H}$ & -4.083028 & -1.694174 & 3.218604 \\
\hline $\mathrm{C}$ & -2.973535 & -0.222011 & 1.254310 \\
\hline $\mathrm{C}$ & -4.861098 & 0.950096 & 0.689041 \\
\hline $\mathrm{C}$ & -4.152239 & 1.445277 & -0.458963 \\
\hline $\mathrm{N}$ & 1.750822 & -1.711161 & 1.518505 \\
\hline $\mathrm{N}$ & -1.011995 & -1.502076 & 1.816757 \\
\hline $\mathrm{N}$ & -4.252888 & 0.103633 & 1.508731 \\
\hline $\mathrm{N}$ & -2.257196 & 0.298671 & 0.249817 \\
\hline $\mathrm{N}$ & -2.877727 & 1.109878 & -0.620095 \\
\hline $\mathrm{C}$ & -6.278799 & 1.382313 & 1.037627 \\
\hline $\mathrm{C}$ & -6.973221 & 1.991786 & -0.200324 \\
\hline $\mathrm{H}$ & -7.311901 & 1.183280 & -0.857192 \\
\hline $\mathrm{H}$ & -7.878178 & 2.510432 & 0.131158 \\
\hline $\mathrm{C}$ & -6.081861 & 2.959490 & -0.983239 \\
\hline $\mathrm{C}$ & -4.802041 & 2.298550 & -1.545593 \\
\hline $\mathrm{H}$ & -5.799439 & 3.805151 & -0.346076 \\
\hline $\mathrm{H}$ & -6.644724 & 3.385050 & -1.819963 \\
\hline 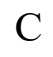 & -7.097749 & 0.179989 & 1.550761 \\
\hline $\mathrm{H}$ & -6.673384 & -0.233185 & 2.467223 \\
\hline $\mathrm{H}$ & -8.121124 & 0.504790 & 1.760781 \\
\hline
\end{tabular}




$\begin{array}{llll}\mathrm{H} & -7.144953 & -0.618516 & 0.803689 \\ \mathrm{C} & -6.158947 & 2.430600 & 2.177288 \\ \mathrm{H} & -7.160324 & 2.742510 & 2.487774 \\ \mathrm{H} & -5.650282 & 1.999117 & 3.043524 \\ \mathrm{H} & -5.607856 & 3.323199 & 1.867504 \\ \mathrm{C} & -5.146066 & 1.362005 & -2.733290 \\ \mathrm{H} & -5.605782 & 1.943591 & -3.537724 \\ \mathrm{H} & -4.243334 & 0.888606 & -3.130102 \\ \mathrm{H} & -5.841294 & 0.567056 & -2.450794 \\ \mathrm{C} & -3.841777 & 3.400826 & -2.036415 \\ \mathrm{H} & -2.956240 & 2.991133 & -2.526301 \\ \mathrm{H} & -4.361915 & 4.034091 & -2.761264 \\ \mathrm{H} & -3.512473 & 4.038501 & -1.209907\end{array}$

$\mathrm{M}=\mathrm{Cm}$

$\begin{array}{lrcc}\mathrm{CM} & -0.000007 & -0.352538 & -0.000029 \\ \mathrm{O} & -0.446760 & 1.553193 & -1.709058 \\ \mathrm{H} & -1.407530 & 1.764466 & -1.580046 \\ \mathrm{O} & 0.446643 & 1.553253 & 1.708897 \\ \mathrm{H} & 0.310236 & 1.379845 & 2.650608 \\ \mathrm{H} & -0.310670 & 1.379513 & -2.650765 \\ \mathrm{H} & 1.407448 & 1.764525 & 1.580145 \\ \mathrm{C} & -2.356074 & -2.571022 & -1.441168 \\ \mathrm{C} & -2.558459 & -3.285628 & -2.670075 \\ \mathrm{C} & -3.736619 & -4.040854 & -2.879527 \\ \mathrm{C} & -4.687664 & -4.084568 & -1.870491 \\ \mathrm{C} & -4.476698 & -3.394080 & -0.646833 \\ \mathrm{C} & -3.328106 & -2.644667 & -0.421924 \\ \mathrm{C} & -0.574527 & -2.221723 & -2.688264 \\ \mathrm{C} & -1.398042 & -3.050067 & -3.453985 \\ \mathrm{H} & -3.888055 & -4.583350 & -3.808217 \\ \mathrm{H} & -5.596458 & -4.663678 & -2.003259 \\ \mathrm{H} & -5.225830 & -3.470717 & 0.136080 \\ \mathrm{H} & -3.174011 & -2.162413 & 0.535591 \\ \mathrm{H} & -1.195634 & -3.446584 & -4.439344 \\ \mathrm{C} & 0.734707 & -1.716696 & -3.036168 \\ \mathrm{C} & 1.378741 & -2.049821 & -4.255580 \\ \mathrm{C} & 2.632394 & -1.534903 & -4.534412 \\ \mathrm{H} & 0.885703 & -2.712310 & -4.956062 \\ \mathrm{C} & 2.567772 & -0.393172 & -2.429092 \\ \mathrm{C} & 3.252462 & -0.680265 & -3.602234 \\ \mathrm{H} & 3.136062 & -1.788609 & -5.462191 \\ \mathrm{H} & 4.232175 & -0.254922 & -3.773013 \\ \mathrm{C} & 3.157123 & 0.506076 & -1.407608 \\ \mathrm{C} & 4.912179 & 1.779798 & -0.672164\end{array}$




\begin{tabular}{|c|c|c|c|}
\hline $\mathrm{C}$ & 4.119959 & 2.130297 & 0.469519 \\
\hline $\mathbf{N}$ & -1.146426 & -1.905222 & -1.457237 \\
\hline $\mathrm{N}$ & 1.343194 & -0.896907 & -2.143150 \\
\hline V & 4.394947 & 0.986213 & -1.602552 \\
\hline $\mathbf{N}$ & 2.404974 & 0.788727 & -0.336293 \\
\hline$v$ & 2.898238 & 1.618520 & 0.587164 \\
\hline $\mathrm{C}$ & 6.322260 & 2.308024 & -0.903409 \\
\hline $\mathrm{C}$ & 6.877221 & 2.937258 & 0.393330 \\
\hline $\mathrm{H}$ & 7.223266 & 2.141208 & 1.061614 \\
\hline $\mathrm{H}$ & 7.763884 & 3.527122 & 0.140864 \\
\hline $\mathrm{C}$ & 5.857762 & 3.818389 & 1.119606 \\
\hline $\mathrm{C}$ & 4.607788 & 3.041526 & 1.593348 \\
\hline $\mathrm{H}$ & 5.544873 & 4.641219 & 0.466819 \\
\hline $\mathrm{H}$ & 6.324828 & 4.284146 & 1.993122 \\
\hline $\mathrm{C}$ & 7.244820 & 1.155618 & -1.355560 \\
\hline $\mathrm{H}$ & 6.911351 & 0.724482 & -2.301168 \\
\hline $\mathrm{H}$ & 8.261226 & 1.538070 & -1.489049 \\
\hline $\mathrm{H}$ & 7.280606 & 0.357143 & -0.607835 \\
\hline $\mathrm{C}$ & 6.240130 & 3.362102 & -2.038873 \\
\hline $\mathrm{H}$ & 7.245288 & 3.728803 & -2.266399 \\
\hline $\mathrm{H}$ & 5.822705 & 2.917314 & -2.945845 \\
\hline $\mathrm{H}$ & 5.620392 & 4.220852 & -1.765188 \\
\hline $\mathrm{C}$ & 4.946023 & 2.151501 & 2.816695 \\
\hline $\mathrm{H}$ & 5.269922 & 2.781687 & 3.650420 \\
\hline $\mathrm{H}$ & 4.069387 & 1.581554 & 3.136805 \\
\hline $\mathrm{H}$ & 5.744420 & 1.436222 & 2.602383 \\
\hline $\mathrm{C}$ & 3.512105 & 4.053030 & 1.991680 \\
\hline $\mathrm{H}$ & 2.643171 & 3.566438 & 2.440228 \\
\hline $\mathrm{H}$ & 3.918283 & 4.751514 & 2.729512 \\
\hline $\mathrm{H}$ & 3.170857 & 4.635401 & 1.130121 \\
\hline $\mathrm{C}$ & 2.356161 & -2.570926 & 1.441127 \\
\hline $\mathrm{C}$ & 2.558531 & -3.285556 & 2.670021 \\
\hline $\mathrm{C}$ & 3.736703 & -4.040758 & 2.879493 \\
\hline $\mathrm{C}$ & 4.687780 & -4.084423 & 1.870485 \\
\hline $\mathrm{C}$ & 4.476838 & -3.393896 & 0.646843 \\
\hline $\mathrm{C}$ & 3.328237 & -2.644501 & 0.421918 \\
\hline $\mathrm{C}$ & 0.574596 & -2.221654 & 2.688207 \\
\hline $\mathrm{C}$ & 1.398098 & -3.050027 & 3.453914 \\
\hline $\mathrm{H}$ & 3.888126 & -4.583267 & 3.808177 \\
\hline $\mathrm{H}$ & 5.596582 & -4.663517 & 2.003261 \\
\hline $\mathrm{H}$ & 5.225999 & -3.470485 & -0.136048 \\
\hline $\mathrm{H}$ & 3.174176 & -2.162205 & -0.535582 \\
\hline $\mathrm{H}$ & 1.195688 & -3.446559 & 4.439266 \\
\hline $\mathrm{C}$ & -0.734657 & -1.716677 & 3.036103 \\
\hline $\mathrm{C}$ & -1.378675 & -2.049831 & 4.255519 \\
\hline $\mathrm{C}$ & -2.632356 & -1.534984 & 4.534349 \\
\hline
\end{tabular}




$\begin{array}{lrrr}\mathrm{H} & -0.885600 & -2.712285 & 4.956006 \\ \mathrm{C} & -2.567770 & -0.393194 & 2.429060 \\ \mathrm{C} & -3.252464 & -0.680361 & 3.602181 \\ \mathrm{H} & -3.136016 & -1.788728 & 5.462121 \\ \mathrm{H} & -4.232207 & -0.255088 & 3.772956 \\ \mathrm{C} & -3.157135 & 0.506096 & 1.407621 \\ \mathrm{C} & -4.912251 & 1.779744 & 0.672183 \\ \mathrm{C} & -4.119969 & 2.130467 & -0.469384 \\ \mathrm{~N} & 1.146492 & -1.905168 & 1.457169 \\ \mathrm{~N} & -1.343171 & -0.896880 & 2.143106 \\ \mathrm{~N} & -4.395013 & 0.986106 & 1.602526 \\ \mathrm{~N} & -2.404999 & 0.788795 & 0.336304 \\ \mathrm{~N} & -2.898260 & 1.618676 & -0.587080 \\ \mathrm{C} & -6.322443 & 2.307714 & 0.903316 \\ \mathrm{C} & -6.877301 & 2.937105 & -0.393390 \\ \mathrm{H} & -7.223107 & 2.141129 & -1.061886 \\ \mathrm{H} & -7.764098 & 3.526778 & -0.140954 \\ \mathrm{C} & -5.857857 & 3.818535 & -1.119330 \\ \mathrm{C} & -4.607710 & 3.041943 & -1.593055 \\ \mathrm{H} & -5.545180 & 4.641266 & -0.466316 \\ \mathrm{H} & -6.324859 & 4.284417 & -1.992812 \\ \mathrm{C} & -7.244883 & 1.155065 & 1.355099 \\ \mathrm{H} & -6.911477 & 0.723788 & 2.300665 \\ \mathrm{H} & -8.261368 & 1.537328 & 1.488525 \\ \mathrm{H} & -7.280434 & 0.356742 & 0.607201 \\ \mathrm{C} & -6.240665 & 3.361581 & 2.039001 \\ \mathrm{H} & -7.245914 & 3.728096 & 2.266426 \\ \mathrm{H} & -5.823333 & 2.916674 & 2.945957 \\ \mathrm{H} & -5.621002 & 4.220474 & 1.765597 \\ \mathrm{C} & -4.945621 & 2.152233 & -2.816722 \\ \mathrm{H} & -5.269433 & 2.782619 & -3.650329 \\ \mathrm{H} & -4.068865 & 1.582472 & -3.136828 \\ \mathrm{H} & -5.743981 & 1.436810 & -2.602756 \\ \mathrm{C} & -3.512054 & 4.053679 & -1.990884 \\ \mathrm{H} & -2.642943 & 3.567297 & -2.439315 \\ \mathrm{H} & -3.918137 & 4.752286 & -2.728652 \\ \mathrm{H} & -3.171097 & 4.635890 & -1.129102\end{array}$

$\left[\mathrm{ML}_{2}\right]^{1+}$

$\mathrm{M}=\mathrm{Eu}$
$\begin{array}{llll}\text { EU } & 0.000000 & 0.758319 & 0.000001\end{array}$
$\begin{array}{llll}\mathrm{C} & -2.192434 & 3.017472 & -1.600091\end{array}$
$\begin{array}{llll}\text { C } & -2.350906 & 3.710509 & -2.843717\end{array}$
$\begin{array}{llll}\text { C } & -3.446442 & 4.576784 & -3.039866\end{array}$ 


$\begin{array}{lccc}\mathrm{C} & -4.363395 & 4.739639 & -1.999602 \\ \mathrm{C} & -4.198867 & 4.056644 & -0.773223 \\ \mathrm{C} & -3.117137 & 3.195421 & -0.559853 \\ \mathrm{C} & -0.494594 & 2.420855 & -2.871365 \\ \mathrm{C} & -1.244203 & 3.314115 & -3.650727 \\ \mathrm{H} & -3.575092 & 5.111158 & -3.976560 \\ \mathrm{H} & -5.212460 & 5.403883 & -2.127122 \\ \mathrm{H} & -4.923615 & 4.211842 & 0.020166 \\ \mathrm{H} & -2.997803 & 2.693299 & 0.396781 \\ \mathrm{H} & -1.032832 & 3.638058 & -4.660784 \\ \mathrm{C} & 0.725075 & 1.708918 & -3.230896 \\ \mathrm{C} & 1.371725 & 1.870294 & -4.477595 \\ \mathrm{C} & 2.525488 & 1.145878 & -4.745971 \\ \mathrm{H} & 0.967089 & 2.555937 & -5.212312 \\ \mathrm{C} & 2.344106 & 0.157904 & -2.572220 \\ \mathrm{C} & 3.032213 & 0.262725 & -3.776992 \\ \mathrm{H} & 3.033273 & 1.259661 & -5.698951 \\ \mathrm{H} & 3.925299 & -0.325199 & -3.943366 \\ \mathrm{C} & 2.802673 & -0.755987 & -1.491329 \\ \mathrm{C} & 4.298514 & -2.280339 & -0.677524 \\ \mathrm{C} & 3.527671 & -2.326019 & 0.526982 \\ \mathrm{~N} & -1.054476 & 2.227248 & -1.623931 \\ \mathrm{~N} & 1.223375 & 0.860930 & -2.302658 \\ \mathrm{~N} & 3.915554 & -1.478437 & -1.670055 \\ \mathrm{H} & 2.048431 & -0.801317 & -0.381006 \\ \mathrm{H} & 2.856 \\ \mathrm{~N} & 2.417748 & -1.592344 & 0.628244 \\ \mathrm{C} & 5.575323 & -3.086319 & -0.880686 \\ \mathrm{C} & 5.685910 & -4.190531 & 0.194008 \\ \mathrm{H} & 5.035201 & -5.028125 & -0.081472 \\ \mathrm{H} & 6.707205 & -4.584336 & 0.182476 \\ \mathrm{C} & 5.333493 & -3.700118 & 1.601193 \\ \mathrm{C} & 3.874952 & -3.205158 & 1.726262 \\ \mathrm{H} & 6.013873 & -2.892822 & 1.894213 \\ \mathrm{H} & 5.489674 & -4.506018 & 2.325445 \\ \mathrm{C} & 5.575659 & -3.728289 & -2.284320 \\ \mathrm{H} & 5.551121 & -2.971449 & -3.070320 \\ \mathrm{H} & 6.483537 & -4.326277 & -2.408270 \\ \mathrm{H} & 4.715293 & -4.391743 & -2.419385 \\ \mathrm{H} & 7.765321 & -2.095632 & -0.781230 \\ \mathrm{H} & 2.83571 & -1.304764 & -1.529659 \\ \mathrm{H} & -1.624503 & 0.203341 \\ \mathrm{H} & -5.398735 & 1.744160 \\ \mathrm{H} & -4.031864 & 2.613315 \\ \mathrm{H} & -5.019424 & 0.847172\end{array}$




\begin{tabular}{|c|c|c|c|}
\hline $\mathrm{C}$ & 3.717475 & -2.404257 & 3.036243 \\
\hline $\mathrm{H}$ & 2.686248 & -2.078902 & 3.185254 \\
\hline & 4.008476 & -3.033081 & 3.883433 \\
\hline 11 & 4.358444 & -1.517057 & 3.039505 \\
\hline $\mathrm{C}$ & 2.192440 & 3.017458 & 1.600105 \\
\hline $\mathrm{C}$ & 2.350916 & 3.710485 & 2.843736 \\
\hline C & 3.446453 & 4.576759 & 3.039888 \\
\hline $\mathrm{C}$ & 4.363402 & 4.739621 & 1.999622 \\
\hline $\mathrm{C}$ & 4.198871 & 4.056635 & 0.773239 \\
\hline $\mathrm{C}$ & 3.117140 & 3.195414 & 0.559866 \\
\hline C & 0.494603 & 2.420833 & 2.871380 \\
\hline $\mathrm{C}$ & 1.244215 & 3.314086 & 3.650746 \\
\hline $\mathrm{H}$ & 3.575106 & 5.111126 & 3.976586 \\
\hline $\mathrm{H}$ & 5.212468 & 5.403864 & 2.127145 \\
\hline $\mathrm{H}$ & 4.923617 & 4.211839 & -0.020151 \\
\hline $\mathrm{H}$ & 2.997803 & 2.693300 & -0.396772 \\
\hline $\mathrm{H}$ & 1.032847 & 3.638021 & 4.660807 \\
\hline $\mathrm{C}$ & -0.725066 & 1.708894 & 3.230908 \\
\hline $\mathrm{C}$ & -1.371712 & 1.870261 & 4.477610 \\
\hline $\mathrm{C}$ & -2.525475 & 1.145844 & 4.745983 \\
\hline $\mathrm{H}$ & -0.967074 & 2.555898 & 5.212332 \\
\hline $\mathrm{C}$ & -2.344101 & 0.157888 & \\
\hline $\mathrm{C}$ & -3.032204 & 0.262700 & 3.776998 \\
\hline $\mathrm{H}$ & -3.033257 & 1.259620 & 5.698965 \\
\hline $\mathrm{H}$ & -3.925290 & -0.325224 & 3.943370 \\
\hline $\mathrm{C}$ & -2.802672 & -0.755993 & 1.491327 \\
\hline $\mathrm{C}$ & -4.298518 & -2.280336 & 0.677513 \\
\hline $\mathrm{C}$ & -3.527681 & -2.326006 & -0.526997 \\
\hline $\mathrm{N}$ & 1.054481 & 2.227235 & 1.623942 \\
\hline $\mathrm{N}$ & -1.223370 & 0.860915 & 2.302665 \\
\hline $\mathrm{N}$ & -3.915554 & -1.478444 & 1.670050 \\
\hline $\mathrm{N}$ & -2.048434 & -0.801315 & 0.381000 \\
\hline $\mathrm{N}$ & -2.417756 & -1.592332 & -0.628256 \\
\hline $\mathrm{C}$ & -5.575326 & -3.086318 & 0.880674 \\
\hline $\mathrm{C}$ & -5.685918 & -4.190520 & -0.194031 \\
\hline $\mathrm{H}$ & -5.035208 & -5.028116 & 0.081439 \\
\hline $\mathrm{H}$ & -6.707213 & -4.584325 & -0.182497 \\
\hline $\mathrm{C}$ & -5.333509 & -3.700093 & -1.601213 \\
\hline $\mathrm{C}$ & -3.874968 & -3.205132 & -1.726284 \\
\hline $\mathrm{H}$ & -6.013890 & -2.892794 & -1.894221 \\
\hline $\mathrm{H}$ & -5.489693 & -4.505986 & -2.325471 \\
\hline $\mathrm{C}$ & -5.575654 & -3.728301 & 2.284302 \\
\hline $\mathrm{H}$ & -5.551112 & -2.971469 & 3.070308 \\
\hline $\mathrm{H}$ & -6.483531 & -4.326291 & 2.408251 \\
\hline $\mathrm{H}$ & -4.715288 & -4.391756 & 2.419355 \\
\hline$C$ & -6.765325 & -2.095630 & 0.781234 \\
\hline
\end{tabular}




$\begin{array}{lrrr}\mathrm{H} & -7.700603 & -2.632559 & 0.964943 \\ \mathrm{H} & -6.669572 & -1.304769 & 1.529670 \\ \mathrm{H} & -6.832547 & -1.624492 & -0.203332 \\ \mathrm{C} & -2.887110 & -4.398709 & -1.744199 \\ \mathrm{H} & -3.089507 & -5.031829 & -2.613360 \\ \mathrm{H} & -1.856672 & -4.039419 & -1.813568 \\ \mathrm{H} & -2.969465 & -5.019408 & -0.847217 \\ \mathrm{C} & -3.717498 & -2.404217 & -3.036257 \\ \mathrm{H} & -2.686271 & -2.078862 & -3.185270 \\ \mathrm{H} & -4.008503 & -3.033033 & -3.883452 \\ \mathrm{H} & -4.358466 & -1.517018 & -3.039506\end{array}$

\section{$\mathrm{M}=\mathrm{Gd}$}

$\begin{array}{lccc}\text { GD } & -0.000003 & 0.791228 & -0.000002 \\ \mathrm{C} & -2.216446 & 3.042100 & -1.281844 \\ \mathrm{C} & -2.514792 & 3.705662 & -2.517009 \\ \mathrm{C} & -3.604251 & 4.605293 & -2.593984 \\ \mathrm{C} & -4.365393 & 4.826957 & -1.454031 \\ \mathrm{C} & -4.059367 & 4.170599 & -0.231860 \\ \mathrm{C} & -2.994269 & 3.281639 & -0.132290 \\ \mathrm{C} & -0.723698 & 2.360135 & -2.764057 \\ \mathrm{C} & -1.540508 & 3.254130 & -3.453703 \\ \mathrm{H} & -3.837914 & 5.115617 & -3.523710 \\ \mathrm{H} & -5.203475 & 5.516247 & -1.487410 \\ \mathrm{H} & -4.668010 & 4.377441 & 0.643339 \\ \mathrm{H} & -2.765466 & 2.804591 & 0.817598 \\ \mathrm{H} & -1.453497 & 3.550356 & -4.490277 \\ \mathrm{C} & 0.421247 & 1.607652 & -3.222475 \\ \mathrm{C} & 0.946851 & 1.678145 & -4.536188 \\ \mathrm{C} & 2.053085 & 0.913291 & -4.871061 \\ \mathrm{H} & 0.482733 & 2.331636 & -5.265243 \\ \mathrm{C} & 2.073865 & 0.047372 & -2.640208 \\ \mathrm{C} & 2.640896 & 0.069521 & -3.905675 \\ \mathrm{H} & 2.466909 & 0.961942 & -5.873692 \\ \mathrm{H} & 3.503370 & -0.545949 & -4.125885 \\ \mathrm{C} & 2.594169 & -0.810670 & -1.549189 \\ \mathrm{C} & 4.106889 & -2.306441 & -0.718676 \\ \mathrm{C} & 3.404876 & -2.258654 & 0.531117 \\ \mathrm{~N} & -1.121406 & 2.212358 & -1.434434 \\ \mathrm{~N} & 0.998167 & 0.795845 & -2.301410 \\ \mathrm{~N} & 3.680495 & -1.566612 & -1.741458 \\ \mathrm{~N} & 1.905697 & -0.772615 & -0.395545 \\ \mathrm{~N} & 2.314066 & -1.501998 & 0.644947 \\ \mathrm{C} & 5.358696 & -3.145155 & -0.936744 \\ \mathrm{C} & 5.520429 & -4.173775 & 0.204277\end{array}$




\begin{tabular}{|c|c|c|c|}
\hline $\mathrm{H}$ & 4.847854 & -5.020138 & 0.025076 \\
\hline & 6.535787 & -4.580270 & 0.162025 \\
\hline C & 5.254414 & -3.582945 & 1.591536 \\
\hline C & 3.810073 & -3.061643 & 1.764770 \\
\hline $\mathrm{H}$ & 5.957788 & -2.766529 & 1.789026 \\
\hline & 5.444052 & -4.339014 & 2.360026 \\
\hline$C$ & 5.270406 & -3.881492 & -2.290636 \\
\hline $\mathrm{H}$ & 5.209263 & -3.180027 & -3.124452 \\
\hline $\mathrm{H}$ & 6.163221 & -4.499683 & -2.423657 \\
\hline $\mathrm{H}$ & 4.396877 & -4.540330 & -2.330162 \\
\hline $\mathrm{C}$ & 6.562896 & -2.166173 & -0.975129 \\
\hline $\mathrm{H}$ & 7.479734 & -2.729585 & -1.171502 \\
\hline $\mathrm{H}$ & 6.433557 & -1.429591 & -1.772137 \\
\hline $\mathrm{H}$ & 6.691271 & -1.627038 & -0.032503 \\
\hline $\mathrm{C}$ & 2.813092 & -4.238292 & 1.916161 \\
\hline $\mathrm{H}$ & 3.059615 & -4.816175 & 2.811860 \\
\hline $\mathrm{H}$ & 1.791831 & -3.861740 & 2.021491 \\
\hline $\mathrm{H}$ & 2.837144 & -4.917242 & 1.058772 \\
\hline $\mathrm{C}$ & 3.734280 & -2.173809 & 3.025142 \\
\hline $\mathrm{H}$ & 2.716001 & -1.827834 & 3.211858 \\
\hline $\mathrm{H}$ & 4.069103 & -2.748918 & 3.893911 \\
\hline $\mathrm{H}$ & 4.380669 & -1.295539 & 2.932994 \\
\hline $\mathrm{C}$ & 2.216461 & 3.042074 & 1.281852 \\
\hline $\mathrm{C}$ & 2.514811 & 3.705626 & 2.517021 \\
\hline $\mathrm{C}$ & 3.604275 & 4.605250 & 2.594003 \\
\hline $\mathrm{C}$ & 4.365418 & 4.826917 & 1.454052 \\
\hline $\mathrm{C}$ & 4.059388 & 4.170571 & 0.231876 \\
\hline $\mathrm{C}$ & 2.994284 & 3.281618 & 0.132299 \\
\hline $\mathrm{C}$ & 0.723708 & 2.360109 & 2.764060 \\
\hline $\mathrm{C}$ & 1.540523 & 3.254093 & 3.453712 \\
\hline $\mathrm{H}$ & 3.837941 & 5.115564 & 3.523733 \\
\hline $\mathrm{H}$ & 5.203505 & 5.516202 & 1.487436 \\
\hline $\mathrm{H}$ & 4.668032 & 4.377416 & -0.643322 \\
\hline $\mathrm{H}$ & 2.765478 & 2.804579 & -0.817593 \\
\hline $\mathrm{H}$ & 1.453516 & 3.550311 & 4.490289 \\
\hline $\mathrm{C}$ & -0.421241 & 1.607631 & 3.222477 \\
\hline $\mathrm{C}$ & -0.946840 & 1.678122 & 4.536192 \\
\hline $\mathrm{C}$ & -2.053077 & 0.913274 & 4.871067 \\
\hline $\mathrm{H}$ & -0.482717 & 2.331608 & 5.265248 \\
\hline $\mathrm{C}$ & -2.073870 & 0.047362 & 2.640212 \\
\hline $\mathrm{C}$ & -2.640897 & 0.069510 & 3.905682 \\
\hline $\mathrm{H}$ & -2.466897 & 0.961925 & 5.873699 \\
\hline $\mathrm{H}$ & -3.503373 & -0.545958 & 4.125892 \\
\hline $\mathrm{C}$ & -2.594179 & -0.810673 & 1.549190 \\
\hline $\mathrm{C}$ & -4.106904 & -2.306434 & 0.718667 \\
\hline $\mathrm{C}$ & -3.404883 & -2.258650 & -0.531123 \\
\hline
\end{tabular}




$\begin{array}{lrrr}\mathrm{N} & 1.121414 & 2.212339 & 1.434436 \\ \mathrm{~N} & -0.998170 & 0.795830 & 2.301412 \\ \mathrm{~N} & -3.680508 & -1.566611 & 1.741453 \\ \mathrm{~N} & -1.905706 & -0.772613 & 0.395547 \\ \mathrm{~N} & -2.314073 & -1.501994 & -0.644949 \\ \mathrm{C} & -5.358717 & -3.145141 & 0.936728 \\ \mathrm{C} & -5.520446 & -4.173764 & -0.204290 \\ \mathrm{H} & -4.847878 & -5.020132 & -0.025079 \\ \mathrm{H} & -6.535808 & -4.580252 & -0.162045 \\ \mathrm{C} & -5.254415 & -3.582943 & -1.591550 \\ \mathrm{C} & -3.810071 & -3.061648 & -1.764773 \\ \mathrm{H} & -5.957784 & -2.766525 & -1.789051 \\ \mathrm{H} & -5.444050 & -4.339016 & -2.360037 \\ \mathrm{C} & -5.270445 & -3.881471 & 2.290624 \\ \mathrm{H} & -5.209304 & -3.180004 & 3.124437 \\ \mathrm{H} & -6.163266 & -4.499655 & 2.423640 \\ \mathrm{H} & -4.396922 & -4.540316 & 2.330161 \\ \mathrm{C} & -6.562911 & -2.166150 & 0.975097 \\ \mathrm{H} & -7.479754 & -2.729555 & 1.171462 \\ \mathrm{H} & -6.433574 & -1.429566 & 1.772104 \\ \mathrm{H} & -6.691271 & -1.627016 & 0.032468 \\ \mathrm{C} & -2.813092 & -4.238303 & -1.916140 \\ \mathrm{H} & -3.059609 & -4.816195 & -2.811835 \\ \mathrm{H} & -1.791829 & -3.861755 & -2.021465 \\ \mathrm{H} & -2.837155 & -4.917242 & -1.058744 \\ \mathrm{C} & -3.734261 & -2.173828 & -3.025153 \\ \mathrm{H} & -2.715978 & -1.827859 & -3.211862 \\ \mathrm{H} & -4.069078 & -2.748944 & -3.893920 \\ \mathrm{H} & -4.380647 & -1.295553 & -2.933021\end{array}$

$\mathrm{M}=\mathrm{Am}$
AM -0.000091
$0.748646 \quad 0.000108$
C $\quad-2.282262 \quad 2.940122 \quad-1.384425$
$\begin{array}{llll}\text { C } & -2.572690 & 3.584915 & -2.630693\end{array}$
C $\quad-3.682984 \quad 4.454338 \quad-2.739530$
$\begin{array}{llll}\text { C } & -4.474393 & 4.665259 & -1.618364\end{array}$
C $\quad-4.177231 \quad 4.026836 \quad-0.384602$
$\begin{array}{llll}\text { C } & -3.091429 & 3.168371 & -0.254516\end{array}$
$\begin{array}{llll}\text { C } & -0.741797 & 2.285607 & -2.827257\end{array}$
C $\quad-1.567801 \quad 3.150563 \quad-3.543053$
$\mathrm{H} \quad-3.909480 \quad 4.950457 \quad-3.678598$
$\mathrm{H} \quad-5.329408 \quad 5.331775 \quad-1.675508$
$\mathrm{H} \quad-4.810272 \quad 4.223658 \quad 0.475391$
$\mathrm{H} \quad-2.871684 \quad 2.704576 \quad 0.704456$
$\mathrm{H} \quad-1.470602 \quad 3.438458 \quad-4.581002$ 


\begin{tabular}{|c|c|c|c|}
\hline $\mathrm{C}$ & 0.423566 & 1.552645 & -3.264419 \\
\hline C & 0.958239 & 1.634127 & -4.573480 \\
\hline $\mathrm{C}$ & 2.079118 & 0.889944 & -4.903278 \\
\hline H & 0.487388 & 2.280544 & -5.304317 \\
\hline$C$ & 2.098745 & 0.019686 & -2.673234 \\
\hline $\mathrm{C}$ & 2.672780 & 0.054630 & -3.935109 \\
\hline $\mathrm{H}$ & 2.499052 & 0.947591 & -5.902775 \\
\hline $\mathrm{H}$ & 3.546239 & -0.547039 & -4.149731 \\
\hline $\mathrm{C}$ & 2.632810 & -0.836281 & -1.588123 \\
\hline $\mathrm{C}$ & 4.167387 & -2.316314 & -0.770270 \\
\hline $\mathrm{C}$ & 3.464557 & -2.287767 & 0.479612 \\
\hline $\mathrm{N}$ & -1.162109 & 2.141944 & -1.506830 \\
\hline $\mathrm{N}$ & 1.008158 & 0.750503 & -2.338432 \\
\hline $\mathrm{N}$ & 3.730386 & -1.574944 & -1.787296 \\
\hline $\mathrm{N}$ & 1.947582 & -0.813444 & -0.434911 \\
\hline $\mathrm{N}$ & 2.366058 & -1.544839 & 0.599796 \\
\hline $\mathrm{C}$ & 5.431525 & -3.135043 & -0.993721 \\
\hline $\mathrm{C}$ & 5.605132 & -4.172588 & 0.137516 \\
\hline $\mathrm{H}$ & 4.943847 & -5.025785 & -0.051137 \\
\hline $\mathrm{H}$ & 6.625765 & -4.565381 & 0.092933 \\
\hline $\mathrm{C}$ & 5.329305 & -3.599158 & 1.530141 \\
\hline $\mathrm{C}$ & 3.878345 & -3.097485 & 1.706030 \\
\hline $\mathrm{H}$ & 6.022120 & -2.776080 & 1.737220 \\
\hline $\mathrm{H}$ & 5.527008 & -4.360583 & 2.291282 \\
\hline $\mathrm{C}$ & 5.356962 & -3.859452 & -2.354802 \\
\hline $\mathrm{H}$ & 5.288463 & -3.150958 & -3.182090 \\
\hline $\mathrm{H}$ & 6.258387 & -4.464235 & -2.491511 \\
\hline $\mathrm{H}$ & 4.492526 & -4.529597 & -2.403102 \\
\hline $\mathrm{C}$ & 6.621866 & -2.138908 & -1.019493 \\
\hline $\mathrm{H}$ & 7.547312 & -2.687061 & -1.218804 \\
\hline $\mathrm{H}$ & 6.483968 & -1.396601 & -1.809767 \\
\hline $\mathrm{H}$ & 6.740103 & -1.606999 & -0.071449 \\
\hline $\mathrm{C}$ & 2.895745 & -4.287847 & 1.844290 \\
\hline $\mathrm{H}$ & 3.147064 & -4.870524 & 2.735570 \\
\hline $\mathrm{H}$ & 1.869619 & -3.924828 & 1.950104 \\
\hline $\mathrm{H}$ & 2.930366 & -4.958947 & 0.981082 \\
\hline $\mathrm{C}$ & 3.789421 & -2.223385 & 2.975135 \\
\hline $\mathrm{H}$ & 2.766335 & -1.893248 & 3.164270 \\
\hline $\mathrm{H}$ & 4.131429 & -2.802672 & 3.838358 \\
\hline $\mathrm{H}$ & 4.423833 & -1.335461 & 2.892418 \\
\hline $\mathrm{C}$ & 2.282798 & 2.938405 & 1.385891 \\
\hline $\mathrm{C}$ & 2.573562 & 3.582313 & 2.632536 \\
\hline $\mathrm{C}$ & 3.684077 & 4.451396 & 2.741787 \\
\hline $\mathrm{C}$ & 4.475387 & 4.662854 & 1.620649 \\
\hline $\mathrm{C}$ & 4.177901 & 4.025304 & 0.386518 \\
\hline $\mathrm{C}$ & 3.091866 & 3.167190 & 0.256023 \\
\hline
\end{tabular}




\begin{tabular}{|c|c|c|c|}
\hline $\mathrm{C}$ & 0.742387 & 2.283323 & 28532 \\
\hline & 1.568701 & 3.147607 & 3.544766 \\
\hline $\mathrm{H}$ & 3.910819 & 4.946850 & 3.681147 \\
\hline $\mathrm{H}$ & 5.330571 & 5.329125 & 1.678110 \\
\hline $\mathrm{H}$ & 4.810872 & 4.222525 & -0.473434 \\
\hline $\mathrm{H}$ & 2.871880 & 2.704076 & -0.703218 \\
\hline & 1.471727 & 3.434848 & 4.582918 \\
\hline & -0.423050 & 1.550290 & 3.265366 \\
\hline 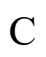 & -0.957507 & 1.630942 & 4.574563 \\
\hline & -2.078439 & 0.886682 & 4.904014 \\
\hline $\mathrm{H}$ & -0.486450 & 2.276781 & 5.305778 \\
\hline$C$ & -2.098512 & 0.017976 & 2.673364 \\
\hline$C$ & -2.672343 & 0.052110 & 3.935357 \\
\hline H & -2.498215 & 0.943687 & 5.903614 \\
\hline $\mathrm{H}$ & -3.545830 & -0.549618 & 4.149701 \\
\hline$C$ & -2.632837 & -0.837216 & 1.587771 \\
\hline $\mathrm{C}$ & -4.167727 & -2.316507 & 0.769159 \\
\hline$C$ & -3.465103 & -2.287187 & -0.480823 \\
\hline $\mathrm{N}$ & 1.162450 & 2.140429 & 1.507945 \\
\hline $\mathrm{N}$ & -1.007899 & 0.748905 & 2.338893 \\
\hline $\mathrm{N}$ & -3.730478 & -1.575872 & 1.786616 \\
\hline$N$ & -1.947765 & -0.813718 & 0.434483 \\
\hline $\mathbf{N}$ & -2.366512 & -1.544339 & -0.600665 \\
\hline $\mathrm{C}$ & -5.431914 & -3.135254 & 0.992268 \\
\hline $\mathrm{C}$ & -5.605856 & -4.171973 & -0.139674 \\
\hline $\mathrm{H}$ & -4.944642 & -5.025385 & 0.048249 \\
\hline $\mathrm{H}$ & -6.626529 & -4.564672 & -0.095182 \\
\hline 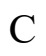 & -5.330215 & -3.597585 & -1.531941 \\
\hline , & -3.879221 & -3.095978 & -1.707741 \\
\hline $\mathrm{H}$ & -6.022960 & -2.774269 & -1.738304 \\
\hline $\mathrm{H}$ & -5.528158 & -4.358441 & -2.293589 \\
\hline 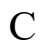 & -5.357163 & -3.860641 & 2.352819 \\
\hline $\mathrm{H}$ & -5.288420 & -3.152743 & 3.180597 \\
\hline $\mathrm{H}$ & -6.258630 & -4.465418 & 2.489276 \\
\hline $\mathrm{H}$ & -4.492794 & -4.530919 & 2.400471 \\
\hline $\mathrm{C}$ & -6.622142 & -2.139009 & 1.018982 \\
\hline 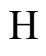 & -7.547606 & -2.687204 & 1.218091 \\
\hline 11 & -6.484007 & -1.397274 & 1.809752 \\
\hline $\mathrm{H}$ & -6.740510 & -1.606419 & 0.071337 \\
\hline $\mathrm{C}$ & -2.896803 & -4.286370 & -1.847035 \\
\hline $\mathrm{H}$ & -3.148364 & -4.868373 & -2.738687 \\
\hline$U$ & -1.870649 & -3.923411 & -1.952778 \\
\hline $\mathrm{H}$ & -2.931355 & -4.958084 & -0.984302 \\
\hline . & -3.790416 & -2.220980 & -2.976237 \\
\hline $\mathrm{H}$ & -2.767320 & -1.890852 & -3.165332 \\
\hline $\mathrm{H}$ & -4.132669 & -2.799601 & -3.839809 \\
\hline
\end{tabular}




\begin{tabular}{lrrr}
$\mathrm{H}$ & -4.424690 & -1.333027 & -2.892765 \\
$\mathrm{M}=\mathrm{Cm}$ & & \\
\multicolumn{4}{c}{} \\
$\mathrm{CM}$ & -0.000128 & -0.714809 & -0.000086 \\
$\mathrm{C}$ & 2.159360 & -3.006544 & -1.374410 \\
$\mathrm{C}$ & 2.417507 & -3.668936 & -2.618425 \\
$\mathrm{C}$ & 3.498023 & -4.574573 & -2.731045 \\
$\mathrm{C}$ & 4.291792 & -4.804123 & -1.615273 \\
$\mathrm{C}$ & 4.025875 & -4.148852 & -0.383390 \\
$\mathrm{C}$ & 2.970270 & -3.254029 & -0.249775 \\
$\mathrm{C}$ & 0.626888 & -2.312541 & -2.810852 \\
$\mathrm{C}$ & 1.418433 & -3.209214 & -3.525045 \\
$\mathrm{H}$ & 3.700070 & -5.083419 & -3.668890 \\
$\mathrm{H}$ & 5.124263 & -5.498452 & -1.675205 \\
$\mathrm{H}$ & 4.658935 & -4.361479 & 0.472908 \\
$\mathrm{H}$ & 2.773219 & -2.777561 & 0.707625 \\
$\mathrm{H}$ & 1.300435 & -3.504253 & -4.558842 \\
$\mathrm{C}$ & -0.528967 & -1.559433 & -3.243225 \\
$\mathrm{C}$ & -1.082366 & -1.637819 & -4.544866 \\
$\mathrm{C}$ & -2.197700 & -0.878013 & -4.860340 \\
$\mathrm{H}$ & -0.632735 & -2.293594 & -5.280834 \\
$\mathrm{C}$ & -2.173478 & -0.001683 & -2.633531 \\
$\mathrm{C}$ & -2.767797 & -0.032309 & -3.886700 \\
$\mathrm{H}$ & -2.632559 & -0.932973 & -5.853692 \\
$\mathrm{H}$ & -3.637539 & 0.578189 & -4.091377 \\
$\mathrm{C}$ & -2.679785 & 0.859627 & -1.537803 \\
$\mathrm{C}$ & -4.192499 & 2.349778 & -0.695083 \\
$\mathrm{C}$ & -3.469947 & 2.318535 & 0.543225 \\
$\mathrm{~N}$ & 1.065489 & -2.170866 & -1.493781 \\
$\mathrm{~N}$ & -1.088232 & -0.744192 & -2.315539 \\
$\mathrm{~N}$ & -3.776000 & 1.605313 & -1.718415 \\
$\mathrm{~N}$ & -1.974174 & 0.835844 & -0.395300 \\
$\mathrm{~N}$ & -2.372162 & 1.571782 & 0.645170 \\
$\mathrm{C}$ & -5.454886 & 3.176078 & -0.899356 \\
$\mathrm{C}$ & -5.605167 & 4.214471 & 0.234444 \\
$\mathrm{H}$ & -4.942097 & 5.063995 & 0.035627 \\
$\mathrm{H}$ & -6.624142 & 4.612974 & 0.205626 \\
$\mathrm{C}$ & -5.311119 & 3.639411 & 1.622659 \\
$\mathrm{H}$ & -3.860262 & 3.130084 & 1.776226 \\
$\mathrm{H}$ & -6.005019 & 2.819936 & 1.840259 \\
$\mathrm{H}$ & -5.493131 & 4.401754 & 2.386785 \\
$\mathrm{H}$ & 3.900043 & -2.261484 \\
$\mathrm{H}$ & 3.191132 & -3.089655 \\
$\mathrm{H}$ & 4.510494 & -2.384363 \\
$\mathrm{H}$ & 4.564754 & -2.323054
\end{tabular}




\begin{tabular}{|c|c|c|c|}
\hline $\mathrm{C}$ & -6.651422 & 2.187044 & -0.907224 \\
\hline 1 & -7.576379 & 2.740779 & -1.092876 \\
\hline $\mathrm{H}$ & -6.529761 & 1.443783 & -1.699268 \\
\hline & -6.758781 & 1.656075 & 0.042661 \\
\hline & -2.869482 & 4.315186 & 1.900061 \\
\hline & -3.104230 & 4.898728 & 2.795293 \\
\hline 7 & -1.843747 & 3.946827 & 1.990230 \\
\hline & -2.913831 & 4.986915 & 1.037773 \\
\hline $\mathrm{C}$ & -3.756479 & 2.254858 & 3.043444 \\
\hline & -2.732231 & 1.919731 & 3.217117 \\
\hline 1 & -4.082621 & 2.835291 & 3.912014 \\
\hline H & -4.396564 & 1.370138 & 2.970024 \\
\hline 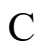 & -2.159911 & -3.006062 & 1.374531 \\
\hline$C$ & -2.418182 & -3.668250 & 2.618628 \\
\hline$C$ & -3.498822 & -4.573725 & 2.731343 \\
\hline$C$ & -4.292593 & -4.803320 & 1.615582 \\
\hline $\mathrm{C}$ & -4.026555 & -4.148252 & 0.383618 \\
\hline $\mathrm{C}$ & -2.970826 & -3.253590 & 0.249909 \\
\hline $\mathrm{C}$ & -0.627379 & -2.312069 & 2.810919 \\
\hline $\mathrm{C}$ & -1.419070 & -3.208538 & 3.525209 \\
\hline $\mathrm{H}$ & -3.700963 & -5.082416 & 3.669252 \\
\hline $\mathrm{H}$ & -5.125160 & -5.497528 & 1.675586 \\
\hline H & -4.659621 & -4.360909 & -0.472668 \\
\hline $\mathrm{H}$ & -2.773686 & -2.777278 & -0.707551 \\
\hline $\mathrm{H}$ & -1.301141 & -3.503452 & 4.559049 \\
\hline $\mathrm{C}$ & 0.528566 & -1.559078 & 3.243265 \\
\hline$C$ & 1.081854 & -1.637415 & 4.544956 \\
\hline $\mathrm{C}$ & 2.197281 & -0.877753 & 4.860444 \\
\hline $\mathrm{H}$ & 0.632062 & -2.293044 & 5.280957 \\
\hline 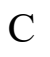 & 2.173374 & -0.001648 & 2.633544 \\
\hline$C$ & 2.767586 & -0.032238 & 3.886764 \\
\hline $\mathrm{H}$ & 2.632052 & -0.932679 & 5.853837 \\
\hline $\mathrm{H}$ & 3.637408 & 0.578144 & 4.091449 \\
\hline $\mathrm{C}$ & 2.679923 & 0.859477 & 1.537782 \\
\hline $\mathrm{C}$ & 4.192963 & 2.349305 & 0.695073 \\
\hline $\mathrm{C}$ & 3.470532 & 2.318060 & -0.543306 \\
\hline $\mathrm{N}$ & -1.065931 & -2.170514 & 1.493814 \\
\hline $\mathrm{N}$ & 1.088033 & -0.744020 & 2.315538 \\
\hline $\mathrm{N}$ & 3.776241 & 1.605003 & 1.718433 \\
\hline $\mathrm{N}$ & 1.974428 & 0.835697 & 0.395209 \\
\hline $\mathrm{N}$ & 2.372639 & 1.571471 & -0.645292 \\
\hline $\mathrm{C}$ & 5.455467 & 3.175414 & 0.899392 \\
\hline $\mathrm{C}$ & 5.606036 & 4.213670 & -0.234494 \\
\hline Ax & 4.943089 & 5.063326 & -0.035827 \\
\hline $\mathrm{H}$ & 6.625075 & 4.612006 & -0.205612 \\
\hline $\mathrm{C}$ & 5.312032 & 3.638525 & -1.622682 \\
\hline
\end{tabular}




$\begin{array}{lrrr}\mathrm{C} & 3.861106 & 3.129424 & -1.776346 \\ \mathrm{H} & 6.005818 & 2.818913 & -1.840132 \\ \mathrm{H} & 5.494249 & 4.400762 & -2.386864 \\ \mathrm{C} & 5.397089 & 3.899521 & 2.261444 \\ \mathrm{H} & 5.345538 & 3.190699 & 3.089679 \\ \mathrm{H} & 6.296763 & 4.509834 & 2.384354 \\ \mathrm{H} & 4.529375 & 4.564382 & 2.322863 \\ \mathrm{C} & 6.651836 & 2.186180 & 0.907477 \\ \mathrm{H} & 7.576868 & 2.739778 & 1.093169 \\ \mathrm{H} & 6.529971 & 1.443016 & 1.699580 \\ \mathrm{H} & 6.759203 & 1.655101 & -0.042346 \\ \mathrm{C} & 2.870535 & 4.314679 & -1.900394 \\ \mathrm{H} & 3.105472 & 4.898096 & -2.795658 \\ \mathrm{H} & 1.844748 & 3.946481 & -1.990634 \\ \mathrm{H} & 2.914907 & 4.986483 & -1.038167 \\ \mathrm{C} & 3.757305 & 2.254094 & -3.043490 \\ \mathrm{H} & 2.733018 & 1.919119 & -3.217233 \\ \mathrm{H} & 4.083630 & 2.834389 & -3.912084 \\ \mathrm{H} & 4.397236 & 1.369275 & -2.969921\end{array}$

$L=1 b i$

\section{$\left[\mathrm{ML}\left(\mathrm{H}_{2} \mathrm{O}\right)_{6}\right]^{2+}$}

$\begin{array}{lrrr}\mathrm{M}=\mathrm{Eu} & & & \\ \mathrm{EU} & 2.063965 & 0.897552 & -0.248026 \\ \mathrm{O} & 0.320071 & 2.716946 & 0.845905 \\ \mathrm{H} & -0.563357 & 2.315600 & 0.614186 \\ \mathrm{O} & 2.034340 & 1.224943 & 2.383552 \\ \mathrm{H} & 1.219413 & 1.747140 & 2.500330 \\ \mathrm{O} & 4.043577 & 1.338401 & -2.180226 \\ \mathrm{H} & 4.107591 & 2.148013 & -2.710238 \\ \mathrm{O} & 3.521967 & 2.934553 & 0.694929 \\ \mathrm{H} & 3.759099 & 3.852715 & 0.501114 \\ \mathrm{O} & 1.190175 & 2.374023 & -2.265625 \\ \mathrm{H} & 1.002370 & 1.766732 & -3.000939 \\ \mathrm{O} & 1.873014 & -0.256015 & -2.730702 \\ \mathrm{H} & 2.781763 & -0.115919 & -3.051671 \\ \mathrm{H} & 0.199105 & 3.675198 & 0.900573 \\ \mathrm{H} & 3.443384 & 2.859417 & 1.661035 \\ \mathrm{H} & 0.623691 & 3.150025 & -2.380570 \\ \mathrm{H} & 4.952931 & 1.099329 & -1.933784 \\ \mathrm{H} & 1.573015 & -1.107770 & -3.080290 \\ \mathrm{H} & 2.143807 & 0.658475 & 3.161415 \\ \mathrm{C} & 5.500542 & -0.393810 & 0.344406\end{array}$




\begin{tabular}{|c|c|c|c|}
\hline $\mathrm{C}$ & 6.204067 & -1.638111 & 0.434474 \\
\hline C & 7.611754 & -1.664839 & 0.531431 \\
\hline $\mathrm{C}$ & 8.302299 & -0.444595 & 0.539939 \\
\hline $\mathrm{C}$ & 7.604498 & 0.770768 & 0.463386 \\
\hline $\mathrm{C}$ & 6.191751 & 0.812744 & 0.367617 \\
\hline $\mathrm{C}$ & 3.953318 & -1.953263 & 0.312644 \\
\hline $\mathrm{C}$ & 5.207648 & -2.642252 & 0.419440 \\
\hline $\mathrm{H}$ & 8.150662 & -2.604847 & 0.601391 \\
\hline $\mathrm{H}$ & 9.384504 & -0.436212 & 0.615724 \\
\hline $\mathrm{H}$ & 8.160782 & 1.702761 & 0.489378 \\
\hline $\mathrm{H}$ & 5.667978 & 1.763216 & 0.353521 \\
\hline $\mathrm{H}$ & 5.364697 & -3.710705 & 0.482733 \\
\hline $\mathrm{C}$ & 2.620353 & -2.565481 & 0.267170 \\
\hline $\mathrm{C}$ & 2.449845 & -3.961650 & 0.329122 \\
\hline $\mathrm{C}$ & 1.162892 & -4.492612 & 0.283310 \\
\hline $\mathrm{H}$ & 3.307544 & -4.617667 & 369 \\
\hline $\mathrm{C}$ & 0.324998 & -2.247021 & 0.136398 \\
\hline $\mathrm{C}$ & 0.073529 & -3.621880 & 0.182899 \\
\hline $\mathrm{H}$ & 1.008139 & -5.566193 & 0.326771 \\
\hline $\mathrm{H}$ & -0.946944 & -3.980054 & 0.141034 \\
\hline $\mathrm{C}$ & -0.805989 & -1.280934 & 0.063642 \\
\hline $\mathrm{C}$ & -3.074865 & -0.905646 & 48 \\
\hline $\mathrm{C}$ & -2.778911 & 0.499345 & 0.201811 \\
\hline $\mathrm{N}$ & 4.112368 & -0.615360 & 0.260727 \\
\hline $\mathrm{N}$ & 1.567248 & -1.724493 & 0.170610 \\
\hline $\mathrm{N}$ & -2.052755 & -1.764998 & 0.033715 \\
\hline $\mathrm{N}$ & -0.499095 & 0.020796 & 0.011741 \\
\hline $\mathrm{N}$ & -1.508189 & 0.896890 & 0.143571 \\
\hline $\mathrm{C}$ & -4.414213 & -1.459480 & -0.242918 \\
\hline $\mathrm{C}$ & -5.400953 & -0.724356 & -0.940224 \\
\hline $\mathrm{C}$ & -4.674486 & -2.783136 & 0.147549 \\
\hline $\mathrm{C}$ & -6.619394 & -1.332984 & -1.228539 \\
\hline $\mathrm{H}$ & -5.214672 & 0.289312 & -1.270469 \\
\hline $\mathrm{C}$ & -5.918274 & -3.375393 & -0.118095 \\
\hline $\mathrm{H}$ & -3.926873 & -3.360937 & 0.676746 \\
\hline $\mathrm{C}$ & -6.896408 & -2.644304 & -0.817201 \\
\hline $\mathrm{H}$ & -7.376228 & -0.783969 & -1.780147 \\
\hline $\mathrm{H}$ & -7.862272 & -3.079937 & -1.043013 \\
\hline $\mathrm{C}$ & -3.769253 & 1.555346 & 0.513670 \\
\hline $\mathrm{C}$ & -4.776845 & 1.331412 & 1.473823 \\
\hline $\mathrm{C}$ & -3.650231 & 2.810509 & -0.096941 \\
\hline $\mathrm{C}$ & -5.640665 & 2.374873 & 1.803147 \\
\hline $\mathrm{H}$ & -4.878547 & 0.368035 & 1.959444 \\
\hline $\mathrm{C}$ & -4.539024 & 3.850262 & 0.227012 \\
\hline $\mathrm{H}$ & -2.898037 & 2.994104 & -0.855969 \\
\hline S & -5.540247 & 3.630195 & 1.188069 \\
\hline
\end{tabular}




$\begin{array}{lrrr}\mathrm{H} & -6.412546 & 2.215457 & 2.549801 \\ \mathrm{H} & -6.238196 & 4.413227 & 1.458015 \\ \mathrm{O} & -6.071131 & -4.648181 & 0.332413 \\ \mathrm{O} & -4.340093 & 5.020296 & -0.441318 \\ \mathrm{C} & -5.249388 & 6.105990 & -0.196358 \\ \mathrm{H} & -4.921737 & 6.916047 & -0.847548 \\ \mathrm{H} & -6.275971 & 5.823909 & -0.453382 \\ \mathrm{H} & -5.200472 & 6.433871 & 0.847805 \\ \mathrm{C} & -7.323370 & -5.311575 & 0.097193 \\ \mathrm{H} & -7.219184 & -6.299500 & 0.544853 \\ \mathrm{H} & -8.148693 & -4.777318 & 0.580469 \\ \mathrm{H} & -7.518812 & -5.415641 & -0.975776\end{array}$

$\mathrm{M}=\mathrm{Gd}$

$\begin{array}{lrrr}\text { GD } & 2.011492 & 0.717166 & 0.109441 \\ \mathrm{O} & 0.526952 & 1.854281 & 1.883486 \\ \mathrm{H} & -0.422843 & 1.956172 & 1.696014 \\ \mathrm{O} & 2.491912 & -0.032180 & 2.492697 \\ \mathrm{H} & 1.863662 & -0.116206 & 3.227025 \\ \mathrm{O} & 3.584506 & 2.010320 & -1.481543 \\ \mathrm{H} & 3.603821 & 2.921130 & -1.812947 \\ \mathrm{O} & 3.213828 & 2.505077 & 1.558984 \\ \mathrm{H} & 3.656036 & 3.349297 & 1.384365 \\ \mathrm{O} & 0.663628 & 2.569482 & -0.942135 \\ \mathrm{H} & 0.634324 & 2.737173 & -1.896520 \\ \mathrm{O} & 1.798579 & 0.132657 & -2.345660 \\ \mathrm{H} & 2.577246 & 0.404914 & -2.857763 \\ \mathrm{H} & 0.835351 & 2.676605 & 2.294099 \\ \mathrm{H} & 3.638338 & 2.118140 & 2.342581 \\ \mathrm{H} & -0.264735 & 2.385277 & -0.670880 \\ \mathrm{H} & 4.519696 & 1.729254 & -1.384006 \\ \mathrm{H} & 1.511365 & -0.720984 & -2.703358 \\ \mathrm{H} & 3.141574 & -0.750310 & 2.568947 \\ \mathrm{C} & 5.382257 & -0.198407 & -0.023405 \\ \mathrm{C} & 6.148038 & -1.383487 & -0.283156 \\ \mathrm{C} & 7.549951 & -1.313337 & -0.448089 \\ \mathrm{C} & 8.175586 & -0.076592 & -0.352003 \\ \mathrm{C} & 7.426379 & 1.090591 & -0.067381 \\ \mathrm{C} & 6.041522 & 1.045918 & 0.104583 \\ \mathrm{C} & 3.963773 & -1.896804 & -0.089855 \\ \mathrm{C} & 5.217602 & -2.460218 & -0.305890 \\ \mathrm{H} & 8.128784 & -2.211076 & -0.642702 \\ \mathrm{H} & 9.250763 & 0.000367 & -0.475525 \\ \mathrm{H} & 7.947265 & 2.037128 & 0.040904 \\ \mathrm{H} & 5.514889 & 1.944527 & 0.412086\end{array}$




\begin{tabular}{|c|c|c|c|}
\hline $\mathrm{H}$ & 5.446382 & -3.503503 & -0.474479 \\
\hline $\mathrm{C}$ & 2.672755 & -2.549868 & -0.059686 \\
\hline $\mathrm{C}$ & 2.517046 & -3.957204 & -0.106205 \\
\hline $\mathrm{C}$ & 1.246216 & -4.508338 & -0.084210 \\
\hline $\mathrm{H}$ & 3.393529 & -4.592080 & -0.153212 \\
\hline C & 0.344100 & -2.290237 & 0.011596 \\
\hline & 0.123081 & -3.658770 & -0.032210 \\
\hline H & 1.114744 & -5.585523 & -0.115459 \\
\hline $\mathrm{H}$ & -0.889452 & -4.041218 & -0.039841 \\
\hline $\mathrm{C}$ & -0.775725 & -1.321310 & 0.008183 \\
\hline $\mathrm{C}$ & -3.029421 & -0.872059 & -0.058959 \\
\hline $\mathrm{C}$ & -2.688984 & 0.539389 & 0.058837 \\
\hline $\mathrm{N}$ & 4.031924 & -0.505323 & 0.077765 \\
\hline IV & 1.586351 & -1.738541 & 0.012396 \\
\hline $\mathrm{N}$ & -2.035977 & -1.765362 & -0.015126 \\
\hline $\mathrm{N}$ & -0.429263 & -0.028728 & -0.035219 \\
\hline $\mathrm{N}$ & -1.407269 & 0.897550 & 0.027165 \\
\hline $\mathrm{C}$ & -4.387262 & -1.393977 & -0.254270 \\
\hline $\mathrm{C}$ & -5.375338 & -0.663585 & -0.957995 \\
\hline $\mathrm{C}$ & -4.668413 & -2.696328 & 0.195362 \\
\hline $\mathrm{C}$ & -6.612677 & -1.255453 & -1.193424 \\
\hline $\mathrm{H}$ & -5.174718 & 0.328897 & -1.338687 \\
\hline $\mathrm{C}$ & -5.931720 & -3.268115 & -0.013871 \\
\hline $\mathrm{H}$ & -3.920017 & -3.271695 & 0.725990 \\
\hline $\mathrm{C}$ & -6.909339 & -2.541394 & -0.720334 \\
\hline $\mathrm{H}$ & -7.369179 & -0.713056 & -1.751841 \\
\hline $\mathrm{H}$ & -7.890108 & -2.962817 & -0.905583 \\
\hline $\mathrm{C}$ & -3.657173 & 1.639812 & 0.275430 \\
\hline $\mathrm{C}$ & -4.646701 & 1.527292 & 1.273869 \\
\hline $\mathrm{C}$ & -3.532372 & 2.825482 & -0.459264 \\
\hline $\mathrm{C}$ & -5.485707 & 2.614125 & 1.517199 \\
\hline $\mathrm{H}$ & -4.755011 & 0.616596 & 1.851386 \\
\hline $\mathrm{C}$ & -4.399923 & 3.907508 & -0.223070 \\
\hline $\mathrm{H}$ & -2.801019 & 2.923023 & -1.254276 \\
\hline $\mathrm{C}$ & -5.380505 & 3.800084 & 0.778335 \\
\hline $\mathrm{H}$ & -6.243206 & 2.542282 & 2.291625 \\
\hline $\mathrm{H}$ & -6.060694 & 4.617691 & 0.983395 \\
\hline $\mathrm{O}$ & -6.103917 & -4.515330 & 0.492398 \\
\hline $\mathrm{O}$ & -4.202324 & 4.997209 & -1.010600 \\
\hline $\mathrm{C}$ & -5.084321 & 6.122494 & -0.854449 \\
\hline $\mathrm{H}$ & -4.757194 & 6.854838 & -1.591884 \\
\hline $\mathrm{H}$ & -6.122147 & 5.837968 & -1.057381 \\
\hline $\mathrm{H}$ & -5.000544 & 6.551760 & 0.149808 \\
\hline . & -7.375126 & -5.161408 & 0.309976 \\
\hline $\mathrm{H}$ & -7.280714 & -6.132255 & 0.795249 \\
\hline $\mathrm{H}$ & -8.178303 & -4.590649 & 0.788538 \\
\hline
\end{tabular}




$$
\begin{array}{llll}
\mathrm{H} & -7.594601 & -5.304393 & -0.753657
\end{array}
$$

$\mathrm{M}=\mathrm{Am}$

$\begin{array}{lrrr}\mathrm{AM} & 1.876240 & 0.663536 & 0.143064 \\ \mathrm{O} & 0.375341 & 1.699659 & 2.029092 \\ \mathrm{H} & -0.565630 & 1.832142 & 1.820047 \\ \mathrm{O} & 2.428743 & -0.129027 & 2.555572 \\ \mathrm{H} & 1.791060 & -0.211079 & 3.282175 \\ \mathrm{O} & 3.488747 & 1.979147 & -1.549549 \\ \mathrm{H} & 3.543586 & 2.893934 & -1.865511 \\ \mathrm{O} & 3.101508 & 2.495789 & 1.671372 \\ \mathrm{H} & 3.514567 & 3.360812 & 1.527519 \\ \mathrm{O} & 0.463304 & 2.681842 & -0.760245 \\ \mathrm{H} & 0.438726 & 3.105505 & -1.630847 \\ \mathrm{O} & 1.576614 & 0.183784 & -2.387205 \\ \mathrm{H} & 2.327965 & 0.517906 & -2.903418 \\ \mathrm{H} & 0.705805 & 2.535969 & 2.393728 \\ \mathrm{H} & 3.538835 & 2.100002 & 2.443389 \\ \mathrm{H} & -0.458108 & 2.393170 & -0.565826 \\ \mathrm{H} & 4.412164 & 1.660707 & -1.473615 \\ \mathrm{H} & 1.295821 & -0.647091 & -2.798969 \\ \mathrm{H} & 3.059397 & -0.863662 & 2.628740 \\ \mathrm{C} & 5.242094 & -0.343500 & -0.105799 \\ \mathrm{C} & 5.983488 & -1.537730 & -0.379157 \\ \mathrm{C} & 7.382560 & -1.489976 & -0.557461 \\ \mathrm{C} & 8.028981 & -0.261775 & -0.457698 \\ \mathrm{C} & 7.302919 & 0.913604 & -0.154203 \\ \mathrm{C} & 5.918347 & 0.887542 & 0.032177 \\ \mathrm{C} & 3.792246 & -2.017259 & -0.150489 \\ \mathrm{C} & 5.032003 & -2.600229 & -0.389319 \\ \mathrm{H} & 7.946509 & -2.394841 & -0.762240 \\ \mathrm{H} & 9.104056 & -0.201665 & -0.591275 \\ \mathrm{H} & 7.839834 & 1.850455 & -0.041458 \\ \mathrm{H} & 5.403546 & 1.788848 & 0.354637 \\ \mathrm{H} & 5.241651 & -3.646354 & -0.565205 \\ \mathrm{C} & 2.489114 & -2.650020 & -0.106308 \\ \mathrm{C} & 2.314277 & -4.053353 & -0.163896 \\ \mathrm{C} & 1.035651 & -4.587353 & -0.138820 \\ \mathrm{H} & 3.180778 & -4.700635 & -0.224132 \\ \mathrm{C} & 0.165863 & -2.357488 & -0.018856 \\ \mathrm{C} & -0.074151 & -3.722935 & -0.075344 \\ \mathrm{H} & 0.889072 & -5.662200 & -0.179260 \\ \mathrm{H} & -1.091840 & -4.091327 & -0.084351 \\ \mathrm{C} & -0.944603 & -1.376717 & -0.013918 \\ \mathrm{C} & -3.194489 & -0.907103 & -0.076395\end{array}$




$\begin{array}{rrrr}\mathrm{C} & -2.841539 & 0.500069 & 0.040869 \\ \mathrm{~N} & 3.888158 & -0.629474 & 0.014615 \\ \mathrm{~N} & 1.415623 & -1.825161 & -0.015405 \\ \mathrm{~N} & -2.208857 & -1.809788 & -0.037497 \\ \mathrm{~N} & -0.588182 & -0.087125 & -0.045444 \\ \mathrm{~N} & -1.556534 & 0.847455 & 0.018821 \\ \mathrm{C} & -4.558707 & -1.416941 & -0.262416 \\ \mathrm{C} & -5.541898 & -0.681976 & -0.967692 \\ \mathrm{C} & -4.851977 & -2.711945 & 0.199712 \\ \mathrm{C} & -6.786666 & -1.262326 & -1.192724 \\ \mathrm{H} & -5.331938 & 0.304734 & -1.358247 \\ \mathrm{C} & -6.122327 & -3.271861 & 0.000820 \\ \mathrm{H} & -4.107597 & -3.291152 & 0.731934 \\ \mathrm{C} & -7.095213 & -2.540866 & -0.707497 \\ \mathrm{H} & -7.539627 & -0.716456 & -1.752565 \\ \mathrm{H} & -8.081187 & -2.953293 & -0.885086 \\ \mathrm{C} & -3.800164 & 1.611683 & 0.245562 \\ \mathrm{C} & -4.785749 & 1.524805 & 1.250025 \\ \mathrm{C} & -3.669878 & 2.782103 & -0.511832 \\ \mathrm{C} & -5.615971 & 2.622091 & 1.476387 \\ \mathrm{H} & -4.898710 & 0.625190 & 1.843962 \\ \mathrm{C} & -4.528054 & 3.874981 & -0.291783 \\ \mathrm{H} & -2.942533 & 2.857224 & -1.313119 \\ \mathrm{C} & -5.505021 & 3.793530 & 0.715378 \\ \mathrm{H} & -6.371010 & 2.570138 & 2.254830 \\ \mathrm{H} & -6.178186 & 4.619881 & 0.908172 \\ \mathrm{O} & -6.305555 & -4.513059 & 0.518543 \\ \mathrm{O} & -4.325287 & 4.948874 & -1.100020 \\ \mathrm{C} & -5.200077 & 6.082083 & -0.962772 \\ \mathrm{H} & -4.871358 & 6.798173 & -1.715330 \\ \mathrm{H} & -6.240247 & 5.799802 & -1.156720 \\ \mathrm{H} & -5.110467 & 6.530235 & 0.032714 \\ \mathrm{C} & -7.584244 & -5.146816 & 0.346706 \\ \mathrm{H} & -7.498347 & -6.114623 & 0.839606 \\ \mathrm{H} & -8.379314 & -4.563511 & 0.823737 \\ \mathrm{H} & -7.809787 & -5.296210 & -0.714793 \\ & & & \end{array}$

$\mathrm{M}=\mathrm{Cm}$

$\begin{array}{llll}\text { CM } & 1.868389 & 0.661863 & 0.119881\end{array}$ $\begin{array}{llll}\mathrm{O} & 0.376010 & 1.664287 & 2.062218\end{array}$

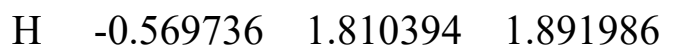

$\begin{array}{llll}\mathrm{O} & 2.451250 & -0.156265 & 2.525454\end{array}$

$\mathrm{H} \quad 1.833196 \quad-0.290343 \quad 3.261204$

$\begin{array}{llll}\mathrm{O} & 3.487505 & 1.981480 & -1.490131\end{array}$

$\begin{array}{llll}\mathrm{H} & 3.539121 & 2.896260 & -1.806630\end{array}$ 


\begin{tabular}{|c|c|c|c|}
\hline $\mathrm{O}$ & 3.078481 & 2.445702 & 888 \\
\hline $\mathrm{H}$ & 3.509124 & 3.302829 & 1.530007 \\
\hline 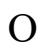 & 0.454626 & 2.641229 & -0.752370 \\
\hline$\pi$ & 0.423180 & 3.064943 & -1.622816 \\
\hline $\mathrm{O}$ & 1.609901 & 0.170183 & -2.389718 \\
\hline $\mathrm{H}$ & 2.369750 & 0.479433 & -2.908928 \\
\hline $\mathrm{H}$ & 0.720123 & 2.478321 & 2.462311 \\
\hline $\mathrm{H}$ & 3.519228 & 2.023516 & 2.425152 \\
\hline $\mathrm{H}$ & -0.468334 & 2.358195 & -0.543665 \\
\hline $\mathrm{H}$ & 4.412447 & 1.669598 & -1.392179 \\
\hline $\mathrm{H}$ & 1.318887 & -0.666305 & -2.783298 \\
\hline $\mathrm{H}$ & 3.103466 & -0.875906 & 2.545074 \\
\hline $\mathrm{C}$ & 5.239370 & -0.333633 & -0.064342 \\
\hline $\mathrm{C}$ & 5.982563 & -1.524966 & -0.354824 \\
\hline $\mathrm{C}$ & 7.384860 & -1.474284 & -0.522432 \\
\hline $\mathrm{C}$ & 8.031156 & -0.250898 & -0.396470 \\
\hline $\mathrm{C}$ & 7.302961 & 0.921601 & -0.079353 \\
\hline $\mathrm{C}$ & 5.918343 & 0.895854 & 0.094894 \\
\hline $\mathrm{C}$ & 3.788961 & -2.003362 & -0.164071 \\
\hline $\mathrm{C}$ & 5.031876 & -2.583991 & -0.398383 \\
\hline $\mathrm{H}$ & 7.948435 & -2.376059 & -0.741513 \\
\hline $\mathrm{H}$ & 9.107205 & -0.188967 & -0.521135 \\
\hline $\mathrm{H}$ & 7.840631 & 1.855686 & 0.052307 \\
\hline $\mathrm{H}$ & 5.404479 & 1.794156 & 0.427061 \\
\hline $\mathrm{H}$ & 5.241822 & -3.626754 & -0.592431 \\
\hline $\mathrm{C}$ & 2.486966 & -2.636519 & -0.139673 \\
\hline $\mathrm{C}$ & 2.313388 & -4.040341 & -0.215314 \\
\hline $\mathrm{C}$ & 1.036347 & -4.576874 & -0.196087 \\
\hline $\mathrm{H}$ & 3.181396 & -4.684974 & -0.281957 \\
\hline $\mathrm{C}$ & 0.160296 & -2.351066 & -0.049139 \\
\hline $\mathrm{C}$ & -0.076473 & -3.715726 & -0.11 \\
\hline $\mathrm{H}$ & 0.892101 & -5.651547 & -0.248926 \\
\hline $\mathrm{H}$ & -1.093133 & -4.086954 & -0.128957 \\
\hline $\mathrm{C}$ & -0.952006 & -1.372218 & -0.032308 \\
\hline $\mathrm{C}$ & -3.202943 & -0.904955 & -0.077854 \\
\hline $\mathrm{C}$ & -2.851295 & 0.503463 & 0.034175 \\
\hline $\mathrm{N}$ & 3.886224 & -0.618548 & 0.033559 \\
\hline $\mathrm{N}$ & 1.409577 & -1.815589 & -0.043264 \\
\hline $\mathrm{N}$ & -2.215875 & -1.806602 & -0.048018 \\
\hline $\mathrm{N}$ & -0.597809 & -0.081568 & -0.063958 \\
\hline $\mathrm{N}$ & -1.566937 & 0.852067 & 0.002668 \\
\hline $\mathrm{C}$ & -4.567742 & -1.417119 & -0.251409 \\
\hline $\mathrm{C}$ & -5.558365 & -0.685191 & -0.949620 \\
\hline $\mathrm{C}$ & -4.854584 & -2.711982 & 0.215475 \\
\hline $\mathrm{C}$ & -6.803880 & -1.268300 & -1.162893 \\
\hline 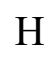 & -5.353541 & 0.301039 & -1.344109 \\
\hline
\end{tabular}




$\begin{array}{lrrr}\mathrm{C} & -6.125597 & -3.274495 & 0.028751 \\ \mathrm{H} & -4.104461 & -3.288923 & 0.742110 \\ \mathrm{C} & -7.105887 & -2.546447 & -0.672479 \\ \mathrm{H} & -7.562594 & -0.724975 & -1.717426 \\ \mathrm{H} & -8.092632 & -2.960962 & -0.840701 \\ \mathrm{C} & -3.809720 & 1.614700 & 0.241373 \\ \mathrm{C} & -4.789982 & 1.529183 & 1.251220 \\ \mathrm{C} & -3.683344 & 2.784046 & -0.518344 \\ \mathrm{C} & -5.618949 & 2.626857 & 1.480434 \\ \mathrm{H} & -4.899996 & 0.630371 & 1.846978 \\ \mathrm{C} & -4.540476 & 3.877150 & -0.295443 \\ \mathrm{H} & -2.959719 & 2.858354 & -1.323077 \\ \mathrm{C} & -5.512080 & 3.797119 & 0.717081 \\ \mathrm{H} & -6.369855 & 2.576040 & 2.262951 \\ \mathrm{H} & -6.184273 & 4.623708 & 0.912200 \\ \mathrm{O} & -6.302106 & -4.514946 & 0.550271 \\ \mathrm{O} & -4.341956 & 4.949871 & -1.106107 \\ \mathrm{C} & -5.215975 & 6.083420 & -0.965964 \\ \mathrm{H} & -4.891002 & 6.798379 & -1.721198 \\ \mathrm{H} & -6.257114 & 5.800898 & -1.154271 \\ \mathrm{H} & -5.121141 & 6.532933 & 0.028416 \\ \mathrm{C} & -7.581189 & -5.151365 & 0.391021 \\ \mathrm{H} & -7.489113 & -6.118025 & 0.885031 \\ \mathrm{H} & -8.372988 & -4.568526 & 0.874014 \\ \mathrm{H} & -7.815815 & -5.303253 & -0.668142\end{array}$

\section{$\left[\mathrm{ML}\left(\mathrm{H}_{2} \mathrm{O}\right)_{5}\right]^{2+}$}

$\mathrm{M}=\mathrm{Eu}$

$\begin{array}{lccc}\text { EU } & 2.101582 & 0.957484 & -0.143193 \\ \mathrm{O} & 3.459418 & 2.822636 & 1.208775 \\ \mathrm{H} & 3.314382 & 2.656661 & 2.154491 \\ \mathrm{O} & 3.923944 & 1.918422 & -1.923578 \\ \mathrm{H} & 4.030278 & 2.766418 & -2.381411 \\ \mathrm{O} & 0.411574 & 2.850764 & 0.136669 \\ \mathrm{H} & 0.306747 & 3.805222 & 0.245773 \\ \mathrm{O} & 1.974801 & 0.753956 & 2.534444 \\ \mathrm{H} & 2.425989 & 0.021122 & 2.982535 \\ \mathrm{O} & 1.546999 & 0.551660 & -2.641903 \\ \mathrm{H} & 2.249139 & 0.741991 & -3.282968 \\ \mathrm{H} & -0.495745 & 2.438453 & 0.123025 \\ \mathrm{H} & 0.800941 & 0.186029 & -3.138793 \\ \mathrm{H} & 3.703399 & 3.755973 & 1.126614 \\ \mathrm{H} & 4.822265 & 1.565104 & -1.807715 \\ \mathrm{H} & 1.195420 & 0.955691 & 3.075504\end{array}$




\begin{tabular}{|c|c|c|c|}
\hline $\mathrm{C}$ & 5.554539 & -0.322645 & 0.212105 \\
\hline & 6.272460 & -1.554250 & 0.075629 \\
\hline C & 7.684338 & -1.568062 & 0.077433 \\
\hline $\mathrm{C}$ & 8.362249 & -0.349386 & 0.220716 \\
\hline $\mathrm{C}$ & 7.650033 & 0.851044 & 0.370603 \\
\hline C & 6.233612 & 0.880107 & 0.372449 \\
\hline $\mathrm{C}$ & 4.021660 & -1.890953 & 0.056177 \\
\hline $\mathrm{C}$ & 5.286212 & -2.564175 & -0.016990 \\
\hline $\mathrm{H}$ & 8.235520 & -2.497998 & -0.024129 \\
\hline $\mathrm{H}$ & 9.446959 & -0.331782 & 0.227703 \\
\hline $\mathrm{H}$ & 8.198503 & 1.778951 & 0.500538 \\
\hline $\mathrm{H}$ & 5.700884 & 1.811287 & 0.538100 \\
\hline $\mathrm{H}$ & 5.455803 & -3.627496 & -0.121600 \\
\hline $\mathrm{C}$ & 2.691819 & -2.510955 & 0.010177 \\
\hline $\mathrm{C}$ & 2.530557 & -3.908578 & -0.024577 \\
\hline $\mathrm{C}$ & 1.244446 & -4.443704 & -0.051155 \\
\hline $\mathrm{H}$ & 3.393912 & -4.562571 & -0.024932 \\
\hline $\mathrm{C}$ & 0.390162 & -2.199472 & -0.010754 \\
\hline $\mathrm{C}$ & 0.147854 & -3.576270 & -0.044636 \\
\hline $\mathrm{H}$ & 1.096075 & -5.518730 & -0.077572 \\
\hline $\mathrm{H}$ & -0.871762 & -3.938416 & -0.072634 \\
\hline $\mathrm{C}$ & -0.747458 & -1.237289 & -0.014604 \\
\hline $\mathrm{C}$ & -3.018596 & -0.870800 & -0.030536 \\
\hline $\mathrm{C}$ & -2.727168 & 0.541066 & 0.118205 \\
\hline $\mathrm{N}$ & 4.165966 & -0.554960 & 0.186119 \\
\hline $\mathrm{N}$ & 1.631269 & -1.673206 & 0.014911 \\
\hline $\mathrm{N}$ & -1.992154 & -1.727003 & -0.022608 \\
\hline $\mathrm{N}$ & -0.446815 & 0.066429 & -0.054593 \\
\hline $\mathrm{N}$ & -1.458202 & 0.942978 & 0.053706 \\
\hline $\mathrm{C}$ & -4.361205 & -1.439574 & -0.226301 \\
\hline $\mathrm{C}$ & -5.370274 & -0.738021 & -0.926304 \\
\hline $\mathrm{C}$ & -4.601968 & -2.749186 & 0.220560 \\
\hline $\mathrm{C}$ & -6.590743 & -1.365414 & -1.160861 \\
\hline $\mathrm{H}$ & -5.199611 & 0.262738 & -1.300955 \\
\hline $\mathrm{C}$ & -5.847925 & -3.358693 & 0.010124 \\
\hline $\mathrm{H}$ & -3.836657 & -3.302640 & 0.750653 \\
\hline $\mathrm{C}$ & -6.848246 & -2.661277 & -0.692041 \\
\hline $\mathrm{H}$ & -7.364414 & -0.843211 & -1.715110 \\
\hline $\mathrm{H}$ & -7.816140 & -3.111438 & -0.877010 \\
\hline $\mathrm{C}$ & -3.723245 & 1.604449 & 0.384237 \\
\hline $\mathrm{C}$ & -4.717514 & 1.421773 & 1.367012 \\
\hline $\mathrm{C}$ & -3.621462 & 2.826334 & -0.292935 \\
\hline $\mathrm{C}$ & -5.586645 & 2.473670 & 1.652134 \\
\hline $\mathrm{H}$ & -4.805823 & 0.483520 & 1.901994 \\
\hline $\mathrm{C}$ & -4.517292 & 3.873633 & -0.013300 \\
\hline $\mathrm{H}$ & -2.880246 & 2.978369 & -1.070037 \\
\hline
\end{tabular}




$\begin{array}{lrrr}\mathrm{C} & -5.504895 & 3.695497 & 0.970482 \\ \mathrm{H} & -6.348543 & 2.346999 & 2.415153 \\ \mathrm{H} & -6.206866 & 4.485676 & 1.207123 \\ \mathrm{O} & -5.980490 & -4.613954 & 0.513255 \\ \mathrm{O} & -4.338206 & 5.007605 & -0.744273 \\ \mathrm{C} & -5.253676 & 6.097332 & -0.546063 \\ \mathrm{H} & -4.940356 & 6.873900 & -1.243398 \\ \mathrm{H} & -6.280837 & 5.793942 & -0.775194 \\ \mathrm{H} & -5.195129 & 6.480689 & 0.478580 \\ \mathrm{C} & -7.232587 & -5.294707 & 0.332710 \\ \mathrm{H} & -7.110180 & -6.264129 & 0.814873 \\ \mathrm{H} & -8.050740 & -4.748322 & 0.814603 \\ \mathrm{H} & -7.451888 & -5.440863 & -0.730677\end{array}$

$\mathrm{M}=\mathrm{Gd}$

$\begin{array}{lccc}\mathrm{GD} & 2.043431 & 0.724317 & -0.010585 \\ \mathrm{O} & 1.533533 & 0.268777 & 2.381429 \\ \mathrm{H} & 2.131479 & 0.646126 & 3.045349 \\ \mathrm{O} & 3.458995 & 2.096472 & -1.631054 \\ \mathrm{H} & 3.392185 & 2.992208 & -1.996459 \\ \mathrm{O} & 3.455327 & 2.075426 & 1.645712 \\ \mathrm{H} & 3.413808 & 2.983910 & 1.982234 \\ \mathrm{O} & 0.602503 & 2.696615 & 0.085543 \\ \mathrm{H} & 0.561380 & 3.661550 & 0.138116 \\ \mathrm{O} & 1.524363 & 0.313139 & -2.407283 \\ \mathrm{H} & 2.155124 & 0.615649 & -3.079058 \\ \mathrm{H} & 1.064308 & -0.467467 & 2.800750 \\ \mathrm{H} & 4.391465 & 1.802189 & 1.689226 \\ \mathrm{H} & -0.337727 & 2.335711 & 0.111752 \\ \mathrm{H} & 4.401623 & 1.844917 & -1.667675 \\ \mathrm{H} & 0.958735 & -0.354471 & -2.822881 \\ \mathrm{C} & 5.410960 & -0.101917 & -0.008196 \\ \mathrm{C} & 6.206361 & -1.294693 & -0.012745 \\ \mathrm{C} & 7.615961 & -1.221258 & -0.017254 \\ \mathrm{C} & 8.224566 & 0.029137 & -0.016379 \\ \mathrm{C} & 7.445292 & 1.208400 & -0.009928 \\ \mathrm{C} & 6.048090 & 1.161082 & -0.005572 \\ \mathrm{C} & 4.017610 & -1.828822 & -0.006402 \\ \mathrm{C} & 5.288968 & -2.385655 & -0.011036 \\ \mathrm{H} & 8.215795 & -2.126233 & -0.021079 \\ \mathrm{H} & 9.306614 & 0.107811 & -0.019767 \\ \mathrm{H} & 7.945443 & 2.171966 & -0.007509 \\ \mathrm{H} & 5.498666 & 2.100316 & 0.003728 \\ \mathrm{H} & 5.543304 & -3.436494 & -0.013277 \\ \mathrm{C} & 2.733546 & -2.497746 & -0.001723\end{array}$




\begin{tabular}{|c|c|c|c|}
\hline $\mathrm{C}$ & 2.588987 & -3.906396 & 0.002196 \\
\hline & 1.320937 & -4.465459 & 0.004536 \\
\hline & 3.469670 & -4.537121 & 0.002253 \\
\hline & 0.396123 & -2.254884 & 0.002816 \\
\hline & 0.188273 & -3.625857 & 0.002206 \\
\hline & 1.198589 & -5.544178 & 0.005307 \\
\hline & -0.820029 & -4.019748 & -0.006460 \\
\hline & -0.728262 & -1.288167 & -0.004344 \\
\hline$C$ & -2.981053 & -0.829790 & -0.037047 \\
\hline & -2.637916 & 0.578049 & 0.111084 \\
\hline $\mathrm{N}$ & 4.058283 & -0.424826 & -0.005773 \\
\hline & 1.637064 & -1.698131 & -0.000135 \\
\hline $\mathrm{N}$ & -1.988524 & -1.728113 & -0.016817 \\
\hline IN & -0.384359 & 0.007919 & -0.039512 \\
\hline $\mathrm{N}$ & -1.356658 & 0.930297 & 0.062049 \\
\hline $\mathrm{C}$ & -4.339218 & -1.344876 & -0.242725 \\
\hline $\mathrm{C}$ & -5.327675 & -0.593561 & -0.923896 \\
\hline $\mathrm{C}$ & -4.621146 & -2.659492 & 0.169645 \\
\hline $\mathrm{C}$ & -6.565951 & -1.177245 & -1.174067 \\
\hline H & -5.126644 & 0.409378 & -1.275837 \\
\hline $\mathrm{C}$ & -5.885371 & -3.223695 & -0.053620 \\
\hline $\mathrm{H}$ & -3.872802 & -3.250714 & 0.682500 \\
\hline $\mathrm{C}$ & -6.863339 & -2.475879 & -0.737293 \\
\hline $\mathrm{H}$ & -7.322815 & -0.618183 & -1.715283 \\
\hline $\mathrm{H}$ & -7.845003 & -2.890635 & -0.932641 \\
\hline 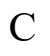 & -3.595056 & 1.678616 & 0.363350 \\
\hline O & -4.595245 & 1.542648 & 1.347611 \\
\hline 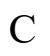 & -3.445888 & 2.888955 & -0.326140 \\
\hline$C$ & -5.422102 & 2.630814 & 1.622946 \\
\hline $\mathrm{H}$ & -4.719159 & 0.614131 & 1.892411 \\
\hline $\mathrm{C}$ & -4.300223 & 3.973128 & -0.056510 \\
\hline $\mathrm{H}$ & -2.703369 & 3.003299 & -1.108646 \\
\hline$\Omega$ & -5.293234 & 3.841812 & 0.929727 \\
\hline $\mathrm{H}$ & -6.187399 & 2.541470 & 2.387789 \\
\hline . & -5.963938 & 4.660751 & 1.159221 \\
\hline $\mathrm{O}$ & -6.058061 & -4.484618 & 0.417075 \\
\hline $\mathrm{O}$ & -4.077997 & 5.091218 & -0.797930 \\
\hline $\mathrm{C}$ & -4.952828 & 6.217607 & -0.613450 \\
\hline 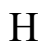 & -4.609769 & 6.973303 & -1.319500 \\
\hline 11 & -5.989994 & 5.949565 & -0.840786 \\
\hline $\mathrm{H}$ & -4.880256 & 6.609986 & 0.406695 \\
\hline $\mathrm{C}$ & -7.330748 & -5.123556 & 0.219599 \\
\hline T & -7.236568 & -6.107810 & 0.677093 \\
\hline 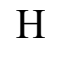 & -8.131856 & -4.565357 & 0.716061 \\
\hline 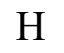 & -7.552924 & -5.236196 & -0.84710 \\
\hline
\end{tabular}


$\mathrm{M}=\mathrm{Am}$

\begin{tabular}{|c|c|c|c|}
\hline 11 & 1.929927 & 0.697259 & 0.004677 \\
\hline $\mathrm{O}$ & 3.433263 & 1.966156 & 1.764833 \\
\hline $\mathrm{H}$ & 4.356919 & 1.652632 & 1.792996 \\
\hline $\mathrm{O}$ & 3.426225 & 1.975814 & -1.720014 \\
\hline $\mathrm{H}$ & 3.383104 & 2.856363 & -2.124795 \\
\hline $\mathrm{O}$ & 0.395172 & 2.693632 & 0.137121 \\
\hline $\mathrm{H}$ & 0.337213 & 3.647758 & 0.286009 \\
\hline $\mathrm{O}$ & 1.334728 & 0.269196 & 2.448340 \\
\hline $\mathrm{H}$ & 0.793448 & -0.413756 & 2.871565 \\
\hline $\mathrm{O}$ & 1.312619 & 0.319290 & -2.451924 \\
\hline $\mathrm{H}$ & 1.956549 & 0.569465 & -3.132924 \\
\hline $\mathrm{H}$ & -0.535513 & 2.312148 & 0.145919 \\
\hline $\mathrm{H}$ & 0.683205 & -0.291200 & -2.864217 \\
\hline $\mathrm{H}$ & 3.435556 & 2.863308 & 2.133829 \\
\hline $\mathrm{H}$ & 4.362779 & 1.700726 & -1.742359 \\
\hline $\mathrm{H}$ & 1.966190 & 0.588568 & 3.112045 \\
\hline $\mathrm{C}$ & 5.259845 & -0.259576 & -0.018594 \\
\hline $\mathrm{C}$ & 6.029910 & -1.466491 & -0.048287 \\
\hline $\mathrm{C}$ & 7.439539 & -1.420383 & -0.078460 \\
\hline $\mathrm{C}$ & 8.072386 & -0.181474 & -0.081497 \\
\hline $\mathrm{C}$ & 7.316632 & 1.012008 & -0.050852 \\
\hline $\mathrm{C}$ & 5.918813 & 0.990816 & -0.018146 \\
\hline $\mathrm{C}$ & 3.832572 & -1.962393 & -0.001733 \\
\hline $\mathrm{C}$ & 5.091589 & -2.541545 & -0.0 \\
\hline $\mathrm{H}$ & 8.021442 & -2.336768 & -0.097799 \\
\hline $\mathrm{H}$ & 9.155521 & -0.123931 & -0.105149 \\
\hline $\mathrm{H}$ & 7.834878 & 1.965933 & -0.050519 \\
\hline $\mathrm{H}$ & 5.384275 & 1.937803 & 0.013425 \\
\hline $\mathrm{H}$ & 5.328129 & -3.596376 & -0.051692 \\
\hline $\mathrm{C}$ & 2.531986 & -2.598667 & 0.010502 \\
\hline $\mathrm{C}$ & 2.358941 & -4.002283 & 0.017434 \\
\hline $\mathrm{C}$ & 1.079469 & -4.534745 & 0.021035 \\
\hline $\mathrm{H}$ & 3.226485 & -4.650948 & 0.018979 \\
\hline $\mathrm{C}$ & 0.204983 & -2.302197 & 0.014883 \\
\hline $\mathrm{C}$ & -0.031655 & -3.669513 & 0.016121 \\
\hline $\mathrm{H}$ & 0.933087 & -5.610377 & 0.024232 \\
\hline $\mathrm{H}$ & -1.048590 & -4.039946 & 0.006231 \\
\hline $\mathrm{C}$ & -0.910128 & -1.324753 & 0.003674 \\
\hline $\mathrm{C}$ & -3.162893 & -0.862481 & -0.040314 \\
\hline $\mathrm{C}$ & -2.817169 & 0.543389 & 0.110109 \\
\hline $\mathrm{N}$ & 3.902300 & -0.561835 & 0.013509 \\
\hline $\mathrm{N}$ & 1.456363 & -1.771268 & 0.012340 \\
\hline 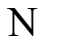 & -2.172564 & -1.761965 & -0.016558 \\
\hline$V$ & -( & -( & -1 \\
\hline
\end{tabular}




$\begin{array}{lrrr}\mathrm{N} & -1.534665 & 0.892210 & 0.070093 \\ \mathrm{C} & -4.522120 & -1.374495 & -0.251675 \\ \mathrm{C} & -5.501933 & -0.624451 & -0.945890 \\ \mathrm{C} & -4.813067 & -2.683866 & 0.169669 \\ \mathrm{C} & -6.741109 & -1.204495 & -1.200551 \\ \mathrm{H} & -5.293633 & 0.374871 & -1.304075 \\ \mathrm{C} & -6.078211 & -3.244392 & -0.058600 \\ \mathrm{H} & -4.071513 & -3.274314 & 0.693306 \\ \mathrm{C} & -7.047683 & -2.498176 & -0.755647 \\ \mathrm{H} & -7.491410 & -0.646308 & -1.751749 \\ \mathrm{H} & -8.029662 & -2.910184 & -0.955057 \\ \mathrm{C} & -3.773109 & 1.646800 & 0.355571 \\ \mathrm{C} & -4.783269 & 1.512818 & 1.329886 \\ \mathrm{C} & -3.613965 & 2.857493 & -0.331170 \\ \mathrm{C} & -5.610057 & 2.602778 & 1.598033 \\ \mathrm{H} & -4.915195 & 0.584101 & 1.872480 \\ \mathrm{C} & -4.468286 & 3.943502 & -0.069060 \\ \mathrm{H} & -2.862569 & 2.971166 & -1.105380 \\ \mathrm{C} & -5.471400 & 3.813980 & 0.907078 \\ \mathrm{H} & -6.383127 & 2.514662 & 2.355189 \\ \mathrm{H} & -6.142299 & 4.634434 & 1.130529 \\ \mathrm{O} & -6.259889 & -4.500849 & 0.421252 \\ \mathrm{O} & -4.236003 & 5.061722 & -0.807305 \\ \mathrm{C} & -5.109602 & 6.190076 & -0.630412 \\ \mathrm{H} & -4.757576 & 6.945570 & -1.332255 \\ \mathrm{H} & -6.145206 & 5.925016 & -0.868296 \\ \mathrm{H} & -5.046214 & 6.581372 & 0.390791 \\ \mathrm{C} & -7.533964 & -5.135404 & 0.219795 \\ \mathrm{H} & -7.447834 & -6.116327 & 0.685983 \\ \mathrm{H} & -8.336076 & -4.569415 & 0.705763 \\ \mathrm{H} & -7.749078 & -5.255777 & -0.847535\end{array}$

$\mathrm{M}=\mathrm{Cm}$

$\begin{array}{lccc}\mathrm{CM} & 1.898438 & 0.674907 & -0.012713 \\ \mathrm{O} & 3.365363 & 2.015271 & 1.697684 \\ \mathrm{H} & 4.295010 & 1.721599 & 1.740026 \\ \mathrm{O} & 3.381601 & 2.021184 & -1.693402 \\ \mathrm{H} & 3.351108 & 2.926841 & -2.039496 \\ \mathrm{O} & 0.416710 & 2.708912 & 0.107586 \\ \mathrm{H} & 0.357050 & 3.672135 & 0.175318 \\ \mathrm{O} & 1.377702 & 0.228449 & 2.432075 \\ \mathrm{H} & 0.923419 & -0.512843 & 2.859805 \\ \mathrm{O} & 1.350011 & 0.301185 & -2.461610 \\ \mathrm{H} & 1.991091 & 0.605570 & -3.123109 \\ \mathrm{H} & -0.512736 & 2.331746 & 0.128092\end{array}$




$\begin{array}{lrrc}\mathrm{H} & 0.776009 & -0.349968 & -2.892322 \\ \mathrm{H} & 3.346902 & 2.928867 & 2.022995 \\ \mathrm{H} & 4.315448 & 1.739183 & -1.723903 \\ \mathrm{H} & 1.984004 & 0.611869 & 3.085291 \\ \mathrm{C} & 5.264439 & -0.249589 & -0.003374 \\ \mathrm{C} & 6.034878 & -1.457489 & -0.004554 \\ \mathrm{C} & 7.445596 & -1.412218 & -0.003366 \\ \mathrm{C} & 8.078220 & -0.173833 & -0.000290 \\ \mathrm{C} & 7.322187 & 1.020865 & 0.002386 \\ \mathrm{C} & 5.924726 & 1.000520 & 0.001050 \\ \mathrm{C} & 3.834894 & -1.947112 & -0.006310 \\ \mathrm{C} & 5.094848 & -2.529589 & -0.006140 \\ \mathrm{H} & 8.027692 & -2.328673 & -0.004639 \\ \mathrm{H} & 9.161644 & -0.116242 & 0.000709 \\ \mathrm{H} & 7.841412 & 1.974330 & 0.006112 \\ \mathrm{H} & 5.389824 & 1.948192 & 0.006113 \\ \mathrm{H} & 5.329024 & -3.585035 & -0.007123 \\ \mathrm{C} & 2.537595 & -2.591624 & -0.005194 \\ \mathrm{C} & 2.371708 & -3.997472 & -0.004457 \\ \mathrm{C} & 1.095880 & -4.538151 & -0.005517 \\ \mathrm{H} & 3.242775 & -4.641350 & -0.004488 \\ \mathrm{C} & 0.203161 & -2.314038 & -0.003833 \\ \mathrm{C} & -0.023912 & -3.681920 & -0.007731 \\ \mathrm{C} & -4.763266 & 1.515593 & 1.349144 \\ \mathrm{H} & 0.957791 & -5.614943 & -0.007383 \\ \mathrm{H} & -1.037729 & -4.061067 & -0.018690 \\ \mathrm{C} & -0.912926 & -1.336764 & -0.009113 \\ \mathrm{C} & -3.162943 & -0.864778 & -0.038788 \\ \mathrm{C} & -2.810999 & 0.540092 & 0.111880 \\ \mathrm{~N} & 3.907125 & -0.545236 & -0.005807 \\ \mathrm{~N} & 1.452179 & -1.775933 & -0.003674 \\ \mathrm{H} & -2.176125 & -1.769260 & -0.021932 \\ \mathrm{~N} & -0.562122 & -0.043395 & -0.040604 \\ \mathrm{~N} & -1.527951 & 0.885877 & 0.063803 \\ \mathrm{C} & -4.524948 & -1.370964 & -0.243542 \\ \mathrm{C} & -5.507252 & -0.614258 & -0.927302 \\ \mathrm{C} & -4.817386 & -2.681657 & 0.173333 \\ \mathrm{C} & -6.749993 & -1.188978 & -1.176132 \\ \mathrm{H} & -5.298128 & 0.386005 & -1.282322 \\ \mathrm{H} & -6.085870 & -3.236841 & -0.048818 \\ \mathrm{H} & -3.057715 & -2.483831 & -0.735332 \\ \mathrm{H} & -0.625708 & -1.719426 \\ \mathrm{H} & -2.891579 & -0.929796 \\ \mathrm{H} & -0.323543\end{array}$




$\begin{array}{lrrr}\mathrm{C} & -5.584219 & 2.608245 & 1.624406 \\ \mathrm{H} & -4.892683 & 0.587608 & 1.893698 \\ \mathrm{C} & -4.453911 & 3.944697 & -0.053866 \\ \mathrm{H} & -2.861863 & 2.966222 & -1.105583 \\ \mathrm{C} & -5.448215 & 3.818730 & 0.931674 \\ \mathrm{H} & -6.350382 & 2.522923 & 2.388879 \\ \mathrm{H} & -6.114354 & 4.641387 & 1.161141 \\ \mathrm{O} & -6.268415 & -4.495051 & 0.425816 \\ \mathrm{O} & -4.224716 & 5.062100 & -0.794493 \\ \mathrm{C} & -5.093943 & 6.192847 & -0.610837 \\ \mathrm{H} & -4.746389 & 6.946823 & -1.316521 \\ \mathrm{H} & -6.132254 & 5.930073 & -0.839239 \\ \mathrm{H} & -5.020392 & 6.584887 & 0.409393 \\ \mathrm{C} & -7.546334 & -5.124090 & 0.231038 \\ \mathrm{H} & -7.460223 & -6.107460 & 0.692018 \\ \mathrm{H} & -8.342639 & -4.557458 & 0.725715 \\ \mathrm{H} & -7.769859 & -5.238745 & -0.835186\end{array}$

$\left[\mathrm{ML}_{2}\left(\mathrm{H}_{2} \mathrm{O}\right)_{2}\right]^{1+}$

$\mathrm{M}=\mathrm{Eu}$

$\begin{array}{lrrr}\text { EU } & 0.000001 & 1.089449 & -0.000012 \\ \mathrm{O} & -0.357133 & -0.817028 & 1.705347 \\ \mathrm{H} & -1.304112 & -1.089165 & 1.617280 \\ \mathrm{O} & 0.357134 & -0.817062 & -1.705331 \\ \mathrm{H} & 0.160376 & -0.752876 & -2.649217 \\ \mathrm{H} & -0.160392 & -0.752801 & 2.649235 \\ \mathrm{H} & 1.304119 & -1.089185 & -1.617272 \\ \mathrm{C} & -2.165078 & 3.463083 & 1.596297 \\ \mathrm{C} & -2.233680 & 4.262132 & 2.786239 \\ \mathrm{C} & -3.349712 & 5.092365 & 3.029589 \\ \mathrm{C} & -4.374242 & 5.126535 & 2.085997 \\ \mathrm{C} & -4.296643 & 4.348442 & 0.906052 \\ \mathrm{C} & -3.203700 & 3.517636 & 0.651339 \\ \mathrm{C} & -0.315887 & 3.074041 & 2.717111 \\ \mathrm{C} & -1.030137 & 3.999118 & 3.495517 \\ \mathrm{H} & -3.408588 & 5.695225 & 3.931274 \\ \mathrm{H} & -5.240100 & 5.761139 & 2.248305 \\ \mathrm{H} & -5.102975 & 4.407019 & 0.180935 \\ \mathrm{H} & -3.152680 & 2.950265 & -0.270487 \\ \mathrm{H} & -0.729856 & 4.434304 & 4.438812 \\ \mathrm{C} & 0.995492 & 2.513483 & 3.000212 \\ \mathrm{C} & 1.710542 & 2.839845 & 4.178732 \\ \mathrm{C} & 2.962441 & 2.286940 & 4.397676 \\ \mathrm{H} & 1.276636 & 3.523015 & 4.898291\end{array}$




\begin{tabular}{|c|c|c|c|}
\hline $\mathrm{C}$ & 2.740826 & 1.126554 & 2.313083 \\
\hline C & 3.502001 & 1.407127 & 3.444156 \\
\hline $\mathrm{H}$ & 3.523206 & 2.534046 & 5.294000 \\
\hline H & 4.480462 & 0.960163 & 3.559643 \\
\hline $\mathrm{C}$ & 3.257254 & 0.204855 & 1.269011 \\
\hline $\mathrm{C}$ & 4.951027 & -1.123563 & 0.470897 \\
\hline $\mathrm{C}$ & 4.062817 & -1.520554 & -0.589324 \\
\hline $\mathrm{N}$ & -0.995109 & 2.723510 & 1.567435 \\
\hline $\mathrm{N}$ & 1.519796 & 1.662372 & 2.087404 \\
\hline $\mathrm{N}$ & 4.489773 & -0.303909 & 1.414249 \\
\hline $\mathrm{N}$ & 2.462186 & -0.038604 & 0.218237 \\
\hline $\mathrm{N}$ & 2.867100 & -0.937721 & -0.680397 \\
\hline $\mathrm{C}$ & 6.367248 & -1.539946 & 0.584477 \\
\hline $\mathrm{C}$ & 7.188464 & -1.681237 & -0.554245 \\
\hline $\mathrm{C}$ & 6.911363 & -1.715096 & 1.863537 \\
\hline $\mathrm{C}$ & 8.534467 & -1.996172 & -0.384389 \\
\hline $\mathrm{H}$ & 6.790906 & -1.526069 & -1.549257 \\
\hline $\mathrm{C}$ & 8.261809 & -2.061687 & 2.022523 \\
\hline $\mathrm{H}$ & 6.295880 & -1.592250 & 2.746659 \\
\hline $\mathrm{C}$ & 9.081869 & -2.199297 & 0.890485 \\
\hline $\mathrm{H}$ & 9.177532 & -2.088139 & -1.254421 \\
\hline $\mathrm{H}$ & 10.129873 & -2.456185 & 0.986234 \\
\hline $\mathrm{C}$ & 4.337988 & -2.575654 & -1.596709 \\
\hline $\mathrm{C}$ & 4.832286 & -3.834976 & -1.202551 \\
\hline $\mathrm{C}$ & 4.036915 & -2.331563 & -2.940841 \\
\hline $\mathrm{C}$ & 5.011880 & -4.824849 & -2.166403 \\
\hline $\mathrm{H}$ & 5.062487 & -4.037947 & -0.163107 \\
\hline $\mathrm{C}$ & 4.237218 & -3.331702 & -3.908144 \\
\hline $\mathrm{H}$ & 3.669155 & -1.363806 & -3.263827 \\
\hline $\mathrm{C}$ & 4.725759 & -4.588592 & -3.518835 \\
\hline $\mathrm{H}$ & 5.382192 & -5.801531 & -1.869538 \\
\hline $\mathrm{H}$ & 4.886291 & -5.376817 & -4.244147 \\
\hline $\mathrm{O}$ & 8.677379 & -2.233991 & 3.311811 \\
\hline $\mathrm{O}$ & 3.923617 & -2.978953 & -5.190022 \\
\hline $\mathrm{C}$ & 4.131057 & -3.945956 & -6.224491 \\
\hline $\mathrm{H}$ & 3.833939 & -3.454910 & -7.151526 \\
\hline $\mathrm{H}$ & 5.185815 & -4.237586 & -6.289185 \\
\hline $\mathrm{H}$ & 3.509450 & -4.835452 & -6.067880 \\
\hline $\mathrm{C}$ & 10.049160 & -2.573072 & 3.538552 \\
\hline $\mathrm{H}$ & 10.156816 & -2.658883 & 4.620094 \\
\hline $\mathrm{H}$ & 10.304292 & -3.531178 & 3.070547 \\
\hline $\mathrm{H}$ & 10.719001 & -1.788543 & 3.167369 \\
\hline $\mathrm{C}$ & 2.165077 & 3.463063 & -1.596356 \\
\hline $\mathrm{C}$ & 2.233678 & 4.262092 & -2.786312 \\
\hline $\mathrm{C}$ & 3.349708 & 5.092324 & -3.029674 \\
\hline $\mathrm{C}$ & 4.374236 & 5.126513 & -2.086081 \\
\hline
\end{tabular}




\begin{tabular}{|c|c|c|c|}
\hline $\mathrm{C}$ & 4.296637 & 4.348441 & -0.906123 \\
\hline & 3.203697 & 3.517635 & -0.651398 \\
\hline & 0.315889 & 3.073997 & -2.717167 \\
\hline & 1.030138 & 3.999062 & -3.495588 \\
\hline & 3.408584 & 5.695169 & -3.931369 \\
\hline & 5.240093 & 5.761117 & -2.248399 \\
\hline & 5.102968 & 4.407031 & -0.181006 \\
\hline & 3.152677 & 2.950280 & 0.270438 \\
\hline 7 & 0.729857 & 4.434231 & -4.438890 \\
\hline & -0.995488 & 2.513430 & -3.000260 \\
\hline & -1.710537 & 2.839769 & -4.178787 \\
\hline & -2.962435 & 2.286857 & -4.397724 \\
\hline $\mathrm{H}$ & -1.276631 & 3.522926 & -4.898359 \\
\hline$C$ & -2.740821 & 1.126510 & -2.313109 \\
\hline 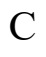 & -3.501995 & 1.407060 & -3.444188 \\
\hline $\mathrm{H}$ & -3.523198 & 2.533946 & -5.294053 \\
\hline $\mathrm{H}$ & -4.480455 & 0.960093 & -3.559668 \\
\hline$C$ & -3.257250 & 0.204831 & -1.269020 \\
\hline $\mathrm{C}$ & -4.951024 & -1.123570 & -0.470880 \\
\hline $\mathrm{C}$ & -4.062818 & -1.520536 & 0.589353 \\
\hline N & 0.995110 & 2.723487 & -1.567484 \\
\hline $\mathrm{N}$ & -1.519792 & 1.662335 & -2.087438 \\
\hline $\mathrm{N}$ & -4.489768 & -0.303937 & -1.414250 \\
\hline$N$ & -2.462184 & -0.038607 & -0.218239 \\
\hline N & -2.867100 & -0.937701 & 0.680415 \\
\hline 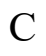 & -6.367245 & -1.539956 & -0.584455 \\
\hline $\mathrm{C}$ & -7.188464 & -1.681222 & 0.554269 \\
\hline 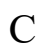 & -6.911356 & -1.715135 & -1.863512 \\
\hline $\mathrm{C}$ & -8.534466 & -1.996162 & 0.384415 \\
\hline $\mathrm{H}$ & -6.790909 & -1.526031 & 1.549278 \\
\hline $\mathrm{C}$ & -8.261802 & -2.061731 & -2.022495 \\
\hline 11 & -6.295871 & -1.592309 & -2.746635 \\
\hline 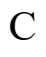 & -9.081864 & -2.199315 & -0.890455 \\
\hline $\mathrm{H}$ & -9.177534 & -2.088109 & 1.254448 \\
\hline $\mathrm{H}$ & -10.129868 & -2.456206 & -0.986201 \\
\hline $\mathrm{C}$ & -4.337992 & -2.575613 & 1.596762 \\
\hline , & -4.832287 & -3.834944 & 1.202632 \\
\hline $\mathrm{C}$ & -4.036924 & -2.331490 & 2.940889 \\
\hline 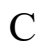 & -5.011884 & -4.824794 & 2.166505 \\
\hline $\mathrm{H}$ & -5.062484 & -4.037939 & 0.163191 \\
\hline$r$ & -4.237231 & -3.331606 & 3.908215 \\
\hline $\mathrm{H}$ & -3.669167 & -1.363724 & 3.263854 \\
\hline $\mathrm{C}$ & -4.725769 & -4.588505 & 3.518933 \\
\hline 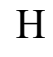 & -5.382194 & -5.801484 & 1.869662 \\
\hline $\mathrm{H}$ & -4.886304 & -5.376714 & 4.244264 \\
\hline $\mathrm{O}$ & -8.677367 & -2.234064 & -3.311779 \\
\hline
\end{tabular}




$\begin{array}{llll}\mathrm{O} & -3.923636 & -2.978827 & 5.190086 \\ \mathrm{C} & -4.131078 & -3.945806 & 6.224577 \\ \mathrm{H} & -3.833965 & -3.454738 & 7.151601 \\ \mathrm{H} & -5.185837 & -4.237436 & 6.289273 \\ \mathrm{H} & -3.509470 & -4.835305 & 6.067989 \\ \mathrm{C} & -10.049148 & -2.573150 & -3.538517 \\ \mathrm{H} & -10.156801 & -2.658986 & -4.620058 \\ \mathrm{H} & -10.304281 & -3.531246 & -3.070490 \\ \mathrm{H} & -10.718990 & -1.788613 & -3.167353\end{array}$

$\mathrm{M}=\mathrm{Gd}$

$\begin{array}{lrrr}\text { GD } & 0.000010 & 1.047850 & -0.002695 \\ \mathrm{O} & -0.359038 & -0.836128 & 1.629939 \\ \mathrm{H} & -1.313597 & -1.098840 & 1.561513 \\ \mathrm{O} & 0.359100 & -0.844308 & -1.625785 \\ \mathrm{H} & 0.140378 & -0.777677 & -2.564887 \\ \mathrm{H} & -0.140372 & -0.764606 & 2.568696 \\ \mathrm{H} & 1.313655 & -1.106687 & -1.556050 \\ \mathrm{C} & -2.343425 & 3.260558 & 1.415347 \\ \mathrm{C} & -2.547029 & 3.970091 & 2.648163 \\ \mathrm{C} & -3.724812 & 4.726404 & 2.858997 \\ \mathrm{C} & -4.674231 & 4.776386 & 1.848680 \\ \mathrm{C} & -4.462165 & 4.091927 & 0.621799 \\ \mathrm{C} & -3.314237 & 3.341724 & 0.395087 \\ \mathrm{C} & -0.565087 & 2.905674 & 2.662023 \\ \mathrm{C} & -1.388420 & 3.730623 & 3.432112 \\ \mathrm{H} & -3.877119 & 5.264234 & 3.790415 \\ \mathrm{H} & -5.583240 & 5.354763 & 1.983489 \\ \mathrm{H} & -5.211192 & 4.170363 & -0.160916 \\ \mathrm{H} & -3.160549 & 2.866108 & -0.565079 \\ \mathrm{H} & -1.184389 & 4.122336 & 4.419105 \\ \mathrm{C} & 0.743954 & 2.399516 & 3.003342 \\ \mathrm{C} & 1.394311 & 2.722654 & 4.222497 \\ \mathrm{C} & 2.650833 & 2.207876 & 4.488900 \\ \mathrm{H} & 0.903440 & 3.378412 & 4.930844 \\ \mathrm{C} & 2.573064 & 1.083318 & 2.375698 \\ \mathrm{C} & 3.267425 & 1.363432 & 3.544909 \\ \mathrm{H} & 3.160559 & 2.455808 & 5.414942 \\ \mathrm{H} & 4.253349 & 0.945798 & 3.699954 \\ \mathrm{C} & 3.151563 & 0.199640 & 1.337612 \\ \mathrm{C} & 4.906863 & -1.048790 & 0.547829 \\ \mathrm{C} & 4.053327 & -1.457070 & -0.539278 \\ \mathrm{~N} & -1.133485 & 2.593032 & 1.428858 \\ \mathrm{~N} & 1.345630 & 1.587047 & 2.099699 \\ \mathrm{~N} & 4.396254 & -0.269799 & 1.500039\end{array}$




\begin{tabular}{|c|c|c|c|}
\hline & 5649 & -0.053290 & \\
\hline & 838219 & -0.921406 & -0.638959 \\
\hline & 334037 & -1.414349 & 487 \\
\hline & 179213 & -1.505059 & -0.447070 \\
\hline & 862582 & -1.589891 & 1.965358 \\
\hline & .533157 & -1.770787 & -0.258325 \\
\hline & 793637 & -1.345975 & -1.4 \\
\hline & .222132 & -1.8 & 2.14 \\
\hline & 087 & -1.5 & 2.83 \\
\hline & 065804 & -1.9 & 1.02 \\
\hline & 194315 & -1.8 & -1.1 \\
\hline & 10.121166 & 3054 & 666 \\
\hline & 340 & -2.4 & -1.56 \\
\hline E & 4.920207 & -3.7 & -1.1 \\
\hline & 4.100143 & -2.2 & -2.9 \\
\hline & 86 & -4.6 & -2.1 \\
\hline $\mathrm{H}$ & 5.139846 & -3.9 & -0.1 \\
\hline & 4.3 & -3.1 & -3.8 \\
\hline $\mathrm{H}$ & 3.704682 & -1.2 & -3.2 \\
\hline & 4.882467 & -4.4 & -3.5 \\
\hline $\mathrm{H}$ & 375 & -5.6 & -1.8 \\
\hline & & -5.2 & \\
\hline $\mathrm{O}$ & 8.6 & -2.0 & 3.4 \\
\hline C & 4.0 & -2.8 & -5.1 \\
\hline $\mathrm{C}$ & 4.3 & -3.7 & -6.2 \\
\hline & 3656 & -3.2 & -7.1 \\
\hline $\mathrm{H}$ & 5.3 & -4.0 & -6.2 \\
\hline $\mathrm{H}$ & 3.726644 & -4.6 & -6.0 \\
\hline $\mathrm{C}$ & 10.002214 & -2.3 & 3.6 \\
\hline $\mathrm{H}$ & 10.094331 & 5573 & 4.7 \\
\hline $\mathrm{H}$ & 10.302803 & -3.2 & 3.2 \\
\hline H & 10.646674 & 9095 & 3.3 \\
\hline $\mathrm{C}$ & 2.343328 & 3609 & -1.43 \\
\hline $\mathrm{C}$ & 2.546941 & 3.9 & -2.66 \\
\hline & 3.724666 & 4.7 & -2.88 \\
\hline C & 4.674021 & 4.7 & -1.872602 \\
\hline $\mathrm{C}$ & 4.461948 & 4.089171 & -0.642288 \\
\hline $\mathrm{C}$ & 3.314078 & 3.3 & -0.41 \\
\hline C & 0.565097 & 2.892253 & -2.676713 \\
\hline $\mathrm{C}$ & 1.388413 & 3.7 & $-3.45 c$ \\
\hline $\mathrm{H}$ & 3.876982 & 5.245379 & -3.816828 \\
\hline & 5.582984 & 5.345209 & -2.010284 \\
\hline 11 & 5.210924 & 4.171635 & 0.140062 \\
\hline & 3.160380 & 2.869238 & 0.550693 \\
\hline $\mathrm{H}$ & 1.184416 & 4.100024 & -4.439910 \\
\hline $\mathrm{C}$ & -0.743888 & 2.384276 & -3.015533 \\
\hline
\end{tabular}




$\begin{array}{lrrr}\mathrm{C} & -1.394184 & 2.701129 & -4.236371 \\ \mathrm{C} & -2.650659 & 2.184923 & -4.500217 \\ \mathrm{H} & -0.903304 & 3.353277 & -4.948039 \\ \mathrm{C} & -2.572969 & 1.071208 & -2.381279 \\ \mathrm{C} & -3.267272 & 1.345299 & -3.551950 \\ \mathrm{H} & -3.160336 & 2.428075 & -5.427553 \\ \mathrm{H} & -4.253171 & 0.926837 & -3.704916 \\ \mathrm{C} & -3.151487 & 0.192828 & -1.338716 \\ \mathrm{C} & -4.906816 & -1.051515 & -0.542578 \\ \mathrm{C} & -4.053316 & -1.454213 & 0.546633 \\ \mathrm{~N} & 1.133438 & 2.585927 & -1.441937 \\ \mathrm{~N} & -1.345570 & 1.576395 & -2.107793 \\ \mathrm{~N} & -4.396183 & -0.277412 & -1.498757 \\ \mathrm{~N} & -2.385584 & -0.054653 & -0.267220 \\ \mathrm{~N} & -2.838190 & -0.918088 & 0.643575 \\ \mathrm{C} & -6.333986 & -1.417745 & -0.672400 \\ \mathrm{C} & -7.179202 & -1.502629 & 0.454580 \\ \mathrm{C} & -6.862480 & -1.599951 & -1.957365 \\ \mathrm{C} & -8.533138 & -1.769338 & 0.267162 \\ \mathrm{H} & -6.793663 & -1.338375 & 1.452772 \\ \mathrm{C} & -8.222021 & -1.898998 & -2.133015 \\ \mathrm{H} & -6.227952 & -1.519201 & -2.831768 \\ \mathrm{C} & -9.065737 & -1.980077 & -1.012716 \\ \mathrm{H} & -9.194327 & -1.816326 & 1.127095 \\ \mathrm{H} & -10.121093 & -2.198810 & -1.121684 \\ \mathrm{C} & -4.386381 & -2.471760 & 1.574606 \\ \mathrm{C} & -4.920173 & -3.721688 & 1.202543 \\ \mathrm{C} & -4.100282 & -2.203596 & 2.917515 \\ \mathrm{C} & -5.153274 & -4.679027 & 2.187547 \\ \mathrm{H} & -5.139725 & -3.942775 & 0.164503 \\ \mathrm{C} & -4.354763 & -3.170627 & 3.905722 \\ \mathrm{H} & -3.704870 & -1.241039 & 3.223136 \\ \mathrm{C} & -4.882542 & -4.418426 & 3.538627 \\ \mathrm{H} & -5.554297 & -5.648817 & 1.908592 \\ \mathrm{H} & -5.085345 & -5.181167 & 4.280400 \\ \mathrm{O} & -8.621829 & -2.084338 & -3.425069 \\ \mathrm{O} & -4.051357 & -2.796945 & 5.183600 \\ \mathrm{C} & -4.316561 & -3.727061 & 6.238816 \\ \mathrm{H} & -4.018992 & -3.222606 & 7.158429 \\ \mathrm{H} & -5.382910 & -3.976078 & 6.289120 \\ \mathrm{H} & -3.726853 & -4.643507 & 6.118635 \\ \mathrm{C} & -10.002035 & -2.374578 & -3.669347 \\ \mathrm{H} & -10.094100 & -2.480161 & -4.750542 \\ \mathrm{H} & -10.302639 & -3.311357 & -3.185506 \\ \mathrm{H} & -10.646522 & -1.556286 & -3.327473\end{array}$


$\mathrm{M}=\mathrm{Am}$

$\begin{array}{lrcc}\text { AM } & -0.000011 & -1.061999 & -0.000181 \\ \mathrm{O} & -0.331874 & 0.909993 & -1.677083 \\ \mathrm{H} & -1.283604 & 1.172079 & -1.588749 \\ \mathrm{O} & 0.332102 & 0.909006 & 1.677828 \\ \mathrm{H} & 0.139777 & 0.827286 & 2.621858 \\ \mathrm{H} & -0.139457 & 0.828829 & -2.621143 \\ \mathrm{H} & 1.283824 & 1.171137 & 1.589550 \\ \mathrm{C} & -2.260233 & -3.316506 & -1.539477 \\ \mathrm{C} & -2.370335 & -4.081616 & -2.748052 \\ \mathrm{C} & -3.524982 & -4.855021 & -3.009552 \\ \mathrm{C} & -4.545951 & -4.865630 & -2.069339 \\ \mathrm{C} & -4.427763 & -4.122338 & -0.865329 \\ \mathrm{C} & -3.301659 & -3.354573 & -0.591064 \\ \mathrm{C} & -0.397513 & -2.997371 & -2.674002 \\ \mathrm{C} & -1.159890 & -3.862740 & -3.459610 \\ \mathrm{H} & -3.607354 & -5.434624 & -3.924433 \\ \mathrm{H} & -5.440644 & -5.455580 & -2.243490 \\ \mathrm{H} & -5.233289 & -4.166394 & -0.138114 \\ \mathrm{H} & -3.222308 & -2.825309 & 0.350341 \\ \mathrm{H} & -0.889927 & -4.289955 & -4.415497 \\ \mathrm{C} & 0.921869 & -2.479589 & -2.967131 \\ \mathrm{C} & 1.635626 & -2.839987 & -4.138511 \\ \mathrm{C} & 2.893448 & -2.309709 & -4.368006 \\ \mathrm{H} & 1.193237 & -3.534170 & -4.842056 \\ \mathrm{C} & 2.695999 & -1.102967 & -2.308789 \\ \mathrm{C} & 3.448773 & -1.414778 & -3.433760 \\ \mathrm{H} & 3.450543 & -2.584755 & -5.258345 \\ \mathrm{H} & 4.432641 & -0.983542 & -3.561783 \\ \mathrm{C} & 3.217673 & -0.172481 & -1.279381 \\ \mathrm{C} & 4.916435 & 1.152866 & -0.487678 \\ \mathrm{C} & 4.028673 & 1.561205 & 0.570725 \\ \mathrm{~N} & -1.056213 & -2.638709 & -1.498136 \\ \mathrm{~N} & 1.466928 & -1.619714 & -2.072759 \\ \mathrm{~N} & 4.451912 & 0.330019 & -1.426463 \\ \mathrm{~N} & 2.421185 & 0.086954 & -0.233572 \\ \mathrm{~N} & 2.828789 & 0.989902 & 0.660657 \\ \mathrm{C} & 6.333428 & 1.563034 & -0.602592 \\ \mathrm{C} & 7.154216 & 1.707923 & 0.536175 \\ \mathrm{C} & 6.879363 & 1.728050 & -1.882418 \\ \mathrm{C} & 8.501709 & 2.015389 & 0.365462 \\ \mathrm{H} & 6.755710 & 1.559013 & 1.531703 \\ \mathrm{H} & \mathbf{2} 31309 & 2.068016 & -2.042385 \\ \mathrm{H} & 1.602070 & -2.765420 \\ \mathrm{H} & 2.208625 & -0.910178\end{array}$




\begin{tabular}{|c|c|c|c|}
\hline $\mathrm{H}$ & 9.144652 & 2.108986 & 35391 \\
\hline & 10.100118 & 2.460079 & -1.006555 \\
\hline & 4.309442 & 2.617800 & 1.574814 \\
\hline C & 4.810681 & 3.873289 & 1.177331 \\
\hline 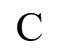 & 4.006110 & 2.378530 & 2.919371 \\
\hline C & 4.994816 & 4.864626 & 2.138824 \\
\hline & 5.042946 & 4.072342 & 0.137575 \\
\hline & 4.210903 & 3.380231 & 3.884176 \\
\hline $\mathrm{H}$ & 3.635107 & 1.412770 & 3.245149 \\
\hline C & 4.706478 & 4.633402 & 3.491610 \\
\hline H & 5.370640 & 5.838507 & 1.839687 \\
\hline & 4.870923 & 5.422602 & 4.214985 \\
\hline 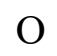 & 8.648700 & 2.230971 & -3.331952 \\
\hline 0 & 3.894526 & 3.032692 & 5.166379 \\
\hline C & 4.109349 & 3.999924 & 6.199440 \\
\hline $\mathrm{H}$ & 3.809606 & 3.512122 & 7.127285 \\
\hline H & 5.166156 & 4.284204 & 6.262789 \\
\hline $\mathrm{H}$ & 3.493602 & 4.893307 & 6.041939 \\
\hline $\mathrm{C}$ & 10.022660 & 2.561222 & -3.559803 \\
\hline $\mathrm{H}$ & 10.131432 & 2.639625 & -4.641758 \\
\hline $\mathrm{H}$ & 10.282470 & 3.520884 & -3.097637 \\
\hline $\mathrm{H}$ & 10.687790 & 1.775302 & -3.183246 \\
\hline $\mathrm{C}$ & 2.260026 & -3.317545 & 1.537912 \\
\hline $\mathrm{C}$ & 2.370038 & -4.083306 & 2.746083 \\
\hline $\mathrm{C}$ & 3.524591 & -4.856990 & 3.007173 \\
\hline $\mathrm{C}$ & 4.545561 & -4.867219 & 2.066959 \\
\hline O & 4.427470 & -4.123261 & 0.863350 \\
\hline $\mathrm{C}$ & 3.301460 & -3.355215 & 0.589491 \\
\hline 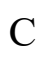 & 0.397352 & -2.998772 & 2.672613 \\
\hline $\mathrm{C}$ & 1.159627 & -3.864649 & 3.457762 \\
\hline $\mathrm{H}$ & 3.606892 & -5.437088 & 3.921747 \\
\hline $\mathrm{H}$ & 5.440183 & -5.457369 & 2.240797 \\
\hline $\mathrm{H}$ & 5.233000 & -4.167015 & 0.136119 \\
\hline $\mathrm{H}$ & 3.222191 & -2.825415 & -0.351620 \\
\hline $\mathrm{H}$ & 0.889610 & -4.292340 & 4.413421 \\
\hline $\mathrm{C}$ & -0.921988 & -2.481030 & 2.966000 \\
\hline . & -1.635737 & -2.841890 & 4.137244 \\
\hline $\mathrm{C}$ & -2.893528 & -2.311647 & 4.366991 \\
\hline $\mathrm{H}$ & -1.193367 & -3.536394 & 4.840484 \\
\hline $\mathrm{C}$ & -2.696053 & -1.104013 & 2.308300 \\
\hline $\mathrm{C}$ & -3.448828 & -1.416285 & 3.433141 \\
\hline 11 & -3.450618 & -2.587047 & 5.257223 \\
\hline $\mathrm{H}$ & -4.432673 & -0.985060 & 3.561368 \\
\hline 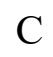 & -3.217680 & -0.173033 & 1.279316 \\
\hline $\mathrm{C}$ & -4.916394 & 1.152702 & 0.488164 \\
\hline $\mathrm{C}$ & -4.028560 & 1.561585 & -0.569969 \\
\hline
\end{tabular}




$\begin{array}{crcc}\mathrm{N} & 1.056090 & -2.639581 & 1.496927 \\ \mathrm{~N} & -1.467014 & -1.620724 & 2.072022 \\ \mathrm{~N} & -4.451928 & 0.329390 & 1.426570 \\ \mathrm{~N} & -2.421124 & 0.086927 & 0.233687 \\ \mathrm{~N} & -2.828668 & 0.990330 & -0.660108 \\ \mathrm{C} & -6.333401 & 1.562794 & 0.603181 \\ \mathrm{C} & -7.154105 & 1.708250 & -0.535574 \\ \mathrm{C} & -6.879435 & 1.727153 & 1.883050 \\ \mathrm{C} & -8.501615 & 2.015610 & -0.364807 \\ \mathrm{H} & -6.755523 & 1.559850 & -1.531148 \\ \mathrm{C} & -8.231397 & 2.067019 & 2.043087 \\ \mathrm{H} & -6.264451 & 1.600733 & 2.766034 \\ \mathrm{C} & -9.050863 & 2.208191 & 0.910890 \\ \mathrm{H} & -9.144494 & 2.109640 & -1.234736 \\ \mathrm{H} & -10.100133 & 2.459581 & 1.007316 \\ \mathrm{C} & -4.309259 & 2.618694 & -1.573534 \\ \mathrm{C} & -4.810549 & 3.873971 & -1.175446 \\ \mathrm{C} & -4.005813 & 2.380121 & -2.918190 \\ \mathrm{C} & -4.994620 & 4.865801 & -2.136444 \\ \mathrm{H} & -5.042905 & 4.072485 & -0.135607 \\ \mathrm{C} & -4.210539 & 3.382317 & -3.882495 \\ \mathrm{H} & -3.634769 & 1.414535 & -3.244434 \\ \mathrm{C} & -4.706166 & 4.635278 & -3.489325 \\ \mathrm{H} & -5.370484 & 5.839522 & -1.836836 \\ \mathrm{H} & -4.870562 & 5.424849 & -4.212306 \\ \mathrm{O} & -8.648888 & 2.229312 & 3.332706 \\ \mathrm{O} & -3.894049 & 3.035444 & -5.164851 \\ \mathrm{C} & -4.108811 & 4.003200 & -6.197432 \\ \mathrm{H} & -3.808986 & 3.515880 & -7.125504 \\ \mathrm{H} & -5.165620 & 4.287490 & -6.260718 \\ \mathrm{H} & -3.493096 & 4.896516 & -6.039426 \\ \mathrm{C} & -10.022870 & 2.559426 & 3.560621 \\ \mathrm{H} & -10.131725 & 2.637275 & 4.642608 \\ \mathrm{H} & -10.282660 & 3.519320 & 3.098925 \\ \mathrm{H} & -10.687959 & 1.773688 & 3.183612\end{array}$

$\mathrm{M}=\mathrm{Cm}$
$\begin{array}{llll}\mathrm{CM} & -0.000371 & 1.014236 & 0.024511\end{array}$
$\begin{array}{llll}\mathrm{O} & 0.368850 & -0.888505 & -1.704452\end{array}$

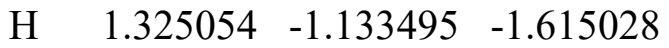
$\begin{array}{llll}\mathrm{O} & -0.367372 & -0.973069 & 1.656957\end{array}$
$\begin{array}{llll}\mathrm{H} & -0.186396 & -0.900417 & 2.603998\end{array}$

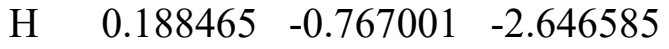

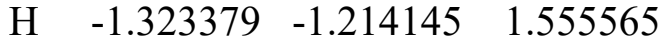
$\begin{array}{llll}\text { C } & 2.310702 & 3.274680 & -1.420824\end{array}$ 


$\begin{array}{lrrr}\mathrm{C} & 2.486091 & 4.016866 & -2.637615 \\ \mathrm{C} & 3.657326 & 4.781166 & -2.852915 \\ \mathrm{C} & 4.628164 & 4.805340 & -1.862184 \\ \mathrm{C} & 4.444458 & 4.086164 & -0.650662 \\ \mathrm{C} & 3.302770 & 3.328324 & -0.419836 \\ \mathrm{C} & 0.507455 & 2.942993 & -2.640404 \\ \mathrm{C} & 1.311963 & 3.791924 & -3.404062 \\ \mathrm{H} & 3.789132 & 5.344172 & -3.772423 \\ \mathrm{H} & 5.533247 & 5.389018 & -2.000555 \\ \mathrm{H} & 5.210956 & 4.143692 & 0.116818 \\ \mathrm{H} & 3.170601 & 2.821213 & 0.528222 \\ \mathrm{H} & 1.088588 & 4.207481 & -4.376986 \\ \mathrm{C} & -0.805392 & 2.437289 & -2.973134 \\ \mathrm{C} & -1.474969 & 2.788284 & -4.173652 \\ \mathrm{C} & -2.733672 & 2.275627 & -4.434805 \\ \mathrm{H} & -0.997799 & 3.463523 & -4.873012 \\ \mathrm{C} & -2.621231 & 1.097655 & -2.352492 \\ \mathrm{C} & -3.333445 & 1.405018 & -3.504368 \\ \mathrm{H} & -3.257608 & 2.545161 & -5.346782 \\ \mathrm{H} & -4.319701 & 0.987323 & -3.656746 \\ \mathrm{C} & -3.184414 & 0.182537 & -1.331850 \\ \mathrm{C} & -4.925066 & -1.103095 & -0.567692 \\ \mathrm{C} & -4.063697 & -1.531619 & 0.505164 \\ \mathrm{~N} & 1.103918 & 2.604071 & -1.427881 \\ \mathrm{~N} & -1.392258 & 1.599256 & -2.083380 \\ \mathrm{C} & -4.3340481 & -3.350640 & 3.812135 \\ \mathrm{~N} & -4.426174 & -0.293490 & -1.500279 \\ \mathrm{~N} & -2.412463 & -0.092593 & -0.271826 \\ \mathrm{~N} & -2.853157 & -0.987527 & 0.614662 \\ \mathrm{C} & -6.349109 & -1.479647 & -0.704074 \\ \mathrm{C} & -7.190195 & -1.603096 & 0.422387 \\ \mathrm{C} & -6.879270 & -1.633407 & -1.991971 \\ \mathrm{C} & -8.541913 & -1.878342 & 0.231536 \\ \mathrm{H} & -6.803345 & -1.461704 & 1.423634 \\ \mathrm{C} & -8.236320 & -1.941256 & -2.172022 \\ \mathrm{H} & -6.248036 & -1.523452 & -2.865664 \\ \mathrm{C} & -9.076017 & -2.060387 & -1.052128 \\ \mathrm{H} & -9.200137 & -1.954898 & 1.091651 \\ \mathrm{H} & -10.129419 & -2.286786 & -1.164163 \\ \mathrm{C} & -4.383727 & -2.582572 & 1.503191 \\ \mathrm{C} & -4.093062 & -2.352439 & 2.852202 \\ \mathrm{H} & -4.591200 & 3.410431\end{array}$




$\begin{array}{lccc}\mathrm{H} & -5.523655 & -5.777902 & 1.747453 \\ \mathrm{H} & -5.046592 & -5.377502 & 4.129980 \\ \mathrm{O} & -8.637917 & -2.096180 & -3.467506 \\ \mathrm{O} & -4.027341 & -3.012989 & 5.099152 \\ \mathrm{C} & -4.279010 & -3.976617 & 6.127288 \\ \mathrm{H} & -3.980455 & -3.497570 & 7.060049 \\ \mathrm{H} & -5.343033 & -4.235829 & 6.175739 \\ \mathrm{H} & -3.682427 & -4.884028 & 5.976372 \\ \mathrm{C} & -10.015759 & -2.394043 & -3.715919 \\ \mathrm{H} & -10.109773 & -2.471799 & -4.799293 \\ \mathrm{H} & -10.305347 & -3.346425 & -3.256410 \\ \mathrm{H} & -10.667621 & -1.591800 & -3.350776 \\ \mathrm{C} & -2.310951 & 3.202395 & 1.578267 \\ \mathrm{C} & -2.487883 & 3.881844 & 2.830958 \\ \mathrm{C} & -3.658660 & 4.635634 & 3.082716 \\ \mathrm{C} & -4.627518 & 4.711504 & 2.092664 \\ \mathrm{C} & -4.442234 & 4.054819 & 0.846402 \\ \mathrm{C} & -3.300962 & 3.308312 & 0.579422 \\ \mathrm{C} & -0.510468 & 2.806823 & 2.782761 \\ \mathrm{C} & -1.315502 & 3.616744 & 3.587146 \\ \mathrm{H} & -3.791618 & 5.151195 & 4.029480 \\ \mathrm{H} & -5.532205 & 5.288487 & 2.258892 \\ \mathrm{H} & -5.207146 & 4.152343 & 0.081383 \\ \mathrm{H} & -3.167498 & 2.850064 & -0.393015 \\ \mathrm{H} & -1.093481 & 3.982033 & 4.580346 \\ \mathrm{C} & 0.801364 & 2.283732 & 3.091758 \\ \mathrm{C} & 1.469064 & 2.572957 & 4.309661 \\ \mathrm{C} & 2.727171 & 2.047177 & 4.546462 \\ \mathrm{H} & 0.990986 & 3.212072 & 5.041583 \\ \mathrm{C} & 2.617760 & 0.976639 & 2.406782 \\ \mathrm{C} & 3.328238 & 1.224848 & 3.573890 \\ \mathrm{H} & 3.249718 & 2.269838 & 5.471787 \\ \mathrm{H} & 4.314193 & 0.799716 & 3.706333 \\ \mathrm{C} & 3.182439 & 0.114777 & 1.341605 \\ \mathrm{C} & 4.924659 & -1.129054 & 0.514482 \\ \mathrm{C} & 4.064669 & -1.502567 & -0.579830 \\ \mathrm{~N} & -1.105005 & 2.530668 & 1.553460 \\ \mathrm{~N} & 1.389318 & 1.491620 & 2.161601 \\ \mathrm{~N} & 4.424319 & -0.368544 & 1.486782 \\ \mathrm{~N} & 2.411682 & -0.106314 & 0.268166 \\ \mathrm{C} & 6.348782 & -1.511329 & 0.632890 \\ \mathrm{C} & -191039 & -1.576708 & -0.497558 \\ \mathrm{H} & -1.730316 & 1.911796 \\ \mathrm{H} & -1.860667 & -0.319645 \\ \mathrm{H} & -1.384580 & -1.490674\end{array}$




$\begin{array}{cccc}\mathrm{C} & 8.234821 & -2.046266 & 2.077268 \\ \mathrm{H} & 6.245628 & -1.665401 & 2.789328 \\ \mathrm{C} & 9.075667 & -2.107720 & 0.953591 \\ \mathrm{H} & 9.201821 & -1.892920 & -1.181888 \\ \mathrm{H} & 10.129080 & -2.339034 & 1.054984 \\ \mathrm{C} & 4.386579 & -2.500588 & -1.630215 \\ \mathrm{C} & 4.913041 & -3.761896 & -1.287383 \\ \mathrm{C} & 4.096758 & -2.201812 & -2.965885 \\ \mathrm{C} & 5.135397 & -4.699435 & -2.293711 \\ \mathrm{H} & 5.135076 & -4.007008 & -0.255233 \\ \mathrm{C} & 4.340239 & -3.149086 & -3.975614 \\ \mathrm{H} & 3.707012 & -1.230042 & -3.249238 \\ \mathrm{C} & 4.860910 & -4.408022 & -3.637696 \\ \mathrm{H} & 5.530676 & -5.677786 & -2.037264 \\ \mathrm{H} & 5.055215 & -5.156065 & -4.396512 \\ \mathrm{O} & 8.635258 & -2.266900 & 3.363556 \\ \mathrm{O} & 4.033841 & -2.746062 & -5.243862 \\ \mathrm{C} & 4.287715 & -3.655162 & -6.319994 \\ \mathrm{H} & 3.989400 & -3.129097 & -7.227149 \\ \mathrm{H} & 5.352120 & -3.910193 & -6.380672 \\ \mathrm{H} & 3.692181 & -4.569895 & -6.216602 \\ \mathrm{C} & 10.012998 & -2.576511 & 3.597744 \\ \mathrm{H} & 10.106065 & -2.709373 & 4.675830 \\ \mathrm{H} & 10.303398 & -3.504113 & 3.090532 \\ \mathrm{H} & 10.664841 & -1.756442 & 3.274579\end{array}$

\section{$\left[\mathrm{ML}_{2}\right]^{1+}$}

$\mathrm{M}=\mathrm{Eu}$

$\begin{array}{llll}\text { EU } & -0.000013 & 1.562959 & -0.000027 \\ \mathrm{C} & 1.899755 & 4.023255 & 1.666775 \\ \mathrm{C} & 1.889096 & 4.806344 & 2.866400 \\ \mathrm{C} & 2.900299 & 5.761355 & 3.100315 \\ \mathrm{C} & 3.898603 & 5.925851 & 2.138315 \\ \mathrm{C} & 3.899163 & 5.155105 & 0.953511 \\ \mathrm{C} & 2.906017 & 4.201690 & 0.705565 \\ \mathrm{C} & 0.132860 & 3.384407 & 2.816432 \\ \mathrm{C} & 0.740395 & 4.380379 & 3.595517 \\ \mathrm{H} & 2.905083 & 6.358661 & 4.007406 \\ \mathrm{H} & 4.685351 & 6.657078 & 2.295947 \\ \mathrm{H} & 4.684748 & 5.311940 & 0.220634 \\ \mathrm{H} & 2.915243 & 3.627358 & -0.216972 \\ \mathrm{H} & 0.408947 & 4.753845 & 4.554959 \\ \mathrm{C} & -1.078144 & 2.625458 & 3.099700 \\ \mathrm{C} & -1.821557 & 2.777082 & 4.292449\end{array}$




\begin{tabular}{|c|c|c|c|}
\hline $\mathrm{C}$ & -2.960335 & 2.006946 & 4.488998 \\
\hline$\theta$ & -1.498589 & 3.487197 & 5.044186 \\
\hline & -2.576257 & 0.995313 & 2.353287 \\
\hline 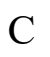 & -3.354457 & 1.085639 & 3.503750 \\
\hline & -3.540204 & 2.111337 & 5.401057 \\
\hline & -4.226016 & 0.454387 & 3.618630 \\
\hline & -2.910708 & 0.043174 & 1.262024 \\
\hline $\mathrm{C}$ & -4.283778 & -1.557149 & 0.366719 \\
\hline$C$ & -3.490647 & -1.487843 & -0.833926 \\
\hline $\mathrm{N}$ & 0.826055 & 3.148085 & 1.646653 \\
\hline $\mathrm{N}$ & -1.472163 & 1.745581 & 2.151369 \\
\hline $\mathbf{N}$ & -3.999655 & -0.724961 & 1.371161 \\
\hline $\mathrm{N}$ & -2.050665 & -0.020926 & 0.231064 \\
\hline $\mathrm{N}$ & -2.368031 & -0.762097 & -0.832163 \\
\hline $\mathrm{C}$ & -5.381261 & -2.522617 & 0.600807 \\
\hline $\mathrm{C}$ & -5.321361 & -3.841487 & 0.101639 \\
\hline $\mathrm{C}$ & -6.458314 & -2.129628 & 1.406202 \\
\hline $\mathrm{C}$ & -6.342361 & -4.733560 & 0.419092 \\
\hline $\mathrm{H}$ & -4.487654 & -4.167268 & -0.507494 \\
\hline $\mathrm{C}$ & -7.496995 & -3.02 & 789 \\
\hline $\mathrm{H}$ & -6.508576 & -1.124902 & 1.808252 \\
\hline $\mathrm{C}$ & -7.437559 & -4.341553 & 1.202571 \\
\hline $\mathrm{H}$ & -6.295960 & -5.754485 & 0.052258 \\
\hline $\mathrm{H}$ & -8.222245 & -5.056528 & 1.418343 \\
\hline $\mathrm{C}$ & -3.827149 & -2.139968 & -2.123692 \\
\hline $\mathrm{C}$ & -5.145648 & -2.108812 & -2.621961 \\
\hline $\mathrm{C}$ & -2.807287 & -2.722073 & -2.883909 \\
\hline $\mathrm{C}$ & -5.413346 & -2.665095 & -3.870580 \\
\hline $\mathrm{H}$ & -5.942511 & -1.646987 & -2.050987 \\
\hline $\mathrm{C}$ & -3.091303 & -3.298492 & -4.133068 \\
\hline $\mathrm{H}$ & -1.785944 & -2.738914 & -2.521953 \\
\hline $\mathrm{C}$ & -4.402673 & -3.268870 & -4.632618 \\
\hline $\mathrm{H}$ & -6.423849 & -2.632899 & -4.266778 \\
\hline $\mathrm{H}$ & -4.646180 & -3.700876 & -5.595570 \\
\hline $\mathrm{O}$ & -8.508129 & -2.529391 & 2.466106 \\
\hline $\mathrm{O}$ & -2.023282 & -3.855639 & -4.779640 \\
\hline $\mathrm{C}$ & -2.250306 & -4.453405 & -6.059162 \\
\hline $\mathrm{H}$ & -1.280438 & -4.829599 & -6.386131 \\
\hline $\mathrm{H}$ & -2.958619 & -5.287404 & -5.988632 \\
\hline $\mathrm{H}$ & -2.617582 & -3.716375 & -6.783075 \\
\hline $\mathrm{C}$ & -9.595051 & -3.399141 & 2.797852 \\
\hline $\mathrm{H}$ & -10.276057 & -2.801844 & 3.404586 \\
\hline $\mathrm{H}$ & -10.117208 & -3.743634 & 1.897460 \\
\hline $\mathrm{H}$ & -9.250344 & -4.261847 & 3.380107 \\
\hline $\mathrm{C}$ & -1.899877 & 4.023086 & -1.666970 \\
\hline O & -1.889270 & 4.806078 & -2.866658 \\
\hline
\end{tabular}




$\begin{array}{rrrr}\mathrm{C} & -2.900500 & 5.761047 & -3.100623 \\ \mathrm{C} & -3.898780 & 5.925600 & -2.138608 \\ \mathrm{C} & -3.899290 & 5.154951 & -0.953741 \\ \mathrm{C} & -2.906115 & 4.201578 & -0.705745 \\ \mathrm{C} & -0.133000 & 3.384185 & -2.816624 \\ \mathrm{C} & -0.740580 & 4.380079 & -3.595774 \\ \mathrm{H} & -2.905323 & 6.358279 & -4.007763 \\ \mathrm{H} & -4.685549 & 6.656797 & -2.296278 \\ \mathrm{H} & -4.684856 & 5.311829 & -0.220854 \\ \mathrm{H} & -2.915302 & 3.627322 & 0.216839 \\ \mathrm{H} & -0.409167 & 4.753474 & -4.555255 \\ \mathrm{C} & 1.078014 & 2.625240 & -3.099865 \\ \mathrm{C} & 1.821391 & 2.776788 & -4.292645 \\ \mathrm{C} & 2.960181 & 2.006662 & -4.489165 \\ \mathrm{H} & 1.498388 & 3.486838 & -5.044429 \\ \mathrm{C} & 2.576183 & 0.995187 & -2.353365 \\ \mathrm{C} & 3.354350 & 1.085441 & -3.503856 \\ \mathrm{H} & 3.540024 & 2.110996 & -5.401247 \\ \mathrm{H} & 4.225920 & 0.454198 & -3.618710 \\ \mathrm{C} & 2.910684 & 0.043139 & -1.262037 \\ \mathrm{C} & 4.283808 & -1.557091 & -0.366651 \\ \mathrm{C} & 3.490711 & -1.487706 & 0.834013 \\ \mathrm{~N} & -0.826157 & 3.147942 & -1.646807 \\ \mathrm{~N} & 1.472077 & 1.745446 & -2.151476 \\ \mathrm{~N} & 3.999642 & -0.724985 & -1.371148 \\ \mathrm{~N} & 2.050672 & -0.020896 & -0.231047 \\ \mathrm{~N} & 2.368083 & -0.761980 & 0.832228 \\ \mathrm{C} & 5.381312 & -2.522547 & -0.600686 \\ \mathrm{C} & 5.321469 & -3.841371 & -0.101391 \\ \mathrm{C} & 6.458328 & -2.129600 & -1.406150 \\ \mathrm{C} & 6.342486 & -4.733443 & -0.418794 \\ \mathrm{H} & 4.487792 & -4.167119 & 0.507801 \\ \mathrm{C} & 7.497027 & -3.027791 & -1.695687 \\ \mathrm{H} & 6.508546 & -1.124909 & -1.808296 \\ \mathrm{C} & 7.437646 & -4.341476 & -1.202345 \\ \mathrm{H} & 6.296129 & -5.754334 & -0.051861 \\ \mathrm{H} & 8.222347 & -5.056447 & -1.418075 \\ \mathrm{C} & 3.827263 & -2.139734 & 2.123814 \\ \mathrm{C} & 5.145780 & -2.108532 & 2.622032 \\ \mathrm{C} & 2.807433 & -2.721794 & 2.884109 \\ \mathrm{C} & 5.413528 & -2.664724 & 3.870681 \\ \mathrm{H} & 5.942618 & -1.646744 & 2.050995 \\ \mathrm{C} & 3.091500 & -3.298121 & 4.133300 \\ \mathrm{H} & 1.786077 & -2.738670 & 2.522191 \\ \mathrm{C} & 4.402887 & -3.268451 & 4.632800 \\ \mathrm{H} & 6.424045 & -2.632492 & 4.266840 \\ & & & \end{array}$




$\begin{array}{cccc}\mathrm{H} & 4.646433 & -3.700386 & 5.595774 \\ \mathrm{O} & 8.508121 & -2.529399 & -2.466083 \\ \mathrm{O} & 2.023507 & -3.855231 & 4.779950 \\ \mathrm{C} & 2.250582 & -4.452902 & 6.059507 \\ \mathrm{H} & 1.280729 & -4.829081 & 6.386538 \\ \mathrm{H} & 2.958900 & -5.286900 & 5.989012 \\ \mathrm{H} & 2.617878 & -3.715816 & 6.783354 \\ \mathrm{C} & 9.595059 & -3.399147 & -2.797783 \\ \mathrm{H} & 10.276027 & -2.801886 & -3.404595 \\ \mathrm{H} & 10.117255 & -3.743540 & -1.897376 \\ \mathrm{H} & 9.250359 & -4.261918 & -3.379947\end{array}$

$\begin{array}{lrrl}\mathrm{M}=\mathrm{Gd} & & & \\ \mathrm{GD} & 0.000012 & 1.629595 & -0.000051 \\ \mathrm{C} & 2.099425 & 3.913193 & 1.420119 \\ \mathrm{C} & 2.283613 & 4.611990 & 2.658411 \\ \mathrm{C} & 3.356219 & 5.522781 & 2.806445 \\ \mathrm{C} & 4.213435 & 5.721375 & 1.732318 \\ \mathrm{C} & 4.020694 & 5.030079 & 0.506301 \\ \mathrm{C} & 2.974278 & 4.129627 & 0.337593 \\ \mathrm{C} & 0.487149 & 3.257404 & 2.782936 \\ \mathrm{C} & 1.234083 & 4.176274 & 3.517745 \\ \mathrm{H} & 3.504155 & 6.058719 & 3.739408 \\ \mathrm{H} & 5.041450 & 6.417993 & 1.821013 \\ \mathrm{H} & 4.703566 & 5.217841 & -0.316926 \\ \mathrm{H} & 2.834433 & 3.624056 & -0.614614 \\ \mathrm{H} & 1.054463 & 4.497798 & 4.534658 \\ \mathrm{C} & -0.688783 & 2.507276 & 3.159816 \\ \mathrm{C} & -1.321330 & 2.599206 & 4.423934 \\ \mathrm{C} & -2.442649 & 1.827001 & 4.684404 \\ \mathrm{H} & -0.924025 & 3.272090 & 5.174480 \\ \mathrm{C} & -2.273150 & 0.917360 & 2.477900 \\ \mathrm{C} & -2.938955 & 0.954033 & 3.694519 \\ \mathrm{H} & -2.935989 & 1.889652 & 5.649603 \\ \mathrm{H} & -3.801972 & 0.322426 & 3.860913 \\ \mathrm{C} & -2.688536 & 0.026676 & 1.369827 \\ \mathrm{C} & -4.091928 & -1.542152 & 0.470400 \\ \mathrm{C} & -3.376885 & -1.391953 & -0.775464 \\ \mathrm{~N} & 1.000957 & 3.078383 & 1.498285 \\ \mathrm{~N} & -1.183198 & 1.673797 & 2.210999 \\ \mathrm{~N} & -3.755089 & -0.765617 & 1.503493 \\ \mathrm{~N} & -1.903388 & 0.041898 & 0.277714 \\ \mathrm{~N} & -2.272824 & -0.642983 & -0.807280 \\ \mathrm{C} & -5.160576 & -2.534311 & 0.715297 \\ \mathrm{C} & -5.127162 & -3.817242 & 0.126478\end{array}$




\begin{tabular}{|c|c|c|c|}
\hline $\mathrm{C}$ & -6.179253 & -2.208283 & 1.621343 \\
\hline & -6.115148 & -4.740578 & 0.457887 \\
\hline & -4.337786 & -4.093083 & -0.561007 \\
\hline & -7.187599 & -3.135793 & 1.924452 \\
\hline & -6.207839 & -1.232701 & 2.091363 \\
\hline & -7.153563 & -4.413766 & 1.342089 \\
\hline & -6.087714 & -5.734853 & 0.022478 \\
\hline & -7.915265 & -5.150861 & 1.565740 \\
\hline 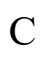 & -3.785143 & -1.982208 & -2.074073 \\
\hline & -5.130652 & -1.934073 & -2.491831 \\
\hline 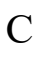 & -2.808972 & -2.518832 & -2.920025 \\
\hline & -5.468454 & -2.428095 & -3.749590 \\
\hline $\mathrm{H}$ & -5.894062 & -1.505065 & -1.853533 \\
\hline e & -3.163397 & -3.033977 & -4.178058 \\
\hline $\mathrm{H}$ & -1.768012 & -2.547532 & -2.619754 \\
\hline$C$ & -4.501902 & -2.986907 & -4.5 \\
\hline $\mathrm{H}$ & -6.500147 & -2.381205 & -4.084904 \\
\hline $\mathrm{H}$ & -4.799769 & -3.370921 & -5.566091 \\
\hline $\mathrm{O}$ & -8.143606 & -2.701612 & 2.795960 \\
\hline 0 & -2.133422 & -3.551436 & -4.912471 \\
\hline $\mathrm{C}$ & -2.432305 & -4.085121 & -6.205911 \\
\hline $\mathrm{H}$ & -1.481724 & -4.438107 & -6.6 \\
\hline $\mathrm{H}$ & -3.132420 & -4.926071 & -6.137027 \\
\hline $\mathrm{H}$ & -2.843300 & -3.314519 & -6.8 \\
\hline $\mathrm{C}$ & -9.198881 & -3.603399 & 3.145617 \\
\hline $\mathrm{H}$ & -9.838480 & -3.054352 & 3.836966 \\
\hline $\mathrm{H}$ & -9.781552 & -3.893656 & 2.263507 \\
\hline $\mathrm{H}$ & -8.807909 & -4.498260 & 3.643974 \\
\hline $\mathrm{C}$ & -2.099371 & 3.913127 & -1.420371 \\
\hline $\mathrm{C}$ & -2.283550 & 4.611845 & -2.658709 \\
\hline $\mathrm{C}$ & -3.356144 & 5.522641 & -2.806802 \\
\hline $\mathrm{C}$ & -4.213356 & 5.721318 & -1.732687 \\
\hline $\mathrm{C}$ & -4.020623 & 5.030100 & -0.506625 \\
\hline $\mathrm{C}$ & -2.974220 & 4.129644 & -0.337859 \\
\hline $\mathrm{C}$ & -0.487105 & 3.257227 & -2.783146 \\
\hline $\mathrm{C}$ & -1.234027 & 4.176058 & -3.518016 \\
\hline 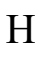 & -3.504073 & 6.058520 & -3.739800 \\
\hline $\mathrm{H}$ & -5.041361 & 6.417942 & -1.821427 \\
\hline $\mathrm{U}$ & -4.703492 & 5.217926 & 0.316590 \\
\hline $\mathrm{H}$ & -2.834381 & 3.624135 & 0.614381 \\
\hline $\mathrm{H}$ & -1.054403 & 4.497513 & -4.534950 \\
\hline $\mathrm{C}$ & 0.688817 & 2.507058 & -3.159977 \\
\hline $\mathrm{C}$ & 1.321366 & 2.598896 & -4.424101 \\
\hline 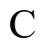 & 2.442674 & 1.826660 & -4.684520 \\
\hline $\mathrm{H}$ & 0.924069 & 3.271736 & -5.174692 \\
\hline & 2.273164 & 0.917168 & -2.477955 \\
\hline
\end{tabular}




$\begin{array}{lrrr}\mathrm{C} & 2.938970 & 0.953752 & -3.694577 \\ \mathrm{H} & 2.936016 & 1.889240 & -5.649723 \\ \mathrm{H} & 3.801979 & 0.322124 & -3.860929 \\ \mathrm{C} & 2.688540 & 0.026553 & -1.369823 \\ \mathrm{C} & 4.091912 & -1.542239 & -0.470295 \\ \mathrm{C} & 3.376873 & -1.391942 & 0.775564 \\ \mathrm{~N} & -1.000915 & 3.078297 & -1.498483 \\ \mathrm{~N} & 1.183222 & 1.673636 & -2.211104 \\ \mathrm{~N} & 3.755082 & -0.765763 & -1.503436 \\ \mathrm{~N} & 1.903392 & 0.041856 & -0.277712 \\ \mathrm{~N} & 2.272821 & -0.642957 & 0.807327 \\ \mathrm{C} & 5.160516 & -2.534455 & -0.715164 \\ \mathrm{C} & 5.127013 & -3.817400 & -0.126378 \\ \mathrm{C} & 6.179228 & -2.208472 & -1.621186 \\ \mathrm{C} & 6.114956 & -4.740783 & -0.457780 \\ \mathrm{H} & 4.337598 & -4.093217 & 0.561072 \\ \mathrm{C} & 7.187531 & -3.136031 & -1.924288 \\ \mathrm{H} & 6.207876 & -1.232885 & -2.091192 \\ \mathrm{C} & 7.153413 & -4.414012 & -1.341947 \\ \mathrm{H} & 6.087452 & -5.735067 & -0.022395 \\ \mathrm{H} & 7.915079 & -5.151144 & -1.565593 \\ \mathrm{C} & 3.785142 & -1.982055 & 2.074235 \\ \mathrm{C} & 5.130633 & -1.933774 & 2.492036 \\ \mathrm{C} & 2.808982 & -2.518661 & 2.920213 \\ \mathrm{C} & 5.468431 & -2.427650 & 3.749853 \\ \mathrm{H} & 5.894030 & -1.504765 & 1.853727 \\ \mathrm{C} & 3.163405 & -3.033659 & 4.178306 \\ \mathrm{H} & 1.768033 & -2.547461 & 2.619913 \\ \mathrm{C} & 4.501894 & -2.986454 & 4.598412 \\ \mathrm{H} & 6.500109 & -2.380647 & 4.085198 \\ \mathrm{H} & 4.799757 & -3.370351 & 5.566423 \\ \mathrm{O} & 8.143580 & -2.701887 & -2.795768 \\ \mathrm{O} & 2.133444 & -3.551119 & 4.912738 \\ \mathrm{C} & 2.432324 & -4.084656 & 6.206239 \\ \mathrm{H} & 1.481755 & -4.437670 & 6.607218 \\ \mathrm{H} & 3.132500 & -4.925564 & 6.137460 \\ \mathrm{H} & 2.843244 & -3.313961 & 6.868939 \\ \mathrm{C} & 9.198815 & -3.603725 & -3.145416 \\ \mathrm{H} & 9.838458 & -3.054702 & -3.836742 \\ \mathrm{H} & 9.781451 & -3.894028 & -2.263297 \\ \mathrm{H} & 8.807805 & -4.498557 & -3.643796 \\ & & & \\ \end{array}$

$\mathrm{M}=\mathrm{Am}$

$\begin{array}{llll}\text { AM } & 0.000015 & 1.514606 & 0.000081\end{array}$ $\begin{array}{llll}\text { C } & 1.970824 & 3.908027 & 1.481237\end{array}$ 


$\begin{array}{lrrr}\mathrm{C} & 2.114999 & 4.608843 & 2.723063 \\ \mathrm{C} & 3.156599 & 5.550883 & 2.891076 \\ \mathrm{C} & 4.023931 & 5.778873 & 1.831314 \\ \mathrm{C} & 3.870389 & 5.085598 & 0.600835 \\ \mathrm{C} & 2.855639 & 4.154194 & 0.413606 \\ \mathrm{C} & 0.358887 & 3.200678 & 2.816690 \\ \mathrm{C} & 1.065947 & 4.139891 & 3.565364 \\ \mathrm{H} & 3.273450 & 6.087395 & 3.828035 \\ \mathrm{H} & 4.828997 & 6.499921 & 1.934463 \\ \mathrm{H} & 4.559469 & 5.296663 & -0.211418 \\ \mathrm{H} & 2.746099 & 3.647498 & -0.542099 \\ \mathrm{H} & 0.862043 & 4.455127 & 4.579632 \\ \mathrm{C} & -0.804607 & 2.423482 & 3.171254 \\ \mathrm{C} & -1.457125 & 2.507174 & 4.425354 \\ \mathrm{C} & -2.571533 & 1.721553 & 4.671075 \\ \mathrm{H} & -1.080011 & 3.186965 & 5.179963 \\ \mathrm{C} & -2.357525 & 0.813480 & 2.466284 \\ \mathrm{C} & -3.041874 & 0.844784 & 3.672799 \\ \mathrm{H} & -3.080248 & 1.778232 & 5.628508 \\ \mathrm{H} & -3.901777 & 0.205296 & 3.823924 \\ \mathrm{C} & -2.762106 & -0.080760 & 1.357540 \\ \mathrm{C} & -4.160896 & -1.649193 & 0.450116 \\ \mathrm{C} & -3.434712 & -1.503232 & -0.789669 \\ \mathrm{C} & -1.806660 & -2.653362 & -2.619306 \\ \mathrm{~N} & 0.898596 & 3.040275 & 1.543392 \\ \mathrm{~N} & -1.269500 & 1.580321 & 2.214821 \\ \mathrm{~N} & -3.830982 & -0.872402 & 1.484986 \\ \mathrm{C} & -1.971286 & -0.066444 & 0.272913 \\ \mathrm{~N} & -2.330951 & -0.754430 & -0.813264 \\ \mathrm{C} & -5.235004 & -2.637986 & 0.686088 \\ \mathrm{C} & -5.193199 & -3.925432 & 0.108198 \\ \mathrm{C} & -6.268955 & -2.303343 & 1.570989 \\ \mathrm{C} & -6.187981 & -4.845004 & 0.429543 \\ \mathrm{H} & -4.392138 & -4.207678 & -0.563094 \\ \mathrm{C} & -7.283809 & -3.227223 & 1.863912 \\ \mathrm{H} & -6.304859 & -1.323878 & 2.032507 \\ \mathrm{C} & -7.241340 & -4.509917 & 1.292725 \\ \mathrm{H} & -6.154189 & -5.842765 & 0.002594 \\ \mathrm{C} & -3.830816 & -2.096741 & -2.090678 \\ \mathrm{C} & -3.106219 & -4.620181\end{array}$




\begin{tabular}{|c|c|c|c|}
\hline $\mathrm{H}$ & -6.527120 & -2.509509 & -4.123822 \\
\hline & -4.809978 & -3.492199 & -5.590341 \\
\hline J & -8.254425 & -2.784652 & 2.714914 \\
\hline & -2.148328 & -3.659675 & -4.914614 \\
\hline 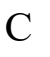 & -2.433933 & -4.195512 & -6.210167 \\
\hline & -1.478383 & -4.544096 & -6.603068 \\
\hline $\mathrm{H}$ & -3.130486 & -5.039843 & -6.146513 \\
\hline H & -2.843140 & -3.427263 & -6.876767 \\
\hline $\mathrm{C}$ & -9.317010 & -3.682170 & 3.053078 \\
\hline $\mathrm{H}$ & -9.967898 & -3.126787 & 3.728648 \\
\hline $\mathrm{H}$ & -9.884452 & -3.978692 & 2.163139 \\
\hline $\mathrm{H}$ & -8.936213 & -4.573555 & 3.565356 \\
\hline $\mathrm{C}$ & -1.970677 & 3.908319 & -1.480781 \\
\hline $\mathrm{C}$ & -2.114774 & 4.609341 & -2.722499 \\
\hline $\mathrm{C}$ & -3.156321 & 5.551461 & -2.890397 \\
\hline $\mathrm{C}$ & -4.023678 & 5.779324 & -1.830629 \\
\hline $\mathrm{C}$ & -3.870216 & 5.085841 & -0.600257 \\
\hline $\mathrm{C}$ & -2.855520 & 4.154356 & -0.413143 \\
\hline $\mathrm{C}$ & -0.358723 & 3.201111 & -2.816287 \\
\hline $\mathrm{C}$ & -1.065712 & 4.140476 & -3.564837 \\
\hline $\mathrm{H}$ & -3.273112 & 6.088128 & -3.827274 \\
\hline $\mathrm{H}$ & -4.828705 & 6.500428 & -1.933691 \\
\hline $\mathrm{H}$ & -4.559316 & 5.296809 & 0.212005 \\
\hline $\mathrm{H}$ & -2.746046 & 3.647494 & 0.542482 \\
\hline $\mathrm{H}$ & -0.861755 & 4.455869 & -4.579045 \\
\hline $\mathrm{C}$ & 0.804759 & 2.423932 & -3.170929 \\
\hline $\mathrm{C}$ & 1.457324 & 2.507802 & -4.424993 \\
\hline $\mathrm{C}$ & 2.571721 & 1.722190 & -4.670796 \\
\hline $\mathrm{H}$ & 1.080255 & 3.187719 & -5.179510 \\
\hline $\mathrm{C}$ & 2.357609 & 0.813779 & -2.466155 \\
\hline $\mathrm{C}$ & 3.042003 & 0.845254 & -3.672640 \\
\hline $\mathrm{H}$ & 3.080472 & 1.779005 & -5.628202 \\
\hline $\mathrm{H}$ & 3.901897 & 0.205769 & -3.823832 \\
\hline $\mathrm{C}$ & 2.762124 & -0.080644 & -1.357535 \\
\hline $\mathrm{C}$ & 4.160848 & -1.649245 & -0.450300 \\
\hline $\mathrm{C}$ & 3.434610 & -1.503470 & 0.789475 \\
\hline $\mathrm{N}$ & -0.898487 & 3.040526 & -1.543036 \\
\hline $\mathrm{N}$ & 1.269594 & 1.580609 & -2.214611 \\
\hline $\mathrm{N}$ & 3.830991 & -0.872286 & -1.485061 \\
\hline $\mathrm{N}$ & 1.971260 & -0.066482 & -0.272939 \\
\hline $\mathrm{N}$ & 2.330864 & -0.754649 & 0.813142 \\
\hline $\mathrm{C}$ & 5.234956 & -2.638011 & -0.686383 \\
\hline $\mathrm{C}$ & 5.193120 & -3.925548 & -0.108697 \\
\hline $\mathrm{C}$ & 6.268942 & -2.303238 & -1.571194 \\
\hline $\mathrm{C}$ & 6.187904 & -4.845079 & -0.430153 \\
\hline H & 4.392034 & -4.207893 & 0.562524 \\
\hline
\end{tabular}




$\begin{array}{llll}\mathrm{C} & 7.283797 & -3.227081 & -1.864228 \\ \mathrm{H} & 6.304872 & -1.323700 & -2.032556 \\ \mathrm{C} & 7.241296 & -4.509865 & -1.293246 \\ \mathrm{H} & 6.154088 & -5.842907 & -0.003364 \\ \mathrm{H} & 8.007722 & -5.244220 & -1.509572 \\ \mathrm{C} & 3.830644 & -2.097196 & 2.090407 \\ \mathrm{C} & 5.172739 & -2.055405 & 2.519701 \\ \mathrm{C} & 2.845042 & -2.629942 & 2.927991 \\ \mathrm{C} & 5.497741 & -2.552150 & 3.779736 \\ \mathrm{H} & 5.943527 & -1.629446 & 1.888291 \\ \mathrm{C} & 3.186499 & -3.147467 & 4.188525 \\ \mathrm{H} & 1.806455 & -2.653867 & 2.618853 \\ \mathrm{C} & 4.521637 & -3.107086 & 4.619781 \\ \mathrm{H} & 6.526850 & -2.510331 & 4.123607 \\ \mathrm{H} & 4.809624 & -3.493225 & 5.589892 \\ \mathrm{O} & 8.254448 & -2.784385 & -2.715125 \\ \mathrm{O} & 2.148003 & -3.660551 & 4.914019 \\ \mathrm{C} & 2.433544 & -4.196610 & 6.209495 \\ \mathrm{H} & 1.477972 & -4.545243 & 6.602296 \\ \mathrm{H} & 3.130087 & -5.040941 & 6.145727 \\ \mathrm{H} & 2.842735 & -3.428479 & 6.876240 \\ \mathrm{C} & 9.317035 & -3.681861 & -3.053396 \\ \mathrm{H} & 9.967952 & -3.126378 & -3.728856 \\ \mathrm{H} & 9.884443 & -3.978530 & -2.163485 \\ \mathrm{H} & 8.936245 & -4.573160 & -3.565829\end{array}$

\section{$\mathrm{M}=\mathrm{Cm}$}

$\begin{array}{lccc}\mathrm{CM} & -0.000002 & 1.522676 & -0.000021 \\ \mathrm{C} & -2.050658 & 3.843554 & -1.494242 \\ \mathrm{C} & -2.207751 & 4.535692 & -2.739176 \\ \mathrm{C} & -3.268910 & 5.454323 & -2.913157 \\ \mathrm{C} & -4.143860 & 5.667420 & -1.856376 \\ \mathrm{C} & -3.978804 & 4.982004 & -0.623256 \\ \mathrm{C} & -2.943917 & 4.074109 & -0.429933 \\ \mathrm{C} & -0.420225 & 3.164979 & -2.825125 \\ \mathrm{C} & -1.147211 & 4.084875 & -3.577488 \\ \mathrm{H} & -3.394911 & 5.984868 & -3.852340 \\ \mathrm{H} & -4.964161 & 6.370470 & -1.964294 \\ \mathrm{H} & -4.674898 & 5.180320 & 0.186314 \\ \mathrm{H} & -2.826492 & 3.572703 & 0.527692 \\ \mathrm{H} & -0.948781 & 4.399658 & -4.592975 \\ \mathrm{C} & 0.757294 & 2.407973 & -3.186810 \\ \mathrm{C} & 1.399490 & 2.498136 & -4.446062 \\ \mathrm{C} & 2.521932 & 1.724791 & -4.698074 \\ \mathrm{H} & 1.009224 & 3.170663 & -5.200538\end{array}$




\begin{tabular}{|c|c|c|c|}
\hline $\mathrm{C}$ & 2.335274 & 0.818058 & -2.491706 \\
\hline & 3.010405 & 0.853218 & -3.703665 \\
\hline$H$ & 3.022416 & 1.786276 & -5.659656 \\
\hline $\mathrm{H}$ & 3.874781 & 0.221725 & -3.862988 \\
\hline $\mathrm{C}$ & 2.748771 & -0.071071 & -1.380976 \\
\hline $\mathrm{C}$ & 4.159520 & -1.633102 & -0.479145 \\
\hline $\mathrm{C}$ & 3.442191 & -1.486660 & 0.765519 \\
\hline $\mathrm{N}$ & -0.958168 & 2.999990 & -1.548720 \\
\hline $\mathrm{N}$ & 1.243945 & 1.574822 & -2.234928 \\
\hline $\mathrm{N}$ & 3.819513 & -0.859083 & -1.512900 \\
\hline $\mathrm{N}$ & 1.963416 & -0.059235 & -0.290127 \\
\hline $\mathrm{N}$ & 2.334750 & -0.743440 & 0.794760 \\
\hline $\mathrm{C}$ & 5.233992 & -2.619581 & -0.721889 \\
\hline $\mathrm{C}$ & 5.201537 & -3.905007 & -0.138780 \\
\hline $\mathrm{C}$ & 6.258034 & -2.285498 & -1.618579 \\
\hline $\mathrm{C}$ & 6.195516 & -4.823084 & -0.466744 \\
\hline $\mathrm{H}$ & 4.408077 & -4.186902 & 0.541663 \\
\hline $\mathrm{C}$ & 7.272295 & -3.207758 & -1.918338 \\
\hline $\mathrm{H}$ & 6.286451 & -1.307703 & -2.084161 \\
\hline $\mathrm{C}$ & 7.239106 & -4.488382 & -1.341867 \\
\hline $\mathrm{H}$ & 6.168765 & -5.819345 & -0.035794 \\
\hline $\mathrm{H}$ & 8.005302 & -5.221500 & -1.563143 \\
\hline $\mathrm{C}$ & 3.850801 & -2.073615 & 2.065600 \\
\hline $\mathrm{C}$ & 5.196495 & -2.026259 & 2.482996 \\
\hline $\mathrm{C}$ & 2.873854 & -2.604829 & 2.914244 \\
\hline $\mathrm{C}$ & 5.533737 & -2.516270 & 3.742459 \\
\hline $\mathrm{H}$ & 5.960659 & -1.600939 & 1.843114 \\
\hline $\mathrm{C}$ & 3.227714 & -3.115710 & 4.174035 \\
\hline $\mathrm{H}$ & 1.832606 & -2.632565 & 2.614458 \\
\hline $\mathrm{C}$ & 4.566434 & -3.069859 & 4.593457 \\
\hline $\mathrm{H}$ & 6.565657 & -2.469981 & 4.077244 \\
\hline $\mathrm{H}$ & 4.863854 & -3.450707 & 5.562806 \\
\hline $\mathrm{O}$ & 8.232902 & -2.765944 & -2.780964 \\
\hline $\mathrm{O}$ & 2.196953 & -3.627963 & 4.911057 \\
\hline $\mathrm{C}$ & 2.495118 & -4.156949 & 6.206594 \\
\hline $\mathrm{H}$ & 1.543852 & -4.505853 & 6.609456 \\
\hline $\mathrm{H}$ & 3.193048 & -4.999995 & 6.140826 \\
\hline $\mathrm{H}$ & 2.908276 & -3.384552 & 6.865930 \\
\hline $\mathrm{C}$ & 9.294419 & -3.661905 & -3.126609 \\
\hline $\mathrm{H}$ & 9.936798 & -3.107367 & -3.810950 \\
\hline $\mathrm{H}$ & 9.871782 & -3.953434 & -2.241413 \\
\hline $\mathrm{H}$ & 8.910806 & -4.556262 & -3.631550 \\
\hline $\mathrm{C}$ & 2.050638 & 3.843604 & 1.494145 \\
\hline $\mathrm{C}$ & 2.207722 & 4.535781 & 2.739059 \\
\hline $\mathrm{C}$ & 3.268876 & 5.454420 & 2.913018 \\
\hline $\mathrm{C}$ & 4.143831 & 5.667488 & 1.856235 \\
\hline
\end{tabular}




$\begin{array}{lrrr}\mathrm{C} & 3.978785 & 4.982033 & 0.623135 \\ \mathrm{C} & 2.943902 & 4.074130 & 0.429834 \\ \mathrm{C} & 0.420199 & 3.165064 & 2.825040 \\ \mathrm{C} & 1.147178 & 4.084985 & 3.577379 \\ \mathrm{H} & 3.394869 & 5.984994 & 3.852186 \\ \mathrm{H} & 4.964130 & 6.370544 & 1.964137 \\ \mathrm{H} & 4.674883 & 5.180327 & -0.186437 \\ \mathrm{H} & 2.826484 & 3.572694 & -0.527776 \\ \mathrm{H} & 0.948740 & 4.399799 & 4.592855 \\ \mathrm{C} & -0.757319 & 2.408065 & 3.186744 \\ \mathrm{C} & -1.399523 & 2.498268 & 4.445988 \\ \mathrm{C} & -2.521965 & 1.724928 & 4.698019 \\ \mathrm{H} & -1.009264 & 3.170821 & 5.200445 \\ \mathrm{C} & -2.335290 & 0.818123 & 2.491682 \\ \mathrm{C} & -3.010430 & 0.853321 & 3.703636 \\ \mathrm{H} & -3.022454 & 1.786444 & 5.659596 \\ \mathrm{H} & -3.874805 & 0.221832 & 3.862974 \\ \mathrm{C} & -2.748777 & -0.071043 & 1.380979 \\ \mathrm{C} & -4.159517 & -1.633104 & 0.479186 \\ \mathrm{C} & -3.442176 & -1.486704 & -0.765476 \\ \mathrm{~N} & 0.958150 & 3.000038 & 1.548643 \\ \mathrm{~N} & -1.243962 & 1.574881 & 2.234886 \\ \mathrm{~N} & -3.819520 & -0.859052 & 1.512919 \\ \mathrm{~N} & -1.963413 & -0.059243 & 0.290137 \\ \mathrm{~N} & -2.334736 & -0.743484 & -0.794731 \\ \mathrm{C} & -5.233992 & -2.619576 & 0.721953 \\ \mathrm{C} & -5.201530 & -3.905022 & 0.138888 \\ \mathrm{C} & -6.258043 & -2.285463 & 1.618621 \\ \mathrm{C} & -6.195512 & -4.823089 & 0.466874 \\ \mathrm{H} & -4.408063 & -4.186940 & -0.541538 \\ \mathrm{C} & -7.272306 & -3.207714 & 1.918402 \\ \mathrm{H} & -6.286465 & -1.307653 & 2.084170 \\ \mathrm{C} & -7.239111 & -4.488357 & 1.341974 \\ \mathrm{H} & -6.168756 & -5.819364 & 0.035958 \\ \mathrm{H} & -8.005309 & -5.221468 & 1.563267 \\ \mathrm{C} & -3.850771 & -2.073706 & -2.065540 \\ \mathrm{C} & -5.196460 & -2.026366 & -2.482953 \\ \mathrm{C} & -2.873814 & -2.604947 & -2.914155 \\ \mathrm{H} & -5.533689 & -2.516422 & -3.742403 \\ \mathrm{H} & -3.227660 & -1.601025 & -1.843094 \\ \mathrm{H} & -3.115873 & -4.173933 \\ \mathrm{H} & -2569 & -2.632671 & -2.614357 \\ \mathrm{H} & -3.070040 & -4.593371 \\ \mathrm{H} & -2.470146 & -4.077200 \\ \mathrm{H} & -365092 & -5.562709 \\ \mathrm{H} & & \\ \mathrm{H} & -1.781002\end{array}$




$\begin{array}{llll}\mathrm{O} & -2.196890 & -3.628150 & -4.910925 \\ \mathrm{C} & -2.495040 & -4.157181 & -6.206447 \\ \mathrm{H} & -1.543768 & -4.506098 & -6.609287 \\ \mathrm{H} & -3.192969 & -5.000227 & -6.140657 \\ \mathrm{H} & -2.908192 & -3.384808 & -6.865814 \\ \mathrm{C} & -9.294442 & -3.661822 & 3.126668 \\ \mathrm{H} & -9.936828 & -3.107260 & 3.810985 \\ \mathrm{H} & -9.871797 & -3.953380 & 2.241477 \\ \mathrm{H} & -8.910833 & -4.556160 & 3.631643\end{array}$

$\mathbf{L}=\mathbf{2} \mathbf{i}$

\section{$\left[\mathrm{ML}\left(\mathrm{H}_{2} \mathrm{O}\right)_{6}\right]^{2+}$}

$\mathrm{M}=\mathrm{Eu}$

$\begin{array}{lrrc}\mathrm{C} & 1.596097 & 1.999560 & 0.108767 \\ \mathrm{C} & 1.974714 & 3.336156 & 0.276711 \\ \mathrm{C} & 0.968187 & 4.309788 & 0.346175 \\ \mathrm{C} & -0.360000 & 3.916349 & 0.221148 \\ \mathrm{C} & -0.660705 & 2.547306 & 0.051316 \\ \mathrm{H} & 3.024784 & 3.594338 & 0.335334 \\ \mathrm{H} & 1.224201 & 5.356438 & 0.478502 \\ \mathrm{H} & -1.160652 & 4.646746 & 0.247006 \\ \mathrm{C} & 2.630462 & 0.941447 & -0.043831 \\ \mathrm{C} & 4.814446 & 0.342299 & -0.165937 \\ \mathrm{C} & 4.393093 & -0.981650 & -0.432545 \\ \mathrm{H} & 5.870162 & 0.599575 & -0.113087 \\ \mathrm{H} & 5.093083 & -1.791789 & -0.610760 \\ \mathrm{C} & -2.017851 & 2.065085 & -0.131194 \\ \mathrm{C} & -3.271280 & 2.689910 & -0.169544 \\ \mathrm{C} & -4.164921 & 1.639905 & -0.398116 \\ \mathrm{H} & -3.512476 & 3.736444 & -0.056909 \\ \mathrm{H} & -5.240063 & 1.671431 & -0.516431 \\ \mathrm{~N} & 3.927531 & 1.305211 & 0.023860 \\ \mathrm{~N} & 2.198949 & -0.310324 & -0.266546 \\ \mathrm{~N} & 3.100959 & -1.280581 & -0.470921 \\ \mathrm{~N} & 0.312138 & 1.599967 & 0.021033 \\ \mathrm{~N} & -2.190860 & 0.704254 & -0.340780 \\ \mathrm{~N} & -3.484802 & 0.448465 & -0.490210 \\ \mathrm{EU} & -0.432479 & -0.982400 & 0.023827 \\ \mathrm{O} & -2.235028 & -1.092599 & 1.956809 \\ \mathrm{H} & -3.133483 & -0.805279 & 1.722901 \\ \mathrm{O} & -2.510635 & -1.965826 & -1.087767 \\ \mathrm{H} & -2.954021 & -2.816493 & -1.216181 \\ \mathrm{O} & 0.682116 & -0.932818 & 2.389122\end{array}$




$\begin{array}{cccc}\mathrm{H} & 0.715292 & -1.833337 & 2.753352 \\ \mathrm{O} & -0.349796 & -0.737138 & -2.549268 \\ \mathrm{H} & -1.216686 & -0.936785 & -2.939317 \\ \mathrm{O} & -0.483054 & -3.252085 & 1.376592 \\ \mathrm{H} & -1.263506 & -3.596743 & 1.838090 \\ \mathrm{O} & 0.974925 & -2.949462 & -0.923127 \\ \mathrm{H} & 0.845973 & -3.317565 & -1.810834 \\ \mathrm{H} & 1.186903 & -0.361499 & 2.986404 \\ \mathrm{H} & 0.108635 & -0.157435 & -3.175375 \\ \mathrm{H} & -3.212049 & -1.260712 & -0.989473 \\ \mathrm{H} & 1.920543 & -2.664435 & -0.871042 \\ \mathrm{H} & -2.098691 & -0.837554 & 2.881925 \\ \mathrm{H} & -0.040850 & -4.000611 & 0.943184\end{array}$

$\mathrm{M}=\mathrm{Gd}$

$\begin{array}{lccc}\mathrm{C} & 1.587791 & 1.950857 & 0.113523 \\ \mathrm{C} & 1.957805 & 3.286299 & 0.251118 \\ \mathrm{C} & 0.938290 & 4.253326 & 0.287989 \\ \mathrm{C} & -0.387104 & 3.851991 & 0.163085 \\ \mathrm{C} & -0.684678 & 2.480140 & 0.027693 \\ \mathrm{H} & 3.004991 & 3.555348 & 0.311742 \\ \mathrm{H} & 1.186389 & 5.304916 & 0.394834 \\ \mathrm{H} & -1.190992 & 4.579408 & 0.160696 \\ \mathrm{C} & 2.607561 & 0.883369 & -0.020358 \\ \mathrm{C} & 4.778711 & 0.238509 & -0.140826 \\ \mathrm{C} & 4.332963 & -1.079631 & -0.408113 \\ \mathrm{H} & 5.839453 & 0.474398 & -0.086239 \\ \mathrm{H} & 5.017900 & -1.901629 & -0.590315 \\ \mathrm{C} & -2.033073 & 1.955399 & -0.154893 \\ \mathrm{C} & -3.311109 & 2.524939 & -0.240319 \\ \mathrm{C} & -4.158681 & 1.424490 & -0.457840 \\ \mathrm{H} & -3.597991 & 3.563728 & -0.167653 \\ \mathrm{H} & -5.231987 & 1.413005 & -0.592560 \\ \mathrm{~N} & 3.912071 & 1.219767 & 0.043576 \\ \mathrm{~N} & 2.155501 & -0.365445 & -0.233826 \\ \mathrm{~N} & 3.036799 & -1.354061 & -0.444170 \\ \mathrm{~N} & 0.298005 & 1.544487 & 0.029720 \\ \mathrm{~N} & -2.138463 & 0.609815 & -0.315251 \\ \mathrm{~N} & -3.442741 & 0.280487 & -0.494858 \\ \mathrm{GD} & -0.400261 & -0.932680 & 0.033295 \\ \mathrm{O} & -2.307756 & -1.219539 & 1.866593 \\ \mathrm{H} & -3.143814 & -0.937246 & 1.448372 \\ \mathrm{O} & -2.321194 & -1.981387 & -1.050485 \\ \mathrm{H} & -2.703764 & -2.858787 & -1.193975 \\ \mathrm{O} & 0.525997 & -0.506464 & 2.360387\end{array}$




$\begin{array}{cccc}\mathrm{H} & 0.726121 & -1.268209 & 2.928512 \\ \mathrm{O} & -0.243399 & -0.539022 & -2.450774 \\ \mathrm{H} & -1.098668 & -0.677398 & -2.890899 \\ \mathrm{O} & -0.337320 & -3.020293 & 1.465726 \\ \mathrm{H} & -1.154143 & -3.236890 & 1.945753 \\ \mathrm{O} & 0.846005 & -2.871884 & -0.992924 \\ \mathrm{H} & 0.684059 & -3.227334 & -1.880685 \\ \mathrm{H} & 0.791810 & 0.291211 & 2.842895 \\ \mathrm{H} & 0.196176 & 0.178060 & -2.932431 \\ \mathrm{H} & -3.071158 & -1.295987 & -0.968966 \\ \mathrm{H} & 1.812318 & -2.665203 & -0.935488 \\ \mathrm{H} & -2.305501 & -0.808362 & 2.745163 \\ \mathrm{H} & 0.037779 & -3.846291 & 1.119481\end{array}$

$\mathrm{M}=\mathrm{Am}$

$\begin{array}{lccc}\mathrm{C} & 1.816000 & 1.952953 & 0.101825 \\ \mathrm{C} & 2.291681 & 3.256023 & 0.230107 \\ \mathrm{C} & 1.356096 & 4.302666 & 0.265549 \\ \mathrm{C} & 0.002572 & 4.007082 & 0.153044 \\ \mathrm{C} & -0.403314 & 2.663631 & 0.027771 \\ \mathrm{H} & 3.357285 & 3.439152 & 0.286605 \\ \mathrm{H} & 1.688828 & 5.331320 & 0.364799 \\ \mathrm{H} & -0.741230 & 4.795670 & 0.155120 \\ \mathrm{C} & 2.757960 & 0.814904 & -0.015298 \\ \mathrm{C} & 4.883776 & 0.026057 & -0.098907 \\ \mathrm{C} & 4.353407 & -1.264357 & -0.343573 \\ \mathrm{H} & 5.957182 & 0.192856 & -0.038454 \\ \mathrm{H} & 4.982896 & -2.135048 & -0.497045 \\ \mathrm{C} & -1.794164 & 2.257276 & -0.128960 \\ \mathrm{C} & -3.013282 & 2.942894 & -0.196544 \\ \mathrm{C} & -3.965156 & 1.924972 & -0.380358 \\ \mathrm{H} & -3.200000 & 4.004859 & -0.134251 \\ \mathrm{H} & -5.037403 & 2.013298 & -0.494221 \\ \mathrm{~N} & 4.082084 & 1.064840 & 0.058735 \\ \mathrm{~N} & 2.225145 & -0.401605 & -0.216964 \\ \mathrm{~N} & 3.042807 & -1.450692 & -0.392664 \\ \mathrm{~N} & 0.497795 & 1.649633 & 0.024983 \\ \mathrm{~N} & -2.027715 & 0.926452 & -0.268014 \\ \mathrm{~N} & -3.363460 & 0.717795 & -0.415327 \\ \mathrm{AM} & -0.430564 & -0.808532 & 0.017377 \\ \mathrm{O} & -2.434188 & -0.952207 & 1.820458 \\ \mathrm{H} & -3.190616 & -0.513851 & 1.380278 \\ \mathrm{O} & -2.492415 & -1.607174 & -1.222607 \\ \mathrm{H} & -2.971255 & -2.439717 & -1.347644 \\ \mathrm{O} & 0.539631 & -0.596226 & 2.429213\end{array}$




$\begin{array}{cccc}\mathrm{H} & 0.594451 & -1.396378 & 2.976406 \\ \mathrm{O} & -0.221822 & -0.512536 & -2.526678 \\ \mathrm{H} & -1.090963 & -0.639860 & -2.943923 \\ \mathrm{O} & -0.751217 & -2.996088 & 1.349624 \\ \mathrm{H} & -1.595229 & -3.145279 & 1.806735 \\ \mathrm{O} & 0.811267 & -2.897525 & -0.896712 \\ \mathrm{H} & 0.663932 & -3.279896 & -1.775781 \\ \mathrm{H} & 0.902117 & 0.132011 & 2.956832 \\ \mathrm{H} & 0.266968 & 0.113319 & -3.082564 \\ \mathrm{H} & -3.163151 & -0.868287 & -1.050689 \\ \mathrm{H} & 1.780805 & -2.703465 & -0.825586 \\ \mathrm{H} & -2.411658 & -0.595053 & 2.721954 \\ \mathrm{H} & -0.409445 & -3.850609 & 1.041040\end{array}$

$\mathrm{M}=\mathrm{Cm}$

$\begin{array}{lccc}\mathrm{C} & 1.761034 & 1.986452 & 0.116046 \\ \mathrm{C} & 2.205852 & 3.298846 & 0.254763 \\ \mathrm{C} & 1.243155 & 4.321961 & 0.294349 \\ \mathrm{C} & -0.102739 & 3.996480 & 0.170734 \\ \mathrm{C} & -0.478085 & 2.644256 & 0.034791 \\ \mathrm{H} & 3.266494 & 3.508570 & 0.314167 \\ \mathrm{H} & 1.550525 & 5.357668 & 0.402336 \\ \mathrm{H} & -0.863651 & 4.768663 & 0.170282 \\ \mathrm{C} & 2.723970 & 0.866834 & -0.019663 \\ \mathrm{C} & 4.861172 & 0.115876 & -0.140352 \\ \mathrm{C} & 4.351100 & -1.178674 & -0.406725 \\ \mathrm{H} & 5.932190 & 0.299733 & -0.086581 \\ \mathrm{H} & 4.994827 & -2.033603 & -0.587682 \\ \mathrm{C} & -1.857356 & 2.204058 & -0.144354 \\ \mathrm{C} & -3.094229 & 2.858239 & -0.221556 \\ \mathrm{C} & -4.015577 & 1.818504 & -0.435231 \\ \mathrm{H} & -3.310570 & 3.913675 & -0.145462 \\ \mathrm{H} & -5.088067 & 1.880505 & -0.562981 \\ \mathrm{~N} & 4.043925 & 1.138342 & 0.044968 \\ \mathrm{~N} & 2.211669 & -0.357746 & -0.234007 \\ \mathrm{~N} & 3.043496 & -1.389448 & -0.442304 \\ \mathrm{~N} & 0.450163 & 1.654774 & 0.035457 \\ \mathrm{~N} & -2.054676 & 0.869154 & -0.304806 \\ \mathrm{~N} & -3.380154 & 0.628429 & -0.478549 \\ \mathrm{CM} & -0.402747 & -0.810764 & 0.025815 \\ \mathrm{O} & -2.383013 & -1.021459 & 1.834486 \\ \mathrm{H} & -3.172033 & -0.640080 & 1.402003 \\ \mathrm{O} & -2.437130 & -1.706977 & -1.141876 \\ \mathrm{H} & -2.895161 & -2.551339 & -1.263655 \\ \mathrm{O} & 0.543742 & -0.498234 & 2.413778\end{array}$




$\begin{array}{cccc}\mathrm{H} & 0.663151 & -1.292120 & 2.960230 \\ \mathrm{O} & -0.234098 & -0.461845 & -2.508897 \\ \mathrm{H} & -1.099105 & -0.597180 & -2.931582 \\ \mathrm{O} & -0.496779 & -2.968467 & 1.465388 \\ \mathrm{H} & -1.335690 & -3.167665 & 1.913105 \\ \mathrm{O} & 0.804308 & -2.865877 & -0.984624 \\ \mathrm{H} & 0.644586 & -3.244978 & -1.862906 \\ \mathrm{H} & 0.861771 & 0.258575 & 2.929674 \\ \mathrm{H} & 0.210737 & 0.238278 & -3.010989 \\ \mathrm{H} & -3.126558 & -0.970377 & -1.020636 \\ \mathrm{H} & 1.772030 & -2.667874 & -0.927074 \\ \mathrm{H} & -2.368715 & -0.645782 & 2.728742 \\ \mathrm{H} & -0.140019 & -3.799940 & 1.112634\end{array}$

$\left[\mathrm{ML}\left(\mathrm{H}_{2} \mathrm{O}\right)_{5}\right]^{2+}$

$\mathrm{M}=\mathrm{Eu}$

$\begin{array}{lccc}\text { EU } & 0.300559 & -1.119849 & 0.008789 \\ \mathrm{O} & -0.552569 & -2.678809 & 1.829550 \\ \mathrm{H} & -1.085083 & -3.485769 & 1.762702 \\ \mathrm{O} & -1.313644 & -2.822031 & -1.006542 \\ \mathrm{H} & -1.341309 & -3.673427 & -1.466940 \\ \mathrm{O} & 2.359917 & -2.505647 & 0.013637 \\ \mathrm{H} & 2.683732 & -3.416591 & 0.053719 \\ \mathrm{O} & 1.035382 & -0.495096 & 2.503371 \\ \mathrm{H} & 1.988205 & -0.504552 & 2.691062 \\ \mathrm{O} & 0.554370 & -0.942675 & -2.502278 \\ \mathrm{H} & 0.031326 & -1.372551 & -3.196019 \\ \mathrm{H} & 3.135114 & -1.897129 & -0.152661 \\ \mathrm{H} & 1.319689 & -0.539809 & -2.941756 \\ \mathrm{H} & -0.193628 & -2.641713 & 2.730098 \\ \mathrm{H} & -2.239120 & -2.512721 & -0.858028 \\ \mathrm{H} & 0.649661 & 0.114711 & 3.151643 \\ \mathrm{C} & -1.284472 & 2.088964 & 0.081070 \\ \mathrm{C} & -1.480435 & 3.471915 & 0.168280 \\ \mathrm{C} & -0.353636 & 4.305871 & 0.155672 \\ \mathrm{C} & 0.908945 & 3.732126 & 0.047685 \\ \mathrm{C} & 1.024931 & 2.326679 & -0.029248 \\ \mathrm{H} & -2.485686 & 3.869611 & 0.232161 \\ \mathrm{H} & -0.466880 & 5.383701 & 0.218735 \\ \mathrm{H} & 1.798700 & 4.350764 & 0.019038 \\ \mathrm{C} & -2.453010 & 1.169851 & 0.024447 \\ \mathrm{C} & -4.698869 & 0.862529 & -0.023237 \\ \mathrm{C} & -4.464108 & -0.517584 & -0.235594 \\ \mathrm{H} & -5.709568 & 1.259925 & 0.041415\end{array}$




$\begin{array}{lrrr}\mathrm{H} & -5.270848 & -1.230723 & -0.372758 \\ \mathrm{C} & 2.308864 & 1.660795 & -0.150335 \\ \mathrm{C} & 3.631997 & 2.116445 & -0.199270 \\ \mathrm{C} & 4.391165 & 0.946145 & -0.294177 \\ \mathrm{H} & 4.002453 & 3.130379 & -0.168851 \\ \mathrm{H} & 5.465147 & 0.831341 & -0.359257 \\ \mathrm{~N} & -3.688144 & 1.707227 & 0.090402 \\ \mathrm{~N} & -2.198721 & -0.140478 & -0.120741 \\ \mathrm{~N} & -3.225886 & -0.990452 & -0.277518 \\ \mathrm{~N} & -0.066903 & 1.518545 & -0.000264 \\ \mathrm{~N} & 2.315278 & 0.268516 & -0.230497 \\ \mathrm{~N} & 3.568233 & -0.155259 & -0.305902\end{array}$

$\mathrm{M}=\mathrm{Gd}$

$\begin{array}{lrrr}\text { GD } & 0.289800 & -1.040704 & 0.032313 \\ \mathrm{O} & -0.471377 & -2.675242 & 1.764683 \\ \mathrm{H} & -0.996607 & -3.470657 & 1.584157 \\ \mathrm{O} & -1.188240 & -2.773563 & -0.994638 \\ \mathrm{H} & -1.138828 & -3.564914 & -1.551615 \\ \mathrm{O} & 2.184108 & -2.465816 & -0.121042 \\ \mathrm{H} & 2.469308 & -3.389963 & -0.106299 \\ \mathrm{O} & 0.873186 & -0.357043 & 2.400984 \\ \mathrm{H} & 1.751226 & 0.049969 & 2.492141 \\ \mathrm{O} & 0.519601 & -0.719082 & -2.390343 \\ \mathrm{H} & 0.050279 & -1.081612 & -3.156980 \\ \mathrm{H} & 3.004866 & -1.847288 & -0.205749 \\ \mathrm{H} & 1.313723 & -0.271542 & -2.725679 \\ \mathrm{H} & -0.024835 & -2.815275 & 2.614959 \\ \mathrm{H} & -2.135667 & -2.512835 & -0.880790 \\ \mathrm{H} & 0.369879 & -0.106963 & 3.191683 \\ \mathrm{C} & -1.272505 & 2.063921 & 0.074260 \\ \mathrm{C} & -1.460997 & 3.441293 & 0.147361 \\ \mathrm{C} & -0.321869 & 4.264606 & 0.133560 \\ \mathrm{C} & 0.937512 & 3.683261 & 0.042888 \\ \mathrm{C} & 1.049417 & 2.278583 & -0.018820 \\ \mathrm{H} & -2.462394 & 3.849604 & 0.202025 \\ \mathrm{H} & -0.426854 & 5.343942 & 0.185445 \\ \mathrm{H} & 1.831932 & 4.295517 & 0.018623 \\ \mathrm{C} & -2.425558 & 1.137360 & 0.018006 \\ \mathrm{C} & -4.664918 & 0.783419 & -0.052190 \\ \mathrm{C} & -4.403494 & -0.596621 & -0.254102 \\ \mathrm{H} & -5.684117 & 1.161078 & -0.000837 \\ \mathrm{H} & -5.195893 & -1.324130 & -0.399079 \\ \mathrm{C} & 2.320864 & 1.571106 & -0.117058 \\ \mathrm{C} & 3.662584 & 1.957590 & -0.198816\end{array}$




$\begin{array}{rrrr}\mathrm{C} & 4.366417 & 0.738303 & -0.280668 \\ \mathrm{H} & 4.082883 & 2.952719 & -0.205147 \\ \mathrm{H} & 5.433205 & 0.577681 & -0.359617 \\ \mathrm{~N} & -3.673818 & 1.648137 & 0.065136 \\ \mathrm{~N} & -2.149186 & -0.173632 & -0.110143 \\ \mathrm{~N} & -3.158312 & -1.045879 & -0.277250 \\ \mathrm{~N} & -0.050508 & 1.485381 & 0.004849 \\ \mathrm{~N} & 2.255356 & 0.205788 & -0.149864 \\ \mathrm{~N} & 3.511861 & -0.298539 & -0.248292\end{array}$

$\mathrm{M}=\mathrm{Am}$

$\begin{array}{lccc}\text { AM } & 0.339358 & -0.925051 & 0.005743 \\ \mathrm{O} & -0.006613 & -2.819113 & 1.700490 \\ \mathrm{H} & -0.482063 & -3.636698 & 1.483642 \\ \mathrm{O} & -1.167874 & -2.783473 & -0.909403 \\ \mathrm{H} & -1.130484 & -3.542264 & -1.510850 \\ \mathrm{O} & 2.451810 & -2.102365 & -0.179438 \\ \mathrm{H} & 2.838192 & -2.988516 & -0.206750 \\ \mathrm{O} & 0.739424 & -0.193575 & 2.439633 \\ \mathrm{H} & 1.473958 & 0.419554 & 2.607176 \\ \mathrm{O} & 0.575605 & -0.679618 & -2.494656 \\ \mathrm{H} & 0.070538 & -1.011098 & -3.253187 \\ \mathrm{H} & 3.192761 & -1.379501 & -0.207690 \\ \mathrm{H} & 1.379077 & -0.266224 & -2.852106 \\ \mathrm{H} & 0.563359 & -3.013868 & 2.461454 \\ \mathrm{H} & -2.114797 & -2.522916 & -0.771080 \\ \mathrm{H} & 0.233619 & -0.257764 & 3.264795 \\ \mathrm{C} & -1.499002 & 2.120601 & 0.056066 \\ \mathrm{C} & -1.798084 & 3.478955 & 0.126988 \\ \mathrm{C} & -0.731152 & 4.392268 & 0.117019 \\ \mathrm{C} & 0.570735 & 3.912679 & 0.040514 \\ \mathrm{C} & 0.793628 & 2.521614 & -0.019412 \\ \mathrm{H} & -2.829214 & 3.804620 & 0.181093 \\ \mathrm{H} & -0.923305 & 5.459594 & 0.166475 \\ \mathrm{H} & 1.413993 & 4.593809 & 0.028135 \\ \mathrm{C} & -2.580302 & 1.111902 & 0.019406 \\ \mathrm{C} & -4.792467 & 0.603550 & -0.005001 \\ \mathrm{C} & -4.439052 & -0.758689 & -0.181308 \\ \mathrm{H} & -5.834114 & 0.912140 & 0.055105 \\ \mathrm{H} & -5.180185 & -1.543857 & -0.291788 \\ \mathrm{C} & 2.122553 & 1.927454 & -0.089108 \\ \mathrm{C} & 3.418463 & 2.444865 & -0.159062 \\ \mathrm{C} & 4.241330 & 1.301695 & -0.220505 \\ \mathrm{H} & 3.737479 & 3.476753 & -0.174145 \\ \mathrm{H} & 5.319440 & 1.246828 & -0.288927\end{array}$




$\begin{array}{lrrr}\mathrm{N} & -3.861076 & 1.535330 & 0.078718 \\ \mathrm{~N} & -2.214584 & -0.177459 & -0.094799 \\ \mathrm{~N} & -3.166456 & -1.118721 & -0.221870 \\ \mathrm{~N} & -0.235334 & 1.640691 & -0.012184 \\ \mathrm{~N} & 2.190302 & 0.563115 & -0.106888 \\ \mathrm{~N} & 3.494861 & 0.187480 & -0.186335\end{array}$

$\mathrm{M}=\mathrm{Cm}$

$\begin{array}{lrcc}\mathrm{CM} & 0.304220 & -0.913268 & 0.028191 \\ \mathrm{O} & -0.281626 & -2.688278 & 1.774466 \\ \mathrm{H} & -0.775229 & -3.498626 & 1.571912 \\ \mathrm{O} & -1.172536 & -2.750061 & -0.990476 \\ \mathrm{H} & -1.127947 & -3.539491 & -1.550607 \\ \mathrm{O} & 2.345866 & -2.220152 & -0.171463 \\ \mathrm{H} & 2.700858 & -3.119673 & -0.196718 \\ \mathrm{O} & 0.889378 & -0.220609 & 2.436863 \\ \mathrm{H} & 1.722920 & 0.268466 & 2.539320 \\ \mathrm{O} & 0.507819 & -0.602069 & -2.448886 \\ \mathrm{H} & 0.061102 & -1.022480 & -3.199871 \\ \mathrm{H} & 3.110809 & -1.537247 & -0.252790 \\ \mathrm{H} & 1.283064 & -0.134933 & -2.801910 \\ \mathrm{H} & 0.220865 & -2.857181 & 2.587438 \\ \mathrm{H} & -2.119673 & -2.492099 & -0.870926 \\ \mathrm{H} & 0.384000 & -0.083288 & 3.253625 \\ \mathrm{C} & -1.430478 & 2.140766 & 0.082976 \\ \mathrm{C} & -1.687489 & 3.506564 & 0.162926 \\ \mathrm{C} & -0.592035 & 4.386873 & 0.154013 \\ \mathrm{C} & 0.694642 & 3.870739 & 0.058725 \\ \mathrm{C} & 0.877947 & 2.474118 & -0.011748 \\ \mathrm{H} & -2.707985 & 3.863981 & 0.219392 \\ \mathrm{H} & -0.751836 & 5.459152 & 0.212300 \\ \mathrm{H} & 1.556513 & 4.527969 & 0.036376 \\ \mathrm{C} & -2.541670 & 1.163300 & 0.021553 \\ \mathrm{C} & -4.765020 & 0.716978 & -0.046613 \\ \mathrm{C} & -4.447039 & -0.650077 & -0.252198 \\ \mathrm{H} & -5.798718 & 1.052477 & 0.006774 \\ \mathrm{H} & -5.208927 & -1.409826 & -0.395130 \\ \mathrm{C} & 2.187630 & 1.841655 & -0.120811 \\ \mathrm{C} & 3.500466 & 2.315377 & -0.205460 \\ \mathrm{C} & 4.281364 & 1.146070 & -0.305587 \\ \mathrm{H} & 3.855444 & 3.335576 & -0.203180 \\ \mathrm{H} & 5.355876 & 1.056813 & -0.392664 \\ \mathrm{~N} & -3.810259 & 1.621436 & 0.073808 \\ \mathrm{~N} & -2.211950 & -0.134187 & -0.114813 \\ \mathrm{~N} & -3.184800 & -1.047549 & -0.279102\end{array}$




$\begin{array}{rrrr}\mathrm{N} & -0.179944 & 1.625880 & 0.011227 \\ \mathrm{~N} & 2.211020 & 0.476021 & -0.168246 \\ \mathrm{~N} & 3.497737 & 0.055445 & -0.280067 \\ & & & \\ \left.\mathbf{M L L}_{\mathbf{2}}\left(\mathbf{H}_{\mathbf{2}} \mathbf{O}\right)_{\mathbf{2}}\right]^{\mathbf{1 +}} & & \end{array}$

$\mathrm{M}=\mathrm{Eu}$

$\begin{array}{lrrr}\text { EU } & 0.025256 & -0.033488 & -0.750882 \\ \mathrm{O} & 0.678632 & 1.742481 & -2.318615 \\ \mathrm{H} & -0.183114 & 2.127826 & -2.694565 \\ \mathrm{O} & -0.514680 & -1.802432 & -2.379601 \\ \mathrm{H} & 0.370488 & -2.126357 & -2.743268 \\ \mathrm{H} & 1.381431 & 1.810773 & -2.977465 \\ \mathrm{H} & -1.190102 & -1.868844 & -3.067110 \\ \mathrm{C} & 2.383806 & 1.655709 & 1.303909 \\ \mathrm{C} & 3.590353 & 2.097432 & 1.846509 \\ \mathrm{C} & 4.776291 & 1.527224 & 1.361138 \\ \mathrm{C} & 4.708142 & 0.558987 & 0.365971 \\ \mathrm{C} & 3.448373 & 0.168600 & -0.133796 \\ \mathrm{H} & 3.589247 & 2.858828 & 2.615563 \\ \mathrm{H} & 5.737186 & 1.842882 & 1.755821 \\ \mathrm{H} & 5.608420 & 0.106642 & -0.033692 \\ \mathrm{C} & 1.091323 & 2.216757 & 1.774181 \\ \mathrm{C} & -0.062270 & 3.653273 & 3.087509 \\ \mathrm{C} & -1.252321 & 3.133458 & 2.539750 \\ \mathrm{H} & -0.080852 & 4.444069 & 3.834458 \\ \mathrm{H} & -2.233358 & 3.491303 & 2.836170 \\ \mathrm{C} & 3.287298 & -0.819729 & -1.192740 \\ \mathrm{C} & 4.188923 & -1.588546 & -1.934645 \\ \mathrm{C} & 3.362672 & -2.326071 & -2.807985 \\ \mathrm{H} & 5.266317 & -1.624963 & -1.867761 \\ \mathrm{H} & 3.647799 & -3.055309 & -3.554485 \\ \mathrm{~N} & 1.118132 & 3.187719 & 2.708681 \\ \mathrm{~N} & -0.031436 & 1.710687 & 1.230990 \\ \mathrm{~N} & -1.223751 & 2.169788 & 1.624985 \\ \mathrm{~N} & 2.306793 & 0.715430 & 0.342666 \\ \mathrm{~N} & 2.016402 & -1.100488 & -1.611113 \\ \mathrm{~N} & 2.068080 & -2.016516 & -2.602603 \\ \mathrm{C} & -2.478119 & -1.650970 & 1.150809 \\ \mathrm{C} & -3.722019 & -2.052672 & 1.633304 \\ \mathrm{C} & -4.862902 & -1.423146 & 1.110963 \\ \mathrm{C} & -4.713273 & -0.437774 & 0.143772 \\ \mathrm{C} & -3.418451 & -0.086781 & -0.296902 \\ \mathrm{H} & -3.784439 & -2.829426 & 2.384211 \\ \mathrm{H} & -5.851694 & -1.706983 & 1.458134\end{array}$




$\begin{array}{lrrr}\mathrm{H} & -5.575939 & 0.063123 & -0.280116 \\ \mathrm{C} & -1.231804 & -2.271800 & 1.664097 \\ \mathrm{C} & -0.184617 & -3.767087 & 3.001001 \\ \mathrm{C} & 1.045922 & -3.287195 & 2.507382 \\ \mathrm{H} & -0.225065 & -4.566912 & 3.737437 \\ \mathrm{H} & 2.000051 & -3.686279 & 2.837038 \\ \mathrm{C} & -3.175018 & 0.924853 & -1.313022 \\ \mathrm{C} & -4.014226 & 1.773801 & -2.052578 \\ \mathrm{C} & -3.124595 & 2.506324 & -2.855315 \\ \mathrm{H} & -5.090616 & 1.858341 & -2.021419 \\ \mathrm{H} & -3.343094 & 3.277705 & -3.581230 \\ \mathrm{~N} & -1.331048 & -3.253175 & 2.582937 \\ \mathrm{~N} & -0.068727 & -1.803431 & 1.173844 \\ \mathrm{~N} & 1.089672 & -2.312338 & 1.605267 \\ \mathrm{~N} & -2.321003 & -0.696173 & 0.210985 \\ \mathrm{~N} & -1.884402 & 1.155483 & -1.674300 \\ \mathrm{~N} & -1.853904 & 2.120877 & -2.616098\end{array}$

$\mathrm{M}=\mathrm{Gd}$

$\begin{array}{lrrr}\text { GD } & 0.000004 & -0.000004 & -0.727181 \\ \mathrm{O} & -0.615602 & -1.771409 & -2.262317 \\ \mathrm{H} & 0.250545 & -2.148238 & -2.642589 \\ \mathrm{O} & 0.615643 & 1.771374 & -2.262344 \\ \mathrm{H} & -0.250499 & 2.148144 & -2.642677 \\ \mathrm{H} & -1.325654 & -1.851404 & -2.912255 \\ \mathrm{H} & 1.325699 & 1.851299 & -2.912288 \\ \mathrm{C} & -2.408348 & -1.681238 & 1.197713 \\ \mathrm{C} & -3.634037 & -2.121380 & 1.693097 \\ \mathrm{C} & -4.798276 & -1.521794 & 1.187435 \\ \mathrm{C} & -4.689311 & -0.527107 & 0.223393 \\ \mathrm{C} & -3.410962 & -0.138279 & -0.231082 \\ \mathrm{H} & -3.665601 & -2.902538 & 2.441396 \\ \mathrm{H} & -5.774291 & -1.835368 & 1.545010 \\ \mathrm{H} & -5.571514 & -0.049496 & -0.187078 \\ \mathrm{C} & -1.134913 & -2.261122 & 1.691492 \\ \mathrm{C} & -0.020218 & -3.726101 & 3.006562 \\ \mathrm{C} & 1.186690 & -3.195163 & 2.506541 \\ \mathrm{H} & -0.023672 & -4.533301 & 3.736008 \\ \mathrm{H} & 2.158162 & -3.559251 & 2.825860 \\ \mathrm{C} & -3.201225 & 0.882366 & -1.247497 \\ \mathrm{C} & -4.062800 & 1.713180 & -1.979906 \\ \mathrm{C} & -3.194283 & 2.466914 & -2.787804 \\ \mathrm{H} & -5.140634 & 1.773168 & -1.942655 \\ \mathrm{H} & -3.435290 & 3.234416 & -3.510732 \\ \mathrm{~N} & -1.188897 & -3.252181 & 2.603309\end{array}$




$\begin{array}{lrrr}\mathrm{N} & 0.005172 & -1.746891 & 1.192019 \\ \mathrm{~N} & 1.186073 & -2.214170 & 1.610812 \\ \mathrm{~N} & -2.291393 & -0.718079 & 0.261995 \\ \mathrm{~N} & -1.918126 & 1.141697 & -1.617010 \\ \mathrm{~N} & -1.914476 & 2.110967 & -2.557634 \\ \mathrm{C} & 2.408326 & 1.681247 & 1.197739 \\ \mathrm{C} & 3.634006 & 2.121409 & 1.693127 \\ \mathrm{C} & 4.798256 & 1.521835 & 1.187473 \\ \mathrm{C} & 4.689309 & 0.527142 & 0.223436 \\ \mathrm{C} & 3.410968 & 0.138294 & -0.231043 \\ \mathrm{H} & 3.665556 & 2.902570 & 2.441422 \\ \mathrm{H} & 5.774265 & 1.835425 & 1.545051 \\ \mathrm{H} & 5.571520 & 0.049541 & -0.187028 \\ \mathrm{C} & 1.134881 & 2.261118 & 1.691509 \\ \mathrm{C} & 0.020164 & 3.726087 & 3.006572 \\ \mathrm{C} & -1.186736 & 3.195139 & 2.506542 \\ \mathrm{H} & 0.023607 & 4.533287 & 3.736018 \\ \mathrm{H} & -2.158213 & 3.559218 & 2.825854 \\ \mathrm{C} & 3.201251 & -0.882354 & -1.247458 \\ \mathrm{C} & 4.062841 & -1.713164 & -1.979853 \\ \mathrm{C} & 3.194341 & -2.466897 & -2.787770 \\ \mathrm{H} & 5.140675 & -1.773147 & -1.942587 \\ \mathrm{H} & 3.435362 & -3.234393 & -3.510700 \\ \mathrm{~N} & 1.188850 & 3.252177 & 2.603327 \\ \mathrm{~N} & -0.005195 & 1.746877 & 1.192027 \\ \mathrm{~N} & -1.186103 & 2.214148 & 1.610811 \\ \mathrm{~N} & 2.291388 & 0.718082 & 0.262024 \\ \mathrm{~N} & 1.918159 & -1.141697 & -1.616984 \\ \mathrm{~N} & 1.914530 & -2.110952 & -2.557622\end{array}$

$\mathrm{M}=\mathrm{Am}$

$\begin{array}{lccc}\text { AM } & -0.000004 & 0.000001 & -0.642601 \\ \mathrm{O} & 0.669378 & 1.799929 & -2.225050 \\ \mathrm{H} & -0.194871 & 2.228612 & -2.552754 \\ \mathrm{O} & -0.669405 & -1.799923 & -2.225047 \\ \mathrm{H} & 0.194839 & -2.228604 & -2.552763 \\ \mathrm{H} & 1.341193 & 1.840758 & -2.918143 \\ \mathrm{H} & -1.341229 & -1.840750 & -2.918132 \\ \mathrm{C} & 2.576379 & 1.623287 & 1.204454 \\ \mathrm{C} & 3.832070 & 2.019329 & 1.660736 \\ \mathrm{C} & 4.955176 & 1.350722 & 1.149988 \\ \mathrm{C} & 4.778200 & 0.330897 & 0.223144 \\ \mathrm{C} & 3.473823 & -0.007523 & -0.195027 \\ \mathrm{H} & 3.917394 & 2.817397 & 2.386652 \\ \mathrm{H} & 5.952394 & 1.627363 & 1.478213\end{array}$




$\begin{array}{lrrr}\mathrm{H} & 5.627912 & -0.204497 & -0.184402 \\ \mathrm{C} & 1.343206 & 2.261686 & 1.726275 \\ \mathrm{C} & 0.327840 & 3.798008 & 3.040755 \\ \mathrm{C} & -0.914337 & 3.283498 & 2.615627 \\ \mathrm{H} & 0.386006 & 4.628675 & 3.740879 \\ \mathrm{H} & -1.860229 & 3.682194 & 2.968253 \\ \mathrm{C} & 3.197686 & -1.056596 & -1.165832 \\ \mathrm{C} & 4.015220 & -1.943421 & -1.880773 \\ \mathrm{C} & 3.106545 & -2.692843 & -2.647235 \\ \mathrm{H} & 5.090833 & -2.040042 & -1.861749 \\ \mathrm{H} & 3.307592 & -3.491510 & -3.348373 \\ \mathrm{~N} & 1.464363 & 3.280455 & 2.600361 \\ \mathrm{~N} & 0.168329 & 1.765087 & 1.295609 \\ \mathrm{~N} & -0.979930 & 2.276699 & 1.752118 \\ \mathrm{~N} & 2.395100 & 0.644488 & 0.295683 \\ \mathrm{~N} & 1.899481 & -1.281862 & -1.502600 \\ \mathrm{~N} & 1.845767 & -2.283829 & -2.409563 \\ \mathrm{C} & -2.576364 & -1.623290 & 1.204482 \\ \mathrm{C} & -3.832050 & -2.019334 & 1.660778 \\ \mathrm{C} & -4.955162 & -1.350725 & 1.150045 \\ \mathrm{C} & -4.778197 & -0.330898 & 0.223202 \\ \mathrm{C} & -3.473826 & 0.007523 & -0.194985 \\ \mathrm{H} & -3.917364 & -2.817403 & 2.386692 \\ \mathrm{H} & -5.952376 & -1.627368 & 1.478282 \\ \mathrm{H} & -5.627914 & 0.204497 & -0.184332 \\ \mathrm{C} & -1.343185 & -2.261691 & 1.726286 \\ \mathrm{C} & -0.327802 & -3.798016 & 3.040748 \\ \mathrm{C} & 0.914370 & -3.283506 & 2.615607 \\ \mathrm{H} & -0.385960 & -4.628685 & 3.740872 \\ \mathrm{H} & 1.860265 & -3.682202 & 2.968220 \\ \mathrm{C} & -3.197701 & 1.056599 & -1.165790 \\ \mathrm{C} & -4.015243 & 1.943426 & -1.880718 \\ \mathrm{C} & -3.106578 & 2.692850 & -2.647190 \\ \mathrm{H} & -5.090856 & 2.040046 & -1.861681 \\ \mathrm{H} & -3.307634 & 3.491519 & -3.348323 \\ \mathrm{~N} & -1.464332 & -3.280462 & 2.600370 \\ \mathrm{~N} & -0.168313 & -1.765090 & 1.295606 \\ \mathrm{~N} & 0.979952 & -2.276704 & 1.752100 \\ -2.395097 & -0.644489 & 0.295710 \\ & -1.899500 & 1.281866 & -1.502573 \\ & -1.845796 & 2.283835 & -2.409534\end{array}$

$\mathrm{M}=\mathrm{Cm}$

$\begin{array}{llll}\text { CM } & -0.000029 & -0.000065 & 0.641838\end{array}$ $\begin{array}{llll}\text { O } & -0.698702 & 1.806879 & 2.199484\end{array}$ 


\begin{tabular}{|c|c|c|c|}
\hline & 22 & 1605 & \\
\hline & & -1.806912 & \\
\hline & .161582 & 646 & \\
\hline & -1.39 & 67 & \\
\hline & 1.396028 & -1.834329 & \\
\hline & -2.567291 & 47 & \\
\hline & -3.824640 & & \\
\hline & -4.94 & 64 & \\
\hline & -4.7 & & -0.2 \\
\hline & -3.4 & -0.0 & \\
\hline & -3.9 & & \\
\hline & -5.9 & 34 & -1.5 \\
\hline & & 41 & \\
\hline & -1.3 & & -1.7 \\
\hline & -0.3 & & \\
\hline & 0.9 & & -2. \\
\hline & & & \\
\hline & 1.8 & & -3 \\
\hline & -3.1 & -1. & \\
\hline & -3.9 & & \\
\hline & -3.0 & -2. & \\
\hline & -5.0 & & \\
\hline & -3.2 & -3 . & \\
\hline & -1.4 & & -2 \\
\hline & -0.1 & & \\
\hline & 0.9 & & -1.7 \\
\hline & -2.3 & & -0 . \\
\hline & -1.8 & -1. & \\
\hline & -1.8 & -2 . & \\
\hline & 2.5 & -1.5 & -1.2 \\
\hline & 3.8 & -1. & -1. \\
\hline & 4.9 & -1.2 & -1 \\
\hline & 4.7 & -0.3 & 44 \\
\hline & 3.45 & & \\
\hline & & -2. & -2. \\
\hline $\mathrm{H}$ & 5.9 & -1.5 & -1. \\
\hline & & & \\
\hline & 1.3 & -2.2 & -1.7 \\
\hline & 0.33 & -3.7 & $-3.127^{\prime}$ \\
\hline 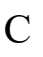 & -0.90 & -3.2 & -2.6 \\
\hline & 0.406105 & -4.5 & -3.8 \\
\hline 11 & -1.8 & -3. & -3 \\
\hline & 3.183030 & 941 & 1.222418 \\
\hline & 3.999062 & 937 & 1.961998 \\
\hline $\mathrm{C}$ & 3.090635 & 2.607543 & 2.758522 \\
\hline & 5.073423 & 1.998730 & 1.935842 \\
\hline
\end{tabular}




$\begin{array}{rrrc}\mathrm{H} & 3.290726 & 3.386469 & 3.481812 \\ \mathrm{~N} & 1.469640 & -3.198653 & -2.688643 \\ \mathrm{~N} & 0.158485 & -1.759519 & -1.314162 \\ \mathrm{~N} & -0.984311 & -2.285101 & -1.769184 \\ \mathrm{~N} & 2.382377 & -0.620225 & -0.310766 \\ \mathrm{~N} & 1.885864 & 1.225919 & 1.577874 \\ \mathrm{~N} & 1.830295 & 2.197181 & 2.515951\end{array}$

\section{$\left[\mathrm{ML}_{2}\right]^{1+}$}

$\mathrm{M}=\mathrm{Eu}$

$\begin{array}{lrrr}\text { EU } & 0.002111 & -0.000743 & 0.404562 \\ \mathrm{C} & -3.379449 & 0.721540 & 0.031539 \\ \mathrm{C} & -4.562953 & 1.242475 & -0.484715 \\ \mathrm{C} & -4.466838 & 2.295303 & -1.410420 \\ \mathrm{C} & -3.215395 & 2.776728 & -1.776139 \\ \mathrm{C} & -2.059760 & 2.192245 & -1.213187 \\ \mathrm{H} & -5.515757 & 0.833620 & -0.173577 \\ \mathrm{H} & -5.365778 & 2.729681 & -1.836886 \\ \mathrm{H} & -3.116354 & 3.589272 & -2.486572 \\ \mathrm{C} & -3.383974 & -0.377115 & 1.029926 \\ \mathrm{C} & -4.472989 & -1.913216 & 2.278164 \\ \mathrm{C} & -3.228365 & -2.316396 & 2.806734 \\ \mathrm{H} & -5.397983 & -2.393933 & 2.589063 \\ \mathrm{H} & -3.136422 & -3.115677 & 3.535183 \\ \mathrm{C} & -0.704963 & 2.617474 & -1.523200 \\ \mathrm{C} & -0.173555 & 3.639648 & -2.305636 \\ \mathrm{C} & 1.220370 & 3.502940 & -2.131762 \\ \mathrm{H} & -0.692042 & 4.375720 & -2.902188 \\ \mathrm{H} & 2.013570 & 4.097743 & -2.565942 \\ \mathrm{~N} & -4.554549 & -0.934958 & 1.387952 \\ \mathrm{~N} & -2.186672 & -0.739051 & 1.528992 \\ \mathrm{~N} & -2.100683 & -1.722019 & 2.427637 \\ \mathrm{~N} & -2.161305 & 1.177575 & -0.323248 \\ \mathrm{~N} & 0.340671 & 1.922964 & -0.936302 \\ \mathrm{~N} & 1.511609 & 2.469658 & -1.307002 \\ \mathrm{C} & 3.382136 & -0.719971 & 0.023213 \\ \mathrm{C} & 4.565137 & -1.238947 & -0.495187 \\ \mathrm{C} & 4.466880 & -2.284525 & -1.429012 \\ \mathrm{C} & 3.214728 & -2.761570 & -1.798299 \\ \mathrm{C} & 2.059363 & -2.179961 & -1.231994 \\ \mathrm{H} & 5.518566 & -0.834931 & -0.179749 \\ \mathrm{H} & 5.365093 & -2.717679 & -1.858292 \\ \mathrm{H} & 3.114666 & -3.569848 & -2.513469 \\ \mathrm{C} & 3.385512 & 0.368378 & 1.031670\end{array}$




$\begin{array}{lrrr}\mathrm{C} & 4.470624 & 1.889435 & 2.302247 \\ \mathrm{C} & 3.224150 & 2.289110 & 2.829565 \\ \mathrm{H} & 5.394932 & 2.365055 & 2.622947 \\ \mathrm{H} & 3.130042 & 3.080444 & 3.566346 \\ \mathrm{C} & 0.702514 & -2.603116 & -1.538519 \\ \mathrm{C} & 0.164382 & -3.622415 & -2.321155 \\ \mathrm{C} & -1.229090 & -3.487265 & -2.133129 \\ \mathrm{H} & 0.677966 & -4.355745 & -2.925436 \\ \mathrm{H} & -2.025438 & -4.080652 & -2.563457 \\ \mathrm{~N} & 4.554901 & 0.921545 & 1.401180 \\ \mathrm{~N} & 2.186444 & 0.727184 & 1.530074 \\ \mathrm{~N} & 2.097545 & 1.700909 & 2.438079 \\ \mathrm{~N} & 2.163241 & -1.170702 & -0.336758 \\ \mathrm{~N} & -0.334304 & -1.912742 & -0.942267 \\ \mathrm{~N} & -1.512448 & -2.460500 & -1.302568\end{array}$

$\mathrm{M}=\mathrm{Gd}$

$\begin{array}{lrrr}\text { GD } & 0.000000 & 0.000061 & 0.300789 \\ \text { C } & -3.390614 & 0.538182 & 0.144740 \\ \text { C } & -4.625884 & 0.997386 & -0.297022 \\ \text { C } & -4.633169 & 2.026701 & -1.256372 \\ \text { C } & -3.430963 & 2.543526 & -1.723410 \\ \text { C } & -2.214935 & 2.022570 & -1.228397 \\ \text { H } & -5.538744 & 0.564851 & 0.092083 \\ \mathrm{H} & -5.575780 & 2.414067 & -1.630668 \\ \mathrm{H} & -3.413872 & 3.334449 & -2.464360 \\ \mathrm{C} & -3.264013 & -0.530591 & 1.161483 \\ \mathrm{C} & -4.154646 & -2.073535 & 2.551235 \\ \mathrm{C} & -2.846383 & -2.416331 & 2.959865 \\ \mathrm{H} & -5.022654 & -2.580903 & 2.966694 \\ \mathrm{H} & -2.649702 & -3.191215 & 3.693812 \\ \mathrm{C} & -0.895370 & 2.469559 & -1.636821 \\ \mathrm{C} & -0.419724 & 3.464503 & -2.492697 \\ \mathrm{C} & 0.983264 & 3.347500 & -2.394456 \\ \mathrm{H} & -0.982298 & 4.166861 & -3.090300 \\ \mathrm{H} & 1.742013 & 3.932987 & -2.897049 \\ \mathrm{~N} & -4.367158 & -1.124717 & 1.651324 \\ \mathrm{~N} & -2.008123 & -0.838730 & 1.544014 \\ \mathrm{~N} & -1.788700 & -1.793090 & 2.451415 \\ \mathrm{~N} & -2.218249 & 1.033284 & -0.304544 \\ \mathrm{~N} & 0.180583 & 1.821153 & -1.084046 \\ \mathrm{~N} & 1.333665 & 2.359929 & -1.549344 \\ \mathrm{C} & 3.390694 & -0.537777 & 0.144563 \\ \mathrm{C} & 4.625989 & -0.996365 & -0.297767 \\ \mathrm{C} & 4.633318 & -2.025029 & -1.257818\end{array}$




$\begin{array}{rrrr}\mathrm{C} & 3.431152 & -2.541959 & -1.724831 \\ \mathrm{C} & 2.215092 & -2.021690 & -1.229151 \\ \mathrm{H} & 5.538840 & -0.563911 & 0.091452 \\ \mathrm{H} & 5.575952 & -2.411858 & -1.632614 \\ \mathrm{H} & 3.414109 & -3.332490 & -2.466201 \\ \mathrm{C} & 3.263947 & 0.530130 & 1.162169 \\ \mathrm{C} & 4.154273 & 2.072170 & 2.553138 \\ \mathrm{C} & 2.845936 & 2.414407 & 2.962038 \\ \mathrm{H} & 5.022182 & 2.579270 & 2.969134 \\ \mathrm{H} & 2.649117 & 3.188674 & 3.696598 \\ \mathrm{C} & 0.895532 & -2.469038 & -1.637215 \\ \mathrm{C} & 0.419889 & -3.463561 & -2.493570 \\ \mathrm{C} & -0.983103 & -3.347297 & -2.394496 \\ \mathrm{H} & 0.982506 & -4.165086 & -3.092113 \\ \mathrm{H} & -1.741849 & -3.932774 & -2.897103 \\ \mathrm{~N} & 4.366974 & 1.124130 & 1.652458 \\ \mathrm{~N} & 2.007998 & 0.837705 & 1.544969 \\ \mathrm{~N} & 1.788381 & 1.791389 & 2.453052 \\ \mathrm{~N} & 2.218375 & -1.032862 & -0.304825 \\ \mathrm{~N} & -0.180450 & -1.821573 & -1.083349 \\ \mathrm{~N} & -1.333515 & -2.360557 & -1.548425\end{array}$

$\mathrm{M}=\mathrm{Am}$
$\begin{array}{llll}\text { AM } & 0.000012 & -0.000043 & 0.036282\end{array}$
$\begin{array}{llll}\text { C } & -3.483516 & 0.018478 & 0.408866\end{array}$
$\begin{array}{llll}\text { C } & -4.827248 & 0.306261 & 0.198303\end{array}$
$\begin{array}{llll}\text { C } & -5.141413 & 1.327909 & -0.716262\end{array}$
C $\quad-4.119336 \quad 2.003198 \quad-1.369076$
$\begin{array}{llll}\text { C } & -2.775950 & 1.653107 & -1.105897\end{array}$
$\mathrm{H} \quad-5.591252 \quad-0.249326 \quad 0.726728$
$\mathrm{H} \quad-6.178279 \quad 1.583331 \quad-0.911727$
$\mathrm{H} \quad-4.336631 \quad 2.790523 \quad-2.081593$
$\begin{array}{llll}\text { C } & -3.052937 & -1.034981 & 1.355291\end{array}$
$\begin{array}{llll}\text { C } & -3.499190 & -2.677018 & 2.842881\end{array}$
C $\quad-2.107978 \quad-2.864599 \quad 3.003975$
$\mathrm{H} \quad-4.215021 \quad-3.284235 \quad 3.392690$
$\mathrm{H} \quad-1.695582 \quad-3.610443 \quad 3.675749$
$\begin{array}{llll}\mathrm{C} & -1.629156 & 2.280446 & -1.731586\end{array}$
$\begin{array}{llll}\text { C } & -1.448771 & 3.328223 & -2.637684\end{array}$
$\begin{array}{llll}\text { C } & -0.048235 & 3.399838 & -2.791587\end{array}$
$\mathrm{H} \quad-2.194963 \quad 3.946415 \quad-3.115050$
$\mathrm{H} \quad 0.526138 \quad 4.078030 \quad-3.408622$
$\begin{array}{llll}\mathrm{N} & -3.976279 & -1.756436 & 2.018605\end{array}$
$\mathrm{N} \quad-1.723857 \quad-1.202616 \quad 1.491148$
$\mathrm{N} \quad-1.237900 \quad-2.125460 \quad 2.326572$ 


$\begin{array}{rrrr}\mathrm{N} & -2.481325 & 0.669549 & -0.220931 \\ \mathrm{~N} & -0.397302 & 1.786433 & -1.394846 \\ \mathrm{~N} & 0.572791 & 2.469020 & -2.041931 \\ \mathrm{C} & 3.483508 & -0.018385 & 0.408928 \\ \mathrm{C} & 4.827256 & -0.306087 & 0.198348 \\ \mathrm{C} & 5.141476 & -1.327691 & -0.716245 \\ \mathrm{C} & 4.119436 & -2.003034 & -1.369066 \\ \mathrm{C} & 2.776033 & -1.653035 & -1.105868 \\ \mathrm{H} & 5.591231 & 0.249529 & 0.726787 \\ \mathrm{H} & 6.178357 & -1.583043 & -0.911725 \\ \mathrm{H} & 4.336775 & -2.790331 & -2.081601 \\ \mathrm{C} & 3.052873 & 1.035014 & 1.355403 \\ \mathrm{C} & 3.498990 & 2.676997 & 2.843088 \\ \mathrm{C} & 2.107763 & 2.864462 & 3.004192 \\ \mathrm{H} & 4.214772 & 3.284243 & 3.392930 \\ \mathrm{H} & 1.695308 & 3.610231 & 3.676011 \\ \mathrm{C} & 1.629256 & -2.280429 & -1.731567 \\ \mathrm{C} & 1.448846 & -3.328161 & -2.637710 \\ \mathrm{C} & 0.048298 & -3.399781 & -2.791565 \\ \mathrm{H} & 2.195024 & -3.946313 & -3.115149 \\ \mathrm{H} & -0.526089 & -4.077946 & -3.408617 \\ \mathrm{~N} & 3.976157 & 1.756499 & 2.018762 \\ \mathrm{~N} & 1.723788 & 1.202544 & 1.491272 \\ \mathrm{~N} & 1.237746 & 2.125298 & 2.326735 \\ \mathrm{~N} & 2.481349 & -0.669498 & -0.220883 \\ \mathrm{~N} & 0.397415 & -1.786467 & -1.394751 \\ \mathrm{~N} & -0.572712 & -2.469009 & -2.041836\end{array}$

$\mathrm{M}=\mathrm{Cm}$

$\begin{array}{lrrr}\text { CM } & 0.000006 & -0.000050 & 0.313207 \\ \mathrm{C} & -3.433537 & 0.555232 & 0.084178 \\ \mathrm{C} & -4.660199 & 1.018281 & -0.378922 \\ \mathrm{C} & -4.649358 & 2.045685 & -1.339268 \\ \mathrm{C} & -3.438163 & 2.557199 & -1.787755 \\ \mathrm{C} & -2.232461 & 2.032201 & -1.273477 \\ \mathrm{H} & -5.580735 & 0.590068 & -0.003528 \\ \mathrm{H} & -5.584795 & 2.435454 & -1.728864 \\ \mathrm{H} & -3.406684 & 3.347019 & -2.529368 \\ \mathrm{C} & -3.335993 & -0.511934 & 1.106812 \\ \mathrm{C} & -4.278111 & -2.040951 & 2.478997 \\ \mathrm{C} & -2.984265 & -2.394797 & 2.921480 \\ \mathrm{H} & -5.161708 & -2.537781 & 2.873747 \\ \mathrm{H} & -2.813946 & -3.167529 & 3.664140 \\ \mathrm{C} & -0.907299 & 2.477106 & -1.668886 \\ \mathrm{C} & -0.426136 & 3.474220 & -2.518104\end{array}$




$\begin{array}{lrrr}\mathrm{C} & 0.976288 & 3.356119 & -2.413896 \\ \mathrm{H} & -0.984228 & 4.179425 & -3.116405 \\ \mathrm{H} & 1.737626 & 3.942904 & -2.910913 \\ \mathrm{~N} & -4.457657 & -1.093147 & 1.571103 \\ \mathrm{~N} & -2.094033 & -0.832826 & 1.519087 \\ \mathrm{~N} & -1.908485 & -1.784842 & 2.437398 \\ \mathrm{~N} & -2.253120 & 1.044342 & -0.349093 \\ \mathrm{~N} & 0.165554 & 1.826203 & -1.114189 \\ \mathrm{~N} & 1.322105 & 2.366140 & -1.571641 \\ \mathrm{C} & 3.433502 & -0.555344 & 0.084472 \\ \mathrm{C} & 4.660232 & -1.018606 & -0.378243 \\ \mathrm{C} & 4.649517 & -2.046394 & -1.338182 \\ \mathrm{C} & 3.438385 & -2.557978 & -1.786752 \\ \mathrm{C} & 2.232604 & -2.032711 & -1.272931 \\ \mathrm{H} & 5.580728 & -0.590252 & -0.002917 \\ \mathrm{H} & 5.585012 & -2.436402 & -1.727405 \\ \mathrm{H} & 3.407023 & -3.348053 & -2.528100 \\ \mathrm{C} & 3.335829 & 0.512178 & 1.106711 \\ \mathrm{C} & 4.277777 & 2.042082 & 2.478007 \\ \mathrm{C} & 2.983912 & 2.395686 & 2.920657 \\ \mathrm{H} & 5.161297 & 2.539383 & 2.872337 \\ \mathrm{H} & 2.813532 & 3.168718 & 3.662991 \\ \mathrm{C} & 0.907478 & -2.477402 & -1.668685 \\ \mathrm{C} & 0.426309 & -3.474680 & -2.517715 \\ \mathrm{C} & -0.976108 & -3.356117 & -2.414046 \\ \mathrm{H} & 0.984446 & -4.180130 & -3.115686 \\ \mathrm{H} & -1.737478 & -3.942872 & -2.911047 \\ \mathrm{~N} & 4.457421 & 1.093925 & 1.570515 \\ \mathrm{~N} & 2.093868 & 0.832775 & 1.519211 \\ \mathrm{~N} & 1.908225 & 1.785140 & 2.437142 \\ \mathrm{~N} & 2.253138 & -1.044591 & -0.348809 \\ \mathrm{~N} & -0.165372 & -1.825920 & -1.114682 \\ \mathrm{~N} & -1.321920 & -2.365717 & -1.572259\end{array}$

$\mathbf{L}=\mathbf{2} \mathbf{a e i}$

\section{$\left[\mathrm{ML}\left(\mathrm{H}_{2} \mathrm{O}\right)_{6}\right]^{2+}$}

$\mathrm{M}=\mathrm{Eu}$

$\begin{array}{lccc}\text { EU } & 0.789517 & -1.058140 & 0.142102 \\ \mathrm{O} & 2.779303 & -1.940761 & 1.717106 \\ \mathrm{H} & 3.611123 & -1.602371 & 1.322170 \\ \mathrm{O} & 0.852173 & -0.205539 & 2.603536 \\ \mathrm{H} & 1.713437 & -0.512767 & 2.938118 \\ \mathrm{O} & -0.791687 & -2.822059 & -0.822277\end{array}$




\begin{tabular}{|c|c|c|c|}
\hline $\mathrm{H}$ & -0.784375 & -3.189825 & -1.718639 \\
\hline D & -0.166664 & -2.728700 & 1.824594 \\
\hline$U$ & -0.646034 & -3.527816 & 1.556364 \\
\hline & 2.600343 & -2.289592 & -1.303253 \\
\hline & 2.840893 & -3.202578 & -1.520468 \\
\hline & 0.685904 & -0.602331 & -2.392845 \\
\hline & 1.470511 & -0.985031 & -2.819493 \\
\hline & 2.967055 & -2.820714 & 2.077610 \\
\hline $\mathrm{H}$ & -0.307345 & -2.596527 & 2.774100 \\
\hline I & 3.435550 & -1.810509 & -1.079437 \\
\hline $\mathrm{H}$ & -1.681304 & -2.398604 & -0.689536 \\
\hline $\mathrm{H}$ & 0.378049 & 0.122246 & -2.956171 \\
\hline & 0.634369 & 0.612640 & 3.073364 \\
\hline $\mathrm{C}$ & 1.575291 & 2.365292 & 0.017129 \\
\hline & 1.476737 & 3.770222 & 0.063960 \\
\hline $\mathrm{C}$ & 0.216068 & 4.357131 & 0.139591 \\
\hline $\mathrm{H}$ & 2.373872 & 4.378488 & 0.042095 \\
\hline 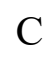 & -0.740759 & 2.150837 & 0.096564 \\
\hline $\mathrm{C}$ & -0.920011 & 3.536902 & 0.153741 \\
\hline $\mathrm{H}$ & 0.114088 & 5.437211 & 0.180609 \\
\hline $\mathrm{H}$ & -1.921421 & 3.945755 & 0.198778 \\
\hline $\mathrm{C}$ & -1.909836 & 1.228109 & 0.052949 \\
\hline $\mathrm{C}$ & -4.178649 & 0.917881 & -0.017565 \\
\hline $\mathrm{C}$ & -3.930312 & -0.491858 & -0.185900 \\
\hline $\mathrm{N}$ & 0.473983 & 1.572606 & 0.040346 \\
\hline $\mathrm{N}$ & -3.142965 & 1.749294 & 0.071993 \\
\hline $\mathrm{N}$ & -1.645657 & -0.080513 & -0.036176 \\
\hline $\mathrm{N}$ & -2.673547 & -0.931529 & -0.182528 \\
\hline $\mathrm{C}$ & -5.572008 & 1.522516 & 0.008219 \\
\hline $\mathrm{C}$ & -6.639484 & 0.417257 & 0.166058 \\
\hline $\mathrm{H}$ & -6.710962 & 0.127724 & 1.219764 \\
\hline $\mathrm{H}$ & -7.613741 & 0.839444 & -0.095542 \\
\hline $\mathrm{C}$ & -6.362916 & -0.815447 & -0.698013 \\
\hline $\mathrm{C}$ & -5.039485 & -1.528431 & -0.335069 \\
\hline $\mathrm{H}$ & -6.344387 & -0.535270 & -1.757024 \\
\hline $\mathrm{H}$ & -7.179784 & -1.534811 & -0.589704 \\
\hline $\mathrm{C}$ & -5.684620 & 2.529973 & 1.174657 \\
\hline $\mathrm{H}$ & -4.987380 & 3.361562 & 1.058114 \\
\hline $\mathrm{H}$ & -6.699665 & 2.935630 & 1.197862 \\
\hline $\mathrm{H}$ & -5.495903 & 2.049275 & 2.139851 \\
\hline $\mathrm{C}$ & -5.761312 & 2.283403 & -1.334445 \\
\hline $\mathrm{H}$ & -6.738381 & 2.773564 & -1.328930 \\
\hline $\mathrm{H}$ & -4.993430 & 3.051186 & -1.457016 \\
\hline 1 & -5.723299 & 1.617347 & -2.200963 \\
\hline $\mathrm{C}$ & -5.172781 & -2.275719 & 1.018390 \\
\hline $\mathrm{H}$ & -5.952865 & -3.037487 & 0.936921 \\
\hline
\end{tabular}




$\begin{array}{lrrr}\mathrm{H} & -4.235246 & -2.775455 & 1.279596 \\ \mathrm{H} & -5.440794 & -1.607666 & 1.840960 \\ \mathrm{C} & -4.694798 & -2.548883 & -1.441066 \\ \mathrm{H} & -3.845217 & -3.181099 & -1.169330 \\ \mathrm{H} & -5.551730 & -3.209483 & -1.598103 \\ \mathrm{H} & -4.478828 & -2.055404 & -2.393901 \\ \mathrm{C} & 2.849885 & 1.666676 & -0.063921 \\ \mathrm{C} & 4.180106 & 2.081805 & -0.139930 \\ \mathrm{C} & 4.907418 & 0.883816 & -0.194553 \\ \mathrm{H} & 4.598652 & 3.076930 & -0.158374 \\ \mathrm{~N} & 2.815994 & 0.281881 & -0.077672 \\ \mathrm{~N} & 4.056414 & -0.193334 & -0.151028 \\ \mathrm{C} & 6.391245 & 0.774813 & -0.289196 \\ \mathrm{O} & 7.105119 & 1.761119 & -0.320429 \\ \mathrm{O} & 6.811224 & -0.501596 & -0.329604 \\ \mathrm{C} & 8.255840 & -0.671073 & -0.423121 \\ \mathrm{H} & 8.740379 & -0.222222 & 0.445882 \\ \mathrm{H} & 8.417889 & -1.747514 & -0.448483 \\ \mathrm{H} & 8.627682 & -0.197520 & -1.333530\end{array}$

$\mathrm{M}=\mathrm{Gd}$

$\begin{array}{lrrr}\text { GD } & 0.781489 & -0.953736 & 0.165378 \\ \mathrm{O} & 2.695942 & -1.837995 & 1.750272 \\ \mathrm{H} & 3.527661 & -1.503264 & 1.341242 \\ \mathrm{O} & 0.789906 & -0.096396 & 2.552553 \\ \mathrm{H} & 1.650282 & -0.381072 & 2.911688 \\ \mathrm{O} & -0.668131 & -2.740449 & -0.824147 \\ \mathrm{H} & -0.624188 & -3.096631 & -1.724549 \\ \mathrm{O} & -0.199867 & -2.577989 & 1.821416 \\ \mathrm{H} & -0.630489 & -3.413586 & 1.583139 \\ \mathrm{O} & 2.494883 & -2.227067 & -1.191440 \\ \mathrm{H} & 2.709724 & -3.155527 & -1.365708 \\ \mathrm{O} & 0.665594 & -0.479407 & -2.300402 \\ \mathrm{H} & 1.447063 & -0.850500 & -2.744049 \\ \mathrm{H} & 2.884099 & -2.713181 & 2.122407 \\ \mathrm{H} & -0.347903 & -2.418008 & 2.766045 \\ \mathrm{H} & 3.347125 & -1.748577 & -0.979955 \\ \mathrm{H} & -1.584897 & -2.371924 & -0.697961 \\ \mathrm{H} & 0.439325 & 0.340134 & -2.764999 \\ \mathrm{H} & 0.591216 & 0.773413 & 2.930604 \\ \mathrm{C} & 1.578926 & 2.372920 & 0.021039 \\ \mathrm{C} & 1.475704 & 3.775919 & 0.059453 \\ \mathrm{C} & 0.215063 & 4.361894 & 0.133845 \\ \mathrm{H} & 2.372677 & 4.384213 & 0.031163 \\ \mathrm{C} & -0.747251 & 2.164819 & 0.105802\end{array}$




$\begin{array}{lrrr}\mathrm{C} & -0.926660 & 3.544905 & 0.154716 \\ \mathrm{H} & 0.114687 & 5.442458 & 0.168399 \\ \mathrm{H} & -1.926653 & 3.957192 & 0.198089 \\ \mathrm{C} & -1.900765 & 1.228328 & 0.062776 \\ \mathrm{C} & -4.160924 & 0.865566 & -0.030134 \\ \mathrm{C} & -3.880370 & -0.541257 & -0.194545 \\ \mathrm{~N} & 0.473963 & 1.585596 & 0.051814 \\ \mathrm{~N} & -3.145383 & 1.720121 & 0.068630 \\ \mathrm{~N} & -1.609852 & -0.076484 & -0.018506 \\ \mathrm{~N} & -2.616101 & -0.952945 & -0.175695 \\ \mathrm{C} & -5.566621 & 1.438987 & -0.021438 \\ \mathrm{C} & -6.613944 & 0.311814 & 0.115562 \\ \mathrm{H} & -6.699875 & 0.019743 & 1.167404 \\ \mathrm{H} & -7.591272 & 0.714625 & -0.164128 \\ \mathrm{C} & -6.296613 & -0.913977 & -0.744377 \\ \mathrm{C} & -4.966074 & -1.600331 & -0.357042 \\ \mathrm{H} & -6.264053 & -0.632591 & -1.802726 \\ \mathrm{H} & -7.100410 & -1.649961 & -0.651570 \\ \mathrm{C} & -5.716123 & 2.440188 & 1.146746 \\ \mathrm{H} & -5.033981 & 3.285782 & 1.042967 \\ \mathrm{H} & -6.739348 & 2.825200 & 1.155613 \\ \mathrm{H} & -5.532660 & 1.959934 & 2.113156 \\ \mathrm{C} & -5.751342 & 2.201576 & -1.364622 \\ \mathrm{H} & -6.738463 & 2.671019 & -1.370446 \\ \mathrm{H} & -4.997997 & 2.985585 & -1.472775 \\ \mathrm{H} & -5.687595 & 1.539886 & -2.232968 \\ \mathrm{C} & -5.106721 & -2.343889 & 0.997826 \\ \mathrm{H} & -5.873145 & -3.118453 & 0.908481 \\ \mathrm{H} & -4.165216 & -2.827846 & 1.274434 \\ \mathrm{H} & -5.397184 & -1.677347 & 1.813898 \\ \mathrm{C} & -4.583386 & -2.618417 & -1.452564 \\ \mathrm{H} & -3.726297 & -3.233329 & -1.164328 \\ \mathrm{H} & -5.424189 & -3.296825 & -1.620030 \\ \mathrm{H} & -4.362343 & -2.125212 & -2.404362 \\ \mathrm{C} & 2.845656 & 1.650645 & -0.061579 \\ \mathrm{C} & 4.188811 & 2.024392 & -0.161099 \\ \mathrm{C} & 4.878535 & 0.799301 & -0.219028 \\ \mathrm{H} & 4.636863 & 3.006324 & -0.194638 \\ \mathrm{~N} & 2.767211 & 0.290987 & -0.060854 \\ \mathrm{C} & 4.008847 & -0.237386 & -0.156015 \\ & 6.357625 & 0.646921 & -0.334201 \\ \mathrm{O} & 7.102841 & 1.607606 & -0.398172 \\ \mathrm{H} & -179660 & -0.643262 & -0.355099 \\ -0.853214 & -0.469442 \\ \mathrm{H} & -0.398487 & 0.379814 \\ \mathrm{H} & -1.934079 & -0.472234\end{array}$




$$
\begin{array}{llll}
\mathrm{H} & 8.548651 & -0.412085 & -1.396917
\end{array}
$$

$\mathrm{M}=\mathrm{Am}$

$\begin{array}{lrrr}\mathrm{AM} & 0.731147 & -0.893636 & 0.171783 \\ \mathrm{O} & 2.722512 & -1.692839 & 1.756954 \\ \mathrm{H} & 3.532424 & -1.342403 & 1.319991 \\ \mathrm{O} & 0.699202 & -0.075750 & 2.632875 \\ \mathrm{H} & 1.575036 & -0.305663 & 2.992076 \\ \mathrm{O} & -0.798193 & -2.735215 & -0.835927 \\ \mathrm{H} & -0.751512 & -3.071110 & -1.744081 \\ \mathrm{O} & -0.210139 & -2.647335 & 1.815098 \\ \mathrm{H} & -0.643721 & -3.462094 & 1.515463 \\ \mathrm{O} & 2.527723 & -2.155259 & -1.246492 \\ \mathrm{H} & 2.786838 & -3.071380 & -1.426335 \\ \mathrm{O} & 0.614448 & -0.497123 & -2.383155 \\ \mathrm{H} & 1.419213 & -0.878514 & -2.774669 \\ \mathrm{H} & 2.937133 & -2.572709 & 2.103634 \\ \mathrm{H} & -0.355590 & -2.560321 & 2.769664 \\ \mathrm{H} & 3.355170 & -1.637547 & -1.030331 \\ \mathrm{H} & -1.696450 & -2.322116 & -0.725890 \\ \mathrm{H} & 0.408809 & 0.304987 & -2.886731 \\ \mathrm{H} & 0.425442 & 0.755011 & 3.050270 \\ \mathrm{C} & 1.486588 & 2.477306 & 0.028540 \\ \mathrm{C} & 1.370898 & 3.878268 & 0.079895 \\ \mathrm{C} & 0.105596 & 4.451665 & 0.164238 \\ \mathrm{H} & 2.261796 & 4.495225 & 0.050674 \\ \mathrm{C} & -0.836007 & 2.245144 & 0.117295 \\ \mathrm{C} & -1.027293 & 3.623181 & 0.176556 \\ \mathrm{H} & -0.005444 & 5.530771 & 0.208592 \\ \mathrm{H} & -2.031248 & 4.025553 & 0.219368 \\ \mathrm{C} & -1.986396 & 1.306873 & 0.054644 \\ \mathrm{C} & -4.246708 & 0.944281 & -0.045009 \\ \mathrm{C} & -3.964972 & -0.459329 & -0.230370 \\ \mathrm{~N} & 0.391055 & 1.677491 & 0.063856 \\ \mathrm{~N} & -3.231723 & 1.797397 & 0.071588 \\ \mathrm{~N} & -1.694344 & 0.005434 & -0.055365 \\ \mathrm{~N} & -2.700486 & -0.870073 & -0.220500 \\ \mathrm{C} & -5.652882 & 1.516922 & -0.030319 \\ \mathrm{C} & -6.699227 & 0.387437 & 0.094818 \\ \mathrm{H} & -6.783152 & 0.083011 & 1.143346 \\ & -7.677280 & 0.792789 & -0.178621 \\ \mathrm{C} & -6.382332 & -0.827906 & -0.779851 \\ \mathrm{H} & -1.517592 & -0.403809 \\ \mathrm{H} & -0.534225 & -1.834938 \\ \mathrm{H} & -1.565782 & -0.693837\end{array}$




$\begin{array}{lrrr}\mathrm{C} & -5.804124 & 2.505792 & 1.147911 \\ \mathrm{H} & -5.123331 & 3.353520 & 1.053209 \\ \mathrm{H} & -6.827926 & 2.889209 & 1.160764 \\ \mathrm{H} & -5.619993 & 2.015791 & 2.109299 \\ \mathrm{C} & -5.837490 & 2.292889 & -1.365846 \\ \mathrm{H} & -6.825111 & 2.761379 & -1.367976 \\ \mathrm{H} & -5.084896 & 3.078813 & -1.465449 \\ \mathrm{H} & -5.772105 & 1.640243 & -2.240873 \\ \mathrm{C} & -5.187229 & -2.278449 & 0.941794 \\ \mathrm{H} & -5.951026 & -3.054537 & 0.843368 \\ \mathrm{H} & -4.243863 & -2.762607 & 1.211776 \\ \mathrm{H} & -5.479422 & -1.623044 & 1.766272 \\ \mathrm{C} & -4.669366 & -2.521381 & -1.513212 \\ \mathrm{H} & -3.814315 & -3.142704 & -1.233095 \\ \mathrm{H} & -5.511951 & -3.195030 & -1.690734 \\ \mathrm{H} & -4.445985 & -2.015601 & -2.457844 \\ \mathrm{C} & 2.760263 & 1.773152 & -0.079130 \\ \mathrm{C} & 4.097744 & 2.166393 & -0.167458 \\ \mathrm{C} & 4.803215 & 0.952522 & -0.259625 \\ \mathrm{H} & 4.533780 & 3.154211 & -0.170400 \\ \mathrm{~N} & 2.699700 & 0.413869 & -0.119273 \\ \mathrm{~N} & 3.948135 & -0.096809 & -0.227968 \\ \mathrm{C} & 6.284213 & 0.822347 & -0.376137 \\ \mathrm{O} & 7.016556 & 1.794040 & -0.415803 \\ \mathrm{O} & 6.686275 & -0.461851 & -0.426832 \\ \mathrm{C} & 8.125496 & -0.650577 & -0.546564 \\ \mathrm{H} & 8.633413 & -0.209290 & 0.312871 \\ \mathrm{H} & 8.273054 & -1.729280 & -0.574783 \\ \mathrm{H} & 8.488436 & -0.183232 & -1.463680\end{array}$

$\mathrm{M}=\mathrm{Cm}$

$\begin{array}{lccc}\mathrm{CM} & 0.721938 & -0.894763 & 0.142397 \\ \mathrm{O} & 2.714528 & -1.761981 & 1.728370 \\ \mathrm{H} & 3.524251 & -1.396403 & 1.301702 \\ \mathrm{O} & 0.753798 & -0.082231 & 2.594727 \\ \mathrm{H} & 1.627124 & -0.360143 & 2.927178 \\ \mathrm{O} & -0.796799 & -2.715668 & -0.854279 \\ \mathrm{H} & -0.770456 & -3.077237 & -1.753231 \\ \mathrm{O} & -0.213035 & -2.615674 & 1.811210 \\ \mathrm{H} & -0.653106 & -3.435260 & 1.536610 \\ \mathrm{O} & 2.508801 & -2.119246 & -1.276692 \\ \mathrm{H} & 2.754710 & -3.039066 & -1.456718 \\ \mathrm{O} & 0.595648 & -0.436088 & -2.376279 \\ \mathrm{H} & 1.392215 & -0.797204 & -2.801832 \\ \mathrm{H} & 2.937309 & -2.639469 & 2.075333\end{array}$




\begin{tabular}{|c|c|c|c|}
\hline $\mathrm{H}$ & -0.343384 & -2.506355 & 65561 \\
\hline & 3.341328 & -1.618910 & -1.042533 \\
\hline & -1.698462 & -2.314341 & -0.726050 \\
\hline & 0.360758 & 0.373950 & -2.853756 \\
\hline & 0.549680 & 0.775490 & 2.997172 \\
\hline & 1.488598 & 2.469564 & 0.027643 \\
\hline 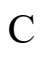 & 1.375103 & 3.871178 & 0.079005 \\
\hline C & 0.110794 & 4.447703 & 0.159201 \\
\hline $\mathrm{H}$ & 2.267425 & 4.486371 & 0.055305 \\
\hline C & -0.836671 & 2.244142 & 0.111564 \\
\hline 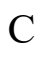 & -1.024963 & 3.622527 & 0.172181 \\
\hline $\mathrm{H}$ & 0.002784 & 5.527178 & 0.203563 \\
\hline $\mathrm{H}$ & -2.027581 & 4.027853 & 0.218499 \\
\hline$C$ & -1.989331 & 1.306113 & 0.058796 \\
\hline $\mathrm{C}$ & -4.250882 & 0.947640 & -0.032179 \\
\hline$c$ & -3.973098 & -0.45 & -0.209758 \\
\hline $\mathbf{N}$ & 0.389103 & 1.674479 & 0.054012 \\
\hline $\mathrm{N}$ & -3.233656 & 1.799515 & 0.073073 \\
\hline $\mathbf{N}$ & -1.701498 & 0.002016 & -0.037823 \\
\hline $\mathrm{N}$ & -2.709751 & -0.871954 & -0.198639 \\
\hline $\mathrm{C}$ & -5.655730 & 1.523458 & -0.014652 \\
\hline $\mathrm{C}$ & -6.70 & 0.3 & 906 \\
\hline $\mathrm{H}$ & -6.785840 & 0.096588 & 1.167826 \\
\hline $\mathrm{H}$ & -7.682172 & 0.803246 & -0.154287 \\
\hline $\mathrm{C}$ & -6.392477 & -0.822633 & -0.752898 \\
\hline $\mathrm{C}$ & -5.061224 & -1.514091 & -0.376926 \\
\hline $\mathrm{H}$ & -6.364183 & -0.532973 & -1.809174 \\
\hline $\mathrm{H}$ & -7.196998 & -1.558101 & -0.662312 \\
\hline $\mathrm{C}$ & -5.800020 & 2.516255 & 1.161262 \\
\hline $\mathrm{H}$ & -5.117525 & 3.362021 & 1.061223 \\
\hline $\mathrm{H}$ & -6.822854 & 2.902133 & 1.176944 \\
\hline $\mathrm{H}$ & -5.613255 & 2.028728 & 2.123410 \\
\hline $\mathrm{C}$ & -5.843758 & 2.295854 & -1.351714 \\
\hline $\mathrm{H}$ & -6.830141 & 2.766924 & -1.351236 \\
\hline $\mathrm{H}$ & -5.089482 & 3.079430 & -1.456783 \\
\hline $\mathrm{H}$ & -5.783747 & 1.640258 & -2.224947 \\
\hline$C$ & -5.197370 & -2.269554 & 0.971810 \\
\hline $\mathrm{H}$ & -5.963319 & -3.044080 & 0.877860 \\
\hline $\mathrm{H}$ & -4.254571 & -2.754817 & 1.241722 \\
\hline $\mathrm{H}$ & -5.486264 & -1.610315 & 1.794380 \\
\hline $\mathrm{C}$ & -4.684731 & -2.523041 & -1.483059 \\
\hline $\mathrm{H}$ & -3.830159 & -3.144678 & -1.201861 \\
\hline $\mathrm{H}$ & -5.528802 & -3.196024 & -1.655932 \\
\hline $\mathrm{H}$ & -4.462691 & -2.021550 & -2.430348 \\
\hline $\mathrm{C}$ & 2.764619 & 1.764388 & -0.064741 \\
\hline$C$ & 4.100639 & 2.162855 & -0.159367 \\
\hline
\end{tabular}




$\begin{array}{cccc}\mathrm{C} & 4.812394 & 0.951410 & -0.231828 \\ \mathrm{H} & 4.531648 & 3.152598 & -0.181070 \\ \mathrm{~N} & 2.710998 & 0.403972 & -0.080193 \\ \mathrm{~N} & 3.962046 & -0.101546 & -0.181424 \\ \mathrm{C} & 6.293905 & 0.827329 & -0.347905 \\ \mathrm{O} & 7.021791 & 1.801936 & -0.399867 \\ \mathrm{O} & 6.702398 & -0.455416 & -0.384143 \\ \mathrm{C} & 8.142559 & -0.638146 & -0.500337 \\ \mathrm{H} & 8.647346 & -0.184430 & 0.354459 \\ \mathrm{H} & 8.295595 & -1.716361 & -0.515843 \\ \mathrm{H} & 8.504229 & -0.179599 & -1.422405\end{array}$

\section{$\left[\mathrm{ML}\left(\mathrm{H}_{2} \mathrm{O}\right)_{5}\right]^{2+}$}

$\mathrm{M}=\mathrm{Eu}$

$\begin{array}{lrrr}\text { EU } & 0.834215 & -1.134321 & 0.123293 \\ \mathrm{~N} & 2.885309 & 0.195952 & -0.117122 \\ \mathrm{C} & 2.914419 & 1.588661 & -0.080510 \\ \mathrm{~N} & 4.125689 & -0.267069 & -0.162688 \\ \mathrm{C} & 4.245916 & 2.006094 & -0.124269 \\ \mathrm{C} & 1.644088 & 2.288824 & -0.001884 \\ \mathrm{C} & 4.976300 & 0.811032 & -0.173226 \\ \mathrm{H} & 4.662637 & 3.002220 & -0.119319 \\ \mathrm{C} & 1.557647 & 3.695420 & 0.038677 \\ \mathrm{~N} & 0.537181 & 1.503168 & 0.029542 \\ \mathrm{C} & 6.462361 & 0.706050 & -0.232442 \\ \mathrm{C} & 0.303198 & 4.293962 & 0.116718 \\ \mathrm{H} & 2.459943 & 4.295499 & 0.008383 \\ \mathrm{C} & -0.670565 & 2.093510 & 0.087335 \\ \mathrm{O} & 6.884659 & -0.565389 & -0.309570 \\ \mathrm{O} & 7.172446 & 1.695896 & -0.206321 \\ \mathrm{C} & -0.837901 & 3.482182 & 0.138669 \\ \mathrm{H} & 0.209990 & 5.374974 & 0.152089 \\ \mathrm{C} & -1.853520 & 1.189069 & 0.052231 \\ \mathrm{C} & 8.330801 & -0.733637 & -0.370961 \\ \mathrm{H} & -1.836126 & 3.898422 & 0.183269 \\ \mathrm{~N} & -3.076142 & 1.735424 & 0.072260 \\ \mathrm{~N} & -1.616520 & -0.125277 & -0.029955 \\ \mathrm{H} & 8.727750 & -0.220943 & -1.249058 \\ \mathrm{H} & 8.791585 & -0.324854 & 0.530210 \\ \mathrm{H} & 8.491625 & -1.808258 & -0.439561 \\ \mathrm{C} & -4.130184 & 0.927482 & -0.006050 \\ \mathrm{~N} & -2.666038 & -0.953192 & -0.166276 \\ \mathrm{C} & -5.509487 & 1.562913 & 0.015868 \\ \mathrm{C} & -3.913091 & -0.488970 & -0.162908\end{array}$




$\begin{array}{lrrr}\mathrm{C} & -6.601240 & 0.484169 & 0.189767 \\ \mathrm{C} & -5.597134 & 2.587843 & 1.169119 \\ \mathrm{C} & -5.684232 & 2.310174 & -1.336744 \\ \mathrm{C} & -5.045636 & -1.502855 & -0.289081 \\ \mathrm{C} & -6.354540 & -0.766155 & -0.658016 \\ \mathrm{H} & -7.566032 & 0.924645 & -0.076612 \\ \mathrm{H} & -6.678081 & 0.210582 & 1.247287 \\ \mathrm{H} & -6.603180 & 3.015453 & 1.189230 \\ \mathrm{H} & -5.416172 & 2.116067 & 2.140157 \\ \mathrm{H} & -4.882670 & 3.402740 & 1.039893 \\ \mathrm{H} & -6.649808 & 2.822608 & -1.335312 \\ \mathrm{H} & -5.663596 & 1.632084 & -2.194452 \\ \mathrm{H} & -4.899183 & 3.058274 & -1.471308 \\ \mathrm{C} & -4.731242 & -2.550631 & -1.377969 \\ \mathrm{C} & -5.188139 & -2.221939 & 1.078898 \\ \mathrm{H} & -7.186428 & -1.465952 & -0.536626 \\ \mathrm{H} & -6.333607 & -0.501370 & -1.720938 \\ \mathrm{H} & -3.897942 & -3.200578 & -1.096455 \\ \mathrm{H} & -4.504864 & -2.080534 & -2.340063 \\ \mathrm{H} & -5.604988 & -3.192095 & -1.520655 \\ \mathrm{H} & -5.985586 & -2.967302 & 1.015455 \\ \mathrm{H} & -4.260595 & -2.737011 & 1.346104 \\ \mathrm{H} & -5.436956 & -1.533002 & 1.890055 \\ \mathrm{O} & 1.127225 & -0.993323 & -2.388634 \\ \mathrm{H} & 0.595811 & -1.342666 & -3.119497 \\ \mathrm{H} & 1.944477 & -0.648504 & -2.781725 \\ \mathrm{O} & -0.837348 & -2.822950 & -0.777319 \\ \mathrm{H} & -0.912648 & -3.591851 & -1.359894 \\ \mathrm{H} & -1.739829 & -2.417734 & -0.651954 \\ \mathrm{O} & 0.083763 & -2.769846 & 1.925696 \\ \mathrm{H} & 0.506069 & -2.909031 & 2.787118 \\ \mathrm{H} & -0.459420 & -3.550793 & 1.739086 \\ \mathrm{O} & 1.483720 & -0.393350 & 2.558095 \\ \mathrm{H} & 0.957438 & -0.061036 & 3.301427 \\ \mathrm{H} & 2.397413 & -0.117575 & 2.734237 \\ \mathrm{H} & 3.653526 & -1.976346 & -0.044484 \\ \mathrm{H} & 2.856895 & -2.570839 & 0.077592 \\ & 3.159782 & -3.487703 & 0.130464\end{array}$

$\mathrm{M}=\mathrm{Gd}$

$\begin{array}{lccc}\text { GD } & 0.822717 & -1.002260 & 0.160870 \\ \text { O } & 0.071820 & -2.574294 & 1.950990 \\ \text { H } & -0.441063 & -3.377244 & 1.769721 \\ \mathrm{O} & -0.689891 & -2.736507 & -0.767236 \\ \mathrm{H} & -0.688351 & -3.506478 & -1.354019\end{array}$




$\begin{array}{lrrc}\mathrm{O} & 2.704960 & -2.468328 & 0.041182 \\ \mathrm{H} & 2.974158 & -3.396706 & 0.067259 \\ \mathrm{O} & 1.431330 & -0.251855 & 2.508385 \\ \mathrm{H} & 2.313366 & 0.148847 & 2.586117 \\ \mathrm{O} & 1.082192 & -0.766802 & -2.272314 \\ \mathrm{H} & 0.593095 & -1.107798 & -3.035902 \\ \mathrm{H} & 3.535544 & -1.871151 & -0.058675 \\ \mathrm{H} & 1.895985 & -0.359393 & -2.611109 \\ \mathrm{H} & 0.524031 & -2.703531 & 2.799565 \\ \mathrm{H} & -1.623237 & -2.394031 & -0.659961 \\ \mathrm{H} & 0.919912 & 0.057846 & 3.272079 \\ \mathrm{C} & 1.644615 & 2.302397 & 0.017321 \\ \mathrm{C} & 1.551125 & 3.706512 & 0.042237 \\ \mathrm{C} & 0.295462 & 4.301783 & 0.110309 \\ \mathrm{H} & 2.452331 & 4.308090 & 0.007194 \\ \mathrm{C} & -0.681215 & 2.110920 & 0.101572 \\ \mathrm{C} & -0.851258 & 3.491820 & 0.137246 \\ \mathrm{H} & 0.201977 & 5.383197 & 0.134007 \\ \mathrm{H} & -1.848499 & 3.910944 & 0.174136 \\ \mathrm{C} & -1.844084 & 1.188363 & 0.063004 \\ \mathrm{C} & -4.111721 & 0.861250 & -0.022323 \\ \mathrm{C} & -3.855196 & -0.552945 & -0.171913 \\ \mathrm{~N} & 0.535475 & 1.521820 & 0.056227 \\ \mathrm{H} & -3.082193 & 1.698264 & 0.067501 \\ \mathrm{H} & -4.180455 & -2.794006 & 1.357417 \\ \mathrm{~N} & -1.573826 & -0.121900 & -0.014368 \\ \mathrm{~N} & -2.598189 & -0.982413 & -0.161199 \\ \mathrm{C} & -5.507053 & 1.458677 & -0.025315 \\ \mathrm{C} & -6.575719 & 0.353450 & 0.125383 \\ \mathrm{H} & -6.673437 & 0.081933 & 1.181590 \\ \mathrm{H} & -7.543697 & 0.769253 & -0.167383 \\ \mathrm{C} & -6.277690 & -0.893560 & -0.710797 \\ \mathrm{C} & -4.960182 & -1.595435 & -0.306799 \\ \mathrm{H} & -6.237836 & -0.633124 & -1.774287 \\ \mathrm{H} & -7.094323 & -1.613602 & -0.605675 \\ \mathrm{C} & -5.642161 & 2.481358 & 1.125908 \\ \mathrm{H} & -4.945361 & 3.313274 & 1.010278 \\ \mathrm{H} & -6.658671 & 2.883817 & 1.125304 \\ \mathrm{H} & -5.469477 & 2.013969 & 2.100542 \\ \mathrm{H} & -5.9042976 & 2.202734 & -1.381790 \\ \mathrm{H} & 2.690743 & -1.397568 \\ \mathrm{H} & 2.970121 & -1.500755 \\ \mathrm{H} & -1.504244 & 1.866790\end{array}$




$\begin{array}{lrrr}\mathrm{C} & -4.600015 & -2.650223 & -1.374275 \\ \mathrm{H} & -3.757265 & -3.276820 & -1.068029 \\ \mathrm{H} & -5.454921 & -3.314965 & -1.523765 \\ \mathrm{H} & -4.367687 & -2.188482 & -2.339040 \\ \mathrm{C} & 2.907546 & 1.574645 & -0.057885 \\ \mathrm{C} & 4.251589 & 1.937664 & -0.139281 \\ \mathrm{C} & 4.936747 & 0.704564 & -0.190360 \\ \mathrm{H} & 4.707245 & 2.916457 & -0.165154 \\ \mathrm{~N} & 2.822683 & 0.206963 & -0.061537 \\ \mathrm{~N} & 4.063939 & -0.320488 & -0.140523 \\ \mathrm{C} & 6.417455 & 0.547669 & -0.284086 \\ \mathrm{O} & 7.163912 & 1.509454 & -0.320638 \\ \mathrm{O} & 6.797598 & -0.740853 & -0.320466 \\ \mathrm{C} & 8.234363 & -0.957708 & -0.413944 \\ \mathrm{H} & 8.735373 & -0.521336 & 0.452053 \\ \mathrm{H} & 8.360827 & -2.039172 & -0.433336 \\ \mathrm{H} & 8.622205 & -0.502868 & -1.327201\end{array}$

$\mathrm{M}=\mathrm{Am}$

$\begin{array}{lrrr}\text { AM } & 0.772834 & -0.968078 & 0.085914 \\ \text { N } & 2.761175 & 0.354157 & -0.034013 \\ \mathrm{C} & 2.811205 & 1.721882 & -0.027608 \\ \mathrm{~N} & 4.019684 & -0.136969 & -0.099451 \\ \mathrm{C} & 4.144493 & 2.122243 & -0.088789 \\ \mathrm{C} & 1.535910 & 2.427388 & 0.021276 \\ \mathrm{C} & 4.864200 & 0.909528 & -0.134751 \\ \mathrm{H} & 4.572509 & 3.113461 & -0.108620 \\ \mathrm{C} & 1.429945 & 3.829956 & 0.063899 \\ \mathrm{~N} & 0.437950 & 1.632883 & 0.024861 \\ \mathrm{C} & 6.348948 & 0.790976 & -0.213136 \\ \mathrm{C} & 0.168568 & 4.413182 & 0.117337 \\ \mathrm{H} & 2.326183 & 4.439689 & 0.056105 \\ \mathrm{C} & -0.783630 & 2.211321 & 0.069516 \\ \mathrm{O} & 6.761441 & -0.487511 & -0.263661 \\ \mathrm{O} & 7.071903 & 1.770934 & -0.227296 \\ \mathrm{C} & -0.968087 & 3.590371 & 0.121017 \\ \mathrm{H} & 0.063582 & 5.493132 & 0.153407 \\ \mathrm{C} & -1.942978 & 1.286516 & 0.031991 \\ \mathrm{C} & 8.204306 & -0.667457 & -0.340320 \\ \mathrm{H} & -1.969950 & 3.998086 & 0.156646 \\ \mathrm{~N} & -3.181568 & 1.797525 & 0.051320 \\ \mathrm{~N} & -1.674508 & -0.022949 & -0.048304 \\ \mathrm{H} & 8.593277 & -0.189140 & -1.241026 \\ \mathrm{H} & 8.682364 & -0.232363 & 0.539173 \\ \mathrm{H} & 8.357949 & -1.745059 & -0.374141\end{array}$




$\begin{array}{rrrr}\mathrm{C} & -4.214019 & 0.962814 & -0.014222 \\ \mathrm{~N} & -2.705417 & -0.881690 & -0.161174 \\ \mathrm{C} & -5.608288 & 1.563412 & -0.010673 \\ \mathrm{C} & -3.962116 & -0.453462 & -0.145313 \\ \mathrm{C} & -6.676560 & 0.464575 & 0.183573 \\ \mathrm{C} & -5.725480 & 2.614668 & 1.116230 \\ \mathrm{C} & -5.792676 & 2.273291 & -1.382992 \\ \mathrm{C} & -5.070816 & -1.497230 & -0.230308 \\ \mathrm{C} & -6.395170 & -0.803464 & -0.626380 \\ \mathrm{H} & -7.648312 & 0.875444 & -0.103659 \\ \mathrm{H} & -6.757703 & 0.219114 & 1.247516 \\ \mathrm{H} & -6.742000 & 3.017136 & 1.121803 \\ \mathrm{H} & -5.536945 & 2.171926 & 2.099371 \\ \mathrm{H} & -5.030910 & 3.443401 & 0.968961 \\ \mathrm{H} & -6.769434 & 2.763768 & -1.397206 \\ \mathrm{H} & -5.753905 & 1.574736 & -2.223565 \\ \mathrm{H} & -5.023887 & 3.035232 & -1.532462 \\ \mathrm{C} & -4.735694 & -2.582318 & -1.275299 \\ \mathrm{C} & -5.195395 & -2.162172 & 1.166956 \\ \mathrm{H} & -7.210301 & -1.519477 & -0.487443 \\ \mathrm{H} & -6.375383 & -0.570078 & -1.696737 \\ \mathrm{H} & -3.892994 & -3.207519 & -0.966237 \\ \mathrm{H} & -4.517001 & -2.147868 & -2.255938 \\ \mathrm{H} & -5.597641 & -3.244376 & -1.392785 \\ \mathrm{H} & -5.980421 & -2.922656 & 1.137579 \\ \mathrm{H} & -4.258316 & -2.651092 & 1.450176 \\ \mathrm{H} & -5.452354 & -1.445650 & 1.951128 \\ \mathrm{O} & 1.072468 & -0.799723 & -2.422122 \\ \mathrm{H} & 0.507490 & -0.960823 & -3.193120 \\ \mathrm{H} & 1.940859 & -0.528581 & -2.763304 \\ \mathrm{O} & -0.891016 & -2.711195 & -0.747424 \\ \mathrm{H} & -0.937396 & -3.389971 & -1.436631 \\ \mathrm{H} & -1.797976 & -2.300532 & -0.622749 \\ \mathrm{O} & 0.284227 & -2.811007 & 1.796930 \\ \mathrm{H} & 0.839142 & -3.082136 & 2.545044 \\ \mathrm{H} & -0.241873 & -3.581606 & 1.530239 \\ \mathrm{O} & 1.234487 & -0.242637 & 2.511363 \\ \mathrm{H} & 0.719288 & -0.264657 & 3.332589 \\ \mathrm{H} & 2.003721 & 0.326704 & 2.676483 \\ \mathrm{H} & 3.588414 & -1.678938 & -0.120393 \\ \mathrm{O} & 2.786937 & -2.330448 & -0.100823 \\ \mathrm{H} & 3.095887 & -3.246066 & -0.132427\end{array}$

$\mathrm{M}=\mathrm{Cm}$

CM $\quad 0.761516 \quad-0.939422 \quad 0.142558$ 


\begin{tabular}{|c|c|c|c|}
\hline 0 & 0.095408 & -2.637924 & 1.930865 \\
\hline 1 & -0.418546 & -3.429921 & 1.708117 \\
\hline $\mathrm{O}$ & -0.826346 & -2.706776 & -0.784873 \\
\hline $\mathrm{H}$ & -0.859298 & -3.460203 & -1.392035 \\
\hline & 2.734927 & -2.377046 & -0.025299 \\
\hline & 3.035554 & -3.295904 & -0.048202 \\
\hline$U$ & 1.397302 & -0.223203 & 2.535380 \\
\hline 1 & 2.253671 & 0.227241 & 2.624277 \\
\hline 0 & 1.026872 & -0.712464 & -2.342343 \\
\hline $\mathrm{H}$ & 0.544735 & -1.078150 & -3.099509 \\
\hline $\mathrm{H}$ & 3.538690 & -1.746711 & -0.116275 \\
\hline H & 1.846534 & -0.320635 & -2.686118 \\
\hline $\mathrm{H}$ & 0.594193 & -2.834304 & 2.739529 \\
\hline H & -1.743843 & -2.325016 & -0.677379 \\
\hline $\mathrm{H}$ & 0.890660 & -0.018487 & 3.336838 \\
\hline $\mathrm{C}$ & 1.545474 & 2.407754 & 0.032203 \\
\hline $\mathrm{C}$ & 1.441049 & 3.810656 & 0.073918 \\
\hline $\mathrm{C}$ & 0.181222 & 4.395678 & 0.146377 \\
\hline $\mathrm{H}$ & 2.337510 & 4.419609 & 0.047199 \\
\hline $\mathrm{C}$ & -0.779562 & 2.197427 & 0.109567 \\
\hline $\mathrm{C}$ & -0.959046 & 3.576681 & 0.160101 \\
\hline H & 0.079399 & 5.475998 & 0.182812 \\
\hline $\mathrm{H}$ & -1.959235 & 3.988397 & 0.198656 \\
\hline $\mathrm{C}$ & -1.941637 & 1.273158 & 0.057208 \\
\hline $\mathrm{C}$ & -4.210383 & 0.949694 & -0.029036 \\
\hline $\mathrm{C}$ & -3.956204 & -0.463125 & -0.190447 \\
\hline $\mathrm{N}$ & 0.442472 & 1.618387 & 0.061962 \\
\hline N & -3.179539 & 1.784345 & 0.068906 \\
\hline $\mathrm{N}$ & -1.673944 & -0.036370 & -0.036605 \\
\hline $\mathrm{N}$ & -2.700020 & -0.894460 & -0.186445 \\
\hline $\mathrm{C}$ & -5.604951 & 1.549607 & -0.026003 \\
\hline $\mathrm{C}$ & -6.674755 & 0.444973 & 0.121036 \\
\hline $\mathrm{H}$ & -6.769060 & 0.166800 & 1.175861 \\
\hline $\mathrm{H}$ & -7.643140 & 0.864007 & -0.165715 \\
\hline $\mathrm{C}$ & -6.381333 & -0.797074 & -0.723978 \\
\hline $\mathrm{C}$ & -5.063166 & -1.503313 & -0.329498 \\
\hline . & -6.345076 & -0.529901 & -1.785963 \\
\hline $\mathrm{H}$ & -7.198540 & -1.516686 & -0.620406 \\
\hline $\mathrm{C}$ & -5.736721 & 2.565955 & 1.131071 \\
\hline $\mathrm{H}$ & -5.039788 & 3.398172 & 1.018456 \\
\hline $\mathrm{H}$ & -6.753023 & 2.968972 & 1.135427 \\
\hline $\mathrm{H}$ & -5.561677 & 2.093062 & 2.102645 \\
\hline $\mathrm{C}$ & -5.772725 & 2.301076 & -1.378092 \\
\hline 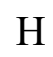 & -6.750046 & 2.790493 & -1.389914 \\
\hline $\mathrm{H}$ & -5.003284 & 3.068106 & -1.494280 \\
\hline $\mathrm{H}$ & -5.721846 & 1.628663 & -2.239057 \\
\hline
\end{tabular}




$\begin{array}{cccc}\mathrm{C} & -5.211687 & -2.217133 & 1.040832 \\ \mathrm{H} & -5.994107 & -2.977613 & 0.970487 \\ \mathrm{H} & -4.278674 & -2.713875 & 1.323887 \\ \mathrm{H} & -5.484647 & -1.529022 & 1.844833 \\ \mathrm{C} & -4.708173 & -2.550373 & -1.406354 \\ \mathrm{H} & -3.867495 & -3.182613 & -1.106082 \\ \mathrm{H} & -5.565730 & -3.210645 & -1.560435 \\ \mathrm{H} & -4.475019 & -2.081355 & -2.367461 \\ \mathrm{C} & 2.818457 & 1.698672 & -0.054319 \\ \mathrm{C} & 4.154123 & 2.090800 & -0.131804 \\ \mathrm{C} & 4.864749 & 0.873849 & -0.206078 \\ \mathrm{H} & 4.589130 & 3.079128 & -0.141658 \\ \mathrm{~N} & 2.762272 & 0.330403 & -0.081532 \\ \mathrm{~N} & 4.014535 & -0.169778 & -0.172756 \\ \mathrm{C} & 6.347993 & 0.749594 & -0.305597 \\ \mathrm{O} & 7.074801 & 1.726836 & -0.324672 \\ \mathrm{O} & 6.754773 & -0.530010 & -0.368313 \\ \mathrm{C} & 8.195412 & -0.715058 & -0.468783 \\ \mathrm{H} & 8.689352 & -0.285736 & 0.404781 \\ \mathrm{H} & 8.344231 & -1.793089 & -0.509939 \\ \mathrm{H} & 8.571752 & -0.234252 & -1.373525\end{array}$

\section{$\left[\mathrm{ML}_{2}\left(\mathrm{H}_{2} \mathrm{O}\right)_{2}\right]^{1+}$}

$\begin{array}{lccc}\mathrm{M}=\mathrm{Eu} & & & \\ \mathrm{EU} & -0.545995 & -0.689416 & -0.054012 \\ \mathrm{O} & 0.520655 & -1.383721 & -2.233939 \\ \mathrm{H} & 1.441222 & -1.683988 & -2.037949 \\ \mathrm{O} & -0.521959 & -2.996636 & 0.899723 \\ \mathrm{H} & -0.418539 & -3.360978 & 1.788102 \\ \mathrm{H} & 0.110266 & -2.006847 & -2.849493 \\ \mathrm{H} & -1.317075 & -3.457764 & 0.458274 \\ \mathrm{C} & -0.215486 & 0.358842 & 3.219630 \\ \mathrm{C} & 0.294391 & 0.608243 & 4.515975 \\ \mathrm{C} & 1.619947 & 0.311764 & 4.794982 \\ \mathrm{H} & -0.356119 & 1.027816 & 5.274306 \\ \mathrm{C} & 1.860847 & -0.450667 & 2.531645 \\ \mathrm{C} & 2.431730 & -0.226545 & 3.782463 \\ \mathrm{H} & 2.027958 & 0.495643 & 5.784213 \\ \mathrm{H} & 3.472846 & -0.468740 & 3.949041 \\ \mathrm{C} & 2.673210 & -1.018578 & 1.423599 \\ \mathrm{C} & 4.668414 & -1.858792 & 0.673181 \\ \mathrm{C} & 4.050361 & -2.059935 & -0.603442 \\ \mathrm{~N} & 0.569701 & -0.175937 & 2.250330 \\ \mathrm{~N} & 3.952646 & -1.342544 & 1.666444\end{array}$




\begin{tabular}{|c|c|c|c|}
\hline $\mathrm{N}$ & 2.072066 & -1.180501 & 0.237814 \\
\hline $\mathrm{N}$ & 2.777782 & -1.706388 & -0.767623 \\
\hline $\mathrm{C}$ & 6.109289 & -2.251295 & 0.973925 \\
\hline $\mathrm{C}$ & 6.878546 & -2.515693 & -0.339057 \\
\hline $\mathrm{H}$ & 7.176130 & -1.559224 & -0.782919 \\
\hline H & 7.809061 & -3.038176 & -0.096444 \\
\hline C & 6.076057 & -3.332879 & -1.354936 \\
\hline $\mathrm{C}$ & 4.780091 & -2.628520 & -1.818054 \\
\hline $\mathrm{H}$ & 5.822307 & -4.310366 & -0.929815 \\
\hline $\mathrm{H}$ & 6.691522 & -3.536054 & -2.236922 \\
\hline $\mathrm{C}$ & 6.808529 & -1.126765 & 1.766741 \\
\hline H & 6.322101 & -0.952592 & 2.728090 \\
\hline H & 7.848952 & -1.409299 & 1.952668 \\
\hline $\mathrm{H}$ & 6.811057 & -0.186025 & 1.206700 \\
\hline 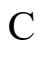 & 6.060522 & -3.529831 & 1.852491 \\
\hline $\mathrm{H}$ & 7.078972 & -3.818882 & 2.127465 \\
\hline $\mathrm{H}$ & 5.495974 & -3.344255 & 2.769827 \\
\hline $\mathrm{H}$ & 5.597636 & -4.373932 & 1.333550 \\
\hline $\mathrm{C}$ & 5.105541 & -1.452131 & -2.773907 \\
\hline $\mathrm{H}$ & 5.604699 & -1.834278 & -3.669231 \\
\hline $\mathrm{H}$ & 4.189857 & -0.941517 & -3.085415 \\
\hline H & 5.763088 & -0.710865 & -2.311441 \\
\hline $\mathrm{C}$ & 3.893318 & -3.649253 & -2.562375 \\
\hline $\mathrm{H}$ & 3.022610 & -3.177349 & -3.023418 \\
\hline $\mathrm{H}$ & 4.475737 & -4.117153 & -3.361591 \\
\hline $\mathrm{H}$ & 3.542648 & -4.441432 & -1.893981 \\
\hline $\mathrm{C}$ & -1.581985 & 0.665841 & 2.854406 \\
\hline $\mathrm{C}$ & -2.649032 & 1.209493 & 3.578992 \\
\hline $\mathrm{C}$ & -3.687866 & 1.265881 & 2.640012 \\
\hline $\mathrm{H}$ & -2.699939 & 1.522023 & 4.610947 \\
\hline $\mathrm{N}$ & -2.002473 & 0.424191 & 1.560213 \\
\hline $\mathrm{N}$ & -3.277211 & 0.787388 & 1.428638 \\
\hline $\mathrm{C}$ & -5.053411 & 1.773821 & 2.911373 \\
\hline $\mathrm{O}$ & -5.395406 & 2.205311 & 4.004425 \\
\hline $\mathrm{O}$ & -5.866076 & 1.708324 & 1.835416 \\
\hline $\mathrm{C}$ & -7.214283 & 2.176057 & 2.060972 \\
\hline $\mathrm{H}$ & -7.209791 & 3.227333 & 2.359252 \\
\hline $\mathrm{H}$ & -7.728320 & 2.046632 & 1.108503 \\
\hline $\mathrm{H}$ & -7.697065 & 1.585417 & 2.843121 \\
\hline $\mathrm{C}$ & -3.218246 & -0.239162 & -2.207640 \\
\hline $\mathrm{C}$ & -4.174251 & 0.367685 & -3.044328 \\
\hline $\mathrm{C}$ & -4.006770 & 1.697394 & -3.412949 \\
\hline $\mathrm{H}$ & -5.030230 & -0.203843 & -3.383832 \\
\hline $\mathrm{C}$ & -1.985389 & 1.733814 & -2.124636 \\
\hline $\mathrm{C}$ & -2.888504 & 2.403149 & -2.948094 \\
\hline $\mathrm{H}$ & -4.735253 & 2.185315 & -4.053291 \\
\hline
\end{tabular}




$\begin{array}{lrrr}\mathrm{H} & -2.712836 & 3.438989 & -3.206295 \\ \mathrm{C} & -0.777991 & 2.420950 & -1.600062 \\ \mathrm{C} & 0.517180 & 4.298610 & -1.439543 \\ \mathrm{C} & 1.396157 & 3.561539 & -0.586354 \\ \mathrm{~N} & -2.141358 & 0.446100 & -1.760078 \\ \mathrm{~N} & -0.567566 & 3.702148 & -1.927413 \\ \mathrm{~N} & 0.045295 & 1.702102 & -0.820538 \\ \mathrm{~N} & 1.135706 & 2.281699 & -0.316371 \\ \mathrm{C} & 0.734841 & 5.762724 & -1.801241 \\ \mathrm{C} & 2.174784 & 6.192775 & -1.444239 \\ \mathrm{H} & 2.861047 & 5.836086 & -2.220569 \\ \mathrm{H} & 2.227927 & 7.285691 & -1.472818 \\ \mathrm{C} & 2.632491 & 5.686641 & -0.073584 \\ \mathrm{C} & 2.668578 & 4.144800 & 0.025619 \\ \mathrm{H} & 1.972441 & 6.081702 & 0.706634 \\ \mathrm{H} & 3.632202 & 6.072737 & 0.150554 \\ \mathrm{C} & 0.490795 & 5.974543 & -3.310463 \\ \mathrm{H} & -0.536137 & 5.730044 & -3.587314 \\ \mathrm{H} & 0.676695 & 7.022697 & -3.563472 \\ \mathrm{H} & 1.164939 & 5.358175 & -3.914041 \\ \mathrm{C} & -0.305027 & 6.592958 & -1.003175 \\ \mathrm{H} & -0.209810 & 7.648995 & -1.272399 \\ \mathrm{H} & -1.320664 & 6.266964 & -1.241303 \\ \mathrm{H} & -0.166401 & 6.504820 & 0.078056 \\ \mathrm{C} & 3.879221 & 3.572026 & -0.752839 \\ \mathrm{H} & 4.810539 & 3.945795 & -0.316294 \\ \mathrm{H} & 3.884595 & 2.479719 & -0.696436 \\ \mathrm{H} & 3.864060 & 3.854256 & -1.809398 \\ \mathrm{C} & 2.785719 & 3.733764 & 1.508135 \\ \mathrm{H} & 2.865413 & 2.650513 & 1.617939 \\ \mathrm{H} & 3.678176 & 4.193706 & 1.944089 \\ \mathrm{H} & 1.917999 & 4.072129 & 2.083109 \\ \mathrm{C} & -3.310479 & -1.626607 & -1.770003 \\ \mathrm{C} & -4.215894 & -2.662946 & -2.012063 \\ \mathrm{C} & -3.708809 & -3.734654 & -1.253479 \\ \mathrm{H} & -5.107133 & -2.677510 & -2.620789 \\ \mathrm{~N} & -2.339006 & -2.078565 & -0.926894 \\ \mathrm{H} & -4.307489 & -5.084893 & -1.156331 \\ \mathrm{H} & -3.615280 & -5.415621 & -1.762437 \\ \mathrm{H} & -7.234685 & -0.192527 \\ \mathrm{H} & -7.738986 & -1.161445 \\ \mathrm{H} & -7.754859 & 0.497422 \\ \mathrm{H} & -7.188087 & 0.210048\end{array}$


$\mathrm{M}=\mathrm{Gd}$

$\begin{array}{lrrr}\mathrm{GD} & -0.556380 & -0.683344 & -0.039226 \\ \mathrm{O} & 0.465844 & -1.380124 & -2.193154 \\ \mathrm{H} & 1.391332 & -1.686702 & -2.022635 \\ \mathrm{O} & -0.518980 & -2.942061 & 0.932383 \\ \mathrm{H} & -0.412349 & -3.269527 & 1.834830 \\ \mathrm{H} & 0.038379 & -1.982026 & -2.818171 \\ \mathrm{H} & -1.317461 & -3.418740 & 0.508828 \\ \mathrm{C} & -0.236546 & 0.393195 & 3.183181 \\ \mathrm{C} & 0.271756 & 0.654470 & 4.476461 \\ \mathrm{C} & 1.593582 & 0.347017 & 4.763975 \\ \mathrm{H} & -0.377036 & 1.090807 & 5.226897 \\ \mathrm{C} & 1.837392 & -0.443720 & 2.513963 \\ \mathrm{C} & 2.406235 & -0.212144 & 3.762785 \\ \mathrm{H} & 1.998809 & 0.539209 & 5.752843 \\ \mathrm{H} & 3.444236 & -0.461764 & 3.937434 \\ \mathrm{C} & 2.640195 & -1.024051 & 1.407942 \\ \mathrm{C} & 4.622725 & -1.886544 & 0.648512 \\ \mathrm{C} & 3.997387 & -2.081722 & -0.626099 \\ \mathrm{~N} & 0.548873 & -0.159895 & 2.226945 \\ \mathrm{~N} & 3.917176 & -1.361787 & 1.644339 \\ \mathrm{~N} & 2.032050 & -1.182952 & 0.224484 \\ \mathrm{~N} & 2.727756 & -1.716800 & -0.783591 \\ \mathrm{C} & 6.059583 & -2.296748 & 0.943887 \\ \mathrm{C} & 6.821037 & -2.571798 & -0.371459 \\ \mathrm{H} & 7.130411 & -1.619608 & -0.816398 \\ \mathrm{H} & 7.745035 & -3.106890 & -0.131553 \\ \mathrm{C} & 6.004651 & -3.378225 & -1.384885 \\ \mathrm{C} & 4.716684 & -2.656643 & -1.843867 \\ \mathrm{H} & 5.739259 & -4.352365 & -0.959189 \\ \mathrm{H} & 6.614583 & -3.589261 & -2.268857 \\ \mathrm{H} & 6.775594 & -1.180856 & 1.734008 \\ \mathrm{H} & 6.294137 & -0.999890 & 2.696561 \\ \mathrm{H} & 7.812771 & -1.476851 & 1.917017 \\ \mathrm{H} & 6.788761 & -0.240581 & 1.173339 \\ \mathrm{C} & 5.997202 & -3.574178 & 1.823455 \\ \mathrm{H} & 7.012840 & -3.875987 & 2.095015 \\ \mathrm{H} & 5.438319 & -3.380716 & 2.742593 \\ \mathrm{H} & 5.521811 & -4.412607 & 1.306593 \\ \mathrm{C} & 5.055043 & -1.482103 & -2.797558 \\ \mathrm{H} & 5.548234 & -1.868210 & -3.694474 \\ \mathrm{H} & 3.722116 & -0.749805 & -2.334519 \\ \mathrm{H} & -3.664232 & -2.588800 \\ \mathrm{H} & -3.180125 & -3.048500\end{array}$




\begin{tabular}{|c|c|c|c|}
\hline $\mathrm{H}$ & 4.390720 & -4.138380 & -3.389577 \\
\hline & 3.455283 & -4.452960 & -1.921463 \\
\hline $\mathrm{C}$ & -1.598361 & 0.700391 & 2.793459 \\
\hline $\mathrm{C}$ & -2.668432 & 1.280321 & 3.473752 \\
\hline $\mathrm{C}$ & -3.692079 & 1.315641 & 2.506423 \\
\hline H & -2.736262 & 1.630035 & 4.492832 \\
\hline $\mathrm{N}$ & -1.993947 & 0.418170 & 1.504654 \\
\hline $\mathrm{N}$ & -3.270185 & 0.795200 & 1.330258 \\
\hline $\mathrm{C}$ & -5.054902 & 1.849526 & 2.737051 \\
\hline $\mathrm{O}$ & -5.410687 & 2.323571 & 3.808084 \\
\hline $\mathrm{O}$ & -5.853630 & 1.758041 & 1.650925 \\
\hline $\mathrm{C}$ & -7.197908 & 2.250001 & 1.842006 \\
\hline $\mathrm{H}$ & -7.184660 & 3.310792 & 2.104412 \\
\hline $\mathrm{H}$ & -7.701439 & 2.094734 & 0.887596 \\
\hline $\mathrm{H}$ & -7.699550 & 1.692956 & 2.636888 \\
\hline $\mathrm{C}$ & -3.208705 & -0.216031 & -2.162762 \\
\hline $\mathrm{C}$ & -4.163385 & 0.402640 & -2.990658 \\
\hline $\mathrm{C}$ & -3.982520 & 1.732079 & -3.356279 \\
\hline $\mathrm{H}$ & -5.029354 & -0.156902 & -3.324785 \\
\hline $\mathrm{C}$ & -1.952129 & 1.742132 & -2.083210 \\
\hline $\mathrm{C}$ & -2.853430 & 2.424633 & -2.897584 \\
\hline $\mathrm{H}$ & -4.710445 & 2.230414 & -3.989173 \\
\hline $\mathrm{H}$ & -2.669785 & 3.459742 & -3.153128 \\
\hline $\mathrm{C}$ & -0.732850 & 2.407896 & -1.559142 \\
\hline $\mathrm{C}$ & 0.589503 & 4.265929 & -1.394051 \\
\hline $\mathrm{C}$ & 1.462617 & 3.510944 & -0.549979 \\
\hline $\mathrm{N}$ & -2.120690 & 0.455642 & -1.723761 \\
\hline $\mathrm{N}$ & -0.505001 & 3.687200 & -1.881245 \\
\hline $\mathrm{N}$ & 0.082646 & 1.673061 & -0.784923 \\
\hline $\mathrm{N}$ & 1.185691 & 2.234309 & -0.284335 \\
\hline $\mathrm{C}$ & 0.824373 & 5.729508 & -1.745662 \\
\hline $\mathrm{C}$ & 2.272424 & 6.137351 & -1.395747 \\
\hline $\mathrm{H}$ & 2.948360 & 5.777114 & -2.179477 \\
\hline $\mathrm{H}$ & 2.340166 & 7.229614 & -1.416830 \\
\hline $\mathrm{C}$ & 2.732482 & 5.615187 & -0.031969 \\
\hline $\mathrm{C}$ & 2.747534 & 4.072346 & 0.056685 \\
\hline $\mathrm{H}$ & 2.083665 & 6.014079 & 0.755636 \\
\hline $\mathrm{H}$ & 3.739113 & 5.985518 & 0.187704 \\
\hline $\mathrm{C}$ & 0.571803 & 5.957675 & -3.251076 \\
\hline $\mathrm{H}$ & -0.460397 & 5.729642 & -3.522244 \\
\hline $\mathrm{H}$ & 0.770040 & 7.005409 & -3.496260 \\
\hline $\mathrm{H}$ & 1.233024 & 5.337667 & -3.865152 \\
\hline $\mathrm{C}$ & -0.198666 & 6.566346 & -0.932504 \\
\hline $\mathrm{H}$ & -0.090857 & 7.623342 & -1.193027 \\
\hline $\mathrm{H}$ & -1.220286 & 6.256335 & -1.166271 \\
\hline $\mathrm{H}$ & -0.053776 & 6.466530 & 0.146859 \\
\hline
\end{tabular}




$\begin{array}{llll}\mathrm{C} & 3.944218 & 3.488095 & -0.734738 \\ \mathrm{H} & 4.883818 & 3.846063 & -0.302773 \\ \mathrm{H} & 3.935000 & 2.395447 & -0.685301 \\ \mathrm{H} & 3.925220 & 3.777443 & -1.789328 \\ \mathrm{C} & 2.869893 & 3.649991 & 1.535562 \\ \mathrm{H} & 2.937219 & 2.565288 & 1.638393 \\ \mathrm{H} & 3.770911 & 4.096346 & 1.968006 \\ \mathrm{H} & 2.010452 & 3.995018 & 2.118872 \\ \mathrm{C} & -3.307466 & -1.602389 & -1.719732 \\ \mathrm{C} & -4.220071 & -2.634633 & -1.945881 \\ \mathrm{C} & -3.713563 & -3.704335 & -1.182441 \\ \mathrm{H} & -5.117263 & -2.647640 & -2.545788 \\ \mathrm{~N} & -2.331566 & -2.054682 & -0.880918 \\ \mathrm{~N} & -2.579578 & -3.331150 & -0.547928 \\ \mathrm{C} & -4.321187 & -5.050097 & -1.069951 \\ \mathrm{O} & -5.334518 & -5.378324 & -1.668426 \\ \mathrm{O} & -3.633118 & -5.866499 & -0.238063 \\ \mathrm{C} & -4.191989 & -7.191485 & -0.086301 \\ \mathrm{H} & -4.223829 & -7.704884 & -1.050141 \\ \mathrm{H} & -3.527009 & -7.709304 & 0.605032 \\ \mathrm{H} & -5.203770 & -7.133476 & 0.321528\end{array}$

$\mathrm{M}=\mathrm{Am}$

$\begin{array}{lrrr}\text { AM } & -0.455251 & -0.679933 & -0.011983 \\ \mathrm{O} & 0.660522 & -1.426794 & -2.171558 \\ \mathrm{H} & 1.601780 & -1.652135 & -1.958001 \\ \mathrm{O} & -0.228556 & -2.964480 & 1.060937 \\ \mathrm{H} & -0.220570 & -3.221695 & 1.992608 \\ \mathrm{H} & 0.272318 & -2.147979 & -2.687329 \\ \mathrm{H} & -0.944140 & -3.514762 & 0.591520 \\ \mathrm{C} & -0.068976 & 0.580733 & 3.212597 \\ \mathrm{C} & 0.463865 & 0.966502 & 4.462565 \\ \mathrm{C} & 1.819768 & 0.799158 & 4.705077 \\ \mathrm{H} & -0.191629 & 1.384437 & 5.217682 \\ \mathrm{C} & 2.041295 & -0.105744 & 2.495562 \\ \mathrm{C} & 2.636688 & 0.250823 & 3.702924 \\ \mathrm{H} & 2.246171 & 1.087647 & 5.661058 \\ \mathrm{H} & 3.698177 & 0.099818 & 3.845994 \\ \mathrm{C} & 2.852253 & -0.690570 & 1.397210 \\ \mathrm{C} & 4.878736 & -1.434551 & 0.625151 \\ \mathrm{C} & 4.234869 & -1.764155 & -0.611553 \\ \mathrm{~N} & 0.723683 & 0.050551 & 2.250058 \\ \mathrm{~N} & 4.160720 & -0.903731 & 1.608594 \\ \mathrm{~N} & 2.224032 & -0.979880 & 0.250386 \\ \mathrm{~N} & 2.935068 & -1.517045 & -0.746051\end{array}$




\begin{tabular}{|c|c|c|c|}
\hline $\mathrm{C}$ & 6.353442 & -1.703864 & 0.895148 \\
\hline C & 7.096231 & -1.995177 & -0.427406 \\
\hline $\mathrm{H}$ & 7.306500 & -1.049868 & -0.939827 \\
\hline I & 8.070670 & -2.432372 & -0.188682 \\
\hline C & 6.323851 & -2.931373 & -1.360623 \\
\hline $\mathrm{C}$ & 4.963942 & -2.354120 & -1.816489 \\
\hline $\mathrm{H}$ & 6.158336 & -3.895792 & -0.867569 \\
\hline $\mathrm{H}$ & 6.923110 & -3.144659 & -2.251311 \\
\hline $\mathrm{C}$ & 6.994520 & -0.485277 & 1.592271 \\
\hline $\mathrm{H}$ & 6.528611 & -0.286170 & 2.558889 \\
\hline $\mathrm{H}$ & 8.058364 & -0.681204 & 1.755827 \\
\hline $\mathrm{H}$ & 6.909981 & 0.416394 & 0.977111 \\
\hline $\mathrm{C}$ & 6.426371 & -2.925109 & 1.850449 \\
\hline $\mathrm{H}$ & 7.471552 & -3.123555 & 2.104735 \\
\hline $\mathrm{H}$ & 5.879664 & -2.722611 & 2.774978 \\
\hline $\mathrm{H}$ & 6.009724 & -3.830807 & 1.400803 \\
\hline $\mathrm{C}$ & 5.168285 & -1.220083 & -2.853700 \\
\hline $\mathrm{H}$ & 5.663414 & -1.621104 & -3.743002 \\
\hline $\mathrm{H}$ & 4.207277 & -0.797081 & -3.160070 \\
\hline $\mathrm{H}$ & 5.784597 & -0.405665 & -2.462934 \\
\hline $\mathrm{C}$ & 4.132076 & -3.482274 & -2.462842 \\
\hline $\mathrm{H}$ & 3.215357 & -3.105367 & -2.922372 \\
\hline $\mathrm{H}$ & 4.722416 & -3.958912 & -3.250996 \\
\hline $\mathrm{H}$ & 3.861413 & -4.251829 & -1.733573 \\
\hline $\mathrm{C}$ & -1.473284 & 0.720259 & 2.877462 \\
\hline $\mathrm{C}$ & -2.568373 & 1.236410 & 3.566992 \\
\hline $\mathrm{C}$ & -3.634760 & 1.080754 & 2.657615 \\
\hline $\mathrm{H}$ & -2.628317 & 1.662257 & 4.557097 \\
\hline $\mathrm{N}$ & -1.896180 & 0.291038 & 1.641597 \\
\hline $\mathrm{N}$ & -3.213660 & 0.510671 & 1.505840 \\
\hline $\mathrm{C}$ & -5.036129 & 1.483092 & 2.921341 \\
\hline $\mathrm{O}$ & -5.390521 & 2.008222 & 3.968638 \\
\hline $\mathrm{O}$ & -5.869938 & 1.211062 & 1.893847 \\
\hline $\mathrm{C}$ & -7.250800 & 1.569491 & 2.119101 \\
\hline $\mathrm{H}$ & -7.344934 & 2.644590 & 2.291175 \\
\hline $\mathrm{H}$ & -7.777618 & 1.276201 & 1.210863 \\
\hline $\mathrm{H}$ & -7.648366 & 1.034232 & 2.984655 \\
\hline $\mathrm{C}$ & -3.201792 & -0.557496 & -2.153514 \\
\hline $\mathrm{C}$ & -4.234729 & -0.080804 & -2.981173 \\
\hline $\mathrm{C}$ & -4.231582 & 1.255328 & -3.366075 \\
\hline $\mathrm{H}$ & -5.020618 & -0.753480 & -3.304275 \\
\hline $\mathrm{C}$ & -2.209550 & 1.547602 & -2.113362 \\
\hline $\mathrm{C}$ & -3.196905 & 2.094358 & -2.930449 \\
\hline $\mathrm{H}$ & -5.022203 & 1.645185 & -3.999810 \\
\hline $\mathrm{H}$ & -3.148345 & 3.138897 & -3.207909 \\
\hline $\mathrm{C}$ & -1.073652 & 2.372172 & -1.628176 \\
\hline
\end{tabular}




$\begin{array}{rrrr}\mathrm{C} & -0.000379 & 4.387672 & -1.511594 \\ \mathrm{C} & 0.988287 & 3.760152 & -0.691020 \\ \mathrm{~N} & -2.212131 & 0.257593 & -1.726425 \\ \mathrm{~N} & -1.026400 & 3.668406 & -1.960148 \\ \mathrm{~N} & -0.142758 & 1.754968 & -0.883509 \\ \mathrm{~N} & 0.890277 & 2.459703 & -0.415808 \\ \mathrm{C} & 0.034907 & 5.865077 & -1.881225 \\ \mathrm{C} & 1.428572 & 6.457801 & -1.577861 \\ \mathrm{H} & 2.122651 & 6.175150 & -2.377451 \\ \mathrm{H} & 1.356550 & 7.549458 & -1.611861 \\ \mathrm{C} & 1.988994 & 6.016470 & -0.223011 \\ \mathrm{C} & 2.203744 & 4.489347 & -0.120833 \\ \mathrm{H} & 1.316287 & 6.339623 & 0.579203 \\ \mathrm{H} & 2.945637 & 6.514936 & -0.035935 \\ \mathrm{C} & -0.286543 & 6.040675 & -3.380646 \\ \mathrm{H} & -1.288725 & 5.680589 & -3.619404 \\ \mathrm{H} & -0.229753 & 7.101893 & -3.640984 \\ \mathrm{H} & 0.430639 & 5.501678 & -4.008203 \\ \mathrm{C} & -1.063536 & 6.574308 & -1.045678 \\ \mathrm{H} & -1.099141 & 7.633348 & -1.317559 \\ \mathrm{H} & -2.043164 & 6.133649 & -1.247218 \\ \mathrm{H} & -0.877218 & 6.506260 & 0.029748 \\ \mathrm{C} & 3.447952 & 4.053476 & -0.934301 \\ \mathrm{H} & 4.343493 & 4.531082 & -0.525058 \\ \mathrm{H} & 3.578133 & 2.968995 & -0.878151 \\ \mathrm{H} & 3.370777 & 4.328975 & -1.989947 \\ \mathrm{C} & 2.410818 & 4.102964 & 1.358692 \\ \mathrm{H} & 2.615978 & 3.036411 & 1.468885 \\ \mathrm{H} & 3.258031 & 4.663540 & 1.766208 \\ \mathrm{H} & 1.527787 & 4.344478 & 1.958688 \\ \mathrm{C} & -3.116473 & -1.941584 & -1.701325 \\ \mathrm{C} & -3.902722 & -3.075478 & -1.909534 \\ \mathrm{C} & -3.261328 & -4.073677 & -1.151021 \\ \mathrm{H} & -4.802391 & -3.197473 & -2.493124 \\ \mathrm{~N} & -2.080187 & -2.270140 & -0.877572 \\ \mathrm{~N} & -2.169940 & -3.567378 & -0.536625 \\ \mathrm{C} & -3.705511 & -5.480737 & -1.022001 \\ \mathrm{O} & -4.679715 & -5.930125 & -1.606395 \\ \mathrm{O} & -2.918029 & -6.203423 & -0.191886 \\ \mathrm{C} & -3.314732 & -7.584023 & -0.024710 \\ \mathrm{H} & -3.295647 & -8.105272 & -0.984642 \\ \mathrm{H} & -2.585867 & -8.013834 & 0.662493 \\ \mathrm{H} & -4.321952 & -7.642599 & 0.394173 \\ & & & \\ \mathrm{M}=\mathrm{Cm} & & & \\ & & & \end{array}$




\begin{tabular}{|c|c|c|c|}
\hline CM & -0.396201 & -0.692509 & $\begin{array}{ll}9 & -0.036740\end{array}$ \\
\hline $\mathrm{O}$ & 0.749446 & -1.219146 & -2.266158 \\
\hline $\mathrm{H}$ & 1.698264 & -1.410195 & -2.060450 \\
\hline ) & 0.008634 & -2.977451 & 0.969171 \\
\hline $\mathrm{H}$ & 0.099703 & -3.253219 & 1.890871 \\
\hline $\mathrm{H}$ & 0.419927 & -1.889450 & -2.881157 \\
\hline$\pi$ & -0.709533 & -3.557443 & 0.536547 \\
\hline & -0.143608 & 0.418503 & 3.221735 \\
\hline 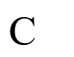 & 0.349325 & 0.748037 & 4.504756 \\
\hline $\mathrm{C}$ & 1.704337 & 0.612606 & 4.769790 \\
\hline $\mathrm{H}$ & -0.335986 & 1.101866 & 5.266086 \\
\hline $\mathrm{C}$ & 2.008702 & -0.150609 & 2.517424 \\
\hline $\mathrm{C}$ & 2.564268 & 0.156870 & 3.756313 \\
\hline $\mathrm{H}$ & 2.098657 & 0.859389 & 5.750962 \\
\hline $\mathrm{H}$ & 3.628232 & 0.041846 & 3.914168 \\
\hline $\mathrm{C}$ & 2.865097 & -0.626206 & 1.399951 \\
\hline $\mathrm{C}$ & 4.932801 & -1.239079 & 0.623203 \\
\hline $\mathrm{C}$ & 4.327285 & -1.501812 & -0.648610 \\
\hline $\mathrm{N}$ & 0.689872 & -0.033524 & 2.253940 \\
\hline $\mathrm{N}$ & 4.175514 & -0.808253 & 1.626233 \\
\hline $\mathrm{N}$ & 2.273612 & -0.850515 & 0.218784 \\
\hline $\mathrm{N}$ & 3.022396 & -1.290728 & -0.797086 \\
\hline $\mathrm{C}$ & 6.410991 & -1.472368 & 0.907611 \\
\hline $\mathrm{C}$ & 7.190907 & -1.648483 & -0.413941 \\
\hline $\mathrm{H}$ & 7.378975 & -0.664186 & -0.856822 \\
\hline $\mathrm{H}$ & 8.174697 & -2.068250 & -0.182517 \\
\hline $\mathrm{C}$ & 6.471076 & -2.544190 & -1.425527 \\
\hline $\mathrm{C}$ & 5.102441 & -1.981660 & -1.873537 \\
\hline $\mathrm{H}$ & 6.327790 & -3.544640 & -1.002107 \\
\hline $\mathrm{H}$ & 7.096132 & -2.677200 & -2.314091 \\
\hline $\mathrm{C}$ & 6.991184 & -0.279776 & 1.697177 \\
\hline $\mathrm{H}$ & 6.499203 & -0.162885 & 2.664337 \\
\hline $\mathrm{H}$ & 8.058351 & -0.446723 & 1.870852 \\
\hline $\mathrm{H}$ & 6.884159 & 0.657083 & 1.140877 \\
\hline $\mathrm{C}$ & 6.511119 & -2.750576 & 1.782524 \\
\hline $\mathrm{H}$ & 7.557765 & -2.926757 & 2.046908 \\
\hline $\mathrm{H}$ & 5.938512 & -2.629995 & 2.705673 \\
\hline $\mathrm{H}$ & 6.138572 & -3.639193 & 1.265142 \\
\hline $\mathrm{C}$ & 5.290124 & -0.772189 & -2.825089 \\
\hline $\mathrm{H}$ & 5.817817 & -1.093978 & -3.727786 \\
\hline $\mathrm{H}$ & 4.321848 & -0.360739 & -3.124337 \\
\hline $\mathrm{H}$ & 5.869526 & 0.032866 & -2.364677 \\
\hline $\mathrm{C}$ & 4.324324 & -3.088859 & -2.615766 \\
\hline $\mathrm{H}$ & 3.405946 & -2.710833 & -3.071137 \\
\hline $\mathrm{H}$ & 4.948122 & -3.490619 & -3.419725 \\
\hline $\mathrm{H}$ & 4.063434 & -3.915280 & -1.947716 \\
\hline
\end{tabular}




\begin{tabular}{|c|c|c|c|}
\hline $\mathrm{C}$ & -1.542482 & 0.547986 & 2.859507 \\
\hline $\mathrm{C}$ & -2.660594 & 0.991011 & 3.563649 \\
\hline $\mathrm{C}$ & -3.704464 & 0.892222 & 2.622089 \\
\hline H & -2.747967 & 1.335156 & 4.583002 \\
\hline $\mathrm{N}$ & -1.931690 & 0.211378 & 1.581944 \\
\hline$N$ & -3.249778 & 0.423409 & 1.437638 \\
\hline $\mathrm{C}$ & -5.117420 & 1.251450 & 2.886228 \\
\hline $\mathrm{O}$ & -5.502843 & 1.683655 & 3.964637 \\
\hline $\mathrm{O}$ & -5.925173 & 1.053247 & 1.821335 \\
\hline $\mathrm{C}$ & -7.315646 & 1.373331 & 2.044712 \\
\hline $\mathrm{H}$ & -7.429647 & 2.428948 & 2.303549 \\
\hline $\mathrm{H}$ & -7.818744 & 1.150126 & 1.103642 \\
\hline $\mathrm{H}$ & -7.723478 & 0.762435 & 2.853577 \\
\hline $\mathrm{C}$ & -3.142443 & -0.708277 & -2.155223 \\
\hline $\mathrm{C}$ & -4.200449 & -0.280815 & -2.978402 \\
\hline $\mathrm{C}$ & -4.266078 & 191 & -3.358014 \\
\hline $\mathrm{H}$ & -4.953590 & -0.990856 & -3.299695 \\
\hline $\mathrm{C}$ & -2.261425 & 1.446463 & -2.103829 \\
\hline $\mathrm{C}$ & -3.277685 & 1.945341 & -2.916107 \\
\hline $\mathrm{H}$ & -5.077081 & 1.406846 & -3.988443 \\
\hline $\mathrm{H}$ & -3.287433 & 2.993801 & -3.182634 \\
\hline $\mathrm{C}$ & -1.182298 & 2.332377 & -1.596938 \\
\hline $\mathrm{C}$ & -0.232772 & 4.407320 & -1.449259 \\
\hline $\mathrm{C}$ & 0.772550 & 3.836026 & -0.608211 \\
\hline $\mathrm{N}$ & -2.191611 & 0.153925 & -1.731891 \\
\hline $\mathrm{N}$ & -1.202994 & 3.630336 & -1.924869 \\
\hline $\mathrm{N}$ & -0.234117 & 1.769312 & -0.830909 \\
\hline $\mathrm{N}$ & 0.745469 & 2.530983 & -0.338882 \\
\hline $\mathrm{C}$ & -0.278117 & 5.886357 & -1.811102 \\
\hline $\mathrm{C}$ & 1.070052 & 6.560087 & -1.472978 \\
\hline $\mathrm{H}$ & 1.797884 & 6.324635 & -2.257747 \\
\hline $\mathrm{H}$ & 0.933042 & 7.645606 & -1.503459 \\
\hline $\mathrm{C}$ & 1.625375 & 6.145178 & -0.107667 \\
\hline $\mathrm{C}$ & 1.929261 & 4.633120 & -0.007565 \\
\hline $\mathrm{H}$ & 0.916474 & 6.422458 & 0.680408 \\
\hline $\mathrm{H}$ & 2.545817 & 6.699111 & 0.103469 \\
\hline $\mathrm{C}$ & -0.575949 & 6.051868 & -3.316497 \\
\hline $\mathrm{H}$ & -1.548738 & 5.633126 & -3.579914 \\
\hline $\mathrm{H}$ & -0.577942 & 7.116238 & -3.570080 \\
\hline $\mathrm{H}$ & 0.186592 & 5.561437 & -3.930310 \\
\hline $\mathrm{C}$ & -1.435643 & 6.522934 & -0.996968 \\
\hline $\mathrm{H}$ & -1.528400 & 7.579817 & -1.263752 \\
\hline $\mathrm{H}$ & -2.382353 & 6.025897 & -1.223229 \\
\hline $\mathrm{H}$ & -1.269764 & 6.458684 & 0.082057 \\
\hline $\mathrm{C}$ & 3.215082 & 4.277535 & -0.794947 \\
\hline $\mathrm{H}$ & 4.071077 & 4.805017 & -0.362907 \\
\hline
\end{tabular}




$\begin{array}{llll}\mathrm{H} & 3.408672 & 3.202407 & -0.741299 \\ \mathrm{H} & 3.145199 & 4.554994 & -1.850646 \\ \mathrm{C} & 2.126363 & 4.250753 & 1.474438 \\ \mathrm{H} & 2.392987 & 3.197702 & 1.583888 \\ \mathrm{H} & 2.928986 & 4.858813 & 1.903599 \\ \mathrm{H} & 1.217230 & 4.434742 & 2.055537 \\ \mathrm{C} & -2.992507 & -2.086966 & -1.701532 \\ \mathrm{C} & -3.713176 & -3.261399 & -1.923988 \\ \mathrm{C} & -3.029426 & -4.226023 & -1.159268 \\ \mathrm{H} & -4.594604 & -3.430299 & -2.523468 \\ \mathrm{~N} & -1.953191 & -2.362009 & -0.861664 \\ \mathrm{~N} & -1.976637 & -3.662645 & -0.527069 \\ \mathrm{C} & -3.396255 & -5.656232 & -1.043705 \\ \mathrm{O} & -4.337820 & -6.155146 & -1.641406 \\ \mathrm{O} & -2.578624 & -6.339904 & -0.209616 \\ \mathrm{C} & -2.900694 & -7.741120 & -0.054586 \\ \mathrm{H} & -2.842376 & -8.254725 & -1.017075 \\ \mathrm{H} & -2.156998 & -8.134500 & 0.638551 \\ \mathrm{H} & -3.907737 & -7.857446 & 0.352506\end{array}$

\section{$\left[\mathrm{ML}_{2}\right]^{1+}$}

$\mathrm{M}=\mathrm{Eu}$

$\begin{array}{lccc}\text { EU } & 0.000065 & 0.394977 & -0.000028 \\ \mathrm{C} & 0.345937 & 1.633727 & -3.170938 \\ \mathrm{C} & 0.908005 & 1.985625 & -4.415325 \\ \mathrm{C} & 2.132500 & 1.439127 & -4.783490 \\ \mathrm{H} & 0.384120 & 2.674215 & -5.068109 \\ \mathrm{C} & 2.167044 & 0.243100 & -2.708338 \\ \mathrm{C} & 2.784038 & 0.544375 & -3.918519 \\ \mathrm{H} & 2.582702 & 1.701448 & -5.736051 \\ \mathrm{H} & 3.737730 & 0.095849 & -4.164895 \\ \mathrm{C} & 2.764301 & -0.703109 & -1.730996 \\ \mathrm{C} & 4.454409 & -2.085417 & -1.062768 \\ \mathrm{C} & 3.710137 & -2.346824 & 0.133771 \\ \mathrm{~N} & 0.984627 & 0.777188 & -2.340042 \\ \mathrm{~N} & 3.957543 & -1.252346 & -1.976872 \\ \mathrm{~N} & 2.034695 & -0.960338 & -0.633559 \\ \mathrm{~N} & 2.513156 & -1.782840 & 0.300223 \\ \mathrm{C} & 5.824794 & -2.688615 & -1.337899 \\ \mathrm{C} & 6.099367 & -3.859179 & -0.368076 \\ \mathrm{H} & 5.568654 & -4.751172 & -0.719384 \\ \mathrm{H} & 7.165198 & -4.103733 & -0.414256 \\ \mathrm{C} & 5.699140 & -3.551451 & 1.077475 \\ \mathrm{C} & 4.187653 & -3.277249 & 1.245584\end{array}$




$\begin{array}{lrrr}\mathrm{H} & 6.264610 & -2.687627 & 1.443962 \\ \mathrm{H} & 5.972759 & -4.390269 & 1.725275 \\ \mathrm{C} & 5.895245 & -3.194551 & -2.794650 \\ \mathrm{H} & 5.760404 & -2.379945 & -3.508347 \\ \mathrm{H} & 6.874429 & -3.649545 & -2.971018 \\ \mathrm{H} & 5.131772 & -3.954331 & -2.990745 \\ \mathrm{C} & 6.868454 & -1.555195 & -1.148267 \\ \mathrm{H} & 7.865525 & -1.941197 & -1.379471 \\ \mathrm{H} & 6.656170 & -0.721032 & -1.821719 \\ \mathrm{H} & 6.881865 & -1.169184 & -0.125369 \\ \mathrm{C} & 3.373987 & -4.592587 & 1.148308 \\ \mathrm{H} & 3.672073 & -5.269354 & 1.954586 \\ \mathrm{H} & 2.304377 & -4.388916 & 1.249483 \\ \mathrm{H} & 3.531426 & -5.109789 & 0.197455 \\ \mathrm{C} & 3.935664 & -2.631296 & 2.624681 \\ \mathrm{H} & 2.870394 & -2.476670 & 2.806547 \\ \mathrm{H} & 4.327673 & -3.286796 & 3.408359 \\ \mathrm{H} & 4.440669 & -1.664184 & 2.709738 \\ \mathrm{C} & -0.932936 & 2.128783 & -2.685889 \\ \mathrm{C} & -1.919744 & 2.943070 & -3.225534 \\ \mathrm{C} & -2.912525 & 2.976287 & -2.218455 \\ \mathrm{H} & -1.960993 & 3.443968 & -4.180841 \\ \mathrm{~N} & -1.339535 & 1.723485 & -1.426673 \\ \mathrm{~N} & -2.545462 & 2.234488 & -1.145568 \\ \mathrm{~N} & -2.034550 & -0.960086 & 0.634034 \\ \mathrm{C} & -4.188757 & 3.725674 & -2.313447 \\ \mathrm{O} & -4.501033 & 4.375628 & -3.301408 \\ \mathrm{O} & -4.955370 & 3.611295 & -1.207662 \\ \mathrm{C} & -6.200313 & 4.344773 & -1.253468 \\ \mathrm{H} & -6.823480 & 3.989700 & -2.077830 \\ \mathrm{H} & -6.682756 & 4.155863 & -0.294420 \\ \mathrm{H} & -6.008897 & 5.412213 & -1.385400 \\ \mathrm{C} & -0.346256 & 1.635544 & 3.170115 \\ \mathrm{C} & -0.908513 & 1.988158 & 4.414213 \\ \mathrm{C} & -2.133048 & 1.441845 & 4.782521 \\ \mathrm{H} & -0.384741 & 2.677145 & 5.066669 \\ \mathrm{C} & -2.167254 & 0.244589 & 2.708073 \\ \mathrm{H} & -2.784436 & 0.546565 & 3.917984 \\ \mathrm{~N} & -3.738153 & 0.098160 & 4.164484 \\ \mathrm{~N} & -1.783173 & -0.299321\end{array}$




$\begin{array}{llll}\mathrm{C} & -5.824706 & -2.688052 & 1.338821 \\ \mathrm{C} & -6.099092 & -3.859220 & 0.369676 \\ \mathrm{H} & -5.568426 & -4.750987 & 0.721626 \\ \mathrm{H} & -7.164927 & -4.103763 & 0.415822 \\ \mathrm{C} & -5.698623 & -3.552378 & -1.075997 \\ \mathrm{C} & -4.187113 & -3.278249 & -1.244016 \\ \mathrm{H} & -6.264047 & -2.688791 & -1.443115 \\ \mathrm{H} & -5.972114 & -4.391602 & -1.723326 \\ \mathrm{C} & -5.895390 & -3.193090 & 2.795872 \\ \mathrm{H} & -5.760683 & -2.378040 & 3.509089 \\ \mathrm{H} & -6.874593 & -3.647995 & 2.972359 \\ \mathrm{H} & -5.131933 & -3.952732 & 2.992562 \\ \mathrm{C} & -6.868361 & -1.554773 & 1.148313 \\ \mathrm{H} & -7.865461 & -1.940652 & 1.379598 \\ \mathrm{H} & -6.656203 & -0.720184 & 1.821278 \\ \mathrm{H} & -6.881615 & -1.169401 & 0.125172 \\ \mathrm{C} & -3.373431 & -4.593505 & -1.145754 \\ \mathrm{H} & -3.671365 & -5.270800 & -1.951644 \\ \mathrm{H} & -2.303810 & -4.389873 & -1.246879 \\ \mathrm{H} & -3.531017 & -5.110095 & -0.194593 \\ \mathrm{C} & -3.934895 & -2.633175 & -2.623481 \\ \mathrm{H} & -2.869597 & -2.478631 & -2.805254 \\ \mathrm{H} & -4.326740 & -3.289192 & -3.406809 \\ \mathrm{H} & -4.439917 & -1.666135 & -2.709253 \\ \mathrm{C} & 0.932671 & 2.130352 & 2.684958 \\ \mathrm{C} & 1.919383 & 2.944977 & 3.224270 \\ \mathrm{C} & 2.912265 & 2.977707 & 2.217277 \\ \mathrm{H} & 1.960488 & 3.446424 & 4.179294 \\ \mathrm{~N} & 1.339461 & 1.724330 & 1.426032 \\ \mathrm{~N} & 2.545401 & 2.235222 & 1.144793 \\ \mathrm{C} & 4.188428 & 3.727247 & 2.311980 \\ \mathrm{O} & 4.500537 & 4.377807 & 3.299596 \\ \mathrm{O} & 4.955190 & 3.612261 & 1.206361 \\ \mathrm{C} & 6.200078 & 4.345849 & 1.251889 \\ \mathrm{H} & 6.823164 & 3.991308 & 2.076541 \\ \mathrm{H} & 6.682656 & 4.156399 & 0.293015 \\ \mathrm{H} & 6.008575 & 5.413354 & 1.383161\end{array}$

$\mathrm{M}=\mathrm{Gd}$
$\begin{array}{llll}\text { GD } & -0.000032 & 0.327498 & -0.000015\end{array}$
$\begin{array}{llll}\text { C } & 0.497481 & 1.725785 & -3.039259\end{array}$
C $\quad 1.121885 \quad 2.133614 \quad-4.235659$
$\begin{array}{llll}\text { C } & 2.354009 & 1.586418 & -4.576346\end{array}$
$\mathrm{H} \quad 0.641445 \quad 2.868850 \quad-4.870782$
$\begin{array}{llll}\text { C } & 2.279085 & 0.284505 & -2.569590\end{array}$ 


\begin{tabular}{|c|c|c|c|}
\hline $\mathrm{C}$ & 2.955663 & 0.637841 & -3.731118 \\
\hline $\mathrm{H}$ & 2.851237 & 1.891863 & -5.491953 \\
\hline $\mathrm{H}$ & 3.914010 & 0.189204 & -3.958470 \\
\hline C & 2.811256 & -0.710227 & -1.605887 \\
\hline $\mathrm{C}$ & 4.437764 & -2.146583 & -0.895959 \\
\hline $\mathrm{C}$ & 3.625780 & -2.435836 & 0.251027 \\
\hline $\mathrm{N}$ & 1.084227 & 0.812083 & -2.231842 \\
\hline $\mathrm{N}$ & 4.005628 & -1.274254 & -1.806318 \\
\hline $\mathrm{N}$ & 2.021241 & -0.992112 & -0.556469 \\
\hline $\mathrm{N}$ & 2.432721 & -1.854737 & 0.374138 \\
\hline $\mathrm{C}$ & 5.811476 & -2.763162 & -1.117058 \\
\hline $\mathrm{C}$ & 6.016216 & -3.970596 & -0.175749 \\
\hline $\mathrm{H}$ & 5.493718 & -4.841676 & -0.586674 \\
\hline $\mathrm{H}$ & 7.079535 & -4.229739 & -0.172576 \\
\hline $\mathrm{C}$ & 5.541845 & -3.706672 & 1.255918 \\
\hline $\mathrm{C}$ & 4.027395 & -3.414526 & 1299 \\
\hline $\mathrm{H}$ & 6.098365 & -2.865211 & 1.683047 \\
\hline $\mathrm{H}$ & 5.767504 & -4.571681 & 1.887491 \\
\hline $\mathrm{C}$ & 5.954878 & -3.218802 & -2.585094 \\
\hline $\mathrm{H}$ & 5.871027 & -2.377749 & -3.275452 \\
\hline $\mathrm{H}$ & 6.935885 & -3.682800 & -2.723543 \\
\hline $\mathrm{H}$ & 5.192994 & -3.959186 & -2.849634 \\
\hline $\mathrm{C}$ & 6.858792 & -1.653159 & -0.830529 \\
\hline $\mathrm{H}$ & 7.861290 & -2.047047 & -1.021206 \\
\hline $\mathrm{H}$ & 6.695329 & -0.792766 & -1.484206 \\
\hline $\mathrm{H}$ & 6.821904 & -1.303518 & 0.204792 \\
\hline $\mathrm{C}$ & 3.201930 & -4.711966 & 1.158056 \\
\hline $\mathrm{H}$ & 3.446386 & -5.424154 & 1.951721 \\
\hline $\mathrm{H}$ & 2.131259 & -4.495482 & 1.209731 \\
\hline $\mathrm{H}$ & 3.403502 & -5.194494 & 0.197397 \\
\hline $\mathrm{C}$ & 3.708254 & -2.817578 & 2.738456 \\
\hline $\mathrm{H}$ & 2.636700 & -2.654373 & 2.868775 \\
\hline $\mathrm{H}$ & 4.048153 & -3.508173 & 3.516220 \\
\hline $\mathrm{H}$ & 4.220454 & -1.862229 & 2.888533 \\
\hline $\mathrm{C}$ & -0.785885 & 2.218237 & -2.565572 \\
\hline $\mathrm{C}$ & -1.741497 & 3.092934 & -3.070344 \\
\hline $\mathrm{C}$ & -2.752541 & 3.088869 & -2.082454 \\
\hline $\mathrm{H}$ & -1.747136 & 3.656238 & -3.991195 \\
\hline $\mathrm{N}$ & -1.229521 & 1.742686 & -1.352011 \\
\hline $\mathrm{N}$ & -2.429833 & 2.273033 & -1.055116 \\
\hline $\mathrm{C}$ & -4.007534 & 3.875855 & -2.154722 \\
\hline $\mathrm{O}$ & -4.279329 & 4.604529 & -3.098438 \\
\hline $\mathrm{O}$ & -4.806916 & 3.702039 & -1.078849 \\
\hline $\mathrm{C}$ & -6.030808 & 4.470258 & -1.102826 \\
\hline $\mathrm{H}$ & -6.639334 & 4.194665 & -1.967571 \\
\hline $\mathrm{H}$ & -6.545498 & 4.224052 & -0.173859 \\
\hline
\end{tabular}




\begin{tabular}{|c|c|c|c|}
\hline $\mathrm{H}$ & -5.809654 & 5.539123 & -1.149188 \\
\hline & -0.497279 & 1.725138 & 3.039577 \\
\hline & -1.121577 & 2.132715 & 4.236119 \\
\hline & -2.353689 & 1.585478 & 4.576780 \\
\hline & -0.641065 & 2.867793 & 4.871369 \\
\hline & -2.278964 & 0.284016 & 2.569724 \\
\hline & -2.955437 & 0.637109 & 3.731386 \\
\hline & -2.850836 & 1.890731 & 5.492496 \\
\hline & -3.913779 & 0.188446 & 3.958714 \\
\hline & -2.811245 & -0.710482 & 1.605837 \\
\hline & -4.437850 & -2.146638 & 0.895726 \\
\hline 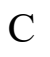 & -3.625991 & -2.435623 & -0.251415 \\
\hline 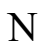 & -1.084117 & 0.811637 & 2.231999 \\
\hline & -4.005609 & -1.274533 & 1.8 \\
\hline V & -2.021333 & -0.992143 & 0.55 \\
\hline $\mathbf{N}$ & -2.432925 & -1.8 & $-0.3^{\prime}$ \\
\hline 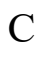 & -5.811539 & -2.763266 & 1.11 \\
\hline $\mathcal{C}$ & -6.016395 & -3.970459 & 0.17 \\
\hline $\mathrm{H}$ & -5.493852 & -4.841647 & 0.58 \\
\hline $\mathrm{H}$ & -7.079715 & -4.229597 & 0.17 \\
\hline C & -5.542192 & -3.706166 & -1.256418 \\
\hline $\mathrm{C}$ & -4.027749 & -3.414011 & -1.3 \\
\hline $\mathrm{H}$ & -6.098753 & -2.864587 & -1.68 \\
\hline $\mathrm{H}$ & -5.767935 & -4.571006 & $-1.8 \varepsilon$ \\
\hline $\mathrm{C}$ & -5.954763 & -3.219284 & 2.58 \\
\hline $\mathrm{H}$ & -5.870824 & -2.378409 & 3.27 \\
\hline $\mathrm{H}$ & -6.935755 & -3.683314 & 2.723218 \\
\hline $\mathrm{H}$ & -5.192850 & -3.959740 & 2.849023 \\
\hline $\mathcal{C}$ & -6.858889 & -1.653189 & 0.830714 \\
\hline $\mathrm{H}$ & -7.861364 & -2.047124 & 1.021413 \\
\hline $\mathrm{H}$ & -6.695345 & -0.792964 & 1.48 \\
\hline $\mathrm{H}$ & -6.822127 & -1.303283 & -0.204522 \\
\hline 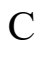 & -3.202277 & -4.711512 & -1.15 \\
\hline $\mathrm{H}$ & -3.446835 & -5.423477 & -1.952953 \\
\hline $\mathrm{H}$ & -2.131609 & -4.495027 & -1.210862 \\
\hline $\mathrm{H}$ & -3.403741 & -5.194303 & -0.198570 \\
\hline O & -3.708772 & -2.816683 & -2.738935 \\
\hline $\mathrm{H}$ & -2.637232 & -2.653451 & -2.869340 \\
\hline I & -4.048773 & -3.507059 & -3.516847 \\
\hline $\mathrm{H}$ & -4.220980 & -1.861287 & -2.888687 \\
\hline $\mathrm{C}$ & 0.786066 & 2.217652 & 2.565905 \\
\hline $\mathrm{C}$ & 1.741748 & 3.092201 & 3.070804 \\
\hline $\mathrm{C}$ & 2.752720 & 3.088317 & 2.082841 \\
\hline . & 1.747474 & 3.655299 & 3.991780 \\
\hline . & 1.229595 & 1.742356 & 1.352206 \\
\hline & 2.429907 & 2.272722 & 1.055344 \\
\hline
\end{tabular}




$\begin{array}{llll}\mathrm{C} & 4.007748 & 3.875238 & 2.155194 \\ \mathrm{O} & 4.279640 & 4.603691 & 3.099052 \\ \mathrm{O} & 4.807046 & 3.701633 & 1.079223 \\ \mathrm{C} & 6.030968 & 4.469802 & 1.103282 \\ \mathrm{H} & 6.639547 & 4.193994 & 1.967921 \\ \mathrm{H} & 6.545581 & 4.223784 & 0.174222 \\ \mathrm{H} & 5.809855 & 5.538664 & 1.149899\end{array}$

$\mathrm{M}=\mathrm{Am}$

$\begin{array}{lccc}\text { AM } & 0.000036 & 0.446819 & -0.000012 \\ \mathrm{C} & 0.408574 & 1.530274 & -3.237321 \\ \mathrm{C} & 0.957977 & 1.758890 & -4.515582 \\ \mathrm{C} & 2.120604 & 1.092967 & -4.883432 \\ \mathrm{H} & 0.473252 & 2.453546 & -5.191716 \\ \mathrm{C} & 2.129825 & 0.027787 & -2.738793 \\ \mathrm{C} & 2.729439 & 0.204906 & -3.980379 \\ \mathrm{H} & 2.559524 & 1.260356 & -5.862249 \\ \mathrm{H} & 3.638022 & -0.330594 & -4.223091 \\ \mathrm{C} & 2.692396 & -0.886914 & -1.715539 \\ \mathrm{C} & 4.296050 & -2.342018 & -0.990854 \\ \mathrm{C} & 3.577536 & -2.451985 & 0.246114 \\ \mathrm{~N} & 0.998884 & 0.669336 & -2.373338 \\ \mathrm{~N} & 3.830659 & -1.546629 & -1.953665 \\ \mathrm{~N} & 1.993600 & -0.994019 & -0.576214 \\ \mathrm{~N} & 2.438457 & -1.780393 & 0.405595 \\ \mathrm{C} & 5.607106 & -3.068142 & -1.256814 \\ \mathrm{C} & 5.825882 & -4.181924 & -0.208999 \\ \mathrm{H} & 5.218013 & -5.053491 & -0.476484 \\ \mathrm{H} & 6.868079 & -4.510921 & -0.266857 \\ \mathrm{C} & 5.499813 & -3.738824 & 1.219871 \\ \mathrm{C} & 4.020319 & -3.334903 & 1.409949 \\ \mathrm{H} & 6.141848 & -2.897942 & 1.504409 \\ \mathrm{H} & 5.730283 & -4.547036 & 1.921080 \\ \mathrm{C} & 5.591898 & -3.683184 & -2.672688 \\ \mathrm{H} & 5.495730 & -2.915241 & -3.442112 \\ \mathrm{H} & 6.527806 & -4.224336 & -2.840265 \\ \mathrm{H} & 4.767551 & -4.393977 & -2.790328 \\ \mathrm{C} & 6.737959 & -2.006795 & -1.181757 \\ \mathrm{H} & 7.695439 & -2.484055 & -1.409698 \\ \mathrm{H} & 6.567104 & -1.210800 & -1.910902 \\ \mathrm{H} & 6.814023 & -1.549019 & -0.191702 \\ \mathrm{C} & 3.105471 & -4.585855 & 1.431929 \\ \mathrm{H} & 3.378679 & -5.225823 & 2.276144 \\ \mathrm{H} & 2.058708 & -4.291853 & 1.549616 \\ \mathrm{H} & 3.189541 & -5.179465 & 0.517041\end{array}$




\begin{tabular}{|c|c|c|c|}
\hline $\mathrm{C}$ & 3.865026 & -2.575185 & 590 \\
\hline $\mathrm{H}$ & 2.821681 & -2.324283 & 2.945080 \\
\hline & 4.231977 & -3.202514 & 3.562658 \\
\hline $\mathrm{H}$ & 4.445522 & -1.647459 & 2.745019 \\
\hline C & -0.793770 & 2.171756 & -2.736802 \\
\hline $\mathrm{C}$ & -1.729081 & 3.055204 & -3.266016 \\
\hline $\mathrm{C}$ & -2.648337 & 3.240569 & -2.208841 \\
\hline $\mathrm{H}$ & -1.777449 & 3.511377 & -4.243149 \\
\hline $\mathrm{N}$ & -1.162401 & 1.875058 & -1.447428 \\
\hline $\mathbf{N}$ & -2.291666 & 2.523194 & -1.120367 \\
\hline $\mathrm{C}$ & -3.849140 & 4.108171 & -2.274486 \\
\hline $\mathrm{O}$ & -4.154891 & 4.741144 & -3.275309 \\
\hline $\mathrm{O}$ & -4.556977 & 4.121168 & -1.124307 \\
\hline $\mathrm{C}$ & -5.724327 & 4.972994 & -1.137955 \\
\hline $\mathrm{H}$ & -6.426300 & 4.648477 & -1.909959 \\
\hline $\mathrm{H}$ & -6.166559 & 3211 & -0.14 \\
\hline $\mathrm{H}$ & -5.437750 & 6.009657 & -1.329644 \\
\hline $\mathrm{C}$ & -0.408804 & 1.531155 & 3.236966 \\
\hline $\mathrm{C}$ & -0.958321 & 1.760099 & 4.515121 \\
\hline $\mathrm{C}$ & -2.120950 & 1.094230 & 4.883061 \\
\hline $\mathrm{H}$ & -0.473682 & 2.454965 & 5.191101 \\
\hline $\mathrm{C}$ & -2.129952 & 0.028460 & 2.738715 \\
\hline $\mathrm{C}$ & -2.729678 & 0.205898 & 3.980202 \\
\hline $\mathrm{H}$ & -2.559956 & 1.261871 & 5.861796 \\
\hline $\mathrm{H}$ & -3.638262 & -0.329568 & 4.222984 \\
\hline $\mathrm{C}$ & -2.692403 & -0.886537 & 1.715662 \\
\hline $\mathrm{C}$ & -4.295928 & -2.341911 & 0.991234 \\
\hline $\mathrm{C}$ & -3.577289 & -2.452200 & -0.245633 \\
\hline $\mathrm{N}$ & -0.999003 & 0.669947 & 2.373178 \\
\hline $\mathrm{N}$ & -3.830659 & -1.546237 & 1.953868 \\
\hline $\mathrm{N}$ & -1.993509 & -0.993914 & 0.576424 \\
\hline $\mathrm{N}$ & -2.438234 & -1.780589 & -0.405203 \\
\hline $\mathrm{C}$ & -5.606989 & -3.068001 & 1.257266 \\
\hline $\mathrm{C}$ & -5.825616 & -4.182097 & 0.209755 \\
\hline $\mathrm{H}$ & -5.217748 & -5.053566 & 0.477561 \\
\hline $\mathrm{H}$ & -6.867809 & -4.511111 & 0.267599 \\
\hline $\mathrm{C}$ & -5.499410 & -3.739407 & -1.219211 \\
\hline $\mathrm{C}$ & -4.019909 & -3.335488 & -1.409249 \\
\hline $\mathrm{H}$ & -6.141444 & -2.898633 & -1.504067 \\
\hline $\mathrm{H}$ & -5.729775 & -4.547835 & -1.920206 \\
\hline $\mathrm{C}$ & -5.591915 & -3.682626 & 2.673322 \\
\hline $\mathrm{H}$ & -5.495860 & -2.914454 & 3.442532 \\
\hline $\mathrm{H}$ & -6.527823 & -4.223762 & 2.840955 \\
\hline $\mathrm{H}$ & -4.767556 & -4.393355 & 2.791263 \\
\hline $\mathrm{C}$ & -6.737868 & -2.006711 & 1.181774 \\
\hline $\mathrm{H}$ & -7.695356 & -2.483934 & 1.409757 \\
\hline
\end{tabular}




$\begin{array}{llll}\mathrm{H} & -6.567115 & -1.210494 & 1.910699 \\ \mathrm{H} & -6.813841 & -1.549233 & 0.191575 \\ \mathrm{C} & -3.105012 & -4.586413 & -1.430741 \\ \mathrm{H} & -3.378103 & -5.226652 & -2.274789 \\ \mathrm{H} & -2.058248 & -4.292408 & -1.548404 \\ \mathrm{H} & -3.189159 & -5.179745 & -0.515680 \\ \mathrm{C} & -3.864496 & -2.576177 & -2.744106 \\ \mathrm{H} & -2.821138 & -2.325302 & -2.944558 \\ \mathrm{H} & -4.231337 & -3.203769 & -3.562020 \\ \mathrm{H} & -4.445022 & -1.648470 & -2.744883 \\ \mathrm{C} & 0.793543 & 2.172570 & 2.736368 \\ \mathrm{C} & 1.728763 & 3.056209 & 3.265426 \\ \mathrm{C} & 2.648086 & 3.241358 & 2.208271 \\ \mathrm{H} & 1.777033 & 3.512635 & 4.242445 \\ \mathrm{~N} & 1.162284 & 1.875564 & 1.447097 \\ \mathrm{~N} & 2.291536 & 2.523684 & 1.119953 \\ \mathrm{C} & 3.848833 & 4.109047 & 2.273782 \\ \mathrm{O} & 4.154472 & 4.742297 & 3.274465 \\ \mathrm{O} & 4.556757 & 4.121787 & 1.123654 \\ \mathrm{C} & 5.724057 & 4.973682 & 1.137172 \\ \mathrm{H} & 6.425991 & 4.649404 & 1.909312 \\ \mathrm{H} & 6.166371 & 4.873670 & 0.145873 \\ \mathrm{H} & 5.437408 & 6.010379 & 1.328573\end{array}$

$\mathrm{M}=\mathrm{Cm}$

$\begin{array}{lccc}\mathrm{CM} & 0.000084 & -0.315914 & 0.000002 \\ \mathrm{C} & 0.537608 & -1.667171 & 3.107595 \\ \mathrm{C} & 1.158690 & -2.042535 & 4.316103 \\ \mathrm{C} & 2.384202 & -1.477758 & 4.651120 \\ \mathrm{H} & 0.680989 & -2.767054 & 4.965444 \\ \mathrm{C} & 2.308735 & -0.222001 & 2.614612 \\ \mathrm{C} & 2.982230 & -0.543854 & 3.787867 \\ \mathrm{H} & 2.879097 & -1.758292 & 5.575963 \\ \mathrm{H} & 3.935508 & -0.082271 & 4.010315 \\ \mathrm{C} & 2.843735 & 0.756751 & 1.635263 \\ \mathrm{C} & 4.475009 & 2.186381 & 0.919494 \\ \mathrm{C} & 3.675585 & 2.452296 & -0.241377 \\ \mathrm{~N} & 1.121157 & -0.768065 & 2.282443 \\ \mathrm{~N} & 4.034821 & 1.328190 & 1.839225 \\ \mathrm{~N} & 2.066286 & 1.015857 & 0.571747 \\ \mathrm{~N} & 2.486411 & 1.865406 & -0.367676 \\ \mathrm{C} & 5.843092 & 2.813569 & 1.146955 \\ \mathrm{C} & 6.052112 & 4.006735 & 0.188416 \\ \mathrm{H} & 5.518490 & 4.880815 & 0.578273 \\ \mathrm{H} & 7.113634 & 4.273049 & 0.194436\end{array}$




$\begin{array}{lrrr}\mathrm{C} & 5.597792 & 3.716077 & -1.244534 \\ \mathrm{C} & 4.086477 & 3.412576 & -1.354633 \\ \mathrm{H} & 6.165039 & 2.871168 & -1.650341 \\ \mathrm{H} & 5.826343 & 4.571819 & -1.887575 \\ \mathrm{C} & 5.966095 & 3.294317 & 2.608823 \\ \mathrm{H} & 5.879345 & 2.464286 & 3.312074 \\ \mathrm{H} & 6.942354 & 3.767019 & 2.751436 \\ \mathrm{H} & 5.196335 & 4.033923 & 2.851972 \\ \mathrm{C} & 6.899987 & 1.705244 & 0.891388 \\ \mathrm{H} & 7.898078 & 2.107575 & 1.087592 \\ \mathrm{H} & 6.733379 & 0.854717 & 1.557150 \\ \mathrm{H} & 6.877726 & 1.338576 & -0.138476 \\ \mathrm{C} & 3.250754 & 4.708352 & -1.198279 \\ \mathrm{H} & 3.500475 & 5.405705 & -2.003432 \\ \mathrm{H} & 2.182129 & 4.483882 & -1.258488 \\ \mathrm{H} & 3.437709 & 5.211816 & -0.245387 \\ \mathrm{C} & 3.790133 & 2.786582 & -2.734152 \\ \mathrm{H} & 2.721384 & 2.614563 & -2.875951 \\ \mathrm{H} & 4.137100 & 3.463689 & -3.520662 \\ \mathrm{H} & 4.309695 & 1.831401 & -2.858255 \\ \mathrm{C} & -0.739618 & -2.185612 & 2.643009 \\ \mathrm{C} & -1.685504 & -3.057305 & 3.169657 \\ \mathrm{C} & -2.695071 & -3.094239 & 2.180849 \\ \mathrm{H} & -1.686406 & -3.594967 & 4.105606 \\ \mathrm{~N} & -1.187943 & -1.751031 & 1.416176 \\ \mathrm{~N} & -2.381121 & -2.304314 & 1.132079 \\ \mathrm{C} & -3.940188 & -3.894459 & 2.274057 \\ \mathrm{O} & -4.204637 & -4.598229 & 3.238539 \\ \mathrm{O} & -4.738949 & -3.762325 & 1.192130 \\ \mathrm{C} & -5.953467 & -4.544524 & 1.235257 \\ \mathrm{H} & -6.567690 & -4.251628 & 2.090239 \\ \mathrm{H} & -6.468343 & -4.331272 & 0.298293 \\ \mathrm{H} & -5.719347 & -5.608819 & 1.312737 \\ \mathrm{C} & -0.538272 & -1.669661 & -3.106333 \\ \mathrm{C} & -1.159763 & -2.046076 & -4.314312 \\ \mathrm{C} & -2.385344 & -1.481527 & -4.649432 \\ \mathrm{H} & -0.682347 & -2.771247 & -4.963135 \\ \mathrm{C} & -2.309176 & -0.223958 & -2.614068 \\ \mathrm{C} & -2.883067 & -0.546833 & -3.786811 \\ \mathrm{H} & -1.762850 & -5.573870 \\ \mathrm{H} & -0.085430 & -4.009367 \\ \mathrm{H} & -0.755650 & -1.635380 \\ \mathrm{H} & 1.326922 & -1.839456\end{array}$




$\begin{array}{lrrr}\mathrm{N} & -2.065991 & 1.015695 & -0.572343 \\ \mathrm{~N} & -2.485670 & 1.866373 & 0.366273 \\ \mathrm{C} & -5.843128 & 2.812687 & -1.147769 \\ \mathrm{C} & -6.051704 & 4.007109 & -0.190697 \\ \mathrm{H} & -5.518522 & 4.880758 & -0.582111 \\ \mathrm{H} & -7.113281 & 4.273215 & -0.196344 \\ \mathrm{C} & -5.596355 & 3.718487 & 1.242341 \\ \mathrm{C} & -4.084945 & 3.415251 & 1.351827 \\ \mathrm{H} & -6.163252 & 2.874109 & 1.649738 \\ \mathrm{H} & -5.824519 & 4.575121 & 1.884332 \\ \mathrm{C} & -5.967361 & 3.291397 & -2.610187 \\ \mathrm{H} & -5.880978 & 2.460426 & -3.312371 \\ \mathrm{H} & -6.943831 & 3.763696 & -2.752697 \\ \mathrm{H} & -5.197944 & 4.030827 & -2.854945 \\ \mathrm{C} & -6.899587 & 1.704465 & -0.889868 \\ \mathrm{H} & -7.897924 & 2.106321 & -1.085797 \\ \mathrm{H} & -6.733326 & 0.853092 & -1.554636 \\ \mathrm{H} & -6.876410 & 1.339164 & 0.140462 \\ \mathrm{C} & -3.249410 & 4.710833 & 1.192765 \\ \mathrm{H} & -3.498639 & 5.409518 & 1.996918 \\ \mathrm{H} & -2.180731 & 4.486521 & 1.252644 \\ \mathrm{H} & -3.437013 & 5.212695 & 0.239159 \\ \mathrm{C} & -3.787550 & 2.791520 & 2.732129 \\ \mathrm{H} & -2.718690 & 2.619791 & 2.873431 \\ \mathrm{H} & -4.133986 & 3.469881 & 3.517792 \\ \mathrm{H} & -4.306962 & 1.836508 & 2.858158 \\ \mathrm{C} & 0.739001 & -2.187800 & -2.641613 \\ \mathrm{C} & 1.684667 & -3.059992 & -3.167836 \\ \mathrm{C} & 2.694490 & -3.096211 & -2.179269 \\ \mathrm{H} & 1.685301 & -3.598358 & -4.103379 \\ \mathrm{~N} & 1.187655 & -1.752274 & -1.415217 \\ \mathrm{~N} & 2.380859 & -2.305467 & -1.131032 \\ \mathrm{C} & 3.939537 & -3.896585 & -2.272197 \\ \mathrm{O} & 4.203537 & -4.601339 & -3.236085 \\ \mathrm{O} & 4.738448 & -3.763920 & -1.190454 \\ \mathrm{C} & 5.952739 & -4.546495 & -1.233157 \\ \mathrm{H} & 6.566954 & -4.254368 & -2.088407 \\ \mathrm{H} & 6.467770 & -4.332732 & -0.296396 \\ \mathrm{H} & 5.718310 & -5.610778 & -1.309869\end{array}$

\section{$\mathbf{L}=\mathbf{2} \mathbf{a m i}$}

\section{$\left[\mathrm{ML}\left(\mathrm{H}_{2} \mathrm{O}\right)_{6}\right]^{2+}$}

$\mathrm{M}=\mathrm{Eu}$ 


$\begin{array}{lccc}\mathrm{EU} & -1.384932 & -1.030359 & 0.139118 \\ \mathrm{O} & -0.578621 & -2.783092 & 1.988169 \\ \mathrm{H} & 0.058814 & -3.508924 & 2.052661 \\ \mathrm{O} & -0.905779 & -0.075097 & 2.521502 \\ \mathrm{H} & -0.515269 & -0.705949 & 3.146481 \\ \mathrm{O} & -3.440651 & -2.478895 & -0.680657 \\ \mathrm{H} & -3.600108 & -3.149418 & -1.360487 \\ \mathrm{O} & -3.155317 & -2.063280 & 1.976891 \\ \mathrm{H} & -3.785273 & -2.523830 & 1.393223 \\ \mathrm{O} & 0.214762 & -2.690736 & -1.009177 \\ \mathrm{H} & 0.273583 & -3.643104 & -1.167910 \\ \mathrm{O} & -1.266525 & -0.704960 & -2.397378 \\ \mathrm{H} & -0.688856 & -1.273668 & -2.928370 \\ \mathrm{H} & -1.410706 & -3.079401 & 2.400298 \\ \mathrm{H} & -3.678163 & -1.602574 & 2.650643 \\ \mathrm{H} & 1.126564 & -2.345618 & -0.806057 \\ \mathrm{H} & -4.137243 & -1.763824 & -0.787474 \\ \mathrm{H} & -1.782607 & -0.160494 & -3.009288 \\ \mathrm{H} & -0.930032 & 0.788662 & 2.957473 \\ \mathrm{C} & -2.092975 & 2.416181 & -0.024284 \\ \mathrm{C} & -1.968907 & 3.815034 & 0.077110 \\ \mathrm{C} & -0.699320 & 4.372262 & 0.206827 \\ \mathrm{H} & -2.851679 & 4.443520 & 0.048808 \\ \mathrm{C} & 0.214336 & 2.149711 & 0.111176 \\ \mathrm{C} & 0.419416 & 3.528784 & 0.216310 \\ \mathrm{H} & -0.576390 & 5.447913 & 0.287494 \\ \mathrm{H} & 1.427455 & 3.915853 & 0.292071 \\ \mathrm{C} & 1.370973 & 1.211512 & 0.052662 \\ \mathrm{H} & 3.640248 & 0.891297 & -0.002608 \\ \mathrm{H} & 6.178351 & 3.192158 & -0.463363 \\ \mathrm{C} & 3.386123 & -0.505359 & -0.244908 \\ \mathrm{~N} & -1.011333 & 1.600649 & 0.010574 \\ \mathrm{~N} & 2.608724 & 1.721589 & 0.121074 \\ \mathrm{~N} & 1.100392 & -0.088972 & -0.095993 \\ \mathrm{~N} & 2.126821 & -0.935980 & -0.269886 \\ \mathrm{C} & 5.038088 & 1.464413 & 0.164276 \\ \mathrm{C} & 6.094781 & 0.482218 & -0.388640 \\ \mathrm{H} & 6.138832 & 0.574553 & -1.478913 \\ \mathrm{H} & 7.077600 & 0.791546 & -0.021690 \\ \mathrm{C} & 5.835955 & -0.974581 & 0.003365 \\ \mathrm{H} & 5.488855 & -1.521314 & -0.524606 \\ \mathrm{H} & 6.638421 & -1.081108 & 1.093357 \\ \mathrm{H} & -1.608890 & -0.384664 \\ \mathrm{H} & 2.719087 & -1.634309\end{array}$




$\begin{array}{lrrr}\mathrm{C} & 5.242639 & 1.694473 & 1.688684 \\ \mathrm{H} & 6.225365 & 2.145005 & 1.851513 \\ \mathrm{H} & 4.484807 & 2.377281 & 2.081929 \\ \mathrm{H} & 5.199141 & 0.764443 & 2.262608 \\ \mathrm{C} & 4.547801 & -1.734842 & -2.060907 \\ \mathrm{H} & 5.325311 & -2.466541 & -2.297126 \\ \mathrm{H} & 3.595215 & -2.118387 & -2.439387 \\ \mathrm{H} & 4.777717 & -0.813899 & -2.602728 \\ \mathrm{C} & 4.191192 & -2.870790 & 0.161058 \\ \mathrm{H} & 3.307708 & -3.361236 & -0.256059 \\ \mathrm{H} & 5.039705 & -3.543976 & 0.011780 \\ \mathrm{H} & 4.047356 & -2.750957 & 1.239470 \\ \mathrm{C} & -3.376147 & 1.746870 & -0.209905 \\ \mathrm{C} & -4.674540 & 2.191261 & -0.401498 \\ \mathrm{C} & -5.433557 & 1.008600 & -0.607799 \\ \mathrm{H} & -5.049973 & 3.204091 & -0.416385 \\ \mathrm{~N} & -3.366274 & 0.354390 & -0.282790 \\ \mathrm{~N} & -4.601488 & -0.078138 & -0.529426 \\ \mathrm{C} & -6.891845 & 0.866871 & -0.877818 \\ \mathrm{H} & -7.178094 & 1.431357 & -1.772498 \\ \mathrm{H} & -7.162668 & -0.180205 & -1.019554 \\ \mathrm{H} & -7.481543 & 1.275053 & -0.048745\end{array}$

$\mathrm{M}=\mathrm{Gd}$

$\begin{array}{lrrr}\text { GD } & -1.356390 & -0.962922 & 0.136506 \\ \mathrm{O} & -1.093946 & -2.836158 & 1.857758 \\ \mathrm{H} & -0.650699 & -3.688915 & 1.733060 \\ \mathrm{O} & -0.618167 & -0.187602 & 2.465472 \\ \mathrm{H} & -0.336795 & -0.871536 & 3.094049 \\ \mathrm{O} & -3.148345 & -2.412396 & -0.658538 \\ \mathrm{H} & -3.349055 & -3.285533 & -1.020546 \\ \mathrm{O} & -3.253003 & -1.272919 & 2.024506 \\ \mathrm{H} & -4.114651 & -1.248225 & 1.569538 \\ \mathrm{O} & 0.186050 & -2.703508 & -0.729894 \\ \mathrm{H} & 0.180333 & -3.494911 & -1.285804 \\ \mathrm{O} & -1.224742 & -0.575820 & -2.319159 \\ \mathrm{H} & -0.672638 & -0.915390 & -3.037895 \\ \mathrm{H} & -1.952709 & -3.000107 & 2.286202 \\ \mathrm{H} & -3.330597 & -0.654820 & 2.767941 \\ \mathrm{H} & 1.120873 & -2.354891 & -0.648722 \\ \mathrm{H} & -3.949704 & -1.794434 & -0.786844 \\ \mathrm{H} & -1.993644 & -0.139967 & -2.719600 \\ \mathrm{H} & -0.362064 & 0.671182 & 2.833271 \\ \mathrm{C} & -2.104278 & 2.358175 & -0.078345 \\ \mathrm{C} & -1.997361 & 3.760177 & -0.015167\end{array}$




$\begin{array}{lrrc}\mathrm{C} & -0.739602 & 4.339143 & 0.125114 \\ \mathrm{H} & -2.888169 & 4.373470 & -0.088564 \\ \mathrm{C} & 0.214456 & 2.137839 & 0.104209 \\ \mathrm{C} & 0.397759 & 3.517055 & 0.171259 \\ \mathrm{H} & -0.635748 & 5.418708 & 0.175848 \\ \mathrm{H} & 1.397873 & 3.925379 & 0.239421 \\ \mathrm{C} & 1.369677 & 1.204119 & 0.052643 \\ \mathrm{C} & 3.636838 & 0.864371 & -0.001504 \\ \mathrm{C} & 3.373416 & -0.535457 & -0.230690 \\ \mathrm{~N} & -1.007451 & 1.566096 & 0.014747 \\ \mathrm{~N} & 2.611704 & 1.702714 & 0.119836 \\ \mathrm{~N} & 1.091531 & -0.097224 & -0.093177 \\ \mathrm{~N} & 2.111795 & -0.954709 & -0.254900 \\ \mathrm{C} & 5.038117 & 1.428940 & 0.156737 \\ \mathrm{C} & 6.088772 & 0.431139 & -0.379455 \\ \mathrm{H} & 6.137015 & 0.508107 & -1.470683 \\ \mathrm{H} & 7.072608 & 0.738454 & -0.013860 \\ \mathrm{C} & 5.818133 & -1.017916 & 0.032412 \\ \mathrm{C} & 4.469320 & -1.562893 & -0.493377 \\ \mathrm{H} & 5.843132 & -1.109733 & 1.123816 \\ \mathrm{H} & 6.617156 & -1.663530 & -0.343621 \\ \mathrm{C} & 5.164173 & 2.772542 & -0.593678 \\ \mathrm{H} & 4.490376 & 3.528097 & -0.186550 \\ \mathrm{H} & -1.189231 & 3.139982 & -0.495104 \\ \mathrm{H} & -7.195451 & 1.037117 & -1.753944 \\ \mathrm{H} & 4.952050 & 2.657063 & -1.661135 \\ \mathrm{C} & 5.242587 & 1.681336 & 1.678252 \\ \mathrm{H} & 6.228804 & 2.126581 & 1.833765 \\ \mathrm{H} & 4.490409 & 2.376960 & 2.059553 \\ \mathrm{H} & 5.192215 & 0.760795 & 2.266781 \\ \mathrm{C} & 4.532785 & -1.795233 & -2.026985 \\ \mathrm{H} & 5.308087 & -2.533009 & -2.250745 \\ \mathrm{H} & -3.580365 & -2.180867 & -2.404156 \\ \mathrm{H} & 4.768361 & -0.882529 & -2.580170 \\ \mathrm{C} & 4.159308 & -2.901501 & 0.208211 \\ \mathrm{H} & 3.274552 & -3.393374 & -0.204424 \\ \mathrm{H} & 5.004083 & -3.581679 & 0.070411 \\ \mathrm{H} & 4.012566 & -2.768054 & 1.284516 \\ \mathrm{H} & -3.358976 & 1.640297 & -0.284831 \\ \mathrm{H} & -0.484026 & -0.853402\end{array}$




$$
\begin{array}{llll}
\mathrm{H} & -7.449673 & 1.036390 & -0.009820
\end{array}
$$

$\mathrm{M}=\mathrm{Am}$

$\begin{array}{lccc}\mathrm{AM} & -1.270936 & -0.870393 & 0.105842 \\ \mathrm{O} & -1.226811 & -2.879737 & 1.838359 \\ \mathrm{H} & -0.850554 & -3.772273 & 1.816137 \\ \mathrm{O} & -0.518571 & -0.233446 & 2.519353 \\ \mathrm{H} & -0.353174 & -0.979192 & 3.118622 \\ \mathrm{O} & -3.166361 & -2.261698 & -0.796237 \\ \mathrm{H} & -3.367853 & -3.048732 & -1.320314 \\ \mathrm{O} & -3.270898 & -1.162721 & 1.940638 \\ \mathrm{H} & -4.095844 & -1.037718 & 1.433029 \\ \mathrm{O} & 0.334473 & -2.639269 & -0.769996 \\ \mathrm{H} & 0.370891 & -3.564670 & -1.048255 \\ \mathrm{O} & -1.036126 & -0.485187 & -2.410458 \\ \mathrm{H} & -0.561889 & -1.017940 & -3.065924 \\ \mathrm{H} & -2.134810 & -2.949196 & 2.184634 \\ \mathrm{H} & -3.339325 & -0.568353 & 2.704298 \\ \mathrm{H} & 1.264830 & -2.285111 & -0.657959 \\ \mathrm{H} & -3.926658 & -1.597111 & -0.883013 \\ \mathrm{H} & -1.732172 & 0.000336 & -2.880213 \\ \mathrm{H} & -0.178512 & 0.566624 & 2.946981 \\ \mathrm{C} & -1.901754 & 2.512862 & -0.077861 \\ \mathrm{C} & -1.755629 & 3.909496 & -0.001604 \\ \mathrm{C} & -0.482811 & 4.451256 & 0.147783 \\ \mathrm{H} & -2.628619 & 4.548244 & -0.070479 \\ \mathrm{C} & 0.407398 & 2.222338 & 0.109788 \\ \mathrm{C} & 0.628243 & 3.595526 & 0.190791 \\ \mathrm{H} & -0.347691 & 5.526760 & 0.209074 \\ \mathrm{H} & 1.639580 & 3.973363 & 0.266561 \\ \mathrm{C} & 1.544620 & 1.267100 & 0.056683 \\ \mathrm{C} & 3.806968 & 0.893223 & 0.013857 \\ \mathrm{C} & 3.522470 & -0.499092 & -0.231607 \\ \mathrm{~N} & -0.830076 & 1.685621 & 0.010694 \\ \mathrm{~N} & 2.794291 & 1.745601 & 0.139340 \\ \mathrm{~N} & 1.246518 & -0.026183 & -0.104729 \\ \mathrm{~N} & 2.254945 & -0.897906 & -0.265355 \\ \mathrm{C} & 5.216275 & 1.434228 & 0.185761 \\ \mathrm{C} & 6.254138 & 0.425237 & -0.354564 \\ \mathrm{H} & 6.310463 & 0.512822 & -1.444602 \\ \mathrm{H} & 7.240501 & 0.712632 & 0.020327 \\ \mathrm{C} & 5.957580 & -1.023603 & 0.040034 \\ \mathrm{H} & 4.603439 & -1.540895 & -0.499688 \\ \mathrm{H} & 5.974205 & -1.127317 & 1.130595 \\ & & & \\ & & \end{array}$




$\begin{array}{lrrr}\mathrm{C} & 5.367416 & 2.782592 & -0.551368 \\ \mathrm{H} & 4.704250 & 3.545125 & -0.139731 \\ \mathrm{H} & 6.397819 & 3.132652 & -0.445289 \\ \mathrm{H} & 5.157789 & 2.680631 & -1.620690 \\ \mathrm{C} & 5.416768 & 1.668897 & 1.710428 \\ \mathrm{H} & 6.408179 & 2.098958 & 1.875488 \\ \mathrm{H} & 4.672197 & 2.370874 & 2.095046 \\ \mathrm{H} & 5.350760 & 0.743339 & 2.289503 \\ \mathrm{C} & 4.671544 & -1.757118 & -2.035494 \\ \mathrm{H} & 5.434805 & -2.506190 & -2.263293 \\ \mathrm{H} & 3.714298 & -2.120498 & -2.422245 \\ \mathrm{H} & 4.926874 & -0.842573 & -2.576694 \\ \mathrm{C} & 4.268697 & -2.882322 & 0.184834 \\ \mathrm{H} & 3.382756 & -3.358426 & -0.243780 \\ \mathrm{H} & 5.105849 & -3.572270 & 0.048993 \\ \mathrm{H} & 4.111291 & -2.758397 & 1.260787 \\ \mathrm{C} & -3.179867 & 1.840572 & -0.286746 \\ \mathrm{C} & -4.507102 & 2.264426 & -0.389889 \\ \mathrm{C} & -5.247885 & 1.076739 & -0.589828 \\ \mathrm{H} & -4.900829 & 3.269198 & -0.336693 \\ \mathrm{~N} & -3.136984 & 0.488576 & -0.427055 \\ \mathrm{~N} & -4.406681 & 0.019066 & -0.597995 \\ \mathrm{C} & -6.725550 & 0.916383 & -0.790783 \\ \mathrm{H} & -7.039920 & 1.361448 & -1.740034 \\ \mathrm{H} & -7.000564 & -0.140107 & -0.802760 \\ \mathrm{H} & -7.287920 & 1.414385 & 0.004254\end{array}$

$\mathrm{M}=\mathrm{Cm}$

$\begin{array}{lrrr}\mathrm{CM} & -1.254019 & -0.870130 & 0.110318 \\ \mathrm{O} & -1.104145 & -2.834210 & 1.844056 \\ \mathrm{H} & -0.692769 & -3.705684 & 1.741512 \\ \mathrm{O} & -0.488946 & -0.189018 & 2.509657 \\ \mathrm{H} & -0.269965 & -0.915041 & 3.115673 \\ \mathrm{O} & -3.149109 & -2.258796 & -0.731102 \\ \mathrm{H} & -3.378686 & -3.100532 & -1.147060 \\ \mathrm{O} & -3.209166 & -1.165302 & 2.001348 \\ \mathrm{H} & -4.058713 & -1.089273 & 1.529393 \\ \mathrm{O} & 0.318096 & -2.647942 & -0.789021 \\ \mathrm{H} & 0.339308 & -3.484789 & -1.273330 \\ \mathrm{O} & -1.080765 & -0.455524 & -2.386054 \\ \mathrm{H} & -0.589049 & -0.910674 & -3.085265 \\ \mathrm{H} & -1.986533 & -2.963316 & 2.234737 \\ \mathrm{H} & -3.274439 & -0.563778 & 2.759569 \\ \mathrm{H} & 1.247604 & -2.292750 & -0.688467 \\ \mathrm{H} & -3.915133 & -1.597085 & -0.846853\end{array}$




\begin{tabular}{|c|c|c|c|}
\hline $\mathrm{H}$ & -1.834793 & -0.008134 & -2.802008 \\
\hline & -0.181338 & 0.635282 & 2.915434 \\
\hline & -1.918173 & 2.501739 & -0.068125 \\
\hline 0 & -1.779461 & 3.899965 & 0.009780 \\
\hline $\mathrm{C}$ & -0.509695 & 4.448966 & 0.159612 \\
\hline $\mathrm{H}$ & -2.655719 & 4.534214 & -0.059843 \\
\hline & 0.395063 & 2.226963 & 0.117314 \\
\hline C & 0.608420 & 3.600966 & 0.199590 \\
\hline $\mathrm{H}$ & -0.381696 & 5.525325 & 0.222216 \\
\hline 1 & 1.617115 & 3.986253 & 0.273981 \\
\hline$C$ & 1.534361 & 1.273190 & 0.057925 \\
\hline$C$ & 3.796718 & 0.900257 & 0.004604 \\
\hline$C$ & 3.512868 & -0.492633 & -0.239957 \\
\hline $\mathrm{N}$ & -0.839597 & 1.684350 & 0.020773 \\
\hline $\mathbf{N}$ & 2.783996 & 1.752203 & 0.134536 \\
\hline $\mathrm{N}$ & 1.238020 & -0.021619 & -0.104447 \\
\hline $\mathbf{N}$ & 2.245730 & -0.893229 & -0.270954 \\
\hline $\mathrm{C}$ & 5.206176 & 1.443024 & 0.169038 \\
\hline $\mathrm{C}$ & 6.242500 & 0.435022 & -0.375931 \\
\hline $\mathrm{H}$ & 6.292549 & 0.521464 & -1.466407 \\
\hline $\mathrm{H}$ & 7.230518 & 0.724347 & -0.006958 \\
\hline $\mathrm{C}$ & 5.950199 & -1.013647 & 0.022158 \\
\hline $\mathrm{C}$ & 4.594128 & -1.533916 & -0.509871 \\
\hline $\mathrm{H}$ & 5.972418 & -1.115677 & 1.112766 \\
\hline $\mathrm{H}$ & 6.740175 & -1.667436 & -0.358831 \\
\hline $\mathrm{C}$ & 5.351864 & 2.791186 & -0.569618 \\
\hline $\mathrm{H}$ & 4.689358 & 3.552940 & -0.155519 \\
\hline $\mathrm{H}$ & 6.382224 & 3.142795 & -0.468419 \\
\hline $\mathrm{H}$ & 5.137597 & 2.688209 & -1.637949 \\
\hline $\mathrm{C}$ & 5.413949 & 1.678985 & 1.692616 \\
\hline $\mathrm{H}$ & 6.405901 & 2.109788 & 1.852388 \\
\hline $\mathrm{H}$ & 4.670827 & 2.380857 & 2.080222 \\
\hline $\mathrm{H}$ & 5.351353 & 0.753854 & 2.272761 \\
\hline $\mathrm{C}$ & 4.656324 & -1.754939 & -2.045185 \\
\hline $\mathrm{H}$ & 5.419054 & -2.504274 & -2.273816 \\
\hline $\mathrm{H}$ & 3.697818 & -2.120381 & -2.427126 \\
\hline $\mathrm{H}$ & 4.908779 & -0.841935 & -2.590381 \\
\hline $\mathrm{C}$ & 4.263734 & -2.873381 & 0.180736 \\
\hline $\mathrm{H}$ & 3.373731 & -3.350167 & -0.238451 \\
\hline $\mathrm{H}$ & 5.099613 & -3.564022 & 0.040617 \\
\hline $\mathrm{H}$ & 4.114924 & -2.745972 & 1.257530 \\
\hline $\mathrm{C}$ & -3.192039 & 1.821260 & -0.285934 \\
\hline $\mathrm{C}$ & -4.520444 & 2.240693 & -0.399727 \\
\hline $\mathrm{C}$ & -5.254203 & 1.052291 & -0.620425 \\
\hline $\mathrm{H}$ & -4.918928 & 3.243261 & -0.340388 \\
\hline $\mathrm{N}$ & -3.142557 & 0.469593 & -0.436704 \\
\hline
\end{tabular}




$\begin{array}{rrrr}\mathrm{N} & -4.407507 & -0.000583 & -0.630542 \\ \mathrm{C} & -6.729451 & 0.887534 & -0.836290 \\ \mathrm{H} & -7.041665 & 1.360368 & -1.772700 \\ \mathrm{H} & -6.995712 & -0.170218 & -0.883796 \\ \mathrm{H} & -7.301228 & 1.354820 & -0.029300\end{array}$

\section{$\left[\mathrm{ML}\left(\mathrm{H}_{2} \mathrm{O}\right)_{5}\right]^{2+}$}

$\mathrm{M}=\mathrm{Eu}$

$\begin{array}{lrrc}\text { EU } & 1.410791 & -1.133141 & 0.084689 \\ \mathrm{O} & 0.689748 & -2.819991 & 1.874861 \\ \mathrm{H} & 0.129924 & -3.568796 & 1.617431 \\ \mathrm{O} & -0.302820 & -2.843455 & -0.772642 \\ \mathrm{H} & -0.396711 & -3.585621 & -1.386301 \\ \mathrm{O} & 3.442881 & -2.578326 & -0.032587 \\ \mathrm{H} & 3.755939 & -3.492756 & -0.009672 \\ \mathrm{O} & 2.035705 & -0.375344 & 2.511849 \\ \mathrm{H} & 2.906288 & 0.009057 & 2.699020 \\ \mathrm{O} & 1.628407 & -0.992089 & -2.450388 \\ \mathrm{H} & 1.071485 & -1.334284 & -3.165201 \\ \mathrm{H} & 4.228625 & -1.973227 & -0.156107 \\ \mathrm{H} & 2.429176 & -0.641094 & -2.870044 \\ \mathrm{H} & 1.132278 & -3.060995 & 2.702613 \\ \mathrm{H} & -1.194971 & -2.417086 & -0.642490 \\ \mathrm{H} & 1.492917 & -0.205972 & 3.296787 \\ \mathrm{C} & 2.204720 & 2.297926 & -0.047327 \\ \mathrm{C} & 2.115358 & 3.702363 & 0.005030 \\ \mathrm{C} & 0.861034 & 4.297943 & 0.103552 \\ \mathrm{H} & 3.014820 & 4.306068 & -0.032565 \\ \mathrm{C} & -0.107942 & 2.097551 & 0.071276 \\ \mathrm{C} & -0.278133 & 3.483896 & 0.134954 \\ \mathrm{H} & 0.766098 & 5.378451 & 0.148409 \\ \mathrm{H} & -1.276178 & 3.897857 & 0.198145 \\ \mathrm{C} & -1.291015 & 1.191765 & 0.050289 \\ \mathrm{C} & -3.568897 & 0.932468 & 0.028217 \\ \mathrm{C} & -3.356311 & -0.483366 & -0.132196 \\ \mathrm{~N} & 1.101595 & 1.510643 & -0.007467 \\ \mathrm{~N} & -2.513213 & 1.739248 & 0.090966 \\ \mathrm{~N} & -1.057027 & -0.122361 & -0.039224 \\ \mathrm{~N} & -2.109901 & -0.948698 & -0.157263 \\ \mathrm{C} & -4.947370 & 1.569773 & 0.072524 \\ \mathrm{C} & -6.036691 & 0.492188 & 0.267334 \\ \mathrm{H} & -6.093885 & 0.219330 & 1.326327 \\ \mathrm{H} & -7.006026 & 0.933177 & 0.018668 \\ \mathrm{C} & -5.806700 & -0.759108 & -0.583729\end{array}$




$\begin{array}{lrrr}\mathrm{C} & -4.491878 & -1.496627 & -0.238342 \\ \mathrm{H} & -5.804866 & -0.494922 & -1.647023 \\ \mathrm{H} & -6.637015 & -1.457967 & -0.446756 \\ \mathrm{C} & -5.014582 & 2.596186 & 1.225581 \\ \mathrm{H} & -4.301484 & 3.410064 & 1.083072 \\ \mathrm{H} & -6.019741 & 3.024855 & 1.262784 \\ \mathrm{H} & -4.816949 & 2.125444 & 2.193883 \\ \mathrm{C} & -5.145010 & 2.315013 & -1.277638 \\ \mathrm{H} & -6.109830 & 2.828690 & -1.260968 \\ \mathrm{H} & -4.361348 & 3.061844 & -1.426812 \\ \mathrm{H} & -5.139527 & 1.635553 & -2.134525 \\ \mathrm{C} & -4.610644 & -2.216567 & 1.131221 \\ \mathrm{H} & -5.408758 & -2.962318 & 1.081544 \\ \mathrm{H} & -3.678341 & -2.731176 & 1.382212 \\ \mathrm{H} & -4.845535 & -1.527895 & 1.946785 \\ \mathrm{C} & -4.197946 & -2.543988 & -1.333299 \\ \mathrm{H} & -3.359530 & -3.193883 & -1.067534 \\ \mathrm{H} & -5.074323 & -3.185199 & -1.460461 \\ \mathrm{H} & -3.988969 & -2.073172 & -2.298999 \\ \mathrm{C} & 3.481147 & 1.601352 & -0.150751 \\ \mathrm{C} & 4.800485 & 2.023005 & -0.222980 \\ \mathrm{C} & 5.558868 & 0.827227 & -0.299396 \\ \mathrm{H} & 5.191172 & 3.030128 & -0.223694 \\ \mathrm{~N} & 3.457716 & 0.205142 & -0.191638 \\ \mathrm{~N} & 4.706018 & -0.248760 & -0.271330 \\ \mathrm{C} & 7.033513 & 0.655127 & -0.420014 \\ \mathrm{H} & 7.564897 & 1.335519 & 0.252131 \\ \mathrm{H} & 7.325506 & -0.372992 & -0.200238 \\ \mathrm{H} & 7.365317 & 0.893587 & -1.438749\end{array}$

$\mathrm{M}=\mathrm{Gd}$

$\begin{array}{lccc}\text { GD } & 1.371159 & -1.031322 & 0.101288 \\ \mathrm{O} & 0.633291 & -2.607708 & 1.898753 \\ \mathrm{H} & 0.113847 & -3.405015 & 1.711539 \\ \mathrm{O} & -0.190369 & -2.750195 & -0.796137 \\ \mathrm{H} & -0.212969 & -3.507887 & -1.398138 \\ \mathrm{O} & 3.228702 & -2.518381 & -0.062326 \\ \mathrm{H} & 3.490397 & -3.448833 & -0.047432 \\ \mathrm{O} & 2.017224 & -0.292269 & 2.439533 \\ \mathrm{H} & 2.894832 & 0.123455 & 2.477970 \\ \mathrm{O} & 1.578173 & -0.789940 & -2.337813 \\ \mathrm{H} & 1.081041 & -1.114285 & -3.103226 \\ \mathrm{H} & 4.063362 & -1.918519 & -0.171714 \\ \mathrm{H} & 2.395727 & -0.387329 & -2.673052 \\ \mathrm{H} & 1.101851 & -2.755425 & 2.735180\end{array}$




\begin{tabular}{|c|c|c|c|}
\hline $\mathrm{H}$ & -1.114575 & -2.390923 & -0.671622 \\
\hline & 1.532238 & 0.007730 & 3.223799 \\
\hline & 2.232648 & 2.256123 & -0.050244 \\
\hline & 2.159603 & 3.661738 & -0.020946 \\
\hline & 0.915140 & 4.276523 & 0.071932 \\
\hline & 3.068756 & 4.249907 & -0.071650 \\
\hline & -0.095165 & 2.101642 & 0.078482 \\
\hline & -0.243820 & 3.484907 & 0.119882 \\
\hline $\mathrm{H}$ & 0.839012 & 5.359209 & 0.099235 \\
\hline 1 & -1.233411 & 3.919486 & 0.177263 \\
\hline & -1.271968 & 1.196171 & 0.062509 \\
\hline 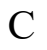 & -3.545162 & 0.901039 & 0.028229 \\
\hline $\mathrm{C}$ & -3.312285 & -0.515362 & -0.133196 \\
\hline $\mathbf{N}$ & 1.110870 & 1.494524 & 0.008058 \\
\hline $\mathrm{N}$ & -2.502399 & 1.723517 & 0.096751 \\
\hline $\mathrm{N}$ & -1.022268 & -0.117650 & -0.024151 \\
\hline $\mathrm{N}$ & -2.061406 & -0.962767 & -0.151344 \\
\hline$C$ & -4.931966 & 1.517639 & 0.063003 \\
\hline $\mathrm{C}$ & -6.010255 & 0.425821 & 0.239484 \\
\hline $\mathrm{H}$ & -6.080100 & 0.149723 & 1.296769 \\
\hline $\mathrm{H}$ & -6.980983 & 0.855685 & -0.022383 \\
\hline $\mathrm{C}$ & -5.753060 & -0.820228 & -0.611480 \\
\hline $\mathrm{C}$ & -4.434286 & -1.542276 & -0.248899 \\
\hline $\mathrm{H}$ & -5.739776 & -0.553910 & -1.674160 \\
\hline $\mathrm{H}$ & -6.576194 & -1.529796 & -0.487371 \\
\hline $\mathrm{C}$ & -5.023194 & 2.538085 & 1.220353 \\
\hline $\mathrm{H}$ & -4.318253 & 3.360788 & 1.089155 \\
\hline $\mathrm{H}$ & -6.033800 & 2.954314 & 1.247775 \\
\hline $\mathrm{H}$ & -4.831286 & 2.065033 & 2.188650 \\
\hline $\mathrm{C}$ & -5.124203 & 2.268028 & -1.286208 \\
\hline $\mathrm{H}$ & -6.095951 & 2.768463 & -1.275538 \\
\hline $\mathrm{H}$ & -4.349163 & 3.025983 & -1.422732 \\
\hline $\mathrm{H}$ & -5.101711 & 1.593375 & -2.146604 \\
\hline $\mathrm{C}$ & -4.560035 & -2.257652 & 1.122710 \\
\hline $\mathrm{H}$ & -5.352634 & -3.008846 & 1.068629 \\
\hline $\mathrm{H}$ & -3.626704 & -2.765674 & 1.383512 \\
\hline $\mathrm{H}$ & -4.806635 & -1.568204 & 1.934048 \\
\hline $\mathrm{C}$ & -4.115519 & -2.590420 & -1.335992 \\
\hline $\mathrm{H}$ & -3.272554 & -3.229891 & -1.058462 \\
\hline $\mathrm{H}$ & -4.982243 & -3.243194 & -1.469487 \\
\hline $\mathrm{H}$ & -3.902779 & -2.121523 & -2.301816 \\
\hline $\mathrm{C}$ & 3.480817 & 1.506600 & -0.149490 \\
\hline $\mathrm{C}$ & 4.830549 & 1.847422 & -0.256498 \\
\hline $\mathrm{C}$ & 5.512582 & 0.606749 & -0.323599 \\
\hline $\mathrm{H}$ & 5.276970 & 2.830995 & -0.288858 \\
\hline $\mathrm{N}$ & 3.371270 & 0.144844 & -0.152438 \\
\hline
\end{tabular}




$\begin{array}{rrrr}\mathrm{N} & 4.616381 & -0.397152 & -0.257315 \\ \mathrm{C} & 6.985186 & 0.352550 & -0.449528 \\ \mathrm{H} & 7.532552 & 0.794290 & 0.388497 \\ \mathrm{H} & 7.188473 & -0.719598 & -0.467940 \\ \mathrm{H} & 7.381572 & 0.795162 & -1.368284\end{array}$

$\mathrm{M}=\mathrm{Am}$

$\begin{array}{lrcc}\text { AM } & 1.285567 & -0.950379 & 0.045387 \\ \mathrm{O} & 0.824991 & -2.796193 & 1.768407 \\ \mathrm{H} & 0.301233 & -3.569412 & 1.505100 \\ \mathrm{O} & -0.387271 & -2.709785 & -0.760329 \\ \mathrm{H} & -0.445292 & -3.390592 & -1.446475 \\ \mathrm{O} & 3.302786 & -2.298977 & -0.166717 \\ \mathrm{H} & 3.622644 & -3.210437 & -0.201070 \\ \mathrm{O} & 1.776517 & -0.221440 & 2.464301 \\ \mathrm{H} & 2.542617 & 0.358992 & 2.602285 \\ \mathrm{O} & 1.522896 & -0.773251 & -2.469457 \\ \mathrm{H} & 0.969966 & -0.986783 & -3.236198 \\ \mathrm{H} & 4.095732 & -1.628477 & -0.202737 \\ \mathrm{H} & 2.372544 & -0.453159 & -2.814842 \\ \mathrm{H} & 1.394106 & -3.067138 & 2.505630 \\ \mathrm{H} & -1.292867 & -2.302481 & -0.619958 \\ \mathrm{H} & 1.279137 & -0.237258 & 3.296391 \\ \mathrm{C} & 2.020460 & 2.442504 & -0.034044 \\ \mathrm{C} & 1.906935 & 3.844684 & 0.009880 \\ \mathrm{C} & 0.644114 & 4.422327 & 0.084258 \\ \mathrm{H} & 2.799515 & 4.459172 & -0.013402 \\ \mathrm{C} & -0.298260 & 2.216597 & 0.053743 \\ \mathrm{C} & -0.488964 & 3.594801 & 0.107400 \\ \mathrm{H} & 0.534816 & 5.501808 & 0.121462 \\ \mathrm{H} & -1.491896 & 3.998047 & 0.159331 \\ \mathrm{C} & -1.453127 & 1.285267 & 0.036105 \\ \mathrm{C} & -3.722362 & 0.947844 & 0.027416 \\ \mathrm{C} & -3.464229 & -0.466187 & -0.108767 \\ \mathrm{~N} & 0.924876 & 1.644614 & -0.011017 \\ \mathrm{~N} & -2.694272 & 1.789114 & 0.075842 \\ \mathrm{~N} & -1.178225 & -0.022585 & -0.047596 \\ \mathrm{~N} & -2.205216 & -0.887152 & -0.144092 \\ \mathrm{C} & -5.120316 & 1.540019 & 0.056022 \\ \mathrm{C} & -6.177673 & 0.434079 & 0.268547 \\ \mathrm{H} & -6.236816 & 0.186257 & 1.333425 \\ \mathrm{H} & -7.157426 & 0.839014 & 0.000590 \\ \mathrm{C} & -5.903249 & -0.830773 & -0.548725 \\ \mathrm{C} & -4.567655 & -1.516949 & -0.178038 \\ \mathrm{H} & -5.904212 & -0.595130 & -1.618775\end{array}$




$\begin{array}{cccc}\mathrm{H} & -6.711375 & -1.552061 & -0.396588 \\ \mathrm{C} & -5.223960 & 2.589079 & 1.186165 \\ \mathrm{H} & -4.536939 & 3.422042 & 1.027688 \\ \mathrm{H} & -6.242606 & 2.985494 & 1.210571 \\ \mathrm{H} & -5.015081 & 2.146225 & 2.165149 \\ \mathrm{C} & -5.334088 & 2.250041 & -1.311630 \\ \mathrm{H} & -6.314022 & 2.734394 & -1.308138 \\ \mathrm{H} & -4.572808 & 3.016885 & -1.474000 \\ \mathrm{H} & -5.305723 & 1.552610 & -2.153559 \\ \mathrm{C} & -4.663994 & -2.188101 & 1.218340 \\ \mathrm{H} & -5.443400 & -2.954696 & 1.199177 \\ \mathrm{H} & -3.718514 & -2.670478 & 1.484248 \\ \mathrm{H} & -4.913510 & -1.476381 & 2.009289 \\ \mathrm{C} & -4.243518 & -2.595835 & -1.232903 \\ \mathrm{H} & -3.391109 & -3.216013 & -0.940961 \\ \mathrm{H} & -5.102838 & -3.263405 & -1.338038 \\ \mathrm{H} & -4.044658 & -2.156083 & -2.215392 \\ \mathrm{C} & 3.296533 & 1.740290 & -0.103966 \\ \mathrm{C} & 4.628681 & 2.146399 & -0.178304 \\ \mathrm{C} & 5.371499 & 0.940917 & -0.236046 \\ \mathrm{H} & 5.027542 & 3.150406 & -0.199227 \\ \mathrm{~N} & 3.249563 & 0.376392 & -0.114766 \\ \mathrm{~N} & 4.524305 & -0.102980 & -0.193851 \\ \mathrm{C} & 6.856436 & 0.758709 & -0.334473 \\ \mathrm{H} & 7.365153 & 1.228821 & 0.512487 \\ \mathrm{H} & 7.113256 & -0.302021 & -0.345593 \\ \mathrm{H} & 7.247837 & 1.218940 & -1.246763\end{array}$

$\mathrm{M}=\mathrm{Cm}$

$\begin{array}{lccc}\mathrm{CM} & 1.269618 & -0.928789 & 0.086636 \\ \mathrm{O} & 0.651969 & -2.644327 & 1.883516 \\ \mathrm{H} & 0.141064 & -3.436780 & 1.655609 \\ \mathrm{O} & -0.341230 & -2.711285 & -0.799314 \\ \mathrm{H} & -0.388724 & -3.455602 & -1.416549 \\ \mathrm{O} & 3.241420 & -2.355314 & -0.129158 \\ \mathrm{H} & 3.549505 & -3.270962 & -0.164898 \\ \mathrm{O} & 1.933285 & -0.209040 & 2.467902 \\ \mathrm{H} & 2.776273 & 0.270994 & 2.521821 \\ \mathrm{O} & 1.467488 & -0.697527 & -2.406060 \\ \mathrm{H} & 0.982435 & -1.064473 & -3.160488 \\ \mathrm{H} & 4.037715 & -1.708298 & -0.232546 \\ \mathrm{H} & 2.280648 & -0.295265 & -2.752833 \\ \mathrm{H} & 1.171284 & -2.852148 & 2.676036 \\ \mathrm{H} & -1.254774 & -2.327066 & -0.672873 \\ \mathrm{H} & 1.450559 & -0.023431 & 3.288298\end{array}$




$\begin{array}{lrrc}\mathrm{C} & 2.036629 & 2.414328 & -0.038751 \\ \mathrm{C} & 1.929226 & 3.817359 & 0.005402 \\ \mathrm{C} & 0.670577 & 4.400783 & 0.103708 \\ \mathrm{H} & 2.823586 & 4.428140 & -0.039449 \\ \mathrm{C} & -0.287325 & 2.201698 & 0.087279 \\ \mathrm{C} & -0.468475 & 3.580629 & 0.141428 \\ \mathrm{H} & 0.568045 & 5.480956 & 0.142177 \\ \mathrm{H} & -1.468128 & 3.991040 & 0.201136 \\ \mathrm{C} & -1.448118 & 1.274660 & 0.060886 \\ \mathrm{C} & -3.717143 & 0.944601 & 0.027415 \\ \mathrm{C} & -3.462905 & -0.466908 & -0.140482 \\ \mathrm{~N} & 0.934008 & 1.625033 & 0.013773 \\ \mathrm{~N} & -2.686933 & 1.782489 & 0.101180 \\ \mathrm{~N} & -1.179041 & -0.034179 & -0.038535 \\ \mathrm{~N} & -2.205577 & -0.894873 & -0.164824 \\ \mathrm{C} & -5.113288 & 1.540349 & 0.065124 \\ \mathrm{C} & -6.174801 & 0.431951 & 0.240487 \\ \mathrm{H} & -6.238793 & 0.152509 & 1.297288 \\ \mathrm{H} & -7.152280 & 0.847700 & -0.019034 \\ \mathrm{C} & -5.900109 & -0.808308 & -0.613372 \\ \mathrm{C} & -4.569574 & -1.510698 & -0.255138 \\ \mathrm{H} & -5.893172 & -0.539766 & -1.675597 \\ \mathrm{H} & -6.711982 & -1.530676 & -0.488902 \\ \mathrm{C} & -5.219095 & 2.556680 & 1.224722 \\ \mathrm{H} & -4.527603 & 3.390850 & 1.094375 \\ \mathrm{H} & -6.236178 & 2.956689 & 1.254787 \\ \mathrm{C} & -3.514398 & -0.151997 & -0.295454 \\ \mathrm{H} & -5.017956 & 2.084652 & 2.191660 \\ \mathrm{C} & -5.318185 & 2.290357 & -1.282366 \\ \mathrm{H} & -6.297270 & 2.776285 & -1.270097 \\ \mathrm{H} & -4.554611 & 3.060047 & -1.418181 \\ \mathrm{H} & -5.286289 & 1.617756 & -2.144093 \\ \mathrm{C} & -4.680897 & -2.230611 & 1.115384 \\ \mathrm{H} & -5.460751 & -2.995065 & 1.061250 \\ \mathrm{H} & -3.738609 & -2.723188 & 1.373791 \\ \mathrm{H} & -4.937837 & -1.546830 & 1.928340 \\ \mathrm{C} & -4.238125 & -2.552060 & -1.345011 \\ \mathrm{H} & -3.387470 & -3.181862 & -1.068881 \\ \mathrm{H} & -5.096793 & -3.215087 & -1.480083 \\ \mathrm{H} & -4.031108 & -2.078115 & -2.309673 \\ \mathrm{H} & 3.307069 & 1.704809 & -0.151005 \\ \mathrm{H} & 5.370292 & 0.886186 & -0.348192 \\ \mathrm{H} & -0.691061 & -0.484930\end{array}$




$\begin{array}{rrrc}\mathrm{H} & 7.385712 & 1.145462 & 0.354448 \\ \mathrm{H} & 7.095902 & -0.372098 & -0.515446 \\ \mathrm{H} & 7.224350 & 1.157927 & -1.401369\end{array}$

\section{$\left[\mathrm{ML}_{2}\left(\mathrm{H}_{2} \mathrm{O}\right)_{2}\right]^{1+}$}

$\mathrm{M}=\mathrm{Eu}$

$\begin{array}{lccc}\text { EU } & -0.718550 & -1.202838 & 0.035421 \\ \mathrm{O} & 0.258852 & -1.284454 & -2.283448 \\ \mathrm{H} & 1.244131 & -1.266155 & -2.204456 \\ \mathrm{O} & 0.216826 & -3.451983 & 0.632238 \\ \mathrm{H} & 0.531071 & -3.820576 & 1.467684 \\ \mathrm{H} & 0.003945 & -2.000453 & -2.882175 \\ \mathrm{H} & -0.467620 & -4.098524 & 0.235089 \\ \mathrm{C} & -3.629202 & -1.481105 & -1.815184 \\ \mathrm{C} & -4.824273 & -1.164767 & -2.489459 \\ \mathrm{C} & -5.139585 & 0.169344 & -2.723559 \\ \mathrm{H} & -5.486369 & -1.959862 & -2.812086 \\ \mathrm{C} & -3.098524 & 0.777879 & -1.624923 \\ \mathrm{C} & -4.261969 & 1.170678 & -2.285697 \\ \mathrm{H} & -6.057931 & 0.433632 & -3.239134 \\ \mathrm{H} & -4.462971 & 2.221970 & -2.443158 \\ \mathrm{C} & -2.123424 & 1.784139 & -1.128853 \\ \mathrm{C} & -1.494642 & 3.967734 & -0.871285 \\ \mathrm{C} & -0.339213 & 3.502764 & -0.172650 \\ \mathrm{~N} & -2.786140 & -0.510657 & -1.396466 \\ \mathrm{~N} & -2.375780 & 3.083626 & -1.332932 \\ \mathrm{~N} & -1.030273 & 1.322160 & -0.500177 \\ \mathrm{~N} & -0.138795 & 2.192201 & -0.024015 \\ \mathrm{C} & -1.800285 & 5.444241 & -1.094780 \\ \mathrm{C} & -0.546913 & 6.298681 & -0.802808 \\ \mathrm{H} & 0.132892 & 6.246760 & -1.660806 \\ \mathrm{H} & -0.851861 & 7.346931 & -0.721830 \\ \mathrm{C} & 0.190112 & 5.872174 & 0.469794 \\ \mathrm{C} & 0.732495 & 4.426617 & 0.403764 \\ \mathrm{H} & -0.477394 & 5.966495 & 1.333616 \\ \mathrm{H} & 1.028780 & 6.550239 & 0.658941 \\ \mathrm{C} & -2.253572 & 5.672948 & -2.552238 \\ \mathrm{H} & -3.168300 & 5.121628 & -2.776810 \\ \mathrm{H} & -2.444323 & 6.738897 & -2.709620 \\ \mathrm{H} & -1.481909 & 5.360568 & -3.263342 \\ \mathrm{C} & -2.963710 & 5.824314 & -0.141897 \\ \mathrm{H} & -3.243124 & 6.869107 & -0.307097 \\ \mathrm{H} & -3.838431 & 5.198625 & -0.336713 \\ \mathrm{H} & -2.692811 & 5.707979 & 0.911296\end{array}$




\begin{tabular}{|c|c|c|c|}
\hline $\mathrm{C}$ & 1.977767 & 4.347914 & -0.513890 \\
\hline $\mathrm{H}$ & 2.778507 & 4.973113 & -0.106764 \\
\hline & 2.339756 & 3.317597 & -0.574110 \\
\hline & 1.765487 & 4.689934 & -1.530882 \\
\hline $\mathrm{C}$ & 1.126064 & 3.965815 & 1.822831 \\
\hline & 1.559770 & 2.964007 & 1.811860 \\
\hline $\mathrm{H}$ & 1.862710 & 4.659567 & 2.240395 \\
\hline $\mathrm{H}$ & 0.258677 & 3.953623 & 2.490328 \\
\hline $\mathrm{C}$ & -3.213253 & -2.848208 & -1.522099 \\
\hline $\mathrm{C}$ & -3.772922 & -4.104433 & -1.781764 \\
\hline C & -2.864881 & -5.020345 & -1.204791 \\
\hline $\mathrm{H}$ & -4.692815 & -4.339739 & -2.297612 \\
\hline $\mathrm{N}$ & -2.047069 & -3.016287 & -0.843711 \\
\hline $\mathrm{N}$ & -1.841173 & -4.341982 & -0.646205 \\
\hline $\mathrm{C}$ & -2.937505 & -6.518836 & -1.159571 \\
\hline $\mathrm{H}$ & -2.993119 & -6.945721 & -2.166302 \\
\hline $\mathrm{H}$ & -2.053438 & -6.924305 & -0.662621 \\
\hline $\mathrm{H}$ & -3.823829 & -6.855175 & -0.611341 \\
\hline $\mathrm{C}$ & -0.311680 & -0.450306 & 3.379723 \\
\hline C & 0.247544 & -0.186326 & 4.652301 \\
\hline $\mathrm{C}$ & 1.622068 & -0.050934 & 4.779107 \\
\hline $\mathrm{H}$ & -0.404435 & -0.091620 & 5.512708 \\
\hline $\mathrm{C}$ & 1.814408 & -0.438792 & 2.420216 \\
\hline $\mathrm{C}$ & 2.434244 & -0.172883 & 3.639069 \\
\hline $\mathrm{H}$ & 2.067176 & 0.151652 & 5.748613 \\
\hline $\mathrm{H}$ & 3.509691 & -0.065950 & 3.684933 \\
\hline $\mathrm{C}$ & 2.619128 & -0.574781 & 1.178038 \\
\hline $\mathrm{C}$ & 4.666332 & -0.605050 & 0.148566 \\
\hline $\mathrm{C}$ & 3.990068 & -0.861899 & -1.086576 \\
\hline $\mathrm{N}$ & 0.479815 & -0.582627 & 2.286637 \\
\hline $\mathrm{N}$ & 3.955092 & -0.474831 & 1.263178 \\
\hline $\mathrm{N}$ & 1.956476 & -0.796531 & 0.034944 \\
\hline $\mathrm{N}$ & 2.661331 & -0.942403 & -1.089998 \\
\hline $\mathrm{C}$ & 6.182937 & -0.516759 & 0.267479 \\
\hline $\mathrm{C}$ & 6.821964 & -0.361793 & -1.130125 \\
\hline $\mathrm{H}$ & 6.732691 & 0.680761 & -1.455028 \\
\hline $\mathrm{H}$ & 7.894858 & -0.560746 & -1.045284 \\
\hline $\mathrm{C}$ & 6.205175 & -1.287787 & -2.181929 \\
\hline $\mathrm{C}$ & 4.703190 & -1.016800 & -2.427889 \\
\hline $\mathrm{H}$ & 6.337833 & -2.333214 & -1.881553 \\
\hline $\mathrm{H}$ & 6.735940 & -1.175260 & -3.132603 \\
\hline $\mathrm{C}$ & 6.573479 & 0.686261 & 1.151837 \\
\hline $\mathrm{H}$ & 6.182083 & 0.581150 & 2.165210 \\
\hline $\mathrm{H}$ & 7.663980 & 0.754906 & 1.207998 \\
\hline $\mathrm{H}$ & 6.198746 & 1.626412 & 0.734283 \\
\hline$C$ & 6.665714 & -1.822017 & 0.95372 \\
\hline
\end{tabular}




$\begin{array}{rrrr}\mathrm{H} & 7.748918 & -1.776043 & 1.099049 \\ \mathrm{H} & 6.191786 & -1.939307 & 1.931622 \\ \mathrm{H} & 6.441477 & -2.711935 & 0.358841 \\ \mathrm{C} & 4.505462 & 0.295036 & -3.229691 \\ \mathrm{H} & 4.981808 & 0.201761 & -4.210198 \\ \mathrm{H} & 3.441767 & 0.496903 & -3.384533 \\ \mathrm{H} & 4.941671 & 1.160677 & -2.723493 \\ \mathrm{C} & 4.107103 & -2.190935 & -3.233057 \\ \mathrm{H} & 3.079668 & -1.992755 & -3.546937 \\ \mathrm{H} & 4.703217 & -2.347838 & -4.137004 \\ \mathrm{H} & 4.118628 & -3.121126 & -2.656874 \\ \mathrm{C} & -1.737364 & -0.587867 & 3.164749 \\ \mathrm{C} & -2.833529 & -0.544270 & 4.030295 \\ \mathrm{C} & -3.947631 & -0.748190 & 3.187158 \\ \mathrm{H} & -2.841830 & -0.398588 & 5.101142 \\ \mathrm{~N} & -2.197778 & -0.790633 & 1.882080 \\ \mathrm{~N} & -3.537613 & -0.894952 & 1.901850 \\ \mathrm{C} & -5.403711 & -0.797553 & 3.544462 \\ \mathrm{H} & -5.758480 & 0.170511 & 3.915657 \\ \mathrm{H} & -5.990590 & -1.065530 & 2.663672 \\ \mathrm{H} & -5.594283 & -1.537678 & 4.328910\end{array}$

$\mathrm{M}=\mathrm{Gd}$

$\begin{array}{lccc}\text { GD } & -0.701092 & -1.206987 & 0.084912 \\ \mathrm{O} & 0.250301 & -1.369010 & -2.220534 \\ \mathrm{H} & 1.236640 & -1.350355 & -2.154148 \\ \mathrm{O} & 0.247076 & -3.351006 & 0.848273 \\ \mathrm{H} & 0.493744 & -3.640615 & 1.736257 \\ \mathrm{H} & -0.015780 & -2.097593 & -2.798925 \\ \mathrm{H} & -0.385641 & -4.050383 & 0.444369 \\ \mathrm{C} & -3.538726 & -1.621415 & -1.780260 \\ \mathrm{C} & -4.729805 & -1.349363 & -2.479826 \\ \mathrm{C} & -5.070270 & -0.029165 & -2.753799 \\ \mathrm{H} & -5.369615 & -2.167354 & -2.789949 \\ \mathrm{C} & -3.057645 & 0.654330 & -1.648238 \\ \mathrm{C} & -4.219605 & 1.003268 & -2.334118 \\ \mathrm{H} & -5.987320 & 0.200929 & -3.287716 \\ \mathrm{H} & -4.440373 & 2.045077 & -2.524695 \\ \mathrm{C} & -2.102635 & 1.688710 & -1.175681 \\ \mathrm{C} & -1.505511 & 3.886878 & -0.977778 \\ \mathrm{C} & -0.341920 & 3.457653 & -0.268429 \\ \mathrm{~N} & -2.723826 & -0.620331 & -1.376525 \\ \mathrm{~N} & -2.372980 & 2.977829 & -1.415757 \\ \mathrm{~N} & -1.003782 & 1.260193 & -0.532134 \\ \mathrm{~N} & -0.123089 & 2.155493 & -0.082040\end{array}$




\begin{tabular}{|c|c|c|c|}
\hline $\mathrm{C}$ & -1.834353 & 5.351916 & -1.237954 \\
\hline & -0.592437 & 6.232144 & -0.975992 \\
\hline H & 0.084144 & 6.166331 & -1.835592 \\
\hline I & -0.912443 & 7.277643 & -0.922603 \\
\hline C & 0.156184 & 5.852054 & 0.304463 \\
\hline $\mathrm{C}$ & 0.718467 & 4.412795 & 0.277302 \\
\hline $\mathrm{H}$ & -0.508495 & 5.961931 & 1.168574 \\
\hline $\mathrm{H}$ & 0.986349 & 6.546493 & 0.470058 \\
\hline $\mathrm{C}$ & -2.300065 & 5.536421 & -2.697736 \\
\hline $\mathrm{H}$ & -3.208182 & 4.966720 & -2.902202 \\
\hline $\mathrm{H}$ & -2.507213 & 6.595158 & -2.880750 \\
\hline $\mathrm{H}$ & -1.528390 & 5.217265 & -3.405808 \\
\hline $\mathrm{C}$ & -2.997916 & 5.738228 & -0.287332 \\
\hline $\mathrm{H}$ & -3.293218 & 6.774505 & -0.476620 \\
\hline $\mathrm{H}$ & -3.864556 & 5.095478 & -0.461560 \\
\hline $\mathrm{H}$ & -2.719625 & 5.651721 & 0.766758 \\
\hline $\mathrm{C}$ & 1.961055 & 4.325424 & -0.643304 \\
\hline $\mathrm{H}$ & 2.754191 & 4.973481 & -0.257726 \\
\hline $\mathrm{H}$ & 2.337894 & 3.299159 & -0.675400 \\
\hline $\mathrm{H}$ & 1.739992 & 4.634987 & -1.668790 \\
\hline $\mathrm{C}$ & 1.123920 & 3.998850 & 1.707370 \\
\hline $\mathrm{H}$ & 1.574892 & 3.004897 & 1.723957 \\
\hline $\mathrm{H}$ & 1.849888 & 4.716668 & 2.102303 \\
\hline $\mathrm{H}$ & 0.258941 & 3.991107 & 2.377994 \\
\hline $\mathrm{C}$ & -3.090526 & -2.966917 & -1.442450 \\
\hline $\mathrm{C}$ & -3.603040 & -4.250771 & -1.668016 \\
\hline $\mathrm{C}$ & -2.678207 & -5.113757 & -1.042978 \\
\hline $\mathrm{H}$ & -4.506515 & -4.533708 & -2.188819 \\
\hline $\mathrm{N}$ & -1.935025 & -3.072747 & -0.736886 \\
\hline $\mathrm{N}$ & -1.687704 & -4.382058 & -0.489462 \\
\hline $\mathrm{C}$ & -2.704534 & -6.611458 & -0.939013 \\
\hline $\mathrm{H}$ & -2.765713 & -7.078203 & -1.927298 \\
\hline $\mathrm{H}$ & -1.799326 & -6.970977 & -0.444639 \\
\hline $\mathrm{H}$ & -3.569091 & -6.952654 & -0.360049 \\
\hline $\mathrm{C}$ & -0.393310 & -0.240841 & 3.337279 \\
\hline $\mathrm{C}$ & 0.140309 & 0.122875 & 4.596713 \\
\hline $\mathrm{C}$ & 1.509957 & 0.288406 & 4.737160 \\
\hline $\mathrm{H}$ & -0.528917 & 0.267999 & 5.436620 \\
\hline $\mathrm{C}$ & 1.753929 & -0.260602 & 2.417100 \\
\hline $\mathrm{C}$ & 2.347414 & 0.098882 & 3.623634 \\
\hline $\mathrm{H}$ & 1.933430 & 0.565565 & 5.697910 \\
\hline $\mathrm{H}$ & 3.420297 & 0.223733 & 3.682283 \\
\hline $\mathrm{C}$ & 2.574757 & -0.468023 & 1.197540 \\
\hline $\mathrm{C}$ & 4.631322 & -0.542457 & 0.189545 \\
\hline $\mathrm{C}$ & 3.969015 & -0.880732 & -1.034309 \\
\hline $\mathrm{N}$ & 0.423887 & -0.436557 & 2.272100 \\
\hline
\end{tabular}




$\begin{array}{lrrr}\mathrm{N} & 3.908511 & -0.348198 & 1.287072 \\ \mathrm{~N} & 1.925904 & -0.770759 & 0.064328 \\ \mathrm{~N} & 2.641835 & -0.976116 & -1.044318 \\ \mathrm{C} & 6.145902 & -0.436685 & 0.317041 \\ \mathrm{C} & 6.798590 & -0.362980 & -1.080853 \\ \mathrm{H} & 6.707976 & 0.657617 & -1.468871 \\ \mathrm{H} & 7.871390 & -0.550900 & -0.973172 \\ \mathrm{C} & 6.197363 & -1.353828 & -2.081233 \\ \mathrm{C} & 4.696488 & -1.106933 & -2.357585 \\ \mathrm{H} & 6.332463 & -2.378631 & -1.717611 \\ \mathrm{H} & 6.737016 & -1.295165 & -3.031741 \\ \mathrm{C} & 6.520604 & 0.819907 & 1.130947 \\ \mathrm{H} & 6.119447 & 0.773754 & 2.144867 \\ \mathrm{H} & 7.610067 & 0.898419 & 1.193534 \\ \mathrm{H} & 6.145035 & 1.730807 & 0.653565 \\ \mathrm{C} & 6.628509 & -1.695393 & 1.086006 \\ \mathrm{H} & 7.709947 & -1.634147 & 1.238549 \\ \mathrm{H} & 6.145583 & -1.755917 & 2.064638 \\ \mathrm{H} & 6.414992 & -2.621090 & 0.544061 \\ \mathrm{C} & 4.499675 & 0.156308 & -3.234274 \\ \mathrm{H} & 4.987485 & 0.011024 & -4.202727 \\ \mathrm{H} & 3.436593 & 0.342141 & -3.412028 \\ \mathrm{H} & 4.924910 & 1.052134 & -2.773296 \\ \mathrm{C} & 4.115938 & -2.328583 & -3.100937 \\ \mathrm{H} & 3.090341 & -2.155957 & -3.435360 \\ \mathrm{H} & 4.721933 & -2.531801 & -3.988913 \\ \mathrm{H} & 4.127762 & -3.224803 & -2.473266 \\ \mathrm{C} & -1.809633 & -0.415699 & 3.097899 \\ \mathrm{C} & -2.933624 & -0.291800 & 3.923461 \\ \mathrm{C} & -4.020578 & -0.568920 & 3.068096 \\ \mathrm{H} & -2.972743 & -0.043570 & 4.974768 \\ \mathrm{~N} & -2.225435 & -0.748380 & 1.834324 \\ \mathrm{~N} & -3.576055 & -0.837701 & 1.820252 \\ \mathrm{C} & -5.488184 & -0.594730 & 3.388705 \\ \mathrm{H} & -5.830393 & 0.368755 & 3.781458 \\ \mathrm{H} & -6.057218 & -0.822302 & 2.484860 \\ \mathrm{H} & -5.718604 & -1.356734 & 4.140928\end{array}$

$\mathrm{M}=\mathrm{Am}$
AM $\quad-0.538424 \quad-1.173300 \quad 0.135793$
O $\quad \begin{array}{llll}0.493857 & -1.427840 & -2.189421\end{array}$
H $\quad \begin{array}{llll}1.473825 & -1.332413 & -2.086376\end{array}$
O $\quad 0.591183 \quad-3.268445 \quad 1.022195$
$\mathrm{H} \quad 0.728569 \quad-3.513435 \quad 1.947127$
$\mathrm{H} \quad 0.305807 \quad-2.260350 \quad-2.646484$ 


\begin{tabular}{|c|c|c|c|}
\hline & 43168 & -4.008882 & \\
\hline & -3.364031 & -1.955157 & \\
\hline & -4.580713 & -1.8 & \\
\hline & -5.080184 & -0.586795 & -2.738802 \\
\hline & -5.115498 & -2.745060 & -2.7 \\
\hline & -3.162504 & 0.364246 & -1.662449 \\
\hline & -4.35 & 0.5 & -2.3 \\
\hline & -6.019181 & -0.4 & -3. \\
\hline & -4.7 & & -2.5 \\
\hline & -2.333260 & 1.5 & -1.2 \\
\hline & -2.0 & & \\
\hline & -0.7 & 3.5 & -0. \\
\hline & -2.6 & -0.8 & \\
\hline & -2.7 & & -1 \\
\hline & -1.1 & 1.2 & -0. \\
\hline & -0.3 & & -0 . \\
\hline & -2.5 & 5.1 & -1 \\
\hline & -1.3 & & \\
\hline & -0.7 & 6.2 & -2 \\
\hline & -1.8 & 7.2 & \\
\hline & -0.5 & 5.9 & 0. \\
\hline & 0.1 & 4.6 & \\
\hline $\mathrm{H}$ & -1.2 & $6 .($ & \\
\hline & 0.1 & 6.7 & \\
\hline & -3.0 & & -2 \\
\hline & -3.8 & 4.5 & -3 \\
\hline & -3.3 & 6.2 & -3 \\
\hline & -2.25 & 5.0 & -3. \\
\hline & -3.70 & 5.4 & -0. \\
\hline & -4.1 & 6.4 & -0 \\
\hline & -4.4 & 4.7 & -0 \\
\hline & -3.3 & 5.4 & \\
\hline & 1.3 & 4.6 & -0.8 \\
\hline H & 2.0 & 5.4 & -0.5 \\
\hline & 1.8 & 3.6 & -0.8 \\
\hline $\mathrm{H}$ & 1.10 & 4.9 & -1.8 \\
\hline & 0.646891 & 4.28 & 1.5 \\
\hline $\mathrm{H}$ & 1.21 & 3.3 & 1.5 \\
\hline & 1.288556 & 5.05 & 1.8 \\
\hline $\mathrm{H}$ & -0.1 & 4.1 & 2. \\
\hline $\mathrm{C}$ & -2.755678 & -3.230402 & -1.3 \\
\hline C & -3.123957 & -4.56 & -1.5 \\
\hline 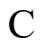 & -2.101821 & -5.310270 & -0.948186 \\
\hline & -3.996731 & -4.956812 & -2.07 \\
\hline $\mathrm{N}$ & -1.588045 & -3.194189 & -0.682 \\
\hline & -1.192185 & -4.465806 & -0.41964 \\
\hline
\end{tabular}




$\begin{array}{lrrr}\mathrm{C} & -1.962020 & -6.799590 & -0.818864 \\ \mathrm{H} & -1.995160 & -7.288891 & -1.797502 \\ \mathrm{H} & -1.011717 & -7.049243 & -0.341701 \\ \mathrm{H} & -2.770556 & -7.221717 & -0.212829 \\ \mathrm{C} & -0.196448 & 0.068620 & 3.366828 \\ \mathrm{C} & 0.324519 & 0.592373 & 4.572184 \\ \mathrm{C} & 1.673472 & 0.905134 & 4.654275 \\ \mathrm{H} & -0.335244 & 0.740340 & 5.419103 \\ \mathrm{C} & 1.916825 & 0.178070 & 2.383080 \\ \mathrm{C} & 2.499306 & 0.696690 & 3.537062 \\ \mathrm{H} & 2.089225 & 1.306068 & 5.573792 \\ \mathrm{H} & 3.556842 & 0.923075 & 3.553609 \\ \mathrm{C} & 2.735667 & -0.067023 & 1.168599 \\ \mathrm{C} & 4.781168 & -0.047057 & 0.133588 \\ \mathrm{C} & 4.141146 & -0.558950 & -1.040330 \\ \mathrm{~N} & 0.607216 & -0.130471 & 2.292757 \\ \mathrm{~N} & 4.053654 & 0.183667 & 1.220715 \\ \mathrm{~N} & 2.106322 & -0.534321 & 0.082129 \\ \mathrm{~N} & 2.828734 & -0.774403 & -1.016122 \\ \mathrm{C} & 6.280164 & 0.211410 & 0.221498 \\ \mathrm{C} & 6.907034 & 0.216196 & -1.190153 \\ \mathrm{H} & 6.713757 & 1.182869 & -1.668342 \\ \mathrm{H} & 7.994134 & 0.142155 & -1.087296 \\ \mathrm{C} & 6.393301 & -0.916574 & -2.082880 \\ \mathrm{C} & 4.872515 & -0.841387 & -2.350769 \\ \mathrm{C} & -2.703545 & -0.213579 & 4.038780 \\ \mathrm{H} & 6.631140 & -1.885249 & -1.629187 \\ \mathrm{H} & 6.914162 & -0.895915 & -3.045369 \\ \mathrm{C} & 6.542636 & 1.567694 & 0.909488 \\ \mathrm{H} & 6.159524 & 1.578466 & 1.931357 \\ \mathrm{H} & 7.620281 & 1.753837 & 0.942550 \\ \mathrm{H} & 6.076323 & 2.391005 & 0.358700 \\ \mathrm{C} & 6.888770 & -0.919800 & 1.092341 \\ \mathrm{H} & 7.961058 & -0.743638 & 1.217874 \\ \mathrm{H} & 6.424046 & -0.934772 & 2.081504 \\ \mathrm{H} & 6.758555 & -1.907573 & 0.641254 \\ \mathrm{C} & 4.544531 & 0.306669 & -3.339418 \\ \mathrm{H} & 5.032582 & 0.115352 & -4.299729 \\ \mathrm{H} & 3.466529 & 0.373089 & -3.511911 \\ \mathrm{H} & 4.886885 & 1.279122 & -2.974751 \\ \mathrm{H} & 3.363895 & -2.139012 & -3.290798 \\ \mathrm{H} & 4.018234 & -2.409073 & -3.838622 \\ \mathrm{H} & -0.710913 & 3.252501\end{array}$




$\begin{array}{rrrr}\mathrm{H} & -2.754334 & 0.139335 & 5.059130 \\ \mathrm{~N} & -1.987812 & -0.800069 & 1.990669 \\ \mathrm{~N} & -3.316994 & -1.057167 & 2.027232 \\ \mathrm{C} & -5.212146 & -0.878502 & 3.622741 \\ \mathrm{H} & -5.669046 & 0.077723 & 3.899798 \\ \mathrm{H} & -5.762552 & -1.292171 & 2.775147 \\ \mathrm{H} & -5.329909 & -1.557451 & 4.474003\end{array}$

$\mathrm{M}=\mathrm{Cm}$

$\begin{array}{lccc}\mathrm{CM} & -0.481935 & -1.164768 & 0.093412 \\ \mathrm{O} & 0.494072 & -1.190195 & -2.293758 \\ \mathrm{H} & 1.470548 & -1.072951 & -2.193668 \\ \mathrm{O} & 0.784428 & -3.216204 & 0.878380 \\ \mathrm{H} & 1.007751 & -3.462361 & 1.785883 \\ \mathrm{H} & 0.329589 & -1.957026 & -2.860726 \\ \mathrm{H} & 0.237551 & -3.979070 & 0.470338 \\ \mathrm{C} & -3.274231 & -2.031031 & -1.757589 \\ \mathrm{C} & -4.498398 & -1.959359 & -2.449463 \\ \mathrm{C} & -5.045765 & -0.713474 & -2.734856 \\ \mathrm{H} & -5.002575 & -2.871755 & -2.745969 \\ \mathrm{C} & -3.160669 & 0.293910 & -1.651703 \\ \mathrm{C} & -4.367293 & 0.445481 & -2.332411 \\ \mathrm{H} & -5.991092 & -0.638023 & -3.263718 \\ \mathrm{H} & -4.752772 & 1.436450 & -2.531818 \\ \mathrm{C} & -2.383915 & 1.475660 & -1.196619 \\ \mathrm{C} & -2.156016 & 3.743672 & -1.015739 \\ \mathrm{C} & -0.933398 & 3.517665 & -0.312020 \\ \mathrm{~N} & -2.626943 & -0.909018 & -1.369744 \\ \mathrm{~N} & -2.865836 & 2.700932 & -1.440590 \\ \mathrm{~N} & -1.223206 & 1.240301 & -0.563445 \\ \mathrm{~N} & -0.500405 & 2.271054 & -0.122478 \\ \mathrm{C} & -2.721246 & 5.133045 & -1.284925 \\ \mathrm{C} & -1.638550 & 6.206468 & -1.036578 \\ \mathrm{H} & -0.963343 & 6.243694 & -1.898998 \\ \mathrm{H} & -2.124636 & 7.186184 & -0.990397 \\ \mathrm{C} & -0.833238 & 5.965219 & 0.243215 \\ \mathrm{C} & -0.042901 & 4.637308 & 0.224312 \\ \mathrm{H} & -1.503953 & 5.972065 & 1.109657 \\ \mathrm{H} & -0.127533 & 6.787667 & 0.399256 \\ \mathrm{C} & -3.216591 & 5.226047 & -2.743746 \\ \mathrm{H} & -4.020382 & 4.513938 & -2.938507 \\ \mathrm{H} & -3.594579 & 6.235041 & -2.934586 \\ \mathrm{H} & -2.405913 & 5.030704 & -3.453252 \\ \mathrm{C} & -3.928521 & 5.332403 & -0.331250 \\ \mathrm{H} & -4.390799 & 6.304271 & -0.528019\end{array}$




$\begin{array}{lccc}\mathrm{H} & -4.678534 & 4.554381 & -0.494778 \\ \mathrm{H} & -3.635276 & 5.303083 & 0.721937 \\ \mathrm{C} & 1.196249 & 4.747666 & -0.698560 \\ \mathrm{H} & 1.874030 & 5.518099 & -0.318033 \\ \mathrm{H} & 1.734939 & 3.796256 & -0.725983 \\ \mathrm{H} & 0.926628 & 5.011724 & -1.725209 \\ \mathrm{C} & 0.426251 & 4.303673 & 1.656096 \\ \mathrm{H} & 1.030296 & 3.394531 & 1.677248 \\ \mathrm{H} & 1.028933 & 5.131000 & 2.044177 \\ \mathrm{H} & -0.425296 & 4.162318 & 2.329140 \\ \mathrm{C} & -2.622472 & -3.288874 & -1.411986 \\ \mathrm{C} & -2.936380 & -4.634641 & -1.637613 \\ \mathrm{C} & -1.891618 & -5.349228 & -1.015095 \\ \mathrm{H} & -3.787026 & -5.049759 & -2.158639 \\ \mathrm{~N} & -1.464032 & -3.220273 & -0.706377 \\ \mathrm{~N} & -1.021460 & -4.478863 & -0.462318 \\ \mathrm{C} & -1.692841 & -6.834004 & -0.913401 \\ \mathrm{H} & -1.693198 & -7.304465 & -1.901827 \\ \mathrm{H} & -0.739420 & -7.054456 & -0.428094 \\ \mathrm{H} & -2.491137 & -7.300795 & -0.326834 \\ \mathrm{C} & -0.188315 & -0.147252 & 3.373058 \\ \mathrm{C} & 0.328171 & 0.282012 & 4.618264 \\ \mathrm{C} & 1.674837 & 0.594399 & 4.729368 \\ \mathrm{H} & -0.335056 & 0.362066 & 5.471554 \\ \mathrm{C} & 1.930109 & 0.055356 & 2.408014 \\ \mathrm{H} & 6.159259 & 1.529237 & 2.073059 \\ \mathrm{H} & 2.505346 & 0.486169 & 3.600472 \\ \mathrm{H} & 2.085120 & 0.923442 & 5.679452 \\ \mathrm{H} & 3.559668 & 0.725146 & 3.636972 \\ \mathrm{C} & 2.748303 & -0.070694 & 1.174139 \\ \mathrm{C} & 4.788779 & 0.062047 & 0.138406 \\ \mathrm{C} & 4.148365 & -0.344133 & -1.076155 \\ \mathrm{~N} & 0.623977 & -0.262275 & 2.293191 \\ \mathrm{~N} & 4.064483 & 0.183362 & 1.245518 \\ \mathrm{~N} & 2.118504 & -0.435891 & 0.048716 \\ \mathrm{~N} & 2.837202 & -0.569984 & -1.069520 \\ \mathrm{C} & 6.285702 & 0.325575 & 0.244853 \\ \mathrm{C} & 6.906466 & 0.465694 & -1.162504 \\ \mathrm{H} & 6.701342 & 1.469885 & -1.549877 \\ \mathrm{H} & 7.994684 & 0.394113 & -1.070446 \\ \mathrm{H} & 6.6780172 & -0.586421 & -2.152922 \\ \mathrm{H} & -0.502555 & -2.408435 \\ \mathrm{H} & -1.589804 & -1.789838 \\ \mathrm{H} & -0.473168 & -3.111091 \\ \mathrm{H} & & -1.09082 & 1.099411\end{array}$




$\begin{array}{lrrr}\mathrm{H} & 6.061260 & 2.481434 & 0.581671 \\ \mathrm{C} & 6.908671 & -0.874312 & 1.006707 \\ \mathrm{H} & 7.979866 & -0.700051 & 1.143645 \\ \mathrm{H} & 6.448742 & -0.983465 & 1.992206 \\ \mathrm{H} & 6.785345 & -1.818198 & 0.468177 \\ \mathrm{C} & 4.535804 & 0.724527 & -3.291592 \\ \mathrm{H} & 5.020812 & 0.622043 & -4.266922 \\ \mathrm{H} & 3.456433 & 0.796472 & -3.453036 \\ \mathrm{H} & 4.872043 & 1.664249 & -2.844735 \\ \mathrm{C} & 4.420523 & -1.786098 & -3.133499 \\ \mathrm{H} & 3.378317 & -1.725986 & -3.455549 \\ \mathrm{H} & 5.033521 & -1.933221 & -4.027758 \\ \mathrm{H} & 4.534747 & -2.669683 & -2.498173 \\ \mathrm{C} & -1.584155 & -0.476218 & 3.168690 \\ \mathrm{C} & -2.691813 & -0.467090 & 4.023758 \\ \mathrm{C} & -3.766166 & -0.868924 & 3.201855 \\ \mathrm{H} & -2.730084 & -0.213904 & 5.073802 \\ \mathrm{~N} & -1.996996 & -0.865119 & 1.920387 \\ \mathrm{~N} & -3.330671 & -1.100709 & 1.944750 \\ \mathrm{C} & -5.212464 & -1.050280 & 3.565401 \\ \mathrm{H} & -5.646640 & -0.125223 & 3.959859 \\ \mathrm{H} & -5.778702 & -1.348930 & 2.680641 \\ \mathrm{H} & -5.337415 & -1.823899 & 4.330649\end{array}$

\section{$\left[\mathrm{ML}_{2}\right]^{1+}$}

$\mathrm{M}=\mathrm{Eu}$

$\begin{array}{lccc}\text { EU } & 0.000006 & 0.886876 & 0.000031 \\ \mathrm{~N} & 1.074251 & 2.241329 & -1.619912 \\ \mathrm{~N} & -1.074268 & 2.241139 & 1.620113 \\ \mathrm{C} & 0.467088 & 2.637109 & -2.795430 \\ \mathrm{~N} & 2.301240 & 2.796079 & -1.536568 \\ \mathrm{~N} & -2.110956 & -0.517226 & -0.332293 \\ \mathrm{~N} & 2.110978 & -0.517233 & 0.332230 \\ \mathrm{~N} & -1.348654 & 1.237590 & -2.178137 \\ \mathrm{~N} & 1.348604 & 1.237305 & 2.178299 \\ \mathrm{C} & -0.467159 & 2.636740 & 2.795719 \\ \mathrm{~N} & -2.301252 & 2.795901 & 1.536798 \\ \mathrm{C} & 1.335234 & 3.483353 & -3.477426 \\ \mathrm{C} & -0.857111 & 2.110931 & -3.087634 \\ \mathrm{C} & 2.482219 & 3.553934 & -2.643586 \\ \mathrm{C} & -2.988032 & -0.283587 & -1.322347 \\ \mathrm{~N} & -2.424170 & -1.381493 & 0.633103 \\ \mathrm{C} & 2.988020 & -0.283736 & 1.322345 \\ \mathrm{~N} & 2.424227 & -1.381363 & -0.633279\end{array}$




\begin{tabular}{|c|c|c|c|}
\hline C & -2.559408 & 0.678844 & -2.371367 \\
\hline & 0.857027 & 2.110516 & 3.087902 \\
\hline $\mathrm{C}$ & 2.559352 & 0.678536 & 2.371494 \\
\hline $\mathrm{C}$ & -1.335335 & 3.482882 & 3.477803 \\
\hline $\mathrm{C}$ & -2.482282 & 3.553588 & 2.643922 \\
\hline H & 1.188330 & 3.977829 & -4.427006 \\
\hline $\mathrm{C}$ & -1.605326 & 2.451806 & -4.234327 \\
\hline $\mathrm{C}$ & 3.746489 & 4.330051 & -2.857283 \\
\hline $\mathrm{N}$ & -4.191089 & -0.861766 & -1.404647 \\
\hline $\mathrm{C}$ & -3.606195 & -1.999879 & 0.611627 \\
\hline $\mathrm{N}$ & 4.191080 & -0.861913 & 1.404598 \\
\hline $\mathrm{C}$ & 3.606257 & -1.999742 & -0.611856 \\
\hline $\mathrm{C}$ & -3.356124 & 0.968228 & -3.475748 \\
\hline $\mathrm{C}$ & 1.605197 & 2.451227 & 4.234674 \\
\hline $\mathrm{C}$ & 3.356027 & 0.967761 & 3.475947 \\
\hline $\mathrm{H}$ & -1.188473 & 3.977214 & 4.427465 \\
\hline $\mathrm{C}$ & -3.746558 & 4.329683 & 2.857674 \\
\hline $\mathrm{C}$ & -2.858156 & 1.878968 & -4.422217 \\
\hline $\mathrm{H}$ & -1.199658 & 3.153852 & -4.953518 \\
\hline $\mathrm{H}$ & 3.550210 & 5.407756 & -2.878804 \\
\hline $\mathrm{H}$ & 4.218202 & 4.066684 & -3.810294 \\
\hline $\mathrm{H}$ & 4.450036 & 4.123634 & -2.048445 \\
\hline $\mathrm{C}$ & -4.534379 & -1.714609 & -0.439937 \\
\hline $\mathrm{C}$ & -3.896279 & -2.958283 & 1.763834 \\
\hline $\mathrm{C}$ & 4.534410 & -1.714610 & 0.439772 \\
\hline $\mathrm{C}$ & 3.896376 & -2.957989 & -1.764185 \\
\hline $\mathrm{H}$ & -4.325834 & 0.499559 & -3.581488 \\
\hline $\mathrm{C}$ & 2.858021 & 1.878362 & 4.422529 \\
\hline $\mathrm{H}$ & 1.199501 & 3.153169 & 4.953950 \\
\hline $\mathrm{H}$ & 4.325735 & 0.499081 & 3.581653 \\
\hline $\mathrm{H}$ & -3.550292 & 5.407390 & 2.879224 \\
\hline $\mathrm{H}$ & -4.450120 & 4.123284 & 2.048845 \\
\hline $\mathrm{H}$ & -4.218242 & 4.066282 & 3.810689 \\
\hline $\mathrm{H}$ & -3.449203 & 2.133253 & -5.296872 \\
\hline $\mathrm{C}$ & -5.906572 & -2.368475 & -0.540291 \\
\hline $\mathrm{C}$ & -2.671411 & -3.857814 & 2.031945 \\
\hline $\mathrm{C}$ & -5.112573 & -3.842286 & 1.408040 \\
\hline $\mathrm{C}$ & -4.181407 & -2.107205 & 3.027347 \\
\hline $\mathrm{C}$ & 5.906613 & -2.368462 & 0.540062 \\
\hline $\mathrm{C}$ & 2.671528 & -3.857507 & -2.032429 \\
\hline $\mathrm{C}$ & 5.112682 & -3.842015 & -1.408491 \\
\hline $\mathrm{C}$ & 4.181507 & -2.106740 & -3.027583 \\
\hline $\mathrm{H}$ & 3.449034 & 2.132521 & 5.297244 \\
\hline $\mathrm{C}$ & -6.970641 & -1.304510 & -0.885576 \\
\hline $\mathrm{C}$ & -6.272693 & -3.052268 & 0.795787 \\
\hline $\mathrm{C}$ & -5.839925 & -3.405365 & -1.692567 \\
\hline
\end{tabular}




$\begin{array}{cccc}\mathrm{H} & -2.908561 & -4.564755 & 2.832942 \\ \mathrm{H} & -2.400235 & -4.436185 & 1.142682 \\ \mathrm{H} & -1.803266 & -3.270466 & 2.337047 \\ \mathrm{H} & -5.448992 & -4.351084 & 2.317043 \\ \mathrm{H} & -4.795296 & -4.631933 & 0.717482 \\ \mathrm{H} & -5.055815 & -1.462065 & 2.904604 \\ \mathrm{H} & -4.363592 & -2.766615 & 3.881336 \\ \mathrm{H} & -3.324798 & -1.469181 & 3.260226 \\ \mathrm{C} & 6.970652 & -1.304520 & 0.885514 \\ \mathrm{C} & 6.272774 & -3.052058 & -0.796106 \\ \mathrm{C} & 5.839969 & -3.405514 & 1.692192 \\ \mathrm{H} & 2.908701 & -4.564342 & -2.833513 \\ \mathrm{H} & 2.400349 & -4.435995 & -1.143244 \\ \mathrm{H} & 1.803378 & -3.270134 & -2.337469 \\ \mathrm{H} & 5.449129 & -4.350679 & -2.317559 \\ \mathrm{H} & 4.795410 & -4.631766 & -0.718049 \\ \mathrm{H} & 5.055905 & -1.461606 & -2.904745 \\ \mathrm{H} & 4.363710 & -2.766035 & -3.881657 \\ \mathrm{H} & 3.324893 & -1.468695 & -3.260388 \\ \mathrm{H} & -7.955974 & -1.778679 & -0.924080 \\ \mathrm{H} & -7.005705 & -0.515743 & -0.127479 \\ \mathrm{H} & -6.772755 & -0.840036 & -1.853189 \\ \mathrm{H} & -7.124755 & -3.717181 & 0.622411 \\ \mathrm{H} & -6.620059 & -2.293448 & 1.505532 \\ \mathrm{H} & -5.121067 & -4.204675 & -1.490974 \\ \mathrm{H} & -6.825018 & -3.861745 & -1.826631 \\ \mathrm{H} & -5.555237 & -2.920284 & -2.629831 \\ \mathrm{H} & 7.955996 & -1.778671 & 0.923969 \\ \mathrm{H} & 7.005712 & -0.515646 & 0.127528 \\ \mathrm{H} & 6.772739 & -0.840186 & 1.853188 \\ \mathrm{H} & 7.124849 & -3.716975 & -0.622810 \\ \mathrm{H} & 6.620135 & -2.293130 & -1.505737 \\ \mathrm{H} & 5.121134 & -4.204811 & 1.490471 \\ \mathrm{H} & 6.825069 & -3.861889 & 1.826211 \\ \mathrm{H} & 5.555251 & -2.920569 & 2.629517\end{array}$
$\mathrm{M}=\mathrm{Gd}$
$\begin{array}{llll}\text { GD } & 0.000002 & 0.970280 & 0.000000\end{array}$
$\begin{array}{llll}\mathrm{C} & -0.818820 & 2.118028 & 3.070793\end{array}$
$\begin{array}{llll}\text { C } & -1.547625 & 2.392249 & 4.248425\end{array}$
$\begin{array}{llll}\text { C } & -2.753111 & 1.737094 & 4.469816\end{array}$
$\mathrm{H} \quad-1.163314 \quad 3.110800 \quad 4.963065$
$\begin{array}{llll}\mathrm{C} & -2.458982 & 0.592977 & 2.389366\end{array}$
$\begin{array}{llll}\text { C } & -3.230525 & 0.810661 & 3.524985\end{array}$
$\mathrm{H} \quad-3.326297 \quad 1.939764 \quad 5.369485$ 


\begin{tabular}{|c|c|c|c|}
\hline & -4.163639 & 79100 & \\
\hline & -2.854767 & -0.362425 & \\
\hline & -4.316760 & -1.864798 & \\
\hline & -3.424554 & -1.999271 & 4840 \\
\hline & -1.289827 & 1.226368 & \\
\hline & -4.008087 & -1.032374 & \\
\hline & -1.989048 & -0.499039 & \\
\hline & -2.278272 & -1.3 & -0.7 \\
\hline & -5.6 & -2.6 & \\
\hline & -5.692033 & -3.75 & \\
\hline & -5.1 & -4.6 & \\
\hline & -6.726714 & -4.09 & -0 . \\
\hline & $-5.1^{\prime}$ & -3.3 & \\
\hline & -3.68 & -2.9 & -1. \\
\hline & -5.7 & -2.5 & -2 \\
\hline & -5.2 & -4.1 & -2 . \\
\hline & -5.8 & -3.1 & \\
\hline & -5.8 & -2.3 & \\
\hline & -6.76 & -3.7 & \\
\hline & -5.0 & -3.8 & \\
\hline & -6.766806 & -1.5 & 0.2 \\
\hline & -7.7 & -2.0 & \\
\hline & -6.71 & -0.7 & \\
\hline & -6.7 & -1.1 & -0 \\
\hline C & -2.7 & -4.1 & \\
\hline & -2.90 & -4.8 & -2 \\
\hline & -1.7 & -3.8 & -1 . \\
\hline & -2.96 & -4.72 & -0.8 \\
\hline & -3.35 & -2.1 & -3.2 \\
\hline F & -2.2 & -1.9 & -3. \\
\hline & -3.58 & -2.8 & $-4 .($ \\
\hline $\mathrm{H}$ & -3.9 & -1.2 & -3 . \\
\hline & 0.45 & 2.72 & 2.7 \\
\hline C & 1.295 & 3.65 & 3.3 \\
\hline & 2.376508 & 3.79 & 2.4 \\
\hline $\mathrm{H}$ & 1.16 & 4.15 & 4.2 \\
\hline & 1.013025 & 2.35 & 1.5 \\
\hline $\mathrm{N}$ & 2.18 & 3.0 & 1.3 \\
\hline $\mathrm{C}$ & 3.594635 & 4.66 & 2.56 \\
\hline $\mathrm{H}$ & 4.17 & 4.4 & 3.4 \\
\hline $\mathrm{H}$ & 4.235415 & 4.533144 & 1.690571 \\
\hline $\mathrm{H}$ & 3.320986 & 5.721554 & 2.637009 \\
\hline C & 0.818814 & 2.118018 & -3.070795 \\
\hline & 1.547624 & 2.392249 & -4.248421 \\
\hline $\mathrm{C}$ & 2.753116 & 1.737103 & -4.469808 \\
\hline & 1.163312 & 3.110799 & -4.96306 \\
\hline
\end{tabular}




\begin{tabular}{|c|c|c|c|}
\hline $\mathrm{C}$ & 2.458981 & 0.592972 & -2.389366 \\
\hline $\mathrm{C}$ & 3.230530 & 0.810667 & -3.524979 \\
\hline $\mathrm{H}$ & 3.326306 & 1.939781 & -5.369473 \\
\hline $\mathrm{H}$ & 4.163647 & 0.279112 & -3.659078 \\
\hline $\mathrm{C}$ & 2.854769 & -0.362427 & -1.325263 \\
\hline $\mathrm{C}$ & 4.316769 & -1.864791 & -0.419098 \\
\hline $\mathrm{C}$ & 3.424565 & -1.999259 & 0.694851 \\
\hline $\mathrm{N}$ & 1.289821 & 1.226355 & -2.166555 \\
\hline $\mathrm{N}$ & 4.008091 & -1.032373 & -1.413168 \\
\hline $\mathrm{N}$ & 1.989052 & -0.499039 & -0.306187 \\
\hline $\mathrm{N}$ & 2.278280 & -1.319028 & 0.705043 \\
\hline $\mathrm{C}$ & 5.642204 & -2.607448 & -0.516036 \\
\hline$C$ & 5.692033 & -3.752087 & 0.519993 \\
\hline $\mathrm{H}$ & 5.115539 & -4.604675 & 0.143782 \\
\hline $\mathrm{H}$ & 6.726712 & -4.099444 & 0.602212 \\
\hline $\mathrm{C}$ & 5.170920 & -3.340226 & 1.899576 \\
\hline $\mathrm{C}$ & 3.685005 & -2.916063 & 1.887478 \\
\hline $\mathrm{H}$ & 5.776902 & -2.517782 & 365 \\
\hline $\mathrm{H}$ & 5.288337 & -4.169774 & 2.604029 \\
\hline $\mathrm{C}$ & 5.819546 & -3.185259 & -1.936537 \\
\hline $\mathrm{H}$ & 5.842241 & -2.395798 & -2.689698 \\
\hline $\mathrm{H}$ & 6.762810 & -3.737336 & -1.985821 \\
\hline $\mathrm{H}$ & 5.010908 & -3.878826 & -2.188982 \\
\hline $\mathrm{C}$ & 6.766819 & -1.570587 & -0.251493 \\
\hline $\mathrm{H}$ & 7.739830 & -2.059736 & -0.354296 \\
\hline $\mathrm{H}$ & 6.713338 & -0.753197 & -0.974975 \\
\hline $\mathrm{H}$ & 6.707720 & -1.139587 & 0.751711 \\
\hline $\mathrm{C}$ & 2.759741 & -4.151495 & 1.750645 \\
\hline $\mathrm{H}$ & 2.900542 & -4.813255 & 2.610442 \\
\hline $\mathrm{H}$ & 1.711187 & -3.842284 & 1.723990 \\
\hline $\mathrm{H}$ & 2.966077 & -4.727193 & 0.843714 \\
\hline $\mathrm{C}$ & 3.351943 & -2.182276 & 3.204060 \\
\hline $\mathrm{H}$ & 2.294911 & -1.915097 & 3.258438 \\
\hline $\mathrm{H}$ & 3.587683 & -2.833548 & 4.051328 \\
\hline $\mathrm{H}$ & 3.940817 & -1.265809 & 3.308946 \\
\hline $\mathrm{C}$ & -0.450127 & 2.728159 & -2.720004 \\
\hline $\mathrm{C}$ & -1.295053 & 3.650884 & -3.338067 \\
\hline $\mathrm{C}$ & -2.376492 & 3.794574 & -2.435671 \\
\hline $\mathrm{H}$ & -1.164302 & 4.150279 & -4.287577 \\
\hline $\mathrm{N}$ & -1.013049 & 2.358627 & -1.525190 \\
\hline $\mathrm{N}$ & -2.189167 & 3.011156 & -1.352956 \\
\hline $\mathrm{C}$ & -3.594698 & 4.663637 & -2.565069 \\
\hline $\mathrm{H}$ & -4.173919 & 4.409560 & -3.459140 \\
\hline 1 & -4.234053 & 4.535230 & -1.689265 \\
\hline 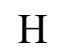 & -3.321022 & 5.721226 & -2.640130 \\
\hline
\end{tabular}


$\mathrm{M}=\mathrm{Am}$

$\begin{array}{lrrr}\mathrm{AM} & 0.000000 & 0.952570 & -0.000001 \\ \mathrm{C} & -0.774000 & 1.960812 & 3.182597 \\ \mathrm{C} & -1.468123 & 2.161462 & 4.395261 \\ \mathrm{C} & -2.657092 & 1.480567 & 4.620907 \\ \mathrm{H} & -1.068036 & 2.846711 & 5.133423 \\ \mathrm{C} & -2.415985 & 0.450726 & 2.473329 \\ \mathrm{C} & -3.152102 & 0.600106 & 3.642843 \\ \mathrm{H} & -3.203622 & 1.627634 & 5.547492 \\ \mathrm{H} & -4.074375 & 0.049902 & 3.775967 \\ \mathrm{C} & -2.846269 & -0.457759 & 1.382970 \\ \mathrm{C} & -4.331877 & -1.931464 & 0.469146 \\ \mathrm{C} & -3.476732 & -2.015708 & -0.678378 \\ \mathrm{~N} & -1.260539 & 1.110805 & 2.243853 \\ \mathrm{~N} & -3.992892 & -1.138472 & 1.485101 \\ \mathrm{~N} & -2.021309 & -0.540011 & 0.328743 \\ \mathrm{~N} & -2.338999 & -1.323164 & -0.702759 \\ \mathrm{C} & -5.650830 & -2.684259 & 0.579362 \\ \mathrm{C} & -5.726273 & -3.792201 & -0.494427 \\ \mathrm{H} & -5.133352 & -4.653359 & -0.166307 \\ \mathrm{H} & -6.760978 & -4.143563 & -0.556873 \\ \mathrm{C} & -5.250764 & -3.328859 & -1.874133 \\ \mathrm{C} & -3.768215 & -2.893293 & -1.893177 \\ \mathrm{H} & -5.874355 & -2.498110 & -2.222442 \\ \mathrm{H} & -5.384213 & -4.134562 & -2.602984 \\ \mathrm{C} & -5.783841 & -3.312747 & 1.982978 \\ \mathrm{H} & -5.789112 & -2.550524 & 2.764011 \\ \mathrm{H} & -6.722157 & -3.872486 & 2.040144 \\ \mathrm{H} & -4.964335 & -4.009352 & 2.187434 \\ \mathrm{C} & -6.787225 & -1.644875 & 0.384542 \\ \mathrm{H} & -7.754903 & -2.142050 & 0.498835 \\ \mathrm{H} & -6.715766 & -0.852934 & 1.134370 \\ \mathrm{H} & -6.759814 & -1.178846 & -0.604263 \\ \mathrm{C} & -2.830505 & -4.125292 & -1.826247 \\ \mathrm{H} & -2.992586 & -4.759036 & -2.703276 \\ \mathrm{H} & -1.783855 & -3.808416 & -1.820947 \\ \mathrm{H} & -3.004679 & -4.732990 & -0.933504 \\ \mathrm{C} & -3.480986 & -2.113620 & -3.193989 \\ \mathrm{H} & -2.427985 & -1.836714 & -3.271869 \\ \mathrm{H} & -3.738869 & -2.738091 & -4.054919 \\ \mathrm{C} & -4.078727 & -1.198554 & -3.249701 \\ \mathrm{C} & 1.324327 & 3.512757 & 3.479561 \\ \mathrm{H} & -3.6197 & 3.955566 & 4.459782\end{array}$




\begin{tabular}{|c|c|c|c|}
\hline & 0.999870 & 045 & 1 \\
\hline & 2.160178 & 3.000309 & 1.433928 \\
\hline & 3.582694 & 4.603445 & 2.691625 \\
\hline & 4.186148 & 4.320405 & 3.560594 \\
\hline & 4.202770 & 4.520772 & 1.796602 \\
\hline & 3.298034 & 5.653411 & 2.817031 \\
\hline & 0.773997 & 1.960800 & -3.182603 \\
\hline & 1.468119 & 2.161446 & -4.395268 \\
\hline $\mathrm{C}$ & 2.657089 & 1.480551 & 0913 \\
\hline H & 1.068031 & 2.846692 & 3433 \\
\hline C & 2.415984 & 0.450719 & -2.4 \\
\hline C & 3.152100 & 0.600094 & -3.642846 \\
\hline $\mathrm{H}$ & 3.203618 & 1.627615 & -5.5 \\
\hline $\mathrm{H}$ & 4.074374 & 0.04 & -3.7 \\
\hline $\mathrm{C}$ & 2.846269 & -0.457763 & 2968 \\
\hline 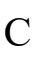 & 4.331878 & -1.9 & -0.4 \\
\hline $\mathrm{C}$ & 3.476734 & -2.015704 & 0.678384 \\
\hline N & 1.260538 & 798 & -2.2 \\
\hline $\mathrm{N}$ & 3.992893 & -1.138476 & 5098 \\
\hline 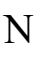 & 2.021310 & -0.540011 & -0.3 \\
\hline $\mathrm{N}$ & 2.339001 & -1.323161 & 0.702763 \\
\hline $\mathrm{C}$ & 5.650832 & -2.684259 & -0.5 \\
\hline $\mathrm{C}$ & 5.726276 & -3.792197 & 0.4 \\
\hline $\mathrm{H}$ & 5.133354 & -4.653356 & 321 \\
\hline $\mathrm{H}$ & 6.760981 & -4.143559 & 5885 \\
\hline$c$ & 5.250768 & -3.328851 & 1.874143 \\
\hline $\mathrm{C}$ & 3.768219 & -2.893285 & 1.893186 \\
\hline $\mathrm{H}$ & 5.874358 & -2.498100 & 2.222448 \\
\hline $\mathrm{H}$ & 5.384217 & -4.134552 & 2.602996 \\
\hline$C$ & 5.783843 & -3.312750 & -1.982969 \\
\hline $\mathrm{H}$ & 5.789113 & -2.550530 & -2.764004 \\
\hline $\mathrm{H}$ & 6.722159 & -3.872490 & -2.040134 \\
\hline $\mathrm{H}$ & 4.964337 & -4.009357 & -2.187422 \\
\hline $\mathrm{C}$ & 6.787226 & -1.644873 & -0.384538 \\
\hline $\mathrm{H}$ & 7.754905 & -2.142048 & -0.498830 \\
\hline $\mathrm{H}$ & 6.715767 & -0.852934 & -1.134369 \\
\hline $\mathrm{H}$ & 6.759815 & -1.178841 & 0.604265 \\
\hline $\mathrm{C}$ & 2.830509 & -4.125284 & 1.826262 \\
\hline $\mathrm{H}$ & 2.992590 & -4.759025 & 2.703292 \\
\hline $\mathrm{H}$ & 1.783859 & -3.808409 & 1.820961 \\
\hline $\mathrm{H}$ & 3.004682 & -4.732986 & 0.933521 \\
\hline $\mathrm{C}$ & 3.480990 & -2.113607 & 3.193996 \\
\hline $\mathrm{H}$ & 2.427990 & -1.836701 & 3.271875 \\
\hline $\mathrm{H}$ & 3.738875 & -2.738075 & 4.054927 \\
\hline $\mathrm{H}$ & 4.078731 & -1.198541 & 3.249704 \\
\hline $\mathrm{C}$ & -0.472041 & 2.613768 & -2.834942 \\
\hline
\end{tabular}




$\begin{array}{llll}\mathrm{C} & -1.324331 & 3.512742 & -3.479572 \\ \mathrm{C} & -2.373133 & 3.724224 & -2.553517 \\ \mathrm{H} & -1.219203 & 3.955547 & -4.459795 \\ \mathrm{~N} & -0.999872 & 2.325037 & -1.606887 \\ \mathrm{~N} & -2.160181 & 3.000301 & -1.433936 \\ \mathrm{C} & -3.582699 & 4.603431 & -2.691638 \\ \mathrm{H} & -4.186148 & 4.320393 & -3.560611 \\ \mathrm{H} & -4.202778 & 4.520753 & -1.796618 \\ \mathrm{H} & -3.298040 & 5.653398 & -2.817039\end{array}$

$\mathrm{M}=\mathrm{Cm}$

$\begin{array}{lrrr}\mathrm{CM} & -0.000048 & 0.852501 & 0.000067 \\ \mathrm{C} & -0.914909 & 2.056889 & 3.073826 \\ \mathrm{C} & -1.666559 & 2.353614 & 4.231018 \\ \mathrm{C} & -2.887415 & 1.720156 & 4.429574 \\ \mathrm{H} & -1.288013 & 3.072599 & 4.948275 \\ \mathrm{C} & -2.561759 & 0.552184 & 2.366653 \\ \mathrm{C} & -3.356815 & 0.793537 & 3.481834 \\ \mathrm{H} & -3.478634 & 1.940381 & 5.313353 \\ \mathrm{H} & -4.301737 & 0.279015 & 3.598135 \\ \mathrm{C} & -2.953711 & -0.408719 & 1.305301 \\ \mathrm{C} & -4.434081 & -1.890358 & 0.392682 \\ \mathrm{C} & -3.523433 & -2.063357 & -0.700366 \\ \mathrm{~N} & -1.378028 & 1.164900 & 2.166766 \\ \mathrm{~N} & -4.124929 & -1.049951 & 1.379635 \\ \mathrm{~N} & -2.072792 & -0.580061 & 0.305817 \\ \mathrm{~N} & -2.362172 & -1.410266 & -0.697592 \\ \mathrm{C} & -5.778530 & -2.600318 & 0.474534 \\ \mathrm{C} & -5.834360 & -3.760567 & -0.543831 \\ \mathrm{H} & -5.285613 & -4.619840 & -0.142142 \\ \mathrm{H} & -6.875011 & -4.085232 & -0.641783 \\ \mathrm{C} & -5.275869 & -3.383944 & -1.918825 \\ \mathrm{C} & -3.780913 & -2.994012 & -1.883044 \\ \mathrm{H} & -5.854230 & -2.554334 & -2.340355 \\ \mathrm{H} & -5.398450 & -4.222200 & -2.612009 \\ \mathrm{C} & -5.997646 & -3.150552 & 1.900120 \\ \mathrm{H} & -6.018085 & -2.348450 & 2.639896 \\ \mathrm{H} & -6.953748 & -3.680996 & 1.938963 \\ \mathrm{H} & -5.209877 & -3.857348 & 2.180399 \\ \mathrm{C} & -6.873023 & -1.542433 & 0.170411 \\ \mathrm{H} & -7.859293 & -2.006725 & 0.261765 \\ \mathrm{H} & -6.814357 & -0.714156 & 0.881042 \\ \mathrm{H} & -6.783968 & -1.130243 & -0.838494 \\ \mathrm{C} & -2.887770 & -4.248006 & -1.706753 \\ \mathrm{H} & -3.026124 & -4.920840 & -2.558360\end{array}$




\begin{tabular}{|c|c|c|c|}
\hline 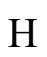 & -1.833010 & -3.962563 & -1.663071 \\
\hline & -3.126107 & -4.803498 & -0.795067 \\
\hline & -3.404319 & -2.290763 & -3.204541 \\
\hline & -2.340185 & -2.049989 & -3.241961 \\
\hline - & -3.638919 & -2.950508 & -4.045598 \\
\hline & -3.968754 & -1.362391 & -3.336356 \\
\hline 0 & 0.371452 & 2.648842 & 2.752167 \\
\hline 0 & 1.211023 & 3.560730 & 3.391878 \\
\hline $\mathrm{C}$ & 2.318701 & 3.690423 & 2.519529 \\
\hline $\mathrm{H}$ & 1.061704 & 4.062479 & 4.337314 \\
\hline $\mathrm{N}$ & 0.961971 & 2.272662 & 1.573619 \\
\hline$N$ & 2.151607 & 2.909578 & 1.433228 \\
\hline $\mathrm{C}$ & 3.543646 & 4.543804 & 2.682397 \\
\hline $\mathrm{H}$ & 4.093674 & 4.284491 & 3.593328 \\
\hline H & 4.206286 & 4.405184 & 1.825580 \\
\hline $\mathrm{H}$ & 3.282063 & 5.605181 & 2.747533 \\
\hline $\mathrm{C}$ & 0.915277 & 2.058127 & -3.073074 \\
\hline $\mathrm{C}$ & 1.667064 & 2.355270 & -4.230070 \\
\hline $\mathrm{C}$ & 2.887900 & 1.721815 & -4.428758 \\
\hline $\mathrm{H}$ & 1.288637 & 3.074570 & -4.947075 \\
\hline $\mathrm{C}$ & 2.561962 & 0.553035 & -2.366339 \\
\hline $\mathrm{C}$ & 3.357144 & 0.794786 & -3.481343 \\
\hline $\mathrm{H}$ & 3.479223 & 1.942359 & -5.312388 \\
\hline $\mathrm{H}$ & 4.302045 & 0.280249 & -3.597757 \\
\hline $\mathrm{C}$ & 2.953750 & -0.408328 & -1.305341 \\
\hline $\mathrm{C}$ & 4.433935 & -1.890444 & -0.393195 \\
\hline $\mathrm{C}$ & 3.523177 & -2.063829 & 0.699699 \\
\hline $\mathrm{N}$ & 1.378248 & 1.165744 & -2.166324 \\
\hline $\mathrm{N}$ & 4.124932 & -1.049607 & -1.379829 \\
\hline $\mathrm{N}$ & 2.072721 & -0.580033 & -0.306017 \\
\hline $\mathrm{N}$ & 2.361954 & -1.410668 & 0.697079 \\
\hline $\mathrm{C}$ & 5.778335 & -2.600478 & -0.475224 \\
\hline $\mathrm{C}$ & 5.833977 & -3.761156 & 0.542661 \\
\hline $\mathrm{H}$ & 5.285185 & -4.620212 & 0.140567 \\
\hline $\mathrm{H}$ & 6.874590 & -4.085956 & 0.640563 \\
\hline $\mathrm{C}$ & 5.275405 & -3.385057 & 1.917766 \\
\hline $\mathrm{C}$ & 3.780485 & -2.994978 & 1.882025 \\
\hline $\mathrm{H}$ & 5.853805 & -2.555675 & 2.339690 \\
\hline $\mathrm{H}$ & 5.397855 & -4.223613 & 2.610610 \\
\hline $\mathrm{C}$ & 5.997529 & -3.150136 & -1.901020 \\
\hline $\mathrm{H}$ & 6.018092 & -2.347729 & -2.640461 \\
\hline $\mathrm{H}$ & 6.953594 & -3.680637 & -1.940002 \\
\hline $\mathrm{H}$ & 5.209731 & -3.856756 & -2.181659 \\
\hline $\mathrm{C}$ & 6.872888 & -1.542809 & -0.170566 \\
\hline $\mathrm{H}$ & 7.859127 & -2.007145 & -0.262021 \\
\hline $\mathrm{H}$ & 6.814355 & -0.714236 & -0.880864 \\
\hline
\end{tabular}




$\begin{array}{lrrr}\mathrm{H} & 6.783775 & -1.131023 & 0.838498 \\ \mathrm{C} & 2.887246 & -4.248823 & 1.705174 \\ \mathrm{H} & 3.025466 & -4.921998 & 2.556533 \\ \mathrm{H} & 1.832515 & -3.963269 & 1.661512 \\ \mathrm{H} & 3.125612 & -4.803984 & 0.793294 \\ \mathrm{C} & 3.403856 & -2.292215 & 3.203771 \\ \mathrm{H} & 2.339740 & -2.051363 & 3.241208 \\ \mathrm{H} & 3.638337 & -2.952309 & 4.044586 \\ \mathrm{H} & 3.968361 & -1.363943 & 3.335991 \\ \mathrm{C} & -0.371076 & 2.650042 & -2.751313 \\ \mathrm{C} & -1.210545 & 3.562192 & -3.390784 \\ \mathrm{C} & -2.318319 & 3.691600 & -2.518515 \\ \mathrm{H} & -1.061113 & 4.064267 & -4.336030 \\ \mathrm{~N} & -0.961750 & 2.273434 & -1.572980 \\ \mathrm{~N} & -2.151387 & 2.910328 & -1.432496 \\ \mathrm{C} & -3.543091 & 4.545284 & -2.681082 \\ \mathrm{H} & -4.091063 & 4.289059 & -3.594107 \\ \mathrm{H} & -4.207537 & 4.403611 & -1.826164 \\ \mathrm{H} & -3.281575 & 5.606945 & -2.741923\end{array}$

$\mathbf{L}=\mathbf{2 a p i}$

\section{$\left[\mathrm{ML}\left(\mathrm{H}_{2} \mathrm{O}\right)_{6}\right]^{2+}$}

$\mathrm{M}=\mathrm{Eu}$

$\begin{array}{lccc}\text { EU } & 0.465632 & -1.163483 & 0.153264 \\ \mathrm{O} & 2.472658 & -2.043168 & 1.823858 \\ \mathrm{H} & 3.296744 & -1.692391 & 1.428894 \\ \mathrm{O} & 0.476172 & -0.359761 & 2.655569 \\ \mathrm{H} & 1.332826 & -0.696708 & 2.973556 \\ \mathrm{O} & -1.243488 & -2.884284 & -0.846138 \\ \mathrm{H} & -1.250744 & -3.221980 & -1.753902 \\ \mathrm{O} & -0.474219 & -2.960482 & 1.763721 \\ \mathrm{H} & -1.012461 & -3.672258 & 1.383354 \\ \mathrm{O} & 2.341663 & -2.424123 & -1.289439 \\ \mathrm{H} & 2.601626 & -3.335329 & -1.488357 \\ \mathrm{O} & 0.428977 & -0.761629 & -2.425560 \\ \mathrm{H} & 1.228896 & -1.180045 & -2.785234 \\ \mathrm{H} & 2.667839 & -2.927834 & 2.167141 \\ \mathrm{H} & -0.673865 & -2.906110 & 2.709657 \\ \mathrm{H} & 3.157821 & -1.929880 & -1.037345 \\ \mathrm{H} & -2.095416 & -2.391587 & -0.718255 \\ \mathrm{H} & 0.179596 & -0.048264 & -3.029879 \\ \mathrm{H} & 0.268016 & 0.435835 & 3.165459 \\ \mathrm{C} & 1.357132 & 2.267616 & 0.064176\end{array}$




$\begin{array}{lrrr}\mathrm{C} & 1.303038 & 3.671392 & 0.133283 \\ \mathrm{C} & 0.061348 & 4.298659 & 0.202735 \\ \mathrm{H} & 2.217184 & 4.253682 & 0.133738 \\ \mathrm{C} & -0.962720 & 2.128330 & 0.112783 \\ \mathrm{C} & -1.099880 & 3.516387 & 0.190464 \\ \mathrm{H} & -0.005896 & 5.380667 & 0.260584 \\ \mathrm{H} & -2.087898 & 3.956222 & 0.232386 \\ \mathrm{C} & -2.166329 & 1.249888 & 0.047358 \\ \mathrm{C} & -4.446573 & 1.037923 & -0.036078 \\ \mathrm{C} & -4.259098 & -0.377064 & -0.216292 \\ \mathrm{~N} & 0.235338 & 1.512185 & 0.060462 \\ \mathrm{~N} & -3.377339 & 1.823227 & 0.066636 \\ \mathrm{~N} & -1.958743 & -0.067461 & -0.055417 \\ \mathrm{~N} & -3.021967 & -0.870526 & -0.212518 \\ \mathrm{C} & -5.813714 & 1.702514 & -0.007920 \\ \mathrm{C} & -6.926238 & 0.642020 & 0.144385 \\ \mathrm{H} & -7.005553 & 0.346304 & 1.195934 \\ \mathrm{H} & -7.883200 & 1.106632 & -0.109723 \\ \mathrm{C} & -6.704048 & -0.593893 & -0.730813 \\ \mathrm{C} & -5.410875 & -1.365092 & -0.378089 \\ \mathrm{H} & -6.675890 & -0.304824 & -1.787254 \\ \mathrm{H} & -7.550636 & -1.278923 & -0.626982 \\ \mathrm{C} & -5.884629 & 2.705821 & 1.164756 \\ \mathrm{H} & -5.151633 & 3.506946 & 1.054169 \\ \mathrm{H} & -6.881316 & 3.154834 & 1.191178 \\ \mathrm{H} & -5.131931 & 0.562393 & -0.224499 \\ \mathrm{C} & -5.716308 & 2.210833 & 2.126540 \\ \mathrm{H} & -5.971254 & 2.478593 & -1.344896 \\ \mathrm{H} & -6.926459 & 3.010345 & -1.337773 \\ \mathrm{H} & -5.170730 & 3.213120 & -1.462929 \\ \mathrm{H} & -5.960484 & 1.816629 & -2.215351 \\ \mathrm{C} & -5.575263 & -2.125495 & 0.964049 \\ \mathrm{H} & -6.384449 & -2.855240 & 0.872375 \\ \mathrm{H} & -4.657968 & -2.664315 & 1.219007 \\ \mathrm{H} & -5.817381 & -1.458235 & 1.795365 \\ \mathrm{C} & -5.109019 & -2.383265 & -1.498558 \\ \mathrm{H} & -4.284141 & -3.051232 & -1.237224 \\ \mathrm{H} & -5.991827 & -3.007079 & -1.663516 \\ \mathrm{H} & -4.874033 & -1.885095 & -2.444449 \\ \mathrm{C} & 2.624793 & 1.535388 & -0.012519 \\ \mathrm{H} & 4.698044 & 0.736247 & -0.138722 \\ \mathrm{H} & -1.690584 & -0.245478\end{array}$




$\begin{array}{cccc}\mathrm{C} & 6.705472 & -0.736500 & -0.289154 \\ \mathrm{C} & 8.373095 & 1.524018 & -0.326648 \\ \mathrm{H} & 6.584235 & 2.692414 & -0.197538 \\ \mathrm{C} & 8.082706 & -0.897621 & -0.370555 \\ \mathrm{H} & 6.056585 & -1.604144 & -0.276150 \\ \mathrm{C} & 8.924241 & 0.230969 & -0.389608 \\ \mathrm{H} & 9.026248 & 2.390410 & -0.341918 \\ \mathrm{H} & 8.514368 & -1.892166 & -0.420502 \\ \mathrm{H} & 10.000467 & 0.103366 & -0.453512\end{array}$

$\mathrm{M}=\mathrm{Gd}$

$\begin{array}{lccc}\text { GD } & 0.477435 & -0.994110 & 0.194441 \\ \mathrm{O} & 2.382526 & -1.857178 & 1.817206 \\ \mathrm{H} & 3.204230 & -1.521000 & 1.383296 \\ \mathrm{O} & 0.479256 & -0.107014 & 2.572001 \\ \mathrm{H} & 1.341538 & -0.401044 & 2.920571 \\ \mathrm{O} & -1.010151 & -2.771425 & -0.772849 \\ \mathrm{H} & -0.967165 & -3.123134 & -1.675059 \\ \mathrm{O} & -0.533751 & -2.586238 & 1.867703 \\ \mathrm{H} & -0.973235 & -3.419471 & 1.638036 \\ \mathrm{O} & 2.164516 & -2.322652 & -1.126843 \\ \mathrm{H} & 2.371833 & -3.259496 & -1.258283 \\ \mathrm{O} & 0.360885 & -0.580111 & -2.288444 \\ \mathrm{H} & 1.150918 & -0.969803 & -2.700283 \\ \mathrm{H} & 2.586829 & -2.720456 & 2.207680 \\ \mathrm{H} & -0.675383 & -2.416618 & 2.811485 \\ \mathrm{H} & 3.018105 & -1.838042 & -0.914076 \\ \mathrm{H} & -1.917749 & -2.380248 & -0.655029 \\ \mathrm{H} & 0.177549 & 0.246342 & -2.759644 \\ \mathrm{H} & 0.303330 & 0.773867 & 2.934939 \\ \mathrm{C} & 1.347663 & 2.301224 & 0.004724 \\ \mathrm{C} & 1.277430 & 3.707075 & 0.024762 \\ \mathrm{C} & 0.031348 & 4.325153 & 0.079033 \\ \mathrm{H} & 2.188931 & 4.293082 & -0.003013 \\ \mathrm{C} & -0.984925 & 2.153154 & 0.072025 \\ \mathrm{C} & -1.131090 & 3.537700 & 0.100453 \\ \mathrm{H} & -0.042412 & 5.408236 & 0.097964 \\ \mathrm{H} & -2.120730 & 3.975315 & 0.129606 \\ \mathrm{C} & -2.160005 & 1.243599 & 0.036617 \\ \mathrm{C} & -4.427068 & 0.931113 & -0.064677 \\ \mathrm{C} & -4.178275 & -0.484256 & -0.198531 \\ \mathrm{~N} & 0.221670 & 1.543871 & 0.035617 \\ \mathrm{~N} & -3.392954 & 1.764166 & 0.024400 \\ \mathrm{~N} & -1.898978 & -0.068913 & -0.018026 \\ \mathrm{~N} & -2.923891 & -0.924727 & -0.163933\end{array}$




\begin{tabular}{|c|c|c|c|}
\hline $\mathrm{C}$ & -5.819401 & 37063 & -0.077738 \\
\hline $\mathrm{C}$ & -6.893169 & 0.437477 & 0.077262 \\
\hline $\mathrm{H}$ & -6.991166 & 0.170066 & 1.134621 \\
\hline $\mathrm{H}$ & -7.859573 & 0.856427 & -0.216505 \\
\hline $\mathrm{C}$ & -6.599646 & -0.813566 & -0.754390 \\
\hline $\mathrm{C}$ & -5.287116 & -1.521554 & -0.345349 \\
\hline $\mathrm{H}$ & -6.555366 & -0.555769 & -1.8 \\
\hline $\mathrm{H}$ & -7.420642 & -1.528811 & -0.650289 \\
\hline $\mathrm{C}$ & -5.952850 & 2.566561 & 1.0 \\
\hline $\mathrm{H}$ & -5.250393 & 3.393529 & 0.949874 \\
\hline $\mathrm{H}$ & -6.966871 & 2.975336 & 1.06 \\
\hline $\mathrm{H}$ & -5.786198 & 2.103274 & 2.045064 \\
\hline $\mathrm{C}$ & -5.978551 & 2.273946 & -1.438184 \\
\hline $\mathrm{H}$ & -6.954426 & 2.765912 & -1.461108 \\
\hline $\mathrm{H}$ & -5.206385 & 3.037637 & -1.5 \\
\hline $\mathrm{H}$ & -5.924675 & 1.591999 & -2.2 \\
\hline $\mathrm{C}$ & -5.451660 & -2.233593 & 586 \\
\hline $\mathrm{H}$ & -6.234553 & -2.992842 & 953 \\
\hline $\mathrm{H}$ & -4.522499 & -2.731978 & 1.315714 \\
\hline $\mathrm{H}$ & -5.731573 & -1.543801 & 895 \\
\hline $\mathrm{C}$ & -4.922088 & -2.570539 & -1.417484 \\
\hline $\mathrm{H}$ & -4.080333 & -3.198049 & 1989 \\
\hline $\mathrm{H}$ & -5.777130 & -3.233259 & -1.575641 \\
\hline $\mathrm{H}$ & -4.6 & -2.1 & -2.377916 \\
\hline $\mathrm{C}$ & 2.594716 & 1.544847 & -0.057258 \\
\hline $\mathrm{C}$ & 3.947490 & 1.886156 & -0.127784 \\
\hline $\mathrm{C}$ & 4.631029 & 0.647660 & -0.179041 \\
\hline $\mathrm{H}$ & 4.385004 & 2.872201 & -0.169207 \\
\hline $\mathrm{N}$ & 2.479018 & 0.192128 & -0.064030 \\
\hline $\mathrm{N}$ & 3.721513 & -0.364176 & -0.135377 \\
\hline $\mathrm{C}$ & 6.080532 & 0.406159 & -0.261000 \\
\hline $\mathrm{C}$ & 6.989488 & 1.421249 & 0.094038 \\
\hline $\mathrm{C}$ & 6.584815 & -0.835449 & -0.692918 \\
\hline $\mathrm{C}$ & 8.366936 & 1.198644 & 0.021040 \\
\hline $\mathrm{H}$ & 6.626280 & 2.381545 & 0.446296 \\
\hline $\mathrm{C}$ & 7.962155 & -1.056818 & -0.766105 \\
\hline $\mathrm{H}$ & 5.898885 & -1.622301 & -0.988675 \\
\hline $\mathrm{C}$ & 8.858543 & -0.040291 & -0.409118 \\
\hline $\mathrm{H}$ & 9.057236 & 1.987778 & 0.301989 \\
\hline $\mathrm{H}$ & 8.339629 & -2.015407 & -1.108665 \\
\hline $\mathrm{H}$ & 9.928672 & -0.211621 & -0.467898 \\
\hline
\end{tabular}




\begin{tabular}{|c|c|c|c|}
\hline $\mathrm{H}$ & 3.237692 & -1.392081 & 1.359131 \\
\hline $\mathrm{O}$ & 0.448202 & -0.087723 & 2.659039 \\
\hline $\mathrm{H}$ & 1.326427 & -0.348310 & 2.992729 \\
\hline O & -1.127372 & -2.774764 & -0.767669 \\
\hline $\mathrm{H}$ & -1.081547 & -3.128523 & -1.668963 \\
\hline D & -0.561775 & -2.619185 & 1.882582 \\
\hline $\mathrm{H}$ & -1.013389 & -3.430472 & 1.601218 \\
\hline & 2.210431 & -2.263408 & -1.181716 \\
\hline $\mathrm{H}$ & 2.458661 & -3.191198 & -1.307353 \\
\hline 0 & 0.329679 & -0.610277 & -2.358998 \\
\hline $\mathrm{H}$ & 1.134220 & -1.023229 & -2.718439 \\
\hline $\mathrm{H}$ & 2.675707 & -2.608049 & 2.193698 \\
\hline $\mathrm{H}$ & -0.696236 & -2.510154 & 2.836362 \\
\hline $\mathrm{H}$ & 3.040796 & -1.742152 & -0.963894 \\
\hline $\mathrm{H}$ & -2.011142 & -2.328714 & -0.678304 \\
\hline $\mathrm{H}$ & 0.177605 & 0.199151 & -2.869730 \\
\hline $\mathrm{H}$ & 0.228765 & 0.767882 & 3.057486 \\
\hline $\mathrm{C}$ & 1.294412 & 2.397167 & 0.021718 \\
\hline $\mathrm{C}$ & 1.218382 & 3.801677 & 0.055102 \\
\hline & -0.030078 & 4.413492 & 0.117890 \\
\hline $\mathrm{H}$ & 2.126838 & 4.392237 & 0.027233 \\
\hline $\mathrm{C}$ & -1.036324 & 2.236304 & 0.088727 \\
\hline $\mathrm{C}$ & -1.187834 & 3.620018 & 0.127990 \\
\hline $\mathrm{H}$ & -0.109280 & 5.495908 & 0.147000 \\
\hline $\mathrm{H}$ & -2.179626 & 4.052690 & 0.154711 \\
\hline $\mathrm{C}$ & -2.212077 & 1.329743 & 0.028515 \\
\hline $\mathrm{C}$ & -4.479956 & 1.027513 & -0.090179 \\
\hline & -4.235316 & -0.385908 & -0.246222 \\
\hline $\mathrm{N}$ & 0.173558 & 1.632833 & 0.055927 \\
\hline $\mathrm{N}$ & -3.443390 & 1.854791 & 0.022693 \\
\hline $\mathrm{N}$ & -1.955107 & 0.018924 & -0.055362 \\
\hline $\mathrm{N}$ & -2.982744 & -0.831371 & -0.214987 \\
\hline $\mathrm{C}$ & -5.870070 & 1.639021 & -0.102234 \\
\hline $\mathrm{C}$ & -6.948416 & 0.541322 & 0.033276 \\
\hline $\mathrm{H}$ & -7.051073 & 0.259541 & 1.086479 \\
\hline $\mathrm{H}$ & -7.912224 & 0.967879 & -0.258091 \\
\hline $\mathrm{C}$ & -6.656272 & -0.698956 & -0.814639 \\
\hline $\mathrm{C}$ & -5.347397 & -1.417306 & -0.411641 \\
\hline $\mathrm{H}$ & -6.607717 & -0.426540 & -1.874744 \\
\hline $\mathrm{H}$ & -7.479986 & -1.412806 & -0.723146 \\
\hline $\mathrm{C}$ & -6.006378 & 2.654210 & 1.055096 \\
\hline $\mathrm{H}$ & -5.301118 & 3.480673 & 0.951804 \\
\hline $\mathrm{H}$ & -7.019214 & 3.065962 & 1.049536 \\
\hline $\mathrm{H}$ & -5.845767 & 2.177968 & 2.027560 \\
\hline C & -6.019364 & 2.393495 & -1.454095 \\
\hline $\mathrm{H}$ & -6.993471 & 2.889041 & -1.476456 \\
\hline
\end{tabular}




$\begin{array}{rrrr}\mathrm{H} & -5.244036 & 3.156097 & -1.560549 \\ \mathrm{H} & -5.962758 & 1.722280 & -2.315595 \\ \mathrm{C} & -5.519033 & -2.149094 & 0.945946 \\ \mathrm{H} & -6.302526 & -2.906115 & 0.853698 \\ \mathrm{H} & -4.591891 & -2.653116 & 1.234956 \\ \mathrm{H} & -5.801654 & -1.470679 & 1.755027 \\ \mathrm{C} & -4.983076 & -2.451578 & -1.498334 \\ \mathrm{H} & -4.148035 & -3.090191 & -1.197762 \\ \mathrm{H} & -5.841951 & -3.105281 & -1.672551 \\ \mathrm{H} & -4.736049 & -1.969590 & -2.449489 \\ \mathrm{C} & 2.545543 & 1.651854 & -0.067141 \\ \mathrm{C} & 3.894105 & 2.006543 & -0.133825 \\ \mathrm{C} & 4.588066 & 0.776021 & -0.225763 \\ \mathrm{H} & 4.324357 & 2.996549 & -0.145760 \\ \mathrm{~N} & 2.441826 & 0.299322 & -0.113981 \\ \mathrm{~N} & 3.688864 & -0.244776 & -0.209284 \\ \mathrm{C} & 6.039056 & 0.549968 & -0.318703 \\ \mathrm{C} & 6.940007 & 1.547328 & 0.101555 \\ \mathrm{C} & 6.552583 & -0.658718 & -0.826792 \\ \mathrm{C} & 8.319059 & 1.339345 & 0.017599 \\ \mathrm{H} & 6.568598 & 2.480739 & 0.512794 \\ \mathrm{C} & 7.931545 & -0.865322 & -0.910691 \\ \mathrm{H} & 5.872527 & -1.428921 & -1.175662 \\ \mathrm{C} & 8.819991 & 0.133101 & -0.488326 \\ \mathrm{H} & 9.003365 & 2.114058 & 0.348845 \\ \mathrm{H} & 8.316523 & -1.797300 & -1.313073 \\ \mathrm{H} & 9.891406 & -0.026656 & -0.555675\end{array}$

$\mathrm{M}=\mathrm{Cm}$

$\begin{array}{lrrr}\mathrm{CM} & 0.440653 & -0.940543 & 0.168725 \\ \mathrm{O} & 2.421126 & -1.795624 & 1.792731 \\ \mathrm{H} & 3.222272 & -1.434011 & 1.341192 \\ \mathrm{O} & 0.471858 & -0.099056 & 2.612684 \\ \mathrm{H} & 1.346218 & -0.392043 & 2.931128 \\ \mathrm{O} & -1.128475 & -2.744343 & -0.802771 \\ \mathrm{H} & -1.105035 & -3.105236 & -1.702062 \\ \mathrm{O} & -0.525947 & -2.631448 & 1.855548 \\ \mathrm{H} & -0.984224 & -3.442284 & 1.585237 \\ \mathrm{O} & 2.196856 & -2.231439 & -1.215828 \\ \mathrm{H} & 2.432670 & -3.161555 & -1.348420 \\ \mathrm{O} & 0.316664 & -0.546547 & -2.366941 \\ \mathrm{H} & 1.118225 & -0.933924 & -2.759355 \\ \mathrm{H} & 2.654642 & -2.662310 & 2.158678 \\ \mathrm{H} & -0.651225 & -2.514641 & 2.809534 \\ \mathrm{H} & 3.031583 & -1.726516 & -0.980148\end{array}$




$\begin{array}{lrrr}\mathrm{H} & -2.017325 & -2.313591 & -0.685246 \\ \mathrm{H} & 0.132710 & 0.272261 & -2.851731 \\ \mathrm{H} & 0.296224 & 0.770604 & 3.002251 \\ \mathrm{C} & 1.296501 & 2.389212 & 0.011317 \\ \mathrm{C} & 1.222727 & 3.794420 & 0.046474 \\ \mathrm{C} & -0.024305 & 4.409251 & 0.107800 \\ \mathrm{H} & 2.132559 & 4.383143 & 0.023883 \\ \mathrm{C} & -1.036328 & 2.235059 & 0.077767 \\ \mathrm{C} & -1.184741 & 3.618976 & 0.120152 \\ \mathrm{H} & -0.100493 & 5.491901 & 0.138305 \\ \mathrm{H} & -2.175118 & 4.054471 & 0.152973 \\ \mathrm{C} & -2.214952 & 1.329629 & 0.031215 \\ \mathrm{C} & -4.484751 & 1.032647 & -0.068666 \\ \mathrm{C} & -4.245545 & -0.382657 & -0.217486 \\ \mathrm{~N} & 0.172106 & 1.629337 & 0.036962 \\ \mathrm{~N} & -3.445069 & 1.857962 & 0.028088 \\ \mathrm{~N} & -1.963244 & 0.016518 & -0.040651 \\ \mathrm{~N} & -2.994232 & -0.831639 & -0.191247 \\ \mathrm{C} & -5.873249 & 1.647855 & -0.072222 \\ \mathrm{C} & -6.953369 & 0.553776 & 0.077590 \\ \mathrm{H} & -7.048071 & 0.277364 & 1.132967 \\ \mathrm{H} & -7.918415 & 0.981500 & -0.207866 \\ \mathrm{C} & -6.671612 & -0.691457 & -0.766602 \\ \mathrm{C} & -5.361715 & -1.411596 & -0.370182 \\ \mathrm{H} & -6.630629 & -0.424301 & -1.828395 \\ \mathrm{H} & -7.496687 & -1.402371 & -0.665122 \\ \mathrm{C} & -5.996719 & 2.668677 & 1.081678 \\ \mathrm{H} & -5.290141 & 3.492724 & 0.968407 \\ \mathrm{H} & -7.008466 & 3.083127 & 1.083076 \\ \mathrm{H} & -5.828884 & 2.196418 & 2.054877 \\ \mathrm{C} & -6.032101 & 2.396626 & -1.426152 \\ \mathrm{H} & -7.004926 & 2.894901 & -1.442298 \\ \mathrm{H} & -5.255494 & 3.156420 & -1.542781 \\ \mathrm{H} & -5.985006 & 1.721248 & -2.284994 \\ \mathrm{C} & -5.525143 & -2.136813 & 0.991976 \\ \mathrm{H} & -6.311317 & -2.892124 & 0.908895 \\ \mathrm{H} & -4.597115 & -2.641730 & 1.276474 \\ \mathrm{H} & -5.800070 & -1.453985 & 1.799982 \\ \mathrm{H} & -5.007945 & -2.451817 & -1.454629 \\ \mathrm{H} & -5.869376 & -3.104687 & -1.618993 \\ \mathrm{H} & -4.767584 & -1.974941 & -2.410131 \\ \mathrm{H} & -1.64796 & 2.003724 & -0.126560 \\ \mathrm{H} & 0.775657 & -0.195443 \\ \mathrm{H} & 2.995599 & -0.153157\end{array}$




$\begin{array}{lrrr}\mathrm{N} & 2.452744 & 0.290006 & -0.088861 \\ \mathrm{~N} & 3.702837 & -0.249016 & -0.167683 \\ \mathrm{C} & 6.050852 & 0.555224 & -0.279022 \\ \mathrm{C} & 6.945660 & 1.573910 & 0.100809 \\ \mathrm{C} & 6.572420 & -0.669984 & -0.736635 \\ \mathrm{C} & 8.326078 & 1.370880 & 0.026752 \\ \mathrm{H} & 6.568912 & 2.521420 & 0.473054 \\ \mathrm{C} & 7.952676 & -0.871834 & -0.810793 \\ \mathrm{H} & 5.897448 & -1.458840 & -1.052100 \\ \mathrm{C} & 8.834845 & 0.148141 & -0.429056 \\ \mathrm{H} & 9.005300 & 2.162571 & 0.326876 \\ \mathrm{H} & 8.343455 & -1.817636 & -1.173482 \\ \mathrm{H} & 9.907257 & -0.007921 & -0.488672\end{array}$

$\left[\mathrm{ML}\left(\mathrm{H}_{2} \mathrm{O}\right)_{5}\right]^{2+}$

$\mathrm{M}=\mathrm{Eu}$

$\begin{array}{lrrc}\text { EU } & 0.524243 & -1.216847 & 0.133684 \\ \mathrm{O} & 0.247002 & -3.261629 & 1.833688 \\ \mathrm{H} & -0.483592 & -3.758091 & 1.423099 \\ \mathrm{O} & -1.359758 & -3.009061 & -0.391415 \\ \mathrm{H} & -1.442168 & -3.605257 & -1.150356 \\ \mathrm{O} & 2.579510 & -2.649433 & -0.582149 \\ \mathrm{H} & 2.899914 & -3.560349 & -0.528649 \\ \mathrm{O} & 0.362694 & -0.539758 & 2.618787 \\ \mathrm{H} & 0.513058 & 0.269739 & 3.128410 \\ \mathrm{O} & 0.722311 & -1.378604 & -2.435692 \\ \mathrm{H} & 1.553744 & -1.822667 & -2.669939 \\ \mathrm{H} & 3.355357 & -2.037895 & -0.436484 \\ \mathrm{H} & 0.403654 & -0.934114 & -3.234569 \\ \mathrm{H} & 0.782114 & -3.897125 & 2.331667 \\ \mathrm{H} & -2.185007 & -2.446064 & -0.367687 \\ \mathrm{H} & 0.166599 & -1.245634 & 3.254402 \\ \mathrm{C} & 1.426706 & 2.223683 & 0.100561 \\ \mathrm{C} & 1.375129 & 3.627991 & 0.170296 \\ \mathrm{C} & 0.135073 & 4.259749 & 0.197698 \\ \mathrm{H} & 2.291023 & 4.206619 & 0.199439 \\ \mathrm{C} & -0.893687 & 2.091595 & 0.080533 \\ \mathrm{C} & -1.027035 & 3.480448 & 0.148406 \\ \mathrm{H} & 0.069276 & 5.342033 & 0.251475 \\ \mathrm{H} & -2.014328 & 3.923319 & 0.158446 \\ \mathrm{C} & -2.105940 & 1.225769 & 0.005308 \\ \mathrm{C} & -4.391882 & 1.055035 & -0.071346 \\ \mathrm{C} & -4.233298 & -0.372009 & -0.166547 \\ \mathrm{~N} & 0.303282 & 1.469408 & 0.063540\end{array}$




\begin{tabular}{|c|c|c|c|}
\hline & 3.307532 & 20849 & \\
\hline & & -0.096678 & -0.070799 \\
\hline & 90 & -0.884191 & 203 \\
\hline & -5.744566 & 1.748145 & 5805 \\
\hline & -6.881633 & 0.728284 & \\
\hline & -6.973784 & 0.522790 & 1. \\
\hline & -7.82 & 1.191729 & \\
\hline & -6.6 & 975 & -0 . \\
\hline & -5.4 & -1.3 & \\
\hline & -6.6 & -0.3 & -1 . \\
\hline & -7.5 & -1.2 & -0 \\
\hline & -5.8 & 295 & 0. \\
\hline & -5.0 & 3.6 & \\
\hline & -6.7 & 00 & \\
\hline & -5.6 & 2.4 & \\
\hline & -5.8 & 2.4 & \\
\hline & -6.8 & 2.9 & -1 . \\
\hline & -5.0 & 3.1 & \\
\hline & -5.8 & 37 & -2. \\
\hline & -5.5 & -1.9 & \\
\hline & -6.4 & -2.6 & 563 \\
\hline & -4.6 & -2.5 & \\
\hline $\mathrm{H}$ & -5.7 & -1.2 & 14 \\
\hline & -5.1 & -2.4 & -1 . \\
\hline $\mathrm{H}$ & -4.3 & -3 & \\
\hline & -6.0 & -3.0 & -1 . \\
\hline $\mathrm{H}$ & -4.8 & -2.0 & -2 \\
\hline & 2.6 & 1.4 & \\
\hline C & 4.01 & 1.9 & 0.0 \\
\hline & 4.77 & 0.7 & -0.0 \\
\hline $\mathrm{H}$ & 4.39 & 2.9 & \\
\hline & 2.6 & 746 & -0. \\
\hline & 3.8 & -0.3 & -0 . \\
\hline $\mathrm{C}$ & 6.19 & 780 & -0. \\
\hline & 7.06 & 1.662441 & -0 . \\
\hline & 6.77 & -0.768501 & 040 \\
\hline & 8.442562 & 1.494769 & -0.1 \\
\hline $\mathrm{H}$ & 6.6 & 2.6 & -0. \\
\hline $\mathrm{C}$ & 8.150759 & -0.929373 & -0.2 \\
\hline $\mathrm{H}$ & & -1.633937 & -0.2 \\
\hline & 8.992856 & 0.199835 & -0.263254 \\
\hline & 9.097824 & 2.359676 & -0.195602 \\
\hline $\mathrm{H}$ & 8.583154 & -1.923535 & -0.315187 \\
\hline & 10.0699 & 0.071927 & -0.312 \\
\hline
\end{tabular}

$\mathrm{M}=\mathrm{Gd}$ 


\begin{tabular}{|c|c|c|c|}
\hline GD & 0.512158 & -1.039423 & 0.190623 \\
\hline $\mathrm{O}$ & -0.285735 & -2.559078 & 2.010555 \\
\hline$H$ & -0.805739 & -3.360389 & 1.843763 \\
\hline $\mathrm{O}$ & -1.035201 & -2.768586 & -0.707377 \\
\hline 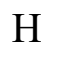 & -1.046585 & -3.543846 & -1.286815 \\
\hline $\mathcal{U}$ & 2.366960 & -2.532964 & 0.122549 \\
\hline $\mathrm{H}$ & 2.628057 & -3.460322 & 0.200257 \\
\hline $\mathrm{O}$ & 1.134578 & -0.264944 & 2.530294 \\
\hline $\mathrm{H}$ & 2.028349 & 0.114349 & 2.576621 \\
\hline $\mathrm{O}$ & 0.783947 & -0.857058 & -2.246782 \\
\hline $\mathrm{H}$ & 1.610552 & -0.460308 & -2.566774 \\
\hline $\mathrm{H}$ & 3.205850 & -1.933742 & 0.014837 \\
\hline $\mathrm{H}$ & 0.309449 & -1.199238 & -3.018752 \\
\hline $\mathrm{H}$ & 0.159288 & -2.672298 & 040 \\
\hline $\mathrm{H}$ & -1.960600 & -2.403291 & -0.614537 \\
\hline $\mathrm{H}$ & 0.641847 & 0.05 & 3.2 \\
\hline $\mathrm{C}$ & 1.394463 & 2.238584 & 0.003325 \\
\hline $\mathrm{C}$ & 1.328760 & 3.645103 & 0.007752 \\
\hline $\mathrm{C}$ & 0.085843 & 4.267779 & 0.055566 \\
\hline $\mathrm{H}$ & 2.242224 & 4.227555 & -0.0 \\
\hline $\mathrm{C}$ & -0.937013 & 2.098944 & 0.070895 \\
\hline $\mathrm{C}$ & -1.078734 & 3.483375 & 4401 \\
\hline $\mathrm{H}$ & 0.015220 & 5.35 & 2237 \\
\hline $\mathrm{H}$ & -2.066978 & 3.924143 & 6423 \\
\hline $\mathrm{C}$ & -2.118219 & 1.199693 & 0.039061 \\
\hline $\mathrm{C}$ & -4.391153 & 0.916093 & -0.055177 \\
\hline $\mathrm{C}$ & -4.162158 & -0.504637 & -0.177798 \\
\hline $\mathrm{N}$ & 0.266912 & 1.484131 & 0.044200 \\
\hline $\mathrm{N}$ & -3.345986 & 1.734288 & 0.026566 \\
\hline $\mathrm{N}$ & -1.873872 & -0.116903 & -0.013732 \\
\hline $\mathrm{N}$ & -2.913942 & -0.958992 & -0.151422 \\
\hline $\mathrm{C}$ & -5.774598 & 1.541133 & -0.077251 \\
\hline $\mathrm{C}$ & -6.865333 & 0.460049 & 0.089198 \\
\hline $\mathrm{H}$ & -6.972067 & 0.209737 & 1.149806 \\
\hline $\mathrm{H}$ & -7.824005 & 0.889190 & -0.214900 \\
\hline $\mathrm{C}$ & -6.588642 & -0.807672 & -0.722916 \\
\hline $\mathrm{C}$ & -5.286691 & -1.527739 & -0.301029 \\
\hline $\mathrm{H}$ & -6.539587 & -0.567237 & -1.790731 \\
\hline $\mathrm{H}$ & -7.419768 & -1.509502 & -0.608327 \\
\hline $\mathrm{C}$ & -5.895247 & 2.587705 & 1.053730 \\
\hline $\mathrm{H}$ & -5.181216 & 3.403140 & 0.926341 \\
\hline $\mathrm{H}$ & -6.903503 & 3.010302 & 1.040445 \\
\hline $\mathrm{H}$ & -5.736470 & 2.135350 & 2.037791 \\
\hline $\mathrm{C}$ & -5.919742 & 2.262209 & -1.448147 \\
\hline 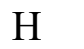 & -6.887709 & 2.769112 & -1.47885 \\
\hline
\end{tabular}




$\begin{array}{rrrr}\mathrm{H} & -5.135345 & 3.011743 & -1.577540 \\ \mathrm{H} & -5.875607 & 1.568077 & -2.292078 \\ \mathrm{C} & -5.458742 & -2.205747 & 1.084463 \\ \mathrm{H} & -6.255249 & -2.952532 & 1.026598 \\ \mathrm{H} & -4.537475 & -2.713200 & 1.386071 \\ \mathrm{H} & -5.723629 & -1.493406 & 1.869814 \\ \mathrm{C} & -4.942016 & -2.606315 & -1.349724 \\ \mathrm{H} & -4.112372 & -3.243235 & -1.029534 \\ \mathrm{H} & -5.808689 & -3.257181 & -1.492619 \\ \mathrm{H} & -4.696488 & -2.164541 & -2.320552 \\ \mathrm{C} & 2.640014 & 1.481831 & -0.050850 \\ \mathrm{C} & 3.992253 & 1.816029 & -0.111712 \\ \mathrm{C} & 4.674357 & 0.571128 & -0.151414 \\ \mathrm{H} & 4.434315 & 2.800216 & -0.154233 \\ \mathrm{~N} & 2.523157 & 0.120576 & -0.053405 \\ \mathrm{~N} & 3.764990 & -0.430000 & -0.110345 \\ \mathrm{C} & 6.123417 & 0.324708 & -0.225504 \\ \mathrm{C} & 7.034836 & 1.335717 & 0.133622 \\ \mathrm{C} & 6.622014 & -0.918878 & -0.657378 \\ \mathrm{C} & 8.411586 & 1.106488 & 0.065924 \\ \mathrm{H} & 6.675040 & 2.297955 & 0.484475 \\ \mathrm{C} & 7.998624 & -1.146448 & -0.725107 \\ \mathrm{H} & 5.932122 & -1.700879 & -0.956762 \\ \mathrm{C} & 8.898483 & -0.134614 & -0.363289 \\ \mathrm{H} & 9.104705 & 1.891967 & 0.350199 \\ \mathrm{H} & 8.372585 & -2.106696 & -1.066759 \\ \mathrm{H} & 9.967998 & -0.311211 & -0.417771\end{array}$

$\mathrm{M}=\mathrm{Am}$

$\begin{array}{lccc}\mathrm{AM} & 0.471841 & -0.992533 & 0.195420 \\ \mathrm{O} & -0.368637 & -2.619817 & 1.995580 \\ \mathrm{H} & -0.879117 & -3.421161 & 1.801362 \\ \mathrm{O} & -1.156222 & -2.759197 & -0.756111 \\ \mathrm{H} & -1.205679 & -3.523855 & -1.347649 \\ \mathrm{O} & 2.439201 & -2.442093 & 0.183795 \\ \mathrm{H} & 2.740892 & -3.339348 & 0.380711 \\ \mathrm{O} & 1.112270 & -0.304260 & 2.631746 \\ \mathrm{H} & 2.034298 & -0.005681 & 2.706076 \\ \mathrm{O} & 0.791089 & -0.859362 & -2.299890 \\ \mathrm{H} & 1.617738 & -0.470532 & -2.629477 \\ \mathrm{H} & 3.248163 & -1.814164 & 0.028460 \\ \mathrm{H} & 0.345332 & -1.270889 & -3.055418 \\ \mathrm{H} & 0.004516 & -2.717176 & 2.885635 \\ \mathrm{H} & -2.057845 & -2.340978 & -0.680725 \\ \mathrm{H} & 0.626963 & 0.136851 & 3.346456\end{array}$




\begin{tabular}{|c|c|c|c|}
\hline $\mathrm{C}$ & 1.342924 & 2.339491 & 0.045620 \\
\hline & 1.275316 & 3.745423 & 0.070166 \\
\hline $\mathrm{C}$ & 0.032019 & 4.365468 & 0.128322 \\
\hline $\mathrm{H}$ & 2.187594 & 4.329810 & 0.039012 \\
\hline C & -0.986986 & 2.194415 & 0.107008 \\
\hline C & -1.130400 & 3.578289 & 0.139257 \\
\hline $\mathrm{H}$ & -0.040767 & 5.448438 & 0.151302 \\
\hline $\mathrm{H}$ & -2.119583 & 4.016949 & 0.159498 \\
\hline $\mathrm{C}$ & -2.170305 & 1.300737 & 0.037672 \\
\hline $\mathrm{C}$ & -4.443735 & 1.029199 & -0.078278 \\
\hline $\mathrm{C}$ & -4.219315 & -0.387957 & -0.238137 \\
\hline $\mathrm{N}$ & 0.218695 & 1.581120 & 0.083955 \\
\hline $\mathrm{N}$ & -3.396030 & 1.840208 & 0.037984 \\
\hline $\mathrm{N}$ & -1.930390 & -0.013171 & -0.062089 \\
\hline $\mathrm{N}$ & -2.973034 & -0.848194 & -0.221217 \\
\hline $\mathrm{C}$ & -5.824492 & 1.660954 & -0.094609 \\
\hline $\mathrm{C}$ & -6.920471 & 0.581155 & 0.042750 \\
\hline $\mathrm{H}$ & -7.032017 & 0.307090 & 1.097004 \\
\hline $\mathrm{H}$ & -7.876176 & 1.021315 & -0.254920 \\
\hline $\mathrm{C}$ & -6.646041 & -0.668659 & -0.797140 \\
\hline $\mathrm{C}$ & -5.347912 & -1.403443 & -0.388593 \\
\hline $\mathrm{H}$ & -6.593067 & -0.404105 & -1.859043 \\
\hline $\mathrm{H}$ & -7.480099 & -1.369788 & -0.700910 \\
\hline $\mathrm{C}$ & -5.948430 & 2.684065 & 1.057000 \\
\hline $\mathrm{H}$ & -5.231048 & 3.499590 & 0.951052 \\
\hline $\mathrm{H}$ & -6.955209 & 3.110307 & 1.046812 \\
\hline $\mathrm{H}$ & -5.796774 & 2.210740 & 2.032289 \\
\hline $\mathrm{C}$ & -5.958097 & 2.410784 & -1.451170 \\
\hline $\mathrm{H}$ & -6.924175 & 2.921555 & -1.478141 \\
\hline $\mathrm{H}$ & -5.170417 & 3.160271 & -1.559633 \\
\hline $\mathrm{H}$ & -5.910108 & 1.734371 & -2.309138 \\
\hline $\mathrm{C}$ & -5.526898 & -2.113546 & 0.979804 \\
\hline $\mathrm{H}$ & -6.324481 & -2.857333 & 0.901321 \\
\hline $\mathrm{H}$ & -4.607724 & -2.629776 & 1.273080 \\
\hline $\mathrm{H}$ & -5.793615 & -1.419293 & 1.780636 \\
\hline $\mathrm{C}$ & -5.005821 & -2.458375 & -1.461926 \\
\hline $\mathrm{H}$ & -4.184097 & -3.110638 & -1.152523 \\
\hline $\mathrm{H}$ & -5.877221 & -3.097732 & -1.626529 \\
\hline $\mathrm{H}$ & -4.749596 & -1.994785 & -2.419693 \\
\hline $\mathrm{C}$ & 2.591308 & 1.592565 & -0.038105 \\
\hline $\mathrm{C}$ & 3.936602 & 1.947603 & -0.114083 \\
\hline $\mathrm{C}$ & 4.635126 & 0.714004 & -0.191380 \\
\hline $\mathrm{H}$ & 4.364425 & 2.938561 & -0.139292 \\
\hline $\mathrm{N}$ & 2.491801 & 0.231695 & -0.065717 \\
\hline $\mathrm{N}$ & 3.740835 & -0.300173 & -0.156875 \\
\hline$C$ & 6.085410 & 0.488238 & -0.288742 \\
\hline
\end{tabular}




$\begin{array}{lrrr}\mathrm{C} & 6.989094 & 1.500287 & 0.088177 \\ \mathrm{C} & 6.593849 & -0.736973 & -0.761269 \\ \mathrm{C} & 8.367362 & 1.290288 & -0.002553 \\ \mathrm{H} & 6.621473 & 2.447591 & 0.470151 \\ \mathrm{C} & 7.971962 & -0.945171 & -0.851808 \\ \mathrm{H} & 5.909637 & -1.518334 & -1.075438 \\ \mathrm{C} & 8.863832 & 0.067591 & -0.472298 \\ \mathrm{H} & 9.054453 & 2.076055 & 0.295195 \\ \mathrm{H} & 8.353605 & -1.890470 & -1.225191 \\ \mathrm{H} & 9.934670 & -0.094008 & -0.544567\end{array}$

$\mathrm{M}=\mathrm{Cm}$

$\begin{array}{lrrc}\mathrm{CM} & 0.473863 & -0.984134 & 0.168252 \\ \mathrm{O} & -0.257532 & -2.628409 & 1.987375 \\ \mathrm{H} & -0.782673 & -3.417857 & 1.783226 \\ \mathrm{O} & -1.157632 & -2.732217 & -0.738666 \\ \mathrm{H} & -1.207581 & -3.493451 & -1.334598 \\ \mathrm{O} & 2.412149 & -2.463261 & 0.054105 \\ \mathrm{H} & 2.701473 & -3.384786 & 0.093119 \\ \mathrm{O} & 1.132739 & -0.257209 & 2.557363 \\ \mathrm{H} & 2.010627 & 0.155972 & 2.612504 \\ \mathrm{O} & 0.753878 & -0.805657 & -2.319455 \\ \mathrm{H} & 1.585941 & -0.424305 & -2.644638 \\ \mathrm{H} & 3.227415 & -1.835617 & -0.044515 \\ \mathrm{H} & 0.290968 & -1.183401 & -3.082418 \\ \mathrm{H} & 0.225528 & -2.805395 & 2.809776 \\ \mathrm{H} & -2.064599 & -2.325091 & -0.643385 \\ \mathrm{H} & 0.644147 & 0.018744 & 3.348389 \\ \mathrm{C} & 1.338167 & 2.331585 & 0.021402 \\ \mathrm{C} & 1.269652 & 3.737763 & 0.045096 \\ \mathrm{C} & 0.025958 & 4.357601 & 0.098325 \\ \mathrm{H} & 2.181901 & 4.322502 & 0.018571 \\ \mathrm{C} & -0.993893 & 2.186692 & 0.081641 \\ \mathrm{C} & -1.136940 & 3.570667 & 0.112346 \\ \mathrm{H} & -0.046740 & 5.440667 & 0.119574 \\ \mathrm{H} & -2.125739 & 4.009927 & 0.136502 \\ \mathrm{C} & -2.179564 & 1.292585 & 0.033724 \\ \mathrm{C} & -4.454926 & 1.025864 & -0.063080 \\ \mathrm{C} & -4.236285 & -0.394683 & -0.200508 \\ \mathrm{~N} & 0.212107 & 1.574639 & 0.052049 \\ \mathrm{~N} & -3.403981 & 1.835695 & 0.029017 \\ \mathrm{~N} & -1.945203 & -0.024675 & -0.038164 \\ \mathrm{~N} & -2.991484 & -0.858229 & -0.181216 \\ \mathrm{C} & -5.834012 & 1.661271 & -0.078350 \\ \mathrm{C} & -6.931742 & 0.586595 & 0.083335\end{array}$




$\begin{array}{lrrr}\mathrm{H} & -7.035700 & 0.328169 & 1.142322 \\ \mathrm{H} & -7.888604 & 1.024993 & -0.213183 \\ \mathrm{C} & -6.667253 & -0.676162 & -0.740329 \\ \mathrm{C} & -5.368467 & -1.408882 & -0.330252 \\ \mathrm{H} & -6.621145 & -0.427106 & -1.806320 \\ \mathrm{H} & -7.502756 & -1.373142 & -0.627978 \\ \mathrm{C} & -5.945756 & 2.700967 & 1.059694 \\ \mathrm{H} & -5.227092 & 3.512923 & 0.936227 \\ \mathrm{H} & -6.951451 & 3.129809 & 1.051754 \\ \mathrm{H} & -5.787313 & 2.241082 & 2.040333 \\ \mathrm{C} & -5.976495 & 2.392182 & -1.444214 \\ \mathrm{H} & -6.941208 & 2.905542 & -1.470631 \\ \mathrm{H} & -5.187418 & 3.137523 & -1.569707 \\ \mathrm{H} & -5.937637 & 1.703431 & -2.292809 \\ \mathrm{C} & -5.540451 & -2.100243 & 1.048651 \\ \mathrm{H} & -6.340475 & -2.842827 & 0.985024 \\ \mathrm{H} & -4.620768 & -2.614844 & 1.343072 \\ \mathrm{H} & -5.800418 & -1.394623 & 1.841731 \\ \mathrm{C} & -5.034989 & -2.478934 & -1.391309 \\ \mathrm{H} & -4.210971 & -3.126894 & -1.078848 \\ \mathrm{H} & -5.907817 & -3.120156 & -1.540284 \\ \mathrm{H} & -4.786261 & -2.028754 & -2.357497 \\ \mathrm{C} & 2.590170 & 1.586191 & -0.045977 \\ \mathrm{C} & 3.936465 & 1.942822 & -0.102809 \\ \mathrm{C} & 4.638214 & 0.710314 & -0.168252 \\ \mathrm{H} & 4.362906 & 2.934373 & -0.127140 \\ \mathrm{~N} & 2.495098 & 0.224046 & -0.074782 \\ \mathrm{~N} & 3.746033 & -0.305702 & -0.145377 \\ \mathrm{C} & 6.091032 & 0.489143 & -0.249661 \\ \mathrm{C} & 6.986793 & 1.505488 & 0.132977 \\ \mathrm{C} & 6.609002 & -0.735553 & -0.711690 \\ \mathrm{C} & 8.366952 & 1.299987 & 0.058631 \\ \mathrm{H} & 6.611994 & 2.453181 & 0.507097 \\ \mathrm{C} & 7.988956 & -0.939524 & -0.786024 \\ \mathrm{H} & 5.931259 & -1.521059 & -1.029553 \\ \mathrm{C} & 8.873060 & 0.077492 & -0.400708 \\ \mathrm{H} & 9.047747 & 2.089427 & 0.361150 \\ \mathrm{H} & 8.377738 & -1.885204 & -1.151103 \\ \mathrm{H} & 9.945186 & -0.080612 & -0.460346\end{array}$

\section{$\left[\mathrm{ML}_{2}\left(\mathrm{H}_{2} \mathrm{O}\right)_{2}\right]^{1+}$}

$\mathrm{M}=\mathrm{Eu}$

$\begin{array}{lllll}\text { EU } & 0.351087 & 0.552297 & -0.073348\end{array}$

$\begin{array}{llll}\mathrm{O} & -0.737231 & 1.525628 & -2.150677\end{array}$ 


\begin{tabular}{|c|c|c|c|}
\hline $\mathrm{H}$ & -1.588620 & 1.944093 & -1.876907 \\
\hline & 0.697819 & 2.799546 & 1.044456 \\
\hline & 0.731941 & 3.075439 & 1.969289 \\
\hline & -0.252722 & 2.142830 & -2.716403 \\
\hline & 1.537214 & 3.143492 & 0.583958 \\
\hline & -0.051789 & -0.672094 & 3.166267 \\
\hline 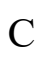 & -0.551242 & -0.944735 & 4.460363 \\
\hline C & -1.811277 & -0.484423 & 4.815591 \\
\hline $\mathrm{H}$ & 0.052794 & -1.509213 & 5.160833 \\
\hline & -2.007015 & 0.472130 & 2.624442 \\
\hline 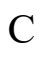 & -2.566406 & 0.239795 & 3.879983 \\
\hline H & -2.210625 & -0.683680 & 5.805460 \\
\hline $\mathrm{H}$ & -3.555126 & 0.615581 & 4.106630 \\
\hline 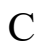 & -2.765193 & 1.232253 & 1.594058 \\
\hline $\mathrm{C}$ & -4.641242 & 2.406632 & 0.999815 \\
\hline$c$ & -4.052616 & 2.603947 & -0.289360 \\
\hline $\mathrm{N}$ & -0.781130 & 0.035908 & 2.271140 \\
\hline $\mathrm{N}$ & -3.971304 & 1.722502 & 1.921132 \\
\hline $\mathrm{N}$ & -2.194247 & 1.387231 & 0.392514 \\
\hline $\mathrm{N}$ & -2.854435 & 2.079670 & -0.539469 \\
\hline $\mathrm{C}$ & -5.994723 & 2.983247 & 1.397240 \\
\hline $\mathrm{C}$ & -6.767844 & 3.448102 & 0.143500 \\
\hline $\mathrm{H}$ & -7.220491 & 2.578193 & -0.345239 \\
\hline $\mathrm{H}$ & -7.600700 & 4.081642 & 0.464297 \\
\hline $\mathrm{C}$ & -5.893815 & 4.209080 & -0.857021 \\
\hline $\mathrm{C}$ & -4.736341 & 3.357846 & -1.427616 \\
\hline $\mathrm{H}$ & -5.480789 & 5.106718 & -0.383348 \\
\hline $\mathrm{H}$ & -6.506948 & 4.561482 & -1.692522 \\
\hline $\mathrm{C}$ & -6.821267 & 1.919644 & 2.150370 \\
\hline $\mathrm{H}$ & -6.327485 & 1.608940 & 3.072782 \\
\hline $\mathrm{H}$ & -7.800046 & 2.336445 & 2.406025 \\
\hline $\mathrm{H}$ & -6.985534 & 1.031070 & 1.532241 \\
\hline $\mathrm{C}$ & -5.722228 & 4.175898 & 2.351735 \\
\hline $\mathrm{H}$ & -6.674399 & 4.589366 & 2.696760 \\
\hline $\mathrm{H}$ & -5.153383 & 3.846267 & 3.224935 \\
\hline $\mathrm{H}$ & -5.161317 & 4.978491 & 1.864536 \\
\hline $\mathrm{C}$ & -5.270168 & 2.313409 & -2.441069 \\
\hline $\mathrm{H}$ & -5.739070 & 2.827138 & -3.285596 \\
\hline $\mathrm{H}$ & -4.453699 & 1.696585 & -2.827180 \\
\hline $\mathrm{H}$ & -6.013986 & 1.646224 & -1.996603 \\
\hline $\mathrm{C}$ & -3.736814 & 4.288790 & -2.146270 \\
\hline $\mathrm{H}$ & -2.963903 & 3.728655 & -2.677360 \\
\hline $\mathrm{H}$ & -4.272939 & 4.892511 & -2.884656 \\
\hline $\mathrm{H}$ & -3.247059 & 4.971410 & -1.445194 \\
\hline $\mathrm{C}$ & 1.254348 & -1.131554 & 2.727675 \\
\hline $\mathrm{C}$ & 2.257346 & -1.843637 & 3.377055 \\
\hline
\end{tabular}




\begin{tabular}{|c|c|c|c|}
\hline $\mathrm{C}$ & 3.281011 & -1.966090 & 2.404629 \\
\hline & 2.264169 & -2.207790 & 4.393416 \\
\hline $\mathrm{N}$ & 1.666408 & -0.861128 & 1.433476 \\
\hline N & 2.887741 & -1.359629 & 1.244039 \\
\hline 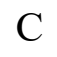 & 4.583960 & -2.619798 & 2.512870 \\
\hline & 4.957251 & -3.318648 & 3.681999 \\
\hline $\mathrm{C}$ & 5.502283 & -2.557436 & 1.440447 \\
\hline C & 6.206563 & -3.932436 & 3.776868 \\
\hline $\mathrm{H}$ & 4.268511 & -3.383909 & 4.518079 \\
\hline $\mathrm{C}$ & 6.750454 & -3.171751 & 1.538676 \\
\hline $\mathrm{H}$ & 5.217615 & -2.018129 & 0.544353 \\
\hline $\mathrm{C}$ & 7.110202 & -3.862518 & 2.706103 \\
\hline $\mathrm{H}$ & 6.480423 & -4.465615 & 4.682300 \\
\hline $\mathrm{H}$ & 7.449177 & -3.112721 & 0.709275 \\
\hline $\mathrm{H}$ & 8.082740 & -4.339315 & 2.781355 \\
\hline $\mathrm{C}$ & 2.842213 & -0.089923 & -2.418300 \\
\hline $\mathrm{C}$ & 3.665448 & -0.739181 & -3.359339 \\
\hline $\mathrm{C}$ & 3.301480 & -1.997327 & -3.826868 \\
\hline $\mathrm{H}$ & 4.571722 & -0.256106 & -3.705700 \\
\hline $\mathrm{C}$ & 1.361379 & -1.886240 & -2.423586 \\
\hline $\mathrm{C}$ & 2.123581 & -2.591945 & -3.354684 \\
\hline $\mathrm{H}$ & 3.923691 & -2.514794 & -4.550873 \\
\hline $\mathrm{H}$ & 1.797316 & -3.567877 & -3.688390 \\
\hline $\mathrm{C}$ & 0.098550 & -2.458525 & -1.883756 \\
\hline $\mathrm{C}$ & -1.419864 & -4.167458 & -1.813036 \\
\hline $\mathrm{C}$ & -2.152369 & -3.412280 & -0.848113 \\
\hline $\mathrm{N}$ & 1.706933 & -0.669206 & -1.965950 \\
\hline $\mathrm{N}$ & -0.291095 & -3.667506 & -2.309680 \\
\hline $\mathrm{N}$ & -0.585906 & -1.718175 & -0.996802 \\
\hline $\mathrm{N}$ & -1.716430 & -2.205193 & -0.482615 \\
\hline $\mathrm{C}$ & -1.844209 & -5.550962 & -2.291895 \\
\hline $\mathrm{C}$ & -3.309755 & -5.827364 & -1.890021 \\
\hline $\mathrm{H}$ & -3.978476 & -5.310061 & -2.587306 \\
\hline $\mathrm{H}$ & -3.509440 & -6.896315 & -2.016135 \\
\hline $\mathrm{C}$ & -3.630583 & -5.404792 & -0.453558 \\
\hline $\mathrm{C}$ & -3.457688 & -3.888084 & -0.211989 \\
\hline $\mathrm{H}$ & -2.991421 & -5.955389 & 0.245732 \\
\hline $\mathrm{H}$ & -4.660588 & -5.681552 & -0.205628 \\
\hline $\mathrm{C}$ & -1.703268 & -5.643600 & -3.825949 \\
\hline $\mathrm{H}$ & -0.667767 & -5.503113 & -4.140778 \\
\hline $\mathrm{H}$ & -2.036353 & -6.630315 & -4.161996 \\
\hline $\mathrm{H}$ & -2.319256 & -4.891068 & -4.328905 \\
\hline $\mathrm{C}$ & -0.886601 & -6.580490 & -1.637009 \\
\hline 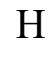 & -1.132335 & -7.585090 & -1.993979 \\
\hline $\mathrm{H}$ & 0.150534 & -6.363534 & -1.905161 \\
\hline $\mathrm{H}$ & -0.960331 & -6.580690 & -0.545811 \\
\hline
\end{tabular}




$\begin{array}{lrrr}\mathrm{C} & -4.621497 & -3.093284 & -0.854599 \\ \mathrm{H} & -5.569744 & -3.385409 & -0.392691 \\ \mathrm{H} & -4.477901 & -2.019981 & -0.701216 \\ \mathrm{H} & -4.700438 & -3.271742 & -1.930840 \\ \mathrm{C} & -3.441847 & -3.613459 & 1.306261 \\ \mathrm{H} & -3.368484 & -2.544993 & 1.517949 \\ \mathrm{H} & -4.364083 & -3.995201 & 1.755836 \\ \mathrm{H} & -2.598152 & -4.115196 & 1.790651 \\ \mathrm{C} & 3.144994 & 1.229498 & -1.874431 \\ \mathrm{C} & 4.189649 & 2.135578 & -2.082623 \\ \mathrm{C} & 3.889277 & 3.222434 & -1.230161 \\ \mathrm{H} & 5.029060 & 2.041728 & -2.755278 \\ \mathrm{~N} & 2.282079 & 1.752365 & -0.961107 \\ \mathrm{~N} & 2.736518 & 2.959083 & -0.565320 \\ \mathrm{C} & 4.637606 & 4.474638 & -1.034494 \\ \mathrm{C} & 5.957684 & 4.606561 & -1.507668 \\ \mathrm{C} & 4.051365 & 5.570367 & -0.371157 \\ \mathrm{C} & 6.669160 & 5.795109 & -1.323001 \\ \mathrm{H} & 6.438680 & 3.772426 & -2.008456 \\ \mathrm{C} & 4.763169 & 6.758161 & -0.184983 \\ \mathrm{H} & 3.031457 & 5.487318 & -0.011928 \\ \mathrm{C} & 6.076358 & 6.877815 & -0.660456 \\ \mathrm{H} & 7.687803 & 5.876588 & -1.690623 \\ \mathrm{H} & 4.294418 & 7.594202 & 0.326174 \\ \mathrm{H} & 6.629231 & 7.801007 & -0.516624\end{array}$

\section{$\mathrm{M}=\mathrm{Gd}$}

$\begin{array}{lrrr}\text { GD } & -0.365551 & 0.553700 & -0.034312 \\ \mathrm{O} & -0.641733 & 2.701085 & 1.143592 \\ \mathrm{H} & -1.467783 & 3.110937 & 0.697580 \\ \mathrm{O} & 0.651884 & 1.525603 & -2.091279 \\ \mathrm{H} & 1.522396 & 1.931854 & -1.855449 \\ \mathrm{H} & -0.689799 & 2.881376 & 2.091741 \\ \mathrm{H} & 0.159391 & 2.131166 & -2.662784 \\ \mathrm{C} & -2.846787 & -0.012110 & -2.322916 \\ \mathrm{C} & -3.690695 & -0.658510 & -3.245827 \\ \mathrm{C} & -3.347263 & -1.924252 & -3.708784 \\ \mathrm{H} & -4.598722 & -0.169371 & -3.578793 \\ \mathrm{C} & -1.381500 & -1.823126 & -2.342917 \\ \mathrm{C} & -2.166933 & -2.527894 & -3.253130 \\ \mathrm{H} & -3.988643 & -2.442143 & -4.415409 \\ \mathrm{H} & -1.858914 & -3.511541 & -3.581672 \\ \mathrm{C} & -0.113942 & -2.391553 & -1.818098 \\ \mathrm{C} & 1.407974 & -4.095982 & -1.743173 \\ \mathrm{C} & 2.180323 & -3.302527 & -0.839853\end{array}$




$\begin{array}{lrrr}\mathrm{N} & -1.709209 & -0.600108 & -1.887479 \\ \mathrm{~N} & 0.270982 & -3.605527 & -2.230422 \\ \mathrm{~N} & 0.579277 & -1.640908 & -0.945773 \\ \mathrm{~N} & 1.735294 & -2.102711 & -0.465427 \\ \mathrm{C} & 1.833647 & -5.480183 & -2.217422 \\ \mathrm{C} & 2.975371 & -6.022069 & -1.329203 \\ \mathrm{H} & 2.553050 & -6.410100 & -0.395734 \\ \mathrm{H} & 3.431306 & -6.879578 & -1.834217 \\ \mathrm{C} & 4.046487 & -4.973116 & -1.017017 \\ \mathrm{C} & 3.499899 & -3.764403 & -0.224482 \\ \mathrm{H} & 4.500229 & -4.617798 & -1.949318 \\ \mathrm{H} & 4.856668 & -5.429943 & -0.439379 \\ \mathrm{C} & 0.630989 & -6.446442 & -2.160496 \\ \mathrm{H} & -0.174149 & -6.121497 & -2.821731 \\ \mathrm{H} & 0.953577 & -7.444476 & -2.472287 \\ \mathrm{H} & 0.229343 & -6.523912 & -1.145215 \\ \mathrm{C} & 2.297494 & -5.341880 & -3.691165 \\ \mathrm{H} & 2.562865 & -6.328321 & -4.082656 \\ \mathrm{H} & 1.494752 & -4.931207 & -4.308896 \\ \mathrm{H} & 3.170831 & -4.691039 & -3.792467 \\ \mathrm{C} & 3.228757 & -4.149443 & 1.251554 \\ \mathrm{H} & 4.162088 & -4.462608 & 1.729660 \\ \mathrm{H} & 2.828319 & -3.293595 & 1.801642 \\ \mathrm{H} & 2.511502 & -4.970001 & 1.340380 \\ \mathrm{C} & 4.535846 & -2.621837 & -0.260364 \\ \mathrm{H} & 4.204457 & -1.767648 & 0.333466 \\ \mathrm{H} & 5.487011 & -2.979254 & 0.146608 \\ \mathrm{H} & 4.714553 & -2.281021 & -1.285489 \\ \mathrm{C} & -3.116251 & 1.310783 & -1.772980 \\ \mathrm{C} & -4.134679 & 2.251476 & -1.955983 \\ \mathrm{C} & -3.790472 & 3.317518 & -1.094505 \\ \mathrm{H} & -4.985492 & 2.192800 & -2.618221 \\ \mathrm{~N} & -2.228552 & 1.795023 & -0.864832 \\ \mathrm{~N} & -2.639651 & 3.011935 & -0.447502 \\ \mathrm{C} & -4.500931 & 4.588917 & -0.871125 \\ \mathrm{C} & -5.850532 & 4.732485 & -1.244319 \\ \mathrm{C} & -3.846268 & 5.687236 & -0.282145 \\ \mathrm{C} & -6.525615 & 5.938616 & -1.035516 \\ \mathrm{H} & -6.382923 & 3.893715 & -1.681602 \\ \mathrm{H} & -2.8028312 & 6.892363 & -0.070879 \\ \mathrm{H} & -5.865258 & 7.024987 & -0.447578 \\ \mathrm{H} & -5.594122 & -0.029936 & -1.324430 \\ \mathrm{H} & -0.781217 & 3.081378\end{array}$




\begin{tabular}{|c|c|c|c|}
\hline $\mathrm{C}$ & 0.509853 & -1.110849 & 4.360964 \\
\hline & 1.775022 & -0.676703 & 4.727448 \\
\hline $\mathrm{H}$ & -0.097569 & -1.697252 & 5.040226 \\
\hline $\mathrm{C}$ & 1.975851 & 0.364229 & 2.577923 \\
\hline$C$ & 2.537679 & 0.077701 & 3.818655 \\
\hline H & 2.175353 & -0.918511 & 5.707459 \\
\hline $\mathrm{H}$ & 3.530386 & 0.434830 & 4.057534 \\
\hline & 2.728612 & 1.146212 & 1.564895 \\
\hline $\mathrm{C}$ & 4.602526 & 2.324602 & 0.972802 \\
\hline $\mathrm{C}$ & 4.007228 & 2.538366 & -0.312180 \\
\hline $\mathrm{N}$ & 0.740979 & -0.041807 & 2.215451 \\
\hline $\mathrm{N}$ & 3.944444 & 1.616098 & 1.883779 \\
\hline $\mathrm{N}$ & 2.137887 & 1.345405 & 0.378358 \\
\hline $\mathbf{N}$ & 2.795215 & 2.043745 & -0.551310 \\
\hline$C$ & 5.984895 & 2.843125 & 1.348641 \\
\hline$C$ & 6.453938 & 3.904220 & 0.328962 \\
\hline $\mathrm{H}$ & 5.971039 & 4.861127 & 0.555512 \\
\hline $\mathrm{H}$ & 7.527283 & 4.067589 & 0.466999 \\
\hline $\mathrm{C}$ & 6.172206 & 3.511170 & -1.123530 \\
\hline $\mathrm{C}$ & 4.665979 & 3.344045 & -1.429611 \\
\hline $\mathrm{H}$ & 6.694593 & 2.578521 & -1.364751 \\
\hline 11 & 6.578787 & 4.270274 & -1.799153 \\
\hline $\mathrm{C}$ & 5.947609 & 3.463873 & 2.761460 \\
\hline $\mathrm{H}$ & 5.672901 & 2.724977 & 3.516212 \\
\hline $\mathrm{H}$ & 6.937510 & 3.858966 & 3.008443 \\
\hline $\mathrm{H}$ & 5.232864 & 4.291242 & 2.814831 \\
\hline $\mathrm{C}$ & 6.945576 & 1.624742 & 1.360592 \\
\hline $\mathrm{H}$ & 7.941177 & 1.951666 & 1.674264 \\
\hline $\mathrm{H}$ & 6.594549 & 0.866548 & 2.065388 \\
\hline $\mathrm{H}$ & 7.037242 & 1.157760 & 0.375757 \\
\hline $\mathrm{C}$ & 3.965205 & 4.724813 & -1.501854 \\
\hline $\mathrm{H}$ & 4.397298 & 5.314179 & -2.315939 \\
\hline $\mathrm{H}$ & 2.895076 & 4.608555 & -1.695235 \\
\hline $\mathrm{H}$ & 4.075630 & 5.295653 & -0.575897 \\
\hline $\mathrm{C}$ & 4.507875 & 2.626078 & -2.786728 \\
\hline $\mathrm{H}$ & 3.464838 & 2.568057 & -3.105487 \\
\hline $\mathrm{H}$ & 5.059067 & 3.178773 & -3.553379 \\
\hline $\mathrm{H}$ & 4.910938 & 1.609163 & -2.750838 \\
\hline $\mathrm{C}$ & -1.298874 & -1.204467 & 2.613423 \\
\hline $\mathrm{C}$ & -2.308237 & -1.975712 & 3.195794 \\
\hline $\mathrm{C}$ & -3.312848 & -2.035510 & 2.204480 \\
\hline $\mathrm{H}$ & -2.324739 & -2.411278 & 4.183883 \\
\hline $\mathrm{N}$ & -1.696888 & -0.835665 & 1.352484 \\
\hline $\mathrm{N}$ & -2.920068 & -1.343255 & 1.105739 \\
\hline $\mathrm{C}$ & -4.619980 & -2.715780 & 2.254683 \\
\hline $\mathrm{C}$ & -4.945214 & -3.589348 & 3.309405 \\
\hline
\end{tabular}




$\begin{array}{llll}\mathrm{C} & -5.574934 & -2.500601 & 1.242206 \\ \mathrm{C} & -6.187833 & -4.229111 & 3.352486 \\ \mathrm{H} & -4.224595 & -3.779452 & 4.098827 \\ \mathrm{C} & -6.816353 & -3.140464 & 1.285355 \\ \mathrm{H} & -5.331389 & -1.822728 & 0.431748 \\ \mathrm{C} & -7.130616 & -4.008331 & 2.340509 \\ \mathrm{H} & -6.421228 & -4.900368 & 4.173850 \\ \mathrm{H} & -7.544545 & -2.959337 & 0.499687 \\ \mathrm{H} & -8.096509 & -4.503072 & 2.374621\end{array}$

$\mathrm{M}=\mathrm{Am}$

$\begin{array}{lccc}\text { AM } & -0.000046 & -0.290882 & 0.000060 \\ \mathrm{~N} & -0.970222 & 0.668737 & -2.211680 \\ \mathrm{~N} & 0.970141 & 0.668892 & 2.211763 \\ \mathrm{C} & -0.196083 & 1.532393 & -2.913930 \\ \mathrm{C} & -2.242047 & 0.447163 & -2.606000 \\ \mathrm{~N} & -2.394684 & -1.103244 & -0.768167 \\ \mathrm{~N} & 2.394629 & -1.103170 & 0.768359 \\ \mathrm{~N} & -1.489509 & 1.172080 & 1.210397 \\ \mathrm{~N} & 1.489471 & 1.171965 & -1.210379 \\ \mathrm{C} & 0.195997 & 1.532583 & 2.913966 \\ \mathrm{C} & 2.241949 & 0.447315 & 2.606129 \\ \mathrm{C} & -0.695757 & 2.176476 & -4.065918 \\ \mathrm{C} & 1.142760 & 1.756060 & -2.398100 \\ \mathrm{C} & -2.803266 & 1.054064 & -3.725379 \\ \mathrm{C} & -3.033563 & -0.492930 & -1.772462 \\ \mathrm{~N} & -3.071632 & -1.961164 & -0.003947 \\ \mathrm{C} & 3.033488 & -0.492793 & 1.772628 \\ \mathrm{~N} & 3.071635 & -1.961030 & 0.004120 \\ \mathrm{C} & -1.142819 & 1.756262 & 2.398081 \\ \mathrm{~N} & -2.761435 & 1.504940 & 0.900545 \\ \mathrm{~N} & 2.761445 & 1.504750 & -0.900637 \\ \mathrm{C} & 0.695641 & 2.176689 & 4.065952 \\ \mathrm{C} & 2.803145 & 1.054241 & 3.725507 \\ \mathrm{C} & -2.001200 & 1.932958 & -4.470581 \\ \mathrm{H} & -0.061228 & 2.863429 & -4.613216 \\ \mathrm{C} & 2.230783 & 2.492259 & -2.872046 \\ \mathrm{H} & -3.830685 & 0.846034 & -3.992351 \\ \mathrm{~N} & -4.329149 & -0.679284 & -2.058073 \\ \mathrm{C} & -4.363880 & -2.194043 & -0.217526 \\ \mathrm{~N} & 4.329085 & -0.679084 & 2.058243 \\ \mathrm{C} & 4.363906 & -2.193806 & 0.217667 \\ \mathrm{C} & -2.230806 & 2.492603 & 2.871885 \\ \mathrm{C} & -3.230199 & 2.302213 & 1.890785 \\ \mathrm{C} & 3.230218 & 2.301882 & -1.890987\end{array}$




$\begin{array}{lrrr}\mathrm{C} & 2.001069 & 1.933164 & 4.470663 \\ \mathrm{H} & 0.061103 & 2.863661 & 4.613213 \\ \mathrm{H} & 3.830555 & 0.846208 & 3.992512 \\ \mathrm{H} & -2.403048 & 2.425704 & -5.350741 \\ \mathrm{H} & 2.290280 & 3.090736 & -3.769008 \\ \mathrm{C} & -5.026256 & -1.503591 & -1.283138 \\ \mathrm{C} & -5.062472 & -3.170459 & 0.725732 \\ \mathrm{C} & 5.026235 & -1.503352 & 1.283309 \\ \mathrm{C} & 5.062581 & -3.170094 & -0.725661 \\ \mathrm{H} & -2.290302 & 3.091180 & 3.768780 \\ \mathrm{C} & -4.602570 & 2.840716 & 1.856743 \\ \mathrm{C} & 4.602640 & 2.840264 & -1.857086 \\ \mathrm{H} & 2.402896 & 2.425926 & 5.350823 \\ \mathrm{C} & -6.503068 & -1.689934 & -1.606766 \\ \mathrm{C} & -4.201351 & -4.434142 & 0.936397 \\ \mathrm{C} & -6.422465 & -3.587419 & 0.120005 \\ \mathrm{C} & -5.265616 & -2.458715 & 2.087570 \\ \mathrm{C} & 6.503043 & -1.689664 & 1.606974 \\ \mathrm{C} & 4.201550 & -4.433812 & -0.936472 \\ \mathrm{C} & 6.422590 & -3.587022 & -0.119949 \\ \mathrm{C} & 5.265708 & -2.458195 & -2.087423 \\ \mathrm{C} & -5.207231 & 3.361785 & 3.016212 \\ \mathrm{C} & -5.339384 & 2.847458 & 0.656202 \\ \mathrm{C} & 5.207304 & 3.361086 & -3.016665 \\ \mathrm{C} & 5.339501 & 2.847137 & -0.656575 \\ \mathrm{C} & -7.161275 & -0.314197 & -1.847805 \\ \mathrm{H} & -4.307166 & -2.140075 & -2.506854 \\ \mathrm{C} & -7.219495 & -2.407426 & -0.441710 \\ \mathrm{C} & -6.589952 & -2.526965 & -2.909900 \\ \mathrm{H} & -4.756579 & -5.150856 & 1.549056 \\ \mathrm{H} & -3.963079 & -4.919750 & -0.015089 \\ \mathrm{H} & -3.262309 & -4.215325 & 1.449781 \\ \mathrm{H} & -7.004688 & -4.093472 & 0.896614 \\ \mathrm{H} & -6.253701 & -4.331154 & -0.667063 \\ \mathrm{H} & -4.307088 & -2.140560 & 2.507004 \\ \mathrm{H} & -5.738582 & -3.147209 & 2.794326 \\ \mathrm{H} & -5.896541 & -1.570502 & 2.002307 \\ \mathrm{C} & 7.161196 & -0.313926 & 1.848154 \\ \mathrm{C} & 7.219541 & -2.407033 & 0.441887 \\ \mathrm{H} & -6.589900 & -2.526801 & 2.910043 \\ \mathrm{H} & 3.963293 & -4.919532 & 0.014961 \\ \mathrm{H} & -3.146580 & -2.794235\end{array}$




$\begin{array}{lrrr}\mathrm{H} & 5.896555 & -1.569936 & -2.002054 \\ \mathrm{C} & -6.507617 & 3.875018 & 2.978095 \\ \mathrm{H} & -4.665466 & 3.356905 & 3.957032 \\ \mathrm{C} & -6.639298 & 3.359747 & 0.618270 \\ \mathrm{H} & -4.873740 & 2.462930 & -0.244840 \\ \mathrm{C} & 6.507739 & 3.874203 & -2.978684 \\ \mathrm{H} & 4.665500 & 3.356101 & -3.957463 \\ \mathrm{C} & 6.639465 & 3.359313 & -0.618779 \\ \mathrm{H} & 4.873853 & 2.462808 & 0.244550 \\ \mathrm{H} & -8.228153 & -0.455250 & -2.046093 \\ \mathrm{H} & -7.061857 & 0.332700 & -0.970979 \\ \mathrm{H} & -6.715730 & 0.196229 & -2.703698 \\ \mathrm{H} & -8.195541 & -2.754067 & -0.795504 \\ \mathrm{H} & -7.424856 & -1.684323 & 0.354943 \\ \mathrm{H} & -6.165189 & -3.527955 & -2.790930 \\ \mathrm{H} & -7.638711 & -2.636873 & -3.200897 \\ \mathrm{H} & -6.058125 & -2.026869 & -3.723419 \\ \mathrm{H} & 8.228068 & -0.454963 & 2.046490 \\ \mathrm{H} & 7.061808 & 0.333028 & 0.971367 \\ \mathrm{H} & 6.715589 & 0.196424 & 2.704059 \\ \mathrm{H} & 8.195592 & -2.753653 & 0.795685 \\ \mathrm{H} & 7.424891 & -1.683857 & -0.354703 \\ \mathrm{H} & 6.165163 & -3.527790 & 2.790974 \\ \mathrm{H} & 7.638652 & -2.636710 & 3.201068 \\ \mathrm{H} & 6.058035 & -2.026783 & 3.723585 \\ \mathrm{C} & -7.231537 & 3.876967 & 1.779021 \\ \mathrm{H} & -6.957321 & 4.272497 & 3.883298 \\ \mathrm{H} & -7.189195 & 3.370492 & -0.319076 \\ \mathrm{C} & 7.231706 & 3.876283 & -1.779639 \\ \mathrm{H} & 6.957445 & 4.271491 & -3.883970 \\ \mathrm{H} & 7.189397 & 3.370169 & 0.318545 \\ \mathrm{H} & -8.239099 & 4.280247 & 1.748294 \\ \mathrm{H} & 8.239307 & 4.279476 & -1.749019 \\ \mathrm{O} & 0.800353 & -2.256854 & -1.448042 \\ \mathrm{H} & 0.798751 & -2.263416 & -2.415129 \\ \mathrm{H} & 1.739369 & -2.380405 & -1.145672 \\ & -0.800167 & -2.257062 & 1.447912 \\ \mathrm{H} & -1.739233 & -2.380629 & 1.145711\end{array}$

$\mathrm{M}=\mathrm{Cm}$

$\begin{array}{llll}\mathrm{CM} & 0.000004 & 0.293162 & 0.000016\end{array}$

$\begin{array}{llll}\mathrm{N} & -0.985885 & -0.729389 & 2.148090\end{array}$

N $\quad 0.985889 \quad-0.729351 \quad-2.148078$

C $\quad-0.219105 \quad-1.615007 \quad 2.829390$ 


\begin{tabular}{|c|c|c|c|}
\hline$r$ & -2.262275 & -0.517678 & 32561 \\
\hline$N$ & 1.522765 & -1.145672 & 1.201193 \\
\hline $\mathbf{N}$ & -1.522782 & -1.145637 & -1.201200 \\
\hline$v$ & 2.374817 & 1.119490 & -0.767371 \\
\hline$\checkmark$ & -2.374800 & 1.119493 & 0.767418 \\
\hline & 0.219103 & -1.614955 & -2.829393 \\
\hline $\mathrm{C}$ & 2.262276 & -0.517632 & -2.532554 \\
\hline $\mathrm{C}$ & -0.738937 & -2.307926 & 3.943876 \\
\hline $\mathrm{C}$ & 1.135687 & -1.803643 & 2.339021 \\
\hline $\mathrm{C}$ & -2.841241 & -1.169562 & 3.616824 \\
\hline $\mathrm{C}$ & -3.034194 & 0.467248 & 1.731919 \\
\hline$N$ & 2.806332 & -1.459331 & 0.918604 \\
\hline $\mathrm{C}$ & -1.135696 & -1.803593 & -2.339034 \\
\hline $\mathbf{N}$ & -2.806355 & -1.459287 & -0.91 \\
\hline $\mathrm{C}$ & 3.034198 & 0.467279 & -1.731902 \\
\hline $\mathrm{N}$ & 3.034147 & 2.0 & -0.026129 \\
\hline$N$ & -3.034118 & 2.010221 & 0.026202 \\
\hline $\mathrm{C}$ & 0.738933 & -2.307859 & -3.943890 \\
\hline $\mathrm{C}$ & 2.841237 & -1.169498 & -3.616831 \\
\hline $\mathrm{C}$ & -2.052119 & -2.082778 & 4.334565 \\
\hline $\mathrm{H}$ & -0.112769 & -3.014659 & 4.475388 \\
\hline $\mathrm{C}$ & 2.208554 & -2.566509 & 2.804 \\
\hline $\mathrm{H}$ & -3.871228 & -0.968280 & 3.879243 \\
\hline $\mathrm{N}$ & -4.331366 & 0.654812 & 2.009066 \\
\hline $\mathrm{C}$ & 3.241331 & -2.316305 & 1.873470 \\
\hline $\mathrm{C}$ & -2.208565 & -2.566441 & -2.804875 \\
\hline $\mathrm{C}$ & -3.241351 & -2.316242 & -1.873518 \\
\hline $\mathrm{N}$ & 4.331361 & 0.654874 & -2.009078 \\
\hline $\mathrm{C}$ & 4.327075 & 2.246423 & -0.233322 \\
\hline $\mathrm{C}$ & -4.327051 & 2.246443 & 0.233384 \\
\hline $\mathrm{C}$ & 2.052113 & -2.082706 & -4.334580 \\
\hline $\mathrm{H}$ & 0.112762 & -3.014583 & -4.475411 \\
\hline $\mathrm{H}$ & 3.871221 & -0.968208 & -3.879254 \\
\hline $\mathrm{H}$ & -2.468600 & -2.612841 & 5.185844 \\
\hline $\mathrm{H}$ & 2.237210 & -3.219299 & 3.664585 \\
\hline $\mathrm{C}$ & -5.008618 & 1.522230 & 1.264083 \\
\hline $\mathrm{C}$ & 4.614084 & -2.854703 & 1.854487 \\
\hline $\mathrm{H}$ & -2.237218 & -3.219216 & -3.664635 \\
\hline $\mathrm{C}$ & -4.614110 & -2.854623 & -1.854560 \\
\hline $\mathrm{C}$ & 5.008621 & 1.522274 & -1.264080 \\
\hline $\mathrm{C}$ & 5.005494 & 3.264247 & 0.680517 \\
\hline $\mathrm{C}$ & -5.005447 & 3.264328 & -0.680405 \\
\hline $\mathrm{H}$ & 2.468591 & -2.612756 & -5.185869 \\
\hline $\mathrm{C}$ & -6.485120 & 1.718770 & 1.584057 \\
\hline $\mathrm{C}$ & 5.173080 & -3.458500 & 2.996540 \\
\hline $\mathrm{C}$ & 5.396958 & -2.779073 & 0.685969 \\
\hline
\end{tabular}




$\begin{array}{lrrr}\mathrm{C} & -5.173101 & -3.458394 & -2.996629 \\ \mathrm{C} & -5.396997 & -2.779003 & -0.686050 \\ \mathrm{C} & 6.485102 & 1.718876 & -1.584112 \\ \mathrm{C} & 4.125990 & 4.522533 & 0.841422 \\ \mathrm{C} & 6.364057 & 3.678408 & 0.069856 \\ \mathrm{C} & 5.208430 & 2.603091 & 2.067597 \\ \mathrm{C} & -4.125962 & 4.522650 & -0.841143 \\ \mathrm{C} & -6.364053 & 3.678406 & -0.069782 \\ \mathrm{C} & -5.208291 & 2.603294 & -2.067555 \\ \mathrm{C} & -7.166930 & 0.346171 & 1.769871 \\ \mathrm{C} & -7.182306 & 2.490398 & 0.442006 \\ \mathrm{C} & -6.567832 & 2.508517 & 2.916763 \\ \mathrm{C} & 6.473572 & -3.972234 & 2.972388 \\ \mathrm{H} & 4.595626 & -3.518235 & 3.913954 \\ \mathrm{C} & 6.696968 & -3.291756 & 0.661965 \\ \mathrm{H} & 4.967231 & -2.329400 & -0.202655 \\ \mathrm{C} & -6.473600 & -3.972112 & -2.972501 \\ \mathrm{H} & -4.595637 & -3.518121 & -3.914038 \\ \mathrm{C} & -6.697014 & -3.291668 & -0.662069 \\ \mathrm{H} & -4.967275 & -2.329349 & 0.202587 \\ \mathrm{C} & 7.166948 & 0.346312 & -1.770045 \\ \mathrm{C} & 7.182322 & 2.490459 & -0.442051 \\ \mathrm{C} & 6.567721 & 2.508707 & -2.916775 \\ \mathrm{H} & 4.666152 & 5.266749 & 1.434463 \\ \mathrm{H} & 3.890185 & 4.972661 & -0.127983 \\ \mathrm{H} & -6.125397 & 3.505837 & 2.837928 \\ \mathrm{H} & 3.185019 & 4.308131 & 1.353105 \\ \mathrm{H} & 6.932971 & 4.221184 & 0.831412 \\ \mathrm{H} & 6.190624 & 4.390105 & -0.745320 \\ \mathrm{H} & 4.251160 & 2.287675 & 2.492113 \\ \mathrm{H} & 5.667799 & 3.321755 & 2.752986 \\ \mathrm{H} & 5.851040 & 1.720592 & 2.017474 \\ \mathrm{H} & -4.666099 & 5.266902 & -1.434162 \\ \mathrm{H} & -3.890239 & 4.972704 & 0.128316 \\ \mathrm{H} & -3.184946 & 4.308316 & -1.352772 \\ \mathrm{H} & -6.932946 & 4.221217 & -0.831329 \\ \mathrm{H} & -6.190682 & 4.390053 & 0.745450 \\ \mathrm{H} & -4.250993 & 2.287928 & -2.492045 \\ \mathrm{H} & -5.667631 & 3.322013 & -2.752907 \\ \mathrm{H} & -5.850892 & 1.720782 & -2.017547 \\ \mathrm{H} & -8.232496 & 0.497408 & 1.967761 \\ \mathrm{H} & -0.625423 & 3.204369\end{array}$




$\begin{array}{lrrr}\mathrm{H} & -6.050619 & 1.969684 & 3.714870 \\ \mathrm{C} & 7.243401 & -3.891960 & 1.805051 \\ \mathrm{H} & 6.887705 & -4.433884 & 3.864001 \\ \mathrm{H} & 7.283223 & -3.237207 & -0.251573 \\ \mathrm{C} & -7.243441 & -3.891847 & -1.805172 \\ \mathrm{H} & -6.887729 & -4.433742 & -3.864126 \\ \mathrm{H} & -7.283279 & -3.237127 & 0.251463 \\ \mathrm{H} & 8.232498 & 0.497597 & -1.967980 \\ \mathrm{H} & 7.073154 & -0.268793 & -0.870084 \\ \mathrm{H} & 6.734796 & -0.203162 & -2.608452 \\ \mathrm{H} & 8.155588 & 2.838383 & -0.802204 \\ \mathrm{H} & 7.392836 & 1.800777 & 0.382462 \\ \mathrm{H} & 6.125259 & 3.506009 & -2.837855 \\ \mathrm{H} & 7.616649 & 2.625663 & -3.204427 \\ \mathrm{H} & 6.050483 & 1.969907 & -3.714888 \\ \mathrm{H} & 8.251323 & -4.295001 & 1.784929 \\ \mathrm{H} & -8.251369 & -4.294875 & -1.785068 \\ \mathrm{O} & 0.767178 & 2.254003 & 1.466515 \\ \mathrm{H} & 0.783776 & 2.262096 & 2.433393 \\ \mathrm{H} & 1.695041 & 2.407239 & 1.146046 \\ \mathrm{O} & -0.767163 & 2.254020 & -1.466470 \\ \mathrm{H} & -0.783786 & 2.262094 & -2.433348 \\ \mathrm{H} & -1.695018 & 2.407265 & -1.145981\end{array}$

$\left.{ }^{\mathrm{ML}_{2}}\right]^{1+}$

$\mathrm{M}=\mathrm{Eu}$

$\begin{array}{lccc}\text { EU } & -0.000040 & 0.357689 & 0.000002 \\ \mathrm{C} & -0.058834 & 1.213725 & 3.375127 \\ \mathrm{C} & 0.279808 & 1.338321 & 4.739692 \\ \mathrm{C} & 1.346680 & 0.603473 & 5.244235 \\ \mathrm{H} & -0.288224 & 2.004379 & 5.378626 \\ \mathrm{C} & 1.669983 & -0.320311 & 3.057919 \\ \mathrm{C} & 2.065795 & -0.249568 & 4.391922 \\ \mathrm{H} & 1.623400 & 0.689244 & 6.290706 \\ \mathrm{H} & 2.904181 & -0.838829 & 4.739684 \\ \mathrm{C} & 2.368669 & -1.201694 & 2.083283 \\ \mathrm{C} & 4.031794 & -2.686252 & 1.581015 \\ \mathrm{C} & 3.515403 & -2.744633 & 0.248317 \\ \mathrm{~N} & 0.639852 & 0.390466 & 2.560449 \\ \mathrm{~N} & 3.427165 & -1.915724 & 2.484455 \\ \mathrm{~N} & 1.881404 & -1.220191 & 0.832114 \\ \mathrm{~N} & 2.457978 & -2.001093 & -0.082884 \\ \mathrm{C} & 5.236345 & -3.495761 & 2.045023 \\ \mathrm{C} & 6.003669 & -4.058314 & 0.827833\end{array}$




\begin{tabular}{|c|c|c|c|}
\hline $\mathrm{H}$ & 6.626164 & -3.266341 & 0.397062 \\
\hline & 6.696038 & -4.829196 & 1.180894 \\
\hline $\mathrm{C}$ & 5.084427 & -4.638978 & -0.250431 \\
\hline $\mathrm{C}$ & 4.130069 & -3.590229 & -0.864297 \\
\hline $\mathrm{H}$ & 4.494726 & -5.462523 & 0.168166 \\
\hline $\mathrm{H}$ & 5.685470 & -5.074320 & -1.055197 \\
\hline $\mathrm{C}$ & 6.177747 & -2.603543 & 2.882176 \\
\hline H & 5.682736 & -2.232901 & 3.781533 \\
\hline $\mathrm{H}$ & 7.053698 & -3.185656 & 3.184033 \\
\hline $\mathrm{H}$ & 6.528689 & -1.742709 & 2.304229 \\
\hline & 4.702972 & -4.643918 & 2.941718 \\
\hline $\mathrm{H}$ & 5.546436 & -5.219789 & 3.333736 \\
\hline & 4.139221 & -4.240744 & 3.787010 \\
\hline $\mathrm{H}$ & 4.050373 & -5.329521 & 2.393653 \\
\hline & 4.894969 & -2.636080 & -1.816428 \\
\hline $\mathrm{H}$ & 5.324179 & -3.208538 & -2.644351 \\
\hline $\mathrm{H}$ & 4.217339 & -1.884963 & -2.230803 \\
\hline $\mathrm{H}$ & 5.709441 & -2.109873 & -1.310759 \\
\hline$C$ & 3.022747 & -4.310751 & -1.661643 \\
\hline $\mathrm{H}$ & 2.355416 & -3.598532 & -2.150596 \\
\hline $\mathrm{H}$ & 3.480150 & -4.940334 & -2.431119 \\
\hline $\mathrm{H}$ & 2.421628 & -4.956248 & -1.012791 \\
\hline $\mathrm{C}$ & -1.156853 & 1.939742 & 2.753567 \\
\hline $\mathrm{C}$ & -2.096144 & 2.836072 & 3.247553 \\
\hline $\mathrm{C}$ & -2.888646 & 3.171993 & 2.118168 \\
\hline $\mathrm{H}$ & -2.198756 & 3.200236 & 4.258712 \\
\hline $\mathrm{N}$ & -1.386727 & 1.760017 & 1.400145 \\
\hline $\mathrm{N}$ & -2.430126 & 2.502336 & 1.019770 \\
\hline$C$ & -4.031923 & 4.079284 & 2.031746 \\
\hline$c$ & -4.530165 & 4.738570 & 3.177025 \\
\hline $\mathrm{C}$ & -4.661423 & 4.315583 & 0.788564 \\
\hline $\mathrm{C}$ & -5.621125 & 5.603168 & 3.083113 \\
\hline $\mathrm{H}$ & -4.064399 & 4.574433 & 4.143240 \\
\hline $\mathrm{C}$ & -5.751183 & 5.180933 & 0.697925 \\
\hline $\mathrm{H}$ & -4.276287 & 3.815200 & -0.092411 \\
\hline $\mathrm{C}$ & -6.237822 & 5.829327 & 1.843603 \\
\hline $\mathrm{H}$ & -5.993092 & 6.103549 & 3.972087 \\
\hline 11 & -6.223467 & 5.357118 & -0.264098 \\
\hline $\mathrm{H}$ & -7.085208 & 6.504224 & 1.771229 \\
\hline $\mathrm{C}$ & 0.059014 & 1.213170 & -3.375272 \\
\hline $\mathrm{C}$ & -0.279526 & 1.337542 & -4.739883 \\
\hline $\mathrm{C}$ & -1.346388 & 0.602645 & -5.244374 \\
\hline $\mathrm{H}$ & 0.288576 & 2.003469 & -5.378891 \\
\hline 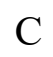 & -1.669881 & -0.320745 & -3.057919 \\
\hline $\mathrm{C}$ & -2.065596 & -0.250220 & -4.391963 \\
\hline $\mathrm{H}$ & -1.623030 & 0.688244 & -6.290880 \\
\hline
\end{tabular}




\begin{tabular}{|c|c|c|c|}
\hline $\mathrm{H}$ & -2.903978 & -0.839510 & -4.739681 \\
\hline & -2.368679 & -1.201932 & -2.083183 \\
\hline & -4.031896 & -2.686345 & -1.580788 \\
\hline & -3.515603 & -2.744527 & -0.248043 \\
\hline 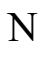 & -0.639756 & 0.390079 & -2.560499 \\
\hline & -3.427169 & -1.915994 & -2.48431 \\
\hline $\mathbf{N}$ & -1.881520 & -1.220224 & -0.8319 \\
\hline v & -2.458184 & -2.000959 & 0.083115 \\
\hline $\mathrm{C}$ & -5.236455 & -3.495875 & -2.044741 \\
\hline & -6.003891 & -4.058173 & -0.827506 \\
\hline $\mathrm{H}$ & -6.626357 & -3.266086 & -0.396904 \\
\hline H & -6.696291 & -4.829068 & -1.180480 \\
\hline$C$ & -5.084752 & -4.638721 & 0.250909 \\
\hline 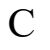 & -4.130365 & -3.589932 & 0.864664 \\
\hline $\mathrm{H}$ & -4.495078 & -5.462371 & -0.16751 \\
\hline H & -5.685870 & -5.073894 & 1.055710 \\
\hline $\mathrm{C}$ & -6.177752 & -2.603752 & -2.882113 \\
\hline H & -5.682659 & -2.233293 & -3.781501 \\
\hline H & -7.053713 & -3.185872 & -3.183931 \\
\hline H & -6.528689 & -1.742799 & -2.304341 \\
\hline $\mathrm{C}$ & -4.703078 & -4.644211 & -2.941203 \\
\hline $\mathrm{H}$ & -5.546544 & -5.220109 & -3.333179 \\
\hline $\mathrm{H}$ & -4.139252 & -4.241209 & -3.786526 \\
\hline $\mathrm{H}$ & -4.050549 & -5.329753 & -2.392977 \\
\hline $\mathrm{C}$ & -4.895259 & -2.635607 & 1.816625 \\
\hline $\mathrm{H}$ & -5.324520 & -3.207923 & 2.644620 \\
\hline $\mathrm{H}$ & -4.217612 & -1.884456 & 2.230910 \\
\hline $\mathrm{H}$ & -5.709694 & -2.109444 & 1.310849 \\
\hline $\mathrm{C}$ & -3.023114 & -4.310396 & 1.662161 \\
\hline $\mathrm{H}$ & -2.355767 & -3.598141 & 2.151039 \\
\hline $\mathrm{H}$ & -3.480582 & -4.939842 & 2.431710 \\
\hline $\mathrm{H}$ & -2.422003 & -4.956019 & 1.013428 \\
\hline$C$ & 1.157011 & 1.939258 & -2.753761 \\
\hline $\mathrm{C}$ & 2.096365 & 2.835473 & -3.247836 \\
\hline $\mathrm{C}$ & 2.888799 & 3.171566 & -2.118455 \\
\hline $\mathrm{H}$ & 2.199060 & 3.199457 & -4.259052 \\
\hline $\mathrm{N}$ & 1.386780 & 1.759762 & -1.400291 \\
\hline $\mathrm{N}$ & 2.430179 & 2.502114 & -1.019970 \\
\hline $\mathrm{C}$ & 4.032101 & 4.078836 & -2.032111 \\
\hline $\mathrm{C}$ & 4.530433 & 4.737921 & -3.177467 \\
\hline $\mathrm{C}$ & 4.661536 & 4.315314 & -0.788930 \\
\hline $\mathrm{C}$ & 5.621416 & 5.602498 & -3.083630 \\
\hline $\mathrm{H}$ & 4.064720 & 4.573644 & -4.143683 \\
\hline 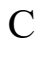 & 5.751319 & 5.180642 & -0.698367 \\
\hline $\mathrm{H}$ & 4.276331 & 3.815086 & 0.092103 \\
\hline & 6.238047 & 5.828835 & -1.844120 \\
\hline
\end{tabular}




$\begin{array}{lrrr}\mathrm{H} & 5.993451 & 6.102724 & -3.972662 \\ \mathrm{H} & 6.223553 & 5.356966 & 0.263656 \\ \mathrm{H} & 7.085452 & 6.503716 & -1.771804\end{array}$

$\mathrm{M}=\mathrm{Gd}$

$\begin{array}{lrcc}\text { GD } & 0.000166 & 0.256807 & -0.000048 \\ \mathrm{C} & -0.088729 & 1.340985 & -3.204151 \\ \mathrm{C} & -0.523387 & 1.582957 & -4.525182 \\ \mathrm{C} & -1.651475 & 0.924476 & -5.000256 \\ \mathrm{H} & 0.020712 & 2.280429 & -5.151378 \\ \mathrm{C} & -1.853102 & -0.162595 & -2.878476 \\ \mathrm{C} & -2.341664 & 0.026541 & -4.166090 \\ \mathrm{H} & -2.000781 & 1.103365 & -6.012671 \\ \mathrm{H} & -3.224923 & -0.504700 & -4.496138 \\ \mathrm{C} & -2.489872 & -1.089006 & -1.909712 \\ \mathrm{C} & -4.140346 & -2.552342 & -1.319007 \\ \mathrm{C} & -3.495423 & -2.702626 & -0.047036 \\ \mathrm{~N} & -0.761661 & 0.474973 & -2.409031 \\ \mathrm{~N} & -3.604932 & -1.748721 & -2.237739 \\ \mathrm{~N} & -1.879298 & -1.202789 & -0.718192 \\ \mathrm{~N} & -2.383177 & -2.015342 & 0.211817 \\ \mathrm{C} & -5.409440 & -3.301646 & -1.700699 \\ \mathrm{C} & -6.074473 & -3.905812 & -0.444029 \\ \mathrm{H} & -6.625560 & -3.120492 & 0.084620 \\ \mathrm{H} & -6.823187 & -4.636115 & -0.766624 \\ \mathrm{C} & -5.076538 & -4.570534 & 0.508234 \\ \mathrm{C} & -4.030790 & -3.585382 & 1.076953 \\ \mathrm{H} & -4.559883 & -5.388972 & -0.005906 \\ \mathrm{H} & -5.612042 & -5.028254 & 1.346003 \\ \mathrm{C} & -6.396984 & -2.341660 & -2.398627 \\ \mathrm{H} & -5.979969 & -1.941469 & -3.324348 \\ \mathrm{H} & -7.316454 & -2.883682 & -2.639010 \\ \mathrm{H} & -6.661589 & -1.501093 & -1.749532 \\ \mathrm{C} & -4.999683 & -4.416065 & -2.700493 \\ \mathrm{H} & -5.895257 & -4.947688 & -3.034849 \\ \mathrm{H} & -4.508626 & -3.984951 & -3.576732 \\ \mathrm{H} & -4.319487 & -5.146541 & -2.253284 \\ \mathrm{C} & -4.667170 & -2.656412 & 2.142572 \\ \mathrm{H} & -5.037625 & -3.257388 & 2.978462 \\ \mathrm{H} & -3.926718 & -1.949953 & 2.526888 \\ \mathrm{H} & -5.505061 & -2.078188 & 1.743638 \\ \mathrm{C} & -2.879563 & -4.380221 & 1.728077 \\ \mathrm{H} & -2.145532 & -3.716498 & 2.189014 \\ \mathrm{H} & -3.285709 & -5.036037 & 2.504155 \\ \mathrm{H} & -2.363984 & -5.007949 & 0.993843\end{array}$




\begin{tabular}{|c|c|c|c|}
\hline C & 1.068347 & 1.960945 & -2.585990 \\
\hline & 2.047039 & 2.851432 & -3.021771 \\
\hline $\mathrm{C}$ & 2.888809 & 3.028849 & -1.894587 \\
\hline $\mathrm{H}$ & 2.135252 & 3.314870 & -3.993093 \\
\hline $\mathrm{N}$ & 1.327149 & 1.639112 & -1.276848 \\
\hline N & 2.433013 & 2.288698 & -0.855768 \\
\hline $\mathrm{C}$ & 4.096324 & 3.866149 & -1.771291 \\
\hline $\mathrm{C}$ & 4.678559 & 4.470111 & -2.901285 \\
\hline $\mathrm{C}$ & 4.691049 & 4.079030 & -0.512711 \\
\hline $\mathrm{C}$ & 5.822335 & 5.265019 & -2.777910 \\
\hline $\mathrm{H}$ & 4.245193 & 4.315805 & -3.884529 \\
\hline $\mathrm{C}$ & 5.834171 & 4.872971 & -0.390122 \\
\hline $\mathrm{H}$ & 4.242038 & 3.622229 & 0.362152 \\
\hline $\mathrm{C}$ & 6.406313 & 5.470766 & -1.521766 \\
\hline $\mathrm{H}$ & 6.258726 & 5.723303 & -3.660515 \\
\hline $\mathrm{H}$ & 6.277718 & 5.033069 & 0.588540 \\
\hline $\mathrm{H}$ & 7.292779 & 6.090177 & -1.425325 \\
\hline $\mathrm{C}$ & 0.088502 & 1.339722 & 3.204547 \\
\hline $\mathrm{C}$ & 0.522880 & 1.581134 & 4.525777 \\
\hline $\mathrm{C}$ & 1.650899 & 0.922498 & 5.000795 \\
\hline $\mathrm{H}$ & -0.021378 & 2.278311 & 5.152163 \\
\hline $\mathrm{C}$ & 1.852992 & -0.163642 & 2.878584 \\
\hline $\mathrm{C}$ & 2.341284 & 0.024942 & 4.166379 \\
\hline $\mathrm{H}$ & 2.000000 & 1.100970 & 6.013354 \\
\hline $\mathrm{H}$ & 3.224483 & -0.506429 & 4.496380 \\
\hline $\mathrm{C}$ & 2.489966 & -1.089639 & 1.909557 \\
\hline $\mathrm{C}$ & 4.140463 & -2.552806 & 1.318509 \\
\hline $\mathrm{C}$ & 3.495691 & -2.702619 & 0.046423 \\
\hline $\mathrm{N}$ & 0.761642 & 0.474113 & 2.409178 \\
\hline $\mathrm{N}$ & 3.604931 & -1.749536 & 2.237495 \\
\hline $\mathrm{N}$ & 1.879610 & -1.202869 & 0.717864 \\
\hline $\mathrm{N}$ & 2.383547 & -2.015123 & -0.212355 \\
\hline $\mathrm{C}$ & 5.409543 & -3.302199 & 1.700070 \\
\hline $\mathrm{C}$ & 6.074629 & -3.906061 & 0.443281 \\
\hline $\mathrm{H}$ & 6.625789 & -3.120633 & -0.085128 \\
\hline $\mathrm{H}$ & 6.823284 & -4.636490 & 0.765727 \\
\hline $\mathrm{C}$ & 5.076715 & -4.570475 & -0.509219 \\
\hline $\mathrm{C}$ & 4.031080 & -3.585100 & -1.077766 \\
\hline $\mathrm{H}$ & 4.559958 & -5.389000 & 0.004681 \\
\hline $\mathrm{H}$ & 5.612244 & -5.028028 & -1.347064 \\
\hline $\mathrm{C}$ & 6.397044 & -2.342344 & 2.398250 \\
\hline $\mathrm{H}$ & 5.979983 & -1.942371 & 3.324045 \\
\hline $\mathrm{H}$ & 7.316516 & -2.884401 & 2.638546 \\
\hline $\mathrm{H}$ & 6.661656 & -1.501628 & 1.749352 \\
\hline $\mathrm{C}$ & 4.999785 & -4.416858 & 2.699591 \\
\hline $\mathrm{H}$ & 5.895364 & -4.948517 & 3.033876 \\
\hline
\end{tabular}




$\begin{array}{lrrr}\mathrm{H} & 4.508657 & -3.985969 & 3.575901 \\ \mathrm{H} & 4.319649 & -5.147264 & 2.252175 \\ \mathrm{C} & 4.667594 & -2.655900 & -2.143104 \\ \mathrm{H} & 5.038072 & -3.256685 & -2.979121 \\ \mathrm{H} & 3.927213 & -1.949299 & -2.527293 \\ \mathrm{H} & 5.505494 & -2.077830 & -1.743965 \\ \mathrm{C} & 2.879840 & -4.379691 & -1.729174 \\ \mathrm{H} & 2.145883 & -3.715797 & -2.189982 \\ \mathrm{H} & 3.285996 & -5.035323 & -2.505401 \\ \mathrm{H} & 2.364175 & -5.007583 & -0.995141 \\ \mathrm{C} & -1.068514 & 1.959861 & 2.586450 \\ \mathrm{C} & -2.047380 & 2.850051 & 3.022446 \\ \mathrm{C} & -2.888998 & 3.027831 & 1.895201 \\ \mathrm{H} & -2.135811 & 3.313038 & 3.993962 \\ \mathrm{~N} & -1.327099 & 1.638484 & 1.277159 \\ \mathrm{~N} & -2.432961 & 2.288135 & 0.856167 \\ \mathrm{C} & -4.096586 & 3.865052 & 1.772053 \\ \mathrm{C} & -4.678395 & 4.469465 & 2.902026 \\ \mathrm{C} & -4.691822 & 4.077405 & 0.513623 \\ \mathrm{C} & -5.822250 & 5.264278 & 2.778780 \\ \mathrm{H} & -4.244607 & 4.315642 & 3.885158 \\ \mathrm{C} & -5.835020 & 4.871256 & 0.391161 \\ \mathrm{H} & -4.243141 & 3.620265 & -0.361230 \\ \mathrm{C} & -6.406740 & 5.469489 & 1.522787 \\ \mathrm{H} & -6.258294 & 5.722921 & 3.661370 \\ \mathrm{H} & -6.278964 & 5.030934 & -0.587390 \\ \mathrm{H} & -7.293269 & 6.088824 & 1.426446\end{array}$

$\mathrm{M}=\mathrm{Am}$

$\begin{array}{lrrr}\text { AM } & 0.000073 & 0.293765 & 0.000023 \\ \text { C } & 0.101047 & 1.226917 & -3.298518 \\ \text { C } & -0.255293 & 1.410257 & -4.651626 \\ \text { C } & -1.374774 & 0.759712 & -5.154796 \\ \text { H } & 0.343286 & 2.058460 & -5.280906 \\ \text { C } & -1.719907 & -0.212352 & -2.994743 \\ \text { C } & -2.132460 & -0.075223 & -4.315121 \\ \text { H } & -1.664552 & 0.895168 & -6.192374 \\ \mathrm{H} & -3.011692 & -0.600276 & -4.664944 \\ \mathrm{C} & -2.436632 & -1.081601 & -2.029673 \\ \mathrm{C} & -4.159303 & -2.476778 & -1.483374 \\ \mathrm{C} & -3.584047 & -2.605283 & -0.176484 \\ \mathrm{~N} & -0.638501 & 0.422758 & -2.495135 \\ \mathrm{~N} & -3.552479 & -1.719656 & -2.397151 \\ \mathrm{~N} & -1.896856 & -1.167407 & -0.804806 \\ \mathrm{~N} & -2.470198 & -1.937515 & 0.120429\end{array}$




$\begin{array}{lrrr}\mathrm{C} & -5.432571 & -3.196837 & -1.906140 \\ \mathrm{C} & -6.174458 & -3.746757 & -0.667561 \\ \mathrm{H} & -6.725536 & -2.931434 & -0.186482 \\ \mathrm{H} & -6.928920 & -4.463597 & -1.006520 \\ \mathrm{C} & -5.243020 & -4.413403 & 0.348546 \\ \mathrm{C} & -4.197438 & -3.442918 & 0.942116 \\ \mathrm{H} & -4.726393 & -5.259298 & -0.119182 \\ \mathrm{H} & -5.830976 & -4.833621 & 1.170625 \\ \mathrm{C} & -6.354961 & -2.224245 & -2.672631 \\ \mathrm{H} & -5.882634 & -1.861088 & -3.587058 \\ \mathrm{H} & -7.279670 & -2.742667 & -2.943178 \\ \mathrm{H} & -6.621618 & -1.359539 & -2.056918 \\ \mathrm{C} & -5.014211 & -4.349195 & -2.857872 \\ \mathrm{H} & -5.910196 & -4.860231 & -3.221965 \\ \mathrm{H} & -4.467987 & -3.957048 & -3.719637 \\ \mathrm{H} & -4.380763 & -5.089522 & -2.360935 \\ \mathrm{C} & -4.855744 & -2.469701 & 1.953467 \\ \mathrm{H} & -5.281297 & -3.038565 & 2.785636 \\ \mathrm{H} & -4.114192 & -1.773631 & 2.354059 \\ \mathrm{H} & -5.657550 & -1.879497 & 1.501460 \\ \mathrm{C} & -3.100960 & -4.252314 & 1.666136 \\ \mathrm{H} & -2.369992 & -3.597152 & 2.143943 \\ \mathrm{H} & -3.561184 & -4.875863 & 2.438678 \\ \mathrm{H} & -2.570532 & -4.913450 & 0.972862 \\ \mathrm{C} & 1.245073 & 1.850127 & -2.661493 \\ \mathrm{C} & 2.275346 & 2.680522 & -3.098629 \\ \mathrm{C} & 3.068675 & 2.894509 & -1.943074 \\ \mathrm{H} & 2.427997 & 3.083428 & -4.088699 \\ \mathrm{C} & 1.429451 & 1.598499 & -1.327681 \\ \mathrm{~N} & 2.537344 & 2.230382 & -0.888815 \\ \mathrm{C} & 4.298559 & 3.696031 & -1.806732 \\ \mathrm{C} & 4.959941 & 4.208451 & -2.938537 \\ \mathrm{C} & 4.836330 & 3.965758 & -0.533415 \\ \mathrm{C} & 6.125160 & 4.969299 & -2.802672 \\ \mathrm{H} & 4.571482 & 4.008627 & -3.932315 \\ \mathrm{C} & 6.000960 & 4.725788 & -0.398341 \\ \mathrm{H} & 4.326533 & 3.580298 & 0.342601 \\ \mathrm{H} & 6.652000 & 5.232084 & -1.531938 \\ \mathrm{H} & 6.622735 & 5.356731 & -3.686833 \\ \mathrm{H} & 7.555031 & 5.825465 & -1.426062 \\ \mathrm{H} & 0.254926 & 1.408245 & 4.652195 \\ \mathrm{H} & -3.9756 & -0.213617 & 2.994768\end{array}$




\begin{tabular}{|c|c|c|c|}
\hline $\mathrm{C}$ & 2.132162 & -0.077049 & 4.315251 \\
\hline & 1.664035 & 0.892526 & 6.192871 \\
\hline $\mathrm{H}$ & 3.011363 & -0.602239 & 4.664944 \\
\hline $\mathrm{C}$ & 2.436597 & -1.082452 & 2.029409 \\
\hline$\tilde{J}$ & 4.159354 & -2.477368 & 1.482710 \\
\hline $\mathrm{C}$ & 3.584226 & -2.605356 & 0.175713 \\
\hline $\mathrm{N}$ & 0.638394 & 0.421692 & 2.495317 \\
\hline V & 3.552423 & -1.720631 & 2.396736 \\
\hline $\mathrm{N}$ & 1.896944 & -1.167767 & 0.804455 \\
\hline $\mathrm{N}$ & 2.470394 & -1.937486 & -0.121039 \\
\hline$C$ & 5.432600 & -3.197564 & 1.905307 \\
\hline$C$ & 6.174608 & -3.746989 & 0.666580 \\
\hline $\mathrm{H}$ & 6.725724 & -2.931472 & 0.185873 \\
\hline $\mathrm{H}$ & 6.929044 & -4.463955 & 1.005328 \\
\hline $\mathrm{C}$ & 5.243273 & -4.413242 & -0.349879 \\
\hline $\mathrm{C}$ & 4.197738 & -3.442532 & -0.943164 \\
\hline $\mathrm{H}$ & 4.726607 & -5.259327 & 0.117465 \\
\hline $\mathrm{H}$ & 5.831310 & -4.833130 & -1.172067 \\
\hline $\mathrm{C}$ & 6.354902 & -2.225245 & 2.672252 \\
\hline $\mathrm{H}$ & 5.882488 & -1.862450 & 3.586777 \\
\hline $\mathrm{H}$ & 7.279599 & -2.743751 & 2.942679 \\
\hline $\mathrm{H}$ & 6.621594 & -1.360297 & 2.056894 \\
\hline $\mathrm{C}$ & 5.014185 & -4.350298 & 2.856558 \\
\hline $\mathrm{H}$ & 5.910150 & -4.861451 & 3.220536 \\
\hline $\mathrm{H}$ & 4.467872 & -3.958497 & 3.718424 \\
\hline $\mathrm{H}$ & 4.380801 & -5.090450 & 2.359278 \\
\hline O & 4.856133 & -2.468900 & -1.954058 \\
\hline$H$ & 5.281776 & -3.037424 & -2.786414 \\
\hline $\mathrm{H}$ & 4.114613 & -1.772678 & -2.354447 \\
\hline $\mathrm{H}$ & 5.657886 & -1.878867 & -1.501735 \\
\hline $\mathrm{C}$ & 3.101342 & -4.251649 & -1.667620 \\
\hline $\mathrm{H}$ & 2.370417 & -3.596302 & -2.145239 \\
\hline $\mathrm{H}$ & 3.561652 & -4.874882 & -2.440365 \\
\hline $\mathrm{H}$ & 2.570850 & -4.913068 & -0.974666 \\
\hline $\mathrm{C}$ & -1.245243 & 1.848912 & 2.662084 \\
\hline $\mathrm{C}$ & -2.275600 & 2.679085 & 3.099437 \\
\hline $\mathrm{C}$ & -3.068806 & 2.893505 & 1.943875 \\
\hline $\mathrm{H}$ & -2.428379 & 3.081589 & 4.089650 \\
\hline $\mathrm{N}$ & -1.429456 & 1.597820 & 1.328149 \\
\hline $\mathrm{N}$ & -2.537327 & 2.229828 & 0.889410 \\
\hline $\mathrm{C}$ & -4.298709 & 3.695031 & 1.807718 \\
\hline $\mathrm{C}$ & -4.960265 & 4.206927 & 2.939658 \\
\hline $\mathrm{C}$ & -4.836323 & 3.965288 & 0.534446 \\
\hline $\mathrm{C}$ & -6.125501 & 4.967779 & 2.803970 \\
\hline $\mathrm{H}$ & -4.571929 & 4.006687 & 3.933401 \\
\hline $\mathrm{C}$ & -6.000969 & 4.725322 & 0.399549 \\
\hline
\end{tabular}




$\begin{array}{lrrr}\mathrm{H} & -4.326390 & 3.580235 & -0.341670 \\ \mathrm{C} & -6.652184 & 5.231094 & 1.533280 \\ \mathrm{H} & -6.623212 & 5.354803 & 3.688233 \\ \mathrm{H} & -6.399543 & 4.931063 & -0.589885 \\ \mathrm{H} & -7.555228 & 5.824480 & 1.427542\end{array}$

$\mathrm{M}=\mathrm{Cm}$

$\begin{array}{lccc}\mathrm{CM} & 0.000049 & 0.193160 & -0.000043 \\ \mathrm{C} & 0.184164 & 1.347119 & 3.224336 \\ \mathrm{C} & 0.648507 & 1.619467 & 4.528865 \\ \mathrm{C} & 1.799656 & 0.988594 & 4.985490 \\ \mathrm{H} & 0.109348 & 2.318726 & 5.157333 \\ \mathrm{C} & 1.963977 & -0.132117 & 2.877542 \\ \mathrm{C} & 2.482977 & 0.088679 & 4.148758 \\ \mathrm{H} & 2.172244 & 1.191092 & 5.985120 \\ \mathrm{H} & 3.384007 & -0.420961 & 4.464336 \\ \mathrm{C} & 2.596289 & -1.066849 & 1.912953 \\ \mathrm{C} & 4.267466 & -2.507895 & 1.322273 \\ \mathrm{C} & 3.597348 & -2.706523 & 0.070578 \\ \mathrm{~N} & 0.850023 & 0.478754 & 2.427081 \\ \mathrm{~N} & 3.733860 & -1.692982 & 2.231898 \\ \mathrm{~N} & 1.963860 & -1.223107 & 0.738733 \\ \mathrm{~N} & 2.465327 & -2.050336 & -0.180093 \\ \mathrm{C} & 5.563381 & -3.215966 & 1.693022 \\ \mathrm{C} & 6.211364 & -3.841160 & 0.437587 \\ \mathrm{H} & 6.731161 & -3.059234 & -0.126741 \\ \mathrm{H} & 6.984292 & -4.545064 & 0.761715 \\ \mathrm{C} & 5.205975 & -4.554937 & -0.470296 \\ \mathrm{C} & 4.124870 & -3.609845 & -1.040859 \\ \mathrm{H} & 4.720303 & -5.369065 & 0.079755 \\ \mathrm{H} & 5.731211 & -5.025120 & -1.307653 \\ \mathrm{C} & 6.544316 & -2.212302 & 2.336834 \\ \mathrm{H} & 6.141152 & -1.795211 & 3.261281 \\ \mathrm{H} & 7.482938 & -2.724458 & 2.568648 \\ \mathrm{H} & 6.771205 & -1.385026 & 1.657042 \\ \mathrm{C} & 5.206469 & -4.309694 & 2.734821 \\ \mathrm{H} & 6.122900 & -4.809073 & 3.062355 \\ \mathrm{H} & 4.725729 & -3.864872 & 3.609930 \\ \mathrm{H} & 4.534370 & -5.069604 & 2.325998 \\ \mathrm{C} & 4.714190 & -2.699675 & -2.148872 \\ \mathrm{H} & 5.076343 & -3.317126 & -2.976405 \\ \mathrm{H} & 3.949300 & -2.020358 & -2.534312 \\ \mathrm{H} & 5.549294 & -2.092680 & -1.788563 \\ \mathrm{C} & 2.976113 & -4.448555 & -1.639363 \\ \mathrm{H} & 2.216962 & -3.815013 & -2.102218\end{array}$




\begin{tabular}{|c|c|c|c|}
\hline $\mathrm{H}$ & 3.377932 & -5.119191 & -2.405024 \\
\hline & 2.491946 & -5.064235 & -0.874137 \\
\hline $\mathrm{C}$ & -0.999909 & 1.941921 & 2.630580 \\
\hline $\mathrm{C}$ & -1.978723 & 2.821217 & 3.086894 \\
\hline$C$ & -2.856886 & 2.975987 & 1.984141 \\
\hline $\mathrm{H}$ & -2.045601 & 3.291865 & 4.056325 \\
\hline $1 \mathrm{~s}$ & -1.292909 & 1.605596 & 1.332994 \\
\hline $\mathrm{N}$ & -2.421479 & 2.234108 & 0.939271 \\
\hline & -4.080663 & 3.793229 & 1.890701 \\
\hline & -4.638710 & 4.397060 & 3.032926 \\
\hline & -4.716127 & 3.986530 & 0.648937 \\
\hline & -5.798227 & 5.172791 & 2.937820 \\
\hline $\mathrm{H}$ & -4.173810 & 4.257566 & 4.003928 \\
\hline & -5.875019 & 4.761237 & 0.554566 \\
\hline $\mathrm{H}$ & -4.286102 & 3.529933 & -0.235674 \\
\hline$C$ & -6.422683 & 5.359074 & 1.698230 \\
\hline $\mathrm{H}$ & -6.215308 & 5.631207 & 3.829624 \\
\hline $\mathrm{H}$ & -6.350050 & 4.906506 & -0.411650 \\
\hline $\mathrm{H}$ & -7.321412 & 5.963652 & 1.623721 \\
\hline C & -0.184025 & 1.346427 & -3.224736 \\
\hline C & -0.648404 & 1.618589 & -4.529295 \\
\hline $\mathrm{C}$ & -1.799597 & 0.987691 & -4.985776 \\
\hline $\mathrm{H}$ & -0.109238 & 2.317741 & -5.157874 \\
\hline $\mathrm{C}$ & -1.963899 & -0.132647 & -2.877623 \\
\hline $\mathrm{C}$ & -2.482933 & 0.087948 & -4.148852 \\
\hline $\mathrm{H}$ & -2.172212 & 1.190032 & -5.985427 \\
\hline $\mathrm{H}$ & -3.384003 & -0.421704 & -4.464297 \\
\hline 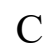 & -2.596230 & -1.067155 & -1.912825 \\
\hline$C$ & -4.267447 & -2.508014 & -1.321796 \\
\hline $\mathrm{C}$ & -3.597379 & -2.706281 & -0.070012 \\
\hline $\mathrm{N}$ & -0.849880 & 0.478228 & -2.427319 \\
\hline $1 \mathrm{v}$ & -3.733802 & -1.693375 & -2.231639 \\
\hline $\mathrm{N}$ & -1.963830 & -1.223115 & -0.738560 \\
\hline $\mathrm{N}$ & -2.465335 & -2.050079 & 0.180490 \\
\hline $\mathrm{C}$ & -5.563323 & -3.216226 & -1.692410 \\
\hline $\mathrm{C}$ & -6.211394 & -3.841028 & -0.436824 \\
\hline 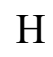 & -6.731248 & -3.058930 & 0.127214 \\
\hline $\mathrm{H}$ & -6.984284 & -4.545048 & -0.760788 \\
\hline $\mathrm{C}$ & -5.206066 & -4.554496 & 0.471371 \\
\hline $\mathrm{C}$ & -4.125006 & -3.609210 & 1.041693 \\
\hline $\mathrm{H}$ & -4.720353 & -5.368808 & -0.078371 \\
\hline $\mathrm{H}$ & -5.731361 & -5.024398 & 1.308848 \\
\hline $\mathrm{C}$ & -6.544233 & -2.212800 & -2.336626 \\
\hline . & -6.141007 & -1.796000 & -3.261177 \\
\hline $\mathrm{H}$ & -7.482824 & -2.725055 & -2.568348 \\
\hline $\mathrm{H}$ & -6.771199 & -1.385312 & -1.657119 \\
\hline
\end{tabular}




$\begin{array}{lrrr}\mathrm{C} & -5.206309 & -4.310291 & -2.733828 \\ \mathrm{H} & -6.122707 & -4.809788 & -3.061272 \\ \mathrm{H} & -4.725504 & -3.865742 & -3.609040 \\ \mathrm{H} & -4.534232 & -5.070055 & -2.324700 \\ \mathrm{C} & -4.714417 & -2.698628 & 2.149324 \\ \mathrm{H} & -5.076676 & -3.315775 & 2.977039 \\ \mathrm{H} & -3.949548 & -2.019195 & 2.534598 \\ \mathrm{H} & -5.549463 & -2.091733 & 1.788713 \\ \mathrm{C} & -2.976318 & -4.447718 & 1.640612 \\ \mathrm{H} & -2.217207 & -3.814019 & 2.103316 \\ \mathrm{H} & -3.378221 & -5.118076 & 2.406472 \\ \mathrm{H} & -2.492082 & -5.063674 & 0.875652 \\ \mathrm{C} & 1.000063 & 1.941324 & -2.631068 \\ \mathrm{C} & 1.978928 & 2.820506 & -3.087503 \\ \mathrm{C} & 2.856909 & 2.975659 & -1.984653 \\ \mathrm{H} & 2.045848 & 3.291137 & -4.056941 \\ \mathrm{~N} & 1.292894 & 1.605426 & -1.333322 \\ \mathrm{~N} & 2.421397 & 2.234112 & -0.939617 \\ \mathrm{C} & 4.080604 & 3.793038 & -1.891345 \\ \mathrm{C} & 4.641711 & 4.392085 & -3.034590 \\ \mathrm{C} & 4.712870 & 3.991265 & -0.648732 \\ \mathrm{C} & 5.801099 & 5.168030 & -2.939637 \\ \mathrm{H} & 4.179407 & 4.248433 & -4.006232 \\ \mathrm{C} & 5.871653 & 4.766165 & -0.554520 \\ \mathrm{H} & 4.280468 & 3.538360 & 0.236621 \\ \mathrm{C} & 6.422355 & 5.359270 & -1.699189 \\ \mathrm{H} & 6.220622 & 5.622683 & -3.832222 \\ \mathrm{H} & 6.344184 & 4.915330 & 0.412326 \\ \mathrm{H} & 7.320978 & 5.964023 & -1.624809\end{array}$

\section{$\mathbf{L}=\mathbf{2 b e i}$}

\section{$\left[\mathrm{ML}\left(\mathrm{H}_{2} \mathrm{O}\right) 6\right]^{2+}$}

$\mathrm{M}=\mathrm{Eu}$

$\begin{array}{lccc}\text { EU } & -1.821225 & -0.956819 & 0.227485 \\ \mathrm{~N} & -3.771528 & 0.465842 & -0.102151 \\ \mathrm{~N} & 0.674773 & -0.077538 & 0.091427 \\ \mathrm{C} & -3.756089 & 1.827956 & -0.154343 \\ \mathrm{~N} & -5.043183 & 0.026914 & -0.186387 \\ \mathrm{~N} & -1.383171 & 1.659073 & 0.008835 \\ \mathrm{C} & 0.982592 & 1.230562 & 0.088365 \\ \mathrm{~N} & 1.664146 & -0.959855 & -0.102943 \\ \mathrm{C} & -5.069855 & 2.292945 & -0.284450 \\ \mathrm{C} & -2.453807 & 2.485322 & -0.074133\end{array}$




\begin{tabular}{|c|c|c|c|}
\hline $\mathrm{C}$ & -5.842800 & 1.120521 & -0.301007 \\
\hline C & -0.146796 & 2.196691 & 0.068351 \\
\hline $\mathrm{N}$ & 2.235930 & 1.700796 & 0.108487 \\
\hline $\mathrm{C}$ & 2.933890 & -0.560624 & -0.194269 \\
\hline $\mathrm{H}$ & -5.446857 & 3.301777 & -0.361097 \\
\hline $\mathrm{C}$ & -2.299929 & 3.886482 & -0.084777 \\
\hline $\mathrm{C}$ & -7.324506 & 1.062946 & -0.426294 \\
\hline $\mathrm{C}$ & 0.085327 & 3.572660 & 0.075221 \\
\hline $\mathrm{C}$ & 3.242717 & 0.830337 & 0.049045 \\
\hline $\mathrm{C}$ & 3.925775 & -1.584716 & -0.594750 \\
\hline $\mathrm{C}$ & -1.021933 & 4.430232 & -0.002307 \\
\hline $\mathrm{H}$ & -3.173411 & 4.524795 & -0.154154 \\
\hline $\mathrm{O}$ & -7.796225 & -0.200695 & -0.411920 \\
\hline $\mathrm{O}$ & -8.010258 & 2.065292 & -0.526784 \\
\hline $\mathrm{H}$ & 1.097937 & 3.949729 & 0.136315 \\
\hline $\mathrm{C}$ & 4.604695 & 1.358227 & 0.258795 \\
\hline $\mathrm{C}$ & 3.868402 & -2.877322 & -0.044529 \\
\hline $\mathrm{C}$ & 4.884522 & -1.271022 & -1.579178 \\
\hline $\mathrm{H}$ & -0.882617 & 5.506912 & -0.002176 \\
\hline $\mathrm{C}$ & -9.240598 & -0.315973 & -0.533187 \\
\hline $\mathrm{C}$ & 4.879897 & 2.677254 & -0.113612 \\
\hline $\mathrm{C}$ & 5.607859 & 0.581926 & 0.893452 \\
\hline $\mathrm{C}$ & 4.788158 & -3.852275 & -0.468593 \\
\hline $\mathrm{H}$ & 3.136482 & -3.100674 & 0.721309 \\
\hline $\mathrm{C}$ & 5.777150 & -2.260692 & -2.014840 \\
\hline $\mathrm{H}$ & 4.918939 & -0.282212 & -2.021289 \\
\hline $\mathrm{H}$ & -9.574226 & 0.122326 & -1.475687 \\
\hline $\mathrm{H}$ & -9.729476 & 0.196167 & 0.297772 \\
\hline $\mathrm{H}$ & -9.448196 & -1.385021 & -0.507047 \\
\hline $\mathrm{C}$ & 6.157695 & 3.229410 & 0.106261 \\
\hline $\mathrm{H}$ & 4.125339 & 3.290873 & -0.590241 \\
\hline $\mathrm{C}$ & 6.863478 & 1.145922 & 1.130953 \\
\hline $\mathrm{H}$ & 5.403185 & -0.426515 & 1.229069 \\
\hline $\mathrm{C}$ & 5.741428 & -3.537174 & -1.466986 \\
\hline $\mathrm{O}$ & 4.852149 & -5.114859 & 0.009147 \\
\hline $\mathrm{H}$ & 6.505186 & -2.028571 & -2.785487 \\
\hline $\mathrm{C}$ & 7.156453 & 2.454019 & 0.737563 \\
\hline $\mathrm{O}$ & 6.320865 & 4.499105 & -0.316793 \\
\hline $\mathrm{H}$ & 7.627691 & 0.560907 & 1.632789 \\
\hline $\mathrm{H}$ & 6.434264 & -4.310348 & -1.781924 \\
\hline $\mathrm{C}$ & 3.947870 & -5.525023 & 1.042751 \\
\hline $\mathrm{H}$ & 8.142622 & 2.861951 & 0.923905 \\
\hline $\mathrm{C}$ & 7.596123 & 5.147058 & -0.133618 \\
\hline 1. & 4.080209 & -4.915153 & 1.943616 \\
\hline $\mathrm{H}$ & 2.909026 & -5.473256 & 0.695975 \\
\hline $\mathrm{H}$ & 4.206167 & -6.560134 & 1.262948 \\
\hline
\end{tabular}




$\begin{array}{crrr}\mathrm{H} & 8.383767 & 4.611969 & -0.673406 \\ \mathrm{H} & 7.843338 & 5.222144 & 0.930039 \\ \mathrm{H} & 7.475436 & 6.144315 & -0.553970 \\ \mathrm{O} & -0.294034 & -2.854479 & -0.640014 \\ \mathrm{H} & -0.338647 & -3.205919 & -1.542144 \\ \mathrm{H} & 0.605495 & -2.453590 & -0.540136 \\ \mathrm{O} & -1.652154 & -0.678459 & -2.338781 \\ \mathrm{H} & -1.462060 & 0.083345 & -2.905085 \\ \mathrm{H} & -2.495929 & -1.058049 & -2.643639 \\ \mathrm{O} & -3.703000 & -2.137332 & -1.247346 \\ \mathrm{H} & -4.038522 & -3.029523 & -1.418003 \\ \mathrm{H} & -4.485965 & -1.564932 & -1.024421 \\ \mathrm{O} & -0.962649 & -2.556475 & 2.036997 \\ \mathrm{H} & -0.603856 & -3.447097 & 1.912470 \\ \mathrm{H} & -0.955448 & -2.350986 & 2.983977 \\ \mathrm{O} & -1.989869 & -0.043309 & 2.674524 \\ \mathrm{H} & -1.860078 & 0.829649 & 3.072614 \\ \mathrm{H} & -2.904479 & -0.321130 & 2.874004 \\ \mathrm{O} & -3.976454 & -1.662039 & 1.765191 \\ \mathrm{H} & -4.316563 & -2.489602 & 2.136112 \\ \mathrm{H} & -4.713581 & -1.239041 & 1.261499\end{array}$

$\mathrm{M}=\mathrm{Gd}$

$\begin{array}{crrr}\mathrm{O} & -3.688038 & -1.109215 & 2.210696 \\ \mathrm{H} & -4.550860 & -1.011879 & 1.764674 \\ \mathrm{O} & -3.601193 & -2.211708 & -0.564736 \\ \mathrm{H} & -3.883208 & -3.135509 & -0.618520 \\ \mathrm{O} & -1.094988 & 0.127568 & 2.611724 \\ \mathrm{H} & -0.711575 & -0.476836 & 3.267400 \\ \mathrm{O} & -1.683132 & -0.747165 & -2.174086 \\ \mathrm{H} & -2.530738 & -0.973807 & -2.590661 \\ \mathrm{O} & -1.454573 & -2.612031 & 2.090389 \\ \mathrm{H} & -2.259187 & -2.845971 & 2.583222 \\ \mathrm{O} & -0.365853 & -2.734624 & -0.418079 \\ \mathrm{H} & -0.494140 & -3.185779 & -1.266645 \\ \mathrm{H} & -0.843711 & 1.027282 & 2.870582 \\ \mathrm{H} & -1.267266 & -0.081516 & -2.742417 \\ \mathrm{H} & -4.421270 & -1.611879 & -0.562115 \\ \mathrm{H} & 0.562625 & -2.357059 & -0.428525 \\ \mathrm{H} & -3.721359 & -0.508981 & 2.972246 \\ \mathrm{H} & -1.016323 & -3.433165 & 1.814962 \\ \mathrm{C} & -0.138150 & 2.221862 & -0.027338 \\ \mathrm{C} & 0.095712 & 3.593677 & -0.091650 \\ \mathrm{C} & -1.011802 & 4.450518 & -0.189533 \\ \mathrm{C} & -2.294781 & 3.911193 & -0.235988\end{array}$




\begin{tabular}{|c|c|c|c|}
\hline $\mathrm{C}$ & -2.453291 & 2.515765 & -0.159030 \\
\hline J & -1.382640 & 1.690903 & -0.033817 \\
\hline $\mathrm{H}$ & -0.867902 & 5.525377 & -0.243059 \\
\hline 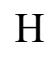 & 1.111393 & 3.967797 & -0.073492 \\
\hline $\mathrm{H}$ & -3.165449 & 4.549255 & -0.336181 \\
\hline$C$ & 0.976469 & 1.239466 & -0.003438 \\
\hline C & 3.231151 & 0.789077 & -0.049468 \\
\hline & 4.589655 & 1.288880 & 0.181463 \\
\hline $\mathrm{C}$ & 2.882186 & -0.604927 & -0.287340 \\
\hline $\mathrm{C}$ & 4.858071 & 2.641922 & -0.094627 \\
\hline $\mathrm{C}$ & 5.597403 & 0.475458 & 0.755854 \\
\hline $\mathrm{C}$ & 3.829204 & -1.658272 & -0.710475 \\
\hline $\mathrm{C}$ & 6.124403 & 3.187490 & 0.160685 \\
\hline $\mathrm{C}$ & 4.745905 & -1.386519 & -1.737513 \\
\hline $\mathrm{C}$ & 6.838988 & 1.036305 & 1.038223 \\
\hline $\mathrm{C}$ & 3.749973 & -2.947460 & -0.141260 \\
\hline $\mathrm{C}$ & 7.120845 & 2.376639 & 0.737825 \\
\hline $\mathrm{C}$ & 5.573817 & -2.416115 & -2.203691 \\
\hline $\mathrm{C}$ & 4.610874 & -3.957971 & -0.592716 \\
\hline $\mathrm{H}$ & 8.105827 & 2.773623 & 0.952550 \\
\hline $\mathrm{C}$ & 5.518311 & -3.686712 & -1.638583 \\
\hline $\mathrm{H}$ & 6.170317 & -4.484694 & -1.977890 \\
\hline $\mathrm{N}$ & 2.234841 & 1.681340 & -0.006672 \\
\hline $\mathrm{N}$ & 0.634119 & -0.057476 & 0.026081 \\
\hline $\mathrm{N}$ & 1.606548 & -0.968027 & -0.172966 \\
\hline $\mathrm{O}$ & 4.652449 & -5.222253 & -0.096725 \\
\hline $\mathrm{O}$ & 6.281087 & 4.492072 & -0.175819 \\
\hline $\mathrm{C}$ & 7.558449 & 5.112738 & 0.051411 \\
\hline $\mathrm{H}$ & 7.449644 & 6.138843 & -0.297999 \\
\hline $\mathrm{H}$ & 7.810564 & 5.114394 & 1.117359 \\
\hline $\mathrm{H}$ & 8.345471 & 4.612774 & -0.523263 \\
\hline $\mathrm{C}$ & 3.806183 & -5.561850 & 1.003608 \\
\hline $\mathrm{H}$ & 4.020070 & -4.933852 & 1.876882 \\
\hline $\mathrm{H}$ & 2.746692 & -5.477727 & 0.729469 \\
\hline $\mathrm{H}$ & 4.034303 & -6.600571 & 1.241542 \\
\hline $\mathrm{H}$ & 3.051503 & -3.133957 & 0.665126 \\
\hline $\mathrm{H}$ & 4.809734 & -0.398865 & -2.179413 \\
\hline $\mathrm{H}$ & 6.274489 & -2.220396 & -3.009205 \\
\hline $\mathrm{H}$ & 5.411107 & -0.562503 & 0.996954 \\
\hline $\mathrm{H}$ & 4.098068 & 3.278566 & -0.529589 \\
\hline $\mathrm{H}$ & 7.611772 & 0.426331 & 1.495442 \\
\hline $\mathrm{C}$ & -3.741647 & 1.832984 & -0.237336 \\
\hline $\mathrm{C}$ & -5.069117 & 2.242760 & -0.388410 \\
\hline $\mathrm{C}$ & -5.794209 & 1.036562 & -0.422580 \\
\hline $\mathrm{H}$ & -5.485176 & 3.235791 & -0.470567 \\
\hline $\mathrm{N}$ & -3.704684 & 0.472009 & -0.188485 \\
\hline
\end{tabular}




$\begin{array}{llll}\mathrm{N} & -4.957165 & -0.019421 & -0.297194 \\ \mathrm{C} & -7.271855 & 0.921625 & -0.577249 \\ \mathrm{O} & -7.988646 & 1.898775 & -0.698040 \\ \mathrm{O} & -7.693514 & -0.357616 & -0.562253 \\ \mathrm{C} & -9.130072 & -0.532816 & -0.717795 \\ \mathrm{H} & -9.294288 & -1.608992 & -0.683973 \\ \mathrm{H} & -9.659059 & -0.031494 & 0.094829 \\ \mathrm{H} & -9.455922 & -0.118821 & -1.673731 \\ \mathrm{GD} & -1.792627 & -0.812112 & 0.346133\end{array}$

$\mathrm{M}=\mathrm{Am}$

$\begin{array}{lrrc}\text { AM } & -1.676190 & -0.795363 & 0.218512 \\ \mathrm{O} & -3.745048 & -1.220542 & 2.066829 \\ \mathrm{H} & -4.532098 & -0.951913 & 1.548875 \\ \mathrm{O} & -3.622049 & -2.048682 & -0.879660 \\ \mathrm{H} & -3.960301 & -2.955596 & -0.904901 \\ \mathrm{O} & -0.969245 & -0.106677 & 2.629650 \\ \mathrm{H} & -0.729075 & -0.791561 & 3.273668 \\ \mathrm{O} & -1.600387 & -0.734047 & -2.346454 \\ \mathrm{H} & -2.453604 & -1.021307 & -2.713492 \\ \mathrm{O} & -1.642136 & -2.823122 & 1.780862 \\ \mathrm{H} & -2.500542 & -3.006101 & 2.200463 \\ \mathrm{O} & -0.133919 & -2.696471 & -0.537046 \\ \mathrm{H} & -0.212950 & -3.111342 & -1.409954 \\ \mathrm{H} & -0.687501 & 0.743016 & 3.001666 \\ \mathrm{H} & -1.220004 & -0.098676 & -2.971788 \\ \mathrm{H} & -4.401110 & -1.420531 & -0.743611 \\ \mathrm{H} & 0.782954 & -2.288230 & -0.493622 \\ \mathrm{H} & -3.806174 & -0.726835 & 2.899434 \\ \mathrm{H} & -1.220909 & -3.661798 & 1.536217 \\ \mathrm{C} & 0.041830 & 2.290355 & -0.040682 \\ \mathrm{C} & 0.297397 & 3.659819 & -0.069464 \\ \mathrm{C} & -0.793677 & 4.537973 & -0.139737 \\ \mathrm{C} & -2.085017 & 4.019851 & -0.184130 \\ \mathrm{C} & -2.264608 & 2.626589 & -0.141530 \\ \mathrm{~N} & -1.209782 & 1.777023 & -0.058118 \\ \mathrm{H} & -0.632020 & 5.611223 & -0.166748 \\ \mathrm{H} & 1.319406 & 4.015199 & -0.041881 \\ \mathrm{H} & -2.946784 & 4.673866 & -0.252059 \\ \mathrm{C} & 1.148917 & 1.301532 & -0.025735 \\ \mathrm{C} & 3.404459 & 0.847636 & -0.037530 \\ \mathrm{C} & 4.761738 & 1.345538 & 0.207807 \\ \mathrm{C} & 3.056649 & -0.544725 & -0.281948 \\ \mathrm{C} & 5.039238 & 2.694086 & -0.079442 \\ \mathrm{C} & 5.757947 & 0.534714 & 0.804896\end{array}$




$\begin{array}{lrrr}\mathrm{C} & 4.009268 & -1.603731 & -0.678968 \\ \mathrm{C} & 6.304100 & 3.237696 & 0.187650 \\ \mathrm{C} & 4.947907 & -1.342576 & -1.688643 \\ \mathrm{C} & 6.997632 & 1.093924 & 1.098883 \\ \mathrm{C} & 3.913716 & -2.888227 & -0.101962 \\ \mathrm{C} & 7.289069 & 2.429720 & 0.787786 \\ \mathrm{C} & 5.781957 & -2.378384 & -2.129506 \\ \mathrm{C} & 4.780250 & -3.905038 & -0.527912 \\ \mathrm{H} & 8.272367 & 2.825387 & 1.012336 \\ \mathrm{C} & 5.710375 & -3.644602 & -1.556294 \\ \mathrm{H} & 6.366668 & -4.447180 & -1.875939 \\ \mathrm{~N} & 2.409238 & 1.740525 & -0.002817 \\ \mathrm{~N} & 0.801671 & 0.007884 & -0.021344 \\ \mathrm{~N} & 1.777596 & -0.902904 & -0.200944 \\ \mathrm{O} & 4.806116 & -5.165924 & -0.021911 \\ \mathrm{O} & 6.470542 & 4.538027 & -0.161098 \\ \mathrm{C} & 7.746664 & 5.156423 & 0.078107 \\ \mathrm{H} & 7.646905 & 6.179110 & -0.283829 \\ \mathrm{H} & 7.983270 & 5.168663 & 1.147550 \\ \mathrm{H} & 8.540160 & 4.647446 & -0.479550 \\ \mathrm{C} & 3.936962 & -5.492932 & 1.064364 \\ \mathrm{H} & 4.137460 & -4.859633 & 1.936971 \\ \mathrm{H} & 2.883332 & -5.404804 & 0.769593 \\ \mathrm{H} & 4.154809 & -6.531089 & 1.314112 \\ \mathrm{H} & 3.197373 & -3.066470 & 0.690667 \\ \mathrm{H} & 5.024435 & -0.358400 & -2.136272 \\ \mathrm{H} & 6.500136 & -2.190938 & -2.921482 \\ \mathrm{H} & 5.563727 & -0.499610 & 1.055314 \\ \mathrm{H} & 4.287971 & 3.329033 & -0.531903 \\ \mathrm{H} & 7.761304 & 0.486115 & 1.573969 \\ \mathrm{C} & -3.571142 & 1.979470 & -0.198723 \\ \mathrm{C} & -4.885364 & 2.434729 & -0.322784 \\ \mathrm{C} & -5.652302 & 1.254911 & -0.339508 \\ \mathrm{H} & -5.268391 & 3.441272 & -0.399834 \\ \mathrm{~N} & -3.577802 & 0.620033 & -0.146013 \\ \mathrm{~N} & -4.851845 & 0.170534 & -0.228181 \\ \mathrm{C} & -7.136030 & 1.189992 & -0.465754 \\ \mathrm{O} & -7.821421 & 2.190944 & -0.570843 \\ & -7.599690 & -0.074569 & -0.445499 \\ \mathrm{H} & -9.044510 & -0.201540 & -0.570782 \\ \mathrm{H} & -538869 & -1.271746 & -0.535319 \\ & 0.314951 & 0.254011 \\ & & 0.225582 & -1.518802\end{array}$

$\mathrm{M}=\mathrm{Cm}$ 


\begin{tabular}{|c|c|c|c|}
\hline $\mathrm{CM}$ & 1.672038 & -0.768382 & 96018 \\
\hline $\mathrm{O}$ & -3.633728 & -1.111896 & 2.122481 \\
\hline $\mathrm{H}$ & -4.471535 & -0.938446 & 1.650683 \\
\hline ) & -3.555196 & -2.109107 & -0.745214 \\
\hline 1 & -3.879235 & -3.020367 & -0.782505 \\
\hline & -0.971336 & 0.074877 & 2.649985 \\
\hline 1 & -0.628178 & -0.574929 & 3.284220 \\
\hline D & -1.557096 & -0.715140 & -2.267605 \\
\hline H & -2.401630 & -1.001304 & -2.654124 \\
\hline O & -1.393117 & -2.677520 & 2.027128 \\
\hline H & -2.205462 & -2.949869 & 2.485430 \\
\hline $\mathrm{O}$ & -0.181205 & -2.728277 & -0.470260 \\
\hline H & -0.280010 & -3.185937 & -1.319272 \\
\hline $\mathrm{H}$ & -0.695576 & 0.951303 & 2.959421 \\
\hline $\mathrm{H}$ & -1.203562 & -0.025177 & -2.849592 \\
\hline $\mathrm{H}$ & -4.349174 & -1.480610 & -0.694986 \\
\hline H & 0.732768 & -2.317882 & -0.469314 \\
\hline $\mathrm{H}$ & -3.666820 & -0.561104 & 2.920539 \\
\hline $\mathrm{H}$ & -0.935193 & -3.477683 & 1.722731 \\
\hline $\mathrm{C}$ & 0.027224 & 2.287069 & -0.014909 \\
\hline $\mathrm{C}$ & 0.276056 & 3.657219 & -0.053936 \\
\hline $\mathrm{C}$ & -0.821178 & 4.528122 & -0.139378 \\
\hline $\mathrm{C}$ & -2.109721 & 4.004056 & -0.199298 \\
\hline $\mathrm{C}$ & -2.284375 & 2.609647 & -0.147794 \\
\hline $\mathrm{N}$ & -1.223330 & 1.771062 & -0.033220 \\
\hline $\mathrm{H}$ & -0.665043 & 5.602083 & -0.172930 \\
\hline $\mathrm{H}$ & 1.295599 & 4.019852 & -0.026205 \\
\hline $\mathrm{H}$ & -2.972520 & 4.653953 & -0.290706 \\
\hline $\mathrm{C}$ & 1.135911 & 1.296888 & -0.004051 \\
\hline $\mathrm{C}$ & 3.389591 & 0.839289 & -0.052669 \\
\hline $\mathrm{C}$ & 4.750574 & 1.333141 & 0.178800 \\
\hline $\mathrm{C}$ & 3.036359 & -0.551322 & -0.301623 \\
\hline $\mathrm{C}$ & 5.025626 & 2.684597 & -0.097576 \\
\hline $\mathrm{C}$ & 5.754457 & 0.514785 & 0.752569 \\
\hline $\mathrm{C}$ & 3.981605 & -1.606035 & -0.726431 \\
\hline $\mathrm{C}$ & 6.294731 & 3.223973 & 0.157464 \\
\hline $\mathrm{C}$ & 4.900751 & -1.334584 & -1.751195 \\
\hline $\mathrm{C}$ & 6.998849 & 1.069452 & 1.034839 \\
\hline $\mathrm{C}$ & 3.898454 & -2.895920 & -0.159510 \\
\hline $\mathrm{C}$ & 7.287306 & 2.408359 & 0.734374 \\
\hline $\mathrm{C}$ & 5.727300 & -2.365290 & -2.217481 \\
\hline $\mathrm{C}$ & 4.757947 & -3.907609 & -0.611057 \\
\hline $\mathrm{H}$ & 8.274226 & 2.800508 & 0.948996 \\
\hline $\mathrm{C}$ & 5.667953 & -3.636734 & -1.654638 \\
\hline $\mathrm{H}$ & 6.318843 & -4.435592 & -1.994035 \\
\hline $\mathrm{N}$ & 2.396424 & 1.734339 & 0.000717 \\
\hline
\end{tabular}




$\begin{array}{lrrr}\mathrm{N} & 0.789592 & 0.001572 & 0.006896 \\ \mathrm{~N} & 1.759302 & -0.911129 & -0.195926 \\ \mathrm{O} & 4.795192 & -5.172988 & -0.117026 \\ \mathrm{O} & 6.457653 & 4.527894 & -0.179097 \\ \mathrm{C} & 7.738076 & 5.142160 & 0.047685 \\ \mathrm{H} & 7.634288 & 6.168823 & -0.301615 \\ \mathrm{H} & 7.990642 & 5.142521 & 1.113540 \\ \mathrm{H} & 8.522418 & 4.638315 & -0.527309 \\ \mathrm{C} & 3.948587 & -5.511047 & 0.983435 \\ \mathrm{H} & 4.164548 & -4.884170 & 1.857041 \\ \mathrm{H} & 2.889059 & -5.423764 & 0.710089 \\ \mathrm{H} & 4.173945 & -6.550550 & 1.220536 \\ \mathrm{H} & 3.197979 & -3.082200 & 0.645333 \\ \mathrm{H} & 4.967717 & -0.346250 & -2.191251 \\ \mathrm{H} & 6.429985 & -2.169739 & -3.021312 \\ \mathrm{H} & 5.562860 & -0.522189 & 0.994025 \\ \mathrm{H} & 4.268750 & 3.325151 & -0.532421 \\ \mathrm{H} & 7.768645 & 0.455636 & 1.491994 \\ \mathrm{C} & -3.583886 & 1.949523 & -0.242224 \\ \mathrm{C} & -4.902292 & 2.390048 & -0.383315 \\ \mathrm{C} & -5.653251 & 1.201016 & -0.440706 \\ \mathrm{H} & -5.297492 & 3.392981 & -0.444578 \\ \mathrm{~N} & -3.576395 & 0.587798 & -0.220204 \\ \mathrm{~N} & -4.839693 & 0.124671 & -0.337922 \\ \mathrm{C} & -7.133177 & 1.121200 & -0.595824 \\ \mathrm{O} & -7.829104 & 2.115732 & -0.694575 \\ \mathrm{O} & -7.582199 & -0.148840 & -0.608140 \\ \mathrm{C} & -9.022224 & -0.289994 & -0.766137 \\ \mathrm{H} & -9.209253 & -1.362934 & -0.755251 \\ \mathrm{H} & -9.540122 & 0.204878 & 0.057518 \\ \mathrm{H} & -9.339554 & 0.151208 & -1.712734\end{array}$

\section{$\left[\mathrm{ML}\left(\mathrm{H}_{2} \mathrm{O}\right)_{5}\right]^{2+}$}

$\mathrm{M}=\mathrm{Eu}$

$\begin{array}{lccc}\text { EU } & 1.889480 & -0.962982 & 0.378974 \\ \mathrm{O} & 0.836743 & -1.427505 & 2.665314 \\ \mathrm{H} & 0.128047 & -1.953054 & 3.062273 \\ \mathrm{O} & 0.325556 & -2.924594 & -0.046291 \\ \mathrm{H} & 0.295670 & -3.883802 & 0.073348 \\ \mathrm{O} & 4.021276 & -2.276693 & 0.723274 \\ \mathrm{H} & 4.375040 & -3.176707 & 0.749404 \\ \mathrm{O} & 3.197683 & -0.213497 & 2.667527 \\ \mathrm{H} & 3.999715 & -0.762988 & 2.619960 \\ \mathrm{O} & 2.205340 & -1.468267 & -2.069299\end{array}$




$\begin{array}{lrrr}\mathrm{H} & 2.987366 & -1.095122 & -2.506328 \\ \mathrm{H} & 4.733398 & -1.660222 & 0.330940 \\ \mathrm{H} & 1.816249 & -2.114628 & -2.676112 \\ \mathrm{H} & 1.425125 & -1.122481 & 3.377777 \\ \mathrm{H} & -0.598572 & -2.567541 & -0.007831 \\ \mathrm{H} & 3.506528 & 0.678469 & 2.891964 \\ \mathrm{C} & 0.245539 & 2.105709 & -0.297911 \\ \mathrm{C} & 0.026176 & 3.463260 & -0.525120 \\ \mathrm{C} & 1.142477 & 4.291056 & -0.722046 \\ \mathrm{C} & 2.414778 & 3.731864 & -0.705405 \\ \mathrm{C} & 2.557395 & 2.348785 & -0.468872 \\ \mathrm{~N} & 1.479319 & 1.556542 & -0.247487 \\ \mathrm{H} & 1.011835 & 5.353584 & -0.902447 \\ \mathrm{H} & -0.984788 & 3.847410 & -0.564742 \\ \mathrm{H} & 3.294159 & 4.341924 & -0.877478 \\ \mathrm{C} & -0.896353 & 1.164413 & -0.163057 \\ \mathrm{C} & -3.164187 & 0.801883 & -0.138483 \\ \mathrm{C} & -4.521449 & 1.376308 & -0.254873 \\ \mathrm{C} & -2.884503 & -0.606546 & 0.012158 \\ \mathrm{C} & -4.750234 & 2.653457 & 0.263818 \\ \mathrm{C} & -5.563256 & 0.697307 & -0.936182 \\ \mathrm{C} & -3.914248 & -1.654656 & 0.215704 \\ \mathrm{C} & -6.020361 & 3.255535 & 0.146815 \\ \mathrm{C} & -4.872850 & -1.497361 & 1.235255 \\ \mathrm{H} & -6.811026 & 1.312991 & -1.071009 \\ \mathrm{H} & -4.385577 & -6.140127 & -2.603309 \\ \mathrm{C} & -3.895295 & -2.816543 & -0.574366 \\ \mathrm{C} & -7.058477 & 2.576312 & -0.530486 \\ \mathrm{C} & -5.804942 & -2.519751 & 1.468280 \\ \mathrm{C} & -4.856808 & -3.819768 & -0.352679 \\ \mathrm{H} & -8.038257 & 3.025206 & -0.640783 \\ \mathrm{C} & -5.807657 & -3.667834 & 0.685486 \\ \mathrm{H} & -6.531947 & -4.460263 & 0.841878 \\ \mathrm{~N} & -2.142835 & 1.655872 & -0.194486 \\ \mathrm{~N} & -0.605777 & -0.143256 & -0.074677 \\ \mathrm{O} & -1.615815 & -1.017909 & 0.020237 \\ \mathrm{O} & -4.962968 & -4.960126 & -1.068551 \\ \mathrm{H} & -6.135510 & 4.474927 & 0.708092 \\ \mathrm{H} & -7.233984 & 5.172083 & 0.636296 \\ \mathrm{H} & -114784 & 1.156457 \\ \mathrm{H} & -2.912972 & -1.370710\end{array}$




$\begin{array}{cccc}\mathrm{H} & -4.880393 & -0.607052 & 1.853669 \\ \mathrm{H} & -6.535152 & -2.412316 & 2.264007 \\ \mathrm{H} & -5.394912 & -0.270051 & -1.390770 \\ \mathrm{H} & -3.965044 & 3.197931 & 0.774420 \\ \mathrm{H} & -7.603592 & 0.803682 & -1.610022 \\ \mathrm{C} & 3.852119 & 1.677538 & -0.450817 \\ \mathrm{C} & 5.175061 & 2.117676 & -0.554210 \\ \mathrm{C} & 5.934959 & 0.943497 & -0.400819 \\ \mathrm{H} & 5.568134 & 3.111406 & -0.708824 \\ \mathrm{~N} & 3.851533 & 0.321170 & -0.266688 \\ \mathrm{~N} & 5.117959 & -0.123430 & -0.219409 \\ \mathrm{C} & 7.420510 & 0.867056 & -0.426560 \\ \mathrm{O} & 8.120076 & 1.852850 & -0.585594 \\ \mathrm{O} & 7.877871 & -0.388305 & -0.251993 \\ \mathrm{C} & 9.325077 & -0.523140 & -0.275324 \\ \mathrm{H} & 9.517960 & -1.585262 & -0.129680 \\ \mathrm{H} & 9.717914 & -0.184500 & -1.235923 \\ \mathrm{H} & 9.771092 & 0.067652 & 0.527161\end{array}$

$\mathrm{M}=\mathrm{Gd}$

$\begin{array}{rrrr}\mathrm{O} & 1.052778 & -1.978066 & 2.456756 \\ \mathrm{H} & 0.476875 & -2.756361 & 2.508091 \\ \mathrm{O} & 0.385651 & -2.786898 & -0.205548 \\ \mathrm{H} & 0.405514 & -3.718490 & -0.465391 \\ \mathrm{O} & 3.760604 & -2.269107 & 0.556213 \\ \mathrm{H} & 4.056540 & -3.162390 & 0.778122 \\ \mathrm{O} & 2.486367 & 0.333640 & 2.528571 \\ \mathrm{H} & 3.383171 & 0.707583 & 2.504783 \\ \mathrm{O} & 2.106209 & -1.120091 & -2.061582 \\ \mathrm{H} & 2.898705 & -0.767515 & -2.497360 \\ \mathrm{H} & 4.571943 & -1.685991 & 0.321455 \\ \mathrm{H} & 1.621685 & -1.642854 & -2.717495 \\ \mathrm{H} & 1.494314 & -1.883235 & 3.315308 \\ \mathrm{H} & -0.561883 & -2.468635 & -0.132153 \\ \mathrm{H} & 1.983367 & 0.871494 & 3.159780 \\ \mathrm{C} & 0.251554 & 2.139532 & -0.243147 \\ \mathrm{C} & 0.039996 & 3.497811 & -0.461740 \\ \mathrm{C} & 1.161773 & 4.319067 & -0.656332 \\ \mathrm{C} & 2.435038 & 3.756898 & -0.633926 \\ \mathrm{C} & 2.570855 & 2.376297 & -0.400384 \\ \mathrm{~N} & 1.485327 & 1.587397 & -0.199674 \\ \mathrm{H} & 1.036182 & 5.382773 & -0.833887 \\ \mathrm{H} & -0.969890 & 3.886425 & -0.494598 \\ \mathrm{H} & 3.316723 & 4.366567 & -0.795787 \\ \mathrm{C} & -0.880005 & 1.186945 & -0.101438\end{array}$




$\begin{array}{lrrr}\mathrm{C} & -3.144957 & 0.776515 & -0.077111 \\ \mathrm{C} & -4.497727 & 1.327784 & -0.199932 \\ \mathrm{C} & -2.825609 & -0.636596 & 0.070289 \\ \mathrm{C} & -4.702460 & 2.661496 & 0.201570 \\ \mathrm{C} & -5.565121 & 0.598775 & -0.781157 \\ \mathrm{C} & -3.812705 & -1.724663 & 0.278306 \\ \mathrm{C} & -5.960041 & 3.265898 & 0.068160 \\ \mathrm{C} & -4.691268 & -1.659015 & 1.367525 \\ \mathrm{C} & -6.798562 & 1.221515 & -0.944526 \\ \mathrm{C} & -3.807885 & -2.843092 & -0.580099 \\ \mathrm{C} & -7.015390 & 2.538687 & -0.516489 \\ \mathrm{C} & -5.560144 & -2.733381 & 1.605503 \\ \mathrm{C} & -4.710188 & -3.894278 & -0.351198 \\ \mathrm{H} & -7.995180 & 2.983931 & -0.641965 \\ \mathrm{C} & -5.579118 & -3.837510 & 0.758297 \\ \mathrm{H} & -6.263670 & -4.663036 & 0.922018 \\ \mathrm{~N} & -2.129161 & 1.650126 & -0.134063 \\ \mathrm{~N} & -0.554242 & -0.111507 & -0.013073 \\ \mathrm{~N} & -1.551735 & -1.014506 & 0.070760 \\ \mathrm{O} & -4.824358 & -5.002165 & -1.128973 \\ \mathrm{O} & -6.051206 & 4.541237 & 0.520866 \\ \mathrm{C} & -7.313335 & 5.222122 & 0.410179 \\ \mathrm{H} & -7.148241 & 6.211660 & 0.834874 \\ \mathrm{H} & -7.616259 & 5.320163 & -0.637837 \\ \mathrm{H} & -8.090372 & 4.704108 & 0.982479 \\ \mathrm{C} & -4.044900 & -5.094150 & -2.323918 \\ \mathrm{C} & 9.245324 & -0.733154 & -0.262243 \\ \mathrm{H} & -4.261140 & -4.261840 & -3.004041 \\ \mathrm{H} & -2.971250 & -5.124826 & -2.097135 \\ \mathrm{H} & -4.337587 & -6.031732 & -2.795828 \\ \mathrm{H} & -3.142841 & -2.860084 & -1.435596 \\ \mathrm{H} & -4.700735 & -0.796004 & 2.023969 \\ \mathrm{H} & -6.236168 & -2.700664 & 2.454146 \\ \mathrm{H} & -5.430337 & -0.416851 & -1.125966 \\ \mathrm{H} & -3.895970 & 3.237146 & 0.638154 \\ \mathrm{H} & -7.615492 & 0.678600 & -1.409388 \\ \mathrm{C} & 3.853398 & 1.679443 & -0.357660 \\ \mathrm{C} & 5.187162 & 2.056434 & -0.514954 \\ \mathrm{C} & 5.905596 & 0.854637 & -0.337769 \\ \mathrm{~N} & 5.615410 & 3.025012 & -0.726329 \\ \mathrm{~N} & 5.060744 & -0.166172 & -0.090081 \\ \mathrm{O} & -1.795212 & -0.078415\end{array}$




$$
\begin{array}{lccc}
\mathrm{H} & 9.620315 & -0.448517 & -1.247039 \\
\mathrm{H} & 9.735743 & -0.128494 & 0.502871 \\
\mathrm{GD} & 1.833781 & -0.861418 & 0.362152
\end{array}
$$

$\mathrm{M}=\mathrm{Am}$

$\begin{array}{lrrr}\mathrm{AM} & 1.724352 & -0.856606 & 0.283391 \\ \mathrm{O} & 1.273167 & -2.295303 & 2.348913 \\ \mathrm{H} & 0.744682 & -3.106307 & 2.283936 \\ \mathrm{O} & 0.133130 & -2.791408 & -0.165150 \\ \mathrm{H} & 0.105624 & -3.644142 & -0.621709 \\ \mathrm{O} & 3.783206 & -2.166699 & 0.339150 \\ \mathrm{H} & 4.122356 & -3.051235 & 0.531856 \\ \mathrm{O} & 2.229951 & 0.332087 & 2.531482 \\ \mathrm{H} & 3.003409 & 0.919203 & 2.544853 \\ \mathrm{O} & 2.025616 & -1.130757 & -2.212832 \\ \mathrm{H} & 2.881923 & -0.899053 & -2.608505 \\ \mathrm{H} & 4.562466 & -1.508585 & 0.183247 \\ \mathrm{H} & 1.456913 & -1.440913 & -2.933608 \\ \mathrm{H} & 1.798198 & -2.349216 & 3.162490 \\ \mathrm{H} & -0.792463 & -2.400645 & -0.114194 \\ \mathrm{H} & 1.697892 & 0.552015 & 3.311713 \\ \mathrm{C} & 0.072535 & 2.217213 & -0.258790 \\ \mathrm{C} & -0.160479 & 3.577733 & -0.442520 \\ \mathrm{C} & 0.946755 & 4.423795 & -0.604026 \\ \mathrm{C} & 2.228318 & 3.882292 & -0.577553 \\ \mathrm{C} & 2.383061 & 2.498074 & -0.381504 \\ \mathrm{~N} & 1.313188 & 1.681884 & -0.223004 \\ \mathrm{H} & 0.804489 & 5.489592 & -0.753872 \\ \mathrm{H} & -1.176544 & 3.949940 & -0.470312 \\ \mathrm{H} & 3.101952 & 4.511067 & -0.705902 \\ \mathrm{C} & -1.049782 & 1.254212 & -0.132235 \\ \mathrm{C} & -3.315672 & 0.839660 & -0.088701 \\ \mathrm{C} & -4.670719 & 1.388738 & -0.198558 \\ \mathrm{C} & -2.991941 & -0.572286 & 0.051065 \\ \mathrm{C} & -4.875665 & 2.720139 & 0.209733 \\ \mathrm{C} & -5.741140 & 0.658896 & -0.772781 \\ \mathrm{C} & -3.973928 & -1.663080 & 0.269284 \\ \mathrm{C} & -6.135875 & 3.321841 & 0.088680 \\ \mathrm{C} & -4.837179 & -1.603000 & 1.370787 \\ \mathrm{C} & -6.977620 & 1.278808 & -0.923553 \\ \mathrm{C} & -3.980952 & -2.777418 & -0.594462 \\ \mathrm{C} & -7.194242 & 2.594025 & -0.489535 \\ \mathrm{C} & -5.702350 & -2.678702 & 1.615786 \\ \mathrm{C} & -4.879294 & -3.830139 & -0.357664 \\ \mathrm{H} & -8.176206 & 3.037090 & -0.605208\end{array}$




$\begin{array}{lrrr}\mathrm{C} & -5.732678 & -3.778959 & 0.763941 \\ \mathrm{H} & -6.414376 & -4.605659 & 0.933502 \\ \mathrm{~N} & -2.301507 & 1.713793 & -0.148778 \\ \mathrm{~N} & -0.719400 & -0.043572 & -0.060731 \\ \mathrm{~N} & -1.717536 & -0.945844 & 0.033665 \\ \mathrm{O} & -5.003863 & -4.934732 & -1.139013 \\ \mathrm{O} & -6.226379 & 4.595507 & 0.546466 \\ \mathrm{C} & -7.491223 & 5.273221 & 0.449371 \\ \mathrm{H} & -7.325104 & 6.261740 & 0.876042 \\ \mathrm{H} & -7.803771 & 5.374079 & -0.595563 \\ \mathrm{H} & -8.261745 & 4.751059 & 1.026719 \\ \mathrm{C} & -4.240758 & -5.021213 & -2.344476 \\ \mathrm{H} & -4.465846 & -4.185816 & -3.017996 \\ \mathrm{H} & -3.164037 & -5.053151 & -2.132291 \\ \mathrm{H} & -4.539681 & -5.956622 & -2.816813 \\ \mathrm{H} & -3.328873 & -2.789669 & -1.460068 \\ \mathrm{H} & -4.837164 & -0.743394 & 2.031785 \\ \mathrm{H} & -6.366230 & -2.650298 & 2.474122 \\ \mathrm{H} & -5.606743 & -0.355464 & -1.121561 \\ \mathrm{H} & -4.067346 & 3.296140 & 0.642477 \\ \mathrm{H} & -7.797190 & 0.735069 & -1.382792 \\ \mathrm{C} & 3.680564 & 1.832677 & -0.330690 \\ \mathrm{C} & 5.000046 & 2.255789 & -0.480812 \\ \mathrm{C} & 5.757410 & 1.075778 & -0.326222 \\ \mathrm{H} & 5.395413 & 3.240952 & -0.678671 \\ \mathrm{~N} & 3.674564 & 0.484040 & -0.099073 \\ \mathrm{~N} & 4.946816 & 0.026311 & -0.096389 \\ \mathrm{C} & 7.243720 & 0.988936 & -0.403804 \\ \mathrm{O} & 7.937222 & 1.970771 & -0.601023 \\ \mathrm{O} & 7.696240 & -0.266135 & -0.233612 \\ \mathrm{C} & 9.142661 & -0.413793 & -0.298339 \\ \mathrm{H} & 9.330338 & -1.475409 & -0.143902 \\ \mathrm{H} & 9.508474 & -0.090859 & -1.274745 \\ \mathrm{H} & 9.615142 & 0.183729 & 0.483464\end{array}$

$\mathrm{M}=\mathrm{Cm}$

$\begin{array}{lccc}\mathrm{CM} & 1.708434 & -0.812145 & 0.338573 \\ \mathrm{O} & 1.031568 & -2.039159 & 2.473608 \\ \mathrm{H} & 0.480338 & -2.836440 & 2.501721 \\ \mathrm{O} & 0.196589 & -2.782014 & -0.210383 \\ \mathrm{H} & 0.181938 & -3.710126 & -0.482954 \\ \mathrm{O} & 3.733280 & -2.190341 & 0.482090 \\ \mathrm{H} & 4.065148 & -3.080170 & 0.663887 \\ \mathrm{O} & 2.383036 & 0.379410 & 2.548702 \\ \mathrm{H} & 3.254775 & 0.807455 & 2.513943\end{array}$




\begin{tabular}{|c|c|c|c|}
\hline $\mathrm{O}$ & 1.986966 & -1.106225 & -2.131427 \\
\hline & 2.787205 & -0.773714 & -2.569528 \\
\hline$H$ & 4.514401 & -1.571084 & 0.247739 \\
\hline & 1.515713 & -1.662476 & -2.769890 \\
\hline H & 1.514249 & -1.988053 & 3.313523 \\
\hline 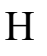 & -0.739276 & -2.430982 & -0.145991 \\
\hline $\mathrm{H}$ & 1.873898 & 0.847045 & 3.229164 \\
\hline $\mathrm{C}$ & 0.076296 & 2.205987 & -0.260377 \\
\hline $\mathrm{C}$ & -0.150780 & 3.562839 & -0.471998 \\
\hline $\mathrm{C}$ & 0.960619 & 4.399082 & -0.661008 \\
\hline $\mathrm{C}$ & 2.240177 & 3.852168 & -0.642214 \\
\hline $\mathrm{C}$ & 2.392989 & 2.471945 & -0.417099 \\
\hline $\mathrm{N}$ & 1.317513 & 1.669302 & -0.218148 \\
\hline $\mathrm{H}$ & 0.821985 & 5.462213 & -0.832254 \\
\hline $\mathrm{H}$ & -1.165079 & 3.939753 & -0.503558 \\
\hline $\mathrm{H}$ & 3.114107 & 4.473455 & -0.801556 \\
\hline $\mathrm{C}$ & -1.049816 & 1.244870 & -0.125889 \\
\hline $\mathrm{C}$ & -3.313981 & 0.827544 & -0.096947 \\
\hline $\mathrm{C}$ & -4.669080 & 1.376034 & -0.210648 \\
\hline $\mathrm{C}$ & -2.990206 & -0.585093 & 0.039405 \\
\hline $\mathrm{C}$ & -4.878144 & 2.703403 & 0.208555 \\
\hline $\mathrm{C}$ & -5.734752 & 0.650328 & -0.798671 \\
\hline $\mathrm{C}$ & -3.973992 & -1.677558 & 0.241036 \\
\hline $\mathrm{C}$ & -6.138343 & 3.304658 & 0.085209 \\
\hline $\mathrm{C}$ & -4.850300 & -1.624959 & 1.332662 \\
\hline $\mathrm{C}$ & -6.970916 & 1.270299 & -0.951836 \\
\hline $\mathrm{C}$ & -3.968604 & -2.787294 & -0.628566 \\
\hline $\mathrm{C}$ & -7.192020 & 2.581060 & -0.506676 \\
\hline $\mathrm{C}$ & -5.716281 & -2.703592 & 1.561646 \\
\hline $\mathrm{C}$ & -4.867957 & -3.842756 & -0.408292 \\
\hline $\mathrm{H}$ & -8.173733 & 3.024068 & -0.624645 \\
\hline $\mathrm{C}$ & -5.734634 & -3.799242 & 0.703444 \\
\hline $\mathrm{H}$ & -6.416978 & -4.627918 & 0.860311 \\
\hline $\mathrm{N}$ & -2.300953 & 1.704503 & -0.149837 \\
\hline $\mathrm{N}$ & -0.720884 & -0.053349 & -0.049081 \\
\hline $\mathrm{N}$ & -1.715542 & -0.959652 & 0.034717 \\
\hline $\mathrm{O}$ & -4.980796 & -4.943254 & -1.197098 \\
\hline $\mathrm{O}$ & -6.233359 & 4.573923 & 0.554349 \\
\hline $\mathrm{C}$ & -7.498339 & 5.251057 & 0.455282 \\
\hline $\mathrm{H}$ & -7.336254 & 6.235724 & 0.892291 \\
\hline $\mathrm{H}$ & -7.804149 & 5.361369 & -0.590690 \\
\hline $\mathrm{H}$ & -8.272019 & 4.722618 & 1.022624 \\
\hline $\mathrm{C}$ & -4.206381 & -5.019253 & -2.396316 \\
\hline $\mathrm{H}$ & -4.427796 & -4.179719 & -3.065852 \\
\hline $\mathrm{H}$ & -3.131543 & -5.049433 & -2.174765 \\
\hline $\mathrm{H}$ & -4.498439 & -5.952161 & -2.877764 \\
\hline
\end{tabular}




$\begin{array}{cccc}\mathrm{H} & -3.305076 & -2.794119 & -1.485456 \\ \mathrm{H} & -4.860129 & -0.768686 & 1.997979 \\ \mathrm{H} & -6.390482 & -2.680962 & 2.412102 \\ \mathrm{H} & -5.596531 & -0.360379 & -1.156529 \\ \mathrm{H} & -4.073134 & 3.276517 & 0.651305 \\ \mathrm{H} & -7.786695 & 0.730109 & -1.421904 \\ \mathrm{C} & 3.687883 & 1.797376 & -0.386103 \\ \mathrm{C} & 5.010241 & 2.207578 & -0.552056 \\ \mathrm{C} & 5.758839 & 1.021853 & -0.395149 \\ \mathrm{H} & 5.412966 & 3.188145 & -0.757778 \\ \mathrm{~N} & 3.675401 & 0.449122 & -0.147436 \\ \mathrm{~N} & 4.942067 & -0.021205 & -0.150548 \\ \mathrm{C} & 7.244166 & 0.924978 & -0.481957 \\ \mathrm{O} & 7.942187 & 1.899769 & -0.698224 \\ \mathrm{O} & 7.690859 & -0.329959 & -0.296622 \\ \mathrm{C} & 9.135549 & -0.487337 & -0.372336 \\ \mathrm{H} & 9.318320 & -1.547661 & -0.203664 \\ \mathrm{H} & 9.494227 & -0.181509 & -1.356872 \\ \mathrm{H} & 9.619110 & 0.118979 & 0.395841\end{array}$

\section{$\left[\mathrm{ML}_{2}\left(\mathrm{H}_{2} \mathrm{O}\right)_{2}\right]^{1+}$}

$\mathrm{M}=\mathrm{Eu}$

$\begin{array}{lrrr}\text { EU } & -0.000006 & 1.809724 & 0.000017 \\ \mathrm{O} & -1.275659 & 3.442071 & 1.310666 \\ \mathrm{H} & -2.028258 & 3.781621 & 0.726673 \\ \mathrm{O} & 1.275514 & 3.442328 & -1.310438 \\ \mathrm{H} & 2.028040 & 3.781918 & -0.726372 \\ \mathrm{H} & -1.031071 & 4.118592 & 1.954909 \\ \mathrm{H} & 1.030861 & 4.118896 & -1.954608 \\ \mathrm{C} & -0.369184 & -0.145916 & 2.913534 \\ \mathrm{C} & -0.181755 & -0.675219 & 4.189864 \\ \mathrm{C} & 0.890398 & -0.192590 & 4.951862 \\ \mathrm{C} & 1.720462 & 0.787234 & 4.416910 \\ \mathrm{C} & 1.462013 & 1.273286 & 3.121770 \\ \mathrm{~N} & 0.425442 & 0.806961 & 2.389714 \\ \mathrm{H} & 1.070807 & -0.579225 & 5.950251 \\ \mathrm{H} & -0.861505 & -1.430342 & 4.562374 \\ \mathrm{H} & 2.558533 & 1.177776 & 4.982385 \\ \mathrm{C} & -1.482859 & -0.609735 & 2.047502 \\ \mathrm{C} & -3.340113 & -1.917657 & 1.746336 \\ \mathrm{C} & -4.343002 & -2.813012 & 2.365066 \\ \mathrm{C} & -3.388945 & -1.431568 & 0.391664 \\ \mathrm{C} & -3.912051 & -3.716639 & 3.346241 \\ \mathrm{C} & -5.716274 & -2.719635 & 2.051777\end{array}$




\begin{tabular}{|c|c|c|c|}
\hline $\mathrm{C}$ & -4.330213 & -1.914754 & -0.650940 \\
\hline $\mathrm{C}$ & -4.829760 & -4.553724 & 3998551 \\
\hline C & -4.469313 & -3.286742 & -0.900569 \\
\hline$C$ & -6.622576 & -3.532941 & 2.727311 \\
\hline $\mathrm{C}$ & -5.044608 & -0.971686 & -1.4132 \\
\hline 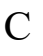 & -6.196966 & -4.458473 & 3.690896 \\
\hline C & -5.325127 & -3.710191 & -1.92552 \\
\hline $\mathrm{C}$ & -5.925106 & -1.410218 & -2.4124 \\
\hline $\mathrm{H}$ & -6.927449 & -5.086423 & 4.186 \\
\hline $\mathrm{C}$ & -6.055476 & -2.788349 & -2.672896 \\
\hline $\mathrm{H}$ & -6.736478 & -3.107342 & -3.454839 \\
\hline $\mathrm{N}$ & -2.334972 & -1.519844 & 2.529650 \\
\hline $\mathrm{N}$ & -1.584450 & -0.050644 & 0.831842 \\
\hline $\mathrm{N}$ & -2.527717 & -0.491920 & -0.004853 \\
\hline $\mathrm{O}$ & -6.688857 & -0.585594 & -3.18563 \\
\hline $\mathrm{O}$ & -4.294523 & -5.413597 & 4.9 \\
\hline $\mathrm{C}$ & -5.183345 & -6.284845 & 5.621350 \\
\hline $\mathrm{H}$ & -4.551694 & -6.872424 & 6.287970 \\
\hline $\mathrm{H}$ & -5.908519 & -5.715939 & 6.214920 \\
\hline $\mathrm{H}$ & -5.711107 & -6.956704 & 4.934344 \\
\hline $\mathrm{C}$ & -6.703439 & 0.812960 & -2.876595 \\
\hline $\mathrm{H}$ & -7.062465 & 0.986345 & -1.85 \\
\hline $\mathrm{H}$ & -5.712751 & 1.262890 & -2.996672 \\
\hline $\mathrm{H}$ & -7.395787 & 1.266929 & -3.585540 \\
\hline $\mathrm{H}$ & -4.907317 & 0.083034 & -1.210407 \\
\hline $\mathrm{H}$ & -3.920279 & -4.014751 & -0.313952 \\
\hline $\mathrm{H}$ & -5.431317 & -4.770239 & -2.135172 \\
\hline $\mathrm{H}$ & -6.071352 & -2.015206 & 1.310803 \\
\hline $\mathrm{H}$ & -2.863392 & -3.787510 & 3.608708 \\
\hline $\mathrm{H}$ & -7.682266 & -3.454848 & 2.504108 \\
\hline $\mathrm{C}$ & 2.276898 & 2.297985 & 2.478608 \\
\hline $\mathrm{C}$ & 3.404674 & 3.019022 & 2.876639 \\
\hline $\mathrm{C}$ & 3.690535 & 3.834849 & 1.763671 \\
\hline $\mathrm{H}$ & 3.943876 & 3.000827 & 3.811666 \\
\hline $\mathrm{N}$ & 1.931270 & 2.681464 & 1.215708 \\
\hline $\mathrm{N}$ & 2.790343 & 3.615446 & 0.779027 \\
\hline $\mathrm{C}$ & 0.369423 & -0.145507 & -2.913726 \\
\hline $\mathrm{C}$ & 0.182098 & -0.674636 & -4.190143 \\
\hline $\mathrm{C}$ & -0.890088 & -0.192014 & -4.952102 \\
\hline $\mathrm{C}$ & -1.720288 & 0.787628 & -4.417025 \\
\hline $\mathrm{C}$ & -1.461935 & 1.273517 & -3.121804 \\
\hline $\mathrm{N}$ & -0.425327 & 0.807202 & -2.389791 \\
\hline $\mathrm{H}$ & -1.070417 & -0.578515 & -5.950557 \\
\hline $\mathrm{H}$ & 0.861946 & -1.429624 & -4.562746 \\
\hline $\mathrm{H}$ & -2.558385 & 1.178161 & -4.982468 \\
\hline 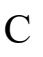 & 1.483092 & -0.609357 & -2.047705 \\
\hline
\end{tabular}




\begin{tabular}{|c|c|c|c|}
\hline $\mathrm{C}$ & 3.340404 & -1.917209 & -1.746602 \\
\hline & 4.343463 & -2.812309 & -2.365422 \\
\hline & 3.389023 & -1.431423 & -0.391813 \\
\hline 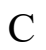 & 3.912744 & -3.715712 & -3.346905 \\
\hline C & 5.716679 & -2.718886 & -2.051903 \\
\hline C & 4.330104 & -1.914864 & 0.650839 \\
\hline $\mathrm{C}$ & 4.830630 & -4.552531 & -3.999307 \\
\hline $\mathrm{C}$ & 4.469241 & -3.286922 & 0.900067 \\
\hline $\mathrm{C}$ & 6.623160 & -3.531925 & -2.727520 \\
\hline $\mathrm{C}$ & 5.044251 & -0.971990 & 1.413605 \\
\hline $\mathrm{C}$ & 6.197781 & -4.457235 & -3.691420 \\
\hline $\mathrm{C}$ & 5.324836 & -3.710640 & 1.925091 \\
\hline $\mathrm{C}$ & 5.924532 & -1.410782 & 2.412898 \\
\hline $\mathrm{H}$ & 6.928398 & -5.084981 & -4.187041 \\
\hline $\mathrm{C}$ & 6.054938 & -2.788985 & 2.672938 \\
\hline $\mathrm{H}$ & 6.735772 & -3.108179 & 3.454945 \\
\hline $\mathrm{N}$ & 2.335317 & -1.519313 & -2.529943 \\
\hline $\mathrm{N}$ & 1.584559 & -0.050448 & -0.831949 \\
\hline $\mathrm{N}$ & 2.527741 & -0.491853 & 0.004772 \\
\hline $\mathrm{O}$ & 6.688040 & -0.586346 & 3.186533 \\
\hline $\mathrm{O}$ & 4.295613 & -5.412202 & -4.915181 \\
\hline $\mathrm{C}$ & 5.184627 & -6.283154 & -5.622546 \\
\hline $\mathrm{H}$ & 4.553134 & -6.870601 & -6.289433 \\
\hline $\mathrm{H}$ & 5.909831 & -5.713999 & -6.215841 \\
\hline $\mathrm{H}$ & 5.712355 & -6.955162 & -4.935659 \\
\hline $\mathrm{C}$ & 6.702616 & 0.812290 & 2.877899 \\
\hline $\mathrm{H}$ & 7.061867 & 0.986001 & 1.856783 \\
\hline $\mathrm{H}$ & 5.711866 & 1.262125 & 2.997861 \\
\hline $\mathrm{H}$ & 7.394778 & 1.266089 & 3.587138 \\
\hline $\mathrm{H}$ & 4.906939 & 0.082784 & 1.211073 \\
\hline $\mathrm{H}$ & 3.920400 & -4.014783 & 0.313086 \\
\hline $\mathrm{H}$ & 5.431050 & -4.770746 & 2.134427 \\
\hline $\mathrm{H}$ & 6.071580 & -2.014624 & -1.310684 \\
\hline $\mathrm{H}$ & 2.864131 & -3.786612 & -3.609545 \\
\hline $\mathrm{H}$ & 7.682809 & -3.453792 & -2.504138 \\
\hline $\mathrm{C}$ & -2.276969 & 2.298010 & -2.478501 \\
\hline $\mathrm{C}$ & -3.404958 & 3.018801 & -2.876369 \\
\hline $\mathrm{C}$ & -3.690933 & 3.834443 & -1.763294 \\
\hline $\mathrm{H}$ & -3.944252 & 3.000516 & -3.811340 \\
\hline $\mathrm{N}$ & -1.931332 & 2.681454 & -1.215595 \\
\hline $\mathrm{N}$ & -2.790597 & 3.615179 & -0.778747 \\
\hline $\mathrm{C}$ & 4.818358 & 4.788017 & 1.661455 \\
\hline $\mathrm{O}$ & 5.683234 & 4.891219 & 2.520843 \\
\hline $\mathrm{O}$ & 4.787793 & 5.518076 & 0.524963 \\
\hline $\mathrm{C}$ & -4.819054 & 4.787230 & -1.660844 \\
\hline $\mathrm{O}$ & -5.684224 & 4.890033 & -2.519989 \\
\hline
\end{tabular}




$\begin{array}{cccc}\mathrm{O} & -4.788417 & 5.517414 & -0.524438 \\ \mathrm{C} & 5.869138 & 6.467077 & 0.376172 \\ \mathrm{H} & 6.831656 & 5.950293 & 0.366024 \\ \mathrm{H} & 5.688411 & 6.964464 & -0.576609 \\ \mathrm{H} & 5.858256 & 7.187901 & 1.196867 \\ \mathrm{C} & -5.870056 & 6.466046 & -0.375411 \\ \mathrm{H} & -6.832383 & 5.948915 & -0.364858 \\ \mathrm{H} & -5.689182 & 6.963631 & 0.577238 \\ \mathrm{H} & -5.859715 & 7.186756 & -1.196212\end{array}$

$\mathrm{M}=\mathrm{Gd}$

$\begin{array}{lrrr}\text { GD } & 0.000003 & 1.781802 & 0.000005 \\ \mathrm{O} & 1.237630 & 3.394405 & -1.337894 \\ \mathrm{H} & 1.979437 & 3.768412 & -0.761216 \\ \mathrm{O} & -1.237608 & 3.394397 & 1.337931 \\ \mathrm{H} & -1.979402 & 3.768430 & 0.761253 \\ \mathrm{H} & 0.974493 & 4.047542 & -1.998717 \\ \mathrm{H} & -0.974447 & 4.047527 & 1.998752 \\ \mathrm{C} & 0.332250 & -0.193297 & -2.867915 \\ \mathrm{C} & 0.121349 & -0.740131 & -4.132668 \\ \mathrm{C} & -0.958798 & -0.260404 & -4.885790 \\ \mathrm{C} & -1.770928 & 0.736710 & -4.355777 \\ \mathrm{C} & -1.490416 & 1.240395 & -3.071994 \\ \mathrm{~N} & -0.449619 & 0.771733 & -2.346012 \\ \mathrm{H} & -1.157388 & -0.661276 & -5.875081 \\ \mathrm{H} & 0.790406 & -1.504959 & -4.504638 \\ \mathrm{H} & -2.611590 & 1.128382 & -4.916588 \\ \mathrm{C} & 1.462724 & -0.642678 & -2.015752 \\ \mathrm{C} & 3.332020 & -1.937445 & -1.735118 \\ \mathrm{C} & 4.322296 & -2.841833 & -2.360622 \\ \mathrm{C} & 3.413670 & -1.421931 & -0.392698 \\ \mathrm{C} & 3.869964 & -3.767599 & -3.311143 \\ \mathrm{C} & 5.702914 & -2.736187 & -2.085680 \\ \mathrm{C} & 4.386040 & -1.875969 & 0.634540 \\ \mathrm{C} & 4.774115 & -4.614353 & -3.969821 \\ \mathrm{C} & 4.544050 & -3.241147 & 0.909050 \\ \mathrm{C} & 6.594948 & -3.559601 & -2.767901 \\ \mathrm{C} & 5.110694 & -0.910863 & 1.358659 \\ \mathrm{C} & 6.148496 & -4.506895 & -3.700400 \\ \mathrm{C} & 5.429322 & -3.635334 & 1.920580 \\ \mathrm{C} & 6.019956 & -1.320368 & 2.344391 \\ \mathrm{H} & 6.868673 & -5.141995 & -4.201898 \\ \mathrm{C} & 6.169647 & -2.691600 & 2.629895 \\ \mathrm{H} & 6.873021 & -2.988146 & 3.400796 \\ \mathrm{~N} & 2.305483 & -1.560088 & -2.500668\end{array}$




$\begin{array}{lrrr}\mathrm{N} & 1.590450 & -0.059357 & -0.813944 \\ \mathrm{~N} & 2.557691 & -0.479856 & 0.007852 \\ \mathrm{O} & 6.794638 & -0.473016 & 3.080957 \\ \mathrm{O} & 4.219145 & -5.495439 & -4.852860 \\ \mathrm{C} & 5.093316 & -6.377270 & -5.565280 \\ \mathrm{H} & 4.447220 & -6.981288 & -6.202720 \\ \mathrm{H} & 5.799766 & -5.817574 & -6.189393 \\ \mathrm{H} & 5.642284 & -7.032428 & -4.878771 \\ \mathrm{C} & 6.788166 & 0.919249 & 2.743446 \\ \mathrm{H} & 7.120598 & 1.074698 & 1.710371 \\ \mathrm{H} & 5.796678 & 1.362765 & 2.878995 \\ \mathrm{H} & 7.493075 & 1.393868 & 3.425930 \\ \mathrm{H} & 4.958310 & 0.138151 & 1.137870 \\ \mathrm{H} & 3.987096 & -3.986186 & 0.352053 \\ \mathrm{H} & 5.550633 & -4.689760 & 2.149508 \\ \mathrm{H} & 6.074082 & -2.014853 & -1.369288 \\ \mathrm{H} & 2.815135 & -3.848155 & -3.544482 \\ \mathrm{H} & 7.659765 & -3.472346 & -2.574493 \\ \mathrm{C} & -2.280572 & 2.288210 & -2.436045 \\ \mathrm{C} & -3.408343 & 3.015405 & -2.824911 \\ \mathrm{C} & -3.663522 & 3.852442 & -1.721291 \\ \mathrm{H} & -3.967129 & 2.985212 & -3.748041 \\ \mathrm{~N} & -1.907464 & 2.688754 & -1.187086 \\ \mathrm{~N} & -2.746298 & 3.640279 & -0.749974 \\ \mathrm{C} & -4.781486 & 4.816303 & -1.612090 \\ \mathrm{O} & -5.662216 & 4.913980 & -2.455992 \\ \mathrm{O} & -4.723062 & 5.563261 & -0.487658 \\ \mathrm{C} & -5.792809 & 6.524262 & -0.333141 \\ \mathrm{H} & -5.589580 & 7.034416 & 0.608299 \\ \mathrm{H} & -5.791085 & 7.232463 & -1.164819 \\ \mathrm{H} & -6.759623 & 6.016712 & -0.296918 \\ \mathrm{C} & -0.332248 & -0.193338 & 2.867898 \\ \mathrm{C} & -0.121343 & -0.740196 & 4.132640 \\ \mathrm{C} & 0.958816 & -0.260495 & 4.885762 \\ \mathrm{C} & 1.770955 & 0.736616 & 4.355757 \\ \mathrm{C} & 1.490437 & 1.240328 & 3.071986 \\ \mathrm{~N} & 0.449626 & 0.771693 & 2.346006 \\ \mathrm{H} & 1.157410 & -0.661387 & 5.875043 \\ \mathrm{H} & -0.790405 & -1.505023 & 4.504602 \\ \mathrm{C} & -1.46271629 & 1.128267 & 4.916566 \\ \mathrm{C} & -3.332029 & -1.937459 & 1.735092 \\ \mathrm{C} & -2.841851 & 2.360596 \\ \mathrm{C} & -1.421917 & 0.392682 \\ & -3.767648 & 3.311081 \\ \mathrm{C} & -2.736175 & 2.085701\end{array}$




\begin{tabular}{|c|c|c|c|}
\hline & 4.386047 & -1.875963 & -0 \\
\hline & -4.774100 & -4.614406 & 3960763 \\
\hline & -4.543973 & -3.241138 & -0.9 \\
\hline & -6.594954 & -3.559593 & 2.767926 \\
\hline & -5.110784 & -0.910868 & -1.358619 \\
\hline & -6.148488 & -4.506920 & 3.700386 \\
\hline & -5.429237 & -3.635331 & -1.9 \\
\hline & -6.020045 & -1.320385 & -2.3 \\
\hline $\mathrm{H}$ & -6.868660 & -5.1 & \\
\hline & -6.169645 & -2.6 & -2.6 \\
\hline $\mathrm{H}$ & -6.873021 & -2.9 & -3.4 \\
\hline $\mathrm{N}$ & -2.305487 & -1.560115 & 2.500641 \\
\hline & -1.590464 & -0.0 & \\
\hline $\mathrm{N}$ & -2.557715 & -0.4 & -0.0 \\
\hline & -6.794820 & -0.4 & -3 \\
\hline $\mathrm{O}$ & -4.219117 & -5.4 & 4.8 \\
\hline & -5.093281 & -6.3 & 5.5 \\
\hline $\mathrm{H}$ & -4.4 & -6.9 & \\
\hline $\mathrm{H}$ & -5.799703 & -5.8 & 6.1 \\
\hline $\mathrm{H}$ & -5.642280 & -7.0 & 4.8 \\
\hline C & -6.788466 & 0.9 & -2.7 \\
\hline & -7.120893 & 1.0 & -1.7 \\
\hline $\mathrm{H}$ & -5.797021 & 805 & -2.8 \\
\hline & -7.493431 & 1.3 & -3.4 \\
\hline $\mathrm{H}$ & -4.958472 & 0.1 & -1.1 \\
\hline $\mathrm{H}$ & -3.986957 & -3.9 & -0.3 \\
\hline 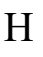 & -5.550482 & -4.6 & -2.1 \\
\hline $\mathrm{H}$ & -6.074106 & -2.0 & 1.3 \\
\hline $\mathrm{H}$ & -2.815122 & -3.848225 & 3.54 \\
\hline $\mathrm{H}$ & -7.659775 & -3.4 & 2.57 \\
\hline $\mathrm{C}$ & 2.280603 & 2.28 & 2.436045 \\
\hline C & 3.408398 & 3.01 & 2.824906 \\
\hline $\mathrm{C}$ & 3.663572 & 3.8 & 1.72 \\
\hline $\mathrm{H}$ & 3.967202 & 2.9 & 3.74 \\
\hline $\mathrm{N}$ & 1.907486 & 2.6 & 1.187098 \\
\hline $\mathrm{N}$ & 2.746329 & 3.6 & 0.749994 \\
\hline $\mathrm{C}$ & 4.781553 & 4.816201 & 1.612101 \\
\hline $\mathrm{O}$ & 5.662292 & 4.913853 & 2.455997 \\
\hline $\mathrm{O}$ & 4.723115 & 5.563196 & 0.487695 \\
\hline $\mathrm{C}$ & 5.792868 & 6.524193 & 0.333190 \\
\hline $\mathrm{H}$ & 5.589627 & 7.034378 & -0.608231 \\
\hline . & 5.791165 & 7.232367 & 1.164890 \\
\hline $\mathrm{H}$ & 6.759676 & 6.016635 & 0.296933 \\
\hline
\end{tabular}

$\mathrm{M}=\mathrm{Am}$ 


\begin{tabular}{|c|c|c|c|}
\hline 31 & 0.000002 & -1.69341 & 0.000013 \\
\hline $\mathrm{O}$ & -1.322329 & -3.355652 & -1.317240 \\
\hline $\mathrm{H}$ & -2.004421 & -3.750796 & -0.684193 \\
\hline U & 1.322557 & -3.355660 & 1.317423 \\
\hline 1 & 2.004622 & -3.750739 & 0.684317 \\
\hline Н & -1.011499 & -4.040334 & -1.924141 \\
\hline $\mathrm{H}$ & 1.012054 & -4.040318 & 1.924519 \\
\hline C & -0.316731 & 0.281799 & -2.944987 \\
\hline $\mathrm{C}$ & -0.103333 & 0.818047 & -4.213684 \\
\hline $\mathrm{C}$ & 0.963195 & 0.313977 & -4.970224 \\
\hline $\mathrm{C}$ & 1.754955 & -0.700247 & -4.442304 \\
\hline $\mathrm{C}$ & 1.471791 & -1.192772 & -3.154505 \\
\hline $\mathrm{N}$ & 0.452236 & -0.693207 & -2.421213 \\
\hline $\mathrm{H}$ & 1.164274 & 0.706282 & -5.962398 \\
\hline $\mathrm{H}$ & -0.760499 & 1.592255 & -4.587565 \\
\hline $\mathrm{H}$ & 2.579352 & -1.115826 & -5.009966 \\
\hline $\mathrm{C}$ & -1.442055 & 0.747127 & -2.095282 \\
\hline $\mathrm{C}$ & -3.294219 & 2.065369 & -1.807847 \\
\hline $\mathrm{C}$ & -4.272690 & 2.985025 & -2.429383 \\
\hline $\mathrm{C}$ & -3.387371 & 1.541792 & -0.468757 \\
\hline $\mathrm{C}$ & -3.807506 & 3.920925 & -3.363234 \\
\hline $\mathrm{C}$ & -5.655832 & 2.883882 & -2.166248 \\
\hline $\mathrm{C}$ & -4.351086 & 2.002558 & 0.562954 \\
\hline $\mathrm{C}$ & -4.701711 & 4.782063 & -4.017158 \\
\hline $\mathrm{C}$ & -4.510977 & 3.369252 & 0.829876 \\
\hline $\mathrm{C}$ & -6.537884 & 3.721766 & -2.843675 \\
\hline $\mathrm{C}$ & -5.061953 & 1.040415 & 1.304863 \\
\hline $\mathrm{C}$ & -6.078704 & 4.679133 & -3.759628 \\
\hline $\mathrm{C}$ & -5.384665 & 3.767260 & 1.849822 \\
\hline $\mathrm{C}$ & -5.957930 & 1.453218 & 2.300817 \\
\hline $\mathrm{H}$ & -6.791294 & 5.325216 & -4.257890 \\
\hline $\mathrm{C}$ & -6.110673 & 2.825997 & 2.577043 \\
\hline $\mathrm{H}$ & -6.804293 & 3.125630 & 3.355565 \\
\hline $\mathrm{N}$ & -2.270348 & 1.681154 & -2.574184 \\
\hline $\mathrm{N}$ & -1.586290 & 0.154794 & -0.900759 \\
\hline $\mathrm{N}$ & -2.546668 & 0.582603 & -0.076023 \\
\hline $\mathrm{O}$ & -6.716430 & 0.607617 & 3.056116 \\
\hline $\mathrm{O}$ & -4.134847 & 5.671693 & -4.883818 \\
\hline $\mathrm{C}$ & -4.998399 & 6.567557 & -5.591719 \\
\hline $\mathrm{H}$ & -4.343879 & 7.175902 & -6.216299 \\
\hline $\mathrm{H}$ & -5.703013 & 6.019853 & -6.228405 \\
\hline $\mathrm{H}$ & -5.549034 & 7.217043 & -4.901158 \\
\hline $\mathrm{C}$ & -6.694208 & -0.789233 & 2.739881 \\
\hline $\mathrm{H}$ & -7.036224 & -0.965583 & 1.713272 \\
\hline $\mathrm{H}$ & -5.694602 & -1.216362 & 2.871115 \\
\hline $\mathrm{H}$ & -7.384735 & -1.262954 & 3.437586 \\
\hline
\end{tabular}




\begin{tabular}{|c|c|c|c|}
\hline $\mathrm{H}$ & -4.907969 & -0.009451 & 1.089744 \\
\hline H & -3.963952 & 4.112623 & 0.261109 \\
\hline & -5.507358 & 4.822902 & 2.072326 \\
\hline $\mathrm{H}$ & -6.036440 & 2.154496 & -1.462922 \\
\hline & -2.750436 & 3.998271 & -3.587662 \\
\hline$\theta$ & -7.604674 & 3.638018 & -2.659747 \\
\hline & 2.237940 & -2.263946 & -2.528025 \\
\hline & 3.357172 & -2.997814 & -2.926768 \\
\hline$C$ & 3.600780 & -3.856178 & -1.837570 \\
\hline$\theta$ & 3.920941 & -2.956214 & -3.846343 \\
\hline$y$ & 1.856461 & -2.681010 & -1.286676 \\
\hline $1 \mathrm{~V}$ & 2.685956 & -3.649203 & -0.864427 \\
\hline 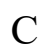 & 4.706454 & -4.835888 & -1.742165 \\
\hline $\mathrm{O}$ & 5.581584 & -4.938386 & -2.590965 \\
\hline U & 4.642782 & -5.591457 & -0.623686 \\
\hline $\mathrm{C}$ & 5.699637 & -6.568584 & -0.482064 \\
\hline $\mathrm{H}$ & 5.493479 & -7.083558 & 0.456110 \\
\hline $\mathrm{H}$ & 5.684150 & -7.269794 & -1.319512 \\
\hline $\mathrm{H}$ & 6.673613 & -6.074898 & -0.446190 \\
\hline$C$ & 0.316727 & 0.281779 & 2.945042 \\
\hline $\mathrm{C}$ & 0.103349 & 0.818017 & 4.213746 \\
\hline $\mathrm{C}$ & -0.963162 & 0.313932 & 4.970303 \\
\hline $\mathrm{C}$ & -1.754931 & -0.700287 & 4.442387 \\
\hline $\mathrm{C}$ & -1.471795 & -1.192788 & 3.154572 \\
\hline $\mathrm{N}$ & -0.452250 & -0.693220 & 2.421273 \\
\hline $\mathrm{H}$ & -1.164213 & 0.706214 & 5.962492 \\
\hline $\mathrm{H}$ & 0.760510 & 1.592233 & 4.587616 \\
\hline $\mathrm{H}$ & -2.579315 & -1.115878 & 5.010061 \\
\hline $\mathrm{C}$ & 1.442040 & 0.747095 & 2.095317 \\
\hline $\mathrm{C}$ & 3.294150 & 2.065393 & 1.807824 \\
\hline $\mathrm{C}$ & 4.272597 & 2.985130 & 2.429271 \\
\hline $\mathrm{C}$ & 3.387312 & 1.541780 & 0.468756 \\
\hline $\mathrm{C}$ & 3.807433 & 3.921000 & 3.363162 \\
\hline $\mathrm{C}$ & 5.655715 & 2.884123 & 2.165964 \\
\hline $\mathrm{C}$ & 4.351074 & 2.002506 & -0.562925 \\
\hline $\mathrm{C}$ & 4.701634 & 4.782224 & 4.016976 \\
\hline $\mathrm{C}$ & 4.511051 & 3.369191 & -0.829828 \\
\hline $\mathrm{C}$ & 6.537770 & 3.722094 & 2.843281 \\
\hline $\mathrm{C}$ & 5.061958 & 1.040332 & -1.304785 \\
\hline $\mathrm{C}$ & 6.078608 & 4.679419 & 3.759287 \\
\hline $\mathrm{C}$ & 5.384819 & 3.767161 & -1.849718 \\
\hline $\mathrm{C}$ & 5.958014 & 1.453098 & -2.300684 \\
\hline $\mathrm{H}$ & 6.791196 & 5.325574 & 4.257458 \\
\hline $\mathrm{C}$ & 6.110831 & 2.825871 & -2.576899 \\
\hline $\mathrm{H}$ & 6.804506 & 3.125485 & -3.355380 \\
\hline 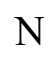 & 2.270315 & 1.681153 & 2.574191 \\
\hline
\end{tabular}




$\begin{array}{lrrr}\mathrm{N} & 1.586249 & 0.154764 & 0.900788 \\ \mathrm{~N} & 2.546614 & 0.582571 & 0.076035 \\ \mathrm{O} & 6.716535 & 0.607466 & -3.055927 \\ \mathrm{O} & 4.134792 & 5.671808 & 4.883696 \\ \mathrm{C} & 4.998346 & 6.567749 & 5.591498 \\ \mathrm{H} & 4.343844 & 7.176034 & 6.216154 \\ \mathrm{H} & 5.703083 & 6.020107 & 6.228101 \\ \mathrm{H} & 5.548843 & 7.217283 & 4.900872 \\ \mathrm{C} & 6.694294 & -0.789372 & -2.739645 \\ \mathrm{H} & 7.036286 & -0.965684 & -1.713019 \\ \mathrm{H} & 5.694691 & -1.216500 & -2.870886 \\ \mathrm{H} & 7.384835 & -1.263124 & -3.437316 \\ \mathrm{H} & 4.907927 & -0.009528 & -1.089667 \\ \mathrm{H} & 3.964040 & 4.112588 & -0.261079 \\ \mathrm{H} & 5.507575 & 4.822800 & -2.072208 \\ \mathrm{H} & 6.036305 & 2.154776 & 1.462587 \\ \mathrm{H} & 2.750380 & 3.998255 & 3.587703 \\ \mathrm{H} & 7.604545 & 3.638452 & 2.659218 \\ \mathrm{C} & -2.237952 & -2.263940 & 2.528071 \\ \mathrm{C} & -3.357167 & -2.997841 & 2.926808 \\ \mathrm{C} & -3.600797 & -3.856155 & 1.837572 \\ \mathrm{H} & -3.920905 & -2.956300 & 3.846406 \\ \mathrm{~N} & -1.856525 & -2.680915 & 1.286676 \\ \mathrm{~N} & -2.686032 & -3.649076 & 0.864398 \\ \mathrm{C} & -4.706489 & -4.835841 & 1.742123 \\ \mathrm{O} & -5.581612 & -4.938370 & 2.590927 \\ \mathrm{O} & -4.642786 & -5.591416 & 0.623651 \\ \mathrm{C} & -5.699635 & -6.568545 & 0.482003 \\ \mathrm{H} & -5.493459 & -7.083510 & -0.456172 \\ \mathrm{H} & -5.684160 & -7.269763 & 1.319445 \\ \mathrm{H} & -6.673612 & -6.074862 & 0.446117\end{array}$

$\mathrm{M}=\mathrm{Cm}$

$\begin{array}{lrrr}\mathrm{CM} & 0.000005 & 1.697752 & 0.000180 \\ \mathrm{O} & -1.320559 & 3.357178 & 1.319641 \\ \mathrm{H} & -2.031649 & 3.720620 & 0.700309 \\ \mathrm{O} & 1.320454 & 3.357696 & -1.318828 \\ \mathrm{H} & 2.031684 & 3.720873 & -0.699507 \\ \mathrm{H} & -1.060081 & 4.040538 & 1.950759 \\ \mathrm{H} & 1.059756 & 4.041358 & -1.949530 \\ \mathrm{C} & -0.387839 & -0.252480 & 2.929019 \\ \mathrm{C} & -0.200523 & -0.780691 & 4.205354 \\ \mathrm{C} & 0.864220 & -0.288306 & 4.972210 \\ \mathrm{C} & 1.684450 & 0.702903 & 4.444166 \\ \mathrm{C} & 1.427741 & 1.189431 & 3.148440\end{array}$




\begin{tabular}{|c|c|c|c|}
\hline & 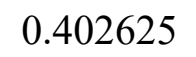 & & \\
\hline $\mathrm{H}$ & & & \\
\hline & .874480 & 41797 & \\
\hline & 512539 & & 716 \\
\hline & 1.500859 & -0.721262 & \\
\hline 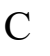 & 7313 & -2.0 & \\
\hline & -4.356174 & & \\
\hline 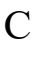 & 53 & & \\
\hline 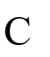 & & & \\
\hline 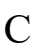 & -5.7 & -2.8 & \\
\hline 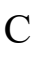 & -4.3 & -2.0 & \\
\hline ¿ & -4.83 & -4.6 & \\
\hline 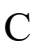 & -4.5 & -3.3 & \\
\hline $\mathrm{C}$ & -6.6 & -3.6 & \\
\hline 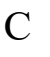 & -5.0 & -1.0 & \\
\hline $\mathrm{C}$ & -6.2 & & \\
\hline $\mathrm{C}^{\prime}$ & -5.3 & -3.8 & -1.8 \\
\hline $\mathrm{C}$ & -5.9 & & \\
\hline $\mathrm{H}$ & -6.9 & -5.2 & \\
\hline $\mathrm{C}$ & -6.0 & -2.8 & \\
\hline $\mathrm{H}$ & -6.7 & -3.2 & -3 \\
\hline $\mathrm{N}$ & -2.3 & -1.6 & \\
\hline $\mathrm{N}$ & -1.6 & -0. & \\
\hline & -2.5 & -0.6 & \\
\hline $\mathrm{O}$ & -6.6 & -0.6 & \\
\hline $\mathrm{O}$ & -4.2 & -5.5 & \\
\hline $\mathrm{C}$ & -5.1 & -6.4 & \\
\hline $\mathrm{H}$ & -4.5 & -7.0 & \\
\hline $\mathrm{H}$ & -5.8 & -5.8 & \\
\hline $\mathrm{H}$ & -5.7 & -7.0 & \\
\hline $\mathrm{C}$ & -6.6 & & \\
\hline $\mathrm{H}$ & -7.02 & 0.9 & \\
\hline $\mathrm{H}$ & -5.6 & & \\
\hline $\mathrm{H}$ & -7.3 & 1.1 & -3 \\
\hline $\mathrm{H}$ & -4.905833 & -0.0 & \\
\hline $\mathrm{H}$ & -3.9 & -4.1 & -0.2 \\
\hline $\mathrm{H}$ & -5.45 & -4.8 & -2.0 \\
\hline $\mathrm{H}$ & -6.0 & -2.1 & \\
\hline $\mathrm{H}$ & -2.8 & -3.9 & \\
\hline $\mathrm{H}$ & -7.65 & -3.5 & \\
\hline $\mathrm{C}$ & 2.23 & 2.2 & 2.520005 \\
\hline $\mathrm{C}$ & 3.35 & 2.9 & \\
\hline $\mathrm{C}$ & 3.63 & 3.78 & 1.834515 \\
\hline $\mathrm{H}$ & & 2.9 & \\
\hline $\mathrm{N}$ & 1.889968 & 2.63 & 1.26 \\
\hline $\mathrm{N}$ & 2.743152 & 3.579029 & 0.842529 \\
\hline
\end{tabular}




\begin{tabular}{|c|c|c|c|}
\hline $\mathrm{C}$ & 4.759554 & 4.751356 & 1.750566 \\
\hline $\mathrm{O}$ & 5.615737 & 4.854976 & 2.618445 \\
\hline $\mathrm{O}$ & 4.733783 & 5.490223 & 0.619340 \\
\hline $\mathrm{C}$ & 5.808090 & 6.449605 & 0.488458 \\
\hline $\mathrm{H}$ & 5.632580 & 6.952337 & -0.462522 \\
\hline $\mathrm{H}$ & 5.782574 & 7.164400 & 1.314110 \\
\hline $\mathrm{H}$ & 6.775259 & 5.941453 & 0.484380 \\
\hline $\mathrm{C}$ & 0.388061 & -0.251648 & -2.929302 \\
\hline $\mathrm{C}$ & 0.200906 & -0.779390 & -4.205849 \\
\hline $\mathrm{C}$ & -0.863654 & -0.286611 & -4.972717 \\
\hline $\mathrm{C}$ & -1.683848 & 0.704521 & -4.444475 \\
\hline $\mathrm{C}$ & -1.427321 & 1.190554 & -3.148524 \\
\hline $\mathrm{N}$ & -0.402394 & 0.708262 & -2.409927 \\
\hline $\mathrm{H}$ & -1.043774 & -0.672862 & -5.971346 \\
\hline $\mathrm{H}$ & 0.874836 & -1.540446 & -4.576673 \\
\hline $\mathrm{H}$ & -2.511839 & 1.106093 & -5.017002 \\
\hline $\mathrm{C}$ & 1.500906 & -0.720812 & -2.063527 \\
\hline $\mathrm{C}$ & 3.357151 & -2.032104 & -1.768442 \\
\hline $\mathrm{C}$ & 4.355813 & -2.929494 & -2.390555 \\
\hline $\mathrm{C}$ & 3.414820 & -1.543528 & -0.414607 \\
\hline $\mathrm{C}$ & 3.918019 & -3.843475 & -3.358792 \\
\hline $\mathrm{C}$ & 5.731776 & -2.828450 & -2.092080 \\
\hline $\mathrm{C}$ & 4.360179 & -2.024123 & 0.625325 \\
\hline $\mathrm{C}$ & 4.832092 & -4.683201 & -4.013004 \\
\hline $\mathrm{C}$ & 4.517027 & -3.395883 & 0.866315 \\
\hline $\mathrm{C}$ & 6.634154 & -3.644387 & -2.769570 \\
\hline $\mathrm{C}$ & 5.057582 & -1.076863 & 1.398366 \\
\hline $\mathrm{C}$ & 6.202017 & -4.580207 & -3.720287 \\
\hline $\mathrm{C}$ & 5.373860 & -3.814414 & 1.892388 \\
\hline $\mathrm{C}$ & 5.938016 & -1.509834 & 2.399742 \\
\hline $\mathrm{H}$ & 6.929687 & -5.209940 & -4.217688 \\
\hline $\mathrm{C}$ & 6.087046 & -2.887859 & 2.650490 \\
\hline $\mathrm{H}$ & 6.768031 & -3.202997 & 3.434035 \\
\hline $\mathrm{N}$ & 2.348585 & -1.634616 & -2.547793 \\
\hline $\mathrm{N}$ & 1.610959 & -0.160072 & -0.849342 \\
\hline $\mathrm{N}$ & 2.557124 & -0.602541 & -0.014885 \\
\hline $\mathrm{O}$ & 6.684224 & -0.679630 & 3.183968 \\
\hline $\mathrm{O}$ & 4.290648 & -5.553145 & -4.915201 \\
\hline $\mathrm{C}$ & 5.175261 & -6.427671 & -5.623767 \\
\hline $\mathrm{H}$ & 4.538851 & -7.023344 & -6.278544 \\
\hline $\mathrm{H}$ & 5.892255 & -5.861582 & -6.229823 \\
\hline $\mathrm{H}$ & 5.712350 & -7.091512 & -4.936187 \\
\hline $\mathrm{C}$ & 6.671163 & 0.722533 & 2.891976 \\
\hline $\mathrm{H}$ & 7.030683 & 0.915858 & 1.874442 \\
\hline $\mathrm{H}$ & 5.670698 & 1.150384 & 3.013539 \\
\hline $\mathrm{H}$ & 7.351215 & 1.181952 & 3.609257 \\
\hline
\end{tabular}




$\begin{array}{lrrr}\mathrm{H} & 4.906101 & -0.022827 & 1.202376 \\ \mathrm{H} & 3.980470 & -4.127616 & 0.272856 \\ \mathrm{H} & 5.493699 & -4.874346 & 2.095241 \\ \mathrm{H} & 6.091710 & -2.115659 & -1.361360 \\ \mathrm{H} & 2.866928 & -3.920547 & -3.609879 \\ \mathrm{H} & 7.695821 & -3.560280 & -2.558167 \\ \mathrm{C} & -2.231707 & 2.232870 & -2.519858 \\ \mathrm{C} & -3.353200 & 2.956369 & -2.932436 \\ \mathrm{C} & -3.637135 & 3.790278 & -1.834066 \\ \mathrm{H} & -3.891115 & 2.925862 & -3.867750 \\ \mathrm{~N} & -1.889716 & 2.632081 & -1.261355 \\ \mathrm{~N} & -2.742841 & 3.579488 & -0.841990 \\ \mathrm{C} & -4.758903 & 4.752445 & -1.749982 \\ \mathrm{O} & -5.614909 & 4.856504 & -2.617981 \\ \mathrm{O} & -4.733206 & 5.490927 & -0.618503 \\ \mathrm{C} & -5.807391 & 6.450427 & -0.487477 \\ \mathrm{H} & -5.631897 & 6.952894 & 0.463646 \\ \mathrm{H} & -5.781706 & 7.165425 & -1.312948 \\ \mathrm{H} & -6.774629 & 5.942405 & -0.483611\end{array}$

\section{$\left[\mathrm{ML}_{2}\right]^{1+}$}

$\mathrm{M}=\mathrm{Eu}$

$\begin{array}{lrll}\mathrm{C} & 1.140810 & -3.241272 & 0.843008 \\ \mathrm{C} & 1.842723 & -4.435717 & 0.975196 \\ \mathrm{C} & 2.904318 & -4.474089 & 1.894536 \\ \mathrm{C} & 3.216887 & -3.339040 & 2.634196 \\ \mathrm{C} & 2.457398 & -2.165206 & 2.446512 \\ \mathrm{~N} & 1.437965 & -2.135128 & 1.555761 \\ \mathrm{H} & 3.473960 & -5.388341 & 2.030865 \\ \mathrm{H} & 1.558279 & -5.297565 & 0.385276 \\ \mathrm{H} & 4.024761 & -3.347149 & 3.356749 \\ \mathrm{C} & 0.000000 & -3.096564 & -0.095712 \\ \mathrm{C} & -1.418563 & -3.958129 & -1.672660 \\ \mathrm{C} & -1.938498 & -5.169773 & -2.340212 \\ \mathrm{C} & -1.970081 & -2.631511 & -1.824181 \\ \mathrm{C} & -1.037653 & -6.196389 & -2.656909 \\ \mathrm{C} & -3.318961 & -5.346744 & -2.579301 \\ \mathrm{C} & -2.937724 & -2.221098 & -2.870334 \\ \mathrm{C} & -1.491649 & -7.388163 & -3.241879 \\ \mathrm{C} & -2.752326 & -2.612771 & -4.203889 \\ \mathrm{C} & -3.762416 & -6.545908 & -3.130257 \\ \mathrm{C} & -4.006707 & -1.374764 & -2.516967 \\ \mathrm{C} & -2.865353 & -7.566889 & -3.476093 \\ \mathrm{C} & -3.642355 & -2.150843 & -5.181639\end{array}$




$\begin{array}{llcl}\mathrm{C} & -4.904460 & -0.940607 & -3.500688 \\ \mathrm{H} & -3.243115 & -8.481318 & -3.917243 \\ \mathrm{C} & -4.714952 & -1.329406 & -4.841212 \\ \mathrm{H} & -5.418412 & -0.978962 & -5.589023 \\ \mathrm{~N} & -0.385236 & -4.133053 & -0.843483 \\ \mathrm{~N} & -0.617293 & -1.904119 & -0.097046 \\ \mathrm{~N} & -1.579836 & -1.664054 & -0.990102 \\ \mathrm{O} & -5.984775 & -0.140919 & -3.263129 \\ \mathrm{O} & -0.525036 & -8.305106 & -3.535207 \\ \mathrm{C} & -0.928030 & -9.547843 & -4.121699 \\ \mathrm{H} & -0.009206 & -10.116004 & -4.267868 \\ \mathrm{H} & -1.597149 & -10.103062 & -3.454115 \\ \mathrm{H} & -1.416004 & -9.389505 & -5.090481 \\ \mathrm{C} & -6.247719 & 0.259815 & -1.916553 \\ \mathrm{H} & -6.424197 & -0.608081 & -1.269996 \\ \mathrm{H} & -5.424092 & 0.860801 & -1.511978 \\ \mathrm{H} & -7.151816 & 0.867672 & -1.960254 \\ \mathrm{H} & -4.121337 & -1.078072 & -1.482466 \\ \mathrm{H} & -1.926759 & -3.257262 & -4.482624 \\ \mathrm{H} & -3.500012 & -2.439578 & -6.218484 \\ \mathrm{H} & -4.031992 & -4.574188 & -2.321626 \\ \mathrm{H} & 0.021823 & -6.080447 & -2.463224 \\ \mathrm{H} & -4.823965 & -6.697688 & -3.300101 \\ \mathrm{C} & 2.683539 & -0.924774 & 3.168261 \\ \mathrm{C} & 3.603344 & -0.511906 & 4.125783 \\ \mathrm{C} & 3.234725 & 0.826842 & 4.387627 \\ \mathrm{H} & 4.413875 & -1.054431 & 4.588354 \\ \mathrm{~N} & 1.838578 & 0.132870 & 2.892742 \\ \mathrm{~N} & 2.167128 & 1.193965 & 3.637068 \\ \mathrm{C} & 3.919518 & 1.722654 & 5.350773 \\ \mathrm{O} & 4.886704 & 1.367614 & 6.010905 \\ \mathrm{O} & 3.364894 & 2.950773 & 5.417100 \\ \mathrm{C} & 3.989843 & 3.852321 & 6.357749 \\ \mathrm{H} & 3.425546 & 4.782034 & 6.285067 \\ \mathrm{H} & 3.934699 & 3.445176 & 7.370107 \\ \mathrm{H} & 5.037946 & 4.013548 & 6.094076 \\ \mathrm{C} & -1.140810 & 3.241272 & 0.843008 \\ \mathrm{C} & -1.842723 & 4.435717 & 0.975196 \\ \mathrm{C} & -2.904318 & 4.474089 & 1.894536 \\ \mathrm{C} & -3.216887 & 3.339040 & 2.634196 \\ \mathrm{H} & -1.437965 & 2.135128 & 1.555761 \\ \mathrm{H} & -3.473960 & 5.388341 & 2.030865 \\ \mathrm{H} & 5.297565 & 0.385276 \\ \mathrm{H} & 3.347149 & 3.356749 \\ \mathrm{H} & 3.096564 & -0.095712\end{array}$




\begin{tabular}{|c|c|c|c|}
\hline 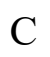 & 1.418563 & 3.958129 & -1.672660 \\
\hline $\mathrm{C}$ & 1.938498 & 5.169773 & -2.340212 \\
\hline $\mathrm{C}$ & 1.970081 & 2.631511 & -1.824181 \\
\hline $\mathrm{C}$ & 1.037653 & 6.196389 & -2.656909 \\
\hline $\mathrm{C}$ & 3.318961 & 5.346744 & -2.579301 \\
\hline$c$ & 2.937724 & 2.221098 & -2.870334 \\
\hline $\mathrm{C}$ & 1.491649 & 7.388163 & -3.241879 \\
\hline C & 2.752326 & 2.612771 & -4.203889 \\
\hline $\mathrm{C}$ & 3.762416 & 6.545908 & -3.130257 \\
\hline e & 4.006707 & 1.374764 & -2.516967 \\
\hline $\mathrm{C}$ & 2.865353 & 7.566889 & -3.476093 \\
\hline $\mathrm{C}$ & 3.642355 & 2.150843 & -5.181639 \\
\hline $\mathrm{C}$ & 4.904460 & 0.940607 & -3.500688 \\
\hline $\mathrm{H}$ & 3.243115 & 8.481318 & -3.917243 \\
\hline $\mathrm{C}$ & 4.714952 & 1.329406 & -4.841212 \\
\hline $\mathrm{H}$ & 5.418412 & 0.978962 & -5.589023 \\
\hline $\mathrm{N}$ & 0.385236 & & -0.843483 \\
\hline $\mathrm{N}$ & 0.617293 & 119 & 7046 \\
\hline $\mathrm{N}$ & 1.579836 & 1.664054 & -0.990102 \\
\hline $\mathrm{O}$ & 5.984775 & 0.14 & -3.263129 \\
\hline $\mathrm{O}$ & 0.525036 & 8.305106 & -3.535207 \\
\hline $\mathrm{C}$ & 0.928030 & 9.547843 & -4.121699 \\
\hline $\mathrm{H}$ & 0.009206 & 10.116004 & -4.267868 \\
\hline $\mathrm{H}$ & 1.597149 & 10.103062 & -3.454115 \\
\hline $\mathrm{H}$ & 1.416004 & 9.389505 & -5.090481 \\
\hline $\mathrm{C}$ & 6.247719 & -0.259815 & -1.916553 \\
\hline $\mathrm{H}$ & 6.424197 & 0.608081 & -1.269996 \\
\hline $\mathrm{H}$ & 5.424092 & -0.860801 & -1.511978 \\
\hline $\mathrm{H}$ & 7.151816 & -0.867672 & -1.960254 \\
\hline $\mathrm{H}$ & 4.121337 & 1.078072 & -1.482466 \\
\hline $\mathrm{H}$ & 1.926759 & 3.257262 & -4.482624 \\
\hline $\mathrm{H}$ & 3.500012 & 2.439578 & -6.218484 \\
\hline $\mathrm{H}$ & 4.031992 & 4.574188 & -2.321626 \\
\hline $\mathrm{H}$ & -0.021823 & 6.080447 & -2.463224 \\
\hline $\mathrm{H}$ & 4.823965 & 6.697688 & -3.300101 \\
\hline $\mathrm{C}$ & -2.683539 & 0.924774 & 3.168261 \\
\hline $\mathrm{C}$ & -3.603344 & 0.511906 & 4.125783 \\
\hline $\mathrm{C}$ & -3.234725 & -0.826842 & 4.387627 \\
\hline $\mathrm{H}$ & -4.413875 & 1.054431 & 4.588354 \\
\hline $\mathrm{N}$ & -1.838578 & -0.132870 & 2.892742 \\
\hline $\mathrm{N}$ & -2.167128 & -1.193965 & 3.637068 \\
\hline $\mathrm{C}$ & -3.919518 & -1.722654 & 5.350773 \\
\hline $\mathrm{O}$ & -4.886704 & -1.367614 & 6.010905 \\
\hline $\mathrm{O}$ & -3.364894 & -2.950773 & 5.417100 \\
\hline $\mathrm{C}$ & -3.989843 & -3.852321 & 6.357749 \\
\hline 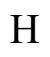 & -3.425546 & -4.782034 & 6.285067 \\
\hline
\end{tabular}




$\begin{array}{lccc}\text { H } & -3.934699 & -3.445176 & 7.370107 \\ \text { H } & -5.037946 & -4.013548 & 6.094076 \\ \text { EU } & 0.000000 & 0.000000 & 1.429090\end{array}$

$\mathrm{M}=\mathrm{Gd}$

$\begin{array}{lrrr}\mathrm{C} & -2.251277 & 0.809278 & 2.541632 \\ \mathrm{C} & -2.945849 & 0.919209 & 3.741236 \\ \mathrm{C} & -2.445889 & 1.811523 & 4.705625 \\ \mathrm{C} & -1.293777 & 2.543768 & 4.439839 \\ \mathrm{C} & -0.646470 & 2.379453 & 3.197613 \\ \mathrm{~N} & -1.136748 & 1.520192 & 2.273631 \\ \mathrm{H} & -2.960931 & 1.931499 & 5.653945 \\ \mathrm{H} & -3.843943 & 0.337108 & 3.903575 \\ \mathrm{H} & -0.893677 & 3.240541 & 5.167393 \\ \mathrm{C} & -2.679508 & -0.097304 & 1.448911 \\ \mathrm{C} & -4.123193 & -1.636733 & 0.562912 \\ \mathrm{C} & -5.442843 & -2.293083 & 0.659390 \\ \mathrm{C} & -3.216535 & -1.766101 & -0.555746 \\ \mathrm{C} & -5.928862 & -2.630941 & 1.930729 \\ \mathrm{C} & -6.251064 & -2.499532 & -0.480388 \\ \mathrm{C} & -3.324244 & -2.780608 & -1.631908 \\ \mathrm{C} & -7.200366 & -3.205057 & 2.078679 \\ \mathrm{C} & -3.588886 & -4.121989 & -1.320855 \\ \mathrm{C} & -7.523941 & -3.039523 & -0.318745 \\ \mathrm{C} & -3.087833 & -2.389229 & -2.964093 \\ \mathrm{C} & -8.006650 & -3.406602 & 0.945753 \\ \mathrm{C} & -3.613103 & -5.069908 & -2.351594 \\ \mathrm{C} & -3.140904 & -3.343171 & -3.988576 \\ \mathrm{H} & -8.996188 & -3.838622 & 1.033457 \\ \mathrm{C} & -3.400484 & -4.691840 & -3.675587 \\ \mathrm{H} & -3.432705 & -5.416200 & -4.482528 \\ \mathrm{~N} & -3.780039 & -0.839511 & 1.579749 \\ \mathrm{~N} & -1.920885 & -0.077335 & 0.339902 \\ \mathrm{~N} & -2.171297 & -0.940894 & -0.646754 \\ \mathrm{O} & -2.952489 & -3.068054 & -5.311860 \\ \mathrm{O} & -7.558293 & -3.521097 & 3.356374 \\ \mathrm{C} & -8.851774 & -4.096320 & 3.573572 \\ \mathrm{H} & -8.922820 & -4.263245 & 4.648491 \\ \mathrm{H} & -9.648067 & -3.412317 & 3.257876 \\ \mathrm{H} & -8.953304 & -5.053594 & 3.049150 \\ \mathrm{C} & -2.719902 & -1.710680 & -5.695265 \\ \mathrm{H} & -3.563233 & -1.067898 & -5.416141 \\ \mathrm{H} & -1.796118 & -1.323518 & -5.248154 \\ & -2.619014 & -1.723480 & -6.780811 \\ & & -1.349555 & -3.176025\end{array}$




\begin{tabular}{|c|c|c|c|}
\hline & 63814 & -4.429544 & -0.29639 \\
\hline & -3.805476 & -6.112826 & -2.119254 \\
\hline & -5.902501 & -2.224388 & -1.467431 \\
\hline & -5.326317 & -2.461852 & 2.814862 \\
\hline & -8.159244 & -3.183792 & -1.187254 \\
\hline & 0.561989 & 3.079150 & 2.795198 \\
\hline & 1.413632 & 3.990353 & 85 \\
\hline & 2.402737 & 4.237754 & 2.4 \\
\hline & 1.363600 & 4.428596 & 4.3 \\
\hline & 1.043037 & 2.822458 & 1.530048 \\
\hline & 2.164083 & 3.529161 & 1.306345 \\
\hline & 3.556876 & 5.152978 & 2.607235 \\
\hline & 3.763815 & 5.766467 & \\
\hline $\mathrm{O}$ & 4.341185 & 5.231315 & 19 \\
\hline & 5.469977 & 6.125022 & 1.6 \\
\hline I & 5.9 & 6.072466 & \\
\hline & 5.130105 & 7.143823 & 09 \\
\hline & 6.128637 & 5.802465 & 48 \\
\hline $\mathrm{C}$ & 2.251308 & 0.809421 & -2.5 \\
\hline & 2.945908 & 0.919425 & -3.7 \\
\hline $\mathrm{C}$ & 2.445968 & 1.811795 & -4.7 \\
\hline & 1.293847 & 2.544021 & -4. \\
\hline $\mathrm{C}$ & 0.646512 & 2.379630 & -3 \\
\hline$\Lambda$ & 1.13 & 1.520316 & -2.2 \\
\hline $\mathrm{H}$ & 2.96 & 1.9 & -5 \\
\hline $\mathrm{H}$ & 3.844007 & 0.337337 & -3.9 \\
\hline $\mathrm{H}$ & 0.893761 & 3.240835 & -5.1 \\
\hline $\mathrm{C}$ & 2.679516 & -0.097224 & 8900 \\
\hline $\mathrm{C}$ & 4.123191 & -1.636701 & -0.562968 \\
\hline $\mathrm{C}$ & 5.442833 & -2.293063 & -0.659467 \\
\hline $\mathrm{C}$ & 3.216511 & -1.766144 & 5662 \\
\hline $\mathrm{C}$ & 5.928880 & -2.630825 & 0821 \\
\hline $\mathrm{C}$ & 6.251015 & -2.499628 & 0.480317 \\
\hline $\mathrm{C}$ & 3.324217 & -2.780714 & 1.631765 \\
\hline 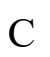 & 7.200378 & -3.204952 & -2.078782 \\
\hline $\mathrm{C}$ & 3.588914 & -4.122066 & 1.320637 \\
\hline $\mathrm{C}$ & 7.523887 & -3.039628 & 0.318664 \\
\hline $\mathrm{C}$ & 3.087761 & -2.389423 & 2.963968 \\
\hline $\mathrm{C}$ & 8.006626 & -3.406607 & -0.945851 \\
\hline $\mathrm{C}$ & 3.613134 & -5.070048 & 2.351318 \\
\hline $\mathrm{C}$ & 3.140834 & -3.343427 & 3.988394 \\
\hline $\mathrm{H}$ & 8.996159 & -3.838639 & -1.033563 \\
\hline $\mathrm{C}$ & 3.400465 & -4.692069 & 3.675329 \\
\hline $\mathrm{H}$ & 3.432687 & -5.416477 & 4.482226 \\
\hline $\mathrm{N}$ & 3.780055 & -0.839416 & -1.579761 \\
\hline $\mathrm{N}$ & 1.920866 & -0.077333 & -0.339907 \\
\hline
\end{tabular}




$\begin{array}{lrrr}\mathrm{N} & 2.171264 & -0.940953 & 0.646700 \\ \mathrm{O} & 2.952374 & -3.068397 & 5.311690 \\ \mathrm{O} & 7.558335 & -3.520891 & -3.356495 \\ \mathrm{C} & 8.851812 & -4.096121 & -3.573704 \\ \mathrm{H} & 8.922884 & -4.262958 & -4.648635 \\ \mathrm{H} & 9.648109 & -3.412160 & -3.257928 \\ \mathrm{H} & 8.953308 & -5.053440 & -3.049359 \\ \mathrm{C} & 2.719740 & -1.711054 & 5.695173 \\ \mathrm{H} & 3.563059 & -1.068231 & 5.416109 \\ \mathrm{H} & 1.795955 & -1.323891 & 5.248064 \\ \mathrm{H} & 2.618826 & -1.723923 & 6.780716 \\ \mathrm{H} & 2.875444 & -1.349495 & 3.175958 \\ \mathrm{H} & 3.763883 & -4.429551 & 0.296165 \\ \mathrm{H} & 3.805548 & -6.112945 & 2.118920 \\ \mathrm{H} & 5.902427 & -2.224563 & 1.467374 \\ \mathrm{H} & 5.326363 & -2.461651 & -2.814957 \\ \mathrm{H} & 8.159162 & -3.183985 & 1.187180 \\ \mathrm{C} & -0.561960 & 3.079301 & -2.795073 \\ \mathrm{C} & -1.413593 & 3.990541 & -3.410818 \\ \mathrm{C} & -2.402727 & 4.237864 & -2.431864 \\ \mathrm{H} & -1.363546 & 4.428844 & -4.396096 \\ \mathrm{~N} & -1.043029 & 2.822529 & -1.529949 \\ \mathrm{~N} & -2.164074 & 3.529225 & -1.306216 \\ \mathrm{C} & -3.556878 & 5.153077 & -2.607050 \\ \mathrm{O} & -3.763756 & 5.766692 & -3.645172 \\ \mathrm{O} & -4.341153 & 5.231421 & -1.511409 \\ \mathrm{C} & -5.469889 & 6.125208 & -1.632095 \\ \mathrm{H} & -5.983797 & 6.072646 & -0.672225 \\ \mathrm{H} & -5.129955 & 7.143995 & -1.832598 \\ \mathrm{H} & -6.128592 & 5.802728 & -2.442165 \\ \mathrm{GD} & -0.000010 & 1.434786 & 0.000023\end{array}$

$\mathrm{M}=\mathrm{Am}$
$\begin{array}{llll}\text { AM } & -0.000007 & 1.299928 & -0.000010\end{array}$
$\begin{array}{llll}\text { C } & -2.354198 & 0.756617 & 2.530078\end{array}$
$\begin{array}{llll}\text { C } & -3.072373 & 0.890424 & 3.713315\end{array}$
$\begin{array}{llll}\text { C } & -2.581407 & 1.782448 & 4.681352\end{array}$
$\begin{array}{llll}\text { C } & -1.414237 & 2.494886 & 4.432557\end{array}$
$\begin{array}{llll}\text { C } & -0.742298 & 2.309516 & 3.206915\end{array}$
$\begin{array}{llll}\mathrm{N} & -1.220444 & 1.446013 & 2.278776\end{array}$
$\begin{array}{llll}\mathrm{H} & -3.115412 & 1.918684 & 5.616821\end{array}$

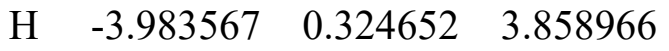
$\mathrm{H} \quad-1.019764 \quad 3.194308 \quad 5.160535$
$\begin{array}{llll}\text { C } & -2.787555 & -0.153509 & 1.443230\end{array}$
$\begin{array}{llll}\text { C } & -4.253399 & -1.673599 & 0.560370\end{array}$ 


\begin{tabular}{|c|c|c|c|}
\hline $\mathrm{C}$ & -5.584768 & -2.307458 & 0.651866 \\
\hline C & -3.339226 & -1.831713 & -0.548236 \\
\hline $\mathrm{C}$ & -6.081563 & -2.637793 & 1.920657 \\
\hline $\mathrm{C}$ & -6.390541 & -2.502029 & -0.491457 \\
\hline C & -3.457918 & -2.853438 & -1.616476 \\
\hline$C$ & -7.362561 & -3.192271 & 2.062863 \\
\hline $\mathrm{C}$ & -3.753929 & -4.186195 & -1.296941 \\
\hline$C$ & -7.672324 & -3.022403 & -0.335846 \\
\hline $\mathrm{C}$ & -3.200399 & -2.478654 & -2.949546 \\
\hline $\mathrm{C}$ & -8.166639 & -3.381719 & 0.926394 \\
\hline $\mathrm{C}$ & -3.788581 & -5.142080 & -2.319935 \\
\hline $\mathrm{C}$ & -3.264094 & -3.439882 & -3.966536 \\
\hline $\mathrm{H}$ & -9.163066 & -3.798502 & 1.009519 \\
\hline $\mathrm{C}$ & -3.555432 & -4.779978 & -3.644945 \\
\hline $\mathrm{H}$ & -3.595353 & -5.510348 & -4.446116 \\
\hline $\mathrm{N}$ & -3.905767 & -0.871149 & 1.5 \\
\hline $\mathrm{N}$ & -2.018042 & -0.161892 & 0.345100 \\
\hline $\mathrm{N}$ & -2.275779 & -1.030522 & -0.6 \\
\hline $\mathrm{O}$ & -3.057376 & -3.179979 & -5.290264 \\
\hline $\mathrm{O}$ & -7.731061 & -3.502493 & 3.339104 \\
\hline $\mathrm{C}$ & -9.033855 & -4.058436 & 3.550357 \\
\hline $\mathrm{H}$ & -9.112385 & -4.224116 & 4.624951 \\
\hline $\mathrm{H}$ & -9.818499 & -3.362802 & 3.230886 \\
\hline $\mathrm{H}$ & -9.147134 & -5.014195 & 3.025548 \\
\hline $\mathrm{C}$ & -2.793006 & -1.831084 & -5.682677 \\
\hline $\mathrm{H}$ & -3.625319 & -1.168584 & -5.416812 \\
\hline $\mathrm{H}$ & -1.865497 & -1.459361 & -5.230144 \\
\hline $\mathrm{H}$ & -2.682311 & -1.855129 & -6.767074 \\
\hline $\mathrm{H}$ & -2.964258 & -1.445141 & -3.168112 \\
\hline $\mathrm{H}$ & -3.945115 & -4.481292 & -0.271720 \\
\hline $\mathrm{H}$ & -4.005239 & -6.178682 & -2.080768 \\
\hline $\mathrm{H}$ & -6.032998 & -2.232486 & -1.476928 \\
\hline $\mathrm{H}$ & -5.480580 & -2.478331 & 2.807725 \\
\hline $\mathrm{H}$ & -8.305538 & -3.157306 & -1.207406 \\
\hline $\mathrm{C}$ & 0.479366 & 2.997936 & 2.830660 \\
\hline $\mathrm{C}$ & 1.330323 & 3.900889 & 3.460275 \\
\hline $\mathrm{C}$ & 2.338962 & 4.134666 & 2.498540 \\
\hline $\mathrm{H}$ & 1.269261 & 4.341877 & 4.443667 \\
\hline $\mathrm{N}$ & 0.978794 & 2.735819 & 1.578064 \\
\hline $\mathrm{N}$ & 2.110959 & 3.426306 & 1.370389 \\
\hline $\mathrm{C}$ & 3.500221 & 5.036172 & 2.691695 \\
\hline $\mathrm{O}$ & 3.696839 & 5.650101 & 3.731557 \\
\hline $\mathrm{O}$ & 4.304434 & 5.102149 & 1.609420 \\
\hline $\mathrm{C}$ & 5.441321 & 5.982983 & 1.746977 \\
\hline $\mathrm{H}$ & 5.970856 & 5.921599 & 0.796150 \\
\hline $\mathrm{H}$ & 5.110123 & 7.006310 & 1.938822 \\
\hline
\end{tabular}




\begin{tabular}{|c|c|c|c|}
\hline $\mathrm{H}$ & 6.082381 & 5.655315 & 2.569047 \\
\hline & 2.354191 & 0.756593 & -2.530087 \\
\hline$\tau$ & 3.072351 & 0.890371 & -3.713336 \\
\hline $\mathrm{C}$ & 2.581379 & 1.782379 & -4.681385 \\
\hline $\mathrm{C}$ & 1.414216 & 2.494829 & -4.432592 \\
\hline $\mathrm{C}$ & 0.742289 & 2.309485 & -3.206939 \\
\hline $\mathrm{N}$ & 1.220443 & 1.446001 & -2.278789 \\
\hline $\mathrm{H}$ & 3.115378 & 1.918596 & -5.616860 \\
\hline H & 3.983538 & 0.324587 & -3.858988 \\
\hline H & 1.019741 & 3.194242 & -5.160578 \\
\hline $\mathrm{C}$ & 2.787555 & -0.153511 & -1.443224 \\
\hline$C$ & 4.253408 & -1.673582 & -0.560344 \\
\hline $\mathrm{C}$ & 5.584772 & -2.307452 & -0.651845 \\
\hline$C$ & 3.339249 & -1.831668 & 0.548277 \\
\hline $\mathrm{C}$ & 6.081549 & -2.637814 & -1.920636 \\
\hline $\mathrm{C}$ & 6.390555 & -2.502010 & 0.491473 \\
\hline $\mathrm{C}$ & 3.457955 & -2.853365 & 1.616541 \\
\hline $\mathrm{C}$ & 7.362541 & -3.192305 & -2.062846 \\
\hline $\mathrm{C}$ & 3.753975 & -4.186127 & 1.297039 \\
\hline $\mathrm{C}$ & 7.672333 & -3.022397 & 0.335856 \\
\hline $\mathrm{C}$ & 3.200440 & -2.478548 & 2.949604 \\
\hline $\mathrm{C}$ & 8.166630 & -3.381739 & -0.926383 \\
\hline $\mathrm{C}$ & 3.788640 & -5.141986 & 2.320056 \\
\hline $\mathrm{C}$ & 3.264148 & -3.439751 & 3.966617 \\
\hline $\mathrm{H}$ & 9.163053 & -3.798532 & -1.009512 \\
\hline $\mathrm{C}$ & 3.555496 & -4.779853 & 3.645058 \\
\hline $\mathrm{H}$ & 3.595428 & -5.510202 & 4.446248 \\
\hline $\mathrm{N}$ & 3.905767 & -0.871154 & -1.571082 \\
\hline $\mathrm{N}$ & 2.018056 & -0.161866 & -0.345085 \\
\hline $\mathrm{N}$ & 2.275803 & -1.030473 & 0.635041 \\
\hline $\mathrm{O}$ & 3.057434 & -3.179816 & 5.290340 \\
\hline $\mathrm{O}$ & 7.731024 & -3.502553 & -3.339086 \\
\hline $\mathrm{C}$ & 9.033811 & -4.058509 & -3.550343 \\
\hline $\mathrm{H}$ & 9.112328 & -4.224209 & -4.624936 \\
\hline $\mathrm{H}$ & 9.818464 & -3.362876 & -3.230894 \\
\hline $\mathrm{H}$ & 9.147088 & -5.014260 & -3.025519 \\
\hline $\mathrm{C}$ & 2.793071 & -1.830911 & 5.682722 \\
\hline $\mathrm{H}$ & 3.625380 & -1.168419 & 5.416826 \\
\hline $\mathrm{H}$ & 1.865554 & -1.459200 & 5.230196 \\
\hline $\mathrm{H}$ & 2.682395 & -1.854929 & 6.767122 \\
\hline $\mathrm{H}$ & 2.964291 & -1.445033 & 3.168146 \\
\hline $\mathrm{H}$ & 3.945158 & -4.481248 & 0.271825 \\
\hline $\mathrm{H}$ & 4.005307 & -6.178592 & 2.080915 \\
\hline $\mathrm{H}$ & 6.033025 & -2.232448 & 1.476943 \\
\hline $\mathrm{H}$ & 5.480557 & -2.478363 & -2.807700 \\
\hline $\mathrm{H}$ & 8.305556 & -3.157290 & 1.207411 \\
\hline
\end{tabular}




$\begin{array}{llll}\mathrm{C} & -0.479371 & 2.997911 & -2.830687 \\ \mathrm{C} & -1.330340 & 3.900834 & -3.460329 \\ \mathrm{C} & -2.338985 & 4.134623 & -2.498603 \\ \mathrm{H} & -1.269277 & 4.341799 & -4.443730 \\ \mathrm{~N} & -0.978805 & 2.735813 & -1.578087 \\ \mathrm{~N} & -2.110979 & 3.426292 & -1.370436 \\ \mathrm{C} & -3.500251 & 5.036114 & -2.691783 \\ \mathrm{O} & -3.696873 & 5.650015 & -3.731661 \\ \mathrm{O} & -4.304465 & 5.102114 & -1.609510 \\ \mathrm{C} & -5.441358 & 5.982937 & -1.747091 \\ \mathrm{H} & -5.970894 & 5.921573 & -0.796263 \\ \mathrm{H} & -5.110166 & 7.006260 & -1.938962 \\ \mathrm{H} & -6.082416 & 5.655243 & -2.569153\end{array}$

$\mathrm{M}=\mathrm{Cm}$

$\begin{array}{lrrr}\mathrm{CM} & 0.000026 & 1.285853 & -0.000035 \\ \mathrm{C} & -2.392737 & 0.790989 & 2.508635 \\ \mathrm{C} & -3.129420 & 0.952074 & 3.677532 \\ \mathrm{C} & -2.642766 & 1.856238 & 4.636978 \\ \mathrm{C} & -1.462506 & 2.551281 & 4.396455 \\ \mathrm{C} & -0.773678 & 2.336672 & 3.184925 \\ \mathrm{~N} & -1.250161 & 1.464965 & 2.266651 \\ \mathrm{H} & -3.189928 & 2.014803 & 5.561370 \\ \mathrm{H} & -4.048871 & 0.398982 & 3.820173 \\ \mathrm{H} & -1.072221 & 3.257074 & 5.120629 \\ \mathrm{C} & -2.809715 & -0.134859 & 1.427064 \\ \mathrm{C} & -4.274836 & -1.656248 & 0.542452 \\ \mathrm{C} & -5.615051 & -2.272791 & 0.619271 \\ \mathrm{C} & -3.340494 & -1.846557 & -0.543658 \\ \mathrm{C} & -6.141588 & -2.570771 & 1.884152 \\ \mathrm{C} & -6.399445 & -2.482147 & -0.536304 \\ \mathrm{C} & -3.449623 & -2.887522 & -1.594380 \\ \mathrm{C} & -7.431599 & -3.107632 & 2.011209 \\ \mathrm{C} & -3.765232 & -4.210748 & -1.254652 \\ \mathrm{C} & -7.690145 & -2.984605 & -0.396509 \\ \mathrm{C} & -3.163728 & -2.541377 & -2.929366 \\ \mathrm{C} & -8.214337 & -3.311771 & 0.862426 \\ \mathrm{C} & -3.790609 & -5.186111 & -2.259422 \\ \mathrm{C} & -3.218301 & -3.521698 & -3.928527 \\ \mathrm{H} & -9.217067 & -3.715454 & 0.933531 \\ \mathrm{C} & -3.529175 & -4.852287 & -3.586550 \\ \mathrm{H} & -3.561494 & -5.597788 & -4.374012 \\ \mathrm{~N} & -3.938164 & -0.837878 & 1.544151 \\ \mathrm{~N} & -2.016192 & -0.174715 & 0.344261 \\ \mathrm{~N} & -2.265759 & -1.059793 & -0.623936\end{array}$




$\begin{array}{lrrr}\mathrm{O} & -2.984248 & -3.289782 & -5.252923 \\ \mathrm{O} & -7.829868 & -3.386781 & 3.285643 \\ \mathrm{C} & -9.142980 & -3.923865 & 3.481304 \\ \mathrm{H} & -9.245360 & -4.066216 & 4.557228 \\ \mathrm{H} & -9.912952 & -3.226479 & 3.131403 \\ \mathrm{H} & -9.256352 & -4.889076 & 2.974102 \\ \mathrm{C} & -2.698737 & -1.951571 & -5.666387 \\ \mathrm{H} & -3.528988 & -1.275740 & -5.428947 \\ \mathrm{H} & -1.775901 & -1.580355 & -5.203956 \\ \mathrm{H} & -2.568315 & -1.997906 & -6.747855 \\ \mathrm{H} & -2.912950 & -1.514761 & -3.163549 \\ \mathrm{H} & -3.978387 & -4.483838 & -0.227623 \\ \mathrm{H} & -4.022107 & -6.215684 & -2.004298 \\ \mathrm{H} & -6.018678 & -2.237265 & -1.519530 \\ \mathrm{H} & -5.557046 & -2.399361 & 2.779950 \\ \mathrm{H} & -8.306985 & -3.130520 & -1.277993 \\ \mathrm{C} & 0.466527 & 2.999723 & 2.814673 \\ \mathrm{C} & 1.313480 & 3.902614 & 3.447679 \\ \mathrm{C} & 2.347194 & 4.109922 & 2.506174 \\ \mathrm{H} & 1.234493 & 4.359694 & 4.422355 \\ \mathrm{~N} & 0.992417 & 2.709972 & 1.575684 \\ \mathrm{~N} & 2.138490 & 3.386686 & 1.385175 \\ \mathrm{C} & 3.513913 & 5.001962 & 2.712762 \\ \mathrm{O} & 3.691910 & 5.630916 & 3.746967 \\ \mathrm{O} & 4.344950 & 5.041331 & 1.649662 \\ \mathrm{C} & 3.449712 & -2.887120 & 1.594731 \\ \mathrm{C} & 5.488271 & 5.911601 & 1.801179 \\ \mathrm{H} & 6.040470 & 5.828432 & 0.865009 \\ \mathrm{H} & 5.164286 & 6.941616 & 1.967942 \\ \mathrm{H} & 6.104844 & 5.590430 & 2.644267 \\ \mathrm{C} & 2.392771 & 0.790796 & -2.508754 \\ \mathrm{C} & 3.129312 & 0.951699 & -3.677761 \\ \mathrm{C} & 2.642559 & 1.855753 & -4.637270 \\ \mathrm{C} & 1.462333 & 2.550832 & -4.396712 \\ \mathrm{C} & 0.773631 & 2.336392 & -3.185067 \\ \mathrm{~N} & 1.250241 & 1.464824 & -2.266735 \\ \mathrm{H} & 3.189625 & 2.014210 & -5.561738 \\ \mathrm{H} & 4.048731 & 0.398562 & -3.820441 \\ \mathrm{C} & 1.071984 & 3.256527 & -5.120946 \\ \mathrm{C} & 2.809807 & -0.134892 & -1.427103 \\ \mathrm{C} & 5.615038 & -2.272891 & -0.619172 \\ \mathrm{C} & -3.107987 & -2.011020\end{array}$




$\begin{array}{lrrc}\mathrm{C} & 3.765366 & -4.210406 & 1.255269 \\ \mathrm{C} & 7.690133 & -2.984604 & 0.396674 \\ \mathrm{C} & 3.163749 & -2.540730 & 2.929642 \\ \mathrm{C} & 8.214289 & -3.311971 & -0.862226 \\ \mathrm{C} & 3.790740 & -5.185572 & 2.260231 \\ \mathrm{C} & 3.218309 & -3.520855 & 3.928991 \\ \mathrm{H} & 9.217007 & -3.715688 & -0.933294 \\ \mathrm{C} & 3.529247 & -4.851499 & 3.587285 \\ \mathrm{H} & 3.561554 & -5.596846 & 4.374893 \\ \mathrm{~N} & 3.938172 & -0.838042 & -1.544190 \\ \mathrm{~N} & 2.016361 & -0.174525 & -0.344248 \\ \mathrm{~N} & 2.265912 & -1.059476 & 0.624057 \\ \mathrm{O} & 2.984173 & -3.288698 & 5.253331 \\ \mathrm{O} & 7.829772 & -3.387328 & -3.285422 \\ \mathrm{C} & 9.142892 & -3.924410 & -3.481025 \\ \mathrm{H} & 9.245272 & -4.066886 & -4.556932 \\ \mathrm{H} & 9.912852 & -3.226969 & -3.131206 \\ \mathrm{H} & 9.256281 & -4.889559 & -2.973707 \\ \mathrm{C} & 2.698543 & -1.950427 & 5.666519 \\ \mathrm{H} & 3.528771 & -1.274587 & 5.429021 \\ \mathrm{H} & 1.775722 & -1.579360 & 5.203939 \\ \mathrm{H} & 2.568034 & -1.996563 & 6.747985 \\ \mathrm{H} & 2.912923 & -1.514078 & 3.163614 \\ \mathrm{H} & 3.978558 & -4.483692 & 0.228301 \\ \mathrm{H} & 4.022275 & -6.215186 & 2.005310 \\ \mathrm{H} & 6.018705 & -2.237053 & 1.519617 \\ \mathrm{H} & 5.556981 & -2.399779 & -2.779832 \\ \mathrm{H} & 8.306990 & -3.130403 & 1.278165 \\ \mathrm{C} & -0.466545 & 2.999504 & -2.814802 \\ \mathrm{C} & -1.313509 & 3.902248 & -3.448013 \\ \mathrm{C} & -2.347211 & 4.109774 & -2.506545 \\ \mathrm{H} & -1.234578 & 4.359042 & -4.422828 \\ \mathrm{H} & -0.992368 & 2.710102 & -1.575689 \\ \mathrm{H} & -2.138440 & 3.386876 & -1.385347 \\ \mathrm{C} & -3.513957 & 5.001738 & -2.713339 \\ \mathrm{O} & -3.692020 & 5.630375 & -3.747727 \\ \mathrm{O} & -4.344925 & 5.041441 & -1.650199 \\ \mathrm{C} & -5.488252 & 5.911669 & -1.801915 \\ \mathrm{H} & -6.040387 & 5.828800 & -0.865679 \\ & -6.1048270 & 6.941629 & -1.969026 \\ & 5.590233 & -2.644858\end{array}$

$\mathrm{L}=\mathbf{2 b m i}$

$\left[\mathrm{ML}\left(\mathrm{H}_{2} \mathrm{O}\right)_{6}\right]^{2+}$ 


\begin{tabular}{|c|c|c|c|}
\hline EU & 2.362997 & -0.869280 & 0.2 \\
\hline $\mathrm{O}$ & 1.448988 & -2.195938 & 2.267836 \\
\hline $\mathrm{O}$ & 2.247096 & -0.991790 & -2.314691 \\
\hline $\mathrm{H}$ & 1.005097 & -3.056016 & 2.219640 \\
\hline $\mathrm{H}$ & 1.315072 & -1.834311 & 3.15 \\
\hline $\mathrm{O}$ & 0.869278 & -2.891881 & -0.316831 \\
\hline $\mathrm{O}$ & 2.397850 & 0.404346 & 2.570840 \\
\hline $\mathrm{H}$ & 3.102607 & -1.375792 & -2.574557 \\
\hline $\mathrm{H}$ & 2.001855 & -0.349249 & -2.9 \\
\hline $\mathrm{H}$ & -0.040080 & -2.508087 & -0.229391 \\
\hline $\mathrm{H}$ & 6 & -3.3 & -1.1 \\
\hline $\mathrm{H}$ & 3.2 & 0.1 & 2.8 \\
\hline $\mathrm{H}$ & 2.245249 & 1.3 & 2.8 \\
\hline $\mathrm{N}$ & -1.1 & -0 & $-0 .($ \\
\hline $\mathrm{C}$ & -2.3 & -0.6 & 0.0 \\
\hline $\mathrm{N}$ & -0.1 & -0 . & -0.1 \\
\hline $\mathrm{C}$ & -2.72 & 0.7 & -0.1 \\
\hline $\mathrm{C}$ & -3.3 & -1.6 & \\
\hline $\mathrm{C}$ & -0.4 & & -0.1 \\
\hline $\mathrm{C}$ & & & \\
\hline $\mathrm{N}$ & -1.7 & & -0.2 \\
\hline $\mathrm{C}$ & -3.3 & -2.8 & -0.5 \\
\hline $\mathrm{C}$ & -4.2 & -1. & 1.3 \\
\hline $\mathrm{C}$ & 0.6 & 2.2 & -0.3 \\
\hline $\mathrm{C}$ & -4.3 & & 0.2 \\
\hline $\mathrm{C}$ & -5.1 & 0.6 & -0.8 \\
\hline $\mathrm{C}$ & -4.2 & -3.8 & -0.2 \\
\hline $\mathrm{H}$ & -2.6 & -2.5 & -1.3 \\
\hline $\mathrm{C}$ & & & \\
\hline $\mathrm{H}$ & -4.31 & -0.6 & 1.9 \\
\hline $\mathrm{C}$ & 319 & 3.5 & -0.5 \\
\hline $\mathrm{N}$ & 23 & 1.6 & -0.2 \\
\hline $\mathrm{C}$ & -5.6 & 69 & 0.1 \\
\hline $\mathrm{H}$ & -3.5 & 49 & 788 \\
\hline $\mathrm{C}$ & -6.386406 & 1.1 & -1.0 \\
\hline $\mathrm{H}$ & -4.9 & -0.3 & -1.3 \\
\hline $\mathrm{C}$ & -5.176811 & -3.760456 & 0.840495 \\
\hline $\mathrm{O}$ & -4.3 & -5.0 & -0.9 \\
\hline $\mathrm{H}$ & -5.885497 & -2.5 & 2.433402 \\
\hline $\mathrm{C}$ & 1.492934 & 4.417834 & -0.678949 \\
\hline $\mathrm{H}$ & -0.622957 & 3.920639 & -0.530148 \\
\hline $\mathrm{C}$ & 2.954432 & 2.507383 & -0.464567 \\
\hline $\mathrm{C}$ & -6.654618 & 2.467330 & -0.507415 \\
\hline $\mathrm{O}$ & -5.762935 & 4.420014 & 0.673528 \\
\hline
\end{tabular}




$\begin{array}{cccc}\mathrm{H} & -7.176344 & 0.654122 & -1.532198 \\ \mathrm{H} & -5.866420 & -4.574880 & 1.035429 \\ \mathrm{C} & -3.499114 & -5.250292 & -2.061456 \\ \mathrm{C} & 2.781272 & 3.890414 & -0.663153 \\ \mathrm{H} & 1.337323 & 5.481662 & -0.829817 \\ \mathrm{C} & 4.268385 & 1.864720 & -0.432140 \\ \mathrm{H} & -7.646329 & 2.889678 & -0.615729 \\ \mathrm{C} & -7.042364 & 5.076403 & 0.597405 \\ \mathrm{H} & -3.662892 & -4.478880 & -2.822749 \\ \mathrm{H} & -2.444771 & -5.267261 & -1.759453 \\ \mathrm{H} & -3.773760 & -6.223568 & -2.466815 \\ \mathrm{H} & 3.645167 & 4.530309 & -0.801707 \\ \mathrm{C} & 5.572489 & 2.330993 & -0.588297 \\ \mathrm{~N} & 4.303269 & 0.514971 & -0.203521 \\ \mathrm{H} & -7.808619 & 4.498708 & 1.124591 \\ \mathrm{H} & -7.336560 & 5.237008 & -0.444959 \\ \mathrm{H} & -6.904700 & 6.037474 & 1.091049 \\ \mathrm{C} & 6.385375 & 1.179852 & -0.436452 \\ \mathrm{H} & 5.913896 & 3.336725 & -0.786207 \\ \mathrm{~N} & 5.592600 & 0.099030 & -0.199760 \\ \mathrm{C} & 7.874557 & 1.068733 & -0.514483 \\ \mathrm{H} & 8.355345 & 1.734790 & 0.209579 \\ \mathrm{H} & 8.235911 & 1.361257 & -1.506261 \\ \mathrm{H} & 8.197380 & 0.045154 & -0.316403 \\ \mathrm{O} & 4.445728 & -1.299532 & 1.989617 \\ \mathrm{H} & 4.754029 & -2.069818 & 2.489656 \\ \mathrm{H} & 5.208718 & -0.955455 & 1.471034 \\ \mathrm{O} & 4.293791 & -2.225374 & -0.945202 \\ \mathrm{H} & 4.632846 & -3.132252 & -0.957817 \\ \mathrm{H} & 5.066598 & -1.618534 & -0.795812\end{array}$

\section{$\mathrm{M}=\mathrm{Gd}$}

$\begin{array}{lrrr}\mathrm{O} & 4.309840 & 1.088537 & 2.007452 \\ \mathrm{H} & 5.112662 & 0.888371 & 1.483538 \\ \mathrm{O} & 4.120346 & 2.122754 & -0.786728 \\ \mathrm{H} & 4.418369 & 3.042621 & -0.819250 \\ \mathrm{O} & 1.687668 & -0.137468 & 2.526074 \\ \mathrm{H} & 1.345180 & 0.481348 & 3.190743 \\ \mathrm{O} & 2.136359 & 0.689762 & -2.281626 \\ \mathrm{H} & 2.976073 & 0.938709 & -2.701761 \\ \mathrm{O} & 2.075934 & 2.593358 & 1.964803 \\ \mathrm{H} & 2.908219 & 2.831721 & 2.406939 \\ \mathrm{O} & 0.902549 & 2.708612 & -0.502457 \\ \mathrm{H} & 1.006231 & 3.144375 & -1.362322 \\ \mathrm{H} & 1.441254 & -1.030500 & 2.810896\end{array}$




\begin{tabular}{|c|c|c|c|}
\hline H & 1.746811 & -0.004423 & -2.834073 \\
\hline $\mathrm{H}$ & 4.931482 & 1.511260 & -0.767596 \\
\hline $\mathrm{H}$ & -0.029054 & 2.341456 & -0.477275 \\
\hline $\mathrm{H}$ & 4.367558 & 0.522711 & 2.793240 \\
\hline 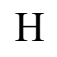 & 1.635463 & 3.411537 & 1.683988 \\
\hline & 0.618848 & -2.248059 & -0.090503 \\
\hline & 0.365505 & -3.616616 & -0.152960 \\
\hline C & 1.459763 & -4.486392 & -0.280829 \\
\hline $\mathrm{C}$ & 2.747878 & -3.962702 & -0.355669 \\
\hline $\mathrm{C}$ & 2.927543 & -2.569742 & -0.277954 \\
\hline $\mathrm{N}$ & 1.869065 & -1.733141 & -0.126203 \\
\hline $\mathrm{H}$ & 1.301141 & -5.559187 & -0.334239 \\
\hline $\mathrm{H}$ & -0.653962 & -3.978138 & -0.110192 \\
\hline $\mathrm{H}$ & 3.607439 & -4.611775 & -0.477543 \\
\hline $\mathrm{C}$ & -0.481571 & -1.251174 & -0.033956 \\
\hline $\mathrm{C}$ & -2.730061 & -0.770132 & -0.016657 \\
\hline $\mathrm{C}$ & -4.089297 & -1.252417 & 0.248376 \\
\hline $\mathrm{C}$ & -2.368834 & 0.619441 & -0.258636 \\
\hline $\mathrm{C}$ & -4.385290 & -2.598808 & -0.030808 \\
\hline $\mathrm{C}$ & -5.068361 & -0.429127 & 0.856699 \\
\hline $\mathrm{C}$ & -3.312877 & 1.687879 & -0.650245 \\
\hline $\mathrm{C}$ & -5.652209 & -3.127684 & 0.255138 \\
\hline $\mathrm{C}$ & -4.261960 & 1.434450 & -1.652128 \\
\hline & -6.310122 & -0.973802 & 1.168723 \\
\hline $\mathrm{C}$ & -3.199886 & 2.972563 & -0.076818 \\
\hline $\mathrm{C}$ & -6.620237 & -2.307276 & 0.865755 \\
\hline $\mathrm{C}$ & -5.088861 & 2.477689 & -2.088811 \\
\hline $\mathrm{C}$ & -4.059209 & 3.997270 & -0.498264 \\
\hline $\mathrm{H}$ & -7.604763 & -2.691449 & 1.104483 \\
\hline $\mathrm{C}$ & -4.999901 & 3.744270 & -1.518880 \\
\hline $\mathrm{H}$ & -5.650292 & 4.552911 & -1.835255 \\
\hline $\mathrm{N}$ & -1.745706 & -1.676162 & -0.003902 \\
\hline $\mathrm{N}$ & -0.120925 & 0.040716 & -0.010462 \\
\hline $\mathrm{N}$ & -1.085503 & 0.964795 & -0.179490 \\
\hline $\mathrm{O}$ & -4.068728 & 5.259479 & 0.005169 \\
\hline $\mathrm{O}$ & -5.837502 & -4.427363 & -0.087143 \\
\hline $\mathrm{C}$ & -7.117141 & -5.030566 & 0.170729 \\
\hline $\mathrm{H}$ & -7.033758 & -6.055407 & -0.189305 \\
\hline $\mathrm{H}$ & -7.339853 & -5.036983 & 1.243219 \\
\hline $\mathrm{H}$ & -7.912233 & -4.514361 & -0.377946 \\
\hline $\mathrm{C}$ & -3.185215 & 5.581411 & 1.081210 \\
\hline $\mathrm{H}$ & -3.381723 & 4.952050 & 1.957593 \\
\hline $\mathrm{H}$ & -2.135699 & 5.483675 & 0.775130 \\
\hline $\mathrm{H}$ & -3.391256 & 6.622029 & 1.330788 \\
\hline $\mathrm{H}$ & -2.475588 & 3.144957 & 0.709641 \\
\hline $\mathrm{H}$ & -4.351705 & 0.450250 & -2.097218 \\
\hline
\end{tabular}




$\begin{array}{lccc}\mathrm{H} & -5.814880 & 2.296014 & -2.874942 \\ \mathrm{H} & -4.859811 & 0.603971 & 1.100606 \\ \mathrm{H} & -3.646897 & -3.242991 & -0.491209 \\ \mathrm{H} & -7.060797 & -0.356184 & 1.651801 \\ \mathrm{C} & 4.222041 & -1.901412 & -0.377755 \\ \mathrm{C} & 5.543737 & -2.329112 & -0.546784 \\ \mathrm{C} & 6.302821 & -1.138636 & -0.583044 \\ \mathrm{H} & 5.919942 & -3.337867 & -0.637510 \\ \mathrm{~N} & 4.201455 & -0.545687 & -0.319029 \\ \mathrm{~N} & 5.475634 & -0.076250 & -0.436916 \\ \mathrm{C} & 7.783011 & -0.973148 & -0.761956 \\ \mathrm{H} & 8.336847 & -1.541085 & -0.008723 \\ \mathrm{H} & 8.100583 & -1.337763 & -1.743688 \\ \mathrm{H} & 8.065264 & 0.078320 & -0.680162 \\ \mathrm{GD} & 2.329863 & 0.761087 & 0.234085\end{array}$

$\mathrm{M}=\mathrm{Am}$

$\begin{array}{lrrr}\text { AM } & -2.176620 & -0.696112 & 0.144277 \\ \mathrm{O} & -4.289742 & -1.086763 & 1.920510 \\ \mathrm{H} & -5.026280 & -0.737572 & 1.371041 \\ \mathrm{O} & -4.131346 & -1.881106 & -1.033684 \\ \mathrm{H} & -4.500361 & -2.776232 & -1.048972 \\ \mathrm{O} & -1.492819 & -0.041672 & 2.573781 \\ \mathrm{H} & -1.283124 & -0.738042 & 3.216041 \\ \mathrm{O} & -2.029666 & -0.651082 & -2.421437 \\ \mathrm{H} & -2.890933 & -0.917556 & -2.786064 \\ \mathrm{O} & -2.218994 & -2.742900 & 1.692323 \\ \mathrm{H} & -3.091161 & -2.919517 & 2.084612 \\ \mathrm{O} & -0.669201 & -2.649046 & -0.588541 \\ \mathrm{H} & -0.740680 & -3.039294 & -1.473415 \\ \mathrm{H} & -1.195619 & 0.797038 & 2.958258 \\ \mathrm{H} & -1.643658 & -0.010242 & -3.037482 \\ \mathrm{H} & -4.887342 & -1.227137 & -0.886717 \\ \mathrm{H} & 0.256736 & -2.268301 & -0.518386 \\ \mathrm{H} & -4.345117 & -0.604178 & 2.759802 \\ \mathrm{H} & -1.808860 & -3.583667 & 1.436035 \\ \mathrm{C} & -0.355374 & 2.333018 & -0.094329 \\ \mathrm{C} & -0.060161 & 3.694513 & -0.129592 \\ \mathrm{C} & -1.124893 & 4.601869 & -0.226445 \\ \mathrm{C} & -2.429311 & 4.119457 & -0.288506 \\ \mathrm{C} & -2.650383 & 2.732394 & -0.237627 \\ \mathrm{~N} & -1.620144 & 1.855492 & -0.130160 \\ \mathrm{H} & -0.932635 & 5.669892 & -0.259329 \\ \mathrm{H} & 0.970780 & 4.021336 & -0.086350 \\ \mathrm{H} & -3.270618 & 4.797220 & -0.375587\end{array}$




\begin{tabular}{|c|c|c|c|}
\hline $\mathrm{C}$ & 0.722425 & 1.313070 & -0.050507 \\
\hline C & 2.963186 & 0.793981 & -0.011614 \\
\hline $\mathrm{C}$ & 4.329702 & 1.253765 & 0.259372 \\
\hline $\mathrm{C}$ & 2.580337 & -0.588710 & -0.255017 \\
\hline $\mathrm{C}$ & 4.654549 & 2.589795 & -0.035330 \\
\hline $\mathrm{C}$ & 5.286912 & 0.419694 & 0.886827 \\
\hline $\mathrm{C}$ & 3.510062 & -1.677767 & -0.624795 \\
\hline $\mathrm{C}$ & 5.929336 & 3.097505 & 0.254602 \\
\hline $\mathrm{C}$ & 4.478696 & -1.450984 & -1.614174 \\
\hline $\mathrm{C}$ & 6.536534 & 0.943949 & 1.202694 \\
\hline $\mathrm{C}$ & 3.363656 & -2.955089 & -0.042765 \\
\hline $\mathrm{C}$ & 6.875658 & 2.266781 & 0.884695 \\
\hline $\mathrm{C}$ & 5.291973 & -2.513526 & -2.029422 \\
\hline $\mathrm{C}$ & 4.209138 & -3.999699 & -0.442849 \\
\hline $\mathrm{H}$ & 7.865404 & 2.634778 & 1.127204 \\
\hline $\mathrm{C}$ & 5.170039 & -3.77 & -1.450678 \\
\hline $\mathrm{H}$ & 5.809477 & -4.596963 & -1.750465 \\
\hline $\mathrm{N}$ & 1.994455 & 1.715830 & -0.003080 \\
\hline $\mathrm{N}$ & 0.337713 & 0.030277 & -0.046136 \\
\hline $\mathrm{N}$ & 1.289760 & -0.909303 & -0.199629 \\
\hline $\mathrm{O}$ & 4.185686 & -5.257807 & 0.070684 \\
\hline $\mathrm{O}$ & 6.143100 & 4.388706 & -0.1 \\
\hline $\mathrm{C}$ & 7.431825 & 4.970154 & 0.158239 \\
\hline $\mathrm{H}$ & 7.371890 & 5.991573 & -0.215939 \\
\hline $\mathrm{H}$ & 7.645016 & 4.986476 & 1.232574 \\
\hline $\mathrm{H}$ & 8.221612 & 4.431282 & -0.376173 \\
\hline $\mathrm{C}$ & 3.280399 & -5.552453 & 1.136432 \\
\hline $\mathrm{H}$ & 3.477828 & -4.920365 & 2.010638 \\
\hline $\mathrm{H}$ & 2.237548 & -5.434705 & 0.814936 \\
\hline $\mathrm{H}$ & 3.460827 & -6.595169 & 1.396870 \\
\hline $\mathrm{H}$ & 2.623817 & -3.107077 & 0.733530 \\
\hline $\mathrm{H}$ & 4.594190 & -0.472438 & -2.065755 \\
\hline $\mathrm{H}$ & 6.033342 & -2.352339 & -2.805658 \\
\hline $\mathrm{H}$ & 5.055449 & -0.605541 & 1.143100 \\
\hline $\mathrm{H}$ & 3.933032 & 3.242390 & -0.510587 \\
\hline $\mathrm{H}$ & 7.270514 & 0.318258 & 1.700825 \\
\hline $\mathrm{C}$ & -3.972969 & 2.119655 & -0.306391 \\
\hline $\mathrm{C}$ & -5.273537 & 2.612400 & -0.444216 \\
\hline $\mathrm{C}$ & -6.092612 & 1.461732 & -0.455406 \\
\hline $\mathrm{H}$ & -5.601065 & 3.638094 & -0.532844 \\
\hline $\mathrm{N}$ & -4.016282 & 0.765952 & -0.240080 \\
\hline $\mathrm{N}$ & -5.318719 & 0.359559 & -0.324000 \\
\hline $\mathrm{C}$ & -7.582757 & 1.371470 & -0.598119 \\
\hline $\mathrm{H}$ & -8.087268 & 1.972664 & 0.163982 \\
\hline $\mathrm{H}$ & -7.904595 & 1.746440 & -1.574613 \\
\hline$H$ & -7.917445 & 0.336806 & -0.501121 \\
\hline
\end{tabular}




\begin{tabular}{|c|c|c|c|}
\hline $\mathrm{CM}$ & 2.166010 & 0.682954 & 0.1 \\
\hline $\mathrm{O}$ & 4.212106 & 1.040662 & 1.920814 \\
\hline $\mathrm{H}$ & 4.984328 & 0.759952 & 1.385770 \\
\hline $\mathrm{O}$ & 4.044061 & 1.959564 & -0.9 \\
\hline $\mathrm{H}$ & 4.393847 & 2.86 & \\
\hline $\mathrm{O}$ & 1.519692 & -0.1 & 2.5 \\
\hline $\mathrm{H}$ & 1.217172 & 0.54 & \\
\hline $\mathrm{O}$ & 1.967964 & 0.62 & -2.3 \\
\hline $\mathrm{H}$ & 2.81 & 0.9 & -2.7 \\
\hline $\mathrm{O}$ & $1.9^{\prime}$ & 2.6 & \\
\hline $\mathrm{H}$ & 2.81 & 2.8 & \\
\hline $\mathrm{O}$ & & & \\
\hline $\mathrm{H}$ & 0.77 & 3.1 & -1.4 \\
\hline $\mathrm{H}$ & 1.2 & -0.9 & \\
\hline $\mathrm{H}$ & 1.62 & -0.0 & -2.9 \\
\hline $\mathrm{H}$ & 4.8 & & -0.8 \\
\hline $\mathrm{H}$ & -0.22 & 2.2 & -0.5 \\
\hline $\mathrm{H}$ & & & \\
\hline $\mathrm{H}$ & 1.52 & & \\
\hline $\mathrm{C}$ & 0.37 & -2.3 & -0.0 \\
\hline $\mathrm{C}$ & & & -0 . \\
\hline $\mathrm{C}$ & 1.16 & -4.5 & -0.2 \\
\hline $\mathrm{C}$ & 2.46 & -4.0 & -0. \\
\hline $\mathrm{C}$ & 2.67 & -2.7 & -0.2 \\
\hline $\mathrm{N}$ & 1.6 & -1.8 & -0 \\
\hline $\mathrm{H}$ & 0.9 & -5.6 & -0.2 \\
\hline $\mathrm{H}$ & & & \\
\hline $\mathrm{H}$ & & -4.7 & -0. \\
\hline $\mathrm{C}$ & -0.70 & -1.3 & \\
\hline $\mathrm{C}$ & -2.9 & -0.7 & -0.0 \\
\hline $\mathrm{C}$ & -4.31 & -1.2 & \\
\hline $\mathrm{C}$ & -2.56 & 11 & -0.2 \\
\hline $\mathrm{C}$ & -4.63 & -2.5 & -0.0 \\
\hline $\mathrm{C}$ & -5.2 & -0.4 & 32 \\
\hline $\mathrm{C}$ & -3.49 & 278 & -0.6 \\
\hline $\mathrm{C}$ & -5.9 & & \\
\hline $\mathrm{C}$ & -4.45 & 93 & -1.6 \\
\hline $\mathrm{C}$ & & -0.9 & 1.1 \\
\hline $\mathrm{C}$ & -3.36 & 2.9 & -0.0 \\
\hline $\mathrm{C}$ & & -2.2 & \\
\hline $\mathrm{C}$ & -5.263642 & 2.484650 & -2.090461 \\
\hline $\mathrm{C}$ & & 3.98 & -0.5 \\
\hline $\mathrm{H}$ & -7.853904 & -2.639128 & 1.099526 \\
\hline
\end{tabular}




$\begin{array}{lrrr}\mathrm{C} & -5.156726 & 3.749309 & -1.519321 \\ \mathrm{H} & -5.796647 & 4.567012 & -1.833760 \\ \mathrm{~N} & -1.976834 & -1.714947 & 0.005879 \\ \mathrm{~N} & -0.327088 & -0.022922 & -0.021967 \\ \mathrm{~N} & -1.278214 & 0.914789 & -0.193096 \\ \mathrm{O} & -4.202296 & 5.250153 & 0.004868 \\ \mathrm{O} & -6.114907 & -4.400791 & -0.096095 \\ \mathrm{C} & -7.404422 & -4.983399 & 0.159472 \\ \mathrm{H} & -7.337814 & -6.008545 & -0.203181 \\ \mathrm{H} & -7.627898 & -4.988941 & 1.231818 \\ \mathrm{H} & -8.190554 & -4.452675 & -0.388303 \\ \mathrm{C} & -3.315244 & 5.557618 & 1.082147 \\ \mathrm{H} & -3.521080 & 4.929243 & 1.957132 \\ \mathrm{H} & -2.266822 & 5.445834 & 0.776819 \\ \mathrm{H} & -3.506932 & 6.600498 & 1.333658 \\ \mathrm{H} & -2.637288 & 3.113274 & 0.704643 \\ \mathrm{H} & -4.554058 & 0.447304 & -2.102188 \\ \mathrm{H} & -5.993341 & 2.313624 & -2.875604 \\ \mathrm{H} & -5.054781 & 0.610506 & 1.105294 \\ \mathrm{H} & -3.905052 & -3.251654 & -0.496191 \\ \mathrm{H} & -7.271692 & -0.314543 & 1.653136 \\ \mathrm{C} & 3.990511 & -2.071728 & -0.374483 \\ \mathrm{C} & 5.297133 & -2.544895 & -0.536014 \\ \mathrm{C} & 6.095315 & -1.381267 & -0.589623 \\ \mathrm{H} & 5.640515 & -3.566520 & -0.610776 \\ \mathrm{~N} & 4.015000 & -0.715749 & -0.335555 \\ \mathrm{~N} & 5.304637 & -0.289530 & -0.460601 \\ \mathrm{C} & 7.580152 & -1.268223 & -0.769781 \\ \mathrm{H} & 8.114275 & -1.847058 & -0.010600 \\ \mathrm{H} & 7.885031 & -1.653400 & -1.747757 \\ \mathrm{H} & 7.898218 & -0.226193 & -0.698581\end{array}$

\section{$\left[\mathrm{ML}\left(\mathrm{H}_{2} \mathrm{O}\right)_{5}\right]^{2+}$}

$\mathrm{M}=\mathrm{Eu}$

$\begin{array}{lccc}\text { EU } & 2.439221 & -0.913438 & 0.303722 \\ \mathrm{O} & 1.318173 & -1.410454 & 2.552497 \\ \mathrm{H} & 0.523471 & -1.842545 & 2.896354 \\ \mathrm{O} & 0.894973 & -2.887433 & -0.202754 \\ \mathrm{H} & 0.865800 & -3.838207 & -0.026587 \\ \mathrm{O} & 4.619590 & -2.250194 & 0.562710 \\ \mathrm{H} & 4.960191 & -3.151131 & 0.468368 \\ \mathrm{O} & 3.794591 & -0.422564 & 2.620951 \\ \mathrm{H} & 4.552612 & -1.023237 & 2.507295 \\ \mathrm{O} & 2.639720 & -1.439462 & -2.162289\end{array}$




\begin{tabular}{|c|c|c|c|}
\hline $\mathrm{H}$ & 3.326895 & -1.093494 & -2.751844 \\
\hline $\mathrm{H}$ & 5.304038 & -1.610407 & 0.180239 \\
\hline $\mathrm{H}$ & 2.144480 & -2.108648 & -2.657580 \\
\hline $\mathrm{H}$ & 1.908918 & -1.221396 & 3.301190 \\
\hline $\mathrm{H}$ & -0.026130 & -2.523970 & -0.116676 \\
\hline $\mathrm{H}$ & 4.161600 & 0.410284 & 2.955814 \\
\hline & 0.755999 & 2.148588 & -0.287800 \\
\hline $\mathrm{C}$ & 0.514023 & 3.510257 & -0.477016 \\
\hline 0 & 1.613437 & 4.361536 & -0.656493 \\
\hline $\mathrm{C}$ & 2.896257 & 3.822872 & -0.661568 \\
\hline $\mathrm{C}$ & 3.060883 & 2.437614 & -0.464860 \\
\hline$N$ & 1.997586 & 1.620945 & -0.260418 \\
\hline $\mathrm{H}$ & 1.463795 & 5.426332 & -0.806127 \\
\hline $\mathrm{H}$ & -0.504182 & 3.876895 & -0.498482 \\
\hline $\mathrm{H}$ & 3.763271 & 4.453633 & -0.820658 \\
\hline $\mathrm{C}$ & -0.372377 & 1.185453 & -0.165346 \\
\hline $\mathrm{C}$ & -2.635182 & 0.789596 & -0.113455 \\
\hline $\mathrm{C}$ & -3.997438 & 1.343881 & -0.223225 \\
\hline $\mathrm{C}$ & -2.327377 & -0.617717 & 0.026546 \\
\hline & -4.230120 & 2.634575 & 0.270184 \\
\hline $\mathrm{C}$ & -5.039689 & 0.643182 & -0.877298 \\
\hline $\mathrm{C}$ & -3.326329 & -1.687415 & 0.264539 \\
\hline $\mathrm{C}$ & -5.501000 & 3.226480 & 0.153837 \\
\hline $\mathrm{C}$ & -4.246482 & -1.555001 & 1.317781 \\
\hline $\mathrm{C}$ & -6.287330 & 1.251651 & -1.016201 \\
\hline $\mathrm{C}$ & -3.303227 & -2.852334 & -0.525806 \\
\hline $\mathrm{C}$ & -6.536789 & 2.527735 & -0.499990 \\
\hline $\mathrm{C}$ & -5.135743 & -2.605282 & 1.586302 \\
\hline $\mathrm{C}$ & -4.224134 & -3.881731 & -0.268584 \\
\hline $\mathrm{H}$ & -7.521080 & 2.966417 & -0.611174 \\
\hline $\mathrm{C}$ & -5.135018 & -3.755469 & 0.804133 \\
\hline $\mathrm{H}$ & -5.831341 & -4.566531 & 0.989211 \\
\hline $\mathrm{N}$ & -1.623781 & 1.659530 & -0.170039 \\
\hline $\mathrm{N}$ & -0.057186 & -0.115773 & -0.118357 \\
\hline $\mathrm{N}$ & -1.052809 & -1.007954 & -0.008230 \\
\hline $\mathrm{O}$ & -4.322567 & -5.029360 & -0.982851 \\
\hline $\mathrm{O}$ & -5.619626 & 4.461553 & 0.693032 \\
\hline $\mathrm{C}$ & -6.888237 & 5.137682 & 0.613275 \\
\hline $\mathrm{H}$ & -6.738427 & 6.094664 & 1.111363 \\
\hline $\mathrm{H}$ & -7.175066 & 5.307045 & -0.429811 \\
\hline $\mathrm{H}$ & -7.666133 & 4.570053 & 1.134424 \\
\hline $\mathrm{C}$ & -3.488894 & -5.210641 & -2.132683 \\
\hline $\mathrm{H}$ & -3.663848 & -4.423183 & -2.874724 \\
\hline $\mathrm{H}$ & -2.428664 & -5.235923 & -1.852350 \\
\hline $\mathrm{H}$ & -3.773604 & -6.174768 & -2.552727 \\
\hline $\mathrm{H}$ & -2.603770 & -2.927134 & -1.349684 \\
\hline
\end{tabular}




$\begin{array}{cccc}\mathrm{H} & -4.264935 & -0.659323 & 1.928309 \\ \mathrm{H} & -5.839870 & -2.518176 & 2.407724 \\ \mathrm{H} & -4.874725 & -0.339355 & -1.299102 \\ \mathrm{H} & -3.442674 & 3.192212 & 0.762430 \\ \mathrm{H} & -7.083866 & 0.727554 & -1.534926 \\ \mathrm{C} & 4.366782 & 1.787053 & -0.479419 \\ \mathrm{C} & 5.672741 & 2.246773 & -0.613978 \\ \mathrm{C} & 6.475367 & 1.082584 & -0.510288 \\ \mathrm{H} & 6.023834 & 3.257456 & -0.763551 \\ \mathrm{~N} & 4.393572 & 0.414842 & -0.317320 \\ \mathrm{~N} & 5.668339 & -0.001293 & -0.320748 \\ \mathrm{C} & 7.960649 & 0.955535 & -0.600099 \\ \mathrm{H} & 8.307156 & 1.165157 & -1.618819 \\ \mathrm{H} & 8.457180 & 1.675107 & 0.058611 \\ \mathrm{H} & 8.280656 & -0.052315 & -0.330505\end{array}$

$\mathrm{M}=\mathrm{Gd}$

$\begin{array}{rrrr}\mathrm{O} & 1.644950 & -1.981959 & 2.416226 \\ \mathrm{H} & 1.084169 & -2.771623 & 2.460231 \\ \mathrm{O} & 0.922780 & -2.790658 & -0.221365 \\ \mathrm{H} & 0.937517 & -3.715541 & -0.504167 \\ \mathrm{O} & 4.312975 & -2.255394 & 0.469510 \\ \mathrm{H} & 4.618246 & -3.146671 & 0.685458 \\ \mathrm{O} & 3.040780 & 0.357781 & 2.458249 \\ \mathrm{H} & 3.917286 & 0.771270 & 2.384773 \\ \mathrm{O} & 2.613191 & -1.112755 & -2.121952 \\ \mathrm{H} & 3.405619 & -0.750865 & -2.550023 \\ \mathrm{H} & 5.117636 & -1.656679 & 0.226888 \\ \mathrm{H} & 2.131311 & -1.628276 & -2.785187 \\ \mathrm{H} & 2.103016 & -1.900168 & 3.267230 \\ \mathrm{H} & -0.022778 & -2.470179 & -0.141216 \\ \mathrm{H} & 2.548630 & 0.868825 & 3.119232 \\ \mathrm{C} & 0.783315 & 2.142336 & -0.287261 \\ \mathrm{C} & 0.568285 & 3.499786 & -0.507987 \\ \mathrm{C} & 1.688223 & 4.319787 & -0.718931 \\ \mathrm{C} & 2.961417 & 3.757487 & -0.709350 \\ \mathrm{C} & 3.101898 & 2.377401 & -0.472932 \\ \mathrm{~N} & 2.017202 & 1.590834 & -0.257498 \\ \mathrm{H} & 1.560586 & 5.382889 & -0.898638 \\ \mathrm{H} & -0.441818 & 3.888541 & -0.529651 \\ \mathrm{H} & 3.840637 & 4.367249 & -0.883203 \\ \mathrm{C} & -0.345577 & 1.189569 & -0.126423 \\ \mathrm{C} & -2.609344 & 0.777305 & -0.068721 \\ \mathrm{C} & -3.965064 & 1.326909 & -0.174000 \\ \mathrm{C} & -2.286959 & -0.634259 & 0.080646\end{array}$




$\begin{array}{lrrr}\mathrm{C} & -4.166713 & 2.659800 & 0.230717 \\ \mathrm{C} & -5.038514 & 0.596234 & -0.741036 \\ \mathrm{C} & -3.270594 & -1.722052 & 0.306983 \\ \mathrm{C} & -5.427196 & 3.261885 & 0.114329 \\ \mathrm{C} & -4.134611 & -1.652294 & 1.407432 \\ \mathrm{C} & -6.275366 & 1.216617 & -0.887496 \\ \mathrm{C} & -3.277023 & -2.843949 & -0.546751 \\ \mathrm{C} & -6.488974 & 2.533219 & -0.456178 \\ \mathrm{C} & -5.000213 & -2.725668 & 1.661156 \\ \mathrm{C} & -4.175731 & -3.894452 & -0.301503 \\ \mathrm{H} & -7.471185 & 2.976655 & -0.568274 \\ \mathrm{C} & -5.030118 & -3.833337 & 0.818862 \\ \mathrm{H} & -5.712155 & -4.658367 & 0.995055 \\ \mathrm{~N} & -1.595871 & 1.651640 & -0.144405 \\ \mathrm{~N} & -0.017741 & -0.108160 & -0.035950 \\ \mathrm{~N} & -1.012751 & -1.011367 & 0.065467 \\ \mathrm{O} & -4.299473 & -5.005933 & -1.073151 \\ \mathrm{O} & -5.514490 & 4.537280 & 0.568769 \\ \mathrm{C} & -6.779292 & 5.215241 & 0.475532 \\ \mathrm{H} & -6.610820 & 6.205061 & 0.898319 \\ \mathrm{H} & -7.096866 & 5.312987 & -0.568205 \\ \mathrm{H} & -7.547478 & 4.695331 & 1.058034 \\ \mathrm{C} & -3.534506 & -5.102860 & -2.276868 \\ \mathrm{H} & -3.759233 & -4.273670 & -2.958092 \\ \mathrm{H} & -2.458157 & -5.131978 & -2.062989 \\ \mathrm{H} & -3.832342 & -6.042667 & -2.741115 \\ \mathrm{H} & -2.622965 & -2.864483 & -1.410584 \\ \mathrm{H} & -4.135381 & -0.786660 & 2.060474 \\ \mathrm{H} & -5.664973 & -2.689565 & 2.518518 \\ \mathrm{H} & -4.906358 & -0.419197 & -1.087595 \\ \mathrm{H} & -3.355334 & 3.236786 & 0.656419 \\ \mathrm{H} & -7.097466 & 0.672165 & -1.341339 \\ \mathrm{C} & 4.383460 & 1.678514 & -0.441391 \\ \mathrm{C} & 5.717254 & 2.053564 & -0.617592 \\ \mathrm{C} & 6.454787 & 0.855695 & -0.447756 \\ \mathrm{H} & 6.118500 & 3.032088 & -0.839442 \\ \mathrm{~N} & 4.336214 & 0.338330 & -0.183270 \\ \mathrm{C} & 5.604749 & -0.156884 & -0.185270 \\ \mathrm{H} & 7.938082 & 0.648383 & -0.529028 \\ \mathrm{H} & 8.463356 & 1.280686 & 0.192940 \\ \mathrm{H} & -190411 & -0.393466 & -0.323622 \\ \mathrm{H} & -0.853410 & 0.307856\end{array}$

$\mathrm{M}=\mathrm{Am}$ 


\begin{tabular}{|c|c|c|c|}
\hline AN & 2.236346 & -0.79328 & 0.234545 \\
\hline $\mathrm{O}$ & 1.830150 & -2.227533 & 2.317706 \\
\hline 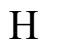 & 1.316312 & -3.048404 & 2.261703 \\
\hline ) & 0.668149 & -2.764165 & -0.180584 \\
\hline $\mathrm{H}$ & 0.645982 & -3.623428 & -0.624801 \\
\hline D & 4.316536 & -2.063069 & 0.272740 \\
\hline $\mathrm{H}$ & 4.679653 & -2.934552 & 0.479365 \\
\hline 0 & 2.747414 & 0.417928 & 2.469977 \\
\hline $\mathrm{H}$ & 3.507712 & 1.021596 & 2.446626 \\
\hline $\mathrm{O}$ & 2.487999 & -1.074138 & -2.266820 \\
\hline $\mathrm{H}$ & 3.322028 & -0.787711 & -2.673656 \\
\hline $\mathrm{H}$ & 5.077197 & -1.379029 & 0.098522 \\
\hline $\mathrm{H}$ & 1.941820 & -1.450031 & -2.973334 \\
\hline $\mathrm{H}$ & 2.362140 & -2.266207 & 3.127439 \\
\hline $\mathrm{H}$ & -0.262384 & -2.389086 & -0.117796 \\
\hline $\mathrm{H}$ & 2.226437 & 0.650752 & 3.253763 \\
\hline $\mathrm{C}$ & 0.514257 & 2.244157 & -0.301487 \\
\hline $\mathrm{C}$ & 0.255705 & 3.599394 & -0.490442 \\
\hline $\mathrm{C}$ & 1.347146 & 4.461837 & -0.672504 \\
\hline $\mathrm{C}$ & 2.637432 & 3.941205 & -0.660779 \\
\hline $\mathrm{C}$ & 2.819406 & 2.560844 & -0.458666 \\
\hline $\mathrm{N}$ & 1.763702 & 1.730054 & -0.279804 \\
\hline $\mathrm{H}$ & 1.185460 & 5.524213 & -0.826908 \\
\hline $\mathrm{H}$ & -0.766539 & 3.954938 & -0.506572 \\
\hline $\mathrm{H}$ & 3.498215 & 4.583829 & -0.805463 \\
\hline $\mathrm{C}$ & -0.589572 & 1.262820 & -0.153288 \\
\hline $\mathrm{C}$ & -2.846558 & 0.808798 & -0.076862 \\
\hline $\mathrm{C}$ & -4.213402 & 1.333196 & -0.170731 \\
\hline $\mathrm{C}$ & -2.496373 & -0.595700 & 0.066702 \\
\hline $\mathrm{C}$ & -4.438098 & 2.660254 & 0.240144 \\
\hline $\mathrm{C}$ & -5.276508 & 0.583471 & -0.731911 \\
\hline $\mathrm{C}$ & -3.456458 & -1.702286 & 0.303183 \\
\hline $\mathrm{C}$ & -5.710870 & 3.238171 & 0.134372 \\
\hline $\mathrm{C}$ & -4.307920 & -1.651042 & 1.414205 \\
\hline $\mathrm{C}$ & -6.526339 & 1.179921 & -0.867456 \\
\hline $\mathrm{C}$ & -3.454108 & -2.821541 & -0.554086 \\
\hline $\mathrm{C}$ & -6.762391 & 2.490875 & -0.430785 \\
\hline $\mathrm{C}$ & -5.151572 & -2.740005 & 1.675022 \\
\hline $\mathrm{C}$ & -4.330996 & -3.888388 & -0.301003 \\
\hline $\mathrm{H}$ & -7.753813 & 2.915418 & -0.534445 \\
\hline $\mathrm{C}$ & -5.172458 & -3.845616 & 0.829793 \\
\hline $\mathrm{H}$ & -5.837610 & -4.683060 & 1.011836 \\
\hline $\mathrm{N}$ & -1.849653 & 1.700526 & -0.156355 \\
\hline $\mathrm{N}$ & -0.235659 & -0.028242 & -0.077372 \\
\hline $\mathrm{N}$ & -1.215662 & -0.947136 & 0.035232 \\
\hline $\mathrm{O}$ & -4.444751 & -4.999809 & -1.074764 \\
\hline
\end{tabular}




$\begin{array}{lrrr}\mathrm{O} & -5.819518 & 4.510420 & 0.593351 \\ \mathrm{C} & -7.097913 & 5.163717 & 0.511686 \\ \mathrm{H} & -6.945674 & 6.155412 & 0.936240 \\ \mathrm{H} & -7.425274 & 5.258296 & -0.529331 \\ \mathrm{H} & -7.851396 & 4.627152 & 1.098309 \\ \mathrm{C} & -3.692993 & -5.079840 & -2.287636 \\ \mathrm{H} & -3.939830 & -4.252516 & -2.963529 \\ \mathrm{H} & -2.613682 & -5.091371 & -2.086791 \\ \mathrm{H} & -3.980152 & -6.023163 & -2.751503 \\ \mathrm{H} & -2.811409 & -2.827580 & -1.426725 \\ \mathrm{H} & -4.315241 & -0.787748 & 2.070328 \\ \mathrm{H} & -5.806054 & -2.718120 & 2.540739 \\ \mathrm{H} & -5.127136 & -0.428369 & -1.082106 \\ \mathrm{H} & -3.635324 & 3.251415 & 0.662738 \\ \mathrm{H} & -7.341075 & 0.620672 & -1.316588 \\ \mathrm{C} & 4.126896 & 1.914600 & -0.421620 \\ \mathrm{C} & 5.439097 & 2.359591 & -0.584889 \\ \mathrm{C} & 6.235788 & 1.197835 & -0.435459 \\ \mathrm{H} & 5.790858 & 3.360419 & -0.790165 \\ \mathrm{~N} & 4.143027 & 0.570541 & -0.187610 \\ \mathrm{~N} & 5.437673 & 0.141494 & -0.195406 \\ \mathrm{C} & 7.727244 & 1.066163 & -0.518792 \\ \mathrm{H} & 8.092557 & 1.365526 & -1.505860 \\ \mathrm{H} & 8.218952 & 1.706732 & 0.219469 \\ \mathrm{H} & 8.031873 & 0.033895 & -0.337169\end{array}$

$\mathrm{M}=\mathrm{Cm}$

$\begin{array}{lccc}\mathrm{CM} & -2.215989 & 0.762196 & 0.278693 \\ \mathrm{O} & -1.599815 & 2.004850 & 2.428759 \\ \mathrm{H} & -1.069059 & 2.816177 & 2.446923 \\ \mathrm{O} & -0.714129 & 2.766494 & -0.220458 \\ \mathrm{H} & -0.704028 & 3.688545 & -0.512853 \\ \mathrm{O} & -4.259543 & 2.108247 & 0.385742 \\ \mathrm{H} & -4.611807 & 2.991785 & 0.558072 \\ \mathrm{O} & -2.886086 & -0.455946 & 2.469471 \\ \mathrm{H} & -3.729190 & -0.932483 & 2.390293 \\ \mathrm{O} & -2.444639 & 1.059644 & -2.198230 \\ \mathrm{H} & -3.236217 & 0.707579 & -2.636557 \\ \mathrm{H} & -5.023961 & 1.464261 & 0.139590 \\ \mathrm{H} & -1.981710 & 1.621503 & -2.837594 \\ \mathrm{H} & -2.100798 & 1.965044 & 3.258317 \\ \mathrm{H} & 0.223447 & 2.423409 & -0.148995 \\ \mathrm{H} & -2.386354 & -0.889555 & 3.178527 \\ \mathrm{C} & -0.525356 & -2.227652 & -0.309753 \\ \mathrm{C} & -0.277088 & -3.580320 & -0.524498\end{array}$




\begin{tabular}{|c|c|c|c|}
\hline $\mathrm{C}$ & -1.375382 & -4.429197 & -0.733776 \\
\hline C & -2.661705 & -3.898506 & -0.730712 \\
\hline $\mathrm{C}$ & -2.837258 & -2.521187 & -0.501618 \\
\hline $\mathbf{N}$ & -1.773473 & -1.707486 & -0.283718 \\
\hline $\mathrm{H}$ & -1.220785 & -5.489647 & -0.907959 \\
\hline & 0.742202 & -3.944350 & -0.542642 \\
\hline $\mathrm{H}$ & -3.524753 & -4.530648 & -0.905256 \\
\hline $\mathrm{C}$ & 0.585441 & -1.252367 & -0.152054 \\
\hline $\mathrm{C}$ & 2.842618 & -0.804576 & -0.082911 \\
\hline $\mathrm{C}$ & 4.207673 & -1.333774 & -0.176492 \\
\hline $\mathrm{C}$ & 2.497647 & 0.602012 & 0.056658 \\
\hline $\mathrm{C}$ & 4.429601 & -2.657951 & 0.245134 \\
\hline $\mathrm{C}$ & 5.271281 & -0.591959 & -0.747127 \\
\hline $\mathrm{C}$ & 3.463434 & 1.706303 & 0.280808 \\
\hline $\mathrm{C}$ & 5.700508 & -3.240297 & 0.141270 \\
\hline $\mathrm{C}$ & 4.323349 & 1.658670 & 1.385547 \\
\hline $\mathrm{C}$ & 6.518962 & -1.193241 & -0.881004 \\
\hline $\mathrm{C}$ & 3.457022 & 2.821169 & -0.582086 \\
\hline $\mathrm{C}$ & 6.752556 & -2.500928 & -0.433255 \\
\hline $\mathrm{C}$ & 5.171602 & 2.746959 & 1.634198 \\
\hline $\mathrm{C}$ & 4.338637 & 3.887035 & -0.341524 \\
\hline $\mathrm{H}$ & 7.742494 & -2.929161 & -0.535893 \\
\hline $\mathrm{C}$ & 5.188744 & 3.848084 & 0.782965 \\
\hline $\mathrm{H}$ & 5.857510 & 4.684696 & 0.955368 \\
\hline $\mathrm{N}$ & 1.843334 & -1.694996 & -0.158512 \\
\hline $\mathrm{N}$ & 0.237812 & 0.040711 & -0.072411 \\
\hline $\mathrm{N}$ & 1.218058 & 0.959502 & 0.033416 \\
\hline $\mathrm{O}$ & 4.448691 & 4.994101 & -1.121960 \\
\hline $\mathrm{O}$ & 5.806823 & -4.508774 & 0.611185 \\
\hline $\mathrm{C}$ & 7.083259 & -5.166254 & 0.532171 \\
\hline $\mathrm{H}$ & 6.929432 & -6.153670 & 0.966021 \\
\hline $\mathrm{H}$ & 7.407706 & -5.271079 & -0.508772 \\
\hline $\mathrm{H}$ & 7.839652 & -4.626467 & 1.112060 \\
\hline $\mathrm{C}$ & 3.690520 & 5.067522 & -2.331508 \\
\hline $\mathrm{H}$ & 3.932501 & 4.235314 & -3.003111 \\
\hline $\mathrm{H}$ & 2.612313 & 5.081955 & -2.125212 \\
\hline $\mathrm{H}$ & 3.976854 & 6.007308 & -2.802960 \\
\hline $\mathrm{H}$ & 2.806385 & 2.824698 & -1.448806 \\
\hline $\mathrm{H}$ & 4.334012 & 0.798581 & 2.045892 \\
\hline $\mathrm{H}$ & 5.832841 & 2.727916 & 2.494860 \\
\hline $\mathrm{H}$ & 5.123540 & 0.417061 & -1.106123 \\
\hline $\mathrm{H}$ & 3.626141 & -3.243309 & 0.674563 \\
\hline $\mathrm{H}$ & 7.333957 & -0.640427 & -1.337588 \\
\hline $\mathrm{C}$ & -4.139566 & -1.861126 & -0.485114 \\
\hline $\mathrm{C}$ & -5.455902 & -2.286606 & -0.673864 \\
\hline$C$ & -6.238900 & -1.115466 & -0.525919 \\
\hline
\end{tabular}




$\begin{array}{lrrr}\mathrm{H} & -5.818218 & -3.281115 & -0.891185 \\ \mathrm{~N} & -4.144794 & -0.518260 & -0.239711 \\ \mathrm{~N} & -5.431268 & -0.069882 & -0.263354 \\ \mathrm{C} & -7.727569 & -0.964243 & -0.628759 \\ \mathrm{H} & -8.081476 & -1.240827 & -1.626625 \\ \mathrm{H} & -8.238973 & -1.611287 & 0.090144 \\ \mathrm{H} & -8.021560 & 0.068679 & -0.433698\end{array}$

\section{$\left[\mathrm{ML}_{2}\left(\mathrm{H}_{2} \mathrm{O}\right)_{2}\right]^{1+}$}

$\mathrm{M}=\mathrm{Eu}$

$\begin{array}{lrrr}\text { EU } & 0.000004 & 2.345295 & 0.000021 \\ \mathrm{O} & 1.412805 & 3.932908 & -1.241980 \\ \mathrm{H} & 2.086600 & 4.299127 & -0.577590 \\ \mathrm{O} & -1.412793 & 3.932889 & 1.242052 \\ \mathrm{H} & -2.086623 & 4.299087 & 0.577686 \\ \mathrm{H} & 1.191357 & 4.611324 & -1.892371 \\ \mathrm{H} & -1.191344 & 4.611307 & 1.892441 \\ \mathrm{C} & 0.597768 & 0.439388 & -2.919432 \\ \mathrm{C} & 0.536373 & -0.035543 & -4.229577 \\ \mathrm{C} & -0.438940 & 0.504439 & -5.078269 \\ \mathrm{C} & -1.300243 & 1.482879 & -4.592025 \\ \mathrm{C} & -1.171826 & 1.912474 & -3.257015 \\ \mathrm{~N} & -0.226764 & 1.389969 & -2.443152 \\ \mathrm{H} & -0.520443 & 0.162989 & -6.105763 \\ \mathrm{H} & 1.235705 & -0.792039 & -4.560595 \\ \mathrm{H} & -2.062702 & 1.918769 & -5.227259 \\ \mathrm{C} & 1.599823 & -0.088362 & -1.958856 \\ \mathrm{C} & 3.363337 & -1.478632 & -1.503370 \\ \mathrm{C} & 4.423765 & -2.358249 & -2.045416 \\ \mathrm{C} & 3.248488 & -1.074706 & -0.127095 \\ \mathrm{C} & 4.111107 & -3.194243 & -3.125612 \\ \mathrm{C} & 5.746529 & -2.308994 & -1.555689 \\ \mathrm{C} & 3.998491 & -1.674536 & 1.004950 \\ \mathrm{C} & 5.095749 & -4.008197 & -3.706250 \\ \mathrm{C} & 4.096509 & -3.066666 & 1.138126 \\ \mathrm{C} & 6.722624 & -3.098748 & -2.157874 \\ \mathrm{C} & 4.558697 & -0.823466 & 1.976279 \\ \mathrm{C} & 6.413244 & -3.957685 & -3.222407 \\ \mathrm{C} & 4.755845 & -3.602310 & 2.251644 \\ \mathrm{C} & 5.240746 & -1.372160 & 3.069929 \\ \mathrm{H} & 7.193891 & -4.569018 & -3.658681 \\ \mathrm{C} & 5.332389 & -2.770156 & 3.209395 \\ \mathrm{H} & 5.860255 & -3.174985 & 4.066368 \\ \mathrm{~N} & 2.474900 & -1.007330 & -2.380280\end{array}$




$\begin{array}{lrrr}\mathrm{N} & 1.587366 & 0.425114 & -0.718200 \\ \mathrm{~N} & 2.393952 & -0.102868 & 0.204014 \\ \mathrm{O} & 5.841717 & -0.636701 & 4.052626 \\ \mathrm{O} & 4.672421 & -4.801913 & -4.733775 \\ \mathrm{C} & 5.635333 & -5.643554 & -5.376192 \\ \mathrm{H} & 5.088329 & -6.177597 & -6.153550 \\ \mathrm{H} & 6.436146 & -5.052263 & -5.835583 \\ \mathrm{H} & 6.064530 & -6.365919 & -4.671905 \\ \mathrm{C} & 5.873159 & 0.784639 & 3.904190 \\ \mathrm{H} & 6.402043 & 1.075218 & 2.988528 \\ \mathrm{H} & 4.863650 & 1.211051 & 3.890265 \\ \mathrm{H} & 6.417119 & 1.160346 & 4.771626 \\ \mathrm{H} & 4.452015 & 0.247441 & 1.858452 \\ \mathrm{H} & 3.663165 & -3.725584 & 0.394418 \\ \mathrm{H} & 4.827291 & -4.679374 & 2.368739 \\ \mathrm{H} & 6.010758 & -1.655383 & -0.734162 \\ \mathrm{H} & 3.103692 & -3.229235 & -3.522546 \\ \mathrm{H} & 7.745930 & -3.054169 & -1.797593 \\ \mathrm{C} & -2.026057 & 2.931914 & -2.658821 \\ \mathrm{C} & -3.084294 & 3.709786 & -3.147509 \\ \mathrm{C} & -3.472566 & 4.504654 & -2.046311 \\ \mathrm{H} & -3.504255 & 3.729174 & -4.143222 \\ \mathrm{~N} & -1.805317 & 3.254996 & -1.356960 \\ \mathrm{~N} & -2.691260 & 4.210283 & -0.985853 \\ \mathrm{C} & -0.597771 & 0.439344 & 2.919443 \\ \mathrm{C} & -0.536379 & -0.035607 & 4.229581 \\ \mathrm{C} & 0.438935 & 0.504358 & 5.078282 \\ \mathrm{C} & 1.300243 & 1.482802 & 4.592055 \\ \mathrm{C} & 1.171828 & 1.912419 & 3.257051 \\ \mathrm{~N} & 0.226765 & 1.389930 & 2.443179 \\ \mathrm{H} & 0.520436 & 0.162891 & 6.105771 \\ \mathrm{H} & -1.235713 & -0.792106 & 4.560586 \\ \mathrm{H} & 2.062703 & 1.918678 & 5.227296 \\ \mathrm{C} & -1.599825 & -0.088388 & 1.958857 \\ \mathrm{C} & -3.363339 & -1.478649 & 1.503346 \\ \mathrm{C} & -4.423767 & -2.358279 & 2.045371 \\ \mathrm{C} & -3.248490 & -1.074699 & 0.127079 \\ \mathrm{C} & -4.111115 & -3.194285 & 3.125560 \\ \mathrm{C} & -5.746525 & -2.309029 & 1.555626 \\ \mathrm{C} & -4.095759 & -1.674503 & -1.004973 \\ \mathrm{C} & -4.008254 & 3.706175 \\ \mathrm{C} & -3.066630 & -1.138164 \\ \mathrm{C} & -3.098799 & 2.157789 \\ \mathrm{C} & -3.957745 & 3.222316 \\ \mathrm{C} & -3.602251 & -2.251686\end{array}$




$\begin{array}{lrrr}\mathrm{C} & -5.240759 & -1.372084 & -3.069945 \\ \mathrm{H} & -7.193895 & -4.569090 & 3.658573 \\ \mathrm{C} & -5.332424 & -2.770077 & -3.209427 \\ \mathrm{H} & -5.860300 & -3.174888 & -4.066403 \\ \mathrm{~N} & -2.474904 & -1.007362 & 2.380266 \\ \mathrm{~N} & -1.587365 & 0.425107 & 0.718209 \\ \mathrm{~N} & -2.393952 & -0.102857 & -0.204014 \\ \mathrm{O} & -5.841721 & -0.636605 & -4.052632 \\ \mathrm{O} & -4.672438 & -4.801979 & 4.733696 \\ \mathrm{C} & -5.635351 & -5.643636 & 5.376090 \\ \mathrm{H} & -5.088353 & -6.177684 & 6.153448 \\ \mathrm{H} & -6.436175 & -5.052356 & 5.835478 \\ \mathrm{H} & -6.064534 & -6.365995 & 4.671789 \\ \mathrm{C} & -5.873142 & 0.784735 & -3.904178 \\ \mathrm{H} & -6.402019 & 1.075310 & -2.988512 \\ \mathrm{H} & -4.863626 & 1.211131 & -3.890251 \\ \mathrm{H} & -6.417098 & 1.160460 & -4.771609 \\ \mathrm{H} & -4.452001 & 0.247491 & -1.858451 \\ \mathrm{H} & -3.663210 & -3.725563 & -0.394463 \\ \mathrm{H} & -4.827356 & -4.679312 & -2.368793 \\ \mathrm{H} & -6.010747 & -1.655412 & 0.734102 \\ \mathrm{H} & -3.103705 & -3.229274 & 3.522505 \\ \mathrm{H} & -7.745923 & -3.054225 & 1.797495 \\ \mathrm{C} & 2.026068 & 2.931861 & 2.658872 \\ \mathrm{C} & 3.084315 & 3.709713 & 3.147569 \\ \mathrm{C} & 3.472595 & 4.504592 & 2.046382 \\ \mathrm{H} & 3.504278 & 3.729082 & 4.143281 \\ \mathrm{~N} & 1.805332 & 3.254962 & 1.357015 \\ \mathrm{~N} & 2.691287 & 4.210242 & 0.985919 \\ \mathrm{C} & 4.548398 & 5.548638 & 1.966058 \\ \mathrm{H} & 4.323587 & 6.402044 & 2.614710 \\ \mathrm{H} & 5.518223 & 5.147492 & 2.277947 \\ \mathrm{H} & 4.641624 & 5.914372 & 0.941228 \\ \mathrm{C} & -4.548357 & 5.548711 & -1.965974 \\ \mathrm{H} & -4.323551 & 6.402111 & -2.614636 \\ \mathrm{H} & -5.518192 & 5.147573 & -2.277841 \\ \mathrm{H} & -4.641560 & 5.914453 & -0.941144\end{array}$

$\mathrm{M}=\mathrm{Gd}$

$\begin{array}{lccc}\text { GD } & -0.000002 & 2.325294 & -0.000042 \\ \mathrm{O} & 1.337137 & 3.889213 & -1.306490 \\ \mathrm{H} & 2.016417 & 4.294670 & -0.669043 \\ \mathrm{O} & -1.337137 & 3.889263 & 1.306351 \\ \mathrm{H} & -2.016496 & 4.294624 & 0.668927 \\ \mathrm{H} & 1.072924 & 4.542564 & -1.966610\end{array}$




\begin{tabular}{|c|c|c|c|}
\hline $\mathrm{H}$ & -1.072933 & 4.542661 & 1.966428 \\
\hline $\mathrm{C}$ & 0.463739 & 0.387069 & -2.883079 \\
\hline C & 0.335635 & -0.112183 & -4.178569 \\
\hline $\mathrm{C}$ & -0.670506 & 0.425834 & -4.992676 \\
\hline$C$ & -1.492692 & 1.428442 & -4.489369 \\
\hline $\mathrm{C}$ & -1.298962 & 1.882142 & -3.170154 \\
\hline$N$ & -0.327643 & 1.356873 & -2.387918 \\
\hline $\mathrm{H}$ & -0.804049 & 0.065048 & -6.008051 \\
\hline $\mathrm{H}$ & 1.009168 & -0.884340 & -4.526383 \\
\hline $\mathrm{H}$ & -2.275246 & 1.865222 & -5.098952 \\
\hline $\mathrm{C}$ & 1.509846 & -0.125367 & -1.962144 \\
\hline $\mathrm{C}$ & 3.293567 & -1.508423 & -1.568005 \\
\hline $\mathrm{C}$ & 4.312230 & -2.416233 & -2.142350 \\
\hline $\mathrm{C}$ & 3.265819 & -1.055675 & -0.202171 \\
\hline $\mathrm{C}$ & 3.926011 & -3.288384 & -3.168970 \\
\hline $\mathrm{C}$ & 5.663690 & -2.361437 & -1.739097 \\
\hline $\mathrm{C}$ & 4.092407 & -1.609908 & 0.899806 \\
\hline $\mathrm{C}$ & 4.865985 & -4.132647 & -3.779468 \\
\hline $\mathrm{C}$ & 4.199611 & -2.995074 & 1.086547 \\
\hline $\mathrm{C}$ & 6.594083 & -3.181817 & -2.371948 \\
\hline $\mathrm{C}$ & 4.718421 & -0.718637 & 1.791487 \\
\hline $\mathrm{C}$ & 6.211837 & -4.076593 & -3.381855 \\
\hline $\mathrm{C}$ & 4.934204 & -3.483060 & 2.174652 \\
\hline $\mathrm{C}$ & 5.474531 & -1.220485 & 2.858749 \\
\hline $\mathrm{H}$ & 6.958992 & -4.710906 & -3.843248 \\
\hline $\mathrm{C}$ & 5.575387 & -2.611330 & 3.052913 \\
\hline $\mathrm{H}$ & 6.161234 & -2.979846 & 3.888330 \\
\hline $\mathrm{N}$ & 2.355820 & -1.061204 & -2.405486 \\
\hline $\mathrm{N}$ & 1.566636 & 0.422227 & -0.737395 \\
\hline $\mathrm{N}$ & 2.429333 & -0.076753 & 0.151069 \\
\hline $\mathrm{O}$ & 6.141302 & -0.444025 & 3.764122 \\
\hline $\mathrm{O}$ & 4.372769 & -4.959960 & -4.747528 \\
\hline $\mathrm{C}$ & 5.286830 & -5.834870 & -5.416475 \\
\hline $\mathrm{H}$ & 4.687721 & -6.392573 & -6.136699 \\
\hline $\mathrm{H}$ & 6.061337 & -5.269423 & -5.947838 \\
\hline $\mathrm{H}$ & 5.754313 & -6.534176 & -4.713301 \\
\hline $\mathrm{C}$ & 6.170052 & 0.968789 & 3.546037 \\
\hline $\mathrm{H}$ & 6.638433 & 1.210399 & 2.584357 \\
\hline $\mathrm{H}$ & 5.164443 & 1.403157 & 3.579107 \\
\hline $\mathrm{H}$ & 6.772954 & 1.380411 & 4.356288 \\
\hline $\mathrm{H}$ & 4.603354 & 0.346429 & 1.634787 \\
\hline $\mathrm{H}$ & 3.716315 & -3.684710 & 0.403962 \\
\hline $\mathrm{H}$ & 5.013872 & -4.554140 & 2.333825 \\
\hline $\mathrm{H}$ & 5.984206 & -1.680648 & -0.960903 \\
\hline $\mathrm{H}$ & 2.895314 & -3.328295 & -3.500254 \\
\hline $\mathrm{H}$ & 7.638467 & -3.133434 & -2.078945 \\
\hline
\end{tabular}




\begin{tabular}{|c|c|c|c|}
\hline $\mathrm{C}$ & -2.103224 & 2.931586 & -2.556663 \\
\hline & -3.161515 & 3.731916 & -3.012334 \\
\hline $\mathrm{C}$ & -3.479914 & 4.552014 & -1.909581 \\
\hline $\mathrm{H}$ & -3.623628 & 3.746901 & -3.989282 \\
\hline $\mathrm{N}$ & -1.820825 & 3.265314 & -1.271428 \\
\hline $\mathrm{N}$ & -2.661417 & 4.251987 & -0.878216 \\
\hline $\mathrm{C}$ & -0.463764 & 0.387189 & 2.883072 \\
\hline $\mathrm{C}$ & -0.335665 & -0.112014 & 4.178582 \\
\hline $\mathrm{C}$ & 0.670481 & 0.426026 & 4.992669 \\
\hline $\mathrm{C}$ & 1.492677 & 1.428606 & 4.489323 \\
\hline $\mathrm{C}$ & 1.298952 & 1.882256 & 3.170090 \\
\hline $\mathrm{N}$ & 0.327628 & 1.356965 & 2.387874 \\
\hline $\mathrm{H}$ & 0.804021 & 0.065277 & 6.008057 \\
\hline $\mathrm{H}$ & -1.009204 & -0.884152 & 4.526426 \\
\hline $\mathrm{H}$ & 2.275236 & 1.865400 & 5.098888 \\
\hline $\mathrm{C}$ & -1.509870 & -0.125280 & 1.962155 \\
\hline $\mathrm{C}$ & -3.293592 & -1.508349 & 1.568064 \\
\hline $\mathrm{C}$ & -4.312268 & -2.416115 & 2.142457 \\
\hline $\mathrm{C}$ & -3.265830 & -1.055665 & 0.202208 \\
\hline $\mathrm{C}$ & -3.926049 & -3.288241 & 3.169099 \\
\hline $\mathrm{C}$ & -5.663739 & -2.361291 & 1.739242 \\
\hline $\mathrm{C}$ & -4.092379 & -1.609967 & -0.899764 \\
\hline $\mathrm{C}$ & -4.866030 & -4.132457 & 3.779650 \\
\hline $\mathrm{C}$ & -4.199519 & -2.995143 & -1.086470 \\
\hline $\mathrm{C}$ & -6.594139 & -3.181623 & 2.372146 \\
\hline $\mathrm{C}$ & -4.718413 & -0.718748 & -1.791484 \\
\hline $\mathrm{C}$ & -6.211891 & -4.076378 & 3.382070 \\
\hline $\mathrm{C}$ & -4.934071 & -3.483191 & -2.174575 \\
\hline $\mathrm{C}$ & -5.474485 & -1.220659 & -2.858744 \\
\hline $\mathrm{H}$ & -6.959053 & -4.710654 & 3.843504 \\
\hline $\mathrm{C}$ & -5.575279 & -2.611513 & -3.052870 \\
\hline $\mathrm{H}$ & -6.161096 & -2.980078 & -3.888286 \\
\hline $\mathrm{N}$ & -2.355849 & -1.061096 & 2.405531 \\
\hline $\mathrm{N}$ & -1.566651 & 0.422261 & 0.737382 \\
\hline $\mathrm{N}$ & -2.429339 & -0.076759 & -0.151067 \\
\hline $\mathrm{O}$ & -6.141277 & -0.444254 & -3.764149 \\
\hline $\mathrm{O}$ & -4.372813 & -4.959751 & 4.747725 \\
\hline $\mathrm{C}$ & -5.286881 & -5.834614 & 5.416725 \\
\hline $\mathrm{H}$ & -4.687769 & -6.392309 & 6.136952 \\
\hline $\mathrm{H}$ & -6.061358 & -5.269127 & 5.948089 \\
\hline $\mathrm{H}$ & -5.754401 & -6.533930 & 4.713586 \\
\hline $\mathrm{C}$ & -6.170094 & 0.968564 & -3.546103 \\
\hline $\mathrm{H}$ & -6.638504 & 1.210180 & -2.584439 \\
\hline $\mathrm{H}$ & -5.164504 & 1.402978 & -3.579166 \\
\hline $\mathrm{H}$ & -6.772999 & 1.380138 & -4.356376 \\
\hline $\mathrm{H}$ & -4.603393 & 0.346327 & -1.634813 \\
\hline
\end{tabular}




$\begin{array}{llll}\mathrm{H} & -3.716202 & -3.684739 & -0.403861 \\ \mathrm{H} & -5.013689 & -4.554279 & -2.333719 \\ \mathrm{H} & -5.984259 & -1.680513 & 0.961040 \\ \mathrm{H} & -2.895345 & -3.328169 & 3.500359 \\ \mathrm{H} & -7.638530 & -3.133216 & 2.079171 \\ \mathrm{C} & 2.103230 & 2.931661 & 2.556555 \\ \mathrm{C} & 3.161553 & 3.731975 & 3.012183 \\ \mathrm{C} & 3.479987 & 4.551996 & 1.909384 \\ \mathrm{H} & 3.623678 & 3.746984 & 3.989125 \\ \mathrm{~N} & 1.820835 & 3.265341 & 1.271307 \\ \mathrm{~N} & 2.661482 & 4.251942 & 0.878032 \\ \mathrm{C} & 4.527720 & 5.622138 & 1.795762 \\ \mathrm{H} & 4.337537 & 6.441111 & 2.497360 \\ \mathrm{H} & 5.526472 & 5.229635 & 2.013202 \\ \mathrm{H} & 4.534991 & 6.034262 & 0.784368 \\ \mathrm{C} & -4.527659 & 5.622146 & -1.795992 \\ \mathrm{H} & -4.338237 & 6.440466 & -2.498552 \\ \mathrm{H} & -5.526579 & 5.229323 & -2.012102 \\ \mathrm{H} & -4.534029 & 6.035219 & -0.784979\end{array}$

$\mathrm{M}=\mathrm{Am}$

$\begin{array}{lrrr}\mathrm{AM} & -0.000075 & -2.225364 & -0.000068 \\ \mathrm{O} & 1.435862 & -3.835635 & 1.268876 \\ \mathrm{H} & 2.036040 & -4.267280 & 0.572776 \\ \mathrm{O} & -1.436142 & -3.835475 & -1.269163 \\ \mathrm{H} & -2.036329 & -4.267142 & -0.573084 \\ \mathrm{H} & 1.115193 & -4.512070 & 1.880064 \\ \mathrm{H} & -1.115548 & -4.511877 & -1.880428 \\ \mathrm{C} & 0.479620 & -0.293594 & 2.965249 \\ \mathrm{C} & 0.364429 & 0.188454 & 4.268325 \\ \mathrm{C} & -0.609444 & -0.386163 & 5.096422 \\ \mathrm{C} & -1.409271 & -1.410184 & 4.600575 \\ \mathrm{C} & -1.229263 & -1.844868 & 3.272785 \\ \mathrm{~N} & -0.296750 & -1.278230 & 2.474417 \\ \mathrm{H} & -0.732725 & -0.039669 & 6.118003 \\ \mathrm{H} & 1.023521 & 0.974706 & 4.612397 \\ \mathrm{H} & -2.161537 & -1.879671 & 5.223785 \\ \mathrm{C} & 1.501008 & 0.248631 & 2.034354 \\ \mathrm{C} & 3.244972 & 1.674937 & 1.614852 \\ \mathrm{C} & 4.244270 & 2.613034 & 2.174236 \\ \mathrm{C} & 3.220012 & 1.212203 & 0.251833 \\ \mathrm{C} & 3.840806 & 3.493929 & 3.186308 \\ \mathrm{C} & 5.596014 & 2.579628 & 1.770030 \\ \mathrm{C} & 4.023397 & 1.775745 & -0.862218 \\ \mathrm{C} & 4.763674 & 4.367770 & 3.781430\end{array}$




$\begin{array}{lrrr}\mathrm{C} & 4.116923 & 3.161692 & -1.051393 \\ \mathrm{C} & 6.509861 & 3.429451 & 2.387853 \\ \mathrm{C} & 4.638212 & 0.889316 & -1.766788 \\ \mathrm{C} & 6.110017 & 4.332976 & 3.383102 \\ \mathrm{C} & 4.827422 & 3.654439 & -2.153257 \\ \mathrm{C} & 5.368365 & 1.395733 & -2.849448 \\ \mathrm{H} & 6.844298 & 4.990186 & 3.832936 \\ \mathrm{C} & 5.456841 & 2.787357 & -3.044561 \\ \mathrm{H} & 6.023178 & 3.160147 & -3.891469 \\ \mathrm{~N} & 2.325861 & 1.209928 & 2.463833 \\ \mathrm{~N} & 1.564085 & -0.303725 & 0.813224 \\ \mathrm{~N} & 2.404492 & 0.210576 & -0.086713 \\ \mathrm{O} & 6.020093 & 0.623308 & -3.768891 \\ \mathrm{O} & 4.254176 & 5.200805 & 4.735970 \\ \mathrm{C} & 5.150355 & 6.105592 & 5.389244 \\ \mathrm{H} & 4.540266 & 6.662684 & 6.100656 \\ \mathrm{H} & 5.936802 & 5.565333 & 5.929192 \\ \mathrm{H} & 5.602671 & 6.802576 & 4.673941 \\ \mathrm{C} & 6.045216 & -0.791424 & -3.562403 \\ \mathrm{H} & 6.527595 & -1.043446 & -2.610373 \\ \mathrm{H} & 5.036785 & -1.220455 & -3.584225 \\ \mathrm{H} & 6.633425 & -1.199279 & -4.385227 \\ \mathrm{C} & -3.244852 & 1.675270 & -1.614725 \\ \mathrm{H} & 4.533921 & -0.176409 & -1.607962 \\ \mathrm{H} & 3.641299 & 3.848329 & -0.360588 \\ \mathrm{H} & 4.896531 & 4.726054 & -2.313805 \\ \mathrm{H} & 5.929747 & 1.892276 & 1.003122 \\ \mathrm{H} & 2.809809 & 3.517887 & 3.518445 \\ \mathrm{H} & 7.554800 & 3.397620 & 2.094518 \\ \mathrm{C} & -2.010286 & -2.918940 & 2.671778 \\ \mathrm{C} & -3.051042 & -3.729365 & 3.146688 \\ \mathrm{C} & -3.369617 & -4.565510 & 2.056558 \\ \mathrm{H} & -3.507347 & -3.736057 & 4.126392 \\ \mathrm{~N} & -1.735001 & -3.262279 & 1.387116 \\ \mathrm{~N} & -2.568054 & -4.265237 & 1.013670 \\ \mathrm{C} & -0.479570 & -0.293262 & -2.965265 \\ \mathrm{C} & -0.364346 & 0.188868 & -4.268307 \\ \mathrm{C} & 0.609495 & -0.385756 & -5.096438 \\ \mathrm{H} & 1.209250 & -1.409867 & -4.600659 \\ \mathrm{H} & 0.296728 & -1.277983 & -3.272901 \\ \mathrm{H} & -2.474500 \\ \mathrm{H} & -0.039200 & -6.117995 \\ \mathrm{H} & 0.975184 & -4.612327 \\ \mathrm{H} & -1.879363 & -2.174076\end{array}$




\begin{tabular}{|c|c|c|c|}
\hline $\mathrm{C}$ & -3.219931 & 1.212400 & -0.251749 \\
\hline & -3.840596 & 3.494456 & -3.185985 \\
\hline $\mathrm{C}$ & -5.595927 & 2.579876 & -1.770042 \\
\hline $\mathrm{C}$ & -4.023286 & 1.775863 & 0.862367 \\
\hline C & -4.763435 & 4.368339 & -3.781092 \\
\hline C & -4.116655 & 3.161789 & 1.051775 \\
\hline C & -6.509741 & 3.429742 & -2.387854 \\
\hline $\mathrm{C}$ & -4.638204 & 0.889355 & 1.766790 \\
\hline $\mathrm{C}$ & -6.109822 & 4.333429 & -3.382925 \\
\hline $\mathrm{C}$ & -4.827116 & 3.654434 & 2.153708 \\
\hline $\mathrm{C}$ & -5.368318 & 1.395675 & 2.849523 \\
\hline $\mathrm{H}$ & -6.844082 & 4.990667 & -3.832754 \\
\hline $\mathrm{C}$ & -5.456646 & 2.787276 & 3.044860 \\
\hline $\mathrm{H}$ & -6.022954 & 3.159990 & 3.891822 \\
\hline $\mathrm{N}$ & -2.325743 & 1.210308 & -2.463735 \\
\hline $\mathrm{N}$ & -1.564039 & -0.303525 & -0.813255 \\
\hline $\mathrm{N}$ & -2.404448 & 0.210713 & 0.086715 \\
\hline $\mathrm{O}$ & -6.020136 & 0.623171 & 3.768836 \\
\hline $\mathrm{O}$ & -4.253864 & 5.201528 & -4.735459 \\
\hline $\mathrm{C}$ & -5.150004 & 6.106375 & -5.388702 \\
\hline $\mathrm{H}$ & -4.539857 & 6.663598 & -6.099961 \\
\hline $\mathrm{H}$ & -5.936368 & 5.566166 & -5.928820 \\
\hline $\mathrm{H}$ & -5.602431 & 6.803236 & -4.673348 \\
\hline $\mathrm{C}$ & -6.045393 & -0.791527 & 3.562130 \\
\hline $\mathrm{H}$ & -6.527772 & -1.043354 & 2.610049 \\
\hline $\mathrm{H}$ & -5.037003 & -1.220656 & 3.583911 \\
\hline $\mathrm{H}$ & -6.633659 & -1.199452 & 4.384877 \\
\hline $\mathrm{H}$ & -4.534022 & -0.176355 & 1.607795 \\
\hline $\mathrm{H}$ & -3.640937 & 3.848488 & 0.361097 \\
\hline $\mathrm{H}$ & -4.896103 & 4.726030 & 2.314435 \\
\hline $\mathrm{H}$ & -5.929722 & 1.892392 & -1.003281 \\
\hline $\mathrm{H}$ & -2.809563 & 3.518505 & -3.518002 \\
\hline $\mathrm{H}$ & -7.554714 & 3.397815 & -2.094651 \\
\hline $\mathrm{C}$ & 2.010136 & -2.918817 & -2.671973 \\
\hline $\mathrm{C}$ & 3.050835 & -3.729283 & -3.146941 \\
\hline $\mathrm{C}$ & 3.369359 & -4.565523 & -2.056868 \\
\hline $\mathrm{H}$ & 3.507156 & -3.735923 & -4.126637 \\
\hline $\mathrm{N}$ & 1.734812 & -3.262248 & -1.387342 \\
\hline $\mathrm{N}$ & 2.567813 & -4.265272 & -1.013961 \\
\hline $\mathrm{C}$ & 4.404588 & -5.649654 & -1.965394 \\
\hline $\mathrm{H}$ & 4.195444 & -6.459661 & -2.672028 \\
\hline $\mathrm{H}$ & 5.405400 & -5.267637 & -2.191756 \\
\hline $\mathrm{H}$ & 4.418922 & -6.071246 & -0.957984 \\
\hline $\mathrm{C}$ & -4.404980 & -5.649505 & 1.964979 \\
\hline $\mathrm{H}$ & -4.196736 & -6.458928 & 2.672542 \\
\hline I & -5.405950 & -5.267078 & 2.189968 \\
\hline
\end{tabular}




\begin{tabular}{|c|c|c|c|}
\hline $\mathrm{H}$ & 418380 & -6.071964 & 57920 \\
\hline \multicolumn{4}{|c|}{$\mathrm{M}=\mathrm{Cm}$} \\
\hline $\mathrm{CM}$ & 0.000008 & -2.217172 & 0.000093 \\
\hline $\mathrm{O}$ & 1.480252 & -3.808761 & 1.242532 \\
\hline $\mathrm{H}$ & 2.093780 & -4.210984 & 0.540742 \\
\hline $\mathrm{O}$ & -1.480174 & -3.808936 & -1.242213 \\
\hline $\mathrm{H}$ & -2.093712 & -4.211083 & -0.540394 \\
\hline $\mathrm{H}$ & 1.237642 & -4.486000 & 1.887253 \\
\hline $\mathrm{H}$ & -1.237510 & -4.486258 & -1.886828 \\
\hline $\mathrm{C}$ & 0.640363 & -0.332199 & 2.937963 \\
\hline $\mathrm{C}$ & 0.59 & 0.1 & 4.25 \\
\hline $\mathrm{C}$ & -0.348651 & -0.4 & 133 \\
\hline $\mathrm{C}$ & -1.198406 & -1.4 & 397 \\
\hline $\mathrm{C}$ & -1.091732 & -1.8 & 3.2 \\
\hline $\mathrm{N}$ & -0.17 & -1.2 & 465 \\
\hline $\mathrm{H}$ & -0.4 & -0.1 & 759 \\
\hline $\mathrm{H}$ & 1.288365 & 0.89 & 4.579346 \\
\hline $\mathrm{H}$ & -1.934386 & -1.8 & 964 \\
\hline $\mathrm{C}$ & 1.617322 & 0.2 & 1.9 \\
\hline $\mathrm{C}$ & 3.35 & 1.6 & 1.4 \\
\hline $\mathrm{C}$ & 4.41 & 2.5 & 2.0 \\
\hline $\mathrm{C}$ & 3.22 & 1.2 & 0.1 \\
\hline $\mathrm{C}$ & 4.1 & 3.3 & 3.1 \\
\hline $\mathrm{C}$ & 5.73 & 2.4 & 1.5 \\
\hline $\mathrm{C}$ & 3.95 & 1.8 & -1.0 \\
\hline $\mathrm{C}$ & 5.08 & 4.1 & 3.6 \\
\hline $\mathrm{C}$ & 4.05 & 3.2 & -1.1 \\
\hline $\mathrm{C}$ & 6.70 & 3.2 & 2.1 \\
\hline $\mathrm{C}$ & & 1.0 & -2.0 \\
\hline $\mathrm{C}$ & 6.39 & 4.1 & 3.1 \\
\hline $\mathrm{C}$ & 4.693826 & 3.7 & -2.26 \\
\hline $\mathrm{C}$ & 5.15 & 1.5 & -3.1 \\
\hline $\mathrm{H}$ & 7.174933 & 4.7 & 3.61 \\
\hline $\mathrm{C}$ & 5.24 & 2.9 & -3.24 \\
\hline $\mathrm{H}$ & 5.753601 & 3.378007 & -4.112053 \\
\hline $\mathrm{N}$ & 2.48 & 1.1 & 2.38 \\
\hline $\mathrm{N}$ & 1.595818 & -0.283088 & 0.720981 \\
\hline $\mathrm{N}$ & 2.382068 & 0.262251 & -0.209745 \\
\hline $\mathrm{O}$ & 5.723450 & 0.838945 & -4.124217 \\
\hline $\mathrm{O}$ & 4.660415 & 4.976569 & 4.711234 \\
\hline $\mathrm{C}$ & 5.620721 & 5.828024 & 5.344727 \\
\hline $\mathrm{H}$ & 5.075141 & 6.35 & 6.125954 \\
\hline $\mathrm{H}$ & 6.430770 & 5.244776 & 5.798136 \\
\hline $\mathrm{H}$ & 6.037181 & 6.553516 & 4.636019 \\
\hline
\end{tabular}




\begin{tabular}{|c|c|c|c|}
\hline $\mathrm{C}$ & 5.737358 & -0.585052 & -3.9989 \\
\hline 1 & 6.280840 & -0.898247 & -3.099458 \\
\hline & 4.721889 & -0.996954 & -3.971594 \\
\hline & 6.257770 & -0.954204 & -4.883427 \\
\hline & 4.385974 & -0.061288 & -1.905690 \\
\hline & 3.643014 & 3.899679 & -0.385630 \\
\hline $\mathrm{H}$ & 4.766322 & 4.868434 & -2.375663 \\
\hline H & 5.994606 & 1.837205 & 0.704601 \\
\hline $\mathrm{H}$ & 3.096150 & 3.388123 & 3.514970 \\
\hline $\mathrm{H}$ & 7.725633 & 3.253130 & 1.752006 \\
\hline $\mathrm{C}$ & -1.935333 & -2.884603 & 2.714345 \\
\hline $\mathrm{C}$ & -2.970101 & -3.681807 & 3.224957 \\
\hline $\mathrm{C}$ & -3.365571 & -4.483689 & 2.134498 \\
\hline $\mathrm{H}$ & -3.373121 & -3.703136 & 4.227517 \\
\hline $\mathrm{N}$ & -1.738369 & -3.202808 & 1.408839 \\
\hline $\mathrm{N}$ & -2.612231 & -4.177198 & 1.057316 \\
\hline $\mathrm{C}$ & -0.640370 & -0.332458 & -2.937944 \\
\hline $\mathrm{C}$ & -0.597574 & 0.126947 & -4.253672 \\
\hline $\mathrm{C}$ & 0.348657 & -0.442074 & -5.117100 \\
\hline $\mathrm{C}$ & 1.198420 & -1.434449 & -4.640280 \\
\hline $\mathrm{C}$ & 1.091742 & -1.848484 & -3.297820 \\
\hline $\mathrm{N}$ & 0.177740 & -1.293541 & -2.46 \\
\hline $\mathrm{H}$ & 0.414621 & -0.112948 & -6.149753 \\
\hline $\mathrm{H}$ & -1.288378 & 0.893435 & -4.579432 \\
\hline $\mathrm{H}$ & 1.934407 & -1.895518 & -5.288806 \\
\hline $\mathrm{C}$ & -1.617331 & 0.220799 & -1.965286 \\
\hline $\mathrm{C}$ & -3.356173 & 1.637612 & -1.494705 \\
\hline $\mathrm{C}$ & -4.412197 & 2.527165 & -2.028316 \\
\hline $\mathrm{C}$ & -3.229757 & 1.240831 & -0.116785 \\
\hline $\mathrm{C}$ & -4.100668 & 3.361501 & -3.109981 \\
\hline $\mathrm{C}$ & -5.731151 & 2.489590 & -1.527478 \\
\hline $\mathrm{C}$ & -3.958159 & 1.853236 & 1.022615 \\
\hline $\mathrm{C}$ & -5.082601 & 4.185165 & -3.681615 \\
\hline $\mathrm{C}$ & -4.057760 & 3.246388 & 1.144319 \\
\hline $\mathrm{C}$ & -6.704970 & 3.288716 & -2.120772 \\
\hline $\mathrm{C}$ & -4.492968 & 1.010502 & 2.015557 \\
\hline $\mathrm{C}$ & -6.396450 & 4.146094 & -3.186847 \\
\hline $\mathrm{C}$ & -4.693821 & 3.790699 & 2.267172 \\
\hline $\mathrm{C}$ & -5.150332 & 1.567406 & 3.119800 \\
\hline $\mathrm{H}$ & -7.175057 & 4.764998 & -3.615998 \\
\hline $\mathrm{C}$ & -5.244667 & 2.966479 & 3.246703 \\
\hline $\mathrm{H}$ & -5.753530 & 3.378397 & 4.111778 \\
\hline $\mathrm{N}$ & -2.485431 & 1.149711 & -2.380521 \\
\hline $\mathrm{N}$ & -1.595811 & -0.283156 & -0.720961 \\
\hline $\mathrm{N}$ & -2.382053 & 0.262266 & 0.209722 \\
\hline $\mathrm{O}$ & -5.723315 & 0.839337 & 4.124228 \\
\hline
\end{tabular}




$\begin{array}{lrrr}\mathrm{O} & -4.660563 & 4.976050 & -4.711696 \\ \mathrm{C} & -5.620897 & 5.827421 & -5.345259 \\ \mathrm{H} & -5.075341 & 6.357146 & -6.126548 \\ \mathrm{H} & -6.430941 & 5.244110 & -5.798596 \\ \mathrm{H} & -6.037360 & 6.552975 & -4.636617 \\ \mathrm{C} & -5.737189 & -0.584674 & 3.999130 \\ \mathrm{H} & -6.280685 & -0.897987 & 3.099682 \\ \mathrm{H} & -4.721710 & -0.996553 & 3.971791 \\ \mathrm{H} & -6.257571 & -0.953738 & 4.883656 \\ \mathrm{H} & -4.385882 & -0.061113 & 1.905764 \\ \mathrm{H} & -3.643069 & 3.899700 & 0.385232 \\ \mathrm{H} & -4.766340 & 4.868652 & 2.375189 \\ \mathrm{H} & -5.994617 & 1.837069 & -0.704718 \\ \mathrm{H} & -3.096243 & 3.387759 & -3.515297 \\ \mathrm{H} & -7.725692 & 3.252852 & -1.752236 \\ \mathrm{C} & 1.935346 & -2.884825 & -2.714109 \\ \mathrm{C} & 2.970153 & -3.682031 & -3.224642 \\ \mathrm{C} & 3.365617 & -4.483831 & -2.134123 \\ \mathrm{H} & 3.373227 & -3.703388 & -4.227181 \\ \mathrm{~N} & 1.738358 & -3.202952 & -1.408590 \\ \mathrm{~N} & 2.612240 & -4.177291 & -1.056979 \\ \mathrm{C} & 4.429312 & -5.542388 & -2.073673 \\ \mathrm{H} & 4.201589 & -6.374163 & -2.748608 \\ \mathrm{H} & 5.407328 & -5.143972 & -2.362751 \\ \mathrm{H} & 4.507634 & -5.938345 & -1.058795 \\ \mathrm{C} & -4.429352 & -5.542164 & 2.074099 \\ \mathrm{H} & -4.202813 & -6.372897 & 2.750701 \\ \mathrm{H} & -5.407752 & -5.143122 & 2.361034 \\ \mathrm{H} & -4.506203 & -5.939687 & 1.059723\end{array}$

\section{$\left[\mathrm{ML}_{2}\right]^{1+}$}

$\mathrm{M}=\mathrm{Eu}$

$\begin{array}{lccc}\text { EU } & -0.000270 & 2.086450 & -0.003205 \\ \mathrm{~N} & -0.798547 & 3.466167 & -1.765133 \\ \mathrm{~N} & 1.426278 & 2.020959 & -2.191740 \\ \mathrm{C} & -0.131550 & 3.637858 & -2.965817 \\ \mathrm{~N} & -1.884094 & 4.260386 & -1.736480 \\ \mathrm{~N} & -1.968909 & 0.450663 & 0.116976 \\ \mathrm{~N} & 1.968955 & 0.451039 & -0.118206 \\ \mathrm{C} & 2.527304 & 1.255463 & -2.316705 \\ \mathrm{C} & 1.076248 & 2.861318 & -3.193380 \\ \mathrm{C} & -0.822917 & 4.578263 & -3.723078 \\ \mathrm{C} & -1.924021 & 4.944562 & -2.907193 \\ \mathrm{C} & -2.813744 & 0.370962 & 1.158519\end{array}$




\begin{tabular}{|c|c|c|c|}
\hline $\mathrm{N}$ & -2.099169 & -0.411492 & -0.892874 \\
\hline & 2.813099 & 0.367553 & -1.160022 \\
\hline 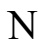 & 2.100132 & -0.407178 & 0.894874 \\
\hline & 3.348639 & 1.287058 & -3.441583 \\
\hline $\mathrm{C}$ & 1.856596 & 2.948003 & -4.366532 \\
\hline 1 & -0.586358 & 4.957864 & -4.706810 \\
\hline $\mathrm{C}$ & -3.015809 & 5.930114 & -3.192812 \\
\hline $\mathrm{C}$ & -2.529044 & 1.263492 & 2.311882 \\
\hline$N$ & -3.890185 & -0.419801 & 1.185306 \\
\hline $\mathrm{C}$ & -3.105859 & -1.290664 & -0.896862 \\
\hline $\mathrm{N}$ & 3.889781 & -0.422956 & -1.184440 \\
\hline $\mathrm{C}$ & 3.107092 & -1.286022 & 0.901592 \\
\hline $\mathrm{C}$ & 2.994923 & 2.158259 & -4.484933 \\
\hline $\mathrm{H}$ & 4.230126 & 0.660535 & -3.486327 \\
\hline $\mathrm{H}$ & 1.566640 & 3.629924 & -5.157556 \\
\hline $\mathrm{H}$ & -3.726675 & 833 & 4628 \\
\hline $\mathrm{H}$ & -3.552887 & 5.673863 & -4.112667 \\
\hline $\mathrm{H}$ & -2.611513 & 6.940160 & -3.323079 \\
\hline $\mathrm{C}$ & -3.351133 & 1.299240 & 3.436083 \\
\hline $\mathrm{N}$ & -1.428191 & 2.028828 & 2.184631 \\
\hline $\mathrm{C}$ & -4.109043 & -1.217030 & 0.136328 \\
\hline $\mathrm{C}$ & -3.066868 & -2.299482 & -1.983710 \\
\hline $\mathrm{C}$ & 4.109596 & -1.216036 & -0.132517 \\
\hline $\mathrm{C}$ & 3.069095 & -2.290674 & 1.992327 \\
\hline $\mathrm{H}$ & 3.610212 & 2.217026 & -5.377716 \\
\hline $\mathrm{C}$ & -2.998378 & 2.174636 & 4.476239 \\
\hline $\mathrm{H}$ & -4.232446 & 0.672610 & 3.482709 \\
\hline $\mathrm{C}$ & -1.079045 & 2.873196 & 3.183219 \\
\hline $\mathrm{C}$ & -5.404300 & -1.931386 & 0.110684 \\
\hline $\mathrm{C}$ & -2.704008 & -1.889797 & -3.281525 \\
\hline $\mathrm{C}$ & -3.318122 & -3.651856 & -1.711190 \\
\hline $\mathrm{C}$ & 5.405132 & -1.929812 & -0.104926 \\
\hline $\mathrm{C}$ & 2.706825 & -1.876139 & 3.288767 \\
\hline $\mathrm{C}$ & 3.320667 & -3.643997 & 1.724857 \\
\hline $\mathrm{C}$ & -1.860203 & 2.964248 & 4.355500 \\
\hline $\mathrm{H}$ & -3.614272 & 2.236710 & 5.368380 \\
\hline $\mathrm{C}$ & 0.128721 & 3.649198 & 2.953471 \\
\hline $\mathrm{C}$ & -5.973189 & -2.329027 & 1.328194 \\
\hline $\mathrm{C}$ & -6.108438 & -2.138539 & -1.095201 \\
\hline $\mathrm{C}$ & -2.616811 & -2.835382 & -4.310917 \\
\hline $\mathrm{H}$ & -2.500765 & -0.842234 & -3.461901 \\
\hline $\mathrm{C}$ & -3.204412 & -4.590486 & -2.744374 \\
\hline $\mathrm{H}$ & -3.588391 & -3.974650 & -0.712535 \\
\hline $\mathrm{C}$ & 5.973453 & -2.331860 & -1.321253 \\
\hline $\mathrm{C}$ & 6.110063 & -2.132119 & 1.101320 \\
\hline$C$ & 2.620531 & -2.817797 & 4.321828 \\
\hline
\end{tabular}




\begin{tabular}{|c|c|c|c|}
\hline 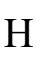 & 15 & 63 & \\
\hline & 207871 & -4.578694 & \\
\hline & 590475 & -3.970531 & 295 \\
\hline & 68 & 38 & \\
\hline & 819218 & 811 & 2 \\
\hline & 00 & & \\
\hline & -7.22 & -2.9 & \\
\hline & -5.4 & -2.1 & \\
\hline & -7.36 & -2.7 & -1.0 \\
\hline & -5.6 & -1.8 & \\
\hline & -2.8 & -4.1 & -4.0 \\
\hline & -2.25 & -2.5 & -5.6 \\
\hline & -3.3 & -5.6 & \\
\hline & 7.22 & -2.9 & -1.3 \\
\hline & 5.4 & -2.1 & \\
\hline & 7.3 & -2.7 & 1.0 \\
\hline & & -1.8 & \\
\hline & 2.8 & -4.1 & \\
\hline & 2.3 & -2.5 & \\
\hline & 3.3 & -5.6 & \\
\hline & 1.9 & 4.9 & \\
\hline H & & 4.9 & \\
\hline & & 4.2 & \\
\hline & -7.9 & -3.1 & \\
\hline & -7.6 & -3.3 & \\
\hline & & & \\
\hline & -2.7 & -4. & \\
\hline & -2.0 & -1.1 & -5 \\
\hline & 7.9 & -3.1 & -0 . \\
\hline & 7.6 & -3.3 & -2.5 \\
\hline $\mathrm{H}$ & 7.9 & -2.8 & 1.9 \\
\hline $\mathrm{H}$ & 2.7 & -4.8 & 4.8 \\
\hline & 2.06 & -1.1 & \\
\hline $\mathrm{C}$ & 3.01 & 5.9 & \\
\hline $\mathrm{H}$ & -8.90 & -3.6 & \\
\hline & -8.94 & -3.9 & \\
\hline & -1.20 & -0.7 & \\
\hline 11 & -2.9 & -0.5 & -5.75 \\
\hline & $-1.8 ?$ & -1.1 & -7.01 \\
\hline 11 & 8.9 & -3.6 & -0.144049 \\
\hline 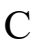 & 8.94 & -3.9 & -2.677 \\
\hline & 2.94 & -0.5 & \\
\hline $\mathrm{H}$ & 1.203591 & -0.7 & 5.401712 \\
\hline & 1.840988 & -1.14 & 7.02 \\
\hline 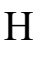 & 2.607242 & 6.953718 & 3.299778 \\
\hline & 3.723361 & 5.956229 & 2.34570 \\
\hline
\end{tabular}




$\begin{array}{crrr}\mathrm{H} & 3.548669 & 5.690770 & 4.094675 \\ \mathrm{H} & -8.959559 & -4.916111 & 2.132361 \\ \mathrm{H} & -9.746714 & -3.315852 & 2.327951 \\ \mathrm{H} & -9.095437 & -4.175074 & 3.749789 \\ \mathrm{H} & 9.746764 & -3.321052 & -2.319494 \\ \mathrm{H} & 8.960325 & -4.920848 & -2.117351 \\ \mathrm{H} & 9.094967 & -4.185918 & -3.737667\end{array}$

\section{$\mathrm{M}=\mathrm{Gd}$}

$\begin{array}{lrrr}\mathrm{C} & -2.477888 & 1.289100 & 2.303775 \\ \mathrm{C} & -3.286946 & 1.372797 & 3.431767 \\ \mathrm{C} & -2.900798 & 2.269204 & 4.444407 \\ \mathrm{C} & -1.745826 & 3.028133 & 4.294087 \\ \mathrm{C} & -0.976276 & 2.889705 & 3.118430 \\ \mathrm{~N} & -1.360144 & 2.026372 & 2.147419 \\ \mathrm{H} & -3.506359 & 2.370152 & 5.340087 \\ \mathrm{H} & -4.182458 & 0.769212 & 3.504737 \\ \mathrm{H} & -1.433013 & 3.726675 & 5.061568 \\ \mathrm{C} & -2.777422 & 0.381058 & 1.170161 \\ \mathrm{C} & -4.088224 & -1.192766 & 0.147962 \\ \mathrm{C} & -5.394258 & -1.884119 & 0.115811 \\ \mathrm{C} & -3.075165 & -1.295213 & -0.876454 \\ \mathrm{C} & -5.987365 & -2.248091 & 1.332874 \\ \mathrm{C} & -6.085870 & -2.100694 & -1.096129 \\ \mathrm{C} & -3.047882 & -2.311074 & -1.956831 \\ \mathrm{C} & -7.250694 & -2.858075 & 1.356110 \\ \mathrm{C} & -3.317413 & -3.658100 & -1.675804 \\ \mathrm{C} & -7.352464 & -2.677357 & -1.059339 \\ \mathrm{C} & -2.677730 & -1.913438 & -3.256295 \\ \mathrm{C} & -7.941329 & -3.070325 & 0.151303 \\ \mathrm{C} & -3.213356 & -4.604478 & -2.702970 \\ \mathrm{C} & -2.601162 & -2.866488 & -4.279868 \\ \mathrm{H} & -8.922149 & -3.530114 & 0.142311 \\ \mathrm{C} & -2.867245 & -4.220309 & -3.996784 \\ \mathrm{H} & -2.798314 & -4.943838 & -4.802172 \\ \mathrm{~N} & -3.866459 & -0.389969 & 1.193015 \\ \mathrm{~N} & -1.918253 & 0.427739 & 0.137379 \\ \mathrm{~N} & -2.050075 & -0.439747 & -0.867624 \\ \mathrm{O} & -2.275313 & -2.584906 & -5.575493 \\ \mathrm{O} & -7.717962 & -3.196788 & 2.592561 \\ \mathrm{C} & -9.008848 & -3.809653 & 2.682269 \\ \mathrm{H} & -9.175985 & -3.990068 & 3.744337 \\ \mathrm{H} & -9.791368 & -3.144780 & 2.298406 \\ \mathrm{H} & -9.033594 & -4.763718 & 2.142839 \\ \mathrm{C} & -2.021852 & -1.223284 & -5.928284\end{array}$




$\begin{array}{lccc}\mathrm{H} & -2.900603 & -0.593879 & -5.743471 \\ \mathrm{H} & -1.159841 & -0.823592 & -5.380314 \\ \mathrm{H} & -1.800568 & -1.230961 & -6.995947 \\ \mathrm{H} & -2.462337 & -0.869441 & -3.443547 \\ \mathrm{H} & -3.594182 & -3.970947 & -0.675729 \\ \mathrm{H} & -3.409302 & -5.651310 & -2.492107 \\ \mathrm{H} & -5.653196 & -1.806716 & -2.043780 \\ \mathrm{H} & -5.475240 & -2.071265 & 2.270903 \\ \mathrm{H} & -7.898903 & -2.830563 & -1.984940 \\ \mathrm{C} & 0.247796 & 3.616563 & 2.838127 \\ \mathrm{C} & 1.004558 & 4.562318 & 3.532106 \\ \mathrm{C} & 2.088501 & 4.846912 & 2.666937 \\ \mathrm{H} & 0.813864 & 4.992063 & 4.505320 \\ \mathrm{~N} & 0.862720 & 3.367919 & 1.637156 \\ \mathrm{~N} & 1.985016 & 4.120401 & 1.534269 \\ \mathrm{C} & 2.477952 & 1.289496 & -2.303549 \\ \mathrm{C} & 3.287045 & 1.373391 & -3.431503 \\ \mathrm{C} & 2.900934 & 2.269985 & -4.443991 \\ \mathrm{C} & 1.745964 & 3.028897 & -4.293567 \\ \mathrm{C} & 0.976379 & 2.890261 & -3.117959 \\ \mathrm{~N} & 1.360209 & 2.026749 & -2.147093 \\ \mathrm{H} & 3.506522 & 2.371090 & -5.339635 \\ \mathrm{H} & 4.182554 & 0.769812 & -3.504555 \\ \mathrm{H} & 1.433180 & 3.727580 & -5.060931 \\ \mathrm{O} & 2.777445 & 0.381247 & -1.170091 \\ \mathrm{~N} & 2.275137 & -2.585909 & 5.575023 \\ \mathrm{C} & 4.088206 & -1.192770 & -0.148138 \\ \mathrm{C} & 5.394223 & -1.884157 & -0.116076 \\ \mathrm{C} & 3.075119 & -1.295393 & 0.876231 \\ \mathrm{C} & 5.987373 & -2.247899 & -1.333187 \\ \mathrm{C} & 6.085772 & -2.101002 & 1.095852 \\ \mathrm{C} & 3.047819 & -2.311439 & 1.956434 \\ \mathrm{C} & 7.250686 & -2.857912 & -1.356491 \\ \mathrm{C} & 3.317408 & -3.658407 & 1.675188 \\ \mathrm{C} & 7.352353 & -2.677691 & 1.059000 \\ \mathrm{C} & 2.677613 & -1.914034 & 3.255953 \\ \mathrm{C} & 7.941262 & -3.070425 & -0.151696 \\ \mathrm{C} & 3.213344 & -4.604963 & 2.702189 \\ \mathrm{H} & 2.601038 & -2.867261 & 4.279361 \\ \mathrm{~N} & 2.867173 & -4.221025 & 3.996056 \\ \mathrm{~N} & -3.196386 & -2.592990\end{array}$




$\begin{array}{lrrr}\mathrm{C} & 9.008876 & -3.809264 & -2.682766 \\ \mathrm{H} & 9.176056 & -3.989465 & -3.744864 \\ \mathrm{H} & 9.791394 & -3.144489 & -2.298731 \\ \mathrm{H} & 9.033573 & -4.763441 & -2.143531 \\ \mathrm{C} & 2.021621 & -1.224355 & 5.928036 \\ \mathrm{H} & 2.900359 & -0.594891 & 5.743361 \\ \mathrm{H} & 1.159617 & -0.824597 & 5.380103 \\ \mathrm{H} & 1.800299 & -1.232220 & 6.995690 \\ \mathrm{H} & 2.462183 & -0.870075 & 3.443375 \\ \mathrm{H} & 3.594227 & -3.971074 & 0.675070 \\ \mathrm{H} & 3.409334 & -5.651753 & 2.491156 \\ \mathrm{H} & 5.653060 & -1.807212 & 2.043544 \\ \mathrm{H} & 5.475294 & -2.070869 & -2.271202 \\ \mathrm{H} & 7.898746 & -2.831103 & 1.984595 \\ \mathrm{C} & -0.247696 & 3.617078 & -2.837562 \\ \mathrm{C} & -1.004424 & 4.562974 & -3.531386 \\ \mathrm{C} & -2.088399 & 4.847409 & -2.666205 \\ \mathrm{H} & -0.813694 & 4.992900 & -4.504514 \\ \mathrm{~N} & -0.862663 & 3.368216 & -1.636658 \\ \mathrm{~N} & -1.984946 & 4.120703 & -1.533659 \\ \mathrm{C} & 3.230355 & 5.799932 & 2.876696 \\ \mathrm{H} & 2.871871 & 6.827319 & 2.999689 \\ \mathrm{H} & 3.806770 & 5.542830 & 3.771722 \\ \mathrm{H} & 3.898281 & 5.769587 & 2.013517 \\ \mathrm{C} & -3.230247 & 5.800464 & -2.875833 \\ \mathrm{H} & -2.871752 & 6.827851 & -2.998781 \\ \mathrm{H} & -3.806722 & 5.543430 & -3.770841 \\ \mathrm{H} & -3.898124 & 5.770073 & -2.012617 \\ \mathrm{GD} & 0.000000 & 1.998452 & 0.000139\end{array}$

$\mathrm{M}=\mathrm{Am}$

$\begin{array}{lrrc}\text { AM } & 0.000025 & 1.792978 & 0.000201 \\ \text { N } & -0.778476 & 3.234956 & -1.662776 \\ \text { N } & 0.778666 & 3.234405 & 1.663569 \\ \text { C } & -0.130383 & 3.518437 & -2.833686 \\ \text { N } & -1.919208 & 3.959098 & -1.580885 \\ \text { C } & 0.130633 & 3.517590 & 2.834584 \\ \text { N } & 1.919445 & 3.958489 & 1.581848 \\ \text { C } & -0.883100 & 4.462637 & -3.534839 \\ \mathrm{C} & 1.115514 & 2.819960 & -3.081266 \\ \mathrm{C} & -2.001045 & 4.706338 & -2.701652 \\ \mathrm{C} & 0.883442 & 4.461531 & 3.535986 \\ \mathrm{C} & -1.115290 & 2.819106 & 3.082009 \\ \mathrm{C} & 2.001374 & 4.705397 & 2.702829 \\ \mathrm{H} & -0.670454 & 4.916465 & -4.492409\end{array}$




$\begin{array}{rrrr}\mathrm{C} & 1.926458 & 3.011276 & -4.220572 \\ \mathrm{~N} & 1.478393 & 1.935695 & -2.119553 \\ \mathrm{C} & -3.155938 & 5.638610 & -2.930427 \\ \mathrm{H} & 0.670864 & 4.915093 & 4.493697 \\ \mathrm{C} & -1.926180 & 3.010125 & 4.221404 \\ \mathrm{~N} & -1.478251 & 1.935143 & 2.120049 \\ \mathrm{C} & 3.156340 & 5.637524 & 2.931834 \\ \mathrm{C} & 3.104677 & 2.286215 & -4.347775 \\ \mathrm{H} & 1.625615 & 3.725637 & -4.978090 \\ \mathrm{C} & 2.623784 & 1.234206 & -2.252379 \\ \mathrm{H} & -2.817293 & 6.676523 & -3.016206 \\ \mathrm{H} & -3.694324 & 5.390918 & -3.851445 \\ \mathrm{H} & -3.853503 & 5.572983 & -2.092933 \\ \mathrm{C} & -3.104427 & 2.285079 & 4.348442 \\ \mathrm{H} & -1.625274 & 3.724250 & 4.979119 \\ \mathrm{C} & -2.623664 & 1.233661 & 2.252718 \\ \mathrm{H} & 2.817769 & 6.675436 & 3.017918 \\ \mathrm{H} & 3.694737 & 5.389532 & 3.852764 \\ \mathrm{H} & 3.853874 & 5.572087 & 2.094299 \\ \mathrm{C} & 3.473193 & 1.373025 & -3.344791 \\ \mathrm{H} & 3.742080 & 2.427763 & -5.215332 \\ \mathrm{C} & 2.919298 & 0.302520 & -1.137797 \\ \mathrm{C} & -3.473022 & 1.372197 & 3.345207 \\ \mathrm{H} & -3.741789 & 2.426403 & 5.216064 \\ \mathrm{C} & -2.919259 & 0.302302 & 1.137884 \\ \mathrm{H} & 4.387535 & 0.796201 & -3.396463 \\ \mathrm{~N} & 2.031688 & 0.289884 & -0.131958 \\ \mathrm{~N} & 4.035226 & -0.431037 & -1.151360 \\ \mathrm{H} & -4.387384 & 0.795393 & 3.396751 \\ \mathrm{~N} & -2.031693 & 0.289918 & 0.132003 \\ \mathrm{~N} & -4.035210 & -0.431224 & 1.151292 \\ \mathrm{~N} & 2.164362 & -0.601595 & 0.851716 \\ \mathrm{C} & 4.253550 & -1.257422 & -0.124591 \\ \mathrm{~N} & -2.164452 & -0.601267 & -0.851927 \\ \mathrm{C} & -4.253611 & -1.257311 & 0.124298 \\ \mathrm{C} & 3.217233 & -1.421679 & 0.867914 \\ \mathrm{C} & 5.579011 & -1.910514 & -0.075871 \\ \mathrm{C} & -3.217355 & -1.421306 & -0.868315 \\ \mathrm{C} & -5.579086 & -1.910366 & 0.075472 \\ \mathrm{C} & 3.194804 & -2.467952 & 1.919064 \\ \mathrm{C} & 6.209734 & -2.234284 & -1.284996 \\ \mathrm{C} & 6.248418 & -2.131248 & 1.147495 \\ \mathrm{C} & -3.195019 & -2.467259 & -1.919785 \\ \mathrm{C} & -6.209733 & -2.234484 & 1.284543 \\ \mathrm{C} & -6.248577 & -2.130728 & -1.147915 \\ \mathrm{C} & 3.519031 & -3.796607 & 1.609944\end{array}$




\begin{tabular}{|c|c|c|c|}
\hline $\mathrm{C}$ & 2.773948 & -2.119972 & 3.217400 \\
\hline & 7.490358 & -2.807858 & -1.290039 \\
\hline & 5.714421 & -2.054298 & -2.231492 \\
\hline & 7.531488 & -2.671231 & 1.129869 \\
\hline & 5.785705 & -1.867970 & 2.090066 \\
\hline & -3.519259 & -3.796001 & -1.611051 \\
\hline & -2.774235 & -2.118891 & -3.218039 \\
\hline & -7.490365 & -2.808039 & 1.289502 \\
\hline $\mathrm{H}$ & -5.714354 & -2.054785 & 2.231060 \\
\hline & -7.531655 & -2.670695 & -1.130363 \\
\hline 7 & -5.785922 & -1.867178 & -2.090438 \\
\hline & 3.419027 & -4.774365 & 2.607621 \\
\hline 1 & 3.834685 & -4.071819 & 0.610352 \\
\hline & 2.701308 & -3.103405 & 4.212042 \\
\hline $\mathrm{H}$ & 2.517511 & -1.089435 & 3.426664 \\
\hline & 8.159109 & -3.02 & -0.073696 \\
\hline J & 7.995166 & -3.109291 & -2.521499 \\
\hline $\mathrm{H}$ & 8.060530 & -2.827057 & 2.065115 \\
\hline 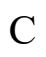 & -3.419330 & -4.773457 & -2.609033 \\
\hline H & -3.834861 & $-4.0^{\prime}$ & -0.611525 \\
\hline 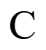 & -2.701671 & -3.102022 & -4.212985 \\
\hline $\mathrm{H}$ & -2.517788 & -1.0 & -3.427004 \\
\hline$C$ & -8.159201 & -3.0 & 0.073139 \\
\hline $\mathrm{O}$ & -7.995096 & -3.1 & 2.520906 \\
\hline $\mathrm{H}$ & -8.060761 & -2.8 & -2.065619 \\
\hline 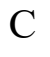 & 3.022825 & -4.438794 & 3.900561 \\
\hline $\mathrm{H}$ & 3.657252 & -5.807584 & 2.374306 \\
\hline 0 & 2.328462 & -2.869773 & 5.504636 \\
\hline $\mathrm{H}$ & 9.152169 & -3.456046 & -0.050274 \\
\hline $\mathrm{C}$ & 9.304426 & -3.684332 & -2.592385 \\
\hline $\mathrm{C}$ & -3.023195 & -4.437500 & -3.901892 \\
\hline $\mathrm{H}$ & -3.657563 & -5.806742 & -2.376019 \\
\hline 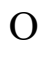 & -2.328897 & -2.868002 & -5.505530 \\
\hline $\mathrm{H}$ & -9.152269 & -3.455835 & 0.049656 \\
\hline $\mathrm{C}$ & -9.304358 & -3.684875 & 2.591709 \\
\hline 11 & 2.956050 & -5.186583 & 4.683674 \\
\hline G & 2.015078 & -1.528664 & 5.886265 \\
\hline $\mathrm{H}$ & 9.343596 & -4.647648 & -2.070506 \\
\hline & 10.058970 & -3.005678 & -2.177827 \\
\hline 11 & 9.500922 & -3.839411 & -3.653433 \\
\hline$-\pi$ & -2.956479 & -5.185051 & -4.685237 \\
\hline $\mathrm{C}$ & -2.015527 & -1.526779 & -5.886770 \\
\hline $\mathrm{H}$ & -9.343575 & -4.648035 & 2.069546 \\
\hline & -10.058921 & -3.006088 & 2.177403 \\
\hline 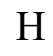 & -9.500785 & -3.840266 & 3.652724 \\
\hline $\mathrm{H}$ & 2.875301 & -0.863189 & 5.745725 \\
\hline
\end{tabular}




\begin{tabular}{|c|c|c|c|}
\hline $\mathrm{H}$ & 1.155558 & -1.144722 & 5.323240 \\
\hline $\mathrm{H}$ & 1.762554 & -1.574296 & 6.946018 \\
\hline $\mathrm{H}$ & -2.875738 & -0.861343 & -5.745978 \\
\hline $\mathrm{H}$ & -1.155972 & -1.143012 & -5.323679 \\
\hline $\mathrm{H}$ & -1.763064 & -1.572091 & -6.946552 \\
\hline \multicolumn{4}{|c|}{$\mathrm{M}=\mathrm{Cm}$} \\
\hline $\mathrm{CM}$ & -0.000098 & -1.780822 & $2-0.000030$ \\
\hline $\mathrm{C}$ & 2.630007 & -1.240983 & 2.256441 \\
\hline $\mathrm{C}$ & 3.481408 & -1.392849 & 3.346089 \\
\hline $\mathrm{C}$ & 3.103628 & -2.306949 & 4.345217 \\
\hline $\mathrm{C}$ & 1.915964 & -3.018202 & 4.219112 \\
\hline $\mathrm{C}$ & 1.105254 & -2.812628 & 3.081996 \\
\hline $\mathrm{N}$ & 1.479635 & -1.930675 & 2.125350 \\
\hline $\mathrm{H}$ & 3.741120 & -2.459529 & 5.210960 \\
\hline $\mathrm{H}$ & 4.402231 & -0.826575 & 3.400060 \\
\hline $\mathrm{H}$ & 1.609256 & -3.730559 & 4.976260 \\
\hline $\mathrm{C}$ & 2.923540 & -0.306054 & 1.142693 \\
\hline $\mathrm{C}$ & 4.267813 & 1.246024 & 0.128548 \\
\hline $\mathrm{C}$ & 5.601230 & 1.881750 & 0.073042 \\
\hline $\mathrm{C}$ & 3.225208 & 1.430724 & -0.853316 \\
\hline $\mathrm{C}$ & 6.248196 & 2.184886 & 1.279023 \\
\hline $\mathrm{C}$ & 6.261534 & 2.105496 & -1.154781 \\
\hline $\mathrm{C}$ & 3.205860 & 2.486004 & -1.895578 \\
\hline $\mathrm{C}$ & 7.536538 & 2.740806 & 1.276911 \\
\hline $\mathrm{C}$ & 3.548150 & 3.808103 & -1.577828 \\
\hline $\mathrm{C}$ & 7.551961 & 2.627793 & -1.144612 \\
\hline $\mathrm{C}$ & 2.770083 & 2.154137 & -3.193191 \\
\hline $\mathrm{C}$ & 8.196139 & 2.959836 & 0.056085 \\
\hline $\mathrm{C}$ & 3.451146 & 4.795581 & -2.566226 \\
\hline $\mathrm{C}$ & 2.700484 & 3.146983 & -4.178658 \\
\hline $\mathrm{H}$ & 9.194743 & 3.378660 & 0.027034 \\
\hline $\mathrm{C}$ & 3.040164 & 4.475788 & -3.858520 \\
\hline $\mathrm{H}$ & 2.975369 & 5.231060 & -4.634589 \\
\hline $\mathrm{N}$ & 4.047495 & 0.414826 & 1.151079 \\
\hline $\mathrm{N}$ & 2.026653 & -0.275381 & 0.142825 \\
\hline $\mathrm{N}$ & 2.162978 & 0.622677 & -0.834859 \\
\hline $\mathrm{O}$ & 2.313858 & 2.928938 & -5.469929 \\
\hline $\mathrm{O}$ & 8.057633 & 3.022882 & 2.506133 \\
\hline $\mathrm{C}$ & 9.375252 & 3.579411 & 2.569622 \\
\hline $\mathrm{H}$ & 9.584321 & 3.721061 & 3.630138 \\
\hline $\mathrm{H}$ & 10.116332 & 2.894831 & 2.140772 \\
\hline $\mathrm{H}$ & 9.422339 & 4.547356 & 2.057039 \\
\hline $\mathrm{C}$ & 1.981075 & 1.595063 & -5.860330 \\
\hline $\mathrm{H}$ & 2.834350 & 0.918061 & -5.732818 \\
\hline
\end{tabular}




\begin{tabular}{|c|c|c|c|}
\hline 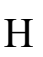 & 1.121718 & 1.216644 & -5.293321 \\
\hline H & 1.720238 & 1.652903 & -6.917464 \\
\hline & 2.499800 & 1.128527 & -3.409106 \\
\hline & 3.875290 & 4.071050 & -0.578592 \\
\hline & 3.703212 & 5.823944 & -2.326072 \\
\hline & 5.786045 & 1.857805 & -2.095241 \\
\hline & 5.759774 & 2.002083 & 2.228566 \\
\hline & 8.073930 & 2.785668 & -2.083491 \\
\hline( & -0.153825 & -3.491720 & 3015 \\
\hline $\mathrm{C}$ & -0.911076 & -4.428367 & 3.537444 \\
\hline 0 & -2.039998 & -4.658095 & 2.714385 \\
\hline $\mathrm{H}$ & -0.694419 & -4.886122 & 4.492216 \\
\hline $\mathrm{N}$ & -0.810440 & -3.196770 & 1.666231 \\
\hline$N$ & -1.961462 & -3.910019 & 1.595369 \\
\hline $\mathrm{C}$ & -2.630201 & -1.240873 & -2.256586 \\
\hline $\mathrm{C}$ & -3.481652 & -1.392753 & -3.3 \\
\hline C & -3.103944 & -2.306895 & -4.3 \\
\hline $\mathrm{C}$ & -1.916304 & -3.018179 & -4.2 \\
\hline $\mathrm{C}$ & -1.105524 & -2.812575 & -3.082179 \\
\hline $\mathrm{N}$ & -1.479812 & -1.930600 & -2.1 \\
\hline $\mathrm{H}$ & -3.741500 & -2.459472 & -5.211011 \\
\hline $\mathrm{H}$ & -4.402471 & -0.826469 & -3.40 \\
\hline $\mathrm{H}$ & -1.609650 & -3.730579 & -4. \\
\hline $\mathrm{C}$ & -2.923654 & -0.305942 & -1.1 \\
\hline $\mathrm{C}$ & -4.267728 & 1.246218 & -0.1 \\
\hline $\mathrm{C}$ & -5.601081 & 1.882079 & -0.072940 \\
\hline $\mathrm{C}$ & -3.225069 & 1.430773 & 0.85 \\
\hline $\mathrm{C}$ & -6.248092 & 2.185240 & -1.278892 \\
\hline $\mathrm{C}$ & -6.261297 & 2.105927 & 1.154914 \\
\hline $\mathrm{C}$ & -3.205585 & 2.485973 & 1.895652 \\
\hline $\mathrm{C}$ & -7.536386 & 2.741270 & -1.276722 \\
\hline $\mathrm{C}$ & -3.547726 & 3.808141 & 1.578036 \\
\hline $\mathrm{C}$ & -7.551675 & 2.628344 & 1.144804 \\
\hline $\mathrm{C}$ & -2.769837 & 2.153933 & 3.193232 \\
\hline $\mathrm{C}$ & -8.195895 & 2.960404 & -0.055866 \\
\hline $\mathrm{C}$ & -3.450596 & 4.795510 & 2.566529 \\
\hline $\mathrm{C}$ & -2.700119 & 3.146672 & 4.178798 \\
\hline $\mathrm{H}$ & -9.194459 & 3.379321 & -0.026772 \\
\hline $\mathrm{C}$ & -3.039638 & 4.475548 & 3.858792 \\
\hline $\mathrm{H}$ & -2.974744 & 5.230744 & 4.634926 \\
\hline $\mathrm{N}$ & -4.047537 & 0.415041 & -1.151101 \\
\hline $\mathrm{N}$ & -2.026713 & -0.275372 & -0.142983 \\
\hline $\mathrm{N}$ & -2.162892 & 0.622649 & 0.834749 \\
\hline $\mathrm{O}$ & -2.313478 & 2.928457 & 5.470038 \\
\hline $\mathrm{O}$ & -8.057524 & 3.023360 & -2.505922 \\
\hline $\mathrm{C}$ & -9.375080 & 3.580049 & -2.569347 \\
\hline
\end{tabular}




$\begin{array}{cccc}\mathrm{H} & -9.584184 & 3.721718 & -3.629854 \\ \mathrm{H} & -10.116219 & 2.895560 & -2.140456 \\ \mathrm{H} & -9.422025 & 4.548002 & -2.056767 \\ \mathrm{C} & -1.980890 & 1.594499 & 5.860322 \\ \mathrm{H} & -2.834241 & 0.917616 & 5.732696 \\ \mathrm{H} & -1.121549 & 1.216027 & 5.293321 \\ \mathrm{H} & -1.720102 & 1.652199 & 6.917475 \\ \mathrm{H} & -2.499651 & 1.128277 & 3.409043 \\ \mathrm{H} & -3.874837 & 4.071228 & 0.578826 \\ \mathrm{H} & -3.702539 & 5.823926 & 2.326474 \\ \mathrm{H} & -5.785780 & 1.858216 & 2.095354 \\ \mathrm{H} & -5.759743 & 2.002369 & -2.228458 \\ \mathrm{H} & -8.073572 & 2.786302 & 2.083708 \\ \mathrm{C} & 0.153524 & -3.491692 & -2.833190 \\ \mathrm{C} & 0.910753 & -4.428385 & -3.537583 \\ \mathrm{C} & 2.039720 & -4.658020 & -2.714561 \\ \mathrm{H} & 0.694042 & -4.886236 & -4.492296 \\ \mathrm{~N} & 0.810144 & -3.196653 & -1.666448 \\ \mathrm{~N} & 1.961224 & -3.909840 & -1.595615 \\ \mathrm{C} & -3.202430 & -5.578458 & 2.953236 \\ \mathrm{H} & -2.873912 & -6.620059 & 3.033961 \\ \mathrm{H} & -3.728595 & -5.326653 & 3.880225 \\ \mathrm{H} & -3.907723 & -5.503809 & 2.123000 \\ \mathrm{C} & 3.202167 & -5.578377 & -2.953381 \\ \mathrm{H} & 2.873751 & -6.620078 & -3.033266 \\ \mathrm{H} & 3.727844 & -5.327109 & -3.880788 \\ \mathrm{H} & 3.907842 & -5.503104 & -2.123525\end{array}$

$\mathrm{L}=\mathbf{2 b p i}$

\section{$\left[\mathrm{ML}\left(\mathrm{H}_{2} \mathrm{O}\right)_{6}\right]^{2+}$}

$\mathrm{M}=\mathrm{Eu}$

$\begin{array}{lrrr}\text { EU } & -1.535722 & -1.090928 & 0.331781 \\ \mathrm{O} & -3.396816 & -1.504544 & 2.197747 \\ \mathrm{H} & -4.296551 & -1.279772 & 1.907812 \\ \mathrm{O} & -3.496856 & -2.448691 & -0.806745 \\ \mathrm{H} & -3.839278 & -3.353542 & -0.814750 \\ \mathrm{O} & -0.738561 & -0.460556 & 2.796606 \\ \mathrm{H} & -0.385205 & -1.270568 & 3.200524 \\ \mathrm{O} & -1.481374 & -1.128130 & -2.273248 \\ \mathrm{H} & -2.317490 & -1.523948 & -2.570228 \\ \mathrm{O} & -1.001765 & -3.125405 & 1.978607 \\ \mathrm{H} & -1.663166 & -3.667238 & 2.434821 \\ \mathrm{O} & 0.213573 & -2.964754 & -0.430056\end{array}$




\begin{tabular}{|c|c|c|c|}
\hline $\mathrm{H}$ & 0.167318 & -3.405826 & -1.291596 \\
\hline $\mathrm{H}$ & -0.312014 & 0.288083 & 3.238420 \\
\hline & -1.172167 & -0.545570 & -2.981617 \\
\hline $\mathrm{H}$ & -4.269543 & -1.831649 & -0.698227 \\
\hline & 1.064129 & -2.440308 & -0.429956 \\
\hline & -3.269878 & -1.071865 & 3.056079 \\
\hline & -0.439600 & -3.719149 & 1.450287 \\
\hline & 0.036248 & 2.135716 & 0.094575 \\
\hline & 0.229958 & 3.519380 & 0.123799 \\
\hline & -0.897008 & 4.349275 & 0.096193 \\
\hline & -2.162959 & 3.772588 & 0.026721 \\
\hline & -2.274616 & 2.371066 & 0.006787 \\
\hline & -1.186647 & 1.567832 & 0.059012 \\
\hline $\mathrm{H}$ & -0.784708 & 5.428871 & 0.117701 \\
\hline & 1.235466 & 3.918202 & 0.161993 \\
\hline 1 & -3.051700 & 4.391466 & -0.015366 \\
\hline & 1.202939 & 1.209292 & 0.058345 \\
\hline $\mathrm{C}$ & 3.482336 & 0.915650 & -0.032178 \\
\hline $\mathrm{C}$ & 4.814221 & 1.504709 & 0.175477 \\
\hline $\mathrm{C}$ & 3.225058 & -0.487533 & -0.294208 \\
\hline $\mathrm{C}$ & 4.997732 & 2.863184 & -0.131084 \\
\hline $\mathrm{C}$ & 5.873480 & 0.765038 & 0.751721 \\
\hline $\mathrm{C}$ & 4.238312 & -1.472032 & -0.735063 \\
\hline 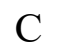 & 6.232967 & 3.487807 & 0.097408 \\
\hline $\mathrm{C}$ & 5.129639 & -1.133339 & -1.763903 \\
\hline $\mathrm{C}$ & 7.084317 & 1.403127 & 1.005488 \\
\hline $\mathrm{C}$ & 4.249550 & -2.766774 & -0.174741 \\
\hline $\mathrm{C}$ & 7.283041 & 2.751271 & 0.675936 \\
\hline $\mathrm{C}$ & 6.024630 & -2.100912 & -2.238761 \\
\hline $\mathrm{C}$ & 5.173720 & -3.714445 & -0.636847 \\
\hline $\mathrm{H}$ & 8.244993 & 3.210236 & 0.870035 \\
\hline $\mathrm{C}$ & 6.057466 & -3.376528 & -1.682553 \\
\hline $\mathrm{H}$ & 6.760363 & -4.126407 & -2.029740 \\
\hline $\mathrm{N}$ & 2.432032 & 1.736138 & 0.059590 \\
\hline $\mathrm{N}$ & 0.945256 & -0.104088 & 0.040576 \\
\hline $\mathrm{N}$ & 1.974910 & -0.937800 & -0.183145 \\
\hline $\mathrm{O}$ & 5.298707 & -4.978539 & -0.149745 \\
\hline $\mathrm{O}$ & 6.306527 & 4.794859 & -0.266480 \\
\hline $\mathrm{C}$ & 7.546366 & 5.492266 & -0.065565 \\
\hline $\mathrm{H}$ & 7.374900 & 6.504174 & -0.431454 \\
\hline 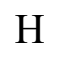 & 7.810651 & 5.528059 & 0.997043 \\
\hline $\mathrm{H}$ & 8.356025 & 5.028956 & -0.639910 \\
\hline $\mathrm{C}$ & 4.477358 & -5.377290 & 0.949131 \\
\hline $\mathrm{H}$ & 4.653009 & -4.743168 & 1.826570 \\
\hline $\mathrm{H}$ & 3.413979 & -5.356399 & 0.678259 \\
\hline $\mathrm{H}$ & 4.769779 & -6.401562 & 1.179862 \\
\hline
\end{tabular}




$\begin{array}{lrrr}\mathrm{H} & 3.565915 & -3.005680 & 0.630456 \\ \mathrm{H} & 5.124288 & -0.140539 & -2.198769 \\ \mathrm{H} & 6.707972 & -1.852581 & -3.044728 \\ \mathrm{H} & 5.750772 & -0.277536 & 1.014261 \\ \mathrm{H} & 4.195351 & 3.444951 & -0.567429 \\ \mathrm{H} & 7.897337 & 0.848371 & 1.463431 \\ \mathrm{C} & -3.566476 & 1.689030 & -0.097094 \\ \mathrm{C} & -4.870640 & 2.144139 & -0.191664 \\ \mathrm{C} & -5.659234 & 0.961369 & -0.291351 \\ \mathrm{H} & -5.220343 & 3.165027 & -0.197540 \\ \mathrm{~N} & -3.570455 & 0.307302 & -0.137336 \\ \mathrm{~N} & -4.822115 & -0.132780 & -0.247814 \\ \mathrm{C} & -7.093432 & 0.834381 & -0.426132 \\ \mathrm{C} & -7.920986 & 1.989440 & -0.462084 \\ \mathrm{C} & -7.704718 & -0.445034 & -0.525268 \\ \mathrm{C} & -9.298982 & 1.867104 & -0.589978 \\ \mathrm{H} & -7.479575 & 2.977164 & -0.389794 \\ \mathrm{C} & -9.083029 & -0.561659 & -0.653535 \\ \mathrm{H} & -7.083488 & -1.332398 & -0.502828 \\ \mathrm{C} & -9.887853 & 0.592774 & -0.686402 \\ \mathrm{H} & -9.923945 & 2.753798 & -0.616723 \\ \mathrm{H} & -9.543088 & -1.541653 & -0.730289 \\ \mathrm{H} & -10.964789 & 0.499958 & -0.787487\end{array}$

$\mathrm{M}=\mathrm{Gd}$

$\begin{array}{lrrr}\text { GD } & -1.501890 & -0.887049 & 0.356134 \\ \mathrm{O} & -3.430704 & -1.250662 & 2.188443 \\ \mathrm{H} & -4.255763 & -1.090039 & 1.685759 \\ \mathrm{O} & -3.263427 & -2.318879 & -0.603949 \\ \mathrm{H} & -3.530524 & -3.248525 & -0.612851 \\ \mathrm{O} & -0.814360 & 0.027420 & 2.627505 \\ \mathrm{H} & -0.453783 & -0.587443 & 3.286187 \\ \mathrm{O} & -1.369996 & -0.824245 & -2.165338 \\ \mathrm{H} & -2.216295 & -1.091407 & -2.560471 \\ \mathrm{O} & -1.168271 & -2.706752 & 2.086427 \\ \mathrm{H} & -1.987456 & -2.957453 & 2.546120 \\ \mathrm{O} & -0.022183 & -2.781485 & -0.404016 \\ \mathrm{H} & -0.138611 & -3.223867 & -1.258891 \\ \mathrm{H} & -0.578659 & 0.923766 & 2.910687 \\ \mathrm{H} & -1.016941 & -0.116902 & -2.725616 \\ \mathrm{H} & -4.094982 & -1.731247 & -0.566995 \\ \mathrm{H} & 0.894574 & -2.378288 & -0.413019 \\ \mathrm{H} & -3.495867 & -0.688669 & 2.976340 \\ \mathrm{H} & -0.712079 & -3.517733 & 1.810369 \\ \mathrm{C} & 0.081199 & 2.185964 & -0.014067\end{array}$




\begin{tabular}{|c|c|c|c|}
\hline$C$ & 0.277928 & 3.563824 & -0.074623 \\
\hline C & -0.853827 & 4.390019 & -0.157817 \\
\hline $\mathrm{C}$ & -2.122100 & 3.816228 & -0.192763 \\
\hline $\mathrm{C}$ & -2.243427 & 2.416484 & -0.121789 \\
\hline $\mathrm{N}$ & -1.148060 & 1.622041 & -0.012290 \\
\hline H & -0.739659 & 5.468591 & -0.208202 \\
\hline $\mathrm{H}$ & 1.283123 & 3.965426 & -0.063849 \\
\hline $\mathrm{H}$ & -3.010171 & 4.431456 & -0.280605 \\
\hline $\mathrm{C}$ & 1.221065 & 1.232916 & 0.001539 \\
\hline $\mathrm{C}$ & 3.485941 & 0.840195 & -0.057166 \\
\hline $\mathrm{C}$ & 4.833868 & 1.376550 & 0.158652 \\
\hline $\mathrm{C}$ & 3.171742 & -0.562956 & -0.284547 \\
\hline $\mathrm{C}$ & 5.067305 & 2.731521 & -0.137341 \\
\hline $\mathrm{C}$ & 5.864573 & 0.595707 & 0.736637 \\
\hline $\mathrm{C}$ & 4.143784 & -1.595665 & -0.703029 \\
\hline $\mathrm{C}$ & 6.321862 & 3.310827 & 0.101705 \\
\hline $\mathrm{C}$ & 5.049512 & -1.310478 & -1.735999 \\
\hline $\mathrm{C}$ & 7.094266 & 1.190014 & 1.002602 \\
\hline $\mathrm{C}$ & 4.099380 & -2.880964 & -0.121740 \\
\hline $\mathrm{C}$ & 7.341612 & 2.532522 & 0.682347 \\
\hline $\mathrm{C}$ & 5.901946 & -2.322938 & -2.195417 \\
\hline $\mathrm{C}$ & 4.983810 & -3.873636 & -0.567191 \\
\hline $\mathrm{H}$ & 8.318065 & 2.956087 & 0.884789 \\
\hline $\mathrm{C}$ & 5.880684 & -3.589315 & -1.618474 \\
\hline $\mathrm{H}$ & 6.551467 & -4.373659 & -1.952911 \\
\hline $\mathrm{N}$ & 2.468012 & 1.707087 & -0.010146 \\
\hline $\mathrm{N}$ & 0.912119 & -0.072065 & 0.034586 \\
\hline $\mathrm{N}$ & 1.905992 & -0.957988 & -0.164109 \\
\hline $\mathrm{O}$ & 5.058263 & -5.132201 & -0.059808 \\
\hline $\mathrm{O}$ & 6.444495 & 4.614638 & -0.253304 \\
\hline $\mathrm{C}$ & 7.707771 & 5.268417 & -0.042903 \\
\hline $\mathrm{H}$ & 7.572310 & 6.287042 & -0.404776 \\
\hline $\mathrm{H}$ & 7.966964 & 5.290050 & 1.021171 \\
\hline $\mathrm{H}$ & 8.502994 & 4.779972 & -0.616278 \\
\hline $\mathrm{C}$ & 4.222707 & -5.482362 & 1.045340 \\
\hline $\mathrm{H}$ & 4.423045 & -4.841679 & 1.912605 \\
\hline $\mathrm{H}$ & 3.160933 & -5.426099 & 0.773030 \\
\hline $\mathrm{H}$ & 4.476326 & -6.513144 & 1.291931 \\
\hline $\mathrm{H}$ & 3.407872 & -3.077708 & 0.688188 \\
\hline $\mathrm{H}$ & 5.086511 & -0.325687 & -2.187233 \\
\hline $\mathrm{H}$ & 6.594688 & -2.117007 & -3.005241 \\
\hline $\mathrm{H}$ & 5.704873 & -0.443142 & 0.992733 \\
\hline $\mathrm{H}$ & 4.288859 & 3.343726 & -0.574873 \\
\hline $\mathrm{H}$ & 7.884615 & 0.604972 & 1.462394 \\
\hline $\mathrm{C}$ & -3.511891 & 1.697135 & -0.186809 \\
\hline $\mathrm{C}$ & -4.853676 & 2.074023 & -0.28535 \\
\hline
\end{tabular}




$\begin{array}{cccc}\mathrm{C} & -5.569099 & 0.853261 & -0.327395 \\ \mathrm{H} & -5.263838 & 3.070476 & -0.351643 \\ \mathrm{~N} & -3.433060 & 0.341843 & -0.172576 \\ \mathrm{~N} & -4.687685 & -0.179046 & -0.249490 \\ \mathrm{C} & -7.022728 & 0.647080 & -0.433306 \\ \mathrm{C} & -7.912931 & 1.679750 & -0.081750 \\ \mathrm{C} & -7.548582 & -0.577684 & -0.886469 \\ \mathrm{C} & -9.293973 & 1.490228 & -0.178058 \\ \mathrm{H} & -7.531983 & 2.627766 & 0.285064 \\ \mathrm{C} & -8.929657 & -0.765944 & -0.982523 \\ \mathrm{H} & -6.875887 & -1.375564 & -1.183211 \\ \mathrm{C} & -9.807629 & 0.267358 & -0.628227 \\ \mathrm{H} & -9.970017 & 2.292691 & 0.099965 \\ \mathrm{H} & -9.323658 & -1.711668 & -1.341856 \\ \mathrm{H} & -10.880426 & 0.121801 & -0.705246\end{array}$

$\mathrm{M}=\mathrm{Am}$

$\begin{array}{lccc}\text { AM } & -1.408733 & -0.884438 & 0.231090 \\ \mathrm{O} & -3.474711 & -1.353953 & 2.055475 \\ \mathrm{H} & -4.239882 & -1.060409 & 1.512889 \\ \mathrm{O} & -3.308041 & -2.192457 & -0.896789 \\ \mathrm{H} & -3.628008 & -3.106090 & -0.887775 \\ \mathrm{O} & -0.694975 & -0.204852 & 2.644956 \\ \mathrm{H} & -0.467811 & -0.899952 & 3.282561 \\ \mathrm{O} & -1.302579 & -0.861533 & -2.339824 \\ \mathrm{H} & -2.158506 & -1.172789 & -2.681007 \\ \mathrm{O} & -1.337715 & -2.921913 & 1.794229 \\ \mathrm{H} & -2.199015 & -3.126694 & 2.197082 \\ \mathrm{O} & 0.198972 & -2.745671 & -0.508148 \\ \mathrm{H} & 0.127035 & -3.146639 & -1.388217 \\ \mathrm{H} & -0.417897 & 0.638709 & 3.033511 \\ \mathrm{H} & -0.972034 & -0.197151 & -2.963197 \\ \mathrm{H} & -4.095855 & -1.573595 & -0.745193 \\ \mathrm{H} & 1.100907 & -2.307160 & -0.468411 \\ \mathrm{H} & -3.558448 & -0.877823 & 2.896085 \\ \mathrm{H} & -0.894927 & -3.749420 & 1.549945 \\ \mathrm{C} & 0.221436 & 2.251449 & -0.036142 \\ \mathrm{C} & 0.431631 & 3.628875 & -0.063445 \\ \mathrm{C} & -0.689061 & 4.469457 & -0.123438 \\ \mathrm{C} & -1.962634 & 3.908230 & -0.159861 \\ \mathrm{C} & -2.096236 & 2.509573 & -0.121511 \\ \mathrm{~N} & -1.011897 & 1.697478 & -0.047537 \\ \mathrm{H} & -0.563682 & 5.547578 & -0.148782 \\ \mathrm{H} & 1.441284 & 4.018280 & -0.041939 \\ \mathrm{H} & -2.845586 & 4.533871 & -0.219904\end{array}$




\begin{tabular}{|c|c|c|c|}
\hline $\mathrm{C}$ & 1.360085 & 1.298872 & -0.026034 \\
\hline- & 3.628490 & 0.917268 & -0.046289 \\
\hline $\mathrm{C}$ & 4.971539 & 1.459908 & 0.188247 \\
\hline $\mathrm{C}$ & 3.324701 & -0.485914 & -0.281792 \\
\hline $\mathrm{C}$ & 5.207019 & 2.811987 & -0.117357 \\
\hline $\mathrm{C}$ & 5.993385 & 0.687443 & 0.791857 \\
\hline $\mathrm{C}$ & 4.309591 & -1.516941 & -0.674727 \\
\hline $\mathrm{C}$ & 6.455937 & 3.396786 & 0.138091 \\
\hline $\mathrm{C}$ & 5.238510 & -1.232902 & -1.687118 \\
\hline $\mathrm{C}$ & 7.216888 & 1.287308 & 1.073795 \\
\hline $\mathrm{C}$ & 4.254760 & -2.800307 & -0.090286 \\
\hline $\mathrm{C}$ & 7.466946 & 2.627098 & 0.744564 \\
\hline $\mathrm{C}$ & 6.104214 & -2.244693 & -2.122594 \\
\hline $\mathrm{C}$ & 5.151635 & -3.792353 & -0.511605 \\
\hline $\mathrm{H}$ & 8.438567 & 3.055120 & 0.960318 \\
\hline $\mathrm{C}$ & 6.072538 & -3.509272 & -1.542084 \\
\hline $\mathrm{H}$ & 6.752978 & -4.292991 & -1.857977 \\
\hline $\mathrm{N}$ & 2.606157 & 1.778366 & -0.008919 \\
\hline $\mathrm{N}$ & 1.054414 & -0.004959 & -0.017657 \\
\hline $\mathrm{N}$ & 2.057666 & -0.884520 & -0.195304 \\
\hline $\mathrm{O}$ & 5.216085 & -5.049371 & 0.001418 \\
\hline $\mathrm{O}$ & 6.581722 & & -0.227842 \\
\hline $\mathrm{C}$ & 7.839123 & 5.356569 & -0.000584 \\
\hline $\mathrm{H}$ & 7.707875 & 6.371375 & -0.374578 \\
\hline $\mathrm{H}$ & 8.078768 & 5.389020 & 1.067811 \\
\hline $\mathrm{H}$ & 8.646060 & 4.864832 & -0.554507 \\
\hline $\mathrm{C}$ & 4.355545 & -5.396727 & 1.088159 \\
\hline $\mathrm{H}$ & 4.535940 & -4.753564 & 1.957959 \\
\hline $\mathrm{H}$ & 3.300174 & -5.341101 & 0.791825 \\
\hline $\mathrm{H}$ & 4.603699 & -6.426773 & 1.343264 \\
\hline $\mathrm{H}$ & 3.544360 & -2.996283 & 0.703473 \\
\hline $\mathrm{H}$ & 5.283716 & -0.249521 & -2.140673 \\
\hline $\mathrm{H}$ & 6.815508 & -2.039609 & -2.916419 \\
\hline $\mathrm{H}$ & 5.831035 & -0.349032 & 1.055975 \\
\hline $\mathrm{H}$ & 4.435081 & 3.418171 & -0.574566 \\
\hline $\mathrm{H}$ & 8.000106 & 0.708778 & 1.553620 \\
\hline $\mathrm{C}$ & -3.379317 & 1.816468 & -0.171369 \\
\hline $\mathrm{C}$ & -4.708719 & 2.232427 & -0.243054 \\
\hline $\mathrm{C}$ & -5.461820 & 1.032872 & -0.272984 \\
\hline $\mathrm{H}$ & -5.089551 & 3.240820 & -0.300059 \\
\hline $\mathrm{N}$ & -3.336916 & 0.460209 & -0.160670 \\
\hline $\mathrm{N}$ & -4.611402 & -0.024816 & -0.213629 \\
\hline $\mathrm{C}$ & -6.921872 & 0.872481 & -0.354530 \\
\hline $\mathrm{C}$ & -7.772420 & 1.950088 & -0.039780 \\
\hline $\mathrm{C}$ & -7.495945 & -0.352684 & -0.745325 \\
\hline$C$ & -9.160010 & 1.804240 & -0.110572 \\
\hline
\end{tabular}




$\begin{array}{cccc}\mathrm{H} & -7.355594 & 2.900491 & 0.278146 \\ \mathrm{C} & -8.883315 & -0.497229 & -0.816599 \\ \mathrm{H} & -6.855688 & -1.187148 & -1.011508 \\ \mathrm{C} & -9.720872 & 0.580883 & -0.498989 \\ \mathrm{H} & -9.804520 & 2.641248 & 0.138870 \\ \mathrm{H} & -9.314213 & -1.444093 & -1.127210 \\ \mathrm{H} & -10.798928 & 0.469149 & -0.556637\end{array}$

$\mathrm{M}=\mathrm{Cm}$

$\begin{array}{lrrc}\mathrm{CM} & -1.402786 & -0.849047 & 0.306934 \\ \mathrm{O} & -3.394206 & -1.267666 & 2.097433 \\ \mathrm{H} & -4.195299 & -1.042525 & 1.578967 \\ \mathrm{O} & -3.235588 & -2.229629 & -0.781545 \\ \mathrm{H} & -3.539998 & -3.148314 & -0.777492 \\ \mathrm{O} & -0.715173 & -0.025136 & 2.665714 \\ \mathrm{H} & -0.392654 & -0.683497 & 3.301748 \\ \mathrm{O} & -1.264085 & -0.802755 & -2.259040 \\ \mathrm{H} & -2.106346 & -1.124672 & -2.622485 \\ \mathrm{O} & -1.115368 & -2.773538 & 2.026907 \\ \mathrm{H} & -1.940011 & -3.062149 & 2.452241 \\ \mathrm{O} & 0.148857 & -2.775884 & -0.452518 \\ \mathrm{H} & 0.063177 & -3.225251 & -1.307375 \\ \mathrm{H} & -0.457282 & 0.848097 & 2.998050 \\ \mathrm{H} & -0.971297 & -0.079071 & -2.833626 \\ \mathrm{H} & -4.041716 & -1.615602 & -0.698832 \\ \mathrm{H} & 1.048518 & -2.336950 & -0.450795 \\ \mathrm{H} & -3.463937 & -0.753056 & 2.916686 \\ \mathrm{H} & -0.637661 & -3.562997 & 1.725312 \\ \mathrm{C} & 0.212457 & 2.251998 & -0.003590 \\ \mathrm{C} & 0.418843 & 3.629287 & -0.040693 \\ \mathrm{C} & -0.706315 & 4.465122 & -0.112351 \\ \mathrm{C} & -1.978433 & 3.901234 & -0.160069 \\ \mathrm{C} & -2.110448 & 2.501717 & -0.112806 \\ \mathrm{~N} & -1.021144 & 1.697989 & -0.012609 \\ \mathrm{H} & -0.584073 & 5.543515 & -0.144166 \\ \mathrm{H} & 1.426722 & 4.023579 & -0.021004 \\ \mathrm{H} & -2.861367 & 4.524796 & -0.240108 \\ \mathrm{C} & 1.350271 & 1.295507 & -0.000128 \\ \mathrm{C} & 3.615689 & 0.904031 & -0.061591 \\ \mathrm{C} & 4.964210 & 1.439527 & 0.155128 \\ \mathrm{C} & 3.302369 & -0.497155 & -0.299679 \\ \mathrm{C} & 5.199323 & 2.794010 & -0.140811 \\ \mathrm{C} & 5.993888 & 0.657369 & 0.732795 \\ \mathrm{C} & 4.276342 & -1.527446 & -0.720544 \\ \mathrm{C} & 6.454552 & 3.371859 & 0.098663\end{array}$




\begin{tabular}{|c|c|c|c|}
\hline $\mathrm{C}$ & 5.183372 & -1.238375 & -1.751154 \\
\hline & 7.224232 & 1.250110 & 0.999277 \\
\hline & 4.232684 & -2.814274 & -0.142693 \\
\hline & 7.473273 & 2.592382 & 0.679345 \\
\hline 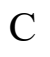 & 6.037948 & -2.248550 & -2.211751 \\
\hline C & 5.119110 & -3.804634 & -0.589316 \\
\hline $\mathrm{H}$ & 8.450122 & 3.014786 & 0.882207 \\
\hline $\mathrm{C}$ & 6.017391 & -3.516497 & -1.638223 \\
\hline $\mathrm{H}$ & 6.689756 & -4.299097 & -1.973581 \\
\hline$N$ & 2.597681 & 1.770048 & -0.004336 \\
\hline $\mathrm{N}$ & 1.042243 & -0.009232 & 0.015558 \\
\hline $\mathbf{N}$ & 2.036624 & -0.893812 & -0.186860 \\
\hline 0 & 5.193786 & -5.064634 & -0.085075 \\
\hline $\mathrm{O}$ & 6.578652 & 4.675734 & -0.256033 \\
\hline $\mathrm{C}$ & 7.842584 & 5.327932 & -0.045239 \\
\hline H & 7.708407 & 6.346847 & -0.406772 \\
\hline $\mathrm{H}$ & 8.101694 & 5.348911 & 1.018879 \\
\hline $\mathrm{H}$ & 8.637337 & 4.838738 & -0.618670 \\
\hline $\mathrm{C}$ & 4.359030 & -5.417336 & 1.019792 \\
\hline $\mathrm{H}$ & 4.559304 & -4.777995 & 1.888101 \\
\hline $\mathrm{H}$ & 3.296956 & -5.361211 & 0.748293 \\
\hline $\mathrm{H}$ & 4.613412 & -6.448387 & 1.264415 \\
\hline $\mathrm{H}$ & 3.540089 & -3.014022 & 0.665712 \\
\hline H & 5.219935 & -0.252280 & -2.199699 \\
\hline $\mathrm{H}$ & 6.731839 & -2.039532 & -3.019829 \\
\hline $\mathrm{H}$ & 5.832655 & -0.381289 & 0.988969 \\
\hline $\mathrm{H}$ & 4.421748 & 3.407401 & -0.578404 \\
\hline $\mathrm{H}$ & 8.013734 & 0.664018 & 1.459223 \\
\hline $\mathrm{C}$ & -3.388092 & 1.799337 & -0.193859 \\
\hline $\mathrm{C}$ & -4.722985 & 2.201100 & -0.282697 \\
\hline $\mathrm{C}$ & -5.459960 & 0.994433 & -0.348445 \\
\hline $\mathrm{H}$ & -5.116405 & 3.205387 & -0.327609 \\
\hline $\mathrm{N}$ & -3.333236 & 0.443109 & -0.206900 \\
\hline $\mathrm{N}$ & -4.597473 & -0.054909 & -0.293556 \\
\hline $\mathrm{C}$ & -6.917269 & 0.816720 & -0.455620 \\
\hline $\mathrm{C}$ & -7.788411 & 1.855041 & -0.074249 \\
\hline $\mathrm{C}$ & -7.465678 & -0.386361 & -0.939253 \\
\hline $\mathrm{C}$ & -9.172810 & 1.692257 & -0.171456 \\
\hline $\mathrm{H}$ & -7.389837 & 2.786246 & 0.316264 \\
\hline $\mathrm{C}$ & -8.850026 & -0.547937 & -1.036153 \\
\hline $\mathrm{H}$ & -6.807757 & -1.187686 & -1.259333 \\
\hline $\mathrm{C}$ & -9.708886 & 0.490816 & -0.652155 \\
\hline $\mathrm{H}$ & -9.833983 & 2.498796 & 0.129597 \\
\hline 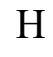 & -9.261443 & -1.476791 & -1.419289 \\
\hline 7 & -10.784251 & 0.366123 & -0.72992 \\
\hline
\end{tabular}




\section{$\left[\mathrm{ML}\left(\mathrm{H}_{2} \mathrm{O}\right)_{5}\right]^{2+}$}

$\mathrm{M}=\mathrm{Eu}$

\begin{tabular}{lccc} 
& & & \\
$\mathrm{EU}$ & 1.541995 & -1.097230 & 0.394707 \\
$\mathrm{O}$ & 0.279428 & -1.676872 & 2.566697 \\
$\mathrm{H}$ & -0.575566 & -2.037763 & 2.841328 \\
$\mathrm{O}$ & -0.106296 & -2.989346 & -0.288384 \\
$\mathrm{H}$ & -0.220335 & -3.926372 & -0.075678 \\
$\mathrm{O}$ & 3.723040 & -2.522255 & 0.751662 \\
$\mathrm{H}$ & 4.018333 & -3.435895 & 0.630136 \\
$\mathrm{O}$ & 2.808003 & -0.768107 & 2.808172 \\
$\mathrm{H}$ & 3.542925 & -1.395603 & 2.688561 \\
$\mathrm{O}$ & 1.758996 & -1.694424 & -2.071901 \\
$\mathrm{H}$ & 2.349853 & -1.415622 & -2.786510 \\
$\mathrm{H}$ & 4.426258 & -1.916788 & 0.378980 \\
$\mathrm{H}$ & 1.144054 & -2.348089 & -2.438990 \\
$\mathrm{H}$ & 0.822604 & -1.549454 & 3.361923 \\
$\mathrm{H}$ & -0.993271 & -2.546004 & -0.191814 \\
$\mathrm{H}$ & 3.177879 & 0.001260 & 3.267062 \\
$\mathrm{C}$ & 0.034791 & 2.076908 & -0.177493 \\
$\mathrm{C}$ & -0.144997 & 3.453047 & -0.333124 \\
$\mathrm{C}$ & 0.990937 & 4.262174 & -0.455269 \\
$\mathrm{C}$ & 2.251700 & 3.670444 & -0.436128 \\
$\mathrm{C}$ & 2.350312 & 2.277342 & -0.273760 \\
$\mathrm{~N}$ & 1.252767 & 1.498193 & -0.128626 \\
$\mathrm{H}$ & 0.889407 & 5.336024 & -0.578102 \\
$\mathrm{H}$ & -1.147249 & 3.860276 & -0.371337 \\
$\mathrm{H}$ & 3.146455 & 4.271443 & -0.549308 \\
$\mathrm{C}$ & -1.140543 & 1.161792 & -0.113299 \\
$\mathrm{C}$ & -3.422094 & 0.876191 & -0.123617 \\
$\mathrm{C}$ & -4.747858 & 1.498613 & -0.264633 \\
$\mathrm{C}$ & -3.180983 & -0.548713 & -0.004395 \\
$\mathrm{C}$ & -4.917437 & 2.809038 & 0.213157 \\
$\mathrm{C}$ & -5.812448 & 0.852449 & -0.935726 \\
$\mathrm{C}$ & -4.225585 & -1.580605 & 0.205116 \\
$\mathrm{C}$ & -6.144093 & 3.472576 & 0.063194 \\
$\mathrm{C}$ & -5.139914 & -1.438846 & 1.257896 \\
$\mathrm{C}$ & -7.013811 & 1.533527 & -1.110973 \\
$\mathrm{C}$ & -4.242549 & -2.728943 & -0.612747 \\
$\mathrm{C}$ & -7.199179 & 2.829694 & -0.610359 \\
$\mathrm{C}$ & -6.066009 & -2.463114 & 1.498684 \\
& -5.198748 & -3.729785 & -0.382208 \\
$\mathrm{H}$ & -8.154141 & 3.322120 & -0.749139 \\
$\mathrm{H}$ & -3.595284 & 0.689587 \\
\hline & -4.382981 & 0.855025
\end{tabular}




$\begin{array}{cccc}\mathrm{N} & -2.365363 & 1.696556 & -0.132975 \\ \mathrm{~N} & -0.885377 & -0.150849 & -0.102787 \\ \mathrm{~N} & -1.926408 & -0.996882 & -0.031109 \\ \mathrm{O} & -5.332744 & -4.860554 & -1.125888 \\ \mathrm{O} & -6.204813 & 4.722655 & 0.592474 \\ \mathrm{C} & -7.433089 & 5.457802 & 0.471168 \\ \mathrm{H} & -7.251963 & 6.412521 & 0.964075 \\ \mathrm{H} & -7.685809 & 5.631993 & -0.580509 \\ \mathrm{H} & -8.254855 & 4.937247 & 0.975009 \\ \mathrm{C} & -4.508943 & -5.027801 & -2.282016 \\ \mathrm{H} & -4.661748 & -4.213008 & -2.999631 \\ \mathrm{H} & -3.447703 & -5.091813 & -2.009266 \\ \mathrm{H} & -4.820681 & -5.969724 & -2.732909 \\ \mathrm{H} & -3.543611 & -2.808293 & -1.436747 \\ \mathrm{H} & -5.133893 & -0.553350 & 1.883504 \\ \mathrm{H} & -6.770822 & -2.369468 & 2.318948 \\ \mathrm{H} & -5.699645 & -0.146528 & -1.335095 \\ \mathrm{H} & -4.109438 & 3.321838 & 0.720289 \\ \mathrm{H} & -7.829378 & 1.053572 & -1.642872 \\ \mathrm{C} & 3.637728 & 1.578856 & -0.266802 \\ \mathrm{C} & 4.945426 & 2.010300 & -0.387693 \\ \mathrm{C} & 5.728794 & 0.821039 & -0.296802 \\ \mathrm{H} & 5.303152 & 3.018713 & -0.528024 \\ \mathrm{~N} & 3.634712 & 0.198603 & -0.114990 \\ \mathrm{~N} & 4.881929 & -0.252991 & -0.123695 \\ \mathrm{C} & 7.162492 & 0.670444 & -0.368229 \\ \mathrm{C} & 7.762874 & -0.617428 & -0.298969 \\ \mathrm{C} & 8.003406 & 1.808771 & -0.512453 \\ \mathrm{C} & 9.142590 & -0.757422 & -0.368727 \\ \mathrm{H} & 7.130682 & -1.491344 & -0.198388 \\ \mathrm{C} & 9.382570 & 1.662517 & -0.580101 \\ \mathrm{H} & 7.570280 & 2.801219 & -0.567946 \\ \mathrm{C} & 9.960100 & 0.380515 & -0.508677 \\ \mathrm{H} & 9.594704 & -1.742751 & -0.318094 \\ \mathrm{H} & 10.018233 & 2.535230 & -0.688702 \\ \mathrm{H} & 11.038682 & 0.269115 & -0.563320\end{array}$

$\mathrm{M}=\mathrm{Gd}$

$\begin{array}{llll}\mathrm{O} & 0.710968 & -1.993588 & 2.494765\end{array}$

$\mathrm{H} \quad 0.125067 \quad-2.763486 \quad 2.555562$

$\begin{array}{llll}\mathrm{O} & 0.048403 & -2.830061 & -0.161616\end{array}$

$\mathrm{H} \quad 0.050644 \quad-3.762483 \quad-0.418733$

$\begin{array}{llll}\text { O } & 3.433229 & -2.356913 & 0.621369\end{array}$

$\mathrm{H} \quad 3.719713 \quad-3.241218 \quad 0.885935$

$\begin{array}{llll}\text { O } & 2.216192 & 0.269065 & 2.556227\end{array}$ 


$\begin{array}{lrrr}\mathrm{H} & 3.125611 & 0.608861 & 2.505936 \\ \mathrm{O} & 1.814126 & -1.209042 & -2.030774 \\ \mathrm{H} & 2.620752 & -0.860795 & -2.443627 \\ \mathrm{H} & 4.253678 & -1.774240 & 0.382991 \\ \mathrm{H} & 1.340955 & -1.725264 & -2.699738 \\ \mathrm{H} & 1.147980 & -1.887580 & 3.354215 \\ \mathrm{H} & -0.892002 & -2.491608 & -0.101517 \\ \mathrm{H} & 1.740540 & 0.851213 & 3.168827 \\ \mathrm{C} & 0.014782 & 2.103268 & -0.242971 \\ \mathrm{C} & -0.165392 & 3.464694 & -0.469302 \\ \mathrm{C} & 0.976900 & 4.259737 & -0.655291 \\ \mathrm{C} & 2.236859 & 3.669909 & -0.617125 \\ \mathrm{C} & 2.341845 & 2.286895 & -0.377875 \\ \mathrm{~N} & 1.235385 & 1.524723 & -0.185236 \\ \mathrm{H} & 0.876579 & 5.325161 & -0.838526 \\ \mathrm{H} & -1.165974 & 3.875413 & -0.514171 \\ \mathrm{H} & 3.132723 & 4.260070 & -0.772290 \\ \mathrm{C} & -1.138042 & 1.175833 & -0.105822 \\ \mathrm{C} & -3.410845 & 0.813238 & -0.095745 \\ \mathrm{C} & -4.751888 & 1.391864 & -0.231545 \\ \mathrm{C} & -3.122697 & -0.604373 & 0.064081 \\ \mathrm{C} & -4.933387 & 2.729697 & 0.166066 \\ \mathrm{C} & -5.828292 & 0.683136 & -0.820207 \\ \mathrm{H} & -4.608503 & -4.221069 & -2.994617 \\ \mathrm{C} & -4.134407 & -1.669782 & 0.272757 \\ \mathrm{C} & -6.177739 & 3.358560 & 0.021049 \\ \mathrm{C} & -5.019750 & -1.577744 & 1.354456 \\ \mathrm{C} & -7.048036 & 1.329642 & -0.994670 \\ \mathrm{C} & -4.147185 & -2.794054 & -0.577729 \\ \mathrm{C} & -7.242440 & 2.651629 & -0.570823 \\ \mathrm{C} & -5.913787 & -2.631168 & 1.592689 \\ \mathrm{C} & -5.073532 & -3.823990 & -0.348667 \\ \mathrm{H} & -8.212164 & 3.115878 & -0.705139 \\ \mathrm{C} & -5.949997 & -3.740667 & 0.753031 \\ \mathrm{H} & -6.653421 & -4.550107 & 0.917007 \\ \mathrm{~N} & -2.377284 & 1.665159 & -0.151425 \\ \mathrm{~N} & -0.840802 & -0.128504 & -0.006281 \\ \mathrm{H} & -1.857000 & -1.009375 & 0.076704 \\ \mathrm{H} & -5.204874 & -4.935143 & -1.119634 \\ \mathrm{H} & -7.494571 & 5.636801 & 0.470865 \\ \mathrm{H} & 5.341665 & 0.348352 \\ \mathrm{H} & 6.328783 & 0.772490 \\ \mathrm{H} & 5.443404 & -0.702321 \\ \mathrm{H} & -2.83673 & -2.069089\end{array}$




$\begin{array}{lccc}\mathrm{H} & -4.724242 & -5.987351 & -2.774031 \\ \mathrm{H} & -3.475294 & -2.831710 & -1.427169 \\ \mathrm{H} & -5.015369 & -0.710205 & 2.004951 \\ \mathrm{H} & -6.595645 & -2.577806 & 2.435606 \\ \mathrm{H} & -5.710615 & -0.335805 & -1.161688 \\ \mathrm{H} & -4.119069 & 3.290105 & 0.608000 \\ \mathrm{H} & -7.871688 & 0.801859 & -1.465093 \\ \mathrm{C} & 3.606176 & 1.560794 & -0.319873 \\ \mathrm{C} & 4.949918 & 1.912121 & -0.448029 \\ \mathrm{C} & 5.662498 & 0.697091 & -0.272246 \\ \mathrm{H} & 5.366839 & 2.884193 & -0.665060 \\ \mathrm{~N} & 3.524225 & 0.218169 & -0.083919 \\ \mathrm{~N} & 4.778750 & -0.303653 & -0.048983 \\ \mathrm{C} & 7.117349 & 0.475722 & -0.309993 \\ \mathrm{C} & 8.005191 & 1.554894 & -0.140449 \\ \mathrm{C} & 7.645034 & -0.812523 & -0.518517 \\ \mathrm{C} & 9.386977 & 1.349432 & -0.175035 \\ \mathrm{H} & 7.622829 & 2.555309 & 0.036851 \\ \mathrm{C} & 9.026656 & -1.016557 & -0.553048 \\ \mathrm{H} & 6.973090 & -1.650567 & -0.671010 \\ \mathrm{C} & 9.902861 & 0.063730 & -0.381129 \\ \mathrm{H} & 10.061535 & 2.188801 & -0.038269 \\ \mathrm{H} & 9.422711 & -2.013231 & -0.721890 \\ \mathrm{H} & 10.976207 & -0.094816 & -0.409976 \\ \mathrm{GD} & 1.537218 & -0.923460 & 0.389908\end{array}$

$\mathrm{M}=\mathrm{Am}$

$\begin{array}{lrrc}\text { AM } & 1.447500 & -0.933325 & 0.317697 \\ \mathrm{O} & 0.899751 & -2.287322 & 2.419631 \\ \mathrm{H} & 0.353318 & -3.088229 & 2.400732 \\ \mathrm{O} & -0.192483 & -2.828817 & -0.135540 \\ \mathrm{H} & -0.244378 & -3.710314 & -0.530645 \\ \mathrm{O} & 3.469410 & -2.288537 & 0.452037 \\ \mathrm{H} & 3.793206 & -3.145886 & 0.758767 \\ \mathrm{O} & 2.033288 & 0.263382 & 2.562338 \\ \mathrm{H} & 2.862525 & 0.768443 & 2.532690 \\ \mathrm{O} & 1.755490 & -1.257718 & -2.170056 \\ \mathrm{H} & 2.598976 & -0.976337 & -2.560733 \\ \mathrm{H} & 4.259503 & -1.640753 & 0.268602 \\ \mathrm{H} & 1.246147 & -1.689742 & -2.871951 \\ \mathrm{H} & 1.386523 & -2.279827 & 3.258214 \\ \mathrm{H} & -1.108729 & -2.418971 & -0.091233 \\ \mathrm{H} & 1.509119 & 0.632160 & 3.289919 \\ \mathrm{C} & -0.125478 & 2.174429 & -0.266177 \\ \mathrm{C} & -0.318198 & 3.539087 & -0.465398\end{array}$




$\begin{array}{lrrr}\mathrm{C} & 0.814910 & 4.349924 & -0.629053 \\ \mathrm{C} & 2.079632 & 3.771141 & -0.590931 \\ \mathrm{C} & 2.194440 & 2.384636 & -0.380820 \\ \mathrm{~N} & 1.098620 & 1.604180 & -0.217524 \\ \mathrm{H} & 0.704866 & 5.417780 & -0.790883 \\ \mathrm{H} & -1.322677 & 3.940573 & -0.503784 \\ \mathrm{H} & 2.971144 & 4.373296 & -0.722623 \\ \mathrm{C} & -1.275741 & 1.244675 & -0.137624 \\ \mathrm{C} & -3.551807 & 0.892980 & -0.107810 \\ \mathrm{C} & -4.891875 & 1.478724 & -0.226241 \\ \mathrm{C} & -3.268279 & -0.525563 & 0.041269 \\ \mathrm{C} & -5.064348 & 2.813494 & 0.184538 \\ \mathrm{C} & -5.976825 & 0.778938 & -0.809340 \\ \mathrm{C} & -4.281865 & -1.588984 & 0.252658 \\ \mathrm{C} & -6.307677 & 3.448335 & 0.056999 \\ \mathrm{C} & -5.152231 & -1.505478 & 1.346849 \\ \mathrm{C} & -7.195911 & 1.431300 & -0.966089 \\ \mathrm{C} & -4.312477 & -2.702398 & -0.611529 \\ \mathrm{C} & -7.381007 & 2.750523 & -0.529803 \\ \mathrm{C} & -6.049288 & -2.556611 & 1.583724 \\ \mathrm{C} & -5.241466 & -3.729972 & -0.382811 \\ \mathrm{H} & -8.350230 & 3.219476 & -0.650560 \\ \mathrm{C} & -6.102892 & -3.655482 & 0.731129 \\ \mathrm{H} & -6.808638 & -4.463015 & 0.894495 \\ \mathrm{~N} & -2.514458 & 1.738966 & -0.167557 \\ \mathrm{C} & -3.801747 & 2.071392 & -0.437714 \\ \mathrm{~N} & -0.982178 & -0.060543 & -0.050835 \\ \mathrm{~N} & -2.004260 & -0.934283 & 0.039654 \\ \mathrm{O} & -5.389081 & -4.831022 & -1.165781 \\ \mathrm{O} & -6.367497 & 4.723290 & 0.517947 \\ \mathrm{C} & -7.613357 & 5.433547 & 0.414207 \\ \mathrm{H} & -7.424846 & 6.416511 & 0.844510 \\ \mathrm{H} & -7.916457 & 5.545004 & -0.632487 \\ \mathrm{H} & -8.401248 & 4.930205 & 0.984889 \\ \mathrm{C} & -4.617886 & -4.937223 & -2.364441 \\ \mathrm{H} & -4.814603 & -4.095818 & -3.039375 \\ \mathrm{H} & -3.544278 & -4.997580 & -2.142991 \\ \mathrm{H} & -4.937323 & -5.864175 & -2.840071 \\ \mathrm{H} & -3.652641 & -2.732815 & -1.470760 \\ \mathrm{H} & -5.133805 & -0.646323 & 2.008184 \\ \mathrm{H} & -5.866510 & -0.237762 & -1.159930 \\ \mathrm{H} & -243736 & 3.367056 & 0.623507 \\ \mathrm{H} & -0.874494 & -0.278157\end{array}$




$\begin{array}{cccc}\mathrm{H} & 5.190165 & 3.057785 & -0.641778 \\ \mathrm{~N} & 3.422607 & 0.333277 & -0.102601 \\ \mathrm{~N} & 4.694423 & -0.151371 & -0.072164 \\ \mathrm{C} & 7.008991 & 0.695291 & -0.321454 \\ \mathrm{C} & 7.574503 & -0.580008 & -0.512077 \\ \mathrm{C} & 7.865594 & 1.802986 & -0.173783 \\ \mathrm{C} & 8.961107 & -0.743439 & -0.550339 \\ \mathrm{H} & 6.927987 & -1.440722 & -0.647534 \\ \mathrm{C} & 9.252531 & 1.638111 & -0.211295 \\ \mathrm{H} & 7.454967 & 2.794645 & -0.011788 \\ \mathrm{C} & 9.805586 & 0.365149 & -0.399571 \\ \mathrm{H} & 9.386020 & -1.730473 & -0.705041 \\ \mathrm{H} & 9.902300 & 2.499273 & -0.091168 \\ \mathrm{H} & 10.883034 & 0.238122 & -0.431168\end{array}$

$\mathrm{M}=\mathrm{Cm}$

$\begin{array}{lrrc}\mathrm{CM} & 1.433754 & -0.883617 & 0.368147 \\ \mathrm{O} & 0.701209 & -2.064470 & 2.513838 \\ \mathrm{H} & 0.137495 & -2.852300 & 2.552812 \\ \mathrm{O} & -0.128033 & -2.826391 & -0.169136 \\ \mathrm{H} & -0.164536 & -3.754907 & -0.437853 \\ \mathrm{O} & 3.422474 & -2.297819 & 0.551438 \\ \mathrm{H} & 3.742317 & -3.179660 & 0.784580 \\ \mathrm{O} & 2.141118 & 0.297751 & 2.581536 \\ \mathrm{H} & 3.032351 & 0.680922 & 2.521427 \\ \mathrm{O} & 1.718133 & -1.202451 & -2.098664 \\ \mathrm{H} & 2.531762 & -0.874141 & -2.514747 \\ \mathrm{H} & 4.215095 & -1.682035 & 0.313910 \\ \mathrm{H} & 1.260935 & -1.758783 & -2.746945 \\ \mathrm{H} & 1.173182 & -1.998861 & 3.358697 \\ \mathrm{H} & -1.054206 & -2.451043 & -0.118932 \\ \mathrm{H} & 1.657981 & 0.826230 & 3.235716 \\ \mathrm{C} & -0.124263 & 2.168569 & -0.256197 \\ \mathrm{C} & -0.313685 & 3.530012 & -0.474456 \\ \mathrm{C} & 0.822288 & 4.335482 & -0.652713 \\ \mathrm{C} & 2.086282 & 3.755045 & -0.617451 \\ \mathrm{C} & 2.201934 & 2.371229 & -0.387901 \\ \mathrm{~N} & 1.101593 & 1.599773 & -0.198630 \\ \mathrm{H} & 0.713800 & 5.401338 & -0.828696 \\ \mathrm{H} & -1.317129 & 3.933604 & -0.518899 \\ \mathrm{H} & 2.977437 & 4.353192 & -0.768675 \\ \mathrm{C} & -1.276152 & 1.237465 & -0.129066 \\ \mathrm{C} & -3.549915 & 0.877998 & -0.117950 \\ \mathrm{C} & -4.890670 & 1.459955 & -0.245873 \\ \mathrm{C} & -3.263678 & -0.540818 & 0.029009\end{array}$




$\begin{array}{lrrr}\mathrm{C} & -5.071609 & 2.791793 & 0.170980 \\ \mathrm{C} & -5.967380 & 0.760033 & -0.844007 \\ \mathrm{C} & -4.277097 & -1.606602 & 0.228225 \\ \mathrm{C} & -6.315749 & 3.423229 & 0.034922 \\ \mathrm{C} & -5.161506 & -1.525533 & 1.311459 \\ \mathrm{C} & -7.186899 & 1.409408 & -1.009280 \\ \mathrm{C} & -4.292904 & -2.720737 & -0.635431 \\ \mathrm{C} & -7.380777 & 2.725354 & -0.566822 \\ \mathrm{C} & -6.057681 & -2.579740 & 1.537816 \\ \mathrm{C} & -5.221246 & -3.751292 & -0.417901 \\ \mathrm{H} & -8.350300 & 3.191839 & -0.694523 \\ \mathrm{C} & -6.096858 & -3.679211 & 0.685150 \\ \mathrm{H} & -6.801921 & -4.489015 & 0.840028 \\ \mathrm{~N} & -2.515264 & 1.728929 & -0.166854 \\ \mathrm{~N} & -0.981480 & -0.068206 & -0.042822 \\ \mathrm{~N} & -1.998847 & -0.948105 & 0.037507 \\ \mathrm{O} & -5.354963 & -4.853224 & -1.201995 \\ \mathrm{O} & -6.384466 & 4.695167 & 0.502812 \\ \mathrm{C} & -7.631633 & 5.401975 & 0.390943 \\ \mathrm{H} & -7.450686 & 6.382897 & 0.829066 \\ \mathrm{H} & -7.924627 & 5.518819 & -0.658032 \\ \mathrm{H} & -8.423453 & 4.892568 & 0.950699 \\ \mathrm{C} & -4.569970 & -4.956105 & -2.392170 \\ \mathrm{H} & -4.762566 & -4.115220 & -3.068920 \\ \mathrm{H} & -3.498673 & -5.012177 & -2.158878 \\ \mathrm{C} & -6.903417 & -1.475368 & -0.769683 \\ \mathrm{H} & -4.880546 & -5.884151 & -2.871476 \\ \mathrm{H} & -3.621293 & -2.749792 & -1.485503 \\ \mathrm{H} & -5.154678 & -0.665823 & 1.972363 \\ \mathrm{H} & -6.738820 & -2.534897 & 2.381845 \\ \mathrm{H} & -5.849950 & -0.254116 & -1.199748 \\ \mathrm{H} & -4.257147 & 3.345519 & 0.621134 \\ \mathrm{H} & -8.010842 & 0.888582 & -1.486932 \\ \mathrm{C} & 3.476201 & 1.661519 & -0.341660 \\ \mathrm{C} & 4.811003 & 2.041209 & -0.477528 \\ \mathrm{C} & 5.549407 & 0.838974 & -0.323752 \\ \mathrm{H} & 5.206397 & 3.023800 & -0.686802 \\ \mathrm{~N} & 3.423277 & 0.315233 & -0.121204 \\ \mathrm{~N} & 4.689071 & -0.181855 & -0.105412 \\ \mathrm{C} & 7.008108 & 0.647877 & -0.377829 \\ \mathrm{C} & 7.559775 & -0.626163 & -0.610312 \\ \mathrm{H} & -261042 & 1.564962 & -0.249386 \\ \mathrm{H} & -9.293170 & -0.479371\end{array}$




$$
\begin{array}{cccc}
\mathrm{H} & 9.919785 & 2.415683 & -0.105821 \\
\mathrm{H} & 9.359198 & -1.787747 & -0.847296 \\
\mathrm{H} & 10.876733 & 0.156787 & -0.519985 \\
& & & \\
\left.\mathbf{M L L}_{\mathbf{2}}\left(\mathbf{H}_{\mathbf{2}} \mathbf{O}\right)_{\mathbf{2}}\right]^{\mathbf{1 +}} & &
\end{array}
$$

$\mathrm{M}=\mathrm{Eu}$

$\begin{array}{lrrr}\text { EU } & -0.000003 & 1.586673 & -0.000008 \\ \mathrm{O} & 1.187648 & 3.247452 & -1.402932 \\ \mathrm{H} & 1.921254 & 3.623902 & -0.820576 \\ \mathrm{O} & -1.187650 & 3.247460 & 1.402909 \\ \mathrm{H} & -1.921233 & 3.623930 & 0.820538 \\ \mathrm{H} & 0.831447 & 3.947768 & -1.964748 \\ \mathrm{H} & -0.831445 & 3.947768 & 1.964733 \\ \mathrm{C} & 0.120788 & -0.401710 & -2.940490 \\ \mathrm{C} & -0.168597 & -0.930353 & -4.198665 \\ \mathrm{C} & -1.270285 & -0.411712 & -4.891339 \\ \mathrm{C} & -2.022529 & 0.605274 & -4.312380 \\ \mathrm{C} & -1.664501 & 1.086315 & -3.038330 \\ \mathrm{~N} & -0.606837 & 0.575783 & -2.369022 \\ \mathrm{H} & -1.530629 & -0.796173 & -5.872837 \\ \mathrm{H} & 0.458740 & -1.709616 & -4.611180 \\ \mathrm{H} & -2.875225 & 1.029554 & -4.829547 \\ \mathrm{C} & 1.287820 & -0.885084 & -2.157717 \\ \mathrm{C} & 3.131691 & -2.234944 & -1.986527 \\ \mathrm{C} & 4.062745 & -3.159951 & -2.672655 \\ \mathrm{C} & 3.305083 & -1.728249 & -0.651310 \\ \mathrm{C} & 3.534434 & -4.081875 & -3.586171 \\ \mathrm{C} & 5.459531 & -3.074837 & -2.489550 \\ \mathrm{C} & 4.313852 & -2.212928 & 0.324795 \\ \mathrm{C} & 4.380515 & -4.945227 & -4.298795 \\ \mathrm{C} & 4.482023 & -3.583984 & 0.562558 \\ \mathrm{C} & 6.292283 & -3.915401 & -3.223920 \\ \mathrm{C} & 5.060881 & -1.265353 & 1.049332 \\ \mathrm{C} & 5.770932 & -4.859157 & -4.120596 \\ \mathrm{C} & 5.400513 & -4.000618 & 1.534579 \\ \mathrm{C} & 5.998571 & -1.696309 & 1.996960 \\ \mathrm{H} & 6.446600 & -5.507445 & -4.665271 \\ \mathrm{C} & 6.161453 & -3.072959 & 2.243897 \\ \mathrm{H} & 6.888540 & -3.386906 & 2.985344 \\ \mathrm{~N} & 2.073336 & -1.827553 & -2.690494 \\ \mathrm{~N} & 1.509351 & -0.302141 & -0.969532 \\ \mathrm{~N} & 2.505542 & -0.755355 & -0.205659 \\ \mathrm{O} & 6.791338 & -0.861392 & 2.732001 \\ \mathrm{O} & 3.755005 & -5.820598 & -5.140197\end{array}$




\begin{tabular}{|c|c|c|c|}
\hline $\mathrm{C}$ & 4.567157 & -6.716354 & -5.905786 \\
\hline $\mathrm{H}$ & 3.871921 & -7.311775 & -6.498112 \\
\hline$H$ & 5.239666 & -6.168432 & -6.576236 \\
\hline $\mathrm{I}$ & 5.150383 & -7.378681 & -5.255232 \\
\hline$C$ & 6.754491 & 0.537747 & 2.433758 \\
\hline $\mathrm{H}$ & 7.046575 & 0.727916 & 1.394268 \\
\hline $\mathrm{F}$ & 5.761511 & 0.963429 & 2.616407 \\
\hline $\mathrm{H}$ & 7.479574 & 1.001663 & 3.103186 \\
\hline $\mathrm{H}$ & 4.897630 & -0.212163 & 0.859111 \\
\hline & 3.906748 & -4.316777 & 0.008228 \\
\hline & 5.530228 & -5.060048 & 1.733906 \\
\hline $\mathrm{H}$ & 5.887234 & -2.356029 & -1.802445 \\
\hline $\mathrm{H}$ & 2.465362 & -4.145670 & -3.749847 \\
\hline H & 7.368753 & -3.844306 & -3.101048 \\
\hline $\mathrm{C}$ & -2.386824 & 2.158306 & -2.361892 \\
\hline$C$ & -3.478813 & 2.950425 & -2.726758 \\
\hline $\mathrm{C}$ & -3.681815 & 3.804153 & -1.615877 \\
\hline H & -4.045585 & 2.920317 & -3.645480 \\
\hline$N$ & -1.972406 & 2.522827 & -1.116400 \\
\hline $\mathrm{N}$ & -2.755819 & 3.522505 & -0.665223 \\
\hline$C$ & -0.120789 & -0.401703 & 2.940479 \\
\hline 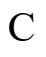 & 0.168600 & -0.930346 & 4.198653 \\
\hline 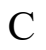 & 1.270291 & -0.411706 & 4.891324 \\
\hline $\mathrm{C}$ & 2.022535 & 0.605278 & 4.312361 \\
\hline $\mathrm{C}$ & 1.664502 & 1.086319 & 3.038312 \\
\hline $\mathrm{N}$ & 0.606835 & 0.575789 & 2.369009 \\
\hline $\mathrm{H}$ & 1.530638 & -0.796167 & 5.872820 \\
\hline $\mathrm{H}$ & -0.458736 & -1.709609 & 4.611172 \\
\hline $\mathrm{H}$ & 2.875234 & 1.029556 & 4.829524 \\
\hline $\mathrm{C}$ & -1.287823 & -0.885078 & 2.157710 \\
\hline $\mathrm{C}$ & -3.131692 & -2.234945 & 1.986530 \\
\hline $\mathrm{C}$ & -4.062744 & -3.159936 & 2.672684 \\
\hline $\mathrm{C}$ & -3.305090 & -1.728252 & 0.651311 \\
\hline $\mathrm{C}$ & -3.534415 & -4.081885 & 3.586164 \\
\hline 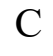 & -5.459539 & -3.074772 & 2.489660 \\
\hline $\mathrm{C}$ & -4.313826 & -2.212963 & -0.324813 \\
\hline 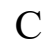 & -4.380484 & -4.945220 & 4.298822 \\
\hline $\mathrm{C}$ & -4.481892 & -3.584021 & -0.562642 \\
\hline $\mathrm{C}$ & -6.292277 & -3.915319 & 3.224064 \\
\hline $\mathrm{C}$ & -5.060927 & -1.265412 & -1.049307 \\
\hline 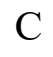 & -5.770908 & -4.859106 & 4.120697 \\
\hline $\mathrm{C}$ & -5.400352 & -4.000680 & -1.534680 \\
\hline 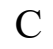 & -5.998592 & -1.696397 & -1.996948 \\
\hline & -6.446567 & -5.507380 & 4.665400 \\
\hline $\mathrm{C}$ & -6.161368 & -3.073048 & -2.243950 \\
\hline $\mathrm{H}$ & -6.888435 & -3.387016 & -2.985407 \\
\hline
\end{tabular}




$\begin{array}{lrrr}\mathrm{N} & -2.073334 & -1.827549 & 2.690490 \\ \mathrm{~N} & -1.509360 & -0.302137 & 0.969526 \\ \mathrm{~N} & -2.505553 & -0.755354 & 0.205658 \\ \mathrm{O} & -6.791435 & -0.861508 & -2.731939 \\ \mathrm{O} & -3.754957 & -5.820621 & 5.140180 \\ \mathrm{C} & -4.567096 & -6.716361 & 5.905801 \\ \mathrm{H} & -3.871846 & -7.311811 & 6.498084 \\ \mathrm{H} & -5.239554 & -6.168428 & 6.576293 \\ \mathrm{H} & -5.150376 & -7.378664 & 5.255269 \\ \mathrm{C} & -6.754711 & 0.537617 & -2.433617 \\ \mathrm{H} & -7.046811 & 0.727702 & -1.394116 \\ \mathrm{H} & -5.761769 & 0.963396 & -2.616241 \\ \mathrm{H} & -7.479835 & 1.001508 & -3.103019 \\ \mathrm{H} & -4.897758 & -0.212219 & -0.859037 \\ \mathrm{H} & -3.906557 & -4.316796 & -0.008350 \\ \mathrm{H} & -5.529985 & -5.060112 & -1.734057 \\ \mathrm{H} & -5.887257 & -2.355937 & 1.802595 \\ \mathrm{H} & -2.465336 & -4.145714 & 3.749785 \\ \mathrm{H} & -7.368752 & -3.844187 & 3.101254 \\ \mathrm{C} & 2.386824 & 2.158309 & 2.361872 \\ \mathrm{C} & 3.478818 & 2.950423 & 2.726731 \\ \mathrm{C} & 3.681808 & 3.804160 & 1.615855 \\ \mathrm{H} & 4.045598 & 2.920309 & 3.645447 \\ \mathrm{~N} & 1.972401 & 2.522831 & 1.116381 \\ \mathrm{~N} & 2.755806 & 3.522516 & 0.665206 \\ \mathrm{C} & -4.704594 & 4.844085 & -1.430164 \\ \mathrm{H} & 6.066428 & 6.832710 & -0.996862 \\ \mathrm{C} & -5.481155 & 5.293448 & -2.517225 \\ \mathrm{C} & -4.932163 & 5.415437 & -0.162068 \\ \mathrm{C} & -6.451877 & 6.282995 & -2.342560 \\ \mathrm{H} & -5.314806 & 4.882869 & -3.508144 \\ \mathrm{C} & -5.902648 & 6.404741 & 0.012117 \\ \mathrm{H} & -4.349325 & 5.072295 & 0.685425 \\ \mathrm{C} & -6.668481 & 6.844143 & -1.076956 \\ \mathrm{H} & -7.035969 & 6.622360 & -3.192851 \\ \mathrm{H} & -6.066466 & 6.832678 & 0.996841 \\ \mathrm{H} & -7.422194 & 7.613601 & -0.941300 \\ \mathrm{C} & 4.704583 & 4.844096 & 1.430141 \\ \mathrm{C} & 4.932139 & 5.415458 & 0.162046 \\ \mathrm{C} & 5.481152 & 5.293453 & 2.517198 \\ \mathrm{H} & 4.349295 & 6.404766 & -0.012140 \\ \mathrm{H} & 5.072321 & -0.685444 \\ \mathrm{H} & 6.622364 & 3.192820\end{array}$




\begin{tabular}{lrrr}
$\mathrm{H}$ & 7.422172 & 7.613623 & 0.941273 \\
$\mathrm{M}=\mathrm{Gd}$ & & & \\
\multicolumn{4}{c}{} \\
$\mathrm{GD}$ & 0.000000 & 1.571300 & 0.000000 \\
$\mathrm{O}$ & 1.166123 & 3.180185 & -1.412044 \\
$\mathrm{H}$ & 1.919987 & 3.562099 & -0.851102 \\
$\mathrm{O}$ & -1.166138 & 3.180168 & 1.412052 \\
$\mathrm{H}$ & -1.919995 & 3.562087 & 0.851104 \\
$\mathrm{H}$ & 0.816637 & 3.861801 & -2.000492 \\
$\mathrm{H}$ & -0.816655 & 3.861783 & 2.000503 \\
$\mathrm{C}$ & 0.172436 & -0.389132 & -2.895479 \\
$\mathrm{C}$ & -0.098835 & -0.913830 & -4.158122 \\
$\mathrm{C}$ & -1.198194 & -0.400736 & -4.860206 \\
$\mathrm{C}$ & -1.967213 & 0.604748 & -4.284369 \\
$\mathrm{C}$ & -1.627819 & 1.084521 & -3.004540 \\
$\mathrm{~N}$ & -0.568532 & 0.582076 & -2.328801 \\
$\mathrm{H}$ & -1.444293 & -0.782794 & -5.846310 \\
$\mathrm{H}$ & 0.539181 & -1.685990 & -4.567506 \\
$\mathrm{H}$ & -2.820367 & 1.021553 & -4.806810 \\
$\mathrm{C}$ & 1.328415 & -0.869115 & -2.096216 \\
$\mathrm{C}$ & 3.181520 & -2.202378 & -1.902372 \\
$\mathrm{C}$ & 4.131962 & -3.114939 & -2.577262 \\
$\mathrm{C}$ & 3.324825 & -1.705038 & -0.559203 \\
$\mathrm{C}$ & 3.627820 & -4.027835 & -3.513611 \\
$\mathrm{C}$ & 5.524121 & -3.027411 & -2.361545 \\
$\mathrm{C}$ & 4.324329 & -2.187223 & 0.427949 \\
$\mathrm{C}$ & 4.492729 & -4.879924 & -4.216876 \\
$\mathrm{C}$ & 4.487356 & -3.557956 & 0.670330 \\
$\mathrm{C}$ & 6.376135 & -3.856143 & -3.087143 \\
$\mathrm{C}$ & 5.068803 & -1.238778 & 1.153705 \\
$\mathrm{C}$ & 5.878532 & -4.790983 & -4.006311 \\
$\mathrm{C}$ & 5.398061 & -3.973962 & 1.649960 \\
$\mathrm{C}$ & 6.000472 & -1.669532 & 2.107821 \\
$\mathrm{H}$ & 6.568697 & -5.430493 & -4.543148 \\
$\mathrm{C}$ & 6.157176 & -3.045921 & 2.360633 \\
$\mathrm{H}$ & 6.879064 & -3.359310 & 3.107376 \\
$\mathrm{~N}$ & 2.133187 & -1.798007 & -2.622929 \\
$\mathrm{~N}$ & 1.518166 & -0.298450 & -0.896150 \\
$\mathrm{~N}$ & 2.506008 & -0.748035 & -0.117248 \\
$\mathrm{O}$ & 6.792319 & -0.835192 & 2.843709 \\
$\mathrm{H}$ & 3.889637 & -5.747525 & -5.082023 \\
$\mathrm{H}$ & 4.042161 & -7.223280 & -6.839004 \\
$\mathrm{H}$ & & -6.074840 & -6.488136 \\
$\mathrm{H}$ & -7.299868 & -5.182717
\end{tabular}




$\begin{array}{lrrr}\mathrm{C} & 6.771785 & 0.561850 & 2.532489 \\ \mathrm{H} & 7.075941 & 0.739324 & 1.494280 \\ \mathrm{H} & 5.781298 & 0.998477 & 2.700840 \\ \mathrm{H} & 7.494453 & 1.024980 & 3.204956 \\ \mathrm{H} & 4.910233 & -0.185543 & 0.959125 \\ \mathrm{H} & 3.914468 & -4.290812 & 0.113465 \\ \mathrm{H} & 5.523753 & -5.033067 & 1.853518 \\ \mathrm{H} & 5.933993 & -2.315459 & -1.656812 \\ \mathrm{H} & 2.562996 & -4.093492 & -3.702113 \\ \mathrm{H} & 7.449293 & -3.782763 & -2.939336 \\ \mathrm{C} & -2.369028 & 2.137613 & -2.322711 \\ \mathrm{C} & -3.479365 & 2.915816 & -2.671757 \\ \mathrm{C} & -3.696469 & 3.743164 & -1.547312 \\ \mathrm{H} & -4.049818 & 2.890371 & -3.588469 \\ \mathrm{~N} & -1.956832 & 2.492019 & -1.077607 \\ \mathrm{~N} & -2.762837 & 3.466011 & -0.604291 \\ \mathrm{C} & -0.172427 & -0.389138 & 2.895476 \\ \mathrm{C} & 0.098849 & -0.913838 & 4.158117 \\ \mathrm{C} & 1.198209 & -0.400745 & 4.860198 \\ \mathrm{C} & 1.967226 & 0.604741 & 4.284362 \\ \mathrm{C} & 1.627827 & 1.084517 & 3.004535 \\ \mathrm{~N} & 0.568539 & 0.582072 & 2.328797 \\ \mathrm{H} & 1.444312 & -0.782805 & 5.846300 \\ \mathrm{H} & -0.539166 & -1.685998 & 4.567501 \\ \mathrm{H} & 2.820381 & 1.021546 & 4.806802 \\ \mathrm{C} & -1.328408 & -0.869118 & 2.096214 \\ \mathrm{C} & -3.181517 & -2.202375 & 1.902375 \\ \mathrm{C} & -4.131964 & -3.114931 & 2.577265 \\ \mathrm{C} & -3.324819 & -1.705040 & 0.559203 \\ \mathrm{C} & -3.627830 & -4.027820 & 3.513624 \\ \mathrm{C} & -5.524122 & -3.027404 & 2.361534 \\ \mathrm{C} & -4.324328 & -2.187222 & -0.427945 \\ \mathrm{C} & -4.492746 & -4.879904 & 4.216889 \\ \mathrm{C} & -4.487377 & -3.557956 & -0.670307 \\ \mathrm{C} & -6.376142 & -3.856132 & 3.087131 \\ \mathrm{C} & -5.068784 & -1.238775 & -1.153715 \\ \mathrm{C} & -5.878546 & -4.790964 & 4.006311 \\ \mathrm{C} & -5.398086 & -3.973961 & -1.649935 \\ \mathrm{H} & -6.000457 & -1.669527 & -2.107829 \\ \mathrm{H} & -6.56716 & -5.430471 & 4.543146 \\ \mathrm{~N} & -3.045916 & -2.360623 \\ \mathrm{H} & -3.359303 & -3.107365 \\ \mathrm{H} & -1.798006 & 2.622930 \\ \mathrm{H} & -0.298456 & 0.896148 \\ \mathrm{H} & -0.835184 & -2.843734\end{array}$




\begin{tabular}{|c|c|c|c|}
\hline D & -3.889661 & -5.747499 & . \\
\hline & -4.721970 & -6.632251 & 5839028 \\
\hline & -4.042197 & -7.223242 & 6.453292 \\
\hline & -5.407412 & -6.074802 & 6.488149 \\
\hline & -5.292590 & -7.299840 & 5.182741 \\
\hline & -6.771723 & 0.561864 & -2.532539 \\
\hline $\mathrm{H}$ & -7.075877 & 0.739364 & 4334 \\
\hline & -5.781226 & 0.998467 & -2.700895 \\
\hline $\mathrm{H}$ & -7.494379 & 1.024998 & -3.205016 \\
\hline $\mathrm{H}$ & -4.910197 & -0.185539 & -0.959150 \\
\hline $\mathrm{H}$ & -3.914502 & -4.290814 & 3431 \\
\hline $\mathrm{H}$ & -5.523794 & -5.033066 & 3478 \\
\hline $\mathrm{H}$ & -5.933987 & -2.315459 & 1.656791 \\
\hline $\mathrm{H}$ & -2.563007 & -4.0 & 136 \\
\hline $\mathrm{H}$ & -7.449299 & 2753 & 9313 \\
\hline C & 2.36 & 2.1 & 2707 \\
\hline $\mathrm{C}$ & 3.479369 & 2.9 & 753 \\
\hline C & 3.696466 & 3.7 & 12 \\
\hline $\mathrm{H}$ & 4.049825 & 2.8 & 8463 \\
\hline $\mathrm{N}$ & 1.956830 & 2.4 & 607 \\
\hline $\mathbf{N}$ & 2.762830 & 3.4 & 0.604294 \\
\hline $\mathrm{C}$ & -4.740659 & 4.7 & -1.2 \\
\hline $\mathrm{C}$ & -5.448813 & 5.2 & 5124 \\
\hline $\mathrm{C}$ & -5.054941 & 5.22 & 8938 \\
\hline $\mathrm{C}$ & -6.441869 & 6.2 & -2.242067 \\
\hline $\mathrm{H}$ & -5.209881 & $4.9^{\prime}$ & -3.443938 \\
\hline 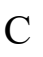 & -6.046075 & 6.18 & 3910 \\
\hline $\mathrm{H}$ & -4.524551 & 4.8 & 0.803652 \\
\hline C & -6.745945 & 6.71 & -0.951499 \\
\hline $\mathrm{H}$ & -6.973111 & 6.66 & -3.097728 \\
\hline $\mathrm{H}$ & -6.277297 & 6.5 & 1.148345 \\
\hline $\mathrm{H}$ & -7.515474 & 7.464523 & -0.801518 \\
\hline $\mathrm{C}$ & 4.740652 & 4.762682 & 1.341661 \\
\hline $\mathrm{C}$ & 5.054930 & 5.223285 & 0.048941 \\
\hline $\mathrm{C}$ & 5.448807 & 5.296843 & 2.435126 \\
\hline $\mathrm{C}$ & 6.046061 & 772 & -0.143906 \\
\hline $\mathrm{H}$ & 4.524539 & 4.813174 & -0.803650 \\
\hline $\mathrm{C}$ & 6.441860 & 6.261796 & 2.242071 \\
\hline $\mathrm{H}$ & 5.209878 & 4.974514 & 3.443939 \\
\hline $\mathrm{C}$ & 6.745932 & 6.713601 & 0.951503 \\
\hline $\mathrm{H}$ & 6.277280 & 6.532499 & -1.148340 \\
\hline 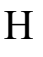 & 6.973103 & 6.668134 & 3.097732 \\
\hline $\mathrm{H}$ & 7.515459 & 7.464545 & 0.801524 \\
\hline
\end{tabular}

$\mathrm{M}=\mathrm{Am}$ 


\begin{tabular}{|c|c|c|c|}
\hline 31 & 0.000013 & 1.496351 & 0.000015 \\
\hline $\mathrm{O}$ & -1.238902 & 3.159496 & 1.402173 \\
\hline $\mathrm{H}$ & -1.938820 & 3.559098 & 0.786338 \\
\hline 0 & 1.239166 & 3.159249 & -1.402242 \\
\hline $\mathrm{H}$ & 1.939056 & 3.558858 & -0.786373 \\
\hline Н & -0.837422 & 3.861897 & 1.931062 \\
\hline $\mathrm{H}$ & 0.837758 & 3.861641 & -1.931197 \\
\hline $\mathrm{C}$ & -0.134432 & -0.460213 & 2.977891 \\
\hline $\mathrm{C}$ & 0.146616 & -0.971604 & 4.243783 \\
\hline $\mathrm{C}$ & 1.234070 & -0.430815 & 4.943402 \\
\hline $\mathrm{C}$ & 1.977770 & 0.591698 & 4.364562 \\
\hline $\mathrm{C}$ & 1.628525 & 1.057075 & 3.081853 \\
\hline $\mathrm{N}$ & 0.588137 & 0.521442 & 2.404605 \\
\hline $\mathrm{H}$ & 1.488033 & -0.801826 & 5.931681 \\
\hline $\mathrm{H}$ & -0.475339 & -1.753833 & 4.658833 \\
\hline $\mathrm{H}$ & 2.816312 & 1.034669 & 4.889069 \\
\hline $\mathrm{C}$ & -1.287147 & -0.960703 & 2.187255 \\
\hline $\mathrm{C}$ & -3.119534 & -2.32 & 1.997646 \\
\hline $\mathrm{C}$ & -4.049869 & -3.255682 & 2.673606 \\
\hline $\mathrm{C}$ & -3.284666 & -1.81 & 9337 \\
\hline $\mathrm{C}$ & -3.523521 & -4.176956 & 3.588938 \\
\hline $\mathrm{C}$ & -5.445602 & -3.178987 & 2.478590 \\
\hline $\mathrm{C}$ & -4.281736 & -2.309018 & -0.325807 \\
\hline $\mathrm{C}$ & -4.370100 & -5.047776 & 4.291838 \\
\hline $\mathrm{C}$ & -4.443192 & -3.681103 & -0.562569 \\
\hline $\mathrm{C}$ & -6.279235 & -4.026542 & 3.203686 \\
\hline $\mathrm{C}$ & -5.022802 & -1.364817 & -1.060994 \\
\hline $\mathrm{C}$ & -5.759534 & -4.969665 & 4.101976 \\
\hline $\mathrm{C}$ & -5.349188 & -4.101990 & -1.544394 \\
\hline $\mathrm{C}$ & -5.948046 & -1.800069 & -2.018880 \\
\hline $\mathrm{H}$ & -6.435755 & -5.623674 & 4.639058 \\
\hline $\mathrm{C}$ & -6.104138 & -3.177853 & -2.264547 \\
\hline $\mathrm{H}$ & -6.821539 & -3.495364 & -3.013884 \\
\hline $\mathrm{N}$ & -2.071191 & -1.908353 & 2.712663 \\
\hline $\mathrm{N}$ & -1.501148 & -0.383637 & 0.995410 \\
\hline $\mathrm{N}$ & -2.485801 & -0.843691 & 0.219882 \\
\hline $\mathrm{O}$ & -6.733910 & -0.969189 & -2.764867 \\
\hline $\mathrm{O}$ & -3.746373 & -5.921628 & 5.135714 \\
\hline $\mathrm{C}$ & -4.559241 & -6.824488 & 5.892487 \\
\hline $\mathrm{H}$ & -3.865084 & -7.416951 & 6.488970 \\
\hline $\mathrm{H}$ & -5.240533 & -6.282369 & 6.558721 \\
\hline $\mathrm{H}$ & -5.132821 & -7.488784 & 5.235428 \\
\hline $\mathrm{C}$ & -6.701182 & 0.431777 & -2.473136 \\
\hline $\mathrm{H}$ & -7.004694 & 0.626776 & -1.437864 \\
\hline $\mathrm{H}$ & -5.706684 & 0.857259 & -2.647638 \\
\hline $\mathrm{H}$ & -7.419363 & 0.891715 & -3.152563 \\
\hline
\end{tabular}




\begin{tabular}{|c|c|c|c|}
\hline $\mathrm{H}$ & -4.865414 & -0.310705 & -0.870916 \\
\hline & -3.872397 & -4.411341 & -0.000315 \\
\hline & -5.473678 & -5.162151 & -1.743158 \\
\hline & -5.872156 & -2.460559 & 1.790378 \\
\hline & -2.455500 & -4.234666 & 3.761673 \\
\hline & -7.355060 & -3.961557 & 3.072126 \\
\hline & 2.341454 & 2.132077 & 2.403929 \\
\hline & 3.448030 & 2.913694 & 2.754026 \\
\hline & 3.647581 & 3.760894 & 1.641362 \\
\hline & 4.031451 & 2.874762 & 3.661925 \\
\hline & 1.912569 & 2.502668 & 1.168964 \\
\hline & 2.708574 & 3.490713 & 0.703476 \\
\hline & 0.134351 & -0.460274 & -2.977854 \\
\hline & -0.146680 & -0.971617 & -4.243769 \\
\hline & -1.234062 & -0.430731 & -4.943424 \\
\hline 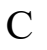 & -1.977712 & 0.591824 & -4.364592 \\
\hline$C$ & -1.628493 & 1.057143 & -3.081855 \\
\hline $\mathrm{N}$ & -0.588171 & 0.521421 & -2.404576 \\
\hline 1 & -1.488005 & -0.801696 & -5.931725 \\
\hline $\mathrm{H}$ & 0.475235 & -1.753883 & -4.658809 \\
\hline H & -2.816186 & 1.034883 & -4.889133 \\
\hline & 1.287025 & -0.960826 & -2.187199 \\
\hline $\mathrm{C}$ & 3.119364 & -2.323780 & -1.997576 \\
\hline $\mathrm{C}$ & 4.049561 & -3.256064 & -2.673446 \\
\hline $\mathrm{C}$ & 3.284554 & -1.818803 & -0.659303 \\
\hline $\mathrm{C}$ & 3.523078 & -4.177308 & -3.588732 \\
\hline $\mathrm{C}$ & 5.445299 & -3.179628 & -2.478368 \\
\hline $\mathrm{C}$ & 4.281726 & -2.309054 & 0.325788 \\
\hline $\mathrm{C}$ & 4.369519 & -5.048334 & -4.291539 \\
\hline$C$ & 4.443211 & -3.681115 & 0.562652 \\
\hline $\mathrm{C}$ & 6.278801 & -4.027391 & -3.203371 \\
\hline $\mathrm{C}$ & 5.022889 & -1.364781 & 1.060781 \\
\hline $\mathrm{C}$ & 5.758961 & -4.970474 & -4.101624 \\
\hline $\mathrm{C}$ & 5.349328 & -4.101910 & 1.544405 \\
\hline $\mathrm{C}$ & 5.948246 & -1.799942 & 2.018601 \\
\hline $\mathrm{H}$ & 6.435080 & -5.624648 & -4.638632 \\
\hline 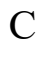 & 6.104365 & -3.177704 & 2.264380 \\
\hline $\mathrm{H}$ & 6.821863 & -3.495146 & 3.013654 \\
\hline $\mathrm{N}$ & 2.071027 & -1.908514 & -2.712595 \\
\hline $\mathrm{N}$ & 1.501016 & -0.383780 & -0.995341 \\
\hline $\mathrm{N}$ & 2.485698 & -0.843813 & -0.219834 \\
\hline $\mathrm{O}$ & 6.734198 & -0.968990 & 2.764412 \\
\hline $\mathrm{O}$ & 3.745663 & -5.922124 & -5.135383 \\
\hline $\mathrm{C}$ & 4.558389 & -6.825200 & -5.892050 \\
\hline 11 & 3.864144 & -7.417576 & -6.488516 \\
\hline $\mathrm{H}$ & 5.239813 & -6.283264 & -6.558298 \\
\hline
\end{tabular}




$\begin{array}{lrrr}\mathrm{H} & 5.131815 & -7.489554 & -5.234914 \\ \mathrm{C} & 6.701473 & 0.431944 & 2.472510 \\ \mathrm{H} & 7.004882 & 0.626809 & 1.437184 \\ \mathrm{H} & 5.707001 & 0.857463 & 2.647068 \\ \mathrm{H} & 7.419730 & 0.891952 & 3.151809 \\ \mathrm{H} & 4.865485 & -0.310687 & 0.870619 \\ \mathrm{H} & 3.872352 & -4.411402 & 0.000524 \\ \mathrm{H} & 5.473849 & -5.162052 & 1.743249 \\ \mathrm{H} & 5.871962 & -2.461241 & -1.790181 \\ \mathrm{H} & 2.455052 & -4.234830 & -3.761505 \\ \mathrm{H} & 7.354632 & -3.962605 & -3.071765 \\ \mathrm{C} & -2.341358 & 2.132199 & -2.403948 \\ \mathrm{C} & -3.447803 & 2.913972 & -2.754110 \\ \mathrm{C} & -3.647338 & 3.761159 & -1.641431 \\ \mathrm{H} & -4.031177 & 2.875126 & -3.662043 \\ \mathrm{~N} & -1.912512 & 2.502710 & -1.168943 \\ \mathrm{~N} & -2.708432 & 3.490835 & -0.703485 \\ \mathrm{C} & 4.682124 & 4.791504 & 1.442072 \\ \mathrm{C} & 5.395202 & 5.314487 & 2.537687 \\ \mathrm{C} & 4.981651 & 5.274476 & 0.153983 \\ \mathrm{C} & 6.379154 & 6.289995 & 2.351271 \\ \mathrm{H} & 5.167386 & 4.974499 & 3.543275 \\ \mathrm{C} & 5.963769 & 6.251341 & -0.032183 \\ \mathrm{H} & 4.447442 & 4.873838 & -0.700818 \\ \mathrm{C} & 6.668811 & 6.763751 & 1.065283 \\ \mathrm{H} & 6.914484 & 6.687232 & 3.208644 \\ \mathrm{H} & 6.183741 & 6.611239 & -1.033129 \\ \mathrm{H} & 7.431313 & 7.522831 & 0.920461 \\ \mathrm{C} & -4.681780 & 4.791876 & -1.442179 \\ \mathrm{C} & -4.981306 & 5.274877 & -0.154101 \\ \mathrm{C} & -5.394757 & 5.314941 & -2.537822 \\ \mathrm{C} & -5.963326 & 6.251848 & 0.032028 \\ \mathrm{H} & -4.447177 & 4.874178 & 0.700720 \\ \mathrm{C} & -6.378612 & 6.290554 & -2.351442 \\ \mathrm{H} & -5.166941 & 4.974930 & -3.543402 \\ \mathrm{C} & -6.668269 & 6.764338 & -1.065464 \\ \mathrm{H} & -6.183299 & 6.611767 & 1.032967 \\ \mathrm{H} & -6.913865 & 6.687850 & -3.208835 \\ & -7.430695 & 7.523500 & -0.920670\end{array}$

$\mathrm{M}=\mathrm{Cm}$
$\begin{array}{llll}\mathrm{CM} & -0.000075 & 1.501395 & -0.000043\end{array}$
$\begin{array}{llll}\text { O } & -1.243609 & 3.159963 & 1.401638\end{array}$
$\mathrm{H} \quad-1.969810 \quad 3.529458 \quad 0.798446$
O $\quad 1.242951 \quad 3.160342 \quad-1.401709$ 


\begin{tabular}{|c|c|c|c|}
\hline $\mathrm{H}$ & 1.969217 & 3.529873 & -0.798617 \\
\hline & -0.891275 & 3.868816 & 1.955720 \\
\hline & 0.890528 & 3.869166 & -1.955771 \\
\hline & -0.215037 & -0.429035 & 2.964689 \\
\hline 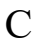 & 0.036723 & -0.932226 & 4.240089 \\
\hline 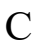 & 1.121832 & -0.403212 & 4.952513 \\
\hline 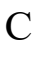 & 1.896407 & 0.596132 & 4.373903 \\
\hline & 1.576843 & 1.055346 & 3.081067 \\
\hline $\mathrm{N}$ & 0.531519 & 0.537354 & 2.396398 \\
\hline $\mathrm{H}$ & 1.352575 & -0.768419 & 5.948694 \\
\hline H & -0.604016 & -1.701011 & 4.651496 \\
\hline H & 2.738095 & 1.024944 & 4.905135 \\
\hline $\mathrm{C}$ & -1.354623 & -0.932279 & 2.155094 \\
\hline $\mathrm{C}$ & -3.193641 & -2.285027 & 1.954433 \\
\hline $\mathrm{C}$ & -4.148585 & -3.192121 & 2.630149 \\
\hline $\mathrm{C}$ & -3.318492 & -1.815894 & 0.599188 \\
\hline $\mathrm{C}$ & -3.653247 & -4.091466 & 3.583863 \\
\hline $\mathrm{C}$ & -5.538016 & -3.112611 & 2.395241 \\
\hline $\mathrm{C}$ & -4.295012 & -2.325380 & -0.397026 \\
\hline $\mathrm{C}$ & -4.524174 & -4.938027 & 4.286561 \\
\hline $\mathrm{C}$ & -4.454542 & -3.702018 & -0.606647 \\
\hline $\mathrm{C}$ & -6.396472 & -3.935364 & 3.119974 \\
\hline $\mathrm{C}$ & -5.018884 & -1.396107 & -1.167369 \\
\hline $\mathrm{C}$ & -5.907430 & -4.856926 & 4.057020 \\
\hline $\mathrm{C}$ & -5.341077 & -4.142948 & -1.597447 \\
\hline $\mathrm{C}$ & -5.925967 & -1.851000 & -2.133596 \\
\hline $\mathrm{H}$ & -6.602175 & -5.492325 & 4.592799 \\
\hline $\mathrm{C}$ & -6.079497 & -3.233520 & -2.352578 \\
\hline $\mathrm{H}$ & -6.782230 & -3.566124 & -3.109238 \\
\hline $\mathrm{N}$ & -2.161345 & -1.858096 & 2.685321 \\
\hline $\mathrm{N}$ & -1.530608 & -0.387039 & 0.941336 \\
\hline $\mathrm{N}$ & -2.499646 & -0.860693 & 0.153353 \\
\hline $\mathrm{O}$ & -6.695728 & -1.035480 & -2.912757 \\
\hline $\mathrm{O}$ & -3.929154 & -5.792502 & 5.170096 \\
\hline $\mathrm{C}$ & -4.767767 & -6.671575 & 5.926763 \\
\hline $\mathrm{H}$ & -4.093718 & -7.252291 & 6.556907 \\
\hline $\mathrm{H}$ & -5.463882 & -6.109253 & 6.560127 \\
\hline $\mathrm{H}$ & -5.326999 & -7.349363 & 5.271109 \\
\hline $\mathrm{C}$ & -6.671525 & 0.370603 & -2.646395 \\
\hline $\mathrm{H}$ & -6.997652 & 0.584088 & -1.621678 \\
\hline $\mathrm{H}$ & -5.674099 & 0.794758 & -2.806651 \\
\hline $\mathrm{H}$ & -7.375384 & 0.816562 & -3.349723 \\
\hline $\mathrm{H}$ & -4.863249 & -0.338292 & -0.997035 \\
\hline 11 & -3.897039 & -4.420571 & -0.016528 \\
\hline $\mathrm{H}$ & -5.463561 & -5.207006 & -1.775622 \\
\hline $\mathrm{H}$ & -5.941156 & -2.410637 & 1.676565 \\
\hline
\end{tabular}




\begin{tabular}{|c|c|c|c|}
\hline $\mathrm{H}$ & -2.590628 & -4.151063 & 3.786755 \\
\hline & -7.467905 & -3.867726 & 2.957478 \\
\hline 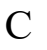 & 2.330621 & 2.101665 & 2.401312 \\
\hline C & 3.439802 & 2.873388 & 2.767148 \\
\hline $\mathrm{C}$ & 3.682846 & 3.695676 & 1.644790 \\
\hline H & 3.994781 & 2.846192 & 3.693093 \\
\hline $\mathrm{N}$ & 1.943915 & 2.454312 & 1.147315 \\
\hline$N$ & 2.765741 & 3.421353 & 0.685626 \\
\hline $\mathrm{C}$ & 0.215225 & -0.429167 & -2.964749 \\
\hline $\mathrm{C}$ & -0.036375 & -0.932349 & -4.240184 \\
\hline $\mathrm{C}$ & -1.121494 & -0.403447 & -4.952674 \\
\hline $\mathrm{C}$ & -1.896233 & 0.595788 & -4.374093 \\
\hline $\mathrm{C}$ & -1.576814 & 1.055015 & -3.081227 \\
\hline $\mathrm{N}$ & -0.531483 & 0.537125 & -2.396490 \\
\hline $\mathrm{H}$ & -1.352120 & -0.768655 & -5.948881 \\
\hline $\mathrm{H}$ & 0.604484 & -1.701049 & -4.651562 \\
\hline $\mathrm{H}$ & -2.737931 & 1.024515 & -4.905379 \\
\hline $\mathrm{C}$ & 1.354795 & -0.932321 & -2.155074 \\
\hline $\mathrm{C}$ & 3.193966 & -2.284845 & -1.954315 \\
\hline $\mathrm{C}$ & 4.149110 & -3.191756 & -2.629992 \\
\hline $\mathrm{C}$ & 3.318598 & -1.815811 & -0.599016 \\
\hline $\mathrm{C}$ & 3.654012 & -4.091071 & -3.583857 \\
\hline $\mathrm{C}$ & 5.538498 & -3.112099 & -2.394883 \\
\hline $\mathrm{C}$ & 4.295078 & -2.325246 & 0.397263 \\
\hline $\mathrm{C}$ & 4.525141 & -4.937456 & -4.286518 \\
\hline $\mathrm{C}$ & 4.454825 & -3.701881 & 0.606739 \\
\hline $\mathrm{C}$ & 6.397155 & -3.934675 & -3.119577 \\
\hline $\mathrm{C}$ & 5.018683 & -1.395937 & 1.167815 \\
\hline $\mathrm{C}$ & 5.908355 & -4.856206 & -4.056781 \\
\hline $\mathrm{C}$ & 5.341307 & -4.142773 & 1.597603 \\
\hline $\mathrm{C}$ & 5.925715 & -1.850785 & 2.134111 \\
\hline $\mathrm{H}$ & 6.603252 & -5.491467 & -4.592527 \\
\hline $\mathrm{C}$ & 6.079462 & -3.233304 & 2.352946 \\
\hline $\mathrm{H}$ & 6.782152 & -3.565875 & 3.109661 \\
\hline $\mathrm{N}$ & 2.161695 & -1.857991 & -2.685284 \\
\hline $\mathrm{N}$ & 1.530571 & -0.387160 & -0.941251 \\
\hline $\mathrm{N}$ & 2.499577 & -0.860756 & -0.153195 \\
\hline $\mathrm{O}$ & 6.695219 & -1.035222 & 2.913480 \\
\hline $\mathrm{O}$ & 3.930347 & -5.791918 & -5.170219 \\
\hline $\mathrm{C}$ & 4.769174 & -6.670812 & -5.926858 \\
\hline $\mathrm{H}$ & 4.095283 & -7.251550 & -6.557152 \\
\hline $\mathrm{H}$ & 5.465305 & -6.108339 & -6.560071 \\
\hline $\mathrm{H}$ & 5.328401 & -7.348594 & -5.271195 \\
\hline $\mathrm{C}$ & 6.670790 & 0.370892 & 2.647297 \\
\hline $\mathrm{H}$ & 6.997016 & 0.584570 & 1.622651 \\
\hline $\mathrm{H}$ & 5.673263 & 0.794841 & 2.807472 \\
\hline
\end{tabular}




$\begin{array}{lrrr}\mathrm{H} & 7.374470 & 0.816890 & 3.350778 \\ \mathrm{H} & 4.862881 & -0.338130 & 0.997590 \\ \mathrm{H} & 3.897530 & -4.420461 & 0.016458 \\ \mathrm{H} & 5.463958 & -5.206830 & 1.775666 \\ \mathrm{H} & 5.941452 & -2.410146 & -1.676080 \\ \mathrm{H} & 2.591429 & -4.150781 & -3.786900 \\ \mathrm{H} & 7.468558 & -3.866922 & -2.956927 \\ \mathrm{C} & -2.330771 & 2.101237 & -2.401516 \\ \mathrm{C} & -3.440074 & 2.872761 & -2.767403 \\ \mathrm{C} & -3.683277 & 3.695056 & -1.645085 \\ \mathrm{H} & -3.995027 & 2.845436 & -3.693360 \\ \mathrm{~N} & -1.944138 & 2.454011 & -1.147531 \\ \mathrm{~N} & -2.766133 & 3.420938 & -0.685899 \\ \mathrm{C} & 4.736900 & 4.708224 & 1.455373 \\ \mathrm{C} & 5.425197 & 5.244691 & 2.560243 \\ \mathrm{C} & 5.080188 & 5.160016 & 0.166886 \\ \mathrm{C} & 6.427498 & 6.203011 & 2.382472 \\ \mathrm{H} & 5.163752 & 4.928990 & 3.565607 \\ \mathrm{C} & 6.080446 & 6.119936 & -0.010746 \\ \mathrm{H} & 4.565461 & 4.747897 & -0.694455 \\ \mathrm{C} & 6.760547 & 6.645953 & 1.095990 \\ \mathrm{H} & 6.943322 & 6.611049 & 3.246714 \\ \mathrm{H} & 6.334230 & 6.455762 & -1.012107 \\ \mathrm{H} & 7.537268 & 7.391745 & 0.957869 \\ \mathrm{C} & -4.737494 & 4.707447 & -1.455739 \\ \mathrm{C} & -5.080847 & 5.159284 & -0.167285 \\ \mathrm{C} & -5.425885 & 5.243717 & -2.560645 \\ \mathrm{C} & -6.081260 & 6.119054 & 0.010279 \\ \mathrm{H} & -4.566048 & 4.747317 & 0.694086 \\ \mathrm{C} & -6.428341 & 6.201888 & -2.382943 \\ \mathrm{H} & -5.164396 & 4.927982 & -3.565987 \\ \mathrm{C} & -6.761454 & 6.644876 & -1.096494 \\ \mathrm{H} & -6.335092 & 6.454917 & 1.011615 \\ \mathrm{H} & -6.944236 & 6.609775 & -3.247214 \\ \mathrm{H} & -7.538295 & 7.390552 & -0.958426\end{array}$

\section{$\left[\mathrm{ML}_{2}\right]^{1+}$}

$\mathrm{M}=\mathrm{Eu}$

$\begin{array}{lccc}\text { EU } & -0.000004 & 1.271644 & 0.000021 \\ \mathrm{~N} & -1.220151 & 2.621093 & -1.595077 \\ \mathrm{~N} & 1.220145 & 2.621034 & 1.595163 \\ \mathrm{C} & -0.818414 & 2.782285 & -2.908994 \\ \mathrm{~N} & -2.327826 & 3.336174 & -1.373026 \\ \mathrm{~N} & -1.967540 & -0.303749 & 0.545585\end{array}$




\begin{tabular}{|c|c|c|c|}
\hline & 29 & -0.303747 & \\
\hline $\mathrm{N}$ & .947419 & 1.252990 & \\
\hline & .947409 & 1.252898 & \\
\hline & 0.818432 & 2.782168 & 2.909092 \\
\hline & 2.327821 & & 1.373124 \\
\hline & -1.707538 & 3.6 & -3.5 \\
\hline & 5 & 2.0 & -3.2 \\
\hline & -2.653569 & 3.972 & 371 \\
\hline & -2.58 & & \\
\hline & -2.3 & 660 & -0 \\
\hline & 2.58 & -0.3 & -1. \\
\hline & 2.34 & -1.1 & \\
\hline & 2.03 & 0.5 & -2.8 \\
\hline & -0.3 & 2.0 & \\
\hline C & -2.0 & & \\
\hline 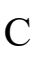 & 1.7 & & \\
\hline$U$ & 2.6 & 3.9 & \\
\hline $\mathrm{H}$ & -1.6 & & \\
\hline & $0.8^{\prime}$ & 2.1 & -4. \\
\hline & -3.8 & & -2 \\
\hline $\mathrm{N}$ & -3.6 & $-1 .($ & \\
\hline & -3.3 & -1. & \\
\hline $1 \mathrm{v}$ & 3.6 & -1. & \\
\hline & 3.3 & -1.9 & \\
\hline$c$ & 2.6 & & -4. \\
\hline C & -0.8 & 2.1 & \\
\hline $\mathrm{C}$ & -2.6 & & \\
\hline $\mathrm{H}$ & 1.6 & & \\
\hline $\mathrm{C}$ & 3.8 & 4.8 & \\
\hline $\mathrm{C}$ & 2.00 & & -5. \\
\hline $\mathrm{H}$ & 0.4 & 2.8 & -5. \\
\hline$C$ & -4.15 & & -3 \\
\hline $\mathrm{C}$ & -4.6 & 5.0 & -1 \\
\hline $\mathrm{C}$ & -4.1 & -1.8 & \\
\hline $\mathrm{C}$ & -3.61 & -2.9 & -1. \\
\hline $\mathrm{C}$ & 4.1 & -1.8 & -1. \\
\hline $\mathrm{C}$ & 3.61 & -2.98 & \\
\hline $\mathrm{H}$ & 3.4 & 0.0 & -4.2 \\
\hline 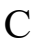 & -2.00 & 1.433934 & 5.0 \\
\hline $\mathrm{H}$ & -0.4 & 2.8 & \\
\hline $\mathrm{H}$ & -3.48 & 0.004839 & 4.2 \\
\hline $\mathrm{C}$ & 4.64 & 5.05 & 1.4 \\
\hline$C$ & 4.15 & 5.506112 & 3.825273 \\
\hline $\mathrm{H}$ & 2.423103 & 1.511040 & -6.0 \\
\hline $\mathrm{C}$ & -5.273727 & 6.337707 & -3.896732 \\
\hline $\mathrm{H}$ & -3.537983 & 5.369917 & -4.70702 \\
\hline
\end{tabular}




\begin{tabular}{|c|c|c|c|}
\hline $\mathrm{C}$ & -5.760915 & 5.883734 & -1.564563 \\
\hline & -4.386134 & 4.552480 & -0.563189 \\
\hline$C$ & -5.453325 & -2.501493 & 1.259104 \\
\hline C & -3.880267 & -4.322133 & -0.938616 \\
\hline $\mathrm{C}$ & -3.505674 & -2.588546 & -2.612464 \\
\hline $\mathrm{C}$ & 5.453324 & -2.501455 & -1.259173 \\
\hline$C$ & 3.880246 & -4.322198 & 0.938448 \\
\hline $\mathrm{C}$ & 3.505633 & -2.588687 & 2.612371 \\
\hline $\mathrm{H}$ & -2.423049 & 1.510789 & 6.023193 \\
\hline $\mathrm{C}$ & 5.760915 & 5.883674 & 1.564716 \\
\hline $\mathrm{H}$ & 4.386104 & 4.552482 & 0.563300 \\
\hline $\mathrm{C}$ & 5.273786 & 6.337515 & 3.896922 \\
\hline $\mathrm{H}$ & 3.538059 & 5.369682 & 4.707206 \\
\hline $\mathrm{C}$ & -6.082985 & 6.530978 & -2.767474 \\
\hline $\mathrm{H}$ & -5.516824 & 6.838452 & -4.829071 \\
\hline $\mathrm{H}$ & -6.382755 & 6.033940 & -0.6 \\
\hline $\mathrm{C}$ & -5.777177 & -2.881082 & 2.568496 \\
\hline $\mathrm{C}$ & -6.401546 & -2.661481 & 0.225870 \\
\hline $\mathrm{C}$ & -4.031609 & -5.260499 & -1.967175 \\
\hline $\mathrm{H}$ & -3.957419 & -4.634626 & 0.096237 \\
\hline $\mathrm{C}$ & -3.682344 & -3.532418 & -3.631822 \\
\hline $\mathrm{H}$ & -3.287477 & -1.552615 & -2.837029 \\
\hline $\mathrm{C}$ & 5.777189 & -2.880986 & -2.568579 \\
\hline $\mathrm{C}$ & 6.401534 & -2.661489 & -0.225937 \\
\hline $\mathrm{C}$ & 4.031578 & -5.260611 & 1.966965 \\
\hline $\mathrm{H}$ & 3.957409 & -4.634643 & -0.096419 \\
\hline $\mathrm{C}$ & 3.682293 & -3.532607 & 3.631687 \\
\hline $\mathrm{H}$ & 3.287432 & -1.552768 & 2.836981 \\
\hline $\mathrm{C}$ & 6.083018 & 6.530848 & 2.767656 \\
\hline $\mathrm{H}$ & 6.382734 & 6.033928 & 0.687017 \\
\hline $\mathrm{H}$ & 5.516908 & 6.838205 & 4.829285 \\
\hline $\mathrm{H}$ & -6.951546 & 7.180030 & -2.823490 \\
\hline $\mathrm{C}$ & -7.026883 & -3.450420 & 2.857329 \\
\hline $\mathrm{H}$ & -5.064751 & -2.748494 & 3.373802 \\
\hline $\mathrm{C}$ & -7.649663 & -3.199280 & 0.528708 \\
\hline $\mathrm{H}$ & -6.175526 & -2.355782 & -0.787821 \\
\hline $\mathrm{C}$ & -3.943144 & -4.876869 & -3.303788 \\
\hline $\mathrm{H}$ & -4.224691 & -6.300563 & -1.722723 \\
\hline $\mathrm{O}$ & -3.617396 & -3.249886 & -4.966803 \\
\hline $\mathrm{C}$ & 7.026898 & -3.450309 & -2.857425 \\
\hline $\mathrm{H}$ & 5.064771 & -2.748361 & -3.373886 \\
\hline $\mathrm{C}$ & 7.649655 & -3.199275 & -0.528787 \\
\hline $\mathrm{H}$ & 6.175504 & -2.355836 & 0.787765 \\
\hline $\mathrm{C}$ & 3.943099 & -4.877042 & 3.303595 \\
\hline $\mathrm{H}$ & 4.224665 & -6.300663 & 1.722467 \\
\hline $\mathrm{O}$ & 3.617330 & -3.250135 & 4.966681 \\
\hline
\end{tabular}




$\begin{array}{crrr}\mathrm{H} & 6.951582 & 7.179893 & 2.823688 \\ \mathrm{C} & -7.972939 & -3.606938 & 1.831124 \\ \mathrm{O} & -7.223359 & -3.808544 & 4.160171 \\ \mathrm{H} & -8.390872 & -3.309814 & -0.256977 \\ \mathrm{H} & -4.072491 & -5.593640 & -4.107780 \\ \mathrm{C} & -3.378623 & -1.896920 & -5.359467 \\ \mathrm{C} & 7.972944 & -3.606873 & -1.831218 \\ \mathrm{O} & 7.223387 & -3.808375 & -4.160281 \\ \mathrm{H} & 8.390856 & -3.309843 & 0.256901 \\ \mathrm{H} & 4.072438 & -5.593849 & 4.107555 \\ \mathrm{C} & 3.378552 & -1.897188 & 5.359404 \\ \mathrm{H} & -8.948096 & -4.035061 & 2.029265 \\ \mathrm{C} & -8.483287 & -4.385558 & 4.518278 \\ \mathrm{H} & -4.170839 & -1.230879 & -4.996960 \\ \mathrm{H} & -2.405450 & -1.542848 & -4.997883 \\ \mathrm{H} & -3.380431 & -1.900991 & -6.449940 \\ \mathrm{H} & 8.948103 & -4.034987 & -2.029368 \\ \mathrm{C} & 8.483319 & -4.385373 & -4.518401 \\ \mathrm{H} & 4.170771 & -1.231130 & 4.996937 \\ \mathrm{H} & 2.405382 & -1.543100 & 4.997826 \\ \mathrm{H} & 3.380348 & -1.901309 & 6.449877 \\ \mathrm{H} & -9.307656 & -3.687688 & 4.330285 \\ \mathrm{H} & -8.659225 & -5.322602 & 3.977011 \\ \mathrm{H} & -8.420108 & -4.591579 & 5.587022 \\ \mathrm{H} & 9.307686 & -3.687511 & -4.330370 \\ \mathrm{H} & 8.659251 & -5.322441 & -3.977175 \\ \mathrm{H} & 8.420150 & -4.591346 & -5.587155\end{array}$

$\mathrm{M}=\mathrm{Gd}$

$\begin{array}{lrrr}\mathrm{C} & 2.034874 & 0.539913 & -2.706328 \\ \mathrm{C} & 2.627459 & 0.625731 & -3.961502 \\ \mathrm{C} & 2.055092 & 1.510706 & -4.892513 \\ \mathrm{C} & 0.936309 & 2.257545 & -4.541097 \\ \mathrm{C} & 0.392481 & 2.118015 & -3.245866 \\ \mathrm{~N} & 0.954304 & 1.265615 & -2.355211 \\ \mathrm{H} & 2.488971 & 1.612522 & -5.882704 \\ \mathrm{H} & 3.502806 & 0.031814 & -4.190949 \\ \mathrm{H} & 0.482899 & 2.947464 & -5.243350 \\ \mathrm{C} & 2.543939 & -0.357915 & -1.641283 \\ \mathrm{C} & 4.042298 & -1.902056 & -0.860585 \\ \mathrm{C} & 5.344393 & -2.572226 & -1.057783 \\ \mathrm{C} & 3.229437 & -2.012072 & 0.328800 \\ \mathrm{C} & 5.717961 & -2.935755 & -2.359402 \\ \mathrm{C} & 6.244244 & -2.767814 & 0.012856 \\ \mathrm{C} & 3.415932 & -3.016811 & 1.403653\end{array}$




$\begin{array}{rrrr}\mathrm{C} & 6.967615 & -3.524655 & -2.604249 \\ \mathrm{C} & 3.649088 & -4.362926 & 1.087983 \\ \mathrm{C} & 7.494297 & -3.323064 & -0.246247 \\ \mathrm{C} & 3.286600 & -2.610108 & 2.745837 \\ \mathrm{C} & 7.865281 & -3.715555 & -1.540512 \\ \mathrm{C} & 3.750284 & -5.299802 & 2.124107 \\ \mathrm{C} & 3.415122 & -3.553280 & 3.773433 \\ \mathrm{H} & 8.840238 & -4.158506 & -1.704115 \\ \mathrm{C} & 3.643723 & -4.906482 & 3.456494 \\ \mathrm{H} & 3.735762 & -5.622314 & 4.266437 \\ \mathrm{~N} & 3.624284 & -1.111470 & -1.853928 \\ \mathrm{~N} & 1.879153 & -0.319031 & -0.473819 \\ \mathrm{~N} & 2.202383 & -1.175873 & 0.496872 \\ \mathrm{O} & 3.331382 & -3.262520 & 5.104571 \\ \mathrm{O} & 7.213409 & -3.865376 & -3.902390 \\ \mathrm{C} & 8.478570 & -4.457268 & -4.217585 \\ \mathrm{H} & 8.457130 & -4.643408 & -5.291525 \\ \mathrm{H} & 9.304852 & -3.776289 & -3.982553 \\ \mathrm{H} & 8.615979 & -5.406393 & -3.686474 \\ \mathrm{C} & 3.132388 & -1.900022 & 5.488195 \\ \mathrm{H} & 3.953201 & -1.263351 & 5.137089 \\ \mathrm{H} & 2.178051 & -1.514802 & 5.108738 \\ \mathrm{H} & 3.115329 & -1.899687 & 6.578431 \\ \mathrm{H} & 3.095824 & -1.566825 & 2.961701 \\ \mathrm{H} & 3.741501 & -4.682421 & 0.056460 \\ \mathrm{H} & 3.919339 & -6.346147 & 1.888987 \\ \mathrm{H} & 5.982399 & -2.472935 & 1.020865 \\ \mathrm{H} & 5.044087 & -2.775136 & -3.192181 \\ \mathrm{H} & 8.199545 & -3.459208 & 0.567912 \\ \mathrm{C} & -0.770208 & 2.832958 & -2.754031 \\ \mathrm{C} & -1.657130 & 3.751953 & -3.311098 \\ \mathrm{C} & -2.573354 & 4.035202 & -2.266668 \\ \mathrm{H} & -1.641767 & 4.164578 & -4.308865 \\ \mathrm{~N} & -1.150660 & 2.595600 & -1.456142 \\ \mathrm{~N} & -2.245039 & 3.326751 & -1.159637 \\ \mathrm{C} & -2.034594 & 0.539165 & 2.706573 \\ \mathrm{C} & -2.627012 & 0.624585 & 3.961853 \\ \mathrm{C} & -2.054456 & 1.509184 & 4.893105 \\ \mathrm{C} & -0.935658 & 2.256058 & 4.541811 \\ \mathrm{C} & -0.392006 & 2.116943 & 3.246461 \\ \mathrm{~N} & -0.954011 & 1.264903 & 2.355575 \\ \mathrm{H} & -2.488201 & 1.610685 & 5.883387 \\ \mathrm{H} & -3.502379 & 0.030658 & 4.191199 \\ \mathrm{H} & -0.482103 & 2.945693 & 5.244250 \\ \mathrm{C} & -2.543873 & -0.358236 & 1.641270 \\ \mathrm{C} & -4.042458 & -1.901972 & 0.860208 \\ & & & \end{array}$




\begin{tabular}{|c|c|c|c|}
\hline $\mathrm{C}$ & -5.344571 & -2.572128 & 1.0573 \\
\hline $\mathrm{C}$ & -3.229769 & -2.011614 & -0.329328 \\
\hline$C$ & -5.717998 & -2.936095 & 2.358872 \\
\hline $\mathrm{C}$ & -6.244562 & -2.767289 & -0.013262 \\
\hline $\mathrm{C}$ & -3.416511 & -3.015924 & -1.404538 \\
\hline C & -6.967658 & -3.525006 & 2.603665 \\
\hline $\mathrm{C}$ & -3.649792 & -4.362131 & -1.089349 \\
\hline $\mathrm{C}$ & -7.494617 & -3.322555 & 0.245799 \\
\hline $\mathrm{C}$ & -3.287299 & -2.608727 & -2.746583 \\
\hline $\mathrm{C}$ & -7.865466 & -3.715478 & 1.539971 \\
\hline $\mathrm{C}$ & -3.751227 & -5.298601 & -2.125816 \\
\hline $\mathrm{C}$ & -3.416060 & -3.551494 & -3.77452 \\
\hline $\mathrm{H}$ & -8.840429 & -4.158429 & 1.7 \\
\hline $\mathrm{C}$ & -3.644782 & -4.904789 & -3.458067 \\
\hline $\mathrm{H}$ & -3.737006 & -5.620303 & -4.26 \\
\hline $\mathrm{N}$ & -3.624250 & -1.111783 & 1.853785 \\
\hline $\mathrm{N}$ & -1.879240 & -0.3 & \\
\hline $\mathrm{N}$ & -2.202667 & -1.1 & -0.4 \\
\hline $\mathrm{O}$ & -3.332448 & -3.260240 & -5.1 \\
\hline $\mathrm{O}$ & -7.213311 & -3.8 & 3.9 \\
\hline $\mathrm{C}$ & -8.478467 & -4.458104 & 4.2 \\
\hline $\mathrm{H}$ & -8.456904 & -4.644625 & 730 \\
\hline $\mathrm{H}$ & -9.304739 & -3.776995 & 3.982170 \\
\hline $\mathrm{H}$ & -8.615995 & -5.407034 & 3.6 \\
\hline $\mathrm{C}$ & -3.133339 & -1.897619 & -5.488691 \\
\hline $\mathrm{H}$ & -3.954032 & -1.260984 & -5.137239 \\
\hline $\mathrm{H}$ & -2.178909 & -1.512658 & -5.109208 \\
\hline $\mathrm{H}$ & -3.116418 & -1.896873 & -6.578929 \\
\hline $\mathrm{H}$ & -3.096426 & -1.565385 & -2.962076 \\
\hline $\mathrm{H}$ & -3.742118 & -4.682006 & -0.057935 \\
\hline $\mathrm{H}$ & -3.920379 & -6.345015 & -1.891072 \\
\hline $\mathrm{H}$ & -5.982820 & -2.472077 & -1.021201 \\
\hline $\mathrm{H}$ & -5.044011 & -2.775811 & 3.191624 \\
\hline $\mathrm{H}$ & -8.199972 & -3.458373 & -0.568322 \\
\hline $\mathrm{C}$ & 0.770678 & 2.831968 & 2.754733 \\
\hline $\mathrm{C}$ & 1.657740 & 3.750697 & 3.312013 \\
\hline $\mathrm{C}$ & 2.573852 & 4.034249 & 2.267568 \\
\hline $\mathrm{H}$ & 1.642534 & 4.162972 & 4.309928 \\
\hline $\mathrm{N}$ & 1.150951 & 2.595038 & 1.456712 \\
\hline $\mathrm{N}$ & 2.245351 & 3.326206 & 1.160331 \\
\hline $\mathrm{C}$ & -3.735705 & 4.942454 & -2.282270 \\
\hline $\mathrm{C}$ & -4.132466 & 5.594176 & -3.464894 \\
\hline 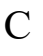 & -4.473766 & 5.175317 & -1.105750 \\
\hline $\mathrm{C}$ & -5.234978 & 6.454225 & -3.472622 \\
\hline $\mathrm{H}$ & -3.583250 & 5.431226 & -4.386933 \\
\hline & -5.575462 & 6.034372 & -1.11416 \\
\hline
\end{tabular}




$\begin{array}{lccc}\mathrm{H} & -4.169142 & 4.680190 & -0.190611 \\ \mathrm{C} & -5.962675 & 6.678829 & -2.297375 \\ \mathrm{H} & -5.526433 & 6.949651 & -4.394107 \\ \mathrm{H} & -6.131968 & 6.206759 & -0.197281 \\ \mathrm{H} & -6.817511 & 7.348196 & -2.302478 \\ \mathrm{C} & 3.736271 & 4.941411 & 2.283344 \\ \mathrm{C} & 4.474211 & 5.174623 & 1.106817 \\ \mathrm{C} & 4.133218 & 5.592700 & 3.466145 \\ \mathrm{C} & 5.575971 & 6.033595 & 1.115396 \\ \mathrm{H} & 4.169443 & 4.679831 & 0.191545 \\ \mathrm{C} & 5.235794 & 6.452666 & 3.474037 \\ \mathrm{H} & 3.584098 & 5.429475 & 4.388192 \\ \mathrm{C} & 5.963369 & 6.677618 & 2.298782 \\ \mathrm{H} & 6.132382 & 6.206254 & 0.198508 \\ \mathrm{H} & 5.527393 & 6.947755 & 4.395658 \\ \mathrm{H} & 6.818254 & 7.346921 & 2.304015 \\ \mathrm{GD} & 0.000020 & 1.224490 & 0.000119\end{array}$

$\mathrm{M}=\mathrm{Am}$

$\begin{array}{lccc}\text { AM } & -0.000015 & 1.085495 & 0.000166 \\ \text { N } & 1.067319 & 2.518156 & 1.512806 \\ \text { N } & -1.066719 & 2.519570 & -1.511690 \\ \text { C } & 0.646160 & 2.775820 & 2.789972 \\ \text { N } & 2.180716 & 3.227350 & 1.242534 \\ \text { C } & -0.645283 & 2.777933 & -2.788620 \\ \text { N } & -2.180010 & 3.228848 & -1.241177 \\ \mathrm{C} & 1.526263 & 3.690443 & 3.366169 \\ \mathrm{C} & -0.542410 & 2.081364 & 3.243940 \\ \mathrm{C} & 2.481638 & 3.946450 & 2.350651 \\ \mathrm{C} & -1.525079 & 3.693111 & -3.364407 \\ \mathrm{C} & 0.543224 & 2.083521 & -3.242819 \\ \mathrm{C} & -2.480577 & 3.948703 & -2.348902 \\ \mathrm{H} & 1.482654 & 4.118217 & 4.356625 \\ \mathrm{C} & -1.134670 & 2.258466 & 4.512662 \\ \mathrm{~N} & -1.079226 & 1.216590 & 2.348078 \\ \mathrm{C} & 3.656110 & 4.836771 & 2.394003 \\ \mathrm{H} & -1.481201 & 4.121483 & -4.354592 \\ \mathrm{C} & 1.135773 & 2.261374 & -4.511303 \\ \mathrm{~N} & 1.079692 & 1.218023 & -2.347447 \\ \mathrm{C} & -3.654848 & 4.839309 & -2.391903 \\ \mathrm{C} & -2.278737 & 1.539542 & 4.836250 \\ \mathrm{H} & -0.697046 & 2.957388 & 5.215914 \\ \mathrm{C} & -2.189529 & 0.520706 & 2.672175 \\ \mathrm{C} & 4.423040 & 5.061992 & 1.234559 \\ \mathrm{C} & 4.036584 & 5.479762 & 3.586802\end{array}$




\begin{tabular}{|c|c|c|c|}
\hline $\mathrm{C}$ & 2.279776 & 1.542467 & -4.835150 \\
\hline $\mathrm{H}$ & 0.698420 & 2.960856 & -5.214166 \\
\hline$C$ & 2.189955 & 0.522187 & -2.671785 \\
\hline$C$ & -4.034957 & 5.483162 & -3.584353 \\
\hline$C$ & -4.421946 & 5.063947 & -1.232457 \\
\hline 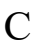 & -2.829156 & 0.646814 & 3.900619 \\
\hline $\mathrm{H}$ & -2.749858 & 1.670322 & 5.805725 \\
\hline $\mathrm{C}$ & -2.688121 & -0.390152 & 1.614090 \\
\hline $\mathrm{C}$ & 5.536492 & 5.905231 & 1.269301 \\
\hline $\mathrm{H}$ & 4.131352 & 4.573870 & 0.311353 \\
\hline $\mathrm{C}$ & 5.150663 & 6.324008 & 3.620870 \\
\hline $\mathrm{H}$ & 3.465878 & 5.321083 & 4.496474 \\
\hline $\mathrm{C}$ & 2.829859 & 0.649020 & -3.900008 \\
\hline $\mathrm{H}$ & 2.751114 & 1.673820 & -5.804443 \\
\hline $\mathrm{C}$ & 2.688182 & -0.389438 & -1.6 \\
\hline $\mathrm{C}$ & -5.148846 & 6.327673 & -3.6 \\
\hline $\mathrm{H}$ & -3.464113 & 5.324959 & -4.494021 \\
\hline $\mathrm{C}$ & -5.535209 & 5.907450 & -1.266858 \\
\hline $\mathrm{H}$ & -4.130539 & 4.575160 & -0.309514 \\
\hline $\mathrm{H}$ & -3.725337 & 0.075420 & 4.105101 \\
\hline $\mathrm{N}$ & -1.990414 & -0.395541 & 0.468615 \\
\hline $\mathrm{N}$ & -3.793902 & -1.111573 & 998 \\
\hline $\mathrm{C}$ & 5.906935 & 6.541245 & 2.462363 \\
\hline $\mathrm{H}$ & 6.115054 & 6.072131 & 0.3 \\
\hline $\mathrm{H}$ & 5.429162 & 6.812584 & 4.549977 \\
\hline $\mathrm{H}$ & 3.725994 & 0.077623 & -4.104687 \\
\hline $\mathrm{N}$ & 1.990234 & -0.395448 & -0.468869 \\
\hline $\mathrm{N}$ & 3.793885 & -1.110914 & -1.813334 \\
\hline $\mathrm{C}$ & -5.905289 & 6.544321 & -2.459576 \\
\hline $\mathrm{H}$ & -5.427062 & 6.816916 & -4.546922 \\
\hline $\mathrm{H}$ & -6.113904 & 6.073888 & -0.362660 \\
\hline $\mathrm{N}$ & -2.307260 & -1.266118 & -0.491763 \\
\hline $\mathrm{C}$ & -4.201970 & -1.915819 & 0.826960 \\
\hline $\mathrm{H}$ & 6.770818 & 7.198412 & 2.487946 \\
\hline $\mathrm{N}$ & 2.306713 & -1.266715 & 0.491001 \\
\hline $\mathrm{C}$ & 4.201605 & -1.915869 & -0.827730 \\
\hline $\mathrm{H}$ & -6.769024 & 7.201693 & -2.484894 \\
\hline $\mathrm{C}$ & -3.359881 & -2.071600 & -0.336598 \\
\hline $\mathrm{C}$ & -5.523411 & -2.554058 & 1.002793 \\
\hline $\mathrm{C}$ & 3.359227 & -2.072278 & 0.335535 \\
\hline $\mathrm{C}$ & 5.522984 & -2.554203 & -1.003683 \\
\hline $\mathrm{C}$ & -3.541896 & -3.094656 & -1.394876 \\
\hline $\mathrm{C}$ & -5.935124 & -2.892458 & 2.299352 \\
\hline $\mathrm{C}$ & -6.401570 & -2.745093 & -0.086252 \\
\hline $\mathrm{C}$ & 3.540827 & -3.096072 & 1.393171 \\
\hline $\mathrm{C}$ & 5.934947 & -2.891794 & -2.300373 \\
\hline
\end{tabular}




\begin{tabular}{|c|c|c|c|}
\hline $\mathrm{C}$ & 6.400856 & -2.746117 & 0.085439 \\
\hline & -3.819075 & -4.427217 & -1.058140 \\
\hline$C$ & -3.363351 & -2.720803 & -2.740989 \\
\hline $\mathrm{C}$ & -7.202728 & -3.451398 & 2.521908 \\
\hline $\mathrm{H}$ & -5.277840 & -2.735434 & 3.146045 \\
\hline & -7.669030 & -3.270366 & 0.149806 \\
\hline $\mathrm{H}$ & -6.109650 & -2.469197 & -1.091447 \\
\hline & 3.817840 & -4.428458 & 1.055607 \\
\hline$C$ & 3.362061 & -2.723084 & 2.739496 \\
\hline & 7.202514 & -3.450789 & -2.523009 \\
\hline $\mathrm{H}$ & 5.277888 & -2.734090 & -3.147114 \\
\hline & 7.668286 & -3.271438 & -0.150676 \\
\hline $\mathrm{H}$ & 6.108746 & -2.470851 & 1.090751 \\
\hline$c$ & -3.915100 & -5.383405 & -2.076902 \\
\hline $\mathrm{H}$ & -3.949145 & -4.721905 & -0.023299 \\
\hline$C$ & -3.486875 & -3.682411 & -3.751909 \\
\hline H & -3.139589 & -1.687522 & -2.973088 \\
\hline $\mathrm{C}$ & -8.078956 & -3.637597 & 1.439717 \\
\hline $\mathrm{O}$ & -7.486289 & -3.769263 & 3.818274 \\
\hline Н & -8.357427 & -3.402617 & -0.679305 \\
\hline $\mathrm{C}$ & 3.913476 & -5.385342 & 2.073753 \\
\hline H & 3.948080 & -4.722479 & 0.020598 \\
\hline $\mathrm{C}$ & 3.485198 & -3.685388 & 3.749801 \\
\hline H & 3.138435 & -1.689916 & 2.972233 \\
\hline $\mathrm{C}$ & 8.078456 & -3.637863 & -1.440738 \\
\hline O & 7.486328 & -3.767820 & -3.819524 \\
\hline $\mathrm{H}$ & 8.356467 & -3.404361 & 0.678507 \\
\hline $\mathrm{C}$ & -3.760069 & -5.022066 & -3.413579 \\
\hline $\mathrm{H}$ & -4.118061 & -6.419752 & -1.824896 \\
\hline $\mathrm{O}$ & -3.357224 & -3.422770 & -5.085902 \\
\hline $\mathrm{H}$ & -9.066743 & -4.057674 & 1.585614 \\
\hline 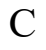 & -8.770783 & -4.330217 & 4.110705 \\
\hline 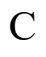 & 3.758224 & -5.024865 & 3.410637 \\
\hline $\mathrm{H}$ & 4.116307 & -6.421557 & 1.821099 \\
\hline $\mathrm{O}$ & 3.355309 & -3.426612 & 5.083940 \\
\hline $\mathrm{H}$ & 9.066209 & -4.058002 & -1.586687 \\
\hline , & 8.770803 & -4.328778 & -4.112033 \\
\hline $\mathrm{H}$ & -3.847409 & -5.752746 & -4.210692 \\
\hline 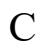 & -3.111093 & -2.074639 & -5.492027 \\
\hline $\mathrm{H}$ & -9.576633 & -3.635453 & 3.846798 \\
\hline $\mathrm{H}$ & -8.915596 & -5.283492 & 3.589046 \\
\hline $\mathrm{H}$ & -8.778917 & -4.501987 & 5.187224 \\
\hline $\mathrm{H}$ & 3.845265 & -5.756092 & 4.207282 \\
\hline $\mathrm{C}$ & 3.109349 & -2.078706 & 5.490909 \\
\hline $\mathrm{H}$ & 9.576700 & -3.634321 & -3.847462 \\
\hline $\mathrm{H}$ & 8.915343 & -5.282431 & -3.590990 \\
\hline
\end{tabular}




$\begin{array}{lrrc}H & 8.779164 & -4.499816 & -5.188667 \\ \mathrm{H} & -3.924632 & -1.409394 & -5.178945 \\ \mathrm{H} & -2.158286 & -1.706009 & -5.092674 \\ \mathrm{H} & -3.062206 & -2.098484 & -6.581036 \\ \mathrm{H} & 3.923080 & -1.413407 & 5.178439 \\ \mathrm{H} & 2.156696 & -1.709628 & 5.091602 \\ \mathrm{H} & 3.060230 & -2.103265 & 6.579891\end{array}$

$\mathrm{M}=\mathrm{Cm}$

$\begin{array}{lrrr}\mathrm{CM} & -0.000053 & 1.083388 & 0.000702 \\ \mathrm{C} & -2.202838 & 0.536937 & 2.671356 \\ \mathrm{C} & -2.849276 & 0.676354 & 3.895284 \\ \mathrm{C} & -2.295299 & 1.572172 & 4.826326 \\ \mathrm{C} & -1.142072 & 2.278985 & 4.505089 \\ \mathrm{C} & -0.545011 & 2.087034 & 3.240684 \\ \mathrm{~N} & -1.087562 & 1.222606 & 2.351081 \\ \mathrm{H} & -2.770347 & 1.714303 & 5.792391 \\ \mathrm{H} & -3.750953 & 0.114042 & 4.100971 \\ \mathrm{H} & -0.702596 & 2.977593 & 5.207596 \\ \mathrm{C} & -2.694322 & -0.379111 & 1.612885 \\ \mathrm{C} & -4.212940 & -1.900324 & 0.823424 \\ \mathrm{C} & -5.542280 & -2.523806 & 0.991043 \\ \mathrm{C} & -3.359546 & -2.075928 & -0.328650 \\ \mathrm{C} & -5.972913 & -2.841846 & 2.286694 \\ \mathrm{C} & -6.409006 & -2.720221 & -0.106251 \\ \mathrm{C} & -3.538333 & -3.109017 & -1.377791 \\ \mathrm{C} & -7.248439 & -3.385804 & 2.500675 \\ \mathrm{C} & -3.829528 & -4.435539 & -1.029182 \\ \mathrm{C} & -7.684183 & -3.230486 & 0.120855 \\ \mathrm{C} & -3.342827 & -2.751591 & -2.725985 \\ \mathrm{C} & -8.113154 & -3.577474 & 1.410184 \\ \mathrm{C} & -3.922354 & -5.402326 & -2.038234 \\ \mathrm{C} & -3.463273 & -3.723518 & -3.727373 \\ \mathrm{H} & -9.106609 & -3.986349 & 1.549249 \\ \mathrm{C} & -3.750472 & -5.057134 & -3.377091 \\ \mathrm{H} & -3.835061 & -5.795999 & -4.166925 \\ \mathrm{~N} & -3.808033 & -1.089612 & 1.805549 \\ \mathrm{~N} & -1.983175 & -0.402554 & 0.473554 \\ \mathrm{~N} & -2.298384 & -1.280997 & -0.480803 \\ \mathrm{O} & -3.317491 & -3.479833 & -5.062718 \\ \mathrm{O} & -7.550956 & -3.684234 & 3.797342 \\ \mathrm{C} & -8.844340 & -4.229059 & 4.080989 \\ \mathrm{H} & -8.867375 & -4.386738 & 5.159438 \\ \mathrm{H} & -9.640072 & -3.530095 & 3.798167 \\ \mathrm{H} & -8.991933 & -5.187616 & 3.569892\end{array}$




\begin{tabular}{|c|c|c|c|}
\hline $\mathrm{C}$ & -3.056756 & -2.138280 & -5.481280 \\
\hline $\mathrm{H}$ & -3.868354 & -1.463389 & -5.184078 \\
\hline $\mathrm{H}$ & -2.105272 & -1.772474 & -5.076199 \\
\hline $\mathrm{H}$ & -2.996848 & -2.174716 & -6.569381 \\
\hline $\mathrm{H}$ & -3.108422 & -1.722783 & -2.967240 \\
\hline $\mathrm{H}$ & -3.972677 & -4.717652 & 0.007483 \\
\hline $\mathrm{H}$ & -4.135952 & -6.434216 & -1.776870 \\
\hline $\mathrm{H}$ & -6.102360 & -2.459661 & -1.111176 \\
\hline 11 & -5.324456 & -2.680148 & 3.139306 \\
\hline 11 & -8.363777 & -3.366655 & -0.714868 \\
\hline C & 0.656561 & 2.763354 & 2.785904 \\
\hline $\mathrm{C}$ & 1.537638 & 3.672612 & 3.366524 \\
\hline $\mathrm{C}$ & 2.508719 & 3.914986 & 2.361889 \\
\hline $\mathrm{H}$ & 1.485338 & 4.105265 & 4.354387 \\
\hline $\mathrm{N}$ & 1.091894 & 2.493295 & 1.512808 \\
\hline $\mathrm{N}$ & 2.216761 & 3229 & 639 \\
\hline $\mathrm{C}$ & 2.204864 & 0.543102 & -2.669381 \\
\hline $\mathrm{C}$ & 2.852614 & 0.685677 & -3.892250 \\
\hline $\mathrm{C}$ & 2.300024 & 1.584417 & -4.821295 \\
\hline $\mathrm{C}$ & 1.146821 & 2.290888 & 213 \\
\hline $\mathrm{C}$ & 0.548394 & 2.095649 & -3.235962 \\
\hline $\mathrm{N}$ & 1.089621 & 1.228423 & -2.348277 \\
\hline $\mathrm{H}$ & 2.776107 & 1.729052 & -5.786479 \\
\hline $\mathrm{H}$ & 3.754210 & 0.123487 & -4.098624 \\
\hline $\mathrm{H}$ & 0.708396 & 2.991696 & -5.200185 \\
\hline $\mathrm{C}$ & 2.694770 & -0.376250 & -1.613048 \\
\hline $\mathrm{C}$ & 4.211822 & -1.900475 & -0.826405 \\
\hline $\mathrm{C}$ & 5.541005 & -2.524175 & -0.994459 \\
\hline $\mathrm{C}$ & 3.357182 & -2.078928 & 0.324298 \\
\hline $\mathrm{C}$ & 5.972745 & -2.838834 & -2.290566 \\
\hline $\mathrm{C}$ & 6.406545 & -2.724093 & 0.103136 \\
\hline $\mathrm{C}$ & 3.534452 & -3.115067 & 1.370692 \\
\hline $\mathrm{C}$ & 7.248201 & -3.382857 & -2.504803 \\
\hline $\mathrm{C}$ & 3.825290 & -4.440748 & 1.018603 \\
\hline $\mathrm{C}$ & 7.681682 & -3.234386 & -0.124132 \\
\hline $\mathrm{C}$ & 3.337872 & -2.761357 & 2.719707 \\
\hline $\mathrm{C}$ & 8.111743 & -3.578009 & -1.414000 \\
\hline $\mathrm{C}$ & 3.916662 & -5.410436 & 2.025000 \\
\hline $\mathrm{C}$ & 3.456871 & -3.736178 & 3.718451 \\
\hline $\mathrm{H}$ & 9.105123 & -3.987010 & -1.553226 \\
\hline $\mathrm{C}$ & 3.743699 & -5.068948 & 3.364667 \\
\hline $\mathrm{H}$ & 3.827164 & -5.810088 & 4.152485 \\
\hline $\mathrm{N}$ & 3.808334 & -1.086740 & -1.806608 \\
\hline $\mathrm{N}$ & 1.982430 & -0.402618 & -0.474527 \\
\hline $\mathrm{N}$ & 2.296251 & -1.283921 & 0.477649 \\
\hline $\mathrm{O}$ & 3.309985 & -3.496193 & 5.054351 \\
\hline
\end{tabular}




\begin{tabular}{|c|c|c|c|}
\hline $\mathrm{O}$ & 7.551843 & -3.677827 & -3.802001 \\
\hline $\mathrm{C}$ & 8.845240 & -4.222490 & -4.085903 \\
\hline $\mathrm{H}$ & 8.869255 & -4.377172 & -5.164766 \\
\hline $\mathrm{H}$ & 9.641033 & -3.524702 & -3.800355 \\
\hline $\mathrm{H}$ & 8.991871 & -5.182540 & -3.577337 \\
\hline 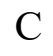 & 3.049725 & -2.155671 & 5.476477 \\
\hline $\mathrm{H}$ & 3.862020 & -1.480461 & 5.181912 \\
\hline $\mathrm{H}$ & 2.098838 & -1.788107 & 5.071581 \\
\hline $\mathrm{H}$ & 2.988816 & -2.195148 & 6.564416 \\
\hline $\mathrm{H}$ & 3.103774 & -1.733114 & 2.963652 \\
\hline $\mathrm{H}$ & 3.969276 & -4.719996 & -0.018721 \\
\hline $\mathrm{H}$ & 4.129971 & -6.441693 & 1.760916 \\
\hline $\mathrm{H}$ & 6.099041 & -2.466164 & 1.108480 \\
\hline $\mathrm{H}$ & 5.325214 & -2.674422 & -3.143363 \\
\hline $\mathrm{H}$ & 8.360382 & -3.373231 & 0.711877 \\
\hline $\mathrm{C}$ & -0.653295 & 2.771281 & -2.780457 \\
\hline $\mathrm{C}$ & -1.533353 & 3.682616 & -3.359365 \\
\hline $\mathrm{C}$ & -2.505289 & 3.922653 & -2.354992 \\
\hline $\mathrm{H}$ & -1.479863 & 4.118051 & -4.345940 \\
\hline $\mathrm{N}$ & -1.090009 & 2.497849 & -1.508559 \\
\hline $\mathrm{N}$ & -2.214780 & 3.197616 & -1.249505 \\
\hline $\mathrm{C}$ & 3.689994 & 4.795842 & 2.416690 \\
\hline $\mathrm{C}$ & 4.054192 & 5.449036 & 3.608973 \\
\hline $\mathrm{C}$ & 4.479771 & 5.001420 & 1.268984 \\
\hline $\mathrm{C}$ & 5.174942 & 6.283974 & 3.654066 \\
\hline $\mathrm{H}$ & 3.465357 & 5.306054 & 4.509663 \\
\hline $\mathrm{C}$ & 5.599735 & 5.835341 & 1.314700 \\
\hline $\mathrm{H}$ & 4.200692 & 4.505220 & 0.346158 \\
\hline $\mathrm{C}$ & 5.954009 & 6.481531 & 2.507244 \\
\hline $\mathrm{H}$ & 5.440691 & 6.780690 & 4.582583 \\
\hline $\mathrm{H}$ & 6.196229 & 5.986983 & 0.419459 \\
\hline $\mathrm{H}$ & 6.823058 & 7.131460 & 2.541332 \\
\hline $\mathrm{C}$ & -3.686064 & 4.804264 & -2.408452 \\
\hline $\mathrm{C}$ & -4.476741 & 5.007158 & -1.260887 \\
\hline $\mathrm{C}$ & -4.048881 & 5.460855 & -3.599290 \\
\hline $\mathrm{C}$ & -5.596233 & 5.841781 & -1.305335 \\
\hline $\mathrm{H}$ & -4.198729 & 4.508327 & -0.339157 \\
\hline $\mathrm{C}$ & -5.169160 & 6.296494 & -3.643114 \\
\hline $\mathrm{H}$ & -3.459336 & 5.319985 & -4.499849 \\
\hline $\mathrm{C}$ & -5.949128 & 6.491366 & -2.496444 \\
\hline $\mathrm{H}$ & -6.193433 & 5.991321 & -0.410211 \\
\hline $\mathrm{H}$ & -5.433840 & 6.795846 & -4.570522 \\
\hline $\mathrm{H}$ & -6.817810 & 7.141836 & -2.529540 \\
\hline
\end{tabular}

